Tina Püthe

\title{
Mittelständische Unternehmen und Genossenschaftsbanken
}

Eine empirische Analyse der Wirkung ökonomischer und verhaltenswissenschaftlicher Faktoren 
Tina Püthe

\section{Mittelständische Unternehmen und Genossenschaftsbanken}

Die Finanzierung über Bankkredite stellt in Deutschland die wichtigste Finanzierungsquelle für mittelständische Unternehmen dar. Aufgrund der zentralen Bedeutung der Bankfinanzierung, die z. T. zu einer enormen Abhängigkeit der Unternehmen von der Bank führt, stellt sich aus Unternehmersicht die Frage, durch welche Einflussfaktoren die zentralen Parameter des Kreditvertrags - der Zinssatz, die Sicherheitenstellung und die Kreditverfügbarkeit - determiniert werden. Ziel der Arbeit ist es zu untersuchen, ob aus verhaltenswissenschaftlichen Aspekten ökonomische Konsequenzen für das Unternehmen resultieren. $\mathrm{Zu}$ diesem Zweck wurde eine empirische Untersuchung bei Genossenschaftsbanken durchgeführt. Die Auswertungsergebnisse zeigen, dass verhaltenswissenschaftliche Elemente insgesamt einen erheblichen Erklärungsbeitrag, insbesondere für die Sicherheitenstellung und die Kreditverfügbarkeit, leisten können.

Tina Püthe absolvierte nach einer Ausbildung zur Bankkauffrau ein Studium der Betriebswirtschaftslehre in Paris und Münster. Seit Abschluss des Studiums ist die Autorin als Unternehmensberaterin bei einer Beratungsgesellschaft in Düsseldorf mit dem Schwerpunkt Bankenberatung tätig. Die Promotion erfolgte im Jahre 2008. 
Mittelständische Unternehmen und Genossenschaftsbanken 


\section{Beiträge zum Controlling}

Herausgegeben von Wolfgang Berens

Band 15

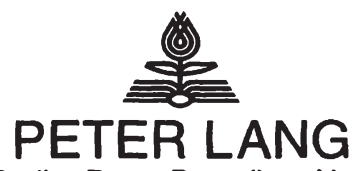

Frankfurt am Main - Berlin - Bern · Bruxelles - New York · Oxford · Wien

Tina Püthe - 978-3-631-75310-1

Downloaded from PubFactory at 01/11/2019 06:20:26AM

via free access 


\title{
Tina Püthe
}

\section{Mittelständische Unternehmen und Genossenschaftsbanken}

\author{
Eine empirische Analyse \\ der Wirkung ökonomischer und \\ verhaltenswissenschaftlicher Faktoren
}

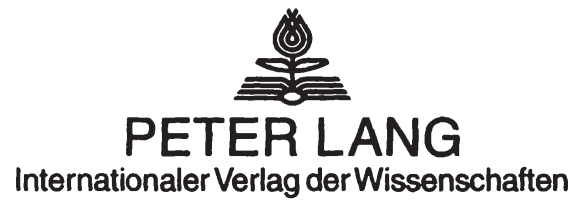

Tina Püthe - 978-3-631-75310-1 
Bibliografische Information der Deutschen Nationalbibliothek Die Deutsche Nationalbibliothek verzeichnet diese Publikation in der Deutschen Nationalbibliografie; detaillierte bibliografische Daten sind im Internet über <http://www.d-nb.de> abrufbar.

Open Access: The online version of this publication is published on www.peterlang.com and www.econstor.eu under the international Creative Commons License CC-BY 4.0. Learn more on how you can use and share this work: http://creativecommons.org/licenses/ by/4.0.

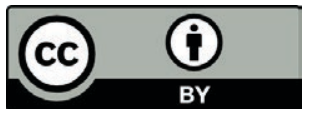

This book is available Open Access thanks to the kind support of ZBW - Leibniz-Informationszentrum Wirtschaft.

Zugl.: Münster, Univ., Diss., 2008

Logo auf dem Umschlag:

Logo des Lehrstuhls für Betriebswirtschaftslehre, insb. Controlling der Westfälischen Wilhelms-Universităt Münster.

Gedruckt auf alterungsbeständigem, säurefreiem Papier.

D 6

ISSN 1618-825X

ISBN 978-3-631-59384-4

ISBN 978-3-631-75310-1 (eBook)

(c) Peter Lang GmbH

Internationaler Verlag der Wissenschaften

Frankfurt am Main 2009

Alle Rechte vorbehalten.

Das Werk einschließlich aller seiner Teile ist urheberrechtlich geschützt. Jede Verwertung außerhalb der engen Grenzen des

Urheberrechtsgesetzes ist ohne Zustimmung des Verlages

unzulässig und strafbar. Das gilt insbesondere für

Vervielfăltigungen, Übersetzungen, Mikroverfilmungen und die Einspeicherung und Verarbeitung in elektronischen Systemen.

www.peterlang.de 


\section{Geleitwort}

Während sich die Unternehmen in kapitalmarktorientierten Finanzsystemen vor allem durch die Emission von Aktien und Anleihen refinanzieren, dominiert in bankbasierten Systemen wie Deutschland die Refinanzierung über Bankkredite. Diese Form der Refinanzierung spielt insbesondere bei den mittelständischen Unternehmen eine zentrale Rolle. Aufgrund der resultierenden Abhängigkeit der Unternehmen von den Bankkrediten stellt sich aus Unternehmersicht die Frage, welche Einflussgrößen auf die Kreditkonditionen wirken. Die zentralen ökonomischen Parameter sind der Kreditzins, die Sicherheitenstellung und die Kreditverfügbarkeit.

Im theoretischen Teil der Arbeit analysiert Frau PÜTHE, welche möglichen Einflussfaktoren zu berücksichtigen sind. Neben den aufsichtsrechtlichen Rahmenbedingungen wie Basel II und MaRisk bildet die Relationship Banking-Forschung eine wesentliche Grundlage. Bei der klassischen Relationship Banking-Forschung wird die Konditionengestaltung vor allem durch die Informationsasymmetrien zwischen den Geschäftspartnern erklärt. Frau PÜTHE betrachtet darüber hinaus die in der Praxis hochgradig relevanten verhaltenswissenschaftlichen Grundlagen einer Kunde-Bank-Beziehung. Theoretisches Fundament dieser Arbeit bildet ein integratives Wirkungsmodell, in dem diese verschiedenen Aspekte vereint werden.

Die bestehenden empirischen Arbeiten zur Analyse der Kunde-Bank-Beziehung fokussieren sich auf die Relationship Banking-Theorie. Trotz der Existenz theoretischer Erkenntnisse über den Einfluss von verhaltenswissenschaftlichen Variablen auf die Kreditkonditionen, finden diese nur geringe Berücksichtigung in bestehenden Studien. Als Erweiterung dieser Studien untersucht Frau PÜTHE im empirischen Teil ihrer Arbeit, ob und in welchem Umfang verhaltenswissenschaftliche Größen die Kreditkonditionen beeinflussen. Sie zeigt, dass die verhaltenswissenschaftlichen Variablen insgesamt einen erheblichen Erklärungsbeitrag leisten können.

Die Integration der verhaltenswissenschaftlichen Variablen in die empirischen Untersuchungen kann dazu beitragen, eine bestehende Lücke in der aktuellen Forschungsdebatte zu schließen. Durch umfangreiche empirische und hypothesengeleitete Analysen ist die Arbeit in der Lage, den Erkenntnisstand zur Konditionengestaltung im Rahmen einer bestehenden Kunde-Bank-Beziehung erheblich zu erweitern. Neben ausführlichen deskriptiven empirischen Erkenntnissen zu Ausgestaltung der Kunde-BankBeziehung liefert die Arbeit wichtige Anhaltspunkte dafür, welche verhaltenswissenschaftlichen Parameter in welchem Umfang die Kreditkonditionen beeinflussen. Besonders hervorzuheben an der vorliegenden Arbeit ist das konsequente Bemühen um eine theoretische Fundierung der zu untersuchenden Zusammenhänge und der detaillierte Abgleich mit empirischem Sekundärmaterial. Insgesamt zeigt die Arbeit vielfältige Implikationen für die Ausgestaltung der Kunde-Bank-Beziehung auf. Ich wünsche ihr daher eine weite Verbreitung in Wissenschaft und Praxis und hoffe, dass einige der angeregten Forschungsideen in zukünftigen Untersuchungen aufgegriffen werden. 


\section{Vorwort}

Die vorliegende Arbeit entstand während meiner Assistententätigkeit als wissenschaftlicher Mitarbeiter am Lehrstuhl für Betriebswirtschaftslehre, insb. Controlling sowie meiner Tätigkeit als Berater für die BMS Consulting $\mathrm{GmbH}$, Düsseldorf, und wurde im Wintersemester 2008/09 an der Westfälischen Wilhelms-Universität Münster als Dissertationsschrift angenommen. Besonderer Dank gilt in diesem Zusammenhang meinem akademischen Lehrer und Erstgutachter PROF. DR. WOLFGANG BERENS. Die Möglichkeit zur Vereinbarkeit von Lehrstuhltätigkeiten, Beratungsaktivitäten und Promotion und die von ihm verfolgte Integration von Wissenschaft und Praxis haben sowohl die Arbeitszeit als auch die Promotionszeit zu einem lehrreichen Erlebnis werden lassen. Frau Prof. DR. THERESIA THEURL danke ich recht herzlich für die Übernahme des Zweitgutachtens.

Spezielle Anerkennung und großer Dank gilt Herrn DR. ANDREAS SIEMES und Herrn DR. KLAUS SEGBERS. Neben konstruktiver Kritik und kreativen Anregungen haben sie durch außerordentliches Engagement und hohen zeitlichen Einsatz zur Entstehung dieser Arbeit mit beigetragen.

Ein herzlicher Dank richtet sich an HENRIKE FISCHER, MICHAEL JÄGER, KLAUS JÜRgens, Bettina Platen, Jörg Püthe, Sonja Tolsdorff, Sebastian Veit sowie MAIK ZUIDINGA für die Unterstützung und aufschlussreichen Diskussionen. Ferner möchte ich MARKUS JÖRIS, SIMONE KNEPPER, JAN OLLE und HILDEGARD WÜBBE für die Unterstützung bei redaktionellen Arbeiten danken. Durch außerordentliches Engagement und hohen zeitlichen Einsatz hat insbesondere URSULA GERKE einen wesentlichen Beitrag zur Qualität der Arbeit geleistet. Insgesamt möchte ich allen Kollegen bei der BMS Consulting GmbH sowie dem gesamten Team am Lehrstuhl für Betriebswirtschaftslehre, insbesondere Controlling für das außerordentlich gute Arbeitsklima danken.

Abschließend sei meinen Eltern für die Geduld, die immerwährende Unterstützung und nicht zuletzt für die notwendige Aufmunterung beim Schreiben der Arbeit ganz herzlich gedankt. 


\section{Inhaltsverzeichnis}

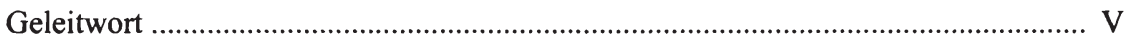

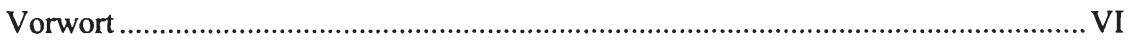

Abbildungsverzeichnis.........................................................................................

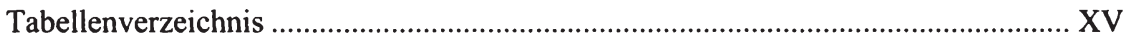

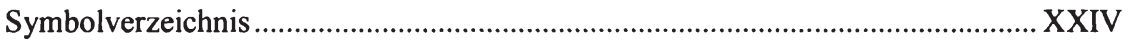

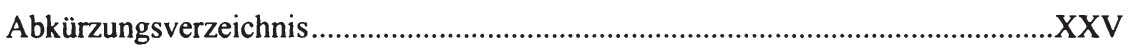

A Literaturgestützte Fundierung der Untersuchung................................................... 1

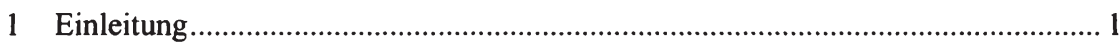

1.1 Problemstellung und Motivation der Arbeit ..................................................... 1

1.2 Zielsetzung der Untersuchung ................................................................. 4

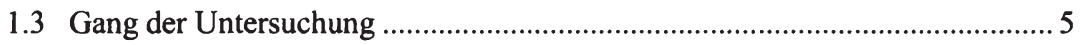

2 Mittelständische Unternehmen und ihre Banken................................................... 9

2.1 Mittelständische Unternehmen ................................................................ 9

2.1.1 Abgrenzung des Mittelstandsbegriffs .................................................. 9

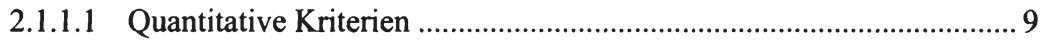

2.1.1.2 Qualitative Kriterien ......................................................................... 11

2.1.1.3 Arbeitsdefinition und gesamtwirtschaftliche Bedeutung.................... 13

2.1.2 Finanzierungsstrukturen und Unternehmensstrukturen in mittelständischen Unternehmen............................................................. 14

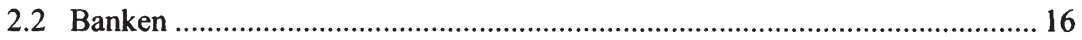

2.2.1 Theoretische Grundlagen sowie Funktionen von Banken ........................ 16

2.2.2 Banksystem in Deutschland mit dem Fokus auf Genossenschafts-

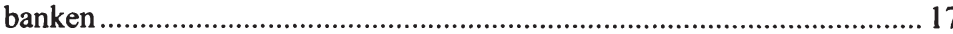

2.2.3 Firmenkundengeschäft mit dem Fokus auf dem Kreditgeschäft als ein Geschäftsfeld der Banken

3 Gesetzliche Rahmenbedingungen und ihre Implikationen in Bezug auf die Konditionengestaltung ................................................................................... 25

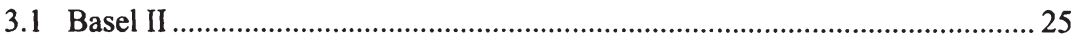

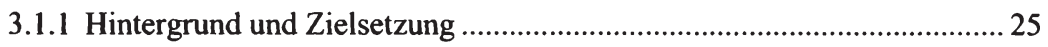

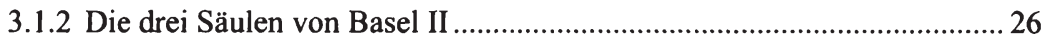




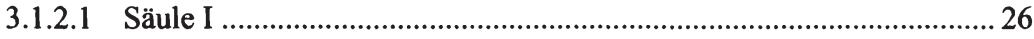

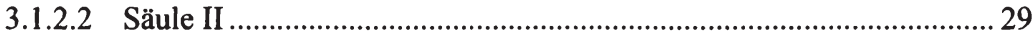

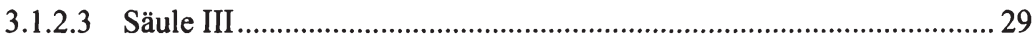

3.2 Mindestanforderungen an das Risikomanagement ......................................... 30

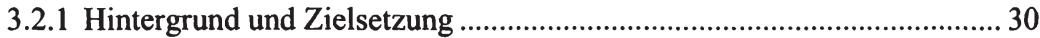

3.2.2 Zentrale Inhalte der Mindestanforderungen an das Risikomanagement .. 30

3.3 Implikationen der gesetzlichen Rahmenbedingungen für den

Gestaltungsspielraum der Banken bei der Konditionengestaltung................. 34

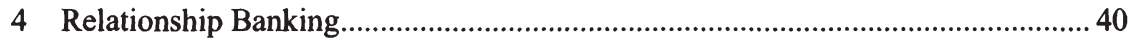

4.1 Definition von Relationship Banking ……………......................................... 40

4.2 Die Neue Institutionenökonomie mit dem Fokus auf der Prinzipal-Agen-

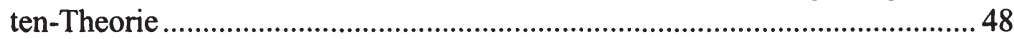

4.2.1 Einordnung und Annahmen der Prinzipal-Agenten-Theorie..................... 49

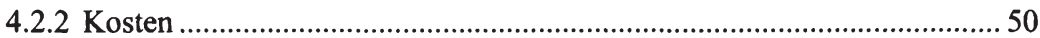

4.2.3 Problemfelder innerhalb der Prinzipal-Agenten-Beziehung .................... 52

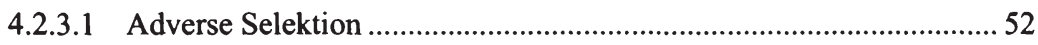

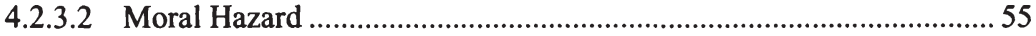

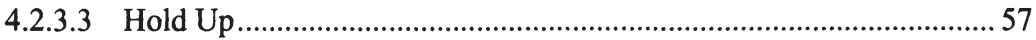

4.2.4 Wiederholte und langfristige Vertragsbeziehungen ................................... 58

4.2.5 Fazit der Neuen Institutionenökonomie in Bezug auf die Kunde-

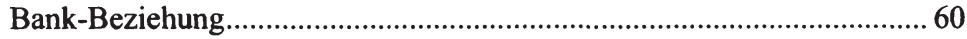

4.3 Stand der theoretischen und empirischen Forschung im Bereich des

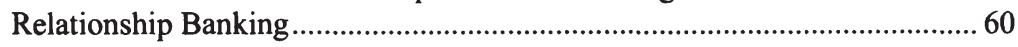

4.3.1 Überblick über die theoretischen Modelle im Bereich des Relation-

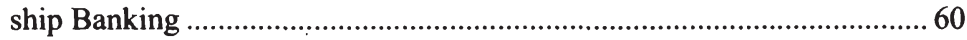

4.3.1.1 Grundlegende Modelle der Finanzintermediation ............................... 61

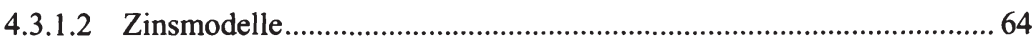

4.3.1.2.1 Beschreibung der Zinsmodelle ...................................................... 64

4.3.1.2.2 Fazit zu den Zinsmodellen........................................................... 75

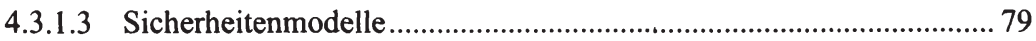

4.3.1.3.1 Beschreibung der Sicherheitenmodelle ....................................... 79

4.3.1.3.2 Fazit zu den Sicherheitenmodellen................................................ 83

4.3.1.4 Modelle zur Kreditverfügbarkeit ......................................................... 85

4.3.1.4.1 Beschreibung der Modelle zur Kreditverfügbarkeit .....................85 
4.3.1.4.2 Fazit zu den Modellen zur Kreditverfügbarkeit 87

4.3.2 Überblick über den Stand der empirischen Forschung im Bereich des Relationship Banking 88

4.3.2.1 Allgemeiner Überblick über den Stand der empirischen Forschung und Darstellung der zentralen verwendeten Variablen 88

4.3.2.2 Zinssatz 95

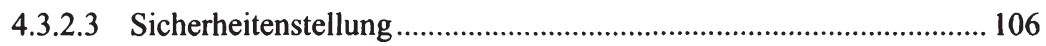

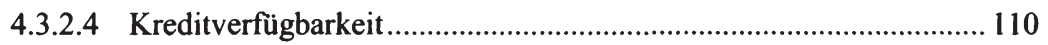

4.3.2.5 Kritische Würdigung der bisherigen empirischen Studien sowie Darstellung bestehender Erweiterungen um verhaltenswissenschaftliche Aspekte

4.3.2.5.1 Kritische Würdigung der bisherigen empirischen Studien......... 119

4.3.2.5.2 Sozial eingebundene Geschäftsbeziehungen bei UzZı

4.3.2.5.3 Integration von Vertrauen in eine Studie zur Analyse der Kunde-Bank-Beziehung durch HARHOFF/KÖRTING

4.3.2.5.4 Integration von Vertrauen in eine Studie zur Analyse der Kunde-Bank-Beziehung durch LEHMANN/NEUBERGER

4.4 Fazit des aktuellen Standes der Relationship Banking-Forschung.

5 Analyse der Geschäftsbeziehung in einem verhaltenswissenschaftlichen

Bezugsrahmen

5.1 Definition der Geschäftsbeziehung im Kontext des Investitions-

gütermarketing

5.2 Interaktionsansätze zur Analyse bestehender Geschäftsbeziehungen

5.2.1 Definitorische Abgrenzung der Begriffe Interaktion und Interaktionsansätze.

5.2.2 Theoretische Modelle zur Analyse von Geschäftsbeziehungen

5.2.2.1 Statische Modelle. 135

5.2.2.1.1 Modellbeschreibung 135

5.2.2.1.2 Fazit und Modellkritik

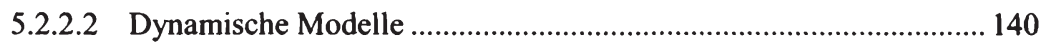

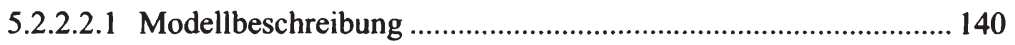

5.2.2.2.2 Fazit und Modellkritik .................................................................. 143

5.2.2.3 Integrierter Ansatz nach SEGBERS ................................................. 144

5.2.2.3.1 Modellbeschreibung ................................................................. 144

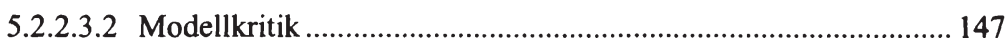


5.2.3 Implikationen der Interaktionsmodelle für die empirische Forschung im Bereich des Relationship Banking. 148

5.2.3.1 Analyse des Konstruktes Vertrauen............................................... 150

5.2.3.1.1 Definition und Dimensionen von Vertrauen ................................ 150

5.2.3.1.2 Stand der empirischen Forschung bei dem Vertrauenskonstrukt sowie Implikationen für die vorliegende Studie ............... 156

5.2.3.2 Analyse des Konstruktes Commitment............................................. 162

5.2.3.2.1 Definition von Commitment........................................................ 162

5.2.3.2.2 Stand der empirischen Forschung bei dem Commitment-Konstrukt sowie Implikationen für die vorliegende Studie

5.2.3.3 Ökonomische Wirkungen von Vertrauen und Commitment im Rahmen der Hausbankbeziehung

B Empirische Untersuchung zur Analyse der Kunde-Bank-Beziehung ............ 183

1 Grundlagen der Untersuchung und deskriptive Auswertung ............................... 183

1.1 Durchführung der Erhebung und Datenaufbereitung ................................. 183

1.1.1 Beschreibung des Datensatzes ............................................................. 189

1.1.2 Analyse der Gefahren von Antwortverfälschungen ............................... 194

1.1.3 Behandlung fehlender Werte sowie Datenbereinigung .......................... 197

1.1.4 Beschreibung der in der Studie verwendeten Variablen ......................... 203

1.2 Deskriptive Auswertung ............................................................................. 212

1.2.1 Finanzkennzahlen der Unternehmen und sonstige unternehmensbezogene Parameter ........................................................................... 213

1.2.2 Beschreibung der Kunde-Bank-Beziehung mit beziehungsbezoge-

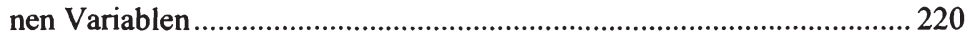

1.2.3 Beschreibung der Kunde-Bank-Beziehung aus verhaltenswissenschaftlicher Perspektive ........................................................................... 237

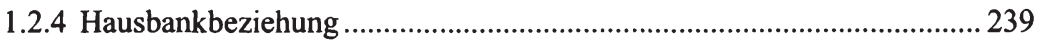

1.2.5 Bank- und marktbezogene Daten......................................................... 247

1.2.6 Zusammenfassung der Ergebnisse der deskriptiven Auswertung .......... 249

2 Hypothesenbildung .............................................................................................. 252

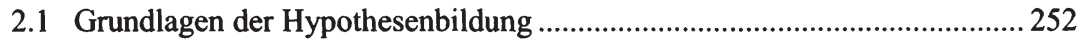

2.2 Hypothesen zum Zinssatz ………………………................................... 253

2.2.1 Vertrauens-basierte Hypothesen zum Zinssatz........................................ 253 
2.2.2 Commitment-basierte Hypothesen zum Zinssatz ................................... 254

2.3 Hypothesen zur Sicherheitenstellung....................................................... 255

2.3.1 Vertrauens-basierte Hypothesen zur Sicherheitenstellung ..................... 255

2.3.2 Commitment-basierte Hypothesen zur Sicherheitenstellung ................. 255

2.4 Hypothesen zur Kreditverfügbarkeit ........................................................... 256

2.4.1 Vertrauens-basierte Hypothesen zur Kreditverfügbarkeit ...................... 256

2.4.2 Commitment-basierte Hypothesen zur Kreditverfügbarkeit ................... 256

3 Statistische Überprüfung der Hypothesen .......................................................... 257

3.1 Methodisches Vorgehen zur Hypothesenprüfung.......................................257

3.2 Konzeptualisierung und Operationalisierung der hypothetischen Konstrukte Vertrauen und Commitment

3.2.1 Grundlagen der Konzeptualisierung und Operationalisierung der hypothetischen Konstrukte Vertrauen und Commitment

3.2.2 Grundlagen zur Beurteilung und Optimierung des Messmodells .......... 265

3.2.3 Vorgehen bei der quantitativen Analyse................................................ 270

3.2.4 Durchführung der quantitativen Analyse........................................... 272

3.3 Allgemeines Vorgehen bei der Korrelationsanalyse ……………................ 278

3.4 Überprüfung der Hypothesen zum Zinssatz ................................................ 281

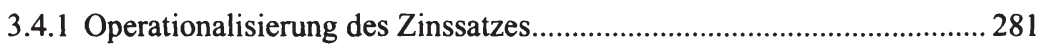

3.4.2 Korrelations- und Regressionsanalyse .................................................. 283

3.4.2.1 Durchführung der Korrelationsanalyse ............................................ 283

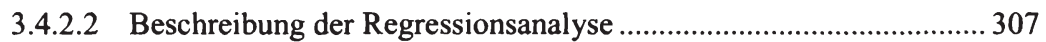

3.4.2.3 Durchführung der Regressionsanalyse ........................................... 310

3.5 Überprüfung der Hypothesen zur Sicherheitenstellung................................. 329

3.5.1 Operationalisierung der Sicherheitenstellung........................................ 329

3.5.2 Sicherheiten - Binärcodierung …………………............................... 331

3.5.2.1 Durchführung der Korrelationsanalyse ........................................... 331

3.5.2.2 Beschreibung der logistischen Regression........................................ 334

3.5.2.3 Durchführung der logistischen Regression ...................................... 337

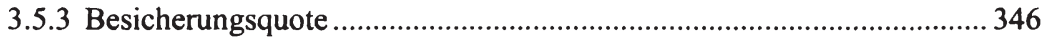

3.5.3.1 Durchführung der Korrelationsanalyse ............................................ 346

3.5.3.2 Durchführung der Regressionsanalyse .......................................... 350

3.6 Überprüfung der Hypothesen zur Kreditverfügbarkeit................................. 358 
3.6.1 Operationalisierung der Kreditverfügbarkeit........................................ 358

3.6.2 Korrelationsanalyse zur Kreditverfügbarkeit .......................................... 360

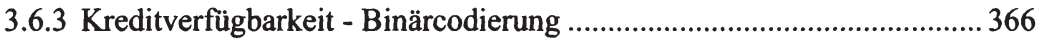

3.6.3.1 Logistische Regression der vergangenheitsbezogenen

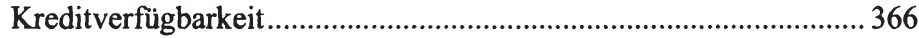

3.6.3.2 Logistische Regression der gegenwartsbezogenen Kreditver-

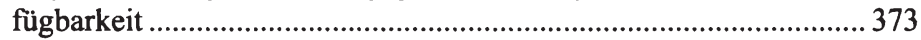

3.6.4 Kreditverfügbarkeit - Dauer der Kreditbewilligung ................................. 382

3.6.4.1 Beschreibung der ordinalen Regression........................................... 382

3.6.4.2 Durchführung der ordinalen Regression............................................ 383

C Abschließende Betrachtung ....................................................................................... 390

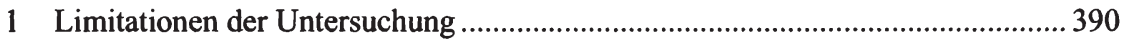

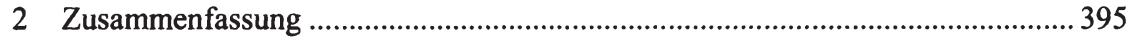

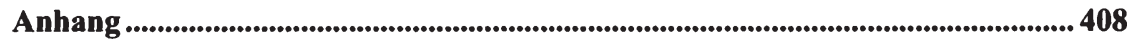

Anhang 1: Fragebogen und Begleitschreiben ................................................................ 409

Anhang 2: Deskriptive Auswertungen................................................................... 426

Anhang 3: Prüfung der Voraussetzungen der Faktorenanalyse .................................... 431

Anhang 4: Vollständige Korrelationsanalyse für die Datenbasis „Zinssatz“ “............ 432

Anhang 5: Ergänzende Auswertungen für den Zinssatz............................................. 442

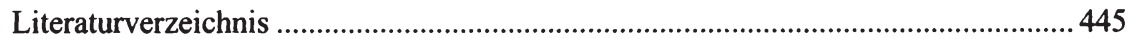




\section{Abbildungsverzeichnis}

Abb. A-1: Aufbau der Arbeit 8

Abb. A-2: Berechnung des Risikogewichtes im IRB-Ansatz....................................... 28

Abb. A-3: Kostenkomponenten des Kreditzinses ..................................................... 36

Abb. A-4: Pay-Off-Struktur der Investitionsalternativen im Modell von PETERSEN/RAJAN..

Abb. A-5: Informationsasymmetrien im Kommunikationsdreieck zwischen Kunde und Banken 70

Abb. A-6: Einflussgrößen des Zinssatzes 78

Abb. A-7: Vorgehen zur direkten Messung der Kreditverfügbarkeit 112

Abb. A-8: Auswirkung von Vertrauen im Rahmen der Kunde-Bank-Beziehung...... 120

Abb. A-9: Ökonomische Wirkungen der Informationsasymmetrie ........................... 130

Abb. A-10: Interaktionsmodell der IMP-GrouP ................................................... 139

Abb. A-11: Dynamisches Modell nach ForD ......................................................... 141

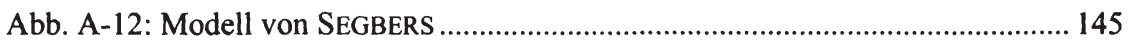

Abb. A-13: Dimensionen von Commitment im Modell von SEGBERS ....................... 147

Abb. A-14: Vertrauensbeziehungen im Rahmen der Kunde-Bank-Beziehung.......... 150

Abb. A-15: Vertrauensdimensionen nach GANESAN/HESS ....................................... 154

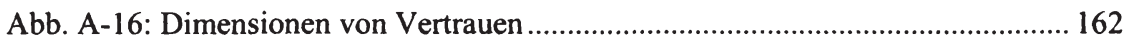

Abb. A-17: Ebenen der Kundenbindung ........................................................... 167

Abb. A-18: Dimensionen von Commitment........................................................ 170

Abb. A-19: Analyse der Auswirkungen der verhaltenswissenschaftlichen Parameter.

Abb. A-20: Einfluss des interpersonalen Wohlwollens auf den Zinssatz

Abb. B-1: Vorgehen bei der Auswahl der teilnehmenden Banken ........................... 185

Abb. B-2: Resonanz der angesprochenen Banken................................................. 186

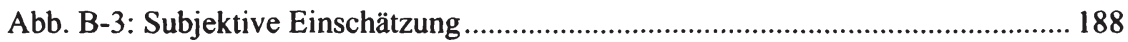

Abb. B-4: Vorgehen bei der Datenaufbereitung ………....................................... 198

Abb. B-5: Ableitung der Variablenbereiche aus der Theorie ....................................... 204

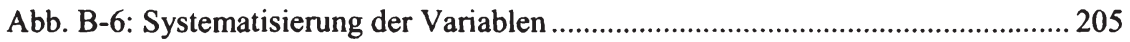

Abb. B-7: Anzahl der Produktbereiche, aus denen Produkte genutzt werden ........... 222

Abb. B-8: Nutzung der Bankprodukte .................................................................. 222 
Abb. B-9: Beratungsgespräche und Kontakthäufigkeiten je Jahr differenziert nach Anzahl der genutzten Produkte

Abb. B-10: Anzahl der Bankverbindungen je Kunde …………………...................... 227

Abb. B-11: Anteil der Bankfinanzierung bei dem befragten Institut .......................... 228

Abb. B-12: Verteilung der Besicherungsquote......................................................... 232

Abb. B-13: Nutzung der verschiedenen Sicherheiten.............................................. 233

Abb. B-14: Sicherheitenart differenziert nach Rechtsform ...................................... 235

Abb. B-15: Einschätzung der Firmenkundenbetreuer zum Zusammenhang zwischen der Bonität des Kunden und der Höhe der

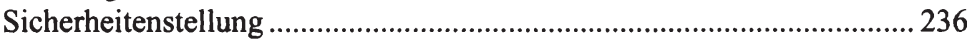

Abb. B-16: Beurteilung des Vertrauensverhältnisses .............................................. 237

Abb. B-17: Kreditverfügbarkeit differenziert nach Nicht-Haus- vs. Hausbank-

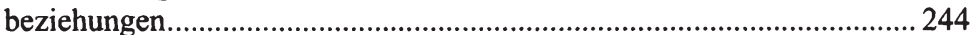

Abb. B-18: Vorgehen zur Hypothesenprüfung ………………................................ 258

Abb. B-19: Repräsentation eines komplexen Phänomens durch mehrere Konstrukte am Beispiel des Vertrauens ........................................................ 261

Abb. B-20: Alternative Vorgehensweisen zur Integration der Konstrukte am

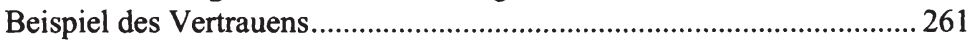

Abb. B-21: Vorgehensweise bei der quantitativen Analyse ....................................... 272

Abb. B-22: Z als Moderatorvariable und als Mediatorvariable ................................... 279

Abb. B-23: Korrelationsanalysen unter Berücksichtigung von Mediatoreffekten ..... 281

Abb. B-24: Vorgehen hinsichtlich der Korrelationsanalysen zum Zinssatz............... 284

Abb. B-25: Zentrale Einflussbereiche in Bezug auf den Kreditzins .......................... 310

Abb. B-26: Vorgehen zur Analyse der Kreditverfügbarkeit ......................................... 361

\section{Anhang Abbildungen}

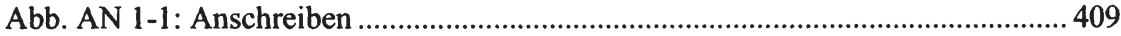

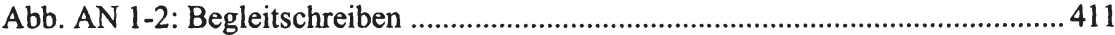

Abb. AN 1-3: Automatischer Datenerhebungsbogen ............................................... 412

Abb. AN 1-4: Manueller Fragebogen ..................................................................... 416

Abb. AN 5-1: Entwicklung des Euribor im Zeitablauf.............................................442 


\section{Tabellenverzeichnis}

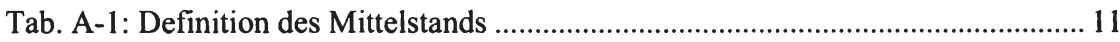

Tab. A-2: Abgrenzungskriterien für mittelständische Unternehmen .......................... 14

Tab. A-3: Eigenkapitalquoten deutscher Unternehmen in 2006 ................................. 15

Tab. A-4: Marktanteile der Kreditinstitute in 2006 .................................................. 19

Tab. A-5: Entwicklung der Volks- und Raiffeisenbanken ab 1970............................. 21

Tab. A-6: Systematisierung der Problemfelder bei Informationsasymmetrie ............... 52

Tab. A-7: Entwicklung der Zinsen im Laufe der Beziehung....................................... 76

Tab. A-8: Zusammenhang von Bonität und Sicherheiten im Rahmen der

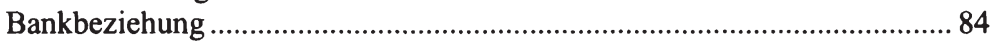

Tab. A-9: Kreditverfügbarkeit im Rahmen der Bankbeziehung ………………...........8 88

Tab. A-10: Zusammenfassung der Ergebnisse der empirischen Studien zum Zinssatz 105

Tab. A-11: Zusammenfassung der Ergebnisse der empirischen Studien zur Sicherheitenstellung 108

Tab. A-12: Zusammenfassung der Ergebnisse der empirischen Studien zur Kreditverfügbarkeit . 118

Tab. A-13: Auswirkung der Vertrauensformen auf die Kreditkonditionen ................ 128

Tab. A-14: Operationalisierung von Vertrauen in bestehenden Studien ...................... 160

Tab. A-15: Operationalisierung von Commitment in bestehenden Studien............... 168

Tab. A-16: Zusammenfassung der Auswirkungen des Vertrauens in die Bank......... 175

Tab. A-17: Zusammenfassung der Auswirkungen des Vertrauens in den Kunden.... 179

Tab. A-18: Ökonomische Wirkungen von Commitment ........................................ 182

Tab. B-1: Reihenfolge der Fragenbereiche inkl. jeweilige Anzahl Fragen im

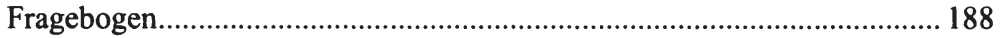

Tab. B-2: Rücklaufquoten je Institut und gesamt ...................................................... 189

Tab. B-3: Verteilung der Fragebögen nach Bundesländern ....................................... 190

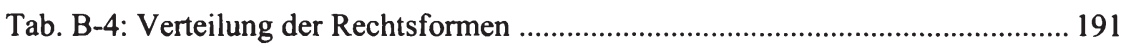

Tab. B-5: Verteilung der Branchen.......................................................................... 192

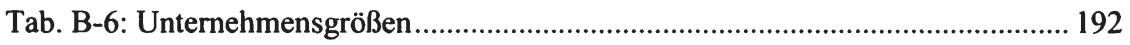

Tab. B-7: Gruppierung der Unternehmen nach Mitarbeiterzahlen............................. 192

Tab. B-8: Unternehmensgrößen in den vergleichbaren Studien ................................. 194 


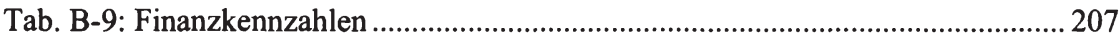

Tab. B-10: Unternehmensbezogene Variablen ............................................................ 207

Tab. B-11: Beziehungsbezogene Variablen................................................................ 209

Tab. B-12: Verhaltenswissenschaftliche Variablen.................................................211

Tab. B-13: Bankbezogene und betreuerbezogene Variablen ..................................... 212

Tab. B-14: Finanzkennzahlen der untersuchten Unternehmen.................................... 215

Tab. B-15: Finanzkennzahlen differenziert nach Kapitalgesellschaft vs. Nicht-

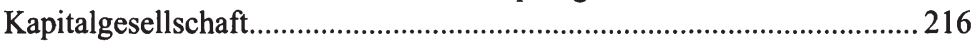

Tab. B-16: Finanzkennzahlen differenziert nach Branchen ...................................... 218

Tab. B-17: Finanzkennzahlen differenziert nach Unternehmensgröße ........................ 219

Tab. B-18: Alter differenziert nach Rechtsform, Branche und Unternehmens-

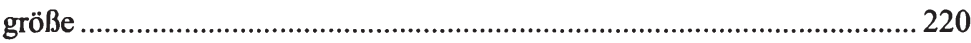

Tab. B-19: Dauer der Beziehung zur Bank und zum Firmenkundenbetreuer ............. 221

Tab. B-20: Beratungsgespräche und Kontakthäufigkeiten je Jahr differenziert nach Anzahl der genutzten Produkte.

Tab. B-21: Beratungsgespräche und Kontakthäufigkeiten je Jahr differenziert nach Umsatzgröße

Tab. B-22: Beratungsgespräche und Kontakthäufigkeiten je Jahr differenziert

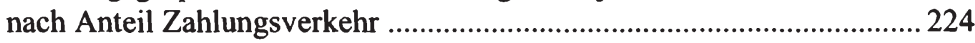

Tab. B-23: Beschreibung der Kunde-Bank-Beziehung ............................................... 225

Tab. B-24: Kunde-Bank-Beziehung differenziert nach Unternehmensgröße (Mitarbeiterzahl)

Tab. B-25: Kunde-Bank-Beziehung differenziert nach Unternehmensgröße (Umsatzklassen).

Tab. B-26: Anzahl der Bankverbindungen im internationalen Vergleich................... 228

Tab. B-27: Geografische Distanz zwischen Bank und Unternehmen ......................... 229

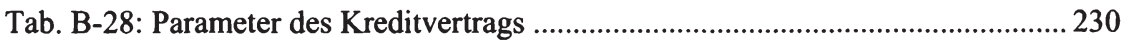

Tab. B-29: Berücksichtigung der Kreditsicherheiten in den empirischen Studien .... 231

Tab. B-30: Sicherheitenquote differenziert nach Branchen ......................................... 233

Tab. B-31: Sicherheitenart differenziert nach Branchen ........................................... 234

Tab. B-32: Sicherheitenquote differenziert nach Rechtsform ..................................... 234

Tab. B-33: Sicherheitenstellung differenziert nach Ausfallwahrscheinlichkeit ......... 235

Tab. B-34: Kreditablehnungen ................................................................................. 236

Tab. B-35: Dauer der Kreditbewilligung ................................................................. 237 
Tab. B-36: Auswertung der verhaltenswissenschaftlichen Fragen.............................. 239

Tab. B-37: Anteile der Hausbankbeziehungen ........................................................ 240

Tab. B-38: Vergleich der Finanzkennzahlen und Finanzierungsstrukturen bei

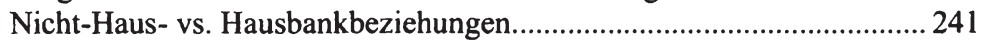

Tab. B-39: Vergleich der Produktnutzung bei Nicht-Haus- vs. Hausbankbeziehungen.

Tab. B-40: Vergleich der Beratungsgespräche und der Besicherung bei NichtHaus- vs. Hausbankbeziehungen.

Tab. B-41: Dauer der Kreditbewilligung differenziert nach Nicht-Haus- vs. Hausbankbeziehungen.

Tab. B-42: Vertrauen bei Nicht-Haus- vs. Hausbankbeziehungen. 245

Tab. B-43: Verhaltenwissenschaftliche Aspekte bei Nicht-Haus- vs. Hausbankbeziehungen. 246

Tab. B-44: Marktanteile und Bilanzsummen der Institute 248

Tab. B-45: Bedeutung der anreizorientierten Vergütung 249

Tab. B-46: Ausbildungsstand der Firmenkundenbetreuer. 249

Tab. B-47: Vor- und Nachteile der Integration auf Konstrukt- und Faktorebene ...... 262

Tab. B-48: Darstellung der Faktoren für Vertrauen und Commitment ........................ 263

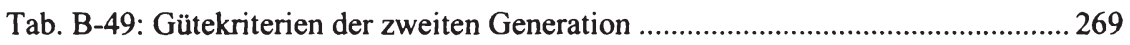

Tab. B-50: Verwendete Gütekriterien inkl. Anspruchsniveau …………………........ 270

Tab. B-51: Prüfung der Anwendungsvoraussetzungen für die Faktorenanalyse ....... 273

Tab. B-52: Untersuchung der organisationalen Glaubwürdigkeit .............................. 273

Tab. B-53: Untersuchung des organisationalen Wohlwollens ................................... 274

Tab. B-54: Untersuchung der personalen Glaubwürdigkeit ....................................... 275

Tab. B-55: Untersuchung des personalen Wohlwollens............................................ 275

Tab. B-56: Untersuchung der organisationalen Gebundenheit.................................... 276

Tab. B-57: Untersuchung der organisationalen Verbundenheit .................................. 276

Tab. B-58: Untersuchung der personalen Verbundenheit ......................................... 276

Tab. B-59: Untersuchung des personalen Wohlwollens und der personalen Verbundenheit

Tab. B-60: Zusammenfassende Beurteilung der Faktoren ...................................... 278

Tab. B-61: Korrelationskoeffizienten in Abhängigkeit vom Skalenniveau ............... 279

Tab. B-62: Bivariate Korrelationen der Finanzkennzahlen ....................................... 287 
Tab. B-63: Bivariate Korrelationen der unternehmensbezogenen Variablen mit den Finanzkennzahlen

Tab. B-64: Bivariate Korrelationen der beziehungsbezogenen Variablen

Tab. B-65: Bivariate Korrelationen der beziehungsbezogenen Variablen mit den Finanzkennzahlen

Tab. B-66: Bivariate Korrelationen der verhaltenswissenschaftlichen Variablen

Tab. B-67: Bivariate Korrelationen der verhaltenswissenschaftlichen Variablen mit den Finanzkennzahlen.

Tab. B-68: Bivariate Korrelationen der verhaltenswissenschaftlichen Variablen mit den unternehmensbezogenen Variablen.

Tab. B-69: Bivariate Korrelationen der verhaltenswissenschaftlichen Variablen mit den beziehungsbezogenen Variablen

Tab. B-70: Bivariate Korrelationen der bankbezogenen Variablen (1)

Tab. B-71: Bivariate Korrelationen der bankbezogenen Variablen (2)

Tab. B-72: Bivariate und partielle Korrelationen der Finanzkennzahlen mit dem Zinssatz

Tab. B-73: Bivariate und partielle Korrelationen der unternehmensbezogenen Variablen mit dem Zinssatz.

Tab. B-74: Bivariate und partielle Korrelationen der beziehungsbezogenen Variablen mit dem Zinssatz.

Tab. B-75: Bivariate und partielle Korrelationen der verhaltenswissenschaftlichen Variablen mit dem Zinssatz nach Bereinigung der Effekte der Finanzkennzahlen

Tab. B-76: Bivariate und partielle Korrelationen der verhaltenswissenschaftlichen Variablen mit dem Zinssatz nach Bereinigung beziehungsbezogener Effekte.

Tab. B-77: Bivariate und partielle Korrelationen der verhaltenswissenschaftlichen Variablen mit dem Zinssatz.

Tab. B-78: Bivariate und partielle Korrelationen der bankbezogenen Variablen ...... 307

Tab. B-79: Regression der Parameter der risikoorientierten Bepreisung ................... 312

Tab. B-80: Regression der Finanzkennzahlen (1) ................................................. 314

Tab. B-81: Regression der Finanzkennzahlen (2) .................................................... 316

Tab. B-82: Regression der Finanzkennzahlen und der unternehmensbezogenen

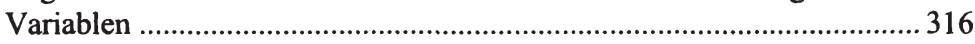

Tab. B-83: Regression der beziehungsbezogenen Variablen (1)................................. 319

Tab. B-84: Regression der beziehungsbezogenen Variablen (2)................................ 322 
Tab. B-85: Regression der beziehungsbezogenen Variablen (3).

Tab. B-86: Regression der Finanzkennzahlen und der beziehungsbezogenen Variablen

Tab. B-87: Regression der verhaltenswissenschaftlichen Variablen.

Tab. B-88: Regression der Finanzkennzahlen, der beziehungsbezogenen und der verhaltenswissenschaftlichen Variablen.

Tab. B-89: Zusammenfassung der Ergebnisse zum Zinssatz....

Tab. B-90: Vergleich des Erklärungsgehalts in Bezug auf den Zinssatz mit anderen Studien

Tab. B-91: Bivariate und partielle Korrelationen der Finanzkennzahlen mit der Sicherheitenstellung

Tab. B-92: Bivariate und partielle Korrelationen der beziehungsbezogenen Variablen mit der Sicherheitenstellung .

Tab. B-93: Bivariate Korrelationen der verhaltenswissenschaftlichen Variablen mit der Sicherheitenstellung

Tab. B-94: Bivariate Korrelationen der bankbezogenen Variablen mit der Sicherheitenstellung

Tab. B-95: Auswirkungen der Veränderung der unabhängigen Variablen 336

Tab. B-96: Logistische Regression der Finanzkennzahlen.

Tab. B-97: Logistische Regression der beziehungsbezogenen Variablen und der Finanzkennzahlen

Tab. B-98: Logistische Regression der verhaltenswissenschaftlichen Variablen

Tab. B-99: Logistische Regression der Finanzkennzahlen, der beziehungsbezogenen und der verhaltenswissenschaftlichen Variablen

Tab. B-100: Zusammenfassung der Ergebnisse zur Sicherheitenstellung.

Tab. B-101: Vergleich des Erklärungsgehalts in Bezug auf die Sicherheitenstellung mit anderen Studien.

Tab. B-102: Bivariate und partielle Korrelation der Finanzkennzahlen mit der Besicherungsquote.

Tab. B-103: Bivariate Korrelation der beziehungsbezogenen Variablen mit der Besicherungsquote.

Tab. B-104: Bivariate Korrelation der verhaltenswissenschaftlichen Variablen mit der Besicherungsquote

Tab. B-105: Regression der Finanzkennzahlen (1)

Tab. B-106: Regression der Finanzkennzahlen (2) 
Tab. B-107: Regression der Finanzkennzahlen und der unternehmensbezogenen

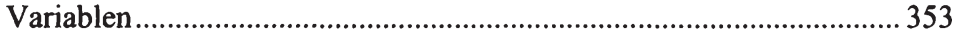

Tab. B-108: Regression der beziehungsbezogenen Variablen ................................... 354

Tab. B-109: Regression der beziehungsbezogenen Variablen und der

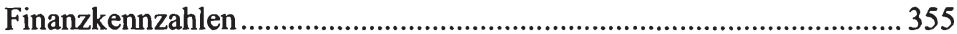

Tab. B-1 10: Regression der verhaltenswissenschaftlichen Variablen.......................... 356

Tab. B-111: Regression der Finanzkennzahlen, der beziehungsbezogenen und der verhaltenswissenschaftlichen Variablen ...........................................356

Tab. B-112: Zusammenfassung der Ergebnisse zur Sicherheitenstellung................... 357

Tab. B-113: Vergleich des Erklärungsgehalts in Bezug auf Sicherheiten mit

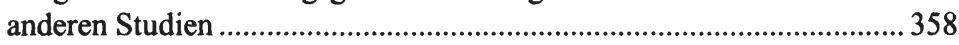

Tab. B-1 14: Bivariate Korrelationen der Finanzkennzahlen mit der

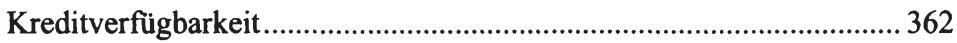

Tab. B-115: Bivariate Korrelationen der beziehungsbezogenen Variablen mit

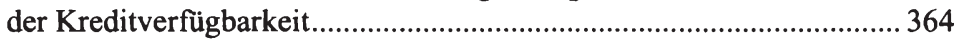

Tab. B-116: Bivariate Korrelationen der verhaltenswissenschaftlichen Variablen mit der Kreditverfügbarkeit.

Tab. B-117: Bivariate Korrelation der bankbezogenen Variablen mit der Kreditverfügbarkeit

Tab. B-118: Regression der Finanzkennzahlen

Tab. B-119: Regression der beziehungsbezogenen Variablen und der

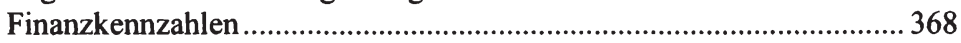

Tab. B-120: Regression der verhaltenswissenschaftlichen Variablen

Tab. B-121: Regression der Finanzkennzahlen, der beziehungsbezogenen und der verhaltenswissenschaftlichen Variablen

Tab. B-122: Vergleich der Güte der verschiedenen Modelle zur Kreditverfügbarkeit

Tab. B-123: Zusammenfassung der Ergebnisse zur Kreditverfügbarkeit

Tab. B-124: Regression der Finanzkennzahlen

Tab. B-125: Regression der Finanzkennzahlen und der beziehungsbezogenen Variablen

Tab. B-126: Regression der verhaltenswissenschaftlichen Variablen.

Tab. B-127: Regression der Finanzkennzahlen, der beziehungsbezogenen und der verhaltenswissenschaftlichen Variablen

Tab. B-128: Vergleich der Güte der verschiedenen Modelle zur Kreditverfügbarkeit. 
Tab. B-129: Zusammenfassung der Ergebnisse zur Kreditverfügbarkeit 379

Tab. B-130: Vergleich der Ergebnisse der beiden Operationalisierungen der Kreditverfügbarkeit 380

Tab. B-131: Vergleich des Erklärungsgehalts in Bezug auf die Kreditverfügbarkeit mit anderen Studien.

Tab. B-132: Ordinale Regression der Finanzkennzahlen

Tab. B-133: Ordinale Regression der Finanzkennzahlen und der beziehungsbezogenen Variablen

Tab. B-134: Ordinale Regression der verhaltenswissenschaftlichen Variablen

Tab. B-135: Ordinale Regression der Finanzkennzahlen, der beziehungsbezogenen, der verhaltenswissenschaftlichen und der bankbezogenen Variablen

Tab. B-136: Vergleich der Güte der verschiedenen Modelle zur Kreditverfügbarkeit.....

Tab. B-137: Zusammenfassung der Ergebnisse zur Dauer der Kreditbewilligung .... 389 


\section{Anhangtabellen}

Tab. AN 1-1: Kennzahlendefinitionen 425

Tab. AN 2-1: Finanzierungsstrukturen differenziert nach Kapitalgesellschaft vs. Nicht-Kapitalgesellschaft 426

Tab. AN 2-2: Finanzierungsstrukturen differenziert nach Unternehmensgröße 427

Tab. AN 2-3: Schiefe und Kurtosis bei der Sicherheitenquote 427

Tab. AN 2-4: Nutzung der verschiedenen Sicherheiten 428

Tab. AN 2-5: Sicherheitenart differenziert nach Rechtsform. 428

Tab. AN 2-6: Hausbankbeziehung - Finanzkennzahlen 429

Tab. AN 2-7: Hausbankbeziehung - Beziehungsbezogene Variablen. 430

Tab. AN 2-8: Kreditverfügbarkeit differenziert nach Nicht-Haus- vs. Hausbankbeziehungen

Tab. AN 3-1: Prüfung der Voraussetzungen der Faktorenanalyse - BARTLETTTest und MSA.

Tab. AN 3-2: Prüfung der Voraussetzungen der Faktorenanalyse DZIUBAN/SHIRKEY

Tab. AN 4-1: Bivariate Korrelationen der Finanzkennzahlen 432

Tab. AN 4-2: Bivariate Korrelationen der Finanzkennzahlen mit den unternehmensbezogenen Variablen

Tab. AN 4-3: Bivariate Korrelationen der beziehungsbezogenen Variablen 435

Tab. AN 4-4: Bivariate Korrelationen der verhaltenswissenschaftlichen Variablen mit den Finanzkennzahlen

Tab. AN 4-5: Korrelationsanalyse der verhaltenswissenschaftlichen Variablen mit den unternehmensbezogenen Variablen

Tab. AN 4-6: Korrelationsanalyse der verhaltenswissenschaftlichen Variablen mit den beziehungsbezogenen Variablen

Tab. AN 4-7: Bivariate Korrelationen der bankbezogenen Variablen 440

Tab. AN 5-1: Bivariate und partielle Korrelationen der verhaltenswissenschaftlichen Variablen mit dem Zinssatz 442

Tab. AN 5-2: Regression der beziehungsbezogenen Variablen (1) 
Tab. AN 5-3: Regression der beziehungsbezogenen Variablen (2) ...........................443

Tab. AN 5-4: Regression der verhaltenswissenschaftlichen Variablen....................... 444

Tab. AN 5-5: Regression der Finanzkennzahlen, der beziehungsbezogenen und der verhaltenswissenschaftlichen Variablen. 444 


\section{Symbolverzeichnis}

$€$

(C)

$\varnothing$

(B)

$\mathrm{H}$

$\mathrm{N}$

$\mathrm{R}$

$\mathrm{R}^{2}$

$\mathrm{R}^{2}$ korr.

$\$$

*

**

***
Euro

Copyright

Durchschnittlich

Amtlich registrierte Marke

Hypothese

Stichprobe

Multiple Korrelation

Quadrierte multiple Korrelation, zugl. Bestimmtheits$\mathrm{maß}$

Korrigiertes Bestimmtheitsmaß

Dollar

Signifikant auf dem 10\%-Niveau

Signifikant auf dem 5\%-Niveau

Signifikant auf dem 1\%-Niveau

Modell von Petersen/Rajan (1995)

D

I

$\mathrm{p}$

$\mathrm{t}$

$\mathrm{Y}^{\mathrm{R}}$

$\mathrm{Y}^{\mathrm{S}}$

\section{Logistische Regression}

B

$\exp$

$\ln$

$\mathrm{P}\left(\mathrm{Y}_{\mathrm{i}}=1\right)$

$\mathrm{P}\left(\mathrm{Y}_{\mathrm{i}}=0\right)$

$\mathrm{X}$
Rückzahlungsbetrag

Investitionsbetrag

Wahrscheinlichkeit für Projekterfolg

Zeitpunkt

Riskanter Projektertrag

Sicherer Projektertrag
Logitkoeffizient

Exponentialfunktion

Natürlicher Logarithmus

Wahrscheinlichkeit für Eintritt des Ereignisses bei $\mathrm{X}=\mathrm{i}$

Wahrscheinlichkeit für Nichteintritt des Ereignisses bei $\mathrm{X}=\mathrm{i}$

Variable der Regression 


\section{Abkürzungsverzeichnis}

Abb.

Abl.

AG

Agg.

AT

BaFin

BGH

BEF

Best.

BMS Consulting GmbH

BMWI

bspw.

BT

BTO

BVR

BWA

bzgl.

bzw.

c.p.

CRD

d.h.

DSGV

DEV

DM
Abbildung

Ablehnung

Aktiengesellschaft

Aggregiert

Allgemeiner Teil

Bundesanstalt für Finanzdienstleistungsaufsicht

Bundesgerichtshof

Belgische Franken

Bestätigung

Berens Mosiek Siemes Consulting GmbH

Bundesministerium für Wirtschaft und Technologie

beispielsweise

Besonderer Teil

Anforderungen an die Aufbau- und Ablauforganisation

Bundesverband der Deutschen Volks- und Raiffeisenbanken

Betriebswirtschaftliche Auswertung

bezüglich

beziehungsweise

ceteris paribus

Capital Requirement Directive

das heißt

Deutscher Sparkassen- und Giroverband

durchschnittliche erklärte Varianz

Deutsche Mark 
DZ BANK AG

eG

et al.

etc.

EU

EUR

evtl.

exkl.

f.

F.

ff.

FKB

FN

FoLL

GB

ggf.

gem.

HGB

Hrsg.

GroMiKV

i.A.

ICAAP

i.d.R.

ifk
Deutsche Zentral-Genossenschaftsbank AG

eingetragene Genossenschaft

et alii

et cetera

Europäische Union

Euro

eventuell

exklusive

folgende

Formel

fort folgende

Firmenkundenbetreuer

Fußnote

Forderungen aus Lieferungen und Leistungen

Geschäftsbeziehung

gegebenenfalls

gemäß

Handelsgesetzbuch

Herausgeber

Großkredit- und Millionenkreditverordnung

in Abhängigkeit

Internal Capital Adequacy Assessment Process

in der Regel

Institut für Kredit- und Finanzwirtschaft 
IfM

IHK

IMP-Group

inkl.

insb.

IRB

ITL

k.A.

KfW

$\mathrm{km}$

KMU

Korrel $^{2}$ Max

KPMG

KWG

MA

MaK

MAR

MaRisk

MCAR

MEUR

$\min$.

MinD

Mio.

Mrd.

o.ä.
Institut für Mittelstandsforschung

Industrie- und Handelskammer

International Marketing and Purchasing Group

inklusive

insbesondere

Internal Ratings Based

Italienische Lira

keine Angabe

Kreditanstalt für Wiederaufbau

Kilometer

Kleine und mittlere Unternehmen

Maximale quadrierte Korrelation zwischen den Konstrukten

Klynveld, Peat, Marwick und Goerdeler

Kreditwesengesetz

Mitarbeiter

Mindestanforderungen an das Kreditgeschäft

Missing at random

Mindestanforderungen an das Risikomanagement

Missing completely at random

Millionen Euro

Minuten

Managementinstrumente und -dialog

Millionen

Milliarden

oder ähnliche 
p.a.

Punktbi. K.

S.

S.o.

sog.

SolvV

Sp.

SPSS

SRP

Tab.

TEUR

Tsd.

Tz.

u.a.

u.dgl.

USA

USD

usw.

u.U.

verhaltenswissenschaftl.

vgl.

vS.

WGZ BANK AG

WZ per annum

Punktbiserialer Korrelationskoeffizient

Seite

siehe oben

so genannte

Solvabilitätsverordnung

Spalte

Statistical Package for the Social Sciences

Supervisory Review Process

Tabelle

Tausend Euro

Tausend

Textziffer

unter anderem

und dergleichen

United States of America

US-Dollar

und so weiter

unter Umständen

verhaltenswissenschaftlich

vergleiche

versus

Westdeutsche Genossenschafts-Zentralbank

Wirtschaftszweig 
zeb/

z.B.

z.T.
Zentrum für Ertragsorientiertes Bankmanagement

zum Beispiel

zum Teil 
Tina Püthe - 978-3-631-75310-1

Downloaded from PubFactory at 01/11/2019 06:20:26AM

via free access 


\section{A Literaturgestützte Fundierung der Untersuchung}

$1 \quad$ Einleitung

\subsection{Problemstellung und Motivation der Arbeit}

Die Finanzierung über Bankkredite stellt in Deutschland die wichtigste Finanzierungsquelle für mittelständische Unternehmen dar.' Aufgrund der kleinen Finanzierungsvolumina ist die Finanzierung über den Kapitalmarkt für diese Unternehmen häufig keine geeignete Möglichkeit. Alternative, eigenkapitalähnliche Finanzierungsformen, wie bspw. Mezzanine, gewinnen zwar zunehmend an Bekanntheit, die Bedeutung an der Gesamtfinanzierung ist allerdings sehr gering. ${ }^{2}$ Obwohl in der Presse Schlagzeilen zu lesen sind wie „Mezzanine - Eine moderne Finanzierungsform für den Mittelstand“ oder „Der Mezzanine-Markt brummt ${ }^{\star / 3}$, nutzen lediglich ca. 1\% der Unternehmen eine Mezzanine-Finanzierung. ${ }^{4}$ Auch in Zukunft wird die Bankfinanzierung die wichtigste Finanzierungsquelle dieser Unternehmen sein. ${ }^{5}$ Aufgrund der zentralen Bedeutung der Bankfinanzierung, die z.T. zu einer enormen Abhängigkeit der Unternehmen von der Bank führt, stellt sich aus Unternehmersicht die Frage, durch welche Einflussfaktoren die zentralen Parameter des Kreditvertrags - der Zinssatz, die Sicherheitenstellung und die Kreditverfügbarkeit - determiniert werden.

Mit der Einführung von Basel II wurde in der Presse vielfach der Eindruck erweckt, dass die Kreditentscheidung und die Höhe des Zinssatzes primär oder gar ausschließlich von der Ratingklasse des Unternehmens abhängt. ${ }^{6}$ Andere Einflussfaktoren wurden bei der Betrachtung häufig vernachlässigt oder gar vollends ignoriert. Um mögliche weitere Einflussfaktoren in Bezug auf die Parameter des Kreditvertrags identifizieren und deren Auswirkungen quantifizieren zu können, stellt die Analyse der Kunde-Bank-Beziehung eine wichtige Voraussetzung dar. Diese Beziehung ist häufig durch eine Vielzahl von Produktbeziehungen sowie durch eine hohe Komplexität gekennzeichnet. ' Es ist zunächst erforderlich, die Funktionsweise einer Bankbeziehung möglichst ganzheitlich zu analysieren und die relevanten Wirkungszusammenhänge zu untersuchen. Nur wenn die Faktoren, die zum Aufbau und Erhalt einer Bankbeziehung beitragen, bekannt sind, können die potenziellen ökonomischen Wirkungen einer Veränderung dieser Faktoren analysiert werden. ${ }^{8}$

Vgl. Berens/Högemann/Segbers (2005), S. 13.

Vgl. hier und im Folgenden mind (2006), S. 17.

Vgl. hierzu und zu weiteren Schlagzeilen zur Bedeutung der Mezzanine-Finanzierung Brezski (2006).

4 Vgl. mind (2006), S. 6. Die Innenfinanzierung als präferierte Finanzierungsform wird hier nicht weiter betrachtet. $\mathrm{Zu}$ den präferierten Finanzierungsformen mittelständischer Unternehmen vgl. mind (2006), S. 6.

Vgl. Hommel/Schneider (2004), S. 577.

Vgl. z.B. Brezski (2006).

Vgl. Moriarty/Kimball/Gay (1983), S. 4.

Vgl. Segbers (2007), S. 3. 
Für die Analyse der Kunde-Bank-Beziehung stellt die Neue Institutionenökonomie einen möglichen Bezugsrahmen dar. Während bei der neoklassischen Finanztheorie vornehmlich quantitative, rein ökonomische Aspekte des Kapitalmarktes betrachtet werden, stehen bei der Neuen Institutionenökonomie vielmehr qualitative, organisatorische und soziale Aspekte im Vordergrund. ${ }^{9}$ Zentrales Element bei der Analyse einer bestehenden Kunde-Bank-Beziehung im Kontext der Neuen Institutionenökonomie sind die Informationsasymmetrien zwischen den Geschäftspartnern. Zu Beginn einer Kunde-Bank-Beziehung sind diese Asymmetrien besonders hoch. Im Laufe der Beziehung sammelt die Bank Informationen, so dass diese Asymmetrien abgebaut werden. ${ }^{10}$ Die Unsicherheit der Bank in Bezug auf das Unternehmen wird aufgrund der verbesserten Informationsbasis reduziert.

Aus der Verschiebung der Informationsasymmetrien resultieren für den Unternehmer möglicherweise dahingehend Konsequenzen, als dass sich die Verschiebung unmittelbar in den Kreditkonditionen und somit in den Determinanten des Kreditvertrages Zinssatz, Sicherheitenstellung und Kreditverfügbarkeit - widerspiegelt.

Bei der Analyse in der vorliegenden Arbeit erfolgt aus nachstehenden Gründen eine Fokussierung auf mittelständische Unternehmen. Zum einen ist die Bankfinanzierung gerade für (nichtbörsengehandelte) mittelständische Unternehmen von elementarer Bedeutung. " Zum anderen ist zu vermuten, dass diese dargelegten Informationsasymmetrien bei der Finanzierung von mittelständischen Unternehmen besonders stark ausgeprägt sind, da für selbige wenige Publizitätsvorschriften existieren. ${ }^{12}$ Des Weiteren wäre bei einer Analyse der Kunde-Bank-Beziehung bezogen auf alle Unternehmensgruppen der Umfang und die Komplexität des ökonomischen Problems zu groß, so dass eine empirische Studie keinen Erklärungsbeitrag liefern könnte.

Es gibt bereits zahlreiche empirische Studien, die die Kunde-Bank-Beziehung vor dem Hintergrund der Neuen Institutionenökonomie untersuchen. Im Fokus der meisten Studien steht der Einfluss der Variablen wie Dauer der Bankbeziehung, Anzahl der genutzten Produkte und Anzahl der Bankverbindungen des Unternehmens in Bezug auf die Parameter des Kreditvertrags Zinssatz, Kreditverfügbarkeit und Sicherheitenstellung. ${ }^{13}$ Die Variablen werden als Ursache für den Umfang der ausgetauschten Informationen betrachtet und in den Studien schließlich als Indikator für den Grad der bestehenden Informationsasymmetrien verwendet. Diese Annahme impliziert, dass bei zunehmender Beziehungsdauer der Umfang der ausgetauschten Informationen zwangsläufig steigt.

\footnotetext{
Vgl. Sjögren (1994), S. 315.
}

Vgl. Lehmann/Neuberger (2000), S. 3.

Vgl. Elsas (2001), S. 7.

$\mathrm{Zu}$ größenabhängigen Erleichterungen für kleine und mittelgroße Kapitalgesellschaften bei der Offenlegung gem. HGB $\S 325 \mathrm{vgl}$. HGB $\S 326$ und 327.

13 Vgl. bspw. Blackwell/Winters (1997), S. 275 ff., Berger/Udell (1995), S. 351 ff., Petersen/Rajan (1994), S. 3 ff. 
Durch diese Annahme wird vernachlässigt, dass die einzelnen beteiligten Personen und deren Interaktion zentrales Element einer Geschäftsbeziehung sind. ${ }^{14} \mathrm{Gemäß}$ einer Definition nach GEMÜNDEN handelt es sich bei einer Geschäftsbeziehung um ,[...] langfristig angelegte, von ökonomischen Zielen geleitete Interaktionsprozesse und Bindungen zwischen Mitgliedern verschiedener Organisationen, die auf eine Folge von Austauschprozessen gerichtet sind". ${ }^{15}$ Im Rahmen der Kunde-Bank-Beziehung steht somit nicht nur die Beziehung zwischen dem Unternehmen und der Bank, sondern auch die Beziehung zwischen dem Unternehmer bzw. dem Ansprechpartner des Unternehmens und dem Firmenkundenbetreuer im Fokus der Betrachtung. Genau dieser Aspekt macht eine Bankbeziehung so besonders im Vergleich zur Finanzierung über den anonymen Markt und verschafft der Bank eine Differenzierungsmöglichkeit: „Perhaps the most competitive service a bank can offer is what bankers call a relationship, which means the customer gets to deal with a real human being, preferably one who is knowledgeable and courteous and who is get to know his name." Die Ausgestaltung der Beziehung hängt somit nicht nur von den beteiligten Organisationen, sondern auch von den beteiligten Personen ab. So werden persönliche Beziehungen auch weiterhin die Grundlage für die Hausbankbeziehung bilden, denn „Banking ist und bleibt People Business." ${ }^{\text {"17 }}$ Personen entwickeln bspw. Meinungen und Einstellungen in Bezug auf die Kontaktperson und das Unternehmen, wodurch bewusst oder unbewusst ihre weiteren Handlungen und Entscheidungen beeinflusst werden. Bei der Beschreibung einer Kunde-Bank-Beziehung sind somit nicht nur objektiv messbare Größen wie die Anzahl der Bankverbindungen, sondern auch verhaltenswissenschaftliche Elemente zu berücksichtigen. Im Rahmen der Kunde-Bank-Beziehung ist aus diesem Grund die globale Atmosphäre eine wesentliche Größe, welche durch Konstrukte wie z.B. Vertrauen, Kundenbindung, Macht oder Abhängigkeit charakterisiert werden kann. ${ }^{18}$ Die Kunde-Bank-Beziehungen unterscheiden sich somit nicht nur durch den Grad der Informationsasymmetrie, sondern bspw. auch durch die Atmosphäre der Geschäftsbeziehung. ${ }^{19}$ Ferner darf sich die Analyse nicht auf die Beziehung zwischen dem Unternehmen und der Bank beschränken, sondern muss erweitert werden um die Beziehung zwischen den jeweiligen Kontaktpersonen.

Möglicherweise werden bei der Festlegung der Kreditkonditionen durch die Bank bzw. durch den Firmenkundenbetreuer neben den Effekten resultierend aus der Informationsasymmetrie andere Einflussgrößen berücksichtigt. Für die Analyse der ökonomischen Parameter der Beziehung erscheint es unerlässlich, den Bezugsrahmen der Neuen Institutionenökonomie um verhaltenswissenschaftliche Aspekte zu erweitern. SEGBERS hat ein integriertes Modell zur Analyse der Kunde-Bank-Beziehung entwickelt. In dem Modell werden diese verhaltenswissenschaftlichen Einflüsse in Bezug

\footnotetext{
Vgl. Segbers (2007), S. 36.

Gemünden (1990), S. 34.

Main (1982), S. 64.

Cromme (2008), S. 431.

Vgl. Håkansson (1982), S. 21 f., Turnbull/Valla (1986), S. 6 f.

Diese beiden Ansätze sind jedoch nicht alternativ, sondern ergänzend zu verstehen, da sich selbige gegenseitig beeinflussen.
} 
auf die Konditionengestaltung integriert. ${ }^{20}$ Diese theoretischen Zusammenhänge bedürfen einer empirischen Validierung.

Im deutschen Raum gibt es empirische Studien, die sich mit der Rolle der Hausbank auseinandersetzen. ${ }^{21}$ Allein die Tatsache, dass es sich bei einer Kunde-Bank-Beziehung um eine Hausbankbeziehung handelt, lässt nicht den Schluss zu, dass die Geschäftsbeziehung von einer guten Atmosphäre getragen wird und dass die beiden Ansprechpartner in einer vertrauensvollen Beziehung stehen. In einigen wenigen Studien wurde bereits der Effekt der Interaktionsvariablen Vertrauen in Bezug auf die genannten ökonomischen Parameter untersucht, ${ }^{22}$ allerdings mangelt es bei diesen Studien, z.B. von HARHOFF/KÖRTING und LEHMANN/NEUBERGER, an einer wissenschaftlich fundierten Konzeptualisierung der verwendeten Interaktionsvariablen. ${ }^{23}$ Ferner liegt der Fokus dieser Studien ausschließlich auf der Vertrauensvariablen, so dass es hier an einer ganzheitlichen Betrachtung mangelt. Aufgrund der Defizite in der empirischen Forschung zur Analyse der Kunde-Bank-Beziehung resultiert die Motivation, eine Studie mit einer ganzheitlicheren Ausrichtung durchzuführen.

In dieser Arbeit erfolgt eine Fokussierung auf die Genossenschaftsbanken. Die vermuteten Zusammenhänge sind aufgrund der unterschiedlichen geschäftspolitischen Ausrichtung der verschiedenen in Deutschland existierenden Bankengruppen möglicherweise unterschiedlich stark ausgeprägt. Aufgrund der Mittelstandsfokussierung und der mit dem Regionalprinzip verbundenen großen Nähe von Genossenschaftsbanken kann davon ausgegangen werden, dass die Zusammenhänge zu den verhaltenswissenschaftlichen Einflussgrößen in diesem Bankensektor von noch stärkerer Bedeutung sind als bei anderen Bankengruppen, wie bspw. den Großbanken. ${ }^{24}$

\subsection{Zielsetzung der Untersuchung}

Vor dem Hintergrund der geschilderten Defizite liegt die Zielsetzung der vorliegenden Arbeit in der Erweiterung des Kenntnisstands über die Ausgestaltung der KundeBank-Beziehung von Unternehmen. Theoretische Grundlage bildet hierbei u.a. das Modell von SEGBERS. ${ }^{25}$ Es wird nicht der Anspruch erhoben, das Modell in seiner Gesamtheit zu prüfen. Stattdessen werden lediglich die Elemente des Modells untersucht, bei denen ökonomische Wirkungen in Bezug auf die Parameter des Kreditver-

20 Vgl. Segbers (2007). Weitere zentrale Modelle sind u.a. das Modell von Petersen/Rajan (1995) aus dem Bereich der Relationship Banking-Theorie sowie das Modell der IMP-Group (1982) und das Modell von Ford (1990) zur Ausgestaltung von Geschäftsbeziehungen aus dem Bereich des Investitionsgütermarketings.

21 Vgl. bspw. Elsas/Krahnen (1998), S. $1283 \mathrm{ff}$. oder Machauer/Weber (1998), S. $1355 \mathrm{ff}$.

22 Vgl. Lehmann/Neuberger (2000), S. 4, Harhoff/Körting (1998a), S. 2 ff., Harhoff/Körting (1998b), S. $1317 \mathrm{ff}$.

23 Vgl. hier und im Folgenden Segbers (2007), S. 181.

24 Zur Mittelstandsfokussierung als Bestandteil der geschäftspolitischen Ausrichtung der Genossenschaftsbanken vgl. BVR (2007a), S. 2. Zu den Besonderheiten der Genossenschaftsbanken vgl. ausführlich Kapitel A.2.2.2.

25 Vgl. Segbers (2007), S. 2 ff. 
trags vermutet werden. Effekte ohne ökonomische Konsequenz sind nicht Gegenstand der vorliegenden Arbeit. Ein Hauptaugenmerk liegt auf der Berücksichtigung der Interaktion zwischen den handelnden Personen, d.h. dem Firmenkundenbetreuer ${ }^{26}$ und dem Ansprechpartner des Unternehmens. Die explizite Integration der persönlichen Interaktionen soll dazu beitragen, ein besseres Verständnis der Wirkungsgrößen in Bezug auf die Kreditkonditionen innerhalb einer derartigen Beziehung zu erlangen.

Während in anderen Studien wie bspw. bei ELSAS der Fokus darauf liegt, die Existenz eines ökonomisch erklärbaren abweichenden Kreditmanagements von Hausbanken zu erklären, ${ }^{27}$ liegt der Fokus dieser Studie auf der Analyse der Existenz eines ökonomisch erklärbaren abweichenden Kreditmanagements in Abhängigkeit von der Ausgestaltung der verhaltenswissenschaftlichen Parameter. So kann nicht davon ausgegangen werden, dass bei allen Hausbankbeziehungen diese Interaktionsvariablen gleichermaßen ausgeprägt sind.

Ziel der Arbeit ist es zu untersuchen, ob aus den verhaltenswissenschaftlichen Elementen in einer Beziehung ökonomische Konsequenzen für das Unternehmen resultieren. Konkret soll geklärt werden, ob es in einer Beziehung, die bspw. durch eine gute Atmosphäre geprägt ist, Unterschiede im Hinblick auf die Zinskonditionen, die Sicherheitenstellung und die Kreditverfügbarkeit gibt.

Insgesamt verfolgt die Untersuchung eine deskriptive und explikative Zielsetzung. Es soll der Kenntnisstand über die Kunde-Bank-Beziehung und insbesondere über die ökonomischen Auswirkungen von verhaltenswissenschaftlichen Aspekten erweitert werden. Es ist nicht das Ziel, auf Basis der empirischen Ergebnisse einen normativen Katalog von Handlungsempfehlungen für die Ausgestaltung der Kunde-Bank-Beziehung abzuleiten.

\subsection{Gang der Untersuchung}

Das Untersuchungsziel wird durch einen dreigeteilten Untersuchungsaufbau verfolgt. Der erste Hauptteil (A) der Arbeit nimmt eine literaturgestützte Darstellung der für die empirische Auswertung grundlegenden Zusammenhänge vor. Die Durchführung der eigenen empirischen Untersuchung schließt sich im zweiten Hauptteil (B) an. Abschließend werden auf Basis der empirischen Ergebnisse im dritten Hauptteil (C) die Zusammenfassung und das Fazit der Untersuchung dargelegt. In Abb. A-1 wird der Gang der Untersuchung visualisiert, wobei nur die Kapitel dargestellt werden, die für das Verständnis der Struktur und der Argumentation in der Arbeit von Relevanz sind.

In Hauptteil A wird im Anschluss an die Einleitung in Kapitel A.2 eine Darstellung der Besonderheiten der beteiligten Beziehungspartner, d.h. der mittelständischen Unternehmen und der Banken, vorgenommen. Es erfolgt zunächst eine Herausarbeitung

\footnotetext{
26 Insbesondere im genossenschaftlichen Sektor ist häufig auch ein Vorstandsmitglied der Bank die Kontaktperson des Unternehmens. Sofern im Folgenden der Begriff Firmenkundenbetreuer verwendet wird, ist darunter auch der Vorstand zu subsumieren. 
der grundlegenden Eigenschaften mittelständischer Unternehmen sowie der besonderen Finanzierungsstrukturen derselbigen. In diesem Kapitel A.2.1 wird das Ziel verfolgt, sowohl den relevanten Untersuchungsgegenstand einzugrenzen als auch die Besonderheiten herauszuarbeiten. Anschließend erfolgt die Darstellung der Funktion von Banken sowie des deutschen Bankensystems. Da die Besonderheiten des deutschen Bankensystems zur Entwicklung des gerade für Deutschland typischen Hausbankprinzips geführt haben ${ }^{28}$ erscheint es notwendig, zunächst die Eigenarten desselbigen darzustellen.

Die veränderten gesetzlichen Rahmenbedingungen haben in der jüngeren Vergangenheit regelmäßig in der Presse eine Diskussion über die Kreditvergabe an mittelständische Kunden ausgelöst. ${ }^{29}$ In diesem Kontext wurde vermehrt von einer risikoorientierten Bepreisung sowie von verschlechterten Rahmenbedingungen für die Kreditvergabe an mittelständische Unternehmen gesprochen. ${ }^{30}$ In Kapitel A.3 wird untersucht, inwiefern die gesetzlichen Rahmenbedingungen einen Gestaltungsspielraum der Banken bei der Kreditvergabe zulassen. Konkret wird geprüft, welche Vorgaben hinsichtlich der relevanten ökonomischen Parameter Kreditzins, Sicherheitenstellung und Kreditverfügbarkeit gemacht werden.

In Kapitel A.4 wird ausführlich der Stand der aktuellen Relationship Banking-Theorie dargestellt. Nach einer Definition des Relationship Banking wird mit der PrinzipalAgenten-Theorie der theoretische Bezugsrahmen für eine bestehende Geschäftsbeziehung geschaffen. Selbige bildet die Grundlage für die in Kapitel A.4.3 beschriebenen Forschungsansätze. Es folgt eine Deskription der theoretischen Modelle sowie der existierenden empirischen Erkenntnisse im Bereich des Relationship Banking. In der kritischen Würdigung dieses Forschungsstands wird aufgezeigt, dass verhaltenswissenschaftliche Elemente z.T. in der Argumentation zu den theoretischen Modellen am Rande erwähnt werden, in den klassischen empirischen Studien zum Relationship Banking aber keinerlei Berücksichtigung finden. Ferner werden in diesem Kapitel erste Erweiterungen der klassischen Ansätze dargestellt. Bei diesen Erweiterungen werden verhaltenswissenschaftliche Elemente bereits integriert, jedoch mangelt es an einer theoretisch fundierten Konzeptualisierung und Operationalisierung. Um dieses Defizit ausgleichen zu können, wird im nächsten Kapitel die theoretische Grundlage für die Berücksichtigung dieser Aspekte in der vorliegenden Studie geschaffen.

In Kapitel A.5 erfolgt die Analyse der Geschäftsbeziehung unter Berücksichtigung der Interaktion zwischen den beteiligten Parteien, d.h. dem Kunden und der Bank bzw. den jeweiligen Kontaktpersonen. Das theoretische Fundament entstammt im Wesentlichen dem Investitionsgütermarketing. Der Definition der Geschäftsbeziehung aus Marketingperspektive in Kapitel A.5.1 folgt die Darstellung bestehender theoretischer Modelle aus der Interaktionstheorie, welche explizit die in Kapitel A.4 monierte fehlende Berücksichtigung der Interaktion integrieren. Die Darstellung der Modelle in Kapitel A.5.2 zeigt, dass die Konstrukte Vertrauen und Commitment in allen beschrie-

28 Vgl. Fischer (1990), S. 3.

29 Vgl. z.B. Wirtschaftswoche (2008) oder FAZ (2005).

30 Vgl. z.B. Brezski (2006). 
benen Modellen von essenzieller Bedeutung und somit bei der Analyse einer bestehenden Geschäftsbeziehung zu berücksichtigen sind. Bevor diese Konstrukte in der vorliegenden empirischen Studie integriert werden, erfolgt eine Analyse des Forschungsstands. Anschließend werden die beiden Konstrukte jeweils definitorisch abgegrenzt. Basierend auf diesen Definitionen werden die jeweils bestehenden empirischen Ansätze dargestellt. Abschließend wird analysiert, inwiefern aus diesen beiden Konstrukten ökonomische Konsequenzen resultieren und eine Beeinflussung der Parameter Zinssatz, Sicherheitenstellung und Kreditverfügbarkeit stattfindet. Diese Analyse bildet schließlich die Grundlage für die Hypothesenbildung im empirischen Teil der Arbeit.

Im Hauptteil B erfolgt die empirische Untersuchung der zuvor gewonnenen Erkenntnisse. In Kapitel B.1 werden die Grundlagen der Untersuchung und die deskriptiven Ergebnisse dargestellt. Zunächst wird das Vorgehen der Datenerhebung sowie die Datenaufbereitung beschrieben. Bei den deskriptiven Auswertungen lassen sich bereits erste Hinweise auf die Besonderheiten der Kunde-Bank-Beziehung identifizieren. Hier erfolgt u.a. eine Analyse ausgewählter Gruppenunterschiede, z.B. zwischen unterschiedlichen Branchen, unterschiedlichen Rechtsformen oder unterschiedlichen Formen der Bankbeziehung. In Kapitel B.2 folgt die Bildung der Hypothesen, basierend auf der im Teil A durchgeführten Analyse der ökonomischen Konsequenzen von Vertrauen und Commitment. In Kapitel B.3 schließt sich die statistische Überprüfung der Hypothesen an. Nach der Beschreibung des methodischen Vorgehens erfolgt basierend auf den theoretischen Erkenntnissen aus Kapitel A.5 zunächst die Konzeptualisierung und Operationalisierung der Konstrukte bzw. der notwendigen Dimensionen von Vertrauen und Commitment. Diese Ergebnisse bilden die Grundlage für die Überprüfung der Hypothesen, denn Vertrauen und Commitment werden in den nachfolgenden Untersuchungen als unabhängige Variablen berücksichtigt.

Anschließend werden die ökonomischen Wirkungen jeweils in Bezug auf die Parameter Zinssatz, Sicherheitenstellung und Kreditverfügbarkeit analysiert. Im Fokus steht hier die Analyse der verhaltenswissenschaftlichen Aspekte. Die gesetzlichen Rahmenbedingungen lassen vermuten, dass die Bonität des Unternehmens eine wichtige Bedeutung bei der Kreditvergabe spielt. Aus diesem Grund wird auch dieser Größe eine besondere Aufmerksamkeit geschenkt. Zusätzlich werden die Erkenntnisse der bestehenden traditionellen Relationship Forschung berücksichtigt. Ziel ist es aufzuzeigen, dass die verhaltenswissenschaftlichen Variablen einen zusätzlichen Erklärungsgehalt zu diesen beiden Einflussbereichen haben. Aus diesem Grund erfolgt jeweils eine isolierte Analyse der Variablen aus den unterschiedlichen Bereichen sowie eine kombinierte Analyse der Variablen in Bezug auf die ökonomischen Parameter. Während bei dem Zinssatz nur eine Form der Operationalisierung gewählt wird, werden bei der Sicherheitenstellung und der Kreditverfügbarkeit verschiedene Operationalisierungen herangezogen und untersucht. Da das Skalenniveau der abhängigen Variablen unterschiedlich ist, kommen verschiedene Verfahren zur Hypothesenprüfung zur Anwendung. Dies sind die lineare Regression, die logistische Regression und die ordinale Regression. In den einzelnen Kapiteln werden zunächst die verwendeten Verfahren beschrieben und anschließend die Ergebnisse der Analyse dargestellt. 
Die Arbeit schließt in Hauptteil C mit einer abschließenden Betrachtung der Untersuchung. In diesem Teil der Arbeit werden der Untersuchungsverlauf sowie die gewonnenen Erkenntnisse zusammengefasst.

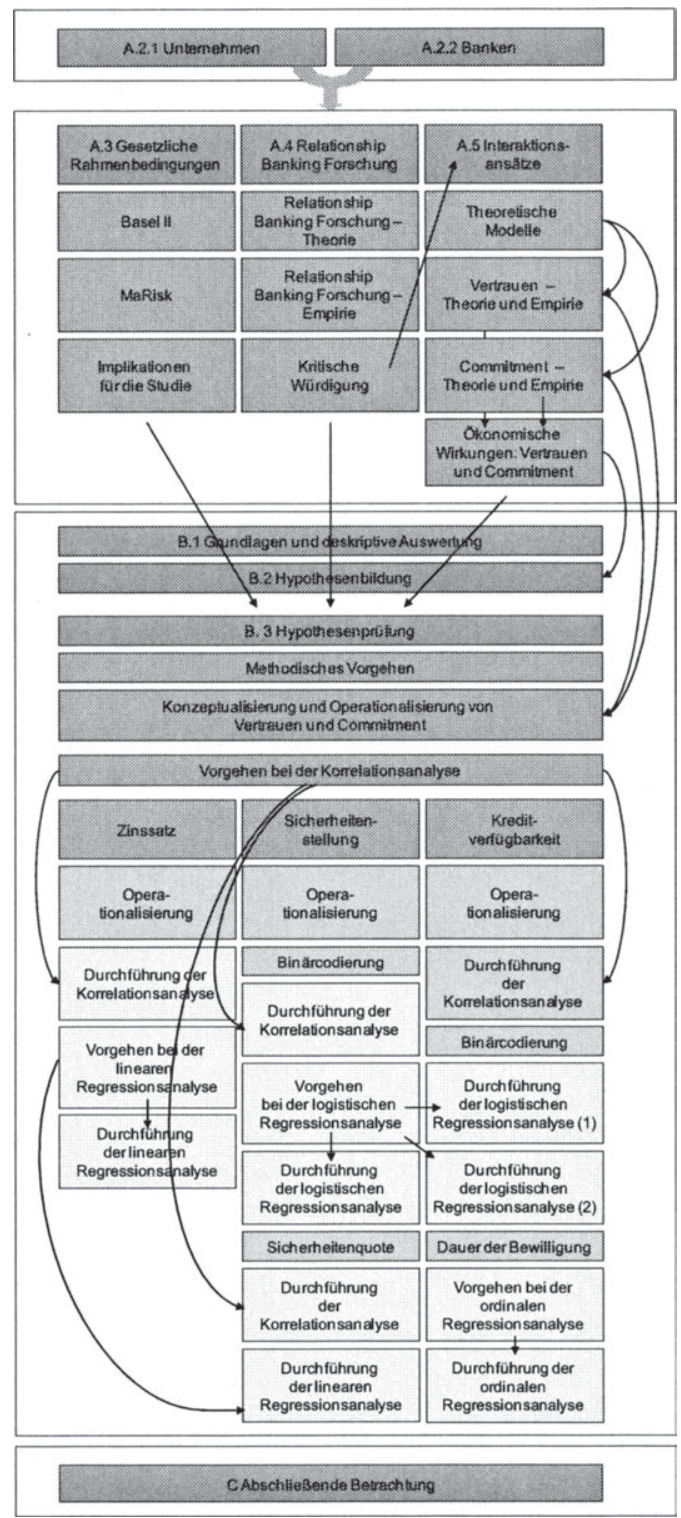

Abb. A-1: Aufbau der Arbeit 


\section{Mittelständische Unternehmen und ihre Banken}

\subsection{Mittelständische Unternehmen}

\subsubsection{Abgrenzung des Mittelstandsbegriffs}

Untersuchungsgegenstand der vorliegenden Arbeit ist die Beziehung zwischen Banken und ihren mittelständischen Firmenkunden. Nach einer Abgrenzung des relevanten Mittelstandsbegriffs erfolgt im Anschluss daran eine Herausarbeitung der Besonderheiten dieser Unternehmen.

Zwar lassen sich in der Literatur zahlreiche Mittelstandsdefinitionen ${ }^{31}$ finden, allerdings existiert weder eine allgemein anerkannte noch eine Legaldefinition des Begriffs Mittelstand. ${ }^{32}$ Ein entscheidendes Hemmnis bei Erstellung einer allgemeingültigen Definition ist die Vielzahl, Unterschiedlichkeit und Ungenauigkeit der Merkmale des Mittelstandes, mit denen man die vielen Gruppen zu einer einheitlichen zu verbinden versucht. Auf dem Gebiet der Mittelstandsforschung hat die umfassende Untersuchung von GANTZEL ${ }^{33}$ aus dem Jahre 1962 die Grundlage für die zahlreichen möglichen Abgrenzungen und Einflussfaktoren der Unternehmensgröße geschaffen. ${ }^{34}$ So werden je nach Autor bei dem Versuch der Erstellung einer Mittelstandsdefinition neben ökonomischen Merkmalen, auch soziologische, rechtliche, historische, politische, psychologische und statistische Merkmale herangezogen. ${ }^{35}$ In Konsequenz ergibt sich eine sehr komplexe Vorstellung des Phänomens Mittelstand. Gerade diese vieldimensionalen, fließenden Grenzen, die Uneinheitlichkeit und die Beweglichkeit des Mittelstandes im modernen Wirtschaftsleben werden als charakteristisch für den Mittelstand erachtet. ${ }^{36}$

Im Folgenden soll eine für diese Arbeit zweckmäßige Abgrenzung mittelständischer Unternehmen hergeleitet und vorgestellt werden, wobei zur Erstellung derselben quantitative und qualitative Kriterien kombiniert werden.

\subsubsection{Quantitative Kriterien}

Bei der Abgrenzung des Begriffs Mittelstand anhand von quantitativen Merkmalen stellt sich zum einen die Frage, welche Merkmale aus der Fülle möglicher Kriterien auszuwählen sind und zum anderen, welche Schwellenwerte verwendet werden sollen. Wesentliche Unterscheidungsmerkmale können u.a. quantitative Größen wie Anzahl

31 Vgl. Günterberg/Wolter (2002), S. 1-21. Gantzel findet insgesamt 190 Definitionen. Vgl. Gantzel (1962), S. 46. Moulin/Aerts finden sogar 200 Definitionen. Vgl. Moulin/Arts (1954), S. 168. Wie auch bei Kosmider (1994) werden im Sinne einer Deckungsgleichheit im Weiteren folgende Begriffe synonym verwandt: Unternehmen, Unternehmung (als finanzielle-rechtliche Einheit) sowie entsprechend kleine und mittlere Unternehmen (KMU), Mittelstand. Vgl. Kosmider (1994), S. 29, 30, FN 92.

Vgl. Hinderer (1984), S. 7.

Vgl. Gantzel (1962), S. 18.

Vgl. Grünberg (1932), S. 137. 
der Beschäftigten, Umsatzhöhe, Bilanzsumme, Quadratmeter Verkaufsfläche, Anzahl der Betten etc. sein. ${ }^{37} \mathrm{KOCH}$ nennt weitere Messzahlen als Abgrenzungskriterium wie die Lohn- und Gehaltssumme, die Rohstoffeinsatzmenge und den Energieverbrauch. ${ }^{38}$ BUSSE VON COLBE gliedert die möglichen heranzuziehenden quantitativen Merkmale in Anlehnung an den betrieblichen Leistungsprozess: Einsatzmengen oder -werte elementarer Produktionsfaktoren, Kapitaleinsatz als Maßgröße, Leistungsmengen oder werte als Maßgröße. ${ }^{39}$ Auch GANTZEL nennt diverse Merkmale wie Jahresumsatz, Betriebskosten, Bilanzvolumen, Investitionskapital. ${ }^{40}$

Die angeführten Maßgrößen zeigen bereits, dass hier z.T. eine Differenzierung nach Branchen vorgenommen wurde. So kann die Anzahl der Betten nur für Branchen wie das Hotelgewerbe oder die Quadratmeter Verkaufsfläche nur für die Handelsbranche sinnvoll sein. Eine differenzierte Aufgliederung nach Branchen ist allerdings nicht geeignet, da dies zu einer Unübersichtlichkeit bei der Ableitung einer sinnvollen Mittelstandsdefinition führen würde. ${ }^{41}$ So verhindert die differenzierte Aufgliederung branchenübergreifende Vergleiche und lässt sich bei branchenübergreifenden Analysen - bei einer solchen handelt es sich im vorliegenden Fall - nicht einsetzen.

Hingegen wird in der Literatur häufig auch die Forderung erhoben, dass die Auswahl der Merkmale nach Zweckmäßigkeit erfolgen soll. ${ }^{42} \mathrm{Da}$ der Gegenstand der vorliegenden Untersuchung die Geschäftsbeziehung der mittelständischen Unternehmen zu ihren Banken ist, werden primär Finanzierungsaspekte beleuchtet, so dass die Abgrenzungskriterien aus dem Finanzbereich stammen sollten.

$\mathrm{Da}$ in den amtlichen Statistiken und im deutschen Recht die Beschäftigtenzahl, die Bilanzsumme und die Umsatzgröße am häufigsten verwendet werden ${ }^{43}$ erscheint ihre Verwendung für diese Untersuchung zweckmäßig. In der Literatur findet man zwecks Abgrenzung des Mittelstandsbegriffs häufig die Definitionen des Instituts für Mittelstandsforschung in Bonn, die Empfehlung 96/280/EG der EU-Kommission vom 1. Januar $2005^{44}$ sowie die Abgrenzung gemäß § 276 HGB (vgl. Tab. A-1). Bei der Definition der EU-Kommission muss neben den Größenkriterien zusätzlich das Kriterium der Unabhängigkeit erfüllt sein, wobei solche Unternehmen als unabhängig gelten, die nicht zu 25\% oder mehr des Kapitals oder der Stimmenanteile im Besitz von einem oder mehreren Unternehmen stehen, welche die Definitionen der KMU nicht erfüllen. ${ }^{45}$

\footnotetext{
$37 \quad$ Vgl. Bussiek (1994), S. 17.

38 Vgl. Koch (1959), S. 83.

39 Vgl. Busse von Colbe (1964), S. $33 \mathrm{ff}$.

40 Vgl. Gantzel (1962), S. 112.

41 Vgl. Gantzel (1962), S. 112.

42 Vgl. Lücke (1967), S. 21.

43 Vgl. Schuster (1991), S. 13, Flacke (2007), S. 11.

44 Vgl. EU Kommission (2003). Diese Definition wird bspw. in einer Anzahl von Gemeinschaftsakten und Programmen übernommen und wird im Bereich staatlicher Beihilfen in die KMUGruppenfreistellungsverordnung (inklusive der F\&E-Beihilfen) sowie der Verordnung bzgl. Beihilfen für Berufsausbildung integriert.

45 Vgl. Welter (2003), S. 29.
} 


\begin{tabular}{|l|c|c|c|c|c|c|c|c|}
\hline & \multicolumn{2}{|c|}{ IfM $^{46}$} & \multicolumn{2}{c|}{ EU-Kommission } & \multicolumn{3}{c|}{ HGB $^{48}$} \\
\cline { 2 - 9 } & $\begin{array}{c}\text { Beschä- } \\
\text { tigten- } \\
\text { zahl }\end{array}$ & $\begin{array}{c}\text { Umsatz } \\
\text { in Mio. } \\
\text { EUR }\end{array}$ & $\begin{array}{c}\text { Beschä- } \\
\text { tigten- } \\
\text { zahl }\end{array}$ & $\begin{array}{c}\text { Umsatz } \\
\text { in Mio. } \\
\text { EUR }\end{array}$ & $\begin{array}{c}\text { Bilanz- } \\
\text { summe } \\
\text { in Mio. } \\
\text { EUR }\end{array}$ & $\begin{array}{c}\text { Beschä- } \\
\text { tigten- } \\
\text { zahl }\end{array}$ & $\begin{array}{c}\text { Umsatz } \\
\text { in Mio. } \\
\text { EUR }\end{array}$ & $\begin{array}{c}\text { Bilanz- } \\
\text { summe } \\
\text { in Mio. } \\
\text { EUR }\end{array}$ \\
\hline $\begin{array}{l}\text { Mikro-/Kleinst- } \\
\text { unternehmen }\end{array}$ & - & - & $<10$ & $<=2$ & $<=2$ & - & - & - \\
\hline $\begin{array}{l}\text { Kleine Unter- } \\
\text { nehmen }\end{array}$ & $<=9$ & $<1$ & $<50$ & $<=10$ & $<=10$ & $<50$ & $<8,0$ & $<4$ \\
\hline $\begin{array}{l}\text { Mittlere Unter- } \\
\text { nehmen }\end{array}$ & $10-499$ & $<=50$ & $<250$ & $<=50$ & $<=43$ & $<250$ & $<32,1$ & $<16$ \\
\hline Großunternehmen & $>500$ & $>50$ & $>=250$ & $>50$ & $>43$ & & & \\
\hline
\end{tabular}

Tab. A-1: Definition des Mittelstands

Vergleicht man die verschiedenen Schwellenwerte hinsichtlich der Mitarbeiteranzahl, schwanken die diversen Angaben zwar, allerdings überschreitet keine den Wert von 500 Mitarbeitern, so dass diese Schwelle als obere Grenze gelten kann. Bei der Ziehung derartiger Grenzen zwischen KMU und großen Unternehmen wohnt ein gewisses Element der Willkür inne. So wird bei zwei qualitativ gleichen Unternehmen das Unternehmen mit 499 Mitarbeitern als KMU eingestuft, das Unternehmen mit 501 Mitarbeitern allerdings als Großunternehmen. Dennoch hat sich in der Wissenschaft die pragmatische, quantitative Definition durchgesetzt, dass es sich um mittelständische Unternehmen handelt, wenn die Beschäftigtenzahl unter 500 Mitarbeitern und der Umsatz unter 50 Mio. Euro liegen. ${ }^{49}$

Die alleinige Abgrenzung des Mittelstands auf Basis dieser quantitativen Kriterien greift allerdings zu kurz. ${ }^{\text {so }} \mathrm{Da}$ die ausschließliche Verwendung der Betriebsgröße als Abgrenzungskriterium des Mittelstands nicht nur äußerst unexakt, sondern wie beschrieben z.T. auch willkürlich und entsprechend unbefriedigend wäre, werden im Folgenden die qualitativen Kriterien erarbeitet.

\subsubsection{Qualitative Kriterien}

Aufgrund der zuvor genannten Probleme bei der Verwendung von quantitativen Abgrenzungskriterien wird den qualitativen Merkmalen in der Mittelstandstheorie relativ große Aufmerksamkeit entgegengebracht. GANTZEL begründet dies auch damit, dass

46 Vgl. Günterberg/Kayser (2004), S. 3.

47 Vgl. Amtsblatt EU (2003a).

48 Gemäß HGB $\S 267$ in der Fassung vom 04. Dezember 2004 gelten als kleine Kapitalgesellschaften solche, die mindestens zwei der drei in Tab. A-1 dargestellten Merkmale für kleine Kapitalgesellschaften nicht überschreiten und als mittelgroße Kapitalgesellschaften solche, die mindestens zwei der drei Merkmale für kleine Kapitalgesellschaften überschreiten und mindestens zwei der drei Merkmale für mittelgroße Kapitalgesellschaften nicht überschreiten. Vgl. HGB (2004), § 267. 
Quantitäten keinen Typ darstellen können. ${ }^{51}$ Die Betriebsgröße ist gemäß GANTZEL als ein Strukturmerkmal derivativer Natur und somit als Folge qualitativer Ursachen zu betrachten. ${ }^{52}$ So beschreibt MUGLER als Kennzeichen mittelständischer Unternehmen nachstehende Eigenschaften: ${ }^{53}$

- Einheit zwischen Unternehmensführung und Eigentum

- Starke Persönlichkeit des Unternehmers

- Existenz eines persönlichen Netzwerkes des Unternehmers zu Lieferanten, Kunden und der Öffentlichkeit

- Leistungserstellung nach individuellen Kundenwünschen

- Häufig enge und informelle Kontakte zwischen der Unternehmensleitung und den Mitarbeitern

- Geringer Formalisierungsgrad der Organisation

- Flexibilität in Bezug auf Umweltveränderungen

- Ein häufig nur geringer Marktanteil, eine geringe Produktpalette bzw. ein geringer Diversifikationsgrad

Insbesondere der erste Aspekt - die Leitung durch den Eigentümer bzw. mehrheitlichen Kapitaleigner - kann als zentrales Kennzeichen von KMU betrachtet werden. ${ }^{54}$ Auch bei der Definition durch die EU-Kommission wurde dieser Aspekt durch die geforderte Konzernunabhängigkeit berücksichtigt. Als konzernunabhängig gelten solche Unternehmen, bei denen sich weniger als $25 \%$ des Kapitals in der Hand eines anderen Unternehmens befinden..$^{55}$ Bei den KMU befindet sich das Eigenkapital typischerweise nicht in den Händen von Großunternehmen, sondern von privaten Eigentümern. ${ }^{56}$ Zwar können Großunternehmen Tochtergesellschaften haben, deren quantitative Obergrenzen sich unterhalb der oben genannten Werte bewegen, allerdings weicht die Führungssituation durch einen angestellten Geschäftsführer und durch die Abhängigkeit von der Muttergesellschaft von derjenigen ab, in der sich ein Unternehmer befindet, der gleichzeitig Kapitaleigner ist und nicht die finanzielle und materielle Unterstützung eines Großunternehmens im Rücken hat. Diese Selbstständigkeit wird z.T. weiter gefasst und zwar als rechtliche und wirtschaftliche (dispositive) Unabhängigkeit. Diese rechtliche und wirtschaftliche Unabhängigkeit ist wohl das signifikanteste Kriterium mittelständischer Unternehmen, wobei die juristische Selbstständigkeit der dispositiven in der Regel vorgelagert wird, ${ }^{57}$ da prinzipiell nur durch sie Handlungsfreiheit gewährleistet wird. ${ }^{58}$

\footnotetext{
Vgl. Gantzel (1962), S. 279.

Vgl. Gantzel (1962), S. 263.

Vgl. Mugler (1998), S. 20.

Vgl. Bussiek (1994), S. 18.

Vgl. EU Kommission (2003b), Art. 3 (2).

Vgl. Bussiek (1994), S. 18.

Vgl. Kosmider (1993), FN 100.

Vgl. Kosmider (1993), S. 32.
} 
Das Unternehmen wird durch die Verantwortlichkeit des Unternehmers geprägt, der das Risiko trägt und dessen Existenzgrundlage und Einkommen durch den wirtschaftlichen Erfolg des Unternehmens bestimmt wird. Dieser Aspekt der eigenverantwortlichen, d.h. der unmittelbar persönlichen Erfolgs- und Risikohaftung aufgrund der selbstständigen Arbeits- bzw. Leistungsentscheidung äußert sich in einer Verflechtung von Unternehmensleitung und Inhaberschaft und wird daher treffend mit der Eigentümerunternehmerschaft umschrieben. ${ }^{59}$ Je nach Mentalität des Unternehmers werden somit besonders risikoreiche Vorgehensweisen oder sehr zurückhaltende Kapitaldispositionen gewählt, um das eigene Risiko möglichst gering zu halten. Aufgrund der bestehenden Kapitalbindung resultiert oft eine lebenslange Bindung an das Unternehmen sowie eine im Vergleich zu Unternehmen mit angestellten Geschäftsführern abweichende Zielsetzung in der Unternehmensleitung. ${ }^{\circ}$ Für den Eigentümer-Unternehmer ist die Unternehmenssicherung und Selbstständigkeit weit wichtiger als die Gewinnsteigerung. Der angestellte Geschäftsführer hingegen misst der Selbstständigkeit eine weit geringere Bedeutung zu, stattdessen ist die Gewinnerwirtschaftung als Indikator seiner Leistung das oberste Ziel. Daraus ergeben sich erhebliche Implikationen für die Führung, da der Eigentümer nicht nur eine reine Steuerungsfunktion ausübt, sondern, anders als bspw. der angestellte Geschäftsführer oder Vorstand, auch persönliche Risiken eingeht.

Ein Problem der qualitativen Abgrenzung ist in der Festlegung der oberen Definitionsgrenze zu sehen. Die durch die Unternehmensperson geschaffene mittelständische Identität des Unternehmens wird durch das Wachstum des Unternehmens nicht plötzlich untergehen. ${ }^{61}$ Eine obere Begriffsabgrenzung mit nur qualitativen Kriterien kann bisher nicht generell gelöst werden. Da qualitative Kriterien nur schwer zu operationalisieren sind, erscheint eine Kombination von quantitativen und qualitativen Kriterien sinnvoll.

\subsubsection{Arbeitsdefinition und gesamtwirtschaftliche Bedeutung}

Da trotz der zahlreichen Ansätze keine einheitliche Definition in der Literatur existiert, sollte die Festlegung der Abgrenzungsmerkmale in Abhängigkeit von dem Ziel der Untersuchung erfolgen.

Aufgrund der weiten Verbreitung in der Literatur wird auch in dieser Studie auf die quantitativen Abgrenzungsmerkmale Mitarbeiterzahl und Umsatz rekurriert. ${ }^{62}$ Als mittelständisch wird ein Unternehmen mit weniger als 500 Beschäftigten und einem Umsatz von weniger als 50 Mio. EUR angesehen. ${ }^{63}$ Diese Abgrenzung erscheint für

\footnotetext{
sy Vgl. Hinderer (1984), S. 9.

60 Vgl. hier und im Folgenden Bussiek (1994), S. 18.

61 Vgl. Hamer (1987), S. 53 f.

62 Vgl. hierzu Kapitel B.1.1.1.

63 Vgl. Welter (2003), S. 29. Für die empirische Untersuchung im Hauptteil B ist es erforderlich, dass für die zu untersuchenden Unternehmen ein bankinternes Rating aus den Ratingsegmenten Mittelstand, Übergangsbereich oder Oberer Mittelstand vorliegt. Denn im Rahmen der Untersuchung wird auf die im Rating ermittelte Ausfallwahrscheinlichkeit zurückgegriffen. Die EinordTina Püthe - 978-3-631-75310-1
} 
die Studie deshalb sinnvoll, da bei größeren Unternehmen die eingangs erwähnten, in den theoretischen Modellen des Relationship Banking zugrunde gelegten Informationsasymmetrien zwischen Kunde und Bank weniger ausgeprägt sind.

Diese rein quantitative Abgrenzung wird noch um die qualitativen Aspekte ergänzt. Bei der qualitativen Abgrenzung wurden insbesondere die rechtliche und wirtschaftliche Selbstständigkeit sowie das Kriterium der Einheit von Eigentum und Leitung als zentral herausgestellt. Das Kriterium der Einheit von Eigentum und Leitung ist zwar für die Studie für die Erklärung verschiedener Phänomene von Interesse, allerdings wird selbiges anders als das Kriterium der Selbstständigkeit nicht als notwendiges Kriterium herangezogen. In Anlehnung an die Definition der EU-Kommission werden konzernabhängige Unternehmen, d.h. Unternehmen bei denen mehr als 25\% des Kapitals in der Hand eines anderen Unternehmens sind, von der Betrachtung ausgeschlossen. Dieses qualitative Merkmal ist für die Analyse der Geschäftsbeziehung zwischen Kunde und Bank insofern von Relevanz, als dass ein Unternehmen, welches in ein Konzernnetzwerk eingebunden ist, vermutlich eine stärkere Verhandlungsposition hat. Ferner sind in diesem Fall die Informationsprozesse zur Bank aufgrund von Konzernvorgaben möglicherweise anders ausgestaltet. Des Weiteren stehen im öffentlichen Markt aufgrund von Publikationen des Konzerns vermutlich mehr Informationen zur Verfügung und im Falle der Zahlungsunfähigkeit greift gegebenenfalls die Konzernhaftung. Zudem erfolgt möglicherweise die Kreditaufnahme bei der Bank nicht durch das konzernabhängige Unternehmen, sondern durch das Mutterunternehmen. Das abhängige Unternehmen wiederum refinanziert sich bei dem Mutterunternehmen, so dass hier besondere Finanzierungsstrukturen vorliegen. In Tab. A-2 werden die herangezogenen Abgrenzungskriterien zusammengefasst.

\begin{tabular}{|l|c|}
\hline Abgrenzungskriterium & Schwellenwert \\
\hline Mitarbeiterzahl & $<500$ \\
\hline Umsatz & 260 Tsd. EUR - 50 Mio. EUR ${ }^{64}$ \\
\hline Kapital in Besitz eines anderen Unternehmens & $<25 \%$ \\
\hline
\end{tabular}

Tab. A-2: Abgrenzungskriterien für mittelständische Unternehmen

\subsubsection{Finanzierungsstrukturen und Unternehmensstrukturen in mittelstän- dischen Unternehmen}

Da mittelständische Unternehmen u.a. charakterisiert sind durch eine geringe Größe und die Einheit zwischen Eigentum und Leitung, resultiert ein Einfluss auf die Wahl

nung in eines der drei Ratingsegmente ist im Wesentlichen vom Umsatz des zu ratenden Unternehmens abhängig. Die Umsatzgrenzen sind wie folgt: Ratingsegment Mittelstand: 260 Tsd. EUR bis 4 Mio. EUR, Übergangsbereich: 4 bis 6 Mio. EUR, Oberer Mittelstand: 6 Mio. EUR bis 1 Mrd. EUR. Vgl. Hromadka/Döhring (2007), S. 259. In Konsequenz werden Unternehmen, deren Umsatz unterhalb der Mindestgröße dieser Ratingsegmente von 260 TEUR liegt, nicht berücksichtigt. Vgl. hierzu Kapitel B.1.1.

64 Zur Abgrenzung nach unten vgl. ausführlich Kapitel B.1.1 sowie Fußnote 63. 
der Finanzierungsinstrumente und damit auf die Kapitalstruktur. ${ }^{65}$ Die Selbstfinanzierung ist die präferierte Finanzierungsform des Mittelstands. ${ }^{66}$ Allerdings reichen die Gewinne mittelständischer Unternehmen in der Regel nicht aus, um das benötigte Kapital allein über die Selbstfinanzierung aufzubringen. Dies ist einerseits begründet durch die teilweise schlechte Ertragslage, andererseits besteht in vielen mittelständischen Unternehmen die Notwendigkeit, dass der Inhaber regelmäßig Entnahmen aus dem Unternehmen zur Bestreitung des Lebensunterhaltes tätigen muss. Entsprechend ist es unerlässlich, auf Finanzierung von außerhalb des Unternehmens zurückzugreifen. ${ }^{67}$ Die Eigenkapitalquoten betragen im bundesweiten Durchschnitt lediglich $29,7 \%$ (vgl. Tab. A-3).

\begin{tabular}{|l|r|r|r|r|c|}
\hline Umsatz in Millionen Euro & Gesamt & $<2$ & $2-<10$ & $10-<50$ & $\geq 50$ \\
\hline $\begin{array}{l}\text { Eigenkapital in Relation } \\
\text { zur Bilanzsumme }\end{array}$ & $29,7 \%$ & $18,9 \%$ & $24,0 \%$ & $28,5 \%$ & $30,0 \%$ \\
\hline
\end{tabular}

Tab. A-3: Eigenkapitalquoten deutscher Unternehmen in $2006^{68}$

Aus eigener Motivation bevorzugen mittelständische Unternehmen neben der Selbstfinanzierung den Bankkredit, weil die Bereitschaft fehlt, die für eine Nutzung des Kapitalmarkts notwendige Transparenz walten zu lassen. ${ }^{69}$ Unabhängig vom eigenen Willen ist für viele mittelständische Unternehmen der Gang an den Kapitalmarkt aber auch objektiv schwierig, weil den von ihnen emittierten Assets das nötige kritische Volumen fehlt. Gleichzeitig verfügen sie aber auch häufig nicht über das Know-how und die personellen Ressourcen, um sich intensiv mit der Finanzierung zu beschäftigen. ${ }^{70}$ Mittelständische Unternehmen müssen auch weiterhin auf die Fortsetzung der engen und teilweise langjährigen Bankbeziehung vertrauen, da alternative Finanzierungsformen nur begrenzt genutzt werden bzw. zur Verfügung stehen. " So lässt sich hinsichtlich der Finanzierungsstrukturen eine starke Konzentration auf Fremdkapitalfinanzierungen konstatieren, die traditionell durch Hausbanken bereitgestellt werden. ${ }^{72}$ Banken sind gemäß der klassischen Betrachtungsweise allerdings nur dann bereit, einem Unternehmen weitere Kredite zu gewähren, wenn ein bestimmtes Verhältnis von haftendem Eigenkapital zu Fremdkapital nicht unterschritten wird, da ihnen bei höherem Fremdkapitalanteil das Risiko zu hoch erscheint. ${ }^{73}$ Dieses Verhältnis ist nach Ländern, Wirtschaftszweigen und Unternehmensgrößen unterschiedlich und u.a. auch von Faktoren wie etwa gestellten Sicherheiten, Finanzierungszweck, Laufzeit etc.

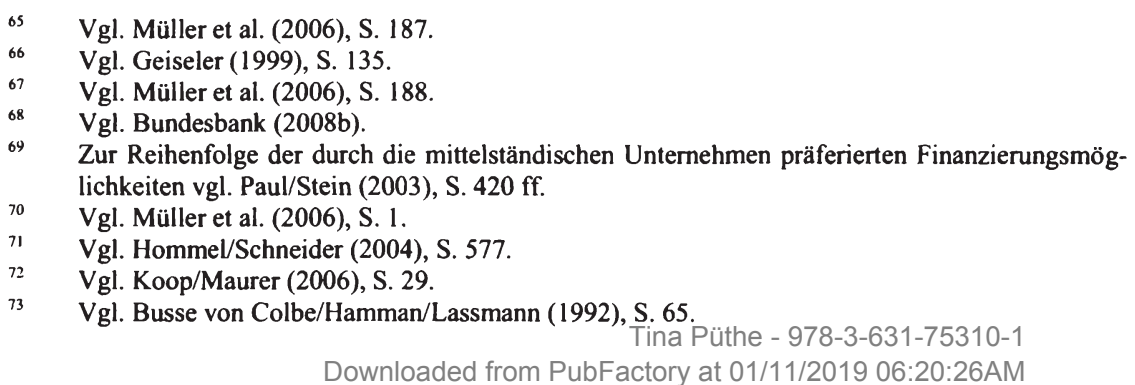


abhängig. Sobald der Eigenkapitalanteil die von der Bank geforderte Grenze unterschreitet, kann die Fremdfinanzierung nur durch die Erhöhung der Eigenkapitalbasis ausgedehnt werden. Wenn die bisherigen Eigentümer nicht selbst über zusätzliche Finanzmittel verfügen, dann ist die Beschaffung von zusätzlichem Eigenkapital für kleine oder mittlere Unternehmen häufig nur durch Aufnahme neuer Gesellschafter möglich. ${ }^{74}$ Aufgrund der zentralen Bedeutung der Bankfinanzierung, die z.T. sogar zu einer enormen Abhängigkeit von der Bank führen kann, erscheint die Notwendigkeit der Analyse der Bankbeziehung evident.

Neben der Bedeutung der Bankfinanzierung für das mittelständische Unternehmen ergeben sich aber auch aus den besonderen Unternehmensstrukturen Implikationen für die Analyse der Bankbeziehung. Der Kreis von Führungskräften ist in mittelständischen Unternehmen in der Regel auf eine oder wenige Personen begrenzt, so dass sich eine große direkte Abhängigkeit des gesamten Betriebsgeschehens von diesen wenigen Personen ergibt. ${ }^{75}$ Charakteristisch für Führungskräfte in mittelständischen Unternehmen ist vielfach die Aufgabenkonzentration sowie die Aufgabenüberlastung. ${ }^{76} \mathrm{Gemäß}$ einer Studie von FLACKE zu mittelständischen Unternehmen werden in $73 \%$ der untersuchten Fälle die Controlling-Aufgaben unter anderem durch die Geschäftsführung und in $34 \%$ der Fälle ausschließlich durch die Geschäftsführung erfüllt." ${ }^{77}$ Resultierend aus der Aufgabenkonzentration ist der Unternehmenseigentümer gleichzeitig auch Ansprechpartner der Bank im Rahmen der Kreditbeschaffung.

Die Besonderheit der Finanzierungsstrukturen mittelständischer Unternehmen sowie deren spezifische Unternehmensstrukturen lassen Implikationen für die Beziehung zur Bank erwarten. Nachdem zunächst die Unternehmensseite betrachtet wurde, wird im Folgenden die Funktion von Banken im Allgemeinen und anschließend das deutsche Banksystem im Speziellen beschrieben. Es folgt eine Konkretisierung durch die Darstellung des Firmenkundengeschäfts und hier insbesondere des Kreditgeschäfts als ein wesentlicher Bestandteil des Firmenkundengeschäfts.

\subsection{Banken}

\subsubsection{Theoretische Grundlagen sowie Funktionen von Banken}

In der Theorie der Finanzintermediation werden Banken als Institutionen erklärt, die durch das Vermitteln von Finanzierungskontrakten und durch das Eintreten in Finanzierungskontrakte Transaktionskosten reduzieren, die aus ungleich verteilten Informationen zwischen den originären Kapitalgebern und den originären Kapitalnehmern resultieren. ${ }^{78}$ Das wohl bekannteste informationsökonomische Modell zur Erklärung

\footnotetext{
${ }_{74}$ Vgl. Busse von Colbe/Hamman/Lassmann (1992), S. 65.

75 Vgl. Kosmider (1993), S. 39.

76 Vgl. Kosmider (1993), S. 39.

77 Vgl. Flacke (2007), S. 134.

78 Vgl. Bömer (2005), S. 53.
} 
der Vorteilhaftigkeit der Intermediärsfinanzierung von DIAMOND basiert auf der Idee, dass Banken Informationsasymmetrien zwischen Kapitalgebern und -nehmern besser reduzieren können als alternative Finanzinstitutionen. ${ }^{79}$

Die Informationstransformationsfunktion wird als eine der wichtigsten volkswirtschaftlichen Funktionen von Banken angesehen. ${ }^{80}$ Die hohe Abstraktheit, die häufig mit einer hohen Erklärungsbedürftigkeit einhergeht, ist ein zentrales Kennzeichen von Bankleistungen ${ }^{81}$ und hat wesentliche Implikationen auf die Art der Beziehung zwischen dem Kunden und der Bank. Die Erklärungsbedürftigkeit ist vor allem evident bei Beratungsleistungen, denn gerade aufgrund des größeren Know-hows des Kundenbetreuers - sei es bei der Kapitalanlage, bei der Kreditaufnahme oder bei der Risikoabsicherung - wünscht der Kunde, eine Beratung und Hilfestellung bei der Problemlösung und -strukturierung zu bekommen. In Konsequenz kann der Kunde die Beratungsleistung des Firmenkundenbetreuers kaum hinreichend beurteilen. ${ }^{82}$ Die fehlende Beurteilungsfähigkeit kommt insbesondere dann zum Tragen, wenn die typischen Merkmale eines mittelständischen Unternehmens erfüllt sind, wie bspw. eine eher technisch statt kaufmännisch orientierte Ausbildung des Geschäftsführers und Ansprechpartners der Bank, ein eher unzureichendes Informationswesen oder fehlende Spezialisten. Die unmittelbare Qualitäts- oder Ergebniskontrolle wird dann durch Vertrauen in die Bank ersetzt.

Dieser Vertrauensaspekt kommt aber auch bereits bei der Informationsbereitstellung zum Tragen, denn Bankprodukte sind vorwiegend Dienstleistungen, die auf der Verarbeitung vertraulicher Kundeninformationen beruhen. Diese Vertraulichkeit der Informationen bewirkt, dass in der Regel alle Schritte der Leistungserstellung, insbesondere im Kreditgeschäft, von der Produktentwicklung über die Bonitätsprüfung bis zur Kreditverwaltung und den Marketing- und Vertriebsaufgaben in der eigenen Bank erledigt werden. ${ }^{83}$ Im genossenschaftlichen Sektor werden nicht alle Schritte in der Bank durchgeführt; die Primärbanken erhalten Unterstützung von den Zentralbanken oder Spezialinstituten, z.B. bei der Produktentwicklung, ${ }^{84}$ oder von den Regionalverbänden und dem BVR, z.B. bei der Entwicklung von Betreuungskonzeptionen. ${ }^{85}$

\subsubsection{Banksystem in Deutschland mit dem Fokus auf Genossenschaftsbanken}

Das Geschäftsbankensystem in der Bundesrepublik ist durch das Universalbankprinzip gekennzeichnet, wobei unter einer Universalbank ein Finanzintermediär verstanden wird, der sämtliche Bankleistungen anbietet. ${ }^{86}$ In der erweiterten Definition, die dem

Vgl. Diamond (1984). Eine kurze Darstellung des Modells folgt in Kapitel A.4.3.1.1.

Vgl. für eine ausführliche Definition Hartmann-Wendels/Pfingsten/Weber (2007), S. 5 ff. in Bezug auf Finanzmärkte und S. $133 \mathrm{ff}$. in Bezug auf Banken.

81 Vgl. Börner (2005), S. 55.

82 Vgl. Börner (2005), S. 55.

83 Vgl. Groß/Michaelis (2002), S. 164.

${ }_{84}$ Vgl. hierzu WGZ (2008), S. 33, DZ Bank (2008a), S. 12, BVR (2008c).

85 Vgl. hierzu bspw. VR Finanzplan Mittelstand (2006), S. 2.

86

Vgl. Hartmann-Wendels/Pfingsten/Weber (2007), S. 62. 
deutschen Verständnis nahe kommt, dürfen Universalbanken darüber hinaus auch solche Leistungen anbieten, die traditionell nicht zu den Bankleistungen zählen. Als Beispiele für derartige Leistungen sind Versicherungsleistungen, die Bereitstellung von Eigenkapital für Unternehmen im Nichtbankensektor oder Beratungsleistungen für Unternehmen zu nennen. ${ }^{87}$ Dabei nehmen jedoch die klassischen Bankgeschäfte wie das Kreditgeschäft und das Einlagengeschäft einen hohen Stellenwert ein. ${ }^{88}$ Das Trennbankensystem, wie zum Beispiel in den USA, ist hingegen dadurch gekennzeichnet, dass die Banken nur jeweils eine Teilmenge der möglichen Bankleistungen anbieten dürfen. ${ }^{89}$

Unter dem Einfluss wirtschaftlicher, politischer, gesellschaftlicher und rechtlicher Entwicklungen haben sich im Laufe der Zeit in Deutschland die verschiedenen Arten von Kreditinstituten herausgebildet. Eine Unterteilung der deutschen Geschäftsbanken ist möglich nach den Kriterien Geschäftsstruktur (in Universal- und Spezialinstitute), geographischer Wirkungsbereich (in lokal, regional, überregional und international tätige Institute), einzelwirtschaftliche Zielsetzung (in erwerbswirtschaftlich, gemeinnützig, und nach einem Förderauftrag ausgerichtete Institute) und - damit zusammenhängend - nach dem Kriterium der Rechtsform (in privatrechtliche, öffentlichrechtliche, genossenschaftliche Institute) ${ }^{90}$ Im pluralistischen Banksystem der Bundesrepublik lassen sich bei den Universalbanken drei Gruppen unterscheiden: ${ }^{91}$

- Kreditbanken

- Sparkassen

- Genossenschaften

Die Gruppe der Kreditbanken kann eingeteilt werden in Großbanken, Regionalbanken, Privatbankiers und Zweigstellen ausländischer Banken,,2 wobei zur ersten Gruppe derzeit die Deutsche Bank, die HypoVereinsbank, die Dresdner Bank ${ }^{93}$, die Commerzbank und die Deutsche Postbank gehören. ${ }^{94}$ Großbanken unterscheiden sich von den Sparkassen und Genossenschaftsbanken zum einen hinsichtlich der Größe der Einzelinstitute, zum anderen aber auch durch ihre nationale und internationale Ausrichtung, die für die Großbanken typisch ist. Damit einher geht auch ein umfangreiches Geschäft mit Großkunden und eine vergleichsweise geringe Präsenz innerhalb der Regio-

\footnotetext{
87 Vgl. Hartmann-Wendels/Pfingsten/Weber (2007), S. 23.

88 Vgl. Hartmann-Wendels/Pfingsten/Weber (2007), S. 26.

89 Vgl. Hartmann-Wendels/Pfingsten/Weber (2007), S. 62.

$90 \quad$ Vgl. Süchting (1992), S. 188.

91 Die Spezialbanken, wie z.B. Hypothekenbanken und Kreditinstitute mit Sonderaufgaben, werden im Rahmen der Untersuchung nicht näher betrachtet.

92 Vgl. Süchting (1992), S. 31.

93 Am 31.08.2008 hat der Aufsichtsrat der Allianz dem Verkauf der Dresdner Bank an die Commerzbank zugestimmt. Der Abschluss der Transaktion steht allerdings noch unter dem Vorbehalt der aufsichts- und kartellrechtlichen Genehmigungen. Es ist geplant, die Dresdner Bank zu einem späteren Zeitpunkt auf die Commerzbank zu verschmelzen. Vgl. Allianz (2008). 
nen. Neben den Großbanken werden unter den Kreditbanken u.a. auch noch Regionalbanken, deren Marktgebiet grundsätzlich auf eine Region bestimmt ist, subsumiert. ${ }^{95}$

Anders als die Großbanken sind Sparkassen und Kreditgenossenschaften ,[...] mit ihrem engmaschigen Netz und ihrer Produktpalette auf das Geschäft mit Privatkunden und mittelständischen Unternehmen ausgerichtet." ${ }^{\text {"96 }}$ Die Sparkassen-Finanzgruppe, welche die Gesamtheit aller Sparkassen, die Landesbanken, die Landesbausparkassen, die Erstversicherergruppen der Sparkassen, die DekaBank sowie zahlreiche Kapitalbeteiligungsgesellschaften und Spezialkreditinstitute umfasst, ${ }^{97}$ ist gemessen sowohl am Geschäftsvolumen als auch an den Einlagen und Krediten - wie in Tab. A-4 ersichtlich - mit Abstand die bedeutendste Bankengruppe in Deutschland.

Neben den bereits angesprochenen Banken gibt es eine Fülle von Spezialbanken, wie bspw. Hypothekenbanken, Bausparkassen und Investmentgesellschaften. ${ }^{98}$ Anders als im Trennbankensystem erfolgte die Fokussierung der Spezialbank auf bestimmte Tätigkeitsgebiete nicht aufgrund gesetzlicher Vorgaben, sondern aufgrund der Marktentwicklung.

\begin{tabular}{|l|r|r|r|}
\hline & Geschaftsvolumen & $\begin{array}{r}\text { Verbindlichkeiten/ } \\
\text { Einlagen }\end{array}$ & Kredite \\
\hline Sparkassen-Finanzgruppe & $35,3 \%$ & $39,1 \%$ & $38,4 \%$ \\
\hline GroBbanken & $29,3 \%$ & $31,7 \%$ & $24,9 \%$ \\
\hline Genossenschaftsbanken & $12,2 \%$ & $18,1 \%$ & $15,0 \%$ \\
\hline Sonstige Kreditbanken & 9 & $11,1 \%$ & $21,7 \%$ \\
\hline
\end{tabular}

Tab. A-4: Marktanteile der Kreditinstitute in $2006^{100}$

Da der Fokus der vorliegenden Studie auf Genossenschaftsbanken liegt, werden von den oben beschriebenen Geschäftsbanken lediglich die Kreditgenossenschaften ausführlicher behandelt. Diese Gruppe des Universalbankenbereichs in Deutschland setzt sich aus den Kreditgenossenschaften (Primärgenossenschaften) in Form von Volksbanken, Raiffeisenbanken, Spar- und Darlehenskassen u.dgl. sowie den Zentralbanken - WGZ BANK AG und DZ BANK AG - zusammen. ${ }^{101}$ Gemeinsames Merkmal aller Genossenschaftsbanken ist der durch $\S 1$ Genossenschaftsgesetz zum rechtlichen Merkmal erhobene Förderzweck, der lautet, dass es Aufgabe ist, den ,[...] Erwerb oder die Wirtschaft ihrer Mitglieder oder deren soziale oder kulturelle Belange durch gemeinschaftlichen Geschäftsbetrieb zu fördern (Genossenschaften) ${ }^{، / 102}$. In der Litera-

\footnotetext{
$95 \quad$ Vgl. Süchting (1992), S. 189.

96 Bundesbank (2003), S. 41.

97 Vgl. Sparkassen-Finanzgruppe (2008).

98 Vgl. hier und im Folgenden Hartmann-Wendels/Pfingsten/Weber (2007), S. 25.

99 Unter dem Begriff „sonstige Kreditbanken“ werden im Wesentlichen Regionalbanken, Privatbankiers und Zweigstellen ausländischer Banken zusammengefasst. Vgl. hierzu Bundesbank (2007b), S. 110.

100 Vgl. DSGV (2006a), S. 20.

101 Vgl. BVR (2007), S. 15.

102 Genossenschaftsgesetz (2007), § 1, Absatz 1.
} 
tur lassen sich verschiedene Definitionen und Thesen zum Förderungsauftrag aus ökonomischer Sicht auffinden. Einigkeit besteht lediglich darin, dass der Hauptzweck der Genossenschaften in der ,wirtschaftliche[n] Förderung der Mitglieder in ihrer Identität als Kunden und Träger der Genossenschaften" ${ }^{\text {"103 }}$ bestehe. Die Mitgliedschaft bei einer Bank ist auf eine längerfristige Geschäftsbeziehung ausgelegt. ${ }^{104}$ Das Prinzip der Mitgliedschaft erlangt im Rahmen der weiteren Studie insofern noch mal Relevanz, als dass es sich hierbei um eine besondere Form der Kundenbindung handelt und möglicherweise Unterschiede im Hinblick auf die Bankbeziehung zu Mitgliedern und Nichtmitgliedern zu beobachten sind.

Die erste Stufe des genossenschaftlichen Bankensektors, die Primärgenossenschaften, die überwiegend in der Rechtsform der eingetragenen Genossenschaft betrieben werden, stellt eine wesentliche Säule des deutschen Bankensystems dar. ${ }^{105}$ Ein wichtiges Merkmal der Primärgenossenschaften ist das vorherrschende, mit dem Sparkassensektor vergleichbare Regionalprinzip. ${ }^{106}$ Es hat in den letzten drei Jahrzehnten eine nachhaltige Tendenz zu Fusionen gegeben, die sich auch heute noch fortsetzt und mittels derer die Bildung leistungsfähigerer und rationellerer Einheiten angestrebt wird. Wie in Tab. A-5 dargestellt, hat sich die Zahl der Institute in den letzten drei Jahrzehnten drastisch verringert: so betrug die Zahl der rechtlich selbstständigen Kreditgenossenschaften 1970 noch 7.096 im Vergleich zu 1.232 Kreditgenossenschaften im Jahr 2007. ${ }^{107}$ Während die Zahl der Primärkreditgenossenschaften seit 1970 um $83 \%$ gesunken ist, ist gleichzeitig die aggregierte Bilanzsumme um $1582 \%$ gestiegen und die durchschnittliche Bilanzsumme von 6 Mio. EUR auf 513 Mio. EUR angewachsen.

\footnotetext{
103 Grosskopf (1989), S. 26.

104 Vgl. Theurl (2005), S. 23.

105 Vgl. BVR (2007a), S. 2.

106 Vgl. Büschgen (1998), S. 95.

107 Vgl. BVR (2008a), S. 1, BVR (2008b), S. 1.
} 


\begin{tabular}{|c|c|c|c|c|c|}
\hline Jahr & $\begin{array}{l}\text { Anzahl } \\
\text { Banken }\end{array}$ & $\begin{array}{c}\text { Anzahl } \\
\text { Bankstellen }\end{array}$ & $\begin{array}{l}\text { Agg. Bilanz- } \\
\text { summe } \\
\text { in Mio. EUR }\end{array}$ & $\begin{array}{l}\text { Ø Bilanz- } \\
\text { summe } \\
\text { in Mio. EUR }\end{array}$ & $\begin{array}{l}\text { Kundenkredite } \\
\text { in Mio. EUR }\end{array}$ \\
\hline 1970 & 7.096 & 18.339 & 39.938 & 6 & 24.874 \\
\hline 1975 & 5.196 & 19.200 & 79.169 & 15 & 45.668 \\
\hline 1980 & 4.226 & 19.769 & 145.206 & 34 & 95.525 \\
\hline 1985 & 3.660 & 19.689 & 210.623 & 58 & 132.874 \\
\hline 1990 & 3.344 & 20.744 & 297.888 & 89 & 170.360 \\
\hline 1995 & 2.589 & 19.724 & 448.733 & 173 & 268.017 \\
\hline 2000 & 1.794 & 17.490 & 534.863 & 298 & 332.692 \\
\hline 2005 & 1.290 & 14.122 & 590.768 & 458 & 353.645 \\
\hline 2006 & 1.255 & 13.858 & 607.590 & 484 & 360.093 \\
\hline 2007 & 1.232 & 13.625 & 632.142 & 513 & 366.965 \\
\hline
\end{tabular}

Tab. A-5: Entwicklung der Volks- und Raiffeisenbanken ab $1970^{108}$

Kreditgenossenschaften bieten heutzutage - oftmals in Zusammenarbeit mit den Zentralbanken oder den für Spezialgeschäfte zuständigen Beteiligungsinstituten des Verbundes - ein Universalleistungsprogramm an. ${ }^{109}$ Im Aktivgeschäft bildet das kurz-, mittel- und langfristige Kreditgeschäft den Schwerpunkt, während das Wertpapierund das Deviseneigengeschäft nur eine nachgeordnete Bedeutung haben. Im Passivgeschäft spielen insbesondere auch unter Refinanzierungsgesichtspunkten die Spareinlagen eine wichtige Rolle. Die Volks- und Raiffeisenbanken, die mit dem Gedanken der Selbsthilfe gegründet worden sind, unterstützen mit einem vielfältigen Angebot, das oft durch neue Sparformen erweitert wird, das Ziel der Vermögensbildung breiter Bevölkerungsteile. Auch im Dienstleistungsgeschäft hat man sich bei den Kreditgenossenschaften - oftmals mit Hilfe der übrigen Verbundinstitute - dem Angebot der Universalbanken angepasst.

Nach Imageuntersuchungen ist wichtigstes Attraktionsmerkmal der Genossenschaftsbanken die in der Regel noch gegebene Möglichkeit des persönlichen Kontaktes zu Mitarbeitern und häufig auch zu den Entscheidungsträgern, ein Umstand der von den Bankkunden in den Randlagen der Städte und auf dem Lande besonders geschätzt wird. ${ }^{110}$ Dies ergibt sich unter anderem aus der Tatsache, dass an der General- bzw. Vertreterversammlung der örtlichen Genossenschaftsbank häufig Unternehmer teilnehmen und auch in den Aufsichtsräten der Genossenschaftsbank vielfach Unternehmer vertreten sind. Aus diesem Grund besitzen genossenschaftliche Institute bessere Voraussetzungen als Sparkassen und Großbanken, sich in der mittelständischen Kundschaft darzustellen. Ferner zeichnen sich die Genossenschaftsbanken durch eine gute

108 Vgl. BVR (2008a), S. 1. Nach der Deutschen Apotheker- und Ärztebank ist die Berliner Volksbank mit 10.280,4 Mio. EUR Bilanzsumme die größte, die Raiffeisenbank eG, Struvenhütten mit 12,5 Mio. EUR die kleinste Genossenschaftsbank. Vgl. BVR (2008a), S. 1.

$109 \mathrm{Vgl}$. hierzu und im Folgenden Büschgen (1998), S. 95.

110 Vgl. Grüger (1991), S. 370. Häufig ist nicht allein der Firmenkundenbetreuer, sondern auch der Vorstand die Kontaktperson des Unternehmers. 
Kenntnis der Gegebenheiten der Region und der regionalen Märkte aus. ${ }^{11}$ Gleichzeitig ermöglichen die Zentral- und Spezialinstitute sowie die Verbände die Nutzung von Größen-, Synergie- und Organisationsvorteilen und von Netzwerkeffekten. Die kurzen und deshalb schnellen Entscheidungswege sowie die vergleichsweise kleinen Marktbereiche geben ihnen weiterhin in der Anpassungsfähigkeit, z.B. der Konditionen an die örtlichen Verhältnisse, Vorteile, die von Kreisparkassen und Großbankfilialen in ihrem übergreifenden Aktionsumfeld nicht realisiert werden können. ${ }^{112}$ So zeichnen sich die Genossenschaftsbanken durch Schnelligkeit bei den Kreditentscheidungen, Flexibilität bei Konditionen und Gebühren sowie günstige Zahlungsverkehrsgebühren und Kreditkonditionen im Vergleich zu anderen Geldinstituten aus. ${ }^{113}$ In allen diesen genannten Kriterien werden die Genossenschaftsbanken gemäß einer Studie der TNS infratest besser bewertet als die Sparkassen, Großbanken und die Postbank.

\subsubsection{Firmenkundengeschäft mit dem Fokus auf dem Kreditgeschäft als ein Geschäftsfeld der Banken}

Der Mittelstand wird zwar von vielen Banken und Bankengruppen als Kernzielgruppe hervorgehoben. ${ }^{114}$ Gleichzeitig werden aber auch die aufgrund der hohen Wettbewerbsintensität geringen Margen in diesem Kundensegment moniert. ${ }^{115}$ Die Ergebnisse der Banken im Firmenkundengeschäft sind häufig zu niedrig, um die Eigenkapitalkosten zu decken. ${ }^{116}$ Ursächlich für die niedrige Rentabilität ist unter anderem die angespannte Risikosituation aufgrund der hohen Insolvenzzahlen der vergangenen Jahre. Das Firmenkundengeschäft gilt aus Sicht des Kapitalmarktes seit Jahren als ein unattraktives Geschäftsfeld mit unzureichenden Renditen, begrenztem Wachstum und hohen Kapitalanforderungen, von dem sich viele Banken gerne trennen würden. ${ }^{17}$ Diese Meinung spiegelt sich auch in den Marktbewertungen von Banken mit Schwerpunkt Firmenkundengeschäft wider, welche im Durchschnitt niedriger ausfallen als die von Wettbewerbern mit anderen Ausrichtungen.

Im gehobenen Firmenkundengeschäft bestehen hingegen umfassende Geschäftsmöglichkeiten, allerdings ist hier die Zahl der potenziellen Kunden begrenzt. ${ }^{118}$ Setzt man die Untergrenze für das klassische Firmenkundengeschäft - wie dies viele deutsche Großbanken vorgeben - beispielsweise bei einer Umsatzgröße von 2,5 Mio. EUR p.a., dann gehören lediglich noch etwas mehr als $5 \%$ der statistisch erfassten Unternehmen zur Zielgruppe des Firmenkundengeschäfts. Absolut gesehen wären dies etwa 130.000

\footnotetext{
III Vgl. hier und im Folgenden Theurl (2005), S. $27 \mathrm{f}$.

112 Vgl. Süchting (1978), S. 5.

113 Vgl. hier und im Folgenden TNS infratest (2008), S. $54 \mathrm{ff}$.

114 Gemäß einer Studie der zeb erzielen die Banken häufig 30 bis $35 \%$ der Erlöse mit mittelständischen Firmenkunden. Vgl. Rinker/Putzer/Käser (2004), S. 5.

IIs Vgl. Berens et al. (2005), S. 784.

116 Vgl. hier und im Folgenden Rinker/Putzer/Käser (2004), S. 7.

117 Vgl. hier und im Folgenden Mattern/Orlopp (2002), S. 51.

118 Vgl. Dahmen/Jacobi (1997), S. 16.
} 
Unternehmen, wobei die Zahl mit zunehmender Unternehmensgröße rasch abnimmt. ${ }^{119}$ $75 \%$ der Kunden von Genossenschaftsbanken haben einen Umsatz von weniger als 1 Mio. EUR und 93\% einen Umsatz von weniger als 5 Mio. EUR. ${ }^{120}$ Das Adresspotenzial für das gehobene Firmenkundengeschäft ist also begrenzt, zumal sich am als „overbanked“ geltenden Bankenplatz Deutschland die meisten Banken gerade um das Zielgruppensegment der gehobenen Firmenkunden besonders bemühen. ${ }^{121}$

Gemäß einer handlungsorientierten Definition des Firmenkundengeschäfts umfasst dieses neben dem klassischen Firmenkundengeschäft (Kredite, Transaktionsdienstleistungen, Anlageprodukte und Asset Finance) auch das Investment Banking mit Firmenkunden (Devisenhandel, Renten, Aktien, Advisory und Derivate). ${ }^{122}$ Mit diesem integrierten Ansatz wird der Tatsache Rechnung getragen, dass schon heute viele Unternehmen ein breites Produktspektrum aus einer Hand fordern und viele Institute durch Cross Selling das klassische Firmenkundenangebot erweitert haben. Somit beinhaltet das Firmenkundengeschäft heute alle Bankgeschäfte und banknahen Geschäfte, wie bspw. auch Versicherungen oder betriebliche Altersvorsorge.

Ein zentrales Geschäftsfeld im Firmenkundenbereich ist das Kreditgeschäft. Die große finanzielle Abhängigkeit vieler mittelständischer Unternehmen von den Banken hat in den vergangenen Jahren zu einer extremen Kreditfokussierung in den Ertragsstrukturen der Banken geführt, so erwirtschaften die Banken teilweise deutlich mehr als 50\% ihrer Gesamterträge ${ }^{123}$ und $71 \%$ ihrer Erträge im Firmenkundensektor ${ }^{124}$ mit dem Kreditgeschäft. Der ausgeprägte Wettbewerb sowie eine lang anhaltende Niedrigzinsphase haben dazu beigetragen, dass die durchschnittliche Kreditzinsmarge im europäischen Firmenkundengeschäft deutlich gesunken ist. Der Ertrag aus kreditdominierten Kundenverbindungen entspricht in der Regel nicht den Deckungsbeitragsanforderungen, die vom Verwaltungsaufwand, der Risikovorsorge und den Kapitalkosten determiniert werden. ${ }^{125}$ Insbesondere die Standardrisikokosten für den erwarteten Verlust sowie die Kapitalverzinsung als „Versicherungsprämie“ für den unerwarteten Verlust treiben die Margen- und Ertragsanforderungen für mittlere und hohe Risikoklassen. Die geringe Spreizung der Kreditmarge zeigt, dass eine angemessene Bezahlung der Risiken der Kreditvergabe im Markt nicht erzielbar ist. Das Kreditgeschäft nimmt dennoch seit jeher eine dominante Rolle im Geschäft mit den Firmenkunden ein. ${ }^{126}$ Allein das Produktportfolio im Firmenkundengeschäft umfasst alle erdenklichen Formen von Kreditprodukten und Sicherheitskonstruktionen, um möglichst jeden Kreditbedarf individuell abdecken zu können. Auch das Know-how der Mitarbeiter in diesem Bereich ist vor-

119 Vgl. Dahmen/Jacobi (1997), S. 16. Zu den Potenzialen und Strukturen im Firmenkundengeschäft vgl. auch Rinker/Putzer/Käser (2004), S. 11.

Vgl. TNS infratest (2008), S. 6.

Vgl. Rickes (2006), S. 152.

Vgl. hier und im Folgenden Mattern/Orlopp (2002), S. 52.

Vgl. Boehm-Bezing (2002), S. 86.

Vgl. Berens et al. (2005), S. 784.

Vgl. hier und im Folgenden Boehm-Bezing (2002), S. 86. Eine ausführliche Darstellung der Parameter der Konditionengestaltung erfolgt in Kapitel A.3.3. 
rangig auf die Kreditvergabe fokussiert, was sich darin zeigt, dass Bonitätsbeurteilungen und Kreditentscheidung noch immer die Kernkompetenz eines Firmenkundenbetreuers sind. Lange Zeit ließ sich das Firmenkundengeschäft auf diese Weise lukrativ betreiben. Spätestens seit Mitte der 90er Jahre kristallisierten sich jedoch Trends und Entwicklungen heraus, die eine Fortführung des bisherigen Ansatzes nicht mehr zulassen und das Firmenkundengeschäft vor neuartige Herausforderungen stellen. ${ }^{127}$ Das Selbstverständnis des Firmenkundenbetreuers als reiner Kreditverkäufer ist nicht mehr zeitgemäß.

Im Rahmen der Kreditvergabe müssen die Banken vielfältige Erfordernisse erfüllen. Einerseits ist das Risiko der jeweiligen Transaktion möglichst genau zu beurteilen und anderseits müssen unter Einhaltung aller regulatorischen Bestimmungen die Bearbeitungszeiten und Kosten möglichst niedrig gehalten werden. Zwar sind Losgröße und Komplexität im mittelständischen Firmenkundensegment signifikant höher als zum Beispiel im Retailbereich, wo häufig bereits ein sehr hoher Grad an Standardisierung und Effizienz in der Bearbeitung erreicht ist, dennoch sind niedrige Prozesskosten unabdingbar für die Profitabilisierung des Kreditgeschäfts mit diesen Kunden, insbesondere im Kontext des sich verschärfenden Wettbewerbs. ${ }^{128}$ Die Automatisierung von Kreditentscheidungen stellt einen großen Hebel sowohl zur Kostensenkung als auch zur Serviceverbesserung im Kreditgeschäft mit mittelständischen Unternehmen dar.

Diese Ausführungen zeigen, dass die Analyse der Kunde-Bank-Beziehung nicht nur für die mittelständischen Unternehmen aufgrund ihrer Abhängigkeit von der Bank, sondern auch für die Bank aufgrund der großen Bedeutung des Kreditgeschäfts mit Firmenkunden von Interesse ist. Folgerichtig werden nicht alle ökonomischen Auswirkungen im Rahmen der Kunde-Bank-Beziehung untersucht, sondern lediglich. die Auswirkungen in Bezug auf die kreditrelevanten Parameter Kreditzins, Sicherheitenstellung und Kreditverfügbarkeit.

Aufgrund diverser Entwicklungen im Bankensektor ist die Kreditvergabe durch Banken in den vergangenen Jahren zusehends restriktiver geworden. ${ }^{129}$ Eine große Rolle spielen die neuen Anforderungen des Gesetzgebers an die Banken, zum einen hinsichtlich ihrer Eigenkapitalausstattung, zum anderen die interne Organisation des Kreditvergabeprozesses betreffend. ${ }^{130}$ Ersteres findet sich in Basel II wieder, Letzteres ist durch die Mindestanforderungen an das Risikomanagement (MaRisk) geregelt und umgesetzt ${ }^{131}$ Nach der Darstellung der relevanten Inhalte von Basel II in Kapitel A.3.1 und den MaRisk in Kapitel A.3.2 wird in Kapitel A.3.3 geprüft, welche Auswirkungen diese gesetzlichen Vorschriften auf die zuvor genannten ökonomischen Parameter haben und inwiefern diese somit möglicherweise eine Beeinflussung derselbigen bspw. durch verhaltenswissenschaftliche Parameter verhindern oder einschränken.

\footnotetext{
127 Vgl. hier und im Folgenden Groß/Michaelis (2002), S. 165.

128 Vgl. Klenke/Pfetsch/Baetge (2007), S. 34.

129 Vgl. hierzu aktuelle Meldungen, z.B. N-TV (2008).

130 Vgl. Müller et al. (2006), S. 4.

131 Vgl. Koop/Maurer (2006), S. 32.
} 


\section{Gesetzliche Rahmenbedingungen und ihre Implikationen in Bezug auf die Konditionengestaltung}

\subsection{Basel II}

\subsubsection{Hintergrund und Zielsetzung}

Am 26. Juni 2004 hat der Baseler Ausschuss für Bankenaufsicht ${ }^{132}$ unter dem Titel „International Convergence of Capital Measurement and Capital Standards, A Revised Frameword" das endgültige Papier, das verkürzt Basel II genannt wird, veröffentlicht. ${ }^{133}$ Bei Basel II handelt es sich um die Revision der bisherigen Eigenkapitalübereinkunft aus dem Jahre 1988. Durch Basel II werden Rahmenvorgaben definiert, innerhalb derer sich im weiteren Umsetzungsprozess der Regulierungen auch Veränderungen ergeben können. Basel II steht deshalb so stark im Interesse der Öffentlichkeit, da die Vorgaben die Geschäfts- oder die Risikoübernahmemöglichkeiten der Institute in mehr oder minder restriktiver Form begrenzen und somit maßgeblich die geschäftspolitischen Rahmenbedingungen der Kreditinstitute bestimmen. Ziel von Basel II ist es, zum einen die regulatorischen Eigenkapitalanforderungen stärker an die Risiken anzupassen, denen die Banken ausgesetzt sind, ${ }^{134}$ und zum anderen die Banken zu einer stärkeren Beachtung des Ausfallrisikos eines Kreditnehmers bei der Vergabe und der Bepreisung von Krediten anzuhalten. ${ }^{135}$

Bei den Ergebnissen des Baseler Ausschusses handelt es sich jedoch lediglich um Empfehlungen, sie haben keinerlei rechtlichen bindenden Charakter. ${ }^{136}$ In der Europäischen Union wurde Basel II mittels der EU-Richtlinien 2006/48/EG und 2006/49/EG vom Juni 2006, die eine ganze Reihe von europäischen Besonderheiten z.B. bei Krediten an mittelständische Unternehmen berücksichtigen, bis Ende 2006 umgesetzt. ${ }^{137}$ Während sich die Baseler Regeln selbst nur an international tätige Kreditinstitute richten, ${ }^{138}$ erlangen die durch die EU-Richtlinien in nationales Recht umgesetzten Vorgaben für alle in der Bundesrepublik Deutschland tätigen Institute Geltung (im Gegen-

132 Der Baseler Ausschuss setzt sich zusammen aus Vertretern von Zentralbanken und Bankenaufsichtsbehörden der Länder Belgien, Deutschland, Frankreich, Großbritannien, Italien, Japan, Kanada, Luxemburg, Niederlande, Schweden, Schweiz, Spanien und den USA. Der Ausschuss entwickelt u.a. Aufsichtsstandards und Empfehlungen für die Bankenaufsicht, wie bspw. die Eigenkapitalvorschriften Basel II. Vgl. Baseler Ausschuss für Bankenaufsicht (2004), S. 1 und BaFin (2008). Die Empfehlungen des Ausschusses werden jedoch häufig auch von anderen Ländern in deren nationales Recht umgesetzt. So wurden z.B. die Empfehlungen des Baseler Akkords von 1988 in mittlerweile über 100 Ländern umgesetzt. Außerdem will der Ausschuss die Zusammenarbeit zwischen den national zuständigen Aufsichtsbehörden verbessern. Vgl. Söhlke (2002), S. 38.

133 Vgl. hier und im Folgenden Schulte-Mattler/Kenne von (2004), S. 37.

${ }_{134} \mathrm{Vgl}$. Baseler Ausschuss für Bankenaufsicht (2006), S. 5.

135 Vgl. Müller et al. (2006), S. 5.

136 Vgl. Schulte-Mattler/Kenne von (2004), S. 37.

137 Vgl. Suyter (2006), S. 1328.

138 Vgl. Baseler Ausschuss für Bankenaufsicht (2004), S. 7 
satz zu der nur partiellen Umsetzung von Basel II in den USA). ${ }^{139}$ In Deutschland werden diese Regeln durch Änderungen des Kreditwesengesetzes (KWG) sowie der Solvabilitätsverordnung (SolvV) beziehungsweise die Großkredit- und Millionenkreditverordnung (GroMiKV) ${ }^{140}$ umgesetzt. ${ }^{141}$ Die Regelungen traten in Deutschland offiziell zum 1. Januar 2007 in Kraft und damit hat auch die Phase der Anwendung der neuen Basel II-Eigenkapitalregeln in Deutschland begonnen. Vorhandene Wahlrechte bzgl. der im Folgenden vorgestellten Ansätze ermöglichten allerdings die Anwendung ab 1. Januar 2008. ${ }^{142}$ Aufgrund der notwendigen vorlaufenden Tätigkeiten besaßen die Auswirkungen von Basel II aber auch schon vor der vorgeschriebenen Einführung Relevanz. ${ }^{143}$

\subsubsection{Die drei Säulen von Basel II}

Nach der Fokussierung der bisherigen Regeln auf quantitative Mindestkapitalstandards werden mit der Basel II-Umsetzung zwei zusätzliche Aspekte eingeführt: der bankgeschäftliche Überprüfungsprozess und die Offenlegungsstandards. ${ }^{144}$ Diese Aspekte spiegeln sich in den drei Säulen von Basel II wider.

\subsubsection{Säule I}

Die erste Säule beschreibt Mindeststandards sowohl quantitativer als auch qualitativer Art für die Eigenkapitalausstattung der Institute zur Deckung der Kreditrisiken und der operationellen Risiken. Mit diesen Vorgaben verfolgt der Baseler Ausschuss das Ziel, durch die Berücksichtung interner und externer Bonitätsbeurteilungen ein flexibleres System zur Erfassung und Unterlegung von Kreditrisiken zu schaffen. ${ }^{145}$

Die Mindestkapitalanforderungen für das Kreditrisiko, Marktrisiko und das operationelle Risiko schreiben vor, dass das Verhältnis von anrechenbarem Eigenkapital zu gewichteten Risikoaktiva nicht geringer als 8\% sein darf. ${ }^{146}$ Zur Ermittlung der gewichteten Risikoaktiva aus dem Kreditgeschäft beschränkten sich die bisherigen Ei-

139 Vgl. Schulte-Mattler/Kenne von (2004), S. 38.

140 Die Verordnung über die angemessene Eigenkapitalausstattung von Instituten, Institutsgruppen und Finanzholding-Gruppen (Solvabilitätsverordnung - SolvV) dient der weiteren Umsetzung der Richtlinie 2006/48/EG des Europäischen Parlaments und des Rates vom 14. Juni 2006 über die Aufnahme und Ausübung der Tätigkeit der Kreditinstitute (Neufassung) (ABI. EU Nr. L 177 S. 1) und der Richtlinie 2006/49/EG des Europäischen Parlaments und des Rates vom 14. Juni 2006 über die angemessene Eigenkapitalausstattung von Wertpapierfirmen und Kreditinstituten (Neufassung) (ABl. EU Nr. L 177 S. 201). Vgl. SolvV (2006), S. 1.

$141 \quad$ Vgl. Bundesbank (2006), S. 72.

142 Vgl. Grüntker/Kühn (2007), S. 716.

143 Vgl. Segbers (2007), S. 105. Die Banken haben bspw. bereits vor der vorgeschriebenen Einführung ein Rating des Kunden durchgeführt. Ferner war für die Entwicklung eines geeigneten Ratingsystems die Sammlung einer umfangreichen Datenbasis erforderlich. Eine faktische Umsetzung der Vorgaben war bei allen untersuchten Kreditinstituten gegeben.

145 Vgl. Schulte-Mattler/Kenne von (2004), S. 38.

146 Vgl. Baseler Ausschuss für Bankenaufsicht (2004), S. 12. 
genkapitalanforderungen des Baseler Akkords (Basel I) auf eine einfache, aufsichtsrechtlich vorgegebene Klassifizierung von Forderungen mit lediglich fünf verschiedenen Risikogewichten $(0 \%, 10 \%, 20 \%, 50 \%$ und $100 \%)$ ohne Berücksichtigung des Ausfallrisikos des einzelnen Kreditnehmers. ${ }^{147}$ Dies führt im Beispiel dazu, dass die bankaufsichtlich geforderte Eigenkapitalunterlegung für einen Kredit nicht das tatsächliche Ausfallrisiko des einzelnen Kreditnehmers reflektiert, da alle gleichartigen Kreditnehmer (z.B. gewerbliche Unternehmen) unabhängig von ihrer Bonität einem bestimmten Risikogewicht zugeordnet werden. ${ }^{148}$ In Konsequenz entstanden dem Kreditinstitut die gleichen Eigenkapitalkosten unabhängig von der Bonität.

Basel II stellt die Ermittlung eines bonitätsabhängigen Risikogewichts für eine Forderung oder eine Geschäftsart in den Mittelpunkt der Kreditrisikoquantifizierung. ${ }^{149}$ Die Ermittlung des Risikogewichts für die Forderung eines Schuldners erfolgt durch eine der nachstehenden Methoden:

- Standardansatz

- IRB-Basisansatz

- IRB fortgeschrittener Ansatz. ${ }^{150}$

Bei dem Standardansatz greifen die Banken auf Ratingbeurteilungen von externen Ratingagenturen zurück, wobei die Verwendung externer Ratings die Zustimmung der Bankenaufsichtsbehörde erfordert. ${ }^{151}$ In Abhängigkeit von der externen Bonitätsbeurteilung werden den Risikopositionen, die bestimmten Forderungsklassen zugeordnet werden müssen, einzelne Risikogewichte beigemessen. ${ }^{152}$ Der Standardansatz findet ferner auch für ungeratete Positionen bzw. für bestimmte Kredite, wie zum Beispiel im Rahmen des Mengengeschäfts oder im Hypothekargeschäft, Anwendung. In diesem Fall hat die feste Zuordnung eines einheitlichen Risikogewichts weiterhin, d.h. wie bereits bei Basel I, Bestand. Besondere Vorteile ergeben sich dabei für die Positionen des Mengengeschäfts, da diese nach den neuen Vorschriften nur noch mit einem Bonitätsgewicht von $75 \%$ statt wie bisher mit $100 \%$ zu gewichten sind. Dies ist vor allem für die mittelständische Wirtschaft vorteilhaft, da grundsätzlich auch kleine und mittelgroße Unternehmen bis zu einer Gesamtverschuldung bei dem jeweiligen Institut von insgesamt 1 Mio. EUR der Forderungsklasse Mengengeschäft zugeordnet werden. Diese geänderten Regelungen dürften insbesondere kleinere und mittelgroße Banken begünstigen, die ihren Schwerpunkt im Mengengeschäft haben. ${ }^{153}$

Sowohl bei dem IRB-Basisansatz als auch bei dem IRB fortgeschrittenen Ansatz bildet ein internes Rating des Kreditnehmers die Grundlage für die Ermittlung der Bonitätsgewichtungsfaktoren. Letztere werden anhand einer Formel ermittelt, welche die Ausfallwahrscheinlichkeit des Kreditnehmers, die Verlustausfallquote, die ausstehenden

Vgl. Bundesbank (2006), S. 71.

Vgl. Bundesbank (2006), S. 69.

Vgl. Schulte-Mattler/Manns (2004), S. 377.

Vgl. Baseler Ausschuss für Bankenaufsicht (2004), S. 14 ff.

Vgl. Schulte-Mattler/Kenne von (2004), S. 38.

Vgl. Bundesbank (2006), S. 79.

Vgl. hier und im Folgenden Bundesbank (2006), S. 79. 
Forderungen bei Ausfall und die effektive Restlaufzeit berücksichtigt. Wie in Abb. A2 dargestellt, müssen die Banken bei dem IRB-Basisansatz die Ausfallwahrscheinlichkeit für jede ihrer Risikoklassen selbst schätzen und für die anderen relevanten Risikokomponenten (Verlustausfallquote, ausstehende Forderungen bei Ausfall und effektive Restlaufzeit) von der Bankenaufsicht vorgegebene Schätzungen verwenden. ${ }^{154}$

Im fortgeschrittenen Ansatz müssen die Banken die effektive Restlaufzeit selbst berechnen und ihre eigenen Schätzungen der Parameter Ausfallwahrscheinlichkeit, Verlustausfallquote und ausstehende Forderungen vorlegen. Die Risikogewichte werden für einzelne Risikopositionen auf Grundlage der individuell geschätzten Parameter aufgeteilt nach bestimmten Forderungsklassen mittels Risikogewichtungsformeln errechnet. ${ }^{155}$ Vor dem Hintergrund, dass bei den IRB-Ansätzen die Risikoparameter durch die Institute selbst geschätzt werden, erfordert deren Verwendung die Zulassung durch die Aufsicht.

Bei den Kreditgenossenschaften wenden ca. $60 \%$ den Standard- und $40 \%$ den IRBBasisansatz an. ${ }^{156}$

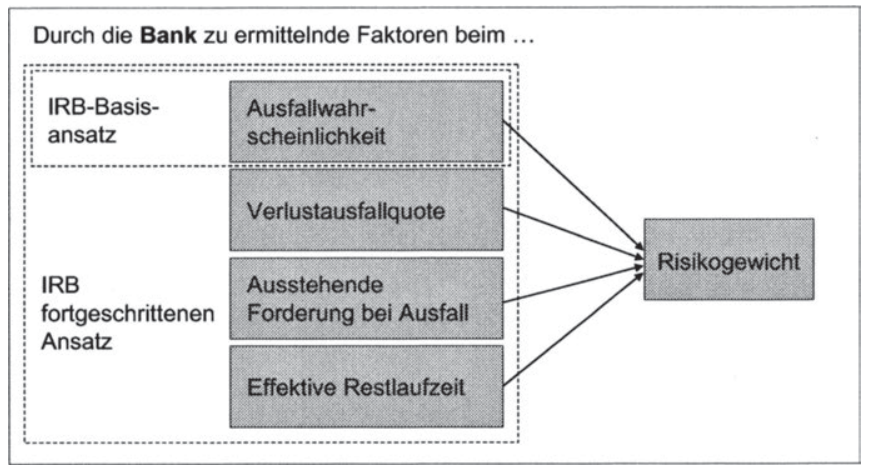

Abb. A-2: Berechnung des Risikogewichtes im IRB-Ansatz ${ }^{157}$

Neben den bisher angesprochenen Kreditrisiken sind auch die operationellen Risiken mit Eigenkapital zu hinterlegen, wobei das operationelle Risiko definiert wird als die Gefahr von Verlusten, die infolge der Unangemessenheit oder des Versagens von internen Verfahren, Menschen und Systemen oder infolge externer Ereignisse eintreten. ${ }^{158}$ Analog zu den Kreditrisiken lassen sich hier wieder verschiedene Ansätze zur Risikoquantifizierung finden. Aufgrund der fehlenden Relevanz für die Arbeit sollen diese aber nicht weiter behandelt werden. ${ }^{159}$

\footnotetext{
154 Vgl. hier und im Folgenden Baseler Ausschuss für Bankenaufsicht (2004), S. 52.

155 Vgl. Bundesbank (2006), S. 80.

156 Vgl. BVR (2005), S. 1.

157 Eigene Darstellung.

158 Vgl. Schulte-Mattler/Kenne von (2004), S. 38.

159 Vgl. zu den Ansätzen Bundesbank (2006), S. 84.
} 


\subsubsection{Säule II}

Der bankenaufsichtliche Überprüfungsprozess (Supervisory Review Process) betont die Notwendigkeit einer qualitativen Bankenaufsicht. Der Aufbau einer funktionstüchtigen Gesamtbanksteuerung und eines internen Eigenkapitalmanagements sowie das institutsspezifische Risikoprofil werden künftig verstärkt den Maßstab für die Festlegung von Zielgrößen für die Kapitalausstattung darstellen. ${ }^{160}$

Deswegen fordert die zweite Säule, dass die einzelnen Institute einen Prozess zur Festsetzung des Kapitalbedarfs vor dem Hintergrund ihres Risikoprofils zu definieren haben. ${ }^{161}$ Somit wird es zur Aufgabe der Institute, die wesentlichen Risiken selbst zu erkennen, deren Höhe angemessen zu steuern und mit Eigenkapital zu unterlegen. ${ }^{162}$ Die Bankenaufsicht flankiert die Regelungen zur Risikoerfassung und Eigenkapitalunterlegung eines Institutes durch einen laufenden Überprüfungsprozess. ${ }^{163}$ Die Aufsichtsinstanzen erwarten von den Banken, dass sie aus einem Vorsichtsprinzip heraus eine höhere Eigenkapitalausstattung als das aufsichtsrechtlich geforderte Mindesteigenkapital vorhalten. Über diese reine Erwartungshaltung hinaus haben die Aufsichtsinstanzen die rechtliche Möglichkeit, von den Banken eine höhere Mindesteigenkapitalausstattung $\mathrm{zu}$ fordern. ${ }^{164}$ Der Überprüfungsprozess soll ein frühes Eingreifen der Aufsicht bei Gefahr der Nichteinhaltung der geforderten Mindestausstattung erlauben.

\subsubsection{Säule III}

Abschließend legt die dritte Säule die Leitlinien für Offenlegungspraktiken zur Stärkung der Marktdisziplin durch erweiterte Transparenzvorschriften fest. Mit den erweiterten Offenlegungsanforderungen (Market Discipline) wird das Ziel verfolgt, durch eine verbesserte Eigenkapitalpublizität zu einer adäquaten Eigenkapitalunterlegung beizutragen. ${ }^{165}$ Dazu ist es nach Ansicht des Baseler Ausschusses erforderlich, den Marktteilnehmern die notwendigen Einblicke in die Geschäftsstrukturen und Risiken eines Instituts zu vermitteln. ${ }^{166}$ Gut geführte Institute sollten vom Markt belohnt und schlecht geführte Institute, d.h. Institute mit unzureichender Offenlegung, z.B. durch erhöhte Risikoprämien bei der Kapitalbeschaffung belastet werden. Die Form der Offenlegung ist flexibel; so kann diese im Rahmen des Jahresabschlusses, der Zwischenberichte oder über moderne Medien, wie z.B. Internet, erfolgen.

\footnotetext{
160 Vgl. Schulte-Mattler/Kenne von (2004), S. 39.

161 Vgl. Baseler Ausschuss für Bankenaufsicht (2004), S. 147.

162 Vgl. Baseler Ausschuss für Bankenaufsicht (2004), S. 146.

163 Vgl. Bundesbank (2006), S. 69.

164 Vgl. hier und im Folgenden Schulte-Mattler/Kenne von (2004), S. 39.

165 Vgl. Baseler Ausschuss für Bankenaufsicht (2004), S. 163.

160 Vgl. hier und im Folgenden Schulte-Mattler/Kenne von (2004), S. 40. 


\subsection{Mindestanforderungen an das Risikomanagement}

\subsubsection{Hintergrund und Zielsetzung}

Am 20. Dezember 2005 wurde die endgültige Fassung der „Mindestanforderungen an das Risikomanagement" (MaRisk) durch die Bundesanstalt für Finanzdienstleistungsaufsicht (BaFin) veröffentlicht. ${ }^{167}$ Diese neuen Mindestanforderungen setzen nunmehr für die Institute in Deutschland zeitlich gestaffelt ab dem 1. Januar 2007 einheitliche Standards für Verfahren zur Aufbau- und Ablauforganisation sowie zur Risikosteuerung und zum Risikocontrolling. ${ }^{168}$ Die MaRisk stellen einen Vorgriff auf die nationale Umsetzung des bankenaufsichtlichen Überprüfungsprozesses (SRP), der zweiten Säule von Basel II, und hierbei speziell des Prozesses zur Bestimmung des Eigenkapitalbedarfs (Internal Capital Adequacy Assessment Process; ICAAP) dar. ${ }^{169}$

Auf Basis des § 25a KWG geben die MaRisk einen praxisnahen Rahmen für die Ausgestaltung des Risikomanagements in Kreditinstituten vor. ${ }^{170}$ Entsprechend der aktuellen nationalen und internationalen aufsichtsrechtlichen Grundhaltung einer qualitativen Aufsicht wird hier ein flexibler Rahmen mit zusätzlichen, explizit genannten Öffnungsklauseln geschaffen. ${ }^{171}$ Die offene Formulierung der MaRisk und die dadurch entstehenden Ermessensspielräume für Institute bei der Umsetzung der aus Säule II resultierenden Anforderungen sowie der vorgesehene aufsichtsrechtliche Grundsatz der doppelten Proportionalität fordern ein hohes Maß an Sachverstand bei der Interpretation und Kreativität bei der konkreten Umsetzung in den Instituten. ${ }^{172}$ Der Grundsatz der doppelten Proportionalität besagt, dass einerseits der bankinterne Prozess proportional zur Größe, zum Geschäftsvolumen und der Risikostruktur sein muss. Andererseits muss die Prüfung durch die Aufsicht hinsichtlich der Häufigkeit und der Intensität der Prüfung proportional zur Ausgestaltung der bankinternen Prozesse sein. ${ }^{173}$ Der Grundsatz trägt der heterogenen Ausgestaltung des Finanzsektors in Deutschland Rechnung, indem die Besonderheiten der jeweiligen Institute Berücksichtigung finden.

\subsubsection{Zentrale Inhalte der Mindestanforderungen an das Risikomanagement}

Zentrales Element der MaRisk ist der Begriff des Risikomanagements. ${ }^{174}$ Basis eines jeden Risikomanagements ist zunächst die Bestandsaufnahme der bestehenden Risiken (Gesamtrisikoprofil) auf der einen und des bestehenden Risikodeckungspotenzials $\mathbf{s}^{175}$

\footnotetext{
167 Vgl. DSGV (2006b), S. 3.

168 Vgl. Stützle (2006), S. 10.

169 Vgl. Mantzel/Ramke/Schöning (2007), S. 88. Die MaRisk setzen die Artikel 22 und 123 der Capital Requirement Directive (CRD) in nationales Aufsichtsrecht um. Vgl. Theileis/Althoff/ Hörlin (2006), S. 8, AT 1 - Tz. 2.

170 Vgl. MaRisk (2007), AT $1-$ Tz. 1.

171 Vgl. Theileis/Althoff/Hörlin (2006), S. 7.

172 Vgl. DSGV (2006b), S. 6.

173 Vgl. DSGV (2006b), S. 17.

174 Vgl. DSGV (2006b), S. 15.

175 Vgl. MaRisk (2007), AT 4.1. 
auf der anderen Seite. Auf dieser Basis sind die Geschäftsstrategie und daraus ableitbare Teilstrategien zu definieren, deren Detaillierungsgrad von Art, Umfang, Komplexität und Risikogehalt der betriebenen Geschäfte abhängt. ${ }^{176}$ Ebenso wichtig für mittelständische Unternehmen ist jedoch die Kreditrisikostrategie einer Bank. ${ }^{177}$ Gemäß MaRisk muss der Vorstand einer jeden Bank eine solche Kreditrisikostrategie entwerfen, an die sich die Bank unbedingt halten muss. Inhalt dieser Strategie ist das Kreditvergabeverhalten hinsichtlich Branchenschwerpunkten, geografischer Streuung, Kreditarten und Verteilung der Engagements in Risiko- und Größenklassen. Die Geschäftsleitung gibt somit genau Branche, Größe und Risiko der Schuldner vor, an welche die Bank Kredite vergeben möchte. Unternehmen, die nicht in die von der Geschäftsleitung beschlossene Kreditrisikostrategie passen, sind im Regelfall von der Kreditvergabe ausgeschlossen.

Weitere Kernelemente sind die funktionale und organisatorische Abtrennung des Marktbereichs von der Marktfolge, die Votierungsanforderungen bei der Kreditvergabe, die Verankerung von Organisationsrichtlinien sowie die Festlegung einer Kreditrisikostrategie und Etablierung eines Risikoklassifizierungs- und -frühwarnsystems. ${ }^{178}$ Der sachgerechten Organisation des Kreditgeschäfts wird deswegen so viel Aufmerksamkeit geschenkt, da selbige, bspw. durch geeignete Risikoklassifizierungs- und -frühwarnsysteme, dazu beiträgt, den Wertberichtigungsbedarf mittel- und langfristig zu reduzieren. ${ }^{179}$

Nach § 25a KWG muss ein Institut über eine ordnungsgemäße Geschäftsorganisation verfügen, welche die Einhaltung der von den Instituten zu beachtenden gesetzlichen Bestimmungen gewährleistet. Alle Geschäftsleiter sind für die ordnungsgemäße Geschäftsorganisation des Instituts verantwortlich. ${ }^{180}$ Eine ordnungsgemäße Geschäftsorganisation umfasst dabei insbesondere eine angemessene Strategie, die auch die Risiken und Eigenmittel des Instituts berücksichtigt. Die MaRisk konkretisieren diesen Paragraphen und fordern in AT 1 - Tz. 1 - Satz 2: „Das Risikomanagement im Sinne dieses Rundschreibens umfasst die Festlegung angemessener Strategien sowie die Einrichtung angemessener interner Kontrollverfahren." ${ }^{\text {"181 }}$

Ein zentrales Prinzip bzgl. der Anforderungen an die Aufbauorganisation ist die Funktionstrennung, wobei in diesem Kontext unter dem Begriff der Funktionstrennung eine Verteilung von nicht zu vereinbarenden Aufgaben (Funktionen) und Tätigkeiten auf verschiedene Personen, Stellen oder Bereiche unter Beachtung des Vier-AugenPrinzips verstanden wird. ${ }^{182}$ Das geforderte Vier-Augen-Prinzip entspricht der Forderung nach einer Aufteilung von Funktionen auf mindestens zwei Personen.

\footnotetext{
176 Vgl. MaRisk (2007), AT 4.2.

177 Vgl. hier und im Folgenden Müller et al. (2006), S. 7.

$178 \mathrm{Vgl}$. Eller/Gruber/Reif (2003), S. V. Eller/Gruber/Reif beziehen sich zwar auf die MaK, selbige wurden allerdings in die MaRisk integriert.

Vgl. Hannemann/Schneider/Hanenberg (2003), S. V.

Vgl. hier und im Folgenden DSGV (2006b), S. 30.

MaRisk (2007), AT 1 - Tz. 1 - Satz 2.

Vgl. DSGV (2006b), S. 43, AT $4.3-$ Tz. 1.
} 
Neben diesem Grundprinzip der Funktionstrennung gibt es spezielle Anforderungen an selbige. So muss die Funktion Markt bis in die Ebene der Geschäftsleitung von Marktfolge, Risikocontrolling, Abwicklung und Kontrolle getrennt sein. ${ }^{183}$ Unter dem Marktbereich werden die Bereiche subsumiert, die Geschäfte initiieren und die bei den Kreditentscheidungen über ein Votum verfügen. ${ }^{184}$ Als Marktfolge wird der Bereich definiert, der bei den Kreditentscheidungen über ein zweites Votum verfügt. ${ }^{185} \mathrm{Gemäß}$ AT 2.3 - Tz. 2 wird unter dem Begriff Kreditentscheidung jegliche Entscheidung über

- Neukredite,

- Krediterhöhungen,

- Beteiligungen,

- Limitüberschreitungen,

- die Festlegung von kreditnehmerbezogenen Limiten sowie von Kontrahentenund Emittentenlimiten,

- Prolongationen und

- Änderungen risikorelevanter Sachverhalte, die dem Kreditbeschluss zugrunde lagen (z.B. Sicherheiten, Verwendungszweck)

subsumiert. ${ }^{186}$ Diese aufbauorganisatorische Trennung zwischen Markt und Marktfolge ist jedoch nur für solche Kreditgeschäfte maßgeblich, die unter Risikogesichtspunkten zwei Voten erfordern. ${ }^{187}$

Hintergrund dieser Funktionstrennung ist die Gefahr von unter Risikogesichtspunkten unausgewogenen Kreditentscheidungen, die in diesem Zusammenhang insbesondere dann zu beobachten sind, wenn die Entscheidungskompetenzen bei den Vertriebseinheiten konzentriert sind. ${ }^{188}$ Ziel ist es, durch die Separierung der Funktionen Interessenkollisionen zu vermeiden. Jede Bank unterliegt im Hinblick auf die Akquisitionstätigkeit des Vertriebes einem mehr oder minder ausgeprägten systemimmanenten Gegensatz: Auf der einen Seite ist der Vertrieb ein unverzichtbares Akquisitionsinstrument, ohne das die Geschäftsstrategie einer Bank nicht umgesetzt werden kann. Häufig wird die Akquisitionstätigkeit des Vertriebs über erfolgsabhängige Vergütungsund Anreizsysteme gesteuert. Auf der anderen Seite führen Entscheidungsmonopole im Vertrieb häufig zu unter Risikogesichtspunkten nicht angemessenen Ausdehnungen des Kreditportfolios, da den Kompetenzträgern mitunter in erster Linie an der Erhöhung ihrer Provisionen oder anderer subjektiver Vorteile gelegen ist.

\footnotetext{
183 Vgl. MaRisk (2007), BTO - Tz. 3.

184 Vgl. MaRisk (2007), BTO - Tz. 1.

185 Vgl. MaRisk (2007), BTO - Tz. 1.

186 Vgl. MaRisk (2007), AT $2.3-$ Tz. 2.

187 Vgl. MaRisk (2007), BTO 1.1 - Tz. 1. In den MaRisk wird zwischen risikorelevanten und nicht risikorelevanten Geschäften unterschieden, wobei die Unterscheidung Auswirkungen sowohl auf die Ablauf- als auch die Aufbauorganisation (Funktionstrennung und Votierung) hat. Allerdings erfolgt in den MaRisk keine Vorgabe bzgl. der konkreten Abgrenzung; die Abgrenzung zwischen risikorelevantem und nicht risikorelevantem Kreditgeschäft liegt im Ermessen des Kreditinstituts. Vgl. DSGV (2006b), S. 78. 
Verschärft wird dieser Konflikt zusätzlich dadurch, dass sich zwischen Vertriebsmitarbeitern und Kunden bei einer langjährigen Geschäftsbeziehung häufig eine enge persönliche Bindung entwickelt, die ggf. dazu beitragen kann, dass die Risiken der einzelnen Kreditvergabe nicht mit der notwendigen Objektivität beurteilt werden. Diese ambivalente Rolle des Vertriebes, zum einen als geschäftspolitisch absolut notwendiges Akquisitionsinstrument und zum anderen als Risikotreiber, macht die Separierung der Funktionen absolut erforderlich. ${ }^{189}$ Der Einfluss der persönlichen Bindung auf die Geschäftsbeziehung zwischen Kunde und Bank, insbesondere auf den Zinssatz, die Kreditvergabe und die Sicherheitenstellung ist zentraler Gegenstand der Untersuchung. In diesem Kontext wird auch untersucht, inwiefern die zuvor erwähnten Vergütungs- und Anreizsysteme Auswirkungen auf das Verhalten der Marktmitarbeiter haben.

Die Anforderungen an die Votierung in den MaRisk wurden inhaltlich identisch aus den zuvor gültigen Mindestanforderungen an das Kreditgeschäft (MaK) übernommen. Wie bisher erfordert jede Kreditentscheidung im risikorelevanten Geschäft zwei zustimmende Voten, die aus den Bereichen Markt und Marktfolge kommen, ohne dass davon weitergehende Beschlussfassungen beeinflusst werden. ${ }^{190}$ Für den Fall voneinander abweichender Voten sind in der Kompetenzzuordnung Entscheidungsregeln derart zu treffen, dass der Kredit entweder abzulehnen oder zur Entscheidung auf eine höhere Kompetenzstufe zu verlagern ist (Eskalationsverfahren). ${ }^{191}$ In der Praxis ist es nicht unüblich, dass zwischen den Votierenden im Vorfeld der Votierung Gespräche über die Engagements geführt werden und die Kreditvorlage auf Grundlage der Ergebnisse dieser Gespräche entsprechend ergänzt und angepasst wird. So kann es z.B. vorkommen, dass die positive Votierung der Marktfolge an weitere Bedingungen geknüpft wird (z.B. Anhebung der Konditionen oder Bestellung zusätzlicher Sicherheiten). ${ }^{192}$ Eine derartige Vorgehensweise trägt dazu bei, sich im Dialog über mögliche Schwachstellen auszutauschen und die Qualität der Kreditvorlage bzw. die Basis für die Kreditentscheidung nachhaltig zu verbessern.

Des Weiteren schreiben die MaRisk vor, dass die Bewertung von Sicherheiten außerhalb des Bereichs Markt zu erfolgen hat. ${ }^{193}$ Soweit Zweifel an der Bonität des Kreditnehmers bestehen, lässt sich das Ausfallrisiko durch die Hereinnahme von Sicherheiten begrenzen. ${ }^{194}$ Aber selbst bei einwandfreier Bonität des Kreditnehmers besteht aus Sicht des Kreditinstituts häufig das Bedürfnis nach einer zusätzlichen Besicherung, da unvorhergesehene Entwicklungen die Bonität des Kreditnehmers trüben können. ${ }^{195}$ Der Sicherheitenwert kann insoweit von ganz erheblicher Bedeutung für die konkrete

\footnotetext{
189 Vgl. Hannemann/Schneider/Hanenberg (2003), S. 86.

190 Vgl. DSGV (2006b), S. 81.

191 Vgl. MaRisk (2007), BTO 1.1 - Tz. 6.

$192 \mathrm{Vgl}$. Hannemann/Schneider/Hanenberg (2003), S. 92.

193 Vgl. DSGV (2006b), S. 97.

194 Vgl. Hannemann/Schneider/Hanenberg (2003), S. 142

$195 \mathrm{Vgl}$. Hannemann/Schneider/Hanenberg (2003), S. 142. Eine Möglichkeit besteht bspw. in der Stellung einer Bürgschaft durch einen beschränkt haftenden Gesellschafter, da dieser dadurch ein persönliches Risiko eingeht. 
Kreditentscheidung sein. In der Vergangenheit hat sich dabei gezeigt, dass Sicherheitenwerte oft zu unkritisch oder zu optimistisch eingeschätzt wurden, wenn die Überprüfung in Vertriebsbereichen durchgeführt wurde und dort gleichzeitig alle Kreditkompetenzen konzentriert waren. Aufgrund dieser Erfahrung hält die BaFin auch im Bereich der Sicherheiten eine konsequente Trennung des Prozesses der Überprüfung vom Vertriebsbereich für erforderlich. Aus den MaRisk kann allerdings kein unmittelbarer Zusammenhang zwischen der Bonität und der Höhe der Sicherheitenstellung hergeleitet werden. Es gibt keine Vorschriften derart, dass bspw. bonitätsmäßig schlechtere Kunden mehr Sicherheiten stellen müssen als bonitätsmäßig einwandfreie Kunden.

\subsection{Implikationen der gesetzlichen Rahmenbedingungen für den Gestaltungsspielraum der Banken bei der Konditionengestaltung}

Nach der Vorstellung der wesentlichen Inhalte von Basel II und den MaRisk wird im Folgenden geprüft, welche Implikationen sich aus diesen Vorschriften in Bezug auf die Kreditkonditionengestaltung ergeben. Die aus Kundensicht zentralen Elemente des Kreditvertrags sind der Kreditzins, die zu stellenden Sicherheiten und das Kreditvolumen. In diesem Kontext werden in Bezug auf den Kreditzins die verschiedenen Kostenbestandteile untersucht. Das Kreditvolumen ist Ausdruck der Kreditverfügbarkeit, denn während selbiges bei einer unbeschränkten Kreditverfügbarkeit den Bedürfnissen des Kunden und somit seinem beantragten Volumen entspricht, führt eine eingeschränkte Kreditverfügbarkeit dazu, dass der Kredit nicht in voller Höher oder gar nicht bewilligt wird.

Die Auswirkungen auf den Zinssatz stellen sich wie folgt dar. Während Basel II ausschließlich Vorgaben hinsichtlich der Risikoermittlung und der Eigenkapitalhinterlegung macht, wird in den MaRisk die Weitergabe der Risikobeurteilung an den Kunden in Form einer "Sollte-Anforderung "196 thematisiert. Bezüglich der Konditionengestaltung sehen die MaRisk vor, dass ein sachlich nachvollziehbarer Zusammenhang zur Einstufung im Risikoklassifizierungsverfahren bestehen sollte. ${ }^{197}$ Angesichts des verschärften Wettbewerbs zwischen den Kreditinstituten, der zunehmenden Mobilität der Kunden und auch den technischen Weiterentwicklungen, die zu einer immer größeren Transparenz auf den Märkten führen, wird kaum noch eine Bank daran vorbeikommen, das jeweilige Risiko mit in die Preisgestaltung einfließen zu lassen. ${ }^{198}$ Kunden mit guter Bonität sind heutzutage nur noch selten bereit, nicht risikogerechte Preise für die Kapitalüberlassung zu zahlen. Bei den Banken, die im Rahmen der Kreditvergabe weiterhin keine risikogerechte Preisfindung durchführen, werden sich zwangsläufig die schlechten Bonitäten ansammeln. Um risikoorientiert Kredite vergeben zu können, müssen die Banken zunächst mit Hilfe von Ratingsystemen das Risiko des Kreditnehmers bestimmen. Basel II macht bei Instituten, die einen auf internen Ratings basie-

\footnotetext{
196 Vgl. DSGV (2006b), S. 1.

197 Vgl. MaRisk (2007), BTO 1.2 - Tz. 6.

198 Vgl. Hannemann/Schneider/Hanenberg (2003), S. 134.
} 
renden Ansatz anwenden, die Erstellung eines Ratings für alle Unternehmen, die bereits Bankkredite nutzen oder solche beantragen, zur Pflicht. Aus dem Ratingergebnis resultieren für kreditsuchende Unternehmen Implikationen in Bezug auf die Höhe der Kreditzinsen. ${ }^{199}$ Während bei der bisherigen Kreditvergabepraxis deutscher Banken die quantitativen Beurteilungskriterien, insbesondere Bilanzkennzahlen, ein deutliches Übergewicht besaßen, wird mit der Umsetzung von Basel II das Gewicht der weichen Beurteilungskriterien, wie bspw. Qualität des Managements, Abhängigkeiten von Lieferanten und Abnehmern, Ausgestaltung des Controllingsystems, deutlich erhöht. ${ }^{200}$ Die Gewichtung der beiden Bereiche schwankt zwischen den Ratingsystemen der verschiedenen Institute. ${ }^{201}$ In der Regel wird aus den beiden Teilratings für beide $\mathrm{Be}$ reiche, deren Ergebnisse in dem Teilscore qualitative Daten und Teilscore Jahresabschluss ihren Niederschlag finden, ein Gesamtrating für das Unternehmen gebildet.

Die Stärke des potenziellen Einflusses auf den Kreditzins soll im Folgenden kurz skizziert werden. Dazu werden die verschiedenen Bestandteile des Kreditzinses beschrieben, wobei die Größenordnung der Anteile unterschiedlich ist und vom Schuldnertyp sowie der Geschäftsart abhängt. ${ }^{202}$ Grundlage bildet der (risikolose) Fremdkapitalmarktzins für die Laufzeit der Forderung. Der Geld- und Kapitalmarktzins entschädigt die Bank für die Kosten der Geldbeschaffung entweder bei den Anlegern der Bank oder auf dem Kapitalmarkt. ${ }^{203}$

Als zusätzliche Komponente sind die prozentualen Standardrisikokosten für die erwarteten Verluste in Abhängigkeit von der Bonität und den gestellten Sicherheiten des einzelnen Kunden zu berücksichtigen. ${ }^{204}$ Diese entsprechen im weitesten Sinne einer Versicherungsprämie, um die für diesen Forderungstyp oder Risikotyp im Durchschnitt zu erwartenden Verluste abzudecken. Die Standardrisikokosten sollen den erwarteten Verlust aus einem Kreditengagement abdecken. ${ }^{205}$ Der erwartete Verlust in Prozent der Inanspruchnahme ergibt sich aus der Multiplikation der Ausfallwahrscheinlichkeit und der Verlustquote bei Ausfall.

Des Weiteren ist eine Kostenprämie für das zu hinterlegende Eigenkapital mit einzubeziehen, welches für die unerwarteten Verluste vorgehalten werden muss. ${ }^{206}$ Die Höhe des vorzuhaltenden Eigenkapitals für diese Risikoklasse wird durch Basel II bestimmt. Auch diese Kosten für die aufsichtsrechtliche Unterlegung von Risiken mit Eigenkapital werden den Unternehmen als Zinsbestandteil in Form des Eigenkapitalkostensatzes angelastet. ${ }^{207} \mathrm{Da}$ Eigenkapital einen höheren Verzinsungsanspruch hat als eine Refinanzierung mit Fremdkapital, sind die Kreditzinsen für Kredite mit hohem Unterle-

\footnotetext{
199 Vgl. Müller et al. (2006), S. 7 f.

$200 \mathrm{Vgl}$. Flacke/Siemes (2005), S. $252 \mathrm{ff}$.

201 Für das Gesamturteil werden je nach Institut die qualitativen Faktoren mit $40 \%$ bis $70 \%$ und die quantitativen Faktoren mit $60 \%$ bis $30 \%$ berücksichtigt. Vgl. Pointl (2003), S. 38 f.

Vgl. Schulte-Mattler/Manns (2004), S. 378.

Vgl. Müller et al. (2006), S. 8.

Vgl. Schulte-Mattler/Manns (2004), S. 378.

Vgl. hier und im Folgenden Müller et al. (2006), S. 8.

Vgl. Schulte-Mattler/Manns (2004), S. 378.

Vgl. Müller et al. (2006), S. 9.
} 
gungsfaktor allein aus diesem Grund teurer als Kredite mit geringerem Unterlegungsfaktor. ${ }^{208}$

Als abschließende Komponente kommen noch die Kosten der Kreditbearbeitung (Betriebskostensatz) und der Margensatz (Gewinnbeitrag) des Instituts hinzu. Der Betriebskostensatz deckt die Kosten der Kreditbearbeitung in der Bank, ${ }^{209}$ hat aber im Vergleich zu den Risiko- und Eigenkapitalkosten geringere Dimensionen. ${ }^{210}$ Eine $\mathrm{Zu}$ sammenfassung der Kostenkomponenten unter Vernachlässigung der jeweiligen Gewichtung kann Abb. A-3 entnommen werden.

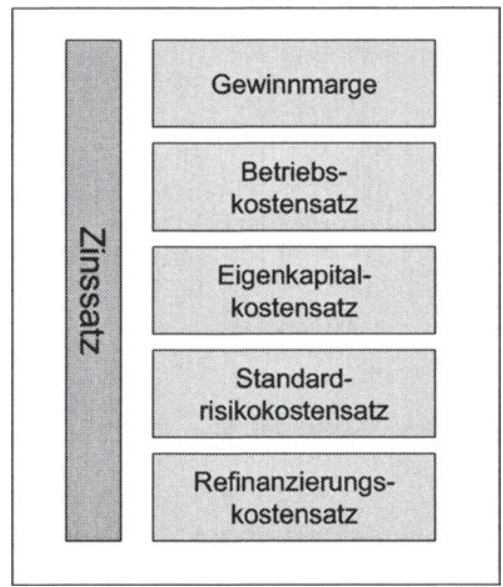

Abb. A-3: Kostenkomponenten des Kreditzinses ${ }^{211}$

Vgl. Müller et al. (2006), S. 4. Die zuvor aufgeworfene Frage, inwiefern ein einzelner Kredit dem Mengengeschäft zugeordnet werden darf, hat Bedeutung für die Frage, welches Risikogewicht heranzuziehen ist und welche spezifische Eigenmittelunterlegung das Kreditinstitut für das Engagement vorzuhalten hat. Aber auch Kredite des Mengengeschäfts werden häufig, allerdings unabhängig von der Ermittlung des zu hinterlegenden Eigenkapitals, einem internen Rating unterzogen, um u.a auf dieser Basis die Standardrisikokosten ermitteln zu können und Anhaltspunkte für die Gesamtbanksteuerung zu gewinnen. Somit sind die beiden zuletzt genannten Kostenkomponenten auch für das Mengengeschäft von Relevanz. Vgl. zum Kreditprozess Berens et al. (2005), S. 785. In der Untersuchung wurden ausschließlich Unternehmen mit internen Ratings berücksichtigt. aller Regel fix, d.h. unabhängig vom Kreditvolumen oder sonstigen kreditrelevanten Parametern, so dass Fixkostendegressionseffekte keine Berücksichtigung finden. 
Zusammengefasst stellen sich die Auswirkungen wie folgt dar. Da die Eigenkapitalkosten aufgrund der Bestimmung von Basel II auf dem Risiko des Unternehmens aufbauen und die Standardrisikokosten sich anhand des Risikos eines Kreditnehmers kalkulieren, ergibt sich eine Abhängigkeit der Kreditzinsen vom Ratingergebnis. ${ }^{212}$ Sowohl gemäß den Vorstellungen des Baseler Ausschusses ${ }^{213}$ als auch gemäß den Mindestanforderungen an das Kreditgeschäft ${ }^{214}$ soll zukünftig ein funktionaler $\mathrm{Zu}$ sammenhang zwischen dem Rating eines Kunden, also seiner Ausfallwahrscheinlichkeit, und dem verlangten Kreditzinssatz bestehen. Gibt der Firmenkundenbetreuer nun günstigere Zinskonditionen als ermittelt, so kann dies auf Einzelgeschäftsebene zu negativen Deckungsbeiträgen oder zumindest zu Deckungsbeiträgen, die unterhalb der Zielvorgabe liegen, führen. Die im Basel-I-System noch übliche Durchschnittsbetrachtung und somit die Quersubventionierung schlechter Bonitäten mit zu niedrigen Zinssätzen soll durch eine risikoadäquate Festlegung der Kreditzinssätze beseitigt werden. ${ }^{215}$ Da sich viele Banken erst in der Einführungsphase befinden, gibt es bisher noch keine umfassenden Studien, die den tatsächlichen Einfluss von Basel II auf die Kreditvergabepraxis quantifizieren können. Bei Banken, die allerdings den einfachen Standardansatz anwenden, wird es weiterhin ein Bonitätsgewicht für alle Schuldner in der Retail-Klasse, d.h. im Bereich des Mengengeschäfts, geben, so dass sich daraus keine erhöhten Zinsen aufgrund einer veränderten Eigenkapitalhinterlegung ergeben. ${ }^{216} \mathrm{Da}$ das Bonitätsgewicht für die Positionen des Mengengeschäfts auf $75 \%$ abgesenkt wurde, reduziert sich die Eigenkapitalanforderung gegenüber dem Status Quo sogar von $8 \%$ auf $6 \%$, so dass die Kreditinstitute für die kleinen und mittleren Firmenkunden ab 2007 deutlich weniger Eigenkapital unterhalten müssen. ${ }^{217}$

Es ist davon auszugehen, dass die Banken unter anderem aufgrund des intensiven Wettbewerbs eine exakte Orientierung der Zinsen am Risiko noch nicht voll durchsetzen können. ${ }^{218}$ Im Wettbewerb zwischen den Banken muss jedes Institut seine Position im Hinblick auf das Verhältnis zwischen der Einforderung expliziter (Risikoprämie im Zins) und impliziter Preise (zugesagte Mehrgeschäfte, Einflussnahme, Sicherheiten) finden. Auch zukünftig wird es demnach eine Flexibilität für individuelle Preisver-

212 Vgl. Müller et al. (2006), S. 9.

213 Vgl. Schulte-Mattler/Manns (2004), S. 378.

214 Vgl. DSGV (2006b), S. 1.

215 Vgl. Schulte-Mattler/Manns (2004), S. 376.

216 In die Retail-Klasse, d.h. in die Gruppe der Kreditnehmer mit einem Exposure unter 1 Mio. EUR, fallen nach Schätzungen der Bundesanstalt für Finanzdienstleistungsaufsicht weit über $90 \%$ aller umsatzsteuerpflichtigen Unternehmen in Deutschland. In einer Studie des ikf Institut für Kredit- und Finanzwirtschaft, die gemeinsam mit der IHK im Herbst 2002 zum Thema Basel II, Mittelstand und Kreditvergabe durchgeführt wurde und bei der 2.596 Unternehmen mit einem Umsatz kleiner 50 Mio. EUR im mittleren Ruhrgebiet befragt wurden, konnte gezeigt werden, dass für einen Großteil der Unternehmen die Retail-Portfolio-Regelung zutrifft. Von den Unternehmen, die sich über Bankkredite finanzieren, greift die Retail-Portfolio-Regelung für 93\% der Unternehmen mit einem Umsatz kleiner 5 Mio. EUR, für 54\% der Unternehmen mit einem Umsatz größer 5 und kleiner 50 Mio. EUR und für $80 \%$ der Unternehmen mit einem Umsatz kleiner 50 Mio. EUR. Vgl. Paul/Stein (2003), S. 421 f.

217 Vgl. Paul/Stein (2003), S. 422.

218 Vgl. Müller et al. (2006), S. 9. 
handlungen mit mittelständischen Unternehmen geben. Nach wie vor werden verhandlungsstarke Unternehmer, die bspw. aufgrund von Mehrfachbankverbindungen über eine hohe Preistransparenz verfügen und die bspw. aufgrund von Zusatzgeschäften mit der Bank in der privaten Vermögensverwaltung eine hohe wirtschaftliche Stärke haben, erfolgreich um Vorzugszinssätze verhandeln können. ${ }^{219}$ So lassen auch die neuen Vorschriften Handlungsspielräume für die Bank sowohl bei der Ausgestaltung der Ratingsysteme als auch bei den auf deren Basis abgeleiteten Konsequenzen zu. Während wie zuvor beschrieben die Quersubventionierung schlechter Bonitäten mit zu niedrigen Zinssätzen durch eine risikoadäquate Festlegung der Kreditzinssätze beseitigt werden soll, ${ }^{220}$ hat das einzelne Institut grundsätzlich die Möglichkeit, eine Risikoprämie im Zins zu substituieren durch:

- Anschlussgeschäfte (und die aus ihnen resultierenden Erträge) mit dem betreffenden Kreditschuldner,

- Zusatzgeschäfte (und die aus ihnen resultierenden Erträge) mit dem betreffenden Kreditschuldner, z.B. Provisionserträge aus der Vermittlung von Versicherungen,

- die Einräumung von Einflussnahme (z.B. in Form eines Beiratsmandats und die dadurch anfallenden „Einblicke“ in die Unternehmung) oder aber

- Kreditsicherheiten, die materieller Art (z.B. Verpfändung beweglicher Gegenstände) sowie immaterieller Natur (exklusive Informationen über die Unternehmensplanung) sein können.

Als weitere aus Kundensicht relevante Komponente der Vertragsgestaltung ist der Umfang der zu stellenden Sicherheiten zu nennen. Hinsichtlich der Sicherheitenstellung haben sich durch die neuen Regeln keine unmittelbaren Implikationen ergeben, so schreiben die MaRisk lediglich eine konsequente Trennung des Prozesses der Überprüfung der Sicherheiten vom Vertriebsbereich vor. Die Höhe der gestellten Sicherheiten wird bei der Ermittlung des Risikogewichts für die jeweilige Forderung berücksichtigt ${ }^{221}$ und beeinflusst somit das für den jeweiligen Kredit vorzuhaltende Eigenkapital der Bank und dadurch die Eigenkapitalkosten des Kredits. Ferner werden die gestellten Sicherheiten je Kredit bei der Ermittlung des erwarteten Verlusts, d.h. der Standardrisikokosten, des Kredits berücksichtigt. ${ }^{222}$

Als dritte zentrale Komponente wurde die Kreditverfügbarkeit genannt. Unter Basel II ersetzt das Rating die bisher von den Banken größtenteils frei gestaltbare Kreditwürdigkeitsprüfung bei der Entscheidungsfindung über die Annahme oder Ablehnung eines Kreditantrags eines Unternehmens. ${ }^{223}$ Wie auch bisher werden Banken den Unternehmen mit einer schlechten Ratingeinstufung nur zögerlich oder unter Auflagen Kredit gewähren. War dies bislang häufig Verhandlungssache zwischen Unternehmen

\footnotetext{
219 Vgl. Paul/Stein (2003), S. 427.

220 Vgl. Schulte-Mattler/Manns (2004), S. 376.

221 Vgl. Baseler Ausschuss für Bankenaufsicht (2004), S. $26 \mathrm{ff}$.

${ }_{222}$ Vgl. Baseler Ausschuss für Bankenaufsicht (2004), S. 74.

223 Vgl. Müller et al. (2006), S. 8.
} 
und Bank, entsteht durch die MaRisk das Erfordernis, das Rating des Unternehmens mit der Kreditrisikostrategie der Bank abzugleichen. Dasselbe gilt für die Größe und Region des Unternehmens. Gehen diese nicht mit der Kreditrisikostrategie der Bank konform, werden Unternehmen nur noch in besonderen Ausnahmefällen mit spezieller Genehmigung der Geschäftsleitung der Bank Kredite erhalten können. Eine Studie der KPMG zeigt, dass sich eine häufigere Kreditverweigerung empirisch bislang nicht nachweisen lässt. ${ }^{224}$ Nur $4 \%$ der befragten Unternehmen haben nachhaltig einen beantragten Kredit nicht erhalten. Dagegen stellen zwei Drittel der befragten Banken und die Hälfte der Unternehmen fest, dass die Kreditentscheidung länger dauert als in der Vergangenheit, was u.a. auf die intensiveren Abstimmungsprozesse in der Bank zurückzuführen ist. Allerdings ist zu erwähnen, dass die Basel II-Regeln erst seit 2007 in Deutschland verbindlich sind und die Studie bereits in den Jahren 2004 bis 2005 erschienen ist. ${ }^{225}$ Infolgedessen konnten in dieser Studie nur die Auswirkungen der vorlaufenden Tätigkeiten berücksichtigt werden.

Abschließend lässt sich zusammenfassen, dass in Zukunft aufgrund von Basel II und der MaRisk zwar ein verstärkter Zusammenhang zwischen der Bonität des Kunden und dessen Kreditzins bestehen wird und die Zinsfestsetzung verstärkt durch die ermittelte Ratingklasse beeinflusst wird. In welchem Umfang die Banken allerdings eine vollständig risikoorientierte Bepreisung auf Einzelgeschäftsebene durchführen bzw. durchführen werden, kann zum gegenwärtigen Zeitpunkt noch nicht hinreichend beurteilt werden. Im Rahmen der vorliegenden Studie wird dies derart berücksichtigt, dass bei der Analyse der Einflussgrößen des Zinssatzes die Bonität des Unternehmens besonders ausführlich betrachtet wird. Hinsichtlich der Kreditverfügbarkeit und der Sicherheitenstellung lässt sich kein unmittelbarer Einfluss der gesetzlichen Rainmenbedingungen auf den Verhaltensspielraum der Banken identifizieren. Bereits an dieser Stelle lässt sich konstatieren, dass auch im Rahmen der Kunde-Bank-Beziehung ein ausgewogenes Verhältnis von Preis und Leistung gepaart mit wechselseitigem Vertrauen und Kontinuität der Geschäftsbeziehungen ein Garant einer langfristigen Bindung des Unternehmens an seine Bank ist. Zwar werden Preise auf Einzelgeschäftsebene ausgehandelt, die Beurteilung des Engagements einer Bank erfolgt jedoch grundsätzlich nur im Gesamtpaket. ${ }^{226}$ Daraus ergibt sich die Notwendigkeit der Analyse der Geschäftsbeziehung über die Einzelgeschäftsebene hinaus.

\footnotetext{
224 Vgl. Müller/KPMG (2004), S. 2 ff.

225 Vgl. Müller et al. (2006), S. 7.

226 Vgl. Hornung (2002), S. 69.
} 


\section{Relationship Banking}

Im Folgenden werden zunächst die verschiedenen Definitionen des Relationship Banking vorgestellt sowie seine wesentlichen Merkmale herausgearbeitet. In diesem Kontext erfolgt eine Abgrenzung des Relationship Banking-Ansatzes vom Hausbankbegriff. Darauf aufbauend werden die für die Analyse der Geschäftsbeziehung wesentlichen Merkmale der Prinzipal-Agenten-Theorie kurz präsentiert, um anschließend die informationsökonomischen Modelle aus der Relationship Banking-Theorie darzustellen und zu analysieren. Dem sich daran anschließenden Überblick über die empirischen Untersuchungen im Bereich Relationship Banking folgt eine kritische Würdigung sowie die Herausarbeitung von weiterem Forschungsbedarf, insbesondere im empirischen Bereich.

\subsection{Definition von Relationship Banking}

MAIN erläutert - wie in Kapitel A.1.1 erwähnt - den Begriff der Bankbeziehung wie folgt: "Perhaps the most competitive service a bank can offer is what bankers call a relationship, which means the customer gets to deal with a real human being, preferably one who is knowledgeable and courteous and who is get to know his name. What the bank customer seems to want more than anything that is a sense of importance, like being recognized by a head waiter."227 Für MAIN spielt die persönliche Beziehung zwischen dem Kunden und dem Firmenkundenbetreuer eine zentrale Rolle für die Kunde-Bank-Beziehung.

MORIARTY/KIMBALL/GAY postulieren, dass sich im Zeitablauf einer Bankbeziehung die Anzahl der Produktbeziehungen vervielfältigen und in Konsequenz die Bank und der Kunde an Bedeutung füreinander gewinnen. Ausgehend von diesen Produktbeziehungen entwickeln sich persönliche Beziehungen, welche einen intangiblen, aber wesentlichen Nutzen für beide Seiten generieren. ${ }^{228}$ Neben der rein persönlichen Komponente wird bei MORIARTY/KIMBALL/GAY somit explizit der Nutzenaspekt integriert. Denn durch diese enge Beziehung wird dem Kunden implizit eine verbesserte Kreditverfügbarkeit zugesichert und gleichzeitig sinkt die wahrgenommene Gefahr, die aufgrund des in der Regel bei dem Firmenkunden nicht vorhandenen Expertenwissens mit dem Kauf von komplexen Bankprodukten verbunden ist. ${ }^{229}$ Der Kunde auf der einen Seite ist aufgrund der persönlichen Beziehung eher bereit auch komplexe Produkte, wie z.B. Zins- und Währungssicherungsgeschäfte oder strukturierte Finanzierungen, mit der Bank abzuschließen. Die Bank auf der anderen Seite erhält Zugang zu Informationen über die Businesspläne des Kunden und über Produktbedarfe des Kunden, woraus ein wesentlicher Wettbewerbsvorteil für die Bank im Verkauf von weiteren Bankprodukten an diesen Kunden resultiert. ${ }^{230}$ So wird der Kunde der Bank einen bestehenden Produktbedarf frühzeitiger und offener kommunizieren, zusätzlich erhält

\footnotetext{
$227 \quad$ Main (1982), S. 64.

228 Vgl. Moriarty/Kimball/Gay (1983), S. 4.

229 Vgl. Moriarty/Kimball/Gay (1983), S. 4.

$230 \mathrm{Vgl}$. Moriarty/Kimball/Gay (1983), S. 4.
} 
die Bank aber auch schneller Informationen über einen latenten Bedarf, wie bspw. die Information, dass der Kunde in das Exportgeschäft einsteigen will und somit einen Bedarf an Beratung im Auslandsgeschäft hat. Vor diesem Hintergrund definieren ONGENA/SMITH die Bankbeziehung als ,connection between a bank and a customer that goes beyond the execution of simple, anonymous, financial transactions". ${ }^{231} \mathrm{Zu}$ sammengefasst besteht der Nutzen der Bankbeziehung im Transfer von proprietären Informationen und dem impliziten Versprechen der Bank, auch in schweren Zeiten die Geschäftsbeziehung aufrecht zu erhalten und liquide Mittel bereitzustellen. ${ }^{232}$

„When financial economists speak of relationship lendings ...[t]hey mean a close relationship between a firm and its banker, in which a single banker has intimate knowledge about the firm's affairs, built up over years of lending." ${ }^{33}$ Während der Zeitfaktor bisher nur implizit berücksichtigt wurde, betont BERLINS Aussage die fundamentale Bedeutung der Langfristigkeit bei der Definition von Relationship Lending. ${ }^{234}$ Langfristigkeit bedeutet in diesem Zusammenhang, dass Bank und Kunde im Zeitablauf immer wieder Kontakt haben und (evtl.) neue Verträge miteinander abschließen. Im Hinblick auf die zentralen Aspekte der Informationssammlung im Zeitablauf steht hinter der Betonung des Langfristcharakters immer auch, dass beide Parteien eine gemeinsame Historie der Beziehung aufbauen und daraus Informationen ziehen und somit ein Lerneffekt hinzukommt. Die Informationen werden unter anderem durch Screening und/oder Monitoring-Tätigkeiten der Bank erlangt. ${ }^{235}$ Der Langfristcharakter ist aber nicht nur für die Informationssammlung, sondern auch für die Informationsverwendung essenziell. Die Informationen können in einer Vielzahl von Interaktionen mit dem gleichen Kunden verwendet werden, so dass die Möglichkeit einer intertemporalen Wiederverwertbarkeit der Informationen geschaffen wird. ${ }^{236}$

Der zuvor bereits auch von MORIARTY/KIMBALL/GAY angesprochene Kundennutzen wird in der Definition von Relationship Lending gemäß PETERSEN/RAJAN explizit integriert und weiter konkretisiert: „by close and continued interaction, a firm may provide a lender with sufficient information about, and a voice in, a firm's affairs so as to lower the cost of and increase the availability of credit." ${ }^{\text {"237 }}$ Der Nutzen des Kunden besteht in dieser Definition somit in niedrigeren Zinsen und einer größeren Kreditverfügbarkeit, resultierend aus den privaten Informationen, die der Bank im Rahmen der Geschäftsbeziehung zukommen. Gleichzeitig wird aber auch ein Mitspracherecht der Bank in Bezug auf die Geschäftsaktivitäten des Unternehmens angenommen. Gemäß AOKI/DINÇ ist Relational Financing eine Form der Finanzierung, bei der vom Financier erwartet wird, dass er , $[\ldots]$ additional financing in a class of uncontractible states

\footnotetext{
$231 \quad$ Ongena/Smith (2000a), S. 224.

232 Vgl. Ongena/Smith (2000a), S. 224.

233 Berlin (1996), S. 1.

234 Aufgrund der in Kapitel A.2.2.3 beschriebenen zentralen Bedeutung des Kreditgeschäfts im Rahmen der Kunde-Bank-Beziehung werden die Begriffe Relationship Banking, Relational Financing und Relationship Lending synonym verwendet.

$235 \mathrm{Vgl}$. Boot (2000), S. 10.

236 Vgl. Boot (2000), S. 10.

237 Petersen/Rajan (1995), S. 5.
} 
in the expectation of future rents over time ${ }^{6238}$ bereitstellt. Analog zu PETERSEN/RAJAN wird der Aspekt der Finanzierungsmittelverfügbarkeit (additional financing) sowie der langfristige Beziehungscharakter (over time) angesprochen. Durch den Hinweis auf nicht kontrahierbare Umweltzustände kommt allerdings ein neuer Aspekt hinzu. Da der Abschluss vollständiger und zustandsabhängiger Verträge in einer Welt mit Informationsasymmetrien nicht möglich ist, versuchen Finanzintermediäre, Effizienz durch die Verwendung von Relationship Lending herzustellen. ${ }^{239}$ Aufgrund des Commitments der Kunden auch in Zukunft Anschlussfinanzierungen bei der Bank durchzuführen, wird die Bank auch bei Eintreten negativer Umweltzustände den Kunden unterstützen, um Erträge aus zukünftigen Geschäften zu generieren.

Den bereits von AOKI/DINÇ angesprochenen Aspekt zukünftiger Renten formulieren MORIARTY/KIMBALL/GAY als Gewinnmaximierungsaspekt der Bank. Sie definieren Relationship Banking wie folgt: "in its simplest form, relationship banking is a recognition that a bank can increase its earning by maximizing the profitability of the total customer relationship over time, rather than seeking to extract the most profit from any one individual or transaction." 240 Auch wenn in den bisher angeführten Definitionen primär der Finanzierungsaspekt der Bankbeziehung beleuchtet wurde und häufig Begriffe wie Kreditnehmer und Kreditgeber Verwendung finden, beschränkt sich Relationship Banking - wie es auch in der Definition von MORIARTY/KIMBALL/GAY zum Ausdruck kommt - nicht ausschließlich auf die Finanzierung, sondern umfasst auch zahlreiche andere Finanzdienstleistungen, z.B. Wechselgeschäft, Einlagen, Zahlungsverkehr und Cash Management Services. ${ }^{241}$ Da die meisten Kunden mehrere Bankprodukte erwerben und als Wiederholungskäufer auftreten, muss eine Bank mehrere Produktbeziehungen aufbauen und aufrechterhalten, um das volle Potenzial des Firmenkunden ausschöpfen zu können. ${ }^{242}$ Die Verschiebung von Gewinnen in die Zukunft setzt eine glaubhafte Bindung des Kunden an die Bank voraus.

Der monetäre Aspekt innerhalb der Bankbeziehung findet sich auch bei BOOT wieder. Zunächst investiert die Bank in die Gewinnung von Informationen über den Kreditnehmer, welche oftmals vertraulich sind und nur durch eine feste Kunde-BankBeziehung gewonnen werden können, und anschließend evaluiert sie die Profitabilität der festen Kunde-Bank-Beziehung nicht durch die Betrachtung einer einzelnen Interaktion mit dem Kreditnehmer, sondern unter Berücksichtigung der mehrfachen Interaktion mit dem Kreditnehmer sowohl in zeitlicher Hinsicht als auch in Bezug auf mehrere Produkte oder Dienstleistungen. ${ }^{243}$

\footnotetext{
238 Aoki/Dinç (1997), S. 5.

239 Vgl. Elsas/Krahnen (1998), S. 1286.

240 Moriarty/Kimball/Gay (1983), S. 4.

241 Vgl. Boot (2000), S. 11.

242 Vgl. Turnbull/Gibbs (1987), S. 362.

243 Vgl. Boot (2000), S. 10. Eine derartige Beurteilung der Beziehung erfordert jedoch die Ermittlung eines Customer-Lifetime-Value, was nach Kenntnis des Autors bei keiner der im Fokus der Analyse stehenden Genossenschaftsbanken erfolgt. Unter dem Customer-Lifetime-Value wird der Deckungsbeitrag verstanden, der mit einem Kunden während seines gesamten KundenleTina Püthe - 978-3-631-75310-1
} 
Die Definition von Relationship Banking und das mehrfach erwähnte Commitment der Bank schließen allerdings nicht aus, dass die Bank auch mal entgegen den Interessen des Kreditnehmers handelt, z.B. im Falle der Liquidation finanziell in Schieflage geratener Unternehmen durch verschiedene Banken. Auch kundenseitig handelt es sich bei dem Konzept des Relationship Banking nicht zwangsläufig um ein durchgängiges Beziehungsmuster, so kann der Kreditnehmer von einigen Kreditgebern ,at arm's length' und von anderen ,relational' finanziert werden. ,Arm's Length Financing "244, welches sich auf eine einzelne Transaktion mit einem Kunden oder auf mehrere identische Transaktionen mit verschiedenen Kunden fokussiert, kann hier als Gegenstück zum Relational Financing betrachtet werden. ${ }^{245}$ Ferner ist eine Relationship BankingBeziehung nicht auf eine Bank beschränkt, so kann ein Kreditnehmer gleichzeitig in mehreren Relationship Banking-Beziehungen stehen. ${ }^{246}$

Im Rahmen der Kunde-Bank-Beziehungen spielen beiderseitige Erwartungen eine zentrale Rolle. Der Unternehmer erwartet bspw. Hilfe für den Fall von temporären, überwindbaren finanziellen Schwierigkeiten und unternimmt deswegen im Laufe der Beziehung Investitionen in firmen-spezifische Assets (human oder non-human assets), wie bspw. den Aufbau eines bankspezifischen Reportingsystems. Die Bank auf der anderen Seite erwartet zukünftige Renten und Anschlussfinanzierungen. ${ }^{247}$ Als zusätzliche Ertragsquelle ist aber auch die Vermittlung von neuen Kundenkontakten denkbar. Es stellt sich die Frage, wie die Erwartung generiert und aufrechterhalten werden kann. Im Wesentlichen handelt es sich hierbei um ein Commitment-Problem, welches in der Definition von Relational Financing inhärent ist. ${ }^{248}$ Gründe für die Bank, sich gemäß ihrem Commitment zu verhalten, könnten bspw. darin liegen, dass sich die Reputation verschlechtern würde, wenn implizit zugesagte Hilfe später nicht geleistet wird oder darin, dass das Informationsmonopol und daraus resultierende Konditionenund Verhaltensspielräume und somit Ertragspotenzial nicht aufrecht erhalten werden kann, wenn der Kunde zu einer andern Bank wechselt. ${ }^{249}$ In diesem impliziten Commitment der Bank, auch zukünftig Kredite bereitzustellen und in Krisensituationen Hilfe zu leisten, besteht möglicherweise der wichtigste Nutzen der Beziehung. ${ }^{.50}$ Dieses Commitment kommt einer Versicherungspolice gleich, die dem Kunden in Zeiten von beschränkter Kreditverfügbarkeit oder finanzieller Schwierigkeiten Zugang zu Krediten zusichert. Der Wert einer Bankbeziehung wird aber häufig erst dann evident für den Kunden, wenn fundamentale Ereignisse den Fortbestand des Unternehmens gefährden. Eine Bank, die bereit ist, dem Kunden in einer Krise beizustehen, entwickelt häufig eine sehr starke und lang andauernde Beziehung, denn gerade in diesen

bens bzw. der Dauer der Geschäftsbeziehung realisiert wird, diskontiert auf den heutigen Tag. Vgl. Hempelmann/Lürwer (2003), S. $336 \mathrm{ff}$.

Die Begriffe Arm's Length Financing, Transaktions-Banking, Transaction-Banking oder Deal-

Based Banking werden synonym verwendet.

Vgl. Boot (2000), S. 10.

Vgl. Aoki/Dinç (1997), S. 6.

Vgl. Aoki/Dinç (1997), S. 6.

Vgl. Aoki/Dinç (1997), S. 9, Mayer (1988), S. 1177 ff., Hellwig (1991), S. 35.

Vgl. Aoki/Dinç (1997), S. 6.

Vgl. hier und im Folgenden Turnbull/Gibbs (1987), S. 363. 
Zeiten kommt es zu intensiven und häufigen Kontakten, so dass sich hieraus Unterschiede zwischen Kunden, die in der Vergangenheit eine Intensivbetreuung erfordert haben, sowie zwischen Kunden, die noch keine Intensivbetreuung in Anspruch nehmen mussten, ergeben. Häufig beschränkt sich die Rolle der Bank bei Firmenkunden, die sich in wirtschaftlichen und/oder finanziellen Schwierigkeiten befinden, stark auf die kurzfristig umsetzbare Reduzierung des Risikos. ${ }^{251}$ Im Falle eines erfolgreichen Workouts kann die intensive Sanierungsbegleitung zu einer nachhaltigen Festigung einer ertragreichen Geschäftsbeziehung führen. Gleichzeitig kann die enge Zusammenarbeit eine positive Wahrnehmung der Bank als Partner auch in der Krise durch den Markt beziehungsweise der Gruppe potenzieller Kunden bewirken. ${ }^{252}$

Für das deutsche Bankensystem ist das Hausbankprinzip, ${ }^{253}$ welches eng mit dem Konzept des Relationship Lendings verbunden ist, typisch. Mittelständische Unternehmen und Banken unterhalten in Deutschland i.d.R. langjährige Geschäftsbeziehungen, in deren Verlauf mehrere Transaktionen abgewickelt und vertrauliche Firmeninformationen an die betreuende Bank weitergeleitet bzw. von dieser aufbereitet werden. Liegt ein solches Verhältnis vor, wird von einer Hausbankbeziehung gesprochen. ${ }^{254}$ Charakteristische und wesentliche Merkmale der Hausbankbeziehung sind die folgenden: ${ }^{255}$

- Eine Hausbank hat den größten, in aller Regel sogar den dominanten Anteil am Kredit- bzw. allgemeiner am Finanzdienstleistungsgeschäft mit dem betreffenden Unternehmen. Als Universalbank ist sie der erste Ansprechpartner des Unternehmens für alle Fragestellungen bzw. Transaktionen, die die Finanzierung des Unternehmens betreffen.

- Hausbankbeziehungen sind langfristige Beziehungen zwischen Banken und Unternehmen. Die Dauer der Beziehung führt ggf. zu persönlichen Kontakten zwischen den Entscheidungsträgern beider Seiten, in jedem Fall begründet sie aber ein besonderes Vertrauensverhältnis sowie einen besonders guten Informationsstand der Bank hinsichtlich der Entwicklung des Unternehmens.

- Ihre Rolle als Financier und ihr hoher Informationsstand verschaffen der Hausbank eine einflussreiche Position bei dem betreffenden Unternehmen.

- Die Hausbank trägt in finanziellen Krisensituationen des Unternehmens eine besondere Verantwortung für den Erhalt bzw. die Sanierung des Unternehmens. Die Stellung als Hausbank führt zu einer größeren Bereitschaft der Bank zur Beteiligung an Sanierungsaktionen.

Da die Hausbank gemäß obiger Definition eine Universalbank ist, erklärt sich der Umstand, warum dieser Begriff in Ländern mit Trennbank- bzw. Spezialbank-

\footnotetext{
251 Vgl. Quitzau (2007), S. 15.

252 Vgl. Quitzau (2007), S. 15.

253 Vgl. Fischer (1990), S. 4.

254 Vgl. Boot (2000), S. 10-12. Eine einheitliche Definition fehlt allerdings in der Literatur. Bspw. sehen einige Autoren in der Langfristigkeit der Beziehung kein notwendiges Kriterium. Vgl. Elsas/Krahnen (1998), S. 1288 oder Hommel/ Schneider (2004), S. 578. 
Systemen nicht existiert. ${ }^{256}$ Für die meisten Banken ist es das langfristige Ziel in einer Bankbeziehung, die Haupt- und Hausbank des Kunden zu werden. ${ }^{257}$ Da viele Kunden mehrere Bankbeziehungen unterhalten und somit ein intensiver Wettbewerb zwischen den Banken besteht, ist es das Ziel einer Bank, die Hauptbank zu werden und schließlich einen größeren Anteil an der Bankfinanzierung des Kunden zu bekommen. Hauptbankbeziehungen sind auch deshalb so bedeutsam, da gezeigt werden kann, dass auch der Marktanteil einer Bank an Non-Credit-Services eng mit dem Anteil an Hauptbankverbindungen zusammenhängt. ${ }^{258}$ So wird in aller Regel auch der Zahlungsverkehr über die Hauptbank abgewickelt. Darüber hinaus ist eine Hauptbank in der Lage größere Margen zu erwirtschaften. Die größere Kundendurchdringung durch die Hauptbank ermöglicht es ihr, sowohl in der Produktion als auch im Vertrieb von Bankdienstleistungen Skaleneffekte zu realisieren. Ferner ist der Kunde in seiner Hauptbankbeziehung potenziell weniger preissensibel, da er einen signifikanten intangiblen Nutzen aus der Beziehung zieht. In welcher Form die Bank die realisierten Skaleneffekte sowie die geringere Preissensibilität bei der Konditionengestaltung berücksichtigt, kann nicht allgemeingültig beantwortet werden. Wichtig für die Kunde-Bank-Beziehung ist aber in jedem Fall, dass die partnerschaftliche Ausrichtung der Geschäftsbeziehung als bankpolitischer Grundsatz in den täglichen Geschäftskontakten und im dauernden Umgang mit dem Kunden seine Umsetzung erfährt. ${ }^{259}$ Ein auf den Einzelabschuss bezogenes Provisionssystem der Bank kommt deshalb bei Hausbankbeziehungen nicht in Betracht. ${ }^{260}$ Im Gegensatz zum Deal-Based-Banking ist die Langfristigkeit ein charakteristisches Merkmal der Hausbankbeziehung. ${ }^{26 !}$ Die Bank wird über einen längeren Zeitraum zum bevorzugten Ansprechpartner für die Unternehmensleitung und erhält vielfach im Vorfeld von Entscheidungen wichtige Informationen über Veränderungen im Unternehmen. ${ }^{262}$ Die Langfristigkeit der Geschäftsbeziehung zwischen Bank und Kunde verändert dann den Handlungsspielraum auf beiden Seiten und eröffnet den Vertragspartnern die Möglichkeit, positive Erfahrungen aus vergangenen Kontrakten in die Zukunft zu extrapolieren und dadurch auf Stabilität in der Geschäftsentwicklung zu bauen. Aufgrund der Dauerhaftigkeit der Bankverbindung sowie des umfassenden Leistungsangebots kommt es zu einer partnerschaftlichen Ausrichtung der Geschäftsbeziehung. Die Bank verfolgt dann nicht mehr nur eigene kurzfristige - Zielsetzungen, sondern trägt in finanziellen Krisensituationen des Unternehmens eine besondere Verantwortung. Wichtige Voraussetzung für die Entstehung

256 Vgl. Arbeitskreis (1988), S. 742.

257 Vgl. Turnbull/Gibbs (1987), S. 363. Der Begriff Hauptbank wird durch den Arbeitskreis Finanzierung wie folgt definiert: „Eine Hauptbankverbindung ist eine Bank, mit der ständig mehrere Arten von Bankgeschäften abgewickelt werden, deren Volumina aus Sicht der Unternehmung bedeutend sind. Es wird auf eine ungefähr gleichgewichtige Verteilung solcher Geschäfte auf eine ggf. bestehende Mehrzahl von Hauptbankverbindungen geachtet, es sei denn, es besteht eine Hausbank als dominierende Hauptbankverbindung." Arbeitskreis (1988), S. 740. Vgl. hier und im Folgenden Turnbull/Gibbs (1987), S. 363.

Vgl. hier und im Folgenden Doberanzke (1993), S. 23.

Vgl. Doberanzke (1993), S. 23.

Vgl. Doberanzke (1993), S. 20. Zum Begriff des Deal-Based-Banking vgl. FN 244.

Vgl. hier und im Folgenden Doberanzke (1993), S. 20 f. 
einer durch Verträge konkretisierten Partnerschaft ist das Vertrauen in die Loyalität des jeweils anderen.

Das Hausbankprinzip beinhaltet - wie auch eine Relationship Banking-Beziehung gemäß BOOT - finanzierungstheoretisch das Arrangement einer intertemporalen Ertragsmaximierung. Sowohl Bank als auch Kreditnehmer maximieren nicht den Ertrag in jeder einzelnen Periode, stattdessen findet vielmehr eine Glättung des Nutzenstroms über verschiedene Umweltzustände statt: Die Bank hält die Kreditbeziehung auch in Zeiten geringer Erträge aufrecht, erhält dafür aber in Zeiten höherer Profitabilität einen Anteil am Mehrgewinn. ${ }^{263}$ Daraus lässt sich keine Aussage über das Zinsniveau einer Hausbank im Vergleich zu selbigem bei einer Nicht-Hausbank ableiten. Das Hausbankprinzip beruht implizit auf der Annahme einer mehrperiodigen Beziehung. Diese kann jedoch nur aufrechterhalten werden, wenn ein Unternehmen den Kreditgeber nach Beendigung der Phase geringer Erträge seitens der Bank nicht wechseln kann, da die Bank anderenfalls keine Möglichkeit zu einer intertemporalen Maximierung des Ertragsstroms hat. Eine derartige Bindung resultiert im Wesentlichen aus den Konstrukten wie Commitment und Vertrauen; vertraglich lässt sich diese Bindung nicht abbilden. Selbst bei einem Darlehensvertrag hat der Kunde nach Ende der Zinsbindungsfrist beliebige Wechselmöglichkeiten und viel entscheidender ist der Umstand, dass der Kunde während der Vertragslaufzeit seine zusätzlichen Produktbedarfe bei einer anderen Bank befriedigen könnte. Je intensiver der Wettbewerb um den Schuldner, desto einfacher ist es für ein Unternehmen, zu anderen Banken zu wechseln. Folgerichtig gerät das Hausbankprinzip in Zeiten intensiven Wettbewerbs unter Druck. ${ }^{264}$ In einer derartigen kompetitiven Situation ist vermutlich auch nicht mehr die negative Signalwirkung resultierend aus einem Wechsel der Hausbank gegeben. In einer Phase geringen Wettbewerbs würde die neue Bank durchaus erst mal kritisch hinterfragen, welche Gründe es für den Wechsel gibt und inwiefern diese Gründe in dem Unternehmen selbst liegen. Bankbedingte Gründe für den Wechsel der Hausbankbeziehung könnten bspw. Unzufriedenheit mit dem Firmenkundenbetreuer, ein erfolgter Wechsel des Firmenkundenbetreuers und damit resultierend ggf. der Verlust der Bindung an die Bank oder eine geänderte Geschäftspolitik sein. Allerdings ist fraglich, inwiefern wirklich die komplette Hausbankbeziehung in einer sehr kompetitiven Umweltsituation auf den Prüfstand gestellt wird oder inwiefern nur vereinzelte Verträge mit einer anderen Bank abgeschlossen werden.

Vorteilhaft an einer Hausbankbeziehung ist aus Kundensicht die Ermöglichung von vorteilhafteren Kreditkonditionen und einer besseren Unterstützung in Krisenzeiten. ${ }^{265}$ Gleichzeitig beschränkt sich die Weitergabe von Firmeninterna auf die Hausbank und eine anderenfalls notwendige Publizität gegenüber dem Kapitalmarkt bzw. der Öffentlichkeit wird vermieden. ${ }^{266}$ Jungen Unternehmen erleichtert das mögliche Zustande-

\footnotetext{
263 Vgl. Fischer (1990), S. 46 f.

264 Vgl. Speyer (2002), S. 206.

265 Vgl. Petersen/Rajan (1994), S. 5, Boot/Thakor (1994), S. $899-920$ oder Hommel/Schneider (2004), S. 578.

266 Vgl. Hommel/Schneider (2004), S. 578.
} 
kommen einer Hausbankbeziehung zudem den Zugang zu Kapital, welches bei einer Nicht-Hausbank ggf. gar nicht erst bereitgestellt worden wäre. Bei jungen Unternehmen ist zu beachten, dass die Hausbankbeziehung per definitionem anstelle einer gemeinsamen langen Historie auf der Perspektive einer langfristigen Beziehung basiert. Sofern Aussicht auf Anschlussgeschäfte besteht, sind Banken eher gewillt, in eine solche Geschäftsbeziehung zu investieren und sich zur Hausbank des Unternehmens zu entwickeln.

Nachteilig wirkt sich allerdings die mit der Intensität der Bankbeziehung steigende Abhängigkeit von der Hausbank aus. Je enger diese Beziehung ist, desto schwieriger wird es für den Kunden, eine gleichartige Beziehung zu einer anderen Bank aufzubauen bzw. den Wechsel der Bankverbindung glaubhaft anzudrohen bzw. der neuen Bank in Aussicht zu stellen. Für eine neue Bank ist es nicht ohne weiteres nachvollziehbar, warum ein Kunde eine etablierte Bankbeziehung aufgibt oder sie nicht über die gesamte Produktpalette ausnutzt. ${ }^{267}$

Die zuvor bereits erwähnte zentrale Bedeutung der Hausbankbeziehung für die Mittelstandsfinanzierung in Deutschland wird durch eine Studie von KPMG unterstützt. So gaben etwa $94 \%$ der befragten Unternehmen an, eine Hausbankbeziehung zu unterhalten. ${ }^{268}$ Durch die sich mit Basel II einstellende Risikoorientierung bei der Kreditvergabe $^{269}$ ist fraglich, ob die Hausbankbeziehung auch in Zukunft aufrechterhalten werden kann. Geht ein Unternehmen nicht mit der Kreditrisikostrategie seiner Hausbank konform, kann diese gezwungen sein, trotz langjähriger Geschäftsbeziehung Kredite zu verweigern. ${ }^{270}$ Dies kann auch nachträglich geschehen, wenn die Branche des Unternehmens in eine Krise gerät, die Bank Bereinigungen des Kreditportfolios vornimmt oder aus anderen Gründen ihre Kreditrisikostrategie ändert. Eine solche Kreditverweigerung würde jedoch der Funktion einer Hausbank - Kreditversorgung auch in Krisenzeiten des Unternehmens - zuwiderlaufen und damit die Hausbankbeziehung zerstören. ${ }^{271}$ In der Folge kann es zu Kündigungen der Geschäftsbeziehung zwischen einer Hausbank und ihren Geschäftskunden kommen, wenn die Branche des Unternehmens nicht in die Kreditrisikostrategie passt. Unternehmen, die dies betrifft, sehen sich gezwungen, alternative Kapitalquellen aufzutun. Gegebenenfalls werden Unternehmen auch von sich aus verstärkt andere Quellen in Anspruch nehmen können und sich vermehrt von der Hausbank abwenden. Ferner würde obiger Aspekt dem Auftrag der Genossenschaftsbanken der Mitgliederförderung zuwider laufen, so dass die negative Wirkung bei dem betroffenen Unternehmen, aber auch bei anderen Unternehmen umso stärker ist.

\footnotetext{
267 Vgl. Farinha/Santos (2002), S. $124 \mathrm{ff}$.

268 Vgl. Müller et al. (2006), S. 10.

$269 \mathrm{Vgl}$. zu den Implikationen aus Basel Il Kapitel A.3.3.

270 Vgl. zur Kreditrisikostrategie einer Bank Kapitel A.3.2.2.

271 Vgl. Müller et al. (2006), S. 10.
} 
Bei einem Vergleich der Definitionen des Relationship Banking und den Hausbankdefinitionen lässt sich abschließend konstatieren, dass die Analogien offensichtlich sind: $:^{272}$

- Sowohl Relationship Lending als auch Hausbankbeziehungen werden als langfristige Beziehungen charakterisiert (close and continued interaction),

- (private) Informationen spielen eine wesentliche Rolle (sufficient information)

- und die Bank hat einen gewissen Einfluss auf die Geschäftstätigkeit des finanzierten Unternehmens bzw. des Kreditnehmers (a voice in a firm's affairs).

Hinsichtlich der Wirkungen werden allerdings unterschiedliche Aspekte angesprochen bzw. akzentuiert:

- Während bei dem Relationship Banking-Ansatz nach PeTERSEN/RAJaN die Senkung der Finanzierungskosten des Unternehmens sowie die Erhöhung der Finanzierungsmittelverfügbarkeit zentraler Bestandteil ist,

- wird im Rahmen der Hausbankbeziehung der Aspekt der „,besonderen Verantwortung" der Hausbank in Krisensituationen des Kreditnehmers betont, wobei selbiger natürlich mit der Finanzierungsmittelverfügbarkeit verbunden ist.

Auf Basis der bisherigen Analysen erfolgt in der weiteren Arbeit eine synonyme Verwendung des Konzeptes des Relationship Banking und des Konstruktes der Hausbank. ${ }^{273}$ Die bisher nur kurz angesprochenen Effekte im Rahmen der Kunde-BankBeziehung werden im Folgenden auf Grundlage der Neuen Institutionenökonomie detaillierter untersucht. Als zentraler Aspekt bei den angeführten Definitionen konnte der Informationsvorsprung der Hausbank herausgearbeitet werden, wobei die Dauer der Beziehung, die wiederholten Interaktionen und/oder die Breite der Produktpalette häufig als dessen Ursache genannt wurde. Bevor in Kapitel A.4.3 der Stand der theoretischen und empirischen Forschung dargestellt wird, erfolgt in Kapitel A.4.2 die Erläuterung der für die weitere Untersuchung zentralen Begriffe der Neuen Institutionenökonomie.

\subsection{Die Neue Institutionenökonomie mit dem Fokus auf der Prinzipal- Agenten-Theorie}

Die Neue Institutionenökonomie analysiert die Entstehung, Struktur und Effizienz von so genannten Institutionen, in deren Rahmen wirtschaftliche Aktivitäten durchgeführt werden. ${ }^{274}$ Durch die Aufgabe der noch in der neoklassischen Theorie vorherrschenden Grundannahme eines vollkommenen Wettbewerbs und insbesondere einer vollständi-

272 Grundlage des folgenden Vergleichs ist die Definition von Relationship Banking gemäß Petersen/Rajan. Vgl. Petersen/Rajan (1995), S. 5. Vgl. hierzu und im Folgenden Elsas (2001), S. 14 und Segbers (2007), S. 122.

273 Die synonyme Verwendung der Begriffe findet sich auch bei Segbers (2007), S. 118 und Elsas (2001), S. 14.

$274 \quad$ Vgl. Ebers/Gotsch (2006), S. 199. 
gen Information aller Marktteilnehmer ${ }^{275}$ ergeben sich nunmehr für die im Markt agierenden Wirtschaftseinheiten Koordinationsaufgaben hinsichtlich der wirtschaftlichen Aktivitäten, was wiederum Transaktionskosten verursacht. ${ }^{276}$ Die Institutionenanalyse geht der Frage nach, welche Form der Koordination sich in einer speziellen Situation als die nach Kosten- und Effizienzgesichtspunkten günstigste erweist. ${ }^{27}$ Darüber hinaus beschäftigt sich die Neue Institutionenökonomie mit den Auswirkungen von Institutionen (z.B. Verträge, Organisationsstrukturen) auf menschliches Verhalten ${ }^{278}$ und untersucht in diesem Kontext insbesondere Möglichkeiten des effizienten Designs derselbigen. ${ }^{279}$ Im Folgenden wird davon ausgegangen, dass es sich bei der Geschäftsbeziehung zwischen Bank und Kunde um eine effiziente Organisationsform handelt, ${ }^{280}$ so dass der Fokus auf der Analyse möglicher Motivationsprobleme sowie auf der Ausgestaltung von Verträgen innerhalb der bestehenden Geschäftsbeziehung liegt.

\subsubsection{Einordnung und Annahmen der Prinzipal-Agenten-Theorie}

Der Prinzipal-Agenten-Ansatz beschäftigt sich insbesondere mit Motivationsproblemen bei vertraglichen Schuldverhältnissen. ${ }^{281}$ Gegenstand der Prinzipal-AgentenTheorie sind Vertragsbeziehungen zwischen Individuen oder Gruppen von Individuen, die sich durch Unsicherheit und ein Informationsdefizit des Auftraggebers (Prinzipal) gegenüber seinem Auftragsempfänger (Agent) auszeichnen. ${ }^{282}$ Die Problematik einer Prinzipal-Agenten-Beziehung, die sich durch die Abhängigkeit einer Person von der Handlung einer anderen Person kennzeichnet, ${ }^{283}$ äußert sich darin, ein Individuum oder eine Gruppe von Individuen zu motivieren, im Interesse eines anderen Individuums oder einer Gruppe von Individuen zu handeln. ${ }^{284}$ Da das Verhalten des Auftragnehmers das Nutzenniveau des Auftraggebers beeinflusst, gilt es diejenige Form der Vertragsgestaltung zu wählen, bei der die Gefahr, dass der Agent nicht im Sinne des Prinzipals handelt, minimiert wird. ${ }^{285}$ Die Lösung der Motivationsprobleme liegt vor allem in der geschickten Gestaltung der Verträge, seien es nun Kauf-, Darlehens-, Miet-, Dienstoder Werkverträge. ${ }^{286}$

275 Coase wird im Allgemeinen als einer der ersten Ökonomen angesehen, der die Grundannahmen der neoklassischen Theorie in Frage stellte. Vgl. hierzu stellvertretend Rotering (1993), S. 95. $\mathrm{Zu}$ den Aussagen von Coase vgl. Coase (1963), S. $331 \mathrm{ff}$.

276 Vgl. Büchs (1991), S. 6.

277 Vgl. Schmidt (1992), Sp. 1854.

278 Vgl. Picot/Diet//Franck (2005), S. 45 f.

279 Vgl. Picot/Diet//Franck (2005), S. 46.

280 Zur Analyse der Existenz von Finanzintermediären auf der Grundlage der Transaktionskosten vgl. bspw. Diamond (1984), S. $393 \mathrm{ff}$.

281 Vgl. Göbel (2002), S. 60.

282 Vgl. Akerlof (1970), S. 488 ff., Arrow (1985), S. 37 ff., Jensen/Meckling (1976), S. 305 ff. oder Fama (1980), S. $39 \mathrm{ff}$.

283 Vgl. Macharzina (1999), S. 52.

284 Vgl. Klaus (2002), S. $121 \mathrm{f}$.

285 Vgl. Macharzina (1999), S. 52.

286 Vgl. Göbel (2002), S. 62. Für weitere Beispiele vgl. Arrow (1985), S. 38 ff. 
Wie auch die anderen institutionenökonomischen Ansätze ist die Prinzipal-AgentenTheorie durch folgende Annahmen bezüglich des menschlichen Verhaltens gekennzeichnet: Individuelle Nutzenmaximierung und begrenzte Rationalität beschreiben und leiten das Handeln der Akteure. ${ }^{287}$ Zudem stützen sich alle neoinstitutionalistischen Ansätze auf das Forschungskonzept des methodologischen Individualismus. Diese Theoriekonstruktion geht grundsätzlich vom individuellen Akteur aus. Institutionen (Organisationsstrukturen) werden als das Ergebnis der Handlungen und Entscheidungen individueller Akteure verstanden und nicht - wie z.B. in soziologischen Ansätzen - als emergente Phänomene sozialer Systeme. ${ }^{288}$

Neben diesen für alle institutionenökonomischen Ansätze übereinstimmenden Annahmen ist die Informationsasymmetrie die zentrale Annahme der Prinzipal-AgentenTheorie, derzufolge der Agent einen Informationsvorsprung vor dem Prinzipal hat. ${ }^{289}$ Diese Annahme impliziert, dass die Erlangung von Informationen etwas kostet und dass prohibitive Kosten der Informationsbeschaffung zu unvollständigem Wissen der Akteure sowie zu seiner Ungleichverteilung führen. Da eine vollständige Kontrolle des Agenten nicht möglich ist, besteht die Gefahr, dass der Agent nicht immer im Sinne des Prinzipals handelt, sondern in der Verfolgung seiner eigenen Interessen versteckte Handlungen zum Schaden des Prinzipals vornimmt. ${ }^{290}$ Dieses aus Sicht des Prinzipals zum Teil suboptimale Handeln des Agenten ist möglich, da der zwischen Prinzipal und Agent geschlossene Vertrag mehr oder weniger unvollständig bleiben muss und in der Vertragsbeziehung nicht alle zukünftigen Unsicherheitsfaktoren geregelt sind. Die opportunistischen Spielräume können so groß sein, dass Verträge erst gar nicht oder nicht im gewünschten Umfang zustande kommen. ${ }^{291}$ Für Agenten und Prinzipal ist es vorteilhaft, nach Möglichkeiten zu suchen, um die Kooperationsschwierigkeiten zu verringern oder zu beseitigen.

Ausgehend von diesen Annahmen kann auch die Finanzierungsbeziehung als AgencyBeziehung betrachtet werden, in der der Kapitalgeber als Prinzipal den Kapitalnehmer als Agenten mit der Durchführung eines renditetragenden Projektes beauftragt. ${ }^{292}$ Asymmetrische Information eröffnet dem Kapitalnehmer einen Handlungsspielraum, den er opportunistisch nutzen kann, z.B. durch eine Änderung der geplanten Mittelverwendung.

\subsubsection{Kosten}

Aufgrund der Informationsasymmetrie und der daraus resultierenden opportunistischen Verhaltensspielräume entstehen Kosten, die den individuellen Zielen der beiden Parteien widersprechen. ${ }^{293}$ Insgesamt werden unter den Agency-Kosten solche Kosten

\footnotetext{
287 Vgl. hier und im Folgenden Picot/Dietl/Franck (2005), S. 46.

288 Vgl. Picot/Diet//Franck (2005), S. 31.

289 Vgl. Richter/Furubotn (1999), S. 196.

290 Vgl. hier und im Folgenden Ebers/Gotsch (2006), S. $210 \mathrm{f}$.

291 Vgl. Lindner-Lehmann (2001), S. 8.

292 Vgl. hier und im Folgenden Lindner-Lehmann (2001), S. 7.

293 Vgl. Klaus (2002), S. 123.
} 
subsumiert, die sich bei der Verringerung dieses Handlungsspielraums ergeben, wobei auch die durch den Handlungsspielraum verbleibende Wohlfahrtsdifferenz im Vergleich zur First-Best-Lösung zu den Agency-Kosten zählt. ${ }^{294}$ Das Kriterium zur effizienten Gestaltung der Vertragsbeziehung zwischen Prinzipal und Agenten bildet die Minimierung dieser Kosten, die sowohl beim Prinzipal als auch beim Agenten anfallen und sich aus drei Komponenten zusammensetzen. ${ }^{295}$ Nach JENSEN/MECKLING lassen sich die Kosten der Kooperation bei asymmetrischer Information in Monitoring Costs, Bonding Costs und Residual Costs unterteilen. ${ }^{2 \%}$

Unter Monitoring Costs werden alle im Rahmen der Überwachung des Agenten anfallenden Kosten für den Prinzipal verstanden, d.h. Kosten zum Abbau der Ex-Ante-, ExInterim und Ex-Post-Unsicherheit. ${ }^{297}$ So fallen beim Prinzipal Überwachungs- und Monitoring-Kosten an, indem er das Handeln des Agenten kontrollieren oder selbigem entsprechende Anreize in Aussicht stellen muss, um dessen Verhalten nicht zu stark von seinen eigenen Vorstellungen abweichen zu lassen. ${ }^{298}$

Unter Bonding Costs werden die Kosten subsumiert, die beim Kontraktpartner (Agent) anfallen, z.B. Kosten für Signalling ${ }^{299}$, Reporting, Commitment. ${ }^{300}$ Durch Eingehen bindender Verpflichtungen kann ein Agent seinen Handlungsspielraum glaubhaft einschränken. ${ }^{301}$ Die Bindungskraft dieser Verpflichtung liegt darin, dass sie dem Agenten Kosten verursacht. Die Investition, welche verschiedene Formen annehmen kann, wie z.B. der Erwerb von Zertifikaten, lohnt sich für den Agenten nur bei ordnungsgemäßer Vertragserfüllung. Dem Agenten entstehen Gewährleistungs- und Bonding-Kosten, indem er entweder zu seinen eigenen Ungunsten auf ein Verhalten verzichtet, das dem Prinzipal schadet, oder indem er bei der Durchführung derartiger Handlungen den Prinzipal entschädigt. ${ }^{302}$

Alle übrigen Kosten werden den Residual Costs zugeordnet. Die Differenz zwischen dem optimalen Nutzen des Prinzipals und dem Nutzen, der sich aufgrund nicht vollständiger Kontrolle ergibt, wird als Residualverlust bezeichnet. ${ }^{303}$ Solche Vertragsoder Kontrolllücken entstehen, weil vollständige Verträge, die jeden potenziellen Umstand definieren, nicht geschrieben werden können. Trotz des Einsatzes von Sicherungs- und Kontrollmaßnahmen ist eine Optimierung der Handlungen des Agenten aus Sicht des Prinzipals somit nicht möglich, so dass ein Verlust in Form so genannter Wohlfahrts- oder Residualkosten in Kauf genommen werden muss. ${ }^{304}$

\footnotetext{
294 Vgl. Lindner-Lehmann (2001), S. 8.

295 Vgl. Klaus (2002), S. 123.

296 Vgl. Jensen/Meckling (1976), S. 305.

297 Vgl. Hartmann-Wendels/Pfingsten/Weber (2007), S. 97.

298 Vgl. Klaus (2002), S. 123.

299 Vgl. hierzu ausführlicher Kapitel A.4.2.3.1.

300 Vgl. Göbel (2002), S. 125.

301 Vgl. hier und im Folgenden Lindner-Lehmann (2001), S. 8.

302 Vgl. Klaus (2002), S. 123.

303 Vgl. hier und im Folgenden Lindner-Lehmann (2001), S. 8.

304 Vgl. Ebers/Gotsch (2006), S. 212.
} 


\subsubsection{Problemfelder innerhalb der Prinzipal-Agenten-Beziehung}

Innerhalb der Prinzipal-Agenten-Beziehung entstehen bedingt durch Interessenunterschiede und asymmetrischer Informationsverteilung opportunistische Verhaltensspielräume. Im Hinblick auf derartige Verhaltensrisiken differenziert man die Problemfelder Adverse Selection, Moral Hazard sowie Hold Up. ${ }^{305}$ Je nach zeitlichem Bezug zum Abschluss des Vertragsverhältnisses lassen sich die Informationsasymmetrien und die daraus resultierenden opportunistischen Verhaltensspielräume in Ex-Ante- und ExPost-Risiken (vgl. Tab. A-6) unterteilen.

\begin{tabular}{|l|c|c|c|}
\hline Kriterium & $\begin{array}{c}\text { Hidden } \\
\text { Characteristics bzw. Hidden } \\
\text { Information }\end{array}$ & $\begin{array}{c}\text { Hidden } \\
\text { Action }\end{array}$ & $\begin{array}{c}\text { Hidden } \\
\text { Intention }\end{array}$ \\
\hline Entstehungszeitpunkt & ex ante & ex post & ex ante und ex post \\
\hline Ursache der Asymmetrie & $\begin{array}{c}\text { nicht beobachtbare/ } \\
\text { beurteilbare Eigenschaften }\end{array}$ & $\begin{array}{c}\text { nicht beobachtbare/ } \\
\text { beurteilbare Handlungen }\end{array}$ & $\begin{array}{c}\text { nicht beobachtbare/ } \\
\text { beurteilbare Absichten }\end{array}$ \\
\hline Problemfeld & Adverse Selection & Moral Hazard & Hold Up \\
\hline
\end{tabular}

Tab. A-6: Systematisierung der Problemfelder bei Informationsasymmetrie ${ }^{306}$

\subsubsection{Adverse Selektion}

Das Problem der adversen Selektion besteht als Risiko der Auswahl unerwünschter Vertragspartner und beruht auf Informationsasymmetrien, die vor Vertragsabschluss zwischen Prinzipal und Agenten auftreten. ${ }^{307}$ Dem Prinzipal bleiben wesentliche Eigenschaften des Agenten bzw. der von ihm angebotenen Produkte und Dienstleistungen vor Aufnahme der Vertragsbeziehung verborgen. ${ }^{308}$ Ein typisches Beispiel ist die Vergabe eines Kredits, bei dem ein in diesem Bereich tätiger Kreditnehmer üblicherweise besser als die Bank über die speziellen Risiken des zu finanzierenden Projekts oder seine finanzielle Situation informiert ist. ${ }^{309}$ Die Qualitätsunsicherheit kann sich auf Eigenschaften des Projektes (hidden characteristic) oder auf Informationen beziehen, die das Risiko und die Rentabilität des Projektes betreffen (hidden information). ${ }^{310}$

Nicht jede bestehende Informationsasymmetrie ist jedoch per se mit opportunistischem Verhalten gleichzusetzen. Der Aspekt, der Informationsasymmetrien und Qualitätsunsicherheit erst zu opportunistischem Verhalten werden lässt, stellt die wissentliche

Eigene Darstellung in Anlehung an Picot/Dietl/Franck (1999), S. 91

${ }_{308}$ Vgl. Richter/Furubotn (1999), S. 165, Ebers/Gotsch (2006), S. 213.

308 Vgl. Ebers/Gotsch (2006), S. 213.

309 Vgl. Hartmann-Wendels/Pfingsten/Weber (2007), S. 98.

310 Vgl. Lindner-Lehmann (2001), S. 15.
} 
Zurückhaltung von Informationen und die opportunistische Ausnutzung des Informationsvorsprungs durch den Agenten dar. ${ }^{311}$

Mit der adversen Selektion wird ein Phänomen bezeichnet, bei dem die Unbeobachtbarkeit der Qualität der Leistung oder des Agenten ex ante zu einem Marktzusammenbruch führt. ${ }^{312}$ Im Bankkontext wäre dieser Fall denkbar, wenn Banken keine Möglichkeit zur Identifizierung der Qualität der Kreditnehmer hätten. ${ }^{313}$ In diesem Fall kann es zu einer Kreditrationierung kommen, bei der die Banken keine weiteren Kredite vergeben, obwohl die Kreditnehmer zur Zahlung von höheren Zinsen bereit wären. ${ }^{314}$

Zur Begrenzung des Adverse Selection-Risikos existieren Maßnahmen, die im Rahmen der Institutionenökonomie als Signalling und Screening bezeichnet werden. ${ }^{315}$ Das Ziel dieser beiden informationsökonomischen Kategorien besteht im Ausgleich des zwischen Prinzipal und Agenten bestehenden vorvertraglichen Informationsunterschiedes.

Im Rahmen des Signalling gehen die Aktivitäten zur Reduzierung der vorvertraglichen Informationsasymmetrien vom Agenten als der besser informierten Partei aus. ${ }^{36}$ Dementsprechend wird Signalling als der aktive Versuch interpretiert, entscheidungsrelevante Informationen zu übermitteln, was sich beispielsweise in Zeugnissen über die Leistungsfähigkeit des Agenten, von Gütesiegeln oder von Garantien manifestiert. ${ }^{317}$ Für die Glaubwürdigkeit und somit die Wirksamkeit von entsprechenden SignallingAktivitäten ist es elementar, dass ein Signal nur von solchen Agenten angeboten werden kann, die die signalisierte Eigenschaft tatsächlich besitzen und dass das Fehlen eines solchen Signals auch das Fehlen der entsprechenden Eigenschaft bedeutet. ${ }^{318}$ Ferner hängt auch die Qualität des Signals von den darauf aufzuwendenden Ressourcen $a b .{ }^{319}$ Übertragen auf den Kreditmarkt bedeutet Signalling, dass der Kreditnehmer der Bank bspw. anbietet, eigenes Kapital zu investieren oder Sicherheiten zu stellen, ${ }^{320}$ und infolgedessen auf die Möglichkeit verzichtet, das Kapital anderweitig zu verwenden bzw. die Sicherheit ein zweites Mal einer anderen Bank zu stellen.

Während das Signalling vom Agenten betrieben wird, gehen die Aktivitäten im Rahmen des Screening vom Prinzipal als der schlechter informierten Partei aus. Die Zielsetzung von Screening-Maßnahmen ist die Differenzierung von Agenten anhand bestimmter Merkmale, die entweder bei Vorgabe diverser Auswahlkriterien als Self

311 Vgl. Ebers/Gotsch (2006), S. 213.

${ }^{312}$ Zum Marktversagen bei Qualitätsunsicherheit vgl. Akerlof (1970), S. 488 ff. Vgl. hierzu auch Kapitel A.4.3.1.1.

Vgl. Segbers (2007), S. 28.

Vgl. Hartmann-Wendels/Pfingsten/Weber (2007), S. 99 f.

Vgl. Klaus (2002), S. $127 \mathrm{f}$.

Vgl. Spence (1973), S. 355 ff. zum Signalling im Allgemeinen.

Vgl. Vogt (1997), S. 110.

Vgl. Klaus (2002), S. 128.

Vgl. Richter/Furubotn (1999), S. 240.

Vgl. Lindner-Lehmann (2001), S. 18. 
Selection oder im Rahmen von Prüfungsaktivitäten erfolgt. ${ }^{321}$ Bei der Self Selection ${ }^{322}$ konstruiert der Prinzipal den Vertrag derart, dass er nur von solchen Agenten akzeptiert wird, die die von ihm gewünschte Qualität aufweisen ${ }^{323}$ Die Forderung von Sicherheiten bei der Kreditvergabe dient unter diesem Gesichtspunkt nicht allein der Beschränkung von Verlusten bei einem Ausfall des Kredites, sondern kann auch als Selbstselektionsmechanismus verstanden werden. Ein Kreditnehmer wird eher bereit sein, viele Sicherheiten zu stellen, wenn er selbst die Ausfallwahrscheinlichkeit seines Projektes als gering einstuft. ${ }^{324}$ Eine Bank kann zwei Alternativverträge anbieten, von denen der eine einen niedrigeren Zins, aber eine hohe Sicherheit verlangt und der andere einen hohen Zins bei niedrigeren Sicherheiten ${ }^{325}$ Auch die Vereinbarung von Covenants, d.h. die Vereinbarung über einzuhaltende Bilanzrelationen o.ä., kann als Selbstselektionsmechanismus herangezogen werden, denn die Nichteinhaltung der Covenants ${ }^{326}$ gibt der Bank die Möglichkeit von Neuverhandlungen und ggf. auch von Vertragskündigungen. Ein Unternehmen, welches beabsichtigt in riskante Objekte zu investieren, wird somit nicht bereit sein, Vereinbarungen hinsichtlich der Entwicklung der Eigenkapitalquote oder der Rentabilität zu treffen, sofern es die Gefahr sieht, dass diese Schwellenwerte unterschritten werden, denn es würde dadurch die Vertragskündigung riskieren.

Vor der Kreditvergabe werden des Weiteren Prüfungsaktivitäten durchgeführt, so dass die Unsicherheit bezüglich der Qualität des Unternehmers durch die Überprüfung von Zeugnissen und eine intensive Analyse der Unterlagen früherer Projekte verringert werden. ${ }^{327}$ Zum einen kann die Unsicherheit bezüglich der Qualität des Unternehmens reduziert werden durch die Prüfung von Unterlagen wie bspw. Jahresabschlüssen, betriebswirtschaftlichen Auswertungen, Businessplänen, Presseartikeln, Kostenplänen oder Investitionsplänen. Zum anderen kann die Unsicherheit hinsichtlich der Qualität des Unternehmers durch Zeugnisse oder Lebensläufe reduziert werden. Insbesondere aufgrund der in Kapitel A.2.1.1.2 betonten Einheit von Eigentum und Leitung bei mittelständischen Unternehmen sind hier allerdings die Übergänge zwischen Qualität des Unternehmens sowie der Qualität des Unternehmers fließend. Derartige Maßnahmen, ebenso wie Screening-Aktivitäten, verursachen jedoch Kosten, die von den Vertragspartnern getragen werden müssen und als Kosten der asymmetrischen Information (dead weight loss) bezeichnet werden..$^{328}$

\footnotetext{
Vgl. Klaus (2002), S. 123, Spence (1976), S. $591 \mathrm{ff}$.

Vgl. Arrow (1985), S. $37 \mathrm{ff}$.

Vgl. Hartmann-Wendels/Pfingsten/Weber (2007), S. 99.

Vgl. Hartmann-Wendels/Pfingsten/Weber (2007), S. 99.

Vgl. Jaffee/Stiglitz (1990), S. 866 f.

$\mathrm{Zu}$ Covenants vgl. ausführlich Hartmann-Wendels/Pfingsten/Weber (2007), S. 177.

Vgl. Hartmann-Wendels/Pfingsten/Weber (2007), S. 95.

Vgl. Hartmann-Wendels/Pfingsten/Weber (2007), S. 95.
} 


\subsubsection{Moral Hazard}

Während das Adverse Selection-Problem vor Vertragsschluss relevant ist, tritt das Moral Hazard-Problem erst während der Leistungsbeziehung und somit auch nach Vertragsabschluss zwischen Prinzipal und Agent auf. ${ }^{329}$ Das Risiko des Moral Hazard wird dadurch begründet, dass der Prinzipal im Rahmen der Vertragsbeziehung das Anstrengungsniveau des Agenten nicht zweifelsfrei beurteilen kann (hidden action). ${ }^{330}$ Letzterer kann möglicherweise eine bewusste Leistungszurückhaltung betreiben. Es wird dann zum Problem, wenn folgende Voraussetzungen erfüllt sind:

- Das vom Agenten bevorzugte Verhalten hat negative Auswirkungen für den Prinzipal.

- Die Auswirkungen des Verhaltens mischen sich mit den ebenfalls nicht beobachtbaren Folgen eines exogenen Risikos. ${ }^{331}$

Zwischen dem Anstrengungsniveau des Agenten und der Wahrscheinlichkeit von für den Prinzipal vorteilhaften Handlungsergebnissen besteht prinzipiell ein positives Verhältnis. ${ }^{332}$ Das Handlungsergebnis ist jedoch nicht nur vom Anstrengungsniveau des Agenten, sondern auch von vertragsexogenen Faktoren, z.B. der wirtschaftlichen Lage, abhängig. ${ }^{333}$ Des Weiteren ist der Prinzipal, obwohl er zwar das Ergebnis der Handlungen des Agenten ex post feststellen kann, nicht in der Lage, dessen Handlungen an sich zu beobachten. ${ }^{334}$ Daraus folgt, dass er nicht eindeutig beurteilen kann, welchen Anteil die Anstrengungen des Agenten und welchen Anteil äußere Einflüsse an dem zustande gekommenen Ergebnis haben. ${ }^{335}$ Im Rahmen einer Projektfinanzierung beeinflusst die unbeobachtbare Anstrengung des Unternehmers zwar seine Rückzahlungsfähigkeit und somit die Erlöse der Bank, die Bank ist jedoch nicht in der Lage das Anstrengungsniveau an sich zu beurteilen. ${ }^{336}$

Bei der Kreditvergabe tritt noch ein weiteres Moral Hazard-Problem auf, das in der Banktheorie große Beachtung gefunden hat. Nach Vertragsabschluss mit fester Rückzahlungsverpflichtung kann ein Unternehmer seinen erwarteten Gewinn steigern, indem er das Projektrisiko erhöht (Projektrisikoerhöhung) oder ein riskanteres als das vereinbarte Projekt durchführt (asset substitution). ${ }^{337}$ Modifiziert er das Projekt so, dass extreme Projektausgänge wahrscheinlicher werden, kann er im Falle eines erfolgreichen Verlaufs, den gesamten Überschuss, d.h. den Projektgewinn nach Rückzahlung des Kredites und der Zinsen, verbuchen. ${ }^{338}$ Das erhöhte Ausfallrisiko muss die Bank

Vgl. Klaus (2002), S. 132.

Vgl. Ebers/Gotsch (2006), S. 213.

Vgl. Hartmann-Wendels/Pfingsten/Weber (2007), S. 100.

Vgl. Klaus (2002), S. 133.

Vgl. Richter/Furubotn (1999), S. 163.

Vgl. Klaus (2002), S. 133.

Vgl. Ebers/Gotsch (2006), S. 213.

Vgl. Greenbaum/Thakor (1995), S. 236-238.

Vgl. Lindner-Lehmann (2001), S. 18.

Vgl. Hartmann-Wendels/Pfingsten/Weber (2007), S. $100 \mathrm{f}$. 
tragen. ${ }^{339}$ Annahmegemäß werden hier zunächst weder Sicherheiten gestellt noch Covenants vereinbart.

Der Einsatz von Monitoring-Tätigkeiten stellt eine Möglichkeit zur Begrenzung des Moral Hazard-Problems dar. Im Mittelpunkt des Monitoring stehen Maßnahmen, deren Zweck es ist, festzustellen, ob der Agent seinen vertraglichen Verpflichtungen nachgekommen ist bzw. diese erfüllt hat. Ferner versucht die Bank mittels MonitoringTätigkeiten herauszufinden, inwiefern der Kunde das Projektrisiko erhöht hat. Beispielweise könnte die Bank regelmäßige Betriebsbesichtigungen oder Besichtigungen der Projektstätte vornehmen. Nachteilig ist allerdings, dass für die Beurteilung des Projektverlaufs bzw. des Verhaltens des Unternehmers u.U. ein derart spezifisches Fachwissen erforderlich ist, dass die Beurteilung durch den Firmenkundenbetreuer gar nicht gewährleistet werden kann. Darüber hinaus könnte anhand von Zahlungsstromanalysen identifiziert werden, wohin die ausgezahlten Mittel fließen und ob bspw. die geplanten Umsätze tatsächlich erwirtschaftet werden. In beiden Fällen entstehen jedoch durch den Arbeitseinsatz des Firmenkundenbetreuers und typischerweise auch der Marktfolge Kosten. Durch diese Monitoring-Tätigkeiten erlangt die Bank allerdings Informationen, welche sie bei zukünftigen Vertragsabschlüssen nutzen kann.

Von besonderem Interesse ist eine zweite Möglichkeit, mit dem Problem der asymmetrischen Informationen umzugehen. In Bereichen, in denen Monitoring aufgrund situativer Gegebenheiten kein geeignetes Kontrollinstrument darstellen, werden Moral Hazard-Risiken durch explizite vertragliche Regelungen teilweise begrenzt. ${ }^{340}$ Das Ziel derartiger Vereinbarungen ist es, die Entlohnung des Agenten derart mit dem Ergebnis seiner Handlungen zu verknüpfen, dass eine möglichst weitgehende Zielkongruenz zwischen Agent und Prinzipal erreicht wird. Durch geschickte Vertragsgestaltung wird der Agent schon aus Eigeninteresse davon abgehalten, Informationen fehlerhaft zu übermitteln oder für den Prinzipal unerwünschtes Verhalten zu zeigen. Im Rahmen eines Kreditvertrages könnte die Ausgestaltung von diesen anreizkompatiblen Verträgen $^{341}$ derart erfolgen, dass die Bank eine Haftungsbeteiligung des Kreditnehmers in Form von Sicherheiten oder Eigenkapital verlangt. Die Einbeziehung des Kreditnehmers in die Haftung schwächt zwar dessen Anreiz zur Risikoerhöhung ab, weil der erwartete Verlust bei einem Scheitern des Projektes steigt. Da aber die Haftung begrenzt ist, wird die Neigung zur Risikoerhöhung nicht gänzlich verdrängt. ${ }^{342}$ Dieser Aspekt ist allerdings bei Personengesellschaften nur von nachrangiger Relevanz, denn hier haften ohnehin die Gesellschafter mit ihrem Vermögen. Bei Kapitalgesellschaften wird zu diesem Zweck häufig eine Bürgschaft der Gesellschafter gefordert. Eine weitere Möglichkeit besteht in der Berücksichtigung von anreizkompatiblen Entlohnungsschemata. ${ }^{343}$ Diese sind insbesondere bei Mezzanine-Finanzierung von Relevanz; so

\footnotetext{
339 Vgl. Hartmann-Wendels/Pfingsten/Weber (2007), S. 101. Hier wird auch ein Beispiel gegeben.

340 Vgl. hier und im Folgenden Klaus (2002), S. $133 \mathrm{f}$.

341 Vgl. Hartmann-Wendels/Pfingsten/Weber (2007), S. 96.

342 Vgl. Lindner-Lehmann (2001), S. 14.

${ }_{343}$ Vgl. Hartmann-Wendels/Pfingsten/Weber (2007), S. 103. Hartmann-Wendels/Pfingsten/Weber (2007) erläutern ferner die Möglichkeiten und Schwierigkeiten der Ausgestaltung. Vgl. ebenda.

Tina Püthe - 978-3-631-75310-1
} 
enthalten die Konditionen bei Mezzanine-Finanzierung häufig eine fixe und eine erfolgsabhängige Komponente. ${ }^{344}$

\subsubsection{Hold Up}

GOLDBERG bezeichnet mit Hold Up das opportunistische Ausnutzen von Vertragslücken. ${ }^{345}$ Das Risiko des Hold Up als Gefahr opportunistischen Verhaltens nach Vertragsabschluss entsteht durch spezifische Investitionen bzw. Vorleistungen des Prinzipals. ${ }^{346}$ Die Transaktionskosten bei Unsicherheit verhindern das Schreiben vollständiger Verträge. Die Ursache ist die Komplexität der Umwelt oder die mangelnde objektive Bewertbarkeit einer Situation. ${ }^{347}$ In diesen Fällen können beide Vertragspartner eine nach Vertragsabschluss eingetretene Umweltsituation beobachten und bewerten, ihre Erkenntnisse Dritten gegenüber, z.B. vor Gericht, aber nicht als Anspruch verifizieren und durchsetzen. Aufgrund der durch die spezifischen Investitionen bedingten Einschränkung bei der Auswahl zukünftiger Beziehungspartner entsteht eine Abhängigkeit vom aktuellen Beziehungspartner, die dieser nach Vertragsabschluss zum Schaden des anderen ausnutzen kann. Je höher die Spezifität einer Investition ist, desto größer ist die Abhängigkeit vom Partner. ${ }^{348}$

Das Hold Up-Problem manifestiert sich im Rahmen der Unsicherheit des Prinzipals über die wahren Absichten des Agenten (hidden intention). ${ }^{349}$ Im Gegensatz zur Informationsasymmetrie im Rahmen der adversen Selektion oder des Moral Hazard, die nach Vertragsabschluss weitgehend unentdeckt bleiben, werden für den Prinzipal diese zunächst verborgenen Absichten des Agenten im Verlauf der Vertragsbeziehungen sichtbar. Die Problematik von spezifischen Investitionen, die den Kern des Hold UpProblems bilden, und die Angst vor ihrer opportunistischen Ausnutzung können gegenseitige vorteilhafte Kooperationen bereits im Keim ersticken. ${ }^{350}$ Beim Hold Up wird ein gewisses Verhalten vom Vertragspartner erwartet, wenngleich dieses erwartete Verhalten nicht explizit vereinbart, vielleicht nicht einmal vom Prinzipal ausgedrückt wurde. Der Prinzipal erhebt implizite Ansprüche (implicit claims). ${ }^{351}$

Besonders anfällig für diese so genannten räuberischen Überfälle sind Vertragsbeziehungen, in denen ein Vertragspartner ex ante partnerspezifische Investitionen getätigt

344 Vgl. hierzu bspw. die Möglichkeiten der Konditionengestaltung der WGZ Initiativkapital. Vgl. WGZ Initiativkapital (2008). Mezzanine-Finanzierung wird im genossenschaftlichen Sektor primär von der VR Mittelstandskapital Unternehmensbeteiligungs AG, der WGZ Initiativkapital, der WGZ Corporate Finance Beratung GmbH und der DZ Equity Partner GmbH und nicht durch die jeweilige Hausbank durchgeführt. Vgl. VR Mittelstandskapital (2008), WGZ Initiativkapital (2008), WGZ Corporate Finance (2008) und DZ Equity Partner (2008).

345 Vgl. Goldberg (1976), S. $426 \mathrm{ff}$.

346 Vgl. Klaus (2002), S. 134.

347 Vgl. hier und im Folgenden Lindner-Lehmann (2001), S. 20.

348 Vgl. Vogt (1997), S. 30.

349 Vgl. Klaus (2002), S. 135.

350 Vgl. Vogt (1997), S. 30.

351 Vgl. Spreemann (1990), S. 568. 
hat. ${ }^{352}$ Spezifische Investitionen auf der Bankseite sind bspw. in den Beratungsgesprächen mit dem Kunden oder dem kurzfristigen Verzicht auf einen risikoadäquaten Zins zu sehen. Die Bank betrachtet ihre Informationsgewinne als Erfolgspotenzial, das sie im Laufe der Geschäftsbeziehung ausbeuten will, damit sich die Investition amortisiert. Auf der Unternehmensseite resultiert die Gefahr des Hold Up aus spezifischen Investitionen, wie z.B. durch das Wohlverhalten in der Geschäftsbeziehung, den Verzicht auf Ertragspotenziale, den Verzicht auf riskante Geschäfte oder eine geordnete Kontoführung. ${ }^{33}$ Diese partnerspezifischen Investitionen sind dadurch gekennzeichnet, dass sie im Rahmen der Vertragsbeziehung mehr wert sind als außerhalb derselben. ${ }^{354}$

Eine Möglichkeit, spezifische Investitionen zu schützen, bietet die Verfügungsgewalt über ein so genanntes Sicherungsgut, das der Vertragspartner als Folge des opportunistischen Handelns verlieren würde. Das Ziel dieser Absicherung besteht darin, ein Gleichgewicht der Verhandlungspositionen herzustellen bzw. der investierenden Partei die Möglichkeit von Gegenmaßnahmen zu geben und dadurch das einseitige Abhängigkeitsverhältnis in ein beidseitiges umzuwandeln. ${ }^{355}$

\subsubsection{Wiederholte und langfristige Vertragsbeziehungen}

Kritisch für die Stabilität der bisherigen Ergebnisse ist die Annahme einer einmaligen Kooperation. ${ }^{356}$ In der Realität kommt es üblicherweise zu einer Folge von Interaktionen. Diese Mehrperiodigkeit der meisten Kooperationen wirkt sich im Allgemeinen positiv auf die Lösung der Probleme durch asymmetrische Information aus. Dabei kommt der Reputation eine zentrale Rolle zu. Reputationseffekte können dazu führen, dass der Agent die Qualitätsunsicherheit und die Vertragslücken nicht egoistisch ausnutzt, sondern sich stattdessen im Sinne des Prinzipals anstrengt. Die Stabilität vieler real existierender Verträge lässt sich durch Reputationseffekte erklären. Bisher wurde unterstellt, dass die Kooperationspartner jede sich bietende Chance zur eigenen Nutzenerhöhung ergreifen. Die Einbeziehung von Reputation bedeutet für diese Denkweise kein Problem; so wird unter Reputation hier keine moralisch-ethische Überlegung, sondern ein reines Kosten-Nutzen-Kalkül verstanden. ${ }^{357}$ Ein Kooperationspartner verhält sich demnach anständig, um damit ein Reputationskapital aufzubauen, das ihm in späteren Kooperationen Vorteile bringen kann.

Die Drohung mit Liquidation, die Androhung zukünftig ungünstiger Kreditkonditionen oder die Verweigerung einer Anschlussfinanzierung wirkt in dynamischen Betrachtungen einem opportunistischen Verhalten entgegen. ${ }^{358}$ Bei wiederholten Kreditbeziehungen können Situationen entstehen, in denen der Kreditvertrag nicht mehr zeitkonsistent ist, d.h. ein ex ante vertraglich vereinbartes Verhalten ex post ineffizient

Vgl. hier und im Folgenden Lindner-Lehmann (2001), S. 20.

Vgl. Segbers (2007), S. 118.

Vgl. Richter/Furubotn (1999), S. 247.

Vgl. Vogt (1997), S. 230.

Vgl. hier und im Folgenden Hartmann-Wendels/Pfingsten/Weber (2007), S. $108 \mathrm{f}$.

Vgl. Hartmann-Wendels/Pfingsten/Weber (2007), S. 108.

Vgl. hier und im Folgenden Lindner-Lehmann (2001), S. 21 f.
} 
wird. Die deterministische Liquidation bei Meldung eines Projektfehlschlags verursacht allerdings Konkurskosten und die Durchführung der Liquidation kann für den Kreditgeber suboptimal werden. Unter Umständen kann eine Neuverhandlung über einen Vergleich beide Parteien besser stellen. Antizipiert der Schuldner, dass die Liquidationsdrohung der Bank bei Erklärung der Zahlungsunfähigkeit nicht mehr glaubwürdig ist, besitzt der Schuldner emeut den Anreiz nicht in allen Fällen den wahren Projekterfolg bekanntzugeben.

Aus Kundensicht ist eine Langfristbeziehung insbesondere dann vorteilhaft, wenn langfristig profitable Projekte mit vorübergehend geringeren Projekterträgen verbunden sind, ${ }^{359}$ oder wenn bei einer Unternehmenskrise die Sanierung mit Forderungsverzicht sinnvoller ist als die sofortige Liquidation. In beiden Fällen müsste der Financier vertraglich festlegen können, dass der betroffene Kreditnehmer nach erfolgreichem Projekt oder erfolgreicher Sanierung die Geschäftsbeziehung aufrechterhält.. ${ }^{360}$ Hier sind aber im Wesentlichen implizite Verträge ${ }^{361}$ von Relevanz, da eine Bindung über rechtliche Verträge an dieser Stelle nicht praktikabel ist. Dieser Zusammenhang gilt auch für die Finanzierung kleinerer Firmen, wenn die kreditgebende Bank hofft, durch die Kreditvergabe einen Anspruch auf die Wachstumserträge in Form einer aufrechterhaltenen Geschäftsbeziehung zu bekommen. ${ }^{362}$

Auch innerhalb der Laufzeit eines einzelnen, langfristigen Vertrages kann sich der Agent Vorteile durch nicht-opportunistisches Verhalten verschaffen. Immer dann, wenn er befürchten muss, eine gute Geschäftsbeziehung durch die Aufdeckung seines Opportunismus zu verlieren, wird er Kosten und Nutzen seines opportunistischen Verhaltens abschätzen. Die Langfristigkeit bzw. die Häufigkeit der Wiederholungen gehen in das Kalkül des Agenten ein und führen zu einer stärkeren Harmonisierung der Ziele von Prinzipal und Agent. ${ }^{363}$

Abschließend kann resümiert werden, dass durch die explizite Einbeziehung des Zeitfaktors in die Prinzipal-Agenten-Beziehung die Agency-Problematik entschärft wird. ${ }^{364}$

\footnotetext{
359 Vgl. von Thadden (1995), S. $557 \mathrm{ff}$.

360 Vgl. Lindner-Lehmann (2001), S. 32. Im Kapitel A.4.3.1.2.1 wird die Langfristigperspektive im Rahmen der Bankbeziehung noch ausführlich behandelt.

361 Implizite Verträge sind ungeschriebene, nicht explizit artikulierte Erwartungen über die Rechte und Pflichten der Transaktionspartner. Vor Gericht sind sie nicht durchsetzbar. Vgl. Richter/ Furubotn (1999), S. 242. Die Theorie impliziter Verträge behandelt unter anderem auch das Phänomen starrer Löhne. Die Theorie modelliert „den Arbeitsmarkt nicht wie eine KassaAuktion, sondern wie eine, auf der Arbeitgeber und Arbeiter wechselseitig vorteilhafte, ungeschriebene, langfristige Verträge eingehen". Taylor (1987), S. 126.

Vgl. Göbel (2002), S. 108.
} 


\subsubsection{Fazit der Neuen Institutionenökonomie in Bezug auf die Kunde-Bank- Beziehung}

Basis der Prinzipal-Agenten-Theorie ist die Interaktion zwischen einem Prinzipal und einem Agenten. Diese Interaktion ist zunächst vor dem Hintergrund von Unsicherheit zu betrachten, die ihren Ursprung in verschiedenen Formen der Informationsasymmetrie hat. Unsicherheit kann in den verschiedenen Formen auftreten und sowohl hinsichtlich der Qualität des Agenten (hidden characteristics) als auch in Bezug auf dessen Verhalten nach Vertragsabschluss (hidden action und hidden intention) bestehen. Die Interaktion wird damit auf der einen Seite durch die Unsicherheit behindert, auf der anderen Seite führt die Interaktion selbst aber erst zu dieser Unsicherheit. Die Prinzipal-Agenten-Theorie versucht, ex ante geeignete Anreiz- und Kontrollmechanismen zu schaffen, die die aus der Informationsasymmetrie resultierenden Probleme vollständig lösen. Maßnahmen hierzu sind bspw. anreizkompatible Verträge oder die Überwachung des Agenten durch den Prinzipal. Sinnvolle Begründungen für das Eingehen bzw. das Aufrechterhalten von Geschäftsbeziehungen werden durch den Abbau von Informationsasymmetrien und aus den daraus resultierenden Verhaltensunsicherheiten sowie durch die Übertragung impliziten Wissens gegeben. Diese Sachverhalte sind auch im Rahmen einer Hausbankbeziehung von zentraler Bedeutung, weil gerade der spezifische Informationsvorteil ein charakteristisches Merkmal einer Hausbank ist. ${ }^{365}$ Insofern bildet die Neue Institutionenökonomie zumindest in Teilen eine geeignete Grundlage um einzelne Charakteristika der Hausbankbeziehung zu analysieren. Eine kritische Würdigung der Eignung der Neuen Institutionenökonomie im Allgemeinen erfolgt an dieser Stelle nicht. In den folgenden Kapiteln wird der aktuelle Stand der Relationship Banking-Forschung auf Basis der Neuen Institutionenökonomie dargestellt, so dass erst nach erfolgter Übertragung auf diesen Kontext eine kritische Würdigung stattfindet.

\subsection{Stand der theoretischen und empirischen Forschung im Bereich des Relationship Banking}

\subsection{1 Überblick über die theoretischen Modelle im Bereich des Relationship Banking}

In diesem Kapitel werden die zentralen Modelle aus dem Bereich des Relationship Banking beschrieben. Diese Modelle bilden die Grundlage sowohl der bereits bestehenden Studien ${ }^{366}$ als auch der vorliegenden Studie. Paradigmatischer Kern aller Modelle ist die bestehende Informationsasymmetrie zwischen der Bank bzw. dem Kundenbetreuer auf der einen Seite und dem Unternehmen bzw. dem Ansprechpartner desselben auf der anderen Seite. Bezüglich der unterschiedlichen Forschungsstränge 
im Bereich des Relationship Banking gibt es unterschiedliche Systematisierungen. ${ }^{367}$ Bei den Modellen lassen sich zum einen die verschiedenen grundlegenden Modelle der Finanzintermediation und zum anderen Modelle, die konkret die Auswirkungen des Relationship Banking auf Zinsen, Sicherheitenstellung oder Kreditverfügbarkeit analysieren, differenzieren. ${ }^{368}$ Im Folgenden werden die verschiedenen existierenden Modelle kurz beschrieben.

\subsubsection{Grundlegende Modelle der Finanzintermediation}

Die Motivation für die weiterführenden Analysen sind die wesentlichen Theorien der Finanzintermediation, z.B. von DIAMOND, RAMAKRISHNAN/THAKOR ${ }^{369}$, BOYD/PRESCOTT, LELAND/ PYLE ${ }^{370}$ oder FAMA. ${ }^{371}$ Zentraler Gegenstand dieser Theorien ist der Informationsvorteil der Bank. LELAND/PYLE, DIAMOND, RAMAKRISHNAN/THAKOR, FAMA und BOYD/PRESCOTT argumentieren, dass die Fähigkeit der Bank, Informationsasymmetrien zwischen Kreditnehmer und Kreditgeber abzubauen, die Bank einzigartig im Vergleich zu anderen Finanzinstitutionen macht. ${ }^{372}$ Finanzintermediäre existieren deshalb, weil sie von economies of scale und/oder komparativen Vorteilen in der Produktion von Informationen über die Kreditgeber profitieren. ${ }^{373}$

Das wohl bekannteste informationsökonomische Modell zur Erklärung der Vorteilhaftigkeit der Intermediärsfinanzierung stammt von DIAMOND und beruht auf der Annahme, dass Banken Informationsasymmetrien zwischen Kapitalgebern und -nehmern besser reduzieren können als alternative Finanzinstitutionen. ${ }^{374}$ Grundlage des Modells von DIAMOND sind die Ex-Post-Informationsasymmetrien zwischen den potenziellen Kreditgebern auf der einen und dem Unternehmer, der Kapital für sein risikobehaftetes Projekt beschaffen muss, auf der anderen Seite. ${ }^{375}$ Es wird angenommen, dass die Informationen, die von einem Kreditgeber generiert und wahrgenommen werden, nicht

Ongena/Smith (2000a), S. 221 ff., Bhattacharya/Thakor (1993), S. 2 ff., Freixas/Rochet (1997), S. $2 \mathrm{ff}$. oder Segbers (2007), S. $121 \mathrm{ff}$. geben einen Überblick über die verschiedenen Forschungsansätze im Bereich des Relationship Banking. den Zinssatz, die Sicherheitenstellung oder die Kreditverfügbarkeit, in den Modellen thematisiert werden, ist allerdings nicht ganz trennscharf. Viele Modelle kombinieren mehrere Effekte. Bei Ramakrishnan/Thakor (1984) übernimmt der Finanzintermediär die Rolle eines reinen Finanzgutachters. Vgl. Ramakrishnan/Thakor (1984), S. 415 ff.

370 Zwar haben sich Leland/Pyle (1977) nicht explizit mit der Suche nach Erklärungen für die Existenz von Finanzintermediären auseinandergesetzt, jedoch haben sie die wesentlichen Aspekte einer informationsökonomischen Betrachtung der zweistufigen Anreizprobleme diskutiert. Vgl. Leland/Pyle (1977), S. 371 ff. Eine Diskussion nehmen Hartmann-Wendels/Pfingsten/Weber vor. Vgl. Hartmann-Wendels/Pfingsten/Weber (2007), S. 145. Für einen Überblick vgl. Berger/Udell (1995), S. 352. Zu den Modellen vgl. Diamond (1984), S. $393 \mathrm{ff}$., Ramakrishnan/Thakor (1984), S. 415 ff., Boyd/Prescott (1986), S. $211 \mathrm{ff}$., Leland/Pyle (1977), S. 371 ff. oder Fama (1985), S. 33 ff.

372 Vgl. Ongena/Smith (2000a), S. 226.

373 Vgl. Berger/Udell (1995), S. 354.

374 Vgl. Elsas (2001), S. 17. Zu dem Modell vgl. Diamond (1984), S. 393 ff.

375 Vgl. Diamond (1984), S. 394. 
direkt von den anderen Kreditgebern ohne Kosten beobachtet werden können. ${ }^{376}$ Die Bank agiert als „delegated monitor“ für ihre Einleger, indem sie für diese das Verhalten der Kreditnehmer überwacht. Wenn jeder Kreditgeber für sich Informationen über die finanzielle Situation und die Perspektiven eines Unternehmens sammeln würde, um auf Basis dieser Beurteilung einen Kredit zu vergeben, und alle Kreditgeber simultan die Handlungen des Kreditnehmers überwachen würden, nachdem selbiger die Investition getätigt hat, wäre dies mit einer Vielzahl von Doppeltätigkeiten verbunden. Für die Investoren ist es effizienter, diese Aufgabe an eine Bank zu delegieren und durch die Intermediation der Bank die Geldanlagen in das Unternehmen zu bringen. ${ }^{377}$ Darüber hinaus generieren Banken im Laufe der Beziehung Informationen über die Kreditnehmer, indem sie das Verhalten des Kreditnehmers in Bezug auf bestehende Kredite, Einlagen und/oder sonstige Dienstleistungen wie Vermögensberatung beobachten. ${ }^{378}$ Das Pooling der Monitoring-Tätigkeiten bei der Bank bewirkt einen großen Kostenvorteil bei der Informationssammlung, da die Alternativen entweder darin bestehen, dass der Prozess der Informationssammlung dupliziert wird, wenn jeder Kreditgeber die Überwachung selbst durchführt, oder dass ein Free-Rider-Problem resultiert, wenn kein Kreditgeber ein Monitoring vollzieht. ${ }^{379} \mathrm{Im}$ Vergleich zum Monitoring durch jeden einzelnen Kreditgeber müssen bei der Durchführung desselbigen durch die Bank die (Fix-)Kosten der Überwachung nicht mehrfach aufgebracht werden, d.h. es werden Skaleneffekte realisiert.

Wenn die Bank allerdings nur in einen Unternehmer investiert, so stehen die Kapitalgeber vor dem gleichen Anreizproblem, vor dem sie auch bei einer direkten Finanzbeziehung mit dem Unternehmer stehen würden. ${ }^{380}$ Das Monitoring wird in diesem Fall nur auf den Finanzintermediär verlagert und das Anreizproblem auf die Beziehung zwischen Kapitalgeber und Finanzintermediär verschoben. Wenn der Finanzintermediär aber gleichzeitig in die Projekte mehrerer Unternehmer investiert, wirken Diversifikationseffekte. Die Bank muss durch ihre Einleger nicht überwacht werden, da die Ausfallrisiken der Kapitelnehmer annahmegemäß unkorreliert sind und die Bank selbst aus Sicht der Einleger aufgrund der perfekten Diversifikation keinem Ausfallrisiko unterliegt. ${ }^{381}$

In seiner Analyse legt DIAMOND den Fokus auf einen Finanzintermediär, der Kapital in Form von Geldeinlagen der Kapitalgeber beschafft, selbigen einen bestimmten Finanzstrom verspricht, das Geld wiederum an den Unternehmer verleiht und dann Ressourcen darauf verwendet, den Kredit zu überwachen, d.h. ein Monitoring durchzuführen und die Kreditverträge mit Kreditnehmern durchzusetzen, die weniger kost-

\footnotetext{
376 Vgl. Diamond (1984), S. 394.

377 Vgl. Longhofer/Santos (2000), S. 58.

378 Vgl. Berger/Udell (1995), S. 354. Eine ausführlichere Darstellung nehmen Allen/Saunders/ Udell oder Nakamura vor. Vgl. Allen/Saunders/Udell (1991), S. 335 ff. oder Nakamura (1994), S. $3 \mathrm{ff}$.

379 Vgl. Diamond (1984), S. 393.

380 Vgl. Hartmann-Wendels/Pfingsten/Weber (2007), S. $122 \mathrm{ff}$.

381 Vgl. Elsas (1991), S. 17. Für eine Diskussion vgl. hierzu auch Freixas/Rochet (1997), S. 29-32. 
spielig sind als Kreditverträge ohne Monitoring ${ }^{382}$ Die Kapitalgeber können zwar die Zahlungen beobachten, die sie vom Intermediär erhalten, sie können aber nicht die Zahlungsströme des Projektes, die Zahlungen des Unternehmers an den Intermediär oder die eingebrachten Ressourcen des Intermediärs im Rahmen des Monitoring beobachten ${ }^{383}$ Das Modell von DIAMOND ist der Prototyp einer Vielzahl statischer Modelle zur Finanzintermediation, die auf informationsökonomischen Argumenten basieren.

Auch FAMA analysiert den Aspekt der Informationssammlung bei der Bank und beobachtet, dass Firmen bereit sind, von Banken Geld zu leihen, obwohl diese im Vergleich zur Finanzierung über den öffentlichen Markt zusätzliche Kosten, wie z.B. die Opportunitätskosten für die nichtzinsbringenden, gesetzlich vorgeschriebenen Reserven, zu tragen haben. ${ }^{384}$ Ebenso wie KANE/MALKIEL argumentiert FAMA, dass Banken vor allem durch das Einlagengeschäft proprietäres Wissen über den Firmenkunden erlangen. ${ }^{385}$ Ferner weist FAMA darauf hin, dass eine Bank zunächst durch das Screening des potenziellen Kreditnehmers vor Vertragsabschluss umfangreiche Informationen gewinnt, und dass sie darüber hinaus während der Kreditlaufzeit die Möglichkeit hat, das Verhalten des Managements zu überwachen. ${ }^{386}$ Aufgrund dieses umfangreichen Zugangs zu privaten Informationen über den Kreditnehmer differenziert FAMA zwischen ,inside debtholder“ und „outside debtholder". ${ }^{387}$ Unter einem ,inside debtholder" wird in diesem Kontext ein Kreditgeber verstanden, der Zugang zu Informationen erhält, die ansonsten nicht öffentlich verfügbar sind, wie z.B. das Rückzahlungsverhalten bei Darlehen oder die Einhaltung von Absprachen mit der Bank. „Inside debtholder" partizipieren u.U., wenn sie z.B. im Beirat oder Aufsichtsrat des Unternehmens vertreten sind, unmittelbar am betrieblichen Entscheidungsprozess. Unter „outside debt“ werden öffentlich gehandelte Kredite subsumiert, wobei der Kreditgeber hier auf öffentlich verfügbare Informationen, z.B. Ratingveröffentlichungen oder Geschäftsberichte, angewiesen ist. Für kleine Unternehmen ist es in der Regel günstiger, einem einzelnen Agenten wie der Bank Zugang zu den Informationen zu verschaffen als der Öffentlichkeit die Informationen, die bei der Finanzierung über den Anleihenmarkt erforderlich sind, bereitzustellen. Positive Signale einer Bank, bspw. über die Verlängerung einer Kreditlinie, erlauben es dann den im Rang vor der Bank stehenden Anspruchsinhabern, auf eine kostspielige Bewertung ihrer Ansprüche zu verzichten, da die Bank das Monitoring übernimmt. Dieser Aspekt der Minimierung von Informationsasymmetrien zwischen Kapitalgeber und -nehmer stellt das Grundprinzip der modernen Theorie der Finanzintermediation dar. ${ }^{388}$

Diese Ansätze betrachten den Bankkredit allgemein als eine Lösungsmöglichkeit für Informationsprobleme in Finanzierungsbeziehungen. Die private Bereitstellung der

Vgl. Diamond (1984), S. 394.

Vgl. Diamond (1984), S. 399.

Vgl. Fama (1985), S. $33 \mathrm{ff}$.

Vgl. Fama (1985), S. 37 f.

Vgl. hier und im Folgenden Fama (1985), S. 36 f.

Vgl. Fama (1985), S. 36.

Vgl. Elsas (2001), S. 17. 
Finanzierung, bei der der Kreditnehmer nur einem oder wenigen Gläubigern gegenüber steht, ist in Verbindung mit dem intertemporalen Aspekt der Informationssammlung ein zentrales Element zur ökonomischen Analyse von Bankbeziehungen. ${ }^{389} \mathrm{Die}$ Ex-Ante-Screening-Aktivität und das Ex-Post-Monitoring der Bank sind im Rahmen statischer Modelle als Erklärungsansatz jedoch insofern unbefriedigend, als dass sie bestimmte empirische Beobachtungen, wie bspw. in einem Fall steigende und in einem anderen Fall sinkende Zinsen im Zeitablauf der Kundenbeziehung, nicht erklären können und darüber hinaus eine Verbindung zwischen Kreditnehmer und Kreditgeber während der Vertragslaufzeit nicht explizit abbilden und analysieren können. ${ }^{390}$ Vor allem die schon von DIAMOND, FAMA und ALLEN betonte Fähigkeit der Bank, im Zeitablauf der Kundenbeziehung Informationen über den Kreditnehmer zu sammeln, kann erst durch die explizite Abbildung dynamischer Aspekte adäquat analysiert werden. ${ }^{391}$

\subsubsection{Zinsmodelle}

\subsection{Beschreibung der Zinsmodelle}

In den bisher beschriebenen informationsökonomischen Modellen zur Intermediärsfinanzierung wurde der Aspekt der Informationsgenerierung im Kontext der Bankbeziehung zwar untersucht, allerdings primär als Erklärung für die Existenz von Banken. Im Folgenden soll analysiert werden, welche Implikationen sich daraus für das Zinssetzungsverhalten im Rahmen der Bankbeziehung ergeben. Die theoretischen Modelle, die diese intertemporale Konditionengestaltung von Kreditverträgen beschreiben, lassen sich im Wesentlichen nach den zugrunde liegenden Problemen, d.h. adverse Selektion, Moral Hazard und Hold Up, unterteilen ${ }^{392}$ Diese Differenzierung ist jedoch nicht immer trennscharf. Beispielsweise werden in dem Modell von PETERSEN/RAJAN das Adverse Selection-Problem mit dem Moral Hazard-Problem kombiniert abgebildet. ${ }^{393}$ Ferner wird hinsichtlich der Auswirkungen auf den Kreditzins differenziert zwischen Modellen, die von einem Zinsrückgang im Laufe der Bankbeziehung ausgehen (z.B. PETERSEN/RAJAN, BoOT/THAKOR), und zwischen Modellen, die von einem Zinsanstieg im Laufe der Zeit ausgehen (z.B. GreENBAUM/KANATAS/VENEZIA, SHARPE, WILSON) ${ }^{394}$

Zentraler Ansatzpunkt aller Modelle sind weiterhin die vorherrschenden Informationsasymmetrien. Der Umfang der Informationsasymmetrien hängt bspw. von den Kreditnehmereigenschaften wie Unternehmensgröße, Unternehmensalter oder Rechtsform

\footnotetext{
389 Vgl. Elsas (2001), S. 19.

390 Vgl. Elsas (2001), S. 18.

391 Vgl. Elsas (2001), S. 18. Zu den Modellen vgl. Diamond (1984), S. 393 ff., Fama (1985), S. 33

ff. und Allen (1990), S. 3 ff.

392 Vgl. Elsas (2001), S. 57.

393 Vgl. Petersen/Rajan (1995), S. 407 ff.

394 Für einen Überblick vgl. Berger/Udell (1995), S. 352. Zu den Modellen vgl. Petersen/Rajan (1995), S. 407 ff., Boot/Thakor (1994), S. 899 ff., Greenbaum/Kanatas/Venezia (1989), S. 221 ff., Sharpe (1990), S. 1069 ff., Wilson (1995), S. 335 ff. 
ab. Typischerweise liefern kleine Firmen den Banken, mit denen sie noch nicht in einer Geschäftsbeziehung stehen, weniger Informationen als große Firmen. Kleine Firmen produzieren in der Regel weniger öffentlich verfügbare Informationen. Dies resultiert zum einen aus den für kleine Unternehmen verhältnismäßig hohen Kosten für die Informationsveröffentlichung und zum anderen aus den fehlenden Vorschriften bzgl. der Veröffentlichung von Unternehmensdaten. ${ }^{395}$ Banken versuchen bestehende Informationsasymmetrien abzubauen, indem sie Informationen beobachten und analysieren. Da die Informationssammlung durch die Bank kostspielig ist, wird selbige die Informationssuche nur so lange ausweiten, bis der erwartete marginale Nettonutzen daraus gleich Null ist. ${ }^{36}$ Ferner werden bspw. durch die Rechtsform die Anreize und Fähigkeiten der Manager bzw. der Ansprechpartner der Bank beeinflusst, das Risiko zur Bank zu transferieren. So führt die beschränkte Haftung eines Unternehmens dazu, dass das Risiko zunächst auf die Bank verlagert wird, da selbige im Falle eines finanziellen Problems keinen Zugriff auf die privaten Vermögensgegenstände hat. Eine Möglichkeit zur Überwindung der Informationsasymmetrie und zur Angleichung der Ziele zwischen Bank und Unternehmen besteht in der Erstellung anreizkompatibler Verträge, z.B. durch geeignete Sicherheitenforderungen in Form von Bürgschaften der Gesellschafter einer $\mathrm{GmbH}$, um die Anreize für die vereinbarte Vertragserfüllung zu erhöhen. ${ }^{397}$

Den Modellen zur adversen Selektion liegt ein initiales Qualitätsauswahlproblem zugrunde. Wie in Kapitel A.4.2.3.1 dargestellt, kann die Bank vor erstmaligem Abschluss des Kreditvertrags nicht zwischen guten und schlechten Kreditnehmern unterscheiden und somit keinen risikoadäquaten Kreditzins vergeben. ${ }^{398}$ Firmenkunden erhalten zwar vor Kreditvergabe ein Rating, ${ }^{394}$ allerdings ist es denkbar, dass die Firmenkundenbetreuer vor der erstmaligen Kreditvergabe die Fragen im qualitativen Bereich des Ratings nicht mit Sicherheit beantworten können und nicht in der Lage sind, bspw. die Managementfähigkeiten der Geschäftsführung oder die Ausgestaltung der Kostenrechnungssysteme und der Planungsrechnungen des Unternehmens hinreichend präzise zu beurteilen. Infolgedessen resultiert eine Mischkalkulation auf der Basis der A-Priori-Erwartung über die Verteilung der Kreditnehmertypen in der Grundgesamtheit, was wiederum Effizienzstörungen im Vergleich zur First-Best-Welt, d.h. der Situation mit perfekten Informationen über die Kreditnehmerqualität, bewirkt. Der individuell nicht mehr risikoadäquate Preis der Kreditfinanzierung wird einen negativen Einfluss auf die Kapitalallokation haben. Unternehmen mit einer schlechten Qualität werden einen größeren Anteil am Kapital erhalten als dieses bei symmetrischer Information der Fall wäre, denn der über alle Kreditnehmer ermittelte Durchschnittspreis ist niedriger als der risikoadäquate Preis für diese schlechten Unternehmen. Die guten Kreditnehmer hingegen werden sich möglicherweise weniger Kapital

\footnotetext{
395 Vgl. Lehmann/Neuberger (2001), S. 6.

${ }_{396}$ Vgl. Lehmann/Neuberger (2001), S. 6.

397 Vgl. Berger/Udell (1995), S. 351.

${ }_{398}$ Vgl. Sharpe (1990), S. 1070.

349 Vgl. zum Kreditprozess Berens et al. (2005), S. 785.
} 
über eine Bank beschaffen, da der Durchschnittspreis über ihrem risikoadäquaten Preis liegt.

Im Gegensatz zum Adverse Selection-Problem tritt das Moral Hazard-Problem, wie in Kapitel A.4.2.3.2 erläutert, erst während der Leistungsbeziehung und somit auch nach Vertragsabschluss zwischen Bank und Kreditnehmer auf. ${ }^{400}$ Die Bank kann das Anstrengungsniveau des Unternehmers nicht zweifelsfrei beurteilen und nicht erkennen, inwiefern dieser eine bewusste Leistungszurückhaltung (hidden action) betreibt. ${ }^{401}$ Zwar kann die Bank das Ergebnis der Handlungen des Unternehmers ex post feststellen, sie ist aber nicht in der Lage, dessen Handlungen zu beobachten. ${ }^{402}$ In Konsequenz kann sie nicht eindeutig beurteilen, welchen Anteil die Anstrengungen des Unternehmers und welchen Anteil äußere Einflüsse an dem zustande gekommenen Ergebnis haben. ${ }^{403}$ So beeinflusst die unbeobachtbare Anstrengung des Unternehmers zwar seine Rückzahlungsfähigkeit und somit die Erlöse der Bank, die Bank ist jedoch nicht in der Lage das Anstrengungsniveau zu beurteilen. ${ }^{404}$ Nach Vertragsabschluss mit fester Rückzahlungsverpflichtung kann ein Unternehmer ferner seinen erwarteten Gewinn steigern, indem er das Projektrisiko erhöht oder ein riskanteres als das vereinbarte Projekt durchführt (asset substitution). ${ }^{405}$ Ansätze, die das Moral Hazard-Problem zugrunde legen, modellieren die Gefahr der Risikoerhöhung durch den Kreditnehmer, z.B. durch die Wahl des risikoreicheren Projektes. ${ }^{406}$

PETERSEN/RAJAN haben ein grundlegendes Modell zur Demonstration des Effekts einer intertemporalen Ertragsverschiebung entwickelt, in welchem die Probleme der adversen Selektion und des Moral Hazard kombiniert Berücksichtigung finden. ${ }^{407}$ PETERSEN/RAJAN analysieren, inwiefern eine Bank in Abhängigkeit von ihrer Marktmacht die Zinsforderungen am Anfang einer Kreditbeziehung niedrig halten kann, um die Probleme asymmetrischer Informationen zu verhindern. ${ }^{408}$

In dem Modell wird der Kredit nicht als eine einmalige Transaktion betrachtet, sondern der Fokus wird auf eine intertemporale Betrachtung der Kreditbeziehung gelegt. Aus diesem Grund wird die Kreditbeziehung, wie in Abb. A-4 dargestellt, in zwei Phasen aufgeteilt. ${ }^{409}$ In dem Modell wird zwischen guten und schlechten Kreditnehmern unterschieden. Die guten Kreditnehmer können in $t_{0}$ einen Betrag $I_{0}$ entweder in ein sicheres oder in ein riskantes Projekt investieren. Bei der Investition in das sichere Projekt kann der gute Kreditnehmer in $t_{1}$ in ein weiteres sicheres Projekt den Betrag $\mathrm{I}_{1}^{\mathrm{s}}$ investieren. Bei der Investition in das riskante Projekt hingegen ergibt sich mit einer

\footnotetext{
$400 \quad$ Vgl. Klaus (2002), S. 132.

401 Vgl. Ebers/Gotsch (2006), S. 213.

402 Vgl. Klaus (2002), S. 133.

403 Vgl. Ebers/Gotsch (2006), S. 213.

404 Vgl. Greenbaum/Thakor (1995), S. $236 \mathrm{ff}$.

${ }_{405} \mathrm{Vgl}$. Lehmann/Neuberger (2001), S. 18.

406 Vgl. Kapitel A.4.2.3.2.

407 Vgl. Petersen/Rajan (1995), S. 407 ff. Einen Überblick über das Modell geben HartmannWendels/Pfingsten/Weber. Vgl. Hartmann-Wendels/Pfingsten/Weber (2007), S. $148 \mathrm{ff}$. 
Wahrscheinlichkeit $p$ ein Rückfluss von $Y_{1}^{R}$, woraufhin der Unternehmer anschließend den Betrag $l_{1}^{R}$ in ein sicheres Projekt investieren kann. Annahmegemäß stehen in der zweiten Periode nur sichere Projekte zur Auswahl. Mit einer Wahrscheinlichkeit von (1-p) generiert die Investition keinen Rückfluss in $t_{1}$, so dass der Unternehmer keine Anschlussinvestition durchführen kann. Die Investitionsprojekte des schlechten Unternehmers erwirtschaften grundsätzlich keine Rückflüsse. Wie in dem vergleichbaren Modell von FISCHER ${ }^{410}$ wird hinsichtlich der Informationsstruktur angenommen, dass die in der ersten Periode finanzierende Bank den wahren Typ des Kreditnehmers erst nach Abschluss der ersten Periode erfährt.

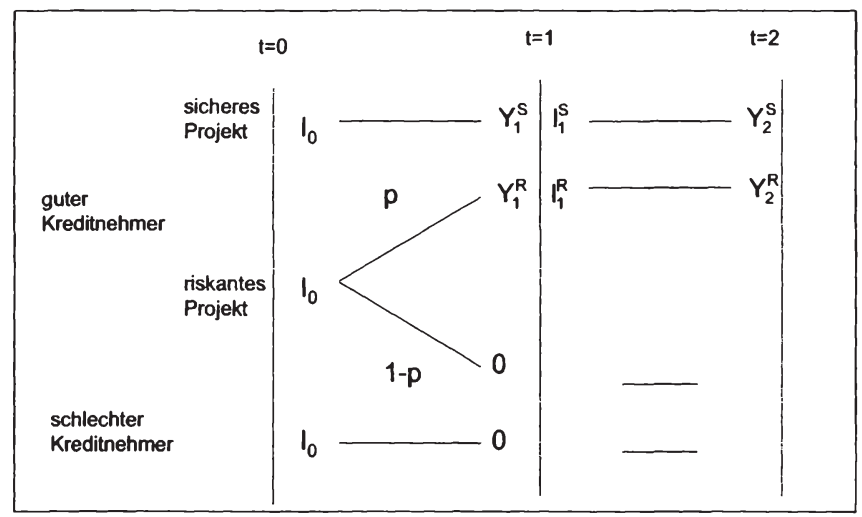

Abb. A-4: Pay-Off-Struktur der Investitionsalternativen im Modell von PETERSEN/RAJAN ${ }^{411}$

Wenn alle Kreditnehmer sich sofort für beide Perioden vollständig finanzieren und Nachverhandlungsmöglichkeiten ausgeschlossen sind, resultieren daraus folgende Probleme: Der Kreditgeber kann die Informationen, die er aus der ersten Periode erhält, nicht verwenden. Somit muss er bei Vertragsabschluss in $t_{0}$ einen Risikozuschlag verlangen, der die durchschnittliche Ausfallwahrscheinlichkeit der schlechten Kreditnehmer kompensiert. Infolgedessen wird die Bank für den gesamten Zeitraum von allen Kreditnehmern einen durchschnittlichen Zins verlangen. Das Problem der adversen Selektion entsteht, weil Kreditsicherheiten annahmegemäß in dem Modell nicht zugelassen sind und somit ein Signalling durch die Auswahl geeigneter ZinsSicherheiten-Kombinationen nicht möglich ist. Gute Kreditnehmer haben nun die Möglichkeit, auf das Projekt zu verzichten und den Markt zu verlassen, so dass die durchschnittliche Kreditnehmerqualität sinkt. Stattdessen können die guten Kreditnehmer, um ihren eigenen erwarteten Ertrag zu erhöhen und die höheren Zinsen aus-

$410 \quad$ Vgl. Fischer (1990), S. 2 ff.

411 Vgl. Hartmann-Wendels/Pfingsten/Weber (2007), S. 150. 
zugleichen, nun auch das Projektrisiko erhöhen, so dass es nunmehr zu einem kombinierten Problem der adversen Selektion und des Moral Hazard kommt.

Um den Gewinn zu optimieren, nimmt ein guter Kreditnehmer einen möglichst geringen Kreditbetrag für die erste Periode auf, allerdings zu den höheren, durchschnittlichen Zinsen. Den restlichen Kreditbetrag für die Finanzierung des Anschlussprojektes wird er in der zweiten Periode aufnehmen, so dass die Bank die Möglichkeit erlangt, den Projekterfolg und somit die Qualität des Kreditnehmers zu beobachten. Die schlechten Kreditnehmer würden sofort den vollen Betrag aufnehmen, da sie nach dem Scheitern des Projektes keine weiteren Kredite mehr von ihrer Bank erhalten. Durch die Wahl der Kreditlaufzeit wäre somit ein Signalling denkbar. Da die schlechten Kreditnehmer dies wiederum antizipieren und schließlich auch eine kurze Kreditlaufzeit wählen, würde das Signalling nicht mehr funktionieren.

Diese Wahlmöglichkeit zwischen einem sicheren erfolgreichen Projekt und einem riskanten Projekt, verbunden mit einer mangelnden Beobachtbarkeit der Projektentscheidung, führt aufgrund der Mischkalkulation über beide Unternehmertypen zu einer ineffizienten Konditionengestaltung und zu einem Risk Shifting-Anreiz ${ }^{412}$ für den guten Unternehmer. Insofern kann in diesem Modell die Gefahr der adversen Selektion ein Moral Hazard-Problem bewirken, was wiederum zu Kreditrationierung führt. ${ }^{413} \mathrm{Als}$ Lösung bietet sich der Abschluss eines zustandsabhängigen Vertrags an, weil die Bank zu Beginn der zweiten Periode gute von schlechten Kreditnehmern unterscheiden kann. ${ }^{414}$ Falls die Bank allerdings über eine noch zu spezifizierende Marktmacht verfügt, muss der zustandsabhängige Kreditvertrag nicht zwangsläufig komplett ex ante abgeschlossen werden, sondern kann aus zwei einzelnen Verträgen bestehen. ${ }^{415} \mathrm{Je}$ niedriger der in der ersten Periode zu fordernde Mindestzins, desto niedriger ist auch der Anreiz zu Moral Hazard, da dann bei Mischkalkulation über die Unternehmertypen die Differenz zwischen Mischzins und risikoadäquaten (First-best) Zins für den guten Typ kleiner werden. ${ }^{416}$ Damit die Hausbank eine Finanzierung in beiden Perioden ermöglicht, muss sie in der Lage sein, Verluste aus einer Mischfinanzierung in der ersten Periode durch Gewinne in der zweiten Periode auszugleichen. Dazu muss der Zins über dem risikoadäquaten Zins liegen. Konkurrieren allerdings in der zweiten Periode Outside-Banken, d.h. Banken, die noch nicht in einer Kreditbeziehung mit den Unternehmern stehen, mit der Hausbank um die Finanzierung des zweiten Projektes, kann der Fall eintreten, dass dieser Wettbewerb die in der zweiten Periode maximal durchzusetzende Zinszahlung beschränkt. Die Hausbank kann möglicherweise die Verluste aus der ersten Finanzierung nicht ausgleichen. Da die Hausbank dies antizipiert, würden die Banken bei Wettbewerb in der zweiten Periode höhere Mischzinsen in der ersten Periode fordern, so dass keine Finanzierung der guten Unternehmen in der ersten Periode realisierbar wäre. Allerdings führt der Informationsvorsprung dazu,

${ }^{412}$ Unter Risk Shifting wird in diesem Kontext verstanden, dass der Unternehmer eine riskantere Projektwahl als vereinbart vornimmt. Vgl. Segbers (2006), S. 149.

413 Vgl. Petersen/Rajan (1995), S. 411.

414 Vgl. Segbers (2007) S. 132.

415 Vgl. Petersen/Rajan (1995), S. 414.

416 Vgl. Elsas (2001), S. 65. 
dass die Hausbank in der zweiten Periode zwischen guten und schlechten Unternehmen unterscheiden kann und nur noch gute Unternehmen finanziert. Infolgedessen hat sie für diese Periode geringere Opportunitätskosten der Finanzierung einzukalkulieren als die konkurrierende Bank.

Auch Sharpe, Kane/Malkiel und Fama haben die Informationsasymmetrien, die zwischen den Agenten der gleichen Marktseite, d.h. den Banken bestehen, untersucht ${ }^{417}$ Die kreditgebende Bank generiert mehr Informationen über die Eigenschaften des Kreditnehmers, so dass diese asymmetrische Entwicklung der Informationen zu einem temporären Informationsmonopol führen kann. ${ }^{418}$ So kann eine Bank die Anlage- und Zahlungsverkehrskonten eines Unternehmens führen und dadurch Informationen produzieren, was wiederum das Monitoring des Kunden in Bezug auf seine Kredite vereinfacht ${ }^{419} \mathrm{Je}$ größer die Bandbreite der genutzten Produkte ist, desto größer ist der Umfang der produzierten Informationen. Hinsichtlich der Entwicklung der Informationsasymmetrien im Zeitablauf ist, wie in Abb. A-5 dargestellt, nach den verschiedenen Beziehungen zu differenzieren. Während die Informationsasymmetrie zwischen Kunde und Inside-Bank im Lauf der Beziehung kleiner wird, steigt die Informationsasymmetrie zwischen Inside- und Outside-Bank. Aus diesem Informationsmonopol resultiert eine Marktmacht, die es der Bank ermöglicht, auch einen höheren als den risikoadäquaten Zinssatz, aber einen niedrigeren als den Mischzinssatz durchsetzen. Unter Vernachlässigung von Wechselkosten würde der Kunde die Bank wechseln, sobald der geforderte Zins über dem Mischzins liegt.

Mit zunehmender Marktmacht und somit größerem Spielraum für höhere Zinsen in späteren Perioden wird die erforderliche durchschnittliche Kreditnehmerqualität geringer. Wenn die Marktmacht steigt, dann erhalten auch Kreditnehmer mit geringerer erwarteter Qualität einen Kredit. Bei großer Marktmacht kann die Bank den geforderten Zins zunächst niedriger ansetzen als in einer kompetitiveren Situation mit einer geringeren Marktmacht, da sie in letzterem Fall die volle Entlohnung des eingegangenen Risikos sofort verlangen muss, weil der Kunde schneller wechseln kann. ${ }^{420}$ Auch in den folgenden Perioden kann die Inside-Bank ihre Konkurrenten bei den Zinsforderungen unterbieten, die Kreditnehmer an sich binden und trotzdem Gewinne machen, weil sie aufgrund des schon stattgefundenen Auswahlprozesses (nach der ersten Periode sind die schlechten Kreditnehmer ausgeschieden) nur noch Kreditnehmer mit guter Qualität bedient. ${ }^{421}$ Die Konkurrenten könnten sich nun überlegen, die Inside-Bank wiederum zu unterbieten und die guten Kreditnehmer abzuwerben. Mit der Dauer der Kunde-Bank-Beziehung würden auch diese Banken höhere Zinsen als Ausgleich erhalten. Allerdings können die konkurrierenden Banken nicht unterscheiden, ob ein guter Kreditnehmer aufgrund der besseren Konditionen vom ursprünglichen Kreditnehmer abgewandert ist, oder ob ein schlechter Kreditnehmer nach Ablehnung seines

\footnotetext{
417 Vgl. Sharpe (1990), S. 1069 ff., Kane/Malkiel (1965), S. 113 ff. und Fama (1985), S. 39 ff.

418 Vgl. Sharpe (1990), S. 1069.

419 Vgl. Fama (1985), S. 38, Black (1975), S. 326.

420 Vgl. Segbers (2007), S. 134.

421 Vgl. hier und im Folgenden Hartmann-Wendels/Pfingsten/Weber (2007), S. 154. 
Kreditantrags nun bei anderen Kreditgebern versucht, einen Kredit zu bekommen. Für die Konkurrenten besteht die Gefahr des so genannten Fluch des Gewinners (Winner's Curse). Die Konkurrenten des Kreditgebers stehen vor der im Modell beschriebenen Situation zum Anfangszeitpunkt und müssten somit einen durchschnittlichen Kreditzins fordern. Ein Unterbieten des ursprünglichen Kreditgebers wird somit für die konkurrierenden Banken erschwert. Ein zusätzliches Hindernis beim Abwerben von Kreditnehmern stellt die Berücksichtigung von Suchkosten für den Kreditnehmer dar. Zudem muss nicht nur der Kreditgeber den Kreditnehmer, sondern auch der Kreditnehmer den Kreditgeber akzeptabel finden.

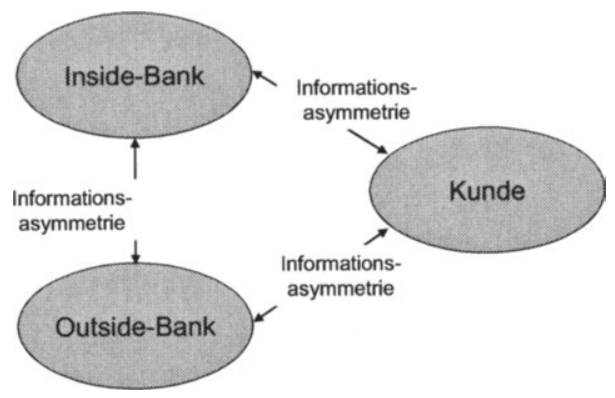

Abb. A-5: Informationsasymmetrien im Kommunikationsdreieck zwischen Kunde und Banken ${ }^{422}$

Selbst bei einer geringen Zahl guter Kreditnehmer wird in diesem Modell keine Kreditrationierung (auch der guten Kreditnehmer) stattfinden, solange eine entsprechende Machtkonzentration bei der Bank vorliegt. In diesem Modell wird, wie auch im Modell von FISCHER, die Kreditrationierung durch die mögliche intertemporale Gestaltung überwunden, ${ }^{423}$ Aus dem Modell von PETERSEN/RAJAN lässt sich ableiten, dass eine Beschränkung von Wettbewerb zugunsten einer Bank die Kapitalallokation verbessern kann. ${ }^{424}$

Voraussetzung für die Vermeidung der Probleme der adversen Selektion und des Moral Hazard ist eine mit zunehmender Dauer fester werdende Bindung der Kunden an die Bank und daraus resultierend eine Marktmacht, die es der Bank gestattet, den verbliebenen, qualitativ hochwertigen Kreditnehmern im Vergleich zum risikoadäquaten Zinssatz höhere Zinsen zu berechnen. ${ }^{425}$ Die Monopolstellung kann darauf beruhen, dass der Kreditgeber alleiniger Anbieter auf dem Kreditmarkt ist oder aber auch darauf, dass er gegenüber den Konkurrenten aufgrund einer längeren Beziehung zu den

$\begin{array}{ll}{ }^{422} & \text { Eigene Darstellung. } \\ { }^{423} & \text { Vgl. Elsas (2001), S. 56. } \\ { }^{424} & \text { Vgl. Hartmann-Wendels/Pfingsten/Weber (2007), S. } 149 . \\ 425 & \text { Vgl. Hartmann-Wendels/Pfingsten/Weber (2007), S. } 149 .\end{array}$

Tina Püthe - 978-3-631-75310-1 
Kunden (hier in der zweiten Periode) einen Informationsvorsprung besitzt. ${ }^{426}$ LONGHOFER/SANTOS zeigen darüber hinaus, dass die Banken in der Lage sind, die Unternehmen über verschiedene Perioden der Entwicklung hinweg zu subventionieren. Das ist insofern von zentraler Bedeutung, da dieser Aspekt es der Bank ermöglicht, eine Beziehung mit dem Unternehmen aufzubauen. ${ }^{427}$ Die Überwachungsaktivitäten, die während des Aufbaus der Beziehung anfallen, sind sehr kostspielig. In Konsequenz ist es für eine Bank häufig unmöglich, mit dem ersten Kreditvertrag eine vollständige Kompensation dieser Kosten zu erlangen. In dem Modell von LONGHOFER/SANTOS kann die Bank in den zukünftigen Kreditverträgen Überrenditen erzielen und genau aus diesem Grund glaubhaft vermitteln, dass sie auch zukünftig mit dem Kunden Geschäfte eingehen wird. ${ }^{428}$ Dies erfordert allerdings die Bindung des Kunden an die Bank.

Zusammengefasst stellen sich die Auswirkungen wie folgt dar. In Bezug auf die Entwicklung des Zinssatzes im Zeitablauf können zwei entgegengesetzte Einflüsse festgehalten werden. Zum einen kann der Zinssatz für einen Kreditnehmer im Zeitablauf sinken, weil die Bank ab der zweiten Periode über die (gute) Qualität des Kreditnehmers informiert ist. Andererseits gewinnt die Bank an Marktmacht, da sie ab der zweiten Periode einen Informationsvorteil gegenüber anderen Banken besitzt, so dass sie den Zinssatz möglicherweise infolgedessen nicht senkt. Durch Forderung eines höheren Zinssatzes in der zweiten Periode kann sie den Verlust der ersten Periode ausgleichen. Gute Kreditnehmer werden aufgrund niedrigerer Zinsen in der ersten Periode eher angeregt sein, das sichere Projekt zu wählen. Die erzielten Effizienzgewinne führen dann dazu, dass auch Kreditnehmer mit einer geringeren erwarteten Qualität finanziert werden. Wenn die Bank sich auf die Kunde-Bank-Beziehung verlassen kann, wird sie in der Anfangsperiode eine im Vergleich zur vollkommenen Konkurrenzsituation niedrigere Rückzahlung fordern, um eine adverse Selektion und eine Risikoerhöhung zu vermeiden. Aufgrund ihrer Marktmacht kann sie in der Folgezeit eine relativ hohe Rückzahlung von den verbleibenden guten Kreditnehmern fordern.

Die Modellüberlegungen haben gezeigt, dass mehrperiodige Kreditbeziehungen, bei denen Konditionen aufgrund von zwischenzeitlich auftretenden Informationen angepasst werden, Effizienzgewinne gegenüber den für den gesamten Zeitraum festgelegten Verträgen aufweisen können. Dabei wird von einer gewissen Monopolstellung der Bank ausgegangen, die den Kreditnehmer über aufeinanderfolgende, aber separate Verträge bindet und es ihr ermöglicht, einen Ausgleich für anfänglich zu niedrige Zinssätze zu schaffen. Die anfänglich niedrigen Zinsen verhindern dabei negative Effekte aus asymmetrischer Information (adverser Selektion) und somit wird Kreditrationierung reduziert. Zu ähnlichen Ergebnissen kommt auch FISCHER. In seinem Modell wird gezeigt, dass Kreditrationierung durch eine Ex-Post-Monopolmacht aufgrund eines Informationsvorsprungs der Hausbank überwunden werden kann. ${ }^{429}$ Die im Anfangszeitpunkt finanzierende Bank kann durch die Finanzierung und die private $\mathrm{Be}$ -

\footnotetext{
426 Vgl. Hartmann-Wendels/Pfingsten/Weber (2007), S. 154.

427 Vgl. Longhofer/Santos (2000), S. 59.

${ }_{428} \mathrm{Vgl}$. Longhofer/Santos (2000), S. 59.

429 Vgl. Fischer (1990), S. $36 \mathrm{ff}$.
} 
obachtung des Rückzahlungsverhaltens ihre A-Priori-Einschätzung bezüglich des Unternehmertyps anpassen. Es wird hier zur Vereinfachung unterstellt, dass die initial finanzierende (Haus-)Bank nach der ersten Periode den Unternehmenstyp mit Sicherheit kennt, während eine nicht finanzierende Outside-Bank im Zeitablauf keine neuen Informationen über den Kreditnehmer erhält. ${ }^{430}$

Ein geringer Wettbewerb hat gemäß PETERSEN/RAJAN somit einen positiven Einfluss auf das Relationship Banking. Je größer der monopolistische Preissetzungsspielraum der Bank ist, desto besser sind die Möglichkeiten der intertemporalen Konditionengestaltung und desto weniger Firmen werden kreditrationiert. ${ }^{431}$ BOOT/THAKOR hingegen zeigen, dass ein größerer Wettbewerb auf dem Bankenmarkt zu mehr Relationship Lending führen kann, weil die Banken bei hohem Wettbewerbsdruck ihre Kunden durch enge Beziehungen langfristig binden wollen. ${ }^{432}$

Wesentliche Kritikpunkte an dem Modell von PETERSEN/RAJAN bestehen hinsichtlich der Modellannahmen zur Informationsasymmetrie und der Berücksichtigung der Unsicherheit. ${ }^{43}$ Es wird angenommen, dass die Bank keinerlei Vorstellung von der Qualität des einzelnen Kreditnehmers hat, was bei Existenzgründern plausibel erscheint, nicht hingegen bei bestehenden Unternehmen. Ferner wird vorausgesetzt, dass die Kreditnehmer vollständig über ihre eigene Qualität Bescheid wissen. Es ist aber zu hinterfragen, aus welchem Grund ein Kreditnehmer einen Kredit aufnehmen sollte, wenn selbiger nicht zurückgezahlt werden kann. Annahmegemäß wird zwar das Privatvermögen nicht zur Haftung herangezogen, jedoch kann bei einer Nicht-Rückzahlung auch von gravierenden Nachwirkungen im sozialen Leben ausgegangen werden, was im Modell keinerlei Beachtung findet. Allerdings ist es für das Modellergebnis unerheblich, ob der Kreditnehmer über seine Qualität Bescheid weiß. Denn halten sie sich für schlecht, so versuchen sie die guten zu imitieren, halten sie sich für gut, so werden sie in der ersten Periode den Investitionsbetrag $\mathrm{I}_{0}$ nachfragen.

Auch die Annahmen bzgl. des Informationszugangs der Bank ${ }^{434}$ und die Bedingung, dass in der zweiten Periode nur sichere Projekte zugelassen sind, wirken nicht als Einschränkung. ${ }^{435}$ Zwar sind diese Prämissen in ihrer Strenge sicherlich nicht realitätskonform, eine Abschwächung ändert aber grundsätzlich nichts an den qualitativen Ergebnissen des Modells. ${ }^{436}$ Die Vereinfachung, dass die Banken außer über das Angebot unterschiedlicher Laufzeiten keine Mechanismen zur Selbstselektion besitzen, ist unrealistisch. So wird von Sicherheiten und Covenants abstrahiert, was die Realität stark vereinfacht bzw. verfälscht.

430 Die Outside-Bank kann also nicht einmal den Erfolg in der ersten Periode beobachten. Vgl. Elsas (2001), S. 61.

431 Vgl. Petersen/Rajan (1995), S. 413.

432 Vgl. Boot/Thakor (1994), S. 899.

433 Eine ausführliche Modellkritik findet sich bei Segbers (2007), S. 135 f. oder HartmannWendels/Pfingsten/Weber (2007), S. $123 \mathrm{f}$.

434 Vgl. Elsas (2001), S. 65, FN 174 oder Segbers (2007), S. 136.

435 Vgl. Machauer (1999), S. 77, Segbers (2005), S. 136.

436 Vgl. hier und im Folgenden Segbers (2007), S. 136. 
Hinsichtlich der Berücksichtigung von Unsicherheit ist zu kritisieren, dass die Bank alle Informationen, mit Ausnahme der Qualität der Kreditnehmer, mit Sicherheit kennt. ${ }^{437}$ Die Rückflüsse der Projekte in einzelnen Zuständen, die Wahrscheinlichkeit, mit denen riskante Projekte erfolgreich sind, sowie die Marktmacht in der zweiten Periode sind bekannt. All diese Informationen werden zu Beginn der ersten Periode von der Bank verarbeitet und auch vom Unternehmer wird das Verhalten der Bank antizipiert, so dass die Bank auf dieser Grundlage den optimalen Kontrakt anbieten kann. Auch diese Annahme erscheint unrealistisch, denn sie impliziert, dass Informationen kostenlos zur Verfügung stehen.

BOOT/THAKOR kommen in ihrem Modell zu ähnlichen Ergebnissen wie PETERSEN/RAJAN und zeigen, dass die Zinsen im Zeitablauf sinken. ${ }^{438}$ Während in dem Modell von Petersen/Rajan das Zinssetzungsverhalten in der zweiten Periode von der Marktmacht abhängt, ${ }^{439}$ werden in dem Modell von BOOT/THAKOR die Monopolrenten an die Kunden weitergegeben. Das mögliche Informationsmonopol wird nicht ausgenutzt. ${ }^{40}$ Sie modellieren ein grenzenlos oft wiederholtes Spiel zwischen Kreditnehmer und Kreditgeber in einem kompetitiven Bankenmarkt. Anders als bei PETERSEN/RAJAN wird die Sicherheitenstellung hier explizit modelliert. ${ }^{441}$ Bevor die Unternehmen einen ersten Projekterfolg bewiesen haben, zahlen sie relativ hohe Zinsen und stellen Sicherheiten, wobei Letzteres zur Reduktion der Moral Hazard-Probleme führt. ${ }^{442}$ Sobald jedoch die Kreditnehmer ein erfolgreiches Investitionsprojekt durchgeführt haben, werden sie keine Sicherheiten mehr stellen und von niedrigeren Zinsen aufgrund der weitergegebenen Monopolrenten profitieren. ${ }^{443}$ Das Zinssetzungsverhalten wird in ihrem Modell insbesondere vor dem Hintergrund der kostenverursachenden Stellung von Sicherheiten analysiert.

Neben den bereits genannten Gründen für das Absinken der Zinsen im Zeitablauf ist als weiterer Grund zum einen die Tatsache zu sehen, dass in jeder Periode diejenigen Kreditnehmer ausfallen, die risikoreiche Projekte ausgewählt haben und selbigen anschließend neue Kredite verwehrt werden, wodurch die durchschnittliche Qualität der Kreditnehmer steigt und weshalb die Banken die Zinsen senken. ${ }^{444}$ Zum anderen veranlasst das Streben nach Reputation die Kreditnehmer dazu, in sichere Projekte zu investieren. Die Kreditnehmer können die Kredite zurückzahlen und bauen sich dadurch eine Reputation auf. DIAMOND geht davon aus, dass wiederholte Kreditaufnahmen bei einer Inside-Bank die Reputation des Unternehmens erhöhen und somit ein besserer Zugang zum öffentlichen Markt ermöglicht wird. ${ }^{445}$ Durch den Aufbau von Reputation

\footnotetext{
${ }_{437} \quad$ Vgl. Segbers (2007), S. 136.

438 Vgl. Boot/Thakor (1994), S. $899 \mathrm{ff}$.

439 Vgl. Petersen/Rajan (1995), S. $407 \mathrm{ff}$.

440 Vgl. Degryse/Van Cayseele (2000), S. 91.

441 Vgl. Boot/Thakor (1994), S. 899 und Kapitel A.4.3.1.3.1.

442 Vgl. Boot/Thakor (1994), S. 903.

443 Vgl. Boot/Thakor (1994), S. 900.

444 Vgl. Angelini/Di Salvo/Ferri (1998), S. 928.

$445 \quad$ Vgl. Diamond (1991), S. 716.
} 
profitieren die Kreditnehmer von niedrigeren Zinsen. ${ }^{46} \mathrm{Da}$ der Reputationseffekt aus dem Rückzahlungsverhalten in Bezug auf Kredite resultiert, ist die Dauer der Kredithistorie, nicht die Dauer der Kundenbeziehung für den Aufbau der Reputation von Relevanz. ${ }^{447}$

Der aus den proprietären Informationen resultierende Informationsvorsprung und die damit verbundene bessere Möglichkeit der Beurteilung der Kreditnehmerqualität kann zu niedrigeren Zinsen führen, unter der Annahme, dass die eingesparten Kosten an den Kunden weitergegeben werden. ${ }^{48}$ Dieses Informationsmonopol kann allerdings, wie bereits zuvor angedeutet, dazu führen, dass die Bank diese Machtstellung ausnutzen und (ex post) hohe Zinsen verlangen kann. SHARPE, VON THADDEN, RAJAN und WILSON zeigen, dass aus diesem Grund die Zinsen mit zunehmender Dauer der Bankbeziehung steigen, ${ }^{449}$ denn der Kunde kann nur unter Inkaufnahme von Suchkosten zu einer anderen Bank wechseln. ${ }^{450}$ Aufgrund von Wettbewerb werden in der Anfangsphase geringe Zinsen gefordert, wobei die Zinsen für alle Kunden gleich sind, da die Banken in dieser Phase noch keine Informationen haben. ${ }^{451}$ In Konsequenz erhalten also Unternehmen mit einer schlechten Qualität einen größeren Anteil am Kapital als dieses bei symmetrischer Information der Fall wäre. Das Unternehmen bleibt bei der Bank, weil es durch das Informationsmonopol gefangen ist und weil es die Information über seine gute Qualität nicht an eine andere Bank übermitteln kann. Unter diesen Voraussetzungen macht die alte Bank das beste Angebot, denn die neue Bank kann die bestehenden Kunden nicht abwerben, ohne gleichzeitig auch die weniger guten Kunden zu attrahieren. ${ }^{452}$ Die Tatsache, dass der Kunde Angebote einholt, kann beim Wettbewerber dahingehend den Verdacht wecken, dass die Angebotsannahme für ihn mit einem Winner's Curse verbunden ist. Unter dem Winner's Curse ist in diesem Fall zu verstehen, dass die neue Bank nur dann gewinnt, wenn sie den Wert des Kunden im Vergleich zu den anderen Banken am höchsten einstuft und gar überschätzt. Denn der Kunde wird das Angebot nur annehmen, wenn das Angebot besser ist als das Angebot der aktuellen Bank, welche allerdings bessere Informationen bei der Preisfindung zugrunde legen kann. Wenn schließlich beide Banken die marginalen Kosten der Informationsproduktion zugrunde legen und selbige bei beiden Banken gleich hoch sind, wird die Konkurrenzbank zwangsläufig einen Verlust machen, wenn der Kunde deren Angebot annimmt. ${ }^{453}$ Eine Möglichkeit für die Kunden, das Hold Up-Problem zu reduzieren, besteht darin, bei mehreren Banken Kredite aufzunehmen. ${ }^{454}$ Daraus resultiert allerdings die Gefahr, dass die Kreditverfügbarkeit reduziert wird, wenn der Wert der

\footnotetext{
$446 \quad$ Vgl. Angelini/Di Salvo/Ferri (1998), S. 928.

447 Vgl. Diamond (1991), S. 716.

448 Vgl. Degryse/Van Cayseele (2000), S. 93.

449 Vgl. Sharpe (1990), S. 1069 ff., von Thadden (2001), S. 2 ff., Rajan (1992), S. 1367 ff. und Wilson (1995), S. $335 \mathrm{ff}$.

$450 \quad$ Vgl. Degryse/Van Cayseele (2000), S. 93.

451 Vgl. Sharpe (1990), S. 1070.

452 Vgl. hier und im Folgenden Sharpe (1990), S. 1070.

453 Vgl. Greenbaum/Kanatas/Venezia (1989), S. 227.

454 Vgl. Boot (2000), S. 17.
} 
Informationsbeschaffung für die einzelne Bank sinkt und der Wettbewerb ex post zu groß wird, so dass keine Gewinne erzielt werden können. ${ }^{455}$

Eine Bank, die den Informationsvorsprung ausbeutet, wird voraussichtlich aber Marktanteile verlieren, da potenzielle Neukunden von diesem Verhalten erfahren werden. Absprachen der Vergangenheit, die nicht eingehalten werden, werden in der Zukunft durch einen Verlust an Glaubwürdigkeit bestraft. ${ }^{456}$ Die Glaubwürdigkeit dieser impliziten Verträge hängt davon $a b$, inwiefern die Bewertung der Bank hinsichtlich der zukünftigen Transaktionen korrekt ist und wie der Informationsmechanismus bezüglich des Verhaltens der Bank ausgestaltet ist. Implizite Verträge werden nur dann eingehalten und sind somit auch nur dann glaubwürdig, wenn die Bank positive Renten von den aktuellen und zukünftigen Kunden erhält. ${ }^{457}$ Vollständige, zeitkonsistente Verträge sind teuer und in einer komplexen Umwelt nur schwer zu realisieren. ${ }^{458}$ Deswegen wird somit durch den Aufbau der Reputation bei der Bank eine Möglichkeit zur Beseitigung der Ineffizienzen und für die Sicherstellung einer effizienteren Kapitalallokation geschaffen. ${ }^{45}$

Das Problem der Hold Up-Kosten wird ebenso von GreEnbaum/Kanatas/VeneZia modelliert. ${ }^{460}$ GreEnBaUm/KanATAS/VEnEZIA vermuten, dass der Wert der Hold UpRenten im Laufe der Beziehung sinkt. ${ }^{461}$ Sie zeigen, dass es Bedingungen gibt, unter denen die Kreditgeber die Kreditnehmer anfänglich subventionieren und später zusätzliche Gewinne aus der Beziehung generieren. Im Zeitablauf der Beziehung kommt es hier zu steigenden Zinsen. In dem Modell von GREENBAUM/KANATAS/VENEZIA emergieren die langfristigen Beziehungen zwischen der Bank und Kreditnehmer endogen. Die Banken entwickeln im Zeitablauf ein Informationsmonopol über die guten Unternehmen. Da Wettbewerb in diesen Modellen die Gesamtgewinne auf ein Nullniveau senkt, kann die Bank nur relativ niedrige Zinsen für Kreditnehmer mit unbekannter Qualität einfordern, um anschließend im Gegenzug das Informationsmonopol auszubeuten. ${ }^{462}$ Firmen mit guter Qualität erfahren somit keine Verbesserung der Finanzierungskonditionen, da sie die Informationen über ihre Qualität nicht auf eine andere Bank übertragen können. Ihr geringes Ausfallrisiko spiegelt sich somit nicht in einem niedrigeren Zinssatz oder sonstigen Parametern (other non-price terms) wider.

\subsection{Fazit zu den Zinsmodellen}

Eine wesentliche Besonderheit der Zinsgestaltung im Rahmen einer Hausbankbeziehung besteht darin, dass diese nicht transaktions-, sondern beziehungsbezogen unter Berücksichtigung des Marktumfeldes erfolgt. Aufgrund dessen kann eine intertempo-

\footnotetext{
455

457 Vgl. Sharpe (1990), S. 1080.

457 Vgl. Sharpe (1990), S. 1084.

458 Vgl. Sharpe (1990), S. 1084.

459 Vgl. Sharpe (1990), S. 1070.

460 Vgl. Greenbaum/Kanatas/Venezia (1989), S. $221 \mathrm{ff}$.

$461 \mathrm{Vgl}$. Greenbaum/Kanatas/Venezia (1989), S. 222.

462 Vgl. Harhoff/Körting (1998a), S. 4 f.
} 
rale Konditionengestaltung resultieren, ${ }^{463}$ die es der Bank ermöglicht, Verluste aus der Anfangsphase der Beziehung mit späteren Gewinnen zu verrechnen. In der Grundidee der intertemporalen Konditionengestaltung kann bei mehrperiodigen Finanzierungsverträgen der Wettbewerb zu jedem Zeitpunkt nachteilig sein, da die Konditionen eines Kreditvertrags dann zu jedem Zeitpunkt auf das kompetitive Niveau beschränkt sind ${ }^{464}$ Bei Wettbewerb kann eine Bank nicht erwarten, etwaige Verluste in Teilperioden der Finanzierung durch Mehrerträge in anderen Perioden wieder ausgleichen zu können. ${ }^{465}$ Dies impliziert für die finanzierende Bank eine Break-Even-Bedingung aus dem Finanzierungsgeschäft zu jedem einzelnen Zeitpunkt und somit eine Art inhärente Kurzfristperspektive.

In Tab. A-7 werden die wesentlichen Modelle dargestellt, die eine Aussage zur Entwicklung der Zinsen im Zeitablauf nennen. Die anderen zuvor erwähnten Modelle, z.B. von LONGHOFER/SANTOS, FAMA oder KANE/MALKIEL, stellen keinen expliziten Zusammenhang zur Entwicklung der Zinsen im Zeitablauf her. Die Zusammenfassung zeigt, dass sowohl steigende Zinsen als auch sinkenden Zinsen im Zeitablauf denkbar sind. Niedrigere Zinsen mit zunehmender Dauer der Bankbeziehung werden durch die präziseren Informationen und daraus resultierende niedrigere Risikoaufschläge bedingt. Steigende Zinsen im Zeitablauf können dadurch begründet werden, dass das Wechselrisiko steigt und der Informationsvorsprung sinkt. ${ }^{466}$ Ferner liefert die Möglichkeit der Ausnutzung einer Hold Up-Situation Ansatzpunkte für steigende Zinsen.

\begin{tabular}{|l|l|}
\hline Modell & $\begin{array}{l}\text { Zinsprognose } \\
\text { im Zeitablauf }\end{array}$ \\
\hline Boot/Thakor (1994) & Sinken \\
\hline Fischer (1990) & Sinken \\
\hline Greenbaum/Kanatas/Venezia (1989) & Steigen \\
\hline Petersen/Rajan (1995) & Sinken \\
\hline Rajan (1992) & Steigen \\
\hline Sharpe (1990) & Steigen \\
\hline Von Thadden (2001) & Steigen \\
\hline Wilson (1993) & Steigen \\
\hline
\end{tabular}

Tab. A-7: Entwicklung der Zinsen im Laufe der Beziehung

$463 \quad$ Vgl. Elsas (2001), S. $56 \mathrm{ff}$.

$464 \quad$ Vgl. Elsas (2001), S. 56.

465 Vgl. hier und im Folgenden Elsas (2001), S. 56.

466 Ongena/Smith haben die Dauer von Bankbeziehungen und deren Einflussgrößen untersucht. Sie kommen zu dem Schluss, dass die Wahrscheinlichkeit der Beendigung einer Bankbeziehung mit zunehmender Dauer steigt. Dieser Effekt wird jedoch relativiert durch die Aussage, dass bei Existenz mehrerer Bankverbindungen insbesondere die relativ jungen Beziehungen beendet werden, während eine spezielle Bankverbindung als Kern über längere Zeit behalten wird. Vgl. Ongena/Smith (2001), S. 473. 
Eine zentrale Frage ist, unter welchen Bedingungen die Bank das Informationsmonopol ausbeutet und unter welchen Bedingungen die Gewinne im Laufe der Beziehung an die Kunden zurückgegeben werden. ${ }^{467}$ Das Ausmaß, in dem eine Bank ein Informationsmonopol ausbeuten kann, ist unklar. SHARPE vermutet, dass die Monopolmacht einer bestehenden Bank durch öffentliche Signale bezüglich der Zahlungsfähigkeit des Unternehmens reduziert wird. ${ }^{468}$ Die Kosten, die unternehmensseitig durch das Hold Up-Problem entstehen, können durch die Reputation der Bank gemäßigt werden. SHARPE argumentiert, dass Banken eine wertvolle Reputation aufbauen können, indem sie darauf verzichten, die Monopolrenten zu extrahieren. ${ }^{469}$ Bonitätsmäßig einwandfreie Unternehmen werden sich nur dann exklusiv an eine Bank binden, wenn sie anschließend nicht befürchten müssen, von der Exklusivbank ausgebeutet zu werden. Exklusiv-Banking bedeutet dann vor allem auch, dass die Bank sich glaubhaft gegenüber dem Kunden bindet. ${ }^{470}$ Eine offensichtlich einfache Lösung des Hold UpProblems aus Sicht des Unternehmens besteht darin, mehr als eine Beziehung mit einer Inside-Bank aufzubauen, so dass sich die Banken die Monopolrenten durch den gegenseitigen Wettbewerb wegnehmen. ${ }^{41}$ RAJAN jedoch warnt, dass es sich hierbei um ein zweischneidiges Schwert handelt. Jede Outside-Bank, die mit bestehenden InsideBanken im Wettbewerb steht und niedrigere Zinsen bietet, wird unter dem Winner's Curse leiden. Die Inside-Bank wird einen Wettbewerbspreis für gute Firmen anbieten, wohingegen schlechte Firmen der Outside-Bank überlassen werden. ${ }^{472}$

Es kann aber auch Fälle geben, in denen der Kreditnehmer bereit ist, die zusätzlichen Kosten aus dem Informationsmonopol zu tragen. Dies ist dann der Fall, wenn er Gewinne aus der Hausbankbeziehung erwartet. Diese Gewinne reflektieren einen intertemporalen, impliziten Vertrag dahingehend, dass Hausbanken einen versicherungsähnlichen Service bieten, eine besondere Verantwortung tragen und im Falle einer finanziellen Schieflage einen niedrigeren als den risikoadäquaten Zinssatz fordern und sich in dieser Situation weniger restriktiv bei der Kreditvergabe verhalten ${ }^{473}$ Es gibt bei der Auswahl-Entscheidung zwischen Hausbank- und Outside-Finanzierung keine per se dominante Finanzierungsform.

Die intertemporale Ertragsverschiebung, die Informationsvorteile einer Hausbank und der Einfluss der Wettbewerbssituation können als einige wichtige Faktoren angesehen werden, die in der Forschung zum Relationship Banking und in der Praxis weitreichende Beachtung gefunden haben. In diesem Kapitel wurde sowohl eine Betrachtung von internen (Informationsgenerierung, Zinssenkungsspielraum im Zeitablauf) als auch von externen Wirkungen (Informationsmonopol gegenüber Wettbewerbern im Zeitablauf) der Beziehung vorgenommen. Zudem wurde gezeigt, dass eine langfristige

\footnotetext{
467 Vgl. Degryse/Van Cayseele (2000), S. 93.

468 Vgl. Sharpe (1990), S. 1070.

469 Vgl. Sharpe (1990), S. 1070.

470 Vgl. Doberanzke (1993), S. 37.

471 Vgl. Ongena/Smith (2000a), S. 234.

472 Vgl. Ongena/Smith (2000a), S. 234. Vgl. hierzu auch von Thadden (2001), S. 2 ff.

473 Vgl. Elsas/Krahnen (2002), S. 11.
} 
Beziehung modellendogen, losgelöst von einer vertraglichen Bindung erklärt werden kann.

Im Hinblick auf die empirische Untersuchung können auf Basis der aktuellen Erkenntnisse keine eindeutigen Ergebnisse erwartet werden. Da der Umfang der Informationsasymmetrien von den Kreditnehmereigenschaften wie Unternehmensgröße, Unternehmensalter oder Rechtsform ${ }^{47}$ abhängt, können hieraus auch Einflüsse in der Empirie vermutet werden. Wie in Abb. A-6 dargestellt, sind auf Unternehmensebene für die Analyse der Bankbeziehung bzw. der Analyse der Auswirkungen auf den Zins neben der Bonität des Unternehmens somit auch diese Parameter hinzuzuziehen. Aus der Beziehungsebene heraus konnten folgende wesentliche Einflussgrößen für die Höhe des Informationsvorteils der Hausbank herausgearbeitet werden: Dauer der Beziehung und Anzahl der Bankverbindungen. Während die Bonität unmittelbar auf den Zinssatz wirkt, beeinflussen die anderen genannten Größen den Grad der Informationsasymmetrie und somit nur mittelbar den Zinssatz.

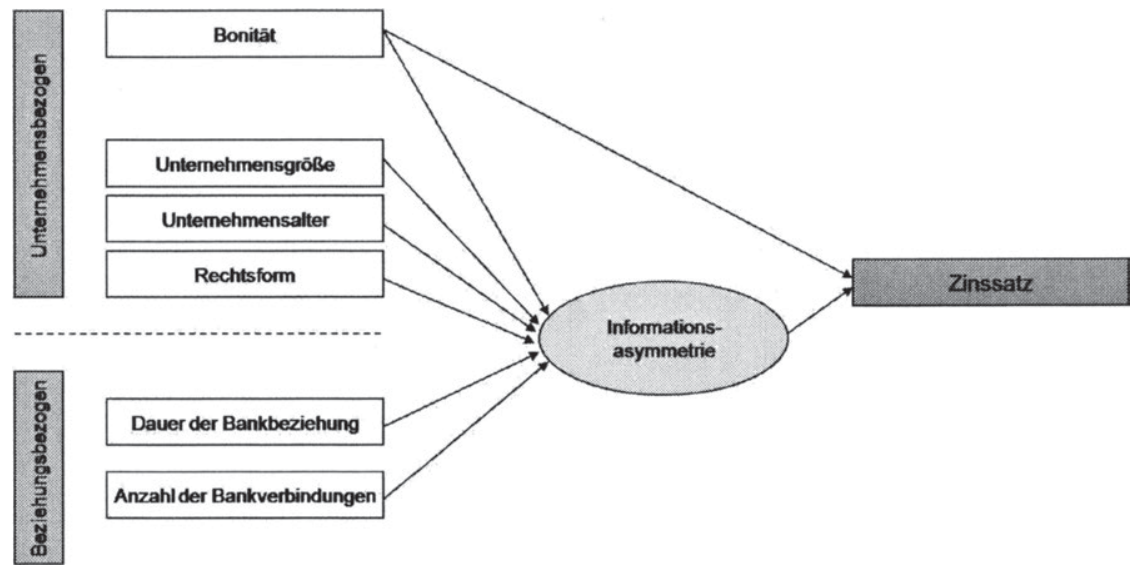

Abb. A-6: Einflussgrößen des Zinssatzes ${ }^{475}$

Als Fazit der theoretischen Ansätze zur Zinsentwicklung kann festgehalten werden, dass basierend auf der Existenz von Hausbankbeziehungen oder der Existenz einer Relationship Banking-Strategie keine eindeutigen Aussagen in Bezug auf die Höhe der Zinsen getroffen werden können. Dies betrifft auf der einen Seite grundsätzlich die Zinshöhe zu einem bestimmten Zeitpunkt (statisch) und auf der anderen Seite die Entwicklung des Zinses im Zeitverlauf einer Geschäftsbeziehung (dynamisch).

\footnotetext{
474 Es ist aber ferner auch denkbar, dass die Unternehmensgröße, das Alter und die Rechtsform des Unternehmens einen Einfluss auf die Bonität haben.

475 Eigene Darstellung.
} 


\subsubsection{Sicherheitenmodelle}

\subsection{Beschreibung der Sicherheitenmodelle}

Im vorherigen Kapitel wurden in einigen Modellen die Sicherheiten z.T. explizit ausgeschlossen (z.B. PeTerSen/RAJAN). ${ }^{476}$ Sofern in den Modellen Sicherheiten berücksichtigt wurden, erfolgte im vorherigen Kapitel keine Analyse derselbigen. In diesem Kapitel wird nun die Abbildung der Sicherheiten in Modellen genauer untersucht. In der Literatur, die sich mit der Analyse der Auswirkungen von Sicherheiten beschäftigt, ist die Sicherheitenstellung in aller Regel nicht die abhängige Variable. So gibt es Modelle, die den Einfluss von Sicherheiten auf Zinsen, z.B. BARRO, oder den Einfluss auf die Kreditrationierung, z.B. BESTER oder BESANKO/THAKOR, untersuchen ${ }^{477}$ Die meisten theoretischen Modelle zeigen, dass erhöhte Sicherheitenstellung mit bonitätsmäßig guten Kreditnehmern und Krediten in Verbindung gebracht werden, z.B. BESTER, BESANKO/THAKOR, CHAN/KANATAS. ${ }^{478}$ Es gibt aber auch Modelle, die vorhersagen, dass risikoreichere Kreditnehmer öfter Sicherheiten stellen, z.B. SWARY/UDELL, BOOT/THAKOR/UDELL. ${ }^{479}$ Einen Überblick über die verschiedenen Annahmen, insbesondere hinsichtlich der Marktstruktur und der Risikoeinstellung sowie der Berücksichtigung von Zinsen in den Modellen, gibt SCHMIDT-MOHR. ${ }^{480}$

Intuitiv könnte man vermuten, dass risikobehaftete Kreditnehmer mehr Sicherheiten stellen müssen oder weniger Kredite bekommen, da die Bank ihr Exposure, d.h. die Höhe der unbesicherten Forderungen, mit diesen Kreditnehmern reduzieren möchte. In Kapitel A.3.1.2.1 wurde dargelegt, dass die Eigenkapitalvorschriften gemäß Basel II von den Banken eine erhöhte Eigenkapitalhinterlegung bei erhöhtem Exposure verlangen. Bei Konstanz des Eigenkapitals schränkt ein erhöhtes Exposure in Bezug auf ein Unternehmen somit die zusätzlichen Kreditvergabemöglichkeiten der Bank ein. Hingegen ist es allerdings wahrscheinlich, dass gute Kreditnehmer mehr Sicherheiten stellen, da sie in der Regel mehr Sicherheiten zur Verfügung haben ${ }^{481}$ oder eher bereit sind, mehr Sicherheiten zu stellen.

Bereits bei der Darstellung des Modells von PETERSEN/RAJAN in Kapitel A.4.3.1.2.1 wurde gezeigt, dass Qualitäts- und Verhaltensunsicherheit in Bezug auf den Kreditnehmer zu adverser Selektion und zu Moral Hazard und in Konsequenz zu Kreditrationierung führen kann. In diesem Kontext sind Sicherheiten als Kreditvertragsbestandteil in zweierlei Hinsicht von elementarer Bedeutung. ${ }^{482}$ Sicherheiten können

\footnotetext{
476 Vgl. hierzu die Modellkritik in Kapitel A.4.3.1.2.1.

477 Vgl. Barro (1976), S. 1 ff., Bester (1985), S. 850 ff., Besanko/Thakor (1987a), S. $671 \mathrm{ff}$.

478 Vgl. Bester (1985), S. 850 ff., Besanko/Thakor (1987a), S. 671 ff., Besanko/Thakor (1987b), S. 167 ff., Chan/Kanatas (1985), S. 84.

479 Vgl. Swary/Udell (1988), S. 1 ff., Boot/Thakor/Udell (1991), S. 605 ff. Einen Überblick geben Berger/Udell (1995), S. 368.

Vgl. Schmidt-Mohr (1997), S. 1322.

Vgl. Machauer/Weber (1998), S. 1360.

Vgl. Hartmann-Wendels/Pfingsten/Weber (2007), S. 146. 
eingesetzt werden, um genau diese Probleme der adversen Selektion und des Moral Hazard zu beseitigen. So sind Kreditsicherheiten dazu geeignet,

- als Signalling-Instrument zu fungieren und gute von schlechten Schuldnern zu unterscheiden (Sortierungseffekt) ${ }^{433}$ sowie

- Schuldner dazu zu veranlassen, sich nach Vertragsabschluss nicht gläubigerschädigend zu verhalten (Anreizeffekt). ${ }^{484}$

Das Problem der adversen Selektion kann dahingehend durch Sicherheiten überwunden werden, als dass diese in Form eines Selbstselektionsmechanismus eingesetzt werden können ${ }^{485}$ BESTER geht in seinem Modell von der Annahme aus, dass die Entscheidung über Zinssatz und Sicherheitenhöhe simultan gefällt wird ${ }^{486}$ Die Bank kann dann über das Angebot von Kreditverträgen mit unterschiedlichen Zins-SicherheitenKombinationen und die anschließende Vertragswahl der Kreditnehmer eine Risikoklassifikation vornehmen. Aus der präferierten Kombination kann die Bank auf die Qualität des Kreditnehmers schließen. ${ }^{487}$ BESTER geht ferner davon aus, dass weniger risikobehaftete Kreditnehmer bereit sind, im Austausch für eine Reduktion des Kreditzinses mehr Sicherheiten anzubieten und dadurch ihre Qualität signalisieren. ${ }^{488}$ Demnach wählen gute Kreditnehmer i.d.R. Verträge, in denen sie niedrige Zinsen zahlen und dafür eher umfangreiche Sicherheiten stellen. Der Grund ist darin zu sehen, dass sie kaum mit einer Inanspruchnahme der Sicherheiten rechnen müssen und sich so vergleichsweise günstige Finanzierungskonditionen verschaffen können. ${ }^{489}$ Sofern derartige Self-Selection-Mechanismen existieren, können Pooling-Mechanismen, d.h. Mechanismen, bei denen zwischen den Kreditnehmertypen nicht differenziert wird und alle den gleichen Zinssatz zahlen, nicht im Wettbewerb überleben. ${ }^{40}$ Ein Gleichgewicht wird in diesem Fall charakterisiert durch die Separation der Kreditnehmer mit verschiedenen Risiken, so dass jeder Kreditnehmer seinen risikoadäquaten Zinssatz

Im Folgenden kann nicht mehr eindeutig zwischen Screening und Signalling differenziert werden, denn es ist theoretisch sowohl denkbar, dass die Bank dem Kunden zunächst mehrere ZinsSicherheiten-Kombinationen zur Auswahl anbietet als auch, dass der Kunde zunächst seine Höhe der Sicherheitenstellung signalisiert und die Bank auf dieser Basis die entsprechende ZinsSicherheiten-Kombination auswählt.

484 Vgl. Hartmann-Wendels/Pfingsten/Weber (2007), S. 146.

485 Zur Funktion der Selbstselektion vgl. Kapitel A.4.2.3.1.

486 Vgl. Bester (1985), S. 850.

487 Siehe hierzu die Modelle von Bester (1985) und Bester (1987) im Kontext von zugrunde liegenden Projekten der Kreditnehmer. In einem größeren Marktkontext sieht Schmidt-Mohr (1997) dies kritisch. Vgl. Bester (1985), S. 850 ff., Bester (1987), S. 887 ff. und Schmidt-Mohr (1997), S. $1321 \mathrm{ff}$.

488 Vgl. Bester (1985), S. 850.

489 Vgl. zu einem entsprechenden Modell mit unterschiedlich hohen Erwartungswerten der Projekte Chan/Kanatas (1985), S. 84 ff. Besanko/Thakor bestätigen diese Erkenntnisse für den Fall einer Wettbewerbssituation. Im Monopolfall hingegen ahmen die schlechten Unternehmen die guten nach und wählen somit dieselbe Zins-Sicherheiten-Kombination wie diese, um Kredite zu erlangen. Vgl. Besanko/Thakor (1987a), S. $671 \mathrm{ff}$. 
zahlt. ${ }^{491}$ Da Sicherheiten, z.B. durch die Bereitstellung und Bewertung, Kosten verursachen, stellen sie bei vollständiger Information nur eine ineffiziente Lösungsmöglichkeit dar, bei unvollständiger Information hingegen sind Sicherheiten ein geeigneter Ansatz. ${ }^{492}$ Bei unvollständiger Information werden keine Kredite abgelehnt, wenn die Bank Sicherheitenforderungen als Self-Selection-Mechanismus verwenden kann. Der Mechanismus funktioniert aber nur, wenn die Unternehmen mit geringem Risiko in der Lage sind, Sicherheiten in hinreichendem Volumen anzubieten, um sich von risikoreichen Unternehmen abzugrenzen. BESTER merkt an, dass die theoretischen Ansätze, die eine Kreditrationierung durch adverse Selektion begründen auch eine Erklärung liefern müssen, warum hier die Signalling-Mechanismen wie Sicherheitenstellung nicht eingesetzt werden können. Das Phänomen der Kreditrationierung aufgrund von adverser Selektion tritt nicht mehr auf. Die Kreditnehmer zahlen Kreditzinsen und stellen Sicherheiten, die ihrer Qualität entsprechen. Es wird also ein negativer Zusammenhang zwischen Firmenrisiko und Höhe der Sicherheiten hergeleitet. ${ }^{493}$ Unter Berücksichtigung der zuvor genannten Funktionen von Sicherheiten wird in diesem Modell der Sortierungseffekt abgebildet. Gemäß dem so genannten „Sorting-by-privateinformation"-Paradigma stellen gute Kreditnehmer mehr Sicherheiten. ${ }^{494}$ Ein wichtiges Ergebnis des Modells ist es, dass unter bestimmten Umständen Sicherheitenstellung dazu führt, dass Kreditrationierungsprobleme verhindert oder beseitigt werden können. ${ }^{495}$ BESTER zeigt theoretisch, dass auch der konträre Zusammenhang, also ein positiver Zusammenhang zwischen Firmenrisiko und Höhe der Sicherheiten, in einem Modell mit Verhaltensunsicherheit und der Möglichkeit von Nachverhandlungen zu erzielen ist. ${ }^{406}$

In dem Modell von BOOT/THAKOR werden durch Sicherheitenstellung Moral HazardProbleme reduziert. Somit kommt hier die zweite zuvor beschriebene Funktion von Sicherheiten, die Anreizfunktion, zum Tragen. ${ }^{497}$ BOOT/THAKOR kommen des Weiteren zu dem Ergebnis, dass die Dauer der Bankbeziehung nicht nur einen Einfluss auf die Kreditzinsen, sondern auch auf die Sicherheitenstellung hat. ${ }^{498}$ Sie zeigen, dass die Unternehmen zu Beginn der Kreditnehmerbeziehung hohe Zinsen zu zahlen und umfangreiche Sicherheiten zu stellen haben. Sobald die Kunden einen ersten Projekterfolg vorzuweisen haben, sinkt der Umfang der Sicherheiten. Gute Kreditnehmer stellen also weniger Sicherheiten. Ein unbesicherter Kredit ist mit relativ hohen Kreditzinsen verbunden, um die Partizipationsbedingung der Bank zu erfüllen. Während der Kreditnehmer bei Projektmisserfolg nicht in der Lage ist die Zinsen zurückzuzahlen, muss er bei Projekterfolg diese relativ hohen Zinsen zahlen, wodurch der marginale

\footnotetext{
491 Vgl. Bester (1985), S. 850.

492 Vgl. hier und im Folgenden Bester (1985), S. 854.

493 Vgl. Hartmann-Wendels/Pfingsten/Weber (2007), S. 147.

494 Vgl. Berger/Udell (1990), S. 24, Bester (1985), S. 855, Besanko/Thakor (1987b), S. 167 f.

495 Vgl. Bester (1985), S. 855.

496 Vgl. Bester (1994), S. 72.

497 Vgl. Boot/Thakor (1994), S. 903.

498 Vgl. hier und im Folgenden Boot/Thakor (1994), S. 899. Zu den Auswirkungen in Bezug auf den Zinssatz gemäß Boot/Thakor vgl. Kapitel A.4.3.1.2.1 
Gewinn in Bezug auf sein Anstrengungsniveau reduziert wird. Ein besichertes Darlehen führt zu einer geringeren Reduktion dieses Gewinns bezogen auf das Anstrengungsniveau, denn es führt zu einer gleichmäßigeren Verteilung der Kosten des Kreditnehmers bei Projekterfolg und Projektmisserfolg. Während die Bank bei Projekterfolg die vergleichsweise niedrigen Zinsen erhält, kann selbige bei Projektmisserfolg auf die Sicherheit zurückgreifen. In Bezug auf Sicherheiten zeigt das Modell von BOOT/THAKOR, dass auch deren Umfang von der Dauer der Bankbeziehung abhängt. Im Laufe der Beziehung, nachdem die Kunden einen Projekterfolg vorgewiesen haben, sinkt der Umfang der Sicherheiten. Das Phänomen, dass Kreditnehmer mit schlechter Bonität mehr Sicherheiten stellen wird auch als „Sorting-by-observed-risk“-Paradigma bezeichnet. ${ }^{499}$

Ferner kann das Arbeitseinsatzproblem durch die Stellung von Sicherheiten reduziert werden, indem der Leistungsanreiz für den Kreditnehmer durch den drohenden Verlust der Sicherheit gesteigert wird. ${ }^{500}$ Das Risk Shifting kann ebenfalls durch die Stellung von Sicherheiten verhindert werden, da der Kreditnehmer in diesem Fall durch den Verlust derselben stärker an den Verlusten eines Projektes partizipiert und deshalb eher das sichere Projekt bevorzugt. ${ }^{501}$

Während bisher gezeigt wurde, dass über die Sortierungsfunktion das Problem der adversen Selektion verhindert werden kann, zeigen STIGLITZ/WEISS in ihrem Modell, dass aus der Erhöhung der Sicherheitenanforderung genau dieser Adverse SelectionEffekt resultiert. ${ }^{502}$ Im Modell von STIGLITZ/WEISS kann eine erhöhte Sicherheitenforderung aufgrund von Moral Hazard genau zu einer Risikoerhöhung des Projektes der bestehenden Kreditnehmer führen. ${ }^{503}$

Weitere Ansätze finden sich darüber hinaus bei CHAN/KanATAS, DE MEZA/SOUTHEY und LANGER/WALLER. ${ }^{504}$ Während bisher die Annahme von asymmetrisch verteilten Informationen bei identischer Erwartungsbildung bzw. Bewertung von Kreditnehmern

Vgl. Berger/Udell (1990), S. 23 f.

Vgl. Chan/Thakor (1987) S. $345 \mathrm{ff}$. oder Boot/Thakor/Udell (1991), S. $605 \mathrm{ff}$.

Vgl. Bester (1987). Dies trifft auch dann zu, wenn die Sicherheit aus Sicht des Kreditgebers keinen direktenWert besitzt. Denn der Verlust der Sicherheit stellt für den Kreditnehmer einen Wertverlust dar. Vgl. Bester/Hellwig (1989), S. $135 \mathrm{ff}$.

Vgl. Stiglitz/Weiss (1981), S. 404.

s03 Vgl. Stiglitz/Weiss (1981), S. 404 ff. Eine ausführliche Modelldarstellung findet sich bei Stiglitz/Weiss. Aufgrund der restriktiven Annahmen wird das Modell hier nicht im Detail betrachtet. So wird angenommen, dass kleine Projekte höherer Misserfolgswahrscheinlichkeiten, d.h. eine Nullrendite, haben und alle Kreditnehmer das gleiche Eigenkapital haben. Eine Erhöhung der Sicherheitenanforderung oder des geforderten Eigenkapitalanteils würde dazu führen, dass mehr kleinere Projekte durchgeführt werden. In diesem Fall würde somit das Risiko dieser Darlehen steigen. Die Erhöhung der Sicherheitenanforderung kann ebenso wie die Erhöhung des Zinssatzes dazu führen, dass vermehrt risikofreudige Kreditnehmer Kredite aufnehmen oder dass die bestehenden Kreditnehmer vermehrt in risikoreichere Projekte investieren, und dass somit die Rendite der Bank sinkt. Vgl. ausführlich Stiglitz/Weiss (1981), S. 404 ff. (2003), S. 2 ff. Eine ausführlichere Darstellung findet sich bei Segbers. Vgl. Segbers (2007), S. 153.
} 
und Kreditgebern Anwendung fand, wird die Annahme nun aufgehoben. Bei CHAN/KanATAS und DE MEZA/ SOUTHEY können auch im Fall symmetrischer Informationen Probleme bei der Kreditvergabe auftauchen, da Unternehmer und Firmenkundenbetreuer die Informationen unterschiedlich interpretieren. ${ }^{505}$ Sie gehen davon aus, dass die Unternehmer im Vergleich zum Firmenkundenbetreuer üblicherweise eine optimistischere Sichtweise ihrer Zukunftsperspektiven haben. ${ }^{506}$ Sicherheiten können in diesem Kontext insofern nützlich sein, als dass der Kreditnehmer aufgrund seiner positiveren Einschätzung nicht mit der Inanspruchnahme derselben rechnet und deswegen in der Sicherheitenstellung ein eher geringes Risiko sieht. In einer derartigen Situation besteht die Funktion der Sicherheiten darin, die Risiken eines Kreditausfalls auf den Kreditnehmer zu übertragen, ohne dass dieser die Situation so wahrnimmt. ${ }^{507}$

LANGER/WALLER betrachten die Sicherheitenstellung in Kombination mit dem Anreizproblem. ${ }^{508}$ Während die zuvor genannten die unterschiedliche Bewertung der Zukunftsperspektiven berücksichtigen, betrachten LANGER/WALLER die unterschiedliche Bewertung der Sicherheit aus Sicht des Kreditnehmers einerseits und des Kreditgebers andererseits. Ihre Bewertungsannahmen basieren auf den Erkenntnissen der Prospect Theory nach KAHNEMAN/TVERSKY.$^{509}$ Gemäß derselben wird der Verlust der Sicherheit durch den Schuldner stärker beurteilt als der Nutzenzuwachs durch den Erhalt der Sicherheit beim Kreditgeber. Dieses Phänomen ergibt sich allein daraus, dass menschliche Individuen eine Verlustaversion haben, d.h. ausgehend vom Status Quo Verluste in ihren Nutzenfunktionen stärker negativ gewichten als Gewinne in gleicher Höhe positiv gewichtet werden. ${ }^{510}$ Die tatsächliche Werthaltigkeit ist hierbei irrelevant. Infolgedessen können bei einer Antizipation dieses Effektes Sicherheiten als Mechanismus zur Überwindung des Arbeitseinsatzproblems eingesetzt werden.

\subsection{Fazit zu den Sicherheitenmodellen}

Anders als bei den Zinsmodellen steht bei den Sicherheitenmodellen weniger der Prozess der Informationsgenerierung im Vordergrund. Lediglich bei BOOT/THAKOR wird die Dauer der Bankbeziehung als Möglichkeit zur Beobachtung eines Projekterfolges explizit in das Modell integriert. ${ }^{511}$ Zentrale Fragestellung ist hier vielmehr, inwiefern gute Kreditnehmer mehr oder weniger Sicherheiten stellen als schlechte Kreditnehmer. Diese Frage lässt sich nur im Kontext mit dem modellierten Problem sowie dem Entstehungszeitpunkt des Problems bzw. der angenommenen Funktion von Sicherheiten beantworten. In Fällen der adversen Selektion als ein Ex-Ante-Problem und einer

\footnotetext{
sos Vgl. Chan/Kanatas (1985), S. 85 und De Meza/Southey (1996), S. 377.

$506 \mathrm{Vgl}$. zu einer überoptimistischen Sichtweise von Unternehmern auch Arabsheibani et al. (2000), S. 35 ff. oder De Meza (2002), S. F25 f.

507 Eine Abschwächung dieses Effektes ergibt sich allerdings, wenn der Kreditgeber auch die Sicherungskraft der Sicherheit pessimistischer einschätzt als der Kreditnehmer. Vgl. Bigus (2003), S. $136 \mathrm{ff}$.

Vgl. Langer/Waller (2003), S. 2 ff.

Siehe hierzu Kahneman/Tversky (1979).

Vgl. Segbers (2007), S. 153.

Vgl. Boot/Thakor (1994), S. 899.
} 
angenommenen Signalling-Funktion von Sicherheiten stellen eher gute Schuldner mehr Sicherheiten, im Falle des Moral Hazard als einem Ex-Post-Problem und einer angenommenen Anreizfunktion stellen eher schlechte Kreditnehmer mehr Sicherheiten. ${ }^{512}$ Anhand von Tab. A-8 wird verdeutlicht, dass die Modellergebnisse in der bestehenden Literatur dementsprechend zu unterschiedlichen Ergebnissen kommen. ${ }^{513}$ Die fehlende Eindeutigkeit eines Zusammenhangs wird evident, wenn der gleiche Autor beide Zusammenhänge modelliert. BESTER zeigt in seinen Modellen, dass sowohl ein positiver als auch ein negativer Zusammenhang zwischẹn Firmenrisiko und Höhe der Sicherheiten, je nach Berücksichtigung der Form der Verhaltensunsicherheit, abgebildet werden kann. ${ }^{514}$

\begin{tabular}{|l|l|}
\hline Modell & Sicherheitenstellung \\
\hline Besanko/Thakor (1987a) & Gute Kreditnehmer stellen mehr Sicherheiten \\
\hline Besanko/Thakor(1987b) & Gute Kreditnehmer stellen mehr Sicherheiten \\
\hline Bester (1985) & Gute Kreditnehmer stellen mehr Sicherheiten \\
\hline Bester (1987) & Schlechte Kreditnehmer stellen mehr Sicherheiten \\
\hline Black/De Meza (1992) & Schlechte Kreditnehmer stellen mehr Sicherheiten \\
\hline Boot/Thakor (1994) & Schlechte Kreditnehmer stellen mehr Sicherheiten \\
\hline Boot/Thakor/Udell (1995) & Schlechte Kreditnehmer stellen mehr Sicherheiten \\
\hline Chan/Kanatas (1987) & Gute Kreditnehmer stellen mehr Sicherheiten \\
\hline Swary/Udell (1988) & Schlechte Kreditnehmer stellen mehr Sicherheiten \\
\hline
\end{tabular}

Tab. A-8: Zusammenhang von Bonität und Sicherheiten im Rahmen der Bankbeziehung

Offen bleibt die Frage, wie sich die Bank bei einem kombinierten Problem von adverser Selektion und Moral Hazard hinsichtlich der Sicherheitenstellung verhält. Aufgrund der Tatsache, dass die Inside-Bank im Laufe der Bankbeziehung Informationen generiert und Informationsasymmetrien abgebaut werden, kann die Bank die Bonität des Kreditnehmers zunehmend präziser einstufen und der Bedarf an SignallingInstrumenten wird reduziert. Das initiale Adverse Selection-Problem wird zu einem Moral Hazard-Problem. Möglicherweise stellen gute Kreditnehmer anfänglich mehr Sicherheiten, um die Qualität zu signalisieren und aufgrund der Self-Selection-Mechanismen von günstigen Zinsen zu profitieren. Im weiteren Verlauf der Beziehung wird ihre Qualiät durch die Projekterfolge transparent und die Sicherheiten übernehmen die Anreizfunktion, so dass die Höhe der geforderten Sicherheiten sinkt. Schlechte Kreditnehmer hingegen stellen anfänglich wenige Sicherheiten und nehmen die höheren

512 Vgl. Bigus/Langer/Schiereck (2005), S. 19. Liegt eine Mischung beider Probleme vor, so sind die zu treffenden Aussagen weniger eindeutig. Dies dürfte aber gerade in vielen Praxisfällen häufiger zutreffen.

513 Wie auch bei der Darstellung der Modelle zum Zinssatz, erfolgt keine vollständige Darstellung aller Sicherheiten-Modelle, sondern lediglich der Modelle, die eine explizite Aussage zur Höhe der Sicherheiten in Abhängigkeit von der Bonität tätigen. 
Zinsen in Kauf. Im weiteren Verlauf der Beziehung erkennen die Banken die Qualität und fordern hohe Sicherheiten um egoistisches Verhalten seitens des Kreditgebers zu verhindern.

Diese Ansätze unterstellen allerdings, dass entweder die Bank dem Kreditnehmer alternative Zins-Sicherheiten-Kombinationen zur Auswahl stellt oder der Kreditnehmer um die Signalling-Funktion weiß und von sich aus mehr Sicherheiten stellt. In dieser Reinform erscheint dies nicht praxisnah. Denkbar wäre es jedoch in der Form, dass die beiden Parteien im Rahmen der anfänglichen Kreditverhandlung die verschiedenen Möglichkeiten prüfen und die Bank bspw. zu Eingeständnissen bei dem Zinssatz bereit ist, wenn der Kunde mehr Sicherheiten stellt.

Auch in Bezug auf die Moral Hazard-Funktion ist zu berücksichtigen, dass bei einer gegebenen Bonität Zinsen und Sicherheiten nicht losgelöst voneinander festgelegt werden. So resultieren aus den Eigenkapitalanforderungen gemäß Basel II und den MaRisk Konsequenzen für Zinsen und Sicherheiten. Allerdings bleibt stets ein Ermessensspielraum bei dem Firmenkundenbetreuer bzw. der Marktfolge bestehen. Die Bank ist somit durchaus in der Lage, bei einem Kunden mehr Sicherheiten zu verlangen als dies durch ein mathematisches Kalkül unter Berücksichtung der verschiedenen Bestandteile des Zinssatzes, d.h. insbesondere der Deckung der Eigenkapital- und Standardrisikokosten als unternehmensabhängige Komponenten, notwendig wäre.

\subsubsection{Modelle zur Kreditverfügbarkeit}

\subsection{Beschreibung der Modelle zur Kreditverfügbarkeit}

Als weitere wesentliche Komponente im Rahmen der Kreditbeziehung soll die Kreditverfügbarkeit (,credit availability“) untersucht werden. Die meisten theoretischen Ansätze, die sich mit der Analyse der Vorteilhaftigkeit von Hausbankbeziehungen beschäftigen, tätigen auch Aussagen hinsichtlich der Kreditverfügbarkeit der Unternehmen.

STIGLITZ/WEISS verstehen unter Kreditrationierung die pauschale Ablehnung einiger Kreditanträge, obwohl es darunter auch potenzielle Kreditnehmer guter Qualität gibt, und obwohl diese bereit wären, höhere Zinsen zu zahlen und alle sonstigen Forderungen der Kreditgeber zu erfüllen. ${ }^{\text {.1 }}$ Der Begriff der Kreditrationierung kann vielfältig verwendet werden. Es ist denkbar, dass Kreditgeber nur begrenzte Refinanzierungsmöglichkeiten besitzen und deshalb ab einem bestimmten Kreditvolumen jeden weiteren Kreditantrag ungeachtet der festgestellten Qualität des Kreditnehmers ablehnen müssen. Ferner kann Kreditrationierung auch derart interpretiert werden, dass Kreditgeber potenzielle Kreditnehmer mit bestimmten negativen Qualitätsmerkmalen ablehnen. ${ }^{516}$

sis Vgl. Stiglitz/Weiss (1981), S. 393. Eine ausführliche Modelldarstellung findet sich bei Stiglitz/Weiss. Vgl. ausführlich Stiglitz/Weiss (1981), S. 404 ff. Vgl. für eine Modellzusammenfassung auch Hartmann-Wendels/Pfingsten/Weber (2007), S. 139.

516 Vgl. Hartmann-Wendels/Pfingsten/Weber (2007), S. 139. 
STIGLITZ/WEISS erklären, dass Marktfriktionen, wie bspw. Informationsasymmetrien und Agency-Kosten, dazu beitragen, dass Kapital nicht immer dem Unternehmen mit den besten Investitionsmöglichkeiten zur Verfügung gestellt wird und somit die Kreditverfügbarkeit für diese Unternehmen eingeschränkt wird. ${ }^{517}$ Die zentrale Annahme des Modells von STIGLITZ/WEISS ist hierbei, dass die Kreditgeber die Qualität der potenziellen Kreditnehmer nicht erkennen und das Verhalten der existierenden Kreditnehmer nicht überwachen können. ${ }^{518}$ Sie zeigen, dass der Zinssatz für eine ex ante äquivalente Gruppe von Kreditnehmern nicht nur die Kapitalnachfrage, sondern auch das Kreditnehmerrisiko des neuen Kreditportfolios bestimmt. ${ }^{519}$ Aufgrund der Informationsasymmetrie zieht ein höherer Zinssatz entweder risikoreichere Kreditnehmer (Adverse Selection-Effekt) an oder beeinflusst Kreditnehmer dahingehend, riskantere Investitionen durchzuführen (Moral Hazard-Effekt). ${ }^{520}$ Je riskanter die finanzierten Projekte sind, desto geringer ist der erwartete Ertrag der Bank aus dem Kreditgeschäft. ${ }^{521}$ Dieser negative Effekt auf den Ertrag des Kreditgebers kann den positiven Effekt der Zinserhöhung überwiegen. Wenn ein Zinsanstieg somit zu einem höheren durchschnittlichen Kreditnehmerrisiko führt, dann sollten Kreditgeber das Kreditvolumen reduzieren anstatt den Kreditzins zu erhöhen, um den Markt zu räumen. ${ }^{522}$ Das Modell von STIGLITZ/WEISS zeigt weiterhin, dass ein optimaler Zins für die Kreditgeber existieren kann, ab dem sich eine Zinserhöhung aufgrund von adverser Selektion oder Moral Hazard nicht mehr lohnt. Sobald dieser Zins erreicht ist, wird bzw. sollte ein Kreditgeber in dem betrachteten Modell keine Kredite mehr vergeben, obwohl es noch Kreditnehmer gibt, die bereit wären, höhere Zinsen zu zahlen, d.h. Kredite werden rationiert. ${ }^{523}$

Petersen/Rajan zeigen theoretisch, dass eine weitere Möglichkeit, das Problem zu lösen bzw. das Phänomen der Kreditrationierung zu umgehen, darin besteht, im Zeitablauf über die Kreditnehmerqualität zu lernen. ${ }^{524}$ In diesem Modell existieren annahmegemäß keine Sicherheiten, so dass aus der Sicherheitenstellung keine Rückschlüsse gezogen werden können. In Kapitel A.4.3.1.2 wurde das Modell hinsichtlich der Entwicklung der Zinsen im Zeitablauf der Beziehung betrachtet. Das Modell von PETERSEN/RAJAN kann auch in der Form interpretiert werden, dass sich bei einem geringen Wettbewerb die Kreditverfügbarkeit für intransparente Unternehmen generell erhöht, weil die Bank die Möglichkeit zur intertemporalen Ertragsverschiebung hat. ${ }^{25}$ Die Bank kann die Zinsen derart setzen, dass es in der ersten Periode nicht zu adverser Selektion und in Konsequenz zu Kreditrationierung kommt. In der zweiten Periode

\footnotetext{
517 Vgl. Stiglitz/Weiss (1981), S. 393.

518 Vgl. Hartmann-Wendels/Pfingsten/Weber (2007), S. 140.

519 Vgl. Stiglitz/Weiss (1981), S. 393.

$520 \quad$ Vgl. Stiglitz/Weiss (1981), S. 393.

521 Vgl. Stiglitz/Weiss (1981), S. 401.

522 Vgl. Stiglitz/Weiss (1981), S. 393.

523 Vgl. Stiglitz/Weiss (1981), S. 401 f.

524 Vgl. Petersen/Rajan (1995), S. 411. Eine Darstellung des Modells erfolgte in Kapitel A.4.3.1.2.1.

525 Vgl. Petersen/Rajan (1995), S. 411. Hinsichtlich der Interpretation in Bezug auf die Kreditverfügbarkeit vgl. Segbers (2007), S. 153.
} 
kann sie dann höhere Zinsen als die risikoadäquaten Zinsen, aber niedrigere als die Mischzinsen aus der ersten Periode fordern, so dass die Kreditverfügbarkeit nicht eingeschränkt wird. Wenn die Bank allerdings nicht in der Lage ist, die Verluste aus der ersten Periode durch Gewinne in der zweiten Periode zu kompensieren, wird es auch in diesem Modell zu Kreditrationierung kommen.

Die Modelle von Bester sowie von BESAnKo/ThaKor lösen das Problem, indem sie Kreditsicherheiten als Selektionskriterium oder Sorting-Device einfügen, um die Kreditnehmerqualität zu identifizieren. ${ }^{526}$ Wie zuvor im Kontext mit den Sicherheitenmodellen erwähnt, tritt gemäß BESTER das Phänomen der Kreditrationierung aufgrund von adverser Selektion nicht mehr auf, wenn Sicherheiten als Signalling-Mechanismen eingesetzt werden, denn die Kreditnehmer zahlen Kreditzinsen und stellen Sicherheiten, die ihrer Qualität entsprechen. ${ }^{527}$ In dem Modell von BESTER führt Sicherheitenstellung dazu, dass Kreditrationierungsprobleme verhindert oder beseitigt werden können. ${ }^{528}$

BooT betrachtet die Kreditverfügbarkeit im Kontext mit dem Hold Up-Problem und der Anzahl der Bankverbindungen. Je größer der Wert der Informationsbeschaffung für die einzelne Bank, je niedriger der Wettbewerb ist und je größer die Macht aus dem Informationsmonopol, desto größer ist die Kreditverfügbarkeit. ${ }^{529}$ Ein geringer Wettbewerb unter den Banken verbessert auf der einen Seite die Kreditverfügbarkeit, ermöglicht auf der anderen Seite das Entstehen des Hold Up-Problems. ${ }^{530}$ Auch in dem Modell von FISCHER wird gezeigt, dass Kreditrationierung durch eine Ex-PostMonopolmacht aufgrund eines Informationsvorsprungs der Hausbank überwunden werden kann. ${ }^{331}$

\subsection{Fazit zu den Modellen zur Kreditverfügbarkeit}

Im Hinblick auf die Kreditverfügbarkeit gibt es sowohl Modelle, die den Zusammenhang zur Sicherheitenstellung herstellen, als auch Modelle, die den Zusammenhang zur Monopolmacht der Bank abbilden. Es lässt sich resümieren, dass die Modelle zu übereinstimmenden Erkenntnissen kommen (vgl.Tab. A-9). Bei den Modellen von BESANKO/THAKOR und BESTER wird ein Zusammenhang zwischen Kreditverfügbarkeit und der Sicherheitenstellung untersucht. Beide kommen zu dem Ergebnis, dass die Kreditverfügbarkeit mit zunehmender Sicherheitenstellung steigt, da Sicherheiten als Sorting-Device verwendet werden, d.h. die in Kapitel A.4.3.1.3.1. beschriebene Sortierungsfunktion erfüllen. Ferner können die Zinsmodelle in der Regel auch als Modelle zur Kreditverfügbarkeit interpretiert werden. ${ }^{532}$ Bei diesen Modellen wird ein Zusam-

\footnotetext{
526 Vgl. Bester (1985), S. 854 und Besanko/Thakor (1987a), S. 671ff. Eine Modellinterpretation findet sich bei Machauer/Weber (1998), S. 1360.

Vgl. Bester (1985), S. 854.

Vgl. Bester (1985), S. 854.

Vgl. Boot (2000), S. 17.

Vgl. Boot (2000), S. 17.

Vgl. Fischer (1990), S. $36 \mathrm{ff}$.

Vgl. hierzu auch Kapitel A.4.3.1.2.2. 
menhang zur Monopolmacht der Bank hergestellt, da nur bei gegebener Monopolmacht ein intertemporaler Konditionenausgleich möglich ist. Wenn ein intertemporaler Konditionenausgleich der Bank umsetzbar ist, kann Kreditrationierung verhindert werden. Die Ursachen der Monopolmacht sind vielfältiger Natur. Neben dem Informationsvorsprung und der Ermangelung an Alternativen wäre es auch denkbar, dass der Kunde schlichtweg eine enge Bindung zur Bank hat. ${ }^{533}$

\begin{tabular}{|l|l|}
\hline Modelle & Kreditverfügbarkeit \\
\hline Besanko/Thakor (1987a) & Steigt mit zunehmender Sicherheitenstellung \\
\hline Bester (1985) & Steigt mit zunehmender Sicherheitenstellung \\
\hline Boot (1990) & Steigt mit zunehmender Monopolmacht \\
\hline Fischer (1990) & Steigt mit zunehmender Monopolmacht \\
\hline Petersen/Rajan (1995) & Steigt mit zunehmender Monopolmacht \\
\hline
\end{tabular}

Tab. A-9: Kreditverfügbarkeit im Rahmen der Bankbeziehung

\subsection{2 Überblick über den Stand der empirischen Forschung im Bereich des Relationship Banking}

\subsubsection{Allgemeiner Überblick über den Stand der empirischen Forschung und Darstellung der zentralen verwendeten Variablen}

Die bisher beschriebenen theoretischen Modelle dienen als Grundlage für den Großteil der empirischen Untersuchungen im Bereich des Relationship Banking. Bei den empirischen Untersuchungen bezüglich des Wertes von Bankbeziehungen lassen sich zwei Forschungsstränge unterscheiden. ${ }^{534}$ Zum einen gibt es Untersuchungen, die sich mit der Frage beschäftigen, inwiefern Banken wertvolle Informationen über die Kreditnehmer produzieren (Studies of „Bank uniqueness"). ${ }^{535}$ JAMES hat im Rahmen einer der ersten Event-Studie zu diesem Thema belegen können, dass die Verkündung des Abschlusses eines Bankkredites eine positive abnormale Aktienrendite am amerikanischen Aktienmarkt zur Folge hatte. ${ }^{536}$ Auch die anderen Studien haben unter anderem gezeigt, dass bereits die bloße Existenz von Bank-Unternehmens-Beziehungen zu einer Steigerung des Firmenwertes führt und die Ankündigung der Erneuerung oder Prolongation von bestehenden Kreditlinien häufig größere abnormale Marktrenditen erzielt als die Ankündigung von neu herausgegebenen Kreditlinien. ${ }^{537}$ Durch den Vergleich der Marktreaktion auf die Ankündigung bei bestehenden versus neuen Kun-

\footnotetext{
s33 Vgl. hierzu auch ausführlich Kapitel A.4.3.1.2.1.

534 Vgl. Berger/Udell (1995), S. 352.

s3s Vgl. James (1987), S. 217 ff., Lummer/McConnell (1989), S. 99 ff., James/Wier (1990), S. 149

ff., Wansley/Elayan/ Collins (1992), S. 2 ff., Shockley/Thakor (1997), S. 517 ff., Kwan (1994),

S. 2 ff., Billet/Flannery/Garfinkel (1995), S. $699 \mathrm{ff}$.

536 Vgl. James (1987), S. $217 \mathrm{ff}$.

${ }_{537}$ Vgl. Berger/Udell (1995), S. 352. 
denbeziehungen wird indirekt bewiesen, dass die Stärke der Bank-UnternehmensBeziehung einen Einfluss auf die Wertsteigerung hat. ${ }^{538}$

Der zweite Forschungsstrang im Bereich des Relationship Lending liefert direkte Untersuchungen über die Auswirkungen der Stärke einer Bankbeziehung in Bezug auf den Zinssatz, die Sicherheitenstellung oder die Kreditverfügbarkeit. ${ }^{539}$ Im Fokus dieser Studien stehen in der Regel kleine, nicht-börsennotierte Unternehmen, für welche die Bankbeziehung von hoher Relevanz ist. ${ }^{540}$ Grundlage für die folgenden Ausführungen ist im Wesentlichen dieser zweite Forschungsstrang. Innerhalb dieses zweiten Forschungsstranges kann differenziert werden nach den ,traditionellen“ Ansätzen sowie nach erweiterten Ansätzen. Letztere berücksichtigen neben den klassischen Variablen, welche u.a. aus den zuvor beschriebenen Modellen abgeleitet wurden, auch erste verhaltenswissenschaftliche Elemente. Da die Berücksichtigung der verhaltenswissenschaftlichen Elemente für diese Arbeit von zentraler Bedeutung ist, erfolgt eine separate Darstellung dieser erweiterten Ansätze in den Kapiteln A.4.3.2.5.2 bis A.4.3.2.5.4. Aufgrund der Heterogenität der Ergebnisse in den verschiedenen Studien liegt der Fokus nicht allein auf der Darstellung derselbigen, sondern auf den verschiedenen Operationalisierungsansätzen sowie den gelieferten Interpretationen. Diese Erkenntnisse bilden eine wesentliche Grundlage für die vorzunehmende Operationalisierung in der vorliegenden Studie.

Im Rahmen der bestehenden empirischen Untersuchungen wird die Stärke der Bankbeziehung insbesondere anhand von zwei Dimensionen gemessen; zum einen an der „Zeitdauer" und zum anderen an dem "Scope“. ${ }^{541}$ Die Bedeutung der Beziehung hängt annahmegemäß von der Länge oder der Dauer der Interaktion zwischen dem Kunden und der Bank ab. ${ }^{542}$ RAJAN erläutert, dass ,relationships may evolve in situations where explicit contracts are inadequate, but a long term interaction between parties is mutually beneficial." ${ }^{433}$ Die Fähigkeit für eine bestehende Bank, eine Beziehung aufrecht zu erhalten, hängt vom Preis und von der Qualität der angebotenen Dienstleistungen ab sowie der Qualität des Kunden und dem Wettbewerbsumfeld, in dem die Bank agiert. ${ }^{54}$ Auf der einen Seite kann es sein, dass eine Bank zwecks Attrahierung von Kunden Zinssätze unterhalb der Kostenschwelle anbietet, in der Hoffnung, vom gleichen Kunden später höhere Zinsen einfordern zu können. Auf der anderen Seite ist ein Unternehmen ggf. bereit, anfänglich höhere Zinssätze zu zahlen, wenn eine langfristige Beziehung auf Dauer niedrige Zinsen verspricht. Daraus ergibt sich die Integration der Dauer der Beziehung in die Untersuchung. Die Bank könnte aber auch niedrige Zinssätze verlangen, in der Annahme die Verluste dadurch auszugleichen, dass die Kunden andere Bankdienstleistungen in Anspruch nehmen. Damit wird die Bedeutung

Vgl. Petersen/Rajan (1994), S. 3 ff., Petersen/Rajan (1995), S. 407 ff., Berger/Udell (1995), S.

$351 \mathrm{ff}$., Degryse/Van Cayseele (2000), S. $90 \mathrm{ff}$.

540 Vgl. Berger/Udell (1995), S. 353.

541 Vgl. Ongena/Smith (2000a), S. 224.

542 Vgl. Ongena/Smith (2000a), S. 224.

543 Rajan (1996), S. 118.

544 Vgl. hier und im Folgenden Ongena/Smith (2000a), S. 235. 
der zweiten Dimension, dem „Scope“ erklärt, worunter die Breite der Dienstleistungen zu subsumieren ist, die der Kunde bei der Bank in Anspruch nimmt. Ferner entsteht durch eine umfangreiche Nutzung der Bankprodukte für die Bank eine größere Möglichkeit zur Informationsproduktion.

Darüber hinaus wird die Bankbeziehung durch eine Vielzahl von externen Faktoren beeinflusst, wie z.B. dem Wettbewerbsumfeld der Banken, dem Entwicklungsstand des Anleihenmarktes, der Art der Regulierung, denen der Investor gegenübersteht, sowie dem Grad der technologischen Entwicklung. ${ }^{545}$ Die wichtigsten Parameter sollen im Folgenden kurz erläutert werden, um anschließend deren Einfluss in den empirischen Studien bezüglich des Kreditzinses, der Sicherheiten und der Kreditverfügbarkeit darzustellen.

\section{Dauer der Bankbeziehung}

Mit steigender Dauer der Bankbeziehung hat die Bank die Möglichkeit, den Kreditnehmer zu beobachten und private Informationen über den Kunden zu generieren. Je länger das Unternehmen bereits in der Vergangenheit Kredite bedient hat, desto größer ist die Wahrscheinlichkeit, dass das Unternehmen überlebensfähig und der Unternehmer vertrauenswürdig ist. ${ }^{546}$ Die Dauer der Bankbeziehung wird somit als Indikator für die Vertrauenswürdigkeit des Unternehmens verwendet. Ausgehend von den Erfahrungen mit dem Unternehmen in der Vergangenheit, erwartet der Kreditgeber, dass die Kredite nun weniger risikobehaftet sind. Dies sollte die Kreditkosten reduzieren und die Kreditverfügbarkeit erhöhen. ${ }^{547}$ Die Dauer der Bankbeziehung dient ferner als Proxy für den zunehmenden Informationsstand mit zunehmender Zeit und somit für die Präzision, mit der die Bank die Qualität des Kreditnehmers beurteilen kann, ${ }^{548}$ und als Proxy für die Möglichkeit, dass das Unternehmen dem Lock-In-Effekt unterliegt und die Bank nicht wechseln kann. ${ }^{549}$

\section{Alter des Unternehmens}

Wenn hinreichende Informationen generiert werden, indem die Interaktion des Kreditnehmers mit anderen Unternehmen oder Personen, wie Angestellten oder anderen Kreditnehmern beobachtet werden, dann ist anstelle der Dauer der Beziehung das Alter des Unternehmens die entscheidende Variable. ${ }^{550}$ Das Alter des Unternehmens

\footnotetext{
545 Vgl. Ongena/Smith (2000a), S. 225.

546 Vgl. Petersen/Rajan (1994), S. 5.

547 Zur Berücksichtigung der Dauer der Bankbeziehung in bestehenden Studien vgl. Petersen/Rajan (1994), S. 27, Petersen/Rajan (1995), S. 428, Harhoff/Körting (1998), S. 1346 f., Uzzi/Gillespie (2002), S. 607 f., Machauer (1999), S. 189, Angelini/Di Salvo/Ferri (1998), S. 944 f., Cole (1998), S. 974 f., Uzzi (1999), S. 497, Cole/Goldberg/White (2001), S. 44 f., Lehmann/Neuberger (2001), S. 352, Petersen/Rajan (2002), S. 2564 oder Scott/Dunkelberg (2003), S. 1010 f.

$548 \mathrm{Vgl}$. Harhoff/Körting (1998a), S. 10.

549 Vgl. Degryse/Van Cayseele (2000), S. 97.

sso Vgl. Petersen/Rajan (1994), S. 6.
} 
spiegelt den Umfang der im Markt verfügbaren Informationen wider, ${ }^{551}$ wohingegen die Dauer der Beziehung als Indikator für den Umfang der privaten Informationen dient, die dem potenziellen Kreditgeber zur Verfügung stehen. ${ }^{552}$ Dadurch wird der Unterschied hervorgehoben, welche Informationen als Ergebnis der Reputation und welche Informationen als Ergebnis des Monitoring-Prozesses generiert werden. ${ }^{553}$ Das Alter der Firmen sollte somit beeinflussen, ob Unternehmen einen Kredit erhalten. Denn Unternehmen, die bereits seit mehreren Jahren im Geschäft sind, haben gezeigt, dass sie in der Lage sind, die Start-Up-Periode zu überleben, und haben ReputationsEffekte generiert. ${ }^{554}$

\section{Scope}

Die Stärke einer Bankbeziehung kann darüber hinaus durch den Scope gemessen werden, wobei selbiger definiert wird als die Breite der Dienstleistungen, die durch die Bank angeboten und vom Kunden genutzt werden. ${ }^{555}$ Im US-amerikanischen Trennbankensystem können die Dienstleistungen einer Bank neben der Kreditvergabe ebenso Einlagen, Zahlungsverkehrsabwicklung, Cash Management-Dienstleistungen und Währungsgeschäfte umfassen. In Ländern mit Universalbanksystemen sowie durch Holding-Unternehmen auch in den USA kann eine Bank darüber hinaus auch Investment Banking, Brokerage, Versicherungen und sonstige Finanzdienstleistungen anbieten. ${ }^{566}$ Der Einsatz dieser Produkte gibt einer Bank die Möglichkeit, zusätzliche Informationen über das Unternehmen zu sammeln, z.B. über die Fähigkeit, Tilgungen pünktlich zu zahlen. ${ }^{557}$ So können aus dem Zahlungsverkehrskonto Informationen über die Unternehmensumsätze oder aus einem Factoring-Geschäft Informationen über die ausstehenden Forderungen generiert werden. ${ }^{558}$ Ein einfacher Zugang zu Informationen über Zahlungsverkehrskonten gibt der Bank einen einzigartigen Vorteil bei der Kreditüberwachung. ${ }^{559}$ Die Bank, die den Großteil der Zahlungsverkehrsleistungen durchführt, kann daraus ein adäquates und verlässliches Bild von den operativen und finanziellen Aktivitäten des Unternehmens erstellen, worauf sie dann bei aktuellen und zukünftigen Kreditentscheidungen zurückgreifen kann. ${ }^{560}$ Ferner wird erst durch die

Zur Berücksichtigung des Alters des Unternehmens in bestehenden Studien vgl. Petersen/Rajan (1994), S. 27, Petersen/Rajan (1995), S. 428, Fischer (2000), S. 41, Harhoff/Körting (1998), S. 1346 f., Uzzi/Gillespie (2002), S. 607 f., Angelini/Di Salvo/Ferri (1998), S. 944 f., Cole (1998), S. 974 f., Uzzi (1999), S. 497, Cole/Goldberg/White (2001), S. 44 f., Lehmann/Neuberger (2001), S. 352, Petersen/Rajan (2002), S. 2564 oder Scott/Dunkelberg (2003), S. 1010 f. „Dauer der Bankbeziehung“ korrespondiert somit mit der Unterscheidung zwischen Reputation und Monitoring bei Diamond. Vgl. Diamond (1991), S. $689 \mathrm{ff}$.

Vgl. Cole (1998), S. 963.

Vgl. Diamond (1991), S. 689 ff. oder Cole (1998), S. 963.

Vgl. Ongena/Smith (2000a), S. 239.

Vgl. Ongena/Smith (2000a), S. 239.

Vgl. Ongena/Smith (2000a), S. 239.

Vgl. Petersen/Rajan (1994), S. 6.

Vgl. Degryse/Van Cayseele (2000), S. 92.

Vgl. Ongena/Smith (2000a), S. 239. 
Nutzung verschiedener Produkte die Grundlage geschaffen, Preise über die verschiedenen Produkte zu kalkulieren (Quersubventionierung). Daraus lassen sich zwei zentrale Größen für die empirischen Studien ableiten: Anteil am Zahlungsverkehr des Kunden und Anteil an der gesamten Bankfinanzierung des Kunden. Beide Größen dienen als Indikator für den Umfang der privaten Informationen, welche die Bank generiert.

Während der Aspekt der besseren Informationsqualität und -breite sowohl zu niedrigeren Zinsen als auch zu einer besseren Kreditverfügbarkeit führen kann, wirkt die Möglichkeit der Quersubventionierung in aller Regel nur zinsreduzierend. ${ }^{561}$ Bei der Quersubventionierung ist es allerdings auch denkbar, dass die Kreditzinsen steigen bzw. unverändert bleiben und andere Produkte günstigere Konditionen erhalten. In den meisten Studien wird aber von einem zinsreduzierenden Effekt ausgegangen. Ein breiter Scope sollte somit zu niedrigeren Zinsen und zu einer besseren Kreditverfügbarkeit führen. ${ }^{562}$

\section{Anzahl der Bankverbindungen}

Unternehmen konzentrieren ggf. ihre Kredite bei einem Kreditgeber, um die gesamten Monitoring-Kosten zu reduzieren, die Kontrolle des Kreditgebers zu verbessern und die Beziehung zu festigen. ${ }^{563}$ Daraus können sich Effekte in Bezug auf den Zinssatz ergeben. Angesichts der Hold Up-Kosten ist die Beziehung zu einer einzigen Bank häufig nicht optimal. ${ }^{54}$ Ein Unternehmen kann durch Wettbewerb zwischen den Banken erreichen, dass die bestehende Bank keine Monopolrenten extrahiert. Der Wettbewerb kann aber auch dazu führen, dass die Renten soweit reduziert werden, dass es sich für keine Bank mehr lohnt, einen Kredit zu vergeben. PETERSEN/RAJAN haben in ihrem Modell den Zusammenhang zwischen der Kreditaufnahmemöglichkeit eines Unternehmens und der Marktmacht der Bank abgebildet. ${ }^{555}$ Der Grad der Abhängigkeit eines Unternehmens von seinem potenziellen Kreditgeber als Quelle von Finanzdienstleistungen sollte beeinflussen, inwiefern das Unternehmen einen Kredit erhält. ${ }^{566}$ Die Anzahl der Bankverbindungen wirkt sich somit nicht nur auf die Höhe der Kreditzinsen, sondern auch auf die Kreditverfügbarkeit aus. ${ }^{567}$

\footnotetext{
s61 Vgl. Petersen/Rajan (1994), S. 6.

562 Vgl. Degryse/Van Cayseele (2000), S. 92. Zur Berücksichtigung des Scopes in bestehenden Studien vgl. auch Petersen/Rajan (1994), S. 27, Uzzi/Gillespie (2002), S. 607 f., Cole (1998), S. 971 ff., Uzzi (1999), S. 497, Cole/Goldberg/White (2001), S. 44 f.

563 Vgl. Petersen/Rajan (1994), S. 16.

564 Vgl. Ongena/Smith (2000a), S. 246 f.

565 Vgl. Petersen/Rajan (1994), S. 16.

566 Vgl. Cole (1998), S. 963.

567 Zur Analyse der Auswirkungen der Anzahl der Bankverbindlichkeiten auf die Kreditverfügbarkeit vgl. auch Petersen/Rajan (1995), S. 428, Harhoff/Körting (1998), S. 1346 f., Uzzi/Gillespie (2002), S. 607 f., Machauer (1999), S. 189, Angelini/Di Salvo/Ferri (1998), S. 944 f., Cole (1998), S. 971 ff., Uzzi (1999), S. 497, Cole/Goldberg/White (2001), S. 44 f., Petersen/Rajan (2002), S. 2564 oder Scott/Dunkelberg (2003), S. 1010 f. 


\section{Marktkonzentration}

Mit Hilfe der Variablen „Marktkonzentration“ wird untersucht, inwiefern eine Bank den Bankenmarkt in einer bestimmten Region dominiert. ${ }^{568}$ Dieser Parameter ist eng mit der Anzahl der Bankverbindungen einer einzelnen Firma verbunden, denn je gröBer die Konzentration auf Marktniveau ist, desto weniger Alternativen bestehen für das Unternehmen. Der Umkehrschluss, dass eine geringe Marktkonzentration zu einer größeren Anzahl an Bankverbindungen je Unternehmen führt, ist allerdings nicht zulässig. Inwiefern eine Bank die Kosteneinsparungen aufgrund verbesserter Informationen an die Kunden weitergibt, hängt vom Wettbewerb im relevanten Kreditmarkt $a b .{ }^{569}$ Der Wettbewerb wird zum einen von der Anzahl der potenziellen Kreditgeber und zum anderen vom Informationsstand derselben beeinflusst. ${ }^{570}$ Wenn die generierten Informationen durch potenzielle neue Kreditgeber verifiziert werden können, dann stehen sie auf gleicher Stufe und unmittelbar im Wettbewerb mit dem aktuellen Kreditgeber. Wenn die Informationen nicht beobachtet werden können, dann hat der aktuelle Kreditgeber ein Informationsmonopol über das Unternehmen. Die Informationsasymmetrien bestehen sowohl zwischen den Banken untereinander als auch zwischen den Banken und dem Kunden. Während die Informationsasymmetrie zwischen Kunde und Inside-Bank primär Ausdruck für das Risiko der Inside-Bank ist und sich somit bspw. in einem Risikoaufschlag der Bank widerspiegelt, so wirkt die Informationsasymmetrie zwischen Inside- und Outside-Bank u.a. auf die Macht der Inside-Bank hinsichtlich der Konditionengestaltung. ${ }^{571}$

\section{Sicherheitenstellung}

Bei asymmetrischer Informationsverteilung besteht die Rolle von Sicherheiten in einem Kreditvertrag in der Signalling-Funktion zur Beseitigung von Adverse SelectionProblemen und in der Anreizwirkung zur Beseitigung von Moral Hazard-Problemen. ${ }^{572}$ Die Variable Sicherheitenstellung fungiert in den Untersuchungen sowohl als abhängige Variable als auch als unabhängige Variable für die Untersuchung des Zinssatzes und der Kreditverfügbarkeit.

\section{Finanzielle Charakteristika}

In vielen Studien werden die finanziellen Charakteristika des Unternehmens herangezogen, um das beobachtbare Risiko des Unternehmens als Einflussgröße zu berücksichtigen. ${ }^{573}$ Es wird erwartet, dass risikoreichere Kreditnehmer höhere Zinsen zu zahlen haben und einen indefiniten Einfluss auf die Sicherheitenstellung haben. Der Einfluss ist indefinit, da je nach zugrunde liegender Modellannahme, gute Kreditnehmer mehr oder weniger Sicherheiten stellen als schlechte Kreditnehmer. Als Beispiele für 
die Berücksichtigung des Risikos sind hier zu nennen: Verschuldungsgrad, Liquidität 3. Grades, Forderungsumschlagshäufigkeit, Vorratsumschlagshäufigkeit, Kreditorenumschlag, Bilanzsumme ${ }^{574}$, Zinsdeckung ${ }^{575}$, Eigenkapitalquote. ${ }^{576}$ COLE verwendet darüber hinaus Messgrößen zur Beurteilung der Kreditwürdigkeit, z.B. Überziehungen des Unternehmens und Überziehungen des Haupteigentümers. ${ }^{577}$

Zudem findet man in den meisten Studien Variablen zur Rechtsform und zu den Eigentümerstrukturen, da erwartet wird, dass sich hier Unterschiede ergeben hinsichtlich der Fähigkeit des Kreditnehmers, das Risiko auf die Bank zu verlagern, und hinsichtlich des Umfangs an Informationen, die der Bank vorliegen. ${ }^{578}$ Die unterschiedlichen Rechtsformen, d.h. insbesondere die Unterscheidung zwischen Kapital- und Personengesellschaft, beeinflussen den Grad der Haftung des Unternehmers und sollten sich aus diesem Grund unmittelbar auf die Sicherheitenstellung auswirken. Ferner beeinflusst die Rechtsform die Kapitalstruktur der Unternehmen und somit auch die Bonität des Unternehmens, sofern selbige ausschließlich auf Basis der Finanzkennzahlen des Unternehmens gemessen wird. Da bei Personengesellschaften eine Verlagerung von Vermögen aus dem Unternehmen in die Privatsphäre erfolgen kann, können hier Ungenauigkeiten bei isolierter Betrachtung des Unternehmens erfolgen. Abgesehen von einigen Ausnahmen gelten die Veröffentlichungspflichten gemäß HGB ausschließlich für Kapitalgesellschaften. ${ }^{579}$ Unter anderem aus diesem Grund ist der Umfang an öffentlich verfügbaren Informationen bei Kapitalgesellschaften größer. Schließlich resultieren möglicherweise indirekte Effekte daraus, dass Kapitalgesellschaften in aller Regel größer sind als Personengesellschaften und deshalb eine größere Verhandlungsmacht als Personengesellschaften haben. ${ }^{580}$ Diese Unterschiede sollten sich auf Zinssatz, Sicherheitenstellung und Kreditverfügbarkeit auswirken.

Zusammenfassend lässt sich feststellen, dass in den Studien sowohl marktbezogene (z.B. Marktkonzentration) als auch unternehmensbezogene (z.B. Alter des Unternehmens) und beziehungsbezogene (z.B. Dauer der Geschäftsbeziehung) Variablen eine Rolle in der Kreditbeziehung spielen. Im Folgenden sollen die Auswirkungen der zentralen, zuvor vorgestellten Variablen sowie einzelner weiterer Variablen in Bezug auf die abhängigen Variablen Zinssatz, Sicherheitenstellung und Kreditverfügbarkeit konkret untersucht werden.

\footnotetext{
$574 \quad$ Vgl. Berger/Udell (1995), S. 359.

575 Vgl. Petersen/Rajan (1994), S. 12.

576 Vgl. Cole (1998), S. 964.

577 Vgl. Cole (1998), S. 964 sowie ebenda FN 6: "More specifically, survey respondents were asked the following two questions: (1) Within the past three years, on how many different personal obligations has the Prinzipal owner been 60 or more days delinquent? (2) Within the past three years, on how many different business obligations has the firm been 60 or more days delinquent?"

578 Vgl. Berger/Udell (1995), S. 359.

579 Vgl. HGB (2004), § $325 \mathrm{ff}$. Zur Anwendung auf bestimmte offene Handelsgesellschaften und Kommanditgesellschaften vgl. HGB $\S 264 a$. 


\subsubsection{Zinssatz}

Der Zinssatz ist in den meisten Studien zum Relationship Banking zentraler Uutersuchungsgegenstand. Hinsichtlich der Operationalisierung lassen sich hier zwei Ansätze unterscheiden. Während einige Studien auf den Zinssatz für Darlehen zurückgreifen, z.B. Petersen/Rajan, Degryse/VAn Cayseele und Lehmann/Neuberger, verwenden andere Studien den Zinssatz für die Kreditlinie bzw. für Kontokorrentkredite, z.B. Berger/Udell, ANGelini/Di Salvo/Ferri, Harhoff/KöRTING und ElSAS/KRAHNEN. ${ }^{581}$

\section{Dauer der Bankbeziehung}

PETERSEN/RAJAN finden heraus, dass die berichtete Dauer der Bankbeziehung keinen signifikanten Einfluss auf den Zinssatz hat. ${ }^{582}$ Sie verwenden den Zinssatz für das zuletzt gewährte Darlehen als abhängige Größe. ${ }^{583}$ Auch bei den deutschen Studien kommen HARHOFF/ KÖRTING sowie ELSAS/KRAHNEN zu dem Ergebnis, dass kein signifikanter Zusammenhang zwischen der Dauer der Bankbeziehung und dem Zinssatz besteht. ${ }^{584}$ PETERSEN/RAJAN führen folgende Gründe für den fehlenden Zusammenhang zwischen der Dauer der Bankbeziehung und dem Zinssatz an. Die Beziehung als solche ist nicht von Relevanz, da alle Informationen öffentlich oder zumindest nachweisbar sind. Wenn eine Outside-Bank das Kreditrisiko genauso gut beurteilen kann wie der Relationship Lender, d.h. dem Kreditgeber, der aktuell in einer Relationship Banking-Beziehung zum Kunden steht, dann hat die spezifische Beziehung keinen Wert. ${ }^{585}$ Ein zweiter Erklärungsansatz besteht darin, dass für kreditrationierte Unternehmen eine höhere Kreditverfügbarkeit von größerer Relevanz als niedrigere Zinsen sei. Schließlich ist es ebenso denkbar, dass der Kreditgeber durch die Marktkräfte nicht dazu gezwungen wird, die Vorteile durch günstigere Zinsen auf die Kunden zu übertragen. ${ }^{586}$

Berger/Udell, die den gleichen Datensatz wie Petersen/Rajan verwenden, führen den fehlenden Zusammenhang zwischen der Dauer der Beziehung und dem Zinssatz bei der Untersuchung von PETERSEN/RAJAN darauf zurück, dass selbige den Darlehenszins anstelle des Zinssatzes für Kreditlinien verwendet haben. ${ }^{577}$ In ihrer Studie zeigen BERGER/UDELL, dass der Zinssatz im Zeitablauf der Beziehung bzw. mit zu-

581 Vgl. Petersen/Rajan (1994), S. 12 f., Petersen/Rajan (1995), S. 436, Degryse/Van Cayseele (1998), S. 12, Degryse/Van Cayseele (2000), S. 100, Lehmann/Neuberger (2001), S. 350, Berger/Udell (1995), S. 364, Angelini/Di Salvo/Ferri (1998), S. 937 f., Harhoff/Körting (1998b), S. 1342 und Elsas/Krahnen (1998), S. 1302. Eine ausführliche Diskussion hinsichtlich einer geeigneten Operationalisierung erfolgt in Kapitel B.3.4.1.

582 Vgl. Petersen/Rajan (1994), S. 12.

583 Vgl. Petersen/Rajan (1994), S. 12.

584 Vgl. Elsas/Krahnen (1998), S. 1302.

585 Vgl. Petersen/Rajan (1994), S. 18.

586 Vgl. Petersen/Rajan (1994), S. 18.

587 Vgl. Berger/Udell (1995), S. 353. 
nehmender Dauer der Bankbeziehung sinkt. ${ }^{588}$ Ebenso finden BLACKWELL/WINTERS heraus, dass längere Bankbeziehungen zu geringeren Zinssätzen führen. ${ }^{589}$ Sie begründen dies damit, dass im Laufe der Bankbeziehung wichtige private Informationen generiert werden und trotz des Informationsvorsprungs gegenüber den Outside-Banken die Inside-Banken die Preise nicht setzen, als ob eine Monopolstellung bestehen würde. ${ }^{590}$ Durch die Fokussierung auf Kreditlinien werden gemäß BERGER/UdELL die Kredite aus der Analyse ausgeschlossen, die eher transaktions- statt beziehungsgetrieben sind, so dass eine Verwässerung der „Relationship Lending“Ergebnisse vermieden wird. ${ }^{591}$ So haben PETERSEN/RAJAN bspw. Hypothekendarlehen und Darlehen für Maschinen oder Fahrzeuge mit in die Untersuchung aufgenommen. Die Ergebnisse von BERGER/UdELl bestätigen somit die theoretischen Modelle von PETERSEN/RAJAN und von BOOT/THAKOR. ${ }^{592}$ Der nicht nur statistisch, sondern auch ökonomisch signifikante Effekt der Beziehungsdauer auf den Zinssatz bestätigt die These, dass die privaten Informationen, die im Laufe der Beziehung generiert werden und nur dem spezifischen Kreditgeber aufgrund von Monitoring zur Verfügung stehen, eine wesentliche Rolle spielen. ${ }^{593}$ Erschwerend bei der empirischen Analyse des Einflusses einer bestehenden Bankbeziehung auf den Zins ist der Umstand, dass es sich um eine kombinierte Untersuchung der nachstehenden Sachverhalte handelt: ${ }^{594}$

- inwiefern kann der Kreditgeber wertvolle Informationen aus Kreditbeziehungen sammeln,

- inwiefern berücksichtigt selbiger die Informationen bei der Kreditbepreisung und

- inwiefern werden die Informationen bei der Zinssetzung für die beobachteten Kredite und nicht bei anderen Krediten des Kunden bei der Bank berücksichtigt.

Dies mag mit ein Grund sein, weshalb HARHOFF/KÖRTING, obwohl sie ebenso wie BERGER/UDELL den Zinssatz für die Kreditlinien verwenden, keinen Zusammenhang nachweisen können. ${ }^{995}$ Zwar handelt es sich bei dem Zinssatz für Kreditlinien in Deutschland typischerweise um einen festen Zinssatz, die Preiskonditionen können allerdings in relativ kurzen Zeiträumen (wie z.B. 3 Monaten) neu verhandelt werden. ${ }^{596}$

Für eine Studie im belgischen Markt finden DEGRYSE/VAN CAYSEELE sogar einen positiven Zusammenhang zwischen der Dauer der Bankbeziehung und dem Zinssatz, hier dem Zinssatz für Darlehen, was darauf hindeutet, dass die untersuchte Bank in der

\footnotetext{
588 Vgl. Berger/Udell (1995), S. 353. Die Dauer der Bankbeziehung wird auf 30 Jahre limitiert, da sie davon ausgehen, dass nach 30 Jahren keine zusätzlichen Informationen generiert werden.

589 Vgl. Blackwell/Winters (1997), S. 283.

$590 \quad$ Vgl. Berger/Udell (1995), S. 353.

591 Vgl. Berger/Udell (1995), S. 353.

592 Vgl. Berger/Udell (1995), S. 353. Vgl. hierzu auch Kapitel A.4.3.1.2.1 und A.4.3.1.2.2.

593 Vgl. Berger/Udell (1995), S. 367.

$594 \quad$ Vgl. Berger/Udell (1995), S. 362.

595 Vgl. Harhoff/Körting (1998a), S. 16.

596 Vgl. Harhoff/Körting (1998a), S. 16. 
Lage ist, Monopolrenten zu extrahieren, und diese Situation auch ausnutzt. ${ }^{597}$ Bezüglich des Kreditzinssatzes verwenden sie den Zinssatz bis zur nächsten Zinsanpassung. Für Kredite mit festem Zinssatz ist der nächste Zinsanpassungstermin das Kreditablaufdatum bzw. das Ende der Zinsbindung. ${ }^{598}$ Für den italienischen Markt finden ANGELINI/DI SALVO/FERRI zwar ebenfalls einen positiven, allerdings nicht signifikanten Zusammenhang zwischen der Dauer der Bankbeziehung und dem Zinssatz. ${ }^{599}$ Ebenso wie BERGER/UDELL rekurrieren sie auf den Zinssatz für die Kreditlinie. ${ }^{600}$ Der positive Zusammenhang entspricht somit den Erkenntnissen aus dem theoretischen Modell von GREENBAUM/KANATAS/VENEZIA. ${ }^{601}$

\section{Alter}

PETERSEN/RAJAN stellen fest, dass das Unternehmensalter die wichtigste explanatorische Variable in Bezug auf Darlehenszinsen ist, wobei ältere Firmen günstigere Zinsen erhalten. ${ }^{602}$ Somit ist der Umfang der öffentlich verfügbaren Informationen von zentraler Bedeutung. Ebenso zeigen DEGRYSE/VAN CAYSEELE für den belgischen Markt, dass der Zinssatz mit zunehmendem Unternehmensalter sinkt. ${ }^{603} \mathrm{Da}$ der Koeffizient für die Dauer der Bankbeziehung größer ist als der Koeffizient für das Unternehmensalter, schlussfolgern sie, dass der Effekt der privaten Informationen, ausgedrückt in der Dauer der Bankbeziehung, den Aspekt der öffentlichen Informationen, ausgedrückt im Unternehmensalter, dominiert. ${ }^{604}$ Auch bei HARHOFF/KÖRTING und bei ANGELINI/DI SALVO/FERRI hat das Unternehmensalter einen negativen Effekt, jedoch ist selbiger bei Letzteren nicht signifikant. ${ }^{605}$

BERGER/UDELL haben den Zeitraum, seit dem sich das Unternehmen im Besitz des aktuellen Eigentümers befindet, untersucht und kommen zu dem Ergebnis, dass ein zinsreduzierender Einfluss besteht, wenngleich auch dieser Effekt statistisch nicht signifikant ist. Sie leiten daraus ab, dass die Reputation oder öffentlich zugängliche Informationen ebenfalls eine Rolle spielen und zu einer Zinsreduktion führen. ${ }^{606}$

597 Vgl. Degryse/Van Cayseele (2000), S. 99. Die Datenbasis von Degryse/Van Cayseele umfasst ca. 18.000 Datensätze von einer belgischen Bank. In den anderen zitierten Studien sind stets Datensätze von mehreren Banken enthalten.

Vgl. Angelini/Di Salvo/Ferri (1998), S. 941.

Vgl. Angelini/Di Salvo/Ferri (1998), S. 936.

Vgl. Angelini/Di Salvo/Ferri (1998), S. 941. Zur Darstellung des Modells von Greenbaum/Kanatas/Venezia vgl. Kapitel A.4.3.1.2.1. Interessant wäre der Vergleich der verschiedenen Studien, wenn die Konkurrenzsituation jeweils herausgerechnet werden könnte, um zu erkennen, inwiefern das unterschiedliche Zinssetzungsverhalten aus der Wettbewerbssituation resultiert.

${ }_{602}$ Vgl. Petersen/Rajan (1994), S. 14.

${ }_{603}$ Vgl. Degryse/Van Cayseele (2000), S. 102.

604 Vgl. Degryse/Van Cayseele (2000), S. 102.

cos Vgl. Harhoff/Körting (1998a), S. 146 und Angelini/Di Salvo/Ferri (1998), S. 940.

${ }_{606}$ Vgl. Berger/Udell (1995), S. 367. 


\section{Scope}

Für den belgischen Markt zeigen DEGRYSE/VAN CAYSEELE, dass die Inanspruchnahme von Dienstleistungen der Bank, die in einem hohen Maße informationsabhängig sind, die Zinskosten senkt. ${ }^{607}$ Diese Form der Stärke der Bankbeziehung wird bei ihnen allerdings allein dadurch gemessen, dass die Bank sich als Hauptbank des Unternehmens einstuft. Die Einstufung erfolgt in Abhängigkeit von einem absoluten Kontoumsatz sowie der Eigenschaft, dass der Kunde mindestens zwei Produkte von der Bank gekauft hat. ${ }^{.08}$ Diese Einstufung ist allerdings insofern kritisch zu betrachten, als dass der Unterhalt von Darlehenskonten bei der Bank andere Informationen preis gibt als Zahlungsverkehrskonten, Versicherungen oder Vermögensanlageberatung.

Währenddessen können PETERSEN/RAJAN allerdings keinen Zusammenhang herstellen zwischen dem Umstand, dass ein Unternehmen Einlagen bei der Bank unterhält oder sonstige Bankdienstleistungen in Anspruch nimmt auf der einen und dem Zinssatz auf der anderen Seite. ${ }^{609}$ Auch BLACKWELL/WINTERS, ElSAS und SCOTT/DUNKELBERG können keinen Zusammenhang zwischen der Inanspruchnahme weiterer Dienstleistungen und dem Zinssatz herstellen. ${ }^{.10}$

Interessant für die vorliegende Studie ist ferner das Ergebnis von ANGELINI/DI SALVO/FERRI, dass Mitglieder von Genossenschaftsbanken günstigere Kredite erhalten als Nicht-Mitglieder. ${ }^{611}$ Zwar handelt es sich bei der Mitgliedschaft bzw. dem Erwerb der erforderlichen Genossenschaftsanteile um ein Produkt, hierbei ist aber weniger der Aspekt der Informationsgenerierung aus der Produktnutzung von Relevanz, sondern vielmehr die Geschäftspolitik der Bank, die hinsichtlich der Kunden nach Mitgliedern und Nicht-Mitgliedern differenziert.

\section{Anzahl der Bankverbindungen}

PETERSEN/RAJAN weisen nach, dass Unternehmen mit mehreren Bankverbindungen höhere Zinsen zahlen müssen als Unternehmen mit nur einer Bankverbindung. ${ }^{612}$ Eine mögliche Interpretation besteht darin, dass Unternehmen schlechter Qualität beim ersten Kreditgeber keine weiteren Kredite mehr bekommen und deswegen andere Banken zwecks Kreditaufnahme kontaktieren müssen. ${ }^{613} \mathrm{Zwar}$ führt die höhere Anzahl von Bankverbindungen zu einer Reduktion der Hold Up-Gefahr. Aus einer größeren Anzahl an Bankverbindungen resultiert aber gleichzeitig die Gefahr, dass der Wert der Informationsbeschaffung für die einzelne Bank sinkt und der Wettbewerb ex post zu

Vgl. Degryse/Van Cayseele (2000), S. 102.

Vgl. Degryse/Van Cayseele (2000), S. 97.

Vgl. Petersen/Rajan (1994), S. 16.

Vgl. Blackwell/Winters (1997), S. 283, Elsas (2001), S. 264 und Scott/Dunkelberg (2003), S. $1010 \mathrm{f}$.

611 Vgl. Angelini/Di Salvo/Ferri (1998), S. 940.

612 Vgl. Petersen/Rajan (1994), S. 16.

613 Vgl. Petersen/Rajan (1994), S. 16. 
groß wird, so dass keine Gewinne erzielt werden können, da die Möglichkeiten für den intertemporalen Konditionenausgleich aufgrund der Wechselgefahr beschränkt sind. ${ }^{614}$

Hingegen finden ANGELINI/DI SALVO/FERRI heraus, dass Unternehmen mit mehreren Bankverbindungen niedrigere Zinsen zahlen müssen. ${ }^{615}$ Das Ergebnis stützt die These, dass die Banken versuchen das Informationsmonopol auszunutzen und dass erst durch mehrere Bankverbindungen der Zinssatz auf ein kompetitives Niveau reduziert wird. Bei HARHOFF/KÖRTING hat die Anzahl der Bankverbindungen keinen Einfluss auf den Zinssatz. $^{616}$

Die konträren Effekte bei ANGelini/Di Salvo/FerRI und PeTERSEN/RAJAN lassen sich möglicherweise auf diverse Unterschiede in der Datenbasis zurückführen. Die Datenerhebung von ANGELINI/DI SALVO/FERRI hat sich ausschließlich auf Genossenschaftsbanken des privaten Sektors beschränkt. ${ }^{617}$ Diese Genossenschaftsbanken haben sich auf die Kreditvergabe an kleine Unternehmen fokussiert. Datenbasis für die Studie von PETERSEN/RAJAN sind die Daten des National Survey of Small Business (NSSBF), welche umfangreiche Informationen über Kreditnehmer sowie Kreditverträge als auch über die Bankbeziehung enthält. Ein Bankenfokus liegt in dieser Studie nicht vor. ${ }^{618}$ Gleichermaßen liegt auch bei HARHOFF/KÖRTING kein Bankenfokus vor. Ferner gibt es Unterschiede hinsichtlich der Größe der untersuchten Unternehmen. Die von ANGELINI/DI SALVO/FERRI untersuchten Unternehmen sind verglichen mit den Unternehmen in der Datenbasis von PETERSEN/RAJAN und HARHOFF/KÖRTING kleiner. ${ }^{619}$ Inwiefern die Unternehmensgrößen einen Einfluss auf die Wirkungsrichtung hat, lässt sich nicht beurteilen. Weitere Ursachen für die abweichenden Ergebnisse könnten aus den unterschiedlichen Banksystemen in Italien und in den USA resultieren. Während in Kontinentaleuropa, insbesondere in Deutschland, Italien und Frankreich, das Universalbankprinzip dominiert, herrscht im angelsächsischen Raum primär das Trennbankensystem vor. ${ }^{620}$

$\begin{array}{ll}614 & \text { Vgl. Boot (2000), S. } 17 . \\ 615 & \text { Vgl. Angelini/Di Salvo/Ferri (1998), S. } 941 . \\ 616 & \text { Vgl. Harhoff/Körting (1998a), S. 17. } \\ 617 & \text { Vgl. Angelini/Di Salvo/Ferri (1998), S. } 927 . \\ 618 & \text { Vgl. Petersen/Rajan (1994), S. 4. }\end{array}$

In der Datengrundlage von ANGELINI/DI SALVO/FERRI beträgt die durchschnittliche Mitarbeiterzahl 10,3 Personen und der durchschnittliche Umsatz 3,3 Mrd. Lira (1,7 Mio. EUR). Umrechnungskurs: ITL/EUR=1.936,27, vgl. EZB (1998), Absatz 1, zur Datenbasis vgl. Angelini/Di Salvo/Ferri (1998), S. 935. Bei Petersen/Rajan sind nur Firmen mit weniger als 500 Mitarbeitern enthalten, die durchschnittliche Mitarbeiterzahl wird nicht angegeben. Die durchschnittliche Bilanzsumme (Median) beträgt 130 Mio. US-Dollar (133 Mio. EUR) und der durchschnittlicher Umsatz (Median) 300 Mio. US-Dollar (307 Mio. EUR). Vgl. Petersen/Rajan (1994), S. 7. Ebenso werden in der Studie von Harhoff/Körting nur Unternehmen mit maximal 500 Mitarbeitern berücksichtigt, die durchschnittliche Mitarbeiterzahl beträgt 41,49 bei einem Median von 10 Mitarbeitern. 80\% der Unternehmen haben weniger als 50 Mitarbeiter. Vgl. Harhoff/Körting (1998a), S. 33. Bei der Umrechnung von US-Dollar in EUR wurde basierend auf dem zum Zeitpunkt des Erscheinens der Studie gültigen Kurs ein Umrechnungskurs von DM/USDollar=2,0 angenommen. Vgl. Elsas (2001), S. 195. Bei der Umrechnung in EUR wurde der Umrechnungskurs DM/EUR=1,95583 herangezogen. Vgl. EZB (1998), Absatz 1. 


\section{Marktkonzentration}

ANGELINI/Di SALVO/FERRI konnten keinen signifikanten Effekt der Wettbewerbsintensität, welche sie aus dem Herfindahl-Index abgeleitet haben, auf den Zinssatz feststellen. ${ }^{621}$ Der Herfindahl-Index ist eine Kennzahl zur Konzentrationsmessung und wird als Summe der quadrierten Anteilswerte ermittelt. ${ }^{622}$ Im konkreten Fall erfolgt die Berechnung auf Basis der quadrierten Marktanteile der Banken. Auch ELSAS/KRAHNEN kommen zu der Erkenntnis, dass der Zinssatz durch die Marktkonzentration, auch hier gemessen am Herfindahl-Index, nicht signifikant beeinflusst wird. ${ }^{623}$ Lediglich PETERSEN/RAJAN zeigen, dass eine erhöhte Bankenkonzentration zu niedrigeren Zinsen führen. ${ }^{624}$ Neben den regionalen Unterschieden und den unterschiedlichen Banksystemen kann auch die unterschiedliche Ermittlung des Herfindahl-Index bzw. des bei der Ermittlung als relevant erachteten Marktes eine Erklärung für die abweichenden Ergebnisse sein. So merken ANGELIN/DI SALVO/FERRI selbst an, dass ihre für die Indexberechnung betrachteten regionalen Einheiten bzw. relevanten Märkte deutlich kleiner sind als selbige von PETERSEN/RAJAN. ${ }^{625}$ Aufgrunddessen sind die Marktanteile der einzelnen Banken größer.

\section{Sicherheitenstellung}

Die meisten empirischen Untersuchungen unterstützen die These, dass Sicherheiten mit risikoreicheren Kreditnehmern und Krediten einhergehen, z.B. die Studien von ORGLER, HESTER, SCOTT/SMITH, BERGER/UDELL. ${ }^{626}$ In der Untersuchung von BERGER/UDELL wurde ein leicht positiver, allerdings statistisch nicht signifikanter $\mathrm{Zu}$ sammenhang zwischen der Sicherheitenstellung und dem Zinssatz festgestellt, wobei die Art der Sicherheit unerheblich war. ${ }^{627}$ Während BERGER/UdELL nur die zwei Zustände Sicherheitenstellung Ja-Nein berücksichtigen, betrachten ELSAS/KRAHNEN den Anteil der gesamten Bankkredite, die nicht besichert sind, d.h. als unabhängige Variable wird das Exposure in Prozent herangezogen. ${ }^{628}$ ELSAS/KRAHNEN kommen zu der Erkenntnis, dass der Zinssatz mit zunehmendem Exposure und somit zunehmendem Risiko der Bank sinkt. ${ }^{629} \mathrm{Je}$ mehr Sicherheiten gestellt werden, desto höher ist der Zinssatz. Die Ergebnisse beider Untersuchungen stimmen somit überein mit der Interpretation von Sicherheiten als Anreizinstrument, d.h. dem „Sorting-by-observed-risk“-

\footnotetext{
$621 \quad$ Vgl. Angelini/Di Salvo/Ferri (1998), S. 936.

622 Vgl. Bleymüller/Gehlert/Gülicher (2008), S. 192.

${ }_{623}$ Vgl. Elsas/Krahnen (1998), S. 1301. Zu gleichen Ergebnissen kommen auch Petersen/Rajan (1994), S. 12 f., Elsas/Krahnen (1998), S. 1302 ff. und Scott/Dunkelberg (2003), S. 1010 f.

${ }_{624}$ Vgl. Petersen/Rajan (1995), S. 436.

625 Vgl. Angelini/Di Salvo/Ferri (1998), S. 936.

626 Vgl. Orgler (1970), S. 435 ff., Hester (1979), S. 349 ff., Scott/Smith (1986), S. 119 ff., Berger/Udell (1990), S. 21 ff., Berger/Udell (1992), S. 1047 ff. Einen Überblick geben Berger/Udell. Vgl. Berger/Udell (1995), S. $368 \mathrm{ff}$.

627 Vgl. Berger/Udell (1995), S. 368.

${ }_{628}$ Vgl. Elsas/Krahnen (1998), S. 1299.

629 Vgl. Elsas/Krahnen (1998), S. 1301. 
Paradigma und widersprechen der Interpretation von Sicherheiten als SignallingInstrument. ${ }^{630}$

Bei der Interpretation von Sicherheiten als Signalling-Instrument ${ }^{631}$ müsste der Zinssatz mit abnehmendem Exposure und somit zunehmender Kreditnehmerqualität sinken. ${ }^{632}$ Bei dieser Sichtweise stellt ein Kreditnehmer mit einem geringen Risiko mehr Sicherheiten und signalisiert dadurch seine Qualität. Die meisten theoretischen Modelle basieren auf diesem „Sorting-by-private-information"-Paradigma. ${ }^{633}$ DEGRYSE/VAN CAYSEELE bestätigen diese Modelle und identifizieren in ihrer Untersuchung einen negativen Zusammenhang zwischen der Sicherheitenstellung und dem Zinssatz; wenn Sicherheiten gestellt werden, dann sinkt der Zinssatz um ca. 0,5 Prozentpunkte. ${ }^{.34}$

Die divergierenden Ergebnisse lassen sich hier nicht auf unterschiedliche Banksysteme zurückführen, denn auch für das Univeralbanksystem kommen ELSAS/KRAHNEN und DEgRYSE/VAN CAYSEELE zu unterschiedlichen Ergebnissen. Bereits bei der Darstellung der theoretischen Modelle hat sich gezeigt, dass sowohl negative als auch positive Zusammenhänge zwischen der Sicherheitenstellung und der Kreditnehmerbonität denkbar sind. ${ }^{635}$ Möglicherweise ist bei der Analyse des Zusammenhangs der Zeitpunkt der Beziehung von Relevanz. Gute Kreditnehmer stellen gegebenenfalls anfänglich mehr Sicherheiten, um die Qualität zu signalisieren und aufgrund der Self-SelectionMechanismen von günstigen Zinsen zu profitieren. Zu einem späteren Zeitpunkt in der Beziehung ist ihre Qualität durch die Projekterfolge bereits transparent geworden und die Sicherheiten übernehmen die Anreizfunktion, so dass die Höhe der geforderten Sicherheiten sinkt. Für die Untersuchung eines derartigen Zusammenhangs erscheint eine detailliertere Analyse im Zeitablauf der Beziehung notwendig, da sich die Wirkungsrichtung an einem Punkt der Beziehung ändern würde.

\section{Finanzielle Charakteristika}

BERGER/UDELL kommen zu dem Ergebnis, dass die von ihnen verwendeten finanziellen Variablen, z.B. Verschuldungsgrad, Liquidität 3. Grades, Forderungsumschlagshäufigkeit, Vorratsumschlagshäufigkeit, Kreditorenumschlag, Bilanzsumme, ${ }^{636}$ keine signifikanten Effekte in Bezug auf die Kreditzinsen haben. Sie schlussfolgern, dass die Zinsen für kleinere Unternehmen idiosynkratisch sind und oft von der Reputation und dem Ansehen des Eigentümers und des Unternehmens abhängen. ${ }^{637}$

\footnotetext{
${ }^{630}$ Vgl. hierzu Berger/Udell (1990), S. 24 ff. und Kapitel A.4.3.1.3.1.

631 Vgl. hierzu Bester (1985), S. 850 ff., Besanko/Thakor (1987a), S. $671 \mathrm{ff}$.

632 Vgl. Elsas/Krahnen (1998), S. 1299.

${ }^{633}$ Vgl. Berger/Udell (1990), S. 24. Vgl. hierzu die Studien von Besanko/Thakor (1987a), S. 671 ff., Besanko/Thakor (1987b), S. 167 ff. und Bester (1985), S. $850 \mathrm{ff}$.

${ }^{634}$ Vgl. Degryse/Van Cayseele (2000), S. 99. Bezüglich der Sicherheiten haben sie nicht differenziert zwischen der Art der Sicherheit. Es wurde ausschließlich untersucht, ob Sicherheiten gestellt wurden oder nicht.

635 Vgl. Kapitel A.4.3.1.3.

${ }_{636}$ Vgl. Berger/Udell (1995), S. 359.

${ }_{637}$ Vgl. Berger/Udell (1995), S. 367.
} 
BLACKWELL/WINTERS konnten zeigen, dass Unternehmen mit einem mittleren Risiko signifikant höhere Zinsen zahlen als Unternehmen mit einem geringeren Risiko. ${ }^{638}$ Allerdings verwenden sie nur eine grobe Einschätzung der Kreditnehmerqualität, indem sie selbige aus der Monitoring-Häufigkeit der kreditgebenden Bank ableiten. ${ }^{639}$ LEHMANN/NEUBERGER kommen zu der Erkenntnis, dass der Zinssatz mit besserer Ratingklasse sinkt. ${ }^{640}$ Dies stimmt auch mit anderen Studien überein, z.B. der Studie von MACHAUER/WEBER ${ }^{641}$ oder ELSAS/KRAHNEN. ${ }^{642}$ Die Ratingklasse selbst ist hier als reine Beurteilung der Kreditwürdigkeit zu sehen, denn die Ratingklasse gibt nur die Ausfallwahrscheinlichkeit wieder und wird nicht durch die bereitgestellten Sicherheiten beeinflusst. ${ }^{643}$ Die Kreditnehmerqualität beeinflusst somit die Kreditzinsen. ${ }^{644}$ Die Ergebnisse der genannten Studien entsprechen zwar den heutigen Anforderungen der MaRisk, welche einen Zusammenhang zwischen der Konditionengestaltung und zur Einstufung im Risikoklassifizierungsverfahren als Sollte-Bestimmung beinhalten. ${ }^{645}$ Allerdings gab es zum Zeitpunkt dieser Studien noch keine Vorschriften, welche diesen Zusammenhang gefordert haben. ${ }^{646} \mathrm{Im}$ Gegensatz zu BERGER/UDELL rekurrieren die deutschen Studien unmittelbar auf die Variable Ratingklasse, welche sich aus der Bewertung von qualitativen und quantitativen Unternehmensdaten zusammensetzt und somit eine Verdichtung der finanziellen Charakteristika enthält. Der Einfluss der Kennzahlen auf den Zinssatz kann sich bei dem Ansatz von BERGER/UDELL nur dann ergeben, wenn die Firmenkundenbetreuer oder die Marktfolge eine systematische Verdichtung der Kennzahlen zu einer Risikoeinschätzung vornehmen und diese in dem Zins berücksichtigen.

\section{Weitere Erkenntnisse}

LEHMANN/NEUBERGER betrachten den Zinssatz für Darlehen und kommen hierbei zu der Erkenntnis, dass der Zinssatz durch die Art der Mittelverwendung beeinflusst wird. ${ }^{67}$ Kredite für Ersatzinvestitionen sind günstiger als Kredite, die mit unspezifischer Mittelverwendung aufgenommen werden. Eine unspezifische Mittelverwendung erfordert höhere Monitoring-Anstrengungen bei der Bank oder führt zu einem erhöhten Risiko bei der Bank, was durch eine höhere Risikoprämie kompensiert wird. ${ }^{648}$

BERGER/UDELL kommen darüber hinaus zu dem Ergebnis, dass bei Unternehmen mit einer Bilanzsumme von weniger als 500.000 USD keine der untersuchten Variablen

\footnotetext{
638 Vgl. Blackwell/Winters (1997), S. 283.

639 Vgl. Blackwell/Winters (1997), S. 283.

640 Vgl. Lehmann/Neuberger (2001), S. 20.

641 Vgl. Machauer/Weber (1998), S. 1366.

642 Vgl. Elsas/Krahnen (1998), S. 1300.

643 Vgl. Elsas/Krahnen (1998), S. 1298.

644 Vgl. Elsas/Krahnen (1998), S. 1300.

645 Vgl. Kapitel A.3.3.

646 Auch die MaK als Vorläufer der MaRisk wurden erst 2002 verabschiedet. Vgl. DSGV (2006b), S. 1.

647 Vgl. Lehmann/Neuberger (2001), S. 20.

648 Vgl. Lehmann/Neuberger (2001), S. 21. 
statistisch signifikant ist und dass bei diesen Untersuchungen das Bestimmtheitsmaß $\mathbf{R}^{2}$ hier deutlich niedriger liegt. Daraus schlussfolgern sie, dass im Vergleich zu den größeren Unternehmen in der Datenbasis die Preissetzung bei kleinen Unternehmen relativ idiosynkratisch erfolgt. ${ }^{649}$ Ursächlich hierfür könnte sein, dass die Reputation sowie die Finanzkonten des Unternehmens und des Unternehmers bei kleinen Unternehmen im Familienbesitz oder bei familiengeführten Unternehmen häufig nicht getrennt werden können. ${ }^{650}$ In diesem Fall würden neben unternehmens- auch unternehmerbezogene Variablen einen Einfluss ausüben. LEHMANN/NEUBERGER und ELSAS/KRAHNEN hingegen kommen zu der Erkenntnis, dass der Zinssatz mit zunehmender Unternehmensgröße sinkt. ${ }^{\text {t51 }}$ Dies indiziert gemäß ELSAS/KRAHNEN, dass Banken die Firmengröße als einen Proxy für das Risiko verwenden und große Unternehmen aufgrund des geringeren Risikos niedrigere Zinsen zahlen. ${ }^{652}$ Ferner zahlen Unternehmen mit einem höheren Anteil an kurzfristigen Krediten höhere Zinsen, wobei auch hier wieder das höhere Risiko des Unternehmens ursächlich sein kann. ${ }^{653}$

LEHMANN/NEUBERGER kommen zu der Erkenntnis, dass der Zinssatz bei besseren Managementqualitäten des Unternehmers sinkt. ${ }^{\circ 4}$ Die Beurteilung der Managementqualitäten erfolgte aus Sicht der Bank. ${ }^{\text {sss }}$ Hintergrund des Zusammenhangs könnte eine bessere Verhandlungsmacht der Kreditnehmer und/oder bessere Informationen seitens der Bank über den „Typ“ des Kreditnehmers sein. ${ }^{656}$ Beides führt zu niedrigerem Risiko und somit zu niedrigeren Zinsen. ELSAS/KRAHNEN zeigen, dass der Zinssatz mit zunehmendem Kreditvolumen sinkt. ${ }^{657}$ Eine mögliche Erklärung besteht darin, dass die prozentualen Betriebskosten mit steigendem Kreditvolumen sinken. ${ }^{658}$ Ebenso führt eine höhere Flexibilität hinsichtlich der Rückzahlungsbedingungen zu höheren Zinsen. ${ }^{659}$ ANGELINI/DI SALVO/FERRI stellen darüber hinaus Unterschiede bezüglich der Branchenzugehörigkeit fest. ${ }^{600}$ Bezüglich der unterschiedlichen Rechtsform gab es

649

650

651

652

653

654

655

Vgl. Berger/Udell (1995), S. 368.

Vgl. Berger/Udell (1995), S. 368.

Vgl. Lehmann/Neuberger (2001), S. 20.

Vgl. Elsas/Krahnen (1998), S. 1301.

Vgl. Angelini/Di Salvo/Ferri (1998), S. 941.

Vgl. Lehmann/Neuberger (2001), S. 22.

Zur Operationalisierung wurden die Bankmitarbeiter aufgefordert die Management-Qualitäten gemäß nachstehender Frage auf einer 5-Punkt-Likert-Skala zu beurteilen: "The management skill/competence is ... below one of the large average (1) .... above average (5)". Vgl. Lehmann/Neuberger (2001), S. 18.

Vgl. Lehmann/Neuberger (2001), S. 22.

Vgl. Elsas/Krahnen (1998), S. 1301.

Zur Erläuterung der Betriebskosten als eine Komponente des Zinssatzes vgl. Kapitel A.3.3. In diesem Kontext ist allerdings das Vorgehen bei der Konditionenkalkulation zu prüfen. Bei der Angebotserstellung liegen dem Firmenkundenbetreuer in aller Regel keine detaillierten Informationen über die tatsächlichen bankinternen Kostenstrukturen vor. Häufig wird mit einem einheitlichen Betriebskostensatz gearbeitet, so dass Fixkostendegressionseffekte keine Berücksichtigung finden.

Vgl. Lehmann/Neuberger (2001), S. 21.

Vgl. Angelini/Di Salvo/Ferri (1998), S. 936. 
keine signifikanten Effekte. ${ }^{661}$ Des Weiteren konnten sie zeigen, dass der Zinssatz größer ist bei Unternehmen, die einen Kreditwunsch haben, und dass der Zinssatz noch größer ist bei Unternehmen, die einen Kreditwunsch haben, der aber abgelehnt wurde bzw. voraussichtlich abgelehnt wird. ${ }^{662}$ Wird eine Kreditablehnung interpretetiert als Indikator für eine schlechte Qualität, so bestätigt dieser Zusammenhang die zuvor dargelegten Erkenntnisse, dass Kreditnehmer mit einer schlechten Ratingklasse höhere Zinsen zahlen. Dies steht allerdings im Widerspruch zu dem Modell von BLACKWELL/SANTOMERO, welche vorhersagen, dass kreditrationierte Unternehmen Zinsen unterhalb des Durchschnitts zahlen müssen. ${ }^{663}$

DEGREYSE/ONGENA zeigen, dass die Distanz zum aktuellen Kreditgeber sowie die Distanz zu potenziellen neuen Kreditgebern einen Einfluss auf den Zins hat. ${ }^{664}$ Der Kreditzins steigt mit zunehmender Distanz zum aktuellen Kreditgeber. Die Distanz zu potenziellen neuen Kreditgebern ist ein Indikator für die Marktmacht der aktuellen Bank. Dementsprechend steigt der Kreditzins mit einer größer werdenden Distanz zu den Konkurrenzbanken. In Tab. A-10 werden die signifikanten Ergebnisse der diversen empirischen Studien hinsichtlich der wesentlichen Einflussparameter in Bezug auf den Zinssatz dargestellt. ${ }^{605}$ Zusammenfassend lässt sich feststellen, dass die Ergebnisse im Allgemeinen sehr ambivalent sind. Während bei den Parametern Kreditnehmerqualität, Größe, Alter, zusätzliche Dienstleistungen, Kreditvolumen und Marktkonzentration zumindest keine widersprüchlichen Einflüsse resultieren, werden bei den Variablen Anzahl der Bankverbindungen, Dauer der Geschäftsbeziehung und Sicherheitenstellung sowohl negative als auch positive Einflüsse auf den Zinssatz ermittelt. Die bisher verwendeten Variablen sind somit nicht in der Lage einen eindeutigen Zusammenhang herzustellen. Hinsichtlich der Dauer der Geschäftsbeziehung wäre es ferner interessant zu prüfen, inwiefern der positive Zusammenhang zum Zinssatz in einer wenig kompetitiven Situation und der negative Zusammenhang zum Zinssatz in einer kompetitiven Situation entstanden ist, so dass im ersteren Fall eine mögliche Hold UpSituation ausgenutzt wurde.

661 Vgl. Angelini/Di Salvo/Ferri (1998), S. 936.

662 Vgl. Angelini/Di Salvo/Ferri (1998), S. 940.

663 Vgl. Blackwell/Santomero (1997), S. $121 \mathrm{ff}$.

${ }_{664}$ Vgl. Degreyse/Ongena (2005), S. 252.

${ }_{665}$ Ein signifikanter positiver Einfluss auf den Zinssatz wird durch „,+“, ein signifkanter negativer Einfluss durch ,"“" und ein nicht-signfikanter Einfluss durch „”“ visualisiert. 


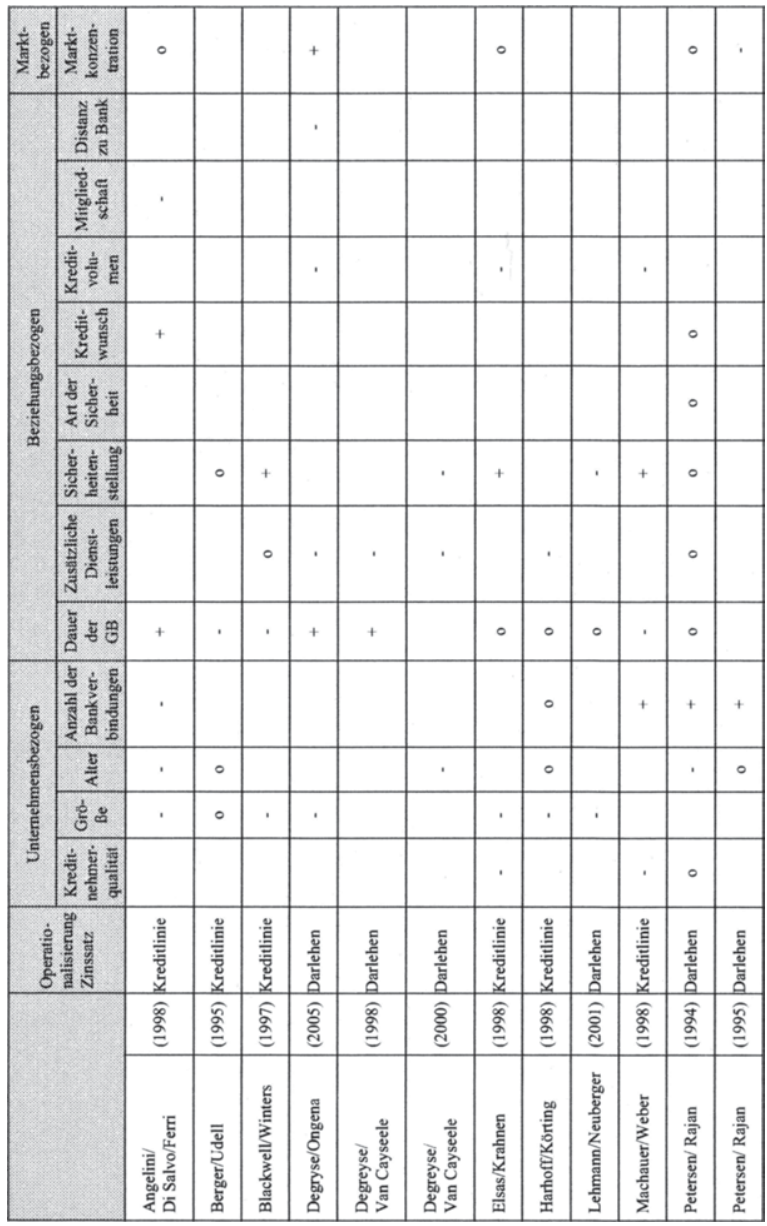

Tab. A-10: Zusammenfassung der Ergebnisse der empirischen Studien zum Zinssatz ${ }^{\text {666 }}$

666 Eigene Darstellung. Angelini/Di Salvo/Ferri (1998), S. 937 f., Berger/Udell (1995), S. 364, Blackwell/Winters (1997), S. 283, Degryse/Van Cayseele (2005), S. 247, 252, Degryse/Van Cayseele (1998), S. 12, Degryse/Van Cayseele (2000), S. 100, Elsas/Krahnen (1998), S. 1302, Harhoff/Körting (1998b), S. 1342, Harhoff/Körting (1998b), S. 1342, Lehmann/Neuberger (2001), S. 350, Machauer/Weber (1998), S. 1362, Petersen/Rajan (1994), S. 12 f., Petersen/Rajan (1995), S. 436. Eine Übersicht mit ähnlichen Studien und weiteren Variablen findet sich bei Segbers (2007), S. 212. 


\subsubsection{Sicherheitenstellung}

Hinsichtlich der Sicherheitenstellung lassen sich die Untersuchungen u.a. dahingehend differenzieren, inwiefern die Sicherheitenstellung ausschließlich als unabhängige oder auch als abhängige Variable betrachtet wird. So wurde die Sicherheitenstellung bereits im Rahmen der Untersuchungen zum Zinssatz als unabhängige Variable analysiert, die Sicherheitenstellung als eigenständiger Bestandteil des Kreditvertrags und somit als abhängige Variable wurde von PETERSEN/RAJAN, ELSAS/KRAHNEN oder ANGELINI/DI SALVO/FERRI allerdings nicht angesprochen. ${ }^{667}$

Die Studien, die die Sicherheitenstellung als abhängige Variable berücksichtigen, lassen sich nach der Art der Operationalisierung unterscheiden. BERGER/UDELL und DEGRYSE/VAN CAYSEELE untersuchen nicht den Einfluss auf die Höhe der Sicherheitenstellung, sondern ob Sicherheiten gestellt werden. ${ }^{668}$ MACHAUER/WEBER hingegen verwendet den Blankoanteil der Kreditlinie. ${ }^{669}$

\section{Dauer}

BERGER/UDELL zeigen, dass Unternehmen in langen Bankbeziehungen mit geringerer Wahrscheinlichkeit Sicherheiten stellen. ${ }^{670}$ Auch HARHOFF/KÖRTING finden für den deutschen Markt, dass mit steigender Dauer der Bankbeziehung die Wahrscheinlichkeit der Sicherheitenstellung sinkt. ${ }^{671}$ Dies entspricht dem Modell von BOOT/THAKOR, welches zeigt, dass Kreditnehmer mit längeren Bankbeziehungen weniger oft Sicherheiten stellen. ${ }^{622}$ Durch Sicherheitenstellung im frühen Stadium einer Beziehung kann das Moral Hazard-Problem abgebaut werden. Junge Firmen mit neuen Bankbeziehungen sind bereit, die Kosten der Sicherheitenstellung zu tragen, da sie wissen, dass das Problem der Informationsasymmetrien dadurch gemindert wird. ${ }^{673}$

Für den belgischen Markt können Degryse/VAN CAYSEELE weder in der Untersuchung von 1998 noch von 2000 einen Zusammenhang zwischen der Dauer der Bankbeziehung und der Wahrscheinlichkeit der Sicherheitenstellung feststellen. ${ }^{674}$

Bei MACHAUER/WEBER hingegen steigt die Sicherheitenquote mit zunehmender Beziehungsdauer, allerdings ist der Effekt nicht signifikant. ${ }^{675}$ Die Vergleichbarkeit mit den Ergebnissen von DEGRYSE/VAN CAYSEELE ist aufgrund der unterschiedlichen Ope-

\footnotetext{
667 Vgl. Petersen/Rajan (1994), S. 3 ff., Petersen/Rajan (1995), S. 407 ff., Elsas/Krahnen (1998), S. 1283 ff., Angelini/Di Salvo/Ferri (1998), S. $925 \mathrm{ff}$.

668 Vgl. Berger/Udell (1995), S. 373, Degryse/Van Cayseele (1998), S. 12 ff. und Degryse/Van Cayseele (2000), S. $100 \mathrm{ff}$.

669 Vgl. Machauer/Weber (1998), S. 1362

670 Vgl. Berger/Udell (1995), S. 373.

671 Vgl. Harhoff/Körting (1998a), S. 14.

672 Vgl. Boot/Thakor (1994), S. 899.

673 Vgl. Berger/Udell (1995), S. 377.

674 Vgl. Ongena/Smith (2000a), S. 239. Während bei den anderen Studien stets mehrere Banken untersucht wurden, haben Degryse/Van Cayseele genau eine Bank betrachtet. Vgl. Degryse/Van Cayseele (2000), S. 106.

675 Vgl. Machauer/Weber (1998), S. 1370.
} 
rationalisierung nur eingeschränkt gegeben. Eine mögliche Erklärung für das abweichende Ergebnis besteht darin, dass die Banken aufgrund der Dauer der Bankbeziehung besser informiert sind über die Vermögensgegenstände, die als Sicherheit verfügbar sind.

\section{Scope}

Für den belgischen Markt stellen DEGRYSE/VAN CAYSEELE fest, dass für einen Kunden mit einer umfangreichen Produktnutzung bei einer Bank die Wahrscheinlichkeit der Sicherheitenstellung steigt. ${ }^{676}$ Die Ursachen hierfür sind allerdings unklar, wenngleich diese Ergebnisse auch in anderen Studien gefunden wurden. ${ }^{677}$ Ein Erklärungsansatz besteht darin, dass die Banken den Lock-In-Effekt über den Scope der Bankbeziehung nutzen. ${ }^{678}$ Der Kunde kann die Bankbeziehung nicht wechseln und - wie bereits bei MACHAUER/WEBER in Bezug auf die Dauer der Bankbeziehung argumentiert - aufgrund der Breite der Bankbeziehung ist die Bank besser informiert über die Vermögensgegenstände, die als Sicherheit verfügbar sind. ${ }^{679}$ Die Bank ist somit aufgrund ihrer Machtposition und ihres Wissensvorsprungs besser in der Lage geeignete, d.h. verwertbare Sicherheiten, zu fordern.

\section{Anzahl der Bankverbindungen}

Für den deutschen Markt finden HARHOFF/KÖRTING, dass mit steigender Anzahl der Bankverbindungen die Wahrscheinlichkeit der Sicherheitenstellung steigt. ${ }^{680}$ Ursächlich hierfür könnte sein, dass in diesem Fall keine Bank einen Informationsvorsprung besitzt und keine Bank das Unternehmen dahingehend beurteilen kann, inwiefern die Gefahr des Moral Hazard existiert bzw. wie groß die Gefahr bei diesem Unternehmen ist. Ferner könnte eine schlechte Unternehmensqualität und die fehlende Kreditverfügbarkeit bei den ersten Banken das Unternehmen dazu veranlassen, mehrere Bankverbindungen aufzubauen. Allerdings hat die Bonität des Unternehmens keinen unmittelbaren Einfluss auf die Sicherheitenstellung.

\footnotetext{
676 Vgl. Degryse/Van Cayseele (2000), S. 92.

677 Vgl. Degryse/Van Cayseele (2000), S. 106.

678 Vgl. Degryse/Van Cayseele (2000), S. 106.

679 Vgl. Degryse/Van Cayseele (2000), S. 106.

680 Vgl. Harhoff/Körting (1998a), S. 14.
} 


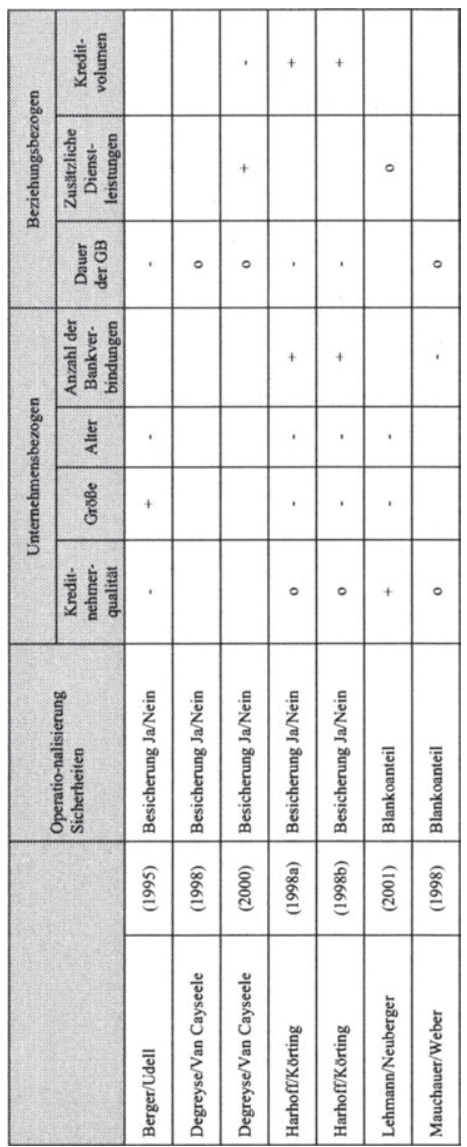

Tab. A-11: Zusammenfassung der Ergebnisse der empirischen Studien zur Sicherheitenstellung ${ }^{681}$

\section{Finanzielle Charakteristika}

BERGER/UDELL haben auch den Zusammenhang zwischen Kreditnehmerrisiko und Sicherheitenstellung untersucht. Ein höherer Leverage Ratio, d.h. eine höhere Relation

681 Eigene Darstellung. Vgl. Berger/Udell (1995), S. 374, Degryse/Van Cayseele (1998), S. 22, Degryse/Van Cayseele (2000), S. 105, Harhoff/Körting (1998a), S. 12, Harhoff/Körting (1998b), S. 1338, Lehmann/Neuberger (2001), S. 351. f., Machauer/Weber (1998), S. 1362. Eine Übersicht mit ähnlichen Studien und weiteren Variablen findet sich bei Segbers (2007), S. 213. 
von Fremd- zu Eigenkapital, und somit ein höheres Kreditnehmerrisiko führt zu einer höheren Wahrscheinlichkeit der Sicherheitenstellung. ${ }^{682}$ Dieses Ergebnis stimmt überein mit früheren Untersuchungen, z.B. von HESTER und BERGER/UDELL, und bestätigt das „Sorting-by-observed-risk“-Paradigma ${ }^{683}$

LEHMANN/NEUBERGER hingegen konnten zeigen, dass Kreditnehmer mit einer schlechten Ratingbeurteilung weniger Sicherheiten stellen als gute Kreditnehmer. ${ }^{684}$ Dies entspricht somit dem „Sorting-by-private-information“-Paradigma gemäß BESANKO/THAKOR ${ }^{685}$ Eine andere Erklärung gemäß LEHMANN/NEUBERGER hierfür ist, dass Kreditnehmer, die mehr Sicherheiten stellen, als weniger risikoreich erachtet werden und ein besseres Rating erhalten, so dass das Rating eigentlich endogen ist. ${ }^{686}$ Die Ratingklasse beinhaltet allerdings nur die Ausfallwahrscheinlichkeit, nicht die Recovery Rate bzw. das Exposure, so dass die Ratingklasse die Sicherheitenstellung nicht berücksichtigen sollte.

Bei MACHAUER/WeBER sinkt zwar der Anteil der Besicherungsquote zunächst für Unternehmen mit einer schlechteren Ratingklasse, allerdings steigt dieser Anteil wiederum für die schlechtesten Ratingklassen und bewegt sich auf dem Niveau der besten Ratingklasse. Es konnte kein eindeutiges Ergebnis erzielt werden. ${ }^{687}$ Denkbar wäre, dass hier den Sicherheiten in Abhängigkeit von der Kreditnehmerqualität mal eine Anreiz- und mal eine Signalling-Funktion zukommt.

\section{Weitere Erkenntnisse}

Ebenso wie Degryse/VAN CAYSEele finden HaRhoff/KöRTING, dass mit steigendem Kreditvolumen die Wahrscheinlichkeit der Sicherheitenstellung steigt. ${ }^{688}$ Für den belgischen Markt zeigen DEGRYSE/VAN CAYSEELE darüber hinaus, dass Kredite mit langer Laufzeit und kleine Kapitalgesellschaften im Vergleich zu Einzelunternehmen häufiger besichert sind. ${ }^{689}$ Letzterer Zusammenhang könnte auf die beschränkte Haftung bei Kapitalgesellschaften zurückzuführen sein, wobei dieser Aspekt nicht weiter untersucht wurde. Bei Einzelunternehmen hingegen haftet der Unternehmer mit seinem kompletten Privatvermögen. LeHMANN/ NEUBERGER hingegen zeigen, dass Kapitalgesellschaften ebenso wie größere Unternehmen weniger Sicherheiten stellen. ${ }^{6 \% 0}$ Unter der Annahme, dass diese Parameter als Proxy für das Unternehmensrisiko stehen, entsprechen die Ergebnisse dem „Sorting-by-observed-risk"-Paradigma. Es ist kritisch zu hinterfragen, inwiefern die Rechtsform Ausdruck des Unternehmensrisikos

\footnotetext{
${ }_{682}$ Vgl. Berger/Udell (1995), S. 377.

${ }^{683}$ Vgl. Hester (1979), S. 349 ff., Berger/Udell (1990), S. 21 ff. und Berger/Udell (1992), S. 1047 ff.

${ }^{684} \mathrm{Vgl}$. Lehmann/Neuberger (2001), S. 23.

685 Vgl. Besanko/Thakor (1987a), S. $671 \mathrm{ff}$.

$686 \mathrm{Vgl}$. Lehmann/Neuberger (2001), S. 23.

687 Vgl. Machauer/Weber (1998), S. $1368 \mathrm{f}$.

688 Vgl. Harhoff/Körting (1998a), S. 13.

${ }_{689}$ Vgl. Degryse/Van Cayseele (2000), S. 106.

690 Vgl. hier und im Folgenden Lehmann/Neuberger (2001), S. 23. 
ist. Möglicherweise besteht zwischen den Variablen Unternehmensgröße und Kapitalgesellschaft ein inhaltlicher und ggf. auch statistischer Zusammenhang, so dass eine isolierte Interpretation der Koeffizienten nicht aussagekräftig ist. Die Ergebnisse zur Unternehmensgröße werden von HARHOFF/KÖRTING bestätigt, sie zeigen, dass mit steigendem Alter und Unternehmensgröße die Wahrscheinlichkeit der Sicherheitenstellung sinkt. ${ }^{691}$ Eine Zusammenfassung der zentralen empirischen Ergebnisse hinsichtlich der Sicherheitenstellung kann Tab. A-11 entnommen werden. Die Resultate hinsichtlich der Kreditnehmerqualität sind sehr heterogen. Sowohl das „Sorting-byprivate-information“- als auch das „Sorting-by-observed-risk“-Paradigma findet Bestätigung.

\subsubsection{Kreditverfügbarkeit}

Bei der Untersuchung des Einflusses von unternehmens-, beziehungs- oder marktbezogenen Parametern auf die Kreditverfügbarkeit muss zunächst die Operationalisierung geklärt werden, denn die Kreditverfügbarkeit ist nicht direkt beobachtbar und somit sind die Operationalisierungen in den bestehenden Studien z.T. sehr unterschiedlich. Ausgangspunkt ist die Definition, dass ein ökonomischer Agent dann als liquiditätsbeschränkt betrachtet wird, wenn er zu einem Zinssatz, der seiner Risikoklasse entspricht ein größeres Kreditvolumen nachfragt, selbiges aber im Markt nicht erlangen kann. ${ }^{692}$ Im Kontext der theoretischen Modelle wurde bereits erläutert, dass STIGLITZ/WEISS unter Kreditrationierung die pauschale Ablehnung einiger Kreditanträge verstehen, obwohl es darunter auch potenzielle Kreditnehmer guter Qualität gibt, und obwohl diese bereit wären, höhere Zinsen zu zahlen und alle sonstigen Forderungen der Kreditgeber zu erfüllen. ${ }^{693}$ Alternativ kann Kreditrationierung auch derart interpretiert werden, dass Kreditgeber potenzielle Kreditnehmer mit bestimmten negativen Qualitätsmerkmalen ablehnen. ${ }^{694} \mathrm{Da}$ in der Realität direkte Messgrößen für Liquiditätsrestriktionen allerdings nicht beobachtet werden können, werden in der empirischen Literatur eine Vielzahl von Proxys verwendet. ${ }^{695}$

FAZZARI/HUBBARD/PETERSEN gruppieren die Firmen auf Basis der Dividendenpolitik und argumentieren, dass es bei Firmen mit einem hohen Anteil an thesaurierten Gewinnen wahrscheinlicher ist, dass Liquiditätsrestriktionen bestehen. ${ }^{6 \%}$ Es wird angenommen, dass Unternehmen mit bestehenden Liquiditätsrestriktionen geringere Ausschüttungen vornehmen. HOSHI/KASHYAP/SCHARFSTEIN verwenden die Kundenbeziehung als Identifikationskriterium und vermuten, dass Firmen mit engen Beziehungen weniger wahrscheinlich unter Liquiditätsrestriktionen leiden. ${ }^{697}$ Allerdings soll dieser Zusammenhang im Folgenden schließlich erst genauer untersucht werden, so dass

\footnotetext{
691 Vgl. Harhoff/Körting (1998a), S. 13 f.

692 Vgl. Angelini/Di Salvo/Ferri (1998), S. 930.

693 Vgl. Stiglitz/Weiss (1981), S. $393 \mathrm{ff}$.

694 Vgl. Hartmann-Wendels/Pfingsten/Weber (2007), S. 139.

695 Vgl. Angelini/Di Salvo/Ferri (1998), S. 930.

69 Für eine ausführliche Darstellung vgl. Fazzari/Hubbard/Petersen (1988), S. $141 \mathrm{ff}$

697

Für eine ausfuihrliche Darstellung vgl. Hoshi/Kashyap/Scharfstein (1990a), S. $67 \mathrm{ff}$. 
dieser Ansatz aus Sicht des Autors für die vorliegende Zielstellung keine Lösungsmöglichkeit bietet.

PETERSEN/RAJAN nehmen an, dass Unternehmen mit Liquiditätsbeschränkungen eher bereit sind, hohe Zinssätze zu zahlen, um zusätzliche Kredite zu bekommen. ${ }^{698}$ Basierend auf dieser Annahme identifizieren sie liquditditätsbeschränkte Firmen als solche, die auf Kredite von nicht-institutionellen Kreditgebern zu Zinssätzen oberhalb des Marktniveaus zurückgreifen. Zur Ableitung eines Indikators für die Kreditverfügbarkeit gehen sie folgendermaßen vor. Wenn ein Unternehmen keine zusätzlichen Kredite von einer Bank bekommt, so ist das Unternehmen gezwungen, auf teurere Finanzierungsquellen zurückzugreifen. Das Unternehmen ist aber nur bereit diesen Preis zu zahlen, sofern die Investitionsrückflüsse die Finanzierungskosten dieser Quelle überschreiten. ${ }^{699}$ Sie untersuchen aus diesem Grund die Verwendung von Lieferantenkredite als eine sehr teure Finanzierungsquelle. Dies operationalisieren sie in ihrer Studie, indem sie den Anteil an Skontoziehungen sowie den Anteil an verspäteten Zahlungen als abhängige Variable berücksichtigen. ${ }^{700}$

Das Problem dieser indirekten Indikatoren besteht darin, dass die Qualität der ausgewählten Proxys nicht verifiziert werden kann. Selbige könnte nur bei Existenz von direkten Indikatoren überprüft werden. Zudem können sich in diesen Proxys unabhängig von der Güte derselben zusätzliche Effekte widerspiegeln, die nichts oder nur wenig mit Liquiditätsrestriktionen zu tun haben. ${ }^{701}$ So kann zwar die Dividendenpolitik durch das Kreditvergabeverhalten der Banken und durch die Kreditverfügbarkeit des Unternehmens beeinflusst werden, zusätzlich können hier aber auch andere Aspekte wie strategische Entscheidungen im Unternehmen oder die Risikofreudigkeit des Unternehmens eine Rolle spielen.

Einen interessanten, weil direkten Ansatz wählen ANGELINI/DI SALVO/FERRI, so dass dieser im Folgenden ausführlicher behandelt werden soll. ${ }^{702}$ Jedes Unternehmen wurde direkt befragt zu bestehenden Kreditwünschen, zur Bereitschaft auch schlechtere Konditionen in Kauf zu nehmen und inwiefern die Bank bereits bezüglich des Kreditwunsches kontaktiert wurde. In ihrer Untersuchung haben sie dann drei verschiedene Definitionen von Kreditverfügbarkeit bzw. Liquidititätsrestriktionen - in der Abb. A-7 fett umrandet dargestellt - herangezogen und als abhängige Variablen verwendet.

Bei Betrachtung nur der in Abb. A-7 schwarz umrandeten Kästchen hatten 16,2\% der Unternehmen in der Studie einen Kreditwunsch, allerdings nur zu den aktuellen Konditionen. 7,4\% der befragten Unternehmen gaben an, dass zwar ein Kreditwunsch auch zu schlechteren Konditionen - existiere, jedoch die Bank noch nicht gefragt wurde. Weitere $2,6 \%$ der befragten Unternehmen gaben an, dass zwar ein Kreditwunsch - auch zu schlechteren Konditionen - existiere, jedoch von einer Ablehnung ausgegangen wird und die Bank deshalb noch nicht gefragt wurde bzw. der Kredit

\footnotetext{
${ }^{698}$ Vgl. Petersen/Rajan (1994), S. 19.

699 Vgl. Petersen/Rajan (1994), S. 19.

700 Vgl. Petersen/Rajan (1994), S. 24.

${ }_{701}$ Vgl. Angelini/Di Salvo/Ferri (1998), S. 931

702 Vgl. hier und im Folgenden Angelini/Di Salvo/Ferri (1998), S. 931.
} 
bereits abgelehnt wurde. Bei diesem Ansatz wird somit explizit berücksichtigt, inwiefern ein Kreditwunsch bei dem Unternehmen besteht. Hinsichtlich der Kreditablehnungen werden sowohl bereits erfolgte als auch durch den Kunden erwartete Kreditablehnungen durch die Bank berücksichtigt. Bei den erwarteten Kreditablehnungen handelt es sich um eine Einschätzung des Firmenkunden. Hier wäre es sinnvoll, zusätzlich die Beurteilung der Bank heranzuziehen.

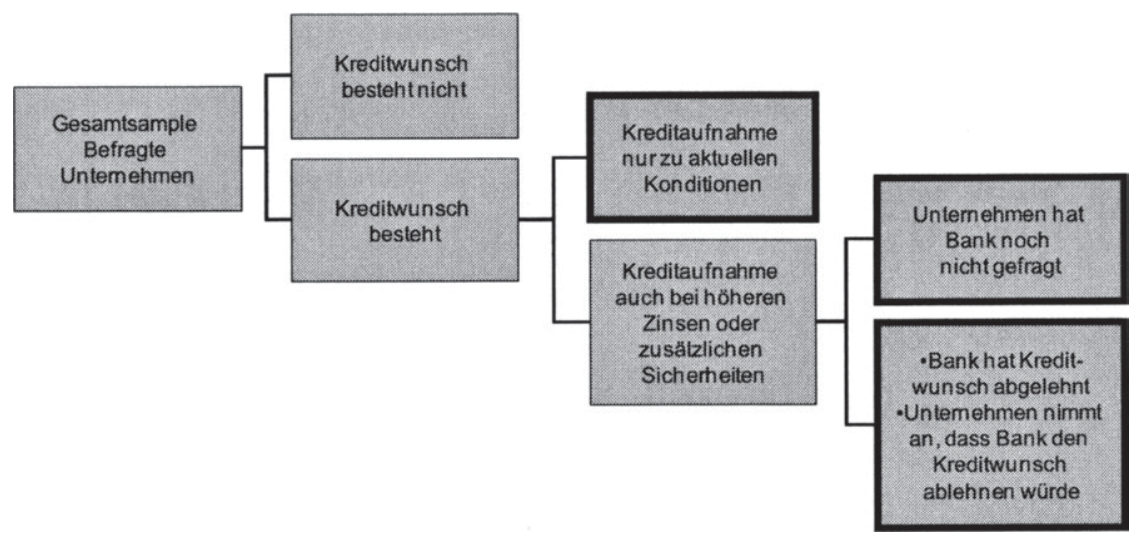

Abb. A-7: Vorgehen zur direkten Messung der Kreditverfügbarkeit ${ }^{703}$

\section{Dauer}

COLE misst ebenso wie ANGelini/Di SALVO/FeRRI den direkten Effekt der beziehungsbezogenen Variablen auf die Kreditverfügbarkeit, indem er untersucht, inwiefern selbige die Wahrscheinlichkeit beeinflusst, dass der potenzielle Kreditnehmer der Bank den Kredit ausdehnt oder ablehnt. ${ }^{704}$ COLE zeigt, dass die Kreditverfügbarkeit nur während des ersten Jahres der Bankbeziehung steigt, später hingegen nicht mehr. ${ }^{705}$ PETERSEN/RAJAN finden heraus, dass die berichtete Dauer der Bankbeziehung einen positiven, signifikanten Einfluss auf die Kreditverfügbarkeit hat, wobei selbige an der Häufigkeit der verspäteten Zahlungen an die Lieferanten gemessen wurde. ${ }^{706}$ Bei Verwendung der Dauer der Bankbeziehung als Proxy für die Informiertheit der Bank lässt sich konstatieren, dass die Unternehmen also weniger häufig mit Verspätung zahlen, wenn die Kreditgeber gut informiert sind. PETERSEN/RAJAN führen zwei theoretische Erklärungen an, warum sich die Dauer der Beziehung auf die Kreditverfügbarkeit, jedoch nur gering auf den Preis auswirkt. Wenn Kreditrationierung nach STIGLITZ/WEISS tatsächlich stattfindet, dann können die marginalen Gewinne aus der Investition deutlich höher sein als die Kreditzinsen. Sofern die Unternehmen in dieser Situation die Wahl hätten, würden sie sich eher mehr Kredite als günstigere Kredite

703 Eigene Darstellung in Anlehnung an Angelini/Di Salvo/Ferri (1998), S. 932.

704 Vgl. Cole (1998), S. 960 f. Datengrundlage für seine Untersuchung war der Datensatz des National Survey of Small Business Finances von 1993.

705 Vgl. Cole (1998), S. $971 \mathrm{f}$.

706 Vgl. hier und im Folgenden Petersen/Rajan (1994), S. 28. 
wünschen. ${ }^{707}$ Die zweite Erklärung besteht darin, dass durch die Dauer der Beziehung zwar die Kosten aufgrund der gestiegenen Informationen sinken, allerdings das Informationsmonopol sich festigt, und deswegen die Einsparungen nicht an die Kunden weitergegeben werden. ${ }^{708}$

Auch für den italienischen Markt kommen ANGELINI/Di SALVO/FERRI zu dem Ergebnis, dass mit steigender Dauer der Bankbeziehung die Kreditverfügbarkeit steigt. ${ }^{79}$ Insbesondere für Unternehmen mit einer Beziehungsdauer von nicht mehr als drei Jahren ist die Kreditverfügbarkeit geringer als bei Unternehmen mit einer längeren Beziehungsdauer. Dies stimmt überein mit den Ergebnissen von COLE, der feststellt, dass die Länge der Beziehung nach mehr als einem Jahr irrelevant wird. ${ }^{710}$ Bei einer Studie von LEHMANN/NEUBERGER ist die Wahrscheinlichkeit, keinen Kredit zu bekommen, dann am größten, wenn das Unternehmen noch nicht Kunde der Bank ist. ${ }^{\prime \prime \prime}$ Dies könnte als ein Versuch der Kundenabwerbung bzw. allgemein der Kundengewinnung interpretiert werden.

Bei deutschen Studien kommen HARHOFF/KöRTING zu dem Ergebnis, dass die Dauer der Bankbeziehung keinen signifikanten Einfluss auf die Kreditverfügbarkeit hat. ${ }^{712}$ Analog zu PETERSEn/Rajan messen sie die Kreditverfügbarkeit anhand einer indirekten Variablen, indem sie ebenfalls auf die Existenz von Lieferantenkrediten rekurrieren. Sie argumentieren gleichermaßen, dass Kreditbeschränkungen indirekt dadurch identifizierbar sind, dass ein Unternehmen auf eine Form der Mittelbeschaffung, bei der die Zinsen deutlich über den Bankzinsen liegen, zurückgreift. Als Variable verwenden sie den Anteil der gezogenen in Relation zu den angebotenen Skontomöglichkeiten. ${ }^{73}$

Alter

PETERSEN/RAJAN können zeigen, dass ältere Firmen die Lieferantenverbindlichkeiten seltener zu spät zurückzahlen, und führen dies auf weniger Kreditrationierungen zurück. ${ }^{714} \mathrm{Da}$ das Alter des Unternehmens und die Dauer der Bankbeziehung einen signifikanten Effekt auf die Häufigkeit der verspäteten Zahlungen haben, kann konstatiert werden, dass die Unternehmen also weniger häufig mit Verspätung zahlen, wenn die Kreditgeber gut informiert sind. Zu gleichen Ergebnissen kommen ANGELINI/DI SALVO/FERRI Und HARHOFF/KÖRTING, auch bei ihrer Studie sinken die Liquiditätsrestrik-

\footnotetext{
707 Vgl. Petersen/Rajan (1994), S. 35.

708 Vgl. Petersen/Rajan (1994), S. 35. Vgl. hierzu auch ausführlich Kapitel A.4.3.1.2.

709 Vgl. Angelini/Di Salvo/Ferri (1998), S. 946.

710 Vgl. Angelini/Di Salvo/Ferri (1998), S. 946 und Cole (1998), S. 971 f.

711 Vgl. Lehmann/Neuberger (2001), S. 24.

712 Vgl. Harhoff/Körting (1998a), S. 18.

713 Vgl. Harhoff/Körting (1998a), S. 18. Der Preisnachlass ist relativ hoch und beträgt in Deutschland üblicherweise $2 \%$, wenn die Zahlung innerhalb von 14 Tagen erfolgt Bei einem Zahlungsziel von 50 Tagen, einer Skontofrist von 14 Tagen und einen Skontosatz von $2 \%$ beträgt der effektive Jahreszins eines Lieferantenkredits 20,41\%. Vgl. Hahn/Meyer (2003), S. $242 \mathrm{ff}$. 
tionen mit zunehmendem Unternehmensalter. ${ }^{715}$ COLE zeigt, dass die Kreditverfügbarkeit zwar mit zunehmendem Unternehmensalter steigt, allerdings nimmt der marginale Effekt ab. ${ }^{716}$ Dieser Effekt zeigt somit, dass nicht nur der Wert der privaten, sondern auch der öffentlichen Informationen im Zeitablauf abnimmt. ${ }^{717}$

\section{Scope}

HODGMAN findet heraus, dass Kundenbetreuer die Qualität einer Geschäftsbeziehung hinsichtlich der Anlagengeschäfte als wesentliches Kriterium für die Entscheidung betrachten, ob ein Darlehen bzw. ein neues Darlehen vergeben werden soll oder nicht. ${ }^{718}$ PETERSEN/RAJAN zeigen, dass Unternehmen, die andere Dienstleistungen von Banken in Anspruch nehmen weniger liquiditätsbeschränkt sind. ${ }^{719}$ Der Einfluss zeigt sich darin, dass der Anteil der verspäteten Zahlungen sinkt. Der Anteil der Skontoziehungen als zweite Form der Operationalisierung wird nicht signifikant beeinflusst.

COLE kommt zu der Erkenntnis, dass die Wahrscheinlichkeit für eine Kreditverlängerung oder Neuvergabe steigt, wenn der potenzielle Kreditgeber bereits Produktlieferant für Spar- oder Anlagekonten und Financial Management-Dienstleistungen war. ${ }^{220}$ COLE hat dazu vier Variablen in der Untersuchung berücksichtigt, die die Art der beanspruchten Finanzdienstleistungen beschreiben. Diese Variablen sind Kontokorrentkonten, Sparkonten, Kredite (Kreditlinien, Darlehen für die Anschaffung von Maschinen oder Automobilen, Hypothekendarlehen, sonstige Kredite und KapitalLeasing) und Financial Management Services (Cash Management-Dienstleistungen, kreditbezogene Dienstleistungen, Wertpapiergeschäfte und Dienstleistungen im Bereich Investment und Pensionsfonds). ${ }^{21}$ Anders als PETERSEN/RAJAN verwendet COLE mehrere Variablen für die jeweiligen Kontoarten. Dies ist dahingehend wichtig, als dass in der Studie von COLE 70\% der Unternehmen, die einen Kredit beantragt haben Kontokorrentkonten beim potenziellen Kreditgeber besitzen, allerdings nur 22\% der Unternehmen ihre Einlagengeschäfte beim selbigen tätigen. ${ }^{722}$ Des Weiteren ist die Art der Information, die beim Monitoring eines Kontokorrentkontos generiert werden, anders als selbige beim Monitoring eines Einlagenkontos. COLE findet in Übereinstimmung mit seiner Hypothese einen positiven Zusammenhang zwischen der Verwendung von Spar- und Einlagekonten und Financial Management-Dienstleistungen auf der einen Seite und der Kreditverfügbarkeit auf der anderen Seite. ${ }^{723}$ Für die Existenz von Kontokorrentkonten ging er von einem positiven Effekt auf die Kreditverfüg-

\footnotetext{
715 Vgl. Angelini/Di Salvo/Ferri (1998), S. 934 und Harhoff/Körting (1998a), S. 18.

716 Vgl. Cole (1998), S. 971.

717 Vgl. Cole (1998), S. $971 \mathrm{f}$.

718 Vgl. Hodgman (1961), S. 257 ff. Dieser Zusammenhang kann in neueren Studien nicht mit dieser Bestimmtheit nachgewiesen werden. Cole findet allerdings einen positiven Zusammenhang zwischen der Kreditverfügbarkeit und der Existenz von Spar- und Einlagekonten bei dem Kreditinstitut. Vgl. Cole (1998), S. 963.

719 Vgl. Petersen/Rajan (1994), S. 26.

720 Vgl. Cole (1998), S. 962.

721 Vgl. Cole (1998), S. 962.

722 Vgl. Cole (1998), S. 963.

723 Vgl. Cole (1998), S. 973. 
barkeit aus, ${ }^{724}$ allerdings war die empirisch ermittelte Wirkrichtung nicht immer eindeutig. Bei Existenz bestehender Kredite führt eine zusätzliche Kreditaufnahme zu einer Erhöhung der Fremdkapitalquote, was den Effekt der Informationsgewinnung konterkariert, so dass die Wirkrichtung ambivalent ist. ${ }^{725}$ Der positive Zusammenhang bei Spar- und Einlagekonten und Financial Management-Dienstleistungen ist konsistent mit vorherigen Studien, die ebenfalls gezeigt haben, dass Banken Informationen über das Kreditrisiko gewinnen, indem sie die Einlagengeschäfte des Kreditnehmers überwachen. ${ }^{726}$ ANGELINI/DI SALVO/FERRI weisen nach, dass Mitglieder von Genossenschaftsbanken (mutual banks) einfacher Kredite erhalten als Nicht-Mitglieder und somit von einer höheren Kreditverfügbarkeit profitieren. ${ }^{727}$

\section{Anzahl der Bankverbindungen}

PETERSEN/RAJAN finden heraus, dass Unternehmen mit mehreren Bankverbindungen eine geringere Kreditverfügbarkeit aufweisen als Unternehmen mit nur einer Bankverbindung. ${ }^{228} \mathrm{Zu}$ ähnlichen Ergebnissen kommen HARHOFF/KÖRTING, ANGELINI/DI SALVO/FERRI und COLE. ${ }^{229}$ Dies lässt sich darin begründen, dass die Informationen über die Firmenspezifika bei einer Bank größer sind, wenn das Unternehmen nur bei einer oder wenigen Banken Kredite aufnimmt. ${ }^{730}$ Dies ist konsistent mit den Ergebnissen von ONGENA/SMITH, welche zeigen, dass Unternehmen mit mehreren Bankbeziehungen eine Bankbeziehung schneller beenden als Unternehmen mit nur einer Bankbeziehung, weshalb vermutet werden kann, dass eine bestehende Bankbeziehung für Unternehmen mit mehreren Verbindungen einen geringeren Wert stiftet. ${ }^{731}$ ANGELINI/Di SALVo/FERrI belegen, dass Unternehmen, die Mitglieder der Bank sind und ausschließlich bei dieser einen Bank Kredit aufnehmen, eine bessere Kreditverfügbarkeit haben als Mitglieder, die mehrere Kreditbankbeziehungen haben oder als NichtMitglieder. ${ }^{732}$

\section{Marktkonzentration}

PETERSEN/RAJAN zeigen, dass der Bankenkreditmarkt für kleine Unternehmen in den USA stark konzentriert ist. ${ }^{733}$ Selbst wenn die Unternehmen verschiedene Kreditquellen haben, so tendieren sie doch dahin, die Kredite bei einer Bank zu konzentrieren. ${ }^{734}$ Dieses Verhalten ist bei größeren Firmen weniger offensichtlich. Das Ausmaß der Kreditmarktkonzentration wird durch den Herfindahl-Index der Kreditgeber innerhalb

\footnotetext{
$724 \quad$ Vgl. Cole (1998), S. 963.

725 Vgl. Cole (1998), S. 963.

726 Vgl. Duca (1998), S. 978. Vgl. hierzu auch die Studien von Fama (1985) und Nakamura (1994).

727 Vgl. Ongena/Smith (2000a), S. 241.

728 Vgl. Petersen/Rajan (1994), S. 26.

${ }_{729}$ Vgl. Harhoff/Körting (1998a), S. 18, Angelini/Di Salvo/Ferri (1998), S. 946 und Cole (1998), S. 963.

730 Vgl. Angelini/Di Salvo/Ferri (1998), S. 946.

731 Vgl. Ongena/Smith (2000a), S. 247.

${ }_{732} \mathrm{Vgl}$. Angelini/Di Salvo/Ferri (1998), S. 949.

${ }_{733}$ Vgl. Petersen/Rajan (1994), S. 26.

734 Vgl. Ongena/Smith (2000a), S. 247. 
der Region des Unternehmens gemessen. Hinsichtlich der Auswirkungen auf die Kreditverfügbarkeit zeigen PETERSEN/RAJAN, dass es einen positiven Zusammenhang zwischen der Marktkonzentration und der Kreditverfügbarkeit gibt, d.h. eine größere Marktkonzentration führt zu einer höheren Kreditverfügbarkeit. ${ }^{735}$

ANGELINI/Di SALVO/FERRI konnten anders als PETERSEN/RAJAN keinen signifikanten Effekt der Wettbewerbsintensität, welche sie ebenfalls aus dem Herfindahl-Index abgeleitet haben, auf die Kreditverfügbarkeit feststellen. ${ }^{736}$ Als eine mögliche Ursache für die im Vergleich zu PETERSEN/RAJAN abweichenden Ergebnisse führen sie an, dass die von ihnen betrachteten Kreditmärkte geographisch kleiner waren als die bei PETERSEN/RAJAN. ${ }^{737}$

BERLIN/MESTER präsentieren Ergebnisse, die den Schluss zulassen, dass Banken mit starker Marktmacht in Bezug auf die Einlagen entgegenkommender und weniger restriktiv in Bezug auf die Kreditvergabe sind. ${ }^{738}$ Die hier genannte Begründung ist, dass Banken, die einen Großteil der Einlagen der Region halten, weniger empfindlich sind in Bezug auf wirtschaftliche Schwankungen.

\section{Größe}

GERTLER/GILCHRIST gehen davon aus, dass große Firmen in der Regel Zugang zu einer größeren Palette an alternativen Finanzierungsquellen haben und deswegen seltener Kreditrationierungen unterliegen als kleine Firmen. ${ }^{739}$ Dieser Effekt wird in anderen Studien bestätigt, ${ }^{70}$ so zahlen größere Firmen die Lieferantenverbindlichkeiten seltener zu spät. Auch hier kann der Informationseffekt ursächlich sein, denn bei größeren Unternehmen ist der Umfang der öffentlich zur Verfügung stehenden Informationen wahrscheinlich größer als bei kleinen Unternehmen. Die Unternehmen zahlen also weniger häufig mit Verspätung, wenn die Kreditgeber gut informiert sind. In weiteren Studien konnte allerdings kein Effekt der Größe auf die Kreditverfügbarkeit konstatiert werden. ${ }^{74}$

\section{Weitere Erkenntnisse}

ANGELINI/Di SALVO/FerRI finden, dass es hinsichtlich der Region und der Branche des Unternehmens signifikante Unterschiede hinsichtlich der Kreditverfügbarkeit gibt, wohingegen die Rechtsform und die Unternehmensperformance keinen Einfluss ausüben. ${ }^{742}$ Gemäß PETERSEN/RAJAN zahlen profitablere Firmen zwar die Lieferantenverbindlichkeiten seltener zu spät als weniger profitable Firmen, jedoch ist dieser Effekt

\footnotetext{
735 Vgl. Petersen/Rajan (1994), S. 28.

736 Vgl. Angelini/Di Salvo/Ferri (1998), S. 936.

737 Vgl. Angelini/Di Salvo/Ferri (1998), S. 936.

$738 \quad$ Vgl. Berlin/Mester (1998), S. 873.

739 Vgl. Gertler/Gilchrist (1994), S. 309 ff.

740 Vgl. Petersen/Rajan (1994), S. 26, Petersen/Rajan (1995), S. 428, Cole (1998), S. 973, Scott/Dunkelberg (2003), $1010 \mathrm{f}$.

741 Vgl. Angelini/Di Salvo/Ferri (1998), S. 934, Lehmann/Neuberger (2001), S. 24.

742 Vgl. Angelini/Di Salvo/Ferri (1998), S. 934.
} 
nicht signifikant ${ }^{74}$ Bei COLE hingegen lässt sich jedoch ein Zusammenhang zwischen der Kreditnehmerqualität und der Verfügbarkeit finden. So zeigt er, dass Zahlungsprobleme in der Vergangenheit, gemessen an der Zahl der Überziehungen, einen negativen Effekt auf die Kreditverfügbarkeit haben. ${ }^{74}$ LEHMANN/NEUBERGER bestätigen die Ergebnisse von COLE, so reduziert eine schlechte Kreditnehmerqualität, gemessen an der Ratingklasse, die Wahrscheinlichkeit der Kreditzusage. ${ }^{745}$

Wie in Tab. A-12 zusammengefasst, lässt sich hinsichtlich der Kreditverfügbarkeit feststellen, dass sich auch hier kein einheitliches Bild abzeichnet. So zeigen die Variablen Alter des Unternehmens, Anzahl der Bankverbindungen, zusätzliche Dienstleistungen und Marktkonzentration eine einheitliche Tendenz, hingegen sind die Ergebnisse bei den Variablen Kreditnehmerqualität, Größe und Dauer der Bankverbindung uneinheitlich. Kritisch zu sehen sind vor allem die indirekten Messungen der Kreditverfügbarkeit. Wie auch bereits von ANGELINI/DI SALVO/FERRI moniert, wirken hier möglicherweise auch noch andere Einflussparameter auf die indirekten Parameter. ${ }^{746}$

743 Vgl. Petersen/Rajan (1994), S. 26.

744 Vgl. Cole (1998), S. 975.

745 Vgl. Lehmann/Neuberger (2001), S. 24.

$746 \mathrm{Vgl}$. Angelini/Di Salvo/Ferri (1998), S. 931. 


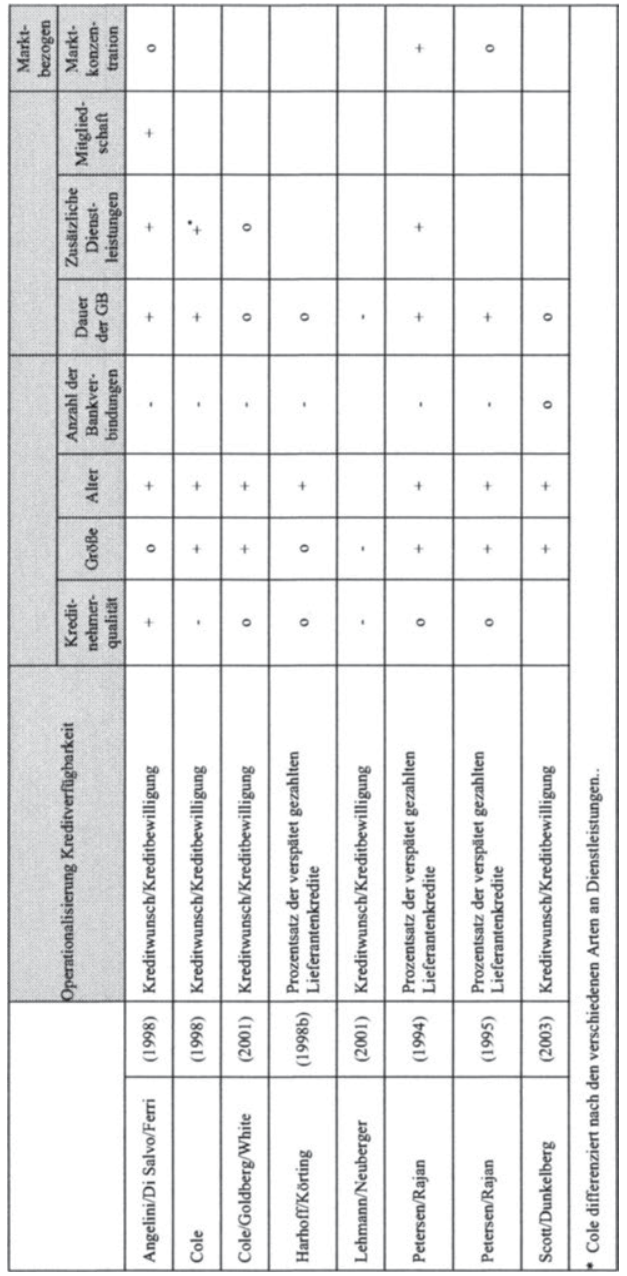

Tab. A-12: Zusammenfassung der Ergebnisse der empirischen Studien zur Kreditverfügbarkeit ${ }^{747}$

747 Eigene Darstellung. Vgl. Angelini/Di Salvo/Ferri (1998), S. 944 f., Cole (1998), S. 971 bzw. S. 974 f., Cole/Gold-berg/White (2001), S. 44 f., Harhoff/Körting (1998b), S. 1346 f., Lehmann/Neuberger (2001), S. 352, Petersen/Rajan (1994), S. 27, Petersen/Rajan (1995), S. 428 und Scott/Dunkelberg (2003), S. 1010 f. Eine Übersicht mit ähnlichen Studien und weiteren Variablen findet sich bei Segbers (2007), S. 211. 


\subsubsection{Kritische Würdigung der bisherigen empirischen Studien sowie Darstellung bestehender Erweiterungen um verhaltenswissenschaftliche Aspekte}

\subsection{Kritische Würdigung der bisherigen empirischen Studien}

Zentrale Parameter bei den zahlreichen Studien sind die Dauer der Beziehung sowie der Scope. Diese Variablen werden jeweils als Indikator für die Stärke der Bankbeziehung und als Medium zur Beseitigung von Informationsasymmetrien herangezogen. Es bleibt hierbei jedoch gänzlich offen, wie die privaten Informationen generiert werden, inwiefern es sich bei der Informationsgenerierung weitestgehend um einen Automatismus, bspw. in Abhängigkeit von der Dauer der Beziehung handelt, und welche Rolle soziale Interaktionen im Rahmen dieser Beziehungen spielen. Diese Aspekte fehlen, obwohl bereits bei MAIN die persönliche Beziehung zwischen dem Firmenkundenbetreuer und dem Kunden als zentrales Merkmal der Kunde-Bank-Beziehung betont wurde und bei MORIARTY/KIMBALL/GAY die persönliche Beziehung als intangibler, aber wesentlicher Nutzen hervorgehoben wurde. ${ }^{748}$

Vor diesem Hintergrund bieten die Interaktionstheorien, welche beide Seiten einer Beziehung betrachten, in der Individuen aktiv involviert sind, eine sinnvolle Erweiterung. ${ }^{799}$ In diesem theoretischen Rahmen haben verschiedene Studien - vornehmlich aus dem Bereich des Industriegütermarketings - versucht, die Determinanten einer erfolgreichen langfristigen Beziehung zu identifizieren. ${ }^{750}$ Eine Erkenntnis ist, dass Vertrauen und Zufriedenheit eine Schlüsselrolle in der Entwicklung einer Beziehung einnehmen. ${ }^{751}$ Im Vergleich zu Gütermärkten sind allerdings die sozialen Interaktionen zwischen Bankmitarbeitern und den Unternehmern weniger klar und sehr variabel. ${ }^{752}$ PERRIEN/RICARD merken an, dass auch innerhalb einer Bank die Bankmitarbeiter eine unterschiedliche Wahrnehmung in Bezug auf die Positionierung der Bank zum Relationship vs. Transaction Banking der eigenen Bank und der Konkurrenzbanken haben, ${ }^{753}$ so dass auch die Person des Firmenkundenbetreuers in den Studien Berücksichtigung finden sollte. ENNEW/BINKS berichten, dass informale Aspekte einer Bankbeziehung das Ausmaß beeinflussen, in dem sich ein Kunde der Bank gegenüber verpflichtet fühlt, und dass der Informationsfluss innerhalb der Bankbeziehung wichtig für das gegenseitige Verstehen der Partner ist. ${ }^{754}$ Auch hier wird noch mal der Aspekt der in der Beziehung agierenden Personen als wesentlich herausgestellt.

Eine Schlüsselvariable für die Beschreibung der sozialen Interaktion ist Vertrauen, welches von positiven Erfahrungen in der Vergangenheit ausstrahlen kann. Da Ver-

\footnotetext{
${ }_{748}$ Vgl. Kapitel A.4.1.

749 Vgl. Lehmann/Neuberger (2001), S. 11. Für eine ausführliche Diskussion vgl. Ford (1990) und Axelssohn/Easton (1992).

Vgl. Perrien/Ricard (1995), S. 40.

Vgl. Ganesan (1994), S. 3 f.

Vgl. Lehmann/Neuberger (2001), S. 11.

Vgl. Perrien/Ricard (1995), S. 40.

Vgl. Ennew/Binks (1995), S. 57 ff.
} 
trauen Moral Hazard-Probleme und somit Monitoring-Kosten reduziert, sind geringere Risikoaufschläge beim Zinssatz erforderlich, ${ }^{755}$ so dass sich daraus, wie in Abb. A-8 dargestellt, ein direkter Effekt auf die Konditionen ergibt. Die Beschaffenheit der Beziehung, die sich unter anderem im Umfang des bestehenden Vertrauens widerspiegelt, wird aber auch die Quantität und die Qualität der Informationen, die der Bank zur Verfügung gestellt werden, beeinflussen. In einer engen Beziehung versteht die Bank das spezifische Geschäfts- und Branchenumfeld des Unternehmens. Die Bank erhält Signale zu Managereigenschaften und Geschäftsperspektiven. ${ }^{756}$ Somit bietet die Beziehung eine Basis für das Verstehen der Kundenbedarfe. Des Weiteren führt der erhöhte Informationsfluss zu einem besseren Verständnis des Geschäftspartners. ${ }^{757}$ Dies führt erneut zu einer Reduktion der Monitoring-Kosten und potenziell auch der Zinssätze. ${ }^{758}$

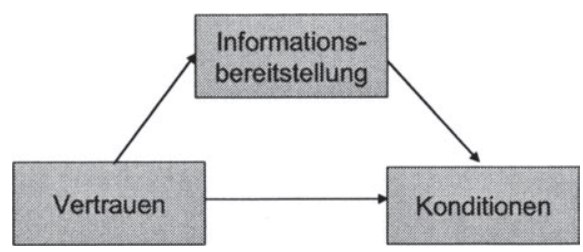

Abb. A-8: Auswirkung von Vertrauen im Rahmen der Kunde-Bank-Beziehung ${ }^{759}$

Dieser Vertrauensaspekt wird häufig in den beschriebenen Studien am Rande angesprochen oder bei langen Bankbeziehungen implizit unterstellt, ohne selbigen näher zu erläutern oder dezidiert zu hinterfragen. Wie die nachstehenden Ausführungen zeigen, werden Begriffe wie „vertrauenswürdig“, „Vertrauen“ und „vertraulich“ zwar im Rahmen der theoretischen Ausführungen verwendet, in der Empirie aber nicht erneut aufgegriffen. So weist BoOT darauf hin, dass vertrauliche Informationen im Rahmen einer festen Kunde-Bank-Beziehung ausgetauscht werden. ${ }^{760}$ Die feste Kunde-BankBeziehung wird in seiner Studie ausschließlich durch die Dauer der Beziehung operationalisiert. Die alleinige Tatsache, dass eine lange Beziehung besteht, lässt allerdings nicht den Schluss zu, dass vertrauliche Informationen ausgetauscht werden, obgleich die Wahrscheinlichkeit höher ist als bei einer noch jungen Beziehung. DOBERANZKE betrachtet Vertrauen als wichtige Voraussetzung für eine Partnerschaft zwischen Bank und Kunde. ${ }^{761}$ Gemäß PETERSEN/RAJAN steigert eine lange Dauer der Bankbeziehung und eine lange gemeinsame Kredithistorie die Wahrscheinlichkeit, dass das Unter-

\footnotetext{
755 Vgl. Lehmann/Neuberger (2001), S. 12.

756 Vgl. Lehmann/Neuberger (2001), S. 12.

757 Vgl. Ennew/Binks (1995), S. 57 ff.

758 Vgl. Lehmann/Neuberger (2001), S. 12.

759 Eigene Darstellung.

760 Vgl. Boot (2000), S. 10.

761 Vgl. Doberanzke (1993), S. 22.
} 
nehmen überlebensfähig und der Unternehmer vertrauenswürdig ist. ${ }^{762}$ Ebenso argumentieren sie, dass bei jungen Unternehmen eine Unsicherheit bezüglich Kompetenz und Vertrauenswürdigkeit besteht. ${ }^{733}$ Zwar sollte mit zunehmender Beziehungsdauer die Beurteilungsfähigkeit hinsichtlich der Vertrauenswürdigkeit steigen, die Schlussfolgerung, dass eine zunehmende Beziehungsdauer zwangsläufig zu einem größeren Vertrauen führt, abstrahiert zu stark von der Komplexität des Phänomens Vertrauen.

Bei dem Prozess des Informationsaustausches und des Vertrauensaufbaus handelt es sich allerdings nicht um einen einseitigen Prozess; der Prozess erfordert Mitwirkung von beiden Seiten. So kann die Bank nur die Kundenwünsche und -bedürfnisse erfüllen, wenn der Unternehmer die richtigen Informationen zeitnah liefert. Diese Kooperation führt wiederum zu einer stabilen Beziehung, in der sich die Partner gegenseitig verpflichtet fühlen. ${ }^{764}$ Ein guter Informationsfluss ist einerseits Ergebnis und andererseits Voraussetzung für eine gute und enge Beziehung. Eine gute und enge Beziehung und Bindung ist aber von wesentlicher Bedeutung, denn die Aufrechterhaltung der Beziehung zwischen Kunde und Bank wurde als eine Voraussetzung für den intertemporalen Konditionenausgleich genannt. Wesentliche Einflussgrößen waren hier die Marktkonzentration und die Anzahl der Bankverbindungen des einzelnen Unternehmens. Diese Größen reflektieren vor allem die Möglichkeit, die Bankverbindung zu wechseln und somit den Grad der Gebundenheit des Kunden an die Bank. Unter Gebundenheit wird hier das Nicht-Wechseln-Können des Kunden verstanden. ${ }^{765}$ Das Nicht-Wechseln-Wollen wurde bisher in den Studien weitestgehend vernachlässigt, so findet sich in den untersuchten Studien keine Variable, die diese eher emotionale Komponente abbildet.

Im Folgenden werden drei Studien angesprochen, die einen ersten Ansatz darstellen, einzelne Aspekte der Theorie der sozialen Interaktion auf die Relationship BankingForschung zu übertragen.

\subsection{Sozial eingebundene Geschäftsbeziehungen bei Uzzi}

UZZI/LANCASTER untersuchen, inwiefern informelle firmenübergreifende Beziehungen den Wissenstransfer und die Lerneffekte über die Unternehmensgrenzen hinaus beeinflussen. ${ }^{766}$ Als theoretische Grundlage greifen sie auf die Theorie der sozialen Eingebundenheit zurück. Bei diesem Ansatz wird die Qualität der informellen Bindungen als variabel angesehen in Abhängigkeit von dem Grad der sozialen Eingebundenheit der Geschäftbeziehung. ${ }^{767}$ Der Grad der Eingebundenheit kann entweder als eingebunden oder als ,at arm's length' charakterisiert werden.

Bei , at arm's length' handelt es sich um die konventionelle Betrachtung der unternehmensübergreifenden Bindungen, hierbei sind die Beziehungen kühl, unpersönlich,

\footnotetext{
762 Vgl. Petersen/Rajan (1994), S. 5.

763 Vgl. Petersen/Rajan (1994), S. 5.

764 Vgl. Lehmann/Neuberger (2001), S. 12.

765 Vgl. Eggert (1999), S. 52 f.

766 Vgl. Uzzi/Lancaster (2003), S. 383.

767 Vgl. Uzzi/Lancaster (2003), S. 383.
} 
atomistisch und die Akteure werden motiviert durch ein instrumentelles Gewinnstreben. Bei sozial eingebundenen Geschäftsbeziehungen findet eine Verwebung von privaten und geschäftlichen Verhaltensweisen und Kontakten in der Form statt, dass keine eindeutige Unterscheidung zwischen diesen mehr möglich ist. ${ }^{768}$ Diese Beziehungen schaffen Verhaltenserwartungen, die bei der atomistischen Betrachtung der Transaktionen irrelevant sind, während sie bei eingebundenen Beziehungen dazu führen, dass eine Verschiebung von Opportunismus zu einem vertrauensvollen, kooperativen Verhalten erwartet wird. ${ }^{769}$

In ihrer Untersuchung unterscheiden UzZ/LANCASTER dabei zwischen zwei Typen von Informationen, öffentlichen und privaten Informationen. ${ }^{770}$ UzzI zeigt, dass Arm's length-Beziehungen den Fluss von öffentlichen Informationen, eingebundene Beziehungen hingegen den Fluss von privaten Informationen, die ja gerade für die Funktion von Hausbankbeziehungen charakteristisch sind, fördern. ${ }^{771}$ Denn die Erwartung von Vertrauen in dieser Beziehung und die Annahme der Reziprozität des Vertrauens liefert eine Absicherung dahingehend, dass die Informationen nur zum beiderseitigen Nutzen verwendet werden. ${ }^{72}$ In einer Feldstudie haben UzZI/LANCASTER Interviews mit 24 Firmenkundenbetreuern von mittelständischen Unternehmen durchgeführt, in der sie genau diesen Zusammenhang bestätigen. Gleichzeitig sind diese Ausführungen ein Hinweis darauf, dass eine Hausbankbeziehung nicht per se zu positiven (ökonomischen) Konsequenzen führt, sondern dass gerade der Grad der Relationalität, verstanden als Ausmaß der sozialen Eingebundenheit, hierbei eine wichtige Rolle spielt. ${ }^{773}$

Gegenstand der Studie von UzzI/GILLESPIE ist die Frage, inwiefern die sozialen Beziehungen und Netzwerke zwischen Banken und Unternehmen einzigartige finanzielle Fähigkeiten und Ressourcen schaffen, die wiederum das Management von Lieferantenkrediten beeinflussen. ${ }^{774}$ In ihrer Studie untersuchen sie konkret, welche Auswirkungen die Dauer der Bankbeziehung, die Multiplexität der Bankbeziehung und die Größe des Banknetzwerkes auf das Zahlungsverhalten in Bezug auf Lieferantenkredite hat. Hierbei unterscheiden sie zwischen dem Anteil an Skontoziehungen sowie dem Anteil an verspäteter Zahlung jeweils in Bezug auf die Lieferantenkredite. ${ }^{775}$ Die Multiplexität wird gemessen anhand der Zahl der Bankdienstleistungen, die vom Unternehmen und vom Unternehmer in Anspruch genommen werden, denn gerade die Dienstleistungen im privaten Bereich führen dazu, dass die sozialen Beziehungen

768 Vgl. lacobucci/Ostrom (1996), S. 53 ff. Dies umfasst bspw. private Einladungen, gemeinsame Hobbies oder auch gemeinsame Bekannte. Hier wird eine gewisse Nähe zur Argumentation in der Studie von Angelini/Di Salvo/Ferri sichtbar. Vgl. Angelini/Di Salvo/Ferri (1998), S. 925 ff.

Vgl. Uzzi/Lancaster (2003), S. 383.

Vgl. Uzzi/Lancaster (2003), S. 385.

Vgl. Uzzi (1999), S. $481 \mathrm{ff}$.

Vgl. Uzzi/Lancaster (2003), S. 385.

Fraglich ist dann, ob bei wenig relationalen Beziehungen überhaupt von Hausbankbeziehungen gesprochen werden kann. An dieser Stelle soll diese Sichtweise inmal beibehalten werden.

774 Vgl. Uzzi/Gillespie (2002), S. 602.

775 Vgl. Uzzi/Gillespie (2002), S. 602. 
vertieft werden. ${ }^{76}$ Die Netzwerkgröße wird gemessen als Anzahl der Bankverbindungen des Unternehmens.

Hinsichtlich der Dauer der Bankbeziehung kommen sie zu dem Ergebnis, dass mit zunehmender Dauer der Bankbeziehung die Skontoziehungen steigen und die verspäteten Zahlungen sinken. Sie leiten daraus ab, dass die Dauer der Bankbeziehung ein Indikator für den Umfang der ausgetauschten privaten Informationen ist und der Anstieg an privaten Informationen zu einer erhöhten Kreditverfügarbeit führt. ${ }^{\text {"7 }}$ Ihr Ergebnis hinsichtlich des Zusammenhangs zwischen Dauer der Bankbeziehung und Kreditverfügbarkeit entspricht somit den Studien von PETERSEN/RAJAN und ANGELI$\mathrm{NI} / \mathrm{DI}$ SALVO/FERRI. ${ }^{778}$

Auch mit zunehmender Multiplexität, d.h. Anzahl der genutzten Produkte und Dienstleistungen, kommt es zu einem Anstieg der Skontoziehungen und somit zu einer verbesserten Kreditverfügbarkeit. Allerdings konnte hinsichtlich der verspäteten Zahlungen kein eindeutiges Ergebnis erzielt werden, woraus UZZI/GILLESPIE schlussfolgern, dass die Multiplexität ein weniger robuster Indikator für die soziale Eingebundenheit ist als bspw. die Dauer der Bankbeziehung. Auch hier unterstützt ihr Ergebnis die vorherigen Studien von PETERSEN/RAJAN und COLE, ${ }^{79}$ wenngleich die Interpretation der Ergebnisse aufgrund der Einbeziehung der Theorie der sozialen Eingebundenheit eine andere ist.

Ferner führt bei UZZı/GILLESPIE eine zunehmende Netzwerkgröße, d.h. eine größere Anzahl von Bankverbindungen, dazu, dass die Skontoziehungen sinken und die verspäteten Zahlungen steigen, d.h. die Kreditverfügbarkeit sinkt. ${ }^{780}$ Auch mit diesem Ergebnis können sie vorherige Studien wie bspw. von PETERSEN/RAJAN bestätigen.

Im Endeffekt führen UzZI/GILLESPIE ihre Ergebnisse zwar auf die soziale Austauschtheorie und die Theorie der sozialen Eingebundenheit zurück, allerdings unterscheidet sich ihr Ansatz bezüglich der verwendeten Parameter nicht von den bestehenden, bereits ausführlich diskutierten Studien, so dass die Ergebnisse noch nicht den gewünschten Erkenntnisgewinn hinsichtlich des Einflusses der sozialen Interaktion auf die Kreditkonditionen verschaffen. Wichtig für diese Arbeit ist die empirisch noch nicht hinreichend untersuchte Aussage, dass nicht (nur) die Hausbankbeziehung als solche, sondern der Grad der sozialen Eingebundenheit ökonomische Konsequenzen hervorruft.

\footnotetext{
776 Vgl. Uzzi/Gillespie (2002), S. 604.

777 Vgl. Uzzi/Gillespie (2002), S. 610.

778 Vgl. Kapitel A.4.3.2.4.

779 Vgl. Kapitel A.4.3.2.4.

$780 \mathrm{Vgl}$. Uzzi/Gillespie (2002), S. 610.
} 


\subsection{Integration von Vertrauen in eine Studie zur Analyse der Kunde-Bank- Beziehung durch HARHOFF/KÖRTING}

In Kapitel A.4.3.2.5.1 zur Kritik der zuvor besprochenen Studien wurde die zentrale Rolle von Vertrauen im Rahmen der Bankbeziehung betont. HARHOFF/KÖRTING haben zwecks Beschreibung der Bankbeziehung neben den Parametern Dauer der Bankbeziehung und Anzahl der Bankverbindungen explizit diesen Vertrauensaspekt berücksichtigt. Dazu haben sie die Unternehmensmanager bezüglich des gegenseitigen Vertrauens zwischen Bank und Unternehmen befragt. ${ }^{781}$ In $61,5 \%$ der betrachteten Fälle $(\mathrm{N}=994)$ wurde nun von einem besonderen Vertrauensverhältnis zwischen Unternehmen und Bank berichtet.

Bei der Analyse der Einflussgrößen des Zinssatzes finden HARHOFF/KÖRTING, wie bereits in Kapitel A.4.3.2.2 erläutert, dass die Anzahl der Bankverbindungen und die Dauer der Bankbeziehung keinen signifikanten Effekt auf den Zinssatz ausüben. Dahingegen weist die Dummyvariable für das Vertrauen einen signifikanten negativen Effekt aus, d.h. die Existenz von Vertrauen führt zu einer Reduktion des Zinssatzes. Der Koeffizient für den Vertrauensparameter beträgt $-0,481$ und erklärt somit die Reduktion von $0,48 \%$ des Zinssatzes, so dass durchaus von einem ökonomisch signifikanten Einfluss gesprochen werden kann.$^{782} \mathrm{Da}$ die Integration der Vertrauensvariable nicht zu einer ökonomisch signifikanten Veränderung der Koeffizienten für die Dauer der Bankbeziehung und die Anzahl der Bankverbindungen führt, wird geschlussfolgert, dass der Vertrauensaspekt gemäß der statistischen Auswertung nicht in den anderen unabhängigen Variablen wie bspw. Dauer der Bankbeziehung enthalten ist und somit eine zusätzliche Erklärung liefert. ${ }^{783}$

Bei der Analyse der Einflussgrößen in Bezug auf die Sicherheitenstellung zeigen HARHOFF/KÖRTING für den deutschen Markt wie zuvor in Kapitel A.4.3.2.3 dargestellt, dass mit steigender Anzahl der Bankverbindungen die Wahrscheinlichkeit der Sicherheitenstellung steigt, während selbige mit zunehmender Dauer der Bankverbindung sowie steigendem Unternehmensalter sinkt. ${ }^{784}$ Bemerkenswert ist aber die Erkenntnis, dass die Wahrscheinlichkeit der Sicherheitenstellung bei Existenz von gegenseitigem Vertrauen sinkt. ${ }^{785}$ Auch bei dieser Auswertung ist der Vertrauensaspekt nicht in den anderen unabhängigen Variablen wie bspw. Dauer der Bankbeziehung enthalten. ${ }^{786}$

Hinsichtlich der Kreditverfügbarkeit konnte kein signifikanter Einfluss der Vertrauensvariablen festgestellt werden. Ferner konnten beim Pseudo- $R^{2}$ nur Werte im

\footnotetext{
${ }_{781}$ Vgl. Harhoff/Körting (1998b), S. 1319.

${ }_{782}$ Vgl. Harhoff/Körting (1998b), S. 1342 f.

783 Vgl. Harhoff/Körting (1998b), S. 1342 f.

784 Vgl. Harhoff/Körting (1998b), S. 1342 f.

785 Vgl. Harhoff/Körting (1998b), S. 1337 f.

786 Vgl. Harhoff/Körting (1998b), S. 1337 f. Die Koeffizienten der Variablen Anzahl der Kreditgeber und Dauer der Beziehung sowie deren Signifikanz sind auch nach Integration der Vertrauensvariablen nahezu unverändert.
} 
Bereich von 0,0150 bis 0,0183 erzielt werden, so dass der Erklärungsgehalt der Regression nur sehr gering ist. ${ }^{787}$

Resümierend lässt sich feststellen, dass Vertrauen zu einer Reduktion des zu zahlenden Zinssatzes und der Wahrscheinlichkeit der Sicherheitenstellung führt, während es keinen signifikanten Einfluss auf die Kreditverfügbarkeit ausübt. Dies könnte dadurch erklärt werden, dass Vertrauen zu einer Reduktion der Risiken eines Moral Hazard und der deswegen erforderlichen Monitoring-Maßnahmen führt, was wiederum in einen geringeren Bedarf an Sicherheiten und einer kostengünstigeren Kreditüberwachung resultiert. Sofern die Bank die Einsparungen an die Kunden weitergibt, sinken die Kreditzinsen für den Kunden. Während in den bisherigen Studien vielfach angenommen wurde, dass das Vertrauen bspw. in der Variablen Dauer der Bankbeziehung enthalten ist, wird hier gezeigt, dass Vertrauen einen zusätzlichen Erklärungsbeitrag in Ergänzung zu sonstigen Beziehungsvariablen wie der Dauer der Beziehung und der Anzahl der Kapitalgeber liefert. Denn die Koeffizienten der genannten Variablen bleiben auch bei zusätzlicher Aufnahme der Vertrauensvariablen nahezu unverändert. ${ }^{788}$ Somit kann also hier festgehalten werden, dass Vertrauen in Bankbeziehungen eine Rolle spielt und ökonomische Konsequenzen mit sich bringt.

Kritisch angemerkt werden muss allerdings die Operationalisierung des Vertrauenskonstruktes. Bei dem Vertrauenskonstrukt handelt es sich um ein vielschichtiges Phänomen, welches nicht über eine einzige Dummyvariable angemessen und vollumfänglich abgebildet werden kann. ${ }^{789}$ Folgerichtig erscheint es erforderlich, das Konstrukt des Vertrauens umfangreicher zu konzeptualisieren sowie seine Determinanten und Wirkungen in einer Hausbankbeziehung zu explizieren. Ferner können sie auch nicht erklären, was die Entwicklung von Vertrauen in Bankbeziehungen beeinflusst. Allein die Dauer der Beziehung sowie die Anzahl der Wettbewerber liefert keine Erklärung für das Entstehen von Vertrauen. ${ }^{790}$ Aufgrund der fehlenden (verhaltens-)wissenschaftlichen Auseinandersetzung mit dem latenten Konstrukt des Vertrauens bleiben auch die Interpretationen der Ergebnisse in der Studie von HARHOFF/KÖRTING eher oberflächlich. ${ }^{91}$

787 Vgl. Harhoff/Körting (1998b), S. 1346 f. Vor Integration der Vertrauensvariablen liegen die Werte für das Pseudo- $R^{2}$ im Bereich von 0,0150 bis 0,0159 . Nach Integration der Variablen liegen die Werte im Bereich von 0,0160 bis 0,0183 . Das Pseudo- $R^{2}$ wird bspw. bei der logistischen Regression oder der Tobit-Analyse herangezogen. Es ist wie das $\mathbf{R}^{2}$ bei der linearen Regression ein $\mathrm{Maß}$ für den Erklärungsgehalt der Regression. Eine auführliche Darstellung dieses auch bei der logistischen Regression zu verwendenden Gütemaßes erfolgt in Kapitel A.3.5.2.2.

788 Vgl. Harhoff/Körting (1998b), S. 1337 und 1342.

789 Siehe hierzu Kapitel A.5.2.3.1.

790 Vgl. Harhoff/Körting (1998a), S. 14.

791 Dieses gewisse Defizit räumen die Autoren selbst ein: „While we do not have information on what determines the evolution of trust in bank-firm relationships, it seems clear that there is more to it than simply time passing by (i.e. duration) or the extent of competition (number of lenders)", Harhoff/Körting (1998b), S. 1337. Vgl. hierzu auch Segbers (2007), S. 180. 


\subsection{Integration von Vertrauen in eine Studie zur Analyse der Kunde-Bank- Beziehung durch LEHMANN/NEUBERGER}

Die Studie von LEHMANN/NEUBERGER bietet dahingehend eine Erweiterung der bestehenden klassischen Studien aus dem Bereich Relationship Banking, als dass sie Interaktionsvariablen, welche die sozialen Beziehungen zwischen Kundenbetreuer und Unternehmensmanager messen, integrieren. ${ }^{792}$ Ferner versuchen sie, das Vertrauenskonstrukt detaillierter und wissenschaftlich fundierter abzubilden als dies in der Studie von HARHOFF/KÖRTING der Fall ist. Sie erweitern die Theorien der Finanzintermediation und die Theorien zum Relationship Lending um die Theorien der sozialen Interaktion und kommen zu dem Untersuchungsergebnis, dass ihre noch zu erläuternden Beziehungs- und Interaktionsvariablen Kreditzinsen, Sicherheitenerfordernisse und Kreditverfügbarkeit beeinflussen. ${ }^{793}$ Die theoretische Grundlage für die Erweiterung bei LEHMANN/NEUBERGER bildet im Wesentlichen die länderübergreifende Studie von FISMAN/KHANNA, in der die Rolle von Vertrauen und Informationen untersucht wird. ${ }^{74}$ FISMAN/KHANNA nehmen eine Differenzierung nach Abschreckungs-, Wissens- und Identifikationsbasierung von Vertrauen vor: ${ }^{795}$

- Zentrales Element des abschreckungsbasierten Vertrauens ist die Androhung von Bestrafung, sofern konsistentes Verhalten nicht aufrechterhalten wird (rationales Vertrauen). Die Grundlage bildet das spieltheoretisch fundierte Gefangenen-Dilemma. Wenn nun die Spieler nicht in der Lage sind, die anderen zu monitoren, so wird das opportunistische Verhalten steigen und weniger Kooperation entstehen, da nicht beurteilt werden kann, inwiefern der andere einen Verrat begangen hat. Dieser Ansatz geht von einer positiven Korrelation zwischen Vertrauen und Information aus. ${ }^{796}$ Vertrauen, welches auf Informationen basiert, reduziert Monitoring-Kosten und induziert damit geringere Zinsen in einer Bankbeziehung.

- Wissensbasiertes Vertrauen entsteht dann, wenn eine Partei über genügend Informationen verfügt, um das Verhalten des anderen korrekt vorherzusagen. Ein besserer Informationsfluss zwischen den Parteien führt in Konsequenz dadurch zu mehr Vertrauen, da man über das Verhalten des anderen lernt.

- Identifikationsbasiertes Vertrauen resultiert, wenn jeder Partner die Präferenzen des anderen vollständig internalisiert hat, so dass die andere Partei als Agent dienen kann und gleichzeitig die Zuversicht besteht, dass dadurch die eigenen Interessen gewahrt bleiben. ${ }^{797}$ Ebenso wie beim wissensbasierten Vertrauen

\footnotetext{
792 Vgl. Lehmann/Neuberger (2000), S. 1.

793 Vgl. Lehmann/Neuberger (2000), S. 1.

794 Vgl. Lehmann/Neuberger (2000), S. 1.

795 Vgl. Fisman/Khanna (1999), S. $79 \mathrm{ff}$.

796 Vgl. Fisman/Khanna (1999), S. 81.

797 Vgl. Fisman/Khanna (1999), S. 81.
} 
führt auch hier ein besserer Informationsfluss zwischen den Parteien zu mehr Vertrauen. ${ }^{798}$

Während in den beschriebenen Vertrauensformen ein höheres Vertrauensniveau mit einem erhöhten Informationsfluss einhergeht, kann allerdings - wie bereits auch von FISMAN/ KHANNA erwähnt - ebenso eine inverse Kausalität vorliegen, d.h. geringeres Vertrauen führt dazu, dass die Individuen mehr in die Informationserlangung investieren und ein Bedürfnis für Monitoring verspüren, um Opportunismus zu reduzieren. In diesem Fall sind Informationen und Vertrauen negativ korreliert. ${ }^{799}$

Um das gegenseitige Vertrauen in einer Bankbeziehung zu messen, operationalisieren LEHMANN/NEUBERGER diese unterschiedlichen Vertrauensformen mit vier Variablen, die den Eindruck der Stabilität, den Informationsfluss, die Verpflichtung zum Partner und die Erfahrungen der Vergangenheit messen. ${ }^{800}$

Die Stabilität der Beziehung hängt vom konsistenten Verhalten ab und dient als Proxy für ein abschreckungsbasiertes Vertrauen. Der Informationsfluss (d.h. die Bereitschaft des Kreditnehmers über Probleme zu informieren) dient als Proxy für wissensbasiertes Vertrauen. ${ }^{801}$ Die Verpflichtung gegenüber dem Kooperationspartner ist ein Proxy für das identifikationsbasierte Vertrauen gem. FISMAN/KHANNA und die vergangenen Erfahrungen reflektieren die Reziprozität in einer Beziehung. ${ }^{802}$ Zur Messung dieser Aspekte haben die Kundenbetreuer der Bank eine Beurteilung auf einer 5-wertigen Likert-Skala vorgenommen. Um ordinale Variablen zu vermeiden, wurden die Werte allerdings in eine Binärskala überführt. Damit geht leider auch ein Informationsverlust einher. ${ }^{\text {.03 }}$

Sowohl die Stabilität der Bankbeziehung (abschreckungsbasiertes Vertrauen) als auch gute Erfahrungen in der Vergangenheit haben einen negativen Effekt auf den Zinssatz, wobei nur die Variable Stabilität einen signifikanten Einfluss ausübt (vgl. Tab. A-13). Die Bereitschaft des Kreditnehmers, die Bank unmittelbar über Probleme zu informieren (wissensbasiertes Vertrauen), übt einen signifikanten positiven Einfluss auf den Zinssatz aus. Eine Erklärung hierfür kann in erhöhten Informationsanforderungen der Banken im Krisenfall vermutet werden. ${ }^{804}$ In diesem Sinne würde allerdings eine umfangreichere Informationsweitergabe durch das Unternehmen weniger ein Ausdruck größeren Vertrauens, sondern vielmehr ein Zeichen von Misstrauen im Krisenfalle

${ }^{998}$ Einen Überblick über die Bedeutung von Vertrauen in Business-to-Business-Beziehungen gibt Blois (1999). Vgl. Blois (1999).

799 Vgl. Fisman/Khanna (1999), S. 82.

800 Vgl. Lehmann/Neuberger (2000), S. 13.

801 Vgl. Lehmann/Neuberger (2000), S. 13.

802 Vgl. Blois (1999), S. 201.

803 Vgl. Lehmann/Neuberger (2001), S. 349.

804 Vgl. auch Lehmann/Neuberger (2001), S. 353. Siehe auch Burghof für ein Beispiel eines derartigen Verhaltens. Vgl. Burghof (2000), S. 282. Segbers/Siemes finden keinen Hinweis auf einen Zusammenhang zwischen der Qualität des Unternehmens und dessen Informationsverhalten gegenüber seiner Bank. Vgl. Segbers/Siemes (2005b), S. 318. Lehmann/Neuberger nehmen jedoch keine explizite Überprüfung dieser These, z.B. durch einen Interaktionsterm mit dem bankinternen Rating, vor. 
sein. Ursächlich hierfür könnte die Erwartung einer finanziellen Schieflage sein, wenn der Kunde Probleme berichtet. ${ }^{805}$

\begin{tabular}{|c|c|c|c|c|}
\hline & $\begin{array}{l}\text { Vertrauensform gem. } \\
\text { Fisman/Khanna }\end{array}$ & Zinssatz & Sicherheiten & $\begin{array}{l}\text { Kreditver- } \\
\text { fügbarkeit }\end{array}$ \\
\hline Stabilität & $\begin{array}{l}\text { Abschreckungsbasiertes } \\
\text { Vertrauen }\end{array}$ & $-* *$ & $+* *$ & + \\
\hline Informationsfluss & $\begin{array}{l}\text { Wissensbasiertes } \\
\text { Vertrauen }\end{array}$ & $+^{*}$ & - & $+* * *$ \\
\hline $\begin{array}{l}\text { Verpflichtung } \\
\text { zum Partner }\end{array}$ & $\begin{array}{l}\text { Identifikationsbasiertes } \\
\text { Vertrauen }\end{array}$ & + & - & + \\
\hline $\begin{array}{l}\text { Erfahrungen } \\
\text { der Vergangenheit }\end{array}$ & $+\cdots$ & - & - & $+* *$ \\
\hline $\begin{array}{l}\text { Gesamtheit der } \\
\text { Interaktionsvariablen }\end{array}$ & $\cdots$ & $+* *$ & + & $+* * *$ \\
\hline $\begin{array}{ll}* & \text { Signifikant auf } \\
* * & \text { Signifikant auf } \\
* * * & \text { Signifikant auf }\end{array}$ & $\begin{array}{l}\text { n 10\%-Niveau. } \\
\text { n 5\%-Niveau. } \\
\text { m 1\%-Niveau. }\end{array}$ & & & \\
\hline
\end{tabular}

Tab. A-13: Auswirkung der Vertrauensformen auf die Kreditkonditionen ${ }^{806}$

Die Interaktionsvariablen üben alle mit Ausnahme der Stabilität einen negativen, allerdings nicht signifikanten Einfluss auf die Sicherheitenstellung aus. Die Variable Stabilität übt einen signifikanten positiven Einfluss aus, was dadurch erklärt werden könnte, dass eine höhere Stabilität dann vorliegt, wenn es sich um eine Hausbankbeziehung handelt. Da Hausbanken in der Regel die ersten Kreditgeber eines Unternehmens sind, bekommen sie wahrscheinlich die besten Sicherheiten. ${ }^{807}$ Die Wirkungsrichtung könnte aber auch umgekehrt sein, so dass eine empfundene Stabilität aus einer höheren Besicherungsquote resultiert. Sicherheiten können in diesem Sinne als Ursache und auch als Wirkung der Stabilität betrachtet werden. ${ }^{808}$

Die Kreditverfügbarkeit, gemessen als die Wahrscheinlichkeit einer Kreditbewilligung, wird positiv beeinflusst durch Erfahrungen aus der Vergangenheit und durch umfangreichere Informationen. Dies ist konsistent zur Sichtweise des Relationship Banking, da beide Faktoren als Ausdruck von proprietärem Wissen verstanden werden können.

Auch wenn hier ein Ansatz zur Erweiterung der bestehenden Studien aus dem Bereich des Relationship Banking um verhaltenswissenschaftliche Aspekte zu sehen ist, so wirkt der Zusammenhang zu den Vertrauensarten teilweise etwas konstruiert. ${ }^{809}$ Es ist

Vgl. Lehmann/Neuberger (2000), S. 22.

Eigene Darstellung.

Vgl. Lehmann/Neuberger (2000), S. $23 \mathrm{f}$.

Vgl. Segbers (2007), S. 182.

Dies zeigt sich auch bei einem Blick auf eine frühere Version des Artikels, in der noch kein Zusammenhang der vorgestellten Indikatoren zu den Vertrauensarten nach Fisman/Khanna hergestellt wurde. Vgl. Lehmann/Neuberger (2000), S. $8 \mathrm{ff}$. 
z.B. fraglich, inwiefern eine empfundene Stabilität als eine Operationalisierung von abschreckungsbasiertem Vertrauen angesehen werden kann. ${ }^{810}$ Des Weiteren kann auch die Verpflichtung der Bank gegenüber dem Kreditnehmer nur bedingt als Indikator für ein hohes Vertrauen eingestuft werden. Schließlich ist zu differenzieren, inwiefern es sich um Vertrauen in den Ansprechpartner oder in das Unternehmen handelt. Ferner fehlt die bei latenten Konstrukten grundsätzlich gebotene Überprüfung der Konstruktreliabilität und -validität gänzlich. ${ }^{811}$ Es bleibt offen, inwiefern die einzelnen Fragen geeignet sind, das zu messen, was sie messen sollen, oder inwiefern die verschiedenen Fragen möglicherweise das Gleiche messen. Bspw. besteht vermutlich ein großer Zusammenhang zwischen einem guten Informationsfluss und den guten Erfahrungen der Vergangenheit. Hinsichtlich der Konzeptualisierung und Operationalisierung des Vertrauens bei LEHMANN/NEUBERGER lässt sich konstatieren, dass es an einer umfassenden verhaltenswissenschaftlichen Fundierung mangelt.

\subsection{Fazit des aktuellen Standes der Relationship Banking-Forschung}

In der Relationship Banking-Theorie liegt der Fokus auf der Analyse der Informationsasymmetrien in der Beziehung zwischen Bank und Kunde. Diese Informationsasymmetrien wirken sich unmittelbar auf den Verhaltenspielraum der Bank und des Kunden aus, was zu opportunistischen und gläubigerschädigendem Verhalten führen kann. Die Banken antizipieren diese Möglichkeiten und berücksichtigen selbige, wie in Abb. A-9 dargestellt, bei der Konditionengestaltung, d.h. der Festlegung der Parameter Kreditzins, Sicherheitenstellung und Kreditverfügbarkeit.

Die Informationsasymmetrien bestehen allerdings nicht nur zwischen dem Kunden und den Banken, sondern auch zwischen der Inside-Bank und den Outside-Banken. Die Informationsasymmetrie zwischen Kunde und Inside-Bank ist im Wesentlichen Ausdruck für das Risiko der Inside-Bank bzw. der Präzision der Risikobeurteilung und wird im Risikoaufschlag der Bank berücksichtigt. Die Informationsasymmetrie zwischen Inside- und Outside-Bank determinieren u.a. die Macht der Inside-Bank hinsichtlich der Konditionengestaltung und der Möglichkeit zur Ausnutzung der Kundenbeziehung. Der Grad der Informationsasymmetrie zwischen Inside-Bank und Kunde beeinflusst die Konditionengestaltung, wobei selbiger insbesondere durch die Intensität und Qualität der Geschäftsbeziehung determiniert wird. Unter anderem aufgrund dieser verschiedenen zu berücksichtigenden Beziehungen ist eine allgemeingültige Aussage zur Wirkungsrichtung in Bezug auf die Konditionen nicht möglich. Während die dargestellten Modelle von einer steigenden Kreditverfügbarkeit mit zunehmender Monopolmacht der Inside-Bank, z.B. aufgrund des Informationsvorsprungs ausgehen, sind die Erkenntnisse in Bezug auf den Kreditzins und die Sicherheitenstellung uneinheitlich.

\footnotetext{
810 Vgl. Segbers (2007), S. 181.

811 Vgl. zur Konstruktreliabilität und -validität und deren Prüfung Homburg/Giering (1996), S. 6 ff. Eine Darstellung der wesentlichen Kriterien erfolgt zudem in Kapitel B.3.2.2. 


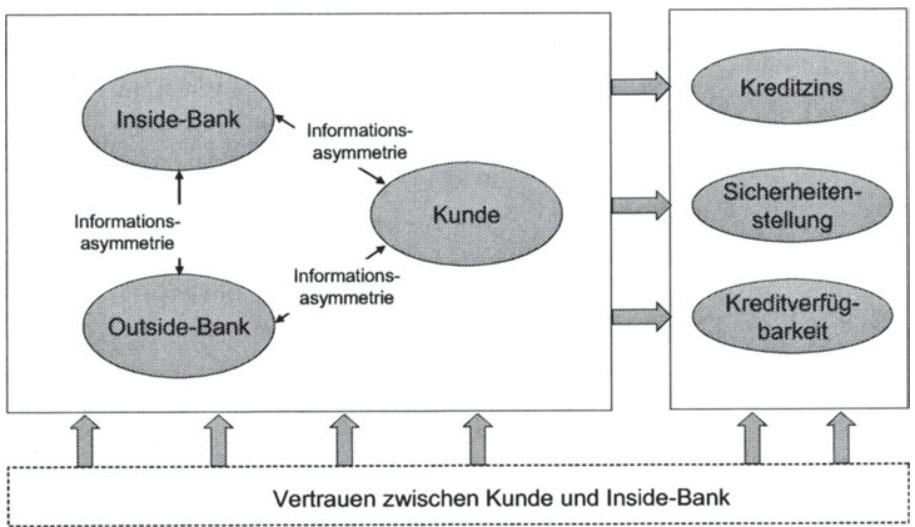

Abb. A-9: Ökonomische Wirkungen der Informationsasymmetrie ${ }^{812}$

Auf der empirischen Ebene dominiert ein Begriffsverständnis, das die Geschäftsbeziehung mit den Dimensionen Intensität und Qualität insbesondere durch die Parameter Dauer der Beziehung und Breite der genutzten Produktpalette beschreibt. Ein Verständnis der Geschäftsbeziehung als ein komplexes Merkmal findet dagegen nur selten Anwendung. Aspekte wie die Interaktionen zwischen den agierenden Personen, die Entwicklung einer gemeinsamen Vertrauensbasis, der Aufbau einer zwischenmenschlichen Beziehung oder einer Beziehung zwischen den beteiligten Unternehmen werden weitestgehend ignoriert. Die bereits kurz skizzierten Ansätze von Uzzı, UzZI/LANCASTER, UZZI/GILLESPIE, HARHOFF/KÖRTING und LEHMANN/NEUBERGER stellen erste Ansätze dar, diese Forschungslücke zu schließen. HARHOFF/KÖRTING und LEHMANN/NEUBERGER haben zu diesem Zweck Vertrauensvariablen integriert. Das Vertrauen wirkt sich zum einen unmittelbar auf die Konditionengestaltung und zum anderen auf den Grad der Informationsasymmetrie und dadurch mittelbar auf die Konditionengestaltung aus.

Im Folgenden soll die Geschäftsbeziehung aus der Perspektive des Marketing im Allgemeinen und der Interaktionstheorie im Speziellen untersucht werden, um daraus weitere Erkenntnisse hinsichtlich der zentralen Determinanten und Dimensionen zur Beschreibung einer Geschäftsbeziehung zu erlangen. Mit der Konzeptualisierung und der Operationalisierung der relevanten, noch im Detail zu erarbeitenden Dimensionen soll die Diskrepanz zwischen dem theoretischen Anspruch und dem operablen Begriffsinhalt verringert werden. 


\section{Analyse der Geschäftsbeziehung in einem verhaltens- wissenschaftlichen Bezugsrahmen}

Der Begriff der Geschäftsbeziehung ist bis heute vornehmlich in den Arbeiten des Investitionsgütermarketing verwendet worden. ${ }^{813}$ Im Folgenden soll im Wesentlichen aufbauend auf den dort behandelten Ansätzen untersucht werden, welche Aspekte aus diesem Bereich der Betriebswirtschaftslehre für das Relationship Banking relevant und somit im Rahmen einer empirischen Analyse der Kunde-Bank-Beziehung zu berücksichtigen sind. Ziel dieses Kapitels ist es, Konstrukte und Variablen zu erarbeiten, die für die empirische Analyse einen weiteren Erklärungsbeitrag liefern, um somit die in Kapitel A.4.3.2.5 und A.4.4 dargestellte Forschungslücke weiter schließen zu können.

In Kapitel A.5.1 erfolgt eine definitorische Abgrenzung des Begriffs der Geschäftsbeziehung, um anschließend die Grundlagen der Interaktionstheorie darzustellen. Diese bilden die Basis für die im nächsten Schritt zu betrachtenden theoretischen Modelle zur Beschreibung von Geschäftsbeziehungen. Die wesentliche Erkenntnis dieser theoretischen Modelle besteht darin, dass die Konstrukte Vertrauen und Commitment eine zentrale Rolle im Rahmen einer langfristigen Geschäftsbeziehung spielen. In einem weiteren Schritt erfolgt eine theoretische Auseinandersetzung mit den beiden Konstrukten sowie die Darstellung der verschiedenen empirischen Untersuchungen zu selbigen aus dem Bereich des Relationship Marketing.

\subsection{Definition der Geschäftsbeziehung im Kontext des Investitions- gütermarketing}

In der Marketingforschung zeigte sich in den letzten Jahren verstärkt, dass die klassischen Modelle aus dem Bereich des Konsumgütermarketing die Realität der Vermarktung von Investitionsgütern nicht adäquat abzubilden vermögen, da selbige primär die Reaktionen der Nachfrager auf die Aktivitäten der Anbieter analysieren. ${ }^{814}$ So wurde festgestellt, dass bei Investitionsgütertransaktionen die real ablaufenden Vorgänge eher durch wechselseitige Austauschbeziehungen zwischen Vertretern der Herstellerund Vertretern der Verwenderfirma gekennzeichnet sind..$^{815}$ In der Literatur wird der organisatorische Rahmen, in dem derartige Austauschbeziehungen stattfinden, in der Regel längerfristige Geschäftsbeziehung genannt. ${ }^{816}$ Das Attribut der Längerfristigkeit weist darauf hin, dass die Beziehung zwischen der Hersteller- und der Verwenderfirma nach Abschluss der Transaktion nicht beendet wird, sondern vielmehr auch danach häufig noch fortbesteht. ${ }^{817}$

PLINKE definiert eine Geschäftsbeziehung als eine Folge von Einzeltransaktionen zwischen selbstständigen Marktpartnern, bei denen eine innere Verbindung besteht. ${ }^{818}$ 
Gemäß einer Definition nach GEMÜNDEN handelt es sich bei einer Geschäftsbeziehung um „langfristig angelegte, von ökonomischen Zielen geleitete Interaktionsprozesse und Bindungen zwischen Mitgliedern verschiedener Organisationen, die auf eine Folge von Austauschprozessen gerichtet sind ${ }^{\text {“819. }}$. Neben der Langfristorientierung betont GEMÜNDEN, dass Mitglieder von Organisationen, somit Personen und nicht die Organisationen selbst eine Bindung zueinander aufbauen, so dass neben der Unternehmensebene die persönliche Ebene explizit in die Definition integriert wird. Diese Ebene wurde zwar zum Teil im Rahmen der in Kapitel A.4.1 dargestellten Definitionen von Relationship Banking integriert, im Rahmen der empirischen Studien ist die persönliche Ebene allerdings nur bei HARHOFF/KÖRTING über einen und bei LEHMANN/NEUBERGER über vier Vertrauensparameter ${ }^{220}$ abgebildet worden.

Nach DILLER/KUSTERER lässt sich eine Geschäftsbeziehung auffassen "als jeden von ökonomischen Zielen zweier Organisationen geleiteten Interaktionsprozess zwischen zwei oder mehr Personen ab dem ersten Geschäftsabschlusss" ${ }^{\text {“821 }}$. Von zentraler Bedeutung bei einer Geschäftsbeziehung ist das persönliche Verhältnis oder das atmosphärische Klima zwischen den Geschäftspartnern. Allerdings umfassen Geschäftsbeziehungen sehr viel weiter die Gesamtheit der von ökonomischen Zielen geleiteten, direkten, integrativen und auf mehrmalige Transaktionen ausgerichteten Interaktionsprozesse zwischen den Geschäftspartnern. ${ }^{822}$

In Analogie zu WERP wird bei den folgenden Ausführungen der in der Definition von DILLER/KUSTERER erhobenen Forderung, dass eine Geschäftsbeziehung erst ab dem ersten Geschäftsabschluss vorliegt, nicht gefolgt. ${ }^{823}$ Das Vorliegen einer Geschäftsbeziehung zwischen zwei Unternehmen ist vielmehr an die Existenz persönlicher Beziehungen zwischen Vertretern aus beiden Unternehmen geknüpft. ${ }^{24}$ Bei WERP wird der Begriff der Geschäftsbeziehung verwendet, um sämtliche zwischen zwei Unternehmen ablaufenden Transaktionen in einem übergeordneten Rahmen zusammenzufassen. Das abstrakte Konstrukt der Geschäftsbeziehung wird als die Gesamtheit aller zwischen zwei Unternehmen existierenden Transaktionen verstanden. ${ }^{825}$ Im Kontext der KundeBank-Beziehung ist somit nicht nur die Dauer der vertraglichen Bindung, sondern auch die Dauer der Bindung zwischen der Person des Firmenkundens und der Person des Firmenkundenbetreuers von Relevanz. Aufgrund der z.T. sehr speziellen und komplexen Produkte werden in Abhängigkeit von der Größe der Bank neben dem Firmenkundenbetreuer zusätzlich noch Spezialisten bei der Beratung mit eingebunden, z.B. der Spezialist für Auslandsgeschäfte, der Spezialist für Versicherungsprodukte oder der Berater für Vermögensanlage, so dass hier unter Umständen mehrere persönliche Beziehungen aufgebaut werden.

\footnotetext{
819 Gemünden (1990), S. 34.

${ }^{820}$ Aufgrund der stark vereinfachten Abbildung des Konstruktes Vertrauens wird hier bewusst nicht der Begriff „Konstrukt" verwendet.

821 Diller/Kusterer (1988), S. 211.

822 Vgl. Diller (1994), S. 3.

823 Vgl. Werp (1998), S. 25.

824 Vgl. Werp (1998), S. 25.

${ }^{825}$ Vgl. Werp (1998), S. 26. 
Die einzelne Transaktion und die Geschäftsbeziehung als Gesamtheit sind als zwei mögliche Bezugsobjekte des Marketings zu verstehen, ${ }^{826}$ bei denen die einzelne Transaktion ein Teilelement der gesamten Geschäftsbeziehung ist. Während die Transaktion ein vergleichsweise einfach strukturiertes Bezugsobjekt ist, das die Aufdeckung grundlegender Gesetzmäßigkeiten im Austauschprozess ermöglicht, steht mit der Geschäftsbeziehung ein Bezugsobjekt zur Verfügung, das auch komplexe Vorgänge im Austauschprozess abzubilden vermag. ${ }^{827}$ Die einzelne Transaktion im Rahmen einer Bankbeziehung, z.B. die Kreditbereitstellung, lässt sich relativ einfach durch die Vertragsparameter beschreiben, d.h. Kreditvolumen, Zinssatz, Sicherheit, Auszahlungszeitpunkt, Laufzeit etc. Hingegen fällt die Beschreibung der Geschäftsbeziehung, auch aufgrund der zuvor bereits erwähnten Komplexität hinsichtlich der vielfältigen persönlichen Bindungen und der Entwicklung im Zeitablauf, schwer. Im nächsten Kapitel erfolgt eine Darstellung bestehender Ansätze zur Analyse der Geschäftsbeziehung, wobei der Fokus auf den Ansätzen liegt, die die wechselseitige Interaktion der Geschäftspartner berücksichtigt.

\subsection{Interaktionsansätze zur Analyse bestehender Geschäftsbeziehun- gen}

\subsubsection{Definitorische Abgrenzung der Begriffe Interaktion und Interaktions- ansätze}

Hinsichtlich der Erforschung von interorganisationalen Beziehungen kann von einer Situation der wissenschaftlichen Pluralität gesprochen werden. ${ }^{828}$ Häufig stehen die Ansätze zur Erforschung dieser Beziehungen dabei unabhängig nebeneinander oder in einem sich ergänzenden Verhältnis zueinander. Eine integrierende Metatheorie, die die unterschiedlichen Ansätze hierarchisieren und integrieren könnte, fehlt. ${ }^{829}$ Im Rahmen der Erklärung von Geschäftsbeziehungen wird häufig die Transaktionskosten-Theorie herangezogen, die sich als ökonomische Theorie in einem geschlossenen theoretischen Rahmen mit der institutionellen Koordination von ökonomischen Aktivitäten auseinandersetzt. ${ }^{830}$ Hingegen setzt sich die Prinzipal-Agenten-Theorie mit bestehenden Geschäftsbeziehungen, insbesondere mit den Problemen der Informationsasymmetrien zwischen den verschiedenen Parteien, auseinander. ${ }^{831}$ Die Interaktionstheorie als ein weiterer Theoriezweig befasst sich mit der Analyse bestehender Geschäftsbeziehungen und untersucht hier im Wesentlichen die wechselseitige Kommunikation und Beeinflussung der Interaktionspartner. ${ }^{832}$

\footnotetext{
826 Vgl. Bliemel/Eggert (1997b), S. 3.

827 Vgl. Eggert (1999), S. 14.

828 Vgl. Söllner (1993), S. 81.

829 Vgl. Söllner (1993), S. 82.

${ }_{830}$ Vgl. Söllner (1993), S. 85.

831 Vgl. Kapitel A.4.2.

832 Vgl. Kirsch/Kutschker (1978), S. 18
} 
Zunächst soll der Begriff der Interaktion definiert werden, wobei hier in der Literatur kein einheitliches Begriffsverständnis vorliegt. Eine Interaktion wird von HOMANS wie folgt definiert: „When we refer to the fact that some unit of activity of some man follows, or (..) is stimulated by some unit of activity of another, (...) then we are referring to interaction." ${ }^{833}$ TRÖNDLE versteht unter dem Begriff der Interaktion ,eine zielgerichtete, wechselseitige Handlung zwischen mindestens zwei agierenden Personen [...] im Rahmen einer Kooperation also als wechselseitige Handlungen zwischen Kooperationsträgern"834. Er betont ferner, dass Interaktion immer zugleich ein Kommunikationsprozess ist. SCHOCH versteht unter einer Interaktion „eine Folge von sinngemäß aufeinander bezogenen und aneinander orientierten verbalen und nicht-verbalen Handlungen (Aktionen) von zwei oder mehreren Individuen in unmittelbarer physischer Gegenwart" ${ }^{633}$. Ebenso wie TRÖNDLE hebt auch SCHOCH in seiner Beschreibung sehr stark die personelle Komponente in einer Interaktion hervor. So bezieht $\mathrm{SCHOCH}$ allerdings neben der Kommunikation auch explizit die Aktionen der an der Interaktion beteiligten Personen mit ein. Allen drei Definitionen ist der Aspekt der Wechselseitigkeit gemein. Auch bei KIRSCH/KUTSCHKER ist neben der Kommunikation zwischen den an der Beziehung beteiligten Partnern auch die wechselseitige Beeinflussung konstituierender Bestandteil einer Interaktion. ${ }^{836}$ Ähnlich definiert KERN eine Interaktion als den Umstand, dass mindestens zwei Individuen miteinander in Kontakt treten, sich eine zeitliche Abfolge von Aktionen und Reaktionen ergibt und die Handlungen der Partner interdependent und sinngemäß aneinander orientiert sind. ${ }^{837}$

Als Interaktion wird an dieser Stelle in Anlehnung an WERP ein iterativer Prozess verstanden, in dem auf eine von einem Unternehmen ausgeführte Aktion eine Reaktion des anderen an der Kooperation beteiligten Unternehmens folgt, ${ }^{838}$ wobei die aktionsbegleitende Kommunikation eine zentrale Rolle spielt. Zentrale Elemente einer Interaktion zwischen zwei Unternehmen sind etwa Verhandlungen zur Abstimmung der Zusammenarbeitsinhalte, Kommunikation, d.h. der Austausch von Informationen, sowie ein Tausch, eine Kombination oder eine Zusammenlegung von Ressourcen. ${ }^{839}$ Neben der Bereitstellung von Ressourcen (z.B. in Form von Krediten) spielt der Informationsaspekt (z.B. der Bereitstellung von Finanzkennzahlen oder auch weichen unternehmerischen Informationen, geplanten Investitionen) eine zentrale Rolle im Rahmen der Kunde-Bank-Beziehung.

Ausgehend von der Definition von Interaktionen behandeln Interaktionstheorien gemäß SÖLLNER , ,...] als deskriptive und explikative Theorien über soziale Austauschprozesse das wechselseitige Verhalten in zwischenmenschlichen Beziehungen ${ }^{\text {"840 }}$. Die Wechselbeziehungen zwischen Individuen stehen im Mittelpunkt der Interaktionstheo-

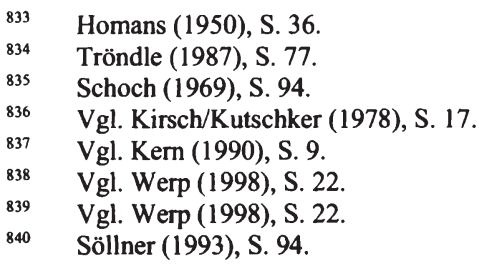


rie von HOMANS, der dieses abstrakte und sehr allgemein gehaltene Theoriegebäude entwickelte, um Erklärungsmuster für elementare Beziehungsverläufe zwischen zwei Individuen abzuleiten ${ }^{841}$ HOMANS geht davon aus, dass sich in einem Interaktionsprozess das Verhalten eines Individuums unmittelbar an dem vorangegangenen Verhalten des anderen beteiligten Individuums orientiert und die von Kosten-NutzenÜberlegungen geleiteten Individuen die Interaktion nur dann fortsetzen, wenn sie einen zufriedenstellenden Nutzen aus der Interaktion ziehen. ${ }^{842}$ Stabile Beziehungen etablieren sich nur dann, wenn beide Individuen über positive Erfahrungen früherer Verhaltensweisen des jeweils anderen Individuums verfügen und sich die Individuen konsistent, d.h. entsprechend den Erwartungen des Gegenübers, verhalten. ${ }^{843}$ Ferner heben die Interaktionsansätze hervor, dass die Aufrechterhaltung und Entwicklung einer Beziehung das Ergebnis sowohl von Aktivitäten der beiden Seiten als auch der sich ändernden Umweltbedingungen im Zeitablauf ist. Bei den Interaktionsansätzen handelt es sich aber weniger um Erklärungsansätze, sondern eher um Analyseansätze für zwischenbetriebliche Zusammenarbeit. ${ }^{844}$

Ausgehend von einer kurzen Darstellung und Analyse verschiedener Modelle aus der Interaktionstheorie, die sich mit Geschäftsbeziehungen auseinandersetzen, werden die bei der Analyse der Geschäftsbeziehung zentralen Konstrukte herausgearbeitet, um anschließend die theoretische Basis zu schaffen sowie die Möglichkeiten der Operationalisierung in empirischen Studien zu prüfen.

\subsubsection{Theoretische Modelle zur Analyse von Geschäftsbeziehungen}

Im Rahmen der Interaktionstheorie lassen sich statische und dynamische Modelle unterscheiden. Während Erstere nur eine Zeitpunktbetrachtung vornehmen, wird bei dynamischen Modellen die Entwicklung der Geschäftsbeziehung im Zeitablauf explizit integriert. Ergänzt werden die beiden Modelle in dieser Arbeit um einen Ansatz von SEGBERS, der ein Modell für die Analyse von Hausbankbeziehungen entwickelt hat. ${ }^{845}$

\subsubsection{Statische Modelle}

\subsection{Modellbeschreibung}

Im Folgenden werden zunächst statische Modelle betrachtet. Bei selbigen stellt das Modell der IMP-GrouP, das auf dem Interaktionsansatz von KUTSCHKER/KIRSCH ${ }^{846}$ aufbaut, ${ }^{847}$ einen zentralen Ansatz dar. Die theoretische Basis des Modells leitet sich aus der Neuen Institutionenökonomie und der sozialen Austauschtheorie ab. Die in dem Modell postulierten Zusammenhänge beruhen auf Daten einer empirischen Unter-

\footnotetext{
${ }^{841} \quad$ Vgl. Schoch (1969), S. $103 \mathrm{ff}$.

${ }_{842}$ Vgl. Werp (1998), S. 70.

843 Vgl. Schrader (1993), S. 235.

${ }^{844}$ Vgl. Werp (1998), S. 51.

845 Vgl. Segbers (2007).

846 Vgl. Kutschker/Kirsch (1978).

${ }^{847}$ Vgl. Kern (1990), S. 46 ff.
} 
suchung zu Geschäftsbeziehungen in internationalen Investitionsgütermärkten ${ }^{848} \mathrm{Un}$ tersuchungsschwerpunkt der Studie und somit des Modells bildet eine dyadische Interaktionsbeziehung zwischen einem Hersteller und einem Verwender. ${ }^{849}$ Diese Erkenntnisse lassen sich auch auf andere Interaktionsbeziehungen, wie bspw. die KundeBank-Beziehung, übertragen. Die Interaktionen zwischen den Partnern werden dabei von vier Faktoren beeinflusst:

- dem Prozess der Interaktion, ${ }^{850}$

- den Teilnehmern/Parteien des Interaktionsprozesses, ${ }^{851}$

- der Makro-Umwelt und

- der Atmosphäre der Beziehung. ${ }^{852}$

Während des Prozesses der Interaktion kommt es zum Austausch von Produkten und Dienstleistungen, zum Informationsaustausch, zum Austausch von Finanzen und zum sozialen Austausch, wobei diese Austausche nicht immer zeitgleich stattfinden. ${ }^{853}$ Der Austausch von Produkten und Dienstleistungen stellt im Rahmen der HerstellerVerwender-Beziehung den Kern des Austausches dar und hat somit einen signifikanten Effekt auf die Geschäftsbeziehung im Ganzen. Ein zentraler Aspekt ist hier die Unsicherheit, die bezüglich des Produktes oder der Dienstleistung besteht. Im Bankkontext kann die Qualität einer Bankdienstleistung, z.B. einer Vermögensberatung, durch den Kunden aufgrund des in der Regel niedrigeren Kenntnisstandes nur schwer beurteilt werden. Beim Austauch von Finanzen ist die Menge oder das ausgetauschte Volumen ein Indikator für die ökonomische Bedeutung der Beziehung. In Bezug auf eine Bankbeziehung kann die absolute Bedeutung sowie bei Existenz mehrerer Bankverbindungen die relative Bedeutung der einzelnen Bankverbindungen beurteilt werden. Ersteres lässt sich anhand des Anteils der Bankverbindlichkeiten einer einzelnen Bank an der Bilanzsumme beurteilen, Letzteres durch Vergleich der Anteile der Bankverbindlichkeiten der verschiedenen Banken. Der soziale Austausch hat die wesentliche Funktion, die Unsicherheit zwischen den beiden Parteien zu reduzieren. ${ }^{854}$ Es kann durchaus Phasen innerhalb der Geschäftsbeziehung geben, in denen es nur zum sozialen Austausch und nicht zum Austausch von Produkten oder Dienstleistungen kommt. Durch sukzessive soziale Austauschperioden werden die zwei Parteien umso stärker miteinander verbunden. ${ }^{85}$ Viele Aspekte innerhalb einer Vereinbarung zwischen Käufer und Verkäufer sind nicht vollständig formalisiert. Das gegenseitige Vertrauen wird zu einer Basis der Beziehung. Der Aufbau von Vertrauen ist ein sozialer Prozess, der Zeit in Anspruch nimmt und auf persönlicher Erfahrung sowie auf der erfolgreichen Durchführung der anderen Austausche basiert.

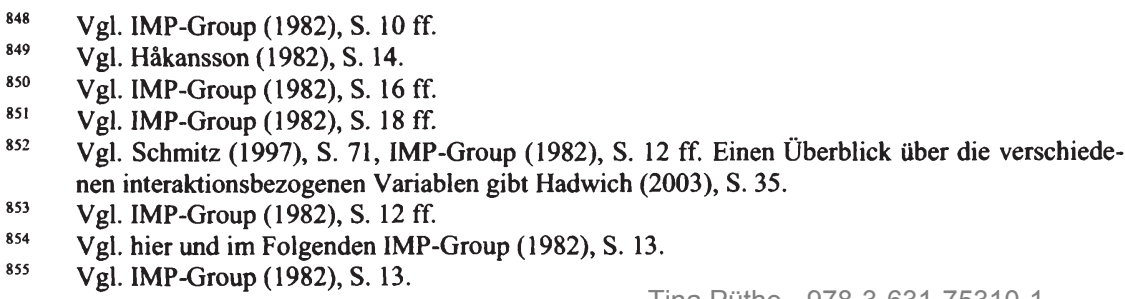


Die Betrachtung der Parteien des Interaktionsprozesses beschränkt sich in diesem Ansatz nicht auf die beiden Unternehmen als organisationale Ebene, sondern die einzelnen Vertreter aus beiden Unternehmen als Integration der personalen Ebene werden explizit in der Untersuchung berücksichtigt. Auf organisationaler Ebene bilden beispielsweise die Strategie und Struktur der Unternehmung sowie die in ihr verfügbaren Ressourcen und Technologien wichtige Untersuchungsschwerpunkte. ${ }^{856}$ Bei einer Bank könnte dies z.B. die Kreditrisikostrategie, die das Kreditvergabeverhalten beeinflusst, oder die Größe der Bank sein. Bei dem Unternehmen als Geschäftspartner der Bank könnte dies ebenfalls die Größe sein, die technischen und personellen Ressourcen für die Unterstützung der Kommunikation gegenüber der Bank, um unterjährige Auswertungen oder Planzahlen zu erstellen. Auf individueller Ebene interessiert sich der Ansatz in erster Linie für die Aufgaben und Funktionen der entscheidenden Unternehmensvertreter sowie für ihre persönlichen Ziele und Berufserfahrungen, z.B. mit dem jeweils anderen Unternehmen. Die Erfahrung, die in den einzelnen Phasen der Geschäftsbeziehung gesammelt wird, führt zu einer Total-Erfahrung ${ }^{857}$ Bei dem Firmenkundenbetreuer stellt sich die Frage, wie stark selbiger mit administrativen Aufgaben betraut ist und inwiefern er bspw. schlechte Erfahrungen mit dem konkreten Unternehmen gemacht hat. Die Total-Erfahrung wird auf personeller Ebene ferner durch die Anzahl und Art der Kontakte, z.B. qualifizierte Kundengespräche oder E-Mailverkehr, mit dem Ansprechpartner und dem Unternehmen beeinflusst.

Die Makro-Umwelt als dritte Dimension umfasst ökonomische und soziale Variablen, wie bspw. die Marktstruktur oder die Marktdynamik, die ebenfalls wesentlichen Einfluss auf den Interaktionsprozess ausüben. ${ }^{858}$ Der Interaktionsansatz der IMP-GrouP stellt eine einzelne Geschäftsbeziehung in einen größeren Zusammenhang, indem die Umwelt des Interaktionsprozesses mit berücksichtigt wird. Der Markt, in dem sich die Unternehmen befinden, kann einen entscheidenden Einfluss auf die Anzahl und Gestalt von Geschäftsbeziehungen ausüben. Dies kann soweit gehen, dass ein Unternehmen quasi aufgrund mangelnder alternativer Partner zu einer Geschäftsbeziehung mit einem bestimmten Unternehmen gezwungen wird. ${ }^{859}$ Das Ausmaß der Konzentration im Markt determiniert die Anzahl der verfügbaren Alternativen der betrachteten Firma. ${ }^{860}$ Dies lässt sich unmittelbar auf den Bankenmarkt übertragen, denn bei einer hohen Marktkonzentration in einem abgegrenzten Markt hat der Firmenkunde per se zunächst einmal geringe Wechselmöglichkeiten. Während im Privatkundengeschäft die Abgrenzung des relevanten Marktes in räumlicher Hinsicht, z.B. aufgrund des Internetbanking, z.T. schwer fällt, ist im Firmenkundengeschäft die räumliche Nähe zur Bank wesentlich. ${ }^{801}$

Die Atmosphäre der Beziehung schließt z.B. Macht- oder Abhängigkeitsverhältnisse, das Kooperationsniveau, Vertrauenswürdigkeit der Partner oder deren Erwartungen

\footnotetext{
${ }_{856}$ Vgl. hier und im Folgenden IMP-Group (1982), S. 15, Werp (1998), S. 81.

857 Vgl. IMP-Group (1982), S. 16.

858 Vgl. IMP-Group (1982), S. $20 \mathrm{f}$.

859 Vgl. Werp (1998), S. 82.

860 Vgl. IMP-Group (1982), S. 16

861 Vgl. Degryse/Ongena (2005), S. $240 \mathrm{ff}$.
} 
ein. ${ }^{862}$ Die globale Atmosphäre ist einer der wichtigsten Aspekte der Beziehung, der durch eine bewusste Planung beeinflusst werden kann. ${ }^{863}$ Die Atmosphäre wird beschrieben durch Parameter wie das Macht-Abhängigkeitsverhältnis, das Spannungsverhältnis und schließlich die Distanz. Hier spielen insbesondere auch die wechselseitigen Erwartungen der beiden Unternehmen an das jeweils andere Unternehmen, die sich im Laufe der Beziehung aufgebaut haben, eine wichtige Rolle. ${ }^{864}$ Insgesamt kann die Atmosphäre einer Geschäftsbeziehung etwa durch Konstrukte wie z.B. Vertrauen, Commitment, Macht, Abhängigkeit oder Distanz charakterisiert werden. ${ }^{865}$ Die Atmosphäre der Geschäftsbeziehung wird auf organisationaler Ebene durch die Gesamtheit der interpersonalen Interaktionsbeziehungen zwischen individuellen Akteuren aus beiden Unternehmen beeinflusst. ${ }^{866}$ Neben dem Machtverhältnis, was bspw. wiederum durch die Größe des Kreditnehmers und durch das Kreditvolumen, die Anzahl der Bankverbindungen und somit der Wechselmöglichkeiten gemessen werden kann, erscheinen auf dieser Ebene Vertrauen und Commitment von essenzieller Bedeutung. Es ist davon auszugehen, dass die Atmosphäre zwischen beiden Unternehmen den Aufbau einer stabilen und dauerhaften Geschäftsbeziehung maßgeblich beeinflusst, ${ }^{867}$ aber auch dass eine gute Atmosphäre aus einer gemeinsamen stabilen und dauerhaften Geschäftsbeziehung resultiert. Aufgrunddessen nimmt dieses Konstrukt eine zentrale Stellung in dem theoretischen Bezugsrahmen ein. In Bezug auf die Kunde-BankBeziehung kann vermutet werden, dass eine gute Atmosphäre bestehende Informationsasymmetrien und den Monitoring-Bedarf reduzieren kann und die Bereitschaft auf beiden Seiten erhöht, spezifische Investitionen, z.B. in Form von speziellen Datenaufbereitungen für die Bank, vorzunehmen. Wie in Abb. A-10 dargestellt, ist die MakroUmwelt zwar als Rahmen der Geschäftsbeziehung zu verstehen, gleichzeitig beeinflusst selbige aber in erheblichem Umfang auch die Atmosphäre der Beziehung. Die Konstrukte der Atomosphäre, z.B. Macht und Abhängigkeit, werden u.a. durch die Marktstrukturen bestimmt.

\footnotetext{
862 Vgl. IMP-Group (1982), S. 17, Håkansson (1982), S. 21.

863 Vgl. IMP-Group (1982), S. 17.

864 Vgl. IMP-Group (1982), S. 17, Werp (1998), S. 81.

865 Vgl. Håkansson (1982), S. 21 f., Turnbull/Valla (1986), S. 6 f.

${ }^{866}$ Vgl. Werp (1998), S. 167.

867 Vgl. Werp (1998), S. 167.
} 


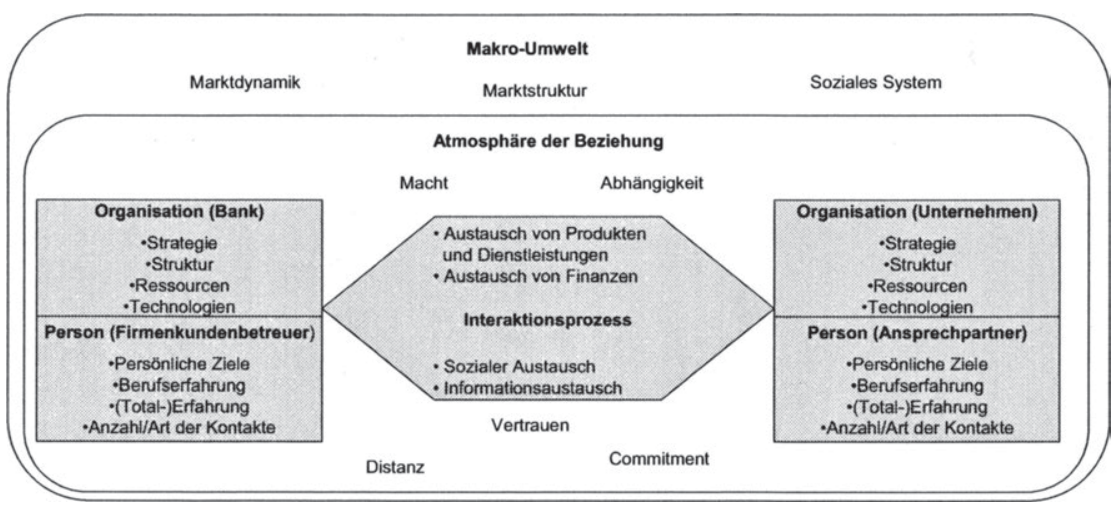

Abb. A-10: Interaktionsmodell der IMP-GROuP ${ }^{868}$

\subsection{Fazit und Modellkritik}

Es ist kritisch anzumerken, dass die IMP-GROUP den obigen Bezugsrahmen in seiner Gesamtheit bisher noch keiner umfassenden empirischen Untersuchung unterzogen hat. ${ }^{869}$ Jedoch liegt eine Reihe von Arbeiten vor, die Teilaspekte aus dem Bezugsrahmen untersucht haben und einige bestätigende Teilergebnisse in Form von Erklärungszusammenhängen zwischen einzelnen Variablen oder Variablengruppen vorlegen konnten ${ }^{870}$ Die empirische Studie von METCALF/FrEAR/KRISHNAN zur Überprüfung von Teilen des Modells, insbesondere den Elementen und den Prozessen der Interaktion, zeigt, dass soziale Austauschprozesse und der Austausch von Informationen positiven Einfluss auf die Kooperation sowie das gegenseitige Vertrauen ausüben. ${ }^{87}$ Die Wirkungsrichtung zwischen Vertrauen und Informationsfluss ist allerdings wie bereits zuvor angemerkt nicht eindeutig. So postuliert SYDOW eine inverse Wirkungsrichtung, vorherrschendes Vertrauen führt zu einem offeneren Informationsaustausch. ${ }^{872}$

Eine mögliche Ursache für das bisherige Fehlen eines fundierten allgemeinen Erklärungszusammenhangs mag an der Vielfalt unterschiedlicher Variablen liegen, die sich zum Teil noch auf einem zu hohen Abstraktionsniveau befinden, um unmittelbar einer empirischen Untersuchung zugänglich gemacht werden zu können. ${ }^{873}$ So bedarf es noch einer exakten Operationalisierung der Variablen bevor diese einer empirischen

\footnotetext{
868 Darstellung in Anlehung an IMP-Group (1982), S. 20.

${ }^{869}$ Vgl. Backhaus/Voeth (2007), S. 125 und Kern (1990), S. 55.

$870 \mathrm{Vgl}$. Hallén/Johanson/Seyed-Mohamed (1991) führten eine Untersuchung zu Anpassungen in Geschäftsbeziehungen durch. Vgl. Hallén/Johanson/Seyed-Mohamed (1991), S. 29 ff.

871 Vgl. Metcalf/Frear/Krishan (1992), S. 45.

872 Vgl. Sydow (1995), S. 181. Dieser Zusammenhang wurde auch in Kapitel A.4.3.2.5.4 bei Lehmann/Neuberger angesprochen.

873 Vgl. Werp (1998), S. 83.
} 
Untersuchung unterzogen werden können, was in Anbetracht abstrakter Konstrukte wie z.B. Macht oder Vertrauen keine triviale Aufgabe darstellt. ${ }^{874}$

Trotz der Untermauerung durch empirische Studien zumindest in Bezug auf Teilelemente des Modells und der Fülle inhärenter Ideen liefert das Modell nach der Meinung von STAHL nicht mehr als einen allgemeinen Bezugsrahmen. ${ }^{875}$ Weiterhin bezieht sich dieses Modell im Wesentlichen auf eine statische Betrachtung und hat lediglich deskriptiven Charakter. Um Geschäftsbeziehungen erklären zu können, müssen jedoch die einzelnen Phasen bzw. auch die zyklischen Zusammenhänge untersucht werden. ${ }^{876}$ $\mathrm{Da}$ in den weiteren Untersuchungen die Geschäftsbeziehungen nicht erklärt, sondern analysiert werden sollen, liefert das Modell für die Untersuchung der Kunde-BankBeziehung interessante Ansätze. Während die genannten Elemente wie Macht und Marktumfeld in vielen empirischen Studien aus dem Bereich des Relationship Banking bereits berücksichtigt worden sind, hat das Vertrauen als Basis des sozialen Austauschs und als wesentliches Element der ersten Dimension, aber auch als wesentliches Element für die Beschreibung der Atmosphäre der Geschäftsbeziehung bisher keine hinreichend adäquate Berücksichtigung gefunden. Aufgrund der angesprochenen Effekte einer guten Atmosphäre einer Geschäftsbeziehung erscheint es unerlässlich, selbige stärker in den empirischen Untersuchungen abzubilden.

\subsubsection{Dynamische Modelle}

\subsection{Modellbeschreibung}

Grundlage des Modells von FORD sind wie im zuvor beschriebenen statischen Modell empirische Erkenntnisse aus dem Projekt der IMP-GrouP. ${ }^{877}$ Gegenstand seines Modells ist im Wesentlichen der Prozess der Etablierung und Entwicklung einer Geschäftsbeziehung. ${ }^{878}$ Er beschreibt die Entwicklung einer Beziehung im Zeitablauf anhand von fünf Phasen, in denen Konstrukte wie Erfahrung, Unsicherheit, Distanz und Commitment einem typischen Entwicklungsprozess unterliegen. Im Zeitablauf der Beziehung wächst die Erfahrung und das Commitment hinsichtlich der Geschäftsbeziehung, während die Unsicherheit und die Distanz zwischen den Unternehmen sinkt (vgl. Abb. A-11). FORD hebt dabei hervor, dass bei Betrachtung einer Geschäftsbeziehung die einzelnen Phasen oder Episoden, die Gesamtbeziehung sowie auch das Verhältnis der beiden zueinander zu analysieren ist. So kann bereits ein Fehler in einer Phase einer Geschäftsbeziehung, z.B. bei einer fehlerhaften Belieferung eines Produzenten mit Rohstoffen, zum Abbruch der gesamten Beziehung führen.

\footnotetext{
874 Vgl. Werp (1998), S. 84.

875 Vgl. Stahl (1996), S. 87.

876 Vgl. Ford/Håkansson/Johanson (1986), S. 38.

877 Vgl. Ford (1990), S. 42.

878 Vgl. hier und im Folgenden Ford (1990), S. 44 ff.
} 


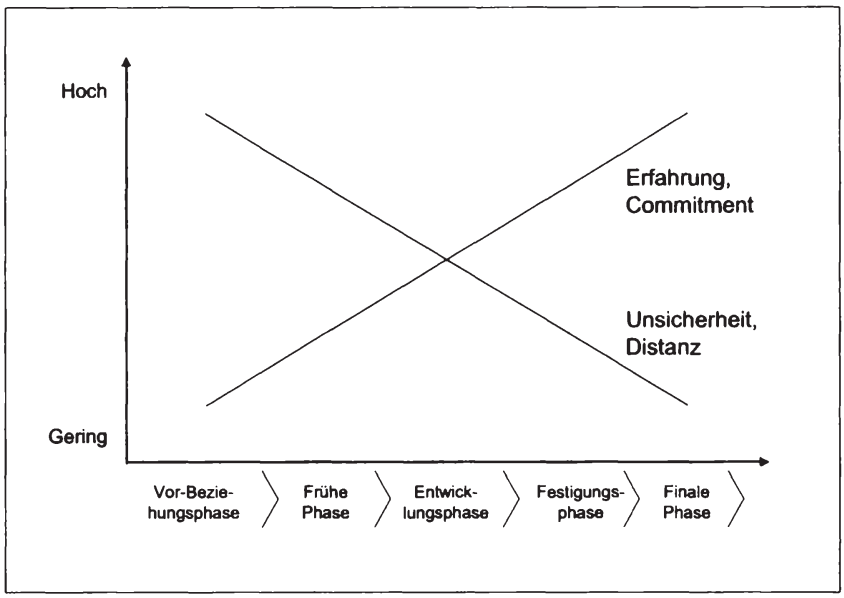

Abb. A-11: Dynamisches Modell nach FORD ${ }^{879}$

Im Laufe der Beziehung steigt die Erfahrung von einer anfänglich vollständig fehlenden Erfahrung der beiden Unternehmen im Umgang miteinander auf eine sehr beträchtliche Erfahrung in einem späten Stadium. Dies führt dazu, dass standardisierte Ablaufprozesse und Verhaltensregeln entwickelt werden sowie Vertrauen aufgebaut wird. ${ }^{880}$

Die Unsicherheit bezüglich des Umgangs mit einem bestimmten Partner wird im Laufe der Beziehung auf ein Minimum reduziert. ${ }^{881}$ Kosten und Nutzen der Beziehung können hinreichend präzise beurteilt, die Sinnhaftigkeit weiterer Anpassungsinvestitionen korrekt evaluiert werden, wobei die Notwendigkeit für Anpassungen bei einem Austausch komplexer Produkte ${ }^{882}$ wächst. ${ }^{883}$ Komplexe Produkte sind in der Regel erklärungsbedürftiger und verlangen somit intensivere persönliche Kontakte, so dass bei beiden Geschäftspartnern größere personelle Ressourcen bereitzuhalten sind. Darüber hinaus handelt es sich bei komplexen Produkten tendenziell häufiger um maßgeschneiderte Lösungen für einen Kunden, die im Vorfeld des eigentlichen Austauschs zusätzliche Informationen und Anpassungen mit sich bringen. ${ }^{884}$ Derartige Bindungen werden weitgehend durch soziale Momente auf persönlicher Ebene wie etwa Vertrauen und Zufriedenheit getragen und stellen eine unabdingbare Voraussetzung dar, um

\footnotetext{
879 Eigene Darstellung.

880 Vgl. Ford (1990), S. 50.

881 Vgl. Ford (1990), S. 51.

882 Im Investitionsgütermarketing werden unter komplexen Produkten meistens Produkte verstanden, die sich aus einer Vielzahl unterschiedlicher Komponenten zusammensetzen, ein spezielles Know-How sowie meistens auch spezielle Produktionsanlagen zur Herstellung erfordern. Im Bankensektor sind hierunter bspw. Projektfinanzierungen zu subsumieren. 
weitere Risiken einzugehen und weitergehende Investitionen und Anpassungen durchzuführen. ${ }^{885}$ Sind diese Voraussetzungen erfüllt, so wird die Bereitschaft, komplexere Produkte wie bspw. Währungsabsicherungen abzuschließen, im Zeitablauf der Bankbeziehung zunehmen bzw. in Abhängigkeit von der Persönlichkeit des Unternehmers wird zumindest die gefühlte Unsicherheit bezüglich der Produkte abnehmen.

Die soziale Distanz, d.h. das Ausmaß, in dem die Art des anderen zu arbeiten sowohl den Individuen als auch den Organisationen innerhalb einer Beziehung unbekannt sind, sinkt mit weiterem Fortschreiten der Beziehung auf ein Minimum. So können sich bspw. enge persönliche Beziehungen zwischen den Individuen der Unternehmen bilden. ${ }^{886}$ Gleichzeitig entwickelt sich ein Vertrauen zwischen den Geschäftspartnern, dessen Stärke sich bspw. in den durchgeführten informellen Anpassungsinvestitionen widerspiegelt.

Das Commitment ${ }^{87}$, d.h. die Bindung an den Geschäftspartner, von Käufer- und Verkäufer-Unternehmen zeigt sich in den extensiven formellen und informellen Anpassungen. ${ }^{88}$ Aus Verkäufer-Sicht sind damit allerdings zwei Gefahren verbunden. Für das Verkäufer-Unternehmen ist es schwierig die Balance zu finden zwischen der Notwendigkeit, Commitment gegenüber einem Kunden zu zeigen auf der einen Seite und der Gefahr, übermäßig abhängig zu werden auf der anderen Seite. ${ }^{889}$ Gleiches gilt auch für ein Commitment des Käufer-Unternehmens. Des Weiteren kann die Wahrnehmung des Kunden bezüglich des Commitment des Verkäufers vom tatsächlichen Commitment-Level abweichen. ${ }^{890}$ So signalisiert die Bindung eines Unternehmens an eine Bank in Form einer Exklusivbankfinanzierung zwar ein hohes Commitment, birgt gleichzeitig aber auch die Gefahr, dass die Bank bspw. aufgrund einer geänderten Kreditrisikostrategie keine Mittel mehr zur Verfügung stellt oder dass die Bank Zinsen oberhalb des Marktniveaus fordert. Ferner stellt sich hier die Frage, ob die Bindung an die Bank in der Exklusivfinanzierung tatsächlich als Commitment wahrgenommen wird oder ob dies lediglich als Ermangelung von Alternativen betrachtet wird. In einem vergleichbaren Modell von DWYER/SCHURR/OH, welches ebenfalls die Phasenorientierung von Geschäftsbeziehungen betont, wird hervorgehoben, dass die Interdependenzen zwischen den Partnern in der „Commitment-Phase“ ihre höchste Intensität erreichen, so dass alternativen Geschäftspartnern der Eintritt in die Beziehung verwehrt wird. ${ }^{891}$

Die letzte Phase, welche mit der Beendigung der Beziehung schließt, ist für Unternehmen mit hohem Commitment nur mit schmerzhaften Verlusten durchzuführen. Den

$885 \quad$ Vgl. Dwyer/Schurr/Oh (1987), S. 18.

886 Vgl. hier und im Folgenden Ford (1990), S. 51.

${ }^{887}$ Diller/Kusterer definieren Commitment als „die innere Bereitschaft eines Geschäftspartners zur Geschäftsbeziehung zu stehen und zwar weitgehend unabhängig vom Zeithorizont und von der ökonomischen Bedeutung.“ Diller/Kusterer (1988), S. 218. Eine ausführliche Definition des Commitment-Begriffs erfolgt in Kapitel A.5.2.3.2.1.

888 Vgl. Ford (1990), S. 51.

${ }_{889}$ V gl. Ford (1990), S. 51.

890 Vgl. Ford (1990), S. 51.

891 Vgl. Dwyer/Schurr/Oh (1987), S. 17. 
Grund vermutet SöLLNER in der Spezifität von Bestandteilen des „Amount at Stake““. ${ }^{892}$ Denn aufgrund der Spezifität der Anpassungen und der durchgeführten Investitionen, z.B. der Etablierung eines speziellen Reporting-Systems, können selbige nicht ohne Verluste in neuen Geschäftsbeziehungen eingesetzt werden.

Zusammenfassend lässt sich die Entwicklung einer Geschäftsbeziehung aus dem Modell von FORD wie folgt beschreiben. Das wahrgenommene und das tatsächliche Commitment, formelle und informelle Anpassungen, Investitionen und Erfahrungen steigen, die Unsicherheit und die Distanz sinken im Zeitablauf. ${ }^{893}$ Investitionen und Anpassungen während des Anbahnungsprozesses werden aufgrund einer positiven Erwartungshaltung durchgeführt. ${ }^{84}$ Enttäuscht der Partner diese Erwartungshaltung nicht und führt seinerseits ebenfalls Investitionen und Anpassungen durch, die bewusst wahrgenommen werden, so entwickelt sich nach mehreren iterativen Investitions- und Anpassungsrunden allmählich eine Bindung zwischen beiden Unternehmen. ${ }^{895}$ Soziale Elemente auf persönlicher Ebene wie bspw. Vertrauen bilden eine zentrale Grundlage derartiger Beziehung und stellen eine zwingende Voraussetzung zum Eingehen weiterer Risiken wie weitergehende Investitionen und Anpassungen dar. ${ }^{896}$

\subsection{Fazit und Modellkritik}

Die Besonderheit des Modells von FORD liegt darin, das er als erster die Dynamik der Geschäftsbeziehung berücksichtigt und somit trotz mangelnder Operationalisierung der Konstrukte einen wesentlichen Beitrag zur Erforschung von Geschäftsbeziehungen geleistet hat. ${ }^{897}$ Bei Betrachtung der einzelnen Konstrukte lassen sich Parallelen zum statischen Modell der IMP-GrouP feststellen, allerdings spielt die soziale Distanz in diesem Modell eine deutlich wichtigere Rolle. Dieser Aspekt wird im statischen Ansatz in der ersten Dimension, dem Interaktionsprozess, nur kurz angesprochen. Das Commitment zwischen den beiden Geschäftspartnern ist von einer derartigen Wichtigkeit, dass DWYER/SCHURR/OH in einem ähnlichen Modell sogar eine explizite Commitment-Phase, d.h. eine Phase mit besonders hohem Commitment, in das Modell integriert haben. Vertrauen wird in dem Modell von FORD als Konsequenz der Erfahrungen mit dem Geschäftspartner sowie als Voraussetzung für das Eingehen von Risiken in Bezug auf den Geschäftspartner genannt. Ferner führt auch die Reduktion von sozialer Distanz zu Vertrauen ${ }^{898}$, so dass dem Vertrauen auch in diesem Modell eine essenzielle Bedeutung zugesprochen wird.

Die Untergliederung in einzelne Phasen und die Darstellung des typischen Ablaufs einer Geschäftsbeziehung lässt aber nicht den Schluss zu, dass es sich hierbei um einen Automatismus handelt. Andernfalls würde die Differenzierung nach den verschiede-

892
893
894
895
896
897
898

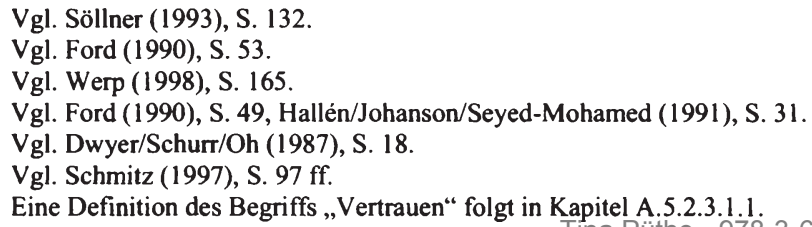


nen Auswirkungen, insbesondere die Hervorhebung des Vertrauens und des Commitments und deren unterschiedliche Ausprägungen, keinen weiteren Nutzen für die vorliegende Arbeit stiften. Bei einem Automatismus könnte man davon ausgehen, dass die Ausprägung allein von der Dauer der Geschäftsbeziehung, möglicherweise auch von der kumulierten Anzahl der Kontakte, abhängt und somit würde es ausreichen, diese Variable in die Untersuchung zu integrieren. Es ist davon auszugehen, dass die Schnelligkeit des Fortschreitens im Phasenmodell von diversen Faktoren abhängt, unter anderem auch von den im statischen Modell genannten Faktoren wie der Makroumwelt. Da diese Faktoren allerdings nicht vollständig bekannt sind, erscheint es notwendig, die aus den jeweiligen Phasen resultierenden Faktoren in die vorliegende Untersuchung zu integrieren; dies könnten die Faktoren Vertrauen, Erfahrung, Zufriedenheit, soziale Distanz oder Commitment sein. Die Unsicherheit spiegelt sich in diesen Variablen wider.

\subsubsection{Integrierter Ansatz nach SEGBERS}

\subsection{Modellbeschreibung}

SEGBERS hat ein Modell zur Deskription und Analyse einer Hausbankbeziehung im Allgemeinen und der ökonomischen Wirkungen im Speziellen entwickelt, ${ }^{899}$ wobei sich das Modell auch auf andere Geschäftsbeziehungen übertragen lässt. Eine zentrale Rolle in diesem Modell spielen die theoretischen Konstrukte Vertrauen und Commitment, welche sich aus den Interaktionen zwischen Firmenkundenbetreuer und dem Unternehmer in einer Hausbankbeziehung ergeben. ${ }^{900}$ Die Geschäftsbeziehung wird gemäß dem Prozessmodell der Interaktion als Wechselspiel einer Bewertung einzelner Transaktionen und einer daraus abgeleiteten kumulierten Bewertung der Geschäftsbeziehung aufgefasst. ${ }^{901}$ Wie in Abb. A-12 dargestellt, werden in diesem Modell drei Bezugsobjekte der Geschäftsbeziehung unterschieden, die Transaktionsebene, die Beziehungsebene und als neues, bisher noch nicht explizit angesprochenes Bezugsobjekt auch die Bindungsebene, wobei die beiden zuletztgenannten im Fokus des Modells stehen. ${ }^{902}$ Durch die Kombination dieser Ebenen gelingt die integrative Abbildung des Bewertungsprozesses der (Haus-)Bankbeziehung, bei der Betrachtung der Transaktionsebene hingegen liegt der Fokus auf dem ,arm's length banking“.

\footnotetext{
899 Vgl. Segbers (2007), S. 306.

900 Vgl. Segbers (2007), S. 306.

901 Vgl. hierzu auch Kapitel A.5.2.1.

902 Vgl. Segbers (2007), S. 308.
} 


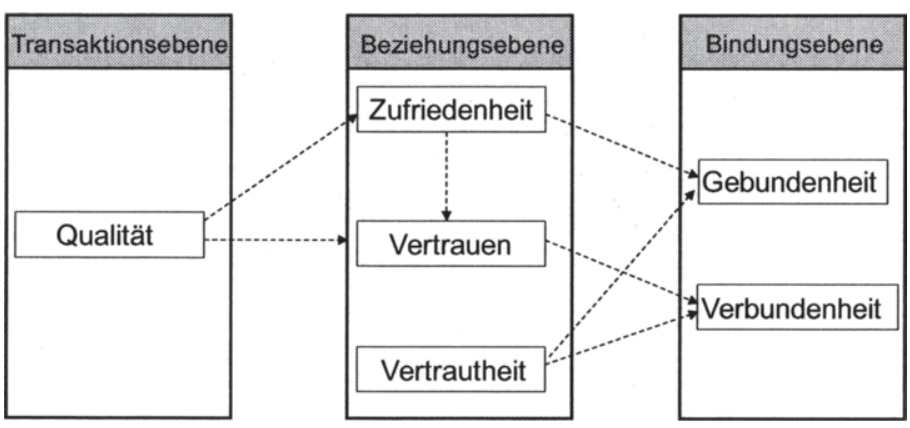

Abb. A-12: Modell von SEGBERS ${ }^{903}$

Auf der Transaktionsebene ist zunächst die Qualität der erbrachten Leistungen durch die Bank von zentraler Bedeutung, da sie die Grundlage für die Konstrukte auf der Beziehungs- und der Bindungsebene bildet. In der Geschäftsbeziehung stellen die Geschäftspartner unterschiedliche Arten von Anforderungen an den Beziehungspartner, wobei hier basierend auf dem Kano-Modell ${ }^{904}$ nach Basis-, Leistungs- und Begeisterungsanforderungen unterschieden wird. ${ }^{905}$ Die Erfüllung der Anforderungen im Rahmen der einzelnen Transaktionen und schließlich die Bewertung derselbigen wirkt sich auf die Beziehungsebene aus.

Auf der Beziehungsebene ist die Zufriedenheit ${ }^{906}$, welche sich aus der Bewertung der einzelnen Transaktionen ergibt, ein zentrales Konstrukt. Die Zufriedenheit mit der gesamten Geschäftsbeziehung ergibt sich aus der Aggregation der Zufriedenheit mit den einzelnen Transaktionen ${ }^{907}$ und ist somit als ein vergangenheitsorientiertes Konstrukt einzustufen. ${ }^{908}$ Die weiteren zentralen Konstrukte der Beziehungsebene sind die Vertrautheit und das Vertrauen. ${ }^{99}$ Vertrautheit wird bei SEGBERS definiert als Grad der Bekanntheit eines Geschäftsbeziehungspartners mit dem anderen Partner. ${ }^{910}$ Es wird unterschieden zwischen drei Dimensionen der Vertrautheit: der Vertrautheit gegenüber der Organisation (also der Bank oder dem Unternehmen), der Vertrautheit gegenüber dem Beziehungspartner in seiner Rolle (also dem Firmenkundenbetreuer oder dem Unternehmer) und der Vertrautheit gegenüber der Person als solchen. Vertrautheit ergibt sich insbesondere aus den Erfahrungen der Vergangenheit mit den Beziehungspartnern und entwickelt sich vor allem bei häufigen Kontakten.

\footnotetext{
903 Eigene Darstellung in Anlehnung an Segbers (2007), S. 339.

904 Zum Kano-Modell vgl. Bailom et al. (1996), S. 118.

905 Vgl. Segbers (2007), S. 312.

906 (Konsumenten-) Zufriedenheit bezeichnet die Übereinstimmung zwischen den subjektiven Erwartungen und der tatsächlich erlebten Motivbefriedigung bei Produkten oder Dienstleistungen. Vgl. Meffert (2000), S. 135.

Vgl. Stauss (1999), S. 6.

Vgl. Segbers (2007), S. 331.

Vgl. Segbers (2007), S. 331.
} 
Im Gegensatz zu den beiden bisher genannten Konstrukten ist Vertrauen zukunftsorientiert. Vertrauen beschreibt das Ausmaß, in dem der Unternehmer oder der Firmenkundenbetreuer bereit ist, eine riskante Vorleistung zu tätigen. Durch diese riskante Vorleistung wird er anfällig für den Opportunismus des anderen.9" Vertrauen ist somit die Verhaltenserwartung gegenüber der anderen Person, dass sich selbige nicht opportunistisch verhält. Vertrauen ist ein personenbezogenes Phänomen, für dessen Entwicklung ein hoher Grad an persönlicher Vertrautheit erforderlich ist.

Vertrauen entsteht durch wiederholt erlebte Zufriedenheit mit einem Anbieter. ${ }^{912}$ Erfolgreichen Interaktionen in der Vergangenheit fördern das Entstehen von Vertrauen. ${ }^{913}$ Wichtig ist hierbei die Unterscheidung zwischen den verschiedenen Ebenen, so kann auf organisationaler Ebene ein vertrauensvolles Verhältnis zwischen den beiden Unternehmen vorherrschen, während die Beziehung auf interpersonaler Ebene eher durch Misstrauen gekennzeichnet ist. ${ }^{914}$ Ferner kann ein Konflikt auf organisationaler Ebene zu schwerwiegenden Missstimmigkeiten führen, ohne aber die Qualität der interpersonalen Beziehung nachhaltig zu beeinträchtigen.

Als dritte Ebene ist die Bindungsebene zu betrachten, wobei hier unter der Bindung oder dem Commitment ${ }^{915}$ die Bereitschaft zur Fortsetzung der Beziehung zu verstehen ist. ${ }^{916}$ Bei diesem Konstrukt lassen sich wiederum mehrere Ebenen unterscheiden. Wie in Abb. A-13 dargestellt, existiert zum einen ein kognitives oder kalkulatives Commitment in Form einer Gebundenheit und zum anderen ein affektives Commitment in Form einer Verbundenheit. Bei der Gebundenheit handelt es sich um einen Zustand der ökonomischen Bindung während bei der Verbundenheit eher eine psychologische Bindung vorliegt. Bei der Gebundenheit ist es für den Kunden aus einem rationalen Kosten-Nutzen-Kalkül heraus nicht sinnvoll, den Lieferanten oder die Bank zu wechseln, z.B. weil die Suchkosten ggf. die Kostenersparnis übersteigen. In diesem Fall ist für die Fortsetzung der Beziehung lediglich das Ergebnis von Relevanz, weshalb hier von einer instrumentellen Beziehung gesprochen werden kann. ${ }^{917}$ Die Gebundenheit des Kunden beruht auf einer wahrgenommenen Einschränkung der zukünftigen Wahlfreiheit durch den Aufbau von Wechselbarrieren. ${ }^{918}$ Die Gebundenheit bezieht sich somit auf die Organisation. Die Verbundenheit resultiert aus emotionalen Ursachen, bspw. wenn sich aus dem rein monetären Nutzen der Bankverbindung ein psychischer Nutzen in Form eines emotionalen Wohlbefindens einstellt. Die Verbundenheit kann zum einen eine Verbundenheit gegenüber dem Interaktionspartner und zum anderen eine Verbundenheit gegenüber der Organisation sein. Verbundenheit basiert unter anderem auf der Zufriedenheit des Kunden mit dem erhaltenen Netto-Nutzen aus einer

\footnotetext{
911 Vgl. Segbers (2007), S. 341.

912 Vgl. Eggert (1999), S. 52.

913 Vgl. Riemer (2005), S. 43.

914 Vgl. Werp (1998), S. 168 f. und Söllner (1993), S. 104 in Bezug auf „Commitment“.

915 Die Begriffe Commitment und Bindung können synonym verwendet werden.

916 Vgl. Segbers (2007), S. 334.

917 Vgl. Segbers (2007), S. 335.

918 Vgl. Eggert (1999), S. 52.
} 
Geschäftsbeziehung. ${ }^{19}$ Die Wirkung der Gebundenheit beruht auf einem Nicht-Wechseln-Können des Kunden, die Verbundenheit hingegen auf einem Nicht-WechselnWollen des Kunden. ${ }^{920}$ Als Einflussparameter auf die Gebundenheit wirken insbesondere das Konstrukt der Zufriedenheit als auch das Konstrukt der Vertrautheit. Denn durch den erhöhten Grad der Vertrautheit entsteht ein Informationsvorteil der Organisation oder des Ansprechpartners. Wesentliche Einflussparameter auf die Verbundenheit sind neben positiven Emotionen in der Bankbeziehung das Vertrauen und die Vertrautheit. Das positive Gefühl der Intimität erweckt den Wunsch, in der Beziehung zu verbleiben, um diesen Zustand nicht bei einer Bank erneut aufbauen zu müssen. ${ }^{921}$

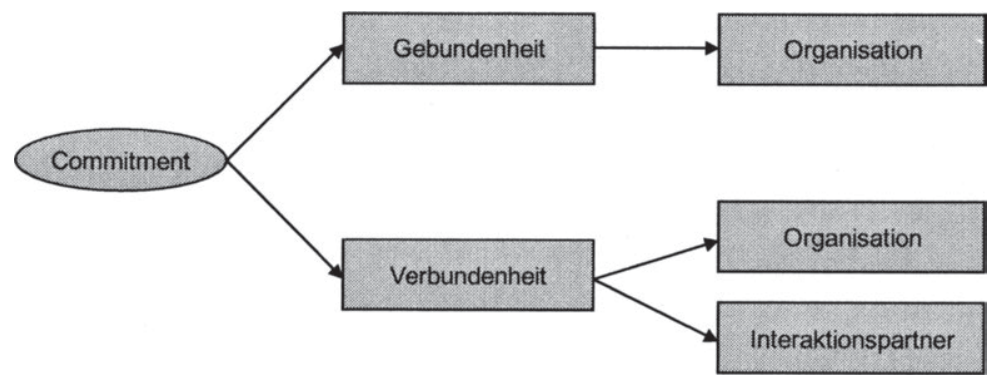

Abb. A-13: Dimensionen von Commitment im Modell von SEGBERS ${ }^{922}$

\subsection{Modellkritik}

Bisher wurden bei der theoretischen Analyse der Kunde-Bank-Beziehung sowie bei der traditionellen empirischen Relationship Banking-Forschung die verhaltenswissenschaftlichen Aspekte vernachlässigt. ${ }^{933}$ Erste Ansätze zur Berücksichtigung dieser Aspekte finden sich in den empirischen Studien von UzzI, LeHMANN/NEUBERGER oder HARHOFF/KÖRTING wieder. Allerdings fehlt hier ein integriertes Gesamtmodell. SEGBERS gelingt es, die Ansätze der klassischen Relationship Banking-Modelle um Ansätze aus der Verhaltenwissenschaft und dem Relationship Marketing zu erweitern. Im Vergleich zu den zuvor beschriebenen Geschäftsbeziehungsmodellen ergänzt SEGBERS ferner die Ebenen der Transaktion und der Geschäftsbeziehung um die Bindungsebene. In seinem Modell stellt er die zentralen Kausalzusammenhänge der einzelnen Konstrukte sowie die Auswirkungen auf die ökonomischen Parameter Kreditzins, Sicherheitenstellung und Kreditverfügbarkeit dar.

Kritisch zu sehen ist allerdings die fehlende empirische Validierung der Zusammenhänge. Zwar existieren empirische Studien, die sich mit Teilbereichen des Modells

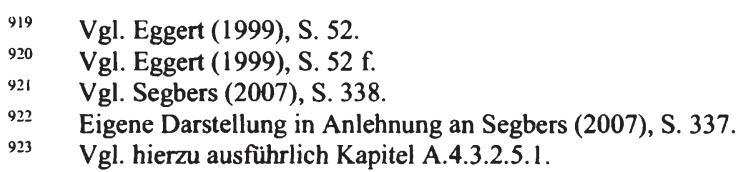


beschäftigen, so hat sich EGGERT intensiv mit den Konstrukten der Verbundenheit und der Gebundenheit auseinandergesetzt, ${ }^{924}$ allerdings wurden die in dem Modell von SEGBERS dargestellten Zusammenhänge noch nicht analysiert. SEGBERS gibt z.T. detaillierte Vorschläge zur Konzeptualisierung und Validierung der einzelnen Konstrukte. ${ }^{925}$

Anders als die zuvor beschriebenen Modelle setzt dieses Modell unmittelbar an der Hausbankbeziehung an. Hier wäre eine stärkere Trennung zwischen Bank- und Kundensicht sinnvoll gewesen. So ist aufgrund der unterschiedlichen Abhängigkeitsverhältnisse fraglich, inwiefern der Zustand der Gebundenheit in dieser Form auch bankseitig zum Tragen kommt. Rechtliche Vorgaben verhindern eine zu große Abhängigkeit der Bank von einzelnen Kunden und somit die Aufnahme von Klumpenrisiken. ${ }^{926}$ Dennoch kann der Verlust eines großen Kunden natürlich negative Konsequenzen haben, sowohl monetärer Art als auch in Bezug auf die Reputation der Bank, was wiederum auch monetäre Konsequenzen hervorrufen kann. Insgesamt ist dieser $\mathrm{Zu}$ stand der Gebundenheit jedoch eher kundenseitig einzuordnen.

\subsubsection{Implikationen der Interaktionsmodelle für die empirische Forschung im Bereich des Relationship Banking}

Die zuvor dargestellten Modelle haben gezeigt, dass verschiedene sozialpsychologische Konstrukte eine wichtige Rolle beim Aufbau und der Fortsetzung von Geschäftsbeziehungen spielen. Das Modell der IMP-GROUP betont unter anderem die Wichtigkeit des Informationsaustauschs und des sozialen Austauschs. Mit der Atmosphäre wurde ferner eine in den Relationship Banking-Ansätzen nahezu völlig abwesende Komponente als bedeutsam herausgearbeitet, die durch Konstrukte wie Vertrauen, Commitment, Abhängigkeit und Distanz beschrieben wird. In dem Modell von FORD wird die Geschäftsbeziehung in verschiedenen Phasen analysiert, in denen Konstrukte wie Erfahrung, Unsicherheit, Distanz und Commitment einer typischen Entwicklung unterliegen. Vertrauen ist in dem Modell eine zentrale Voraussetzung für die Beseitigung von Unsicherheit. In dem Modell von SEGBERS spielen auf der Beziehungsebene die Konstrukte Zufriedenheit, Vertrauen und Vertrautheit sowie auf der Bindungsebene das Konstrukt Commitment in der Form der Ge- und der Verbundenheit eine zentrale Rolle. Für die Relationship Banking-Forschung erscheint es unerlässlich, auch Elemente aus der Atmosphäre der Geschäftsbeziehung bei den Studien zu berücksichtigen. Nach einem umfassenden Literaturstudium können Vertrauen und Commitment als die beiden zentralen Grundelemente der Atmosphäre einer Geschäftsbeziehung betrachtet werden. ${ }^{927}$ MORGAN/HUNT betonen die Wichtigkeit von Commitment und

\footnotetext{
924 Vgl. Eggert (1999), S. 1 ff.

925 Vgl. Segbers (2007), S. 348.

926 Bspw. müssen Banken gemäß § 13 HGB der Bundesbank Großkredite unverzüglich anzeigen. Großkredite liegen dann vor, wenn das Kreditvolumen an einen Kreditnehmer insgesamt $10 \%$ des haftenden Eigenkapitals des Instituts erreicht oder übersteigt. Vgl. HGB (2004), § 13 (1). commitment and trust." Vgl. hierzu auch Werp (1998), S. 168. 
Vertrauen im Rahmen einer Geschäftsbeziehung. ${ }^{928}$ Die Konstrukte motivieren die Partner dazu, (1) daran zu arbeiten, die Relationship Investments aufrecht zu erhalten, indem mit dem Partner kooperiert wird, (2) auf andere attraktive kurzfristige Alternativen zugunsten von erwarteten langfristigen Nutzen aus der Beziehung mit dem aktuellen Partner zu verzichten und (3) auch bei riskanteren Aktionen darauf zu vertrauen, dass sich der Partner nicht opportunistisch verhält. Auch bei DWYER/SCHURR/OH sind Vertrauen und Commitment die kritischen Konstrukte hinsichtlich des Prozesses der Entwicklung von Geschäftsbeziehungen. ${ }^{.29}$

Zum Teil wird ausschließlich Vertrauen als zentraler oder kritischer Faktor herausgestellt. WILSON beschreibt „Trust is a fundamental relationship model building block and as such is included in most relationship models. ${ }^{\text {“9930 }}$ Vertrauen ermöglicht offene Kommunikation, Informationsaustausch und Konfliktmanagement. ${ }^{931}$ Die zentrale Stellung im Modell von DILLER/KUSTERER zeigt - und sie formulieren es auch explizit -, dass Vertrauen gleichermaßen das Ergebnis wie auch der Ausgangspunkt des Kräftespiels im Beziehungsgefüge darstellt. ${ }^{932}$ Im Idealfall kann Vertrauen eine positive Erfolgsspirale in Gang setzen, in gewissem Umfang Kontrolle ersetzen ${ }^{933}$ und die Effektivität von Interaktionen erhöhen. ${ }^{934}$ RöSSL hebt die Zirkularität des Vertrauens und dessen sich selbst voraussetzenden sowie gleichzeitig sich selbst bestätigenden Charakter hervor. ${ }^{935}$ Vertrauen ist aus dem Grund kritisch, als dass es die Vorhersagbarkeit, Anpassungsfähigkeit und die strategische Flexibilität erhöht. ${ }^{936}$ Vertrauen kann darüber hinaus die Transaktionskosten und soziale Komplexität reduzieren. Im Rahmen der ökonomischen Analyse der Kunde-Bank-Beziehung lassen sich die verschiedenen, in Abb. A-14 dargestellten Vertrauensbeziehungen unterscheiden. Vertrauensgeber ist dabei stets eine Person, d.h. der Ansprechpartner des Unternehmens oder der Firmenkundenbetreuer. Das Vertrauen kann sich dabei auf die andere Organisation oder die Kontaktperson derselbigen beziehen.

\footnotetext{
928 Vgl. Morgan/Hunt (1994), S. 22.

929 Vgl. Dwyer/Schurr/Oh (1987), S. 22. Bejou gibt einen kurzen Überblick über die Entstehung des Beziehungsmarketing und die wichtigsten statischen und dynamischen Modelle. Vgi. Bejou (1997), S. 729.

Vgl. Wilson (1995), S. 337.

Vgl. Seppänen/Blomqvist/Sundqvist (2007), S. 249.

Vgl. Diller/Kusterer (1988), S. 218.

Vgl. Sydow (1995), S. 181.

Vgl. Jung (1999), S. 172.

Vgl. Rössl (1994), S. 200.

Vgl. Seppänen/Blomqvist/Sundqvist (2007), S. 249. 


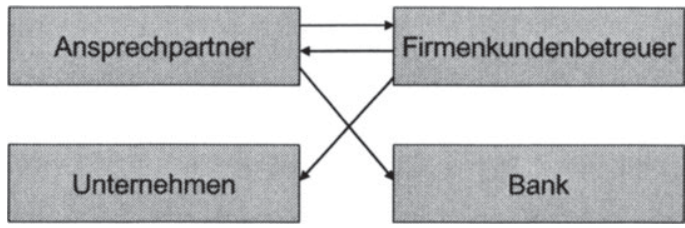

Abb. A-14: Vertrauensbeziehungen im Rahmen der Kunde-Bank-Beziehung

Als weiteres zentrales Element wurde Commitment herausgearbeitet. Auch hier sind wieder zwei Perspektiven, die des Unternehmens sowie die der Bank, und zwei Ebenen, die der Organisation sowie die des Interaktionspartners, zu unterscheiden. Bevor eine dezidierte Analyse der ökonomischen Auswirkungen der beiden Konstrukte Vertrauen und Commitment erfolgt, sollen im Folgenden die bestehenden theoretischen Ansätze sowie die empirische Operationalisierung dieser Konstrukte dargestellt werden. So wurde beispielsweise in dem Ansatz von LEHMANN/NEUBERGER deutlich, dass es sich bei dem Vertrauen nicht um ein eindimensionales Konstrukt handelt. ${ }^{937}$ Da daraus möglicherweise unterschiedliche, ökonomische Konsequenzen resultieren, bedarf es zunächst einer Klärung der Dimensionen der Konstrukte. In den bisherigen Modellen spielen zwar auch weitere Konstrukte, wie z.B. Zufriedenheit und Vertrautheit eine wesentliche Bedeutung, in dem Modell von SEGBERS wirken diese aber nur mittelbar über die Konstrukte Vertrauen und Commitment. ${ }^{938}$

\subsubsection{Analyse des Konstruktes Vertrauen}

\subsection{Definition und Dimensionen von Vertrauen}

Bevor im Rahmen der empirischen Studie eine Konzeptualisierung und Operationalisierung des Vertrauenskonstruktes erfolgen kann, sollen zunächst eine Definition sowie die verschiedenen aktuell in der Literatur verwendeten Dimensionen erarbeitet werden. In der Literatur findet sich keine eindeutige Definition von Vertrauen. ${ }^{939}$ Viel-

937 Vgl. Lehmann/Neuberger (2000), S. $1 \mathrm{ff}$.

938 Beim IMP-Ansatz ist darüber hinaus die Macht als zentrales Element der Atmosphäre der Geschäftsbeziehung zu berücksichtigen. So untersucht Jung den Einfluss von Macht und Vertrauen. Jung interessieren für die Erweiterung der bestehenden Geschäftsbeziehungsansätze insbesondere jene sozialpsychologischen Konstrukte und deren Interdependenzen, die die Transaktionskosten beeinflussen. Diese zusätzlichen Aspekte sollen im weiteren Verlauf allerdings vernachlässigt werden, denn mit der vorliegenden empirischen Untersuchung wird nicht das Ziel verfolgt, die Geschäftsbeziehung in ihrer Gänze vollumfänglich zu analysieren. Der Fokus liegt auf der Analyse der ökonomischen Wirkungen von Vertrauen und Commitment. Vgl. Jung (1999), S. 172.

939 Einen Überblick über verschiedene theoretische Ansätze sowie eine Systematisierung der verschiedenen Modelle zum Vertrauenskonstrukt geben Bigley/Pearce sowie etwas kürzer Lewicki/ Tomlinson/Gillespie. Vgl. Bigley/Pearce (1998), S. 405 ff. und Lewicki/Tomlinson/Gillespie (2006), S. 991 ff. Ferner findet sich bei Segbers ein Überblick über die Entstehung und Wirkung von Vertrauen. Vgl. Segbers (2007), S. $237 \mathrm{ff}$. 
mehr existiert eine Vielzahl von Vertrauensdefinitionen, die verschiedene Schwerpunkte besitzen und es ist - wie DWYER/LAGACE es festhalten - ,[...] difficult to identify an integrative or broadly accepted definition of trust". ${ }^{940}$ Ein Grund für die große Diversität sind die unterschiedlichen Forschungsbereiche, in denen das Vertrauenskonstrukt behandelt wird. So ist es nicht verwunderlich, dass in der Sozialpsychologie andere Schwerpunkte gesetzt werden als in der Marketingforschung. Die Konzeptualisierungen von Vertrauen gehen in der Literatur im Wesentlichen auf die Überlegungen von ROTTER zurück. ${ }^{941}$ So hat ROTTER den Begriff des interpersonalen Vertrauens geprägt. ${ }^{942}$ Mit diesem Begriff werden die Erwartungen einer Person beschrieben, sich auf Versprechen, schriftliche oder verbale Äußerungen einer anderen Person oder einer anderen Gruppe verlassen zu können. ${ }^{943}$ Die Erwartungen beruhen dabei im Wesentlichen auf Erfahrungen der Vergangenheit. Diese Erfahrungen erzeugen Erwartungen an zukünftiges Verhalten. Die positive Erwartung findet sich ebenso bei SCHURR/OZANNE, sie definieren Vertrauen als „believe that a party's word or promise is reliable and that a party will fullfil his/her obligations in an exchange relationship." ${ }^{\prime 944}$ Die elementare Bedeutung der positiven Erwartung findet sich auch bei zahlreichen anderen Definitionen wieder.

MOORMAN/DESHPANDÉ/ZALTMAN definieren Vertrauen "as a willingness to rely on an exchange partner in whom one has confidence." ${ }^{\text {445 }}$ MORGAN/HUNT beschreiben Vertrauen "as existing when one party has confidence in an exchange partner's reliability and integrity." ${ }^{946}$ Beide Definitionen heben die Bedeutung von Zuversicht (confidence) hervor. Bei MOORMAN/DESHPANDÉ/ZALTMAN ist zudem die Verhaltensabsicht des Vertrauenden elementar, denn ihrer Ansicht nach liegt Vertrauen erst dann vor, wenn der Partner als vertrauenswürdig eingestuft wird und der Vertrauensgeber bereit ist, sich darauf zu verlassen. ${ }^{947}$ Diese Bereitschaft und Verhaltensabsicht wird von MORGAN/HUNT implizit unterstellt. Nur wenn selbige vorliegen, kann eine Person als vertrauend beschrieben werden. ${ }^{948}$

\footnotetext{
940 Dwyer/Lagace (1987), S. 11.

941 Vgl. Rotter (1967), S. $651 \mathrm{ff}$.

942 Vgl. Rotter (1967), S. 652.

943 Dieser Ansatz wird unter anderem von Anderson/Weitz, Morgan/Hunt und Schurr/Ozanne genutzt. Vgl. Anderson/Weitz (1989), S. 18 ff., Morgan/Hunt (1994), S. 20 ff. und Schurr/Ozanne (1985), S. 939 ff.

Schurr/Ozanne (1985), S. 940. Anderson/Weitz definieren Vertrauen als "one party's belief that it needs will be fulfilled in the future by actions undertakten by the other party." Anderson/Weitz (1989), S. 312. Lewicki/McAllister/Blies definieren Vertrauen als „,confident positive expectations regarding another's conduct“. Lewicki/McAllister/Blies (1998), S. 439. Anderson/Narus verknüpfen ihre Vertrauensdefinition mit einem positiven Ergebnis für das Unternehmen. Individuen werden nicht explizit mit in die Definition integriert:"[Trust is] the firm's belief that it needs will be fulfilled in the future by actions undertaken by the other party." Anderson/Narus (1990), S. 45. Bei allen Definitionen ist die positive Erwartung elementar. Moorman/Deshpandé/Zaltman (1992), S. 315, Schurr/Ozanne (1985), S. 940, Moorman/Deshpandé/Zaltman (1993), S. 82. Morgan/Hunt (1994a), S. 23.

947 Vgl. Moorman/Deshpandé/Zaltman (1992), S. 315.

Vgl. Morgan/Hunt (1994a), S. 23.
} 
In einer Vertrauensdefinition, die auf CURRALL/JUDGE zurückgeht, wird deutlich, dass auch die Bereitschaft, ein Risiko einzugehen, wichtiges Strukturmerkmal des Vertrauens ist. ${ }^{949}$ Vertrauen wird definiert als Umstand, bei dem sich ein Individuum bei der Wahl seines Verhaltens unter Eingehen eines Risikos auf eine andere Person verlässt. ${ }^{90}$ Sie definieren Vertrauen als ,an individual's behavioral reliance on another person under a condition of risk ${ }^{\text {(9951 }}$. Die Vertrauensvergabe ist stets mit Risiko verbunden, denn wenn der Vertrauensnehmer das erbrachte Vertrauen nicht erweist, ist dies für den Vertrauensgeber von Nachteil. ${ }^{952}$ Möglicherweise wäre es für den Vertrauensnehmer zwar von Vorteil, das Vertrauen zu brechen, allerdings kann daraus ein Reputationsverlust entstehen, was langfristig schwerwiegende Nachteile haben kann. ${ }^{933}$ Die Wahrnehmung des Risikos und der explizite Wille, ein Risiko auf sich zu nehmen, ist eines der wenigen Merkmale, das in allen Vertrauenssituationen vorkommt. ${ }^{954}$ In allen bisher genannten Definitionen bezieht sich Vertrauen implizit auf in der Zukunft erwartete Verhaltensweisen des Gegenübers. Die Entwicklung von persönlichem Vertrauen ist dabei an Risiko gebunden, d.h. der Interaktionspartner muss also die Möglichkeit haben, auch anders zu handeln und frei von Normen zu sein. Wird das Vertrauen bestätigt, so stabilisiert sich die Zuschreibung positiver Eigenschaften und erleichtert positive Erwartungen für die Zukunft. ${ }^{955}$ Die Bereitschaft zu vertrauen wirkt sich auf den Umfang der ausgetauschten Informationen, auf den Bindungs- und Regelungsgrad sowie auf die Wirkung vertrauensbildender und -bewahrender Maßnahmen aus. ${ }^{956}$

Gemäß dem systemtheoretischen, funktionalistischen Ansatz von LUHMAN kommt dem Vertrauen die Funktion der Komplexitätsreduktion zu. ${ }^{957}$ Ausgangspunkt seines Ansatzes ist die Erkenntnis, dass ein Individuum nicht in der Lage ist, alle Informationen zu verarbeiten. ${ }^{958}$ Vertrauen erschließt durch Reduktion von Komplexität Handlungsmöglichkeiten, die ohne Vertrauen unwahrscheinlich und unattraktiv geblieben wären. ${ }^{95}$

\footnotetext{
949 Vgl. Curral/Judge (1995), S. 151.

950 Vgl. Curral/Judge (1995), S. 151.

951 Curral/Judge (1995), S. 151. Ebenso definieren Rousseau et al. Vertrauen als einen Zustand, der die Absicht, Verwundbarkeit zu akzeptieren, behinhaltet basierend auf positiven Erwartungen über die Absichten oder das Verhalten eine anderen Person. Vgl. Rousseau et al. (1998), S. 395. Coleman beschreibt Vertrauen als den Transfer von Kontrolle über Ressourcen, Handlungen oder Ereignisse. Vgl. Coleman (1982a), S. 282.

952 Vgl. Coleman (1982a), S. 283.

953 Vgl. Coleman (1982b), S. 303 f. Dieser Aspekt findet sich in ähnlicher Form auch bei der Neuen Institutionenökonomie wieder. Vgl. hierzu auch Kapitel A.4.2.4.

954 Vgl. Johnson-George/Swap (1982), S. 1306.

955 Vgl. Koller (1997), S. 19.

956 Vgl. Schade/Schott (1993a), S. 500 f.

957 Vgl. Luhmann (2000), S. 1-14.

$958 \quad$ Vgl. Koller (1997), S. 19.

959 Luhmann (2000), S. 30
} 
LUHMANN und GIDDENS unterscheiden nach personalem Vertrauen und Systemvertrauen. ${ }^{960}$ Personales Vertrauen wird durch Handeln, im Fall von Unternehmensnetzwerken vor allem durch Managementhandeln, produziert und reproduziert. ${ }^{961} \mathrm{Da}$ Handlungen Ausgangspunkt des Vertrauens sind, ist die Entstehung und Stabilisierung desselbigen an Personen und an Persönlichkeiten gebunden. Bei dem Systemvertrauen ist das Bezugsobjekt nicht die konkrete Person, sondern ein abstraktes, soziales oder technisches System. Bei der Unternehmung handelt es sich um ein derartiges System. Somit rekurriert die Unterscheidung von personalem Vertrauen und Systemvertrauen auf das Objekt des Vertrauens. Personales Vertrauen bezieht sich grundsätzlich auf personale Akteure und drückt sich aus in dem Vertrauen in die fachliche Kompetenz einer Person oder in dem Vertrauen in die Persönlichkeit. ${ }^{962}$ Die Entwicklung von personalem Vertrauen setzt voraus, dass handelnde Personen miteinander in Kontakt kommen. Auch SCHMITZ nimmt eine Differenzierung nach individuellem Vertrauen und Systemvertrauen vor. ${ }^{963}$ Beim persönlichen Vertrauen von LUHMANN wird auf die private Persönlichkeit abgezielt, das individuelle Vertrauen zielt hingegen auf die beruflich dargestellte und sozial sichtbar gemachte Persönlichkeit. ${ }^{964}$ Objekte des Systemvertrauens sind technische oder soziale Systeme. Das Vertrauen basiert dabei nicht nur auf personaler Interaktion, sondern basiert zu einem wesentlichen Teil in dem „faith in the correctness of principles"\%65. Interpersonales Vertrauen ist ein zentrales Element in allen sozialen Situationen, die Kooperation und Interdependenz erfordern. ${ }^{966}$ Der Vertrauensgeber muss entscheiden, ob es bei Betrachtung des möglichen positiven Outputs Wert ist, das Risiko einzugehen, verletzlich und abhängig zu werden. Dieses Risikoelement ist charakteristisch für die Entscheidungssituation. Trotz jeglicher Sorgfalt bei der Beurteilung der Intentionen einer Person, der Fähigkeiten und Motive besteht dennoch keine Sicherheit bezüglich eines zufrieden stellenden Ergebnisses. Die Vertrauensbereitschaft wird durch verschiedene spezifische Faktoren bestimmt. Beispielsweise könnte der Fall auftreten, dass man einer Person zwar die Katze zur Beaufsichtigung während der Ferien anvertraut, aber der gleichen Person nicht den Wagen zur Reparatur übergibt. Ferner kann das Systemvertrauen von dem personalen Vertrauen profitieren, ${ }^{967}$ so dass die beiden Formen des Vertrauens nicht isoliert betrachtet werden können. GANESAN/HESS unterscheiden sogar vier Arten: interpersonales, intraorganisationales, organisationales und interorganisationales Vertrauen (vgl. Abb. A-15). ${ }^{968}$ Interpersonales Vertrauen besteht zwischen Personen, ggf. zwischen Personen unterschiedlicher Organisationen. Während sie unter dem Begriff intraorganisationales Vertrauen das Vertrauen einer Person in die eigene Organisation

Vgl. Luhmann (2000), S. 47 ff. und 60 ff., Giddens (1990), S. 33f. Für einen Vergleich vgl. Sydow (1995), S. 183.

Vgl. Luhmann (2000), S. 51, Giddens (1990), S. 33f.

Vgl. Sydow (1995), S. 189.

Eine Abgrenzung der Vertrauensbegriffe nimmt Schmitz vor. Vgl. Schmitz (1997), S. $161 \mathrm{ff}$.

Vgl. Schmitz (1997), S. $161 \mathrm{ff}$.

Vgl. Giddens (1990), S. 33 f.

Vgl. hier und im Folgenden Johnson-George/Swap (1982), S. 1306.

Vgl. Sydow (1995), S. 190.

Vgl. hier und im Folgenden Ganesan/Hess (1997), S. $440 \mathrm{f}$. 
verstehen, ist das organisationale Vertrauen das Vertrauen einer Person in eine andere Organisation. Das interorganisationale Vertrauen beschreibt das gegenseitige Vertrauen zwischen den Organisationen.

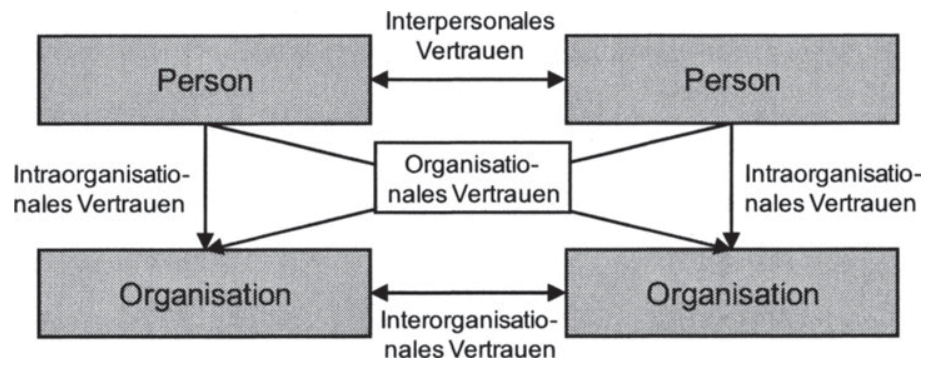

Abb. A-15: Vertrauensdimensionen nach GANESAN/HESS ${ }^{969}$

Während zuvor die verschiedenen potenziellen Bezugsobjekte des Vertrauens angesprochen wurden, wird im Folgenden nach verschiedenen inhaltlichen Dimensionen unterschieden. DONEY/CANNON definieren Vertrauen "as perceived credibility and the benevolence of a target of trust." ${ }^{" 970}$ Ebenso für GANESAN besteht Vertrauen aus den beiden Dimensionen Wohlwollen und Glaubwürdigkeit. ${ }^{971}$ GANESAN versteht unter Wohlwollen (benevolence) „the qualities, intentions, and the characteristics attributed to the partner rather than its specific behaviors" ${ }^{\text {"972 }}$ Glaubwürdigkeit (credibility) definiert er als "the belief, that the other party would make commitments that are reliable and has representatives who perform the selling/buying functions effectively." ${ }^{\prime 973}$ GANESAN/HESS gehen bei ihrer Definition noch einen Schritt weiter: "The first dimension, credibility, is based upon a focal partner's intention and ability to keep promises and deals with partner characteristics such as task specific competencies, reliability in the delivery of goods and services, and predictability in terms of job related behaviors. The second dimension, benevolence, is based on the qualities, intentions, and characteristics attributed to the focal partner that demonstrate a genuine concern and care for the partner through sacrifices that exceed a purely egocentric profit motive." 974 Diese verschiedenen inhaltlichen Dimensionen können sich wiederum auf die zuvor erwähnten verschiedenen Bezugsobjekte bzw. Ebenen beziehen. Die Vertrauensdefinitionen von GANESAN sowie von GANESAN/HESS beziehen sich auf die persönliche 
Ebene. KUMAR/SCHEER/STEENKAMP unterscheiden ebenfalls zwischen Glaubwürdigkeit bzw. Ehrlichkeit und Wohlwollen, sie zielen aber auf die Organisationsebene ab. ${ }^{975}$

In der Literatur wird davon ausgegangen, dass das Vertrauen mit der Anzahl der positiv verlaufenen Transaktionen zwischen beiden Unternehmen wächst. ${ }^{976}$ So fördert eine auf gegenseitigem Vertrauen basierende Geschäftsbeziehung - wie auch in Kapitel A.4.3.2.5.4 kurz angesprochen - den Informationsaustausch und die Kommunikation zwischen beiden Unternehmen. ${ }^{977}$ Vertrauen erleichtert auch die Durchführung erster Investitionen und Anpassungen in der Anbahnungsphase. ${ }^{978}$ Derartige Investitionen und Anpassungen sind in einigen Fällen nahezu ausschließlich geschäftsbeziehungsspezifisch, so dass die Unternehmen eher bereit sein werden, diese speziellen Investitionen und Anpassungen vorzunehmen, wenn sie Geschäftspartnern vertrauen. ${ }^{979}$ Eine Investitions- und Anpassungsbereitschaft erfordert zwar auf der einen Seite Vertrauen, kann aber auch als vertrauensbildende Maßnahme angesehen werden. Der Aufbau einer Geschäftsbeziehung setzt sich somit auf der Basis des zunehmenden Vertrauens in einer Art „Aufschaukelprozess“ fort. ${ }^{980}$

Im Rahmen einer Geschäftsbeziehung erfüllt Vertrauen diverse Funktionen. So stabilisiert ein höheres Vertrauensniveau soziale Beziehungen und erleichtert allein deshalb die Koordination, macht komplexe vertragliche Vereinbarungen überflüssig und ermöglicht einen offeneren Informationsaustausch und führt insgesamt zu niedrigeren Transaktionskosten. ${ }^{981}$ Vertrauensbeziehungen im interorganisationalen Kontext sind u.a. durch nachstehende Merkmale geprägt: ${ }^{922}$

- einen offeneren Informationsaustausch zwischen den Unternehmungen,

- ein reduziertes $\mathrm{Ma} ß$ an Kontrolle der Austauschbeziehungen,

- ein höheres $\mathrm{Ma} \beta$ an (gewährter) Autonomie auch der abhängigen Unternehmung bzw. an Toleranz gegenüber Beeinflussungsversuchen durch die autonomere Unternehmung,

- eine Langfristigkeit und Stabilität interorganisationaler Beziehungen, die weder allein in ein- oder wechselseitiger Abhängigkeit noch in gemeinsamen Anreizen oder präzisen vertraglichen Vereinbarungen begründet ist und

- ein besonderes Risiko auf Seiten des bzw. der Vertrauenden.

Vertrauen im Rahmen einer Kunden-Lieferanten-Beziehung ist insbesondere dann wichtig, wenn es sich bei Wiederkäufen nicht um so genannte unmodifizierte

\footnotetext{
$975 \mathrm{Vgl}$. Kumar/Scheer/Steenkamp (1995), S. 350. Sie verwenden die Dimensionen „Honesty“ und „Benevolence“.

976 Vgl. Werp (1998), S. 172.

977 Vgl. Werp (1998), S. 172.

978 Vgl. Hallén/Johanson/Seyed-Mohamed (1991), S. $29 \mathrm{ff}$.

979 Vgl. Werp (1998), S. 172.

980 Vgl. Werp (1998), S. 165.

${ }_{981}$ Vgl. Sydow (1995), S. 178.

982 Vgl. Sydow (1995), S. $181 \mathrm{f}$. 
(,Straight Rebuys“) ${ }^{983}$, sondern um modifizierte Wiederkäufe („Modified Rebuys“") ${ }^{984}$ handelt. ${ }^{985}$ Dies gilt gleichermaßen für die Kunde-Bank-Beziehung, denn nahezu jeder Investitionskredit unterscheidet sich durch die veränderte Sicherheitenstellung vom vorherigen und jeder Abschluss von Versicherungsgeschäften oder Anlagegeschäften unterscheidet sich durch geänderte Konditionen oder geänderte makroökonomische Daten. Bereits SYDOW weist auf die besondere Bedeutung von Vertrauen im Finanzdienstleistungssektor hin. ${ }^{986}$ Da Finanzdienstleistungsprodukte Vertrauensqualitäten aufweisen, d.h. ihre tatsächliche Qualität - anders als bei Erfahrungsgütern - selbst nach „Gebrauch“ kaum feststellbar ist, gibt die Qualität der Geschäftsbeziehung deshalb einen wichtigen Interpretationsrahmen für die Beurteilung der Leistungsqualität ab. $^{987}$

\subsection{Stand der empirischen Forschung bei dem Vertrauenskonstrukt sowie Implikationen für die vorliegende Studie}

Die verschiedenen zuvor dargestellten Definitionen des Vertrauens spiegeln sich auch in den verschiedenen Vorgehensweisen der Autoren hinsichtlich der Konzeptualisierung und Operationalisierung von Vertrauen wider, so dass sich unterschiedliche Ansätze identifizieren lassen. Vielfach wurde Vertrauen bezüglich der Konstruktdimensionen als eindimensional angesehen ${ }^{988} \mathrm{Im} \mathrm{Kern} \mathrm{wird} \mathrm{das} \mathrm{Vertrauen} \mathrm{hier} \mathrm{auf} \mathrm{die} \mathrm{Zu}$ verlässigkeit (reliability) des anderen Objekts bzw. Vertrauensnehmers bezogen.

Einige Autoren, wie GANESAN und ANDALEEB, widersprechen dieser Vorstellung und sehen Vertrauen als zweidimensionales Konstrukt an. ${ }^{989}$ ANDALEEB ergänzt die Zuverlässigkeit um die Dimension der Fähigkeit (ability) des Vertrauensnehmers, ${ }^{900}$ die gegebenen Versprechen einzuhalten. GANESAN hingegen verwendet mit der Glaubwürdigkeit (credibility) und dem Wohlwollen (benevolence) zwei neue Dimensionen. Er fand in seiner Studie heraus, dass die Glaubwürdigkeit im Gegensatz zum Wohl-

"Modified Rebuys" oder modifizierte Wiederholungskäufe sind seiner Art nach nicht neu. Der Kaufentscheid ist nicht so innovativ wie beim Erstkauf, aber auch nicht routinisiert. Vgl. Pepels (2004), S. $172 \mathrm{ff}$.

984 "Straight Rebuys", unmodifizierte Käufe oder reine Wiederholungskäufe sind durch folgende Merkmale charakterisiert: es liegen habitualisierte Kaufprozesse vor, die sich vergleichsweise häufig wiederholen, es erfolgt eine Nachfrage nach denselben normierten und ggf. vorproduzierten Leistungen, die Komplexität des Kaufobjektes ist vergleichsweise gering. Vgl. Pepels (2004), S. $172 \mathrm{ff}$.

Vgl. Hadwich (2003), S. 59.

Vgl. Sydow (1995), S. 182 f.

Vgl. Sydow (1995), S. 182 f.

Vgl. Anderson/Weitz (1989), S. 310 ff., Anderson/Narus (1990), S. 42 ff., Crosby/Evans/Cowles (1990), S. 68 ff., Dwyer/Schurr/Oh (1987), S. 11 ff., Moorman/Deshpandé/Zaltman (1993), S. $81 \mathrm{ff}$. oder Schurr/Ozanne (1985), S. $939 \mathrm{ff}$.

Vgl. Ganesan (1994), S. 12. und Andaleeb (1992), S. 11.

Trust can, thus, be defined in the context of risk of potential loss to A due to B's behavior in which B can be counted upon (1) to be motivated positively and/or (2) to have the ability to produce positive outcomes or consequences from the association." Andaleeb (1992), S. 11. 
wollen einen Einfluss auf die langfristige Ausrichtung einer Geschäftsbeziehung hat. Um für den Käufer glaubwürdig zu sein, muss der Verkäufer den nötigen Sachverstand und die Kompetenz besitzen und seine Aufgabe effektiv und zuverlässig erfüllen. Die Zuverlässigkeit wird hier also als Teil der Glaubwürdigkeit angesehen. Das Wohlwollen bezieht sich auf den Glauben des Käufers, dass der Verkäufer grundsätzlich zugunsten des Käufers handelt. DONEY/CANNON stützen sich ebenfalls auf diese Dimensionen, bemerken aber, dass beide Dimensionen soweit verflochten sind, dass eine getrennte Operationalisierung nicht gelingen kann. ${ }^{991}$ Die Ergebnisse ihrer Studie zum Vertrauen von Einkaufsmanagern zu ihren Zulieferunternehmen unterstützen diese Vermutung.

Auch aus empirischer Sicht scheint sich kein einheitliches, weit verbreitetes und akzeptiertes Instrument zur Messung von Vertrauen entwickelt zu haben. ${ }^{992}$ Dies ergibt sich unter anderem aus der Verschiedenartigkeit der Beziehungen, in den Vertrauen untersucht werden soll. So wurde die Vertrauensskala von REMPEL/HOLMES/ZANNA primär für enge, intime Beziehungen wie z.B. eine Ehe entwickelt. ${ }^{993}$ Eine derartige Skala lässt sich nicht ohne Modifikationen auf einen intra- oder interorganisatorischen Kontext übertragen. MORGAN/HUNT haben zur Vertrauensmessung im Rahmen einer Geschäftsbeziehung zwischen Zulieferern und Händlern von Autoreifen die dyadische Vertrauensskala von LARZELER/HUSTON modifiziert, ${ }^{9 / 4}$ welche ebenso wie die Skala von REMPEL/HOLMES/ZANNA originär für die enge, intime Beziehungen entwickelt und angewendet wurde. ${ }^{995}$

In einer Überblicksarbeit, die die empirischen Vertrauensskalen im organisatorischen Kontext analysiert, zeigen MCEVILY/TORTORIELLO, dass von 156 untersuchten Studien 124 Studien eine eindimensionale Vertrauensskala angewendet haben. ${ }^{9 \%}$ Die anderen 32 Studien haben eine mehrdimensionale Konzeptualisierung vorgenommen, wobei in der Mehrzahl maximal vier Dimensionen herangezogen wurden. Bei drei Studien wurde ein 12-dimensionales Vertrauenskonstrukt herangezogen, welches von BUTLER $^{997}$ entwickelt wurde. Insgesamt konnten sie 33 unterschiedliche Dimensionen in den 32 verschiedenen Studien ausmachen, wobei hier eindeutig inhaltlich übereinstimmende Dimensionen verschiedener Studien zusammengefasst worden sind. ${ }^{908}$

Während MCEVILY/TORTORIELLO Vertrauensskalen im organisatorischen Kontext analysiert haben, vergleichen SEPPÄNEN/BLOMQVIST/SUNDQVIST in ihrer Arbeit Vertrauensskalen im interorganisatorischen Kontext. ${ }^{999}$ Die empirischen Vertrauensskalen unterscheiden sich u.a. hinsichtlich des Subjektbezugs, bspw. untersuchen DoNEY/CANNON das Vertrauen in Zulieferer und MOORMAN/DESHANDÉ/ZALTMAN das

\footnotetext{
991 Vgl. hier und im Folgenden Doney/Cannon (1997), S. 35 ff.

992 Vgl. McEvily/Tortoriello (2007), S. 2.

993 Vgl. Rempel/Holmes/Zanna (1985), S. $95 \mathrm{ff}$.

994 Vgl. Morgan/Hunt (1994), S. 28.

995 Vgl. Larzeler/Huston (1980), S. $595 \mathrm{ff}$.

996 Vgl. McEvily/Tortoriello (2007), S. $16 \mathrm{f}$.

997 Vgl. Butler (1991), S. $643 \mathrm{ff}$.

998 Vgl. McEvily/Tortoriello (2007), S. 18.

999 Vgl. McEvily/Tortoriello (2007), S. 2 ff. und Seppänen/Blomqvist/Sundqvist (2007), S. 250 ff. 
Vertrauen in Marktforschung (vgl. Tab. A-14). ${ }^{1000}$ Ferner kann nach der Anzahl der Dimensionen und den Inhalten der Dimensionen differenziert werden. So finden sich Studien mit ein oder zwei Dimensionen, wobei sich die Dimensionen als solche ebenfalls unterscheiden, z.B. Wohlwollen, Glaubwürdigkeit, Ehrlichkeit. In den 15 untersuchten Studien werden 21 Dimensionen von Vertrauen verwendet, wie z.B. Wohlwollen, Verlässlichkeit, Abhängigkeit, Glaubwürdigkeit. ${ }^{1001}$ Während GANESAN bspw. die Glaubwürdigkeit und das Wohlwollen auf personaler Ebene untersucht hat, haben KUMAR/SCHEER/STEENKAMP diese Dimensionen auf Unternehmensebene operationalisiert. ${ }^{1002}$ GANESAN/HESS führen eine Synthese dieser Ansätze durch und untersuchen die Glaubwürdigkeit und das Wohlwollen auf personaler Ebene und auf Unternehmensebene. ${ }^{1003}$ Neben den Unterschieden bei den Dimensionen bestehen weitere in der Anzahl der Items, die zur Messung der verschiedenen Dimensionen herangezogen werden, den Ausprägungen bzw. der Skala sowie der Reliabilität. Unter der Reliabilität wird die Messgenauigkeit eines Tests verstanden. ${ }^{1004}$ Diese Unterschiede werden in Tab. A-14 dargestellt.

\begin{tabular}{|l|c|l|l|c|l|c|}
\hline Autor & Jahr & Dimensionen & Beispiel & Items & Skala & $\begin{array}{c}\text { Re- } \\
\text { liab. }\end{array}$ \\
\hline Ganesan/Hess & 1997 & $\begin{array}{l}\text { (interperso- } \\
\text { nale) Glaub- } \\
\text { würdigkeit }\end{array}$ & $\begin{array}{l}\text { Die Kontaktperson des } \\
\text { Herstellers hat sich uns } \\
\text { gegenüber stets offen und } \\
\text { aufrichtig verhalten. }\end{array}$ & 7 & $\begin{array}{l}\text { Trifft auf jeden Fall } \\
\text { zu/trifft überhaupt } \\
\text { nicht zu (1-7). }\end{array}$ & 0,72 \\
\cline { 2 - 7 } & $\begin{array}{l}\text { (interperso- } \\
\text { nales) Wohl- } \\
\text { wollen }\end{array}$ & $\begin{array}{l}\text { Die Kontaktperson des } \\
\text { Herstellers hat bereits in } \\
\text { der Vergangenheit Opfer } \\
\text { erbracht. }\end{array}$ & 6 & $\begin{array}{l}\text { Trifft auf jeden Fall } \\
\text { zu/trifft überhaupt } \\
\text { nicht zu (1-7). }\end{array}$ & 0,91 \\
\cline { 2 - 7 } & $\begin{array}{l}\text { (organisatio- } \\
\text { nale) Glaub- } \\
\text { würdigkeit }\end{array}$ & $\begin{array}{l}\text { Der Partner hält seine } \\
\text { Versprechen ein. }\end{array}$ & 4 & $\begin{array}{l}\text { Trifft auf jeden Fall } \\
\text { zu/trifft überhaupt } \\
\text { nicht zu (1-7). }\end{array}$ & 0,75 \\
\cline { 2 - 4 } $\begin{array}{l}\text { (organisatio- } \\
\text { nales) Wohl- } \\
\text { wollen }\end{array}$ & $\begin{array}{l}\text { Wenn wir dem Partner } \\
\text { von unseren Problemen } \\
\text { berichten, können wir } \\
\text { mit Unterstützung rech- } \\
\text { nen. }\end{array}$ & 4 & $\begin{array}{l}\text { Trifft auf jeden Fall } \\
\text { zu/trifft überhaupt } \\
\text { nicht zu (1-7). }\end{array}$ & 0,87 \\
\hline $\begin{array}{l}\text { Doney/ } \\
\text { Cannon }\end{array}$ & 1997 & $\begin{array}{l}\text { Vertrauen in } \\
\text { Zulieferer }\end{array}$ & $\begin{array}{l}\text { Der Zulieferer hält seine } \\
\text { Versprechen ein. }\end{array}$ & 8 & - & 0,94 \\
\hline Kim/Frazier & 1997 & $\begin{array}{l}\text { Vertrauens- } \\
\text { würdigkeit des } \\
\text { Herstellers }\end{array}$ & $\begin{array}{l}\text { Ich glaube das, was mir } \\
\text { der Partner sagt. }\end{array}$ & 4 & $\begin{array}{l}\text { Lehne stark ab/stimme } \\
\text { stark zu (1-7). }\end{array}$ & - \\
\hline Andaleeb & 1996 & $\begin{array}{l}\text { Vertrauen } \\
\text { Vartner 1 sollte nicht }\end{array}$ & 2 & $\begin{array}{l}\text { Lehne stark ab/stimme } \\
\text { zögern, Vorschläge von } \\
\text { Partner 2 anzunehmen. }\end{array}$ & 0,82 \\
\hline
\end{tabular}

1000 Vgl. Doney/Canon (1997), S. 35 ff., Moorman/Deshandé/Zaltman (1993), S. 81.

1001 Vgl. Seppänen/Blomqvist/Sundqvist (2007), S. 255.

1002 Vgl. Ganesan (1994) und Kumar/Scheer/Steenkamp (1995). Kumar/Scheer/Steenkamp (1995) verwenden aber den Begriff „Honesty“ anstelle von „Credibility“.

1003 Vgl. Ganesan/Hess (1997), S. 439.

1004 Vgl. Bühner (2004), S. 26. Zu den Gütemaßen der Reliabilität vgl. ausführlich Kapitel B.3.2.1. 


\begin{tabular}{|c|c|c|c|c|c|c|}
\hline Autor & Jahr & Dimensionen & Beispiel & Items & Skala & $\begin{array}{l}\text { Re- } \\
\text { liab. }\end{array}$ \\
\hline Andaleeb & 1995 & Vertrauen & $\begin{array}{l}\text { Partner } 1 \text { ist sehr zuver- } \\
\text { lässig. }\end{array}$ & 4 & $\begin{array}{l}\text { Vertrauenswürdig/ } \\
\text { vertrauensunwürdig; } \\
\text { Fair/unfair; ehrenhaft/ } \\
\text { nicht ehrenhaft }\end{array}$ & 0,96 \\
\hline \multirow[t]{2}{*}{$\begin{array}{l}\text { Kumar/ } \\
\text { Scheer/ } \\
\text { Steenkamp }\end{array}$} & \multirow[t]{2}{*}{1995} & $\begin{array}{l}\text { (organisatio- } \\
\text { nales) Ver- } \\
\text { trauen in } \\
\text { Ehrlichkeit }\end{array}$ & $\begin{array}{l}\text { Der Partner hält seine } \\
\text { Versprechen ein. }\end{array}$ & 5 & $\begin{array}{l}\text { Lehne stark ab/stimme } \\
\text { stark zu (1-7). }\end{array}$ & \\
\hline & & $\begin{array}{l}\text { (organisatio- } \\
\text { nales) Ver- } \\
\text { trauen in } \\
\text { Wohlwollen }\end{array}$ & $\begin{array}{l}\text { Wenn wir dem Partner } \\
\text { von unseren Problemen } \\
\text { berichten, können wir } \\
\text { mit Unterstützung rech- } \\
\text { nen. }\end{array}$ & 5 & $\begin{array}{l}\text { Lehne stark ab/stimme } \\
\text { stark zu (1-7). }\end{array}$ & \\
\hline \multirow[t]{4}{*}{ Ganesan } & \multirow[t]{4}{*}{1994} & $\begin{array}{l}\text { (interperso- } \\
\text { nales) Wohl- } \\
\text { wollen des } \\
\text { Herstellers }\end{array}$ & $\begin{array}{l}\text { Die Kontaktperson des } \\
\text { Herstellers hat bereits in } \\
\text { der Vergangenheit Opfer } \\
\text { erbracht. }\end{array}$ & 5 & $\begin{array}{l}\text { Trifft auf jeden Fall } \\
\mathrm{zu} / \text { trifft überhaupt } \\
\text { nicht zu (1-7). }\end{array}$ & 0,88 \\
\hline & & $\begin{array}{l}\text { (interperso- } \\
\text { nales) Wohl- } \\
\text { wollen des } \\
\text { Händlers }\end{array}$ & $\begin{array}{l}\text { Der Einkäufer, der das } \\
\text { Unternehmen repräsen- } \\
\text { tiert, hat unseretwegen } \\
\text { schon Opfer gebracht. }\end{array}$ & 3 & $\begin{array}{l}\text { Trifft auf jeden Fall } \\
\mathrm{zu} / \text { trifft überhaupt } \\
\text { nicht zu (1-7). }\end{array}$ & 0,76 \\
\hline & & $\begin{array}{l}\text { (interperso- } \\
\text { nale) Glaub- } \\
\text { würdigkeit des } \\
\text { Herstellers }\end{array}$ & $\begin{array}{l}\text { Die Kontaktperson des } \\
\text { Herstellers hat sich uns } \\
\text { gegenüber stets offen und } \\
\text { aufrichtig verhalten. }\end{array}$ & 7 & $\begin{array}{l}\text { Trifft auf jeden Fall } \\
\mathrm{zu} / \text { trifft überhaupt } \\
\text { nicht zu (1-7). }\end{array}$ & 0,90 \\
\hline & & $\begin{array}{l}\text { (interperso- } \\
\text { nale) Glaub- } \\
\text { würdigkeit des } \\
\text { Händlers }\end{array}$ & $\begin{array}{l}\text { Der Einkäufer, der das } \\
\text { Unternehmen repräsen- } \\
\text { tiert, hat sich stets offen } \\
\text { und aufrichtig uns ge- } \\
\text { genüber verhalten. }\end{array}$ & 4 & $\begin{array}{l}\text { Trifft auf jeden Fall } \\
\text { zu/trifft überhaupt } \\
\text { nicht zu (1-7). }\end{array}$ & 0,80 \\
\hline $\begin{array}{l}\text { Morgan/ } \\
\text { Hunt }\end{array}$ & 1994 & Vertrauen & Der Partner ist integer. & 7 & $\begin{array}{l}\text { Stimme stark zu/ } \\
\text { stimme überhaupt } \\
\text { nicht zu. }\end{array}$ & 0,95 \\
\hline $\begin{array}{l}\text { Mohr/ } \\
\text { Spekman }\end{array}$ & 1994 & Vertrauen & $\begin{array}{l}\text { Die Beziehung ist sehr } \\
\text { harmonisch. }\end{array}$ & 3 & Niedrig/hoch (1-5) & 0,75 \\
\hline $\begin{array}{l}\text { Moorman/ } \\
\text { Deshandé/ } \\
\text { Zaltman }\end{array}$ & 1992 & $\begin{array}{l}\text { Vertrauen in } \\
\text { Marktfor- } \\
\text { schung }\end{array}$ & $\begin{array}{l}\text { Ich traue dem Marktfor- } \\
\text { scher Dinge zu, die ich } \\
\text { selbst nicht kann. }\end{array}$ & 5 & $(1-7)$ & 0,84 \\
\hline \multirow[t]{2}{*}{$\begin{array}{l}\text { Anderson/ } \\
\text { Narus }\end{array}$} & \multirow[t]{2}{*}{1990} & $\begin{array}{l}\text { Vertrauen aus } \\
\text { Händlersicht }\end{array}$ & $\begin{array}{l}\text { Wie würden Sie auf } \\
\text { Basis Ihrer bisherigen } \\
\text { Erfahrungen den Ver- } \\
\text { trauensgrad zum Her- } \\
\text { steller einschätzen? }\end{array}$ & 3 & $\begin{array}{l}\text { Vertraue dem Her- } \\
\text { steller nicht/vertraue } \\
\text { dem Hersteller total } \\
(1-7) .\end{array}$ & - \\
\hline & & $\begin{array}{l}\text { Vertrauen aus } \\
\text { Herstellersicht }\end{array}$ & $\begin{array}{l}\text { Wie würden Sie auf } \\
\text { Basis Ihrer bisherigen } \\
\text { Erfahrungen den Ver- } \\
\text { trauensgrad zum Händler } \\
\text { einschätzen? }\end{array}$ & 4 & $\begin{array}{l}\text { Vertraue dem Händler } \\
\text { nicht/vertraue dem } \\
\text { Händler total (1-7). }\end{array}$ & - \\
\hline $\begin{array}{l}\text { Anderson/ } \\
\text { Weitz }\end{array}$ & 1989 & - & $\begin{array}{l}\text { Wie stark ist Ihr Ver- } \\
\text { trauen in das faire Ver- } \\
\text { halten des Partners aus- } \\
\text { geprägt? }\end{array}$ & 2 & $\begin{array}{l}\text { Wenig/sehr großes } \\
\text { Vertrauen (1-7) }\end{array}$ & 0,84 \\
\hline Dwyer/Oh & 1987 & Vertrauen & $\begin{array}{l}\text { Ich kann mich auf die } \\
\text { Ehrlichkeit des Partners } \\
\text { verlassen. }\end{array}$ & 4 & $(1-5)$ & 0,79 \\
\hline
\end{tabular}




\begin{tabular}{|c|c|c|c|c|c|c|}
\hline Autor & Jahr & Dimensionen & Beispiel & Items & Skala & $\begin{array}{l}\text { Re- } \\
\text { liab. }\end{array}$ \\
\hline $\begin{array}{l}\text { Schurr/ } \\
\text { Ozanne }\end{array}$ & 1985 & Vertrauen & $\begin{array}{l}\text { Vertrauenswürdig/nicht } \\
\text { vertrauenswürdig; ehr- } \\
\text { lich/unehrlich; aufrich- } \\
\text { tig/nicht aufrichtig; } \\
\text { offen/verschlossen; } \\
\text { direkt/irreführend; läs- } \\
\text { tig/nicht lästig; zuverläs- } \\
\text { sig/nicht zuverlässig }\end{array}$ & 7 & $(1-7)$ & 0,90 \\
\hline
\end{tabular}

Tab. A-14: Operationalisierung von Vertrauen in bestehenden Studien ${ }^{1005}$

Grundsätzlich gibt es zwei Möglichkeiten zur Erfassung von Vertrauen. Die erste Möglichkeit besteht darin, eine bestehende Vertrauensskala an den spezifischen Untersuchungskontext durch Umformulierungen oder Eliminierung von Items zu adaptieren. Daraus resultiert die Gefahr, dass die modifizierte Skala nicht mehr das Vertrauenskonstrukt sowie die zugrunde liegenden Dimensionen in der ursprünglich konzeptionalisierten Form wiedergibt. ${ }^{1006}$ Die zweite Möglichkeit besteht darin, eine neue Vertrauensskala für den spezifischen Untersuchungskontext zu entwickeln. Der Vorteil dieser Vorgehensweise liegt in der Natur des Phänomens Vertrauen. Da Vertrauen kontextabhängig ist, ${ }^{1007}$ wird es nur mit inhaltlichen Einschränkungen gelingen, eine allgemeingültige Vertrauensskala zu entwickeln. Der Nachteil besteht darin, dass dies zu einem individuellen Messinstrument für das Vertrauenskonstrukt in jeder einzelnen Studie führen würde, so dass selbige nicht mehr vergleichbar sind. ${ }^{1008}$ Die Mehrheit der empirischen Untersuchungen zur Messung von Vertrauen im interorganisatorischen Kontext bezieht sich auf technologie-intensive Branchen. ${ }^{1009}$ Die exakte Nachbildung von bestehenden Studien ist nicht weit verbreitet. Die Items, selbst wenn diese auf Literaturrecherche und vorherigen Untersuchungen basieren, werden häufig durch die Autoren modifiziert und an den spezifischen Untersuchungskontext adaptiert. ${ }^{1010}$

Die Basis für die Konzeptualisierung des Vertrauenskonstruktes im Rahmen der folgenden empirischen Untersuchung bilden sowohl die bestehenden theoretischen Konzeptualisierungen, die zur Erklärung des Vertrauenskonstruktes entwickelt wurden, als auch empirische Studien, die versuchen, die Vertrauensdimensionen zu operationalisieren und messbar zu machen. Die exakte Verwendung der bisherigen empirischen Untersuchungen als Ausgangsbasis für die weitere Analyse ist kritisch zu bewerten. So gibt es gemäß SEPPÄNEN/BLOMQVIST/SUNDQVIST keine Studie im Dienstleistungssektor. ${ }^{1011}$

\footnotetext{
1005 In Anlehnung an Jung (1999), S. 176 f. und Seppänen/Blomqvist/Sundqvist (2007), S. 251.

1006 Vgl. McEvily/Tortoriello (2007), S. 5.

1007 Vgl. Rousseau et al. (1998), S. 401. "Conceptualizing trust in only one form in a given relationship risks missing the rich diversity of trust in organizational settings." Zur Kontextabhängigkeit vgl. Kapitel A.5.2.3.1.1.
}

1008 Vgl. McEvily/Tortoriello (2007), S. 5.

1009 Vgl. Seppänen/Blomqvist/Sundqvist (2007), S. 251.

1010 Vgl. Seppänen/Blomqvist/Sundqvist (2007), S. 260.

1011 Vgl. Seppänen/Blomqvist/Sundqvist (2007), S. 251. 
Aufgrund der Komplexität des Vertrauenskonstruktes erscheint die eindimensionale Abbildung des Konstruktes nicht zielführend. Auch wenn die Mehrzahl der Studien nicht zwischen dem interpersonalen und dem interorganisationalen Vertrauen unterscheidet, so ist diese Trennung unerlässlich. Zwar handeln stets die Personen und nicht die Organisationen, so kann dennoch grundsätzlich ein vertrauensvolles Verhältnis zu einem Unternehmen existieren, obwohl ein einzelner Ansprechpartner des Unternehmens nicht als vertrauenswürdig erachtet wird. Wenn über einen längeren Zeitraum dieser Ansprechpartner der einzige Zugangspunkt zu dem Unternehmen ist, so wird sich vermutlich die Einschätzung der Beziehung zu dem Ansprechpartner auf die Beurteilung der Beziehung zum Unternehmen auswirken. Ebenso kann eine sehr vertrauensvolle Beziehung zum Ansprechpartner des Unternehmens von einer nur wenig vertrauensvollen Beziehung zum Unternehmen umrahmt werden. Die Unterscheidung ist insbesondere dann von Relevanz, wenn es sich bei dem Ansprechpartner nicht um den Geschäftsführer handelt und selbiger somit ggf. nicht für die Investitionsentscheidungen verantwortlich ist. Dies könnte sich derart zeigen, dass Firmenkundenbetreuer und Ansprechpartner sehr vertrauensvoll miteinander umgehen, im Unternehmen aber durch einen Dritten eine Entscheidung zu Ungunsten der Bank getroffen wird, z.B. eine risikoreichere Investition durchgeführt wird als anfänglich geplant.

Ferner soll wie bei GANESAN, KUMAR/SCHEER/STEENKAMP und GANESAN/HESS eine Unterscheidung nach Glaubwürdigkeit und Wohlwollen vorgenommen werden. ${ }^{1012}$ Es erscheint plausibel, dass die Glaubwürdigkeit einen Einfluss auf die langfristige Ausrichtung einer Geschäftsbeziehung hat. Um für den Firmenkundenbetreuer glaubwürdig zu sein, muss der Kunde den nötigen Sachverstand und die notwendige Kompetenz besitzen. Die Zuverlässigkeit wird hier also als Teil der Glaubwürdigkeit angesehen. Dabei bezieht sich der Sachverstand sowohl auf finanzielle Bereiche als auch auf Bereiche, die das Kerngeschäft des Unternehmens betreffen. Das Wohlwollen bezieht sich auf den Glauben des Firmenkundenbetreuers, dass der Kunde grundsätzlich zu Gunsten der Bank bzw. des Firmenkundenbetreuers handelt. Abschließend lässt sich resümieren, dass für die vorliegende empirische Untersuchung die Abbildung von Vertrauen als vierdimensionales Konstrukt (vgl. Abb. A-16) sinnvoll erscheint.

1012 Vgl. Ganesan (1994), S. 1 ff., Kumar/Scheer/Steenkamp (1995), S. 348 ff. und Ganesan/Hess (1997), S. $439 \mathrm{ff}$. 


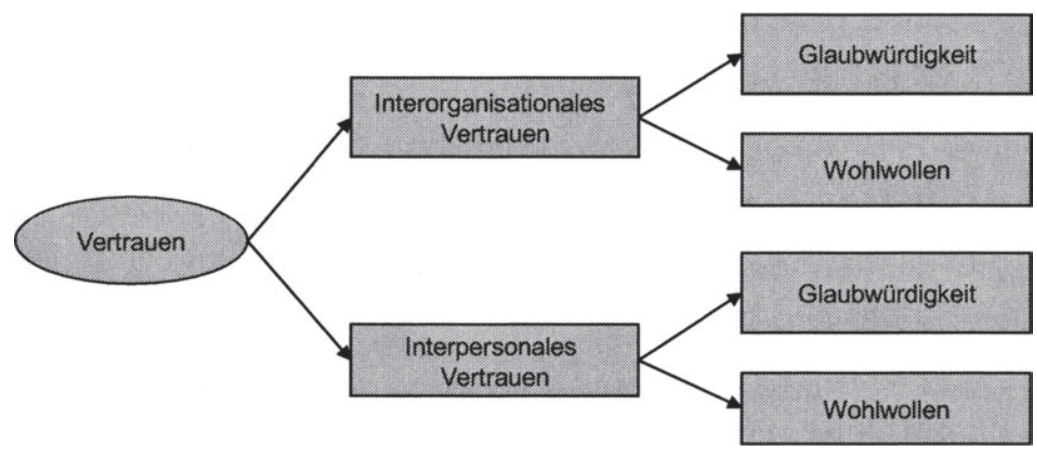

Abb. A-16: Dimensionen von Vertrauen ${ }^{1013}$

\subsubsection{Analyse des Konstruktes Commitment}

\subsection{Definition von Commitment}

Der Ursprung des Konstruktes Commitment liegt in der Verhaltensforschung, insbesondere in der Sozialpsychologie. Aufgrund der verschiedenen Forschungsschwerpunkte gibt es kein einheitliches Bild in der Commitment-Forschung. ${ }^{1014}$ Bezugnehmend auf das Relationship Marketing in Dienstleistungsunternehmen gehen BERRY/PARASURAMAN davon aus, dass , , [...] relationships are built on the foundation of

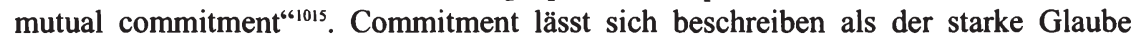
eines Beziehungspartners, dass die Beziehung zum Unternehmen derart wichtig für ihn ist, dass er alle Anstrengungen zur Fortsetzung der Beziehung unternimmt. ${ }^{1016}$ Diese Definition ähnelt der Definition von MOORMAN/Zaltman/DeSHAPANDÉ: „Commitment to the relationship is defined as a desire to maintain a valued relationship." 1017 In beiden Definitionen kann Commitment nur dann existieren, wenn die Beziehung von Bedeutung ist, allerdings wird nicht beschrieben, ob es sich hier um eine reine ökonomische oder auch um eine emotionale Betrachtungsweise handelt. DILLER/KUSTERER definieren Commitment als „die innere Bereitschaft eines Geschäftspartners zur Geschäftsbeziehung zu stehen und zwar weitgehend unabhängig vom Zeithorizont und von der ökonomischen Bedeutung." ${ }^{\text {"1018 }}$ In ihrer Definition wird also die ökonomische Bedeutung der Beziehung explizit als zentrales Element aus der Definition ausgeschlossen. Als commitment-fördernde Elemente betrachten sie gemeinsame Erfolge der Geschäftspartner gegenüber Dritten, den Austausch vertraulicher Informationen und die Offenheit in der Kommunikation sowie persönliche Sympathien und Gemein-

\footnotetext{
1013 Eigene Darstellung.

1014 Einen Überblick gibt Söllner (1993), S. 92 ff.

1015 Berry/Parasuraman (1991), S. 139.

1016 Vgl. Morgan/Hunt (1994), S. 23.

1017 Moorman/Zaltman/Deshapandé (1993), S. 92.

1018 Diller/Kusterer (1988), S. 218.
} 
samkeiten. ${ }^{1019}$ Commitment ist somit im Wesentlichen ein Resultat der Vergangenheit. Commitment erhöht die Austrittsbarrieren von Geschäftsbeziehungen, indem es die Toleranz gegenüber und die Treue zum Geschäftspartner fördert. So wird in einer derartigen Beziehung die Bereitschaft groß sein, über Fehler des anderen hinwegzusehen oder auch mal Unannehmlichkeiten in Kauf zu nehmen. Commitment stellt ein zentrales beziehungsrelevantes bzw. bei Einführung der Dimension der Bindung ${ }^{1020}$ ein bindungsrelevantes Konstrukt dar; es bezieht sich nicht auf einzelne Leistungen des Anbieters, sondern auf den Anbieter als solchen. ${ }^{1021}$ DWYER/SCHURR/OH haben in ihrem Interaktionsmodell eine „Commitment-Phase“ eingefügt. ${ }^{1022}$ In dieser Phase haben die Interaktionspartner aus den Austauschprozessen ein derartiges Zufriedenheitsniveau erreicht, dass potenzielle alternative Geschäftspartner ausgeschlossen werden, auch wenn sie ähnlichen Nutzen stiften könnten. Eine Loyalität von Kunden und Anbieter wird erreicht. Commitment beinhaltet dann die implizite oder explizite Zusicherung von Kontinuität zwischen den Geschäftspartnern. Als gemeinsame Basis des Commitment-Inhalts kann festgehalten werden, dass ,ein Individuum in einer Beziehung ein Commitment gegenüber dem Beziehungspartner empfindet, wenn die Beziehung insgesamt als positiv eingeschätzt wird und diese positive Einschätzung als relativ sicher wahrgenommen wird"“1023.

MORGAN/HUNT postulieren, dass ein erhöhtes Commitment zu einer gesteigerten Ergebenheit, einer geringeren Wahrscheinlichkeit, die Beziehung zu beenden, und mehr Kooperationsbereitschaft führt. ${ }^{1024}$ Gemäß MOSER kann Commitment verwendet werden, um konsistentes Verhalten zu erklären, wobei konsistent hier als das Andauern über die Zeit bedeutet. ${ }^{1025}$ Commitment besteht aus drei Facetten: zeitliches Andauern des Verhaltens, Verfolgen eines gleich bleibenden Ziels und Zurückweisung von Alternativen. ${ }^{1026}$

DWYER/SCHURR/OH messen Commitment anhand dreier Kriterien: Input, Beständigkeit und Konsistenz. ${ }^{1027}$ Unter dem ersten Kriterium verstehen sie, dass signifikante ökonomische, kommunikative und/oder emotionale Ressourcen ausgetauscht werden. Eine Beständigkeit setzt voraus, dass die Geschäftspartner den Nutzen der Beziehung erkennen und annehmen, dass die Umwelt eine Fortsetzung derselben ermöglicht. Eine Beständigkeit ist deswegen erforderlich, damit die Geschäftspartner bereit sind, in die Beziehung zu investieren. Das konsistente Verhalten bezieht sich auf die zu leistenden Inputs. Wenn der Input des einen Geschäftspartners stark fluktuiert, so hat der andere

\footnotetext{
1019 Vgl. Diller/Kusterer (1988), S. 218.

1020 Die Bindungsebene und die Berücksichtigung von Commitment erfolgt bspw. im Modell von Segbers in Kapitel A.5.2.2.3.1.

1021 Vgl. Hadwich (2003), S. 45. Zu den verschiedenen Ebenen der Transaktion, der Beziehung und der Bindung vgl. auch Kapitel A.5.2.2.3.

1022 Vgl. Dwyer/Schurr/Oh (1987), S. 19.

1023 Söllner (1993), S. 102.

1024 Vgl. Morgan/Hunt (1994), S. 23.

1025 Vgl. Moser (1996), S. 1.

1026 Vgl. Moser (1996), S. 1.

1027 Vgl. hier und im Folgenden Dwyer/Schurr/Oh (1987), S. 19. 
Geschäftspartner Schwierigkeiten, den Outcome der Austauschbeziehung vorherzusagen. Inkonsistentes Verhalten spiegelt ein geringes Commitment wider und führt zu einer geringeren Verlässlichkeit in Bezug auf den Outcome durch den anderen Partner.

Im Rahmen einer Arbeitsdefinition definiert EGGERT Kundenbindung, wobei der Begriff der Kundenbindung im Folgenden synonym zum Begriff des Commitment verwendet wird, als einen inneren Zustand des Kunden: ${ }^{1028}$ „Aus Kundensicht liegt immer dann eine Kundenbindung vor, wenn der Kunde eine Bindung wahrnimmt, d.h. wenn sich der Kunde in einem affektiven, einem kognitiven und/oder einem normativen Zustand der Bindung befindet." ${ }^{\text {"1029 }}$ Die Kundenbindung aus Kundensicht kann sowohl positive als auch negative (z.B. im Sinne von Nicht-Wechseln-Können aufgrund von Wechselkosten) Ausprägungsformen beinhalten. ${ }^{1030}$ Im Rahmen der Konzeptualisierung unterscheidet EGGERT genau die drei oben genannten Bindungszustände: den affektiven, den kognitiven und den normativen Bindungszustand. ${ }^{1031}$

Der affektive Bindungszustand ist Ausdruck des Affiliationsmotivs, d.h. dem Wunsch des Kunden nach sozialen Kontakten zum Anbieter bzw. den Mitarbeitern desselbigen, ${ }^{1032}$ im Kontext der Bankbeziehung der Wunsch des Kunden nach sozialen Kontakten zur Bank und den Firmenkundenbetreuern. Dieser affektive Zustand zeigt sich darin, dass der Kunde die Geschäftsbeziehung zu seinem Anbieter als angenehm empfindet. ${ }^{1033}$ Der Kunde würde den Abbruch der Geschäftsbeziehung persönlich bedauern. In einer derartigen Situation der Bindung, d.h. wenn der Kunde sich dem Anbieter gegenüber persönlich verbunden fühlt, kann eine Geschäftsbeziehung unabhängig von ihrem ökonomischen Wert an Bedeutung gewinnen. ${ }^{1034}$ In vielen Situationen bilden affektive Motive die dominierenden Antriebskräfte des Menschen. ${ }^{1035}$ Der Einflussbereich betrifft sowohl private als auch gewerbliche Einkäufer. ${ }^{1036}$ Hierbei geht es um den Wunsch des Kunden bei demselben Anbieter wieder kaufen zu wollen. Diese Ausprägungsform ist zumeist persönlich verortet und affektiv motiviert. ${ }^{1037}$

Der kognitive Bindungszustand ist das Ergebnis kognitiver Bindungsmotive. Hierin manifestiert sich das Streben des Kunden nach instrumenteller Rationalität, d.h. der Fokus dieser Form der Rationalität liegt auf der bewussten Wahl geeigneter Mittel zur Erreichung eines Ziels. Es handelt sich hierbei um eine rationale und gefühlskalte Form der Bindung. Diese Form der Bindung geht teilweise mit Sachzwängen und dem

1028 Hierbei ist allerdings zu beachten, dass Commitment sowohl bankseitig als auch kundenseitig existieren kann, wohingegen Kundenbindung allein aufgrund der Begrifflichkeit sich ausschließlich auf die Kundenperspektive beschränkt. Im Folgenden wird aufgrunddessen der Begriff Commitment verwendet.

1029 Eggert (1999), S. 99.

1030 Vgl. Eggert (1999), S. 96.

1031 Vgl. Eggert (1999), S. 96 f.

1032 Vgl. Diller (1994), S. 8.

1033 Vgl. Rusbult (1983), S. 102.

1034 Vgl. Buchanan (1974), S. 533.

1035 Vgl. Hirschman/Holbrook (1982), S. 92.

1036 Vgl. Hirschman/Holbrook (1982), S. 92.

1037 Vgl. hier und im Folgenden Eggert (1999), S. 98. 
Bewusstsein der Abhängigkeit einher und wird dann von den Kunden i.d.R. auch negativ beurteilt. Diese Form der Bindung kann bspw. dann entstehen, wenn ein Anbieterwechsel mit zusätzlichen Kosten verbunden ist. Gleiches gilt für den Mangel an verfügbaren Alternativen. Dieser Mangel an Alternativen wurde in bestehenden empirischen Arbeiten zum Relationship Banking operationalisiert als die Anzahl der bestehenden Bankverbindungen des Kunden sowie der Marktkonzentration. Für den Kunden entstehen aber möglicherweise bei dem Eingehen einer neuen Bankverbindung Kosten, da er der neuen Bank mehr Informationen bereitstellen muss.

Der normative Bindungszustand ist Ausdruck des Kunden, im Einklang mit den eigenen und gesellschaftlich vorgegebenen Werten zu leben. Da Menschen in einer Gemeinschaft leben und somit nicht nur ihren eigenen Nutzen maximieren, empfinden sie i.d.R. eine Verpflichtung gegenüber moralischen Werten. Im Rahmen der KundeBank-Beziehung ist der normative Bindungszustand vermutlich primär bankseitig ausgeprägt bzw. von Relevanz. So wird eine Bank möglicherweise im Falle einer finanziellen Schieflage des Unternehmens nicht nur eigene Interessen verfolgen, sondern auch berücksichtigen, dass bei fehlender Unterstützung Arbeitsplätze gefährdet sind.

MEYER/ALLEN unterscheiden zwischen affektivem und fortsetzungsbezogenem Commitment, wobei es sich bei ihnen um organisationales Commitment handelt. ${ }^{1038}$ Unter affektivem Commitment kann eine positive Haltung zur Organisation verstanden werden, die sich in einer relativ starken Übereinstimmung hinsichtlich Normen und Werten ausdrückt. ${ }^{1039}$ Fortsetzungsbezogenes Commitment hingegen beruht darauf, dass die gegenwärtige Position mit weniger Strafen verbunden ist als alternative Positionen. ${ }^{1040}$ Es resultiert daraus, drohende Verluste oder Opfer abzuwenden. Diese Unterscheidung ähnelt der Unterscheidung von EGGERT, wobei das affektive Commitment weitestgehend identisch definiert wird und das fortsetzungsbezogene Commitment im Wesentlichen dem kognitiven Commitment entspricht.

Neben diesen unterschiedlichen inhaltlichen Dimensionen kann wie bei dem Vertrauenskonstrukt eine Unterscheidung hinsichtlich des Bezugsobjekts vorgenommen werden. So weist SöLLNER darauf hin, dass bei der Anwendung des CommitmentKonstruktes auf der Ebene der interorganisationalen Beziehung eine Trennung zwischen organisationaler und personaler Ebene erforderlich ist. Häufig wird das organisationale Verhalten als dem Individualverhalten vergleichbar angenommen. ${ }^{1041}$ Allerdings handeln nie Unternehmen, sondern Individuen mit eigenen, individuellen Vorstellungen über Belohnung und Kosten. Bei mittelständischen Unternehmen fällt eine Differenzierung zwischen Unternehmen und Person schwer, da die Identität von Eigentum und Leitung zentrales Charakteristikum ist und somit die Beurteilung des Unternehmens nicht losgelöst von der Person des Unternehmers erfolgen kann.

\footnotetext{
$1038 \mathrm{Vgl}$. Meyer/Allen (1984), S. $372 \mathrm{ff}$.

1039 Vgl. Moser (1996), S. 6.

1040 Vgl. Moser (1996), S. 5.

1041 Vgl. Söllner (1993), S. 105.
} 
Im Folgenden wird der Stand der empirischen Forschung zur Untersuchung von Commitment dargestellt, um daraus weitere Erkenntnisse für die Konzeptualisierung und Operationalisierung des Commitment-Konstruktes im Rahmen der empirischen Erhebung zu erlangen.

\subsection{Stand der empirischen Forschung bei dem Commitment-Konstrukt sowie Implikationen für die vorliegende Studie}

Aufgrund der Komplexität der Beziehung findet man keine Studien, die alle genannten Dimensionen - die organisationale, die intraorganisationale, die interorganisationale und die interpersonale Dimension - ggf. in Kombination mit den inhaltlichen Dimensionen, abbilden. So gibt es bisher nur wenige Studien, in denen interorganisationales Commitment gemessen wird. Hingegen gibt es zahlreiche Studien, in denen intraorganisationales Commitment erhoben wird, bspw. die Studien von MEYER/ALLEN und von MOWDAY/STEERS/PORTER. ${ }^{1042}$ MORGAN/HUNT haben darauf aufbauend eine eigene Skala zur Messung von interorganisationalem Commitment entwickelt. Zur Messung von Commitment verwenden sie sieben Items, wobei Commitment hier als eindimensionales Konstrukt betrachtet wird. ${ }^{1043}$ Eine Itemformulierung lautet beispielsweise: „The relationship that my firm has with my major supplier deserves our firm's maximum effort to maintain." ${ }^{1044}$ Die Messung erfolgt auf einer 7-Punkte-Skala. Ebenfalls aufbauend auf den oben genannten Studien haben KUMAR/SCHEER/STEENKAMP Commitment anhand der drei Dimensionen affektives Commitment, Erwartung von Kontinuität und Bereitschaft zu weiteren Investitionen gemessen, wobei sie teilweise bestehende Ansätze aus dem intraorganisationalen Commitment adaptiert haben. ${ }^{1045}$

EGGERT hat das Konstrukt der Kundenbindung zunächst durch drei Bindungszustände - affektives, kognitives und normative Kundenbindung - operationalisiert, wobei die beiden ersten Dimensionen aus fünf und die letzte Dimension aus vier Items bestanden. Als Ergebnis hat er allerdings erhalten, dass die Kundenbindung durch zwei einfaktorielle Konstrukte repräsentiert wird. ${ }^{1046}$ Es lassen sich unterscheiden zum einen die Verbundenheit, die auf affektive und normative Bindungszustände zurückzuführen ist, und zum anderen die Gebundenheit des Kunden, die auf kognitiven Bindungsmotiven beruht (vgl. Abb. A-17)..$^{1047}$

\footnotetext{
1042 Vgl. Meyer/Allen (1984), S. $372 \mathrm{ff}$. und von Mowday/Steers/Porter (1979), S. $224 \mathrm{ff}$.

1043 Vgl. Morgan/Hunt (1994), S. 28.

1044 Morgan/Hunt (1994), S. 35.

1045 Grundlage der Studie von Kumar/Scheer/Steenkamp sind vor allem die Arbeiten von Anderson/Weitz, Mohr/Nevin, Meyer/Allen, Noordewier/John/Nevin. Vgl. Kumar/Scheer/Steenkamp (1995), S. 348 ff., Anderson/Weitz (1992), S. 18 ff., Mohr/Nevin (1990), S. 36 ff., Meyer/Allen (1984), S. 372, Noordewier/John/Nevin (1990), S. $80 \mathrm{ff}$.

1046 Vgl. Eggert (2000), S. 126.

1047 Vgl. Eggert (1999), S. 130.
} 


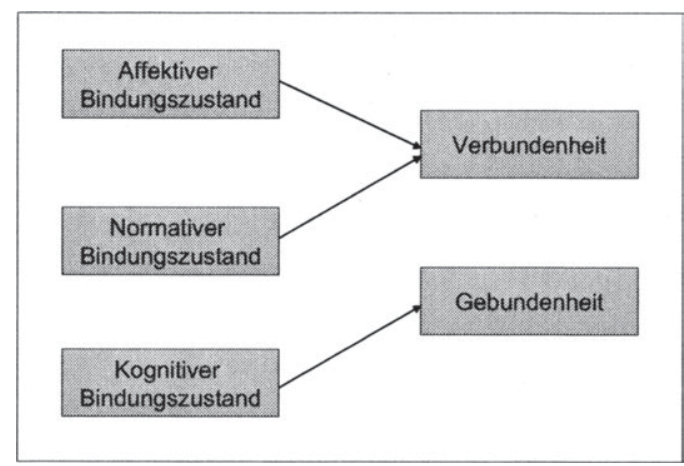

Abb. A-17: Ebenen der Kundenbindung ${ }^{1048}$

In Tab. A-15 wird ein Überblick über einige Studien gegeben, die sich mit organisationalem und interorganisationalem Commitment beschäftigen, wobei diese Trennung in den vorliegenden Studien nicht trennscharf ist. Auf die Darstellung der Studien, die sich mit intraorganisationalem Commitment beschäftigen, wird verzichtet, da intraorganisationales Commitment im weiteren Verlauf der Arbeit nicht von Relevanz ist.

Hinsichtlich der Ableitung eines geeigneten Instrumentariums zur CommitmentMessung existieren die gleichen Probleme wie bei der Vertrauensmessung. So hat man die Möglichkeit, ein bestehendes Instrumentarium exakt zu übernehmen, es zu adaptieren oder ein vollständig neues zu entwickeln. Vor dem Hintergrund, dass es bisher keine integrierte Studie mit einer sauberen Trennung sowohl zwischen der organisationalen und der personalen Ebene als auch zwischen den inhaltlichen Dimensionen wie Gebundenheit und Verbundenheit gibt, werden die bestehenden Studien in der vorliegenden Arbeit adaptiert. Wesentliche Grundlage bildet hier die Studie von EGGERT. Im Folgenden werden zunächst die für diese Arbeit zugrunde gelegten inhaltlichen Dimensionen näher beschreiben. 


\begin{tabular}{|c|c|c|c|c|c|c|}
\hline Autor & Jahr & Dimensionen & Beispiel & $\begin{array}{l}\text { Anzahl } \\
\text { Items }\end{array}$ & Skala & $\begin{array}{l}\text { Re- } \\
\text { liabi- } \\
\text { litait }\end{array}$ \\
\hline Morgan/Hunt & 1994 & $\begin{array}{l}\text { interorganisa- } \\
\text { tionales } \\
\text { Commitment }\end{array}$ & $\begin{array}{l}\text { The relationship my firm } \\
\text { has with my major supplier } \\
\text { deserves our firm's maxi- } \\
\text { mum effort to maintain. }\end{array}$ & 7 & $\begin{array}{l}\text { 7-Punkte- } \\
\text { Skala } \\
\text { (Stimme ich } \\
\text { stark zu/ } \\
\text { Lehne ich } \\
\text { stark ab) }\end{array}$ & 0,90 \\
\hline \multirow[t]{3}{*}{$\begin{array}{l}\text { Kumar/Scheer/ } \\
\text { Steenkamp }\end{array}$} & \multirow[t]{3}{*}{1995} & $\begin{array}{l}\text { affektives } \\
\text { Commitment }\end{array}$ & $\begin{array}{l}\text { Unsere positiven Gefühle } \\
\text { für den Lieferanten sind der } \\
\text { Hauptgrund für die weitere } \\
\text { gemeinsame Arbeit. }\end{array}$ & 3 & $\begin{array}{l}\text { 7-Punkte- } \\
\text { Skala } \\
\text { (Stimme ich } \\
\text { stark zu/ } \\
\text { Lehne ich } \\
\text { stark ab) }\end{array}$ & k.A. \\
\hline & & $\begin{array}{l}\text { Erwartung von } \\
\text { Kontinuität }\end{array}$ & $\begin{array}{l}\text { Wir gehen davon aus, dass } \\
\text { die Beziehung mit unserem } \\
\text { Lieferanten noch lange } \\
\text { Bestand haben wird. }\end{array}$ & 3 & $\begin{array}{l}\text { 7-Punkte- } \\
\text { Skala } \\
\text { (Stimme ich } \\
\text { stark zu/ } \\
\text { Lehne ich } \\
\text { stark ab) }\end{array}$ & k.A. \\
\hline & & $\begin{array}{l}\text { Bereitschaft zu } \\
\text { weiteren } \\
\text { Investitionen }\end{array}$ & $\begin{array}{l}\text { Wenn der Lieferant es } \\
\text { fordern würde, wären wir } \\
\text { bereit, weitere Investitionen } \\
\text { zur Optimierung der Liefer- } \\
\text { kette vorzunehmen. }\end{array}$ & 3 & $\begin{array}{l}\text { 7-Punkte- } \\
\text { Skala } \\
\text { (Stimme ich } \\
\text { stark zu/ } \\
\text { Lehne ich } \\
\text { stark ab) }\end{array}$ & k.A. \\
\hline \multirow[t]{2}{*}{ Eggert } & \multirow[t]{2}{*}{2000} & $\begin{array}{l}\text { organisation- } \\
\text { ale Gebun- } \\
\text { denheit }\end{array}$ & $\begin{array}{l}\text { Ich bin auf den Anbieter } \\
\text { angewiesen, weil es zurzeit } \\
\text { keine gleichwertigen Alter- } \\
\text { nativen auf dem Markt gibt. }\end{array}$ & 3 & k.A. & k.A. \\
\hline & & $\begin{array}{l}\text { organisation- } \\
\text { ale Verbun- } \\
\text { denheit }\end{array}$ & $\begin{array}{l}\text { Ich empfinde es als an- } \\
\text { genehm, mit dem Anbieter } \\
\text { zusammenzuarbeiten. }\end{array}$ & 7 & k.A. & k.A. \\
\hline
\end{tabular}

Tab. A-15: Operationalisierung von Commitment in bestehenden Studien ${ }^{1049}$

Für die weitere Untersuchung ist es wichtig, dass der Kunde die Bindung wahrnimmt. Nur wenn diese Voraussetzung erfüllt ist, können die generischen Bindungszustände, d.h. Verbundenheit und Gebundenheit, das Verhalten des Kunden in der Geschäftsbeziehung prädisponieren. ${ }^{1050}$ Es erscheint plausibel, dass der Zustand der Verbundenheit die Verhaltensabsichten bzw. die Verhaltensweisen der Kunden positiv prädisponiert. ${ }^{1051}$ Dies könnte sich darin äußern, dass der Kunde seinen Anbieter im Allgemeinen bzw. seine Bank im Speziellen weiterempfiehlt oder dass der Kunde bereit ist, die Geschäftsbeziehung zu intensivieren und auszuweiten. Darüber hinaus lässt sich vermuten, dass der Kunde im Zustand der Verbundenheit nur wenig nach anderen Alternativen sucht und keine extremen Wechselabsichten besitzt. ${ }^{1052}$ In diesem Kontext führt SöLLNER den „Amount at stake“ als wesentliche Größe ein. Der „Amount at stake“

1049 Eigene Darstellung. Hinsichtlich der Tabellenbeschriftung vgl. Kapitel A.5.2.3.1.2.

1050 Vgl. Eggert (1999), S. 130.

1051 Vgl. Eggert (1999), S. 143.

1052 Vgl. Eggert (1999), S. 144. 
beschreibt Werte, die als „Input“" von einem Unternehmen in eine Geschäftsbeziehung eingebracht worden sind bzw. die im Laufe der Geschäftsbeziehung entstehen und die bei einem potenziellen Abbruch gefährdet sind. ${ }^{1053}$ Die Bereitschaft, zusätzlich in die Beziehung zu investieren, wird bei gegebener Verbundenheit größer sein. Verbundenheit entsteht durch die Kombination von Kundenzufriedenheit und Kundenvertrauen. Verbundenheit ist eine Bindung, die vom Interesse des Kunden ausgeht und seinem Willen entspricht, und ist ferner auch mit einer emotionalen und zukunftsorientierten Komponente behaftet. ${ }^{1054}$ Der Kunde möchte auch in Zukunft die Beziehung, die bei ihm eine Verbundenheit erzeugt, beibehalten.

Der Zustand der Gebundenheit hingegen könnte dazu führen, dass der Kunde sich verstärkt nach alternativen Anbietern umsieht, um sich aus der Gebundenheit zu befreien. Die Gebundenheit kann somit auch einen eher negativen Bindungszustand beschreiben. ${ }^{1055}$ Bei der Gebundenheit handelt es sich um eine Form der Bindung, die vom Interesse des Anbieters geleitet wird. ${ }^{1056}$

In Kapitel A.5.2.3.2.1 wurde erläutert, dass die Differenzierung nach inhaltlichen Dimensionen um die verschiedenen Bezugsebenen zu erweitern ist. Die Differenzierung nach Gebundenheit und Verbundenheit ist somit mit der Trennung nach organisationaler und personaler Ebene zu verbinden (vgl. Abb. A-18). Wie beim Vertrauen ${ }^{1057}$ lassen sich aufgrund der verschiedenen möglichen Beziehungen vier Ausprägungen unterscheiden: organisationales, interorganisationales, intraorganisationales und interpersonales Commitment. Das intraorganisationale Commitment, bspw. das Commitment zwischen einem Angestellten und seinem Arbeitgeber, wird in der vorliegenden Arbeit nicht weiter behandelt.

\footnotetext{
1053 Vgl. Söllner (1993), S. 112.

1054 Vgl. Bliemel/Eggert (1998), S. 41.

1055 Vgl. Eggert (1999), S. 144.

1056 Vgl. Bliemel/Eggert (1997), S. 41.

1057 Vgl. hierzu Kapitel A.5.2.3.1.2 und insbesondere Abb. A-15.
} 


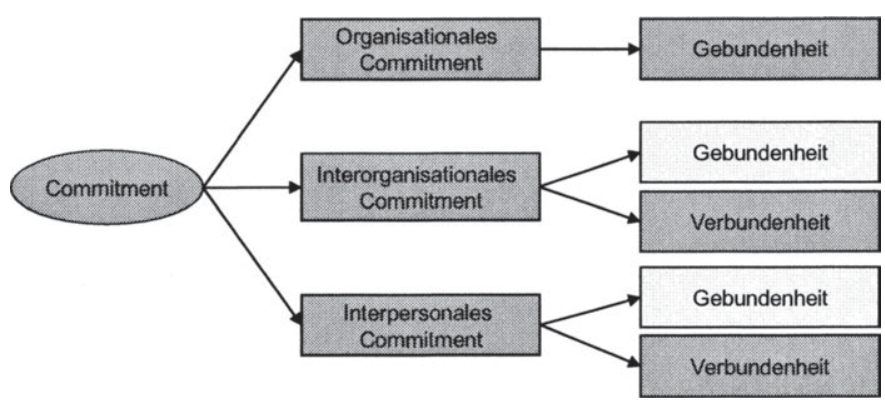

Abb. A-18: Dimensionen von Commitment ${ }^{1058}$

Um die verschiedenen Formen des Commitment zu erläutern, wird im Folgenden Bezug auf eine bestehende Kunde-Bank-Beziehung genommen. Eine organisationale Gebundenheit des Kunden ergibt sich bspw. bei fehlenden Alternativen zu einer bestehenden Bankverbindung. Die fehlenden Alternativen können sowohl Konsequenz der Marktbedingungen sein, d.h. geringer Konkurrenzintensität, oder schlichtweg aus der Anzahl der Bankverbindungen eines einzelnen Unternehmens resultieren. Eine geringe Anzahl an Bankverbindungen führt aber nur dann zu einer organisationalen Gebundenheit des Unternehmens, wenn bspw. aufgrund einer schlechten Bonität kein Aufbau neuer Bankverbindungen möglich ist. Eine bankseitige organisationale Gebundenheit könnte dann vorliegen, wenn es sich bei dem Kunden um einen großen Kunden handelt, den die Bank nicht verlieren möchte, weil er zu wichtig für die Bank ist. Die Gebundenheit der Bank kann hier aus rein monetären Aspekten hinsichtlich des einzelnen Kunden resultieren, weil das Geschäftsvolumen mit dem Kunden so groß ist und die Bank umfangreiche Erträge aus dem Kunden generiert. Ferner kann die Gebundenheit auch daher resultieren, dass die Abwanderung dieses Kunden über den rein monetären Verlust auf Einzelkundenebene hinaus mit Reputationsverlusten oder gar mit Abwanderung von anderen Kunden verbunden wäre. Eine Gebundenheit der Kontaktperson des Unternehmens zum Firmenkundenbetreuer und vice versa könnte eventuell auch aus bilateralen Absprachen resultieren, bspw. wenn die Kontaktperson den Abschluss von Anschlussverträgen dem Firmenkundenbetreuer verbal zugesichert hat und andere Personen bei diesen Absprachen nicht involviert waren. Möglicherweise könnten derartige Absprachen auch als eine Form der interorganisationalen Gebundenheit interpretiert werden, wenn aus den Absprachen eine Verpflichtung gegenüber der Bank resultiert. Eine Gebundenheit zwischen Personen bzw. zwischen einer Person und der fremden Organisation erscheint aber eher von sekundärer Bedeutung.

Eine Verbundenheit erfordert immer die Beteiligung einer Person, denn Organisationen können keine emotionale Bindung aufbauen, so dass eine Verbundenheit zum eigenen Unternehmen, zum jeweils anderen Unternehmen und zum Ansprechpartner des anderen Unternehmens aufgebaut werden kann. Die Verbundenheit zum eigenen 
Unternehmen, d.h. die intraorganisationale Ebene, ist in dieser Arbeit nicht von Relevanz. Die Kontaktperson des Unternehmens kann somit sowohl eine Verbundenheit zur Bank als auch zum Firmenkundenbetreuer aufbauen. Während der Grad der Gebundenheit zwischen Bank und Unternehmen stark asymmetrisch ist und in der Regel nur auf Seiten des Unternehmens existiert, kann hinsichtlich der Verbundenheit von einer Reziprozität ausgegangen werden, denn aufgrund der starken emotionalen Komponenten bei der Verbundenheit erscheint ein Ungleichgewicht auf lange Sicht hin nicht stabil. ${ }^{1059}$

In Bezug auf das Commitment lässt sich resümieren, dass die Abbildung desselbigen in dieser Arbeit als dreidimensionales Konstrukt mit den Dimensionen organisationale Gebundenheit, interorganisationale Verbundenheit und interpersonale Verbundenheit geeignet erscheint.

\subsubsection{3 Ökonomische Wirkungen von Vertrauen und Commitment im Rahmen der Hausbankbeziehung}

In Kapitel A.3.3 wurden die Einflüsse der gesetzlichen Rahmenbedingungen auf die ökonomischen Parameter Zins, Sicherheitenstellung und Kreditverfügbarkeit analysiert. Nachdem im Kapitel A.4.3 der aktuelle Stand der Relationship BankingForschung vorgestellt wurde, konnte in Kapitel A.4.4 die mangelnde Berücksichtigung von verhaltenswissenschaftlichen Einflüssen im Rahmen der Kunde-Bank-Beziehung dargelegt werden. In Kapitel A.5.2.2 wurde aufgezeigt, dass Vertrauen und Commitment im Rahmen einer Geschäftsbeziehung von zentraler Bedeutung sind. Während bis zu diesem Punkt die zentrale Bedeutung von Vertrauen und Commitment im Rahmen einer Geschäftsbeziehung allgemein herausgearbeitet wurde, sollen im Folgenden die Auswirkungen, insbesondere die ökonomischen Auswirkungen, im Rahmen der Hausbankbeziehung herausgearbeitet werden. ${ }^{1060}$ So postuliert HADWICH, dass Vertrauen als eine Dimension der Beziehungsqualität eine unmittelbare ökonomische Wirkung auslöst. ${ }^{1061}$ SEGBERS vermutet konkrete ökonomische Wirkungen aus den Konstrukten Vertrauen und Commitment auf die Parameter Zinssatz, Sicherheitenstellung und Kreditverfügbarkeit im Rahmen einer Hausbankbeziehung. ${ }^{1062}$ Eine differenzierte Analyse der Auswirkungen der unterschiedlichen Dimensionen von Vertrauen und Commitment auf diese Parameter existiert nach Kenntnis des Verfassers nicht. Aus diesem Grund soll im Folgenden analysiert werden, welche Wirkung konkret durch die einzelnen, in Kapitel A.5.2.3.1.2 und A.5.2.3.2.2 angesprochenen Dimensionen verursacht werden. Diese verschiedenen Dimensionen werden somit hinsichtlich ihrer Auswirkungen auf den Kreditzins, die Sicherheitenstellung und die Kreditverfügbarkeit untersucht (vgl. Abb. A-19).

\footnotetext{
1059 Hinsichtlich der emotionalen Komponenten vgl. Bliemel/Eggert (1998), S. 41.

$1060 \mathrm{Vgl}$. zu den ökonomischen Auswirkungen auch Segbers (2007), S. 352 f.

1061 Vgl. Hadwich (2003), S. 83 ff.

1062 Vgl. Segbers (2007), S. 357 ff.
} 


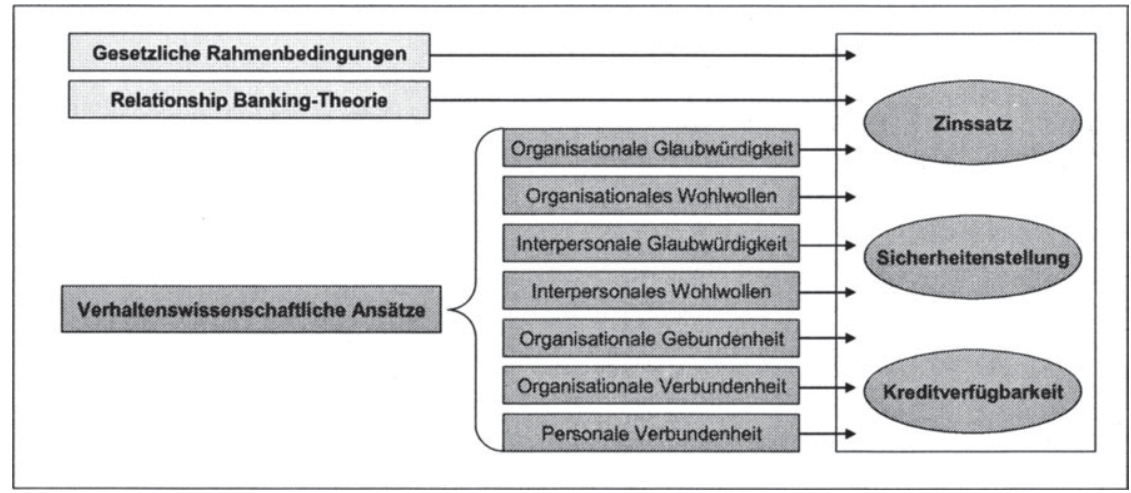

Abb. A-19: Analyse der Auswirkungen der verhaltenswissenschaftlichen Parameter ${ }^{1063}$

Es werden zunächst die vermuteten Auswirkungen des Vertrauenskonstruktes und anschließend des Commitment-Konstruktes analysiert. Hierbei wird jeweils unterschieden zwischen den Ausprägungen auf Kunden- und auf Bankseite, da sich hieraus unterschiedliche Effekte ableiten lassen. Eine Annahme hinsichtlich des Commitment ist es, dass jeweils die durch die andere Person wahrgenommene Ausprägung der Dimension von Relevanz ist. So wirkt sich nicht die tatsächliche Verbundenheit, sondern die wahrgenommene Verbundenheit des Kunden auf das Verhalten des Firmenkundenbetreuers aus. Die hier erarbeiteten Zusammenhänge bilden die Grundlage für die Bildung der Hypothesen in Kapitel B.2.

\section{Kundenseitiges Vertrauen in den Firmenkundenbetreuer}

Interpersonales Vertrauen seitens des Ansprechpartners im Unternehmen in Bezug auf den Firmenkundenbetreuer wird die Kommunikation zwischen dem Firmenkundenbetreuer und dem Ansprechpartner des Unternehmens positiv beeinflussen. ${ }^{1064}$ Dies kann sich in einer erhöhten Informationsbereitstellung äußern, indem bspw. auch vertrauensvolle oder intime Informationen mitgeteilt werden. Da die Kommunikation primär über einen Ansprechpartner erfolgt, ist hier das interpersonale Vertrauen nicht nur ein Förderer der Kommunikation, sondern eine Conditio sine qua non; denn der Ansprechpartner würde ansonsten gegebenenfalls bewusst Informationen zurückhalten. Hinsichtlich des Informationsflusses ist insbesondere das wahrgenommene Wohlwollen, weniger die wahrgenommene Glaubwürdigkeit des Firmenkundenbe-

1063 Eigene Darstellung. Da im weiteren Verlauf der Arbeit der Fokus auf der Unterscheidung zwischen der personalen und der organisationalen Ebene liegt, wird nachstehend nicht mehr differenziert zwischen dem organisationalen und dem interorganisationalen Commitment, stattdessen werden vereinfachend die Begriffe organisationale Ge- und Verbundenheit verwendet. Aus dem gleichen Grund werden im Folgenden die Begriffe organisationale Glaubwürdigkeit und organisationales Wohlwollen verwendet. 
treuers, z.B. in Form von fachlicher Kompetenz, von Relevanz. Daraus ergibt sich ein mittelbarer Effekt für den Kunden. Die umfangreichere Informationsbereitstellung führt zu einer präziseren Risikoeinschätzung durch die Bank über den Kunden. Die erhöhte Informationsbereitstellung durch den Kunden reduziert somit die bankseitige Entscheidungsunsicherheit, die sowohl hinsichtlich der grundsätzlichen Kreditbereitstellung als auch hinsichtlich der Höhe des zu fordernden Zinssatzes besteht. Die präzisere Beurteilung und der Verzicht auf einen Risikoaufschlag für die Unsicherheitskomponente führt somit in der Regel zu günstigeren Zinsen (vgl. Abb. A-20) und einer besseren Kreditverfügbarkeit. Dies setzt voraus, dass die Bank den niedrigeren Risikoaufschlag auch an die Kunden weitergibt, anderenfalls steigt die Gewinnmarge der Bank. Wird das Kriterium der Kreditverfügbarkeit allerdings nicht derart interpretiert, ob, sondern wie schnell gegebenenfalls der Kredit bereitgestellt wird, so kann aufgrund der erhöhten Informationen davon ausgegangen werden, dass der Kreditentscheid als solcher schneller getroffen wird.

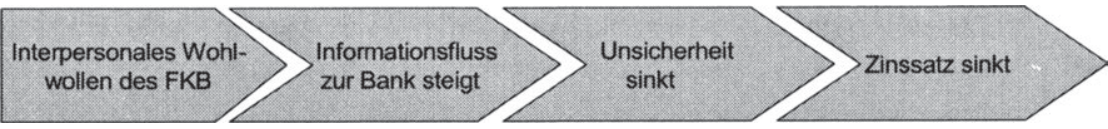

Abb. A-20: Einfluss des interpersonalen Wohlwollens auf den Zinssatz ${ }^{1065}$

Zuvor wurde die Wirkungskette unter der Annahme der Reduktion der Verhaltensunsicherheit aufgrund eines gesteigerten Informationsflusses betrachtet. Basierend auf der Annahme, dass intime Informationen insbesondere in Krisenzeiten relevant sind, ist in Bezug auf den Zinssatz aber auch eine weitere Wirkungskette denkbar. Ein erhöhter Informationsfluss resultiert aus einem höheren betrieblichen Risiko bzw. aus einer finanziell angespannten Lage des Unternehmens. In diesem Szenario steigen die Zinsen. In diesem Fall ist das Vertrauen zwar eine notwendige, aber keine hinreichende Bedingung für den erhöhten Informationsfluss. Neben dem Vertrauen ist die angespannte finanzielle Lage zumindest ein Auslöser für einen erhöhten Informationsfluss.

Hinsichtlich der Sicherheitenstellung kann keine eindeutige Aussage getroffen werden. Den Sicherheiten werden zwei Funktionen, die Sortierung- und die Anreizfunktion, zugeschrieben, die bisher im Wesentlichen noch parallel nebeneinander existieren. Unter der Annahme, dass die Sortierungsfunktion der Sicherheiten primär vor Beginn der Geschäftsbeziehung von Relevanz ist und die Anreizfunktion erst im Laufe der Geschäftsbeziehung zum Einsatz kommt, kann sich das Vertrauen nur auf die Anreizfunktion auswirken, denn das Vertrauen in den Firmenkundenbetreuer entwickelt sich erst im Laufe der Geschäftsbeziehung. Der gestiegene Informationsfluss kann dann dazu führen, dass das Moral Hazard-Risiko besser eingeschätzt werden kann und möglicherweise im Durchschnitt niedrigere Sicherheiten gefordert werden, da der Unsicherheitsfaktor reduziert wird. Es kann ferner angenommen werden, dass bei Bekanntwerden der Information, dass ein bestimmter Kunde ein großes Moral HazardRisiko birgt, dieser keine Kredite mehr bekommt und in Konsequenz solche Kunden

1065 Eigene Darstellung. 
aus dem Portfolio der Bank verschwinden. Das gesamte Moral Hazard-Risiko der Bank sinkt bei Betrachtung des Gesamtportfolios.

Das kundenseitige interpersonale Vertrauen in den Firmenkundenbetreuer spiegelt sich somit im Informationsfluss wider, wird dadurch für Firmenkundenbetreuer sichtbar und wirkt sich schließlich ggf. auf die Konditionen aus. Ein durch den Kunden wahrgenommenes Wohlwollen des Firmenkundenbetreuers könnte sich dadurch mittelbar auf die Konditionen auswirken.

Ferner kann Vertrauen die Entscheidungsunsicherheit bei dem Unternehmen bzw. dem Ansprechpartner reduzieren. ${ }^{1066}$ Ein erhöhtes Vertrauen in die fachliche Kompetenz der Bank bzw. des Beraters, wobei es sich hierbei um ein Element der Glaubwürdigkeit der Bank bzw. des Beraters handelt, ${ }^{1067}$ führt dazu, dass der Kunde auch komplexere Produkte bei der Bank abschließt. In diesem Fall wirkt sowohl die wahrgenommene Kompetenz des Beraters als auch die Kompetenz der Bank im Allgemeinen, so dass sowohl die personale als auch die organisationale Glaubwürdigkeit zu vermehrten Produktabschlüssen führen wird. Beispielsweise wird der Kunde unter Umständen ex ante weniger Vergleiche mit anderen Anbietern und ex interim weniger Kontrollen der tatsächlichen Vorteilhaftigkeit der Produkte durchführen. Im Rahmen der vorliegenden Studie wird dieser Zusammenhang nicht detailliert untersucht, denn die Nutzung einer breiten Produktpalette und die resultierende Möglichkeit der Quersubventionierung ist hier Einflussparameter in Bezug auf die Zinsen und wird nicht als abhängige Variable untersucht. Der mittelbare Effekt über die breitere Produktpalette könnte jedoch gerade aufgrund der Möglichkeit zur Quersubventionierung zu niedrigeren Zinsen führen. Weitere mittelbare Effekte sind zwar noch denkbar, sollen aber aufgrund der eher geringeren ökonomischen Auswirkung nicht weiter betrachtet werden. Eine Zusammenfassung der wesentlichen Auswirkungen des Vertrauens in die Bank kann Tab. A16 entnommen werden.

1066 Vgl. Morgan/Hunt (1994), S. 35.

1067 Vgl. hierzu ausführlich Kapitel A.5.2.3.1. 


\begin{tabular}{|l|c|c|c|c|}
\hline & $\begin{array}{c}\text { Informationen } \\
\text { Richtung } \\
\text { Bank }\end{array}$ & Zinssatz & Sicherheiten & $\begin{array}{c}\text { Kredit- } \\
\text { verfügbarkeit }\end{array}$ \\
\hline $\begin{array}{l}\text { Interpersonales } \\
\text { Wohlwollen (des FKB) }\end{array}$ & + & - & - & + \\
\hline $\begin{array}{l}\text { Interpersonale } \\
\text { Glaubwürdigkeit (des FKB) }\end{array}$ & 0 & $(-)$ & 0 & 0 \\
\hline $\begin{array}{l}\text { Organisationales } \\
\text { Wohlwollen (der Bank) }\end{array}$ & 0 & 0 & 0 & 0 \\
\hline $\begin{array}{l}\text { Organisationale } \\
\text { Glaubwürdigkeit (der Bank) }\end{array}$ & 0 & $(-)$ & 0 & 0 \\
\hline
\end{tabular}

Tab. A-16: Zusammenfassung der Auswirkungen des Vertrauens in die Bank ${ }^{1068}$

\section{Bankseitiges Vertrauen und Kreditzinsen}

Hinsichtlich des interpersonalen Wohlwollens kann von einer Reziprozität ausgegangen werden, so dass schließlich auch ein erhöhtes wahrgenommenes interpersonales Wohlwollen in Bezug auf die Kontaktperson zu besseren Informationen führt und die Unsicherheit in Bezug auf die Risikoeinschätzung des Unternehmens sinkt. Infolgedessen sinken die Risikokosten der Bank und dem Kunden kann ein niedrigerer Zinssatz gegeben werden.

Denkbar wäre aber auch ein direkter Effekt derart, dass der Firmenkundenbetreuer das interpersonale Wohlwollen der Kontaktperson wahrnimmt und derselbigen einen Gefallen tun möchte, den Zinssatz allein deshalb senkt und der Kontaktperson dadurch ein Erfolgsgefühl vermittelt. Je nach Ausgestaltung des Anreizsystems bei dem Unternehmen kann sich dieser Erfolg sogar monetär bei der Kontaktperson auswirken. Einen vergleichbaren Effekt kann das wahrgenommene Wohlwollen des Unternehmens bei dem Firmenkundenbetreuer auslösen, so dass der Firmenkundenbetreuer den Wunsch verspürt, dem Unternehmen, ggf. aufgrund einer finanziell schwierigen Lage, günstigere Konditionen zu geben.

Die Effekte aus der Glaubwürdigkeit sind stärker rationaler Natur. Die interpersonale Glaubwürdigkeit des Ansprechpartners führt dazu, dass den gelieferten Zahlen und Berichten sowie den mündlichen Aussagen eher Glauben geschenkt wird. Die organisationale Glaubwürdigkeit wirkt sich primär auf die Zuversicht des Firmenkundenbetreuers bezüglich des Erfolges eines zu finanzierenden Projektes aus. Beides hat zur Konsequenz, dass weniger Prüf- und Überwachungsaktivitäten durchgeführt werden und somit die Transaktionskosten sinken, wobei der Effekt aus der organisationalen Glaubwürdigkeit überwiegen wird. Dieser Effekt führt zu niedrigeren Betriebskosten und somit zu niedrigeren geforderten Zinsen. Sofern der Ansprechpartner auch die

1068 Eigene Darstellung. Ein „,“" symbolisiert einen verstärkenden bzw. erhöhenden Effekt, ein „”“ einen reduzierenden Effekt und ein "o" einen indefininiten bzw. keinen Einfluss. Durch die Klammem wird ein eher schwacher Einfluss und durch „+ " bzw. .- " ein besonders starker Effekt visualisiert. 
Investitionsentscheidungen, für den Projekterfolg zentrale Personalentscheidungen oder Entscheidungen hinsichtlich der vertragsgerechten Kreditrückzahlung trifft und nicht nur die Verträge mit der Bank abschließt oder vorbereitet, wirkt die interpersonale Glaubwürdigkeit umso stärker transaktionskostensenkend, da die interpersonale Glaubwürdigkeit dann weitreichendere Konsequenzen hat. Es resultiert ein nahezu fließender Übergang zur organisationalen Glaubwürdigkeit. Unter der Annahme, dass ein positiver Zusammenhang zwischen einer hohen wahrgenommenen Glaubwürdigkeit und der tatsächlichen Kompetenz des Unternehmens besteht, steigt die Erfolgswahrscheinlichkeit des Unternehmens mit zunehmender Glaubwürdigkeit. Dieser Zusammenhang führt zu niedrigeren erwarteten Verlusten und somit zu niedrigeren Risikokosten der Bank und niedrigeren geforderten Zinsen. Diesem vermuteten $\mathrm{Zu}$ sammenhang zwischen Zinsen und Vertrauen bzw. Glaubwürdigkeit liegt die Annahme zugrunde, dass Kostenersparnisse unmittelbar an die Unternehmen weiter gegeben werden. Wie im Rahmen der theoretischen Modelle und insbesondere im Modell von PETERSEN/RAJAN dargestelit, ${ }^{1069}$ spielt bei der Weitergabe der Kostenersparnis die Marktmacht der Bank und der anderen im Markt agierenden Banken eine zentrale Rolle, so dass auf den ersten Blick, d.h. ohne Berücksichtigung dieser Einflussgröße, die Effekte nicht eindeutig sind. Bei einer vertrauensvollen Beziehung kann jedoch davon ausgegangen werden, dass die Bank das Informationsmonopol nicht ausnutzt und damit langfristig die Vertrauensbasis gefährdet. Diese Hold Up-Gefahr kann somit durch ein gegenseitiges Vertrauen weitestgehend eliminiert werden, was wiederum die Weitergabe der Kostenersparnis für den Kunden und somit eine Zinsreduktion bewirkt.

\section{Bankseitiges Vertrauen und Sicherheiten}

Im nächsten Schritt wird der Einfluss des Vertrauens auf die Sicherheitenstellung untersucht. Wesentliche Funktionen von Sicherheiten sind die Reduzierung der Verlustquote im Insolvenzfall sowie die Sortierungs- und die Anreizfunktion. Die Einschätzung der Wahrscheinlichkeit durch die Bank, dass es zum Insolvenzfall kommt, fällt in einer Vertrauenssituation niedriger aus, da die positiven Erfahrungen der Vergangenheit in die Zukunft projiziert werden. Auch hier erscheint die organisationale Glaubwürdigkeit, d.h. das Vertrauen in die Unternehmensentscheidungen im Allgemeinen und das Vertrauen in sinnvolle Investitionsentscheidungen im Speziellen gewichtiger als das Vertrauen in den einzelnen Ansprechpartner. Sofern hier Identität des Entscheiders und des Ansprechpartners des Unternehmens vorliegt, ist wiederum eine Separation zwischen interpersonaler und organisationaler Glaubwürdigkeit nur schwer möglich. In Bezug auf die Sortierungsfunktion ist auch an dieser Stelle zu berücksichtigen, dass diese im Wesentlichen vor Aufnahme der Geschäftsbeziehung von Relevanz ist, so dass der Aufbau von Vertrauen bzw. die Beurteilung der Glaubwürdigkeit und des Wohlwollens des Unternehmens und des Ansprechpartners noch nicht möglich war. Hinsichtlich der Funktion der Anreizsteigerung entfällt die Grundlage bei vorherrschendem Vertrauen, da in einer derartigen Beziehung keine extrinsischen 
Anreize zur Leistungssteigerung notwendig sind. ${ }^{1070}$ Es gilt wiederum, dass die organisationale Glaubwürdigkeit wichtiger ist als die interpersonale Glaubwürdigkeit. Vom Grundsatz her widerspricht die Sicherheitenstellung als solche sogar in Teilen der Vertrauensdefinition. So wurden als wesentliche Elemente des Vertrauens für einen Großteil der Definitionen das bewusste Eingehen einer Risikosituation und die Verwundbarkeit herausgearbeitet. ${ }^{1071}$ Eine vertrauensvolle Beziehung erfordert allerdings kein blindes und grenzenloses Vertrauen, so dass die Existenz von Vertrauen in Form von Glaubwürdigkeit nicht den Verzicht auf Sicherheiten impliziert. Ferner gibt es rechtliche Vorschriften, die zu beachten sind. Auch wenn zu allen Kunden eine vertrauensvolle Beziehung besteht, kann eine Bank nicht ausschließlich Blankokredite vergeben, denn die Verlusthöhe im Falle des Kreditausfalls hat Einfluss auf das zu hinterlegende Eigenkapital der Bank, so dass Blankokredite das Kreditvergabevolumen reduzieren. ${ }^{1072}$

Hinsichtlich des Wohlwollens wird angenommen, dass selbiges die Gefahr des Moral Hazard reduziert. Ein wohlwollendes Unternehmen und ein wohlwollender Ansprechpartner wird nicht versuchen, der Bank zu schaden. Ferner kann - ähnlich wie bereits zuvor angenommen werden, dass das organisationale und das personale Wohlwollen den Firmenkundenbetreuer ggf. dazu verleitet, weniger Sicherheiten einzufordern. Während das organisationale Wohlwollen eher dazu führt, dass der Firmenkundenbetreuer dem Unternehmen einen monetären Vorteil in der Form verschaffen will, dass der Unternehmer aufgrund der größeren noch zur Verfügung stehenden Sicherheiten einen größeren Finanzierungsspielraum hat, bewirkt das personale Wohlwollen eher, dass der Firmenkundenbetreuer dem Ansprechpartner einen Gefallen tun möchte und somit einen aus Kundensicht vorteilhafteren Vertrag abschließt.

Als konterkarierender Effekt ist hier wiederum die vermehrte Informationsbereitstellung bei einer Vertrauensbeziehung durch den Kunden zu berücksichtigen, die dem Firmenbetreuer ggf. auch Zugang zu mehr unvorteilhaften Informationen verschafft. Somit kann seine Einschätzung des Kunden zwar präziser, aber negativer ausfallen. ${ }^{1073}$ Während der Ausgangspunkt für die erstgenannten Effekte das bankseitige Vertrauen ist, wirkt bei der erhöhten Informationsbereitstellung durch den Kunden die interpersonale Glaubwürdigkeit und das interpersonale Wohlwollen des Firmenkundenbetreuers. Da Vertrauen reziprok ist, erscheint eine saubere Trennung nicht immer möglich und notwendig.

\section{Bankseitiges Vertrauen und Kreditverfügbarkeit}

Die Unsicherheit der Bank bzw. des Firmenkundenbetreuers bezüglich der Auswahl eines investitionsrechnerisch guten Projektes und die Verhaltensunsicherheit hinsichtlich einer möglichen Asset Substitution sinkt bei einem größeren organisationalen Vertrauen. Ausschlaggebend sind hier die Glaubwürdigkeit, Zuverlässigkeit und

\footnotetext{
1070 Vgl. hierzu auch ausführlicher Segbers (2007), S. 356.

1071 Vgl. hierzu Kapitel A.5.2.3.1.1.

1072 Vgl. hierzu auch Kapitel A.3.1.2.1 und A.3.3.

1073 Vgl. hierzu auch ausführlicher Segbers (2007), S. 356.
} 
Kompetenz des Unternehmens, weniger das Wohlwollen des Unternehmens gegenüber der Bank. Es ist aber auch denkbar, dass der Firmenkundenbetreuer das Wohlwollen des Unternehmens bei der Kreditvergabe berücksichtigt. Beispielsweise könnte sich der Firmenkundenbetreuer dafür revanchieren, dass der Kunde sich trotz bankseitiger Probleme, wie bspw. ein temporärer Ausfall des Online-Banking, sehr verständnisvoll erwiesen hat.

Die Effekte auf interpersonaler Ebene sollten in Bezug auf die Kreditverfügbarkeit von sekundärer Bedeutung sein. Während die Zinshöhe leichter von zwischenmenschlichen Komponenten beeinflusst wird, sollte dieser Effekt aufgrund der größeren Auswirkungen bei der Kreditvergabe eher nachrangig sein. Denn ein halber Prozentpunkt weniger an Zinsertrag bei einem einzelnen Kredit ist für eine Bank mit geringeren Konsequenzen verbunden als ein fälschlicherweise vergebener Kredit, der zu einem Ausfall führt. Aufgrund der Reziprozität des Vertrauens führt jedoch ein erhöhtes interpersonales Wohlwollen zu einer erhöhten Informationsbereitstellung und bewirkt eine bessere Risikoeinschätzung durch den Firmenkundenbetreuer. Insbesondere bei einem risikoaversen Firmenkundenbetreuer wird somit die Kreditverfügbarkeit steigen, denn während selbiger bei Nichtkenntnis der Informationen tendenziell den Kredit eher ablehnen würde, werden ceteris paribus mehr Kunden einen Kredit erhalten, da der Kundenbetreuer bei einigen Fällen, die mit Unsicherheit behaftet waren, nun eine präzise, positive Einschätzung vornehmen kann. Die personelle Verflechtung bei kleineren Unternehmen erschwert eine saubere Trennung zwischen der organisationalen Ebene und der personalen Ebene, aber auch bei größeren Unternehmen wird möglicherweise die organisationale Glaubwürdigkeit durch die personale Glaubwürdigkeit beeinflusst, weshalb die interpersonale Glaubwürdigkeit auch zu einer Erhöhung der Kreditverfügbarkeit führen kann. Eine Zusammenfassung der wesentlichen Auswirkungen des Vertrauens in die Kunden in Bezug auf den Informationsfluss und die ökonomischen Parameter kann Tab. A-17 entnommen werden. 


\begin{tabular}{|l|c|c|c|c|}
\hline & $\begin{array}{c}\text { Informationen } \\
\text { Richtung } \\
\text { Kunde }\end{array}$ & Zinssatz & $\begin{array}{c}\text { Sicher- } \\
\text { heit }\end{array}$ & $\begin{array}{c}\text { Kredit- } \\
\text { verfügbarkeit }\end{array}$ \\
\hline $\begin{array}{l}\text { Interpersonales } \\
\text { Wohlwollen (des Kunden) }\end{array}$ & + & - & - & + \\
\hline $\begin{array}{l}\text { Interpersonale } \\
\text { Glaubwürdigkeit (des Kunden) }\end{array}$ & + & - & - & + \\
\hline $\begin{array}{l}\text { Organisationales } \\
\text { Wohlwollen }\end{array}$ & 0 & - & - & + \\
\hline $\begin{array}{l}\text { Organisationale } \\
\text { Glaubwürdigkeit }\end{array}$ & 0 & -- & -- & ++ \\
\hline
\end{tabular}

Tab. A-17: Zusammenfassung der Auswirkungen des Vertrauens in den Kunden ${ }^{1074}$

\section{Commitment}

Während in den bestehenden Commitment-Studien in der Regel untersucht wurde, welche Effekte das Commitment des Kunden auf sein Wiederkaufverhalten ${ }^{1075}$ oder welche Effekte das Commitment eines Angestellten in Bezug auf seinen Arbeitgeber ${ }^{1076}$ hat, ist im Rahmen der Analyse der ökonomischen Wirkung von Commitment in der Hausbankbeziehung vielmehr das wahrgenommene Commitment von zentraler Bedeutung. Der Firmenkundenbetreuer kann bei der Kreditvergabe und der Konditionenfestsetzung lediglich berücksichtigen, inwiefern er davon ausgeht, dass der Kunde auch in Zukunft - u.a. aufgrund von Verbundenheit und Gebundenheit - weitere Produkte bei der Bank abschließt. Dabei kann das tatsächliche Commitment des Kunden vom wahrgenommenen Commitment differieren. Wie auch in den in Kapitel A.5.2.3.3 dargestellten Untersuchungen wird hier nur das kundenseitige Commitment bzw. das wahrgenommene kundenseitige Commitment betrachtet.

\section{Commitment und Zinsen}

Die Gebundenheit und die Verbundenheit des Unternehmens einerseits sowie die Verbundenheit der Kontaktperson andererseits schaffen die wesentlichen Grundlagen für eine intertemporale Konditionengestaltung. Die Gebundenheit der Kontaktperson ist nachrangig, denn Gebundenheit resultiert primär aus vertraglichen Vereinbarungen zwischen Unternehmen und wird deswegen nicht weiter behandelt. Die Bank kann sich bei bestehendem Commitment darauf verlassen, dass sie nach anfänglich niedrigen Zinsen zu einem späteren Zeitpunkt höhere Zinsen fordern und somit Verluste aus der Anfangsphase kompensieren kann. ${ }^{1077}$ Im Modell von PETERSEN/RAJAN ist die Macht der Bank bzw. das Wissen, dass der Kunde nicht wechseln möchte oder nicht kann, essenziell, um zunächst günstigere Kredite als bei vollständiger Konkurrenz

\footnotetext{
1074 Eigene Darstellung.

1075 Vgl. Eggert (2000), S. 119.

1076 Vgl. Meyer/Allen (1984), S. $372 \mathrm{ff}$.

1077 Vgl. hierzu das Modell von Petersen/Rajan (1995) in Kapitel A.4.3.1.2.1. 
vergeben zu können, dadurch Kreditrationierung zu vermeiden und anschließend höhere Zinsen in den Folgeperioden verlangen zu können. Während die Gebundenheit in Ermangelung an Alternativen auch in einer Anfangsphase einer Kunde-Bank-Beziehung auftreten kann, entwickelt sich die Verbundenheit im Laufe der Beziehung und festigt sich erst in einem vergleichsweise späten Stadium. ${ }^{1078}$ Das Bewusstsein des Firmenkundenbetreuers hinsichtlich des vorherrschenden Commitments kann zur Folge haben, dass selbiger diese Machtsituation ausnutzt und höhere Zinsen fordert. Bei einer bloßen Gebundenheit ist diese Gefahr evident. Bei Existenz von Verbundenheit auf Unternehmensebene oder Verbundenheit auf Ebene der Kontaktperson bei gleichzeitiger Abwesenheit von Gebundenheit ist die Gefahr allerdings nicht wirklich gegeben, denn die Bank würde riskieren, das Verbundenheitsgefühl zu verletzen und den Kunden schließlich sogar zu verlieren. Bei Existenz von Gebundenheit und Verbundenheit könnte der Firmenkundenbetreuer versuchen, die Gebundenheit so lange auszureizen bis die Verbundenheit gerade noch nicht negativ tangiert wird.

Es resultiert bei vorherrschender Ge- und Verbundenheit des Unternehmens und der Kontaktperson in Bezug auf die Bank und den Firmenkundenbetreuer allerdings auch ein gegenläufiger Effekt. In diesem Fall ist davon auszugehen, dass der Kunde nicht nur einen Kreditvertrag bei der Bank unterhält, sondern auch in Zukunft weitere Produkte abschließt. Der Bank eröffnet sich dadurch die Möglichkeit zur Quersubventionierung, so dass aufgrund dieses Effektes die Zinsen im Durchschnitt niedriger sind. Aufgrund der konterkarierenden Effekte ist der Einfluss der Gebundenheit und der Verbundenheit auf die Kreditzinsen indeterminiert.

\section{Commitment und Sicherheiten}

Als eine Funktion der Sicherheiten wurde die Reduzierung der Verlustquote bei Kreditausfall genannt. Die Wahrscheinlichkeit des Ausfalls ist als unabhängig von einem wahrgenommenen Kunden-Commitment zu betrachten. Den Sicherheiten kommt ferner die Anreizfunktion zu. Bei einer hohen Verbundenheit wird sich der Kunde intrinsisch motiviert anstrengen, so dass die Funktion der Anreizsteigerung durch Sicherheiten nicht mehr notwendig ist. Eine hohe organisationale Verbundenheit sollte somit zu einer Reduktion der Sicherheitenstellung führen. Inwiefern die personale Verbundenheit des Ansprechpartners einen Effekt auf die Sicherheitenstellung hat, hängt von seiner Stellung im Unternehmen ab. Bei einem weitreichenden Einfluss der Kontaktperson im Unternehmen können sich seine erhöhten Anstrengungen auch auf das gesamte Unternehmen auswirken, so dass tendenziell eher ein reduzierender Effekt zu erwarten ist. Die Gebundenheit des Kunden bewirkt, dass die Bank eine gewisse Machstellung erlangt und somit höhere Sicherheitenforderungen stellt.

$1078 \mathrm{Vgl}$. hierzu das phasenorientierte Interaktionsmodell von Dwyer/Schurr/Oh (1987), S. $11 \mathrm{ff}$. sowie das Modell von Ford (1990) in Kapitel A.5.2.2.2.1. 


\section{Commitment und Kreditverfügbarkeit}

Unter der Annahme, dass eine geringe Anzahl von Bankverbindungen automatisch mit einer hohen Gebundenheit des Kunden einhergeht, kann argumentiert werden, dass Unternehmen mit einer höheren Gebundenheit mit höherer Wahrscheinlichkeit zusätzliche Kredite bekommen. Dies lässt sich darin begründen, dass der Informationsstand einer Bank über ein bestimmtes Unternehmen größer ist, wenn das Unternehmen nur bei einer oder wenigen Banken Kredite aufnimmt. ${ }^{1079}$ Die Bank ist somit besser in der Lage, die Kreditwürdigkeit zu beurteilen und vergibt eher Kredite, wobei zusätzliche negative Informationen auch an dieser Stelle genau das Gegenteil bewirken können. Eine geringe Anzahl von Bankverbindungen muss allerdings nicht mit einer hohen Gebundenheit einhergehen. Sofern Alternativen im relevanten Markt existieren, findet ein gutes Unternehmen relativ schnell eine neue Bank. Die geringe Anzahl von Bankverbindungen kann auch schlichtweg Konsequenz einer hohen Verbundenheit sein. Ceteris paribus wird aber davon ausgegangen, dass eine hohe Gebundenheit seitens des Unternehmens zu einer höheren Kreditverfügbarkeit führt.

Zudem eröffnet eine kundenseitige hohe Gebundenheit und/oder Verbundenheit Möglichkeiten für die intertemporale Konditionengestaltung durch die Bank. Da selbige für das Zustandekommen eines Kreditvertrags in dem Modell von PETERSEN/RAJAN notwendige Voraussetzung ist, steigt dadurch die Kreditverfügbarkeit. Denn wenn der Kunde auch in Zukunft bei der Bank bleibt, dann kann die Bank anfängliche Verluste durch spätere Gewinne kompensieren und ist bereit, den Vertrag abzuschließen. Hinsichtlich der potenziell unterschiedlichen Auswirkungen der organisationalen Ge- und Verbundenheit sowie der personalen Verbundenheit ist zu hinterfragen, welches Phänomen den Kundenwechsel am stärksten verhindert. Da die Gebundenheit aus vertraglichen Gegebenheiten resultiert, hat diese vermutlich den stärksten Effekt. Das Gefühl der Verbundenheit hingegen kann möglicherweise schnell durch ein Fehlverhalten der anderen Partei zerstört werden. Allerdings erscheint eine Differenzierung hinsichtlich der Stabilität der beiden Phänomene schwierig. Die Verbundenheit des Ansprechpartners kann sehr wichtig sein; das Ausmaß der Bedeutung hängt von dem Einfluss im Unternehmen ab. Wenn der Ansprechpartner einen Bankwechsel nicht verhindern kann, so hat seine Verbundenheit keinen Effekt. Ferner ist bei einer großen Verbundenheit und Gebundenheit des Kunden davon auszugehen, dass die Bank eine höhere Verpflichtung zur Unterstützung des Kunden fühlt und somit die Kreditverfügbarkeit im Sinne einer größeren Wahrscheinlichkeit der Kreditbereitstellung steigt. Dies geht einher mit der Verantwortung, welche die Hausbank in finanziellen Krisenzeiten trägt. Eine Zusammenfassung der wesentlichen Auswirkungen des kundenseitigen Commitments kann Tab. A-18 entnommen werden. 


\begin{tabular}{|l|c|c|c|}
\hline & Zinssatz & Sicherheit & $\begin{array}{c}\text { Kredit- } \\
\text { verfügbarkeit }\end{array}$ \\
\hline $\begin{array}{l}\text { Organisationale } \\
\text { Gebundenheit }\end{array}$ & o & + & ++ \\
\hline $\begin{array}{l}\text { Organisationale } \\
\text { Verbundenheit }\end{array}$ & o & -- & ++ \\
\hline $\begin{array}{l}\text { Interpersonale } \\
\text { Verbundenheit }\end{array}$ & o & - & + \\
\hline
\end{tabular}

Tab. A-18: Ökonomische Wirkungen von Commitment

Zusammenfassend lässt sich feststellen, dass hinsichtlich der Konstrukte Vertrauen und Commitment bzw. ihrer verschiedenen Dimensionen von einem Einfluss auf die Kreditkonditionen ausgegangen werden kann. Die Wirkungsrichtung der verschiedenen Dimensionen von Vertrauen und Commitment in Bezug auf die Variablen Zinssatz, Sicherheitenstellung und Kreditverfügbarkeit scheint identisch bzw. zumindest nicht konträr zu sein. Allerdings wird eine unterschiedliche Einflussintensität vermutet. Die Unterschiede der Einflussintensität bei Betrachtung der organisatorischen und der persönlichen Ebene hängen vermutlich auch davon $a b$, inwiefern der jeweilige in der Lage ist, hinsichtlich dieser beiden Ebenen zu unterscheiden und inwiefern der Ansprechpartner einen Einfluss auf unternehmensweite Entscheidungen hat. Dieser Punkt hängt vermutlich auch von der Unternehmensgröße ab sowie von der Frage, wo der Ansprechpartner des Unternehmens innerhalb der Unternehmensorganisation angesiedelt ist. 


\section{B Empirische Untersuchung zur Analyse der Kunde-Bank- Beziehung}

\section{Grundlagen der Untersuchung und deskriptive Auswer- tung}

Mit der vorliegenden Arbeit soll ein Beitrag zur Analyse der Einflussgrößen der ökonomischen Parameter Zinssatz, Sicherheitenstellung und Kreditverfügbarkeit im Rahmen der Kunde-Bank-Beziehung geleistet werden. Es wird vermutet, dass die Konditionen - wie in Kapitel A.3.3 dargelegt - durch die gesetzlichen Rahmenbedingungen beeinflusst werden. Ferner haben die in der Relationship Banking-Forschung verwendeten und in Kapitel A.4 dargestellten Variablen einen Einfluss auf die Konditionen. Durch die Integration verhaltenswissenschaftlicher Elemente erfolgt eine Erweiterung bestehender Erklärungsversuche, um dadurch Ansatzpunkte für zukünftige wissenschaftliche Arbeiten zu schaffen. Ziel ist es zu untersuchen, ob verhaltenswissenschaftliche Elemente im Rahmen der Kunde-Bank-Beziehung einen Einfluss ausüben, ohne dadurch den Anspruch zu erheben, durch die Integration dieser Elemente die ökonomischen Parameter der Kunde-Bank-Beziehung vollständig erklären zu wollen.

Zunächst werden in Kapitel B.1 mit der Durchführung der Datenerhebung, der Datensatzbeschreibung, der Datenbereinigung und der Darstellung der deskriptiven Ergebnisse die Grundlagen der empirischen Studie beschrieben. Es folgt in Kapitel B.2 die Hypothesenbildung mit dem Fokus auf den verhaltenswisschenschaftlichen Elementen, so dass im Wesentlichen die theoretischen Erkenntnisse hinsichtlich der ökonomischen Wirkungen von Vertrauen und Commitment aus Kapitel A.5.2.3.3 die Grundlage für dieses Kapitel bilden. Im darauf folgenden Kapitel B.3 werden nach der Beschreibung der methodischen Grundlagen die aufgestellten Hypothesen für die drei ökonomischen Parameter mittels statistischer Verfahren überprüft.

\subsection{Durchführung der Erhebung und Datenaufbereitung}

Für die Festlegung einer adäquaten Form der Datenerhebung müssen zunächst die erforderlichen Daten und somit die potenziellen Datenquellen bekannt sein. Da die Art der für diese vorliegende Studie zu erhebenden Daten sehr heterogen ist, muss auf verschiedene Datenquellen zurückgegriffen werden. Zum einen handelt es sich hierbei um objektive Daten wie Jahresabschlusskennzahlen, Ratingdaten, Verbindlichkeiten gegenüber der jeweiligen Bank oder Vertragsdaten wie Zinssätze. Zum anderen werden subjektive Einschätzungen der Firmenkundenbetreuer ${ }^{1080}$, z.B. für die Abbildung der Konstrukte Vertrauen und Commitment benötigt. Für die Erhebung der Kennzahlen und der objektiven Daten kann auf Bankanwendungen zurückgegriffen werden.

1080 Es wäre auch denkbar, das Vertrauen des Kunden in die Bank bzw. den Firmenkundenbetreuer zu erheben. In Kapitel A.5.2.3.3 wurde dargelegt, dass vor allem das bankseitige Vertrauen in den Ansprechpartner bzw. das Unternehmen sowie das durch den Firmenkundenbetreuer wahrgenommene Commitment für die Untersuchungen relevant sind. Aus diesem Grund wird ausschließlich eine Befragung der Firmenkundenbetreuer vorgenommen. 
Angesichts der zentralen Stellung der genannten Konstrukte in dieser Arbeit, ist die Auswahl einer geeigneten Erhebungsmethode besonders für diesen Bereich kritisch. Aufgrund der im Folgenden dargelegten Gründe wurde die quantitative Erhebungsmethode ausgewählt. ${ }^{1081}$ Im Rahmen der empirischen Sozialforschung versuchen quantitative Methoden theoretische Konstrukte mit Hilfe einer nummerischen, standardisierten Messung von Variablenausprägung direkt zu erfassen. ${ }^{1082}$ In der Regel antworten die Probanden bei dieser Vorgehensweise auf Fragen mit vorformulierten Antwortmöglichkeiten oder drücken den Grad ihrer Zustimmung zu einer Aussage durch Ankreuzen auf einer Skala aus. Quantitative Daten gestatten zahlreiche Analysen auf Basis statistischer Verfahren und sind Voraussetzung zur Prüfung von Hypothesen. Da das Ziel der vorliegenden Untersuchung in der Hypothesenprüfung besteht, ist die Anwendung dieser Methode für die Zielerreichung erforderlich.

Zur Entwicklung eines geeigneten Instruments sind bei den quantitativen Verfahren im Vergleich zu den qualitativen Verfahren mehr Vorkenntnisse erforderlich. Die Verwendung nicht relevanter Dimensionen kann beim Entwurf eines Fragebogens zu verfälschten oder nicht aussagekräftigen Ergebnissen führen. ${ }^{1083}$ Die Verwendung und Entwicklung von Fragebögen bietet sich insbesondere zur Erfassung von Konstrukten an, über die bereits hinreichende Informationen aus theoretischen Vorüberlegungen und früheren empirischen Untersuchen vorliegen. ${ }^{1084}$ Aufgrund der vorhergehenden Darstellung der empirischen Studien zum Vertrauen und zum Commitment kann der Stand der Forschung hinsichtlich dieser Konstrukte durchaus als elaboriert betrachtet werden. Da ein Fragebogen mit vorgegebenen Antwortmöglichkeiten und zahlenmäBig abgestuften Antwortkategorien direkt zu quantitativen Daten und damit unter Beachtung der methodologischen Voraussetzungen zu präzisen Vergleichsmöglichkeiten und zur Generalisierbarkeit der Ergebnisse führt, musste dieser für die Zielsetzung der Untersuchung das Mittel der Wahl sein. Neben der Datenstruktur ist auch die Datenmenge und Stichprobengröße als kritischer Faktor zu betrachten. Auch um umfangreiche Datenmengen ${ }^{1085}$ größerer Stichproben in relativ kurzer Zeit zu erheben und zu analysieren, bleibt die Datenerhebung mittels einer schriftlichen Befragung die Methode sine qua non. ${ }^{1086}$ Vor diesem Hintergrund wurde die quantitative Erhebungsmethode in Form einer schriftlichen Befragung gewählt.

Es wurde eine zweigeteilte Datenerhebung vorgenommen. Die systemseitig vorliegenden Daten wurden per Datenbankabfragen ermittelt, für die Einschätzung der Firmenkundenbetreuer wurde ein Fragebogen erstellt.

\footnotetext{
1081 Vgl. zur quantitativen Erhebungsmethode Unterreitmeier (2004), S. 49.

1082 Vgl. Unterreitmeier (2004), S. 49.

1083 Vgl. Unterreitmeier (2004), S. 49.

$1084 \mathrm{Vgl}$. Berekhoven/Eckert/Ellenrieder (2001), S. 114.

1085 Der Fragebogen für den einzelnen Firmenkundenbetreuer umfasste 58 Fragen.

1086 Vgl. Unterreitmeier (2004), S. 49. Ferner wäre es auch denkbar gewesen, die Firmenkundenbetreuer persönlich oder telefonisch zu interviewen. Aufgrund der erforderlichen Datenmenge schied diese Möglichkeit allerdings aus.
} 
Vor der eigentlichen Datenerhebung wurden Pre-Tests mit vier aktiven Firmenkundenbetreuern sowie sechs Bankkaufleuten zur Überprüfung der Verständlichkeit und Nachvollziehbarkeit des Fragebogens durchgeführt, der geringfügigen Modifikationsbedarf bei der Formulierung der Fragen erkennen ließ. Nach den Pre-Tests erfolgte die Bankenansprache (vgl. Abb. B-1). An der Datenerhebung konnten ausschließlich Genossenschaftsbanken teilnehmen, die die Software MinD.banker ${ }^{\circledR}$ im Einsatz haben, da diese Software für einen Teil der Daten als Medium für die Erhebung verwendet wurde. Daraus ergab sich zum Zeitpunkt der Studie eine Grundgesamtheit von ca. 90 Genossenschaftsbanken deutschlandweit. Aus dieser Grundgesamtheit wurden die 30 Banken per Zufall ausgewählt. Nach Durchführung der Pre-Tests wurden an diese Banken Briefe mit einer Erläuterung des Forschungsvorhabens, einer Beschreibung des Ablaufs der Datenerhebung sowie einer Anfrage bezüglich der Teilnahme an der Befragung verschickt. ${ }^{1087}$ Den Banken wurde als Gegenleistung für ihre Kooperationsbereitschaft eine zweistündige Beratungstätigkeit in Form von Anwenderschulungen oder Konfigurationstätigkeiten für die Software MinD.bankerß angeboten. Zwei Wochen nach der Ankündigung der geplanten Erhebung wurden die Leiter des Bereichs Firmenkunden oder die für diesen Bereich zuständigen Vorstände telefonisch kontaktiert, um weitere Hintergründe zur Befragung zu erläutern und Termine abzustimmen. Von den 30 angesprochenen Banken haben 15 Banken an der Erhebung teilgenommen (vgl. Abb. B-2). Die Datenerhebung bei den Banken wurde im Zeitraum von Ende 2007 bis Anfang 2008 durchgeführt, wobei $90 \%$ der Daten im Dezember und Januar erhoben worden sind.

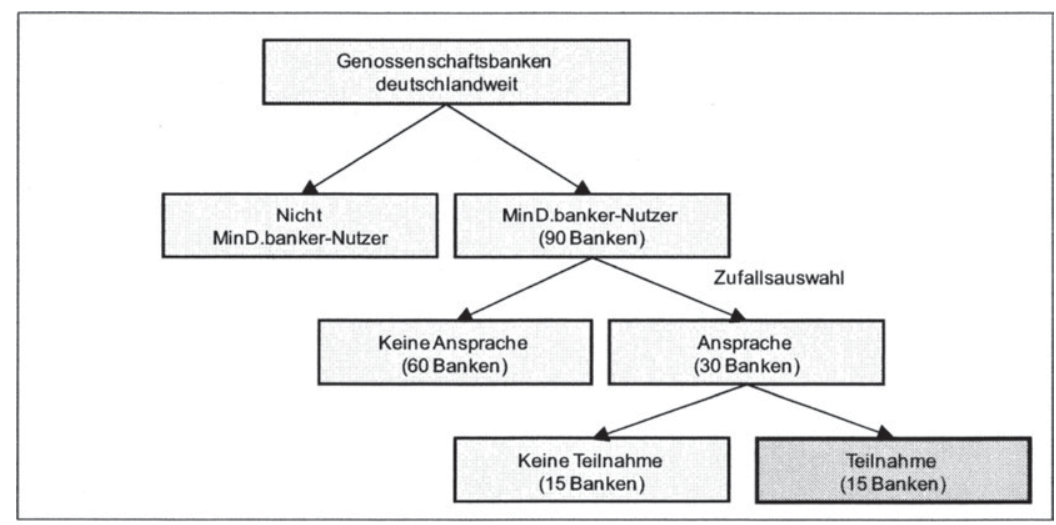

Abb. B-1: Vorgehen bei der Auswahl der teilnehmenden Banken 


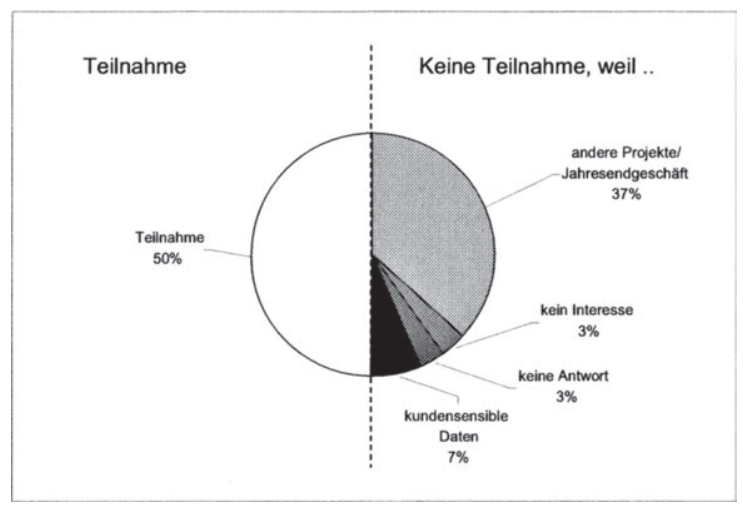

Abb. B-2: Resonanz der angesprochenen Banken

In den einzelnen Banken wurden anhand von Listen mit Kunden, für die ein Rating vorliegt ${ }^{1088}$ per Zufallsauswahl jeweils Kunden ausgewählt, zu denen die Firmenkundenbetreuer Fragen zu beantworten hatten. Jeder Firmenkundenbetreuer sollte für maximal vier seiner Kunden Fragebögen ausfüllen. Nach erfolgter Kundenauswahl wurden in einem zweiten Schritt solche Kunden ausgeschlossen, die mehr als 500 Mitarbeiter haben ${ }^{1089}$ und die aktuell keine Geschäftskonten bei dem jeweiligen Institut unterhalten. ${ }^{1090}$ Die Datenerhebung setzte sich wie zuvor beschrieben aus zwei Elementen zusammen. Ein Teil der Daten wurde aus der bestehenden Bankenanwendung MinD.banker@ mittels einer programmierten Datenabfrage automatisiert erhoben. ${ }^{1091}$ Hierbei handelte es sich um Daten wie bspw. Jahresabschlusskennzahlen, Ratingklassen oder Teilscores des Ratings. In einem weiteren Schritt haben die Firmenkundenbetreuer einen Fragebogen zu den ausgewählten Kunden erhalten, um die Daten, die systemseitig nicht hinterlegt waren bzw. die nicht automatisiert abgefragt werden konnten, wie z.B. die subjektive Beurteilung der Geschäftsbeziehung, zu erheben. Die Firmenkundenbetreuer konnten die automatisiert generierten Daten nicht einsehen, so dass die subjektiven Einschätzungen weitestgehend losgelöst von den Kennzahlen aus der automatisierten Datenerhebung vorgenommen werden konnten. Eine Kenntnis des Firmenkundenbetreuers hinsichtlich der erhobenen objektiven Daten, wie z.B. Ratingklassen oder Jahresabschlusskennzahlen, kann nicht ausgeschlossen werden.

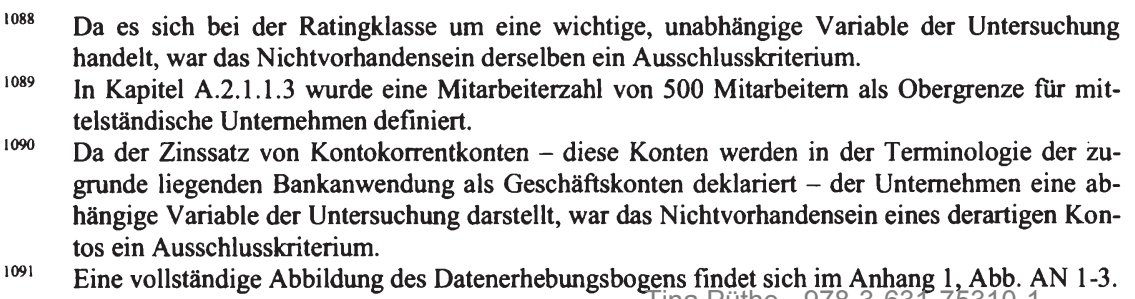
Tina Püthe - 978-3-631-75310-1 
Die Verteilung der Fragebögen an die Firmenkundenbetreuer innerhalb der einzelnen Institute ist in der Regel durch die Leiter des Bereichs Firmenkunden vorgenommen worden. Der Fragebogen umfasste 58 Fragen und wurde von einem Anschreiben begleitet. ${ }^{1092}$ Dieses beinhaltete neben der Beschreibung des Anliegens der Untersuchung die Anweisungen zum Ausfüllen und die Gewährleistung der Anonymität. Zudem wurden die Fragebogenbeantwortenden darauf hingewiesen, dass es keine „richtigen“ oder "falschen“ Antworten gebe, um sie somit zum ehrlichen Antworten zu ermutigen und ihnen die Scheu vor dem Ankreuzen extremer Werte zu nehmen. In diesem Begleittext wurde auf die Begriffe Vertrauen und Commitment bewusst verzichtet, um das Antwortverhalten nicht zu beeinflussen. Stattdessen wurde das Ziel der Befragung nur sehr allgemein formuliert. Letztlich wurde im bewusst kurz gehaltenen Begleittext darum gebeten, nach kurzem Überlegen einzuschätzen, inwieweit einer Aussage zugestimmt oder inwiefern diese abgelehnt wird, um daraufhin der Skalierung entsprechend, die jeweilige Antwortausprägung anzukreuzen.

Der Fragebogen selbst beinhaltete 25 Fragen zu den Konstrukten Vertrauen und Commitment. Bei den Fragen zur Messung des Vertrauens und des Commitments wurde eine 6-stufige Skala verwendet. Zwar wurden in den Fragebögen zur Vertrauensforschung häufig 5- oder 7-stufige Skalen verwendet, ${ }^{1093}$ jedoch wird durch die Verwendung von geradzahligen Skalen der Beantwortende gezwungen, zumindest ein tendenziell in eine Richtung weisendes Urteil abzugeben. ${ }^{1094}$ Hinsichtlich der Anzahl der Ausprägungen wurde berücksichtigt, dass eine zunehmende Anzahl der Skalenstufen zwar zu einer erhöhten Differenzierungsfähigkeit der Skala führt, aber auch gleichzeitig bewirkt, dass irgendwann die Differenzierungskapazität der Urteilenden ausgeschöpft ist. ${ }^{1095}$ Es wurde eine Ratingskala verwendet, d.h. es wurden durch Zahlen markierte Abschnitte eines Merkmalskontinuums markiert, die die Urteilenden als gleich groß bewerten sollen. Hier wird angenommen, dass die Stufen der Ratingskala eine Intervallskala bilden, ${ }^{1096}$ so dass die Antworten in den statistischen Auswertungen als intervallskalierte Merkmale berücksichtigt werden. Neben den Überschriften zu den Bedeutungen der einzelnen Ausprägungen wurde ferner jeweils in einem kurzen Erläuterungstext zur Frage das Vorgehen beschrieben. Bei den Selbsteinstufungen zum Vertrauen und zum Commitment wurden unipolare Skalen eingesetzt. Darunter ist zu verstehen, dass die Abstufungen sich auf die Ausprägungen eines Merkmals beziehen, d.h. nur positive Zahlen umfassen und somit Intensitätsabstufungen einer Bezeichnung angeben, der in mehr oder minder ausgeprägtem Maße zugestimmt werden kann bzw. die mehr oder minder abgelehnt werden kann. ${ }^{1097}$ Wie in Abb. B-3 ersichtlich, wurde die nummerische Skala ferner um eine verbale Skala (,trifft voll zu“ etc.) ergänzt. ${ }^{1098}$

\footnotetext{
1092 Vgl. Anhang 1, Abb. AN 1-2 und Anhang 1, Abb. AN 1-4.

1093 Vgl. Kapitel A.5.2.3.1.2

1094 Vgl. Bortz/Döring (2006), S. 180, Pepels (1995), S. 288.

1095 Vgl. Bortz/Döring (2006), S. 180.

$1096 \mathrm{Zu}$ diesem Vorgehen vgl. Bortz/Döring (2006), S. 177. Hier findet sich auch eine Diskussion hinsichtlich des Skalenniveaus wieder. Ebenda, S. $182 \mathrm{f}$.

Vgl. Pepels (1995), S. 287.

Vgl. Pepels (1995), S. 288.
} 


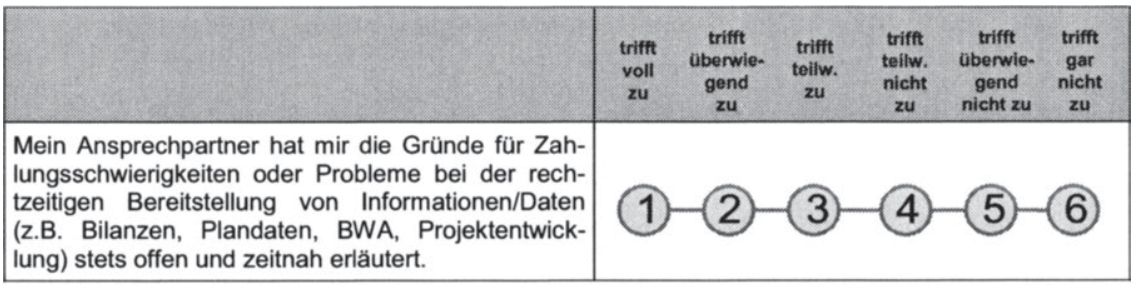

Abb. B-3: Subjektive Einschätzung

Des Weiteren umfasste der Fragebogen zwölf Fragen zum Unternehmen im Allgemeinen, wie z.B. der Mitarbeiteranzahl und der Gesellschafteranzahl, ferner acht Fragen zu den Kreditverträgen, wie z.B. die Besicherungsquote des Kunden oder inwiefern es eine Kreditablehnung in den vergangenen drei Jahren gab, sowie neun Fragen zur Produktnutzung des Kunden, wie z.B. dem Anteil des Zahlungsverkehrs bei der Bank oder dem Besitz von Genossenschaftsanteilen. Abschließend wurden vier Fragen zum Firmenkundenbetreuer und zur Bank gestellt, wie z.B. Alter und Ausbildung des Firmenkundenbetreuers oder Marktumfeld der Bank. ${ }^{1099}$ Ein Überblick über die verschiedenen Fragenbereiche, die Reihenfolge derselben sowie die Anzahl der jeweils enthaltenen Fragen kann Tab. B-1 entnommen werden.

\begin{tabular}{|l|l|r|}
\hline & Fragenbereich & Anzahl Fragen \\
\hline 1 a & Unternehmensdaten & 12 \\
\hline 1 b & Vertrauen und Commitment (organisationale Ebene) & 11 \\
\hline 2 & Daten zum Kreditvertrag & 8 \\
\hline 3 & Daten zur Produktnutzung des Kunden & 9 \\
\hline 4 & $\begin{array}{l}\text { Geschäftsbeziehung } \\
\text { Vertrauen und Commitment (personale Ebene) }\end{array}$ & 14 \\
\hline 5 & Daten zur Bank und zum Firmenkundenbetreuer & 4 \\
\hline
\end{tabular}

Tab. B-1: Reihenfolge der Fragenbereiche inkl. jeweilige Anzahl Fragen im Fragebogen

Die Rückgabe der Fragebögen erfolgte anonym und auf postalischem Wege. In den ausgefüllten Fragebögen waren zwecks Identifikation die Bezeichnung des Instituts sowie eine laufende Nummer des Fragebogens enthalten, so dass ein Rückschluss weder auf den Firmenkundenbetreuer noch auf den einzelnen Kunden möglich war. Die Rücklaufquote innerhalb der einzelnen Institute liegt zwischen $60,00 \%$ und $100 \%$,

1099 Eine vollständige Abbildung des Fragebogens findet sich im Anhang 1, Abb. AN 1-4.

1100 In dem Fragebogen tauchten die Begriffe Vertrauen und Commitment nicht auf. Die in kursiv dargestellten Bereiche bzw. Bezeichnungen wurden in der obigen Tabelle mit aufgenommen, um den Zusammenhang zu den Konstrukten herzustellen. Die organisationale Ebene der Konstrukte wurde in den Fragenbereich „Unternehmensdaten“ integriert und die personale Ebene wurde in einem eigenständigen Fragenbereich „Geschäftsbeziehung" abgebildet. 
während der Gesamtdurchschnitt $82,37 \%$ beträgt. Insgesamt wurde ein Rücklauf von 229 Fragebögen erzielt (vgl. Tab. B-2). ${ }^{1101}$

\begin{tabular}{|r|r|r|r|}
\hline $\begin{array}{r}\text { Instituts- } \\
\text { nummer }\end{array}$ & $\begin{array}{r}\text { Ausgeteilte } \\
\text { Fragebögen }\end{array}$ & Rückläufe & Rücklaufquote \\
\hline 1 & 25 & 19 & $76,00 \%$ \\
\hline 2 & 12 & 11 & $91,67 \%$ \\
\hline 3 & 15 & 14 & $93,33 \%$ \\
\hline 4 & 15 & 9 & $60,00 \%$ \\
\hline 5 & 18 & 18 & $100,00 \%$ \\
\hline 6 & 5 & 5 & $100,00 \%$ \\
\hline 7 & 17 & 17 & $100,00 \%$ \\
\hline 8 & 11 & 11 & $100,00 \%$ \\
\hline 9 & 17 & 11 & $64,71 \%$ \\
\hline 10 & 18 & 15 & $83,33 \%$ \\
\hline 11 & 15 & 9 & $60,00 \%$ \\
\hline 12 & 44 & 34 & $77,27 \%$ \\
\hline 13 & 14 & 13 & $92,86 \%$ \\
\hline 14 & 20 & 18 & $90,00 \%$ \\
\hline 15 & 32 & 25 & $78,13 \%$ \\
\hline Gesamt & 278 & $\mathbf{2 2 9}$ & $\mathbf{8 2 , 3 7 \%}$ \\
\hline
\end{tabular}

Tab. B-2: Rücklaufquoten je Institut und gesamt

\subsubsection{Beschreibung des Datensatzes}

An der Datenerhebung haben ausschließlich Banken aus den Postleitregionen 2, 3, 4 und 5 teilgenommen. Dies umfasst die Bundesländer Nordrhein-Westfalen, Niedersachsen, Schleswig-Holstein und Bremen. Die Bilanzsumme der 15 teilnehmenden Banken beträgt zwischen 260 Mio. EUR und 4.046 Mio. EUR ${ }^{1102}$, wobei die durchschnittliche Bilanzsumme von 920,6 Mio. EUR deutlich über dem bundesweiten Durchschnitt von 513,1 Mio. EUR liegt. ${ }^{1103} 32,8 \%$ der Firmenkundenbetreuer haben das Umfeld ihrer Bank als „eher ländlich“, 18,8\% als „eher städtisch“ und die verbleibenden $48,5 \%$ als ,sowohl städtisch als auch ländlich“ eingestuft.

Ausgehend von den 229 zurückgesandten Fragebögen wurde ein Fragebogen eliminiert, weil mehr als die Hälfte der Fragen nicht beantwortet war. Hier erfolgte der Ausschluss, da ansonsten die Gefahr einer Verzerrung der Ergebnisse durch einen zu hohen Anteil imputierter Werte bestand. Ferner wurden die Fragebögen ausgeschlossen, die den Kriterien hinsichtlich des dargelegten Mittelstandsverständnisses nicht

\footnotetext{
1101 Bei diesen Quoten wurden nur solche Fragebögen berücksichtigt, die auch tatsächlich ausgefüllt worden sind. Beispielsweise wurden einige Fragebögen unbeantwortet zurückgeschickt, da der Kunde die Bank mittlerweile gewechselt hatte.

1102 Datengrundlage war der Jahresabschluss 2007.

1103 Eigene Berechnung basierend auf BVR $(2007 \mathrm{c})$.
} 
gerecht wurden. So wurden neun Fragebögen ausgeschlossen, weil sich mehr als 25\% des Kapitals dieser Unternehmen im Besitz eines anderen Unternehmens befand. ${ }^{1104}$ Ferner wurden drei weitere Fragebögen ausgeschlossen, da die maximale Mitarbeiterzahl von 500 überschritten worden ist. ${ }^{1105}$ Somit erfüllten 217 Unternehmen die Kriterien hinsichtlich des maximalen Umsatzes von 50 Mio. EUR, einer Mitarbeiterzahl von maximal 500 Mitarbeitern sowie der geforderten Eigentümerstruktur.

Die regionale Verteilung der Unternehmen ergibt sich im Wesentlichen aus dem Sitz der Bank. 67,74\% der teilnehmenden Unternehmen haben ihren Sitz in NordrheinWestfalen, dies entspricht ungefähr dem Anteil der Datensätze, die bei Banken in Nordrhein-Westfalen erhoben wurde (67,28\%). Wie in Tab. B-3 ersichtlich haben einige Unternehmen den Sitz auch in anderen Bundesländern als die betreuende Bank.

\begin{tabular}{|l|r|r|}
\hline Bundesland & Sitz der Bank & Sitz des Unternehmen \\
\hline Bremen & $7,83 \%$ & $7,37 \%$ \\
\hline Hessen & --- & $0,46 \%$ \\
\hline Niedersachsen & $15,21 \%$ & $11,52 \%$ \\
\hline Nordrhein-Westfalen & $67,28 \%$ & $67,74 \%$ \\
\hline Sachsen & --- & $0,46 \%$ \\
\hline Sachsen-Anhalt & --- & $2,30 \%$ \\
\hline Schleswig-Holstein & $9,68 \%$ & $9,68 \%$ \\
\hline Thüringen & --- & $0,46 \%$ \\
\hline & $100,00 \%$ & $100,00 \%$ \\
\hline
\end{tabular}

Tab. B-3: Verteilung der Fragebögen nach Bundesländern

Aus Tab. B-4 ist zu entnehmen, dass mit $60,83 \%$ der überwiegende Teil der betrachteten Unternehmen in der Rechtsform der $\mathrm{GmbH}$ firmiert. Es zeigt sich eine signifikante Abweichung von der bundesweiten Statistik zugunsten von Kapitalgesellschaften. Diese ergibt sich unter anderem aus dem Umstand, dass in der Untersuchung nur geratete Unternehmen berücksichtigt wurden und zum gegenwärtigen Umsetzungsstand der bankinternen Unternehmensratings im genossenschaftlichen Sektor tendenziell eher größere Unternehmen geratet werden. Das in der Untersuchung zugrunde gelegte Ratingverfahren für mittelständische Unternehmen findet erst bei Unternehmen mit einem Umsatz von mindestens 260 Tsd. EUR Anwendung. Bei größeren Unternehmen finden Kapitalgesellschaften eine stärkere Verbreitung, da die Haftung auf das Gesell-

1104 Der Ausschluss von Tochterunternehmen erfolgt zum einen aufgrund der in Kapitel A.2.1.1.3 abgeleiteten Mittelstandsdefinition. Zum anderen erscheint es sinnvoll, derartige Unternehmen auszuschließen, da die Besonderheiten dieser Unternehmen zu einer Verfälschung der Aussagen führen können. Im Insolvenzfall werden die Verbindlichkeiten auf das Mutterunternehmen transferiert, so dass diese Unternehmen geringe echte Insolvenzraten haben. Häufig wird stattdessen eine freiwillige Auflösung vorgenommen. Vgl. hierzu auch Harhoff/Körting (1998a), S. 9.

1105 Im Rahmen der Kundenauswahl wurde bereits anhand systemseitiger Daten geprüft, inwiefern die Kriterien hinsichtlich Umsatz und Mitarbeiterzahl bei den ausgewählten Kunden erfüllt sind. $\mathrm{Zu}$ weiteren Ausschlüssen ist es deshalb gekommen, weil die Daten hinsichtlich der Mitarbeiterzahlen durch die Fragebogenausfüllenden aktualisiert worden sind. 
schaftsvermögen bzw. für den Gesellschafter auf seine Beteiligung beschränkt ist. ${ }^{1106}$ Aus diesem Grund ist der Anteil an Kapitalgesellschaften in der vorliegenden Studie höher als im bundesweiten Durchschnitt, der auch die kleineren Unternehmen berücksichtigt. Die Vorgaben hinsichtlich der Existenz des Ratings haben in Konsequenz dazu geführt, dass Kapitalgesellschaften überrepräsentiert sind. Insgesamt handelt es sich bei $61,29 \%$ der Unternehmen um Kapitalgesellschaften und bei $83,41 \%$ der Unternehmen liegt keine unbeschränkte Haftung durch natürliche Personen vor. ${ }^{1107}$

\begin{tabular}{|c|c|c|c|}
\hline Rechtsform & Häufigkeit & Prozent & $\begin{array}{l}\text { Deutschland } \\
\text { gesamt }^{1108}\end{array}$ \\
\hline Genossenschaft & 1 & $0,46 \%$ & $0,17 \%$ \\
\hline $\mathrm{GmbH}$ & 132 & $60,83 \%$ & $14,68 \%$ \\
\hline $\mathrm{AG}$ & 0 & $0,00 \%$ & $0,24 \%$ \\
\hline GmbH \& Co. KG ${ }^{1109}$ & 48 & $22,12 \%$ & $4,11 \%$ \\
\hline Einzelunternehmen $^{1110}$ & 25 & $11,52 \%$ & $70,33 \%$ \\
\hline OHG & 5 & $2,30 \%$ & $8,47 \%$ \\
\hline$K G^{1111}$ & 6 & $2,76 \%$ & -- \\
\hline Sonstige & -- & $-\cdots$ & $2,00 \%$ \\
\hline Gesamt & 217 & $100,00 \%$ & $100,00 \%$ \\
\hline
\end{tabular}

Tab. B-4: Verteilung der Rechtsformen

Hinsichtlich der Verteilung nach Branchen muss festgestellt werden, dass die Dienstleistungsunternehmen in der vorliegenden Studie im Vergleich zum bundesweiten Durchschnitt deutlich unterrepräsentiert sind (vgl. Tab. B-5). Ursächlich hierfür ist unter anderem die Beschränkung auf bestimmte Größenklassen, so dass Branchen, die tendenziell wenig Umsatz erzielen, z.T. komplett ausgeschlossen werden. ${ }^{1112}$

1106 Vgl. Flacke (2007), S. 119.

1107 Bei der GmbH \& Co. KG handelt es sich um eine Sonderform der Kommanditgesellschaft (KG) und somit um eine Personengesellschaft. Während bei einer typischen Kommanditgesellschaft der persönlich haftende Gesellschafter (Komplementär) eine natürliche Person ist, ist dies bei der $\mathrm{GmbH} \& \mathrm{Co}$. KG eine Gesellschaft mit beschränkter Haftung (GmbH). Intention dieser gesellschaftsrechtlichen Konstruktion ist es, Haftungsrisiken für die hinter der Gesellschaft stehenden Personen auszuschließen oder zu reduzieren. Keine unbeschränkte Haftung einer natürlichen Person liegt bei der Genossenschaft, derm GmbH, der AG und der GmbH \& Co. KG vor. Vgl. Statistisches Bundesamt (2007b).

In den Daten des statistischen Bundesamtes werden die GmbH \& Co. KG sowie die KG gemeinsam ausgewiesen. Vgl. Statistisches Bundesamt (2007b).

In dem erhobenen Datensatz werden unter den Einzelunternehmen auch Freiberufler und Gewerbetreibende subsumiert.

In den Daten des statistischen Bundesamtes werden GmbH \& Co. KG sowie KG gemeinsam ausgewiesen.

Grundlage für die Einteilung der Branchen ist der WZ2003-Schlüssel des statistischen Bundesamtes. Vgl. Statistisches Bundesamt (2007c). Relevant ist lediglich die Anzahl der Unternehmen, es erfolgt keine Gewichtung nach Umsatz o.ä. Die Zuordnung zu den Branchen ist wie folgt: Produktion: Verarbeitenden Gewerbes (D); Handel: (G) - Handel; Instandhaltung und Reparatur von Kraftfahrzeugen und Gebrauchsgütern; Dienstleistung: 63300 Reisebüros und Reiseveranstalter, 64000 Nachrichtenübermittlung, (H) Gastgewerbe, (J) Kredit- und Versiche- 


\begin{tabular}{|l|r|r|r|r|}
\hline Branche & Hăufigkeit & \multicolumn{1}{c|}{ Anteil } & NRW $^{113}$ & Deutschland $^{114}$ \\
\hline Produktion & 57 & $26,27 \%$ & $12,37 \%$ & $8,54 \%$ \\
\hline Handel & 58 & $26,73 \%$ & $29,34 \%$ & $21,56 \%$ \\
\hline Dienstleistung & 35 & $16,13 \%$ & $49,83 \%$ & $58,08 \%$ \\
\hline Baugewerbe & 50 & $23,04 \%$ & $5,42 \%$ & $10,00 \%$ \\
\hline Sonstiges & 17 & $7,83 \%$ & $3,04 \%$ & $1,83 \%$ \\
\hline Gesamt & 217 & $100,00 \%$ & $100,00 \%$ & $100,00 \%$ \\
\hline
\end{tabular}

Tab. B-5: Verteilung der Branchen

Die Unternehmen der Stichprobe verfügen über durchschnittlich 32,06 Mitarbeiter (Median: 20,00, Standardabweichung: 37,73), erwirtschaften durchschnittlich einen Umsatz von 5.212,82 Tsd. EUR (Median: $2.463,00$ Tsd. EUR, Standardabweichung: $6.927,36)$ und weisen im Durchschnitt eine Bilanzsumme von $2.480,25$ Tsd. EUR aus (Median: 1.289,00 Tsd. EUR, Standardabweichung: 3.979,29 Tsd. EUR) (vgl. Tab. B6).

\begin{tabular}{|l|r|r|r|r|r|}
\hline & \multicolumn{1}{|c|}{ Mittelwert } & \multicolumn{1}{c|}{ Median } & $\begin{array}{c}\text { Standard- } \\
\text { abweichung }\end{array}$ & \multicolumn{1}{c|}{ Minimum } & \multicolumn{1}{c|}{ Maximum } \\
\hline Mitarbeiter (Anzahl) & 32,06 & 20,00 & 37,73 & 1 & 300 \\
\hline Umsatz (TEUR) & $5.212,82$ & $2.463,00$ & $6.927,36$ & 18,75 & $45.000,00$ \\
\hline Bilanzsumme (TEUR) & $2.480,25$ & $1.289,00$ & $3.979,29$ & 0,20 & $37.041,10$ \\
\hline
\end{tabular}

Tab. B-6: Unternehmensgrößen

Der Großteil der untersuchten Unternehmen hat eine Mitarbeiterzahl von 10-25 Mitarbeitern, mehr als $60 \%$ der Unternehmen haben weniger als 25 Mitarbeiter (vgl. Tab. B7).

\begin{tabular}{|l|r|r|r|r|r|}
\hline & $\mathbf{0 - 1 0}$ MA & $>\mathbf{1 0 - 2 5}$ MA & $>\mathbf{2 5 - 5 0}$ MA & $>\mathbf{5 0}$ MA & \multicolumn{1}{c|}{ Gesamt } \\
\hline Anzahl Unternehmen & 40 & 93 & 56 & 28 & 217 \\
\hline Anteil in \% & $18,43 \%$ & $42,86 \%$ & $25,81 \%$ & $12,90 \%$ & $100,00 \%$ \\
\hline Arithmetisches Mittel & 8,25 & 16,77 & 36,82 & 101,93 & 32,06 \\
\hline
\end{tabular}

Tab. B-7: Gruppierung der Unternehmen nach Mitarbeiterzahlen

Nachstehend wird die Vergleichbarkeit der befragten Unternehmen hinsichtlich der Größe mit bereits existierenden, im Verlaufe der Arbeit häufig zitierten Studien untersucht. In der Studie von DEGRYSE/VAN CAYSEELE sind $81 \%$ Unternehmen mit genau

rungsgewerbe, $(\mathrm{K})$ Grundstücks- und Wohnungswesen, Vermietung beweglicher Sachen, Erbringung von wirtschaftlichen Dienstleistungen, anderweitig nicht genannt, (N) Gesundheits-, Veterinär- und Sozialwesen, (O) Erbringung von sonstigen öffentlichen und persönlichen Dienstleistungen; Baugewerbe: (F) Baugewerbe; Sonstige: (I) - Verkehr und Nachrichtenübermittlung exkl. 63300 Reisebüros und Reiseveranstalter, 64000 Nachrichtenübermittlung, (A) Land- und Forstwirtschaft.

1113 Eigene Berechnungen. Als Datenbasis diente die Landesdatenbank NRW. Vgl. Landesdatenbank NRW (2007).

1114 Vgl. Statistisches Bundesamt (2007a). 
einem Mitarbeiter enthalten, $17 \%$ Unternehmen mit weniger als 10 Mitarbeitern und einem Umsatz von weniger als 250 Mio. BEF (6,2 Mio. EUR) ${ }^{1115}, 1 \%$ Unternehmen mit mindestens 10 Mitarbeitern oder einem Umsatz mindestens als 250 Mio. BEF und weniger als 1 Mrd. BEF (161 Mio. EUR), sowie 1\% Unternehmen mit mehr als 1 Bio. BEF (161 Mio. EUR). ${ }^{1116}$ In der Datengrundlage von ANGELINI/DI SALVO/FERRI beträgt die durchschnittliche Mitarbeiterzahl 10,3 Personen und der durchschnittliche Umsatz 3,3 Mrd. Lira (1,7 Mio. EUR) ${ }^{1117}$. $^{118}$ In der Studie von BERGER/UdELL hatten $80 \%$ der Unternehmen weniger als 50 Mitarbeiter, 10\% 51-100 Mitarbeiter und 10\% 101-500 Mitarbeiter. ${ }^{119}$ Die durchschnittliche Bilanzsumme beträgt 2,3 Mio. USDollar (2,4 Mio. EUR) ${ }^{1120}$. Auch bei PETERSEN/RAJAN sind nur Firmen mit weniger als 500 Mitarbeitern enthalten. ${ }^{1121}$ Die durchschnittliche Bilanzsumme (Median) beträgt 130 Mio. US-Dollar (133 Mio. EUR) und der durchschnittlicher Umsatz (Median) 300 Mio. US-Dollar (307 Mio. EUR). Ebenso in der Studie von HARHOFF/KÖRTING werden nur Unternehmen mit maximal 500 Mitarbeitern berücksichtigt, die durchschnittliche Mitarbeiterzahl beträgt 41,49 bei einem Median von 10 Mitarbeiter. $80 \%$ der Unternehmen haben weniger als 50 Mitarbeiter. ${ }^{1122}$ In der Studie von MACHAUER/WEBER sowie in der Studie von ELSAS/KRAHNEN sind Unternehmen mit einem Umsatz von 50 bis 500 Mio. DM (25,56 - 255,64 Mio. EUR) Umsatz enthalten. ${ }^{1123}$

Sofern in den Studien eine Obergrenze für die Mitarbeiterzahlen angegeben war, beträgt selbige stets $500 \mathrm{MA}$. Die Unternehmen in der Datenbasis der vorliegenden Studie entsprechen ungefähr der Größe der Unternehmen in den meisten zuvor genannten Studien, so dass diesbezüglich eine Vergleichbarkeit angenommen werden kann. ${ }^{1124}$

i115 Umrechnungskurs: BEF/EUR= 40,3399. Vgl. EZB (1998), Absatz 1.

1116 Vgl. Degryse/Van Cayseele (1998), S. 13 f.

1117 Umrechnungskurs: ITL/EUR=1.936,27. Vgl. EZB (1998), Absatz 1.

1118 Vgl. Angelini/Di Salvo/Ferri (1998), S. 935.

1119 Vgl. Berger/Udell (1995), S. 356.

1120 Um eine Vergleichbarkeit zu gewährleisten, wurde wie bei Elsas ein Umrechnungskurs von DM/US-Dollar=2,0 angenommen. Vgl. Elsas (2001), S. 195. Bei der Umrechnung in EUR wurde der Umrechnungskurs DM/EUR=1,95583 herangezogen. Vgl. EZB (1998), Absatz 1.

1121 Vgl. Petersen/Rajan (1994), S. 7.

1122 Vgl. Harhoff/Körting (1998a), S. 33.

1123 Vgl. Machauer/Weber (1998), S. 1361, Elsas/Krahnen (1998), S. 1285.

1124 Die Unternehmen in den Studien von Angelini/Di Salvo Ferri und Degryse/Van Cayseele sind eher etwas kleiner, Unternehmen in den Studien von Machauer/Weber, Elsas/Krahnen und Petersen/Rajan sind eher etwas größer, die Unternehmen in den anderen Studien sind ungefähr genauso groß. 


\begin{tabular}{|c|c|c|c|c|c|c|c|c|}
\hline & $\begin{array}{c}\text { Angelini/Di } \\
\text { Salvo/Ferri } \\
\text { (1998) }\end{array}$ & $\begin{array}{l}\text { Berger/ } \\
\text { Udell } \\
\text { (1995) } \\
\end{array}$ & $\begin{array}{l}\text { Degryse/ } \\
\text { Van Cay- } \\
\text { seele (1998) }\end{array}$ & $\begin{array}{c}\text { Elsas/ } \\
\text { Krahnen } \\
(1998)\end{array}$ & $\begin{array}{c}\text { Harheff/ } \\
\text { Körting } \\
\text { (1998) }\end{array}$ & $\begin{array}{l}\text { Machauer/ } \\
\text { Weber } \\
\text { (1998) }\end{array}$ & $\begin{array}{l}\text { Petersen/ } \\
\text { Rajan } \\
\text { (1994) }\end{array}$ & $\begin{array}{l}\text { Vorliegende } \\
\text { Studie }\end{array}$ \\
\hline Land & Italien & USA & Belgien & Deutschland & $\begin{array}{l}\text { Deutsch- } \\
\text { land }\end{array}$ & $\begin{array}{l}\text { Deutsch- } \\
\text { land }\end{array}$ & USA & Deutschland \\
\hline $\begin{array}{l}\text { Mitarbei- } \\
\text { terzahl }\end{array}$ & Ø 10,3 & $<500$ & $\cdots$ & $\cdots$ & $\begin{array}{c}<500 ; \\
\emptyset 41,49 \\
(10)\end{array}$ & $\cdots$ & $<500$ & $\begin{array}{c}<500 ; \\
\text { ஏ } 32,06(20)\end{array}$ \\
\hline Umsatz & $\begin{array}{l}\text { 1,7 Mio. } \\
\text { EUR }\end{array}$ & $\cdots$ & $\begin{array}{c}98 \% \text { der } \\
\text { Unternehmen: } \\
<6,2 \text { Mio. } \\
\text { EUR }\end{array}$ & $\begin{array}{c}25,56 \text { - } \\
255,64 \text { Mio. } \\
\text { EUR }\end{array}$ & - & $\begin{array}{c}25,56- \\
255,64 \\
\text { Mio. EUR }\end{array}$ & $\begin{array}{c}-;(307 \\
\text { Mio. EUR) }\end{array}$ & $\begin{array}{c}5,2 \text { Mio. } \\
\text { EUR ( } 2,4 \\
\text { Mio. EUR) }\end{array}$ \\
\hline $\begin{array}{l}\text { Bilanz - } \\
\text { summe }\end{array}$ & $\cdots$ & $\begin{array}{l}\text { 2,3 Mio. } \\
\text { US-Dollar } \\
\text { (2,4 Mio. } \\
\text { EUR) }\end{array}$ & $\cdots$ & $\cdots$ & $\cdots$ & $\cdots$ & $\begin{array}{c}--;(130 \\
\text { Mio. US- } \\
\text { Dollar (133 } \\
\text { Mio. EUR)) }\end{array}$ & $\begin{array}{l}2,4 \text { Mio. } \\
\text { EUR (1,2 } \\
\text { Mio. EUR) }\end{array}$ \\
\hline
\end{tabular}

Tab. B-8: Unternehmensgrößen in den vergleichbaren Studien ${ }^{1125}$

Nach Abschluss der Datenerhebung wird üblicherweise eine so genannte Datenaufbereitung durchgeführt, die aus der Erfassung, Prüfung und Bereinigung der Daten besteht. ${ }^{1126}$ Bevor die Daten in den weiteren Auswertungen verarbeitet werden können, erfolgt zunächst eine Analyse, inwiefern aufgrund der Form der Datenerhebung die Gefahr von Antwortverfälschungen existiert sowie in welchem Umfang Daten fehlen und somit Bereinigungen vorzunehmen sind.

\subsubsection{Analyse der Gefahren von Antwortverfälschungen}

Im ersten Schritt erfolgt eine Prüfung der Datenqualität. Aufgrund der Verwendung von Fragebögen resultiert die Gefahr von Testverfälschungen. ${ }^{1127}$ Sofern möglich wurde bereits bei der Fragebogenkonstruktion diese Gefahr durch die entsprechenden, im Folgenden auch beschriebenen Gegenmaßnahmen eliminiert bzw. reduziert. Im Wesentlichen sind hier die nachstehenden Effekte bzw. Gefahren zu nennen:

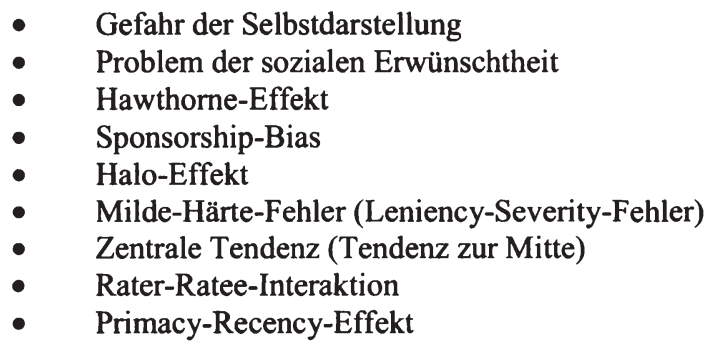

Es ist zunächst die Gefahr der Selbstdarstellung zu erwähnen. ${ }^{1128}$ Der Befragungsteilnehmer stellt beim Nachdenken zwecks Beantwortung des Fragebogens fest, dass eigene Erlebens- oder Verhaltensweisen widersprüchlich, unvernünftig oder unakzep-

1125 Eigene Darstellung. Sofern in den einzelnen Studien angegeben, wird jeweils das arithmetische Mittel und in Klammern der Median ausgewiesen.

1126 Vgl. Bankhofer (1995), S. 6, Pepels (1995), S. $371 \mathrm{f}$.

1127 Vgl. Bortz/Döring (2006), S. $231 \mathrm{ff}$.

1128 Vgl. Bortz/Döring (2006), S. $231 \mathrm{ff}$. 
tabel sind und beantwortet die Fragen somit gemäß seiner Wunschvorstellung. Dieses Verhalten dient z.T. der Fremd- oder Selbsttäuschung und könnte sich z.B. darin bemerkbar machen, dass der Firmenkundenbetreuer eine größere Anzahl an jährlichen Beratungsgesprächen angibt, als sie den Tatsachen entspricht, oder dass der Firmenkundenbetreuer gerne eine freundschaftliche Beziehung zum Firmenkunden hätte und deswegen eine Frage nach der Existenz der freundschaftlichen Beziehung im Fragebogen bejaht.

Das Problem der sozialen Erwünschtheit resultiert aus dem Bemühen dem Interviewer zu gefallen, wobei dies auch eine Form der Selbstdarstellung ist. ${ }^{1129}$ Diese Gefahr ist im Rahmen der vorliegenden Studie deswegen evident, weil die Datenerhebung durch Mitarbeiter der BMS Consulting GmbH erfolgt. Bei den Banken handelt es sich ausnahmslos um Kunden der BMS Consulting $\mathrm{GmbH}$, so dass teilweise bereits Projekte mit den Banken durchgeführt worden sind. Ziel ist es zu vermeiden, dass die Firmenkundenbetreuer die Antworten derart geben, dass sie die vermuteten Zusammenhänge bewusst bestätigen, um dem datenerhebenden Mitarbeiter bzw. der BMS Consulting $\mathrm{GmbH}$ einen Gefallen zu tun. Aus diesem Grund ist den Fragebogenteilnehmern das Ziel der Untersuchung nicht im Detail kommuniziert worden. ${ }^{130}$

Schließlich wirkt der Hawthorne-Effekt. ${ }^{1131}$ Dieser besagt, dass allein das Bewusstsein, Teilnehmer einer Untersuchung zu sein, Auswirkungen auf die Reaktion und das Antwortverhalten des Befragten hat. Ferner spielt eine geringe Bereitschaft zur Selbstenthüllung - Self Disclosure - eine Rolle, ${ }^{1132}$ denn der Befragte möchte möglicherweise ein von Bankvorgaben abweichendes Verhalten nicht aufdecken. Wenn die Betreuungskonzeption der Bank bspw. drei Beratungsgespräche jährlich festlegt, so wird es einem Firmenkundenbetreuer schwer fallen eine geringere Anzahl anzugeben, wenn er befürchten muss, dass die Antworten zu ihm zurückverfolgt werden könnten. Dies geht einher mit der Antizipation negativer Konsequenzen bei bestimmten Antworten, z.B. weil ein derartiges Verhalten vom Vorgesetzten nicht positiv beurteilt wird. Aus diesem Grund erfolgte die Rückgabe der Fragebögen nicht über den Vorgesetzten, sondern in der Regel unmittelbar an den Befragungsdurchführenden.

Des Weiteren ist der Sponsorship-Bias zu erwähnen, das heißt konkrete Vermutungen über den Auftraggeber bzw. seine Untersuchungsziele beeinflussen das Antwortverhalten. Problematisch bei derartigen Antwortverfälschungen ist es, dass die wahren Merkmalsausprägungen in der Regel unbekannt sind, weshalb es nicht so einfach möglich ist, die Urteilsfehler zu identifizieren. Insgesamt kann aber aufgrund der vorgenommenen Maßnahmen, d.h. direkte Rückgabe der Fragebögen sowie fehlende Kommunikation des konkreten Untersuchungsziels, von geringen Testverfälschungen ausgegangen werden.

\footnotetext{
1129 Vgl. Bortz/Döring (2006), S. 231 ff.

1130 Vgl. hierzu auch Kapitel B.1.1. Das Anschreiben zum Ausfüllen des Fragebogens ist im Anhang 1, Abb. AN 1-2 dargestellt.

1131 Vgl. Bortz/Döring (2006), S. $231 \mathrm{ff}$.

1132 Vgl. Bortz/Döring (2006), S. $231 \mathrm{ff}$. 
Neben diesem allgemeinen Problem der Antwortverfälschungen können zusätzliche Probleme bei bestimmten Fragentypen auftreten. So können bei Ratingskalen die abgegebenen Urteile durch systematische Urteilsfehler eingeschränkt werden. Nachfolgend werden kurz die wichtigsten Urteilsfehler dargestellt. ${ }^{1133}$ Unter dem Halo-Effekt versteht man die Tendenz, die Beurteilung mehrerer Merkmale eines Objektes von einem globalen Pauschalurteil abhängig zu machen, die Unfähigkeit oder mangelnde Bereitschaft des Urteilers auf unterschiedliche Ausprägungen verschiedener Merkmale zu achten, oder die Tendenz eines Urteilers, ein Objekt bezüglich verschiedener Merkmale gleich einzustufen. ${ }^{134}$ So könnte eine gute Ratingklasse des betrachteten Kunden den Beantwortenden dazu verleiten, die Fragen zur Beurteilung der Geschäftsbeziehung tendenziell positiver zu beantworten als bei einem Kunden mit einer schlechten Ratingklasse. Sofern möglich wurden u.a. aus diesem Grund die Jahresabschlusskennzahlen und Ratinginformationen dem Firmenkundenbetreuer nicht explizit vorgelegt, sondern in einem separaten Datenerhebungsbogen erfasst.

Unter dem Milde-Härte-Fehler (Leniency-Severity-Fehler) versteht man den Effekt, dass die Einstufungen mehrerer Merkmale systematisch zu negativ oder positiv ausfallen. Dieser Effekt erscheint häufig im Zusammenhang mit Personenbeurteilungen. ${ }^{1135}$ Der Effekt der Zentralen Tendenz (Tendenz zur Mitte) besagt, dass Urteilsobjekte im mittleren Bereich der Urteilsskala eingestuft und extreme Ausprägungen vermieden werden. Dieser Fehler zeigt sich insbesondere dann, wenn die zu beurteilenden Personen den Urteilern nur wenig bekannt sind. Aufgrund der in dieser Erhebung verwendeten 6-er-Skalierung wurde der Beantwortende zumindest dazu gezwungen, eine Tendenzaussage zu tätigen.

Ferner ist die Rater-Ratee-Interaktion zu beachten. ${ }^{1136}$ Dieser so genannte Ähnlichkeits- oder Kontrastfehler des Urteilers kann bei Personenbeurteilungen in Abhängigkeit von der eigenen Position auf der zu beurteilenden Dimension entstehen. Wenn ein Urteiler mit extremer Merkmalsausprägung diese Merkmalsausprägung bei einer anderen Person beurteilen soll, kann daraus ein Fehler derart resultieren, dass sich der Urteilende in Richtung der eigenen Merkmalsausprägung oder in Richtung auf das gegensätzliche Extrem verschätzt. Ein Firmenkundenbetreuer, der selbst zuverlässig ist und die notwendigen Unterlagen und Informationen dem Kunden immer sehr pünktlich zur Verfügung stellt, wird die Zuverlässigkeit des Firmenkunden anders beurteilen, als ein Firmenkundenbetreuer bei dem dieses Verhalten nicht gegeben ist. Dieser Effekt kann allerdings nur schwer beeinflusst bzw. im Rahmen der Datenerhebung vermieden werden.

Unter dem Primacy-Recency-Effekt versteht man Urteilsverzerrungen, die mit der sequenziellen Position der zu beurteilenden Objekte, insbesondere der Anfangs- und der Endposition, zusammenhängen. Wenn Objekte mit einer extremen Merkmalsausprägung am Beginn beurteilt werden, können die nachfolgenden Beurteilungen von

\footnotetext{
1133 Vgl. Bortz/Döring (2006), S. $183 \mathrm{f}$.

1134 Vgl. Bortz/Döring (2006), S. 183 sowie die hier angegebene Literatur.

1135 Vgl. Bortz/Döring (2006), S. 183.

1136 Vgl. Bortz/Döring (2006), S. 183.
} 
den ersten Beurteilungen derart abhängen, dass bspw. der Kontrast überbetont wird. ${ }^{1137}$ Aus diesem Grund wurden die Fragen, die in Form einer Ratingskala gestellt wurden, in mehrere Blöcke aufgeteilt, so dass die Beeinflussung innerhalb der Fragenbereiche zum Teil entzerrt wurde.

\subsubsection{Behandlung fehlender Werte sowie Datenbereinigung}

Im Rahmen der Datenaufbereitung hat eine Prüfung der fehlenden Werte („Missing Values“) zu erfolgen. So können einige Verfahren wie bspw. die Faktoren- oder Regressionsanalyse im Fall fehlender Werte nicht mehr unmittelbar angewandt werden. ${ }^{1138}$ Bei den Daten, die für diese Studie automatisiert aus den Bankanwendungen erhoben wurden, besteht die Gefahr, dass Daten gegebenenfalls nicht vollständig gepflegt sind oder dass bestimmte Informationen aufgrund von technischen Filtern für einzelne Kundentypen oder für bestimmte Ratingsegmente in der Bankanwendung nicht hinterlegt werden können. ${ }^{1139}$ Ferner wurde im Rahmen der Datenaufbereitung eine Aussonderung nicht auswertbarer Erhebungselemente vorgenommen. ${ }^{1140}$ Eine Aussonderung kann aufgrund falscher oder widersprüchlicher Ausfüllung, Inkonsistenzen in der Beantwortung, Fälschungen oder mangelnder Lesbarkeit erforderlich sein. Das Vorgehen bei der Datenaufbereitung kann der Abb. B-4 entnommen werden.

\footnotetext{
1137 Vgl. Bortz/Döring (2006), S. 184.

1138 Vgl. Bankhofer/Praxmarer (1998), S. 109.

1139 Für das Ratingsegment „Mittelstand“ ist bspw. die Anzahl der Überziehungen von mehr als 90 Tagen keine im Banksystem zu hinterlegende Information. Somit war dieses Feld bei der automatisierten Erhebung stets leer.

1140 Vgl. Pepels (1995), S. $371 \mathrm{f}$.
} 


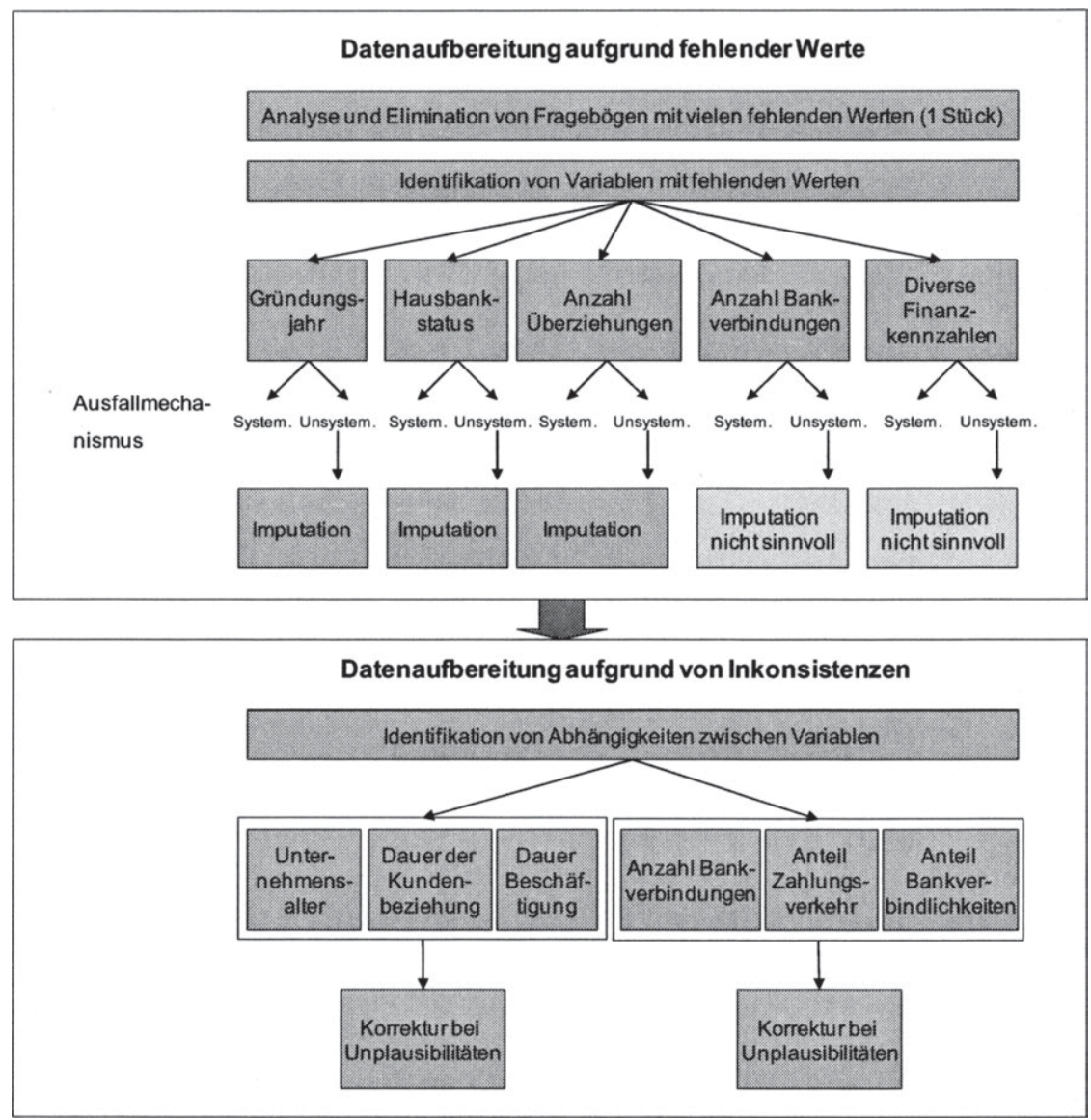

Abb. B-4: Vorgehen bei der Datenaufbereitung ${ }^{1141}$

Hinsichtlich des durch den Firmenkundenbetreuer zu beantwortenden Fragebogens kommen verschiedene Gründe für das Fehlen von Antworten in Frage, z.B. das Übersehen von Fragen, Motivationsprobleme, fehlendes Wissen, eine bewusste Antwortverweigerung, Verständnisprobleme, Meinungslosigkeit, Zeitprobleme oder Filterführung des Befragers. ${ }^{1142}$ Fehlende Werte können zu Auswertungsverfälschungen führen, wenn unbeabsichtigte Konzentrationen fehlender Werte in der Datenmatrix vorhanden sind, d.h. ihre Streuung nicht zufällig bzw. nicht durch fragebogentechnische Besonderheiten wie Filterfragen begründet ist. Es ist zu untersuchen, inwiefern es Probanden

\footnotetext{
1141 Eigene Darstellung.

1142 Vgl. Bankhofer (1995), S. 11.
} 
oder Variablen mit besonders vielen fehlenden Werten gibt. Ein Fragebogen musste eliminiert werden, da der Anteil der nicht beantworteten Fragen zu hoch war. ${ }^{113}$

Anschließend wird geprüft, inwiefern eine Konzentration von fehlenden Werten für eine Variable vorliegt. Die Behandlung fehlender Werte ${ }^{1 / 44}$ in der Literatur kann zum einen durch die Eliminierung jener Fälle, die fehlende Werte für mindestens eine der einbezogenen Variablen aufweisen, erfolgen. Vor dem Hintergrund der Gefährdung der Forderung nach Repräsentativität bei knapp kalkulierten Stichproben wird die Eliminierung fehlender Werte weniger oft verwendet. ${ }^{145}$ Ferner können die bereits vorhandenen Daten mit Hilfe von Imputationsverfahren ${ }^{1146}$ um Schätzungen für die fehlenden Werte ergänzt werden. Hinsichtlich der weiteren Vorgehensweise ist zunächst die Frage nach dem Mechanismus, der zum Fehlen der Daten führt, zu beantworten. Es lassen sich im Wesentlichen zwei Arten von fehlenden Daten unterscheiden: ${ }^{1147}$

- Unsystematisch bzw. zufällig fehlende Daten

- $\quad$ Systematisch bzw. nicht zufällig fehlende Daten

Infolgedessen wird auch zwischen unsystematischen bzw. ignorierbaren und zwischen systematischen bzw. nicht ignorierbaren Ausfallmechanismen differenziert. Die Feststellung, ob die Daten zufällig oder systematisch fehlen, beeinflusst die anschließenden Analyseschritte, deswegen erfolgt hier eine Unterscheidung.

Zufällig bzw. unsystematisch fehlende Daten lassen sich auf Einflussfaktoren zurückführen, die sich nicht eindeutig auf bestimmte Untersuchungseinheiten oder Merkmale fokussieren. Bei dem unsystematischen Ausfallmechanismus lassen sich zwei Fälle unterscheiden, die Daten sind MAR („Missing at random“) oder die Daten sind MCAR („Missing completely at random“). ${ }^{148}$ Die Daten sind dann MAR, wenn das Fehlen zwar unabhängig von der Ausprägung der jeweiligen Daten, allerdings abhängig von anderen vorhandenen Daten ist. Man spricht deshalb auch von einem intervariablen Ausfallmechanismus. ${ }^{1149}$ So könnte bspw. das Fehlen der Einschätzung der Qualität der Geschäftsbeziehung nicht von der Qualität selbst, sondern von dem Alter des Firmenkundenbetreuers abhängen. Die Daten sind MCAR, wenn das Fehlen nicht in Beziehung zu vorhandenen oder fehlenden Daten steht. In Abhängigkeit vom Ausfallmechanismus erfolgt die Datenbereinigung.

1143 Vgl. Kapitel B.1.1.1. Grundlage für diese Datenbereinigung war der Datensatz nach Ausschluss der Fragebögen, die die inhaltlichen Voraussetzungen nicht erfüllten. Vgl. hierzu ebenfalls Kapitel B.1.1.1.

Einen Überblick über die verschiedenen Ursachen fehlender Werte geben Bankhofer/Praxmarer (1998), S. 109.

1145 Vgl. Bankhofer/Praxmarer (1998), S. 110.

1146 Die Begriffe Imputationsverfahren, Ersetzungsverfahren, Ergänzung oder Vervollständigungsverfahren können synonym verwendet werden. Vgl. Bankhofer (1995), S. 104.

1147 Vgl. hier und im Folgenden Bankhofer/Praxmarer (1998), S. 110.

1148 Vgl. Bankhofer/Praxmarer (1998), S. 111.

1149 Vgl. Wagner/Themme/Decker (1998), S. 400. 
Bei einem systematischen Ausfallmechanismus können die fehlenden Daten nur dann adäquat behandelt werden, wenn selbiger bekannt ist. ${ }^{1150}$ Besteht der Grund des Fehlens der Daten bspw. darin, dass eine die Angabe verweigernde Person eine bestimmte Merkmalsausprägung aufweist, so liegt ein systematischer Fehler vor. ${ }^{1151}$ Die Verweigerung einer Antwort kann auch durch die Ausprägung der Antwort selbst bedingt sein (intra-variabler Ausfallmechanismus). ${ }^{1152}$ Dies ist bspw. dann der Fall, wenn der Firmenkundenbetreuer nicht zugeben möchte, dass er weniger Beratungsgespräche je Jahr durchführt als er eigentlich gemäß Vorgaben der Bank durchführen sollte. In Abhängigkeit vom zugrunde liegenden Ausfallmechanismus kommen die entsprechenden Verfahren zur Behandlung der fehlenden Daten zum Einsatz. Einen Überblick über die verschiedenen Verfahren inklusive der Zielsetzung und der Voraussetzungen geben BANKHOFER/PRAXMARER. ${ }^{1153}$

Bei den Imputationsverfahren wird das Datenmaterial durch geeignete Schätzwerte für die fehlenden Daten vervollständigt. Eine Möglichkeit besteht in der Verwendung von Lageparametern als Imputationswert. ${ }^{154}$ In Abhängigkeit vom Skalenniveau werden die fehlenden Werte durch das arithmetische Mittel, den Median oder den Modus ersetzt. ${ }^{1155}$

Vor diesem Hintergrund wurden folgende Ergänzungen durchgeführt. In vier Fällen war das Gründungsjahr des Unternehmens nicht im Banksystem hinterlegt. Diese Daten sind MCAR, denn die Eingabe im Banksystem erfolgt völlig losgelöst von der aktuellen Erhebung und es kann nicht davon ausgegangen werden, dass bei der Erfassung der Daten in der Bankanwendung bewusst auf die Eingabe verzichtet wurde. Aus dem „Gründungsjahr“ wird die Variable „Alter des Unternehmens" ermittelt, das "Gründungsjahr" selbst wird nicht weiter verwendet. Zunächst wurde die Variable „Alter des Unternehmens“ durch das arithmetische Mittel der vorhandenen Daten ersetzt. Um inhaltliche Unplausibilitäten zu vermeiden wurde nachstehend beschriebene Logik eingebaut. In der Untersuchung wurde das Maximum aus den Werten: „Mittelwert des Alters im Datenbestand“, „Dauer, seit der sich der Geschäftsführer im Unternehmen befindet"1156 und „Dauer der Kundenbeziehung mit der Bank“ für das Alter des Unternehmens angesetzt. Die beiden zuletzt beschriebenen Variablen können aus inhaltlichen Gründen nicht größer sein als das wahre Unternehmensalter.

Bei der Frage nach dem Hausbankstatus fehlte in drei Fällen die Antwort. Da die Frage mit „Ja“, „Nein“ oder „Unbekannt“ zu beantworten war, wurden zunächst die Gemeinsamkeiten innerhalb dieser drei Gruppen herausgearbeitet. Als zentrale Merkmale für den Hausbankstatus können der Anteil des Zahlungsverkehrs und der Anteil der

\footnotetext{
1150 Vgl. Bankhofer/Praxmarer (1998), S. 112.

1151 Vgl. Bankhofer/Praxmarer (1998), S. 110.

1152 Vgl. Wagner/Themme/Decker (1998), S. 400.

1153 Vgl. Bankhofer/Praxmarer (1998), S. 113.

1154 Vgl. Bankhofer/Praxmarer (1998), S. 114.

1155 Vgl. Wagner/Themme/Decker (1998), S. 400.
}

1156 Diese Variable wird in der Untersuchung nicht weiter verwendet und wurde nur zu Kontrollzwecken erhoben. 
Bankverbindlichkeiten beim betrachteten Institut herangezogen werden. Wenn die Bankverbindung als Hausbankbeziehung eingestuft wurde, so beträgt das arithmetische Mittel $82 \%$ bzw. 77\%, ansonsten 25\% und 23\%. In zwei Fällen lagen der Anteil Zahlungsverkehr und Anteil der Bankverbindlichkeiten über $80 \%$ somit wurde hier ein Hausbankstatus angenommen. In einem Fall lagen beide Werte unter 30\%, so dass hier ein Nicht-Hausbankstatus unterstellt wurde.

Die Frage nach der „Anzahl der Überziehung von mehr als 90 Tagen“ ist nur für das Ratingsegment „Oberer Mittelstand" relevant und somit fehlt diese automatisiert erhobene Information bei Kunden des Ratingsegments „Mittelstand“. Sofern keine Überziehung von mehr als 60 Tagen vorliegt, muss zwangsläufig die Anzahl der Überziehung von mehr als 90 Tagen ebenfalls Null sein. In den verbleibenden sieben Fällen lagen fünfmal eine und zweimal zwei Überziehungen von mehr als 60 Tagen vor. Es wurde jeweils der Mittelwert für die „Anzahl der Überziehung von mehr als 90 Tagen“ gebildet in der Gruppe der mit ein und zwei Überziehungen von mehr als 60 Tagen. Der Mittelwert wurde dann als Imputationswert verwendet.

Bei der Anzahl der Bankverbindungen existierten ebenfalls fehlende Werte, aufgrund der Bedeutung der Variable erfolgt hier allerdings keine Imputation. So wurden im Teil A der Arbeit bereits an diversen Stellen mögliche Einflussparameter ermittelt, dennoch gibt es nach Ansicht des Autors kein geeignetes Verfahren einen Imputationswert zu ermitteln, ohne die Ergebnisse der weiteren Auswertungen zu verfälschen. Eine Korrektur der fehlenden Werte wurde deshalb nicht vorgenommen.

Einige Finanzkennzahlen lassen sich in Abhängigkeit von der Branche nicht ermitteln. Das Kreditorenziel ${ }^{1157}$ ist bspw. bei Dienstleistungsunternehmen häufig nicht ermittelbar, da dort kein Materialaufwand vorliegt. Gleichermaßen ist die Umschlagshäufigkeit der Vorräte ${ }^{1158}$ für Dienstleistungsunternehmen häufig nicht ermittelbar. Sofern das Unternehmen im Vorjahr keinen Zinsaufwand hatte, da alle Konten auf Guthabenbasis gepflegt waren, beträgt die Kennzahl Zinsdeckung Null. Hier wurde keine Bereinigung der Daten vorgenommen, da dies den Aussagegehalt der Daten verfälschen würde. Weitere fehlende Daten lagen nicht vor. Insgesamt ist das Problem der fehlenden Daten aufgrund der hohen Beantwortungsquote von eher nachrangiger Bedeutung.

Im nächsten Schritt wurde die Datenkonsistenz geprüft. So liegt die Information vor, wann das Unternehmen gegründet wurde, seit wann die Kundenbeziehung besteht und seit wann der Geschäftsführer in dem Unternehmen arbeitet. Wie bereits bei der Ermittlung des Imputationswerts für das Unternehmensalter beschrieben, müssen sachlogisch folgende Bedingungen erfüllt sein:

1157 Das Kreditorenziel wird wie folgt berechnet: Verbindlichkeiten aus Lieferungen und Leistungen zzgl. Wechsel in Relation zum Materialaufwand multipliziert mit 360. Die vollständigen Kennzahlendefinitionen können dem Anhang entnommen werden. Vgl. Anhang 1, Tab. AN 1-1.

1158 Die Umschlagshäufigkeit der Vorräte ist der Quotient aus Umsatz zu Vorräten. Vgl. Anhang 1, Tab. AN 1-1. 
1. Unternehmensalter $\geq$ Dauer der Kundenbeziehung

2. Unternehmensalter $\geq$ Dauer der Beschäftigung des Geschäftsführers im Unternehmen

Sofern eine inhaltliche Diskrepanz vorlag, wurde das Minimum aus den drei Jahreszahlen verwendet. Sofern ausschließlich eine Diskrepanz zwischen Gründungsjahr und dem Jahr der Kundenanlage besteht wurde ferner geprüft, inwiefern die Diskrepanz weniger als zwei Jahre beträgt. In diesem Fall wird angenommen, dass die Bank das Unternehmen ggf. in der Gründungsphase bereits beraten hat, so dass hier nicht mit Sicherheit von einer Diskrepanz ausgegangen werden kann. Ursachen für diese Diskrepanz sind bspw. darin zu sehen, dass in der Bankanwendung ein Rechtsformwechsel als Neugründung interpretiert wird. Ferner besteht ein Interpretationsspielraum hinsichtlich der Dauer der Kundenbeziehung zum Unternehmen, da hier der Begriff des Unternehmens aus Sicht des Kundenbetreuers nicht eindeutig ist. Auch für diesen Fall gilt das bereits erwähnte Problem des Rechtsformwechsels, so dass die Beziehung zum Unternehmen als wirtschaftliches Gebilde länger bestehen kann als die Dauer der Existenz in der aktuellen Rechtsform.

Dieses Problem kann ferner auch ursächlich sein für eine Inkonsistenz zwischen der Dauer der Beziehung zwischen dem befragten Firmenkundenbetreuer und dem Unternehmen. Sachlogisch kann selbige nicht länger sein als die Beziehung zwischen Bank und Kunde, jedoch besteht auch hier die Möglichkeit, dass der Befragte eine andere Interpretation bei der Frage zur Dauer der persönlichen Beziehung zugrunde legt als dies der Fall bei der systemseitig hinterlegten Information zum Beginn der Beziehung zwischen Bank und Kunde war. Hier wurde auf eine Bereinigung verzichtet.

Weitere Inkonsistenzen sind aufgetreten bei der Angabe der Anzahl der Bankverbindungen. Deswegen wurde eine Variable „korrigierte Anzahl Bankverbindungen“ eingefügt. Sofern der Anteil des Zahlungsverkehrs oder der Anteil der Bankverbindlichkeiten bei dem befragten Institut unter 100\% liegt und die Anzahl der Bankverbindungen mit eins angegeben wurde, erfolgte eine Korrektur auf zwei, da ansonsten $100 \%$ der Bankgeschäfte bei dem aktuellen Institut hätten abgewickelt werden müssen. Tendenziell kommt es dadurch eher zu einer Unterschätzung der Anzahl der Bankverbindungen, da die wahre Anzahl nicht bekannt ist. Nach Abschluss der Datenbereinigung wird im nächsten Schritt die deskriptive Auswertung durchgeführt. Zu diesem Zweck erfolgt eine Darstellung der verwendeten Variablen. 


\subsubsection{Beschreibung der in der Studie verwendeten Variablen}

In Teil A der Arbeit wurden die zentralen Einflussgrößen für die Ausgestaltung der Kunde-Bank-Beziehung bzw. in Bezug auf die ökonomischen Parameter Zins, Sicherheitenstellung und Kreditverfügbarkeit erarbeitet. Insbesondere im Rahmen der theoretischen Modelle der Relationship Banking-Theorie sowie bei den Interaktionsansätzen werden in der Regel abstrakte Begriffe oder Konstrukte verwendet, die im nächsten Schritt eine Operationalisierung erfordern. In Abb. B-5 wird zunächst dargestellt, welche Konstrukte aus den rechtlichen Rahmenbedingungen und den theoretischen Modellen abgeleitet werden können.

Als eine Grundlage wurden in Kapitel A.3 zunächst die gesetzlichen Rahmenbedingungen dargestellt. Die MaRisk fordern einen Zusammenhang zwischen der Bonität und den Kreditkonditionen. ${ }^{1159}$ Die theoretischen Modelle aus der Relationship Banking-Forschung - wie in Kapitel A.4.3.1.2, A.4.3.1.3 und A.4.3.1.4 dargestellt - dienen als weiterer Erklärungsansatz für die Ausgestaltung der ökonomischen Parameter. Neben der Bonität des Kunden wurden hier insbesondere der Grad der Informationsasymmetrie und die Marktmacht der Bank als wesentliche Einflussgrößen herausgearbeitet. Da die Macht der Bank auch von der Macht des Unternehmens, bspw. der GröBe des Unternehmens, abhängt, wurde die Macht des Unternehmens separat abgebildet, obwohl in den theoretischen Modellen in der Regel nur der Begriff Marktmacht der Bank verwendet wird. In Kapitel A.4.3.2.2, A.4.3.2.3 und A.4.3.2.4 wurde dargelegt, wie diese beiden zentralen Konstrukte im Rahmen der bestehenden empirischen Relationship Banking-Forschung operationalisiert wurden. Die zentralen und auch in vielen Studien verwendeten Variablen werden in Abb. B-6 dargestellt. HARHOFF/ KÖRTING und LEHMANN/NEUBERGER haben in ihren Studien darüber hinaus die Interaktionsvariable Vertrauen integriert und deren Einfluss auf die Konditionen geprüft, allerdings fehlt es hier an einem ganzheitlichen Modell. Da sich in ihren Studien bereits ein Ansatz zur Verknüpfung der klassischen Relationship Banking-Forschung mit den Interaktionsansätzen findet, erfolgt in der Abb. B-5 ein separater Ausweis ihrer Studie.

Mit Ausnahme der zuletzt genannten Studien fehlt in der traditionellen Relationship Banking-Theorie und somit auch in der empirischen Forschung die Berücksichtigung von verhaltenswissenschaftlichen Elementen. Aus diesem Grund wurden in den Kapiteln A.5.2.2.1 bis Kapitel A.5.2.2.3 das Modell der IMP-GrouP ${ }^{1160}$ sowie das Modell von FORD ${ }^{1161}$ zur Analyse der Geschäftsbeziehung im Allgemeinen und das Modell von SEGBERS ${ }^{1162}$ zur Analyse der Kunde-Bank-Beziehung im Speziellen dargestellt. Als zentrale Größen in allen Modellen stellen sich die Konstrukte Vertrauen und Commitment dar. Ferner spielen in dem Modell der IMP-GrouP die Marktstrukturen als Bestandteil der Makro-Umwelt und das Machtverhältnis als Bestandteil der Atmosphäre der Geschäftsbeziehung eine wichtige Rolle. Zudem sind der soziale Austausch

\footnotetext{
$115 y$ Vgl. zu den Auswirkungen der gesetzlichen Rahmenbedingungen Kapitel A.3.3.

1160 Vgl. Kapitel A.5.2.2.1.

1161 Vgl. Kapitel A.5.2.2.2.

1162 Vgl. Kapitel A.5.2.2.3.
} 
als Element des Interaktionsprozesses sowie die Erfahrung in der Beziehung und die Struktur der Organisation der Bank als Einflussgrößen der Parteien des Interaktionsprozesses in diesem Modell wesentlich.

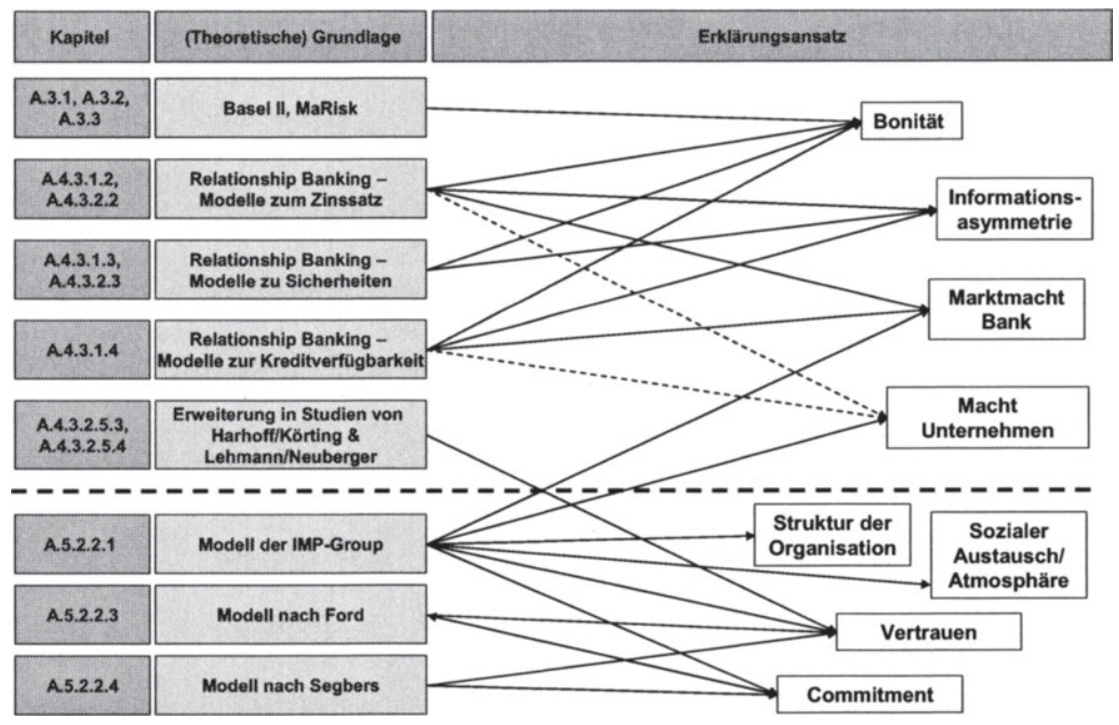

Abb. B-5: Ableitung der Variablenbereiche aus der Theorie

Im nächsten Schritt erfolgt eine erste grobe Operationalisierung der genannten Konstrukte. Grundlage hierfür bildet insbesondere die empirische Relationship BankingForschung sowie die empirische Forschung zu den Konstrukten Vertrauen und Commitment. In Abb. B-6 erfolgt eine Darstellung der zentralen Variablen, die im Rahmen der vorliegenden Studie verwendet werden. Der Aspekt der Quersubventionierung wurde im Vergleich zu Abb. B-5 ergänzt, da dieser Aspekt in den empirischen Studien vermehrt als Erklärung herangezogen wird, allerdings nicht Bestandteil der beschriebenen Modelle ist. ${ }^{1163}$ Die Zuordnung der Variablen zu den einzelnen Bereichen ist nicht überschneidungsfrei. Beispielsweise beeinflusst die Anzahl der Bankverbindungen des Kunden sowohl den Grad der Informationsasymmetrie als auch die Macht der Bank. Die Branche des Unternehmens kann zwar Einflussgröße in Bezug auf die Bonität sein. Möglicherweise ist die Branche aber auch bspw. eine Variable zur Beschreibung der Struktur des Unternehmens. Ferner resultieren aus den einzelnen Bereichen Einflüsse auf andere Bereiche. Aufgrund der theoretischen Ausführungen in Kapitel A.5.2 kann von einer erheblichen Beeinflussung des Grads der Informationsasymmetrie durch die Atmosphäre der Geschäftsbeziehung und das Vertrauen zwi-

1163 Vgl. zur Quersubventionierung in der Empirie Kapitel A.4.3.2.2, A.4.3.2.3 und A.4.3.2.4. Bspw. Petersen/Rajan weisen explizit auf diese Möglichkeit hin. Vgl. Petersen/Rajan (1994), S. 6. 
schen den Beziehungspartner ausgegangen werden. Aus Gründen der Übersichtlichkeit wird darauf verzichtet, die weiteren Interdependenzen darzustellen. Der Fokus der Auswertungen in dieser Studie liegt auf der Integration von Vertrauen und Commitment bzw. den jeweiligen Dimensionen.

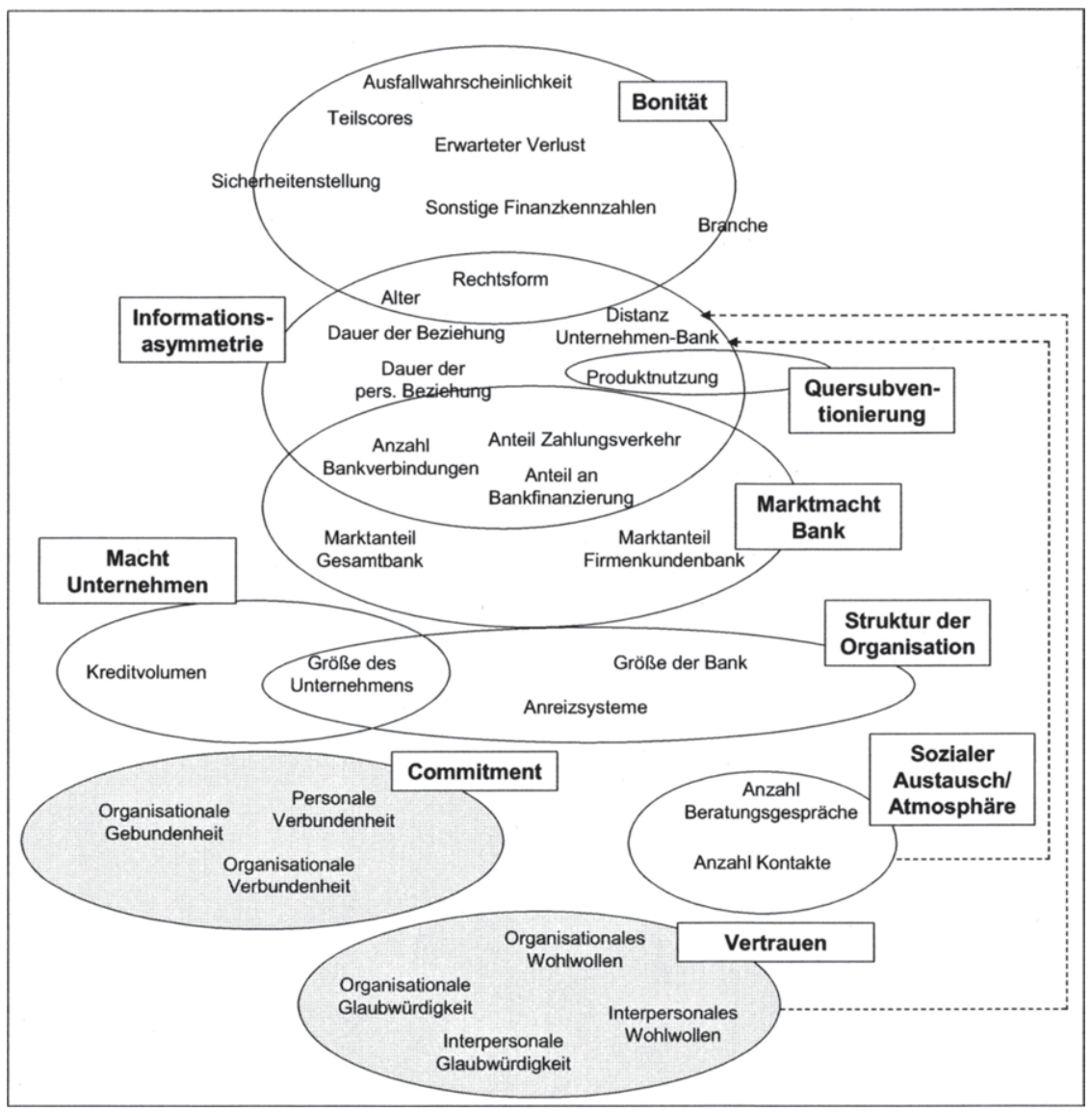

Abb. B-6: Systematisierung der Variablen

Die konkrete Operationalisierung der Variablen wird in den nachstehenden Tabellen dargestellt. Wie zuvor dargelegt ist die Zuordnung zu den verschiedenen Bereichen nicht überschneidungsfrei. Aus diesem Grund wird in den folgenden Tabellen als auch im weiteren Verlauf der Arbeit nachstehende Systematik der Variablen herangezogen: 
- Finanzkennzahlen: im Wesentlichen aus dem Jahresabschluss, den Ratingdaten und dem Ratingergebnis abgeleitete Kennzahlen ${ }^{164}$

- Sonstige unternehmensbezogene Variablen: für alle Marktteilnehmer beobachtbare Größen

- Beziehungsbezogene Variablen: nur für die Inside-Bank beobachtbare Größen

- Verhaltenswissenschaftliche Variablen: die diversen Dimensionen von Vertrauen und Commitment

- Bankbezogene Variablen: Variablen zur Beschreibung der Bankstruktur bzw. der Mitarbeiterstruktur

\begin{tabular}{|c|c|}
\hline Variablenbezeichnung & Definition \\
\hline $\begin{array}{l}\text { VERB_KI_LANG_R } \\
\text { VERB_KI_LANG_A } \\
\text { VERB_KI_LANG_LN } \\
\text { VERB_KI_LANG_A_LN }\end{array}$ & $\begin{array}{l}\text { Anteil (in Relation zur Bilanzsumme) und Betrag (in TEUR) der } \\
\text { langfristigen Verbindlichkeiten gegenüber Kreditinstituten zzgl. dem } \\
\text { jeweiligen Logarithmus }{ }^{1165}\end{array}$ \\
\hline $\begin{array}{l}\text { VERB_KI_KURZ_R } \\
\text { VERB_KI_KURZ_A } \\
\text { VERB_KI_KURZ_LN } \\
\text { VERB_KI_KURZ_A_LN }\end{array}$ & $\begin{array}{l}\text { Anteil (in Relation zur Bilanzsumme) und Betrag (in TEUR) der } \\
\text { kurzfristigen Verbindlichkeiten gegenüber Kreditinstituten zzgl. dem } \\
\text { jeweiligen Logarithmus }\end{array}$ \\
\hline $\begin{array}{l}\text { VERB_KI_R } \\
\text { VERB_KI_A } \\
\text { VERB_KI_LN } \\
\text { VERB_KI_A_LN }\end{array}$ & $\begin{array}{l}\text { Anteil (in Relation zur Bilanzsumme) und Betrag (in TEUR) der } \\
\text { gesamten Verbindlichkeiten gegenüber Kreditinstituten zzgl. dem } \\
\text { jeweiligen Logarithmus }\end{array}$ \\
\hline $\begin{array}{l}\text { VERM_LA_R } \\
\text { VERM_LA_A } \\
\text { VERM_LA_LN } \\
\text { VERM_LA_A_LN }\end{array}$ & $\begin{array}{l}\text { Anteil (in Relation zur Bilanzsumme) und Betrag (in TEUR) des } \\
\text { langfristigen Vermögens zzgl. dem jeweiligen Logarithmus }\end{array}$ \\
\hline $\begin{array}{l}\text { KASSE_R } \\
\text { KASSE_A } \\
\text { KASSE_LN } \\
\text { KASSE_A_LN }\end{array}$ & $\begin{array}{l}\text { Anteil (in Relation zur Bilanzsumme) und Betrag (in TEUR) der } \\
\text { Kassenposition zzgl. dem jeweiligen Logarithmus }\end{array}$ \\
\hline $\begin{array}{l}\text { BILANZS } \\
\text { BILANZS_LN }\end{array}$ & Bilanzsumme (in TEUR) zzgl. dem jeweiligen Logarithmus \\
\hline $\begin{array}{l}\text { UMSATZ } \\
\text { UMSATZ_LN }\end{array}$ & Umsatz (in TEUR) zzgl. dem jeweiligen Logarithmus \\
\hline EKQ & Eigenkapitalquote* \\
\hline DEBZIEL & Debitorenziel* \\
\hline UMSATZRENT & Umsatzrentabilität* \\
\hline GESAMTRENT & Gesamtrentabilität* \\
\hline ZINSDECK & Zinsdeckung* \\
\hline
\end{tabular}

1164 Die Anzahl der Überziehungen ist eine Kennzahl, welche in das Rating der Bank mit einfließt und Ausdruck der Bonität des Unternehmens ist. Um in den weiteren Untersuchungen den Einfluss der Bonität korrekt untersuchen zu können, wurde die Variable als Finanzkennzahl betrachtet. Bei einer Definition der Finanzkennzahlen als rein unternehmensbezogene, für Outside-Banken beobachtbare Variablen hingegen dürfte diese Variable allerdings hier keine Berücksichtigung finden und müsste stattdessen als beziehungsbezogene Variable betrachtet werden.

1165 Der Logarithmus der Variablen wurde deswegen mit eingeführt, da davon ausgegangen wird, dass möglicherweise vorhandene Effekte in Bezug auf die abhängigen Variablen sich bei einer Veränderung bspw. von einem Verbindlichkeitenvolumen in Höhe von 0,5 Mio. EUR auf 1 Mio. EUR anders auswirken als von 10 Mio. EUR auf 10,5 Mio. EUR. 


\begin{tabular}{|l|l|}
\hline Variablenbezeichnung & Definition \\
\hline KREDZIEL & Kreditorenziel* \\
\hline UMHANDEL & Umschlagshäufigkeit Handel* \\
\hline UMIND & Umschlagshäufigkeit Industrie* \\
\hline UMSATZW & Umsatzwachstum* \\
\hline UMVORR & Umschlagshäufigkeit der Vorräte* \\
\hline ANZ_ÜB_30 & Anzahl Überziehungen von mehr als 30 Tagen \\
\hline ANZ_ÜB_60 & Anzahl Überziehungen von mehr als 60 Tagen \\
\hline ANZ_ÜB_90 & Anzahl Überziehungen von mehr als 90 Tagen \\
\hline ANZ_ÜB_GES & Gesamtzahl der Überziehungen in Tagen \\
\hline AUSFALLW_B & Ausfallwahrscheinlichkeit gemäß dem letzten durchgeführten Rating \\
\hline TSC_JA_AGG & Teilscore für den Jahresabschluss ${ }^{1166}$ \\
\hline TSC_QA_AGG & Teilscore für die qualitativen Daten ${ }^{1167}$ \\
\hline * Die exakte Kennzahlendefinition kann dem Anhang 1, Tab. AN 1-1 entnommen werden. \\
\hline
\end{tabular}

Tab. B-9: Finanzkennzahlen

\begin{tabular}{|l|l|}
\hline Variablenbezeichnung & Definition \\
\hline PROD & Dummyvariable für Produktionsunternehmen \\
\hline HAND & Dummyvariable für Handelsunternehmen \\
\hline DIENST & Dummyvariable für Dienstleistungsunternehmen \\
\hline BAU & Dummyvariable für Bauunternehmen \\
\hline KAPGESELL & Dummyvariable für Kapitalgesellschaften \\
\hline KAP_GMBHCOKG & Dummyvariable für Kapitalgesellschaften inkl. GmbH \& Co. KG \\
\hline ALTER & Alter des Unternehmens in Jahren \\
\hline ALTER_LN & Logarithmus des Alters \\
\hline
\end{tabular}

Tab. B-10: Unternehmensbezogene Variablen

\begin{tabular}{|c|c|}
\hline Variablenbezeichnung & Definition \\
\hline $\begin{array}{l}\text { VERB_KI_EIG_LANG_R } \\
\text { VERB_KI_EIG_LANG_A } \\
\text { VERB_KI_EIG_LANG_LN } \\
\text { VERB_KI_EIG_LANG_A_LN }\end{array}$ & $\begin{array}{l}\text { Anteil (in Relation zur Bilanzsumme) und Betrag (in TEUR) der } \\
\text { langfristigen Verbindlichkeiten gegenüber dem eigenen Kreditinstitut } \\
\text { zzgl. dem jeweiligen Logarithmus }\end{array}$ \\
\hline $\begin{array}{l}\text { VERB_KI_EIG_KURZ_R } \\
\text { VERB_KI_EIG_KURZ_A } \\
\text { VERB_KI_EIG_KURZ_LN } \\
\text { VERB_KI_EIG_KURZ_A_LN }\end{array}$ & $\begin{array}{l}\text { Anteil (in Relation zur Bilanzsumme) und Betrag (in TEUR) der } \\
\text { kurzfristigen Verbindlichkeiten gegenüber dem eigenen Kreditinstitut } \\
\text { zzgl. dem jeweiligen Logarithmus }\end{array}$ \\
\hline $\begin{array}{l}\text { VERB_KI_EIG_R } \\
\text { VERB_KI_EIG_A } \\
\text { VERB_KI_EIG_LN } \\
\text { VERB_KI_EIG_A_LN } \\
\end{array}$ & $\begin{array}{l}\text { Anteil (in Relation zur Bilanzsumme) und Betrag (in TEUR) der } \\
\text { gesamten Verbindlichkeiten gegenüber dem eigenen Kreditinstitut } \\
\text { zzgl. dem jeweiligen Logarithmus }\end{array}$ \\
\hline INT_BET & $\begin{array}{l}\text { Dummyvariable für „Kunde befindet sich bzw. befand sich in den } \\
\text { letzten drei Jahren in der Intensivbetreuung“ }\end{array}$ \\
\hline DAU_BEZ_ERR & $\begin{array}{l}\text { Dauer der Kundenbeziehung zwischen Bank und Unternehmen in } \\
\text { Jahren }\end{array}$ \\
\hline
\end{tabular}

1166 Bei Kunden des Ratingsegments Oberer Mittelstand wurde der Teilscore des Oberen Mittelstand-Ratings, bei Kunden des Mittelstands der Teilscore des Mittelstand-Ratings und bei Kunden des Übergangsbereichs der gleichgewichtete Teilscore aus den beiden Ratingsegmenten verwendet.

1167 Das Vorgehen entspricht dem Vorgehen bei dem Teilscore für den Jahresabschluss. 


\begin{tabular}{|c|c|}
\hline Variablenbezeichnung & Definition \\
\hline DAU_PERS_ERR & Dauer der Beziehung zwischen FKB und Unternehmen in Jahren \\
\hline HAUSBANK_K & $\begin{array}{l}\text { Subjektive Einschätzung des FKB, inwiefern die Bank die Hausbank } \\
\text { des Unternehmens ist }\end{array}$ \\
\hline ANZ_BER_J & $\begin{array}{l}\text { Anzahl der qualifizierten Beratungsgespräche mit dem Kunden im } \\
\text { letzten Jahr }\end{array}$ \\
\hline ANZ_KONT_J & Anzahl der Kontakte mit dem Kunden im letzten Jahr \\
\hline GK_SALD & Saldo des relevanten Geschäftskontos (Kontokorrentkonto) in EUR \\
\hline GK_LIM_EX & $\begin{array}{l}\text { Externes Limit des relevanten Geschäftskontos (Kontokorrentkonto) } \\
\text { in EUR }\end{array}$ \\
\hline GES_KREDIT & $\begin{array}{l}\text { Gesamtkreditvolumen des Kunden bei der Bank in EUR (Summe } \\
\text { aller betragsmäßigen Darlehenssalden zzgl. des Maximums aus ex- } \\
\text { ternem Limit und dem Betrag eines negativen Saldos je Kontokor- } \\
\text { rentkonto) }\end{array}$ \\
\hline GK_ZINS & $\begin{array}{l}\text { Zinssatz des relevanten Geschäftskontos (Kontokorrentkonto) in } \\
\text { Prozent }\end{array}$ \\
\hline ANT_BANK_IN & $\begin{array}{l}\text { Durch den FKB geschätzter Anteil des jeweiligen Instituts an der } \\
\text { gesamten Bankfinanzierung des Unternehmens }\end{array}$ \\
\hline ANT_BANK_HB & $\begin{array}{l}\text { Durch den FKB geschätzter Anteil der Hauptbank an der gesamten } \\
\text { Bankfinanzierung des Unternehmens; Wert entspricht } \\
\text { ANT_BANK_IN, sofern es sich bei dem befragten Institut um die } \\
\text { Hauptbank handelt }\end{array}$ \\
\hline ANZ_B_AGG & Korrigierte Anzahl der Bankverbindungen \\
\hline ZINS_VERFÜG & $\begin{array}{l}\text { Einschätzung des FKB, inwiefern für den Kunden ein niedriger Zins- } \\
\text { satz oder eine hohe Verfügbarkeit wichtiger ist (0-1-Codierung) }\end{array}$ \\
\hline ANT_ZV & $\begin{array}{l}\text { Durch den FKB geschätzter Anteil des jeweiligen Instituts an der } \\
\text { gesamten Zahlungsverkehrsabwicklung des Kunden }\end{array}$ \\
\hline MITGLIED & $\begin{array}{l}\text { Dummyvariable für "Kunde besitzt Genossenschaftsanteile der be- } \\
\text { fragten Bank“ }\end{array}$ \\
\hline DARL & $\begin{array}{l}\text { Dummyvariable für „Kunde unterhält Darlehen bei der befragten } \\
\text { Bank““1168 }\end{array}$ \\
\hline VERM_ANL & Dummyvariable für „Kunde tätigt Vermögensanlage bei der Bank“ \\
\hline VERSICH & $\begin{array}{l}\text { Dummyvariable für „Kunde hat Versicherungen bei der befragten } \\
\text { Bank“ }\end{array}$ \\
\hline PRIVATKONT & $\begin{array}{l}\text { Dummyvariable für „Unternehmer bzw. Geschäftsführer hat seine } \\
\text { Privatkonten bei der befragten Bank“ }\end{array}$ \\
\hline SICH_Q & Besicherungsquote des Kunden bei der Bank \\
\hline EL & $\begin{array}{l}\text { Erwarteter Verlust, definiert als Multiplikation aus Blankoanteil und } \\
\text { Ausfallwahrscheinlichkeit des Kunden }\end{array}$ \\
\hline GRUNDS & $\begin{array}{l}\text { Dummyvariable für „Großteil der gestellten Sicherheiten gehört der } \\
\text { Sicherheitenart Grundschuld an“ }\end{array}$ \\
\hline BÜRG & $\begin{array}{l}\text { Dummyvariable für „Großteil der gestellten Sicherheiten gehört der } \\
\text { Sicherheitenart Bürgschaft an“ }\end{array}$ \\
\hline SÜ & $\begin{array}{l}\text { Dummyvariable für „Großteil der gestellten Sicherheiten gehört der } \\
\text { Sicherheitenart Sicherungsübereignung an“ }\end{array}$ \\
\hline FORD_AB & $\begin{array}{l}\text { Dummyvariable für „Großteil der gestellten Sicherheiten gehört der } \\
\text { Sicherheitenart Forderungsabtretung an“ }\end{array}$ \\
\hline
\end{tabular}

1168 Die Variable DARL sagt lediglich etwas über die Nutzung von Darlehen bei der Bank aus. Sofern die Variable VERB_KI_EIG_LANG_R größer Null ist, unterhält der Kunde Darlehen bei der Bank und die Variable DARL nimmt den Wert 1 an. Diese Variable wird insbesondere verwendet, um zu prüfen, inwiefern aus der Anzahl der Nutzung der Produkte aus den verschiedenen Produktbereichen ein Effekt resultiert. 


\begin{tabular}{|l|l|}
\hline Variablenbezeichnung & Definition \\
\hline VERPFÄ & $\begin{array}{l}\text { Dummyvariable für „Großteil der gestellten Sicherheiten gehört der } \\
\text { Sicherheitenart Verpfändung an“ }\end{array}$ \\
\hline SONST & $\begin{array}{l}\text { Dummyvariable für „Großteil der gestellten Sicherheiten gehört der } \\
\text { Sicherheitenart „Sonstiges“ an“ }\end{array}$ \\
\hline DIST_UNT & Distanz zwischen Unternehmen und Bank gemessen in km \\
\hline ANT_VERB_EIG_LANG ${ }^{1169}$ & $\begin{array}{l}\text { Anteil der Verbindlichkeiten des jeweiligen Instituts an den gesamten } \\
\text { langfristigen Bankverbindlichkeiten (Daten aus Banksystem erhoben) }\end{array}$ \\
\hline ANT_VERB_EIG_KURZ & $\begin{array}{l}\text { Anteil der Verbindlichkeiten des jeweiligen Instituts an den gesamten } \\
\text { kurzfristigen Bankverbindlichkeiten (Daten aus Banksystem erhoben) }\end{array}$ \\
\hline ANT_VERB_EIG_GES & $\begin{array}{l}\text { Anteil der Verbindlichkeiten des jeweiligen Instituts an den gesamten } \\
\text { Bankverbindlichkeiten (Daten aus Banksystem erhoben) }\end{array}$ \\
\hline ABL_KRED_VER & $\begin{array}{l}\text { Angabe des FKB, inwiefern der Kunde in den letzten 3 Jahren eine } \\
\text { vollständige Kreditablehnung erfahren hat. }\end{array}$ \\
\hline ABL_KRED_VER_EUN & s.o., exkl. Antworttyp unbekannt \\
\hline PAR_KRED_VER & $\begin{array}{l}\text { Angabe des FKB, inwiefern der Kunde in den letzten 3 Jahren eine } \\
\text { teilweise Kreditablehnung erfahren hat. }\end{array}$ \\
\hline PAR_KRED_VER_EUN & s.o., exkl. Antworttyp unbekannt \\
\hline AUS_KRED_HEU & $\begin{array}{l}\text { Angabe des FKB, inwiefern der Kunde zum gegenwärtigen Zeitpunkt } \\
\text { eine Kreditausweitung bekommen würde. }\end{array}$ \\
\hline AUS_KRED_HEU_EUN & s.o., exkl. Antworttyp unbekannt \\
\hline DAU_KRED_BEW & $\begin{array}{l}\text { Einschätzung des Firmenkundenbetreuers hinsichtlich der Dauer der } \\
\text { Bewilligung des letzten genehmigten Kredits }\end{array}$ \\
\hline
\end{tabular}

Tab. B-11: Beziehungsbezogene Variablen

\begin{tabular}{|l|l|l|}
\hline $\begin{array}{l}\text { Faktor- } \\
\text { bezeichnung }\end{array}$ & $\begin{array}{l}\text { Variablen- } \\
\text { bezeichnung }\end{array}$ & Aussage \\
\hline \multirow{5}{*}{$\begin{array}{l}\text { ORG_GLAUB } \\
\text { 1170 }\end{array}$} & $\begin{array}{l}\text { Wir können uns auch dann auf die Informationen verlassen, } \\
\text { wenn uns das Unternehmen zu außergewöhnlichen Sachverhal- } \\
\text { ten (z.B. auffällige Kennzahlenentwicklung, starke Ver- } \\
\text { änderung der Lieferantenstruktur) auf den ersten Blick eher } \\
\text { unwahrscheinliche Erklärungen liefert. }\end{array}$ \\
\cline { 2 - 4 } & EINHALT_ABS & $\begin{array}{l}\text { Das Unternehmen hält die Absprachen ein, die es mit uns } \\
\text { getroffen hat (z.B. schnellere Einreichung des Jahresab- } \\
\text { schlusses im Folgejahr). }\end{array}$ \\
\cline { 2 - 3 } & $\begin{array}{l}\text { Wir können uns darauf verlassen, dass das Unternehmen bspw. } \\
\text { bei der Durchführung von Investitionsprojekten oder Erschlie- } \\
\text { Bung neuer Märkte die richtigen Entscheidungen trifft. }\end{array}$ \\
\cline { 2 - 4 } & VERLÄSS_ENT & $\begin{array}{l}\text { Die Qualifikation der Mitarbeiter ist aus meiner Sicht sowohl } \\
\text { im kaufmännischen als auch im technischen Bereich hervorra- } \\
\text { gend. }\end{array}$ \\
\hline
\end{tabular}

1169 Während die Variable VERB_KI_EIG_LANG_R den Anteil der Verbindlichkeiten des Unternehmens bei dem jeweiligen Institut in Relation zur Bilanzsumme darstellt, misst die Variable ANT_VERB_EIG_LANG den Anteil des jeweiligen Instituts an der gesamten Bankfinanzierung. Die erste Variable tätigt eine Aussage über die Abhängigkeit des Unternehmens vom Institut in Bezug auf die Gesamtfinanzierung, die zweite Variable hingegen sagt aus, wie stark die Abhängigkeit des Unternehmens vom Institut in Bezug auf die Bankfinanzierung ist.

1170 Die verhaltenswissenschaftlichen Faktoren werden erst in Kapitel B.3.2 ermittelt. Um eine vollständige Variablenübersicht zu haben, wurden diese Faktoren dennoch bereits an dieser Stelle mit aufgeführt. 


\begin{tabular}{|c|c|c|}
\hline $\begin{array}{l}\text { Faktor- } \\
\text { bezeichnung }\end{array}$ & $\begin{array}{l}\text { Variablen- } \\
\text { bezeichnung }\end{array}$ & Aussage \\
\hline \multirow{4}{*}{ ORG_WOHL } & NICHT_NACHTEIL & $\begin{array}{l}\text { Wir können uns darauf verlassen, dass das Unternehmen sich } \\
\text { nicht zu unserem Nachteil verhält. } \\
\text { Auch wenn sich unerwartet neue Möglichkeiten auftun, würde } \\
\text { das Unternehmen unsere Mittel (KK-Linie) nicht zu ünserem } \\
\text { Nachteil in extrem riskante Projekte stecken oder bei einer sich } \\
\text { anbahnenden Verschlechterung der Unternehmenslage würde } \\
\text { das Unternehmen keine zusätzlichen Mittel aufnehmen ohne } \\
\text { die aktuelle Situation mit uns zu besprechen. }\end{array}$ \\
\hline & ERWAR_VERSTÄ & $\begin{array}{l}\text { Wenn wir dem Unternehmen von aufgetretenen Problemen } \\
\text { berichten (z.B. Bearbeitungsfehler, Falschbuchungen, Verzöge- } \\
\text { rungen im Zahlungsverkehr), können wir kein Verständnis von } \\
\text { diesem Unternehmen erwarten. }\end{array}$ \\
\hline & RECHT_INFO & $\begin{array}{l}\text { Wir können uns darauf verlassen, dass das Unternehmen uns } \\
\text { bei einschneidenden Entscheidungen, die die be- } \\
\text { triebswirtschaftliche Entwicklung des Unternehmens maßgeb- } \\
\text { lich betreffen, rechtzeitig und umfassend informiert (z.B. } \\
\text { Standortschließung, personelle Veränderungen in der Ge- } \\
\text { schäftsleitung, Umsatzeinbruch). }\end{array}$ \\
\hline & VERTMITT_KUND & $\begin{array}{l}\text { Das Unternehmen hat uns schon mal einen Kunden vermittelt } \\
\text { bzw. würde uns bei Gelegenheit Kunden vermitteln. }\end{array}$ \\
\hline \multirow{4}{*}{ PERS_GLAUB } & OFF_ERLÄUT & $\begin{array}{l}\text { Mein Ansprechpartner hat mir die Gründe für Zahlungs- } \\
\text { schwierigkeiten oder Probleme bei der rechtzeitigen Bereitstel- } \\
\text { lung von Informationen/Daten (z.B. Bilanzen, Plandaten, } \\
\text { BWA, Projektentwicklung) stets offen und zeitnah erläutert. }\end{array}$ \\
\hline & BRANCHINFO & $\begin{array}{l}\text { Mein Ansprechpartner ist stets auf dem aktuellsten Stand was } \\
\text { branchenspezifische Themen angeht (z.B. Konkurrenzsituation, } \\
\text { Produktneuheiten, Branchenwachstum). }\end{array}$ \\
\hline & KENNT_BWL & $\begin{array}{l}\text { Mein Ansprechpartner hat nur geringe Kenntnisse im betriebs- } \\
\text { wirtschaftlichen Bereich (z.B. Interpretation von Bilanzkenn- } \\
\text { zahlen, Erstellung von Plänen, Interpretation der Controllingda- } \\
\text { ten). }\end{array}$ \\
\hline & $\begin{array}{l}\text { STELL_UNANG_ } \\
\text { FORD }\end{array}$ & $\begin{array}{l}\text { Mein Ansprechpartner stellt keine unangemessenen For- } \\
\text { derungen. So würde er mich bezüglich seiner Konditionen } \\
\text { (Zinsen und Besicherung) bei anderen Banken in Ver- } \\
\text { handlungen nicht anlügen, um dadurch bessere Konditionen bei } \\
\text { uns zu erzielen. }\end{array}$ \\
\hline \multirow{4}{*}{ PERS_WOHL } & $\begin{array}{l}\text { IN- } \\
\text { KAUF_FORM_TÄT }\end{array}$ & $\begin{array}{l}\text { Mein Ansprechpartner nimmt die aus seiner Sicht eher forma- } \\
\text { len Tätigkeiten, wie z.B. Aufstellung Warenlager, Erstellung } \\
\text { Zessionslisten, nur widerwillig in Kauf, er kann die Notwen- } \\
\text { digkeit für uns nicht nachvollziehen. }\end{array}$ \\
\hline & PERS_KONT_UNZU & $\begin{array}{l}\text { Mein Ansprechpartner würde bei Unzufriedenheit mit unserer } \\
\text { Bank oder unseren Konditionen unmittelbar den persönlichen } \\
\text { Kontakt zu mir suchen. }\end{array}$ \\
\hline & INKAUF_UNAN & $\begin{array}{l}\text { Mein Ansprechpartner hat in der Vergangenheit auch schon mal } \\
\text { Unannehmlichkeiten in Kauf genommen (z.B. Terminverschie- } \\
\text { bungen oder Termine außerhalb der normalen Arbeitszeiten } \\
\text { akzeptiert). }\end{array}$ \\
\hline & FREUND_BEZ & $\begin{array}{l}\text { Die Beziehung zu meinem Ansprechpartner würde ich als } \\
\text { freundschaftlich bezeichnen. }\end{array}$ \\
\hline ORG_GEB & WECHS_BANK & $\begin{array}{l}\text { Ein Wechsel der (Haus-)Bankbeziehung wäre für das Unter- } \\
\text { nehmen nicht so leicht möglich. (z.B. weil das Unternehmen } \\
\text { aktuell keine zweite Bankbeziehung hat und/oder weil aufgrund } \\
\text { der betriebswirtschaftlichen Situation weitere Bankverbindun- } \\
\text { gen nicht möglich sind). }\end{array}$ \\
\hline
\end{tabular}




\begin{tabular}{|c|c|c|}
\hline $\begin{array}{l}\text { Faktor- } \\
\text { bezeichnung }\end{array}$ & $\begin{array}{l}\text { Variablen- } \\
\text { bezeichnung }\end{array}$ & Aussage \\
\hline & INFO_NEU_BANK & $\begin{array}{l}\text { Das Unternehmen müsste der neuen Bank zunächst deutlich } \\
\text { umfangreichere Informationen liefern als uns, da wir das } \\
\text { Unternehmen bereits gut kennen. }\end{array}$ \\
\hline & VERTR_AKT_BANK & $\begin{array}{l}\text { Das Unternehmen ist z.B. aufgrund bestehender Kredite ver- } \\
\text { traglich an meine Bank gebunden. }\end{array}$ \\
\hline \multirow{3}{*}{ ORG_VER } & ANGEN_ZSARB & $\begin{array}{l}\text { Der Ansprechpartner empfindet es als angenehm, mit unserer } \\
\text { Bank zusammenzuarbeiten. (z.B. nimmt er gerne an Kunden- } \\
\text { veranstaltungen unserer Bank teil) }\end{array}$ \\
\hline & UNT_GEN_ID & $\begin{array}{l}\text { Der Ansprechpartner unterstützt die genossenschaftliche Idee } \\
\text { (z.B. der Ansprechpartner ist als Privatkunde Mitglied der } \\
\text { Bank). }\end{array}$ \\
\hline & UNT_GP & $\begin{array}{l}\text { Der Ansprechpartner unterstützt unsere Geschäftspolitik, so } \\
\text { dass ihm ein Wechsel zu einer anderen Bank schwer fallen } \\
\text { würde (z.B. kann er die Geschäftspolitik der privaten Banken } \\
\text { nicht unterstützen.). }\end{array}$ \\
\hline \multirow{3}{*}{ PERS_VER } & WICHT_WECH_FKB & $\begin{array}{l}\text { Dem Ansprechpartner wäre es egal, wenn der Firmen- } \\
\text { kundenbetreuer wechseln würde (z.B. weil für ihn aus- } \\
\text { schließlich die Qualität der Beratung entscheidend ist). }\end{array}$ \\
\hline & WICHT_PERS_KON & $\begin{array}{l}\text { Meinem Ansprechpartner ist es wichtig, dass wir auch regel- } \\
\text { mäßig im persönlichen Kontakt (z.B. Beratungsgespräche, } \\
\text { Telefonate) stehen. }\end{array}$ \\
\hline & KEIN_BANK_WE & $\begin{array}{l}\text { Der Ansprechpartner würde die Bank auch bei besseren Kondi- } \\
\text { tionen nicht so schnell wechseln, da er weiß, dass ich mich in } \\
\text { der Vergangenheit sehr stark um das Unternehmen bemüht und } \\
\text { viel Zeit investiert habe. }\end{array}$ \\
\hline
\end{tabular}

Tab. B-12: Verhaltenswissenschaftliche Variablen

\begin{tabular}{|l|l|}
\hline Variablenbezeichnung & Definition \\
\hline FKB_JÜ30 & Angabe, ob der FKB jünger als 30 Jahre ist \\
\hline FKB_30_50 & Angabe, ob der FKB zwischen 30 und 50 Jahre alt ist \\
\hline FKB_ÜB50 & Angabe, ob der FKB älter als 50 Jahre ist \\
\hline FBK_BANK & Angabe, ob der FKB ein Banklehre absolviert hat \\
\hline FKB_BERUF_ST & Angabe, ob der FKB ein berufsbegleitendes Studium absolviert hat \\
\hline FKB_STUD & Angabe, ob der FKB ein Vollzeitstudium absolviert hat \\
\hline MARKTAN_GES & Marktanteil des Instituts in Bezug auf den relevanten Markt \\
\hline MARKTAN_FK & $\begin{array}{l}\text { Marktanteil des Instituts in Bezug auf den relevanten Firmenkun- } \\
\text { denmarkt }\end{array}$ \\
\hline UMFELD_LÄND & Angabe, ob die Bank in einem ländlichen Umfeld agiert \\
\hline UMFELD_LÄSTÄ & Angabe, ob die Bank in einem ländlich bis städtischen Umfeld agiert \\
\hline UMFELD_STÄ & Angabe, ob die Bank in einem städtischen Umfeld agiert \\
\hline LEI_WERT_FKB & $\begin{array}{l}\text { Angabe, ob der FKB eine personenbezogene, wertorientierte Ver- } \\
\text { gütung erhält }\end{array}$ \\
\hline LEI_WERT_BA & $\begin{array}{l}\text { Angabe, ob der FKB eine bankbezogene, wertorientierte Vergütung } \\
\text { erhält }\end{array}$ \\
\hline LEI_VOL & $\begin{array}{l}\text { Angabe, ob der FKB eine personenbezogene, volumensorientierte } \\
\text { Vergütung erhält }\end{array}$ \\
\hline LEI_AKT & Angabe, ob der FKB eine aktivitätenorientierte Vergütung erhält \\
\hline
\end{tabular}




\begin{tabular}{|l|l|}
\hline Variablenbezeichnung & Definition \\
\hline LEI_KEIN & $\begin{array}{l}\text { Angabe, ob der FKB überhaupt eine leistungsorientierte Vergütung } \\
\text { erhält }\end{array}$ \\
\hline RISIKO_BEPREIS & $\begin{array}{l}\text { Einschätzung des FKB, ob die Bank eine risikoorientierte Beprei- } \\
\text { sung praktiziert }\end{array}$ \\
\hline BIL_BA & Bilanzssumme der Bank in Mio. EUR \\
\hline
\end{tabular}

Tab. B-13: Bankbezogene und betreuerbezogene Variablen

\subsection{Deskriptive Auswertung}

Bevor die Aufstellung und Überprüfung der Hypothesen vorgenommen wird, erfolgt zunächst eine Darstellung der Ergebnisse der deskriptiven Auswertung. Ziel ist es, einen Überblick über die Kunde-Bank-Beziehung von mittelständischen Unternehmen mit den Genossenschaftsbanken zu geben. Im ersten Schritt werden dazu die Finanzierungsstrukturen sowie weitere unternehmensbezogene Daten der untersuchten Unternehmen ausgewertet. Nach der isolierten Betrachtung der Unternehmensseite folgt die Analyse der Bankbeziehung basierend auf den objektiven, in der bisherigen Relationship Banking-Forschung verwendeten beziehungsbezogenen Merkmalen. Dem schließt sich die zunächst rein deskriptive Auswertung der Kunde-Bank-Beziehung aus verhaltenswissenschaftlicher Perspektive an. Bei den Auswertungen wird zum Teil, d.h. sofern es inhaltlich sinnvoll erscheint, eine Differenzierung nach Größenklassen, Branche und/oder Rechtsform vorgenommen. Aufgrund der besonderen Bedeutung des Hausbankstatus in der Relationship Banking-Forschung im deutschen Raum wird der Beschreibung der Besonderheiten von Hausbanken ein separates Kapitel gewidmet. Abschließend werden einige bankbezogene Daten ausgewertet. Der Fokus der deskriptiven Auswertungen liegt auf der Betrachtung der Durchschnittswerte. Da einige Variablen eine sehr schiefe Verteilung aufweisen und zum Teil erhebliche Ausreißer vorliegen, ist das arithmetische Mittel nicht immer sehr aussagekräftig, so dass der Median ebenfalls ausgewiesen wird. ${ }^{1171}$

Sofern unterschiedliche Teilgruppen miteinander verglichen werden, wird zusätzlich die Signifikanz der Gruppenunterschiede ausgewiesen. Die Auswahl des Verfahrens zur Ermittlung der Signifkanz hängt zum einen davon ab, ob genau zwei oder mehr als zwei Stichproben mit einander verglichen werden. Zum anderen richtet sich das zu verwendende Testverfahren nach den Verteilungsannahmen. Bei dem Vergleich zweier Teilgruppen kommen der T-Test und der Kolmogorov-Smirnov-Test zur Anwendung. Der T-Test setzt voraus, dass die betrachtete Variable in der Grundgesamtheit normalverteilt ist. ${ }^{1172} \mathrm{Da}$ der T-Test allerdings sehr robust auf Verletzungen der Normalverteilungsannahme reagiert, wird diese Annahme häufig nicht als allzu kritisch erachtet. ${ }^{173}$ Mit Hilfe des Levene-Tests wurde zunächst die Varianzgleichheit in den betrachteten Fallgruppen geprüft. In Abhängigkeit davon, ob die Varianz der betrachteten Variablen gleich groß ist, wurde das entsprechende Verfahren, d.h. der

\footnotetext{
1171 Zu diesem Vorgehen vgl. Harhoff/Körting (1998a), S. 9.

1172 Vgl. Brosius (2002), S. 452.

1173 Vgl. Brosius (2002), S. 452.
} 
pooled-Variance T-Test bzw. der separate Variance T-Test, gewählt. ${ }^{1174}$ Sofern die Variablen nicht perfekt bzw. nicht nahezu perfekt normalverteilt sind, wurde zusätzlich mit dem Kolmogorov-Smirnov-Test ein nicht-parametrischer Test durchgeführt. Dadurch wird die Robustheit des Signifikanztests erhöht, da keine Verteilungsannahmen erforderlich sind. ${ }^{1175}$ Nicht-parametrische Tests sind bspw. dann vorzuziehen, wenn die für die parametrischen Tests erforderlichen Annahmen über die Verteilung der Grundgesamtheit hinsichtlich ihrer Gültigkeit angezweifelt werden müssen. ${ }^{1176}$ Der Kolmogorov-Smirnov-Test vergleicht die Verteilungen der beiden Stichproben untereinander. Dieser Test erfordert Intervallskalenniveau der Testvariablen und testet die Nullhypothese: Beide Stichproben entstammen derselben Grundgesamtheit. ${ }^{177}$

Analog zum vorherigen Vorgehen bei zwei Teilgruppen der Grundgesamtheit werden auch bei der Analyse der Gruppenunterschiede zwischen mehreren Teilgruppen in Abhängigkeit von den Verteilungsannahmen zwei Signifikanztests durchgeführt. Zum einen wird eine einfaktorielle ANOVA, welche ebenfalls die Normalverteilung der Variablen voraussetzt, als analoges Testverfahren zum T-Test durchgeführt. Dieses Verfahren testet die Nullhypothese, dass alle miteinander verglichenen Gruppenmittelwerte der betrachteten Variablen in der Grundgesamtheit identisch sind. ${ }^{1178}$ Zum anderen wird mit dem Kruskal-Wallis-Test zusätzlich ein nicht-parametrischer Test für unabhängige Stichproben durchgeführt. ${ }^{179}$

Sofern die Analyse der Variablen getrennt nach Gruppen durchgeführt wird, erfolgt in aller Regel ausschließlich ein Ausweis der Variablen mit signifikanten Gruppenunterschieden. Lediglich wenn die Variable für die Untersuchung eine wesentliche Bedeutung besitzt und eine wichtige Erkenntnis gewonnen wird, werden fallbezogen auch Variablen ohne signifikante Gruppenunterschiede ausgewiesen. Die Auswertungen wurden mit SPSS $\otimes 16.0$, Version 16.0.1 durchgeführt.

\subsubsection{Finanzkennzahlen der Unternehmen und sonstige unternehmens- bezogene Parameter}

Die Analyse der Finanzierungsstrukturen der in dem Datensatz enthaltenen Unternehmen basiert auf Jahresabschlussdaten, die in den Bankanwendungen erfasst sind. Aufgrund der besonderen Zielstellung der Banken bei der Bilanzanalyse werden bestimmte Sachverhalte in Bankanwendungen anders abgebildet als dies beim Unternehmer der Fall ist. Beispielsweise werden nachstehende Bilanzpositionen stets als so genannte „eigenkapitalmindernde Posten“ erfasst: Aufwendungen für Ingangsetzung und Erweiterung des Geschäftsbetriebes und nicht werthaltige Forderungen gegen Gesellschafter. Infolgedessen weichen die Absolutbeträge sowie die auf dieser Basis ermittelten Kennzahlen unter Umständen von den Originaldaten des Unternehmens ab. Daten-

\footnotetext{
1174 Vgl. Brosius (2002), S. 464.

1175 Vgl. hierzu auch Elsas (2001), S. 93.

1176 Vgl. Pepels (1995), S. 367.

1177 Vgl. Brosius (2002), S. 821.

1178 Vgl. Brosius (2002), S. 478.

1179 Vgl. Brosius (2002), S. 822.
} 
grundlage ist der letzte der Bank vorliegende und erfasste Jahresabschluss, im Regelfall (bei $70,5 \%$ der Datensätze) war dies der Jahresabschluss für das Geschäftsjahr 2006.

In Tab. B-14 sind die Finanzkennzahlen der Unternehmen des Untersuchungspanels im Vergleich zum bundesweiten Durchschnitt dokumentiert. Die Auswertungsergebnisse bestätigen die in Kapitel A.2.1.2 herausgearbeiteten Besonderheiten deutscher mittelständischer Unternehmen. Die immense Bedeutung der Bankfinanzierung spiegelt sich in der Quote Verbindlichkeiten gegen Kreditinstitute in Relation zur Bilanzsumme wider, so beträgt der Anteil der Bankfinanzierung im arithmetischen Mittel $34,06 \%$ ( $22,40 \%$ im Median). Auch die zuvor bereits erwähnte Eigenkapitalschwäche deutscher Unternehmen findet in der Untersuchung ihre Bestätigung, so liegt die Eigenkapitalquote im Median bei 17,65\%, im arithmetischen Mittel sogar bei nur $13,82 \%$. Das niedrigere arithmetische Mittel ist unter anderem auch darauf zurückzuführen, dass mehrere Unternehmen ein negatives bilanzielles Eigenkapital ausweisen. ${ }^{1180}$ Das Umsatzwachstum beträgt $6,90 \%$ im Median. ${ }^{1181}$ Die durchschnittliche Anzahl der Überziehungen beträgt 31,99. Die Ausfallwahrscheinlichkeit liegt mit 1,98\% (Median: 0,50\%) über dem bundesweiten Durchschnitt. ${ }^{112}$ Die Ermittlung der Ausfallwahrscheinlichkeit basiert auf einem Unternehmensrating, d.h. es erfolgt keine Berücksichtigung von Sicherheiten.

\begin{tabular}{|l|r|r|r|r|r|r|r|}
\hline & Einheit & $\begin{array}{c}\text { Mittel- } \\
\text { wert }\end{array}$ & Median & $\begin{array}{c}\text { Standard- } \\
\text { abwei- } \\
\text { chung }\end{array}$ & Minimum & Maximum & $\begin{array}{c}\text { Bundes- } \\
\text { weiter } \\
\text { Mittelwert }\end{array}$ \\
\hline VERB_KI_LANG_R & $\%$ & 21,66 & 12,50 & 26,05 & 0,00 & 144,30 & 4,1 \\
\hline VERB_KI_KURZ_R & $\%$ & 12,40 & 5,50 & 18,85 & 0,00 & 100,90 & 3,4 \\
\hline VERB_KI_R & $\%$ & 34,06 & 22,40 & 34,94 & 0,00 & 219,40 & 7,5 \\
\hline VERM_LA_R & $\%$ & 34,50 & 32,60 & 24,12 & 0,20 & 95,40 & 37,2 \\
\hline KASSE_R & $\%$ & 9,09 & 3,30 & 12,67 & 0,00 & 82,50 & 5,4 \\
\hline VERB_KI_LANG_A & TEUR & 574,20 & 104,77 & $2.317,79$ & 0,00 & $32.262,80$ & --- \\
\hline VERB_KI_KURZ_A & TEUR & 275,33 & 48,05 & 837,76 & 0,00 & $7.918,90$ & --- \\
\hline VERB_KI_A & TEUR & 849,53 & 220,25 & $2.747,40$ & 0,00 & $34.670,47$ & --- \\
\hline VERM_LA_A & TEUR & 909,27 & 315,70 & $1.684,61$ & 0,10 & $11.233,84$ & --- \\
\hline KASSE_A & TEUR & 210,30 & 36,63 & 695,51 & 0,00 & $8.125,34$ & --- \\
\hline BILANZS & TEUR & $2.480,25$ & $1.289,00$ & $3.979,29$ & 0,20 & $37.041,10$ & $40.959,8$ \\
\hline
\end{tabular}

1180 Ein negatives bilanzielles Eigenkapital ergibt sich dann, wenn der Jahresfehlbetrag oder die eigenkapitalmindernden Positionen sehr groß sind. Unter den eigenkapitalmindernden Positionen werden bspw. diverse immaterielle Vermögensgegenstände aufgeführt.

1181 Aufgrund von Ausreißern ist bei dem Umsatzwachstum der Median aussagekräftiger als das arithmetische Mittel.

1182 Bei der Ausfallwahrscheinlichkeit handelt es sich um eine unternehmensbezogene Eigenschaft, denn selbige reflektiert die Bonität des Unternehmens unabhängig von der bewertenden Bank. Allerdings ist es denkbar, dass unterschiedliche Banken aufgrund unterschiedlicher Ratingsysteme unterschiedliche Ausfallwahrscheinlichkeiten ermitteln. 


\begin{tabular}{|c|c|c|c|c|c|c|c|}
\hline & Einheit & $\begin{array}{c}\text { Mittel- } \\
\text { wert }\end{array}$ & Median & $\begin{array}{c}\text { Standard- } \\
\text { abwei- } \\
\text { chung }\end{array}$ & Minimum & Maximum & $\begin{array}{c}\text { Bundes- } \\
\text { weiter }^{1183} \\
\text { Mittelwert }^{118}\end{array}$ \\
\hline UMSATZ & TEUR & $5.212,82$ & $2.463,00$ & $6.927,36$ & 18,75 & $45.000,00$ & $58.017,0$ \\
\hline DEBZIEL & Tage & 34,02 & 29,06 & 26,93 & 0,00 & 206,06 & -- \\
\hline EKQ & $\%$ & 13,82 & 17,65 & 42,11 & $-99,09$ & 85,73 & 29,7 \\
\hline UMSATZRENT & $\%$ & 4,67 & 2,91 & 8,73 & $-13,36$ & 85,17 & $3,9^{1184}$ \\
\hline GESAMTRENT & $\%$ & 13,06 & 9,26 & 16,85 & $-74,50$ & 94,44 & 5,6 \\
\hline ZINSDECK & $\%$ & $1.726,74$ & 271,89 & $9.413,05$ & $-2.900,00$ & $131 \cdot 150,00$ & - \\
\hline KREDZIEL & Tage & 110,19 & 41,76 & 345,36 & 0,00 & $3.105,00$ & -- \\
\hline UMHANDEL & - & 40,48 & 9,80 & 100,84 & 0,00 & 792,66 & -- \\
\hline UMIND & - & 362,44 & 23,45 & $1.020,55$ & 0,00 & $6.489,33$ & $\cdots$ \\
\hline UMSATZW $^{1185}$ & $\%$ & 12,04 & 6,90 & 27,21 & $-96,54$ & 167,84 & $\cdots$ \\
\hline UMVORR & - & 70,92 & 12,83 & 207,96 & 0,62 & $2.251,00$ & -- \\
\hline ANZ_ÜB_30 & Anzahl & 0,17 & 0,00 & 0,54 & 0,00 & 3,00 & -- \\
\hline ANZ_ÜB_60 & Anzahl & 0,06 & 0,00 & 0,33 & 0,00 & 3,00 & - \\
\hline ANZ_ÜB_90 & Anzahl & 0,06 & 0,00 & 0,31 & 0,00 & 3,00 & $\cdots$ \\
\hline ANZ_ÜB_GES & Anzahl & 31,99 & 1,00 & 64,21 & 0,00 & 315,00 & -- \\
\hline AUSFALLW_B & $\%$ & 1,98 & 0,50 & 9,59 & 0,07 & 100,00 & $1,00 \% \%^{1186}$ \\
\hline TSC_JA_AGG & - & 58,44 & 62,00 & 21,75 & 4,00 & 95,00 & -- \\
\hline TSC_QA_AGG & - & 68,80 & 69,00 & 16,14 & 5,00 & 100,00 & -- \\
\hline
\end{tabular}

Tab. B-14: Finanzkennzahlen der untersuchten Unternehmen ${ }^{1187}$

Weitere Erkenntnisse lassen sich aus einer nach Kapital- und Nicht-Kapitalgesellschaft differenzierten Auswertung gewinnen. So zeigen sich signifikante Unterschiede bei den Finanzierungsstrukturen. Während der Anteil der Bankverbindlichkeiten bei Nicht-Kapitalgesellschaften im arithmetischen Mittel 45,52\% beträgt, finanzieren sich die Kapitalgesellschaften nur zu 26,82\% über Banken. Die Unterschiede sind ausschließlich im langfristigen Bereich signifikant, bei der kurzfristigen Finanzierung lassen sich keine Unterschiede beobachten. Damit einher geht die deutlich niedrigere Eigenkapitalquote bei Nicht-Kapitalgesellschaften von $3,41 \%$ versus $20,39 \%$ bei Kapitalgesellschaften. Ursächlich hierfür ist der Umstand, dass bei NichtKapitalgesellschaften in der Regel das Vermögen des Gesellschafters ohnehin unbeschränkt haftet und somit die von den Kreditgebern geforderte Eigenkapitalquote

1184 Abweichend von der Definition im Datensatz sind in der Umsatzrentabilität auf Basis der Bundesbankdaten das unregelmäßige und außerordentliche Ergebnis enthalten. Vgl. Bundesbank (2008a und 2008b).

1185 Bei der Berechnung der Parameter dieser Kennzahl wurde ein Ausreißer mit einem Umsatzwachstum von mehr als 300\% ausgeschlossen, da dieser zu einer Verzerrung der Ergebnisse führt.

1186 Vgl. Angele (2007), S. 358.

1187 Aufgrund der mangelnden Interpretierbarkeit wurden die logarithmierten Werte nicht dargestellt. 
niedriger ist. Allerdings lassen sich keine signifikanten Gruppenunterschiede bei der Ausfallwahrscheinlichkeit feststellen.

\begin{tabular}{|c|c|c|c|c|c|c|}
\hline & \multicolumn{2}{|c|}{ Kapitalgesellschaften } & \multicolumn{2}{|c|}{$\begin{array}{c}\text { Nicht- } \\
\text { Kapitalgesellschaften }\end{array}$} & \multicolumn{2}{|c|}{ Signifikanz } \\
\hline & Mittelwert & Median & Mittelwert & Median & T-Test & $\begin{array}{c}\text { Kolmogorov- } \\
\text { Smirnov }\end{array}$ \\
\hline VERB_KI_LANG_R & 16,21 & 9,50 & 30,29 & 23,30 & 0,0001 & 0,0006 \\
\hline VERB_KI_KURZ_R & 10,61 & 5,30 & 15,24 & 5,70 & 0,0782 & 0,0841 \\
\hline VERB_KI_R & 26,82 & 19,60 & 45,52 & 39,05 & 0,0001 & 0,0011 \\
\hline VERM_LA_R & 29,44 & 25,20 & 42,51 & 39,45 & 0,0001 & 0,0003 \\
\hline KASSE_R & 10,80 & 3,80 & 6,38 & 2,55 & 0,0119 & 0,0109 \\
\hline VERB_KI_LANG_A & 639,33 & 67,68 & 471,08 & 175,30 & 0,6036 & 0,0489 \\
\hline KASSE_A & 224,28 & 51,95 & 188,17 & 24,93 & 0,7104 & 0,0860 \\
\hline UMSATZ & $5.441,17$ & $2.890,10$ & $4.851,26$ & $2.013,50$ & 0,5424 & 0,0220 \\
\hline EKQ & 20,39 & 19,08 & 3,41 & 12,25 & 0,0036 & 0,0023 \\
\hline UMSATZRENT & 3,15 & 2,15 & 7,07 & 4,89 & 0,0011 & 0,0014 \\
\hline GESAMTRENT & 9,36 & 7,93 & 2098,52 & 16,37 & 0,2069 & 0,0001 \\
\hline UMSATZW & 222,67 & 10,65 & 14,71 & 2,03 & 0,4137 & 0,0171 \\
\hline ANZ_ÜB_GES & 25,65 & 1,00 & 42,01 & 0,50 & 0,0674 & 0,0177 \\
\hline AUSFALLW_B & 1,67 & 0,50 & 2,45 & 0,50 & 0,5596 & 0,2819 \\
\hline TSC_JA_AGG & 61,56 & 64,50 & 53,72 & 56,50 & 0,0156 & 0,0565 \\
\hline TSC_QA_AGG & 70,48 & 71,00 & 66,38 & 67,00 & 0,0951 & 0,3286 \\
\hline $\mathrm{N}$ & & 133 & & 84 & & \\
\hline
\end{tabular}

Tab. B-15: Finanzkennzahlen differenziert nach Kapitalgesellschaft vs. Nicht-Kapitalgesellschaft ${ }^{1188}$

Im nächsten Schritt erfolgte eine Analyse der Finanzkennzahlen differenziert nach Branchen. In Tab. B-16 sind neben den Kennzahlen, die signifikante Gruppenunterschiede ausweisen, aufgrund ihrer Wichtigkeit auch die Eigenkapitalquote und die Ausfallwahrscheinlichkeit dargestellt.

Die Untersuchung der Finanzierungsstrukturen nach Branchen zeigt, dass Handelsunternehmen sich mit einem arithmetischen Mittel von 44,08\% für den Anteil der Bankfinanzierung am stärksten über Banken refinanzieren, wohingegen Bauunternehmen nur einen Anteil der Bankfinanzierung von 19,71\% ausweisen. Die Eigenkapitalquote beträgt bei den sonstigen Unternehmen im Durchschnitt 22,92\%, während die Dienstleistungsunternehmen eine Eigenkapitalquote von $-0,02 \%$ ausweisen. Die Bauunternehmen weisen nach den „sonstigen Unternehmen“ mit 19,52\% die zweithöchste Eigenkapitalquote auf. Die Ursachen liegen u.a. an dem niedrigen Anteil an Kapitalge-

1188 Hier erfolgt nur ein Ausweis der Kennzahlen, die zumindest bei einem der beiden Tests auf dem 10\%-Niveau signifikante Unterschiede aufweisen. Für eine vollständige Abbildung der Finanzkennzahlen vgl. Anhang 2, Tab. AN 2-1. 
sellschaften bei Dienstleistungsunternehmen, so firmieren nur $51,43 \%$ der Dienstleistungsunternehmen in der Rechtsform der Kapitalgesellschaft im Vergleich zu 66,00\% bei den Bauunternehmen. Die Eigenkapitalquote für Bauunternehmen im bundesweiten Durchschnitt ist mit 8,43\% signifikant niedriger. ${ }^{1189}$ Die Gruppenunterschiede sind hinsichtlich der Eigenkapitalquote statistisch nicht signifikant.

Handelsunternehmen weisen mit 22,46 Tagen das niedrigste Debitorenziel aus. Dies deutet darauf hin, dass hohe Barumsätze getätigt oder die Rechnungen schnell gezahlt werden. Insbesondere bei Einzelhandelsunternehmen werden die Rechnungen im Wesentlichen direkt bar bezahlt. Dementsprechend ist das Debitorenziel bei Bauunternehmen mit 42,42 Tagen am höchsten, da hier i.d.R. längere Zahlungsziele gewährt werden, die Zahlungsmoral der Abnehmer ggf. schlechter und das Mahnwesen möglicherweise optimierungsbedürftig ist.

Die Ausfallwahrscheinlichkeit der Produktionsunternehmen beträgt 4,28\% im Mittel und liegt deutlich über dem Wert in der Baubranche von $0,89 \%$. Die vergleichsweise sehr niedrige Ausfallwahrscheinlichkeit bei Bauunternehmen könnte auf bereits durchgeführte Bereinigungen des Kreditportfolios zurückzuführen sein, so dass während der jahrelangen Krise in der Baubranche bonitätsmäßig schlechte Unternehmen keine Kredite mehr erhalten haben. Unter der Annahme, dass die Eigenkapitalquote eine zentrale Größe bei der Ermittlung der Ausfallwahrscheinlichkeit ist, kann dieser Zusammenhang auch als Erklärung für die im Vergleich zum Bundesdurchschnitt sehr niedrige Eigenkapitalquote bei Bauunternehmen herangezogen werden. Die Gruppenunterschiede hinsichtlich der Ausfallwahrscheinlichkeit sind statistisch nicht signifikant.

1189 Eigene Berechnungen auf Basis des Datenmaterials der Bundesbank. Vgl. Bundesbank (2008b). 


\begin{tabular}{|c|c|c|c|c|c|c|c|c|c|}
\hline & & $\begin{array}{c}\text { Produk- } \\
\text { tion }\end{array}$ & Handel & $\begin{array}{c}\text { Dienst- } \\
\text { Istg. }\end{array}$ & Bau & $\begin{array}{c}\text { Sonsti- } \\
\text { ges }\end{array}$ & $\begin{array}{c}\text { Ge- } \\
\text { samt }\end{array}$ & $\begin{array}{l}\text { ANO- } \\
\text { VA }\end{array}$ & $\begin{array}{c}\text { Kruskal- } \\
\text { Wallis }\end{array}$ \\
\hline \multirow{2}{*}{ VERB_KI_R } & Mittelwert & 32,65 & 44,08 & 42,89 & 19,71 & 28,57 & 34,06 & \multirow{2}{*}{0,0026} & \multirow{2}{*}{0,0044} \\
\hline & Median & 29,10 & 39,15 & 20,90 & 14,35 & 10,20 & 22,40 & & \\
\hline \multirow{2}{*}{ VERM_LA_R } & Mittelwert & 36,70 & 30,70 & 42,07 & 26,04 & 49,42 & 34,50 & \multirow{2}{*}{0,0010} & \multirow{2}{*}{0,0073} \\
\hline & Median & 37,10 & 27,30 & 45,30 & 20,45 & 53,10 & 32,60 & & \\
\hline \multirow{2}{*}{ KASSE_R } & Mittelwert & 7,52 & 6,15 & 13,69 & 9,15 & 14,73 & 9,09 & \multirow{2}{*}{0,0162} & \multirow{2}{*}{0,0900} \\
\hline & Median & 2,60 & 2,35 & 7,10 & 5,35 & 6,50 & 3,30 & & \\
\hline \multirow{2}{*}{ DEBZIEL } & Mittelwert & 36,17 & 22,46 & 34,91 & 42,42 & 39,77 & 34,02 & \multirow{2}{*}{0,0018} & \multirow{2}{*}{0,0000} \\
\hline & Median & 30,96 & 18,55 & 27,49 & 37,31 & 41,88 & 29,06 & & \\
\hline \multirow{2}{*}{ EKQ } & Mittelwert & 17,17 & 11,29 & $-0,02$ & 19,52 & 22,92 & 13,82 & \multirow{2}{*}{0,1944} & \multirow{2}{*}{0,5306} \\
\hline & Median & 17,65 & 14,94 & 15,47 & 21,44 & 26,28 & 17,65 & & \\
\hline \multirow{2}{*}{ KREDZIEL } & Mittelwert & 68,43 & 31,50 & 222,28 & 131,36 & 283,96 & 110,19 & \multirow{2}{*}{0,0265} & \multirow{2}{*}{0,0001} \\
\hline & Median & 40,29 & 27,95 & 62,61 & 54,135 & 50,03 & 41,76 & & \\
\hline \multirow{2}{*}{ AUSFALLW_B } & Mittelwert & 4,28 & 1,28 & 1,39 & 0,89 & 1,03 & 1,98 & \multirow{2}{*}{0,3414} & \multirow{2}{*}{0,3997} \\
\hline & Median & 0,35 & 0,50 & 0,50 & 0,50 & 0,35 & 0,50 & & \\
\hline $\mathrm{N}$ & & 57 & 58 & 35 & 50 & 17 & 217 & & \\
\hline
\end{tabular}

Tab. B-16: Finanzkennzahlen differenziert nach Branchen

Unterschiede bei den Finanzierungsstrukturen zeigen sich ebenso bei einer Differenzierung nach Größenklassen. Im Folgenden wird eine Gruppierung der Datenbasis nach Unternehmen mit mehr als bzw. weniger gleich 2,5 Mio. EUR Umsatz vorgenommen (vgl. Tab. B-17). ${ }^{1190}$ Der Anteil der Bankfinanzierung und somit die Abhängigkeit von Banken ist bei kleineren Unternehmen mit $41,25 \%$ deutlich größer als bei größeren Unternehmen (26,80\%). Die Bindung der kleineren Unternehmen an die untersuchten Banken scheint größer zu sein, denn die Bindung eines Unternehmens an eine Bank wird um so stärker sein, je größer die Bedeutung der Bankkredite im Vergleich zu anderen Finanzierungsquellen ist. ${ }^{1191}$ Erhebliche Unterschiede zeigen sich auch hinsichtlich der Eigenkapitalausstattung, so beträgt die Eigenkapitalquote bei Unternehmen mit einem Umsatz von größer gleich 2,5 Mio. EUR 24,50\% verglichen mit 3,23\% bei den kleineren Unternehmen. Unter der Annahme, dass die Eigenkapitalquote eine wichtige Größe zur Bestimmung der Ausfallwahrscheinlichkeit ist, wird das Ergebnis durch die signifikant höhere Ausfallwahrscheinlichkeit von 3,15\% bei kleineren Unternehmen im Vergleich zu $0,79 \%$ bei größeren Unternehmen bestätigt. Der Anteil der kleinen Unternehmen, die als Kapitalgesellschaft firmieren, beträgt 55,0\% verglichen mit $67,6 \%$ bei den größeren Unternehmen, so dass einige Gruppenunterschiede, wie bspw. die niedrigere Eigenkapitalquote bei kleineren Unternehmen, nicht nur auf die Größe, sondern auch auf den geringeren Anteil an Kapitalgesellschaften zurückzuführen ist. Kapitalgesellschaften weisen gemäß Tab. B-15 signifikant höhere Eigenkapitalquoten auf als Nicht-Kapitalgesellschaften.

1190 Die Schwelle von 2,5 Mio. EUR wurde mit dem Ziel festgelegt, die Datenbasis in zwei ungefähr gleich große Gruppen zu unterteilen.

1191 Vgl. Fischer (1990), S. 59. 
Als abschließende unternehmensbezogene Variable soll noch das Unternehmensalter untersucht werden. Das durchschnittliche Alter der Unternehmen in der Stichprobe beträgt 24,70 Jahre (Median: 22, Standardfehler: 1,4080; Standardabweichung: 20,7417). Das Alter der Unternehmen reicht von einem Jahr bis hin zu 198 Jahren. Das Durchschnittsalter bei Nicht-Kapitalgesellschaften liegt mit 29,87 Jahren über dem Durchschnitt bei Kapitalgesellschaften von 21,44. Unternehmen der Dienstleistungsbranche stellen mit einem Durchschnittsalter von 18,69 Jahren die jüngsten Unternehmen, während die Handelsunternehmen mit 31,31 Jahren das höchste Durchschnittsalter aufweisen. Ein Zusammenhang zur Bonität und somit zur Überlebenswahrscheinlichkeit der Unternehmen kann nicht abgeleitet werden.

\begin{tabular}{|l|r|r|r|r|r|r|}
\hline & \multicolumn{2}{|c|}{$\begin{array}{c}\text { Umsatz kleiner } \\
\mathbf{2 , 5} \text { Mio. EUR }\end{array}$} & \multicolumn{2}{c|}{$\begin{array}{c}\text { Umsatz gröBer } \\
\mathbf{2 , 5} \text { Mio. EUR }\end{array}$} & \multicolumn{2}{c|}{ Signifikanz } \\
\cline { 2 - 8 } & Mittelwert & Median & Mittelwert & Median & T-Test & $\begin{array}{c}\text { Kolmogorov- } \\
\text { Smirnov }\end{array}$ \\
\hline VERB_KI_LANG_R & 26,83 & 15,00 & 16,43 & 10,70 & 0,0031 & 0,1047 \\
\hline VERB_KI_KURZ_R & 14,42 & 6,50 & 10,37 & 3,80 & 0,1139 & 0,0809 \\
\hline VERB_KI_R & 41,25 & 28,10 & 26,80 & 20,85 & 0,0021 & 0,0799 \\
\hline VERM_LA_R & 37,38 & 34,90 & 31,60 & 29,10 & 0,0774 & 0,3458 \\
\hline BILANZS & $1.219,75$ & 517,90 & $3.752,43$ & $2.606,00$ & 0,0000 & 0,0000 \\
\hline UMSATZ & $1.287,45$ & $1.163,00$ & $9.174,53$ & $5.894,35$ & 0,0000 & 0,0000 \\
\hline EKQ & 3,23 & 13,37 & 24,50 & 21,51 & 0,0002 & 0,0172 \\
\hline KREDZIEL & 164,30 & 42,17 & 60,58 & 41,03 & 0,0305 & 0,1677 \\
\hline UMIND & 126,77 & 23,67 & 512,78 & 22,39 & 0,0720 & 0,8669 \\
\hline UMSATZW & 14,49 & 3,57 & 269,11 & 8,44 & 0,3044 & 0,0337 \\
\hline UMVORR & 114,28 & 18,46 & 31,31 & 10,35 & 0,0047 & 0,0032 \\
\hline ANZ_ÜB_30 & 0,27 & 0,00 & 0,06 & 0,00 & 0,0054 & 0,3363 \\
\hline ANZ_ÜB_60 & 0,10 & 0,00 & 0,03 & 0,00 & 0,0996 & 1,0000 \\
\hline ANZ_ÜB_90 & 0,10 & 0,00 & 0,03 & 0,00 & 0,0996 & 1,0000 \\
\hline ANZ_ÜB_GES & 46,28 & 4,00 & 17,56 & 0,00 & 0,0009 & 0,0249 \\
\hline AUSFALLW_B & 3,15 & 0,75 & 0,79 & 0,35 & 0,0700 & 0,0018 \\
\hline TSC_JA_AGG & 52,35 & 53,00 & 64,80 & 68,00 & 0,0001 & 0,0000 \\
\hline TSC_QA_AGG & 66,19 & 66,00 & 71,76 & 73,25 & 0,0208 & 0,0079 \\
\hline N & & 109 & & 108 & & \\
\hline
\end{tabular}

Tab. B-17: Finanzkennzahlen differenziert nach Unternehmensgröße $\mathrm{B}^{1192}$

1192 In dieser Tabelle erfolgt nur ein Ausweis der Kennzahlen, die zumindest bei einem der beiden Tests auf dem 10\%-Niveau signifikante Unterschiede aufweisen. Für eine vollständige Abbildung der Finanzkennzahlen vgl. Anhang 2, Tab. AN 2-2. 


\begin{tabular}{|l|l|r|r|r|r|}
\hline Kriterium & Ausprägung & N & Alter & $\begin{array}{l}\text { T-Test bzw. } \\
\text { ANOVA }^{1193}\end{array}$ & $\begin{array}{l}\text { Kolmogorov- } \\
\text { Smirnov bzw. } \\
\text { Kruskal-Wallis }\end{array}$ \\
\hline Gesamt & X & 217 & 24,7005 & $\mathrm{x}$ & $\mathbf{x}$ \\
\hline \multirow{2}{*}{ Rechtsform } & Kapital & 133 & 21,4361 & 0,0033 & 0,0022 \\
\cline { 2 - 4 } & Nicht-Kapital & 84 & 29,8690 & & \\
\hline \multirow{3}{*}{ Branche } & Produktion & 57 & 20,2632 & & \\
\cline { 2 - 4 } & Handel & 58 & 31,3103 & & \\
\cline { 2 - 4 } & Dienstleistung & 35 & 18,6857 & \multirow{2}{*}{0,1106} & \\
\cline { 2 - 4 } & Bau & 50 & 24,6000 & & \\
\cline { 2 - 3 } & Sonstiges & 17 & 29,7059 & & \\
\hline \multirow{2}{*}{ Größe } & Umsatz kleiner 2.500 TEUR & 109 & 26,8056 & & \\
\cline { 2 - 4 } & Umsatz größer 2.500 TEUR & 108 & 22,6147 & 0,1367 & \\
\hline
\end{tabular}

Tab. B-18: Alter differenziert nach Rechtsform, Branche und Unternehmensgröße

Während bisher ausschließlich unternehmensbezogene Variablen untersucht wurden, wird in einem nächsten Schritt die Geschäftsbeziehung zwischen Bank und Unternehmen betrachtet. Zunächst erfolgt die Fokussierung hierbei auf die klassischen Beziehungsvariablen, die Variablen zu den Konstrukten Vertrauen und Commitment werden aufgrund der besonderen Bedeutung in einem separaten Kapital untersucht.

\subsubsection{Beschreibung der Kunde-Bank-Beziehung mit beziehungsbezogenen Variablen}

Als unternehmensbezogene Variable kann das Unternehmensalter als Indikator dafür verwendet werden, in welchem Umfang öffentliche Informationen zur Verfügung stehen. ${ }^{1194}$ Die Informationen sind Inside- und Outside-Banken gleichermaßen zugänglich. Um hingegen den Umfang der privaten Informationen, die der jeweiligen Bank vorliegen, messen zu können, ist eine beziehungsbezogene Variable erforderlich. Grundsätzlich zeigen empirische Studien, dass ein intensiverer Kontakt zu einer besseren Beziehungsqualität und einem besseren Vertriebserfolg führt. ${ }^{1195} \mathrm{Da}$ die Informationssammlung als kumulativer Prozess zu verstehen ist und die Geschäftbeziehung gemäß der phasenorientierten Interaktionsmodelle erst im Zeitablauf an Intensität gewinnt, ${ }^{1196}$ ist die Dauer der Kundenbeziehung (DAU_BEZ_ERR) von elementarer Bedeutung. Die durchschnittliche Dauer der Kundenbeziehung beträgt 19,27 Jahre (Median: 20, Standardabweichung: 12,47). In fast $90 \%$ der Fälle dauert die Geschäftsbeziehung fünf Jahre oder länger. Die maximale Dauer der Kundenbeziehung beträgt 86 Jahre. Da es unwahrscheinlich erscheint, dass die gesammelten Informationen auch bei einem Beraterwechsel uneingeschränkt weitergegeben werden, insbesondere vor

1193 Bei dem Branchenkriterium werden die Werte für die ANOVA und den Kruskal-Wallis-Test ausgewiesen, da die Gruppenzahl größer als zwei ist.

1194 Vgl. Berger/Udell (1995), S. 963.

1195 Vgl. Crosby/Evans/Cowles (1990), S. 76 oder Homburg/Schäfer (2002), S. 20.

1196 Vgl. hierzu die Ausführungen in Kapitel A.5.2.2.2.1. 
dem Hintergrund, dass es sich hierbei auch um weiche, intersubjektiv nicht überprüfbare Informationen handelt, wurde zusätzlich die Dauer der Beziehung zum Firmenkundenbetreuer (DAU_PERS_ERR) untersucht. Die Dauer der persönlichen Beziehung ist ferner deswegen relevant, da der intensive persönliche Kontakt im Kontext der Geschäftsbeziehung auch losgelöst vom reinen Informationsprozess als wesentliche Komponente beschrieben wird. Im Modell der IMP-GrouP wurde der soziale Austausch als ein wesentliches Element zur Beschreibung der Interaktion hervorgehoben. ${ }^{1197}$ So baut sich eine vertrauensvolle Beziehung in der Regel im Zeitablauf auf. Die Dauer der persönlichen Beziehung zwischen dem Firmenkundenbetreuer und dem jeweiligen Ansprechpartner im Unternehmen beträgt 7,36 (Median: 6,00, Standardabweichung: 6,1160). Die Beziehungsdauer reicht von einem halben Jahr bis hin zu einer maximalen Dauer von 30 Jahren. In 59,10\% der Fälle beträgt die Dauer 5 Jahre oder mehr.

\begin{tabular}{|l|r|r|r|}
\hline & Mittelwert & Median & $\begin{array}{c}\text { Standard- } \\
\text { abweichung }\end{array}$ \\
\hline DAU_BEZ_ERR & 19,2719 & 20,00 & 12,4720 \\
\hline DAU_PERS_ERR & 7,3605 & 6,00 & 6,1160 \\
\hline
\end{tabular}

Tab. B-19: Dauer der Beziehung zur Bank und zum Firmenkundenbetreuer

Als weitere zentrale Dimension für die Beurteilung des Informationsvorsprungs der jeweiligen Bank wurde in Kapitel A.4.3.2.1 die Breite der in Anspruch genommenen Dienstleistungen genannt. COLE hat zu diesem Zweck vier Variablen in der Untersuchung berücksichtigt, die die Art der beanspruchten Finanzdienstleistungen beschreiben. Er verwendet Variablen für die Nutzung von Kontokorrentkonten, Sparkonten, Kredite und Financial Management Services, da die Nutzung derselben in unterschiedlichem Umfang zur Informationsgenerierung beiträgt. ${ }^{1198}$ In Anlehnung an COLE wurde in der vorliegenden Studie abgefragt, welche der nachstehenden Produkte und Leistungen der Kunde bei dieser Bank nutzt: Privatkonten, Vermögensanlage, Mitgliedschaft, ${ }^{1199}$ Versicherungen, Darlehen, Zahlungsverkehr. So nutzen 58,93\% der Unternehmen Produkte aus mindestens vier Bereichen (vgl. Abb. B-7) und in immerhin mehr als 72,56\% der Fälle unterhält der Unternehmer bzw. der Hauptgeschäftsführer auch seine Privatkonten bei dieser Bank (vgl. Abb. B-8).

\footnotetext{
1197 Vgl. hierzu die Ausführungen in Kapitel A.5.2.2.1.1.

1198 Vgl. Kapitel A.4.3.2.4 und Cole (1998), S. 962.

1199 Zwar handelt es sich bei der Mitgliedschaft auch um ein Produkt, denn der Kunde unterhält Genossenschaftsanteile. Wie in den weiteren Untersuchungen noch geprüft wird, wird allerdings aus der Nutzung dieses Produktes nicht nur aufgrund der Informationsgenerierung, sondern vielmehr aufgrund der resultierenden Bindungswirkung ein Einfluss erwartet.
} 


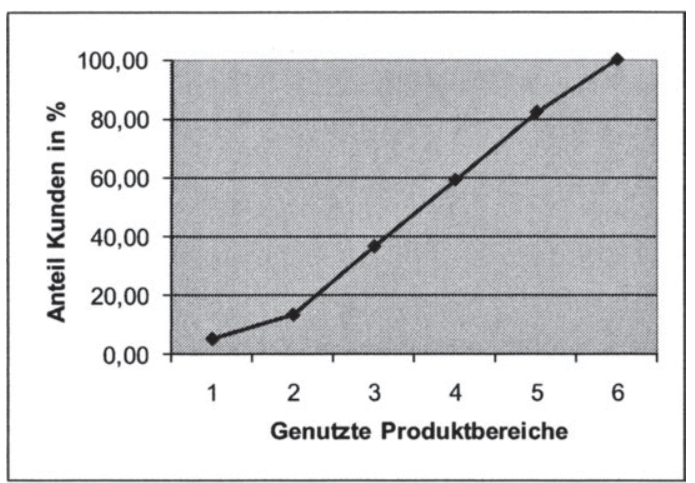

Abb. B-7: Anzahl der Produktbereiche, aus denen Produkte genutzt werden

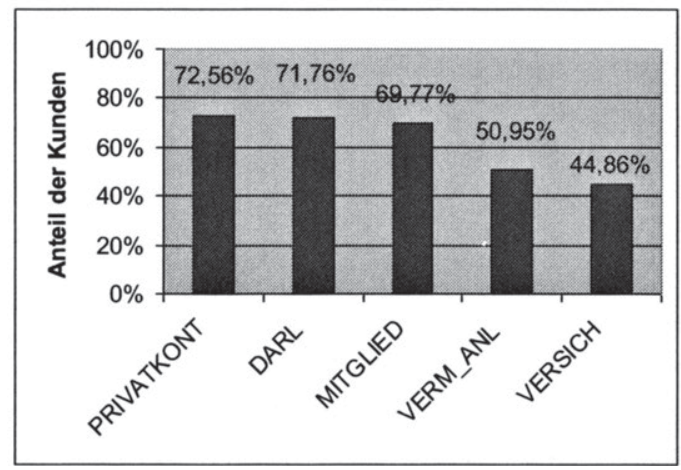

Abb. B-8: Nutzung der Bankprodukte

Der vermutete Informationsvorsprung der Inside-Bank in Bezug auf private Informationen resultiert zum einen unmittelbar aus der Produktnutzung. Das Rückzahlungsverhalten hinsichtlich der bereits aufgenommenen Darlehen lässt Rückschlüsse auf die Zahlungsfähigkeit zu, die Transaktion auf den Zahlungsverkehrskonten ermöglichen darüber hinaus einen tiefen Einblick in das Zahlungsverhalten des Kunden. Zum anderen geht eine vermehrte Produktnutzung vermutlich auch mit einer größeren Kontakthäufigkeit einher. Losgelöst von den zugrunde liegenden Produkten führt ein Anstieg der Kontakthäufigkeit auch zum vermehrten Informationsaustausch. So beträgt die Anzahl der qualifizierten Beratungsgespräche je Jahr im Durchschnitt 2,79 (Median: 2, Standardabweichung: 1,75) und die Anzahl der jährlichen Kontakte, seien es E-Mails, Telefonate oder Briefe, 11,29 (Median: 8, Standardabweichung: 16,55) bei einer maxi- 
malen Kontaktzahl von 200 Stück. Der Hauptansprechpartner für die Bank ist in $95,35 \%$ der Fälle in der Geschäftsführung angesiedelt, somit wird die in Kapitel A.2.1.2 beschriebene Aufgabenkonzentration bei der Geschäftsführung - zumindest in Bezug auf den Abschluss von Finanzgeschäften - bestätigt. Bei einer Differenzierung nach der Anzahl der genutzten Produkte lässt sich eine steigende Anzahl von Beratungsgesprächen sowie eine steigende Kontakthäufigkeit mit zunehmender Zahl der genutzten Produkte bzw. der Nutzung von Produkten aus den verschiedenen Bereichen erkennen (vgl. Tab. B-20 und Abb. B-9). Die Kontakthäufigkeit nimmt wieder ab, wenn Produkte aus mindestens fünf Bereichen genutzt werden. Die Anzahl der Beratungsgespräche steigt zwar auch mit zunehmender Unternehmensgröße, gemessen am Umsatz, tendenziell an (vgl. Tab. B-20 und Tab. B-21), jedoch ist bei Unternehmen mit einem Umsatz von 1-2,5 Mio. EUR die Anzahl mit 2,81 im Mittel größer als bei Unternehmen mit mehr als 7,5 Mio. EUR Umsatz. Hinsichtlich der Anzahl der Kontakte allgemein lässt sich hier keine steigende Tendenz mit zunehmender Größe beobachten. Die Anzahl der Kontakte wird anscheinend nicht direkt durch die Unternehmensgröße determiniert. Die Gruppierung nach dem Anteil des Zahlungsverkehrs beim jeweiligen Institut liefert bessere Resultate (vgl. Tab. B-22). Die Gruppenunterschiede sind allerdings nicht gravierend, der Umfang des Zahlungsverkehrs scheint auch nicht ursächlich zu sein für die Anzahl der Beratungsgespräche und Kontakte je Jahr.

\begin{tabular}{|l|r|r|r|r|}
\hline \multirow{2}{*}{$\begin{array}{l}\text { Anzahl genutzter } \\
\text { Produkte }\end{array}$} & \multicolumn{2}{|c|}{ ANZ_BER_J } & \multicolumn{2}{c|}{ ANZ_KONT_J } \\
\cline { 2 - 5 } & $\begin{array}{c}\text { Mittel- } \\
\text { wert }\end{array}$ & Median & $\begin{array}{c}\text { Mittel- } \\
\text { wert }\end{array}$ & Median \\
\hline 1 & 2,1000 & 2 & 8,0000 & 7,5 \\
\hline 2 & 2,5294 & 2 & 9,0588 & 5 \\
\hline 3 & 2,4792 & 2 & 9,3958 & 6,5 \\
\hline 4 & 2,8298 & 3 & 14,7660 & 10 \\
\hline 5 & 2,9167 & 2 & 13,6875 & 8,5 \\
\hline 6 & 3,0811 & 3 & 8,6216 & 8 \\
\hline Gesamt & 0,1897 & 2 & 0,2071 & 8 \\
\hline ANOVA & & 0,3985 & & 0,3999 \\
\hline Kruskal-Wallis & \multicolumn{3}{|c}{0,1897} & \multicolumn{3}{|c}{0,2071} \\
\hline
\end{tabular}

Tab. B-20: Beratungsgespräche und Kontakthäufigkeiten je Jahr differenziert nach Anzahl der genutzten Produkte 


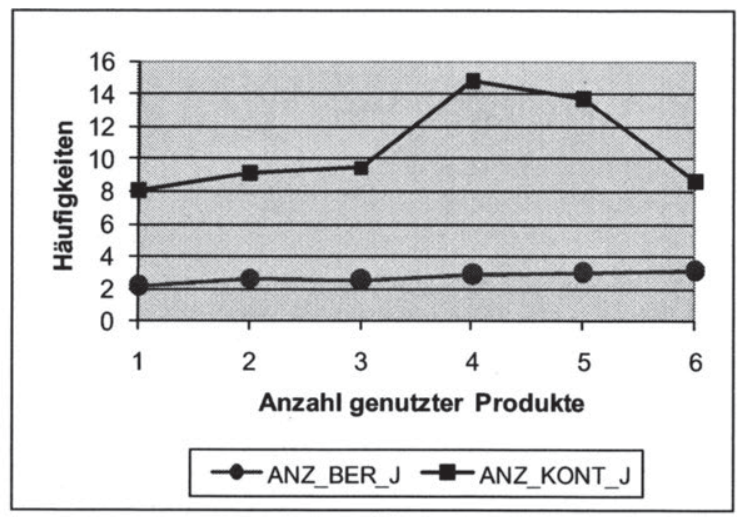

Abb. B-9: Beratungsgespräche und Kontakthäufigkeiten je Jahr differenziert nach Anzahl der genutzten Produkte

\begin{tabular}{|c|c|c|c|c|c|c|c|c|c|c|}
\hline \multirow{2}{*}{$\begin{array}{l}\text { UMSATZ } \\
\text { (in Mio. EUR) }\end{array}$} & \multicolumn{2}{|l|}{$<1$} & \multicolumn{2}{|c|}{$1-2,5$} & \multicolumn{2}{|c|}{$2,5-7,5$} & \multicolumn{2}{|c|}{$>7,5$} & \multicolumn{2}{|c|}{ Gesamt } \\
\hline & $\begin{array}{c}\text { Mittel- } \\
\text { wert }\end{array}$ & $\begin{array}{l}\text { Me- } \\
\text { dian }\end{array}$ & $\begin{array}{c}\text { Mittel- } \\
\text { wert }\end{array}$ & $\begin{array}{l}\text { Me- } \\
\text { dian }\end{array}$ & $\begin{array}{c}\text { Mittel- } \\
\text { wert }\end{array}$ & $\begin{array}{l}\text { Me- } \\
\text { dian }\end{array}$ & $\begin{array}{c}\text { Mittel- } \\
\text { wert }\end{array}$ & $\begin{array}{l}\text { Me- } \\
\text { dian }\end{array}$ & $\begin{array}{c}\text { Mittel- } \\
\text { wert }\end{array}$ & $\begin{array}{l}\text { Me- } \\
\text { dian }\end{array}$ \\
\hline ANZ_BER_J & 2,40 & 2 & 2,81 & 3 & 3,23 & 3 & 2,71 & 2 & 2,79 & 2 \\
\hline ANZ_KONT_J & \begin{tabular}{|l|}
9,65 \\
\end{tabular} & 6 & 12,99 & 6 & 12,60 & 10 & 9,62 & 10 & 11,29 & 8 \\
\hline $\mathrm{N}$ & & 40 & & 69 & & 43 & & 65 & & 217 \\
\hline
\end{tabular}

Tab. B-21: Beratungsgespräche und Kontakthäufigkeiten je Jahr differenziert nach Umsatzgröße

\begin{tabular}{|c|c|c|c|c|c|c|c|c|}
\hline \multirow[b]{2}{*}{ ANT_ZV (in \%) } & \multicolumn{2}{|c|}{$<50$} & \multicolumn{2}{|c|}{ 50- 80 (exkl.) } & \multicolumn{2}{|c|}{ 80-100 (exkl.) } & \multicolumn{2}{|c|}{100} \\
\hline & $\begin{array}{c}\text { Mittel- } \\
\text { wert }\end{array}$ & Median & $\begin{array}{c}\text { Mittel- } \\
\text { wert }\end{array}$ & Median & $\begin{array}{c}\text { Mittel- } \\
\text { wert }\end{array}$ & Median & $\begin{array}{c}\text { Mittel- } \\
\text { wert }\end{array}$ & Median \\
\hline ANZ_BER_J & 2,55 & 2,13 & 2,57 & 2 & 3,00 & 3 & 3,57 & 3 \\
\hline ANZ_KONT_J & 9,68 & 7,21 & 9,62 & 6 & 15,79 & 10 & 14,75 & 10 \\
\hline $\mathrm{N}$ & & 67 & & 53 & & 35 & & 59 \\
\hline
\end{tabular}

Tab. B-22: Beratungsgespräche und Kontakthäufigkeiten je Jahr differenziert nach Anteil Zahlungsverkehr

Zentrale Variablen bei der Untersuchung der Kunde-Bank-Beziehung sind ferner die Anzahl der Bankverbindungen der einzelnen Unternehmen sowie der Anteil der einzelnen Banken an der gesamten Bankfinanzierung des Unternehmens. Gemäß der Einschätzung der Firmenkundenbetreuer refinanzieren sich die Unternehmen der Stichprobe zu 66,63\% (Median: 80,00\%) bei dem jeweiligen Institut und unterhalten im Schnitt ca. 2,23 Bankverbindungen (vgl. Tab. B-23). Die maximale Anzahl an Bankverbindungen bei den untersuchten Unternehmen beträgt immerhin neun Bankverbindungen. 


\begin{tabular}{|l|r|r|r|r|r|}
\hline & $\begin{array}{c}\text { Mittel- } \\
\text { wert }\end{array}$ & Median & $\begin{array}{c}\text { Standard- } \\
\text { abweichung }\end{array}$ & Minimum & Maximum \\
\hline ANT_BANK_IN & 66,6266 & 80 & 35,0327 & 0 & 100 \\
\hline ANZ_B_AGG & 2,2275 & 2 & 1,1042 & 1 & 9 \\
\hline
\end{tabular}

Tab. B-23: Beschreibung der Kunde-Bank-Beziehung

Diese Variablen reflektieren einen möglichen Informationsvorsprung der Bank, bedingt durch den hohen Anteil am gesamten Geschäftsvolumen des Unternehmens. Sie sind gleichzeitig aber auch Ausdruck der Verhandlungsmacht bzw. Marktmacht der Bank gegenüber dem Unternehmen. Im Modell von PETERSEN/RAJAN wurde die Marktmacht der Bank und daraus resultierend eine geringe Gefahr des Bankwechsels durch den Kunden als Voraussetzung für die intertemporale Konditionengestaltung betrachtet. ${ }^{1200}$ Die Marktmacht der Bank bestimmt, inwiefern mögliche Effizienzgewinne an den Kunden weitergegeben werden. Hinsichtlich der optimalen Anzahl an Bankverbindungen kommen somit zwei gegenläufige Effekte zum Tragen. Auf der einen Seite liegt die Vorteilhaftigkeit der Finanzintermediation in der Nutzung von Skaleneffekten hinsichtlich der Informationsproduktion, -sammlung und -verarbeitung durch die jeweilige Bank. ${ }^{1201}$ Durch eine niedrige Anzahl von Bankverbindungen bzw. enge Kontakte zu wenigen oder gar einer Bank können intensive persönliche Beziehungen und schließlich eine gute Vertrauensbasis geschaffen werden. Denn persönliche Beziehungen bilden die Basis für das langfristige Vertrauen untereinander. ${ }^{1202}$ Schließlich sind enge persönliche Kontakte die Grundlage für schnelle Entscheidungen und eine unkomplizierte Abwicklung der Geschäfte. So kommt es bei einer parallelen Existenz von mehreren Bankverbindungen regelmäßig zu längeren Verhandlungszeiten und einem relativ umfangreichen Schriftverkehr. Seitens der Bank ist die Ausschließlichkeit der Bankverbindung im Hinblick auf die Bindung des Unternehmens von großer Bedeutung, weil durch sie der Wettbewerb mit anderen Banken weitgehend ausgeschaltet werden kann. ${ }^{1203}$ Dies setzt aber voraus, dass ein Wechsel der Bankverbindung nicht möglich ist. Das könnte dadurch verhindert werden, dass die Hausbank gegenüber anderen Banken einen Informationsvorsprung hinsichtlich der „Qualität" des Unternehmens hat.

Auf der anderen Seite streben Unternehmen - vergleichbar mit dem Problem der Lieferantenauswahl im Sachgüterbereich - häufig eine Diversifikation ihrer Hauptbankverbindung an. ${ }^{1204}$ Mögliche Gründe für die Diversifikation sind u.a. die folgenden:

\footnotetext{
$1200 \mathrm{Vgl}$. zu dem Modell von Petersen/Rajan sowie zur Bedeutung der Anzahl der Bankverbindungen ausführlich in Kapitel A.4.3.1.2.1.

Vgl. Elsas (2005), S. 110.

Vgl. Cromme (2008), S. 431.

Vgl. Fischer (1990), S. 19.

Vgl. Arbeitskreis (1988), S. 747.
} 
- Die Nutzung des Konditionenwettbewerbs zwischen den Kreditinstituten und

- die Vermeidung von temporären Kreditengpässen, die bei der Konzentration auf eine Bankverbindung aufgrund der Risikostrategie oder Kapazitätsbeschränkungen in dieser Bank auftreten können.

Das Streben nach Diversifikation wird allerdings dadurch begrenzt, dass die Geschäftsvolumina der einzelnen Bankverbindungen in einer hinreichenden Größenordnung sein müssen, so dass die Geschäftsbeziehung für Banken noch interessant ist. ${ }^{1205}$ So ist zu vermuten, dass die Anzahl der Bankverbindungen mit zunehmender Unternehmensgröße steigt und in Konsequenz auch der Finanzierungsanteil der einzelnen Banken und somit auch der Bank in der Studie abnimmt. Da beiden Variablen keine Normalverteilung gegeben ist, wurde für den Test auf Gruppenunterschiede der Kruskal-Wallis-Test herangezogen. Während der Anteil der befragten Bank an der gesamten Bankfinanzierung mit zunehmender Unternehmensgröße - sowohl gemessen an Mitarbeiterzahlen als auch am Umsatz - streng sinkt, steigt die Anzahl der Bankverbindungen dementsprechend (vgl. Tab. B-24 und Tab. B-25). Während insgesamt nur $23,3 \%$ der Unternehmen genau eine Bankverbindung unterhalten, besitzen auch bei den Unternehmen mit weniger als 1 Mio. EUR Umsatz nur 31,4\% genau eine Bankverbindung. Es zeigt sich somit, dass auch die kleineren Unternehmen in der Regel fast $70 \%-$ mehr als eine Bankverbindung aufweisen.

\begin{tabular}{|c|c|c|c|c|c|c|c|c|}
\hline \multirow{2}{*}{ Mitarbeiter } & \multicolumn{4}{|c|}{ ANT BANK IN } & \multicolumn{4}{|c|}{ ANZ B AGG } \\
\hline & $<=10$ & $>10-20$ & $>20-40$ & $>40$ & $\ll=10$ & $>10-20$ & $>20-40$ & $>40$ \\
\hline Mittelwert & 76,41 & 68,91 & 66,50 & 52,82 & 1,85 & 1,95 & 2,38 & 2,82 \\
\hline Median & 100 & 82,5 & 70 & 50 & 2 & 2 & 2 & 3 \\
\hline $\mathrm{N}$ & 39 & 72 & 58 & 39 & 33 & 66 & 52 & 38 \\
\hline $\begin{array}{l}\text { Kruskall- } \\
\text { Wallis }\end{array}$ & & & & 0,0293 & & & & 0,000 \\
\hline
\end{tabular}

Tab. B-24: Kunde-Bank-Beziehung differenziert nach Unternehmensgröße (Mitarbeiterzahl)

\begin{tabular}{|c|c|c|c|c|c|c|c|c|}
\hline \multirow{2}{*}{$\begin{array}{l}\text { Umsatz } \\
\text { (Mio. EUR) }\end{array}$} & \multicolumn{4}{|c|}{ ANT_BANK_IN } & \multicolumn{4}{|c|}{ ANZ B AGG } \\
\hline & $<=1$ & $>1-2,5$ & $>2,5-7,5$ & $>7,5$ & $<=1$ & $>1-2,5$ & $>2,5-7,5$ & $>7,5$ \\
\hline Mittelwert & 77,5000 & 70,9853 & 62,8571 & 54,5213 & 1,8000 & 1,9273 & 2,3276 & 2,8537 \\
\hline Median & 95 & 93,5 & 70 & 50 & 2 & 2 & 2 & 3 \\
\hline $\mathrm{N}$ & 38 & 68 & 63 & 39 & 35 & 55 & 58 & 41 \\
\hline $\begin{array}{l}\text { Kruskall- } \\
\text { Wallis }\end{array}$ & & & & 0,0109 & & & & 0,0000 \\
\hline
\end{tabular}

Tab. B-25: Kunde-Bank-Beziehung differenziert nach Unternehmensgröße (Umsatzklassen) 
Gemäß HOMMEL/SCHNEIDER scheint die Obergrenze für den breiten Mittelstand ungeachtet firmenspezifischer Faktoren bei zwei solcher Geschäftsverbindungen erreicht zu sein. ${ }^{1206}$ In der vorliegenden Studie haben $91,01 \%$ der Unternehmen höchstens drei Bankverbindungen (vgl. Abb. B-10), so dass die Ergebnisse im Wesentlichen die Aussage von HOMMEL/SCHNEIDER bestätigen. Dieser Zusammenhang spiegelt sich auch in dem Anteil der Bankfinanzierung bei dem befragten Institut wider (vgl. Abb. B-11). Wird eine bestimmte Grenze überschritten, geht der Informationsvorsprung der Hausbanken bei gleichzeitigem Anstieg der Transaktionskosten verloren. ${ }^{1207}$ Die damit einhergehenden direkten und indirekten Kosten scheinen die Vorteile einer größeren Diversifikation und damit die Abmilderung der eingangs erwähnten Hold UpProblematik zu überwiegen. Die empirischen Ergebnisse der Studie bestätigen damit die für den deutschen Mittelstand vermutete Beziehungspflege zu wenigen Hausbanken. ${ }^{1208}$

Im internationalen Vergleich (vgl. Tab. B-26) zeigt sich, dass die Anzahl der Bankverbindungen zwischen 1,3 und 6 im Mittelwert schwanken. Auch die kleinen Unternehmen im amerikanischen Raum haben trotz des dort herrschenden Trennbankensystems nur eine durchschnittliche Anzahl von 1,3 Bankverbindungen.

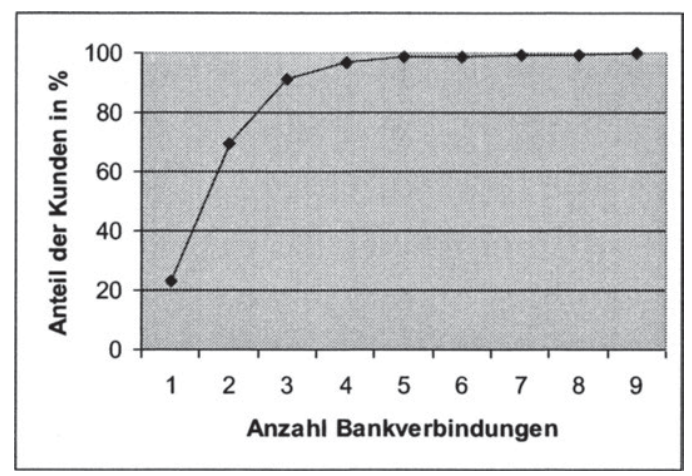

Abb. B-10: Anzahl der Bankverbindungen je Kunde

\footnotetext{
1206 Vgl. Hommel/Schneider (2004), S. 583.

1207 Vgl. Hommel/Schneider (2004), S. 583.

1208 Vgl. Hommel/Schneider (2004), S. 583.
} 


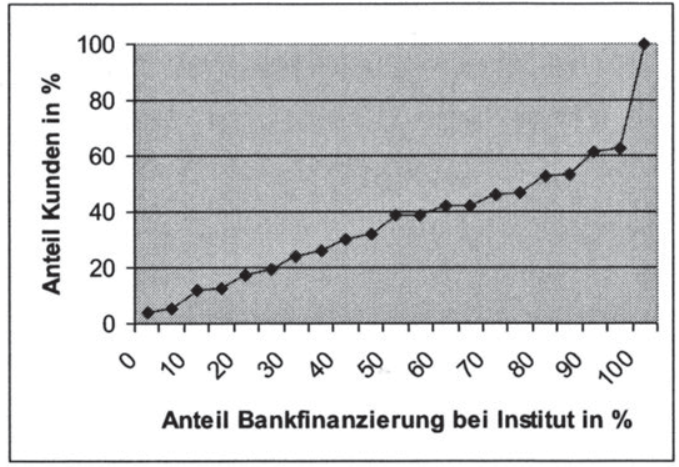

Abb. B-11: Anteil der Bankfinanzierung bei dem befragten Institut

\begin{tabular}{|l|c|c|c|c|c|c|c|}
\hline Land & USA & Japan & USA & $\begin{array}{c}\text { Deutsch- } \\
\text { land }\end{array}$ & $\begin{array}{c}\text { Deutsch- } \\
\text { land }\end{array}$ & $\begin{array}{c}\text { Norwe- } \\
\text { gen }\end{array}$ & $\begin{array}{c}\text { Deutsch- } \\
\text { land }\end{array}$ \\
\hline $\begin{array}{l}\text { Größen- } \\
\text { kategorie }\end{array}$ & Klein & Klein & Groß & Mittel & Klein & Mittel & Klein \\
\hline Zeitraum & 1987 & 1992 & $\begin{array}{c}1989- \\
1990\end{array}$ & $\begin{array}{c}1992- \\
1997\end{array}$ & 1997 & $\begin{array}{c}1979- \\
1995\end{array}$ & 2007 \\
\hline Quelle & $\begin{array}{c}\text { Petersen/ } \\
\text { Rajan } \\
(1994)\end{array}$ & $\begin{array}{c}\text { Horiuchi } \\
(1994)\end{array}$ & $\begin{array}{c}\text { Houston/ } \\
\text { James } \\
(1996)\end{array}$ & $\begin{array}{c}\text { Elsas/ } \\
\text { Krahnen } \\
(1998)\end{array}$ & $\begin{array}{c}\text { Harhoff/ } \\
\text { Körting } \\
(1998)\end{array}$ & $\begin{array}{c}\text { Ongena/ } \\
\text { Smith } \\
(2000 \mathrm{~b})\end{array}$ & $\begin{array}{c}\text { Vorlie- } \\
\text { gende } \\
\text { Studie }\end{array}$ \\
\hline Größe [Mio. \$] & 1 & $\begin{array}{c}1,3 /> \\
1,3\end{array}$ & 1502 & 56,4 & 5 & $\begin{array}{c}150 \\
\text { (Markt- } \\
\text { wert EK) }\end{array}$ & $8,2^{1209}$ \\
\hline Stichprobe & 3404 & $126 / 309$ & $\varnothing 250$ & 200 & 994 & $\varnothing 111$ & 217 \\
\hline $\begin{array}{l}\emptyset \text { (Median) } \\
\text { Anzahl Bank- } \\
\text { verbindungen }\end{array}$ & $1,3(1)$ & $2,9 / 3,1$ & 5,2 & $6(5)$ & 1,8 & $1,4(1)$ & $2,22(2)$ \\
\hline
\end{tabular}

Tab. B-26: Anzahl der Bankverbindungen im internationalen Vergleich ${ }^{1210}$

DEGRYSE/ONGENA haben in ihrer Studie zusätzlich die Distanz zwischen Unternehmen und Bank als Einflussgröße auf den Zinssatz ausführlich untersucht und räumliche Preisdifferenzierungen identifiziert. Die Zinssätze sind mit zunehmender Distanz zwischen Unternehmen und Bank gesunken, während selbige bei ansteigender Distanz zwischen der Bank und den Wettbewerbern gestiegen sind. Beide Effekte haben sich

1209 Es wurde der Dollar/EUR-Kurs vom 07.07.2008 zugrunde gelegt: 1,5647. Vgl. Comdirect (2008).

1210 Größenkategorien nach Umsatz in Mio. \$: Klein < 25/ mittel $[25 ; 250]$ / groß > 250, Umrechnungsfaktor Beschäftigte: 125.000 \$/Beschäftigtem; ø bezeichnet den Durchschnitt über die einzelnen Jahre des Beobachtungszeitraums; Quelle: In Anlehnung an Elsas (2001), S. 69 und Ongena/Smith (2000b), S. 53. 
als statistisch und ökonomisch signifikant herausgestellt. ${ }^{1211}$ In der Studie von PETERSEN/RAJAN, welche auf dem Datensatz des National Survey of Small Business Finance von 1993 basiert, beträgt das arithmetische Mittel 68,397 km (42,5 Meilen). ${ }^{1212}$ In der vorliegenden Stichprobe beträgt die durchschnittliche Distanz 13,42 km (Median: 6 $\mathrm{km}$, Standardabweichung: $42,31 \mathrm{~km}$ ), bei $90,8 \%$ der Unternehmen ist die Distanz kleiner gleich $20 \mathrm{~km}$. Die insgesamt relativ niedrige Distanz resultiert im Wesentlichen aus dem Regionalprinzip des genossenschaftlichen Sektors. ${ }^{1213}$ Verglichen mit der Studie von DEGRYSE/ONGENA ist die räumliche Distanz dennoch deutlich größer, was unter anderem aber auch auf durchschnittlich größere Unternehmensgröße in der vorliegenden Studie zurückzuführen ist. So sind in der Studie von DEGRYSE/ONGENA $82,98 \%$ Unternehmen mit nur einem Mitarbeiter enthalten, ${ }^{1214}$ während der Median in der Studie von PETERSEN/RAJAN 2-4 Mitarbeiter ${ }^{1215}$ und in der vorliegenden Studie 20 Mitarbeiter beträgt.

\begin{tabular}{|l|r|r|r|}
\hline DIST_UNT & \multicolumn{1}{|c|}{$\begin{array}{c}\text { Degryse/ } \\
\text { Ongena }^{1216}\end{array}$} & $\begin{array}{c}\text { Petersen/ } \\
\text { Rajan }\end{array}$ & $\begin{array}{c}\text { Vorliegende } \\
\text { Studie }\end{array}$ \\
\hline Mittelwert & 1,380 & 68,397 & 13,4194 \\
\hline Median & 0,858 & 6,436 & 6,0000 \\
\hline Standardabweichung & 1,4600 & -- & 42,3124 \\
\hline Minimum & 0,000 & --- & 0 \\
\hline Maximum & 10,200 & --- & 470 \\
\hline $\mathrm{N}$ & 15.044 & 5.981 & 217 \\
\hline
\end{tabular}

Tab. B-27: Geografische Distanz zwischen Bank und Unternehmen ${ }^{1217}$

Bisher wurde die Kunde-Bank-Beziehung auf aggregierter Ebene betrachtet. Die Analyse der Bankbeziehung auf Vertragsebene ergibt folgendes Bild. Im arithmetischen Mittel beträgt der Saldo des Hauptgeschäftskontos -24,88 Tsd. EUR (Median: -14,03 Tsd. EUR, Standardabweichung: 188,78 Tsd. EUR) und das dem Kunden zugesagte Limit 168,65 Tsd. EUR (Median: 100,00 Tsd. EUR, Standardabweichung: 225,58 Tsd. EUR). Das Kreditvolumen der Kunden als Summe der Darlehenssalden und dem Maximum aus Limit und tatsächlicher Inanspruchnahme je Konto liegt im arithmetischen

1211 Vgl. Degryse/Ongena (2005), S. 262.

1212 Vgl. Petersen/Rajan (2002), S. 2537. Bei der Umrechnung wurde folgendes Verhältnis zugrunde gelegt: 1 Meile $=1,609344$ Kilometer. Die Studie besteht aus 3 Teilsamples. Der Median beträgt für die Jahre 1973-1979 2 Meilen (Mittelwert: 15,8), 4 Meilen für das Teilsample der 19801989 (Mittelwert: 34), 5 Meilen für die Jahre 1990-1993 (Mittelwert: 67,8).

1213 Vgl. zu den Besonderheiten des genossenschaftlichen Sektors Kapitel A.2.2.2.

1214 Vgl. Degryse/Ongena (2005), S. 245.

1215 In der Datenbasis des National Survey of Small Business Finance von 1993 beträgt der Median gemäß Cole/Wolken 2-4 Mitarbeiter. Petersen/Rajan tätigen zur Mitarbeiterzahl keine Aussage. Vgl. hierzu Cole/Wolken (1995), S. 631.

1216 Degryse/Ongena haben die geografische Distanz in Reiseminuten angegeben. Bei der Umrechnung der Werte von Degryse/Ongena in $\mathrm{km}$ wurde in obiger Darstellung angenommen, dass eine Reisezeit von 5 min. einer Strecke von $1 \mathrm{~km}$ entspricht.

1217 Eigene Darstellung. Vgl. hinsichtlich der Daten Degryse/Ongena (2005), S. 262 und Petersen/Rajan (2002), S. 2537. 
Mittel bei 491,39 Tsd. EUR (Median: 221,31 Tsd. EUR, Standardabweichung: 1.046,63 Tsd. EUR). Diese Größe drückt aus, wie hoch das Risiko der Bank in Bezug auf diese Kunden ist. Bei einem arithmetischen Mittel von 10,38\% weist der Zinssatz des Hauptgeschäftskontos über alle Kunden ein Minimum von 5,85\% und ein Maximum von $14,50 \%$ auf, so dass immerhin eine Spannweite von 8,65 Prozentpunkten beobachtbar ist.

\begin{tabular}{|l|r|r|r|r|r|r|}
\hline & Mittelwert & Median & $\begin{array}{c}\text { Standard- } \\
\text { abweichung }\end{array}$ & Spannweite & Minimum & Maximum \\
\hline GK_SALD & $-24,88$ & $-14,03$ & 188,78 & $2.039,18$ & $-790,26$ & $1.248,92$ \\
\hline GK_LIM_EX & 168,65 & 100,00 & 225,58 & $1.752,92$ & 0,00 & $1.752,92$ \\
\hline GK_ZINS & 10,38 & 10,25 & 1,70 & 8,65 & 5,85 & 14,50 \\
\hline GES_KREDIT & 491,39 & 221,31 & $1.046,63$ & $11.423,08$ & 0,00 & $11.423,08$ \\
\hline
\end{tabular}

Tab. B-28: Parameter des Kreditvertrags

Als weiterer zentraler Parameter im Rahmen der Kreditbeziehung wird die Besicherung untersucht. ${ }^{1218}$ Zunächst soll ein Überblick über die Vorgehensweise und Ergebnisse anderer empirischer Studien zur Besicherung von Kreditverträgen vorangestellt werden. Von den dargestellten Studien untersuchen MACHAUER/WEBER ${ }^{1219}$ und ELSAS den Blankoanteil. Die anderen Studien hingegen unterscheiden nicht, ob die Besicherung $1 \%$ oder $100 \%$ beträgt, sondern untersuchen lediglich, ob eine Besicherung vorliegt.

In der durchgeführten Studie wurde bei der Besicherungsquote ein Mittelwert von 55,90\% (Median: 61,00\%, Standardabweichung: 38,79\%) bzw. ein Blankoanteil von 44,10\% (Median 39,00\%) ermittelt. Insgesamt weisen 76,06\% der Unternehmen eine Besicherungsquote größer Null auf. ${ }^{1220}$ Der Anteil liegt deutlich über den in den in anderen Studien ermittelten und in Tab. B-29 dargestellten Anteilen an besicherten Darlehen. Die erhebliche Abweichung zur Studie von DEGRYSE/VAN CAYSEELE ergibt sich möglicherweise daraus, dass bei selbiger der Bezugspunkt der Dummyvariable Besicherung das Darlehen und nicht der Kunde ist. ${ }^{1221}$

\footnotetext{
1218 Der Bezugspunkt ist in den Studien nicht einheitlich. Während bspw. Degryse/Van Cayseele die Besicherung in Bezug auf ein konkretes Darlehen untersuchen, betrachten Machauer/Weber die Besicherungsquote des Kunden. Vgl. Degryse/Van Cayseele (1998), S. 12 f. und Machauer/Weber (1998), S. 1368.

1219 Vgl. Machauer/Weber (1998), S. 1368 und Elsas (2001), S. 195.

1220 In der vorliegenden Studie wurde in vier Fällen keine Antwort gegeben, unterstellt man hierfür, dass keine Besicherung vorliegt, so beträgt dieser Anteil $74,65 \%$.

1221 Vgl. Degryse/Van Cayseele (1998), S. 12 f.
} 


\begin{tabular}{|c|c|c|c|c|c|c|c|}
\hline Studie & $\begin{array}{c}\text { Berger/ } \\
\text { Udell } \\
(1990)\end{array}$ & $\begin{array}{c}\text { Berger/ } \\
\text { Udell } \\
\text { (1995) }\end{array}$ & $\begin{array}{c}\text { Machauer/ } \\
\text { Weber } \\
\text { (1998) }\end{array}$ & $\begin{array}{c}\text { Harhoff/ } \\
\text { Körting } \\
\text { (1998) }\end{array}$ & $\begin{array}{c}\text { Degrysel } \\
\text { Van Cay- } \\
\text { seele (1998) }\end{array}$ & $\begin{array}{c}\text { Elsas } \\
(2001)\end{array}$ & $\begin{array}{l}\text { Vorlie- } \\
\text { gende } \\
\text { Studie }\end{array}$ \\
\hline $\begin{array}{l}\text { Größen- } \\
\text { kategorie }\end{array}$ & Klein & Klein & Mittel & Klein & Klein & Mittel & Mittel \\
\hline Zeitraum & $1977-1988$ & 1988 & $1992-1996$ & 1997 & 1997 & $1992-1996$ & $2007-2008$ \\
\hline Land & USA & USA & Deutschland & Deutschland & Belgien & Deutschland & Deutschland \\
\hline $\begin{array}{l}\text { Größe } \\
\text { [Mio. \$] }\end{array}$ & $\begin{array}{c}\cdots(0,1 \\
\text { Kreditvo- } \\
\text { lumen })\end{array}$ & 1 & $25-250$ & 5 & $\emptyset<1,25$ & $25-250$ & 7,65 \\
\hline $\begin{array}{l}\text { Stich- } \\
\text { probe }\end{array}$ & $\begin{array}{c}340 \text { Banken/ } \\
\emptyset 25.200 \\
\text { Kredite }\end{array}$ & $\begin{array}{l}863 \text { Daten- } \\
\text { sătze }\end{array}$ & $\begin{array}{c}200 \\
\text { Datensătze }\end{array}$ & $\begin{array}{c}994 \\
\text { Datensătze }\end{array}$ & $\begin{array}{l}17.776 \\
\text { Kredite }\end{array}$ & $\begin{array}{l}200 \text { Daten- } \\
\text { sätze }\end{array}$ & $\begin{array}{l}15 \text { Banken/ } \\
217 \text { Daten- } \\
\text { sătze }\end{array}$ \\
\hline $\begin{array}{l}\text { Anteil } \\
\text { besichert }\end{array}$ & $58 \%$ & $53 \%$ & $\begin{array}{c}66 \% \text { (Besi- } \\
\text { cherungsquote: } \\
68,6 \%)^{1222}\end{array}$ & $62 \%$ & $27 \%$ & $\begin{array}{c}69,4 \% \text { (Be- } \\
\text { sicherungs- } \\
\text { quote: } \\
31,5 \%) \\
\end{array}$ & $\begin{array}{c}76,1 \%(\mathrm{Be}- \\
\text { sicherungs- } \\
\text { quote: } \\
55,9 \%) \\
\end{array}$ \\
\hline $\begin{array}{l}\text { Sicherhei- } \\
\text { tenproxy }\end{array}$ & $\begin{array}{c}\text { Dummys } \\
\text { („,Besicherung } \\
\text { ja/nein“ sowie } \\
\text { zwei Si- } \\
\text { cherheiten- } \\
\text { arten) }\end{array}$ & $\begin{array}{l}\text { Dummy } \\
\text { („Besiche- } \\
\text { rung } \\
\text { ja/nein“) }\end{array}$ & Blankoanteil & $\begin{array}{c}\text { Dummy } \\
\text { („Besicherung } \\
\text { ja/nein“) }\end{array}$ & $\begin{array}{c}\text { Dummy } \\
\text { („Besicherung } \\
\text { ja/nein“) }\end{array}$ & Blankoanteil & $\begin{array}{l}\text { Blankoanteil } \\
\text { sowie } \\
\text { Dummy } \\
\text { (,Besiche- } \\
\text { rung } \\
\text { ja/nein“) }\end{array}$ \\
\hline
\end{tabular}

Tab. B-29: Berücksichtigung der Kreditsicherheiten in den empirischen Studien ${ }^{1223}$

Die Besicherungsquote unterliegt keiner Normal- oder Gleichverteilung, so dass sich hieraus Probleme bei der Anwendung der diversen statistischen Verfahren ergeben und diesem Aspekt bei den weiteren Auswertungen Rechnung getragen werden muss. ${ }^{1224}$ Die Besicherungsquote ist asymmetrisch, so ist der Schiefe-Wert mehr als doppelt so groß wie sein Standardfehler. ${ }^{1225}$ Ferner gibt es eine Häufung bei $0,00 \%$ sowie bei $100,00 \%$ (vgl. Abb. B-12), letzteres ergibt sich daraus, dass eine Besicherungsquote von mehr als $100,00 \%$ einer Übersicherung gleich käme. ${ }^{1226}$

1222 Machauer/Weber (1998) verwenden die gleiche Datenbasis wie Elsas (2001). „The average collateralized percentage of all borrowers in sample $\mathrm{A}$ is $68.6 \%$, with $8.8 \%$ of the borrowers fully collateralized and 33.8\% not collateralized at all." Machauer/Weber (1998), S. 1368. Quelle: In Anlehnung an Elsas (2001), S. 195. Größenkategorien nach Umsatz in Mio. \$ mit $\mathrm{DM} / \$=2,-;$ klein $<25 /$ mittel [25;50] / groß $>250$, Umrechnungsfaktor Beschäftigte: $125.000 \$ /$ Beschäftigtem; $\emptyset$ bezeichnet den Durchschnitt über die einzelnen Jahre des Beobachtungszeitraums.

1224 Vgl. hierzu auch ausführlicher Elsas (2001), S. 202.

1225 Vgl. hierzu auch Anhang 2, Tab. AN 2-3.

1226 Eine Übersicherung kann rechtliche Konsequenzen für die Bank haben. Es wird hier unterschieden zwischen anfänglicher und nachträglicher Übersicherung. Bei einer anfänglichen Übersicherung ist nach der Rechtsprechung des BGH ein solcher Sicherungsvertrag gar sittenwidrig. Dazu muss ein „krasses Missverhältnis“ zwischen dem Sicherungsbetrag und der Sicherheit vorliegen. Bei einer nachträglichen Übersicherung tritt das Übersicherungsereignis erst zu einem späteren Zeitpunkt ein, bspw. durch Reduzierung der zu sichernden Forderung oder durch eine Werterhöhung einer sicherungsübereigneten Lagerhalle. Eine solche nachträgliche Übersicherung hat zur Folge, dass in Höhe der Übersicherung der zunächst bedingte Rückgewähranspruch zu einem unbedingten wird, d.h. die Bank hat Waren in Höhe der Übersicherung freizugeben. $\mathrm{Da}$ in der vorliegenden Studie bestehende Geschäftsbeziehungen betrachtet werden, käme lediglich die nachträgliche Übersicherung in Betracht. Allerdings kann nicht vollständig 


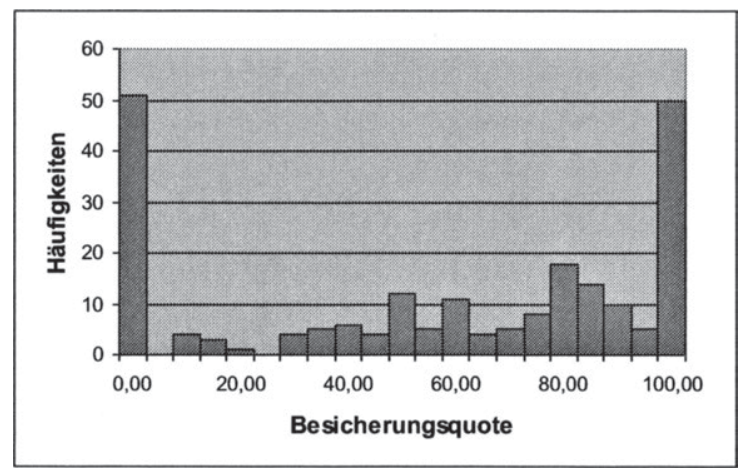

Abb. B-12: Verteilung der Besicherungsquote

Hinsichtlich der Art der Sicherheiten stellen Grundschulden die mit Abstand wichtigste Sicherheit dar. So haben 64,62\% der Unternehmen Grundschulden als Sicherheiten gestellt. Berücksichtigt man nur die Unternehmen, bei denen die Besicherungsquote größer Null ist und die somit überhaupt Sicherheiten gestellt haben, so steigt der Anteil auf 74,53\%. Der in Abb. B-13 ersichtliche Bedeutungsrückgang bei Bürgschaften von $39,80 \%$ bei Berücksichtigung aller Antworten auf $36,65 \%$ bei Berücksichtigung der Unternehmen mit einer Sicherheitenquote größer $0,00 \%$ ergibt sich daraus, dass immerhin $54,29 \%$ der Unternehmen Bürgschaften gestellt haben, obwohl die Sicherheitenquote $0,00 \%$ beträgt. Das Vorliegen von Sicherheiten bei einer Sicherheitenquote von $0,00 \%$ hängt mit der Frage zusammen, inwiefern die Bank die Sicherheiten auch bewerten kann. Die Bank lässt sich unter Umständen zwar die Sicherheiten formal stellen, bewertet diese aber nicht. Klassisches Beispiel ist hier die Bürgschaft, die häufig nicht bewertet werden kann, da der Bürge bspw. seine Vermögensverhältnisse nicht offengelegt hat. Ferner werden solche Sicherheiten in der Besicherungsquote nicht berücksichtigt, bei denen die Bank aufgrund bestehender Vorlasten (Ansprüche anderer Banken) die Sicherheiten nicht oder nicht in Höhe der formal bestehenden Sicherheit bewerten kann. So sind bei den Grundschulden vermutlich die Vorlasten anderer Banken ursächlich, bei der Sicherungsübereignung hingegen der Umstand, dass der Sicherungsgegenstand steuerlich oder bilanziell schon abgeschrieben ist, aber noch Marktwerte bestehen. Für eine Zession ist eine regelmäßige Prüfung der zugrunde liegenden Forderungen erforderlich, um diese bewerten zu können. Darauf verzichten viele Banken und bewerten diese intern mit 0 EUR. Die Sicherheit besteht aber rechtlich einwandfrei. Im Verwertungsfall legt die Bank dann die Zession offen, in der Erwartung hier Erlöse zu erzielen. 


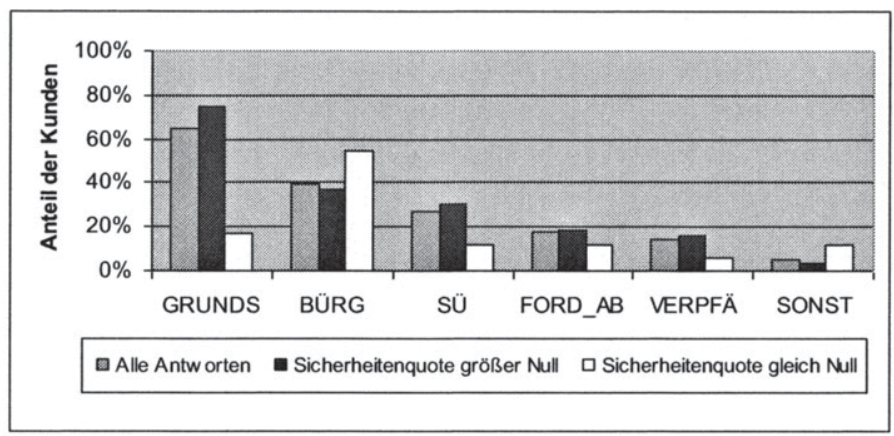

Abb. B-13: Nutzung der verschiedenen Sicherheiten ${ }^{1227}$

Die Fähigkeit, Sicherheiten zu stellen, und schließlich die Art der gestellten Sicherheiten richtet sich unter anderem nach der Vermögensstruktur des Unternehmens. Die Branche ist eine wichtige Größe zur Beeinflussung der Vermögensstruktur. Zwar lassen sich in Tab. B-30 und Tab. B-31 Unterschiede zwischen den Branchen erkennen, allerdings sind diese statistisch nicht signifikant. Lediglich bei den Bürgschaften lässt sich feststellen, dass Dienstleistungsunternehmen deutlich weniger Bürgschaften als Unternehmen anderer Branchen stellen. ${ }^{1228}$

\begin{tabular}{|l|r|r|r|r|r|r|r|}
\hline & Produktion & Handel & Dienstlstg & Bau & Sonstiges & Gesamt & $\begin{array}{c}\text { Kruskall- } \\
\text { Wallis }\end{array}$ \\
\hline Mittelwert & $71,09 \%$ & $75,04 \%$ & $85,51 \%$ & $70,53 \%$ & $63,86 \%$ & $55,90 \%$ & \multirow{2}{*}{0,7399} \\
\cline { 1 - 6 } Median & $80,00 \%$ & $79,50 \%$ & $83,50 \%$ & $75,00 \%$ & $60,00 \%$ & $61,00 \%$ & \\
\hline $\mathrm{N}$ & 41 & 46 & 23 & 38 & 14 & 162 & \\
\hline
\end{tabular}

Tab. B-30: Sicherheitenquote differenziert nach Branchen

1227 Bei dieser Frage wurden die Beantwortenden aufgefordert, die drei wichtigsten Sicherheitenarten des Kunden anzukreuzen. Die Frage wurde dann als beantwortet betrachtet, wenn zumindest eine Sicherheit angekreuzt wurde. Die detaillierten Werte können dem Anhang 2, Tab. AN 2-4 entnommen werden.

1228 Warum Dienstleistungsunternehmen in 18,52\% der Fälle und somit überdurchschnittlich häufig „sonstige Sicherheiten“ stellen, ist aus Sicht des Autors nicht nachvollziehbar. 


\begin{tabular}{|l|r|r|r|r|r|r|r|}
\hline & Produktion & Handel & Dienstlstg. & \multicolumn{1}{c|}{ Bau } & Sonstiges & Gesamt & $\begin{array}{c}\text { Kruskal- } \\
\text { Wallis }\end{array}$ \\
\hline GRUNDS & $60,00 \%$ & $73,68 \%$ & $66,67 \%$ & $63,04 \%$ & $43,75 \%$ & $64,29 \%$ & 0,2310 \\
\hline BÜRG & $54,00 \%$ & $42,11 \%$ & $14,81 \%$ & $39,13 \%$ & $31,25 \%$ & $39,80 \%$ & 0,0189 \\
\hline SÜ & $38,00 \%$ & $26,32 \%$ & $14,81 \%$ & $23,91 \%$ & $25,00 \%$ & $27,04 \%$ & 0,2542 \\
\hline FORD_AB & $20,00 \%$ & $21,05 \%$ & $7,41 \%$ & $19,57 \%$ & $6,25 \%$ & $17,35 \%$ & 0,3845 \\
\hline VERPFÄ & $14,00 \%$ & $15,79 \%$ & $14,81 \%$ & $10,87 \%$ & $18,75 \%$ & $14,29 \%$ & 0,9372 \\
\hline SONST & $6,00 \%$ & $3,51 \%$ & $18,52 \%$ & $0,00 \%$ & $0,00 \%$ & $5,10 \%$ & 0,0084 \\
\hline N & 50 & 57 & 27 & 46 & 16 & 196 & \\
\hline
\end{tabular}

Tab. B-31: Sicherheitenart differenziert nach Branchen

Die Vermutung, dass der Anteil von Bürgschaften nicht von der Branche, sondern vielmehr von der Rechtsform abhängt, konnte nicht bestätigt werden. Es wurde vermutet, dass bei Kapitalgesellschaften die Stellung von Sicherheiten, insbesondere von Bürgschaften, nahezu obligatorisch ist und dass die persönliche Haftung bei einer Personengesellschaft eher zu einer Reduktion der Sicherheitenquote führt. In der vorliegenden Datenbasis konnten keine statistisch signifikanten Unterschiede zwischen Kapital- und Nicht-Kapitalgesellschaften hinsichtlich der Sicherheitenquote und der Sicherheitenart (vgl. Tab. B-32 und Abb. B-14) festgestellt werden. Die Sicherheitenquote ist bei Nicht-Kapitalgesellschaften sogar ca. 7 Prozentpunkte größer als bei Kapitalgesellschaften. Eine Erklärung für die fehlende Signifikanz der Gruppenunterschiede könnte folgender Zusammenhang sein: Die Hereinnahme von Sicherheiten bewirkt eine Vorrangigkeit bei der Befriedigung der Ansprüche im Insolvenzfall. Insofern ist die Stellung von Sicherheiten möglicherweise unabhängig von der Rechtsform.

\begin{tabular}{|l|r|r|r|}
\hline & $\begin{array}{r}\text { Kapital- } \\
\text { gesellschaft }\end{array}$ & $\begin{array}{c}\text { Nicht- } \\
\text { Kapital- } \\
\text { gesellschaft }\end{array}$ & $\begin{array}{c}\text { Kolmogorov- } \\
\text { Smirnov }\end{array}$ \\
\hline Mittelwert & $53,26 \%$ & $60,05 \%$ & \multirow{2}{*}{0,5174} \\
\hline Median & $60,00 \%$ & $73,00 \%$ & \\
\hline N & 130 & 83 & \\
\hline
\end{tabular}

Tab. B-32: Sicherheitenquote differenziert nach Rechtsform

In der Literatur finden sich hinsichtlich der Sicherheitenstellung verschiedene Ansätze. Zum einen wird argumentiert, dass Sicherheiten als Signalling-Instrument fungieren und somit gute Unternehmen mehr Sicherheiten stellen, um das Adverse SelectionProblem zu überwinden. Zum anderen wird argumentiert, dass Sicherheiten zur Vermeidung von Moral Hazard dienen und negative Anreize reduzieren sollen. ${ }^{1229}$ In Tab. B-33 wird gezeigt, dass in der vorliegenden Datenbasis die Sicherheitenquote bei

1229 Vgl. hierzu auch ausführlich Kapitel A.4.3.1.3 bzgl. der Annahmen in den theoretischen Modellen sowie Kapitel A.4.3.2.2 zu den Erkenntnissen in den empirischen Studien. 
Unternehmen mit einer größeren Ausfallwahrscheinlichkeit statistisch und ökonomisch signifikant höher ist als bei Unternehmen mit einer niedrigen Ausfallwahrscheinlichkeit. ${ }^{1230}$

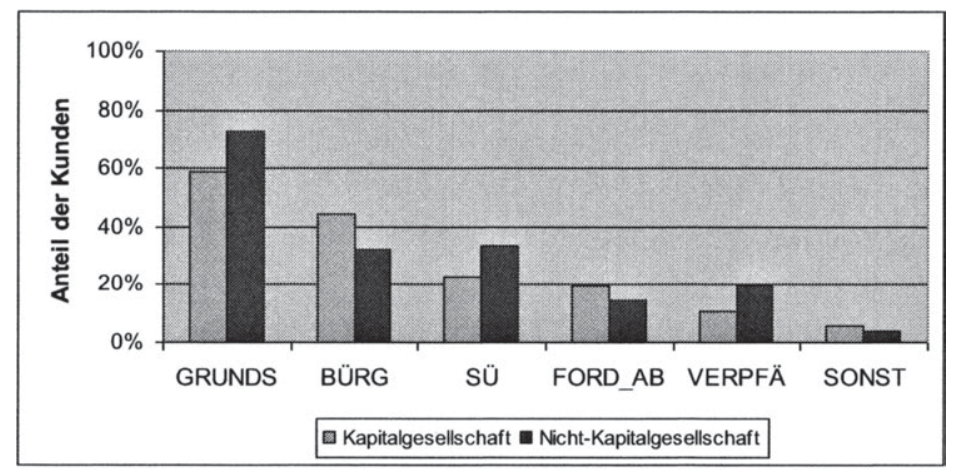

Abb. B-14: Sicherheitenart differenziert nach Rechtsform ${ }^{1231}$

\begin{tabular}{|c|c|c|c|}
\hline & \multicolumn{2}{|c|}{ Ausfallwahrscheinlichkeit } & \multirow{2}{*}{$\begin{array}{l}\text { Kolmogorov- } \\
\text { Smirnov }\end{array}$} \\
\hline & Kleiner $\mathbf{0 , 5} \%$ & Größer gleich $0,5 \%$ & \\
\hline Mittelwert & $50,72 \%$ & $63,56 \%$ & \multirow{2}{*}{0,0049} \\
\hline Median & $53,00 \%$ & $80,00 \%$ & \\
\hline $\mathrm{N}$ & 127 & 86 & \\
\hline
\end{tabular}

Tab. B-33: Sicherheitenstellung differenziert nach Ausfallwahrscheinlichkeit

Dieser Zusammenhang spiegelt sich auch in der Einschätzung der Firmenkundenbetreuer wider. Auf die Frage, ob bonitätsmäßig gute oder bonitätsmäßig schlechte Kunden tendenziell mehr Sicherheiten stellen, antworteten $70,23 \%$, dass bonitätsmäßig schlechte Kunden mehr Sicherheiten stellen (vgl. Abb. B-15). Somit findet gemäß der Auswertung in Bezug auf die Ausfallwahrscheinlichkeit und gemäß der Beurteilung der Firmenkundenbetreuer eher der Ansatz Anwendung, dass Sicherheiten zur Überwindung von Moral Hazard-Problemen dienen. ${ }^{1232}$

1230 Aufgrund der Tatsache, dass die Sicherheitenquote nicht normalverteilt ist, wurde ausschließlich ein nicht-parametrischer Test zur Prüfung von Gruppenunterschieden verwendet. Die Schiefe und Kurtosis kann dem Anhang 2, Tab. AN 2-3 entnommen werden.

1231 Die detaillierten Werte können dem Anhang 2, Tab. AN 2-5 entnommen werden.

1232 Aus Praxissicht spiegelt sich darin vermutlich auch der Wunsch nach höheren Verwertungserlösen wider. 


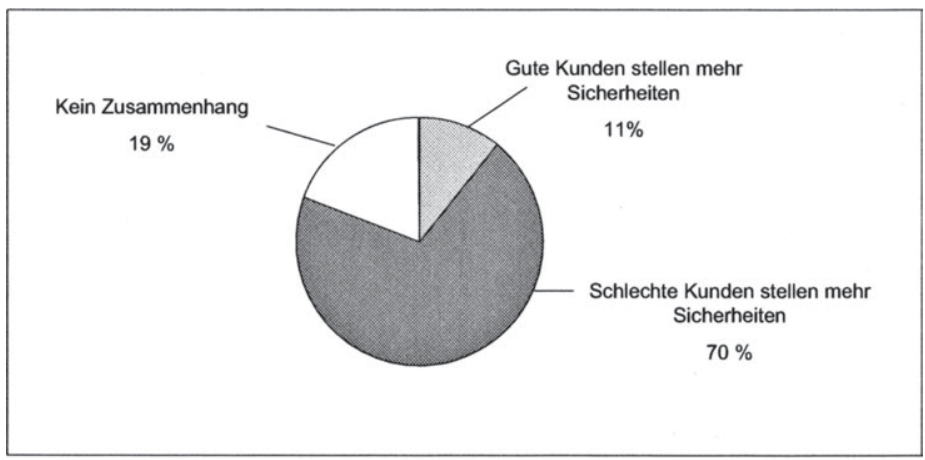

Abb. B-15: Einschätzung der Firmenkundenbetreuer zum Zusammenhang zwischen der Bonität des Kunden und der Höhe der Sicherheitenstellung

Fast jedes zehnte Unternehmen befand sich in den vergangenen Jahren oder befindet sich gegenwärtig in der Intensivbetreuung. Bei 15,67\% der Unternehmen ist es in den vergangenen drei Jahren zu Kreditablehnungen (ABL_KRED_VER) bzw. zu teilweisen Kreditablehnungen (PAR_KRED_VER), z.B. in Form von Volumensreduktionen, gekommen. ${ }^{1233}$ Bei $11,98 \%$ der Unternehmen würde der Firmenkundenbetreuer heute keine Kreditausweitung ermöglichen. Diese Erkenntnisse deuten daraufhin, dass in der bestehenden Datenbasis bei vielen Kunden Liquiditätsbeschränkungen in der Vergangenheit bestanden bzw. gegenwärtig weiterhin bestehen. Die Klärung der Einflussfaktoren in Bezug auf die Kreditverfügbarkeit ist für diese Kunden somit von erheblicher Bedeutung.

\begin{tabular}{|l|r|r|r|}
\hline & \multicolumn{1}{|c|}{ Nein } & \multicolumn{1}{c|}{ Ja } & Unbekannt \\
\hline INT_BET & $89,40 \%$ & $9,68 \%$ & $0,92 \%$ \\
\hline ABL_KRED_VER & $88,94 \%$ & $10,14 \%$ & $0,92 \%$ \\
\hline PAR_KRED_VER & $90,78 \%$ & $7,83 \%$ & $1,38 \%$ \\
\hline AUS_KRED_HEU & $11,98 \%$ & $81,57 \%$ & $5,53 \%$ \\
\hline
\end{tabular}

Tab. B-34: Kreditablehnungen

Während zuvor die Kreditverfügbarkeit in der Form untersucht wurde, ob es hinsichtlich der Volumen oder der grundsätzlichen Bereitstellung Unterschiede gibt, stellt auch die Dauer der Kreditbewilligung aus Kundensicht eine entscheidende Größe dar. Zwar haben 48,34\% der Firmenkundenbetreuer angegeben, dass die Kreditbewilligung durchschnittlich lange gedauert hat, so haben gleichzeitig aber immerhin $9,00 \%$ eine erheblich schnellere Bewilligung angegeben.

1233 Da es bei einigen Kunden sowohl vollständige als auch partielle Kreditablehnungen gab, entspricht die Summe der beiden Anteile für ABL_KRED_VER und PAR_KRED_VER in Tab. B-34 nicht dem Wert von $15,67 \%$. 


\begin{tabular}{|l|r|r|r|}
\hline & N & Prozent & $\begin{array}{c}\text { Kumulierte } \\
\text { Prozent }\end{array}$ \\
\hline Viel schneller & 19 & $9,00 \%$ & $9,00 \%$ \\
\hline Schneller & 75 & $35,55 \%$ & $44,55 \%$ \\
\hline Durchschnittlich & 102 & $48,34 \%$ & $92,89 \%$ \\
\hline Langsamer & 12 & $5,69 \%$ & $98,58 \%$ \\
\hline Deutlich langsamer & 3 & $1,42 \%$ & $100,00 \%$ \\
\hline Gesamt & 211 & $100,00 \%$ & \\
\hline
\end{tabular}

Tab. B-35: Dauer der Kreditbewilligung

Während bisher primär die beobachtbaren und klassischen beziehungsbezogenen Variablen der Kunde-Bank-Beziehung untersucht wurden, stehen im nächsten Kapitel verhaltenswissenschaftliche Aspekte im Vordergrund. Basis bilden hier die subjektiven Beurteilungen der Firmenkundenbetreuer.

\subsubsection{Beschreibung der Kunde-Bank-Beziehung aus verhaltenswissenschaft- licher Perspektive}

Eine zentrale Fragestellung im Rahmen der Studie betrifft die Analyse des Vertrauensverhältnisses zwischen dem Firmenkundenbetreuer und dem Ansprechpartner des Unternehmens. Die Firmenkundenbetreuer wurden gebeten, ihr Vertrauen in den Kunden einzuschätzen. Während drei Viertel der Firmenkundenbetreuer angegeben haben, dass sie ein hohes Vertrauen in den Ansprechpartner haben, so hat immerhin ein Viertel nur ein geringeres bzw. mittleres Vertrauen.

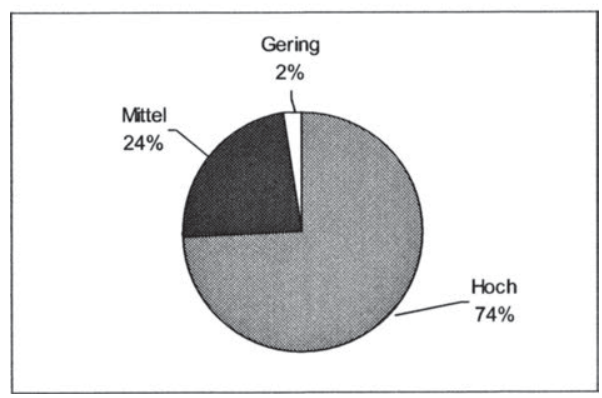

Abb. B-16: Beurteilung des Vertrauensverhältnisses

In Kapitel A.5.2.3.1 wurde gezeigt, dass es sich bei dem Phänomen Vertrauen nicht um ein eindimensionales, sondern um ein vielschichtiges Konstrukt handelt. Ferner wurden in Kapitel A.5.2.3.2 die unterschiedlichen Facetten des Konstruktes Commitment herausgearbeitet. Um diese Vielschichtigkeit der beiden Konstrukte adäquat abzubilden, wurden in der Befragung 25 Fragen zu diesen verhaltenswissenschaftlichen Konstrukten gestellt, wobei die Bewertung nach dem Schulnotensystem erfolgte 
und eine „Eins“ den besten und eine „Sechs“ den schlechtesten Wert darstellt. Bei den Fragen wurden Ratingskalen verwendet, so dass bei den deskriptiven Auswertungen der Mittelwert herangezogen werden kann. Hintergrund ist die Annahme, dass es sich um intervallskalierte Daten handelt. ${ }^{1234}$

Bei fast allen Fragen wurde die 6er-Skala vollständig ausgenutzt. Der Effekt der Zentralen Tendenz (Tendenz zur Mitte), welcher besagt, dass Urteilsobjekte im mittleren Bereich der Urteilsskala eingestuft und extreme Ausprägungen vermieden werden, ${ }^{1235}$ ist somit nicht oder höchstens in Ansätzen eingetreten. Es sind deutliche Unterschiede in den Lageparametern festzustellen. So weist die Frage, inwiefern sich der Ansprechpartner stets auf dem neuesten Stand in Bezug auf Brancheninformationen befindet (BRANCHINFO), mit einem Mittelwert von 1,5787 mit Abstand den besten Wert auf, allerdings dicht gefolgt von der Frage, ob der Kunde bei Unzufriedenheit mit der Bank oder dem Firmenkundenbetreuer zunächst den Firmenkundenbetreuer direkt kontaktieren würde (PERS_KONT_UNZU) (Mittelwert: 1,8148). Bei der Frage, inwiefern der Kunde die Bankverbindung leicht wechseln könne, da er z.B. ohnehin mehrere Beziehungen hat oder sich in einer guten wirtschaftlichen Lage befindet (WECHS_BANK), beträgt der Mittelwert der Antworten 4,0737.

Auf eine weitergehende Analyse dieser Daten wird an dieser Stelle verzichtet, um nicht den Auswertungen zur Hypothesenprüfung vorzugreifen, da es sich bei diesen Auswertungen um ein zentrales Element handelt. Um die Dimensionen der Konstrukte Vertrauen und Commitment abzubilden, erfolgt im weiteren Verlauf der Arbeit eine Verdichtung der Rohdaten. ${ }^{1236}$

\footnotetext{
1234 Vgl. Bühner (2004), S. 78.

1235 Vgl. hierzu ausführlich Kapitel B.1.1.2.

1236 Vgl. Kapitel B.3.2.
} 


\begin{tabular}{|c|c|c|c|c|c|}
\hline & Mittelwert & Median & $\begin{array}{c}\text { Standard- } \\
\text { abweichung }\end{array}$ & Minimum & Maximum \\
\hline VERLÄSS_INF & 1,9535 & 2 & 0,8303 & 1 & 6 \\
\hline EINHALT_ABS & 1,9493 & 2 & 0,9585 & 1 & 5 \\
\hline VERLÄSS_ENT & 2,1014 & 2 & 0,8044 & 1 & 5 \\
\hline QUAL_MA & 2,1250 & 2 & 0,9636 & 1 & 6 \\
\hline NICHT_NACHTEIL & 1,9631 & 2 & 0,9172 & 1 & 5 \\
\hline ERWAR_VERSTÄ & 2,7189 & 2 & 1,4686 & 1 & 6 \\
\hline RECHT_INFO & 2,2350 & 2 & 0,9790 & 1 & 6 \\
\hline VERTMITT_KUND & 3,4259 & 3 & 1,5977 & 1 & 6 \\
\hline WECHS_BANK & 4,0737 & 5 & 1,5940 & 1 & 6 \\
\hline INFO_NEU_BANK & 3,2304 & 3 & 1,6051 & 1 & 6 \\
\hline VERTR_AKT_BANK & 3,3594 & 3 & 1,6273 & 1 & 6 \\
\hline OFF_ERLÄUT & 1,9808 & 2 & 1,1119 & 1 & 6 \\
\hline BRANCHINFO & 1,5787 & 1 & 0,7736 & 1 & 5 \\
\hline KENNT_BWL & 2,6372 & 2 & 1,4941 & 1 & 6 \\
\hline STELL_UNANG_FORD & 2,1713 & 2 & 1,1011 & 1 & 6 \\
\hline INKAUF_FORM_TÄT & 3,0000 & 3 & 1,5039 & 1 & 6 \\
\hline PERS_KONT_UNZU & 1,8148 & 2 & 0,9216 & 1 & 5 \\
\hline INKAUF_UNAN & 2,5990 & 2 & 1,4906 & 1 & 6 \\
\hline FREUND_BEZ & 2,6512 & 2 & 1,4320 & 1 & 6 \\
\hline WICHT_WECH_FKB & 3,0926 & 3 & 1,3845 & 1 & 6 \\
\hline WICHT_PERS_KON & 2,4306 & 2 & 1,1553 & 1 & 6 \\
\hline KEIN_BANK_WE & 2,6884 & 2 & 1,2269 & 1 & 6 \\
\hline ANGEN_ZSARB & 2,4306 & 2 & 1,1226 & 1 & 6 \\
\hline UNT_GEN_ID & 2,6326 & 2 & 1,5131 & 1 & 6 \\
\hline UNT_GP & 3,2140 & 3 & 1,3537 & 1 & 6 \\
\hline
\end{tabular}

Tab. B-36: Auswertung der verhaltenswissenschaftlichen Fragen

\subsubsection{Hausbankbeziehung}

Im Kapitel A.4.1 wurde die Hausbank als Besonderheit des deutschen Finanzsystems herausgearbeitet. Aufgrund der herausragenden Bedeutung der Hausbankbeziehung sowie aufgrund der Ähnlichkeit zum Konzept des Relationship Banking sollen in diesem Kapitel einige zentrale Erkenntnisse dargestellt werden. Der Indikator „Hausbank" sollte nicht endogen aus den erhobenen Daten konstruiert, sondern unbeeinflusst von theoretisch erwarteten Eigenschaften berücksichtigt werden. ${ }^{1337} \mathrm{Zu}$ diesem Zweck wurde eine Selbsteinschätzung des Firmenkundenbetreuers erfragt. Sofern der bloße Hausbankstatus mit ökonomischen Konsequenzen verbunden ist - so wie es Gegenstand der Untersuchung von ELSAS war -, ist es notwendig, dass sich die Beteiligten 
auch über die bestehende Hausbankbeziehung bewusst sind. ${ }^{1238}$ Auch wenn die Analyse der Konsequenzen nicht im Fokus der vorliegenden Studie steht, erscheint diese Vorgehen auch für diese Auswertung sinnvoll.

\begin{tabular}{|l|r|r|}
\hline & $\mathbf{N}$ & Prozent \\
\hline Nein & 48 & $22,12 \%$ \\
\hline Ja & 168 & $77,42 \%$ \\
\hline Unbekannt & 1 & $0,46 \%$ \\
\hline Gesamt & 217 & $100,00 \%$ \\
\hline
\end{tabular}

Tab. B-37: Anteile der Hausbankbeziehungen

Bei $77,42 \%$ der untersuchten Bankverbindungen handelt es sich gemäß Einschätzung des Firmenkundenbetreuers um Hausbankbeziehungen. Ein Firmenkundenbetreuer hat angegeben, dass ihm der Hausbankstatus „Unbekannt" sei. In den verbleibenden $22,12 \%$ handelt es sich um Nicht-Hausbankbeziehungen.

Als zentrale Merkmale der Hausbankbeziehung wurden in Kapitel A.4.1 die im Folgenden beschriebenen Kennzeichen herausgearbeitet. Im Vergleich zu den Konkurrenzbanken hat die Hausbank einen relativ großen, häufig dominanten Anteil an der Kreditfinanzierung des Unternehmens und wickelt darüber hinaus die meisten sonstigen Finanzdienstleistungen des Unternehmens $a b .{ }^{1239}$ In der durchgeführten Studie kann dies dahingehend bestätigt werden, als dass die relativen Anteile der Finanzierung durch die befragte Bank in Bezug auf die gesamte Finanzierung des Unternehmens bei den Hausbankverbindungen deutlich größer als bei Nicht-Hausbankverbindungen sind. Wie aus Tab. B-38 ersichtlich, betrifft dies sowohl den Anteil der langfristigen als auch der gesamten Finanzierung des jeweiligen Instituts im Verhältnis zur Bilanzsumme des Unternehmens (VERB_EIG_LANG_R, VERB_EIG_R). Ferner ist aber auch der relative Anteil der jeweiligen Bank an der gesamten Bankfinanzierung ökonomisch und statistisch signifikant größer (ANT_VERB_EIG_LANG, ANT_VERB_EIG_KURZ, ANT_VERB_EIG_GES). So beträgt der Anteil der Finanzierung des befragten Instituts an der gesamten Bankfinanzierung $62,20 \%$ bei Hausbankverbindungen und $24,67 \%$ bei Nicht-Hausbankverbindungen. Grundlage für diese Daten sind die in der Bankanwendung, in der Regel durch Mitarbeiter der Marktfolge und nicht durch die Firmenkundenbetreuer erfassten Werte. Diese Daten wurden im Rahmen einer Bilanzanalyse des Kunden losgelöst von dieser Befragung im Banksystem hinterlegt.

1238 Vgl. Elsas (2001), S. 96.
1239 Vgl. Arbeitskreis (1988)

Vgl. Arbeitskreis (1988), S. 741, Fischer (1990), S. 3, Elsas (2001), S. 12 sowie Kapitel A.4.1. 


\begin{tabular}{|c|c|c|c|c|c|c|}
\hline & \multicolumn{2}{|c|}{$\begin{array}{c}\text { Nicht- } \\
\text { Hausbankbeziehung }\end{array}$} & \multicolumn{2}{|c|}{ Hausbankbeziehung } & \multicolumn{2}{|c|}{ Signifikanz } \\
\hline & Mittelwert & Median & Mittelwert & Median & T-Test & $\begin{array}{c}\text { Kolmogorov- } \\
\text { Smirnov }\end{array}$ \\
\hline KASSE_R & 4,87 & 1,2 & 10,13 & 4,1 & 0,0101 & 0,0045 \\
\hline VERB_KI_LANG_A & $1.096,71$ & 118,4 & 428,33 & 103,0 & 0,0787 & 0,4582 \\
\hline VERB_KI_KURZ_A & 308,13 & 105,7 & 267,59 & 36,4 & 0,7276 & 0,0589 \\
\hline KASSE_A & 182,80 & 16,5 & 218,06 & 44,0 & 0,6726 & 0,0439 \\
\hline DEBZIEL & 41,00 & 34,0 & 31,83 & 27,3 & 0,0404 & 0,0858 \\
\hline GESAMTRENT & $3.649,78^{1240}$ & 8,0 & 13,82 & 9,3 & 0,0615 & 0,8392 \\
\hline KREDZIEL & 128,03 & 62,4 & 105,84 & 38,3 & 0,7094 & 0,0149 \\
\hline UMHANDEL & 18,24 & 9,3 & 41,74 & 9,8 & 0,0262 & 0,6188 \\
\hline UMIND & 316,22 & 9,0 & 377,20 & 26,2 & 0,8017 & 0,0478 \\
\hline VERB_EIG_LANG_R & 3,53 & 0,0 & 15,76 & 4,8 & 0,0011 & 0,0001 \\
\hline VERB_EIG_R & 7,93 & 3,9 & 23,02 & 9,1 & 0,0025 & 0,0003 \\
\hline ANT_VERB_EIG_LANG & 18,06 & 0,0 & 67,66 & 79,9 & 0,0000 & 0,0000 \\
\hline ANT_VERB_EIG_KURZ & 35,34 & 28,6 & 58,18 & 84,9 & 0,0052 & 0,0012 \\
\hline ANT_VERB_EIG_GES & 24,67 & 13,8 & 62,20 & 69,3 & 0,0002 & 0,0000 \\
\hline VERB_EIG_LANG_A & 64,12 & 0,0 & 212,44 & 43,2 & 0,0225 & 0,0010 \\
\hline VERB_EIG_KURZ_A & 46,95 & 12,3 & 72,62 & 0,0 & 0,2121 & 0,4861 \\
\hline VERB_EIG_A & 111,07 & 27,6 & 285,05 & 97,3 & 0,0252 & 0,0106 \\
\hline
\end{tabular}

Tab. B-38: Vergleich der Finanzkennzahlen und Finanzierungsstrukturen bei NichtHaus- vs. Hausbankbeziehungen ${ }^{1241}$

Vergleichbare Unterschiede zeigen sich bei den Angaben der Firmenkundenbetreuer, welche in Tab. B-39 dargestellt sind. Sowohl der geschätzte Anteil der gesamten Finanzierung des befragten Instituts (ANT_BANK_IN) als auch der Anteil des Zahlungsverkehrs, der beim befragten Institut abgewickelt wird (ANT_ZV), ist ökonomisch und statistisch signifikant größer. Die Unterscheidung nach im System erfassten Werten und der Einschätzung des Firmenkundenbetreuers ist insofern interessant, als dass möglicherweise Unterschiede zwischen dem tatsächlichen Anteil der Finanzierung und dem durch den Firmenkundenbetreuer geschätzten Anteil der Finanzierung durch die Bank existieren. Bei Hausbankverbindungen liegt der geschätzte Wert mit $77,73 \%$ deutlich über dem systemseitig, im Rahmen der Jahresabschlussanalyse hinterlegten Wert von $62,20 \%$. Ursächlich können hier Fehleinschätzungen des Firmenkundenbetreuers sein. Der Timelag zwischen dem Zeitpunkt der Erfassung und dem Zeitpunkt der Einschätzung durch den Firmenkundenbetreuer erklärt zwar auf Einzel-

1240 In der Datenbasis ist ein Ausreißer enthalten. Werden ausschließlich Unternehmen mit einer Gesamtkapitalrentabilität von weniger als $150 \%$ berücksichtigt, so beträgt der Mittelwert $10,41 \%$.

1241 In dieser erfolgt nur ein Ausweis der Kennzahlen, die zumindest bei einem der beiden Tests auf dem 10\%-Niveau signifikante Unterschiede aufweisen. Für eine vollständige Abbildung der Finanzkennzahlen vgl. Anhang 2, Tab. AN 2-6. Für eine vollständige Abbildung der beziehungsbezogenen Parameter vgl. Anhang 2, Tab. AN 2-7. 
kundenebene Abweichungen, aber nicht die systematische Abweichung im Gesamtbestand. Ferner ist auch der Anteil der Produktnutzung im Bereich der Vermögensanlage und Versicherungen sowie der Anteil der bei der befragten Bank unterhaltenen Privatkonten bei Hausbankbeziehungen deutlich größer.

\begin{tabular}{|l|r|r|r|r|r|r|}
\hline & \multicolumn{2}{|c|}{ Nicht-Hausbankbeziehung } & \multicolumn{2}{|c|}{ Hausbankbeziehung } & \multicolumn{2}{c|}{ Signifikanz } \\
\cline { 2 - 7 } & \multicolumn{1}{|c|}{ Mittelwert } & \multicolumn{1}{c|}{ Median } & Mittelwert & Median & T-Test & $\begin{array}{c}\text { Kolmogorov- } \\
\text { Smirnov }\end{array}$ \\
\hline GES_KREDIT & 268,93 & 102,26 & 556,25 & 249,97 & 0,0108 & 0,0064 \\
\hline ANT_ZV & 24,91 & 20,0 & 82,63 & 90,0 & 0,0000 & 0,0000 \\
\hline ANT_BANK_IN & 22,75 & 20,0 & 77,73 & 90,0 & 0,0000 & 0,0000 \\
\hline MITGLIED & 0,58 & 1,0 & 0,73 & 1,0 & 0,0436 & 0,3590 \\
\hline DARL & 0,48 & 0,0 & 0,78 & 1,0 & 0,0000 & 0,0019 \\
\hline VERM_ANL & 0,17 & 0,0 & 0,61 & 1,0 & 0,0000 & 0,0000 \\
\hline VERSICH & 0,29 & 0,0 & 0,50 & 0,0 & 0,0152 & 0,0214 \\
\hline PRIVATKONT & 0,50 & 0,5 & 0,80 & 1,0 & 0,0000 & 0,0030 \\
\hline
\end{tabular}

Tab. B-39: Vergleich der Produktnutzung bei Nicht-Haus- vs. Hausbankbeziehungen ${ }^{1242}$

Die höhere Produktnutzung spiegelt sich auch in der im deutlich größeren Anzahl an qualifizierten. Beratungsgesprächen und „sonstigen Kontakten“" pro Jahr bei Hausbankbeziehungen von 3,05 bzw. 12,89 zu 1,90 bzw. 5,79 bei Nicht-Hausbankbeziehungen wider (vgl. hier zu Spalte Mittelwert in Tab. B-40). Ein weiteres wesentliches Merkmal von Hausbankbeziehungen ist deren langfristige Natur. ${ }^{1243}$ Hinsichtlich der Dauer der Beziehung zwischen Bank und Unternehmen sowie der Dauer der Beziehung zwischen dem Firmenkundenbetreuer und dem Unternehmen konnten keine signifikanten Unterschiede zwischen Haus- und Nicht-Hausbankverbindungen identifiziert werden. So beträgt die durchschnittliche Dauer der Kundenbeziehung 19,87 Jahre bei Hausbanken und 17,35 Jahre bei Nicht-Hausbanken. Des Weiteren ist die Besicherungsquote bei Hausbankbeziehungen mit 61,91\% im Vergleich zu 36,00\% deutlich größer. Dies entspricht den empirischen Ergebnissen von DEGRYSE/VAN CAYSEELE. ${ }^{1244}$

\footnotetext{
1242 In dieser Tabelle erfolgt nur ein Ausweis der Kennzahlen, die zumindest bei einem der beiden Tests auf dem 10\%-Niveau signifikante Unterschiede aufweisen. Für eine vollständige Abbildung der beziehungsbezogenen Parameter vgl. Anhang 2, Tab. AN 2-7. 


\begin{tabular}{|l|r|r|r|r|r|r|}
\hline & \multicolumn{2}{|c|}{ Nicht-Hausbankbeziehung } & \multicolumn{2}{|c|}{ Hausbankbeziehung } & \multicolumn{2}{|c|}{ Signifikanz } \\
\cline { 2 - 7 } & Mittelwert & Median & Mittelwert & Median & T-Test & $\begin{array}{c}\text { Kolmogorov- } \\
\text { Smirnov }\end{array}$ \\
\hline ANZ_BER_J & 1,90 & 2,0 & 3,05 & 3,0 & 0,0000 & 0,0001 \\
\hline ANZ_KONT_J & 5,79 & 5,0 & 12,89 & 10,0 & 0,0086 & 0,0002 \\
\hline DAU_BEZ_ERR & 17,35 & 16,5 & 19,87 & 20,0 & 0,1813 & 0,6653 \\
\hline DAU_PERS_ERR & 10,58 & 5,0 & 7,43 & 6,0 & 0,5990 & 0,5309 \\
\hline ANZ_B_AGG & 2,72 & 2,5 & 2,07 & 2,0 & 0,0001 & 0,0040 \\
\hline SICH_Q & 36,00 & 40,0 & 61,91 & 73,0 & 0,0001 & 0,0001 \\
\hline
\end{tabular}

Tab. B-40: Vergleich der Beratungsgespräche und der Besicherung bei Nicht-Hausvs. Hausbankbeziehungen

Auch hinsichtlich der Kreditverfügbarkeit lassen sich signifikante Unterschiede feststellen. Bei Nicht-Hausbankbeziehungen ist es in 19,15\% der Unternehmen in der Vergangenheit zu Kreditablehnungen gekommen, verglichen mit nur 7,78\% bei Hausbankbeziehungen (vgl.

Abb. B-17). Während bei den bestehenden Hausbankbeziehungen 10,00\% der Firmenkundenbetreuer nicht bereit waren, dem Kunden zusätzliche Kredite zu geben, beträgt dieser Anteil bei Nicht-Hausbankbeziehungen immerhin 23,81\%. ${ }^{1245}$ Ferner ist auch die Dauer der Kreditbewilligung bei Hausbankbeziehungen gemessen anhand einer Ordinalskala auf dem 5\%-Niveau statistisch signifikant niedriger als bei NichtHausbankbeziehungen (Tab. B-41). ${ }^{1246}$ Dies ist somit ein erstes Indiz der Bestätigung für die von ELSAS häufig angeführte Liquiditätsversicherungsfunktion der Hausbank. ${ }^{1247}$

Ein weiteres wesentliches Merkmal von Hausbankbeziehungen ist das häufig vorzufindende besondere Vertrauensverhältnis. ${ }^{1248}$ In die Befragung wurde eine Kontrollvariable zur Erhebung des Vertrauens eingeführt. Die fundierte Operationalisierung des Vertrauenskonstruktes, d.h. unter Berücksichtigung der verschiedenen Dimensionen sowie der verschiedenen Ebenen der Organisation und der Person, erfolgt an späterer Stelle. ${ }^{1249}$ Während bei Hausbankbeziehungen $81,33 \%$ der Befragten das Vertrauen zum Unternehmen als hoch eingestuft haben, betrug dieser Anteil bei Nicht-Hausbankbeziehungen nur 50,00\% (vgl. Tab. B-42). Die Unterschiede sind auf Basis des MannWhitney-U-Tests auf dem 1\%-Niveau signifikant.

1245 Aus Gründen der Übersichtlichkeit wurde hier die Inverse der Variablen AUS_KRED_HEU_EUN abgebildet. Während die Variable AUS_KRED_HEU_EUN den Anteil der Kunden ausdrückt, die gegenwärtig vom Firmenkundenbetreuer einen Kredit bekommen würden, wurde in der Grafik der Anteil der Kunden abgetragen, die gegenwärtig vom Firmenkundenbetreuer keinen Kredit bekommen würden. Die detaillierten Werte können dem Anhang 2, Tab. AN 2-8 entnommen werden.

Die Prüfung erfolgte anhand eines Mann-Whitney-U-Tests. Der Signifkanzwert beträgt 0,0381 .

Vgl. Elsas (2001), S. $23 \mathrm{ff}$.

Vgl. Elsas (2001), S. 12 sowie Kapitel A.4.1.

Vgl. hierzu Kapitel B.3.2. 
Auch die Analyse der detaillierten verhaltenswissenschaftlichen Parameter zeigt, dass signifikante Unterschiede hinsichtlich der Ausgestaltung der Geschäftsbeziehung bestehen. Mit Ausnahme der beiden Parametern ERWAR_VERST $\ddot{A}^{1250}$ und KENNT_BWL ${ }^{1251}$ weisen alle Parameter im arithmetischen Mittel niedrigere und somit bessere Werte auf. Die beiden Variablen drücken aus, inwiefern die Bank bei Problemen Verständnis vom Kunden erwarten kann bzw. inwiefern der Ansprechpartner umfangreiche Kenntnisse im betriebswirtschaftlichen Bereich hat. Die Unterschiede bei diesen Variablen sind aber weder ökonomisch groß noch statistisch signifikant. Die Unterschiede bei den anderen Parametern sind vielfach auf dem 1\%-Niveau bzw. 5\%Niveau signifikant und, wie die Werte in der Spalte Mittelwertdifferenz in Tab. B-43 zeigen, auch bedeutsam.

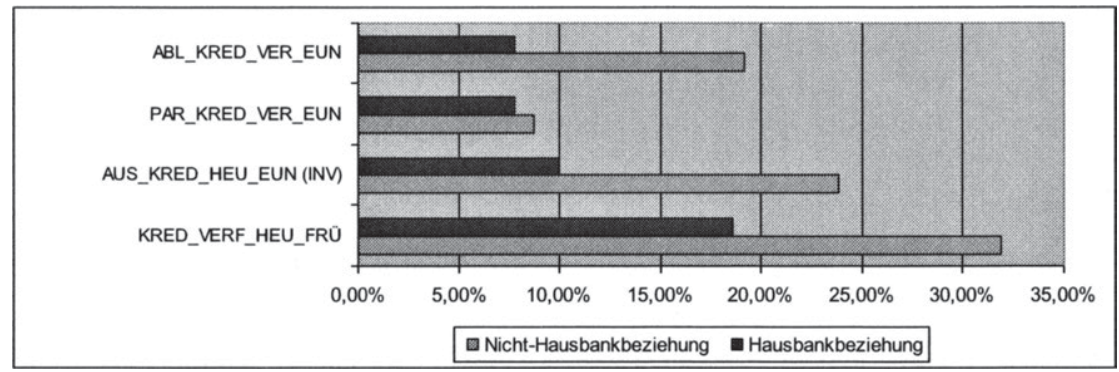

Abb. B-17: Kreditverfügbarkeit differenziert nach Nicht-Haus- vs. Hausbankbeziehungen ${ }^{1252}$

1250 Die Variable basiert auf nachstehender, durch den Firmenkundenbetreuer einzuschätzenden Aussage: „Wenn wir dem Unternehmen von aufgetretenen Problemen berichten (z.B. Bearbeitungsfehler, Falschbuchungen, Verzögerungen im Zahlungsverkehr), können wir kein Verständnis von diesem Unternehmen erwarten.“

1251 Die Variable basiert auf nachstehender, durch den Firmenkundenbetreuer einzuschätzenden Aussage: „Mein Ansprechpartner hat nur geringe Kenntnisse im betriebswirtschaftlichen Bereich (z.B. Interpretation von Bilanzkennzahlen, Erstellung von Plänen, Interpretation der Controllingdaten).“ Bei der Codierung wurde die Skala der Variable gedreht, so dass ein niedriger Wert gute betriebswirtschaftliche Kenntnisse bedeutet.

1252 Bei diesem Vergleich der Gruppenunterschiede wurde eine korrigierte Variable verwendet, bei der ausschließlich die Antworten „Ja“ und „Nein“ berücksichtigt worden sind, die Antwort „Unbekannt" wurde ausgeschlossen. Die Anzahl der bei dieser Auswertung berücksichtigten Werte liegt somit geringfügig unter der Anzahl der insgesamt gegebenen Antworten. Während die Variable AUS_KRED_HEU_EUN die Möglichkeit der Kreditausweitung darstellt, stellen die anderen Variablen Kreditablehnungen dar. Aus Gründen der Vergleichbarkeit in der Grafik wurde Variable AUS_KRED_HEU_EUN invertiert (AUS_KRED_HEU_EUN (INV)). Zu den Auswertungsdetails vgl. auch Anhang 2, Tab. AN 2-8. 


\begin{tabular}{|l|r|r|r|r|}
\hline \multirow{2}{*}{} & \multicolumn{2}{|c|}{$\begin{array}{c}\text { Nicht- } \\
\text { Hausbankbeziehung }\end{array}$} & \multicolumn{2}{c|}{ Hausbankbeziehung } \\
\cline { 2 - 5 } & Prozent & $\begin{array}{c}\text { Kum. } \\
\text { Prozent }\end{array}$ & Prozent & $\begin{array}{c}\text { Kum. } \\
\text { Prozent }\end{array}$ \\
\hline Viel schneller & $4,35 \%$ & $4,35 \%$ & $10,37 \%$ & $10,37 \%$ \\
\hline Schneller & $28,26 \%$ & $32,61 \%$ & $37,80 \%$ & $48,17 \%$ \\
\hline Durchschnittlich & $56,52 \%$ & $89,13 \%$ & $45,73 \%$ & $93,90 \%$ \\
\hline Langsamer & $8,70 \%$ & $97,83 \%$ & $4,88 \%$ & $98,78 \%$ \\
\hline Deutlich langsamer & $2,17 \%$ & $100,00 \%$ & $1,22 \%$ & $100,00 \%$ \\
\hline N & & 46 & & 164 \\
\hline
\end{tabular}

Tab. B-41: Dauer der Kreditbewilligung differenziert nach Nicht-Haus- vs. Hausbankbeziehungen

\begin{tabular}{|l|r|r|}
\hline & $\begin{array}{c}\text { Nicht- } \\
\text { Hausbankbeziehung }\end{array}$ & Hausbankbeziehung \\
\hline Hoch & $50,00 \%$ & $81,33 \%$ \\
\hline Mittel & $43,75 \%$ & $17,47 \%$ \\
\hline Gering & $6,25 \%$ & $1,20 \%$ \\
\hline Gesamt & $100,00 \%$ & $100,00 \%$ \\
\hline $\mathrm{N}$ & 48 & 168 \\
\hline
\end{tabular}

Tab. B-42: Vertrauen bei Nicht-Haus- vs. Hausbankbeziehungen

Im theoretischen Teil der Arbeit wurde gezeigt, dass u.a. der Informationsvorsprung der Hausbank gegenüber den Outside-Banken eine Bindung des Unternehmens an die Bank erklären kann. ${ }^{1253}$ Auch wenn dieses nicht zentraler Untersuchungsgegenstand ist, bestätigt die Untersuchung, dass die Hausbank einen Informationsvorsprung hat, der es dem Unternehmen erschwert, einen Bankwechsel durchzuführen. Zur Überprüfung des Informationsvorsprungs wurden die Teilnehmer aufgefordert, die Aussage „Das Unternehmen müsste der neuen Bank zunächst deutlich umfangreichere Informationen liefern als uns, da wir das Unternehmen bereits gut kennen.“ (INFO_NEU_BANK) auf einer Skala von 1 bis 6 zu bewerten, wobei 1 den besten Wert darstellt. Die Aussage wurde bei Hausbanken mit einer Note von 3,1 und bei Nicht-Hausbanken mit einer Note von 3,7 bewertet (vgl. Tab. B-43). ${ }^{1254}$

$1253 \quad$ Vgl. Fischer (1990), S. 68.

1254 Fischer hat zu diesem Thema Interviews bei Banken durchgeführt. Mit einer Ausnahme waren alle interviewten Banken der Auffassung, dass sich die Voraussetzungen für eine qualitative Risikobeurteilung im Laufe der Kreditbeziehung aufgrund der nachstehenden Effekte verbessern: 1. Die Beurteilungsmöglichkeit der Qualität des Managements im Allgemeinen sowie der Zuverlässigkeit der vom Management abgegebenen Prognosen hinsichtlich Umsatzentwicklung im Speziellen verbessert sich. 2. Eine genauere Interpretation der Jahresabschlüsse, z.B. hinsichtlich der genutzten Ansatz- und Bewertungswahlrechte, ist aufgrund von längeren Zeitreihen möglich. 3. Die Erfahrungen aus dem bisherigen Zahlungsverkehr des Kunden liefern wichtige Informationen. Gleichzeitig gibt die Beurteilung der Kreditüberwachung insgesamt aber auch Hinweise, dass die im Rahmen einer langfristigen Kreditbeziehung gewonnenen Zusatzinformationen möglicherweise für die Bindung des Unternehmens an die Bank weniger bedeutsam sind.Vgl. Fischer (1990), S. 68. 


\begin{tabular}{|c|c|c|c|c|c|c|c|}
\hline & \multicolumn{2}{|c|}{$\begin{array}{c}\text { Nicht- } \\
\text { Hausbank- } \\
\text { beziehung }\end{array}$} & \multicolumn{2}{|c|}{$\begin{array}{l}\text { Hausbank- } \\
\text { beziehung }\end{array}$} & \multicolumn{2}{|c|}{ Signifikanz } & \multirow{2}{*}{$\begin{array}{c}\text { Mittel- } \\
\text { wert- } \\
\text { differenz }\end{array}$} \\
\hline & $\begin{array}{c}\text { Mittel- } \\
\text { wert }\end{array}$ & Median & $\begin{array}{l}\text { Mittel- } \\
\text { wert }\end{array}$ & Median & T-Test & $\begin{array}{c}\text { Kolmogorov- } \\
\text { Smirnov }\end{array}$ & \\
\hline VERLÄSS_INF & 2,2128 & 2 & 1,8743 & 2 & 0,0131 & 0,5629 & 0,3385 \\
\hline EINHALT_ABS & 2,2500 & 2 & 1,8631 & 2 & 0,0135 & 0,1706 & 0,3869 \\
\hline VERLÄSS_ENT & 2,2500 & 2 & 2,0536 & 2 & 0,1514 & 0,7261 & 0,1964 \\
\hline QUAL_MA & 2,2500 & 2 & 2,0838 & 2 & 0,3010 & 0,9885 & 0,1662 \\
\hline NICHT_NACHTEIL & 2,3333 & 2 & 1,8512 & 2 & 0,0044 & 0,1027 & 0,4821 \\
\hline ERWAR_VERSTÄ & 2,6667 & 2 & 2,7262 & 2 & 0,8005 & 0,9999 & $-0,0595$ \\
\hline RECHT_INFO & 2,7708 & 3 & 2,0774 & 2 & 0,0000 & 0,0210 & 0,6934 \\
\hline VERTMITT_KUND & 4,4167 & 5 & 3,1377 & 3 & 0,0000 & 0,0003 & 1,2790 \\
\hline WECHS_BANK & 4,5000 & 5 & 3,9464 & 4 & 0,0316 & 0,1573 & 0,5536 \\
\hline INFO_NEU_BANK & 3,7083 & 4 & 3,0952 & 3 & 0,0137 & 0,1706 & 0,6131 \\
\hline VERTR_AKT_BANK & 4,0625 & 3,5 & 3,1488 & 3 & 0,0008 & 0,0119 & 0,9137 \\
\hline OFF_ERLÄUT & 2,4000 & 2 & 1,8580 & 2 & 0,0036 & 0,2508 & 0,5420 \\
\hline BRANCHINFO & 1,6667 & 1 & 1,5509 & 1 & 0,3628 & 0,9869 & 0,1158 \\
\hline KENNT_BWL & 2,6042 & 2 & 2,6325 & 2 & 0,9088 & 0,9085 & $-0,0283$ \\
\hline STELL_UNANG_FORD & 2,5417 & 2 & 2,0599 & 2 & 0,0073 & 0,1906 & 0,4818 \\
\hline INKAUF_FORM_TÄT & 3,0638 & 3 & 2,9701 & 2 & 0,7167 & 1,0000 & 0,0937 \\
\hline PERS_KONT_UNZU & 1,8958 & 2 & 1,7725 & 2 & 0,4533 & 1,0000 & 0,1233 \\
\hline INKAUF_UNAN & 2,9318 & 2 & 2,5092 & 2 & 0,1113 & 0,5252 & 0,4226 \\
\hline FREUND_BEZ & 3,1277 & 3 & 2,5150 & 2 & 0,0094 & 0,1149 & 0,6127 \\
\hline WICHT_WECH_FKB & 3,6875 & 4 & 2,9162 & 3 & 0,0014 & 0,0020 & 0,7713 \\
\hline WICHT_PERS_KON & 2,9167 & 3 & 2,2874 & 2 & 0,0008 & 0,1536 & 0,6293 \\
\hline KEIN_BANK_WE & 3,2500 & 3 & 2,5181 & 2 & 0,0005 & 0,0025 & 0,7319 \\
\hline ANGEN_ZSARB & 2,9375 & 3 & 2,2814 & 2 & 0,0013 & 0,0765 & 0,6561 \\
\hline UNT_GEN_ID & 3,5106 & 3 & 2,3832 & 2 & 0,0000 & 0,0007 & 1,1274 \\
\hline UNT_GP & 4,0638 & 4 & 2,9760 & 3 & 0,0000 & 0,0001 & 1,0878 \\
\hline
\end{tabular}

Tab. B-43: Verhaltenwissenschaftliche Aspekte bei Nicht-Haus- vs. Hausbankbeziehungen

In Bezug auf Unterschiede zwischen Haus- und Nicht-Hausbankbeziehungen lässt sich resümieren, dass in der Studie die wesentlichen, im theoretischen Teil der Arbeit hervorgehobenen Unterschiede bestätigt werden. ${ }^{1255}$ So ist der Anteil an der Finanzierung sowie der Anteil am Zahlungsverkehr des Kunden bei der Hausbank höher. Ferner ist die Produktdurchdringung bei Hausbanken größer. Schließlich konnte auch die Liquiditätsversicherungsfunktion der Hausbank bestätigt werden. Abschließend wurde auch das besondere Vertrauensverhältnis zwischen Kunde und Hausbank im vorliegenden Datensatz nachgewiesen. 


\subsubsection{Bank- und marktbezogene Daten}

Nachdem zunächst die unternehmensbezogenen und anschließend die beziehungsbezogenen Daten ausgewertet wurden, erfolgt in einem letzten Abschnitt die Auswertung der rein bankbezogenen Daten. In einem einflussreichen Modell haben BoOT/THAKOR die Auswirkungen der Wettbewerbssituation auf die Entscheidung der Bank hinsichtlich der Durchführung von Relationship Banking theoretisch modelliert. ${ }^{1256}$ In diesem Modell muss unterschieden werden, ob es sich um Wettbewerb seitens des Kapitalmarktes oder seitens des Kreditmarktes, d.h. um Wettbewerb durch andere Banken, handelt. ${ }^{1257}$ Die Konkurrenz anderer Banken hinsichtlich der eigenen Kunden führt tendenziell zu einer Stärkung des Relationship Banking, ${ }^{1258}$ d.h. Banken nutzen Relationship Banking mit dem Ziel, sich von ihren Wettbewerbern zu differenzieren. ${ }^{1259}$ Auch in dem Modell der IMP-GrouP wurde die Marktstruktur als wichtiges Element der Makro-Umwelt der Geschäftbeziehung hervorgehoben. ${ }^{1260}$ Ebenso hat FORD in seinem dynamischen Modell die Macht als eine Dimension zur Beschreibung der Geschäftsbeziehung verwendet. ${ }^{1261}$

Hinsichtlich der Berücksichtigung der Wettbewerbssituation gibt es in den bisherigen Studien unterschiedliche Ansätze zur Operationalisierung. ANGELINI/DI SALVO/FERRI haben verschiedene Varianten des Herfindahl-Indexes ${ }^{1262}$ in ihren Untersuchungen berücksichtigt: den Herfindahl-Index auf Grundlage der Einlagen, auf Grundlage der Darlehen und schließlich auf Grundlage der Bankstellen in Relation zur Bevölkerung. ${ }^{1263}$ Der Ansatz von DEGRYSE/ONGENA berücksichtigt die Anzahl der Filialen der Bank in der Postleitzahlenzone des Kreditnehmers und den Herfindahl-Index auf Basis des gesamten Marktanteils der Bank, gemessen anhand der Anzahl der Filialen in der jeweiligen Postleitzahlenzone. ${ }^{1264}$ Problematisch hieran ist, dass in Deutschland die regionale Bankstellendichte bezogen auf die Einwohnerzahl wenig aussagekräftig ist, da bspw. die Postbank ebenfalls berücksichtigt wird und somit jede Postfiliale als Bankstelle dient. ${ }^{1265}$ Gleiches gilt für die Geschäftsstellendichte. Im Firmenkundensek-

1256

Vgl. Boot/Thakor (1994), S. 899 ff. sowie Kapitel A.4.3.1.2.1.

Die Autoren betonen allerdings, dass der Terminus "Relationship Bank“ weit zu fassen ist. Dieser umfasst alle Formen einer Finanzierung, bei der spezifische Investitionen in informationsintensive Aktivitäten stattfinden, d.h. eine über das Einzelgeschäft hinausgehende Betrachtung angestrebt wird. Darunter sind dann auch z.B. Venture Capital-Finanzierungen zu verstehen. Vgl. Boot/Thakor (2000), S. 684.

Die Intensivienung der Relationship Banking-Aktivitäten wird ausgedrückt über das Verhältnis der Kapazitäten, die entweder für Relationship oder Transaction Lending zur Verfügung gestellt werden. Vgl. Boot/Thakor (2000), S. 704.

Vgl. hierzu auch Hauswald/Marquez (2002), S. 2 oder Dell'Ariccia/Marquez (2004), S. 187. Deren Ergebnisse stellen einen Widerspruch zu den Ergebnissen von Petersen/Rajan dar, in deren Modell gerade bei geringerem Wettbewerb eine Hausbankbeziehung mit der Wirkung einer intertemporalen Ertragsverschiebung zustande kommt. Vgl. Petersen/Rajan (1995), S. $411 \mathrm{ff}$.

Vgl. hierzu ausführlich Kapitel A.5.2.2.1.

Vgl. hierzu ausführlich Kapitel A.5.2.2.2.

Zur Ermittlung des Herfindahl-Indexes vgl. Kapitel A.4.3.2.2.

Vgl. Angelini/Di Salvo/Ferri (1998), S. 936, FN 7.

Vgl. Degryse/Ongena (2005), S. 249.

Vgl. Rickes (2006), S. 155. 
tor erscheint die Bankendichte als geeigneter, denn die Nähe zur nächsten Filiale ist weniger bedeutsam, da die Betreuung der Firmenkunden in der Regel nicht in den einzelnen Filialen erfolgt. Allerdings ist auch die reine Anzahl der Institute absolut gesehen wenig aussagekräftig, denn ein harter Konkurrenzkampf zu einer ortsansässigen Sparkasse kann die gleichen Auswirkungen haben wie der Konkurrenzkampf mit einer Vielzahl an anderen Banken. Ferner kann die Konkurrenz zwar im Privatkundengeschäft erheblich sein, jedoch im Firmenkundengeschäft gering. Da die Abgrenzung des räumlich relevanten Marktes sowie die Abgrenzung zwischen Firmenkunden- und Privatkundengeschäft auf Basis öffentlich verfügbarer Materialen nicht sinnvoll möglich war, wurden die Firmenkundenbetreuer aufgefordert, ihre Einschätzung zu den Marktanteilen der eigenen Bank bezogen auf den subjektiv relevanten Markt anzugeben - sowohl für die Gesamtbank als auch für das Firmenkundengeschäft. Die betrachteten Institute sind hinsichtlich ihrer Marktanteile und ihrer Größe sehr heterogen (vgl. Tab. B-44). Das größte Institut ist mit einer Bilanzsumme von 4 Mrd. EUR 15-mal so groß wie das kleinste Institut.

\begin{tabular}{|l|r|r|r|r|r|r|}
\hline & Einheit & Mittelwert & Median & $\begin{array}{c}\text { Standard- } \\
\text { abweichung }\end{array}$ & Minimum & Maximum \\
\hline MARKTAN_GES & $\%$ & 33,9066 & 35,00 & 16,0356 & 3,0 & 80,0 \\
\hline MARKTAN_FK & $\%$ & 36,4896 & 37,60 & 17,9942 & 1,0 & 95,0 \\
\hline BIL_BA & MEUR & $1.107,3134$ & 926,00 & $1.030,5772$ & 283,3 & $3.763,8$ \\
\hline
\end{tabular}

Tab. B-44: Marktanteile und Bilanzsummen der Institute

Hinsichtlich der risikoorientierten Bepreisung haben 91,71\% der Firmenkundenbetreuer geantwortet, dass selbige in ihrer Bank umgesetzt wird. Die Beantwortung innerhalb eines Instituts erfolgte nicht immer einheitlich. Dies könnte zum einen darauf zurückzuführen sein, dass gerade bei größeren Instituten die Umsetzung der risikoorientierten Bepreisung nicht in allen Geschäftsgebieten und Kundensegmenten einheitlich und zeitgleich eingeführt wurde. Zum anderen ist es aber auch denkbar, dass zwar die Vorgaben identisch sind, aber die Umsetzung durch die einzelnen Firmenkundenbetreuer einer Bank in unterschiedlichem Maße praktiziert wird.

Die Anreizstrukturen im Belohnungssystem einer Bank können dazu führen, dass selbige auf die Kreditvergabe oder -überwachung Einfluss nimmt und dass bspw. eine Verschlechterung der Kreditwürdigkeit des Kunden nicht sofort in vollem Umfang gemeldet wird, weil damit eventuell eine Wertberichtigung auf den ausstehenden Kredit verbunden wäre. Die mit einer Wertberichtigung im eigenen Verantwortungsbereich ggf. verbundenen Nachteile könnten dazu führen, dass man die Auslösung einer Wertberichtigung in der Hoffnung auf eine Besserung der Situation des Kunden hinauszögert. ${ }^{1266}$ Das tatsächliche Auftreten dieses Verhaltens hängt von der konkreten 
Ausgestaltung der Entlohnungsstrukturen ab. 56,81\% der Firmenkundenbetreuer gaben an, keinerlei leistungsorientierte Bezahlung zu beziehen (vgl. Tab. B-45). Bei den verbleibenden 43,19\% dominiert die wertorientierte Bezahlung, die sich am jährlichen Zins-/Provisionsergebnis des Firmenkundenbetreuers orientiert (31,13\%), gefolgt von der aktivitätenorientierten Bezahlung, z.B. Anzahl qualifizierter Gespräche je Jahr $(20,66 \%)$. Eine volumenorientierte Vergütung erhalten $15,96 \%$ und eine wertorientierte Vergütung, die sich am Zins-/Provisionsergebnis der Bank orientiert, erhalten 9,86\%. ${ }^{1267}$ Innerhalb einer Bank ist der Einsatz von anreizorientierten Vergütungssystemen nicht einheitlich, was möglicherweise auf das unterschiedliche Alter und unterschiedliche Ausbildungsstände der Firmenkundenbetreuer zurückzuführen ist.

\begin{tabular}{|l|r|}
\hline & Anteile \\
\hline LEI_WERT_FKB & $31,13 \%$ \\
\hline LEI_WERT_BA & $9,86 \%$ \\
\hline LEI_VOL & $15,96 \%$ \\
\hline LEI_AKT & $20,66 \%$ \\
\hline LEI_KEIN & $56,81 \%$ \\
\hline
\end{tabular}

Tab. B-45: Bedeutung der anreizorientierten Vergütung

Schließlich wurde auch der Ausbildungsstand der Firmenkundenbetreuer untersucht (vgl. Tab. B-46), da sich auch hieraus möglicherweise Unterschiede bezüglich des Verhaltens derselbigen ergeben können. Zwei Drittel der Firmenkundenbetreuer haben eine Bankausbildung absolviert, ca. $60 \%$ haben ein berufsbegleitendes Studium und ca. $21 \%$ ein (Fach-)Hochschulstudium abgeschlossen.

\begin{tabular}{|l|r|}
\hline & Anteile \\
\hline FBK_BANK & $66,82 \%$ \\
\hline FKB_BERUF_ST & $60,83 \%$ \\
\hline FKB_STUD & $20,74 \%$ \\
\hline
\end{tabular}

Tab. B-46: Ausbildungsstand der Firmenkundenbetreuer

\subsubsection{Zusammenfassung der Ergebnisse der deskriptiven Auswertung}

Die zuvor dargestellten Ergebnisse der deskriptiven Auswertung bestätigen in großen Teilen die zu erwartenden Zusammenhänge. Hinsichtlich der Finanzkennzahlen kann konstatiert werden, dass signifikante Unterschiede zwischen Kapital- und NichtKapitalgesellschaften, zwischen den verschiedenen Branchen und den verschiedenen Größenklassen vorliegen. So ist die Eigenkapitalquote bei Kapitalgesellschaften signifikant höher als bei Nicht-Kapitalgesellschaften. Bei den Branchen gibt es erhebliche

1267 Die verschiedenen Vergütungssysteme können innerhalb einer Bank kombiniert zum Einsatz kommen, so dass die Gesamtsumme in Tab. B-45 größer als $100 \%$ ist. 
Unterschiede hinsichtlich der Debitoren- und der Kreditorenziele. Die Unterschiede konnten im Wesentlichen auf die unterschiedliche Abnehmerstruktur bzw. Art der Umsatzerzielung - Barumsätze vs. Rechnungsstellung - zurückgeführt werden. Bei der Unterscheidung nach Größenklassen wurde aufgezeigt, dass kleine Unternehmen stärker von Bankkrediten abhängig sind als große Unternehmen.

Die Analyse der Kunde-Bank-Beziehung in Bezug auf die Produktnutzung hat gezeigt, dass fast drei Viertel der Unternehmer oder Hauptgeschäftsführer die Privatkonten bei der untersuchten Bank unterhalten und dass die Produktdurchdringung relativ hoch ist. $63,78 \%$ der Unternehmen nutzen bei der jeweiligen Bank Produkte aus mindestens vier von sechs möglichen Bereichen. Hinsichtlich der Kontakthäufigkeit konnten zwar große Unterschiede bei den einzelnen Unternehmen aufgezeigt werden, allerdings konnten keine signifikanten Gruppenunterschiede für Unternehmen mit unterschiedlicher Produktnutzung, unterschiedlicher Größe oder mit unterschiedlichen Anteilen am Zahlungsverkehr identifiziert werden. Es lässt sich ferner beobachten, dass die Anzahl der Bankverbindungen mit zunehmender Unternehmensgröße steigt und dementsprechend der Anteil des betrachteten Instituts an der gesamten Kreditfinanzierung sinkt. Hinsichtlich der Sicherheitenquote kann im Vergleich zu anderen Studien festgestellt werden, dass die Quote in der vorliegenden Studie etwas größer ist, z.T. ist dies durch die unterschiedlichen Messverfahren bedingt. Innerhalb der durchgeführten Studie lassen sich zwar Unterschiede in Bezug auf die Art der Sicherheitenstellung zwischen verschiedenen Branchen und Rechtsformen erkennen, diese sind jedoch mit Ausnahme von Bürgschaften nicht signifikant. Allerdings kann gezeigt werden, dass Unternehmen mit einer schlechten Bonität und somit einer größeren Ausfallwahrscheinlichkeit mehr Sicherheiten stellen. Die Untersuchung der Kreditverfügbarkeit zeigt, dass fast jedes sechste Unternehmen in den vergangenen Jahren bereits eine vollständige oder partielle Kreditablehnung erfahren hat und dass fast jedes neunte Unternehmen heute keine weiteren Kredite mehr bekommen würde. Die Bedeutung des Problems einer fehlenden Kreditverfügbarkeit kann somit in der vorliegenden Untersuchung bestätigt werden.

Hinsichtlich der verhaltenswissenschaftlichen Parameter lässt sich konstatieren, dass für nahezu alle Parameter die komplette Bandbreite der Skala ausgenutzt wurde. Die Firmenkundenbetreuer haben durchaus auch negative Urteile abgeben. Als besonders positiv wurde der Stand der Ansprechpartner hinsichtlich der Kenntnis der aktuellen Brancheninformationen beurteilt. Die Möglichkeit des Kunden, die Bank zu wechseln, wurde hingegen mit einem aus Kundenperspektive schlechten Durchschnittswert auf der Notenskala von 4,0737 eingestuft. 
Bei dem Vergleich zwischen Nicht-Hausbank- und Hausbankbeziehungen konnten signifikante Unterschiede hinsichtlich des Anteils der Bankfinanzierung bei dem befragten Institut festgestellt werden, so war dieser Anteil bei Hausbanken deutlich gröBer. Der Unterschied resultiert auch aus der jeweils zugrunde gelegten Begriffsdefinition, denn der Finanzierungsanteil der jeweiligen Bank ist eines der zentralen Kriterien hinsichtlich des Hausbankverständnisses. Des Weiteren liegt die Anzahl der jährlichen Beratungsgespräche sowie der jährlichen Kontakte bei Hausbanken deutlich über dem Wert von Nicht-Hausbanken. Ferner war die Anzahl der genutzten Produkte bei Hausbankbeziehungen ebenfalls signifikant größer. Die Sicherheitenquote liegt bei Hausbanken mit $61,91 \%$ deutlich über dem arithmetischen Mittel von 36,00\% bei NichtHausbanken. Ferner ist die Kreditverfügbarkeit gemessen in Form von Kreditablehnungen bzw. Kreditausweitungen sowie in Form der Dauer der Kreditbewilligung bei Hausbanken deutlich höher. Bei den verhaltenswissenschaftlichen Parametern erhält der jeweilige Mittelwert im Durchschnitt eine um 0,5 Punkte bessere Note. Auf Basis der unverdichteten Daten ist zwar nur eine eingeschränkte Aussage möglich, dennoch scheint die Kunde-Bank-Beziehung aus verhaltenswissenschaftlicher Perspektive bei Hausbanken besser ausgestaltet zu sein.

In Bezug auf die bankbezogenen Parameter lässt sich feststellen, dass die untersuchten Banken in Hinblick auf Marktanteile gesamt und Marktanteile im Firmenkundensektor sowie in Hinblick auf die Bilanzsumme sehr heterogen sind. Aber auch innerhalb der Banken lassen sich Unterschiede in Bezug auf die Umsetzung der risikoorientierten Bepreisung konstatieren. Der Einsatz von leistungsorientierter Vergütung sowie Ausbildungsstand ist innerhalb der einzelnen Banken sehr unterschiedlich.

Nachdem bisher eine rein deskriptive Auswertung der Ergebnisse durchgeführt wurde, werden im Folgenden die Hypothesen hinsichtlich der Einflüsse der verhaltenswissenschaftlichen Parameter auf die ökonomischen Parameter geprüft. Im Kapitel A.5.2.3.3 wurden die ökonomischen Wirkungen der verhaltenswissenschaftlichen Parameter analysiert. Im nächsten Schritt werden die zu prüfenden Hypothesen aufgestellt. 


\section{$2 \quad$ Hypothesenbildung}

\subsection{Grundlagen der Hypothesenbildung}

Bei der Hypothesenformulierung lassen sich wissenschaftliche und statistische Hypothesen unterscheiden. Wissenschaftliche Hypothesen beziehen sich auf reale Sachverhalte, die empirisch untersuchbar sind. ${ }^{1268}$ Sie werden aus begründeten Vorannahmen oder aus Theorien abgeleitet und stellen verbale Behauptungen über kausale oder nicht-kausale Beziehungen zwischen Variablen dar. ${ }^{1269}$ Es handelt sich bei den Hypothesen um Wahrscheinlichkeitsaussagen (probabilistische Aussagen), die sich durch konträre Einzelfälle prinzipiell nicht falsifizieren lassen. ${ }^{1270}$ Zur Transformation in eine statistische Hypothese werden die in der wissenschaftlichen Hypothese angesprochenen Variablenbeziehungen in eine quantitative Form gebracht. Statistische Hypothesen haben die Besonderheit, dass sie stets von einem Hypothesenpaar, der sog. Alternativhypothese und der Nullhypothese, ausgehen. Die wissenschaftliche oder Forschungshypothese entspricht üblicherweise der Alternativhypothese. ${ }^{1271}$ Die Alternativhypothese postuliert in der Regel einen bestimmten Effekt, den die Nullhypothese negiert. ${ }^{1272}$ Bei den in den folgenden Kapiteln dargestellten Hypothesen handelt es sich um Forschungshypothesen, in der Regel in Form von gerichteten Hypothesen, d.h. es wird ein Zusammenhang zwischen den untersuchten Größen in eine bestimmte Richtung angenommen. ${ }^{1273}$

Ergebnis der empirischen Untersuchung ist nicht der endgültige Beweis der Richtigkeit der zugrunde liegenden Theorien, denn die Verifikation allgemeingültiger Aussagen über die Population ist anhand von Stichprobendaten nicht möglich. ${ }^{1274}$ Hingegen ist es möglich zu zeigen, dass eine theoretische Behauptung mit Allgemeingültigkeitsanspruch falsch ist. Gemäß dem kritischen Rationalismus, der auf POPPER zurückgeht, ist wissenschaftlicher Fortschritt nur durch systematische Eliminierung falscher Theorien mittels empirischer Falsifikation möglich. Der kritische Rationalismus lehnt unter Berufung auf HUME die Vorstellung der Verifizierbarkeit einer wissenschaftlichen Aussage auf empirischem Wege ab. ${ }^{1275}$ So tritt hier an die Stelle der Verifizierbarkeit das Prinzip der Falsifikation. Bei Anwendung dieser Theorie kann eine wissenschaftliche Aussage durch empirische Prüfung nur widerlegt, nicht aber als richtig bewiesen werden. Mit dem wissenschaftlichen Realismus wird ein grundlegend anderer Ansatz verfolgt. Die Komplexität in den Sozial- und Wirtschaftswissenschaften verhindert die im kritischen Rationalismus geforderte Falsifikation von Theorien, „denn von einer schlüssigen Falsifikation kann nur dann gesprochen werden, wenn alle relevanten

\footnotetext{
1268 Vgl. Bortz/Döring (2006), S. 4. Für die weiteren Voraussetzungen siehe ebenda.

1269 Vgl. Bortz/Döring (2006), S. 8.

1270 Vgl. hier und im Folgenden Bortz/Döring (2006), S. 10.

1271 Vgl. Bortz/Döring (2006), S. 24.

1272 Vgl. Bortz/Döring (2006), S. 25.

1273 Vgl. Bortz (1999), S. 108.

1274 Vgl. hier und im Folgenden Bortz/Döring (2006), S. 18.

1275 Vgl. Popper (1963), S. 42.
} 
Einflussfaktoren beim Hypothesentest kontrolliert werden (was in der Regel unrealistisch sein dürfte) ${ }^{61276}$. Der wissenschaftliche Realismus hingegen besitzt eine gute Anpassung an die Forschungsbedingungen im Marketing im Speziellen und den Wirtschaftswissenschaften im Allgemeinen. ${ }^{127}$ Hier wird eine Aussage durch empirische Bestätigung zwar nicht mit endgültiger Sicherheit verifiziert, aber mit zunehmender Sicherheit bestätigt. ${ }^{1278}$ Somit entwickeln sich in dieser Konzeption die Wissenschaften nicht nur durch Falsifikation von Aussagen und Theorien, sondern auch durch deren Bestätigung weiter. Aufgrund der Tatsache, dass der wissenschaftliche Realismus eine induktive Vorgehensweise nicht grundsätzlich ablehnt und ferner die Existenz von Messfehlern explizit berücksichtigt, ${ }^{1279}$ beschreibt selbiger einen geeigneten wissenschaftstheoretischen Rahmen für die vorliegende Arbeit. Dieser Konzeption folgend können die bestehenden Relationship Banking-Theorien nicht nur durch Falsifikation von Aussagen und Theorien, sondern auch durch deren Bestätigung weiterentwickelt werden.

In Kapitel A.5.2.3.3 wurde bereits eine ausführliche Analyse des Einflusses der verschiedenen Vertrauensdimensionen wie Glaubwürdigkeit und Wohlwollen sowie der verschiedenen Commitment-Dimensionen wie Gebundenheit und Verbundenheit in Bezug auf die ökonomischen Parameter Zinssatz, Sicherheitenstellung und Kreditverfügbarkeit durchgeführt. Die Erkenntnisse werden in den folgenden Kapiteln als Forschungshypothesen formuliert.

\subsection{Hypothesen zum Zinssatz}

\subsubsection{Vertrauens-basierte Hypothesen zum Zinssatz}

Bei der Formulierung der Hypothesen wird insgesamt davon ausgegangen, dass Vertrauen einen zinsreduzierenden Effekt hat, wobei sich die Einflussintensität der verschiedenen Vertrauensdimensionen unterscheidet. Bei den Hypothesen zum Vertrauen ist insbesondere auf personaler Ebene der Aspekt der Reziprozität von Relevanz. Ein erhöhtes Wohlwollen, insbesondere auf personaler Ebene, fördert den Informationsfluss - für die Argumentation ist der Informationsfluss in Richtung Bank bedeutsam und führt schließlich aufgrund der resultierenden größeren Präzision bei der Risikoschätzung zu niedrigeren Zinsen. Ferner kann sowohl das personale als auch das organisationale Wohlwollen dazu führen, dass der Firmenkundenbetreuer sich verpflichtet fühlt, dem Kunden durch niedrigere Zinsen ebenfalls sein Entgegenkommen zu signalisieren. In einer vertrauensvollen Beziehung wird der Firmenkundenbetreuer eine gegebenenfalls existierende Marktmacht der Bank nicht ausnutzen, so dass eine mögliche Hold Up-Gefahr weitestgehend eliminiert wird.

\footnotetext{
1276 Homburg (2000), S. 56. Weitere Argumente, die gegen eine Anwendung des kritischen Rationalismus im Bereich des Markting sprechen, finden sich bei Eggert. Vgl. Eggert (1999), S. 58.

1277 Vgl. Eggert (1999), S. 58.

1278 Vgl. McKullin (1984), S. 26.

1279 Vgl. Hunt (1990), S. 9.
} 
Die Glaubwürdigkeit des Firmenkunden führt zu geringeren Prüf- und Kontrolltätigkeiten und somit zu niedrigeren Transaktionskosten. Dies trifft im Wesentlichen auf das Unternehmen zu, aber mit zunehmender Entscheidungskompetenz auch auf den einzelnen Ansprechpartner. Im Rahmen einer vertrauensvollen Beziehung kann von einer Weitergabe der Kosteneinsparungen an den Kunden ausgegangen werden, da die Bank ansonsten das in der gemeinsamen Historie mühevoll aufgebaute Vertrauen aufs Spiel setzt. Insgesamt wird vermutet, dass die organisationale Glaubwürdigkeit zu einer stärkeren Zinssatzreduktion als die anderen Vertrauensdimensionen führt. $\mathrm{Zu}$ sammengefasst lassen sich folgende Hypothesen in Bezug auf den Zinssatz formulieren: ${ }^{1280}$

H1: Je größer die organisationale Glaubwürdigkeit des Unternehmens, desto niedriger ist der Zinssatz des Kunden.

H2: Je größer das organisationale Wohlwollen des Unternehmens, desto niedriger ist der Zinssatz des Kunden.

H3: Je größer die interpersonale Glaubwürdigkeit des Ansprechpartners im Unternehmen, desto niedriger ist der Zinssatz des Kunden.

H4: Je größer das interpersonale Wohlwollen des Ansprechpartners im Unternehmen, desto niedriger ist der Zinssatz des Kunden.

\subsubsection{Commitment-basierte Hypothesen zum Zinssatz}

Die Existenz von kundenseitigem Commitment kann dazu führen, dass die Bank die Machtsituation ausnutzt und höhere Zinsen fordert. Bei alleiniger Existenz von Verbundenheit, d.h. bei Nichtexistenz von Gebundenheit, ist diese Gefahr hingegen nicht gegeben, da die Bank bei fehlender Gebundenheit das Risiko nicht eingehen wird, die ggf. über lange Zeit erarbeitete Verbundenheit aufs Spiel zu setzen. Als gegenläufiger Effekt steigt die Wahrscheinlichkeit, dass der Kunde bei bestehender Ge- und Verbundenheit nicht nur einen Produktkauf bei der Bank, sondern zahlreiche Produktkäufe getätigt hat und tätigen wird. Daraus resultiert für die Bank die Möglichkeit zur Quersubventionierung, so dass aufgrund dieses Effektes die Zinsen im Durchschnitt niedriger sind. Der Totaleffekt der Ver- und Gebundenheit ist somit indeterminiert.

Es wird im Folgenden davon ausgegangen, dass weder die organisationale Gebundenheit, noch die organisationale Verbundenheit oder die personale Verbundenheit einen signifikanten Effekt auf den Zinssatz ausüben. Aus diesem Grund werden keine commitment-basierten Hypothesen zum Zinssatz aufgestellt.

1280 Aus Gründen der Nachvollziehbarkeit wird unabhängig von der Wichtigkeit der verschiedenen Dimensionen bei der Darstellung der Hypothesen stets die gleiche Reihenfolge gewählt. 


\subsection{Hypothesen zur Sicherheitenstellung}

\subsubsection{Vertrauens-basierte Hypothesen zur Sicherheitenstellung}

Eine hohe organisationale Glaubwürdigkeit und damit einhergehend ein Vertrauen in die Unternehmensentscheidungen im Allgemeinen und das Vertrauen in sinnvolle Investitionsentscheidungen im Speziellen führt zu einer niedrigeren Einschätzung der Ausfallwahrscheinlichkeit und bedingt somit tendenziell niedrigere Sicherheitenforderungen. Ferner entfällt bei gegebener Glaubwürdigkeit die Notwendigkeit zu extrinsischen Anreizen, denn der Kunde erscheint dem Kundenbetreuer kompetent und wird sich ohnehin anstrengen, so dass aus diesem Grund weniger Sicherheiten gefordert werden. Der Effekt der organisationalen Glaubwürdigkeit überwiegt im Vergleich zur personalen Glaubwürdigkeit. Der Einfluss der Kontaktperson im Unternehmen kann jedoch derart gewichtig sein, dass die personale Glaubwürdigkeit einen verstärkenden Effekt ausübt. Das Wohlwollen kann dazu führen, dass der Firmenkundenbetreuer dem Unternehmen oder dem Ansprechpartner einen Gefallen tun möchte und somit weniger Sicherheiten einfordert, jedoch erscheint dieser Effekt eher nachrangig. Wichtiger ist die geringere Gefahr eines Moral Hazard bei der Existenz von Wohlwollen.

H5: Je größer die organisationale Glaubwürdigkeit des Unternehmens, desto weniger Sicherheiten werden gestellt.

H6: Je größer das organisationale Wohlwollen des Unternehmens, desto weniger Sicherheiten werden gestellt.

H7: Je größer die interpersonale Glaubwürdigkeit des Ansprechpartners im Unternehmen, desto weniger Sicherheiten werden gestellt.

H8: Je größer das interpersonale Wohlwollen des Ansprechpartners im Unternehmen, desto weniger Sicherheiten werden gestellt.

\subsubsection{Commitment-basierte Hypothesen zur Sicherheitenstellung}

Eine hohe organisationale Verbundenheit führt zu einer erhöhten Motivation des Unternehmens, so dass die Anreizfunktion der Sicherheiten nicht mehr notwendig ist. In Konsequenz sollte dies zu einer Reduktion der Sicherheitenstellung führen. Die personale Verbundenheit wird nur dann einen reduzierenden Effekt auf die Sicherheitenstellung ausüben, wenn der Einfluss des Ansprechpartners im Unternehmen hinreichend groß ist, so dass seine Entscheidungen für den unternehmerischen Erfolg bedeutsam sind. Da ausschließlich mittelständische Unternehmen Gegenstand der Untersuchung sind und bei selbigen häufig der Ansprechpartner der Bank gleichzeitig der Geschäftsführer ist, ${ }^{1281}$ wird für die vorliegende Datenbasis ein Zusammenhang vermutet. Die Gebundenheit bewirkt eine größere Machtposition der Bank und daraus resultieren höhere Sicherheitenforderungen der Bank.

1281 Vgl. zur Rolle des Eigentümer-Unternehmers Kapitel A.2.1.1.2 und A.2.1.2. In der vorliegenden Datenbasis ist der Hauptansprechpartner der Bank ist in 95,35\% der Fälle in der Geschäftsführung angesiedelt. Vgl. Kapitel B.1.2.2. 
H9: Je größer die organisationale Gebundenheit des Unternehmens, desto mehr Sicherheiten werden gestellt.

H10: Je größer die organisationale Verbundenheit des Unternehmens, desto weniger Sicherheiten werden gestellt.

H11: Je größer die personale Verbundenheit des Ansprechpartners im Unternehmen, desto weniger Sicherheiten werden gestellt.

\subsection{Hypothesen zur Kreditverfügbarkeit}

\subsubsection{Vertrauens-basierte Hypothesen zur Kreditverfügbarkeit}

Die Unsicherheit der Bank bzw. des Firmenkundenbetreuers in Bezug auf die Auswahl eines investitionsrechnerisch guten Projektes und die Verhaltensunsicherheit hinsichtlich einer möglichen Asset Substitution sinkt bei einer größeren organisationalen Glaubwürdigkeit. Eine untergeordnete Rolle könnte auch die gefühlte Verpflichtung des Firmenkundenbetreuers spielen, dem Unternehmen einen Gefallen tun zu wollen, da das Unternehmen selbst auch sehr wohlwollend ist. Ein Einfluss auf personaler Ebene resultiert ggf. wiederum aus der Entscheidungskompetenz des Ansprechpartners. Bei einer weitreichenden Entscheidungskompetenz ist eine Trennung zwischen personaler und organisationaler Ebene nur schwer möglich.

H12: Je größer die organisationale Glaubwürdigkeit des Unternehmens, desto größer ist die Kreditverfügbarkeit und desto weniger Kreditablehnungen gibt es.

H13: Je größer das organisationale Wohlwollen des Unternehmens, desto größer ist die Kreditverfügbarkeit und desto weniger Kreditablehnungen gibt es.

H14: Je größer die interpersonale Glaubwürdigkeit des Ansprechpartners im Unternehmen, desto größer ist die Kreditverfügbarkeit und desto weniger Kreditablehnungen gibt es.

H15: Je größer das interpersonale Wohlwollen des Ansprechpartners im Unternehmen, desto größer ist die Kreditverfügbarkeit und desto weniger Kreditablehnungen gibt es.

\subsubsection{Commitment-basierte Hypothesen zur Kreditverfügbarkeit}

Erst eine kundenseitig hohe Gebundenheit und/oder Verbundenheit eröffnen der Bank Möglichkeiten für die intertemporale Konditionengestaltung. Bei der Bindung des Kunden an die Bank kann selbige anfängliche Verluste durch spätere Gewinne kompensieren und ist aus diesem Grund bereit, dem Kunden einen Kredit zu gewähren.

H16: Je größer die organisationale Gebundenheit, desto größer ist die Kreditverfügbarkeit und desto weniger Kreditablehnungen gibt es.

H17: Je größer die organisationale Verbundenheit, desto größer ist die Kreditverfügbarkeit und desto weniger Kreditablehnungen gibt es.

H18: Je größer die personale Verbundenheit, desto größer ist die Kreditverfügbarkeit und desto weniger Kreditablehnungen gibt es. 


\subsection{Methodisches Vorgehen zur Hypothesenprüfung}

Im nächsten Schritt werden die in Kapitel B.2 aufgestellten Forschungshypothesen einer Prüfung unterzogen, um dadurch die hypothesenprüfende oder deduktive Funktion empirischer Forschung zu erfüllen. ${ }^{1282}$ Durch die empirischen Untersuchungen soll getestet werden, inwiefern sich die aus Theorien und Voruntersuchungen abgeleiteten Hypothesen in der Realität bewähren. Allerdings ist es, wie in Abb. B-18 zum Vorgehen der Hypothesenprüfung dargestellt, erforderlich, für die Konstrukte Vertrauen und Commitment bzw. deren jeweiligen Dimensionen im Vorfeld eine Verdichtung mittels einer Faktorenanalyse vorzunehmen.

Anschließend wird eine umfangreiche Korrelationsanalyse aller potenziellen Einflussfaktoren/Input-Parameter untereinander sowie mit den abhängigen Variablen vorgenommen. Durch dieses Vorgehen können erste Zusammenhänge zwischen den Kreditkonditionen und den diversen potenziellen Einflussparametern identifiziert werden. Aus nachstehend beschriebenen Gründen wird die Korrelationsanalyse zunächst für die Einflussfaktoren des Zinssatzes und anschließend für die Einflussfaktoren der Sicherheitenstellung und der Kreditverfügbarkeit durchgeführt. Die Korrelationsanalysen für die Analyse des Zinssatzes sowie seiner Einflussparameter erfolgt auf einem reduzierten Datensatz im Vergleich zu den Korrelationsanalysen für die Variablen Sicherheitenstellung und Kreditverfügbarkeit. Es wird angenommen, dass bei Kunden, die sich in der Ratingklasse 3E oder schlechter befinden und somit eine Ausfallwahrscheinlichkeit von $20,00 \%$ oder mehr haben, ein besonderes Zinssetzungsverhalten stattfindet. Eine Bank, die ansonsten eine vollständig risikoorientierte Bepreisung praktiziert, wird bei diesen Kunden andere Kriterien für die Zinsfestlegung heranziehen. Aus diesem Grund wurden zwei Kunden bei Überprüfung der Hypothesen zum Zinssatz und somit konsequenterweise auch bei den Korrelationsanalysen in Bezug auf den Zinssatz ausgeschlossen. Bei den Variablen Sicherheitenstellung und Kreditverfügbarkeit wird hingegen sowohl für die Hypothesenprüfung als auch für die vorgelagerten Korrelationsanalysen der vollständige Datensatz verwendet. Aufgrund der Ähnlichkeit der Auswertungen wird auf die vollumfängliche Darstellung der Korrelationsanalysen für die Variablen Sicherheitenstellung und Kreditverfügbarkeit verzichtet.

Anschließend wird, je nach Skalenniveau der abhängigen Variablen, das entsprechende statistische Verfahren angewendet. Die Analyse der Einflussgrößen in Bezug auf den Zinssatz erfolgt auf Basis einer linearen Regression. Ziel ist es zu untersuchen, welchen Anteil der Varianz der abhängigen Variablen die unabhängigen Variablen zusammen erklären können und welchen Regressionskoeffizienten die einzelnen Variablen besitzen. $\mathrm{Zu}$ diesem $\mathrm{Zweck}$ wird eine Regression mit den Variablen vorgenommen, die hohe Korrelationen mit dem Zinssatz aufweisen. Dieses Vorgehen wurde gewählt, da ausschließlich Hypothesen für die verhaltenswissenschaftlichen Variablen aufgestellt wurden. Um den Anstieg des Erklärungsgehalts bei Integration der verhal-

1282 Vgl. Bortz/Döring (2006), S. 31. 
tenswissenschaftlichen Variablen zu ermitteln, wird zunächst versucht, ein möglichst gutes Regressionsmodell ohne Berücksichtigung der verhaltenswissenschaftlichen Variablen zu erstellen. Anschließend werden selbige integriert und es erfolgt ein Vergleich der Regressionsmodelle. Es wird, sofern möglich und von Relevanz, sowohl der statistische Einfluss als auch der ökonomische Einfluss ermittelt und dargestellt.

In Bezug auf die Sicherheitenstellung werden in Abhängigkeit von der Operationalisierung derselbigen verschiedene Verfahren angewendet. Die Sicherheitenstellung wird zum einen binär codiert, d.h. es wird nur differenziert, ob der Kunde Sicherheiten gestellt hat oder nicht. In diesem Fall findet die logistische Regression Anwendung. Zum anderen erfolgt eine lineare Regression mit der intervallskalierten Variablen Sicherheitenquote. Eine ausführliche Darstellung der Operationalisierung erfolgt in Kapitel B.3.5.1.

Für die Überprüfung der Hypothesen zur Kreditverfügbarkeit werden mit der logistischen und der ordinalen Regressionsanalyse ebenfalls zwei unterschiedliche Verfahren zur Überprüfung der Hypothesen eingesetzt. Die Verfahren werden wiederum in Abhängigkeit der vorgenommenen Operationalisierung der Variablen Kreditverfügbarkeit gewählt. Im nächsten Schritt erfolgt zunächst die für die Hypothesenprüfung erforderliche Konzeptualisierung und Operationalisierung der Konstrukte Vertrauen und Commitment.

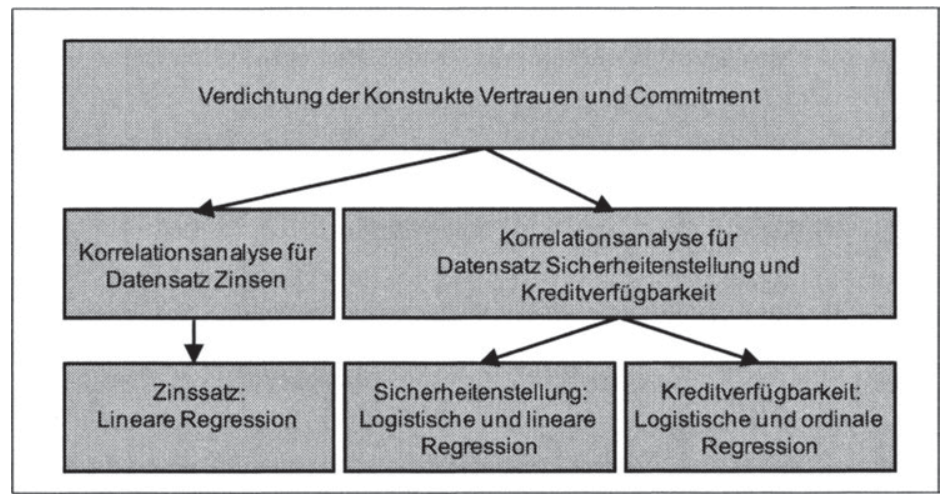

Abb. B-18: Vorgehen zur Hypothesenprüfung 


\subsection{Konzeptualisierung und Operationalisierung der hypothetischen Konstrukte Vertrauen und Commitment}

\subsubsection{Grundlagen der Konzeptualisierung und Operationalisierung der hypo- thetischen Konstrukte Vertrauen und Commitment}

Ein zentrales Element dieser Studie ist die Erweiterung der klassischen Relationship Banking-Forschung um die theoretischen verhaltenswissenschaftlichen Konstrukte Vertrauen und Commitment, wobei unter Konstrukten latente Variablen verstanden werden, die nicht direkt beobacht- und messbar sind: „Theoretical concepts are abstract, unobservable properties or attributes of a social unit or entity.“'1283

Ausgangspunkt der weiteren Analysen ist eine wissenschaftlich korrekte Konzeptualisierung und Operationalisierung der Konstrukte. Unter dem Begriff der Konzeptualisierung verstehen HOMBURG/GIERING die Erarbeitung der Konstruktdimensionen, während sie unter dem Begriff der Operationalisierung die darauf aufbauende Entwicklung eines Messinstrumentes subsumieren. ${ }^{1284}$ Ziel einer jeden Konstruktmessung ist es, Beziehungen zwischen den beobachtbaren Variablen - auch als Indikatorvariablen oder Indikatoren bezeichnet - einerseits und dem interessierenden Konstrukt andererseits zu spezifizieren, um auf dieser Basis das Konstrukt messbar zu machen. Die empirische Konzeptualisierung dieser Modellkonstrukte ist Grundlage für die Überprüfung des Wirkungsmodells, d.h. der Überprüfung des Einflusses auf den Zinssatz, die Sicherheitenstellung und die Kreditverfügbarkeit. Die Konzeptualisierung liefert Informationen über die vermutete semantische Struktur eines hypothetischen Konstruktes, wobei hier gemäß HOMBURG/GIERING zwei grundlegende Konstruktstrukturen unterschieden werden:

- der einfaktorielle Fall und

- der mehrfaktorielle Fall.

Bei einem einfaktoriellen Konstrukt entspricht das Messmodell genau einem Faktor. Während im einfaktoriellen Fall eine hohe Konvergenzvalidität der Indikatoren eines hypothetischen Konstruktes vorliegt, ist die mehrfaktorielle Konstruktstruktur erforderlich, wenn diese Konvergenzvalidität nicht gegeben ist. ${ }^{1285} \mathrm{Im}$ mehrfaktoriellen Fall werden so lange Faktoren gebildet, bis alle einem Faktor zugeordneten Indikatoren untereinander ein hohes $\mathrm{Ma} \beta$ an Konvergenzvalidität erreichen und die Indikatoren, die unterschiedlichen Faktoren zugeordnet werden, ein hohes Maß an Diskriminanzvalidität besitzen. Bei den mehrfaktoriellen Konstruktstrukturen lassen sich wiederum der eindimensionale und der mehrdimensionale Fall unterscheiden: ${ }^{1286}$

\footnotetext{
1283 Bagozzi/Phillips (1982), S. 465.

$1284 \mathrm{Vgl}$. hier und im Folgenden Homburg/Giering (1996), S. 5.

1285 Vgl. Eggert (1999), S. 100.

1286 Vgl. Homburg/Giering (1996), S. 6.
} 
- Bei dem eindimensionalen Fall beschreiben alle Faktoren die gleiche inhaltliche Dimension des hypothetischen Konstrukts, so dass auf Ebene der Faktoren ein hohes $\mathrm{Ma}$ an Konvergenzvalidität erreicht wird.

- Wenn die Faktoren allerdings verschiedene inhaltliche Dimensionen des hypothetischen Konstruktes beschreiben, so wird erst auf der Ebene der Dimensionen eine ausreichende Konvergenzvalidität erreicht.

Ferner kann differenziert werden zwischen der Konzeptualisierung eines komplexen Konstruktes und der Konzeptualisierung eines komplexen Phänomens. Während Ersteres aus mehreren Faktoren bzw. Dimensionen besteht, die sich zu einer latenten Variablen zusammenfassen lassen, versteht man unter einem komplexen Phänomen mehrere eigenständige, aber begrifflich zusammengehörige Konstrukte, die nicht zu einer latenten Variablen zusammengefasst werden können. ${ }^{1287}$ Manchmal ist es nicht erwünscht oder nicht möglich, ein komplexes Phänomen durch ein einzelnes hypothetisches Konstrukt abzubilden. So ist die Repräsentation eines komplexen Phänomens durch ein einzelnes Konstrukt bspw. nicht erwünscht, wenn das Forschungsvorhaben die Zusammenhänge zwischen den einzelnen Dimensionen bzw. Faktoren aufdecken möchte. In einem derartigen Fall sind die einzelnen Dimensionen oder Faktoren als eigenständige Konstrukte zu behandeln, obwohl sie sich grundsätzlich zu einem komplexen Konstrukt zusammenfassen ließen. ${ }^{1288}$ Die Repräsentation eines komplexen Phänomens durch ein einzelnes hypothetisches Konstrukt ist nicht möglich, wenn keine ausreichende Konvergenzvalidität erreicht wird. In Konsequenz muss das komplexe Phänomen durch mehrere eigenständige Konstrukte abgebildet werden. In Abb. B-19 wird am Beispiel des Vertrauens dargestellt, wie eine Abbildung erfolgen würde, unter der Annahme, dass es sich bei dem Vertrauen um ein komplexes Phänomen handelt.

Erfolgt die Integration jedoch auf Konstruktebene so werden Vertrauen und Commitment jeweils als eigenständige Modellkonstrukte in das Wirkmodell eingebunden. In diesem Fall dienen die Faktoren bzw. Dimensionen nur zur Messung des Gesamtkonstruktes. Wie in Abb. B-20 dargestellt, erfolgt die Einbindung dann in einer aggregierten Betrachtung, d.h. trotz einer vermuteten mehrfaktoriellen Struktur wird das Konstrukt als ein einfaktorielles Konstrukt behandelt. ${ }^{1289}$ In Tab. B-47 werden die Vor- und Nachteile der Integration auf Konstrukt- und auf Faktorebene dargestellt.

\footnotetext{
1287 Vgl. Eggert (1999), S. 100.

1288 Vgl. Eggert (1999), S. 102 f

1289 Vgl. Homburg (2000), S. 167
} 


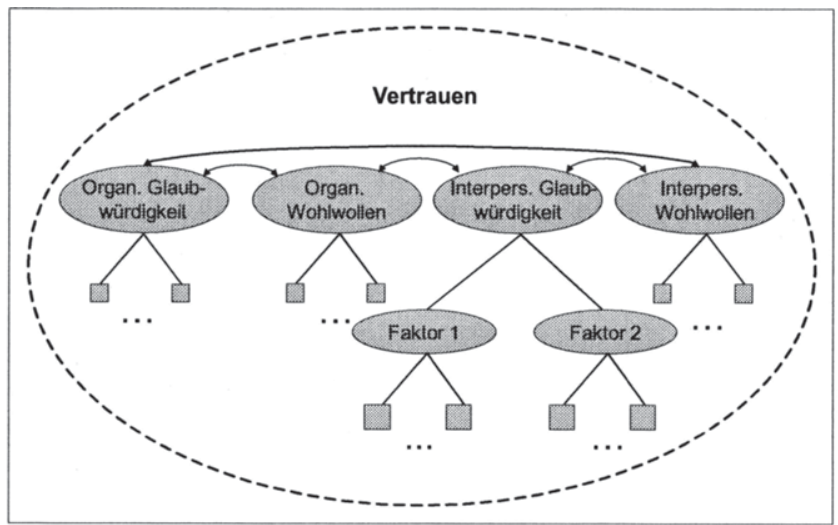

Abb. B-19: Repräsentation eines komplexen Phänomens durch mehrere Konstrukte am Beispiel des Vertrauens ${ }^{1290}$

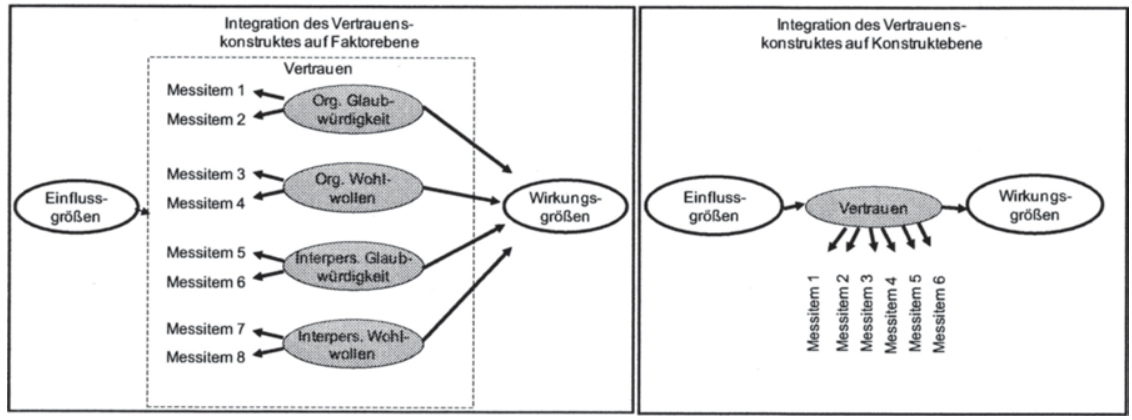

Abb. B-20: Alternative Vorgehensweisen zur Integration der Konstrukte am Beispiel des Vertrauens ${ }^{1291}$

$1290 \quad$ In Anlehnung an Bagozzi (1982), S. 568.

${ }_{1291}$ Vgl. Hadwich (2003), S. 27. In der vorliegenden Arbeit werden die Einflussgrößen in Bezug auf Vertrauen und Commitment nur am Rande behandelt, zentraler Gegenstand sind die Wirkungsgrößen Zinssatz, Sicherheitenstellung und Kreditverfügbarkeit. 


\begin{tabular}{|c|c|c|}
\hline & Vorteile & Nachteile \\
\hline $\begin{array}{l}\text { Integration auf } \\
\text { Konstruktebene }\end{array}$ & $\begin{array}{l}\text { Vertrauen und Commitment } \\
\text { können jeweils als Zielgrößen des } \\
\text { Relationship Banking formuliert } \\
\text { werden. Hierdurch ist eine Steue- } \\
\text { rung und Kontrolle besser möglich } \\
\text { als bei einer Integration auf Fakto- } \\
\text { rebene, da hier die verschiedenen } \\
\text { Dimensionen zur Zielgröße wür- } \\
\text { den. } \\
\text { Es gibt methodische Vorteile der } \\
\text { aggregierten Betrachtung, da diese } \\
\text { eine geringere Modellkomplexität } \\
\text { aufweist. Die geringere Komplexi- } \\
\text { tät kann dazu genutzt werden, die } \\
\text { Wirkungsgrößen differenzierter zu } \\
\text { analysieren. } \\
\text { Ein derartiges Vorgehen erscheint } \\
\text { aber nur dann sinnvoll, wenn die } \\
\text { empirische Konzeptualisierung er- } \\
\text { gibt, dass die Faktoren bzw. Di- } \\
\text { mensionen eindeutig den jeweili- } \\
\text { gen Konstrukten zugeordnet wer- } \\
\text { den können. }\end{array}$ & $\begin{array}{l}\text { - Als Nachteil der Aggregation ist } \\
\text { der mögliche Verlust an erklärter } \\
\text { Streuung zu nennen, was wiede- } \\
\text { rum negative Konsequenzen für } \\
\text { die statistische Güte des Struktur- } \\
\text { modells haben kann. } \\
\text { - Eine weitere Konsequenz der } \\
\text { (methodischen) Aggregation ist } \\
\text { die inhaltliche Aggregation von } \\
\text { Aussagen bezüglich der Faktoren } \\
\text { bzw. Dimensionen von Vertrauen } \\
\text { und Commitment, was zur Folge } \\
\text { hat, dass Erkenntnisse über Wir- } \\
\text { kungszusammenhänge der einzel- } \\
\text { nen Faktoren mit anderen Kons- } \\
\text { trukten nicht möglich sind. }\end{array}$ \\
\hline $\begin{array}{l}\text { Integration auf } \\
\text { Faktorebene }\end{array}$ & $\begin{array}{l}\text { Ein Vorteil der Einbindung auf } \\
\text { Faktorebene besteht darin, dass } \\
\text { Detailerkenntnisse bezüglich der } \\
\text { Wirkungsmechanismen zwischen } \\
\text { den verschiedenen Vertrauensdi- } \\
\text { mensionen sowie zwischen den } \\
\text { verschiedenen Commitment-Di- } \\
\text { mensionen, zwischen den Dimen- } \\
\text { sionen der beiden Konstrukte und } \\
\text { schließlich in Bezug auf die Wir- } \\
\text { kungsgrößen gewonnen werden } \\
\text { können. }\end{array}$ & $\begin{array}{l}\text { - Als Nachteil der differenzierten } \\
\text { Analyse ist die zunehmende } \\
\text { Komplexität zu nennen. }\end{array}$ \\
\hline
\end{tabular}

Tab. B-47: Vor- und Nachteile der Integration auf Konstrukt- und Faktorebene ${ }^{1292}$

Die Analyse der relevanten Literatur soll hierbei Aufschluss darüber geben, wie die Konstrukte zuvor definiert wurden und aus welchen Dimensionen oder Komponenten sie bestehen. ${ }^{1293}$ In den Kapiteln B.5.2.3.1 und B.5.2.3.2 wurde der aktuelle Forschungsstand zu den Konstrukten ausführlich dargestellt. Die Nachteile der Integration auf Konstruktebene sowie die Vorteile der Integration auf Faktorebene überwiegen im Untersuchungskontext, so dass eine differenzierte Integration der Konstrukte sinnvoll erscheint: Zum einen werden für die verschiedenen Dimensionen unterschiedliche Einflüsse in Bezug auf die Wirkungsgrößen vermutet und zum anderen existieren für

1292 Eigene Darstellung. Zu den Argumenten vgl. Hadwich (2003), S. 27 f.

1293 Vgl. Churchill (1979), S. 67. 
die Steuerung in einer Bank unterschiedliche Stellschrauben zur Beeinflussung der Dimensionen. Während bei einer geringen Glaubwürdigkeit des Ansprechpartners im Unternehmen im Extremfall ein Austausch desselbigen von der Bank empfohlen werden könnte, bestehen auf organisationaler Ebene die Möglichkeiten der Unterstützung in Form von Unternehmensberatung oder Steuerberatung. Bevor der Einfluss dieser verschiedenen, in Tab. B-48 dargestellten Dimensionen der Konstrukte Vertrauen und Commitment auf die abhängigen Variablen getestet werden kann, müssen diese Dimensionen zunächst mittels statistischer Verfahren gebildet werden.

\begin{tabular}{|l|l|}
\hline Vertrauen & Commitment \\
\hline$\bullet$ Organisationale Glaubwürdigkeit & $\bullet$ Organisationale Gebundenheit \\
• Organisationales Wohlwollen & $\bullet$ Organisationale Verbundenheit \\
- Interpersonale Glaubwürdigkeit & $\bullet$ Personale Verbundenheit \\
\hline
\end{tabular}

Tab. B-48: Darstellung der Faktoren für Vertrauen und Commitment ${ }^{1294}$

Nach Abschluss der Konzeptualisierung ist im nächsten Schritt die Operationalisierung der Dimensionen, d.h. die Entwicklung eines Modells zur Messung der hypothetischen Konstrukte, erforderlich. ${ }^{1295}$ Ziel hierbei ist die Generierung von Items, die jede der Konstruktdimensionen möglichst ausschöpfend erfassen. ${ }^{1296}$ Bei der Konstruktbildung werden je nach Richtung der Beziehung zwischen einem Faktor und seinen Indikatoren reflektive und formative Indikatoren unterschieden. ${ }^{1297}$ Somit ist bei der Konstruktbildung zwischen nachstehenden Fällen zu differenzieren:

- Die herangezogenen Variablen sind Ausdruck einer gemeinsamen, nicht beobachtbaren Variablen und stellen somit reflektive Indikatoren dar. Die Indikatoren werden als Messung des Faktors betrachtet. Ein Faktor verursacht die ihm zugeordneten beobachtbaren Variablen. Das hypothetische Konstrukt stellt eine nicht direkt beobachtbare, aber eigenständig existierende Variable dar.

- Das resultierende Konstrukt ist eine Funktion der Indikatoren und somit besitzen die Indikatoren einen Einfluss auf das Konstrukt (formative Indikatoren).

Aus der Beziehung zwischen Faktor und Indikator resultieren Konsequenzen hinsichtlich der zu verwendenden Methoden. ${ }^{1298}$ Während im ersten Fall die Verdichtung mittels einer konfirmatorischen Faktorenanalyse erfolgt, wird im zweiten Fall ein

\footnotetext{
1294 Vgl. hierzu Kapitel A.5.2.3.1.2 und A.5.2.3.2.2.

1295 Vgl. Homburg/Giering (1996), S. 5. Hadwich unterscheidet nicht zwischen den Phasen der Konzeptualisierung und der Operationalisierung. Vgl. Hadwich (2003), S. $106 \mathrm{ff}$.

1296 Vgl. Unterreitmeier (2004), S. 56. Vor Durchführung der Datenerhebung wird empfohlen, die Indikatoren in einem Pre-Test auf Verständlichkeit und Eindeutigkeit hin zu überprüfen und sofern notwendig - zu überarbeiten oder aus der Untersuchung auszuschließen. Vgl. Homburg/Giering (1996), S. $11 \mathrm{ff}$.

1297 Vgl. Homburg/Giering (1996), S. 6.

1298 Vgl. Homburg/Giering (1996), S. 6.
} 
Indexwert gebildet. Ferner variieren die Tests zur Beurteilung der Güte der Modelle. Während bei reflektiven Faktoren verschiedene statistische Güteprüfungen zwingend erforderlich sind, können selbige bei formativen Faktoren nur schwer durchgeführt werden. In dieser Arbeit wird ein reflektiver Zusammenhang unterstellt. Es wird vermutet, dass die Faktoren die ihnen zugeordneten, beobachtbaren Variablen verursachen. Bspw. führt ein hohes personales Wohlwollen des Ansprechpartners (Faktor) dazu, dass selbiger auch schon mal Unannehmlichkeiten in Kauf nimmt (Indikator). Das Wohlwollen ist die Ursache für das Verhalten. Dieser reflektive Zusammenhang wird auch bei den in dieser Arbeit zitierten empirischen Studien zur Messung von Vertrauen ${ }^{1299}$ und Commitment ${ }^{1300}$ unterstellt.

Das Vorgehen zur Identifikation der Indikatoren in der vorliegenden Studie erfolgt auf Basis des kombinierten Einsatzes von Primär- und Sekundärforschung. So wurden in Kapitel A.5.2.3.1.2 und A.5.2.3.2.2 die existierenden empirischen Studien ausführlich untersucht mit dem Fazit, dass diese Studien zwar eine Grundlage bilden, jedoch eine Adaption der Items an den bankspezifischen Kontext erfordern. Entsprechend den Empfehlungen der einschlägigen Literatur werden die Vertrauens- und CommitmentDimensionen durch mehrere Indikatoren operationalisiert. So ist die Verwendung mehrerer Indikatoren eine notwendige Voraussetzung zur validen Messung hypothetischer Konstrukte, denn einzelne Indikatoren können i.d.R. nicht alle relevanten Facetten eines hypothetischen Konstruktes erfassen. ${ }^{1301}$ Im Ergebnis entstand ein erster, vorläufiger Fragebogen.

Im Anschluss wurden Pre-Tests durchgeführt, um die Eindeutigkeit und Verständlichkeit der Indikatoren bzw. Fragen zu überprüfen und die inhaltliche Relevanz der Indikatoren für das zu messende Konstrukt abzusichern. ${ }^{1302}$ Für die Durchführung des PreTests sind entweder Experten oder für die Grundgesamtheit als repräsentativ erachtete Personen geeignet. ${ }^{103} \mathrm{Im}$ Rahmen dieser Studie wurden vier aktive Firmenkundenbetreuer sowie sechs Bankkaufleute befragt. Zunächst wurde den Personen das Ziel der Befragung sowie die Konstrukte Vertrauen und Commitment kurz erläutert. Anschließend wurden die Personen aufgefordert, anzugeben, inwiefern die einzelnen Indikatoren verständlich sind, die Zuordnung nachvollziehbar und die inhaltliche Relevanz gegeben ist. Im Nachhinein wurden im Wesentlichen Umformulierungen mit dem Ziel

\footnotetext{
1299 Vgl. Andaleeb (1996), S. 77 ff., Andaleeb (1995), S. 157 ff., Anderson/Narus (1990), S. 42 ff., Anderson/Weitz (1989), S. 310 ff., Doney/Cannon (1997), S. 35 ff., Dwyer/Oh (1987), S. 347 ff., Ganesan (1994), S. 1 ff., Ganesan/ Hess (1997), S. 439 ff., Kim/Frazier (1997), S. 847 ff., Kumar/Scheer/Steenkamp (1995), S. 348 ff., Mohr/Spekman (1994), S. 135 f., Moorman/Deshandé/Zaltman (1992), S. 314 ff., Morgan/Hunt (1994), S. 20 ff., Schurr/Ozanne (1985), S. 939 ff.

1300 Vgl. Morgan/Hunt (1994), S. 20 ff., Kumar/Scheer/Steenkamp (1995), S. 348 ff., Eggert (2000), S. $130 \mathrm{ff}$.

1301 Vgl. Eggert (1999), S. 115.

1302 Vgl. Homburg/Giering (1996), S. 13.

1303 Vgl. Anderson/Gerbing (1991), S. 733. 
vorgenommen, die Fragestellung für Praktiker verständlicher zu gestalten. ${ }^{1304} \mathrm{Im}$ Anschluss daran wurde die Datenerhebung durchgeführt. Nach der Datenerhebung erfolgte die quantitative Analyse zur Beurteilung und Optimierung des Messmodells. ${ }^{1305}$

\subsubsection{Grundlagen zur Beurteilung und Optimierung des Messmodells}

Bei der Verwendung hypothetischer Konstrukte muss die Güte ihrer Messmodelle belegt und gerechtfertigt werden, denn reliable und valide Messungen sind eine Conditio sine qua non einer empirischen Wissenschaft. ${ }^{1306} \mathrm{Da}$ die Zuordnung der Indikatoren zu den Konstrukten häufig umstritten ist, kommt der Überprüfung der Reliabilität und der Validität eine wesentliche Bedeutung zu. Bei der Gütebeurteilung von Daten und Konstrukten wird auf die Gütedimensionen Objektivität, Reliabilität (Zuverlässigkeit) und Validität (Gültigkeit) zurückgegriffen. Selbige werden im Folgenden vorgestellt und, sofern die Überprüfung nicht erst im Rahmen der nachfolgenden statistischen Auswertungen stattfindet, hinsichtlich des Erfüllungsgrades in der vorliegenden Studie untersucht.

Unter der Objektivität in Bezug auf die Erhebung der Daten versteht man den Grad, in dem die Ergebnisse eines Tests unabhängig vom Untersucher sind ${ }^{1307}$ In diesem Kontext lassen sich verschiedene Arten der Objektivität unterscheiden. Die Durchführungsobjektivität ${ }^{1308}$ verlangt, dass sich die Durchführung des Tests zwischen den Untersuchungen nicht unterscheiden darf und dass die Bedingungen der Testdurchführung genau definiert sein müssen. Somit sollte eine Sorgfalt hinsichtlich der Instruktionen angewendet werden, um dadurch Rückfragen zu minimieren, da die zusätzlichen Erläuterungen Einfluss auf die Ergebnisse haben können. Eine hohe Durchführungsobjektivität kann durch standardisierte Instruktionen (Bearbeitungsanweisungen für die Probanden) erreicht werden, so dass der Testanwender während der Durchführung keinen Spielraum mehr hat. ${ }^{1309}$ In der vorliegenden Studie erfolgte die Datenerhebung ausschließlich durch eine Person. Ferner wurden die Instruktionen in schriftlicher Form erteilt, so dass die Durchführungsobjektivität als gegeben erachtet werden kann.

Bei gegebener Auswertungsobjektivität ermittelt jeder Auswerter die gleichen Punktwerte für einen Probanden, weshalb genaue Auswertungsvorschriften erforderlich sind. ${ }^{1310}$ So müssen Regeln definiert werden, ab wann ein Ergebnis zu werten ist und wann nicht. Ferner sollte eindeutig vorgeschrieben sein, wie viele Punkte für eine Antwort zu vergeben sind. ${ }^{1311}$ Die Interpretationsobjektivität schließlich führt dazu, dass jeder Auswerter zur gleichen Beurteilung oder Interpretation der Testergebnisse

1304 Der vollständige, finale Fragebogen kann dem Anhang 1, Abb. AN 1-4 entnommen werden. Eine Übersicht über die Fragen und den zugehörigen Variablen wird ferner in Tab. B-12 gegeben.

1305 Vgl. Homburg/Giering (1996), S. 12.

1306 Vgl. Peter (1979), S. 6.

1307 Vgl. Bühner (2004), S. 28.

1308 Vgl. Bühner (2004), S. $28 \mathrm{f}$.

1309 Vgl. Bortz/Döring (2006), S. 195.

1310 Vgl. Bühner (2004), S. 29.

1311 Vgl. Bortz/Döring (2006), S. 195. 
kommt. ${ }^{1312}$ So dürfen individuelle Deutungen nicht in die Interpretation eines Testwertes einfließen. ${ }^{1313}$ Auch diese kann als gegeben betrachtet werden. Zum einen wurden die Auswertungen ausschließlich durch eine Person vorgenommen. Zum anderen konnten die Antworten der Befragten aufgrund der Verwendung von vorgegeben Antwortmöglichkeiten in Form einer Skala ohne weitere Interpretation oder Transformation in den Auswertungen berücksichtigt werden.

Unter der Reliabilität wird die Messgenauigkeit eines Tests verstanden. ${ }^{1314}$ Die einzelnen Indikatoren stellen dann reliable Messungen des zugehörigen Faktors dar, wenn der wesentliche Anteil ihrer Varianz durch die Assoziation mit dem Faktor erklärt wird und somit der Einfluss von Messfehlervariablen gering ist. Der Zufallsfehler sollte gleich Null sein, d.h. bei wiederholter Messung unter gleichen Bedingungen würde das gleiche Ergebnis erzielt. Zur Beurteilung der Reliabilität stehen im Wesentlichen drei Verfahren zur Verfügung: Retest-Reliabilität, Paralleltest-Reliabilität und interne Konsistenz-Reliabilität. Zur Prüfung der Retest-Reliabilität (oder Stabilität) wird derselbe Test mit einem gewissen zeitlichen Abstand durchgeführt und der Zusammenhang zwischen erster und zweiter Testung bestimmt. Das Zeitintervall zwischen den beiden Tests kann verändert werden. ${ }^{1315}$ Zur Prüfung der Paralleltest-Reliabilität (Äquivalenz) erhält die gleiche Gruppe der Probanden ähnliche Testversionen. Dabei sollten beide Versionen das gleiche Ergebnis hervorbringen. Die beiden Parallel-Tests entstehen, indem je ein Itemzwilling zufällig der einen und zufällig der anderen Testform zugeordnet wird. ${ }^{1316}$ Schließlich wird der Zusammenhang zwischen zwei Tests mit unterschiedlichen Items, die das gleiche Konstrukt messen sollen, ermittelt. ${ }^{1317}$ Es wird somit die Korrelation zwischen zwei Tests mit inhaltlich möglichst ähnlichen Items (,Itemzwillingen“) berechnet. ${ }^{1318}$ Anders als bei den zuvor genannten Verfahren entsteht bei der internen Konsistenz-Reliabilität (oder Halbierungs-Reliabilität) kein untersuchungstechnischer Mehraufwand. Bei der Testhalbierungsreliabilität wird der Test in möglichst gleiche Testhälften, z.B. per Zufallsauswahl, gerade vs. ungerade Fragen, erste vs. zweite Hälfte, unterteilt. Anschließend werden diese miteinander korreliert. ${ }^{1319}$ Unter der Konsistenzanalyse wird verstanden, dass jedes einzelne Item als eigenständiger Testteil angesehen und der mittlere Zusammenhang unter Berücksichtigung der Testlänge ermittelt wird. Jedes einzelne Item wird somit wie ein „Parallel-Test" behandelt. ${ }^{1320}$ Die Korrelation zwischen den Items spiegelt die „wahre" Varianz wider. Die größte Verbreitung in den empirischen Wissenschaften hat in diesem Kontext der Alphakoeffizient (Cronbachs Alpha). ${ }^{1321}$ Alpha bestimmt den Mittelwert aller Korrelationen, die sich ergeben, „wenn die dem Faktor zugeordneten Indikatoren

\footnotetext{
1312 Vgl. Bühner (2004), S. 29.

1313 Vgl. Bortz/Döring (2006), S. 195.

1314 Vgl. hier und im Folgenden Bühner (2004), S. 26.

1315 Vgl. hier und im Folgenden Bortz/Döring (2006), S. 196.

1316 Vgl. Bortz/Döring (2006), S. 196.

1317 Vgl. Bühner (2004), S. 26.

1318 Vgl. Bühner (2004), S. 30.

1319 Vgl. Bühner (2004), S. 29.

1320 Vgl. hier und im Folgenden Bortz/Döring (2006), S. 198.

1321 Vgl. Peter (1979), S. 8.
} 
auf alle möglichen Arten in zwei Hälften geteilt und die Summe der jeweils resultierenden Variablenhälften anschließend miteinander korreliert werden ${ }^{\text {“1322. }}$. Der Wertebereich liegt zwischen null und eins, wobei ein hoher Wert eine hohe Reliabilität ausdrückt. Eine wichtige Voraussetzung bei der Anwendung des Alphakoeffizienten ist es, dass die Fehleranteile der Items wechselseitig unkorreliert sind. Jedoch wird diese Voraussetzung häufig verletzt, da die aktuelle Stimmung, Motivation oder Gefühle der Probanden Einfluss auf die Beantwortung aller Items haben können. In Konsequenz wird ein überhöhter Alphakoeffizient ermittelt. ${ }^{1323}$ Bei heterogenen bzw. mehrdimensionalen Tests hingegen unterschätzt der Alphakoeffizient die Reliabilität. ${ }^{1324}$ Bei diesem $\mathrm{Ma} ß$ ist zu kritisieren, dass keine inferenzstatistische Beurteilung möglich ist, und dass die Größe von der Anzahl der Indikatoren abhängt. Je größer die Zahl der Items ist und je mehr große positive Itemkorrelationen vorliegen, desto größer ist Alpha. ${ }^{1325}$ D.h. wenn mehr Items inhaltlich zu einer Skala passen, steigt der Alphakoeffizient. Aufgrund der weiten Verbreitung dieses Koeffizienten wird selbiger in dieser Arbeit trotz der genannten Kritikpunkte für die Beurteilung der Reliabilität herangezogen. Zusätzlich sollte auch die mittlere Iteminterkorrelation und die Präzision des Koeffizienten betrachtet werden. ${ }^{1326}$ Der Koeffizient kann erhöht werden, wenn der Indikator mit kleinster Item-to-Total-Korrelation entfernt wird. ${ }^{1327}$

Als dritte Gütedimension ist die Validität der Messung zu prüfen. Die Validität beschreibt die konzeptionelle Richtigkeit einer Messung und gibt an, inwiefern das Messverfahren auch wirklich das misst, was es messen soll. ${ }^{1328}$ Eine valide Messung fordert, dass auch der systematische Fehler gleich Null ist. Der im Rahmen der reflektiven Konstruktmessung zu berücksichtigende Messfehler lässt sich aufteilen in einen zufälligen und in einen systematischen Anteil. Wenn der zufällige Messfehler einer Messung den Wert Null annimmt, so wird diese Messung als vollständig reliabel bezeichnet. Nimmt darüber hinaus der systematische Messfehler den Wert Null an, so wird die Messung als vollständig valide bezeichnet. Es können verschiedene Formen der Validität unterschieden werden. Die Inhaltsvalidität bezeichnet den Grad, zu dem die Variablen eines Messmodells dem inhaltlich-semantischen Bereich des Konstruktes angehören und die konstruierenden Items alle Bedeutungsinhalte des Konstruktes vollends abbilden. Das zu messende Konstrukt wird durch den Inhalt der Items in seinen wichtigsten Aspekten erschöpfend erfasst. Die Beurteilung, inwiefern die Inhaltsvalidität gegeben ist, basiert allein auf subjektiven Einschätzungen. ${ }^{1329}$ Das Messmodell ist dann inhaltsvalide, wenn möglichst alle Aspekte des zu messenden Konstruktes durch die Indikatoren repräsentiert werden. Die Konstruktvalidität ist gegeben, wenn aus dem zu messenden Zielkonstrukt Hypothesen ableitbar sind, die anhand der

\footnotetext{
1322 Homburg/Giering (1996), S. 8.

1323 Vgl. Bortz/Döring (2006), S. 199.

1324 Vgl. Bortz/Döring (2006), S. 198.

1325 Vgl. Bortz/Döring (2006), S. $198 \mathrm{f}$.

1326 Vgl. Bühner (2004), S. 122.

1327 Vgl. Eggert (1999), S. 107.

${ }_{1328}$ Vgl. Bühner (2004), S. 30.

1329 Vgl. hier und im Folgenden Bortz/Döring (2006), S. $200 \mathrm{f}$. 
Testwerte bestätigt werden können. Bei der Konstruktvalidität lassen sich die Konvergenzvalidität, die Diskriminanzvalidität und die nomologische Validität unterscheiden. Konvergenzvalidität ist dann gegeben, wenn zwischen den Indikatoren, die demselben Faktor zuzuordnen sind, eine ausreichend starke Beziehung besteht. Dies lässt sich analog auf die Faktoren einer Dimension übertragen. Die Diskriminanzvalidität beschreibt, dass zwischen den Indikatoren, die unterschiedlichen Faktoren zugeordnet sind, bzw. zwischen den Faktoren unterschiedlicher Dimensionen eine geringere Beziehung besteht. ${ }^{130}$ Die nomologische Validität beschreibt die Einbindung eines Konstruktes in einen übergeordneten theoretischen Rahmen. ${ }^{1331}$ Dieses Kriterium wird allerdings oft als problematisch angesehen, da hierfür die Existenz einer abgesicherten Theorie für das Gesamtmodell vorausgesetzt wird, die allerdings häufig nicht gegeben ist. ${ }^{1332}$ Das Zurückweisen der hinsichtlich des Gesamtmodells aufgestellten Hypothesen kann entweder auf eine mangelnde nomologische Validität des Konstruktes oder auf eine fehlende Unterstützung der Hypothesen zurückzuführen sein. Auch im vorliegenden Modell liegt keine gesicherte Theorie für das Gesamtmodell vor. Aufgrunddessen soll das Vorliegen der Einordnung in einen theoretischen Bezugsrahmen als ausreichend angesehen werden. ${ }^{1333}$

Zwischen den Gütekriterien besteht folgender Zusammenhang: Die Objektivität ist die Voraussetzung für die Reliabilität, und Letztere ist die Voraussetzung für die Validität eines Messinstruments. ${ }^{1334}$ Während die Objektivität - wie bereits dargelegt - als gegeben erachtet werden kann, sind die Reliabilität und Validität noch zu prüfen. Hinsichtlich der zu verwendenden Reliabilitäts- und Validitätskriterien werden Verfahren der ersten und der zweiten Generation unterschieden. Die frühen Methoden zur Bewertung der Reliabilität und der Validität von Messmodellen stammen aus der Psychologie/Psychometrie. ${ }^{1335}$ Im Rahmen dieser Arbeit werden zunächst diejenigen Ansätze der ersten Generation betrachtet, die auch von CHURCHILL vorgeschlagen werden. ${ }^{1336}$ Hier ist als erstes Kriterium die Faktorladung zu nennen, die als Beurteilungskriterium für die Konvergenz- und die Diskriminanzvalidität herangezogen werden kann. Ferner sind hier Cronbachs Alpha ${ }^{1337}$ und die Item-To-Total-Korrelationen zu verwenden. ${ }^{1338}$ Letztere werden als Eliminationskriterium betrachtet, mit deren Hilfe man Cronbachs Alpha steigern kann, indem die Indikatorvariable mit der niedrigsten Item-To-TotalKorrelation eliminiert wird.

Die genannten Reliabilitäts- und Validitätskriterien können durch Verfahren der zweiten Generation aus dem Bereich der konfirmatorischen Faktorenanalyse ergänzt werden. In der konfirmatorischen Faktorenanalyse wird „eine Struktur der Beziehungen

\footnotetext{
1330 Vgl. Bortz/Döring (2006), S. 201.

1331 Vgl. Bagozzi/Philipps (1982), S. 468.

1332 Vgl. Homburg (2000), S. $73 \mathrm{ff}$.

1333 Vgl. Flacke (2007), S. 200.

1334 Vgl. Berekhoven/Eckert/Ellenrieder (2001), S. 89.

1335 Vgl. Homburg/Giering (1996), S. 8.

1336 Vgl. Churchill (1979), S. 68 f.

1337 Vgl. Cortina (1993), S. 101.

1338 Vgl. Homburg/Giering (1996), S. 8.
} 
zwischen Indikatoren und Faktoren a priori unterstellt und auf die einzelnen Reliabilitäts- und Validitätsaspekte untersucht ${ }^{\text {"1339 }}$. Mittels inferenzstatistischer Verfahren wird ermittelt, inwiefern aufgrund der Untersuchung einer relativ kleinen Anzahl der Einheiten einer Grundgesamtheit (Population) auf die Verteilung der Merkmale aller Einheiten in der Grundgesamtheit geschlossen werden kann. ${ }^{1340}$ Aus der zweiten Generation sind im Wesentlichen die in Tab. B-49 beschriebenen Kriterien zu nennen. Werden die Gütekriterien mit einem Anspruchsniveau verbunden und mit den jeweiligen, zuvor beschriebenen Gütedimensionen verknüpft, so ergeben sich zusammengefasst je Gütedimension die in Tab. B-50 beschriebenen Messgrößen.

\begin{tabular}{|l|l|l|}
\hline Messgröße & Beschreibung & Gütedimension \\
\hline Indikatorreliabilität & $\begin{array}{l}\text { Anteil der durch den Faktor erklärten Va- } \\
\text { rianz an der Gesamtvarianz des Indikators; } \\
\text { Wertebereich 0 bis 1 mit 1 gleich Optimum }\end{array}$ & Reliabilität \\
\hline Faktorreliabilität & $\begin{array}{l}\text { Beschreibt, wie gut der Faktor durch alle ihm } \\
\text { zugeordneten Variablen gemessen wird; } \\
\text { Wertebereich 0 bis 1 mit 1 gleich Optimum }\end{array}$ & $\begin{array}{l}\text { Reliabilität und } \\
\text { Konvergenzvalidität }\end{array}$ \\
\hline $\begin{array}{l}\text { Durchschnittlich erfasste } \\
\text { Varianz eines Faktors }\end{array}$ & $\begin{array}{l}\text { Misst, wie gut der Faktor durch alle ihm } \\
\text { zugeordneten Variablen gemessen wird }\end{array}$ & $\begin{array}{l}\text { Reliabilität und } \\
\text { Konvergenzvalidität }\end{array}$ \\
\hline Fornell/Larcker-Kriterium & $\begin{array}{l}\text { Fordert, dass die durchschnittliche erfasste } \\
\text { Varianz eines Faktors größer als jede quad- } \\
\text { rierte Korrelation dieses Faktors mit einem } \\
\text { anderen Faktor ist }{ }^{1341}\end{array}$ & Diskriminanzvalidität \\
\hline
\end{tabular}

Tab. B-49: Gütekriterien der zweiten Generation ${ }^{1342}$

$\begin{array}{ll}1339 & \text { Homburg (2000), S. 81. } \\ 1340 & \text { Vgl. Bortz (2005), S. 85. } \\ 1341 & \text { Vgl. Fornell/Larcker (1981), S. 46. } \\ 1342 & \text { Vgl. Homburg/Giering (1996), S. } 10\end{array}$ 


\begin{tabular}{|c|c|c|c|}
\hline $\begin{array}{l}\text { Güte- } \\
\text { dimension }\end{array}$ & Bereich & Messgröße & Anspruchsniveau \\
\hline Objektivität & & --- (Qualitative Überprüfung) & $\mathrm{x}$ \\
\hline \multirow{4}{*}{ Reliabilität } & \multirow{4}{*}{$\begin{array}{l}\text { Interne Konsistenz- } \\
\text { Reliabilität }\end{array}$} & Cronbachs Alpha & $0,4^{1343} / 0,7^{1344}$ \\
\hline & & Indikatoreliabilität & $0,4^{1345}$ \\
\hline & & Faktorreliabilität & $0,6^{1346}$ \\
\hline & & $\begin{array}{l}\text { DEV - durchschnittlich } \\
\text { erfasste Varianz eines Faktors }\end{array}$ & 0,5 \\
\hline \multirow{6}{*}{ Validität } & Inhaltsvalidität & Qualitative Prüfung & \\
\hline & \multirow{3}{*}{ Konvergenzvalidität } & Faktorreliabilität & 0,6 \\
\hline & & DEV & 0,5 \\
\hline & & Faktorladung & $0,5^{1347}$ \\
\hline & Diskriminanzvalidität & Fornell/Larcker-Kriterium & DEV $>$ Korrel $^{2} \max$ \\
\hline & Nomologische Validität & --- (Qualitative Prüfung) & $\mathrm{x}$ \\
\hline
\end{tabular}

Tab. B-50: Verwendete Gütekriterien inkl. Anspruchsniveau ${ }^{1348}$

\subsubsection{Vorgehen bei der quantitativen Analyse}

Nach Durchführung der Datenerhebung wird eine quantitative Analyse zur Beurteilung und Optimierung des Messmodells durchgeführt. Das Vorgehen wird im Folgenden dargestellt. In der Untersuchungsstufe A (vgl. Abb. B-21) erfolgt eine sukzessive Auseinandersetzung mit den einzelnen Faktoren des Konstruktes, wobei hier die hypothetische Faktorenstruktur zugrunde gelegt wird. ${ }^{1349}$ Zunächst werden Verfahren der ersten Generation angewendet: Cronbachs Alpha und die exploratorische Faktorenanalyse. Sofern Cronbachs Alpha einen Wert kleiner als 0,7 annimmt und somit der Reliabilitätswert als zu gering erachtet wird, erfolgt eine Prüfung, inwiefern eine Verbesserung desselben durch eine Elimination von Items mit einer zu geringen Item-to-TotalKorrelation möglich ist. ${ }^{1350}$

Die verbleibenden Indikatoren werden mit Hilfe einer exploratorischen Faktorenanalyse untersucht. So lässt sich mit deren Hilfe ein Variablensatz auf eine ordnende Struktur hin untersuchen. ${ }^{1351}$ Ziel ist es, die Variablenzahl auf wenige, wichtige Einflussfak-

\footnotetext{
1343 Bei nur drei für die Konstruktbildung verwendeten Indikatoren verwendet Unterreitmeier eine Schwelle von 0,4. Vgl. Unterreitmeier (2004), S. 118.

1344 Vgl. Nunnally (1978), S. 245.

1345 Hadwich unterscheidet hier zwischen Grenzwert und Anspruchsniveau. Während das Anspruchsniveau mit dem genannten Werten identisch ist, verwendet er als Grenzwert für die Indikatorreliabiliät 0,1. Vgl. Hadwich (2003), S. 122.

1346 Auch bei der Faktorreliablität ist das Anspruchsniveau mit dem genannten Werten identisch, als Grenzwert verwendet er 0,4. Vgl. Hadwich (2003), S. 122.

1347 Vgl. Homburg/Giering (1996), S. 8.

1348 Vgl. Homburg/Giering (1996), S. 12, Flacke (2007), S. 202.

1349 Vgl. Homburg/Giering (1996), S. 12.

1350 Vgl. Churchill (1979), S. 68.

1351 Vgl. Bortz (2005), S. 495. 
toren zu reduzieren. ${ }^{1352}$ Dabei liegen a priori keine Hypothesen über die Faktorzuordnung vor. Da bei der Konzeptualisierung angenommen worden ist, dass es sich bei den Indikatoren um reflektive Indikatoren handelt und die Faktoren somit die ihm zugeordneten Indikatoren verursachen, impliziert diese Kausalität die Anwendung der Hauptachsenanalyse als Faktorextrahierungsmethode. Bei der Hauptachsen-Faktorenanalyse wird unterstellt, dass die Varianz einer Variablen in einen Anteil zerlegt werden kann, den diese Variable mit den restlichen Variablen gemein hat sowie in einen solchen, der ausschließlich auf die spezifische Variable zurückzuführen ist. Lediglich die gemeinsamen Varianzen der Variablen, die so genannten Kommunalitäten, sollen durch das Modell erklärt werden. ${ }^{1353} \mathrm{Da}$ in allen Fällen alle Indikatoren nur auf einen Faktor hochladen, ist eine Rotation der Faktoren nicht nötig. ${ }^{1354}$ Nachdem die Indikatoren mit Hilfe der explorativen Faktorenanalyse zu Faktoren verdichtet worden sind, können Aussagen zur Konvergenz- und Diskriminanzvalidität getroffen werden. ${ }^{1355}$ Wenn alle Indikatoren auf einen Faktor hinreichend hoch laden und gleichzeitig in Bezug auf alle anderen Faktoren deutlich niedrigere Faktorladungen aufweisen, so kann von einer hinreichenden Konvergenz- und Diskriminanzvalidität ausgegangen werden. ${ }^{1356}$ Anhand des Kaiser-Kriteriums wird geprüft, ob mittels der Faktorextraktion auch nur ein Faktor extrahiert wird. Andernfalls kann kein sinnvolles $\mathrm{Ma} B$ an konvergenter Validität gegeben sein. ${ }^{1357}$ Des Weiteren muss durch diesen Faktor mindestens $50 \%$ der Varianz der zugehörigen Indikatoren erklärt werden. Ist dies nicht der Fall, wird geprüft, inwiefern durch die Elimination der Indikatoren mit den zu geringen Faktorladungen eine Verbesserung erzielt werden kann.

Anschließend werden die übrig gebliebenen Indikatoren mit einer konfirmatorischen Faktorenanalyse unter der Annahme einer einfaktoriellen Struktur analysiert. In diesem Kontext wird auf die zuvor dargestellten Gütekriterien der zweiten Generation zurückgegriffen. ${ }^{1358}$ Dazu werden für jeden Faktor die Indikatorreliabilität, die Faktorreliabilität und die durchschnittlich erfasste Varianz ermittelt. Werden allerdings mehrere Kriterien nicht eingehalten, so wird geprüft, inwiefern durch Elimination der Indikatoren mit einer niedrigen Faktorladung eine Verbesserung erzielt werden kann. Im Ergebnis liegen mehrere Faktoren vor, die jeweils auf einer unter den Gesichtspunkten der Reliabilität und der konvergenten Validität bereinigten Indikatormenge basieren.

Die letzte Untersuchungsstufe B bezieht sich auf das gesamte Messmodell. In dieser Untersuchungsstufe kommt das Fornell/Larcker-Kriterium zur Überprüfung der Diskriminanzvalidität der Faktoren zum Einsatz. Ferner erfolgt in diesem Schritt auch die Beurteilung der nomologischen Validität.

\footnotetext{
1352 Vgl. Backhaus et al. (2006), S. $259 \mathrm{ff}$.

1353 Vgl. Pepels (1995), S. 338.

1354 Vgl. hierzu die Auswertungen in Kapitel B.3.2.4.

1355 Vgl. Unterreitmeier (2004), S. 118.

1356 Vgl. Unterreitmeier (2004), S. 118.

1357 Vgl. hier und im Folgenden Homburg/Giering (1996), S. 12.

1358 Vgl. Homburg/Giering (1996), S. 12.
} 


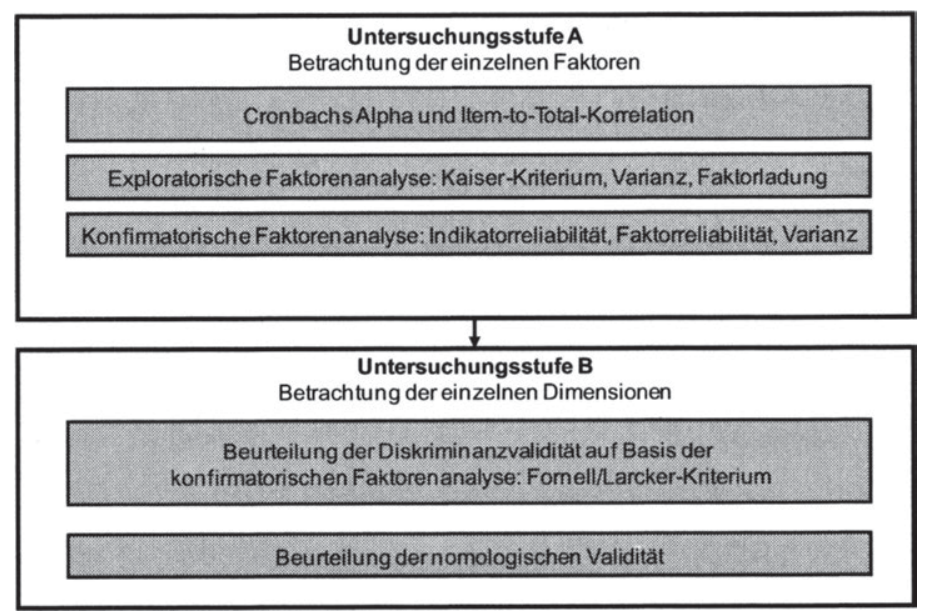

Abb. B-21: Vorgehensweise bei der quantitativen Analyse (139 $^{139}$

\subsubsection{Durchführung der quantitativen Analyse}

Bevor die Faktorenanalyse eingesetzt wird, werden zunächst die Anwendungsvoraussetzungen geprüft. Die dazu durchgeführten Schritte und Ergebnisse sind in Tab. B-51 dargestellt.

1359 Eigene Darstellung in Anlehnung an Homburg/Giering (1996), S. 12. 


\begin{tabular}{|l|l|l|}
\hline Anwendungsvoraussetzung & Test & Beurteilung \\
\hline $\begin{array}{l}\text { Ausreichende Korrelation der } \\
\text { Variablen (Sphärizität) }\end{array}$ & $\begin{array}{l}\text { Bartlettest auf Nicht-Sphärizität } \\
\text { mit Überprüfung der Signifikanz } \\
\text { des Chi-Quadrat-Wertes } 160\end{array}$ & $\begin{array}{l}\text { Bei allen untersuchten Faktoren } \\
\text { gegeben. }\end{array}$ \\
\hline $\begin{array}{l}\text { Näherungsweise Diagonalma- } \\
\text { trixform der Anti-Image-Kova- } \\
\text { rianz-Matrix }\end{array}$ & $\begin{array}{l}\text { Kriterium nach Dziuban/Shir- } \\
\text { key: Anteil der Nicht-Diagonal- } \\
\text { Elemente mit Werten ungleich } \\
\text { null (>0,09) in der Anti-Image- } \\
\text { Kovarianz-Matrix muss geringer } \\
\text { als 25\% sein }{ }^{1361}\end{array}$ & $\begin{array}{l}\text { Der Anteil ist bei mehreren Fakto- } \\
\text { ren größer 25\%. Die Vorausset- } \\
\text { erfilt. }\end{array}$ \\
\hline $\begin{array}{l}\text { Vorabprüfung der Zusammen- hier nur eingeschränkt } \\
\text { gehörigkeit von Variablen i.S.d. } \\
\text { "Measure of Sampling Ade- } \\
\text { quacy“ (MSA) }\end{array}$ & $\begin{array}{l}\text { Globales MSA-Kriterium (Kai- } \\
\text { ser-Meyer-Olkin-Kriterium) auf } \\
\text { Basis der Anti-Image-Korrelati- } \\
\text { onsmatrix }{ }^{1362}\end{array}$ & $\begin{array}{l}\text { Die Werte sind bei allen Faktoren } \\
\text { "Mäßig“ bis „Mittelprächtig“. }\end{array}$ \\
\hline $\begin{array}{l}\text { Fallanzahl entspricht mind. der } \\
\text { Variablenanzahl }\end{array}$ & $\begin{array}{l}\text { Vergleich der Fallanzahl und der } \\
\text { Variablenzahl }\end{array}$ & $\begin{array}{l}\text { Die Fallzahl liegt im schlechtesten } \\
\text { Fall bei N=207. Die maximale } \\
\text { Variablenzahl je Untersuchung } \\
\text { beträgt 4. }\end{array}$ \\
\hline $\begin{array}{l}\text { Mindestens Intervallskalierung } \\
\text { der Variablen }\end{array}$ & $\begin{array}{l}\text { Prüfung des Skalenniveaus } \\
\text { Ratingskala vor. }\end{array}$ \\
\hline
\end{tabular}

Tab. B-51: Prüfung der Anwendungsvoraussetzungen für die Faktorenanalyse ${ }^{1363}$

Die Anwendungsvoraussetzungen für die Faktorenanalyse wurden somit im Wesentlichen eingehalten. Bei BACKHAUS ET AL. wird das MSA-Kriterium als wichtigstes Kriterium angesehen und selbiges ist bei allen Faktoren erfüllt. ${ }^{1364} \mathrm{Im}$ Folgenden werden nun die Untersuchungsergebnisse für die einzelnen Faktoren dargestellt. Es wird an dieser Stelle vorweggenommen, dass im Rahmen der exploratorischen Faktorenanalyse stets genau ein Faktor extrahiert wurde.

\begin{tabular}{|c|c|c|c|c|c|c|c|}
\hline Indikator & $\begin{array}{l}\text { Cron- } \\
\text { bachs } \\
\text { Alpha }\end{array}$ & $\begin{array}{l}\text { Faktor- } \\
\text { ladung }\end{array}$ & $\begin{array}{l}\text { Indikator- } \\
\text { reliabilităt }\end{array}$ & $\begin{array}{l}\text { Faktor- } \\
\text { reliabilităt }\end{array}$ & DEV & $\begin{array}{c}\text { Korrel }^{2} \\
\max \end{array}$ & $\begin{array}{l}\text { Fornell/ } \\
\text { Larcker }\end{array}$ \\
\hline VERLÄSS_INF & \multirow{4}{*}{$\begin{array}{c}0,8052 \\
\text { (für } 4 \text { von } \\
4 \text { Items) }\end{array}$} & 0,7242 & 0,5245 & \multirow{4}{*}{0,8087} & \multirow{4}{*}{$51,55 \%$} & \multirow{4}{*}{0,4509} & \multirow{4}{*}{1,1431} \\
\hline EINHALT_ABS & & 0,6234 & 0,3886 & & & & \\
\hline VERLÄSS_ENT & & 0,7308 & 0,5342 & & & & \\
\hline QUAL MA & & 0,7839 & 0,6146 & & & & \\
\hline
\end{tabular}

Tab. B-52: Untersuchung der organisationalen Glaubwürdigkeit

Bei der Vertrauensdimension „Organisationale Glaubwürdigkeit" wurden mit Ausnahme der Indikatorreliabilität bei dem Indikator EINHALT_ABS alle Gütekriterien erfüllt (vgl. Tab. B-52). Cronbachs Alpha liegt mit 0,8052 über dem Wert von GANE-

\footnotetext{
1360 Vgl. Backhaus et al. (2006), S. $273 \mathrm{f}$.

1361 Vgl. Backhaus et al. (2006), S. $275 \mathrm{f}$.

1362 Vgl. Backhaus et al. (2006), S. 276.

1363 Vgl. Hadwich (2003), S. 127. Zu den Anwendungsvoraussetzungen vgl. ausführlich Backhaus et al. (2006), S. $273 \mathrm{ff}$. Die detaillierten Untersuchungsergebnisse können dem Anhang 3, Tab. AN 3-1 und Tab. AN 3-2 entnommen werden. 
SAN/HESS von 0,75 , die in ihrer Studie ebenfalls eine Messung der organisationalen Glaubwürdigkeit vorgenommen haben. ${ }^{1365}$

\begin{tabular}{|c|c|c|c|c|c|c|c|}
\hline Indikator & $\begin{array}{l}\text { Cron- } \\
\text { bachs } \\
\text { Alpha }\end{array}$ & $\begin{array}{l}\text { Faktor- } \\
\text { ladung }\end{array}$ & $\begin{array}{l}\text { Indikator- } \\
\text { reliabilität }\end{array}$ & $\begin{array}{l}\text { Faktor- } \\
\text { reliabilität }\end{array}$ & DEV & $\begin{array}{c}\text { Korrel }^{2} \\
\max \end{array}$ & $\begin{array}{l}\text { Fornelly } \\
\text { Larcker }\end{array}$ \\
\hline NICHT_NACHTEIL & \multirow{4}{*}{$\begin{array}{c}0,5977 \\
\text { (für } 4 \text { von } \\
4 \text { Items) }\end{array}$} & 0,5814 & 0,3381 & \multirow{4}{*}{0,6179} & \multirow{4}{*}{$30,48 \%$} & \multirow{4}{*}{0,3526} & \multirow{4}{*}{0,8644} \\
\hline ERWAR_VERSTÄ & & 0,3372 & 0,1137 & & & & \\
\hline RECHT_INFO & & 0,7508 & 0,5637 & & & & \\
\hline VERTMITT_KUND & & 0,4511 & 0,2035 & & & & \\
\hline
\end{tabular}

Tab. B-53: Untersuchung des organisationalen Wohlwollens

Bei der Vertrauensdimension „Organisationales Wohlwollen“ wurden einige GüteKriterien nicht erfüllt (vgl. Tab. B-53). Während in der vorliegenden Untersuchung nur ein Alpha von 0,5977 ermittelt wurde, haben GANESAN/HESS einen Alphakoeffizienten von 0,87 erzielt. ${ }^{1366}$ Dies könnte unter anderem eine Konsequenz der erforderlichen Adaption an den Bankenkontext sein. Eine Verbesserung der Güte durch Elimination einzelner Indikatoren oder durch Änderung der Faktorenstruktur konnte nicht erzielt werden. ${ }^{1367}$ So wurde geprüft, inwiefern durch eine Aufhebung der Trennung zwischen organisationalem und personalem Wohlwollen bessere Ergebnisse erzielt werden, da bei den Unternehmen der Datenbasis vielfach eine Einheit von Eigentum und Leitung besteht und somit diese beiden Dimensionen aus Sicht des Firmenkundenbetreuers möglicherweise nicht separierbar sind. Ferner wurde auch geprüft, ob die Aufhebung der Trennung zwischen organisationalem Wohlwollen und organisationaler Glaubwürdigkeit zu einer Verbesserung der Qualität führt, da möglicherweise die Trennung dieser beiden Dimensionen nicht der Wahrnehmung des Firmenkundenbetreuers entspricht. Aber auch hier konnte keine Verbesserung erzielt werden. Bei der Weiterverwendung dieses Faktors in den weiteren Untersuchungen muss diese Einschränkung berücksichtigt werden.

\footnotetext{
1365 Vgl. Ganesan/Hess (1997), S. 444

1366 Vgl. Ganesan/Hess (1997), S. 444.
}

1367 Sofern die Werte für Cronbachs Alpha nicht über der geforderten Schwelle von 0,7 liegen, wurde jeweils durch Elimination der Indikatoren mit der niedrigsten Item-To-Total-Korrelation geprüft, inwiefern dadurch bessere Werte für Cronbachs Alpha erzielt werden können. In den dargestellten Tabellen wird nur das Ergebnis nach Prüfung dieses Schritts ausgewiesen. D.h. in der vorliegenden Untersuchung konnte durch die Elimination einzelner Kriterien keine Verbesserung erzielt werden. 


\begin{tabular}{|c|c|c|c|c|c|c|c|}
\hline Indikator & $\begin{array}{l}\text { Cron- } \\
\text { bachs } \\
\text { Alpha }\end{array}$ & $\begin{array}{l}\text { Faktor- } \\
\text { ladung }\end{array}$ & $\begin{array}{l}\text { Indikator- } \\
\text { reliabilităt }\end{array}$ & $\begin{array}{l}\text { Faktor- } \\
\text { reliabilităt }\end{array}$ & DEV & $\begin{array}{c}\text { Korrel }^{2} \\
\max \end{array}$ & $\begin{array}{l}\text { Fornell/ } \\
\text { Larcker }\end{array}$ \\
\hline OFF_ERLÄUT & \multirow{4}{*}{$\begin{array}{c}0,6448 \\
\text { (für } 4 \text { von } \\
4 \text { Items) }\end{array}$} & 0,7574 & 0,5736 & \multirow{4}{*}{0,6749} & \multirow{4}{*}{$35,80 \%$} & \multirow{4}{*}{0,4509} & \multirow{4}{*}{0,7938} \\
\hline BRANCHINFO & & 0,7099 & 0,5039 & & & & \\
\hline KENNT_BWL & & 0,4178 & 0,1745 & & & & \\
\hline STELL_UNANG_FORD & & 0,4240 & 0,1798 & & & & \\
\hline
\end{tabular}

Tab. B-54: Untersuchung der personalen Glaubwürdigkeit

Bei der Vertrauensdimension „Personale Glaubwürdigkeit“ wurden ebenfalls einige Gütekriterien nicht erfüllt (vgl. Tab. B-54). Cronbachs Alpha liegt mit 0,6448 nur ganz knapp unter dem Schwellenwert und unter den entsprechenden Werten von GANESAN/HESS (Alpha: 0,72) ) $^{1368}$ und GANESAN (Alpha für Personale Glaubwürdigkeit des Herstellers bzw. des Händlers: 0,88 bzw. 0,76). ${ }^{1369}$

\begin{tabular}{|c|c|c|c|c|c|c|c|}
\hline Indikator & $\begin{array}{l}\text { Cron- } \\
\text { bachs } \\
\text { Alpha }\end{array}$ & $\begin{array}{l}\text { Faktor- } \\
\text { ladung }\end{array}$ & $\begin{array}{l}\text { Indikator- } \\
\text { reliabilität }\end{array}$ & $\begin{array}{l}\text { Faktor- } \\
\text { reliabilität }\end{array}$ & DEV & $\begin{array}{c}\text { Korrel }^{2} \\
\max \end{array}$ & $\begin{array}{l}\text { Fornelly } \\
\text { Larcker }\end{array}$ \\
\hline INKAUF_FORM_TÄT & \multirow{4}{*}{$\begin{array}{c}0,5734 \\
\text { (für } 4 \text { von } \\
4 \text { Items) }\end{array}$} & 0,1784 & 0,0318 & \multirow{4}{*}{0,6138} & \multirow{4}{*}{$31,75 \%$} & \multirow{4}{*}{0,4421} & \multirow{4}{*}{0,7180} \\
\hline PERS_KONT_UNZU & & 0,5688 & 0,3236 & & & & \\
\hline INKAUF UNAN & & 0,5629 & 0,3169 & & & & \\
\hline FREUND BEZ & & 0,7731 & 0,5976 & & & & \\
\hline
\end{tabular}

Tab. B-55: Untersuchung des personalen Wohlwollens

Ebenso wurden bei der Vertrauensdimension „Personales Wohlwollen“ nicht alle Gütekriterien erfüllt (vgl. Tab. B-55). Cronbachs Alpha liegt mit 0,5734 unter dem Anspruchsniveau und auch deutlich unter den entsprechenden Werten von GANESAN/HESS (Alpha: 0,91) 1370 und GANESAN (Alpha für Personales Wohlwollen des Hersteller bzw. des Händlers: 0,88 bzw. 0,76) ${ }^{137}$. Während bisher die Vertrauensdimensionen betrachtet wurden, erfolgt im Folgenden die Analyse der CommitmentDimensionen.

\footnotetext{
1368 Vgl. Ganesan/Hess (1997), S. 444.

1369 Vgl. Ganesan (1994), S. 17.

1370 Vgl. Ganesan/Hess (1997), S. 444

1371 Vgl. Ganesan (1994), S. 17.
} 


\begin{tabular}{|c|c|c|c|c|c|c|c|}
\hline Indikator & $\begin{array}{l}\text { Cron- } \\
\text { bachs } \\
\text { Alpha }\end{array}$ & $\begin{array}{l}\text { Faktor- } \\
\text { ladung }\end{array}$ & $\begin{array}{l}\text { Indikator- } \\
\text { reliabilităt }\end{array}$ & $\begin{array}{l}\text { Faktor- } \\
\text { reliabilităt }\end{array}$ & DEV & $\underset{\max }{\text { Korrel }^{2}}$ & $\begin{array}{l}\text { Fornelly } \\
\text { Larcker }\end{array}$ \\
\hline WECHS_BAI & \multirow{3}{*}{$\begin{array}{c}0,7740 \\
\text { (für } 3 \text { von } \\
3 \text { Items) }\end{array}$} & 0,7732 & 0,5978 & \multirow{3}{*}{0,7746} & \multirow{3}{*}{$53,44 \%$} & \multirow{3}{*}{0,0992} & \multirow{3}{*}{5,3867} \\
\hline INFO_NEU_BANK & & 0,7162 & 0,5129 & & & & \\
\hline VERTR_AKT_BANK & & 0,7017 & 0,4924 & & & & \\
\hline
\end{tabular}

Tab. B-56: Untersuchung der organisationalen Gebundenheit

Hinsichtlich der Commitment-Dimension „Organisationale Gebundenheit" konnten alle Gütekriterien erfüllt werden (vgl. Tab. B-56). Eine Verwendung in den weiteren Untersuchungen ist ohne Einschränkungen möglich.

\begin{tabular}{|c|c|c|c|c|c|c|c|}
\hline Indikator & $\begin{array}{l}\text { Cron- } \\
\text { bachs } \\
\text { Alpha }\end{array}$ & $\begin{array}{l}\text { Faktor- } \\
\text { ladung }\end{array}$ & $\begin{array}{l}\text { Indikator- } \\
\text { reliabilität }\end{array}$ & $\begin{array}{l}\text { Faktor- } \\
\text { reliabilität }\end{array}$ & DEV & $\begin{array}{c}\text { Korrel }^{2} \\
\max \end{array}$ & $\begin{array}{l}\text { Fornell/ } \\
\text { Larcker }\end{array}$ \\
\hline ANGEN_ZSARB & \multirow{3}{*}{$\begin{array}{c}0,7729 \\
\text { (für 3 von } \\
3 \text { Items) }\end{array}$} & 0,6251 & 0,3908 & \multirow{3}{*}{0,7785} & \multirow{3}{*}{$54,31 \%$} & \multirow{3}{*}{0,3658} & \multirow{3}{*}{1,4848} \\
\hline UNT_GEN_ID & & 0,7299 & 0,5327 & & & & \\
\hline UNT_GP & & 0,8400 & 0,7057 & & & & \\
\hline
\end{tabular}

Tab. B-57: Untersuchung der organisationalen Verbundenheit

Bei der Commitment-Dimension „Organisationale Verbundenheit“ konnten mit Ausnahme der Indikatorreliabilität des Indikators ANGEN_ZSARB, welcher die geforderte Schwelle von 0,4 nur minimal unterschritten hat, alle Gütekriterien erfüllt werden (vgl. Tab. B-57). Eine Verwendung in den weiteren Untersuchungen ist ohne Einschränkungen möglich. ${ }^{1372}$

\begin{tabular}{|c|c|c|c|c|c|c|c|}
\hline Indikator & $\begin{array}{l}\text { Cron- } \\
\text { bachs } \\
\text { Alpha }\end{array}$ & $\begin{array}{l}\text { Faktor- } \\
\text { ladung }\end{array}$ & $\begin{array}{l}\text { Indikator- } \\
\text { reliabilität }\end{array}$ & $\begin{array}{l}\text { Faktor- } \\
\text { reliabilität }\end{array}$ & DEV & $\begin{array}{c}\text { Korrel }^{2} \\
\text { Max }\end{array}$ & $\begin{array}{l}\text { Fornell } \\
\text { Larcker }\end{array}$ \\
\hline WICHT_WECH_FK & \multirow{3}{*}{$\begin{array}{c}0,7488 \\
\text { (für } 3 \text { von } \\
3 \text { Items) }\end{array}$} & 0,6008 & 0,3610 & \multirow{3}{*}{0,7525} & \multirow{3}{*}{$50,76 \%$} & \multirow{3}{*}{0,4421} & \multirow{3}{*}{1,1482} \\
\hline WICHT_PERS_KON & & 0,6908 & 0,4773 & & & & \\
\hline KEIN_BANK_WE & & 0,8275 & 0,6847 & & & & \\
\hline
\end{tabular}

Tab. B-58: Untersuchung der personalen Verbundenheit

Ebenso konnten bei der Commitment-Dimension „Personale Verbundenheit“ mit Ausnahme der Indikatorreliabilität des Indikators WICHT_WECH_FKB, welcher die geforderte Schwelle von 0,4 geringfügig unterschritten hat, alle Gütekriterien erfüllt werden (vgl. Tab. B-58). Eine Verwendung in den weiteren Untersuchungen ist ohne Einschränkungen möglich.

1372 Die Faktorreliabilität ist gemäß Homburg/Giering das deutlich wichtigere Kriterium. Vgl. Homburg/Giering (1996), S. 12. 


\begin{tabular}{|c|c|c|c|c|c|c|c|}
\hline Indikator & $\begin{array}{l}\text { Cron- } \\
\text { bachs } \\
\text { Alpha }\end{array}$ & $\begin{array}{l}\text { Faktor- } \\
\text { ladung }\end{array}$ & $\begin{array}{l}\text { Indikator- } \\
\text { reliabilität }\end{array}$ & $\begin{array}{l}\text { Faktor- } \\
\text { reliabilităt }\end{array}$ & DEV & $\begin{array}{c}\text { Korrel }^{2} \\
\text { Max }\end{array}$ & $\begin{array}{l}\text { Fornell/ } \\
\text { Larcker }\end{array}$ \\
\hline WICHT_PERS_KON & \multirow{4}{*}{$\begin{array}{c}0,8020 \\
\text { (für } 4 \text { von } \\
4 \text { Items) }\end{array}$} & 0,7655 & 0,5860 & \multirow{4}{*}{0,8042} & \multirow{4}{*}{$50,81 \%$} & \multirow{4}{*}{0,3677} & \multirow{4}{*}{1,3817} \\
\hline KEIN_BANK_WE & & 0,7488 & 0,5607 & & & & \\
\hline FREUND BEZ & & 0,7055 & 0,4977 & & & & \\
\hline PERS_KONT_UNZU & & 0,6229 & 0,3880 & & & & \\
\hline
\end{tabular}

Tab. B-59: Untersuchung des personalen Wohlwollens und der personalen Verbundenheit

In den bisherigen, dem Autor bekannten Studien wurden die Konstrukte Vertrauen und Commitment nie gemeinsam in vergleichbarer Form, d.h. unter Berücksichtigung der verschiedenen Dimensionen, untersucht. Es besteht allerdings eine inhaltliche Nähe zwischen der personalen Verbundenheit und dem personalen Wohlwollen. Die personale Verbundenheit ist in gewisser Weise eine Voraussetzung oder ein Förderer des personalen Wohlwollens. Es konnte eine leichte Verbesserung der Güte erreicht werden, indem diese beiden Dimensionen zusammengefasst und in einem gemeinsamen Faktor untersucht wurden (vgl. Tab. B-59). In den weiteren Untersuchungen wird dieser zusätzliche Faktor somit jeweils ergänzend betrachtet.

In Tab. B-60 wird eine zusammenfassende Beurteilung der Faktoren hinsichtlich der Erfüllung der Gütekriterien und somit der Verwendungsmöglichkeit für die weiteren Untersuchungen gegeben. Bei Verwendung der von HADWICH vorgeschlagenen Grenzwerte überschreiten die Faktorladungen von allen Faktoren den Grenzwert von 0,4 und alle Indikatorreliabilitäten mit Ausnahme des Indikators INKAUF_FORM_TÄT den Grenzwert von 0,1. ${ }^{1373}$ Im Rahmen der vorliegenden Konstruktmessung wurde für jedes Unternehmen ein Faktorwert ermittelt, der in den Analysen verwendet werden kann.

Wie in Kapitel B.3.2.1 dargelegt, kann die Beurteilung der nomologischen Qualität aufgrund der fehlenden Theorie für den Gesamtzusammenhang nicht adäquat erfolgen. Aus diesem Grund wurde die bereits vorgenommene Einordnung in den theoretischen Bezugsrahmen als ausreichend für die Beurteilung erachtet. Nach der Bildung der Faktoren für die verschiedenen Vertrauens- und Commitment-Dimensionen folgt nun die eigentliche Hypothesenprüfung. 


\begin{tabular}{|l|l|}
\hline Faktor & Weitere Verwendung \\
\hline Organisationale Glaubwürdigkeit & ohne Einschränkung \\
\hline Organisationales Wohlwollen & nur mit leichter Einschränkung \\
\hline Personale Glaubwürdigkeit & nur mit leichter Einschränkung \\
\hline Personales Wohlwollen & nur mit leichter Einschränkung \\
\hline Organisationale Gebundenheit & ohne Einschränkung \\
\hline Organisationale Verbundenheit & ohne Einschränkung \\
\hline Personale Verbundenheit & ohne Einschränkung \\
\hline Personales Wohlwollen und Verbundenheit & ohne Einschränkung \\
\hline
\end{tabular}

Tab. B-60: Zusammenfassende Beurteilung der Faktoren

\subsection{Allgemeines Vorgehen bei der Korrelationsanalyse}

In den nachfolgenden Kapiteln wird der Einfluss der unabhängigen Variablen auf die abhängigen Variablen untersucht. Die Analyse des Einflusses erfolgt zunächst in einem univariaten und anschließend in einem multivariaten Zusammenhang. Die Korrelationsanalyse liefert aufgrund der univariaten Betrachtung erste Erkenntnisse für potenzielle Zusammenhänge zu den ökonomischen Parametern und somit eine Grundlage für die Auswahl der in den weiteren Analysen zu verwendenden Variablen. So kann mittels des Korrelationskoeffizienten die Stärke des Zusammenhangs zweier Variablen bestimmt werden, wobei der Korrelationskoeffizient darauf beschränkt ist, lineare Zusammenhänge zu identifizieren, ${ }^{1374}$ eine Aussage über die Richtung des $\mathrm{Zu}$ sammenhangs kann mit Hilfe der Korrelationsanalyse jedoch nicht getätigt werden. ${ }^{1375}$ Bei der Ermittlung der Korrelationskoeffizienten ist in Abhängigkeit vom Skalenniveau der getesteten Variablen das entsprechende Korrelationsmaß (vgl. Tab. B-61) auszuwählen, wobei in Tab. B-61 nur die für die vorliegende Studie relevanten Maße dargestellt werden.

Die Verwendung von bivariaten Korrelationskoeffizienten kann - bei theoriefreier Auswertung der Ergebnisse - schnell zu falschen Schlussfolgerungen führen. Bei der Interpretation der Ergebnisse der Korrelationsanalyse ist zu überlegen, wie die Variablen aufeinander wirken. Bei der Analyse der Korrelationen zwischen den ökonomischen Parametern und den Einflussfaktoren ist zu hinterfragen, woher der Zusammenhang resultiert. Dies wird insbesondere bei der Interpretation der noch folgenden Regressionsanalysen bedeutsam. Es muss eine Unterscheidung zwischen Moderator- und Mediatoreffekten vorgenommen werden (vgl. Abb. B-22). Ein Moderatoreffekt liegt dann vor, wenn eine Variable (die sog. „Moderatorvariable“) den Effekt einer (oder mehrerer) X-Variablen beeinflusst. Die Moderatorvariable beeinflusst somit den Effekt auf die Y-Variable, nicht unmittelbar die Ausprägung der Y-Variable. ${ }^{1376}$

\footnotetext{
1374 Vgl. Brosius (2002), S. 495.

1375 Vgl. Berekhoven/Eckert/Ellenrieder (2001), S. 199.

1376 Vgl. Urban/Mayerl (2006), S. 293.
} 


\begin{tabular}{|l|l|}
\hline Korrelationsmaß & Skalenniveau der Variablen \\
\hline Pearsons Korrelationskoeffizient ${ }^{1377}$ & $\begin{array}{l}\text { Zwei metrische (intervallskalierte Variablen) } \\
\text { mit gemeinsamer zweidimensionaler Nor- } \\
\text { malverteilung in Grundgesamtheit }\end{array}$ \\
\hline Punktbiserialer Korrelationskoeffizient ${ }^{1378}$ & $\begin{array}{l}\text { Eine metrische (intervallskalierte Variable) } \\
\text { und eine dichotome Variable }\end{array}$ \\
\hline${\text { Rangkorrelationskoeffizient Spearmans } \text { Rho }^{1379}}^{1379}$ & Zwei mind. ordinale, eine nicht-metrische \\
\hline Kendall's Tau $^{1380}$ & Zwei mind. ordinale, eine nicht-metrische \\
\hline
\end{tabular}

Tab. B-61: Korrelationskoeffizienten in Abhängigkeit vom Skalenniveau
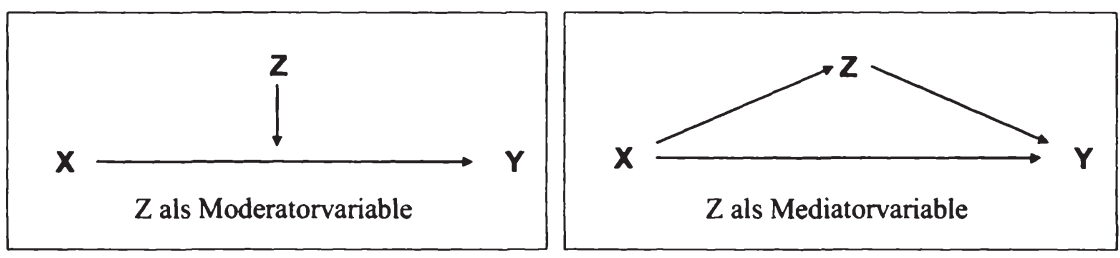

Abb. B-22: Z als Moderatorvariable und als Mediatorvariable ${ }^{1381}$

Im Unterschied dazu spricht man von einem Mediatoreffekt, wenn ein direkter Effekt zwischen zwei Variablen durch den Einfluss einer weiteren Variablen (der sog. „Mediatorvariablen") unterbrochen wird. ${ }^{1382}$ Während Moderatorvariablen den Einfluss einer unabhängigen Variablen auf die abhängige Variable verändern, spricht man von Mediatorvariablen, wenn eine unabhängige Variable nicht oder nicht ausschließlich direkt, sondern über ein dritte Variable auf die abhängige Variable einwirkt. ${ }^{1383} \mathrm{Im}$ Rahmen der Regressionsanalyse sind Mediatoreffekte zu berücksichtigen. Denn die Mediatorvariable ist dann sowohl eine abhängige Variable (in Bezug auf X) als auch eine unabhängige Variable (in Bezug auf Y). Bspw. beeinflusst die Branche die Finanzierungsstruktur des Unternehmens. Die Finanzierungsstruktur des Unternehmens wiederum beeinflusst die Kreditkonditionen. Die Branche beeinflusst somit indirekt die Kreditkonditionen. Möglicherweise hat die Branche selbst aber auch einen direkten Einfluss auf die Kreditkonditionen, weil bspw. die Risikopolitik der Bank vorschreibt, nur in Ausnahmefällen Kredite an Bauunternehmen zu vergeben. Eine Auseinandersetzung mit den Zusammenhängen der unabhängigen Variablen scheint ferner aus folgendem Grund geboten. Die Integration einer Mediatorvariablen in das Regressionsmodell kann dazu führen, dass eine X-Variable, die keinen signifikanten totalen Effekt auf $Y$ aufweist, starke statistisch signifikante indirekte und direkte Effekte auf $\mathrm{Y}$ ausübt, die jedoch in gegenläufiger Richtung wirken und sich daher in der Summe

\footnotetext{
1377 Vgl. Brosius (2002), S. 500.

1378 Vgl. Diaz-Bone (2006), S. 108.

1379 Vgl. Brosius (2002), S. 508.

1380 Vgl. Brosius (2002), S. 508.

1381 Vgl. Urban/Mayerl (2006), S. 294.

1382 Vgl. Urban/Mayerl (2006), S. 293.

1383 Vgl. Bortz/Döring (2006), S. 3.
} 
im totalen Effekt aufheben. Dies wäre bspw. denkbar bei gleichzeitiger Integration der Eigerkapitalquote und der Fremdkapitalquote in eine Regression. Während die Eigenkapitalquote einen stark positiven, und die Fremdkapitalquote einen stark negativen Effekt auf die abhängige Variable ausübt, kann die inverse Relation der beiden Variablen bei der gemeinsamen Berücksichtigung in einer Regression dazu führen, dass der Gesamteffekt der Variablen oder einer der Variablen aufgehoben wird.

Wenn also eine Korrelation zwischen $\mathrm{X}$ und $\mathrm{Z}$ sowie zwischen $\mathrm{Y}$ und $\mathrm{Z}$ besteht, so besteht auch eine Korrelation zwischen $X$ und $Y$. Wenn die Korrelation zwischen $X$ und $\mathrm{Y}$ allerdings bei Ausschalten von $\mathrm{Z}$ verschwindet, so handelt es sich hierbei lediglich um eine Scheinkorrelation zwischen X und Y ${ }^{1384}$ In diesem Fall ist eine Partialkorrelation zu ermitteln. ${ }^{1385}$ Unter der Partialkorrelation wird die Korrelation verstanden, die zwischen zwei Variablen verbleibt, nachdem die Korrelation entfernt wurde, die aus dem wechselseitigen Zusammenhang mit den anderen Variablen stammt.

Bevor die Korrelationen zwischen der abhängigen und den unabhängigen Variablen ermittelt werden, muss somit geprüft werden, ob bivariate oder partielle Korrelationen heranzuziehen sind. Partielle Korrelationen werden schließlich für all die Fälle berechnet, für die zuvor eine mediierende Beziehung zweier unabhängiger Variablen unterstellt wurde. Bei der Ermittlung partieller Korrelationskoeffizienten können Kontrollvariablen angegeben werden, von denen vermutet wird, dass sie einen Einfluss auf die Werte ausüben und somit die Korrelationskoeffizienten verzerren. ${ }^{1386}$ Die Festlegung, ob bei einer Variablen eine mediierte Beziehung vorliegt, basiert sowohl auf der berechneten bivariaten Korrelation zwischen den unabhängigen Variablen als auch auf inhaltlich plausiblen Überlegungen. Das Vorgehen ist folgerichtig derart, dass zunächst die bivariaten Korrelationen ermittelt und anschließend die Zusammenhänge inhaltlich hinterfragt werden. In Abhängigkeit von diesen Ergebnissen werden bivariate oder partielle Korrelationen mit den abhängigen Variablen ermittelt. Sofern diese ermittelten Korrelationen signifikant sind, kann von einem Zusammenhang mit der abhängigen Variablen ausgegangen werden. Diese Variablen werden schließlich in den weiteren Regressionsanalysen mit den abhängigen Variablen berücksichtigt. Zusammengefasst stellt sich das Vorgehen hinsichtlich der Korrelationsanalyse, wie in Abb. B-23 visualisiert, dar.

\footnotetext{
1384 Vgl. Bortz/Döring (2006), S. 510.

1385 Zur Auspartialisierung von Drittvariablen bei der Beziehung von zwei Variablen vgl. Diaz-Bone (2006), S. 120.

1386 Vgl. Brosius (2002), S. 512.
} 


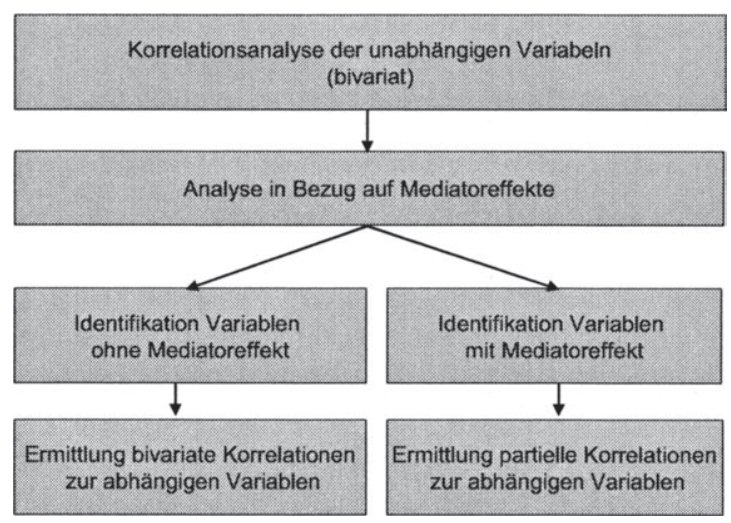

Abb. B-23: Korrelationsanalysen unter Berücksichtigung von Mediatoreffekten

\section{4 Überprüfung der Hypothesen zum Zinssatz}

\subsubsection{Operationalisierung des Zinssatzes}

Aufgrund der unterschiedlichen Herangehensweise in den existierenden Studien ${ }^{1387}$ sowie aufgrund der Vielzahl der Produktbeziehungen zwischen Kunde und Bank und somit verschiedener in Frage kommender Zinssätze ist in einem ersten Schritt zu klären, was der relevante Zinssatz ist, der im weiteren Verlauf als abhängige Variable untersucht werden wird. Während einige Studien auf den Zinssatz für Darlehen zurückgreifen, z.B. Petersen/Rajan, Degryse/Van Cayseele und LehmanN/NeuBERGER, verwenden andere Studien den Zinssatz für die Kreditlinie, z.B. BERGER/UDELl, ANGELINI/Di SALVO/FERRI, HARHOFF/KÖRTING und ELSAS/KRAHNEN. ${ }^{1388}$

PETERSEN/RAJAN ziehen den Zinssatz für Darlehen heran, so dass in die Untersuchung somit bspw. auch Hypothekendarlehen und Darlehen für Maschinen oder Fahrzeuge mit einfließen. ${ }^{1389}$ Ein ähnliches Vorgehen wählen DEGRYSE/VAN CAYSEELE. Für Darlehen mit Festzinssatz verwenden sie den Effektivzins und für Darlehen mit variablem Zinssatz den Zinssatz bis zur nächsten Zinsanpassung. ${ }^{1390}$

Der geeignetste Zinssatz gemäß BERGER/UDELL ist der variable Zinssatz bei Kreditlinien. ${ }^{1391}$ Durch die Fokussierung auf Kreditlinien werden gemäß BERGER/UDELL korrekterweise die Kredite aus der Analyse ausgeschlossen, die eher transaktions- statt

\footnotetext{
1387 Vgl. hierzu auch Kapitel A.4.3.2.2.

1388 Vgl. Petersen/Rajan (1994), S. 12, Degryse/Van Cayseele (2000), S. 95, Lehmann/Neuberger, S. 350, Berger/Udell (1995), S. 353, Angelini/Di Salvo/Ferri (1998), S. 936, Harhoff/Körting (1998a), S. 10, Elsas/Krahnen (1998), S. 1302.

1389 Vgl. Petersen/Rajan (1994), S. 12.

1390 Vgl. Degryse/Van Cayseele (2000), S. 95.

1391 Vgl. Berger/Udell (1995), S. 353.
} 
beziehungsgetrieben sind, so dass dadurch eine Verwässerung der „Relationship Lending"-Ergebnisse vermieden wird. ${ }^{1392}$ Ebenso wie BERGER/UDELL rekurrieren auch ANGELINI/DI SALVO/FERRI ${ }^{1933}$ und HARHOFF/KÖRTING ${ }^{1394}$ auf den Zinssatz für die Kreditlinie.

Es erscheint auch für die vorliegende Studie sinnvoll, auf den Zinssatz für die Kreditlinie zurückzugreifen. Zunächst soll allerdings kurz die Besonderheit des Betriebsmittelkredits, der in Form dieser Kreditlinie zur Verfügung gestellt wird, erläutert werden, da sich aus den Besonderheiten im Vergleich zu Darlehen Implikationen für die Untersuchung ergeben. Betriebsmittelkredite dienen in der Regel zur Finanzierung von Roh, Hilfs- und Betriebsstoffen oder bezogenen Fertigerzeugnissen. ${ }^{1395}$ Es existiert anders als bei Darlehen üblicherweise kein direkter Bezug zu einem konkreten Finanzierungsobjekt. Die Bereitstellung erfolgt in Form einer Kreditlinie auf dem Kontokorrentkonto der Unternehmung und die Rückzahlung wird in aller Regel aus Umsatzerlösen geleistet. Als Sicherheit dient häufig die Zession der Kundenforderungen des Unternehmens oder die Sicherungsübereignung von Lagerbeständen des Unternehmens. Die Inanspruchnahme kann innerhalb der vereinbarten Laufzeit bis zur Höhe des eingeräumten Verfügungsrahmens beliebig erfolgen. Ferner ist der Zins in aller Regel variabel, d.h. abhängig von Marktzinssätzen, z.B. dem 3-Monats-Euribor. Bei Darlehen hingegen existiert in aller Regel ein konkretes Finanzierungsobjekt, welches häufig als Sicherheit herangezogen wird. Die Rückzahlung erfolgt gemäß einem festen Tilgungsplan. ${ }^{1396}$

Aufgrund der zuvor genannten Argumente wird der Zinssatz des Kontokorrentkontos des Kunden verwendet. Sofern der Kunde mehrere Kontokorrentkonten bei der Bank unterhält, wurde in dieser Studie das Kontokorrentkonto mit dem größten externen Limit, d.h. dem größten Verfügungsrahmen, herangezogen. Im Kernzeitraum der Datenerhebung schwankte der 3-Monats-Euribor in einer Bandbreite von 4,576\% am 11 . Januar und 4,953\% am 12. Dezember 2007. ${ }^{1397} \mathrm{Da}$ allerdings unbekannt ist, inwiefern diese Änderungen bereits im Kreditzins eingepreist und somit an den Kunden weitergegeben worden sind, wird auf eine Korrektur verzichtet. Die konkrete Änderung des Kundenzinssatzes durch das einzelne Institut steht aufgrund der sog. Zinsanpassungsklausel im billigen Ermessen des Instituts in Abhängigkeit von der jeweiligen Refinanzierungssituation desselben. ${ }^{1398}$ Gemäß der Zinsanpassungsklausel des BVR aus dem Jahr 2001 erfolgt die Anpassung in einem einmonatigen Prüfintervall, die Margenanpassung bei dem Kunden wird bei Überschreiten einer Veränderung des Referenzzinssatzes von mindestens 0,25 Prozentpunkten vorgenommen und als Referenzzins-

\footnotetext{
1392 Vgl. Berger/Udell (1995), S. 353.

1393 Vgl. Angelini/Di Salvo/Ferri (1998), S. 936.

1394 Vgl. Harhoff/Körting (1998a), S. 10.

1395 Vgl. Hartmann-Wendels/Pfingsten/Weber (2007), S. 179.

1396 Häufig besteht die Möglichkeit, neben den festgelegten Tilgungen Sondertilgungen zu leisten.

1397 Vgl. Bundesbank (2007) und Bundesbank (2008c). Die detaillierte Zinsentwicklung kann dem Anhang 4, Abb. AN 4-1 entnommen werden. 
satz wird der 3-Monats-Euribor verwendet. ${ }^{1399}$ Es ist unbekannt, zu welchen Stichtagen die Banken der vorliegenden Studie jeweils die Prüfung und zu welchen Stichtagen die Banken jeweils die Anpassung vornehmen. Zwar gab es innerhalb der einzelnen Monate Tage, an denen der Zinssatz um mehr als 0,25-Prozentpunkten im Vergleich zum Stichtag gestiegen bzw. gefallen ist, bei ausschließlicher Betrachtung der Monatsstichtage hingegen befanden sich die Werte weitestgehend im Schwankungsbereich, so dass keine explizite Berücksichtigung des Marktzinsniveaus erforderlich ist. ${ }^{1400} \mathrm{Im}$ Rahmen des billigen Ermessens bleibt es der Bank überlassen, ob sie die Zinsänderungen in voller Höhe an den Kunden weitergibt. Neben den Veränderungen der Marktkonditionen könnten aufgrund des Ermessensspielraums möglicherweise auch kundenoder beziehungsspezifsche Aspekte, wie die Zinssensibilität des Kunden, berücksichtigt werden. Bei den weiteren Auswertungen wird somit ein unbereinigter Zins des Kontokorrentkontos des jeweils betrachteten Unternehmens verwendet.

\subsubsection{Korrelations- und Regressionsanalyse}

\subsubsection{Durchführung der Korrelationsanalyse}

Im ersten Schritt erfolgt eine bivariate Korrelationsanalyse aller unabhängigen Variablen unter Berücksichtigung des Skalenniveaus. Im zweiten Schritt werden die Variablen insbesondere auf mögliche Mediatoreffekte hin untersucht. Schließlich werden die bivariaten und ggf. auch partiellen Korrelationen in Bezug auf den Zinssatz ermittelt. Datengrundlage für die Korrelationsanalysen mit Hinblick auf den Kreditzins ist wie zuvor erwähnt ein reduzierter Datensatz. Kunden mit einer Ausfallwahrscheinlichkeit größer gleich 20,00\% werden aus den Untersuchungen zum Zinssatz ausgeschlossen, da bei einer Ausfallwahrscheinlichkeit in dieser Größenordnung davon ausgegangen wird, dass der Zinssatz auch bei einer ansonsten vollständig risikoorientierten Bepreisung nach anderen Kriterien festgelegt wird. Für die folgenden Analysen wird somit eine Datenbasis mit nunmehr 214 Datensätzen zugrunde gelegt.

\section{Korrelationsanalyse der unabhängigen Variablen}

In Kapitel A.3.3 wurde beschrieben, dass zunächst eine Korrelationsanalyse der unabhängigen Variablen erfolgen muss, um Interaktionseffekte zwischen den unabhängigen Variablen zu identifizieren. Die Korrelationsanalysen werden zu diesem Zweck zunächst separat für die verschiedenen inhaltlichen Bereiche durchgeführt, da insbesondere innerhalb der einzelnen Bereiche starke Zusammenhänge erwartet werden:

\footnotetext{
1394 Vgl. BVR (2007b), S. 3.

1400 Folgende Stichtags-Werte für den 3-Monats-Euribor wurden herangezogen: 31.10.2007: 4,603\%, 30.11.2007: 4,81\% 31.12.2007: 4,684 \%, 31.01.2008: 4,374\%. Vgl. Bundesbank (2007) und Bundesbank (2008c). Bei einer Bank wurde die Datenerhebung kurz nach dem 31.01.2008 durchgeführt, hier könnte möglicherweise eine Anpassung stattgefunden haben. Auf diese Korrektur wurde allerdings verzichtet.
} 
- Finanzkennzahlen des Unternehmens

- Sonstige unternehmensbezogene Daten

- Beziehungsbezogene Daten

- Verhaltenswissenschaftliche Daten

- Bankbezogene Daten

Anschließend werden Interdependenzen zwischen den Variablen unterschiedlicher Bereiche analysiert, bei denen ein inhaltlicher Zusammenhang vermutet wird. Es folgt die Analyse der Korrelationen mit dem Zinssatz.

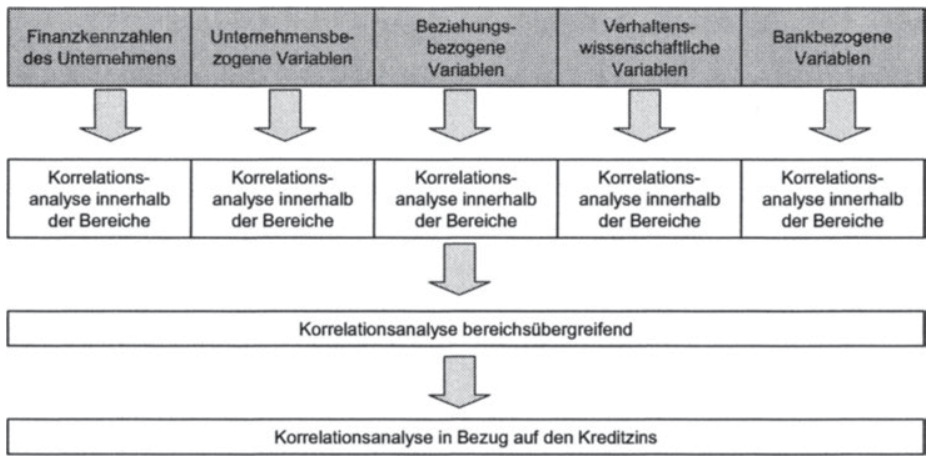

Abb. B-24: Vorgehen hinsichtlich der Korrelationsanalysen zum Zinssatz

\section{Finanzkennzahlen des Unternehmens}

Im ersten Schritt muss festgelegt werden, bei welchen Finanzkennzahlen ein Einfluss auf den Kreditzins vermutet wird und welche Kennzahlen infolgedessen im Rahmen der Analyse berücksichtigt werden sollen. Hinsichtlich der Finanzkennzahlen sind im Wesentlichen folgende Szenarien hinsichtlich der Bedeutung für den Zinssatz denkbar:

- Szenario 1: Ausschlaggebend ist allein die Ausfallwahrscheinlichkeit des Kunden als verdichtete Größe und alle relevanten Finanzkennzahlen sind in der Ausfallwahrscheinlichkeit berücksichtigt. Es werden keine weiteren Finanzkennzahlen bei der Bepreisung berücksichtigt.

- Szenario 2: Die Ausfallwahrscheinlichkeit wird bei der Bepreisung zwar als Anhaltspunkt verwendet, dennoch werden weitere ergänzende Finanzkennzahlen bei der Festlegung des Zinssatzes berücksichtigt.

- Szenario 3: Die Ausfallwahrscheinlichkeit wird überhaupt nicht explizit berücksichtigt. Vielmehr zieht der Firmenkundenbetreuer bzw. die Marktfolge ausschließlich klassische Kennzahlen bei der Bepreisung heran, losgelöst vom Rating. Dieser Fall ist nur relevant, sofern die klassischen Kennzahlen nicht bei der Ermittlung der Ausfallwahrscheinlichkeit berücksichtigt werden bzw. so- 
fern die Kennzahlen nicht unter Verwendung eines linearen Zusammenhangs im Rating verwendet wurden. Andernfalls würde zumindest der quantitative Teil des Ratings schlichtweg nachgestellt werden.

- Szenario 4: Der Kreditzins wird unabhängig von der Ausprägung der Finanzkennzahlen, sondern ausschließlich auf Basis anderer Daten bzw. vollkommen idiosynkratisch festgelegt.

Hinsichtlich der Abbildung der genannten Szenarien gibt es in den bestehenden Studien zwei Vorgehensweisen. Während in den Studien von BERGER/Udell bspw. unmittelbar auf Finanzkennzahlen rekurriert wird ${ }^{1401}$ verwendet bspw. die Studie vON ELSAS/KRAHNEN die Ratingklasse des jeweiligen Unternehmens. ${ }^{102}$ Zunächst lässt sich vermuten, dass im Bereich der Finanzkennzahlen erhebliche Korrelationen vorliegen, die z.T. aus unmittelbaren mathematischen Zusammenhängen resultieren. So ergibt die Multiplikation aus dem Anteil der Verbindlichkeiten gegenüber Kreditinstituten und der Bilanzsumme das absolute Volumen der Verbindlichkeiten gegenüber Kreditinstituten. Wie in Kapitel B.1.1.4 dargestellt werden bei den Finanzkennzahlen relative, absolute und logarithmierte Größen verwendet. Der Logarithmus der Variablen wurde eingeführt, da davon ausgegangen wird, dass möglicherweise vorhandene Größeneffekte in Bezug auf den Zinssatz sich bei einer Veränderung von 0,5 Mio. EUR auf 1 Mio. EUR anders auswirken als von 10 Mio. EUR auf 10,5 Mio. EUR. Welche Finanzkennzahlen jedoch von den Firmenkundenbetreuern tatsächlich herangezogen werden, lässt sich im Vorfeld nicht beurteilen, da hier sowohl statistisch abgeleitete Ratingkennzahlen aus der Bankanwendung als auch betriebswirtschaftlich fundierte Finanzkennzahlen herangezogen werden können. Um nicht aufgrund einer fehlerhaften Kennzahlenauswahl zu falschen Ergebnissen zu kommen, wurde eine relativ große Menge an Finanzkennzahlen erhoben.

Wie zu erwarten, bestehen bei zahlreichen Finanzkennzahlen signifikante Korrelationen, so dass es aus Gründen der Übersichtlichkeit nicht sinnvoll erscheint, alle Effekte einzeln zu analysieren. Die Variable Bilanzsumme (BILANZS) ist mit den VERB_KI_LANG, VERB_KI_KURZ, VERB_KI, VERM_LA und KASSE ${ }^{1403}$ sowohl bei der Absolutbetrachtung als auch bei Betrachtung des Logarithmus des Absolutwertes auf einem Niveau von 0,4 bis 0,8 korreliert, wobei die Korrelationen auf dem $1 \%$-Niveau signifikant sind. ${ }^{144}$ Dieser Zusammenhang ist technisch bedingt, denn die genannten Variablen werden als Verhältnis zur Bilanzsumme ermittelt. Ferner bestehen Zusammenhänge zwischen der Eigenkapitalquote und den diversen Verbindlichkeitenquoten. Aus diesem Grund wird nur punktuell auf die Korrelationen eingegangen.

Im Folgenden werden die auf dem 1\%- und dem 5\%-Niveau signifikanten Korrelationen der Finanzkennzahlen mit den Variablen AUSFALLW_B, TSC_JA_AGG und TSC_QA_AGG dargestellt (vgl. Tab. B-62), da diese Variablen im Rahmen der risi-

\footnotetext{
$1401 \quad$ Vgl. Berger/Udell (1995), S. 359.

1402 Vgl. Elsas/Krahnen (1998), S. 1298.

1403 Die Variablendefinitionen können Tab. B-9 auf S. 204 entnommen werden.

1404 Die vollumfänglichen Korrelationsanalysen aller Finanzkennzahlen können dem Anhang 4, Tab. AN 4-1 entnommen werden.
} 
koorientierten Bepreisung eine zentrale Rolle spielen. Korrelationen, die auf dem 5\%Niveau signifikant sind werden mit „\#*“ und Korrelationen, die auf dem 1\%-Niveau signifikant sind, werden mit,${ }^{* * * *}$ gekennzeichnet. ${ }^{1405}$ Interessant ist die hohe Korrelation des TSC_QA_AGG mit den Finanzkennzahlen. Unter anderem werden bei dem Teilscore für die qualitativen Daten auch die Anzahl der Überziehungen berücksichtigt, so dass sich dadurch automatisch ein Zusammenhang zu den Finanzkennzahlen ergibt. Denn bspw. wird ein Unternehmen, welches eine hohe Kassenposition hat, in aller Regel auch keine Überziehungen haben. Dadurch lässt sich vermutlich auch die Korrelation zwischen den Variablen TSC_JA_AGG und TSC_QA_AGG erklären. Schließlich ist es aber auch denkbar, dass die guten Rahmenbedingungen, z.B. die Ausgestaltung des Controllings oder eine aktive Produktweiterentwicklung, die im Rahmen des qualitativen Teilscores berücksichtigt werden, die finanzielle Situation des Unternehmens positiv beeinflussen. ${ }^{1406}$ Schließlich kann aber auch die gute finanzielle Situation des Unternehmens die Wahrnehmung in Bezug auf die qualitativen Daten des Unternehmens positiv beeinflussen. Da sowohl die Bilanzsumme als auch der Umsatz positive Korrelationen aufweisen, zeigen die Ergebnisse, dass größere Unternehmen, d.h. Unternehmen mit einer größeren Bilanzsumme oder einem größeren Umsatz, tendenziell eher einen hohen Teilscore für die qualitativen Daten haben. Dieser Aspekt ist insofern nachvollziehbar, als dass bspw. die Ausgestaltung des Controllingsystems und die Häufigkeit der Planerstellung im Rahmen des Ratings beurteilt werden ${ }^{1407}$ und größere Unternehmen eher in der Lage sind, ein Controllingsystem zu implementieren.

1405 Auf den Ausweis der Korrelationen, die nur auf dem 10\%-Niveau signifikant sind, wird hier und im Folgenden verzichtet.

1406 Eine Erläuterung zu dem qualitativen Bereich des Ratings gibt Flacke (2007), S. $73 \mathrm{ff}$.

1407 Vgl. Flacke (2007), S. 79. 


\begin{tabular}{|c|c|c|c|}
\hline & AUSFALLW_B & TSC_JA_AGG & TSC_QA_AGG \\
\hline VERB_KI_LANG_R & 0,0142 & $-0,4118^{* * *}$ & $-0,1282$ \\
\hline VERB_KI_KURZ_R & $0,4315^{* * *}$ & $-0,5266^{* * *}$ & $-0,4529^{* * *}$ \\
\hline VERB_KI_R & $0,2434^{* * *}$ & $-0,5939 * * *$ & $-0,3397 * * *$ \\
\hline KASSE_R & $-0,0905$ & $0,3441^{* * *}$ & $0,2036^{* * *}$ \\
\hline VERM_LA_A & $-0,0663$ & 0,1404 & $0,2465^{* * *}$ \\
\hline KASSE_A & $-0,0472$ & $0,2158^{* * *}$ & $0,2186^{* * *}$ \\
\hline BILANZS & $-0,0693$ & 0,0502 & $0,1748^{* *}$ \\
\hline UMSATZ & $-0,0793$ & $0,1568^{* *}$ & $0,1928^{* * *}$ \\
\hline EKQ & $-0,4396^{* * *}$ & $0,6715^{* * *}$ & $0,4121^{* * *}$ \\
\hline ANZ_ÜB_30 & 0,1281 & $-0,3206^{* * *}$ & $-0,3655^{* * *}$ \\
\hline ANZ_ÜB_60 & 0,0323 & $-0,2277^{* * *}$ & $-0,3147^{* * *}$ \\
\hline ANZ_ÜB_90 & 0,0323 & $-0,2277^{* * *}$ & $-0,3147^{* * *}$ \\
\hline ANZ_ÜB_GES & $0,1637 * *$ & $-0,4503^{* * *}$ & $-0,4744^{* * *}$ \\
\hline VERB_KI_LANG_R_LN & 0,0025 & $-0,3587^{* * *}$ & $-0,1267$ \\
\hline VERB_KI_KURZ_R_LN & $0,2434^{* * *}$ & $-0,4748^{* * *}$ & $-0,3982 * * *$ \\
\hline VERB_KI_R_LN & $0,1738^{* *}$ & $-0,4802^{* * *}$ & $-0,2782^{* * *}$ \\
\hline VERM_LA_R_LN & $-0,1872^{* * *}$ & $0,1826^{* *}$ & $0,3492^{* * *}$ \\
\hline KASSE_R_LN & $-0,1310$ & $0,3043^{* * *}$ & $0,2291^{* * *}$ \\
\hline VERB_KI_LANG_A_LN & $-0,1904 * *$ & $-0,0183$ & $0,2353^{* * *}$ \\
\hline VERM_LA_A_LN & $-0,1872^{* * *}$ & $0,1826^{* *}$ & $0,3492^{* * *}$ \\
\hline KASSE_A_LN & $-0,2520^{* * *}$ & $0,4054 * * *$ & $0,3981^{* * *}$ \\
\hline BILANZS_LN & $-0,1883^{* * *}$ & $0,1801^{* *}$ & $0,3515^{* * *}$ \\
\hline UMSATZ_LN & $-0,1325$ & $0,1804^{* *}$ & $0,1849 * *$ \\
\hline AUSFALLW_B & 1,0000 & $-0,3051^{* * *}$ & $-0,1793 * *$ \\
\hline TSC_JA_AGG & $-0,3051^{* * *}$ & & $0,5468^{* * *}$ \\
\hline TSC_QA_AGG & $-0,1793 * *$ & $0,5468 * * *$ & \\
\hline
\end{tabular}

Tab. B-62: Bivariate Korrelationen der Finanzkennzahlen

Im Rahmen der Korrelationsanalysen in Bezug auf den Zinssatz erscheint es somit erforderlich, partielle Korrelationen zu ermitteln. In diesem Kontext ist zu prüfen, inwiefern die Variable BILANZS selbst einen unmittelbaren Effekt auf den Zinssatz ausübt oder inwiefern dieser Effekt möglicherweise aufgrund der erwähnten Korrelationen vollständig durch die Variablen VERB_KI_LANG, VERB_KI_KURZ und VERB_KI mediiert wird. Möglicherweise ist nicht die Größe des Unternehmens, sondern das Volumen der Bankverbindlichkeiten ausschlaggebend. Ferner ist hier zu prüfen, inwiefern die Variablen VERB_KI_KURZ R, VERB_KI R, EKQ, ANZ ÜB_GES, VERB_KI_KURZ_R_LN, VERM_LA_A_LN, KASSE_A_LN und BILANES_LN einen unmittelbaren Effekt auf den Zinssatz ausüben oder inwiefern dieser Effekt vollständig in den Teilscores bzw. der Ausfallwahrscheinlichkeit enthalten ist. 
Im weiteren Verlauf der Analyse wird den umfangreichen Korrelationen dahingehend Rechnung getragen, als dass im Rahmen der Regressionsanalyse die stark korrelierenden Variablen nicht gemeinsam bei der Analyse betrachtet werden. Im Folgenden werden signifikante Korrelationen größer als 0,25 als stark betrachtet. Die Ausfallwahrscheinlichkeit und die Teilscores hingegen werden z.T. trotz der Korrelationen auch mit den sonstigen Finanzkennzahlen gemeinsam in die Analysen integriert, um das Szenario prüfen zu können, dass ausgewählte Finanzkennzahlen ergänzend zu den Ratingergebnissen herangezogen werden.

\section{Unternehmensbezogene Daten}

Bei den unternehmensbezogenen Daten wurden im Kapitel B.1.2.1 im Wesentlichen die Parameter Branche, Alter und Rechtsform untersucht. Der zusätzlich relevante Größenaspekt ist bereits in den Finanzkennzahlen abgebildet. Ferner wird hier die Variable ALTER_LN berücksichtigt, da die Effekte, die aus dem Anstieg des Unternehmensalters resultieren, vermutlich nicht linear wirken. Ein Anstieg des Unternehmensalters von 0 auf 5 Jahre wird andere Effekte haben als ein Anstieg von 100 auf 105 Jahre. In Tab. B-63 werden die signifikanten Korrelationen der unternehmensbezogenen Daten untereinander sowie die Korrelationen mit den Finanzkennzahlen dargestellt. Es besteht eine signifikante positive Korrelation zwischen der Variablen HAND und ALTER, d.h. Handelsunternehmen sind tendenziell älter als NichtHandelsunternehmen. Schließlich besteht eine negative Korrelation zwischen der Variablen KAPGESELL und ALTER, d.h. Kapitalgesellschaften sind tendenziell jünger als Nicht-Kapitalgesellschaften. Dieser Zusammenhang hat sich bereits auch im Rahmen der deskriptiven Auswertung in Kapitel B.1.2.1 gezeigt.

Ein Einfluss der Branche auf den Zinssatz könnte zum einen daher resultieren, dass bspw. bestimmte Branchen tendenziell als risikobehafteter eingestuft werden und Unternehmen dieser Branche grundsätzlich durch den Firmenkundenbetreuer einen Risikoaufschlag auf den Zinssatz erhalten. Eine derartige Vorgabe könnte in der Risikostrategie der Bank fixiert worden sein. Zum anderen kann die Branche aber auch in einem indirekten Zusammenhang mit dem Zinssatz stehen, da die Branche des Unternehmens sich in den Finanzkennzahlen des Unternehmens widerspiegelt. So haben Produktionsunternehmen i.d.R. ein höheres Anlagevermögen als Dienstleistungsunternehmen. Diese möglichen Scheinkorrelationen sind im weiteren Verlauf der Analyse zu berücksichtigen. Die Variable PROD weist lediglich eine signifikante Korrelation mit der Variablen AUSFALLW_B auf, d.h. die Ausfallwahrscheinlichkeit von Produktionsunternehmen ist tendenziell höher als selbige von Nicht-Produktionsunternehmen. Auch dieser Effekt wurde bereits bei der deskriptiven Auswertung in Kapitel B.1.2.1 aufgezeigt. Ferner weisen die Branchendummys HAND, DIENST und BAU zu den diversen Kennzahlen der Finanzierungsstruktur Korrelationen auf. Hier erscheint es notwendig, im Rahmen der Analysen die tatsächliche Ursache für bestimmte Effekte kritisch zu hinterfragen: Ist die Branche an sich oder die resultierende Finanzierungsoder Kapitalstruktur bzw. eine daraus resultierende Ausfallwahrscheinlichkeit ausschlaggebend? 


\begin{tabular}{|c|c|c|c|c|c|c|c|}
\hline & PROD $^{1408}$ & HAND & DIENST & BAU & $\begin{array}{c}\text { KAP- } \\
\text { GESELL }\end{array}$ & ALTER & $\begin{array}{c}\text { ALTER- } \\
\text { LN }\end{array}$ \\
\hline PROD & -- & -- & - & -- & 0,0051 & $-0,1244$ & $-0,1530^{* *}$ \\
\hline HAND & $\cdots$ & $\ldots$ & -- & $\cdots$ & 0,0084 & $0,1915^{* * *}$ & $0,1903^{* * *}$ \\
\hline DIENST & -- & - & -- & -- & $-0,0903$ & $-0,1292$ & $-0,1354^{* *}$ \\
\hline BAU & -- & -- & -- & -- & 0,0521 & $-0,0044$ & 0,0299 \\
\hline KAPGESELL & 0,0051 & 0,0084 & $-0,0903$ & 0,0521 & 1,0000 & $-0,2044^{* * *}$ & $-0,1487^{* *}$ \\
\hline ALTER & $-0,1244$ & $0,1915^{* * *}$ & $-0,1292$ & $-0,0044$ & $-0,2044^{* * *}$ & 1,0000 & \\
\hline VERB_KI_LANG_R & 0,0011 & 0,0876 & $0,1366^{* *}$ & $-0,2288^{* * *}$ & $-0,2639^{* * *}$ & 0,0981 & 0,0365 \\
\hline VERB_KI_KURZ_R & $-0,0461$ & $0,2009^{* * *}$ & 0,0173 & $-0,1013$ & $-0,1198$ & 0,0087 & 0,0590 \\
\hline VERB_KI_R & $-0,0240$ & $0,1737^{* *}$ & 0,1111 & $-0,2252^{* * *}$ & $-0,2614^{* * *}$ & 0,0778 & 0,0579 \\
\hline VERM_LA_R & 0,0545 & $-0,0954$ & $0,1379^{* *}$ & $-0,1924^{* * *}$ & $-0,2647^{* * *}$ & $0,2215^{* * *}$ & $0,1833^{* * *}$ \\
\hline KASSE_R & $-0,0742$ & $-0,1404 * *$ & $0,1597^{* *}$ & 0,0026 & $0,1705^{* *}$ & $-0,1769^{* * *}$ & $-0,1473^{* *}$ \\
\hline VERB_KI_KURZ_A & $-0,0551$ & $0,2863^{* * *}$ & $-0,0778$ & $-0,1382^{* *}$ & 0,0127 & 0,0469 & 0,0996 \\
\hline VERM_LA_A & 0,0965 & 0,0371 & $-0,0024$ & $-0,1793^{* * *}$ & $-0,0584$ & $0,1655^{*}$ & $0,2062^{* *}$ \\
\hline BILANZS & 0,0540 & 0,0802 & $-0,0038$ & $-0,1562^{* *}$ & 0,0202 & 0,1323 & $0,1918^{* *}$ \\
\hline UMSATZ & 0,0203 & $0,3032 * * *$ & $-0,1842 * * *$ & $-0,1672^{* *}$ & 0,0416 & 0,1292 & $0,1922 * *$ \\
\hline EKQ & 0,0476 & $-0,0363$ & $-0,1445^{* *}$ & 0,0743 & $0,1969^{* * *}$ & 0,0189 & 0,0276 \\
\hline VERB_KI_LANG_R_LN & 0,0780 & $-0,0815$ & 0,0798 & $-0,1361$ & $-0,3395^{* * *}$ & 0,0478 & $-0,0068$ \\
\hline VERB_KI_KURZ_R_LN & $-0,0754$ & $0,1761^{* *}$ & $-0,0879$ & $-0,0542$ & 0,0034 & $-0,0517$ & $-0,0160$ \\
\hline VERB_KI_R_LN & $-0,0375$ & 0,1387 & 0,0343 & $-0,1660^{* *}$ & $-0,2194^{* * *}$ & 0,0549 & 0,0335 \\
\hline VERM_LA_R_LN & 0,1156 & $0,1337^{* *}$ & $-0,1060$ & $-0,2724 * * *$ & $-0,0698$ & $0,2479 * * *$ & $0,2753^{* * *}$ \\
\hline KASSE_R_LN & $-0,0960$ & $-0,1416^{* *}$ & $0,1449 * *$ & 0,0580 & 0,0683 & $-0,1703^{* *}$ & $-0,1165$ \\
\hline VERB_KI_LANG_A_LN & 0,0625 & 0,0801 & $-0,0114$ & $-0,2530^{* * *}$ & $-0,1510$ & 0,1181 & 0,1201 \\
\hline VERB_KI_KURZ_A_LN & 0,0260 & $0,2711^{* * *}$ & $-0,1634^{* *}$ & $-0,2344^{* * *}$ & 0,0757 & 0,0459 & 0,1387 \\
\hline VERB_KI_A_LN & 0,0541 & $0,2309^{* *}$ & $-0,0477$ & $-0,3336^{* * *}$ & $-0,0926$ & $0,1597^{* *}$ & $0,1896^{* * *}$ \\
\hline VERM_LA_A_LN & 0,1156 & $0,1337^{* *}$ & $-0,1060$ & $-0,2724^{* * *}$ & $-0,0698$ & $0,2479^{* * *}$ & $0,2753^{* * *}$ \\
\hline BILANZS_LN & 0,1121 & $0,1561^{* *}$ & $-0,1659^{* *}$ & $-0,2045^{* * *}$ & 0,0910 & $0,1667^{* *}$ & $0,2346^{* * *}$ \\
\hline UMSATZ_LN & 0,0704 & $0,2817^{* * *}$ & $-0,2733^{* * *}$ & $-0,1680^{* *}$ & 0,1246 & $0,1418^{* *}$ & $0,1939^{* * *}$ \\
\hline AUSFALLW_B & $0,1436^{* *}$ & $-0,0441$ & $-0,0270$ & $-0,0619$ & $-0,0398$ & $-0,0371$ & $-0,0399$ \\
\hline TSC_JA_AGG & 0,1110 & $-0,1391$ & $-0,0158$ & 0,0147 & $0,1770^{* * *}$ & $-0,0087$ & 0,0396 \\
\hline
\end{tabular}

Tab. B-63: Bivariate Korrelationen der unternehmensbezogenen Variablen mit den Finanzkennzahlen ${ }^{109}$

1408 Aufgrund der mangelnden Interpretierbarkeit wurden die Korrelationen zwischen den Branchen nicht dargestellt. Bei der Codierung der Branchen wurde jedes unternehmen genau einer Branche zugeordnet. Ein Produktionsunternehmen kann nicht gleichzeitig ein Handels-, Dienstleistungs- oder Bauunternehmen sein. Aus diesem Grund weisen die Branchendummies jeweils negative Korrelationen zu den anderen drei Branchen aus.

1409 Die vollumfänglichen Korrelationsanalysen der unternehmensbezogenen Variablen mit den Finanzkennzahlen können dem Anhang 4, Tab. AN 4-2 entnommen werden. 
Ähnliche Effekte sind hinsichtlich der Rechtsform zu konstatieren. So haben die deskriptiven Auswertungen gezeigt, dass sich die Kapitalstrukturen bei Personen- und Kapitalgesellschaften voneinander unterscheiden. Dies zeigt sich auch bei den Korrelationsanalysen. Bei Kapitalgesellschaften ist die Eigenkapitalquote tendenziell höher und dementsprechend der Anteil der Bankfinanzierung niedriger als bei NichtKapitalgesellschaften. ${ }^{1410}$ Des Weiteren ist der Teilscore für den Jahresabschluss bei Kapitalgesellschaften tendenziell höher als bei Nicht-Kapitalgesellschaften.

Ferner können sich aus dem Alter Unterschiede hinsichtlich der Möglichkeiten der Mittelbeschaffung ergeben. Die Studie zeigt folgende Zusammenhänge. Je älter das Unternehmen ist (ALTER oder ALTER_LN), desto größer ist der Anteil an VERM_LA_R und desto geringer ist der Anteil an KASSE_R. Schließlich sind ältere Unternehmen tendenziell größer als kleine Unternehmen; sowohl die Bilanzsumme als auch der Umsatz sind positiv mit dem logarithmierten Alter korreliert.

\section{Beziehungsbezogene Daten}

Bei den beziehungsbezogenen Parametern wurden im Wesentlichen die ebenso in anderen Studien verwendeten Parameter herangezogen, wie bspw. die Dauer der Bankverbindung oder die Anzahl der Bankbeziehungen. Auch in diesem Bereich lassen sich zahlreiche Korrelationen erwarten. Im Folgenden werden jedoch aus Gründen der Übersichtlichkeit lediglich die auf dem 1\%- und 5\%-Niveau signifikanten und die inhaltlich für den weiteren Verlauf der Untersuchung relevanten Korrelationen dargestellt (vgl. Tab. B-64). Einige Korrelationen hinsichtlich des Hausbankstatus ergeben sich allein aus der Definition des Begriffs Hausbank, so ist bspw. die Korrelation mit dem Anteil am Zahlungsverkehr und dem Anteil Bankverbindlichkeiten evident. ${ }^{1411}$ Es kann folgerichtig davon ausgegangen werden, dass die diversen Variablen hinsichtlich der genutzten Produkte sowie der Anteil an der Finanzierung und am gesamten Zahlungsverkehr durch den Hausbankstatus bedingt werden. Hingegen ist es nicht intuitiv, dass es keine signifikanten Korrelationen zwischen dem Hausbankstatus und der Dauer der Beziehung gibt. Es hätte vermutet werden können, dass der Kunde bei seiner Hausbank eine höhere Verweildauer hat als bei anderen Banken. In Konsequenz sind hier Mediatoreffekte zu erwarten, allerdings bleibt zum gegenwärtigen Untersuchungszeitpunkt offen, ob es sich um vollständig oder partielle Mediatoreffekte handelt, da allein aus dem Hausbankstatus eine besondere Verantwortung resultiert, deren möglichen Auswirkungen auf den Zinssatz zu prüfen sind. Interessant ist ferner die Erkenntnis, dass eine höhere Sicherheitenquote mit einer längeren Dauer der Bankbeziehung, einer längeren Beziehung zum Firmenkundenbetreuer, dem Hausbankstatus und einem höheren Finanzierungsanteil der Bank einhergeht.

1410 Vgl. Kapitel B.1.2.1. So weisen die Kapitalgesellschaften in dieser Studie eine Eigenkapitalquote von $20,39 \%$ und Nicht-Kapitalgesellschaften eine Eigenkapitalquote von 3,41\% auf.

1411 Vgl. zu den Merkmalen des Hausbankstatus Kapitel A.4.1. 


\begin{tabular}{|c|c|c|c|c|c|c|}
\hline & $\begin{array}{l}\text { HAUS- } \\
\text { BANK K }\end{array}$ & $\begin{array}{c}\text { DAU_BEZ } \\
\text { ERR }\end{array}$ & $\begin{array}{c}\text { DAU_PERS } \\
\text { ERR }\end{array}$ & $\begin{array}{c}\text { ANT }_{\text {- }} \\
\text { BANK IN }\end{array}$ & SICH_Q & $\begin{array}{l}\text { MIT- } \\
\text { GLIED }\end{array}$ \\
\hline INT_BET & $-0,0353$ & 0,0247 & $-0,0100$ & $-0,0546$ & $-0,0008$ & 0,0607 \\
\hline DAU_BEZ_ERR & 0,0657 & $1,0000^{* * *}$ & $0,3114^{* * *}$ & 0,0232 & $0,1553^{* *}$ & $0,3154 * * *$ \\
\hline DAU_PERS_ERR & $-0,0329$ & $0,3114 * *$ & $1,0000^{* * *}$ & $-0,0474$ & $0,1494^{* *}$ & $0,1355^{* *}$ \\
\hline HAUSBANK_K & 1,0000 & 0,0657 & $-0,0329$ & $0,6309^{* * *}$ & $0,2643 * * *$ & 0,1197 \\
\hline GK_SALD & 0,0196 & 0,0429 & $-0,0197$ & 0,0961 & $-0,2077 * * *$ & 0,0027 \\
\hline GK_LIM_EX & 0,0968 & 0,0886 & 0,0192 & 0,0323 & 0,0483 & 0,0299 \\
\hline GES_KREDIT & 0,1038 & 0,1068 & 0,0171 & 0,0360 & 0,0483 & 0,0690 \\
\hline ANT_BANK_IN & $0,6309^{* * *}$ & 0,0232 & $-0,0474$ & $1,0000 * * *$ & $0,3242 * * *$ & 0,0775 \\
\hline ANT_BANK_HB & $-0,2473^{* *}$ & 0,0090 & $-0,2354 * *$ & $-0,3905^{* * *}$ & $-0,1601$ & $-0,0252$ \\
\hline ANZ_B_AGG & $-0,2579 * * *$ & 0,1307 & $0,2249 * * *$ & $-0,3640 * * *$ & $-0,1206$ & $-0,0430$ \\
\hline ZINS_VERFÜG & 0,0437 & 0,1238 & $-0,0196$ & $-0,0080$ & $-0,1745^{* *}$ & 0,1054 \\
\hline ANT_ZV & $0,7740 * * *$ & 0,0723 & $-0,0046$ & $0,6561^{* * *}$ & $0,3072 * * *$ & 0,0848 \\
\hline MITGLIED & 0,1197 & $0,3154 * * *$ & $0,1355^{* *}$ & 0,0775 & 0,1187 & $1,0000^{* * *}$ \\
\hline DARL & $0,2916^{* * *}$ & $0,1494 * *$ & $-0,0316$ & $0,2650^{* * *}$ & $0,4816^{* * *}$ & 0,0971 \\
\hline ZV_KK & 0,1275 & 0,1002 & 0,0711 & 0,1229 & $-0,0792$ & 0,1036 \\
\hline VERM_ANL & $0,3482 * * *$ & 0,1093 & 0,1070 & $0,2812^{* * *}$ & $0,3023 * * *$ & 0,0654 \\
\hline VERSICH & $0,1473^{* *}$ & $-0,0182$ & 0,0638 & $0,1816^{* * *}$ & $0,1607^{* *}$ & $0,1477^{* *}$ \\
\hline PRIVATKONT & 0,2546 & $0,1675^{* *}$ & $0,1436^{* *}$ & 0,1356 & 0,1304 & 0,0950 \\
\hline SICH_Q & $0,2643 * * *$ & $0,1553^{* *}$ & $0,1494 * *$ & $0,3242 * * *$ & $1,0000^{* * *}$ & 0,1187 \\
\hline EL & $-0,2091^{* * * *}$ & $-0,1129$ & $-0,0773$ & $-0,2364 * * *$ & $-0,3578^{* * *}$ & 0,0107 \\
\hline
\end{tabular}

Tab. B-64: Bivariate Korrelationen der beziehungsbezogenen Variablen ${ }^{1412}$

Die Dauer der Beziehung mit dem Firmenkundenbetreuer (DAU_PERS_ERR) ist zwar signifikant negativ korreliert mit dem Anteil der Finanzierung béi der Hauptbank (ANT_BANK_HB), allerdings nicht signifikant mit dem Anteil der Finanzierung bei dem jeweiligen Institut, auf welches sich die Beziehungsdauer bezieht (ANT_BANK_IN). Die beiden Variablenausprägungen sind identisch, wenn das aktuelle Institut die Hauptbank des Unternehmens ist. Es hätte vermutet werden können, dass eine lange Dauer der Beziehung mit dem Firmenkundenbetreuer als Ausdruck einer guten Beziehung zu einem höheren Anteil des Instituts an der gesamten Bankfinanzierung führt. Ferner weist die Variable eine positive Korrelation mit der Anzahl der Bankverbindungen (ANZ_B_AGG) auf. Dies könnte daher resultieren, dass mit zunehmender Dauer der Beziehung das Unternehmen gleichzeitig wächst und aufgrund der Größe alternative Bankverbindungen aufbaut. Eine weitere potenzielle Erklärung könnte darin liegen, dass das Unternehmen mit zunehmender Beziehungsdauer ein Gefühl der Abhängigkeit verspürt und sich deshalb nach Alternativen umsieht, um weniger abhängig zu sein. Dies stimmt überein mit dem Modell von GREENBAUM/KANATAS/VENEZIA, in welchem eine längere Bindungsdauer zu einer geringe-

1412 Die vollständige Übersicht der Korrelation der beziehungsbezogenen Variablen kann dem Anhang 4, Tab. AN 4-3 entnommen werden. 
ren Restbindungsdauer führt. ${ }^{143}$ Die Unternehmen bereiten sich auf die Beendigung der Beziehung durch den Aufbau weiterer Bankverbindungen vor.

Die beziehungsbezogenen Variablen weisen ferner einige interessante Korrelationen zu den Finanzkennzahlen auf (vgl. Tab. B-65). Es werden im Folgenden nur die Korrelationen zu den Variablen BILANZS und UMSATZ als Größenindikatoren sowie EKQ, AUSFALLW_B, TSC_JA_AGG und TSC_QA_AGG als Bonitätsindikatoren dargestellt. So weisen die Korrelationen zwischen INT_BET und GK_SALD auf der einen Seite und AUSFALLW_B, TSC_JA_AGG und TS $\bar{S} C$ QQA_AGG auf der anderen Seite die erwarteten Vorzeichen auf. Ein Kunde, der sich in der Intensivbetreuung befindet oder befand, weist demzufolge schlechtere Ratingergebnisse auf. Gleiches gilt für die Unternehmen, deren Saldo auf dem Hauptgeschäftskonto niedrig bzw. gar negativ ist. Bei der Sicherheitenquote zeigt sich, dass bonitätsmäßig schlechte Unternehmen mehr Sicherheiten stellen als bonitätsmäßig gute Unternehmen. Die SICH_Q weist eine signifikante negative Korrelation mit den Variablen EKQ und TSC_JA_AGG und eine signifikante positive Korrelation mit der Variablen AUSFALLW_B auf. Dieser Zusammenhang bestätigt, wie zuvor bereits auch die deskriptive Auswertung in Kapitel B.1.2.2, die Theorie der Anreizfunktion und nicht die Theorie der Signalling-Funktion von Sicherheiten. ${ }^{1414} \mathrm{Da}$ eine detaillierte Analyse der Sicherheitenstellung in Kapitel B.3.5 folgt, wird dieser Aspekt hier nicht weiter untersucht. 


\begin{tabular}{|c|c|c|c|c|c|c|}
\hline & BILANZS & UMSATZ & EKQ & $\begin{array}{c}\text { AUS- } \\
\text { FALLW_B }\end{array}$ & $\begin{array}{c}\text { TSC_JA } \\
\text { - } \mathbf{A G G}\end{array}$ & $\frac{\text { TSC_QA }_{\overline{\mathbf{G G}}}}{\mathrm{A}_{-}}$ \\
\hline INT_BET & $-0,0183$ & 0,0279 & $-0,3362 * * *$ & $0,3615^{* * *}$ & $-0,3235^{* * *}$ & $-0,2788^{* * *}$ \\
\hline DAU_BEZ_ERR & 0,0915 & $0,1732^{* *}$ & 0,0227 & $-0,0330$ & 0,0228 & 0,1046 \\
\hline DAU_PERS_ERR & 0,0387 & 0,0926 & 0,0401 & $-0,0632$ & 0,1250 & 0,1440 \\
\hline HAUSBANK_K & $-0,1411^{* *}$ & $-0,0186$ & $-0,0035$ & $-0,0369$ & 0,0383 & 0,0792 \\
\hline GK_SALD & 0,0114 & $-0,1165$ & 0,1158 & $-0,1819^{* * *}$ & $0,1837^{* *}$ & $0,1775 * *$ \\
\hline GK_LIM_EX & $0,5085^{* * *}$ & $0,4649 * * *$ & 0,1103 & $-0,0410$ & 0,1206 & 0,1443 \\
\hline GES_KREDIT & $0,3716^{* * *}$ & $0,3177 * *$ & 0,0524 & $-0,0471$ & $-0,0747$ & $0,1641^{* *}$ \\
\hline ANT_BANK_IN & $-0,2371^{* * *}$ & $-0,1709 * *$ & $-0,0189$ & $-0,0158$ & $-0,0540$ & 0,0546 \\
\hline ANT_BANK_HB & $-0,0031$ & $-0,0355$ & $-0,3499 * * *$ & $0,2741^{* *}$ & $-0,3164 * * *$ & $-0,1467$ \\
\hline ANZ_B_AGG & $0,3863^{* * *}$ & $0,3403 * * *$ & $0,1489^{* *}$ & $-0,0866$ & 0,1218 & 0,0517 \\
\hline ZINS_VERFÜG & 0,0234 & $-0,0491$ & $0,3264 * * *$ & $-0,2727 * * *$ & $0,2787 * * *$ & $0,2308 * * *$ \\
\hline ANT_ZV & $-0,2038^{* * *}$ & $-0,0635$ & $-0,0789$ & $-0,0494$ & $-0,0328$ & 0,0323 \\
\hline MITGLIED & $-0,0575$ & 0,0005 & 0,0074 & $-0,0254$ & 0,0099 & 0,0697 \\
\hline DARL & $-0,0323$ & $-0,0115$ & $-0,1844^{* * *}$ & 0,0699 & $-0,1346$ & 0,0271 \\
\hline ZV_KK & $-0,5929 * * *$ & 0,0314 & 0,0226 & $-0,0711$ & 0,1418 & 0,0328 \\
\hline VERM_ANL & $-0,0424$ & $-0,0315$ & 0,0279 & $-0,0724$ & $-0,0136$ & 0,0646 \\
\hline VERSICH & $-0,1212$ & $-0,0730$ & $-0,0354$ & $-0,0369$ & $-0,0359$ & 0,0068 \\
\hline PRIVATKONT & $-0,0656$ & $-0,0891$ & 0,0088 & $-0,1257$ & 0,1002 & 0,1363 \\
\hline SICH_Q & $-0,0195$ & $-0,0309$ & $-0,1704^{* *}$ & $0,1498^{* *}$ & $-0,2830 * * *$ & $-0,0642$ \\
\hline EL & $-0,0861$ & $-0,0440$ & $-0,4455^{* * *}$ & $0,5759 * * *$ & $-0,3615^{* * *}$ & $-0,3509^{* * *}$ \\
\hline
\end{tabular}

Tab. B-65: Bivariate Korrelationen der beziehungsbezogenen Variablen mit den Finanzkennzahlen

\section{Verhaltenswissenschaftliche Daten}

Während bisher primär Variablen untersucht worden sind, die zumindest in ähnlicher Form in bestehenden empirischen Studien bereits enthalten waren, werden im Folgenden mit den Faktoren der Konstrukte Vertrauen und Commitment Variablen analysiert, die im Rahmen des Relationship Banking bisher keine Berücksichtigung gefunden haben. Insgesamt besteht zwischen vielen Faktoren eine positive signifikante Korrelation (vgl. Tab. B-66). Eine Ausnahme bildet die negative Korrelation des Faktors ORG_GEB mit dem Faktor ORG_GLAUB. Eine hohe organisationale Glaubwürdigkeit, die u.a. Ausdruck einer hohen betriebswirtschaftlichen Kompetenz ist, führt zu einer niedrigeren Gebundenheit des Unternehmens an die Bank, da der Kunde vermutlich leichter in der Lage ist, die Bank zu wechseln, als ein Unternehmen, welches in finanziellen Schwierigkeiten steckt bzw. bei welchem die Kompetenzvermutung nicht gegeben ist. Hinsichtlich der Korrelation der ORG_GEB zu den Variablen ORG_WOHL und PERS_WOHL stellt sich die Frage, inwiefern das Wohlwollen möglicherweise eine berechnende Konsequenz der Gebundenheit ist und der Kunde versucht durch sein Wohlwollen mögliche negative Konsequenzen aus der Abhängigkeit zu überwinden. Die hohen Korrelationen zwischen ORG_GLAUB und PERS_GLAUB, ORG_WOHL und PERS_WOHL sowie zwischen ORG_VER und PERS_VER deuten 
an, dass die Wahrnehmung hinsichtlich des Unternehmens auf der einen Seite und hinsichtlich des Ansprechpartners auf der anderen Seite in Bezug auf Glaubwürdigkeit und Verbundenheit ähnlich sind. Ursächlich hierfür könnte - wie in Kapitel A.5.2.3.3 - sein, dass der Firmenkundenbetreuer nicht zwischen Organisation und Person trennen kann und somit die Wahrnehmung überträgt oder dass die Trennung aufgrund der Einheit von Eigentum und Leitung in dem Unternehmen nicht möglich ist.

\begin{tabular}{|c|c|c|c|c|c|c|c|c|}
\hline & $\begin{array}{c}\text { ORG } \\
\text { GLAUB }\end{array}$ & $\begin{array}{c}\text { ORG } \\
\text { WOHL }\end{array}$ & $\begin{array}{l}\text { PERS } \\
\text { GLAUB }\end{array}$ & $\begin{array}{l}\text { PERS } \\
\text { WOHL }\end{array}$ & $\mathrm{ORG}_{\text {GEB }}^{-}$ & $\begin{array}{l}\text { ORG }_{\text {VER }} \\
\text { VE }\end{array}$ & $\begin{array}{c}\text { PERS_- } \\
\text { VER }\end{array}$ & $\begin{array}{l}\text { PERS } \\
\text { VER } \\
\text { WOHL }\end{array}$ \\
\hline ORG_GLAUB & 1,0000 & & & & & & & \\
\hline ORG_WOHL & $0,4368^{* * *}$ & 1,0000 & & & & & & \\
\hline PERS_GLAUB & $0,6614^{* * *}$ & $0,4964^{* * *}$ & 1,0000 & & & & & \\
\hline PERS_WOHL & $0,3128^{* * *}$ & $0,5282 * * *$ & $0,5040^{* * *}$ & 1,0000 & & & & \\
\hline ORG_GEB & $-0,3151^{* * *}$ & $0,0873^{* *}$ & $0,0024 * * *$ & $0,1585^{* * *}$ & 1,0000 & & & \\
\hline ORG_VER & $0,2371^{* * *}$ & $0,4815^{* * *}$ & $0,3715 * * *$ & $0,4281^{* * *}$ & 0,3041 & 1,0000 & & \\
\hline PERS_VER & $0,3410^{* * *}$ & $0,5814^{* * *}$ & $0,5126^{* * *}$ & $0,6584^{* * *}$ & $0,2291^{* * *}$ & $0,6019^{* * *}$ & 1,0000 & \\
\hline PERS_VER_WOHL & $0,3910^{* * *}$ & $0,5926^{* * *}$ & $0,5705^{* * *}$ & $0,8452^{* * *}$ & $0,1851^{* * *}$ & $0,5761^{* * *}$ & $0,9204^{* * *}$ & 1,0000 \\
\hline
\end{tabular}

Tab. B-66: Bivariate Korrelationen der verhaltenswissenschaftlichen Variablen

Ein weiteres Indiz für die mangelnde Trennung hinsichtlich der organisationalen und der personalen Ebene findet sich bei der Analyse der Korrelationen der beiden Faktoren ORG_GLAUB und PERS_GLAUB mit den Finanzkennzahlen. Beide weisen erhebliche signifikante Korrelationen mit den Finanzkennzahlen auf. Ferner zeigt auch der Faktor ORG_GEB hohe Korrelationen mit den Finanzkennzahlen. Die Vorzeichen der Korrelationen verhalten sich in allen Fällen wie erwartet; während schlechte Finanzkennzahlenausprägungen tendenziell eher einen hohen Notenwert auf der Glaubwürdigkeits-Skala und somit eine geringe personale und organisationale Glaubwürdigkeit bewirken, führen sie gleichzeitig zu einer hohen Gebundenheit. Eine gute Bonität des Unternehmens scheint somit die personale und organisationale Glaubwürdigkeit zu fördern. Es ist aber auch die inverse Wirkungsrichtung denkbar, so dass die Glaubwürdigkeit aus Eigenschaften wie betriebswirtschaftlichen oder technischen Fähigkeiten resultiert und somit erst zu einer guten Bonität führt. Die anderen Faktoren weisen deutlich weniger signifikante und deutlich geringere Korrelationen auf. Sie scheinen somit Aspekte zu messen, die in keinerlei Zusammenhang zu den Finanzkennzahlen stehen. 


\begin{tabular}{|c|c|c|c|c|c|c|c|c|}
\hline & $\begin{array}{l}\text { ORG } \\
\text { GLAŪB }\end{array}$ & $\begin{array}{l}\text { ORG } \\
\text { WOHL }\end{array}$ & $\begin{array}{l}\text { ORG } \\
\text { GEB }\end{array}$ & $\begin{array}{l}\text { ORG } \\
\text { VER }\end{array}$ & $\begin{array}{l}\text { PERS } \\
\text { GLAUB }\end{array}$ & $\begin{array}{l}\text { PERS } \\
\text { WOHL }\end{array}$ & $\begin{array}{l}\text { PERS } \\
\text { VER }\end{array}$ & $\begin{array}{l}\text { PERS } \\
\text { VER } \\
\text { WOHL }\end{array}$ \\
\hline VERB_KI_LANG_R & $0,2200^{* * *}$ & 0,0384 & $-0,2372^{* * *}$ & $-0,0520$ & 0,1109 & $-0,0174$ & $-0,0400$ & $-0,0234$ \\
\hline VERB_KI_KURZ_R & $0,3353 * * *$ & 0,0265 & $-0,2401^{* * *}$ & $-0,0046$ & $0,2357^{* * *}$ & 0,0128 & 0,0156 & 0,0240 \\
\hline VERB_KI_R & $0,3387 * * *$ & 0,0427 & $-0,3026^{* * *}$ & $-0,0416$ & $0,2047^{* * *}$ & $-0,0069$ & $-0,0222$ & $-0,0052$ \\
\hline VERM_LA_R & 0,0281 & $-0,0106$ & $-0,0270$ & $-0,0671$ & 0,0732 & 0,0078 & $-0,0774$ & $-0,0484$ \\
\hline KASSE_R & $-0,2055^{* * *}$ & $-0,0788$ & $0,1953^{* * *}$ & 0,0042 & 0,0311 & $-0,0138$ & 0,0319 & 0,0241 \\
\hline VERM_LA_A & $-0,1688^{* *}$ & $-0,1043$ & $0,1889 * * *$ & 0,0460 & $-0,1356$ & $-0,1042$ & $-0,0829$ & $-0,0927$ \\
\hline KASSE_A & $-0,1001$ & $-0,0982$ & $0,2120^{* * *}$ & 0,0814 & $-0,0622$ & $-0,0632$ & $-0,0233$ & $-0,0500$ \\
\hline EKQ & $-0,3646$ & $-0,0790$ & $0,3227 * * *$ & $-0,0047$ & $-0,2674$ & $-0,0538$ & $-0,0554$ & $-0,0602$ \\
\hline BILANZS & $-0,1624^{* *}$ & $-0,1050$ & $0,2054^{* * *}$ & 0,1119 & $-0,1925^{* * *}$ & $-0,0906$ & $-0,0301$ & $-0,0610$ \\
\hline UMSATZ & $-0,1814^{* * *}$ & $-0,1469 * *$ & 0,0627 & $-0,0513$ & $-0,2409^{* * *}$ & $-0,1254$ & $-0,0635$ & $-0,0945$ \\
\hline ANZ_OB_30 & $0,2190^{* * *}$ & $-0,0309$ & $-0,0807$ & $-0,0119$ & $0,1931^{* * *}$ & 0,1174 & 0,0528 & 0,1048 \\
\hline ANZ_ÖB_60 & $0,1747^{* *}$ & $-0,0248$ & $-0,0739$ & 0,0226 & $0,2069^{* * *}$ & 0,0976 & 0,0576 & 0,0848 \\
\hline ANZ_ÜB_90 & $0,1747^{* *}$ & $-0,0248$ & $-0,0739$ & 0,0226 & $0,2069^{* * *}$ & 0,0976 & 0,0576 & 0,0848 \\
\hline ANZ_ÖB_GES & $0,3592 * * *$ & 0,0115 & $-0,1938^{* * *}$ & 0,0342 & $0,3301 * * *$ & 0,1203 & 0,0557 & 0,1125 \\
\hline AUSFALLW_B & $0,4128 * * *$ & 0,0808 & $-0,2985^{* * *}$ & 0,0775 & $0,3020^{* * *}$ & 0,0668 & 0,0367 & 0,0549 \\
\hline VERB_KI_LANG_R_LN & $0,1818^{* *}$ & $-0,0100$ & $-0,1085$ & 0,0067 & 0,1189 & $-0,0224$ & $-0,1014$ & $-0,0587$ \\
\hline VERB_KI_KURZ_R_LN & $0,3605^{* * *}$ & 0,1095 & $-0,1597$ & $-0,0060$ & $0,2302^{* * *}$ & 0,0290 & 0,0486 & 0,0213 \\
\hline VERB_KI_R_LN & $0,2873^{* * *}$ & 0,0366 & $-0,2188^{* * *}$ & $-0,0577$ & 0,1338 & $-0,0529$ & $-0,0833$ & $-0,0710$ \\
\hline VERM_LA_R_LN & $-0,1521^{* *}$ & $-0,0888$ & $0,1406^{* *}$ & $-0,0254$ & $-0,1810^{* * *}$ & $-0,1395^{* *}$ & $-0,1539 * *$ & $-0,1723^{* *}$ \\
\hline KASSE_R_LN & $-0,1957^{* * *}$ & $-0,0835$ & $0,2215^{* * *}$ & 0,0715 & 0,0814 & $-0,0244$ & 0,0523 & 0,0357 \\
\hline VERB_KI_LANG_A_LN & $-0,0501$ & $-0,1227$ & 0,1180 & 0,0655 & $-0,1681^{* *}$ & $-0,1023$ & $-0,1957^{* *}$ & $-0,1776^{* *}$ \\
\hline VERB_KI_KURZ_A_LN & 0,0718 & $-0,0322$ & 0,0512 & $-0,0172$ & $-0,0952$ & $-0,0770$ & $-0,0636$ & $-0,0975$ \\
\hline VERB_KI_A_LN & $-0,0104$ & $-0,0823$ & 0,0608 & $-0,0215$ & $-0,1603^{* *}$ & $-0,1395$ & $-0,1644^{* *}$ & $-0,1754^{* *}$ \\
\hline VERM_LA_A_LN & $-0,1521^{* *}$ & $-0,0888$ & $0,1406^{* *}$ & $-0,0254$ & $-0,1810^{* * *}$ & $-0,1395 * *$ & $-0,1539 * *$ & $-0,1723^{* *}$ \\
\hline KASSE_A_LN & $-0,3081^{* * *}$ & $-0,1669^{* *}$ & $0,3404 * * *$ & 0,1144 & $-0,1199$ & $-0,0930$ & $-0,0266$ & $-0,0655$ \\
\hline BILANZS_LN & $-0,1961^{* * *}$ & $-0,1487^{* *}$ & $0,2200^{* * *}$ & 0,0275 & $-0,2606^{* * *}$ & $-0,1636^{* *}$ & $-0,1585^{* *}$ & $-0,1979 * * *$ \\
\hline UMSATZ_LN & $-0,1765^{* *}$ & $-0,1636^{* *}$ & 0,0948 & $-0,0575$ & $-0,3356^{* * *}$ & $-0,1773 * *$ & $-0,0685$ & $-0,1284$ \\
\hline TSC_JA_AGG & $-0,4471^{* * *}$ & $-0,0633$ & $0,4166^{* * *}$ & $-0,0049$ & $-0,2724^{* * *}$ & $-0,0790$ & 0,0022 & $-0,0270$ \\
\hline TSC_QA_AGG & $-0,3881^{* * *}$ & $-0,1236$ & $0,3611^{* * *}$ & $-0,0621$ & $-0,2706^{* * *}$ & $-0,0747$ & $-0,1354$ & $-0,1200$ \\
\hline
\end{tabular}

Tab. B-67: Bivariate Korrelationen der verhaltenswissenschaftlichen Variablen mit den Finanzkennzahlen ${ }^{1415}$

Die Analyse des Zusammenhangs dieser Faktoren mit den sonstigen unternehmensbezogenen Variablen (vgl. Tab. B-68) zeigt, dass bei Kapitalgesellschaften der Faktor ORG_GEB tendenziell höher und somit die Gebundenheit niedriger ausgeprägt ist. Diese Interdependenz könnte wiederum auch auf andere Einflussfaktoren zurückzuführen sein, denn inhaltlich gibt es hierfür keine Begründung. Eine mögliche Erklärung liefert der Unterschied hinsichtlich des Anteils der Finanzierung bei dem jeweili-

1415 Die vollständige Übersicht der Korrelation der verhaltenswissenschaftlichen Variablen mit den Finanzennzahlen kann dem Anhang 4, Tab. AN 4-5 entnommen werden. 
gen Institut in Relation zur gesamten Bilanzsumme. Während dieser Wert bei Kapitalgesellschaften $13,30 \%$ beträgt, liegt der Wert bei Nicht-Kapitalgesellschaften bei $29,52 \%$. Der Gruppenunterschied ist auf dem 1\%-Niveau signifikant. Unterschiede in der Bonität konnten nicht beobachtet werden. ${ }^{1416}$ Ein höheres Alter (ALTER_LN) geht ebenfalls mit einer höheren Faktorausprägung von ORG_GEB und somit einer niedrigeren organisationalen Gebundenheit einher. Das personale Wohlwollen (PERS_WOHL) ist positiv korreliert und somit schlechter bei Dienstleistungsunternehmen und bei Kapitalgesellschaften. Das zunehmende Unternehmensalter hingegen führt zu einer niedrigeren Faktorausprägung von PERS_WOHL und somit zu zunehmendem personalen Wohlwollen. Eine Erklärung für letzteren Zusammenhang könnte darin bestehen, dass das zunehmende Alter zu einer längeren Dauer der Beziehung zum Firmenkundenbetreuer und über diesen Zusammenhang zu einem höheren Wohlwollen führt. Das Unternehmensalter und die Dauer der Beziehung sind signifikant positiv korreliert (Korrelationskoeffizient: 0,1329, Signifikanzniveau: 10\%). An dieser Stelle kann resümiert werden, dass das bloße Alter des Unternehmens somit insgesamt nicht relevant für die Ausprägung der verhaltenswissenschaftlichen Faktoren zu sein scheint und dass das Alter und die verhaltenswissenschaftlichen Faktoren unterschiedliche Dinge messen. Ein Automatismus derart, dass ein höheres Alter zwangsläufig zu einer höheren Glaubwürdigkeit führt, kann nicht beobachtet werden.

Ferner liefert die Analyse der Korrelationen der verhaltenswissenschaftlichen Variablen mit den beziehungsbezogenen Variablen (vgl. Tab. B-69) aufschlussreiche Erkenntnisse. Das Vorliegen einer aktuellen oder einer vergangenen Intensivbetreuung geht mit einer niedrigen Glaubwürdigkeit sowohl auf personaler als auch auf organisationaler Ebene und gleichzeitig mit einer stärkeren organisationalen Gebundenheit einher. Letzteres könnte zum einen daher resultieren, dass eine andere Bank dem Kunden keinen Kredit geben würde, da die Ursache der Intensivbetreuung möglicherweise eine eingeschränkte Kreditwürdigkeit ist, oder dass der Informationsvorsprung der bestehenden Bank im Vergleich zu anderen Banken aufgrund der intensiven Betreuung erheblich ist. Alle Faktoren der personalen Ebene PERS_GLAUB, PERS_WOHL, PERS_VER und PERS_VER_WOHL sind mit der Dauer der persönlichen Beziehung (DAU_PERS_ERR) derart korreliert, dass eine längere Beziehung mit besseren Ausprägungen der einzelnen Faktoren einhergeht. Zwar hat die Dauer der Bankbeziehung (DAU_BEZ_ERR) ebenfalls einen Effekt auf das PERS_WOHL allerdings mit deutlich niedrigerer Intensität. Ferner besteht eine Interdependenz zwischen einer langen Kunde-Bank-Beziehung und einer hohen organisationalen Verbundenheit. Bei isolierter Betrachtung weist der beschriebene Zusammenhang auf einen gewissen Automatismus hin, so wie selbiger in dem Modell von FORD bereits angedeutet wurde. ${ }^{1417}$ In diesem Modell wurde mit zunehmender Beziehungsdauer eine reduzierte Unsicherheit und ein erhöhtes Commitment postuliert. Neben diesen Korrelationen können ferner auch hohe Korrelationen mit der Anzahl der jährlichen Beratungsgespräche und mit

\footnotetext{
1416 Vgl. zu Unterschieden bei der Bonität Tab. B-15, S. 215.

1417 Zur Beschreibung des Modells von Ford vgl. ausführlich Kapitel A.5.2.2.2.1. Zur Kritik an dem dort teilweise unterstellten Automatismus vgl. Kapitel A.5.2.2.2.2.
} 
der Kontakthäufigkeit je Jahr beobachtet werden. Dies zeigt, dass nicht allein die Dauer der Beziehung, sondern auch die Interaktionen insbesondere für das Wohlwollen und die Verbundenheit von Relevanz sind. Eine Trennung der Effekte ist aber nur schwer möglich. Bei einer langen Beziehungsdauer haben bei Betrachtung der Gesamtdauer vermutlich auch schon viele Kontakte stattgefunden. Hieraus resultiert die nicht zu beantwortende Frage, wie 50 Kontakte verteilt über eine Dauer von 10 Jahren im Vergleich zu 50 Kontakten verteilt über eine Dauer von einem Jahr zu bewerten sind. Hinsichtlich der organisationalen Gebundenheit lässt sich ferner vermuten, dass eine niedrige Gebundenheit in Verbindung mit der Existenz alternativer Bankverbindungen eher zu einer geringeren Anzahl an Beratungsgesprächen und Kontakten führt, da der Kunde diese Beratungsgespräche auch bei seinen anderen Banken erhält.

\begin{tabular}{|c|c|c|c|c|c|c|c|c|}
\hline & $\begin{array}{l}\text { ORG }_{\text {GLAUB }} \\
\text { GLe }\end{array}$ & $\begin{array}{l}\text { ORG } \\
\text { WOHL }\end{array}$ & $\begin{array}{l}\text { PERS } \\
\text { GLAUB }\end{array}$ & $\begin{array}{l}\text { PERS } \\
\text { WOHL }\end{array}$ & $\mathrm{ORG}_{-}^{\mathrm{GEB}_{-}}$ & $\begin{array}{l}\text { ORG } \\
\text { VER }\end{array}$ & $\begin{array}{c}\text { PERS } \\
\text { VER }\end{array}$ & $\begin{array}{l}\text { PERS } \\
\text { VER_- } \\
\text { WOHL }\end{array}$ \\
\hline PROD & $-0,0809$ & $-0,1464^{* *}$ & $-0,1172$ & $-0,1078$ & $-0,0149$ & 0,0389 & $-0,1288$ & $-0,1215$ \\
\hline DIENST & 0,0356 & 0,0930 & 0,1365 & $0,1443^{* *}$ & 0,0480 & 0,0298 & 0,0333 & 0,0866 \\
\hline KAPGESELL & $-0,1110$ & 0,0335 & $-0,0618$ & $0,1614 * *$ & $0,2432^{* *}$ & 0,0789 & 0,0541 & 0,0725 \\
\hline ALTER & $-0,1301$ & $-0,0571$ & $-0,1060$ & $-0,1502 * *$ & 0,0711 & $-0,1331$ & $-0,0713$ & $-0,1245$ \\
\hline ALTER_LN & $-0,1279$ & $-0,0652$ & $-0,0948$ & $-0,1603^{* *}$ & $0,1542^{* *}$ & $-0,1577$ & $-0,0892$ & $-0,1371^{* *}$ \\
\hline
\end{tabular}

Tab. B-68: Bivariate Korrelationen der verhaltenswissenschaftlichen Variablen mit den unternehmensbezogenen Variablen ${ }^{1418}$

Der Hausbankstatus steht im Zusammenhang mit einer niedrigeren und somit besseren Ausprägung der Faktoren ORG_WOHL, ORG_GEB, ORG_VER, PERS_GLAUB, PERS_WOHL, PERS_VER und PERS_VER_WOHL, hat aber keinen signifikanten Effekt auf die Glaubwürdigkeit, weder auf die organisationale noch auf die personale Glaubwürdigkeit. Während die Ausprägung der anderen Faktoren durch die Ausgestaltung der Beziehung und durch Wechselwirkungen bspw. zwischen dem Wohlwollen des Firmenkundenbetreuers und dem Wohlwollen das Ansprechpartners beeinflusst wird, liegt die Glaubwürdigkeit in dem Unternehmen bzw. der Person des Ansprechpartners selbst verwurzelt. Ein absolut betrachtet hohes Gesamtkreditvolumen bei der Bank (GES_KREDIT) ist signifikant korreliert mit ORG_GLAUB, ORG_WOHL, PERS_GLAŪB, PERS_GLAUB, PERS_WOHL, PERS_VER und PERS̄_VER_WOH $\bar{L}$, so dass ein höheres Kreditvolumen mit einer besseren Glaubwürdigkeit und höherem Wohlwollen auf personaler und organisationaler Ebene einhergeht.

1418 Eine vollumfängliche Darstellung der Korrelationen der verhaltenswissenschaftlichen Variablen mit den unternehmensbezogenen Variablen kann dem Anhang 4, Tab. AN 4-6 entnommen werden. 


\begin{tabular}{|c|c|c|c|c|c|c|c|c|}
\hline & $\begin{array}{l}\text { ORG } \\
\text { GLAUB }\end{array}$ & $\begin{array}{l}\text { ORG } \\
\text { WOHL }\end{array}$ & $\begin{array}{l}\text { PERS } \\
\text { GLAUB }\end{array}$ & $\begin{array}{l}\text { PERS } \\
\text { WOHL }\end{array}$ & $\begin{array}{c}\text { ORG } \\
\text { GEB }\end{array}$ & $\begin{array}{l}\text { ORG } \\
\text { VER }\end{array}$ & $\begin{array}{c}\text { PERS } \\
\text { VER }\end{array}$ & $\begin{array}{l}\text { PERS_- } \\
\text { VER_- } \\
\text { WOHL }\end{array}$ \\
\hline INT_BET & $0,2874^{* *}$ & 0,0521 & $0,1447^{* *}$ & 0,0831 & $-0,1988^{* *}$ & $-0,0041$ & 0,0691 & 0,0906 \\
\hline DAU_BEZ_ERR & $-0,0971$ & $-0,0846$ & $-0,0668$ & $-0,1662^{* *}$ & 0,1265 & $-0,2089^{* *}$ & $-0,1031$ & $-0,1548^{* *}$ \\
\hline DAU_PERS_ERR & $-0,0863$ & $-0,1429 * *$ & $-0,1516^{* *}$ & $-0,2343 * *$ & 0,0934 & $-0,1057$ & $-0,2369 * *$ & $-0,2574^{* *}$ \\
\hline DAU_BEZ_ERR_LN & $-0,0865$ & $-0,0932$ & $-0,0307$ & $-0,1464^{* *}$ & $0,1356^{* *}$ & $-0,2245^{* *}$ & $-0,1062$ & $-0,1384^{* *}$ \\
\hline DAU_PERS_ERR_LN & $-0,1182$ & $-0,1487$ & $-0,1494^{* *}$ & $-0,2713^{* *}$ & 0,0574 & $-0,1181$ & $-0,2535^{* *}$ & $-0,2720^{* *}$ \\
\hline ANZ_BER_J & 0,0170 & $-0,2859 * * *$ & $-0,1555^{* *}$ & $-0,2728^{* * *}$ & $-0,2760^{* * *}$ & $-0,1846 * * *$ & $-0,2944^{* * *}$ & $-0,2932^{* * *}$ \\
\hline ANZ_KONT_J & 0,0110 & $-0,1367^{* *}$ & $-0,0393$ & $-0,1237^{*}$ & $-0,1465^{* *}$ & $-0,1166^{*}$ & $-0,2003^{* * *}$ & $-0,1845^{* * *}$ \\
\hline HAUSBANK_K & $-0,1011$ & $-0,2930^{* *}$ & $-0,1278$ & $-0,1485^{* *}$ & $-0,2047^{* *}$ & $-0,3446^{* *}$ & $-0,2513^{* *}$ & $-0,2023 * *$ \\
\hline GK_SALD & $-0,1668^{* *}$ & $-0,0425$ & $-0,0594$ & $-0,0194$ & $0,3003^{* *}$ & 0,0417 & 0,1050 & 0,0445 \\
\hline GK_LIM_EX & $-0,1819^{* *}$ & $-0,1695^{* *}$ & $-0,1699^{* *}$ & $-0,1315$ & $-0,0154$ & $-0,0607$ & $-0,1349$ & $-0,1413^{* *}$ \\
\hline GES_KREDIT & $-0,1376^{* *}$ & $-0,1773 * *$ & $-0,1854 * *$ & $-0,1885^{* *}$ & $-0,0033$ & $-0,0433$ & $-0,1375^{* *}$ & $-0,1839^{* *}$ \\
\hline ANT_BANK_IN & 0,0231 & $-0,3155^{* *}$ & $-0,0620$ & $-0,1850^{* *}$ & $-0,2245^{* *}$ & $-0,3106^{* *}$ & $-0,2481^{* *}$ & $-0,2175^{* *}$ \\
\hline ANT_BANK_HB & 0,2073 & 0,2121 & $0,2640^{* *}$ & 0,2120 & $-0,0564$ & 0,2134 & $0,2961^{* *}$ & $0,2382^{* *}$ \\
\hline ANZ_B_AGG & $-0,1334$ & 0,0577 & $-0,0896$ & 0,0058 & $0,1805^{* *}$ & 0,0281 & 0,0656 & 0,0262 \\
\hline ZINS_VERFUG & $-0,1802^{* *}$ & 0,0594 & 0,0036 & 0,0741 & $0,3468^{* *}$ & $0,1439^{* *}$ & $0,2278^{* *}$ & $0,1673^{* *}$ \\
\hline ANT_ZV & $-0,0765$ & $-0,3075^{* *}$ & $-0,1074$ & $-0,1563 * *$ & $-0,2994 * *$ & $-0,3585^{* *}$ & $-0,2569 * *$ & $-0,2320^{* *}$ \\
\hline DARL & 0,1093 & $-0,0877$ & $-0,0947$ & $-0,1585^{* *}$ & $-0,2311^{* *}$ & $-0,1620^{* *}$ & $-0,1183$ & $-0,0874$ \\
\hline ZV_KK & 0,0191 & 0,0438 & 0,0715 & $-0,0001$ & $-0,0438$ & $-0,0862$ & $-0,0104$ & 0,0022 \\
\hline VERM_ANL & $-0,1062$ & $-0,2099 * *$ & $-0,0259$ & $-0,2146^{* *}$ & $-0,0348$ & $-0,2832^{* *}$ & $-0,3346^{* *}$ & $-0,2896^{* *}$ \\
\hline VERSICH & 0,0495 & $-0,1268$ & $-0,0430$ & $-0,0956$ & $-0,2353^{* *}$ & $-0,2090^{* *}$ & $-0,2039^{* *}$ & $-0,1362^{* *}$ \\
\hline PRIVATKONT & $-0,0886$ & $-0,1146$ & $-0,0179$ & $-0,1251$ & 0,0407 & $-0,1537^{* *}$ & $-0,2220^{* *}$ & $-0,1770^{* *}$ \\
\hline SICH_Q & $0,1596^{* *}$ & $-0,0951$ & $-0,0294$ & $-0,1788^{* *}$ & $-0,2656^{* *}$ & $-0,1586^{* *}$ & $-0,2041^{* *}$ & $-0,1636^{* *}$ \\
\hline EL & $0,2421^{* *}$ & 0,1306 & $0,2197^{* *}$ & $0,1702^{* *}$ & $-0,0424$ & $0,1439^{* *}$ & $0,1553^{* *}$ & $0,1608^{* *}$ \\
\hline DIST_UNT & 0,0896 & 0,0159 & 0,0572 & $-0,0607$ & $-0,0072$ & 0,0399 & 0,0274 & 0,0383 \\
\hline
\end{tabular}

Tab. B-69: Bivariate Korrelationen der verhaltenswissenschaftlichen Variablen mit den beziehungsbezogenen Variablen ${ }^{1419}$

Während die organisationale Gebundenheit eine Interdependenz mit der Nutzung von Darlehen und Versicherungsprodukten aufweist, ist die organisationale Verbundenheit auch mit der Nutzung von Produkten aus dem Bereich der Vermögensanlage sowie Privatkonten negativ korreliert. Der Wirkungszusammenhang könnte derart sein, dass eine intensivere organisationale Verbundenheit zu stärkerer Nutzung der genannten Produkte führt oder dass die stärkere Nutzung der Produkte eine in der Wahrnehmung des Firmenkundenbetreuers größere Verbundenheit bewirkt.

1419 Eine vollumfängliche Darstellung der Korrelationen der verhaltenswissenschaftlichen Variablen mit den beziehungsbezogenen Variablen kann dem Anhang 4, Tab. AN 4-7 entnommen werden. 


\section{Bankbezogene Daten}

Die Variable FKB_STUD zeigt eine signifikante positive Korrelation mit der Einschätzung des $\mathrm{FKB}$ auf, dass eine risikoorientierte Bepreisung durchgeführt wird (Korrelationskoeffizient: 0,1538, Signifikanzniveau: $5 \%$ ) (vgl. Tab. B-70). Dies ist insofern intuitiv, als dass sich ein Firmenkundenbetreuer mit einem akademischen Hintergrund vermutlich eher gemäß den theoretischen Vorgaben hinsichtlich einer risikoorientierten Bepreisung verhält.

\begin{tabular}{|c|c|c|c|c|c|c|c|c|c|}
\hline & $\begin{array}{l}\frac{3}{2} \\
\frac{8}{x}\end{array}$ & $\begin{array}{l}\text { है। }_{1} \\
\tilde{m}^{\prime} \\
\frac{m}{2}\end{array}$ & $\begin{array}{l}\frac{8}{5} \\
\frac{\infty}{2} \\
\frac{\infty}{1}\end{array}$ & $\frac{\frac{1}{2}}{\frac{1}{a}}$ & 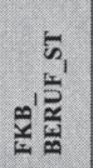 & $\begin{array}{l}0 \\
\frac{5}{\infty} \\
\frac{\infty}{5}\end{array}$ & $\frac{3}{3}$ & $\frac{\frac{3}{2}}{\frac{5}{2}}$ & 宊 \\
\hline FKB_JÜ30 & 1,0000 & & & & & & & & \\
\hline FKB_30_50 & $-0,3988^{* * *}$ & 1,0000 & & & & & & & \\
\hline FKB_ÜB50 & $-0,1371^{* *}$ & $-0,8537^{* * *}$ & 1,0000 & & & & & & \\
\hline FBK_BANK & 0,0551 & $-0,1230$ & 0,1016 & 1,0000 & & & & & \\
\hline $\begin{array}{l}\text { FKB_ } \\
\text { BERUF_ST }\end{array}$ & $-0,0776$ & 0,1026 & $-0,0668$ & $-0,3449 * * *$ & 1,0000 & & & & \\
\hline FKB_STUD & $0,2057^{* * *}$ & 0,0231 & $-0,1418^{* *}$ & 0,0466 & $-0,0553$ & 1,0000 & & & \\
\hline $\begin{array}{l}\text { MARKT- } \\
\text { AN_GES }\end{array}$ & $0,3674^{* * *}$ & $-0,1094$ & $-0,0905$ & $0,2027^{* * *}$ & 0,0330 & $-0,0048$ & 1,0000 & & \\
\hline $\begin{array}{l}\text { MARKT- } \\
\text { AN_FK }\end{array}$ & $0,3987^{* * *}$ & $-0,1330$ & $-0,0828$ & $0,1723^{* *}$ & $-0,0011$ & 0,0583 & $0,8792^{* * *}$ & 1,0000 & \\
\hline $\begin{array}{l}\text { UMFELD_ } \\
\text { LÄND }\end{array}$ & $0,1514^{* *}$ & $-0,0289$ & $-0,0547$ & $0,1848^{* * *}$ & $-0,0561$ & 0,0017 & $0,4025^{* * *}$ & $0,2491^{* * *}$ & 1,0000 \\
\hline $\begin{array}{l}\text { UMFELD_ } \\
\text { LÄSTÄ }\end{array}$ & $-0,1247$ & 0,0321 & 0,0362 & $-0,1272$ & $0,1462^{* *}$ & $-0,0129$ & $-0,0815$ & $-0,0359$ & $-0,6760^{* * *}$ \\
\hline $\begin{array}{l}\text { UMFELD_ } \\
\text { STÄ }\end{array}$ & $-0,0232$ & $-0,0060$ & 0,0197 & $-0,0599$ & $-0,1191$ & 0,0145 & $-0,3802^{* * *}$ & $-0,2539 * * *$ & $-0,3401^{* * *}$ \\
\hline $\begin{array}{l}\text { LEI_ } \\
\text { WERT_FKB }\end{array}$ & 0,0550 & 0,1177 & $-0,1582 * *$ & 0,0910 & 0,0865 & 0,1332 & $0,3032 * * *$ & $0,3837^{* * *}$ & 0,0841 \\
\hline $\begin{array}{l}\text { LEI_ } \\
\text { WERT_BA }\end{array}$ & $-0,0812$ & $-0,2215^{* * *}$ & $0,2851^{* * *}$ & 0,0607 & $-0,0842$ & $-0,0554$ & 0,0321 & 0,1078 & $-0,0699$ \\
\hline LEI_VOL & $-0,1052$ & $0,1468^{* *}$ & $-0,0998$ & 0,1099 & 0,0149 & $-0,1000$ & $0,2124^{* * *}$ & $0,2551^{* * *}$ & $-0,0947$ \\
\hline LEI_AKT & $-0,1236$ & 0,1254 & $-0,0663$ & 0,0558 & 0,0606 & $-0,0936$ & $0,2883^{* * *}$ & $0,2960^{* * *}$ & $-0,1195$ \\
\hline LEI_KEIN & 0,0062 & 0,0022 & $-0,0059$ & $-0,1175$ & $-0,0912$ & $-0,1060$ & $-0,3517^{* * *}$ & $-0,4006^{* * *}$ & 0,0020 \\
\hline $\begin{array}{l}\text { RISIKO_- } \\
\text { BEPREIS }\end{array}$ & 0,0763 & $0,1419^{* *}$ & $-0,1967^{* * *}$ & 0,0010 & $-0,0360$ & $0,1538^{* *}$ & $-0,0209$ & 0,0594 & $-0,1784^{* * *}$ \\
\hline BIL_BA & $-0,0624$ & $-0,1408^{* *}$ & $0,1876^{* * *}$ & $-0,4497^{* * *}$ & 0,0177 & 0,0271 & $-0,2210^{* * *}$ & $-0,1024$ & $-0,2229^{* * *}$ \\
\hline
\end{tabular}

Tab. B-70: Bivariate Korrelationen der bankbezogenen Variablen (1)

Die Einschätzung zur risikoorientierten Bepreisung ist ferner auch positiv korreliert mit dem städtischen Umfeld (Korrelationskoeffizient: 0,1451, Signifikanzniveau: 5\%) sowie mit der wertorientierten, personenbezogenen Vergütung (Korrelationskoeffizient: 0,2048, Signifikanzniveau: $1 \%$ ). Ein erster Schluss könnte sein, dass im städti- 
schen Umfeld die Bepreisung rationaler erfolgt und bspw. zwischenmenschliche Aspekte von nachrangiger Bedeutung sind. Bei dem Zusammenhang zur Vergütung sind zu viele Faktoren zu berücksichtigen, als dass eine sinnvolle Einschätzung abgegeben werden könnte. So müsste bspw. die genaue Ausgestaltung der wertorientierten Vergütung analysiert werden.

Ein hoher Marktanteil insgesamt (MARKTAN_GES) sowie im Bereich Firmenkunden (MARKTAN_FK) ist positiv korreliert mit der Einschätzung, dass die Bank im ländlichen Umfeld (UMFELD_LÄND) agiert, und negativ korreliert mit dem städtischen Umfeld (UMFELD_STÄ); d.h. die Marktanteile in ländlichen Regionen sind tendenziell höher. Ferner ist der Marktanteil signifikant positiv korreliert mit der wertorientierten, personenbezogenen Vergütung. Es wäre denkbar, dass die wertorientierte, personenbezogene Vergütung einen derart großen Anreiz für die Firmenkundenbetreuer stiftet, dass der Marktanteil aufgrund der Motivation der Firmenkundenbetreuer steigt.

\begin{tabular}{|c|c|c|c|c|c|c|c|c|c|}
\hline & 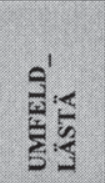 & 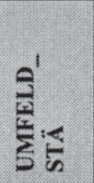 & 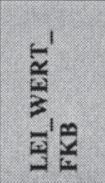 & 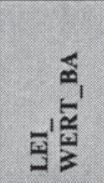 & $\begin{array}{l}\text { o } \\
\text { 혹 }\end{array}$ & $\begin{array}{l}\frac{5}{2} \\
\frac{1}{3} \\
\frac{1}{3}\end{array}$ & $\begin{array}{l}\frac{2}{3} \\
\frac{1}{1} \\
\frac{1}{2}\end{array}$ & 商 & $\begin{array}{l}\overleftrightarrow{m} \\
\dot{m}\end{array}$ \\
\hline $\begin{array}{l}\text { UMFELD_ } \\
\text { LÄSTÄ }\end{array}$ & 1,0000 & & & & & & & & \\
\hline $\begin{array}{l}\text { UMFELD_ } \\
\text { STÄ }\end{array}$ & $-0,4630^{* * *}$ & 1,0000 & & & & & & & \\
\hline $\begin{array}{l}\text { LEI_ } \\
\text { WERT_FKB }\end{array}$ & $-0,0358$ & $-0,0563$ & 1,0000 & & & & & & \\
\hline $\begin{array}{l}\text { LEI_ } \\
\text { WERT_BA }\end{array}$ & $-0,0648$ & $0,1692^{* *}$ & $-0,0183$ & 1,0000 & & & & & \\
\hline LEI_VOL & 0,1211 & $-0,0406$ & $0,4002 * * *$ & $0,2429 * * *$ & 1,0000 & & & & \\
\hline LEI_AKT & $0,1376^{* *}$ & $-0,0317$ & $0,2839 * * *$ & $0,2203^{* * *}$ & $0,6958^{* * *}$ & 1,0000 & & & \\
\hline LEI_KEIN & 0,0200 & $-0,0283$ & $-0,7473^{* * *}$ & $-0,3475^{* * *}$ & $-0,4222^{* * *}$ & $-0,4915^{* * *}$ & 1,0000 & & \\
\hline $\begin{array}{l}\text { RISIKO_ } \\
\text { BEPREIS }\end{array}$ & 0,0544 & $0,1451^{* *}$ & $0,2048^{* * *}$ & 0,1005 & 0,1324 & $0,1550^{* *}$ & $-0,2649^{* * *}$ & 1,0000 & \\
\hline BIL_BA & 0,0896 & $0,1537^{* *}$ & $-0,0433$ & $-0,0740$ & $-0,0169$ & $-0,1052$ & 0,0896 & 0,1077 & 1,0000 \\
\hline
\end{tabular}

Tab. B-71: Bivariate Korrelationen der bankbezogenen Variablen (2)

\section{Zusammenfassung der Korrelationsanalyse der unabhängigen Variablen}

Abschließend lässt sich konstatieren, dass im Bereich der Finanzkennzahlen erhebliche Mediatoreffekte zu berücksichtigen sind, insbesondere aufgrund der Tatsache, dass es sich bei der Ausfallwahrscheinlichkeit sowie bei den Teilscores um verdichtete Daten handelt, in denen möglicherweise einzelne Finanzkennzahlen bereits berücksichtigt worden sind.

Hinsichtlich der Parameter Branchenzugehörigkeit und Rechtsform auf der einen Seite und Finanzkennzahlen auf der anderen Seite besteht ferner ein erheblicher Zusammenhang, so dass auch hier von einem mediierenden Effekt der Finanzkennzahlen ausge- 
gangen werden kann, inwiefern es sich hierbei um einen vollständigen oder einen partiellen Mediatoreffekt handelt, kann noch nicht beurteilt werden.

Bei den beziehungsbezogenen Variablen kann hinsichtlich des Hausbankstatus davon ausgegangen werden, dass diverse Variablen, z.B. die Anzahl der genutzten Produkte sowie der Anteil an der Finanzierung und am gesamten Zahlungsverkehr, durch den Hausbankstatus bedingt werden. Auch hier sind somit Mediatoreffekte zu erwarten, allerdings bleibt zunächst offen, ob es sich um vollständige oder partielle Mediatoreffekte handelt. Es ist zu prüfen, inwiefern der Hausbankstatus oder die oben genannten Variablen im weiteren Verlauf der Analysen einen Einfluss auf die ökonomischen Parameter ausüben. Da aus dem Hausbankstatus eine besondere Verantwortung resultiert, können über den Anteil der Finanzierung und des Zahlungsverkehrs hinaus zusätzliche Auswirkungen auf den Zinssatz resultieren.

Im Bereich der verhaltenswissenschaftlichen Variablen weist die organisatorische Glaubwürdigkeit signifikante Korrelationen mit den Finanzkennzahlen auf. Hier ist im weiteren Verlauf zu prüfen, inwiefern es sich bei dieser Variable um eine Mediatorvariable handelt, die selbst vollständig durch andere Variablen wie Finanzkennzahlen erklärt oder die zusätzliche Auswirkungen auf den Zinssatz hat.

\section{Korrelationsanalyse der abhängigen Variablen}

Nachdem zunächst die Korrelationen zwischen den unabhängigen Variablen untereinander untersucht worden sind, erfolgt im nächsten Schritt eine univariate Analyse des Zusammenhangs zwischen dem Zinssatz und den bisher untersuchten Variablen. In Tab. B-72 wird die Analyse der bivariaten und partiellen Korrelationen der Finanzkennzahlen mit dem Zinssatz aufgezeigt. Es wurden diejenigen Variablen als Kontrollvariablen integriert, die zu vielen Kennzahlen signifikante Korrelationen aufweisen. Während es zahlreiche signifikante bivariate Korrelationen zwischen den Finanzkennzahlen und dem Zinssatz gibt, sind nach Bereinigung der Einflüsse von TSC_JA_AGG und BILANZS bzw. von AUSFALLW_B und BILANZS nur noch die Variablen KASSE_A und UMIND signifikant mit dem Zinssatz korreliert. Zwar weist selbige eine negative bivariate Korrelation auf, jedoch wurde eine signifikante positive partielle Korrelation ermittelt. Eine Erklärung kann hierfür nicht gefunden werden. Ein erstes Fazit an dieser Stelle ist, dass im Bereich der Finanzkennzahlen fast ausschließlich vollständige Mediatoreffekte vorliegen und alle Zusammenhänge der Finanzkennzahlen zum Zinssatz auf die Ausfallwahrscheinlichkeit bzw. den Teilscore für den Jahresabschluss sowie die Bilanzsumme zurückzuführen sind. Die Kennzahlen, die bei isolierter Betrachtung einen Effekt auf den Zinssatz haben, werden in den Ratingergebnissen und in der Bilanzsumme berücksichtigt. 


\begin{tabular}{|c|c|c|c|c|c|c|c|}
\hline Kontrollvariablen & & EKQ & $\begin{array}{c}\text { BI- } \\
\text { LANZS }\end{array}$ & $\begin{array}{c}\text { AUS- } \\
\text { FALLW } \\
\text { B }\end{array}$ & $\begin{array}{c}\text { TSC_JA } \\
\ldots \text { AGG }\end{array}$ & $\begin{array}{c}\text { AUS- } \\
\text { FALLW_B } \\
\text { \& BI- } \\
\text { LANZS }\end{array}$ & $\begin{array}{c}\text { TSC_JA } \\
\text { AGG \& } \\
\text { BI- } \\
\text { LANZS }\end{array}$ \\
\hline VERB_KI_LANG_R & 0,1125 & $-0,0322$ & 0,0879 & 0,0445 & 0,0077 & 0,0302 & $-0,0007$ \\
\hline VERB_KI_KURZ_R & 0,0981 & $-0,0847$ & 0,0995 & $-0,1072$ & $-0,0548$ & $-0,0748$ & $-0,0360$ \\
\hline VERB_KI_R & $0,1349^{* *}$ & $-0,0788$ & 0,1173 & $-0,0128$ & $-0,0230$ & $-0,0094$ & $-0,0199$ \\
\hline VERM_LA_R & $-0,0534$ & $-0,0758$ & $-0,0131$ & $-0,0638$ & $-0,0534$ & $-0,0250$ & $-0,0109$ \\
\hline KASSE_R & 0,0522 & 0,1109 & 0,0490 & 0,1172 & $0,1598^{* *}$ & 0,1060 & 0,1224 \\
\hline VERB_KI_LANG_A & $-0,2579 * * *$ & $-0,2737^{* * *}$ & $-0,0398$ & $-0,2559 * * *$ & $-0,2092^{* * *}$ & $-0,0577$ & $-0,0231$ \\
\hline VERB_KI_KURZ_A & $-0,1788^{* * *}$ & $-0,1971^{* * *}$ & 0,0369 & $-0,2047 * * *$ & $-0,1691^{* *}$ & $-0,0075$ & 0,0104 \\
\hline VERB_KI_A & $-0,2432 * * *$ & $-0,2622 * * *$ & $-0,0008$ & $-0,2561^{* * *}$ & $-0,2149 * * *$ & $-0,0384$ & $-0,0080$ \\
\hline VERM_LA_A & $3510^{* * *}$ & $3291 * * *$ & $-0,0536$ & $-0,3328^{* * *}$ & $-0,2962^{* * *}$ & $-0,0640$ & 0,0111 \\
\hline KASSE_A & $-0,0625$ & $-0,0089$ & 0,1165 & $-0,0273$ & $-0,1417$ & $0,1382^{* *}$ & 0,0444 \\
\hline UMIND & $0,2871^{* * *}$ & $-0,2876^{* * *}$ & $-0,2460^{* *}$ & $-0,2659 * *$ & $-0,2733^{* *}$ & $-0,2329 * *$ & $-0,2272^{* *}$ \\
\hline NZS & $-0,3715^{* * *}$ & $-0,3379 * * *$ & & $-0,3458^{* * *}$ & $-0,3372^{* * *}$ & & \\
\hline UMSATZ & $-0,3614^{* * *}$ & $-0,3456^{* * *}$ & $-0,1284$ & $-0,3454 * * *$ & $-0,3129 * * *$ & $-0,1344$ & $-0,0977$ \\
\hline EKQ & $-0,2616^{* * *}$ & & $-0,2066^{* * *}$ & $-0,1040$ & $-0,1174$ & $-0,0640$ & $-0,0904$ \\
\hline ANZ_ÜB_30 & 0,1844 & $0,1338^{* * *}$ & $0,1661^{* *}$ & 0,0673 & 0,1181 & 0,0664 & 0,1145 \\
\hline ANZ_ÜB_60 & 0,1161 & 0,0730 & 0,0957 & 0,0245 & 0,0475 & 0,0173 & 0,0482 \\
\hline ANZ_ÜB_90 & 0,1161 & 0,0730 & 0,0957 & 0,0245 & 0,0475 & 0,0173 & 0,0482 \\
\hline ANZ_ÜB_GES & 2221 & 0,1279 & $0,1784^{* * *}$ & 0,0766 & 0,0978 & 0,0508 & 0,0720 \\
\hline VERB_KI_LANG_R_LN & 002 & 910 & 077 & 0,1404 & 0,0969 & 0,1526 & 0,1218 \\
\hline VERB_KI_KURZ_R_LN & 48 & 084 & 502 & 1906 & $-0,2094$ & $-0,1396$ & $-0,1452$ \\
\hline VERB_KI_R_LN & 0,0575 & 0,0991 & $0,2559^{* *}$ & 0,0957 & 0,0446 & 0,1190 & 0,0931 \\
\hline VERM_LA_R_LN & $-0,3303^{* * *}$ & $-0,3509 * * *$ & $-0,1871$ & $-0,3518^{* * *}$ & $-0,3635^{* * *}$ & $-0,1258$ & $-0,1594$ \\
\hline KASSE_R_LN & 0,0347 & 0,0260 & 0,0574 & 0,0558 & 0,0888 & 0,0433 & 0,0720 \\
\hline VERB_KI_LANG_A_LN & $-0,3011^{* * *}$ & $-0,2268 * *$ & 0,0619 & $-0,2163^{* *}$ & $-0,2420^{*}$ & 0,0548 & 0,0130 \\
\hline VERB_KI_KURZ_A_LN & $-0,3135^{* * *}$ & $-0,2891^{* * *}$ & $-0,0398$ & $-0,3717^{* * *}$ & $-0,3790^{* * *}$ & $-0,1804$ & $-0,1944$ \\
\hline VERB_KI_A_LN & $-0,3280^{* * *}$ & $-0,2755^{* *}$ & 0,0534 & $-0,3040^{* *}$ & $-0,3259 * * *$ & $-0,0172$ & $-0,0578$ \\
\hline VERM_LA_A_LN & $-0,3303^{* * *}$ & $-0,3509 * * *$ & $-0,1871$ & $-0,3518^{* * *}$ & $-0,3635^{* * *}$ & $-0,1258$ & $-0,1594$ \\
\hline KASSE_A_LN & $-0,2114^{* * *}$ & $-0,2066$ & $-0,0357$ & $-0,2033$ & $-0,1726$ & $-0,0164$ & 0,0041 \\
\hline BILANZS_LN & $-0,3403^{* * *}$ & $-0,3761^{* * *}$ & $-0,1919$ & $-0,3886^{* * *}$ & $-0,3828^{* * *}$ & $-0,1264$ & $-0,1409$ \\
\hline UMSATZ_LN & $-0,3377^{* * *}$ & $-0,3631^{* * *}$ & $-0,1740$ & $-0,3533^{* * *}$ & $-0,3255^{* * *}$ & $-0,1019$ & $-0,0806$ \\
\hline AUSFALLW_B & $0,2813^{* * *}$ & 0,1648 & $0,1843^{*}$ & & 0,1078 & & 0,0647 \\
\hline TSC_JA_AGG & $-0,3134^{* * *}$ & $-0,2521^{* *}$ & $-0,2990^{* * *}$ & $-0,1499$ & & $-0,0972$ & \\
\hline TSC_QA_AGG & $-0,2667 * * *$ & $-0,3641^{* * *}$ & $-0,3333^{* * *}$ & $-0,3025^{* * *}$ & $-0,2955^{* * *}$ & $-0,2034$ & $-0,2130$ \\
\hline
\end{tabular}

Tab. B-72: Bivariate und partielle Korrelationen der Finanzkennzahlen mit dem Zinssatz

Im nächsten Schritt erfolgt eine Analyse der bivariaten und partiellen Korrelationen der unternehmensbezogenen Variablen mit dem Zinssatz. Die Analyse dieser Korrelationen zeigt, dass im bivariaten Kontext für die Variablen HAND und ALTER sowie ALTER_LN signifikante Korrelationen mit dem Zinssatz existieren (vgl. Tab. B-73). Zuvor wurde der Zusammenhang der Branchen-Variablen zur Unternehmensgröße bereits untersucht, wobei der Umsatz die einzige Variable war, die zu drei der vier Branchen signifikante Korrelationen aufweist. Die Integration der Kontrollvariablen Umsatz in die Korrelationsanalyse führt dazu, dass keine signifikanten Korrelationen mehr existieren. Ferner zeigte auch die Variable VERB KI_KURZ A LN signifikan- 
te Korrelationen zu drei Branchen. Zwar werden auch durch diese Variable einige Korrelationen eliminiert, der Effekt resultierend aus dem Umsatz ist aber deutlicher. Der Zusammenhang zwischen den sonstigen unternehmensbezogenen Variablen und dem Zinssatz scheint somit vielmehr auf die Unternehmensgröße, hier gemessen am Umsatz, und weniger auf die Variablen selbst zurückzuführen sein.

\begin{tabular}{|l|r|r|r|}
\hline Kontrollvariablen & \multicolumn{1}{|c|}{} & UMSATZ & VERB_KI_KURZ_A_LN \\
\hline PROD & 0,0064 & 0,0200 & 0,0150 \\
\hline HAND & $-0,1823^{* * *}$ & $-0,0874$ & $-0,1730^{* *}$ \\
\hline DIENST & 0,1301 & 0,0710 & 0,0881 \\
\hline BAU & 0,0225 & $-0,0425$ & 0,0719 \\
\hline KAPGESELL & $-0,0187$ & $-0,0074$ & $-0,0105$ \\
\hline ALTER & $-0,1350^{* *}$ & $-0,0992$ & $-0,1562$ \\
\hline ALTER_LN & $-0,1669^{* *}$ & $-0,1088$ & $-0,2093 * *$ \\
\hline
\end{tabular}

Tab. B-73: Bivariate und partielle Korrelationen der unternehmensbezogenen Variablen mit dem Zinssatz

Die Korrelationsanalyse der beziehungsbezogenen Variablen mit dem Zinssatz zeigt, dass die Variablen DAU_BEZ_ERR, GK_LIM_EX, GES_KREDIT, ANZ_B_AGG, ZINS_VERFÜG und MITGLIED eine signifikante negative Korrelation und die Variablen INT_BET, ANT_BANK_HB und EL eine signifikante positive Korrelation mit dem Zinssatz aufweisen (vgl. Tab. B-74). Die Vorzeichen entsprechen der Erwartung, denn eine längere Beziehungsdauer, ein höheres externes Limit, ein größeres Gesamtkreditvolumen, eine größere Anzahl an Bankbeziehungen, eine Präferenz von niedrigen Zinsen im Vergleich zu einer höheren Verfügbarkeit für den Kunden oder die Mitgliedschaft des Kunden bei der Bank führen somit zu niedrigeren Zinsen, wohingegen eine aktuelle oder vergangene Intensivbetreuung sowie ein höherer erwarteter Verlust erwartungsgemäß auch zu höheren Zinsen führt.

Die Korrelationsanalyse zwischen den beziehungsbezogenen Variablen und den Finanzkennzahlen hat gezeigt, dass zahlreiche signifikante Korrelationen zur Ausfallwahrscheinlichkeit, zum Teilscore und zur Bilanzsumme bestehen. Nach Integration der Ausfallwahrscheinlichkeit und der Bilanzsumme weisen nur noch die Variablen INT_BET, GK_LIM_EX, ANT_BANK_HB und MITGLIED, bei Integration des Teilscores und der Bilanzsumme die Variablen GK_LIM_EX und ANT_BANK_HB, einen signifikanten Zusammenhang zum Zinssatz auf. Einige Korrelationen zwischen dem Zinssatz und den beziehungsbezogenen Variablen scheint somit auf die Finanzkennzahlen zurückzuführen zu sein. Bspw. ist vermutlich eine gute Liquiditätssituation ursächlich für die Präferenz für niedrigere Zinsen im Vergleich zu einer höheren Verfügbarkeit. Inwiefern die beziehungsbezogenen Variablen auch im multivariaten Kontext nur einen derart geringen Zusammenhang zum Zinssatz aufweisen, ist zu prüfen. 


\begin{tabular}{|c|c|c|c|c|c|c|}
\hline Kontrollvariablen & - & $\begin{array}{c}\text { AUS- } \\
\text { FALLW_B }\end{array}$ & $\underset{\mathbf{A G G}}{\mathrm{TSC}_{\bar{G}} \mathbf{J A}}$ & BILANZS & $\begin{array}{c}\text { AUS- } \\
\text { FALLW_B \& } \\
\text { BLLANZS }\end{array}$ & $\begin{array}{c}\text { TSC_JA } \\
\text { AGG \& } \\
\text { BILANZS }\end{array}$ \\
\hline INT_BET & $0,2345^{* * *}$ & $0,2549 * *$ & 0,2403 & $0,4137^{* * *}$ & $0,2550^{* *}$ & 0,2463 \\
\hline DAU_BEZ ERR & $-0,1450^{* *}$ & $-0,0586$ & $-0,0250$ & 0,0068 & 0,0342 & 0,0490 \\
\hline DAU_PERS_ERR & $-0,0462$ & $-0,1173$ & $-0,0642$ & $-0,1407$ & $-0,1002$ & $-0,0440$ \\
\hline DAU_BEZ_ERR_LN & $-0,0731$ & 0,0126 & 0,0611 & 0,0435 & 0,1021 & 0,1235 \\
\hline DAU_PERS_ERR_LN & 0,0075 & $-0,1306$ & $-0,0259$ & $-0,1437$ & $-0,0919$ & 0,0094 \\
\hline HAUSBANK $\mathrm{K}$ & $-0,0423$ & $-0,2277$ & $-0,1955$ & $-0,2184$ & $-0,1784$ & $-0,1676$ \\
\hline GK_SALD & 0,0256 & 0,1882 & 0,1992 & 0,1258 & 0,1671 & 0,2215 \\
\hline GK_LIM_EX & $-0,3819^{* * *}$ & $-0,5680^{* * *}$ & $-0,5503^{* * *}$ & $-0,3875^{* * *}$ & $-0,3960^{* * *}$ & $-0,4153^{* * *}$ \\
\hline GES_KREDIT & $-0,1799^{* * *}$ & $-0,1804$ & $-0,2667 * *$ & $-0,0019$ & 0,0124 & $-0,0876$ \\
\hline ANT_BANK_IN & 0,0365 & $-0,2408^{* *}$ & $-0,2570$ & $-0,3273^{* * *}$ & $-0,2933$ & $-0,2641$ \\
\hline ANT_BANK_HB & $0,3579 * * *$ & $0,3495 * * *$ & $0,4496 * * *$ & $0,5044^{* * *}$ & $0,4383 * * *$ & $0,4904 * * *$ \\
\hline ANZ_B_AGG & $-0,2165^{* * *}$ & $-0,3428 * * *$ & $-0,3156 * *$ & $-0,2314$ & $-0,2484$ & $-0,2294$ \\
\hline ZINS_VERFÜG & $-0,1955^{* * *}$ & $-0,0234$ & $-0,0874$ & $-0,1622$ & $-0,0784$ & $-0,0904$ \\
\hline SICH_Q & 0,0889 & $-0,1773$ & $-0,2501$ & $-0,0723$ & $-0,1037$ & $-0,1838$ \\
\hline ANT_ZV & 0,0326 & $-0,1633$ & $-0,1131$ & $-0,2016$ & $-0,1731$ & $-0,1369$ \\
\hline MITGLIED & $-0,1654^{* *}$ & $-0,2219$ & $-0,2569$ & $-0,245 I^{* *}$ & $-0,2754^{* * *}$ & $-0,2670$ \\
\hline DARL & 0,0562 & 0,0148 & 0,0853 & 0,1169 & 0,0993 & 0,1296 \\
\hline VERM_ANL & $-0,0301$ & $-0,2117$ & $-0,2146$ & $-0,1220$ & $-0,1110$ & $-0,1284$ \\
\hline VERSICH & $-0,0132$ & $-0,1033$ & $-0,1845$ & $-0,1669$ & $-0,1177$ & $-0,1534$ \\
\hline PRIVATKONT & $-0,0025$ & $-0,0019$ & 0,0287 & $-0,1112$ & 0,0104 & 0,0276 \\
\hline EL & $0,1536^{* *}$ & 0,0277 & 0,1026 & $0,3017^{* *}$ & $-0,0245$ & 0,0685 \\
\hline DIST_UNT & $-0,0941$ & 0,0520 & 0,0221 & 0,0688 & 0,0945 & 0,0264 \\
\hline
\end{tabular}

Tab. B-74: Bivariate und partielle Korrelationen der beziehungsbezogenen Variablen mit dem Zinssatz

Bei den verhaltenswissenschaftlichen Parametern weisen die Faktoren ORG_GLAUB, ORG_GEB, PERS_GLAUB und PERS_WOHL signifikante Korrelationen mit dem Zinssatz auf (vgl. Tab. B-75). Eine erhöhte Glaubwürdigkeit sowohl auf organisationaler als auch auf personaler Ebene sowie ein erhöhtes personales Wohlwollen geht bei Betrachtung der bivariaten Korrelationen mit niedrigeren Zinsen einher. Da die Glaubwürdigkeit in gewisser Weise ein Indikator für die Kompetenz ist, entspricht der Zusammenhang der vermuteten Richtung. Die verhaltenswissenschaftlichen Variablen weisen hohe bivariate Korrelationen zu der Ausfallwahrscheinlichkeit, der Größe und der Teilscores auf, so dass hier ebenfalls eine Bereinigung um mögliche Einflüsse und die Berechnung von partiellen Korrelationen erfolgt. Da die Korrelationen weiterhin signifikant sind, scheint die organisationale Glaubwürdigkeit nicht vollends in den Finanzkennzahlen enthalten zu sein. Die personale Glaubwürdigkeit hingegen korreliert nach Bereinigung dieser Einflüsse nicht mehr signifikant mit dem Zinssatz. Eine plausible Erklärung kann nicht gefunden werden. Das personale Wohlwollen weist, wie aufgrund des nur geringen inhaltlichen und statistischen Zusammenhangs zu erwarten, auch nach Bereinigung um mögliche Einflüsse aus den Teilscores weiterhin signifikante Korrelationen auf. Eine erhöhte organisationale Gebundenheit steht im Zusammenhang mit höheren Zinsen, allerdings entfällt dieser Zusammenhang bei Bereinigung um die Einflüsse der Bilanzsumme und der Ausfallwahrscheinlichkeit. 
Dies kann dadurch erklärt werden, dass der Faktor organisationale Gebundenheit das „Nicht-Wechseln-Können“ des Unternehmens widerspiegelt. Bei guten Bonitäten und bei größeren Unternehmen mit mehreren Bankverbindungen erscheint es einfacher die Bank zu wechseln. Diese Aspekte werden u.a. in der organisationalen Gebundenheit abgebildet.

\begin{tabular}{|l|r|r|r|r|r|r|}
\hline Kontrollvariablen & - & BILANZS & $\begin{array}{c}\text { AUS } \\
\text { FALLW_B }\end{array}$ & $\begin{array}{c}\text { TSC_JA_ } \\
\text { AGG }\end{array}$ & $\begin{array}{c}\text { AUS } \\
\text { FALLW_B \& } \\
\text { BILANZS }\end{array}$ & $\begin{array}{c}\text { TSC_JA } \\
\text { AGG \& BI- } \\
\text { LANZS }\end{array}$ \\
\hline ORG_GLAUB & $0,2760^{* * *}$ & $0,2167^{* * *}$ & $0,1675^{* *}$ & $0,1623^{* *}$ & 0,1211 & 0,1149 \\
\hline ORG_WOHL & 0,0669 & 0,0522 & 0,0519 & 0,0205 & 0,0271 & $-0,0136$ \\
\hline PERS_GLAUB & $0,1906^{* * *}$ & 0,1325 & 0,0993 & 0,0683 & 0,0548 & 0,0277 \\
\hline PERS_WOHL & $0,1859^{* * *}$ & $0,1702^{* *}$ & $0,1934^{* * *}$ & $0,1741^{* *}$ & $0,1623 * *$ & 0,1351 \\
\hline ORG_GEB & $-0,2319^{* * *}$ & $-0,1408$ & $-0,1393$ & $-0,1688^{* *}$ & $-0,0725$ & $-0,1087$ \\
\hline ORG_VER & 0,0796 & 0,0897 & 0,0221 & $-0,0065$ & 0,0605 & 0,0345 \\
\hline PERS_VER & 0,0763 & 0,0786 & 0,0697 & 0,0755 & 0,0673 & 0,0771 \\
\hline PERS_VER_WOHL & 0,1189 & 0,1228 & 0,1224 & 0,1208 & 0,1090 & 0,1069 \\
\hline
\end{tabular}

Tab. B-75: Bivariate und partielle Korrelationen der verhaltenswissenschaftlichen Variablen mit dem Zinssatz nach Bereinigung der Effekte der Finanzkennzahlen ${ }^{1420}$

Ferner wurde im Rahmen der Korrelationsanalysen der verhaltenswissenschaftlichen Faktoren mit den beziehungsbezogenen Variablen gezeigt, dass insbesondere hohe Korrelationen der Variablen HAUSBANK_K, DAU_BEZ_ERR, ANT_BANK_IN und ANZ_BER_J mit den Faktoren besteht. Eine Bereinigung um die Einflüsse dieser Faktoren führt jedoch nicht zu einer Änderung der Signifikanz der Korrelationen mit dem Zinssatz (vgl. Tab. B-76). Es scheint über den Effekt der Kontrollvariablen hinaus eine Interdependenz mit dem Zinssatz zu bestehen.

\begin{tabular}{|l|r|r|r|r|r|}
\hline Kontrollvariablen & - & $\begin{array}{c}\text { HAUS } \\
\text { BANK K }\end{array}$ & $\begin{array}{c}\text { DAU_BEZ_ } \\
\text { ERR }\end{array}$ & $\begin{array}{c}\text { ANT_ } \\
\text { BANK_IN }\end{array}$ & ANZ_BER_J \\
\hline ORG_GLAUB & $0,2760^{* * *}$ & $0,2719^{* * *}$ & $0,2631^{* * *}$ & $0,2886^{* * *}$ & $0,2760^{* * *}$ \\
\hline ORG_WOHL & 0,0669 & 0,0695 & 0,0700 & 0,1311 & 0,0831 \\
\hline PERS_GLAUB & $0,1906^{* * *}$ & $0,1836^{* *}$ & $0,1777^{* *}$ & $0,1856^{* *}$ & $0,1898^{* * *}$ \\
\hline PERS_WOHL & $0,1859^{* * *}$ & $0,1996^{* * *}$ & $0,1869^{* *}$ & $0,2407^{* * *}$ & $0,2106^{* * *}$ \\
\hline ORG_GEB & $-0,2319^{* * *}$ & $-0,2380^{* * *}$ & $-0,2024^{* * *}$ & $-0,2048^{* * *}$ & $-0,2301^{* * *}$ \\
\hline ORG_VER & 0,0796 & 0,0361 & 0,0250 & 0,0761 & 0,0517 \\
\hline PERS_VER & 0,0763 & 0,0703 & 0,0699 & $0,1490^{* *}$ & 0,0833 \\
\hline PERS_VER_WOHL & 0,1189 & 0,1303 & 0,1208 & $0,2004^{* *}$ & 0,1427 \\
\hline
\end{tabular}

Tab. B-76: Bivariate und partielle Korrelationen der verhaltenswissenschaftlichen Variablen mit dem Zinssatz nach Bereinigung beziehungsbezogener Effekte

Unter der Annahme, dass der Faktor organisationale Glaubwürdigkeit auch auf die anderen Faktoren ausstrahlt, wurde eine Bereinigung des Einflusses um diesen Faktor

1420 Dem Anhang 5, Tab. AN 5-1 können die partiellen Korrelationen für die Kontrollvariablen UMSATZ und TSC_QA_AGG entnommen werden. 
vorgenommen (vgl. Tab. B-77). Bei einer nicht möglichen Trennung zwischen Organisation und Person müssten die Effekte aus der personalen Glaubwürdigkeit eliminiert werden. Ferner ist es denkbar, dass Glaubwürdigkeit die Voraussetzung für die Wahrnehmung des Wohlwollens ist. Nach Bereinigung um diesen Effekt weist allein die organisationale Gebundenheit signifikante Korrelationen zum Zinssatz auf.

\begin{tabular}{|l|r|r|}
\hline Kontrollvariablen & \multicolumn{1}{|c|}{-} & ORG_GLAUB \\
\hline ORG_WOHL & 0,0669 & $-0,0481$ \\
\hline PERS_GLAUB & $0,1906^{* * *}$ & 0,0095 \\
\hline PERS_WOHL & $0,1859^{* * *}$ & 0,1267 \\
\hline ORG_GEB & $-0,2319^{* * *}$ & $-0,1473 * *$ \\
\hline ORG_VER & 0,0796 & $-0,0138$ \\
\hline PERS_VER & 0,0763 & $-0,0236$ \\
\hline PERS_VER_WOHL & 0,1189 & 0,0292 \\
\hline
\end{tabular}

Tab. B-77: Bivariate und partielle Korrelationen der verhaltenswissenschaftlichen Variablen mit dem Zinssatz

Neben den unternehmens- und beziehungsbezogenen Aspekten sind aber auch Einflüsse, die aus der Person des Firmenkundenbetreuers sowie Einflüsse die aus Bankvorgaben und dem Bankumfeld resultieren, zu berücksichtigen. Ein erhöhter Ausbildungsstand des Firmenkundenbetreuers, ein größerer Marktanteil im Firmenkundengeschäft, eine wertorientierte Vergütung des Firmenkundenbetreuers sowie die Durchführung einer risikoorientierten Bepreisung stehen im Zusammenhang mit niedrigeren Zinsen, wohingegen die Nichtexistenz einer leistungsorientierten Vergütung im Zusammenhang mit höheren Zinssätzen steht (vgl. Tab. B-78). Zwischen der Ausbildung des Firmenkundenbetreuers, der Vergütung des Firmenkundenbetreuers sowie der Praktizierung der risikoorientierten Bepreisung bestehen hohe Korrelationen und ein hoher inhaltlicher Zusammenhang. So weist die Variable FKB_STUD nach Integration der Variablen für die Vergütung keine signifikanten Korrelationen auf. Gleiches gilt bei der Korrektur der Korrelation der Variablen LEI_WERT_FKB um den Einfluss der Variablen FKB_STUD. Eine Aussage hinsichtlich Ursache und Wirkung erscheint zumindest in Bezug auf Vergütungsstrukturen und Ausbildung nicht möglich. Der denkbare Erklärungsansatz, dass Firmenkundenbetreuer mit abgeschlossenem Studium eher in größeren Banken mit professionelleren Strukturen arbeiten und diese Banken eher eine risikoorientierte Bepreisung praktizieren, kann anhand dieser Analysen nicht bestätigt werden. Weder die risikoorientierte Bepreisung noch der Abschluss eines Studiums weist signifikante Korrelationen zur Bilanzsumme der Bank auf. 


\begin{tabular}{|l|r|r|r|r|r|r|}
\hline Kontrollvariablen & - & FKB_STUD & $\begin{array}{c}\text { LEI_WERT } \\
\text { FKB }\end{array}$ & $\begin{array}{c}\text { MARKTAN } \\
\text { FK }\end{array}$ & LEI_KEIN & $\begin{array}{r}\text { RISIKO } \\
\text { BEPREIS }\end{array}$ \\
\hline FKB_JÜ30 & $-0,1194$ & $-0,0885$ & $-0,1100$ & $-0,0617$ & $-0,1208$ & $-0,1080$ \\
\hline FKB_30_50 & 0,1255 & 0,1203 & $0,1387 * *$ & 0,0956 & 0,1180 & $0,1483^{* *}$ \\
\hline FKB_ÜB50 & $-0,0670$ & $-0,0821$ & $-0,0878$ & $-0,0702$ & $-0,0588$ & $-0,0996$ \\
\hline FBK_BANK & 0,0413 & 0,0413 & 0,0513 & 0,0603 & 0,0521 & 0,0310 \\
\hline FKB_BERUF_ST & $-0,0411$ & $-0,0488$ & $-0,0235$ & $-0,0401$ & $-0,0239$ & $-0,0465$ \\
\hline FKB_STUD & $-0,1387^{* *}$ & & $-0,1198$ & $-0,1362$ & $-0,1264$ & $-0,1213$ \\
\hline MARKTAN_GES & $-0,1213$ & $-0,1257$ & $-0,0732$ & 0,0336 & $-0,0713$ & $-0,1287$ \\
\hline MARKTAN_FK & $-0,1602^{* *}$ & $-0,1539 *$ & $-0,0974$ & & $-0,1023$ & $-0,1519 * *$ \\
\hline UMFELD_LÄND & 0,0247 & 0,0195 & 0,0384 & 0,0677 & 0,0253 & $-0,0038$ \\
\hline UMFELD_LÄSTÄ & 0,0159 & 0,0210 & 0,0114 & 0,0104 & 0,0140 & 0,0263 \\
\hline UMFELD_STÄ & $-0,0500$ & $-0,0508$ & $-0,0613$ & $-0,0958$ & $-0,0488$ & $-0,0295$ \\
\hline LEI_WERT_FKB & $-0,1779 * *$ & $-0,0766$ & & $-0,1298$ & $-0,0813$ & $-0,1543^{* *}$ \\
\hline LEI_WERT_BA & $-0,0660$ & $-0,1637 * *$ & $-0,0731$ & $-0,0513$ & $-0,0089$ & $-0,0535$ \\
\hline LEI_VOL & $-0,0602$ & $-0,0689$ & 0,0187 & $-0,0168$ & 0,0155 & $-0,0366$ \\
\hline LEI_AKT & $-0,0207$ & $-0,0320$ & 0,0380 & 0,0297 & 0,0732 & 0,0065 \\
\hline LEI_KEIN & $0,1689 * *$ & $0,1562 * *$ & 0,0504 & 0,1174 & & 0,1354 \\
\hline RISIKO_BEPREIS & $-0,1551^{* *}$ & $-0,1330$ & $-0,1197$ & $-0,1446 * *$ & $-0,1133$ & \\
\hline BIL_BA & $-0,0515$ & $-0,0278$ & $-0,0405$ & $-0,0448$ & $-0,0459$ & $-0,0168$ \\
\hline
\end{tabular}

Tab. B-78: Bivariate und partielle Korrelationen der bankbezogenen Variablen

Nach Durchführung einer umfänglichen Korrelationsanalyse wird im Folgenden nun eine Regressionsanalyse in Bezug auf den Zinssatz durchgeführt. Zunächst erfolgt die Beschreibung der Methodik und der verwendeten Gütemaße.

\subsubsection{Beschreibung der Regressionsanalyse}

Nach Durchführung der Korrelationsanalyse wird für den Konditionsparameter Zinssatz eine Regressionsanalyse vorgenommen. In Ergänzung zu den bisherigen Analysen wird nun geprüft, ob die Determinanten der univariaten Analyse auch im multivariaten Kontext, d.h. unter Berücksichtigung der Interdependenzen zwischen den Determinanten selbst, einen systematischen Einfluss auf den Zinssatz haben. Bei der Regressionsanalyse wird eine Wirkungsrichtung angenommen, so dass hier eine gerichtete Beziehung oder ein asymmetrischer Zusammenhang untersucht wird. ${ }^{1421}$ Die Regressionsanalyse kann nur lineare Zusammenhänge abbilden, d.h. es wird immer eine lineare Beziehung zwischen der bzw. den erklärenden Variablen und der abhängigen Variablen unterstellt. Allerdings können durch Logarithmierung auch nicht-lineare Zusammenhänge abgebildet werden. ${ }^{1422}$ Zielsetzung der folgenden empirischen Untersuchung ist die Beantwortung der nachstehenden Fragestellungen: ${ }^{1423}$

\footnotetext{
1421 Vgl. Diaz-Bone (2006), S. 64.

1422 Vgl. Brosius (2002), S. 530. Dieser Möglichkeit wurde bspw. für die diversen Finanzkennzahlen, das Alter des Unternehmens und die Beziehungsdauern genutzt. 
- Wie verhält sich der Einfluss der unabhängigen Variablen in einem multivariaten Kontext?

- Welchen Anteil der Schwankungen der abhängigen Variablen können die unabhängigen Variablen erklären?

- Wie stark ist der Einfluss der verschiedenen unabhängigen Variablen auf die abhängige Variable?

Nachstehend beschriebene Voraussetzungen müssen bei Durchführung der Regressionsanalyse erfüllt sein. Die Residuen einer Regressionsschätzung sollten zufällig auftreten und einer Normalverteilung folgen ${ }^{1424}$ Wenn selbiges nicht gegeben ist, dann ist die Berechnung der Signifikanz der Regressionskoeffizienten der unabhängigen Variablen verzerrt und nicht mehr gültig. Zu diesem Zweck wurde eine visuelle Prüfung hinsichtlich der Normalverteilung vorgenommen. ${ }^{1425}$ Als zweite Voraussetzung sollte erfüllt sein, dass die Residuen keine Autokorrelation aufweisen. Die Prüfung kann mit Hilfe des Durbin-Watson-Tests durchgeführt werden. Im Rahmen des Durbin-WatsonTests sind Werte zwischen 0 und 4 möglich, je näher die Werte an 2 liegen, desto besser ist dies für die Regressionsanalyse. Werte zwischen 1,5 und 2,5 gelten als akzeptabel, wohingegen bei Werten unter 1 oder über 3 eine starke Autokorrelation vorliegt. ${ }^{1426}$ Es wird an dieser Stelle vorweggenommen, dass in allen verwendeten Regressionen die Werte in der Bandbreite von 1,5 und 2,5 liegen. Die Werte werden jeweils bei den Auswertungsergebnissen ausgewiesen, es wird aber nicht weiter darauf eingegangen. Ferner darf keine Multikollinearität der unabhängigen Variablen vorliegen. ${ }^{1427}$ Bei empirischen Daten besteht häufig ein gewisser Grad an Multikollinearität, dies wird aber erst dann zum Problem, wenn eine starke lineare Abhängigkeit besteht. ${ }^{1428}$ Die Multikollinearität steigt, je mehr miteinander korrelierte Variablen in der Regression enthalten sind. ${ }^{1429}$ Bei perfekter Korrelation der Variablen kann die Regressionsgleichung nicht eindeutig geschätzt werden. Von zwei Variablen mit hohem statistischem und inhaltlichem Zusammenhang sollte nur eine verwendet werden. Hierzu werden die Erkenntnisse der bivariaten Korrelationsanalyse aus Kapitel B.3.4.2.1 berücksichtigt. Es resultiert allerdings das Problem, welche Variable ausgeschlossen werden soll. Hier wird im weiteren Verlauf eine fallweise, auf inhaltlichen Kriterien beruhende Entscheidung getroffen. Schließlich muss die Homoskedastizität, d.h. die Varianzgleichheit, der Regressionsresiduen gegeben sein. ${ }^{1430} \mathrm{Wenn}$ diese nicht gegeben ist, dann ist die Berechnung der Signifikanz der Regressionskoeffizienten der unabhängigen Variablen verzerrt und nicht mehr gültig und die Effizienz der Modellschätzung nicht gegeben. Die Erfüllung dieser Voraussetzung erfolgte durch visuelle Prüfung.

\footnotetext{
1424 Vgl. Brosius (2002), S. 553 oder Backhaus et al. (2006), S. 32.

1425 Vgl. Flacke (2007), S. 213.

1426 Vgl. Brosius (2002), S. $558 \mathrm{f}$.

1427 Vgl. Berekhoven/Eckert/Ellenrieder (2001), S. 209.

1428 Vgl. Backhaus et al. (2006), S. 33.

1429 Vgl. Berekhoven/Eckert/Ellenrieder (2001), S. 209.

1430 Vgl. Backhaus et al. (2006), S. 35.
} 
Die Güte der Regressionsgleichung kann durch verschiedene Maße beurteilt werden. Das Bestimmtheitsmaß $\mathrm{R}^{2}$ gibt die Relation zwischen der Quadratsumme der erklärten Streuung und der Quadratsumme der gesamten Streuung an. ${ }^{1431}$ Ein $\mathbf{R}^{2}$ von über 0,60 gilt als zufriedenstellend. ${ }^{1432}$ Bei dem korrigierten $\mathrm{R}^{2}$ wird die Anzahl der bei der Schätzung verwendeten erklärenden Variablen berücksichtigt. ${ }^{1433}$ Im weiteren Verlauf der Arbeit werden aber auch die jeweiligen $\mathrm{R}^{2}$ anderer, vergleichbarer Studien ausgewiesen, um den Erklärungsgehalt der in dieser Arbeit durchgeführten Regressionen zu beurteilen. Der F-Wert liefert als weiteres Gütemaß eine Beurteilung der Signifikanz der gesamten Regressionsgleichung. ${ }^{1434}$ Neben dem gesamten Modell sind aber auch die einzelnen Regressionskoeffizienten der einzelnen erklärenden Variablen hinsichtlich des theoretisch erwarteten Zusammenhangs zu bewerten. Damit der Erklärungsgehalt der einzelnen Variablen miteinander verglichen werden kann, werden nicht nur die Regressionskoeffizienten, sondern auch die standardisierten Koeffizienten, so genannte Beta-Koeffizienten, betrachtet. ${ }^{1435}$ Der Vergleich der BetaKoeffizienten ist nur dann zulässig, wenn die unabhängigen Variablen nicht miteinander korreliert sind. ${ }^{1436}$ Der standardisierte Regressionskoeffizient ist dimensionslos und ermöglicht den Vergleich der Effektstärken der unabhängigen Variablen eines Regressionsmodells untereinander. Allerdings gibt es für die standardisierten Regressionskoeffizienten keine anschauliche Interpretation. ${ }^{1437}$ Ferner ist die Signifikanz der Regressionskoeffizienten zu prüfen. Häufig wird ein Mindestwert von 0,05 gefordert. ${ }^{1438}$

Hinsichtlich der Auswahl der in der Regressionsgleichung zu berücksichtigenden Variablen werden zwei Methoden angewendet: das Einschlussverfahren und die schrittweise Regression. Bei dem Einschlussverfahren werden alle ausgewählten unabhängigen Variablen in die Regressionsgleichung aufgenommen. ${ }^{1439}$ Bei der schrittweisen Regression erfolgt zunächst eine Regression mit derjenigen unabhängigen Variablen, die am stärksten mit der abhängigen Variablen korreliert. ${ }^{1440}$ Mit jedem weiteren Schritt wird geprüft, durch welche weitere Variable das Vorhersagepotenzial, d.h. $\mathrm{R}^{2}$, maximal erhöht werden kann. Die Variablen werden bei jedem Schritt auf Ausschluss oder Aufnahme hinsichtlich der jeweiligen Signifikanzniveaus geprüft. ${ }^{.411}$ Der Prüfprozess endet dann, wenn für keine Variable mehr die Notwendigkeit des Ausschlusses und für keine Variable mehr die Möglichkeit der Aufnahme existiert. Während bei dem Einschlussverfahren jeweils die Signifikanz der Regressionskoeffizienten ausgewiesen wird, wird bei der schrittweisen Regression gemäß dem in der Literatur

\footnotetext{
1431 Vgl. Brosius (2002), S. 533, Urban/Mayerl (2006), S. 56.

1432 Vgl. Urban/Mayerl (2006), S. 59.

1433 Vgl. Brosius (2002), S. 545.

1434 Vgl. Berekhoven/Eckert/Ellenrieder (2001), S. 208.

1435 Vgl. Brosius (2002), S. 553.

1436 Vgl. Brosius (2002), S. 553.

1437 Vgl. Diaz-Bone (2006), S. 193.

1438 Vgl. Brosius (2002), S. 547.

1439 Vgl. Brosius (2002), S. 568.

1440 Vgl. Bortz (2005), S. 447 f.

144] Vgl. Brosius (2002), S. 569.
} 
geforderten Mindestwert eine Grenze von 5\% für die Aufnahme neuer Variabeln definiert.

\subsubsection{Durchführung der Regressionsanalyse}

Im folgenden Kapitel wird analysiert, wie sich der Einfluss der unabhängigen Variablen im multivariaten Kontext in Bezug auf den Zinssatz verhält und welchen Anteil der Schwankung des Zinssatzes die unabhängigen Variablen erklären können.

Im theoretischen Teil der Arbeit wurden drei wesentliche Einflussbereiche in Bezug auf den Kreditzins herausgearbeitet: rechtliche Vorschriften bzw. etwas darüberhinausgehend, losgelöst von diesen rechtlichen Vorschriften eine risikoadjustierte Bepreisung, die Einflüsse aus dem Bereich der Relationship Banking-Forschung sowie diejenigen Einflüsse, die sich aus verhaltenswissenschaftlichen Ansätzen ergeben (vgl. Abb. B-25). Diese drei zentralen Einflussbereiche werden im Rahmen der weiteren Untersuchung sukzessive analysiert mit dem Fokus auf den verhaltenswissenschaftlichen Ansätzen. Während sich der Einfluss der rechtlichen Vorgaben und der risikoadjustierten Bepreisung primär über Ratingklasse und weitere Finanzkennzahlen auswirkt, finden sich die Relationship Banking-Ansätze vornehmlich in den beziehungsbezogenen Variablen wieder.

In Kapitel A.3.3 wurde ausführlich erläutert, dass bei Anwendung der risikoorientierten Bepreisung ein Zusammenhang zwischen der Ausfallwahrscheinlichkeit des Unternehmens und den Kreditkonditionen bestehen sollte. In den MaRisk ist dieser $\mathrm{Zu}-$ sammenhang lediglich in Form einer Sollte-Bestimmung verankert. ${ }^{142}$ Aufgrund dieser Vorgaben wird der Einfluss der Finanzkennzahlen besonders ausführlich untersucht.

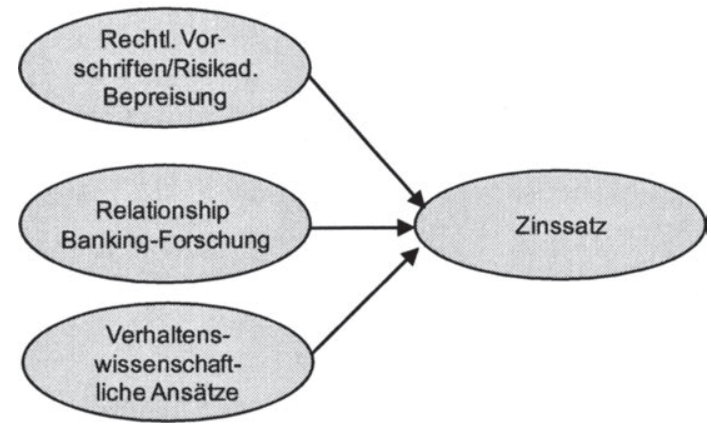

Abb. B-25: Zentrale Einflussbereiche in Bezug auf den Kreditzins

Unter der Annahme, dass der Kontokorrentzins ausschließlich nach den Gesichtspunkten einer risikoadjustierten Bepreisung ermittelt wird, ergäbe sich - basierend auf den Ausführungen zu den Komponenten des Zinssatzes in Kapitel A.3.3 - nachstehend 
beschriebener Zusammenhang, so dass die beziehungsbezogenen und verhaltenswissenschaftlichen Variablen keinerlei Auswirkung haben:

$\begin{aligned} \text { Zinssatz Kontokorrent }= & \beta_{1} \cdot \text { risikoloser Zins } \\ & \beta_{2} \cdot \text { EK-Kosten (in \%) für unerwart. Verlust aus Kunden- } \\ & \text { geschäft }+ \\ & \beta_{3} \cdot \text { Refinanzierungskosten (in \%) }+ \\ & \beta_{4} \cdot \text { erwarteter Verlust aus Kundengeschäft (in \%) }+ \\ & \beta_{5} \cdot \text { Standardbetriebskosten (in \%) }+ \\ & \beta_{6} \cdot \text { Gewinnmarge der Bank (in \%) }+ \\ & \beta_{7} \cdot \text { Residuen, }\end{aligned}$

wobei sich der erwartete Verlust aus der Multiplikation der Ausfallwahrscheinlichkeit des Kunden mit seinem Blankoanteil ergibt. Für die unerwarteten Verluste einer Bank muss Eigenkapital vorgehalten werden. Das zu hinterlegende Eigenkapital wird mit einem der in Kapitel A.3.1.2.1 beschriebenen Verfahren ermittelt. In Abhängigkeit vom verwendeten Verfahren handelt es sich auch bei den Eigenkapitalkosten um eine kundenindividuelle Kostenkomponente. Bei Verwendung des Standardansatzes stellt ausschließlich der erwartete Verlust und bei Verwendung eines IRB-Ansatzes stellen der erwartete Verlust sowie die Eigenkapitalkosten eine kundenindividuelle Komponente dar. Wenn die Banken den IRB-Ansatz anwenden, sind sie zur Ermittlung eines kundenindividuellen Ratings und zur Hinterlegung der Forderung mit Eigenkapital verpflichtet, wobei die Höhe des zu hinterlegenden Eigenkapitals und somit die resultierenden Kosten von dem Rating abhängen. ${ }^{1443}$ Basierend auf der Annahme, dass alle obigen Parameter mit Ausnahme der kundenindividuellen Parameter in der vorliegenden Studie konstant sind, müsste der Zinssatz weitestgehend durch den erwarteten Verlust in Prozent determiniert werden. Unter der Annahme, dass alle Kostenkomponenten exakt an die Kunden weitergegeben werden, würden die Koeffizienten $B_{1}$ bis $B_{6}$ jeweils eins betragen. Wie die Ergebnisse in Tab. B-79 zeigen, können aber weder der erwartete Verlust noch die Ausfallwahrscheinlichkeit oder die Kombination aus Ausfallwahrscheinlichkeit und Besicherungsquote den Zinssatz erklären. Das korrigierte $\mathrm{R}^{2}$ liegt zwischen $1,89 \%$ und $7,61 \%$. Die Untersuchungsergebnisse deuten daraufhin, dass keine vollständig risikoorientierte Bepreisung praktiziert wird. Die Vorzeichen hinsichtlich des erwarteten Verlusts und hinsichtlich der Ausfallwahrscheinlichkeit sind erwartungsgemäß positiv. Bei Annahme der risikoorientierten Bepreisung wäre bei der Sicherheitenquote ein negatives Vorzeichen zu erwarten. Unter Bezugnahme auf die in Kapitel A.4.3.1.2.1 dargelegten Funktionen von Sicherheiten unterstützt ein positives Vorzeichen den Ansatz der Anreizfunktion und nicht der Signalling-Funktion von Sicherheiten. ${ }^{1444}$ Bonitätsmäßig schlechte Kunden müssen mehr Sicherheiten stellen. Allerdings ist der Koeffizient nicht signifikant.

1443 Vgl. hierzu ausführlich Kapitel A.3.1.2.1.

1444 Vgl. zur Funktion von Sicherheiten ausführlich Kapitel A.4.3.1.2.1. 


\begin{tabular}{|c|c|c|c|c|c|c|}
\hline \multirow[b]{2}{*}{ Einflussgröße } & \multicolumn{2}{|c|}{ Regression 1} & \multicolumn{2}{|c|}{ Regression 2} & \multicolumn{2}{|c|}{ Regression 3} \\
\hline & Beta & $\begin{array}{c}\text { Beta } \\
\text { stand. }\end{array}$ & Beta & $\begin{array}{c}\text { Beta } \\
\text { stand. }\end{array}$ & Beta & $\begin{array}{l}\text { Beta } \\
\text { stand. }\end{array}$ \\
\hline Konstante & 10,2720 & & 10,0321 & & 9,9363 & \\
\hline EL & 0,3000 & $0,1541^{* *}$ & & & & \\
\hline AUSFALLW B & & & 0,3217 & $0,2814^{* * * *}$ & 0,3194 & $0,2809^{* * *}$ \\
\hline SICH Q & & & & & 0,0021 & 0,0472 \\
\hline $\mathbf{R}$ & & 0,1536 & & 0,2814 & & 0,2916 \\
\hline R-Quadrat & & 0,0236 & & 0,0792 & & 0,0851 \\
\hline Korrigiertes $\mathbf{R}^{2}$ & & 0,0189 & & 0,0748 & & 0,0761 \\
\hline Signifikanz F-Test & & 0,0268 & & 0,0000 & & 0,0000 \\
\hline Durbin-Watson & & 1,8850 & & 2,0308 & & 2,0579 \\
\hline $\mathbf{N}$ & & 208 & & 208 & & 208 \\
\hline
\end{tabular}

Tab. B-79: Regression der Parameter der risikoorientierten Bepreisung ${ }^{1445}$

In Anlehnung an die in Kapitel B.3.4.2.1 beschriebenen, verschiedenen denkbaren Zusammenhänge der Finanzkennzahlen mit dem Zinssatz ist das weitere Vorgehen wie folgt. Es wird zunächst untersucht, inwiefern die Finanzkennzahlen alleine oder eine Kombination aus Finanzkennzahlen und Ratingergebnissen einen besseren Erklärungsgehalt liefern. Im Anschluss daran werden die unternehmensbezogenen sowie die beziehungsbezogenen Variablen isoliert und in Kombination mit den Ergebnissen aus der Regression mit den Finanzkennzahlen analysiert. Schließlich werden die verhaltenswissenschaftlichen Variablen wiederum isoliert und in Kombination mit den vorherigen Regressionen analysiert. Es werden jeweils die Ergebnisse mit dem höchsten Erklärungsgehalt in den weiteren Analysen verwendet. Das Vorgehen ist deshalb erforderlich, weil insbesondere im Bereich der Finanzkennzahlen ex ante, z.B. auf Basis eines Literaturstudiums, keine Ableitung sinnvoller Kennzahlen erfolgen kann. Bei der Verwendung der Finanzkennzahlen können bspw. genossenschaftliche Besonderheiten zum Tragen kommen, weil die Firmenkundenbetreuer durch gemeinsame Seminare geprägt sind, in denen spezielle Kennzahlen als relevant erachtet wurden.

Im nächsten Schritt wird eine Regressionsanalyse mit den originären Finanzkennzahlen durchgeführt. ${ }^{146}$ Bei dieser Analyse wird folgerichtig berücksichtigt, dass sich die Kreditbepreisung unter Umständen nicht an der Ausfallwahrscheinlichkeit orientiert, sondern dass die Firmenkundenbetreuer die originären Finanzkennzahlen zugrunde legen, weil diese aus Sicht der Firmenkundenbetreuer möglicherweise transparenter sind als die aus statistischen Verfahren abgeleiteten Ratingkennzahlen. Eine systematische Auswahl ist deswegen schwierig, weil die Auswahl der Kennzahlen möglicherweise von den zuvor erwähnten gemeinsamen Seminaren oder von Erfahrungskreisen

1445 Selbst bei einer Differenzierung nach Firmenkundenbetreuern, die eine risikoorientierten Bepreisung in ihrer Bank angegeben haben vs. Firmenkundenbetreuer, die keine risikorientierte Bepreisung angegeben haben, schwanken die Werte für das korrigierte $R^{2}$ nur gering. Bei dem erwarteten Verlust bspw. liegen die Werte bei 0,0248 und bei 0,0252. Das Ergebnis ist dahingehend erstaunlich, als dass der Wert bei angenommener risikoorientierter Bepreisung sogar geringfügig niedriger ist.

1446 Es erfolgt ein listenweiser Fallausschluss. 
bzw. Fortbildungen an der genossenschaftlichen Akademie abhängt und diese Mechanismen nicht bekannt sind. Aus diesem Grund wurden zunächst die Kennzahlen ausgewählt, die im univariaten Kontext hohe signifikante Korrelationen mit dem Zinssatz, d.h. eine absolute Korrelation größer 0,25, aufgewiesen haben. Da sowohl bei der Variablen BILANZS als auch bei der Variablen UMSATZ hohe bivariate Korrelationen mit dem Zinssatz vorliegen und diese beiden Variablen untereinander ebenfalls hohe Korrelationen aufweisen, wird mit der Variablen BILANZS die Variable mit der größeren Korrelation zum Zinssatz berücksichtigt. Aufgrund der Korrelationen zwischen Verbindlichkeiten und der Eigenkapitalquote wurde hier ebenfalls stets nur eine der beiden Variablen in der Regression berücksichtigt. Ferner wurde bei hohen Korrelationen der Kennzahlen, wie z.B. zwischen den relativen und den absoluten Verbindlichkeiten, die Kennzahl mit der höheren Korrelation ausgewählt. Die Regression auf Basis von logarithmierten Größen führte immerhin $\mathrm{zu}$ einem korrigierten $\mathbf{R}^{2}$ von 0,1308 (vgl. Tab. B-80, Regression 1). Da dieses Vorgehen aber noch nicht zu zufriedenstellenden Ergebnissen führte, wurden im nächsten Schritt ausschließlich nichtlogarithmierte Größen verwendet, wobei wiederum die Kennzahlen mit den höchsten Korrelationskoeffizienten verwendet wurden. Diese Regression weist ein korrigiertes $\mathrm{R}^{2}$ von 0,1892 auf (vgl. Tab. B-80, Regression 2). Zwar hat die Bilanzsumme den größten Beta-Koeffizienten, jedoch ist dieser ebenso wie der Koeffizient für die Variablen VERB_KI_LANG_A und VERM_LA_A nicht signifikant. ${ }^{1447}$ Die Kennzahl UMIND $^{1448}$ weist bei Betrachtung des Beta-Koeffizienten ebenfalls einen erheblichen und zugleich auch auf dem geforderten 5\%-Niveau einen signifikanten Einfluss auf. Allerdings sind diese Ergebnisse nur für Unternehmen zutreffend, für welche die Kennzahl „Umschlagshäufigkeit Industrie“ (UMND) ermittelt werden kann. Die Datenbasis umfasst lediglich 92 Unternehmen. Für Dienstleistungsunternehmen und Handelsunternehmen kann die Kennzahl in aller Regel nicht ermittelt werden, da selbige keinen Materialaufwand haben. Bei Verzicht auf die Kennzahl UMIND kann ein guter Erklärungsbeitrag erzielt werden, wenn die Kennzahl langfristiges Vermögen (VERM_LA_A), Bilanzsumme (BILANZS) und Eigenkapitalquote (EKQ) verwendet werden (vgl. Tab. B-80, Regression 3). Sowohl die Bilanzsumme als auch die Eigenkapitalquote weisen statistisch und ökonomisch signifikante Einflüsse auf. Eine Erhöhung der Bilanzsumme um 1 Mio. EUR führt zu einer Zinsreduktion von 0,1 Prozentpunkten und die Erhöhung der Eigenkapitalquote um 10 Prozentpunkte führt zu einer vergleichbar hohen Zinsreduktion um 0,09 Prozentpunkte.

1447 Aufgrund der hohen Korrelationen und der daraus resultierenden Multikollinearität zwischen BILANZS, VERB_KI_LANG_A und VERM_LA_A ist eine isolierte Interpretion der Koeffizienten möglicherweise nicht korrekt. Vgl. hierzu auch Kapitel B.3.4.2.2.

1448 Die Kennzahl UMIND ist die Relation aus Materialaufwand zu Roh-, Hilfs- und Betriebsstoffen. 


\begin{tabular}{|c|c|c|c|c|c|c|}
\hline \multirow[b]{2}{*}{ Einflussgröße } & \multicolumn{2}{|c|}{ Regression 1} & \multicolumn{2}{|c|}{ Regression 2} & \multicolumn{2}{|c|}{ Regression 3} \\
\hline & Beta & $\begin{array}{r}\text { Beta } \\
\text { stand. }\end{array}$ & Beta & $\begin{array}{l}\text { Beta } \\
\text { stand. }\end{array}$ & Beta & $\begin{array}{l}\text { Beta } \\
\text { stand. }\end{array}$ \\
\hline Konstante & 15,4037 & & 10,8841 & & 10,8826 & \\
\hline VERB_KI LANG_A & & & $-0,0001$ & $-0,0323$ & & \\
\hline VERM LA A & & & 0,0000 & $-0,0514$ & $-0,0001$ & $-0,1394$ \\
\hline BILANZS & & & $-0,0001$ & $-0,3130$ & $-0,0001$ & $-0,2286 * *$ \\
\hline UMIND & & & $-0,0004$ & $-0,2251^{* *}$ & & \\
\hline VERB_KI_A_LN & $-0,2337$ & $-0,2122 * *$ & & & & \\
\hline VERM LA A LN & $-0,1215$ & $-0,1238$ & & & & \\
\hline KASSE_A_LN & $-0,1295$ & $-0,1430$ & & & & \\
\hline BILANZS LN & $-0,0396$ & $-0,0308$ & & & & \\
\hline EKQ & & & & & $-0,0090$ & $-0,2093^{* * *}$ \\
\hline $\mathbf{R}$ & & 0,3889 & & 0,4737 & & 0,4343 \\
\hline R-Quadrat & & 0,1512 & & 0,2244 & & 0,1886 \\
\hline Korrigiertes $\mathbf{R}^{2}$ & & 0,1308 & & 0,1892 & & 0,1769 \\
\hline Signifikanz F-Test & & 0,0000 & & 0,0002 & & 0,0000 \\
\hline Durbin-Watson & & 2,0749 & & 2,1608 & & 1,9877 \\
\hline $\mathbf{N}$ & & 211 & & 92 & & 211 \\
\hline
\end{tabular}

Tab. B-80: Regression der Finanzkennzahlen (1)

Zwar können mit Hilfe des Einschlussverfahrens durch gezielte Auswahl der auf Basis der Korrelationsanalyse als relevant erachteten Kennzahlen erste gute Ergebnisse erzielt werden. Aufgrund der vermuteten hohen Bedeutung der Finanzkennzahlen soll aber mittels der schrittweisen Regression versucht werden, zusätzliche Erkenntnisse zu gewinnen. Die Ergebnisse der schrittweisen Regression werden jeweils mit dem Einschlussverfahren validiert. ${ }^{1449}$ Zunächst wurde eine schrittweise Regression unter Berücksichtigung aller erhobenen Finanzkennzahlen vorgenommen, wobei ein listenweiser Fallausschluss verwendet wurde und die Kennzahlen mit untereinander hohen Korrelationen ausgeschlossen worden sind. Bei Betrachtung der kleinen Datenbasis wird durch die Unternehmensgröße - gemessen am logarithmierten Umsatz - der Zinssatz am Besten erklärt, so dass ein korrigiertes $\mathrm{R}^{2}$ von 0,3597 (vgl. Tab. B-81, Regression 1) erreicht wird. Ferner ist auch der Koeffizient statistisch signifikant. Die Berücksichtigung der beiden Kennzahlen Umschlagshäufigkeit Handel und Umschlagshäufigkeit Industrie führen allerdings bei dem listenweisen Fallausschluss wie auch zuvor bereits für UMIND erläutert - zu einer starken Reduktion der Datenbasis. Denn in Abhängigkeit der Branche kann in der Regel nur eine der beiden Kennzahlen berechnet werden, so dass die Ergebnisse dieser ersten Regression nicht als repräsentativ erachtet werden können. In der zweiten Regression wird bei Ausschluss dieser beiden Variablen ein korrigiertes $\mathrm{R}^{2}$ von 0,2905 erzielt (vgl. Tab. B-81, Regression 2). Selbiges ist somit etwas niedriger. Neben der Variablen EKQ wurde hier erneut mit der Kennzahl BILANZS ein Indikator für die Unternehmensgröße aufgenommen. Abschließend wurde noch eine Regression unter Einschluss der beiden Variablen BILANZS und EKQ durchgeführt. Der Wert für das korrigierte $\mathrm{R}^{2}$ ist bei die-

1449 Bei der schrittweisen Regression wurden als Grenzen für die F-Wahrscheinlichkeiten der einzelnen Variablen für die Aufnahme 5\% und für den Ausschluss 10\% festgelegt. 
ser Analyse mit 0,1669 deutlich schlechter. Der Unterschied in den Ergebnissen resultiert daraus, dass bei der schrittweisen Regression mehr Fälle ausgeschlossen worden sind und somit die Datenbasis geringer als bei Anwendung des Einschlussverfahrens ist.

Im nächsten Schritt wird mittels schrittweiser Regression geprüft, inwiefern bei der Zinsfestsetzung sowohl die im Rahmen des Ratings ermittelten Größen als auch die einzelnen Finanzkennzahlen herangezogen werden. Dazu werden neben den Finanzkennzahlen auch die Ausfallwahrscheinlichkeit und die beiden Teilscores bei der Regression berücksichtigt. Bei einer schrittweisen Regression können durch die beiden Variablen UMSATZ_LN und KREDZIEL 54,25\% der Varianz (vgl. Tab. B-82, Regression 1) erklärt werden. Aufgrund der geringen Stichprobengröße können diese Ergebnisse trotz der gegebenen Signifikanz aber nicht als repräsentativ angesehen werden. Werden die beiden Kennzahlen Umschlagshäufigkeit Handel und Umschlagshäufigkeit Industrie erneut aus der Analyse ausgeschlossen, so wird mit den beiden Variablen BILANZS_LN und AUSFALLW_B ein korrigiertes $\mathrm{R}^{2}$ von 0,2808 ermittelt (vgl. Tab. B-82, Regression 2). In beiden Rēgressionen sind die einzelnen Koeffizienten sowie die gesamte Regressionsgleichung signifikant. Allerdings ist die Datenbasis aufgrund der in die Analyse einbezogenen Teilscores, welche nicht für alle Kunden vorlagen, immer noch relativ gering. Eine Imputation der fehlenden Daten war bei den Teilscores nicht möglich, da hierzu der Ratingalgorithmus bekannt sein müsste. Aus diesem Grund wurde erneut eine Regression unter Einschluss der beiden Variablen BILANZS_LN und AUSFALLW_B durchgeführt, mit dem Ergebnis, dass das korrigierte $\mathrm{R}^{2}$ nunmehr lediglich $0,15 \overline{3} 8$ beträgt (vgl. Tab. B-82, Regression 3). ${ }^{1450}$ Diese Ergebnisse bestätigen somit die Erkenntnisse der partiellen Korrelationsanalyse aus Tab. B-72, denn nach Bereinigung um die Einflüsse der Bilanzsumme und der Ausfallwahrscheinlichkeit wies ausschließlich die Variable KASSE_A noch eine signifikante Korrelation mit dem Zinssatz auf. Der Einfluss der Variablen KASSE_A kann in der Regression allerdings nicht mehr bestätigt werden.

1450 Das Einschlussverfahren führte bei einer Regression nur mit den beiden Variablen UMSATZ_LN und KREDZIEL zu einem korrigierten $\mathbf{R}^{2}$ von 0,1063 . 


\begin{tabular}{|c|c|c|c|c|c|c|}
\hline \multirow[b]{2}{*}{ Einflussgrŏße } & \multicolumn{2}{|c|}{ Regression 1} & \multicolumn{2}{|c|}{ Regression 2} & \multicolumn{2}{|c|}{ Regression 3} \\
\hline & Beta & $\begin{array}{r}\text { Beta } \\
\text { stand. }\end{array}$ & Beta & $\begin{array}{r}\text { Beta } \\
\text { stand. }\end{array}$ & Beta & $\begin{array}{r}\text { Beta } \\
\text { stand. }\end{array}$ \\
\hline Konstante & 19,9085 & & 11,0076 & & 10,9078738 & \\
\hline UMSATZ LN & $-1,1692(1)$ & $-0,6236^{* * *}$ & & & & \\
\hline BIL.ANZS & & & $-0,0002(1)$ & $-0,4273^{* * *}$ & $-0,0002$ & $-0,3328^{* * *}$ \\
\hline EKQ & & & $-0,0148(2)$ & $-0,2776^{* * *}$ & $-0,0084$ & $-0,1956^{* * *}$ \\
\hline $\mathbf{R}$ & & 0,6235 & & 0,5523 & & 0,4181 \\
\hline R-Quadrat & & 0,3888 & & 0,3050 & & 0,1748 \\
\hline Korrigiertes $\mathrm{R}^{2}$ & & 0,3597 & & 0,2905 & & 0,1669 \\
\hline Signifikanz F-Test & & 0,0015 & & 0,0000 & & 0,0000 \\
\hline Durbin-Watson & & 1,7660 & & 1,8162 & & 1,9180 \\
\hline $\mathbf{N}$ & & 23 & & 186 & & 211 \\
\hline
\end{tabular}

Tab. B-81: Regression der Finanzkennzahlen (2)

\begin{tabular}{|c|c|c|c|c|c|c|c|c|}
\hline \multirow[b]{2}{*}{ Einflussgröße } & \multicolumn{2}{|c|}{ Regression 1} & \multicolumn{2}{|c|}{ Regression 2} & \multicolumn{2}{|c|}{ Regression 3} & \multicolumn{2}{|c|}{ Regression 4} \\
\hline & Beta & $\begin{array}{l}\text { Beta } \\
\text { stand. }\end{array}$ & Beta & $\begin{array}{l}\text { Beta } \\
\text { stand. }\end{array}$ & Beta & $\begin{array}{l}\text { Beta } \\
\text { stand. }\end{array}$ & Beta & $\begin{array}{l}\text { Beta } \\
\text { stand. }\end{array}$ \\
\hline Konstante & 21,5392 & & 15,3944 & & 12,8037 & & 12,8522 & 0,0000 \\
\hline UMSATZ LN & $-1,2999(1)$ & $-0,6529^{* * * *}$ & & & & & & \\
\hline KREDZIEL & $0,0331(2)$ & $0,3699 * *$ & & & & & & \\
\hline BILANZS LN & & & $-0,6541(1)$ & $-0,4289 * * *$ & $-0,3821$ & $-0,2941^{* * * *}$ & $-0,3647$ & $-0,2807 * * *$ \\
\hline AUSFALLW B & & & $0,4192(2)$ & $0,2889^{* * *}$ & 0,2510 & $0,2195^{* * *}$ & 0,2515 & $0,2200^{* * *}$ \\
\hline ALTER & & & & & & & $-0,0070$ & $-0,0855$ \\
\hline $\mathbf{R}$ & & 0,7685 & & 0,5466 & & 0,4023 & & 0,4111 \\
\hline R-Quadrat & & 0,5906 & & 0,2988 & & 0,1618 & & 0,1690 \\
\hline Korrigiertes $\mathbf{R}^{2}$ & & 0,5425 & & 0,2808 & & 0,1538 & & 0,1570 \\
\hline $\begin{array}{l}\text { Signifikanz F- } \\
\text { Test }\end{array}$ & & 0,0005 & & 0,0000 & & 0,0000 & & 1,5610 \\
\hline Durbin-Watson & & 1,9407 & & 1,8528 & & 2,0325 & & 2,0475 \\
\hline $\mathbf{N}$ & & 19 & & 81 & & 211 & & 211 \\
\hline
\end{tabular}

Tab. B-82: Regression der Finanzkennzahlen und der unternehmensbezogenen Variablen

Zusammenfassend lässt sich in Bezug auf die Finanzkennzahlen feststellen, dass die Variablen BILANZS_LN und AUSFALLW_B den größten Erklärungsanteil für den Zinssatz liefern. Ferner lässt sich beobachten, dass in allen Regressionen eine Kennzahl der Unternehmensgröße mit einem negativen Koeffizienten enthalten war und somit die These gestützt wird, das große Unternehmen - gemessen an der Bilanzsumme oder am Umsatz - niedrigere Zinsen erhalten. Die Ergebnisse stimmen überein mit LEHMANN/NEUBERGER und ELSAS/KRAHNEN, die ebenfalls zu der Erkenntnis kommen, dass der Zinssatz mit zunehmender Unternehmensgröße sinkt. ${ }^{1451}$ ELSAS/KRAHNEN vermuten hier, dass Banken die Firmengröße als einen Proxy für das Risiko verwenden und große Unternehmen aufgrund des geringeren Risikos niedrigere Zinsen 
zahlen. ${ }^{1452}$ Ursächlich könnte ferner die größere Machtstellung des Unternehmens sein. Diese Machtstellung könnte dadurch entstehen, dass nicht die reine Größe, sondern ein resultierender höherer Verbindlichkeitenbestand gegenüber dem jeweiligen Kreditinstitut ausschlaggebend ist und die Bank den Kunden nicht verlieren möchte. Dies kann erst bei Analyse der beziehungsbezogenen Variablen berücksichtigt werden. Zudem wäre es aber auch denkbar, dass die Unternehmensgröße zu einem besseren Ausbildungsniveau des Ansprechpartners führt und dass die Bank aufgrund der besseren betriebswirtschaftlichen Qualifikation desselbigen keine höheren Zinsen durchsetzen kann. ${ }^{1453}$ Schließlich können auch Imageeffekte eine Rolle spielen, so dass die Zufriedenheit der größeren Kunden wichtiger ist, da selbige stärker als Multiplikator in der Region fungieren. Die Größe des Unternehmens hat somit auch bei Ergänzung der Ausfallwahrscheinlichkeit weiterhin einen erheblichen Einfluss auf die Konditionengestaltung.

Ebenso wie bei LEHMANN/NEUBERGER wird gezeigt, dass der Zinssatz mit einer besseren Ratingklasse sinkt. ${ }^{1454}$ Hier besteht ebenfalls eine Übereinstimmung mit den Studien von MACHAUER/WEBER ${ }^{1455}$ oder ELSAS/KRAHNEN. ${ }^{1456}$ Zwar sind BERGER/ UDELL zu dem Ergebnis gekommen, dass die von ihnen verwendeten finanziellen Variablen keine signifikanten Effekte in Bezug auf die Kreditzinsen haben, jedoch lagen ihnen keine Ausfallwahrscheinlichkeiten vor, was die Herstellung eines Zusammenhangs zwischen der Bonität des Unternehmens und dem Zinssatz erschwert. ${ }^{1457} \mathrm{Um}$ diesen Zusammenhang herstellen zu können, hätten sie genau die Finanzkennzahlen ermitteln müssen, die von den Firmenkundenbetreuern herangezogen werden. Das Vorliegen einer verdichteten Variablen wie der Ratingklasse vereinfacht zum einen für den Firmenkundenbetreuer die bonitätsabhängige Zinsfestsetzung und zum anderen den Nachweis eines statistischen Zusammenhangs. BERGER/UDELL schlussfolgerten aufgrunddessen, dass die Zinsen für kleinere Unternehmen idiosynkratisch sind und oft von der Reputation und dem Ansehen des Eigentümers und des Unternehmens abhängen. ${ }^{1458}$ Ferner wurde die Studie von BERGER/UDELL durchgeführt, bevor bankaufsichtliche Vorschriften eine risikoadjustierte Bepreisung - in Form einer SollteVorschrift - forderten. Anders als die anderen zuvor genannten Studien stammt selbige nicht aus dem deutschen, sondern dem amerikanischen Raum.

1452 Vgl. Elsas/Krahnen (1998), S. 1301.

1453 Die Integration der Variablen BWL_AUSB kann diese These aber nicht bestätigen, denn nach Integration sinkt das korrigierte $\mathbf{R}^{2}$ auf 0,1511 . Der Koeffizient der Variablen selbst weist zwar mit einem Wert von -0,1807 das korrekte negative Vorzeichen auf, jedoch ist der Einfluss nicht signifikant. Lehmann/Neuberger kommen zu der Erkenntnis, dass der Zinssatz bei besseren Management-Qualitäten des Unternehmers sinkt. Hintergrund könnte eine bessere Verhandlungsmacht der Kreditnehmer und/oder bessere Informationen seitens der Bank über den "Тур“ des Kreditnehmers sein. Beides führt zu niedrigerem Risiko und somit zu niedrigeren Zinsen. Vgl. Lehmann/Neuberger (2001), S. 22.

1454 Vgl. Lehmann/Neuberger (2001), S. 20.

1455 Vgl. Machauer/Weber (1998), S. 1366.

1456 Vgl. Elsas/Krahnen (1998), S. 1300.

1457 Vgl. Berger/Udell (1995), S. 367.

1458 Vgl. Berger/Udell (1995), S. 367. 
Da allein die gesetzlichen Vorschriften die Zinshöhe nicht erklären können, wird im Folgenden der Einfluss der Variablen geprüft, die in den in Kapitel A.4.3.2 beschriebenen Studien der Relationship Banking-Forschung herangezogen wurden. Dies sind neben einigen unternehmensbezogenen ${ }^{1459}$ Variablen vor allem die beziehungsbezogenen Variablen.

Die Integration der sonstigen unternehmensbezogenen Daten brachte keine wesentliche Verbesserung der Ergebnisse, lediglich die Integration der Variable ALTER führte zu einer geringfügigen Verbesserung der erklärten Varianz (vgl. Tab. B-82, Regression 4). ${ }^{1460}$ Der Koeffizient für die Variable ALTER weist bei einer Regression im Einschlussverfahren mit den Variablen BILANZS_LN und Ausfallwahrscheinlichkeit einen geringfügig negativen Wert auf $(-0,0070)$, allerdings ist dieser nicht signifikant. Signifikante Einflüsse konnten weder beim Alter, bei der Rechtsform noch bei der Branche nachgewiesen werden. Dies entspricht den Ergebnissen der Korrelationsanalyse. Bereits bei den Korrelationsanalysen wurde vermutet, dass das Alter und die Rechtsform sich auf die Unternehmensgröße auswirken und mögliche Effekte dieser Variablen lediglich auf den Zusammenhang zur Unternehmensgröße zurückzuführen sind. Die Wirkungsrichtung der Variablen ALTER entspricht den Ergebnissen der meisten Studien, z.B. ANGelini/Di Salvo/Ferri, Petersen/Rajan und BerGER/UDELL. ${ }^{1461}$ Inwiefern die Unternehmensgröße und die resultierende Verhandlungsmacht oder die zusätzlichen öffentlich verfügbaren Informationen ursächlich dafür sind, dass ältere Unternehmen geringere Zinsen zahlen, bleibt offen.

Im nächsten Schritt erfolgt eine Analyse der beziehungsbezogenen Variablen, wobei hier unmittelbar eine schrittweise Regression vorgenommen worden ist. Die isolierte Betrachtung der beziehungsbezogenen Parameter ist insofern interessant, als dass allein durch die Parameter GK_LIM_EX, ANT_BANK_HB und INT_BET immerhin ein korrigiertes $\mathrm{R}^{2}$ von 0,5078 erzielt wird (vgl. Tab. B-83), auch wenn die zugrunde liegende Datenmenge mit $\mathrm{N}=62$ relativ gering ist. Der Parameter INT_BET sagt im Vergleich zur Ratingklasse zwar relativ undifferenziert etwas über die Qualität des Unternehmens aus, liefert aber dennoch ex post Anhaltspunkte, so dass zumindest auch bei diesem Ansatz die Bonität in gewisser Weise berücksichtigt wird. Ein Unternehmen, welches sich aktuell in der Intensivbetreuung befindet oder in der Vergangenheit befand, zahlt ca. 1,20\% höhere Zinsen als ein Unternehmen, welches sich noch nie in der Intensivbetreuung befand. Dies bestätigt somit - wie auch die Regression der Finanzkennzahlen - den Zusammenhang, dass bonitätsmäßig schlechte Unternehmen höhere Zinsen zahlen als bonitätsmäßig gute Unternehmen. Bei Betrachtung der standardisierten Koeffizienten haben die Parameter GK_LIM_EX und ANT_BANK_-

1459 Der Begriff der unternehmensbezogenen Daten wird in Abgrenzung zum Begriff beziehungsbezogene Daten verwendet. Die verwendeten Variablen sind für Inside- und Outside-Banken identisch. Finanzkennzahlen werden aufgrund ihrer Wichtigkeit separat betrachtet, obgleich Finanzkennzahlen auch unternehmensbezogen sind.

1460 Der Koeffizient für die Variable ALTER_LN ist negativ und ebenfalls nicht signifikant. Der Koeffizient der Variablen KAPGESELL ist positiv und ebenfalls nicht signifikant.

1461 Vgl. Angelini/Di Salvo/Ferri (1998), S. 940, Petersen/Rajan (1994), S. 13, Petersen/Rajan (1995), S. 436, Berger/Udell (1995), S. 371. 
HB jedoch einen größeren Einfluss auf den Zinssatz als INT_BET. Ein Anstieg des externen Limits um 100.000 EUR führt zu einer Reduktion des Zinssatzes um 0,3966 Prozentpunkte. ${ }^{1462}$ Schwierig zu interpretieren ist der Einfluss der Variablen ANT_BANK_HB. Diese Variable gibt an, wie hoch der Anteil der Finanzierung bei der Hausbank ist. Wenn das eigene Institut nicht die Hausbank ist, dann bedeutet eine hohe Ausprägung dieser Variablen, dass der Finanzierungsanteil des Instituts gering ist. Weder die Integration der Variablen HAUSBANK_K noch der Variablen ANT_BANK_IN, d.h. dem Finanzierungsanteil des jeweiligen Instituts, liefert zusätzliche Erkenntnisse; beide Variablen weisen keine signifikanten Koeffizienten auf. ${ }^{1463}$ Eine mögliche Erklärung könnte darin bestehen, dass eine starke Hausbankbeziehung generell den Kreditzins senkt.

\begin{tabular}{|l|r|r|}
\hline Einflussgröße & \multicolumn{1}{|c|}{ Beta } & \multicolumn{1}{|c|}{$\begin{array}{c}\text { Beta } \\
\text { stand. }\end{array}$} \\
\hline Konstante & 9,5319 & \\
\hline GK_LIM EX & $-0,0000(1)$ & $-0,4729 * * *$ \\
\hline ANT_BANK HB & $0,0204(2)$ & $0,2978^{* * *}$ \\
\hline INT BET & $1,1977(3)$ & $0,2625^{* * *}$ \\
\hline R & & 0,7291 \\
\hline R-Quadrat & & 0,5316 \\
\hline Korrigiertes R & & 0,5078 \\
\hline Signifikanz F-Test & & 0,0000 \\
\hline Durbin-Watson & & 1,8295 \\
\hline N & & 62 \\
\hline
\end{tabular}

Tab. B-83: Regression der beziehungsbezogenen Variablen (1)

Im nächsten Schritt wurde eine Regression nach dem Einschlussverfahren durchgeführt, wobei alle beziehungsbezogenen Variablen mit signifikanten Korrelationen berücksichtigt worden sind (vgl. Tab. B-84, Regression 1). Aufgrund der schwierigen inhaltlichen Interpretierbarkeit wurde die Variable ANT_BANK_HB nicht weiter betrachtet. Der erwartete Verlust als Kombination einer unternehmensbezogenen Bonitätskennzahl und der beziehungsbezogenen Variablen Sicherheitenquote wurde ausgeschlossen, um nicht eine Verfälschung der beziehungsbezogenen Einflüsse zu erzeugen. Stattdessen wurde lediglich die Sicherheitenquote als ein Element des erwarteten Verlusts herangezogen. Die Integration der Sicherheitenquote erfolgt ferner deshalb, weil der Zusammenhang zwischen Zinssatz und Sicherheitenquote in den Theorien des Relationship Banking von zentraler Bedeutung und gleichzeitig als Ele-

1462 Da das externe Limit in der Einheit EUR erfasst wurde, ist diese Veränderung in der Tab. B-83 nicht ersichtlich.

1463 Es wurden drei Regressionen bei Anwendung des Einschlussverfahrens durchgeführt mit den Variablen GK_LIM_EX und INT_BET. Es wurde jeweils eine Variable ANT_BANK_HB, HAUSBANK_K oder ANT_BANKK_IN ergänzt um die Regressionen zu vergleichen. ANT_BANK_HB (korrigiertes $\mathrm{R}^{2}$ : 0,4166; Koeffzient: 0,0142*) HAUSBANK_K: (korrigiertes $R^{2}: 0,1857$; Koeffzient: 0,0207), ANT_BANK_IN (korrigiertes $R^{2}: 0,1582$; Koeffzient: 0,0030 ). Die Variable ANT_BANK_HB führt zu einem deutlich größeren Erklärungsanteil. Vgl. Anhang 5, Tab. AN 5-2. 
ment einer risikoorientierten Bepreisung eine zentrale Größe ist. Schließlich wurde eine schrittweise Regression mit diesen Variablen (vgl. Tab. B-84, Regression 2 und 3) vorgenommen. Im Anschluss werden die Ergebnisse im Einschlussverfahren validiert (vgl. Tab. B-85), denn aufgrund des listenweisen Fallauschlusses wird die Datenmenge reduziert, so dass durch diese abschließende Regression geprüft wird, inwiefern die Ergebnisse auch für den gesamten Datenbestand zutreffen. Es zeigt sich, dass auch ohne Berücksichtigung von Finanzkennzahlen im Einschlussverfahren mit beziehungsbezogenen Variablen immerhin $24,61 \%$ der Varianz erklärt werden. Der Erklärungsgehalt der beziehungsbezogenen Variablen liegt über dem Erklärungsgehalt der Regression mit den Finanzkennzahlen - zumindest bei Betrachtung der Regressionen, bei denen eine vergleichbare Datenbasis, d.h. N größer 200 verwendet wurde. Neben den Variablen GK_LIM_EX und der INT_BET haben bei Betrachtung der standardisierten Koeffizienten die Variablen MITGLIED und ZINS_VERFÜG einen wesentlichen Einfluss. Mitglieder zahlen 0,6263 Prozentpunkte weniger Zinsen als NichtMitglieder und somit können die Ergebnisse von ANGELINI/DI SALVO/FERRI, dass Mitglieder von Genossenschaftsbanken günstigere Kredite erhalten als NichtMitglieder, ${ }^{1464}$ bestätigt werden.

Die Variable ZINS_VERFÜG zeigt, dass ein Kunde, für den laut Einschätzung des Firmenkundenbetreuers niedrige Zinsen eine größere Bedeutung als die Kreditverfügbarkeit haben, ebenfalls deutlich niedrigere Zinsen zahlt als ein Kunde, für den die Kreditverfügbarkeit wichtiger ist. Offen bleibt allerdings, welches die Hintergründe für diese Einschätzung des Firmenkundenbetreuers sind. Es könnte sich hierbei um einen Kunden handeln, der problemlos die Bankbeziehung wechseln kann und mehrere Alternativen für die Mittelbeschaffung hat oder es kann sich schlichtweg um einen zinsbewussten Kunden handeln. Die Elimination dieser Variablen führt sowohl bei der schrittweisen Regression (vgl. Tab. B-84, Regression 2 und 3) als auch beim Einschlussverfahren (vgl. Tab. B-85, Regression 1 und 2) zu einer Reduktion des Erklärungsgehalts.

In der Regression 1 in Tab. B-84 geht eine hohe Sicherheitenquote mit einem hohen Zinssatz einher, allerdings ist der Koeffizient nur auf dem 10\%-Niveau signifikant. Die Ergebnisse stützen wie auch bei BERGER/UDELL die Theorie, dass bonitätsmäßig schlechte Kunden, die aufgrunddessen mehr Zinsen zahlen müssen, eher mehr Sicherheiten stellen. ${ }^{1465}$ Die hier gefundenen Ergebnisse stimmen überein mit der Interpretation von Sicherheiten als Anreizinstrument - wie in Kapitel A.4.3.1.3.1 dargestellt und widersprechen der Interpretation von Sicherheiten als Signalling-Instrument. Dieser Zusammenhang wurde bereits im Vorfeld bei den Korrelationsanalysen in Kapitel B.3.4.2.1.beobachtet. Während bei BERGER/UDELL allerdings nur die zwei Zustände Sicherheitenstellung Ja-Nein berücksichtigt werden, wird in dieser Untersuchung ebenso wie bei ELSAS/KRAHNEN der Anteil der gesamten Bankkredite, der besichert bzw. der nicht besichert ist, in die Untersuchung integriert. ${ }^{1466}$ Auch ELSAS/KRAHNEN

\footnotetext{
1464 Vgl. Angelini/Di Salvo/Ferri (1998), S. 948.

1465 Vgl. Berger/Udell (1995), S. 368.

1466 Vgl. Elsas/Krahnen (1998), S. 1299.
} 
kommen zu der Erkenntnis, dass der Zinssatz mit abnehmendem Exposure der Bank steigt. ${ }^{1467} \mathrm{Je}$ mehr Sicherheiten gestellt werden, desto höher ist der Zinssatz.

Hinsichtlich der Dauer der Bankbeziehung kann festgestellt werden, dass der Kreditzins umso niedriger ist, je länger die Bankbeziehung dauert (vgl. Tab. B-84, Regression 1). Der Zusammenhang ist allerdings nicht signifikant. Dies stimmt überein mit den Ergebnissen von PETERSEN/RAJAN. ${ }^{1468}$ Auch bei den deutschen Studien können HARHOFF/KÖRTING und ELSAS/KRAHNEN keinen signifikanten Zusammenhang zwischen der Dauer der Bankbeziehung und dem Zinssatz feststellen. ${ }^{149}$ Eine längere Bankverbindung und somit ein vermuteter besserer Informationsstand führt nicht zwangsläufig zu günstigeren Zinsen. Ursächlich hierfür könnte sein, dass der zunehmende Informationsstand auch negative Informationen enthüllt. Eine weitere Erklärung besteht darin, dass die Outside-Banks allein aus der Tatsache, dass das Unternehmen eine lange Bankhistorie hat, relevante Informatioen ableiten können. ${ }^{140}$

Eine größere Anzahl an Bankverbindungen hat einen zinsreduzierenden Effekt, d.h. je mehr Bankverbindungen das Unternehmen hat, desto niedriger ist der Zinssatz. Der Einfluss ist aber nicht signifikant. Die alternativen Finanzierungsmöglichkeiten des Kunden reduzieren die Marktmacht der Bank, selbige kann einen möglichen Lock-InEffekt aufgrund eines Informationsvorsprungs nur begrenzt ausnutzen. Inwiefern es bei der Existenz mehrerer Bankverbindungen überhaupt zu einem Informationsvorsprung und Lock-In-Effekt kommt, bleibt offen. Dieser Zusammenhang stimmt auch mit bestehenden Studien, z.B. HARHOFF/KÖRTING ${ }^{147}$, überein.

Die Durchführung einer Regression unter Vernachlässigung der Ergebnisse der Korrelationsanalyse und basierend auf der im Rahmen der bisherigen empirischen Relationship Banking-Studien verwendeten Variablen brachte keine neuen Erkenntnisse. ${ }^{1472}$ Es konnten keine weiteren signifikanten Einflüsse erarbeitet werden. Ebenso wie bspw. bei PETERSEN/RAJAN kann kein signifikanter Zusammenhang hergestellt werden zwischen dem Umstand, dass ein Unternehmen Einlagen bei der Bank unterhält oder sonstige Bankdienstleistungen in Anspruch nimmt auf der einen und dem Zinssatz auf der anderen Seite. ${ }^{1473}$ Die produktbezogenen Variablen (ANZAHL_PRODUKTE, DARL, ZV_KK, VERM_ANL VERSICH, PRIVATKONT) weisen keine signifikanten Koeffizienten auf. Gleiches gilt für die häufig verwendeten Variablen wie Anteil am Zahlungsverkehr und Anteil der Bankverbindlichkeiten sowie den Hausbankstatus.

\footnotetext{
1467 Vgl. Elsas/Krahnen (1998), S. 1301.

1468 Vgl. Petersen/Rajan (1994), S. 14, Ongena/Smith (2000a), S. 238.

1469 Vgl. Harhoff/Körting (1998a), S. 17, Elsas/Krahnen (1998), S. 1302.

1470 Vgl. Segbers (2007), S. 123. James (1987) hat gezeigt, dass die bloße Verkündung der Gewährung eines Bankkredits als positives Signal durch die anderen Marktteilnehmer aufgefasst wird. Bei einer längeren Bankhistorie wird dieser Effekt verstärkt und die anderen Marktteilnehmer leiten ggf. aus der langen Bankhistorie ab, dass es sich um ein Unternehmen mit einer guten Bonität handelt. Vgl. James (1987), S. 217 ff. Vgl. Harhoff/Körting (1998a), S. 17.

Vgl. Anhang 5, Tab. AN 5-3.

Vgl. Petersen/Rajan (1994), S. 16, Ongena/Smith (2000a), S. 241.
} 


\begin{tabular}{|c|c|c|c|c|c|c|}
\hline \multirow[b]{2}{*}{ Einflussgröße } & \multicolumn{2}{|c|}{ Regression 1} & \multicolumn{2}{|c|}{ Regression 2} & \multicolumn{2}{|c|}{ Regression 3} \\
\hline & Beta & $\begin{array}{l}\text { Beta } \\
\text { stand. }\end{array}$ & $\begin{array}{c}\text { Beta } \\
\text { stand. }\end{array}$ & $\begin{array}{l}\text { Beta } \\
\text { stand. }\end{array}$ & Beta & $\begin{array}{l}\text { Beta } \\
\text { stand. }\end{array}$ \\
\hline Konstante & 11,6382 & & 11,4910 & & 11,2064 & \\
\hline INT BET & 0,9835 & $0,2032 * * *$ & $0,9447(2)$ & $0,2327 * *$ & $1,0885(2)$ & $0,2327^{* *}$ \\
\hline DAU BEZ ERR & $-0,0052$ & $-0,0370$ & & & & \\
\hline GK LIM EX & 0,0000 & $-0,3847^{* * *}$ & $0,0000(1)$ & $-0,3523 * * *$ & $0,0000(1)$ & $-0,3523^{* * *}$ \\
\hline GES KREDIT & 0,0000 & 0,0477 & & & & \\
\hline MITGLIED & $-0,6263$ & $-0,1673^{* *}$ & $-0,5839(3)$ & $-0,1595^{* *}$ & $-0,5918(3)$ & $-0,1595^{* *}$ \\
\hline ZINS VERFÜG & $-0,4318$ & $-0,1238^{*}$ & $-0,5428(4)$ & $-0,1583^{* *}$ & & \\
\hline SICH Q & 0,0041 & 0,0919 & & & & \\
\hline ANZ B AGG & $-0,1699$ & $-0,1056$ & & & & \\
\hline $\mathbf{R}$ & & 0,5290 & & 0,4981 & & 0,4433 \\
\hline R-Quadrat & & 0,2798 & & 0,2481 & & 0,1965 \\
\hline Korrigiertes $\mathbf{R}^{2}$ & & 0,2461 & & 0,2329 & & 0,1819 \\
\hline Signifikanz F-Test & & 0,0000 & & 0,0000 & & 0,0000 \\
\hline Durbin-Watson & & 1,9045 & & 1,9002 & & 1,9025 \\
\hline $\mathbf{N}$ & & 178 & & 202 & & 170 \\
\hline
\end{tabular}

Tab. B-84: Regression der beziehungsbezogenen Variablen (2)

\begin{tabular}{|c|c|c|c|c|}
\hline \multirow[b]{2}{*}{ Einflussgröße } & \multicolumn{2}{|c|}{ Regression 1} & \multicolumn{2}{|c|}{ Regression 2} \\
\hline & Beta & $\begin{array}{c}\text { Beta } \\
\text { stand. }\end{array}$ & Beta & $\begin{array}{l}\text { Beta } \\
\text { stand. }\end{array}$ \\
\hline Konstante & 11,4625 & & 11,1830 & \\
\hline GK LIM EX & 0,0000 & $-0,3807 * * *$ & 0,0000 & $-0,3728^{* * * *}$ \\
\hline INT BET & 0,9617 & $0,1936^{* * *}$ & 1,1794 & $0,2366^{* * *}$ \\
\hline MITGLIED & $-0,5746$ & $-0,1549^{* *}$ & $-0,6497$ & $-0,1748^{* * *}$ \\
\hline ZINS VERFÜG & $-0,5436$ & $-0,1587^{* *}$ & & \\
\hline $\mathbf{R}$ & & 0,4957 & & 0,4773 \\
\hline R-Quadrat & & 0,2457 & & 0,2278 \\
\hline Korrigiertes $\mathbf{R}^{2}$ & & 0,2308 & & 0,2165 \\
\hline Signifikanz F-Test & & 1,5009 & & 0,0000 \\
\hline Durbin-Watson & & 1,9029 & & 1,8727 \\
\hline $\mathbf{N}$ & & 207 & & 208 \\
\hline
\end{tabular}

Tab. B-85: Regression der beziehungsbezogenen Variablen (3)

In der folgenden Regression werden die Finanzkennzahlen und die beziehungsbezogenen Variablen gemeinsam betrachtet. Es werden jeweils die Variablen herangezogen, die die besten Ergebnisse bei der isolierten Betrachtung der beiden Bereiche erzielt haben und deren Koeffizienten statistisch signifikant waren. Es soll geprüft werden, inwiefern durch die gemeinsame Betrachtung von Finanzkennzahlen und beziehungsbezogenen Variablen der Erklärungsbeitrag steigt. Zu diesem Zweck wurden jeweils unter Verwendung des listenweisen Fallausschlusses zwei Regressionen, zum einen eine auf Basis der Einschlussmethode und zum anderen eine schrittweise Regression, durchgeführt. Bei gemeinsamer Betrachtung der Variablen steigt das korrigierte $\mathrm{R}^{2}$ auf 0,2695. Da alle Variablen bei der Regression auf Basis der Einschlussmethode signifikant sind, werden bei einer schrittweisen Regression keine Variablen ausgeschlossen; die schrittweise Regression kommt infolgedessen zu den gleichen Ergebnissen (vgl. 
Tab. B-86, Regression 1 und 2). ${ }^{1474}$ Obwohl vermutet wurde, dass die Variable INT_BET Ausdruck der Bonität ist, liefert selbige auch bei Integration der Variablen AUSFALLW_B signifikante Ergebnisse. Möglicherweise liefert die Intensivbetreuung Informationen, die nicht im Rating oder der Ausfallwahrscheinlichkeit berücksichtigt werden, aber im Rahmen einer zusätzlichen Zinskorrektur bei der Zinsfestlegung einfließen.

\begin{tabular}{|c|c|c|c|c|}
\hline \multirow[b]{2}{*}{ Einflussgröße } & \multicolumn{2}{|c|}{ Regression 1} & \multicolumn{2}{|c|}{ Regression 2} \\
\hline & Beta & $\begin{array}{l}\text { Beta } \\
\text { stand. }\end{array}$ & Beta & $\begin{array}{c}\text { Beta } \\
\text { stand. }\end{array}$ \\
\hline Konstante & 12,6029 & & 12,6029 & \\
\hline BIL.ANZS LN & $-0,2109$ & $-0,1627^{* *}$ & $-0,2109(5)$ & $-0,1627^{* *}$ \\
\hline AUSFALLW B & 0,1630 & $0,1427^{* * *}$ & $0,1630(2)$ & $0,1427^{* *}$ \\
\hline GK LIM EX & 0,0000 & $-0,2976^{* * * *}$ & $0,0000(1)$ & $-0,2976^{* * *}$ \\
\hline INT_BET & 0,7655 & $0,1541^{* *}$ & $0,7655(6)$ & $0,1541^{* *}$ \\
\hline MITGLIED & $-0,5813$ & $-0,1567 * *$ & $-0,5813(4)$ & $-0,1567^{*}$ \\
\hline ZINS VERFÜG & $-0,3704$ & $-0,1081^{*}$ & $-0,3704(3)$ & $-0,1081^{*}$ \\
\hline $\mathbf{R}$ & & 0,5392 & & 0,5392 \\
\hline R-Quadrat & & 0,2908 & & 0,2908 \\
\hline Korrigiertes $\mathbf{R}^{2}$ & & 0,2695 & & 0,2695 \\
\hline Signifikanz F-Test & & 0,0000 & & 0,0000 \\
\hline Durbin-Watson & & 1,9293 & & 1,9293 \\
\hline $\mathbf{N}$ & & 206 & & 206 \\
\hline
\end{tabular}

Tab. B-86: Regression der Finanzkennzahlen und der beziehungsbezogenen Variablen

Im Folgenden werden nun die bestehenden Regressionen um verhaltenswissenschaftliche Variablen ergänzt. In einem ersten Schritt werden ausschließlich die verhaltenswissenschaftlichen Variablen untersucht, um zu prüfen, wie hoch deren isolierter Erklärungsbeitrag ist (vgl. Tab. B-87, Regression 1). In einem zweiten Schritt werden die bisherigen Regressionen um die verhaltenswissenschaftlichen Variablen ergänzt (vgl. Tab. B-87, Regression 2).

Bei isolierter Betrachtung erklären die verhaltenswissenschaftlichen Parameter immerhin $10,49 \%$ der Varianz (vgl. Tab. B-87, Regression 1). Allerdings sind nur die Variablen ORG_GLAUB, ORG_GEB und PERS_WOHL signifikant. Im Modell mit der schrittweisen Regression (vgl. Tab. B-87, Regression 2) wurden genau diese drei Parameter ORG_GLAUB, ORG_GEB und PERS_WOHL berücksichtigt. Bei der schrittweisen Regression steigt die erklärte Varianz geringfügig auf $10,95 \% .{ }^{1475} \mathrm{Der}$ Einfluss der drei Faktoren ist vergleichbar. So schwankt der standardisierte Koeffizient im Modell der schrittweisen Regression zwischen 0,15 und 0,19. Ein Anstieg der organisationalen Glaubwürdigkeit, d.h. ein niedrigerer Wert auf der Ratingskala, führt zu besseren Zinskonditionen. Dies ist insofern nachvollziehbar, als dass eine höhere Kompetenzvermutung durch den Firmenkundenbetreuer mit einem geringeren Risiko

1474 Es gibt somit keinen Unterschied zwischen den beiden Regressionen.

1475 Im Anhang 5 wird die Regression auch mit dem modifizierten Faktor dargestellt. Vgl. Anhang 5, Tab. AN 5-4. 
und somit einer geringeren Zinsmarge einhergeht. Die organisationale Glaubwürdigkeit wirkt sich positiv auf die Zuversicht des Firmenkundenbetreuers bezüglich des Projekterfolges aus und hat zur Konsequenz, dass weniger Prüf- und Überwachungsaktivitäten durchgeführt werden. Die niedrigeren Transaktionskosten werden an die Kunden weitergegeben. Auch wenn der Koeffizient zum organisationalen Wohlwollen nicht signifikant ist, soll dennoch das Vorzeichen untersucht werden. Eine bessere Note und somit ein Anstieg des organisationalen Wohlwollens führt zu höheren Zinsen. Dies lässt sich nicht erklären. Während H2 nicht bestätigt werden kann, wird bezüglich $\mathrm{H} 1$ das Vorzeichen bei isolierter Betrachtung der verhaltenswissenschaftlichen Parameter auf dem 5\%-Signifikanzniveau bestätigt.

H1: Je größer die organisationale Glaubwürdigkeit des Unternehmens, desto niedriger ist der Zinssatz des Kunden. (Best. - 5\%-Niveau)

H2: Je größer das organisationale Wohlwollen des Unternehmens, desto niedriger ist der Zinssatz des Kunden. (Abl. - keine Signifikanz)

\begin{tabular}{|c|c|c|c|c|}
\hline \multirow[b]{2}{*}{ Einflussgröße } & \multicolumn{2}{|c|}{ Regression 1} & \multicolumn{2}{|c|}{ Regression 2} \\
\hline & Beta & $\begin{array}{l}\text { Beta } \\
\text { stand. }\end{array}$ & Beta & $\begin{array}{l}\text { Beta } \\
\text { stand. }\end{array}$ \\
\hline Konstante & 10,4058 & & 10,4185 & \\
\hline ORG GLAUB & 0,4274 & $0,2152^{* *}$ & $0,3105(1)$ & $0,1563^{* *}$ \\
\hline ORG WOHL & $-0,2592$ & $-0,1198$ & & \\
\hline PERS_GLAUB & $-0,0230$ & $-0,0113$ & & \\
\hline PERS WOHL & 0,5724 & $0,2731^{* * *}$ & $0,3813(3)$ & $0,1820^{* *}$ \\
\hline ORG GEB & $-0,3515$ & $-0,1812^{* * *}$ & $-0,3818(2)$ & $-0,1969 * * *$ \\
\hline ORG_VER & 0,1263 & 0,0652 & & \\
\hline PERS_VER & $-0,2023$ & $-0,1011$ & & \\
\hline $\mathbf{R}$ & & 0,3717 & & 0,3517 \\
\hline R-Quadrat & & 0,1382 & & 0,1237 \\
\hline Korrigiertes $\mathbf{R}^{2}$ & & 0,1049 & & 0,1095 \\
\hline Signifikanz F-Test & & 0,0003 & & 0,0000 \\
\hline Durbin-Watson & & 2,0807 & & 1,9536 \\
\hline $\mathbf{N}$ & & 188 & & 188 \\
\hline
\end{tabular}

Tab. B-87: Regression der verhaltenswissenschaftlichen Variablen

Hinsichtlich der interpersonalen Glaubwürdigkeit des Ansprechpartners wurde vermutet, dass bei Existenz derselbigen den gelieferten Zahlen und Berichten sowie den mündlichen Aussagen eher Glauben geschenkt wird und in Konsequenz weniger Prüfund Überwachungsaktivitäten durchgeführt werden. Eine Weitergabe der geringeren Kosten würde niedrigere Zinsen bewirken. Die Ergebnisse der Regression weisen aber genau den gegenteiligen Zusammenhang auf, d.h. eine höhere Glaubwürdigkeit und somit eine niedrigere Faktorausprägung führt zu höheren Zinsen. Der Zusammenhang ist allerdings nicht signifikant. Die Hypothese $\mathrm{H} 3$ kann nicht bestätigt werden.

H3: Je größer die interpersonale Glaubwürdigkeit des Ansprechpartners im Unternehmen, desto niedriger ist der Zinssatz des Kunden. (Abl. - keine Signifikanz) 
Lediglich das personale Wohlwollen weist auf personaler Ebene signifikante Ergebnisse auf. Hinsichtlich der Auswirkungen des personalen Wohlwollens wurde von einer Reziprozität desselbigen ausgegangen. Ein erhöhtes Wohlwollen führt zu einem intensiveren Informationsaustausch und somit zu einer präziseren Risikoeinschätzung, was wiederum niedrigere Zinsen erfordert. Zusätzlich wirkt möglicherweise auch der direkte Effekt, dass der Firmenkundenbetreuer aufgrund des interpersonalen Wohlwollens der Kontaktperson auch sein Wohlwollen zeigen möchte und den Zinssatz allein deshalb senkt. Die Hypothese H4 kann bestätigt werden. Die Ergebnisse sind bei der Regression im Einschlussverfahren auf dem 1\%-Niveau signifikant.

H4: Je größer das interpersonale Wohlwollen des Ansprechpartners im Unternehmen, desto niedriger ist der Zinssatz des Kunden. (Best. - 1\%-Niveau)

In Ermangelung eines eindeutigen Zusammenhangs wurden keine Hypothesen für die Wirkung des Commitments formuliert, dennoch sollen die beobachteten Einflüsse analysiert werden. So sind auch bei den Variablen, die die Dimensionen des Commitments operationalisieren, die Ergebnisse nicht durchgängig signifikant. Das Commitment des Kunden wurde als Grundlage für die intertemporale Konditionengestaltung betrachtet. Eine Gebundenheit des Unternehmens verschafft der Bank gemäß dem Modell von PETERSEN/RAJAN darüber hinaus die Möglichkeit, die Machtsituation auszunutzen. ${ }^{1476}$ Die gleiche Gefahr resultiert bei Verbundenheit auf Unternehmensebene oder Verbundenheit auf Ebene der Kontaktperson, wobei die Gefahr bei gleichzeitiger Abwesenheit von Gebundenheit nicht wirklich gegeben ist, denn die Bank würde riskieren, die Verbundenheit zu verspielen und den Kunden zu verlieren. Aufgrund der konterkarierenden Effekte, die z.B. aus einer vermehrten Produktnutzung resultierten und somit Möglichkeiten der Quersubventionierung bieten, ist der Einfluss der Gebundenheit und der Verbundenheit auf die Kreditzinsen indeterminiert.

In der vorliegenden Studie wird auf dem 5\%-Niveau bestätigt (vgl. Tab. B-87, Regression 1), dass die Banken eine organisationale Gebundenheit ausnutzen und höhere Zinsen fordern. Eine höhere organisationale Verbundenheit hingegen geht mit niedrigeren Zinsen einher, allerdings sind die Ergebnisse nicht signifikant. Es kommt somit nicht zu einem Ausnutzen der Verbundenheit und des Nicht-Wechseln-Wollens. Auf die resultierende Gefahr des Kundenverlusts bei Ausnutzen der Verbundenheit wurde bereits mehrfach hingewiesen. Eine höhere personale Verbundenheit hingegen führt zu höheren Zinsen, was derart erklärt werden könnte, dass die Verbundenheit der Kontaktperson ausgenutzt wird. Allerdings erscheint die Begründung nicht plausibel in Verbindung mit der organisationalen Verbundenheit, denn die Effekte sind gegenläufig. Es ist unwahrscheinlich, dass die Bank die höhere Verbundenheit des Ansprechpartners, nicht hingegen selbige des Unternehmens ausnutzt. Das Ausnutzen wäre nur dann als Argument plausibel, wenn es auf beiden Ebenen stattfindet. 


\begin{tabular}{|c|c|c|c|c|}
\hline \multirow[b]{2}{*}{ Einflussgröße } & \multicolumn{2}{|c|}{ Regression 1} & \multicolumn{2}{|c|}{ Regression 2} \\
\hline & Beta & $\begin{array}{l}\text { Beta } \\
\text { stand. }\end{array}$ & Beta & $\begin{array}{r}\text { Beta } \\
\text { stand. }\end{array}$ \\
\hline Konstante & 11,9632 & & 12,4206 & \\
\hline BILANZS LN & $-0,1184$ & $-0,0912$ & $-0,2090(5)$ & $-0,1606^{* *}$ \\
\hline AUSFALLW B & 0,1826 & $0,1627^{*}$ & $0,2160(2)$ & $0,1919^{* * *}$ \\
\hline GK LIM EX & 0,0000 & $-0,3372^{* * *}$ & $0,0000(1)$ & $-0,3063^{* * *}$ \\
\hline INT BET & 0,5745 & 0,1181 & $0,7893(4)$ & $0,1613^{* *}$ \\
\hline MITGLIED & $-0,5173$ & $-0,1372^{* *}$ & $-0,6338(3)$ & $-0,1692 * * *$ \\
\hline ZINS VERFÜG & $-0,2862$ & $-0,0822$ & & \\
\hline ORG_GLAUB & 0,1515 & 0,0757 & & \\
\hline ORG WOHL & $-0,2980$ & $-0,1369$ & & \\
\hline PERS GLAUB & $-0,0713$ & $-0,0353$ & & \\
\hline PERS WOHL & 0,3646 & $0,1732^{*}$ & & \\
\hline ORG_GEB & $-0,2137$ & $-0,1095$ & & \\
\hline ORG_VER & 0,1389 & 0,0717 & & \\
\hline PERS VER & $-0,0895$ & $-0,0444$ & & \\
\hline $\mathbf{R}$ & & 0,5859 & & 0,5406 \\
\hline R-Quadrat & & 0,3433 & & 0,2923 \\
\hline Korrigiertes $\mathbf{R}^{2}$ & & 0,2886 & & 0,2764 \\
\hline Signifikanz F-Test & & 0,0000 & & 0,0000 \\
\hline Durbin-Watson & & 2,0125 & & 1,8726 \\
\hline $\mathbf{N}$ & & 183 & & 183 \\
\hline
\end{tabular}

Tab. B-88: Regression der Finanzkennzahlen, der beziehungsbezogenen und der verhaltenswissenschaftlichen Variablen

Anschließend wurden sowohl die Finanzkennzahlen als auch die beziehungsbezogenen und die verhaltenswissenschaftlichen Parameter in eine gemeinsame Regression integriert. Dazu wurden bei Anwendung der Einschlussmethode die bisher verwendeten Variablen für die Finanzkennzahlen und die beziehungsbezogenen Parameter (vgl. Tab. B-86) um die sieben verhaltenswissenschaftlichen Faktoren erweitert. Das korrigierte $\mathrm{R}^{2}$ kann dadurch auf 0,2886 gesteigert werden (vgl. Tab. B-88, Regression 1). Für die meisten verhaltenswissenschaftlichen Faktoren werden allerdings keine signifikanten Koeffizienten ermittelt, lediglich der Einfluss des personalen Wohlwollens ist auf dem 10\%-Niveau signifikant. Die Vorzeichen entsprechen selbigen aus der Regression 1 und der Regression 2 in Tab. B-87. Aufgrund der fehlenden Signifikanz werden diese Faktoren im Rahmen der schrittweisen Regression ausgeschlossen, allerdings sinkt der Anteil an erklärter Varianz durch den Ausschluss der Faktoren um etwas mehr als einen Prozentpunkt. Auch durch die Integration des kombinierten Faktors PERS_WOHL_VER kann keine Ergebnisverbesserung erzielt werden. ${ }^{1477}$

Es lässt sich feststellen, dass für die verhaltenswissenschaftlichen Parameter auch im multivariaten Kontext ein Einfluss nachgewiesen werden kann. Die Ergebnisse der Korrelationsanalyse hingegen werden nicht vollständig bestätigt. Zwar konnte bei ausschließlicher Betrachtung der verhaltenswissenschaftlichen Variablen der Einfluss bestätigt werden (vgl. Tab. B-87, Regression 1 und Regression 2), jedoch gilt dies

1477 Im Anhang 5 wird die Regression auch mit dem modifizierten Faktor dargestellt. Vgl. Anhang 5, Tab. AN 5-5. 
nicht für die gemeinsame Regression mit den Finanzkennzahlen und den beziehungsbezogenen Variablen. Die Ergebnisse werden in Tab. B-89 zusammengefasst, wobei hier die isolierte Betrachtung der verhaltenswissenschaftlichen Parameter aus der Regression 1 in Tab. B-87 sowie die kombinierte Betrachtung aus Regression 1 in Tab. B-88 als Grundlage dient.

\begin{tabular}{|c|c|c|c|c|c|c|c|c|}
\hline & \multirow{3}{*}{$\begin{array}{c}\text { Je größer ...., } \\
\text { desto ... }\end{array}$} & \multicolumn{7}{|c|}{... der Zinsatz. } \\
\hline & & \multirow[b]{2}{*}{ Hypothese } & \multicolumn{3}{|c|}{ Isolierte Betrachtung ${ }^{1478}$} & \multicolumn{3}{|c|}{ Kombinierte Betrachtung ${ }^{1479}$} \\
\hline & & & Empirie & $\begin{array}{l}\text { Signi- } \\
\text { fikanz }\end{array}$ & Fazit & Empirie & $\begin{array}{l}\text { Signi- } \\
\text { fikanz }\end{array}$ & Fazit \\
\hline $\mathrm{H} 1$ & $\begin{array}{l}\text { die organisationale } \\
\text { Glaubwürdigkeit }\end{array}$ & niedriger & niedriger & $5 \%$ & Best. & niedriger & & (Best.) \\
\hline $\mathrm{H} 2$ & $\begin{array}{l}\text { das organisatio- } \\
\text { nale Wohlwollen }\end{array}$ & niedriger & größer & & (Abl.) & größer & & (Abl.) \\
\hline $\mathrm{H} 3$ & $\begin{array}{l}\text { die interpersonale } \\
\text { Glaubwürdigkeit }\end{array}$ & niedriger & größer & & (Abl.) & größer & & (Abl.) \\
\hline $\mathrm{H} 4$ & $\begin{array}{l}\text { das interpersonale } \\
\text { Wohlwollen }\end{array}$ & niedriger & niedriger & $1 \%$ & Best. & niedriger & $10 \%$ & Best. \\
\hline $\mathrm{x}$ & $\begin{array}{l}\text { die organisationale } \\
\text { Gebundenheit }\end{array}$ & $\mathrm{x}$ & größer & $5 \%$ & $\mathrm{x}$ & größer & & $\mathrm{x}$ \\
\hline $\mathrm{x}$ & $\begin{array}{l}\text { die organisationale } \\
\text { Verbundenheit }\end{array}$ & $\mathrm{x}$ & niedriger & & $\mathrm{x}$ & niedriger & & $\mathrm{x}$ \\
\hline $\mathrm{x}$ & $\begin{array}{l}\text { die personale } \\
\text { Verbundenheit }\end{array}$ & $\mathrm{x}$ & größer & & $\mathrm{x}$ & größer & & $\mathrm{x}$ \\
\hline
\end{tabular}

Tab. B-89: Zusammenfassung der Ergebnisse zum Zinssatz ${ }^{1480}$

Während bisher untersucht wurde, inwiefern durch die Integration zusätzlicher Variablen oder Variablengruppen der Erklärungsgehalt gesteigert werden kann, erfolgt nun ein Vergleich mit bereits bestehenden Relationship Banking-Studien (vgl. Tab. B-90). In der Tabelle werden sowohl die signifikanten als auch die nicht signifikanten Variablen der jeweiligen Studien abgebildet.

Das korrigierte $\mathrm{R}^{2}$ der vorliegenden Studie beträgt $0,29 .{ }^{1481}$ Lediglich in der Studie von MACHAUER/WEBER kann mit einem $\mathrm{R}^{2}$ von 0,59 ein besserer Erklärungsgehalt erzielt werden. Der Erklärungsgehalt der Auswertungen von ANGELINI/Di SALvo/FerRI, Berger/Udell, Blackwell/Winters, Degreyse/Van Cayseele und Petersen/ RAJAN liegt deutlich unter dem Wert der vorliegenden Studie; die Werte liegen im Bereich von 0,16 bis 0,22 . Der Erklärungsgehalt in den Studien von HARHOFF/KÖRTING, LEHMANN/NEUBERGER und ELSAS/KRAHNEN befindet sich mit einem $\mathbf{R}^{2}$ von 0,28 bzw. 0,26 auf einem gleichen Niveau wie die vorliegende Studie.

1478 Vgl. Tab. B-87, Regression 1.

1479 Vgl. Tab. B-88, Regression 1.

1480 Die Einträge in der Spalte Fazit sind wie folgt zu verstehen: Best. - die Hypothese wird bestätigt, das Ergebnis ist signfikant; (Best.) - die Wirkungsrichtung der Hypothese wird bestätigt, das Ergebnis ist nicht signifikant; Abl. - die Hypothese wird abgelehnt, das Ergebnis ist signifikant; (Abl.) - die Hypothese wird abgelehnt, das Ergebnis ist nicht signfikant. 
Es fält auf, dass die Studien, in denen ein relativ hoher Erklärungsgehalt erzielt werden kann, allesamt aus Deutschland stammen. Möglicherweise unterscheidet sich das Zinssetzungsverhalten in den verschiedenen Ländern. Ursächlich scheint jedoch nicht das Finanzsystem zu sein. Denn der Erklärungsgehalt ist auch bei den Studien aus Belgien und Italien vergleichsweise niedrig, obwohl hier - ebenso wie in Deutschland - ein bankorientiertes Finanzsystem existiert. Auch der Vergleich der in den Studien jeweils verwendeten Variablen liefert keine Erklärung. So lässt sich keine Systematik dahingehend erkennen, dass bei den Studien mit einem hohen Erklärungsgehalt Variablen integriert worden sind, die in anderen Studien nicht berücksichtigt wurden.

\begin{tabular}{|c|c|c|c|c|c|c|c|c|c|c|c|c|}
\hline & & 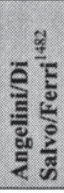 & 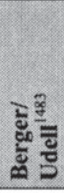 & 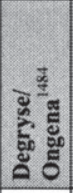 & 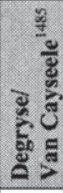 & 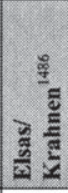 & 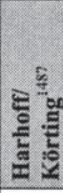 & 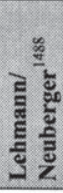 & 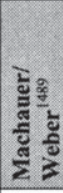 & 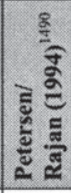 & 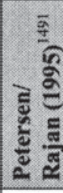 & 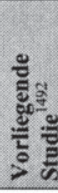 \\
\hline \multirow{6}{*}{$\begin{array}{l}\text { Unter- } \\
\text { neh- } \\
\text { mens- } \\
\text { bezogen }\end{array}$} & Rechtsform & & $\mathrm{x}$ & & $\mathrm{x}$ & & $\mathrm{x}$ & $\mathrm{x}$ & $\mathrm{x}$ & & $\mathrm{x}$ & \\
\hline & Branche & & $\mathrm{x}$ & & $\mathrm{x}$ & & $\mathrm{x}$ & $\mathrm{x}$ & & & & \\
\hline & $\begin{array}{l}\text { Kreditneh- } \\
\text { merqualităt }\end{array}$ & $\mathrm{x}$ & $\mathrm{x}$ & & & $\mathrm{x}$ & $\mathrm{x}$ & $\mathrm{x}$ & $\mathrm{x}$ & $\mathrm{x}$ & $\mathrm{x}$ & $\mathrm{x}$ \\
\hline & Größe & $\mathrm{x}$ & $\mathrm{x}$ & & $\mathrm{x}$ & $\mathrm{x}$ & $\mathrm{x}$ & $\mathrm{x}$ & & & $\mathrm{x}$ & $\mathrm{x}$ \\
\hline & Alter & $(\mathrm{X})$ & $\mathrm{x}$ & & $(\mathrm{X})$ & & $\mathrm{x}$ & & & $\mathrm{x}$ & & \\
\hline & $\begin{array}{l}\text { Anzahl der } \\
\text { Bankverbin- } \\
\text { dungen }\end{array}$ & $\mathrm{x}$ & & & & & $\mathrm{x}$ & & $\mathrm{x}$ & $\mathrm{x}$ & $\mathrm{x}$ & \\
\hline
\end{tabular}

1482 Angelini/Di Salvo/Ferri führen die Regression sowohl inklusive als auch exklusive der Variablen ALTER durch. Das $\mathrm{R}^{2}$ ist in beiden Fällen gleich hoch. Vgl. Angelini/Di Salvo/Ferri (1998), S. $937 \mathrm{f}$.

1483 Berger/Udell führen die Regression für verschiedenen Unternehmensgrößen durch: Bilanzsumme größer als 500.000 USD, Bilanzsumme kleiner gleich 500.000 USD, alle Unternehmen. Das hier ausgewiesene $R^{2}$ bezieht sich ausschließlich auf das Teilsample mit Unternehmen, die eine Bilanzsumme größer als 500.000 USD aufweisen. Bei Berücksichtigung aller Unternehmen beträgt das $\mathrm{R}^{2}$ lediglich 0,089. Vgl. Berger/Udell (1995), S. $364 \mathrm{ff}$. Vgl. Degreyse/Ongena (2005), S. 247.

Die abhängige Variable der herangezogenen Regression ist der Zins. Bei Integration der Variablen ALTER konnte für dieses Teilsample von 18,75\% des Gesamtdatenbestands - die Variable Alter lag nicht bei allen Unternehmen vor - das $R^{2}$ auf 0,302 gesteigert werden. Wenn anstelle des Zinssatzes der Termspread als abhängige Variable verwendet wird, beträgt das $R^{2} 0,363$. Im Teilsample mit $18,75 \%$ der Daten konnte bei Integration der Variablen ALTER das $R^{2}$ in diesem Fall auf 0,401 gesteigert werden. Vgl. Degreyse/Van Cayseele (1998), S. 33 f. Vgl. Elsas/Krahnen (1998), S. 1302. Elsas/Krahnen weisen jeweils die Werte für die Jahre 1993 bis 1996 aus. In obiger Tabelle werden die Werte für das Jahr 1996 verwendet. Das $R^{2}$ beträgt auch bei der Regression ohne Berücksichtigung der Vertrauensvariable 0,28. Vgl. Harhoff/Körting (1998a), S. 37 f.

Das $R^{2}$ beträgt bei der Regression ohne Berücksichtigung der Vertrauensvariablen 0,24 . Vgl. Lehmann/Neuberger (2001), S. 30.

1489 Vgl. Machauer/Weber (1998), S. $1366 \mathrm{ff}$.

1490 Vgl. Petersen/Rajan (1994), S. 30.

1491 Vgl. Petersen/Rajan (1995), S. 436.

1492 Vgl. hierzu Tab. B-88, Regression 1. 


\begin{tabular}{|c|c|c|c|c|c|c|c|c|c|c|c|c|}
\hline & & 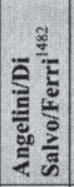 & 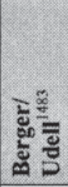 & 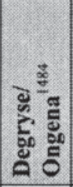 & 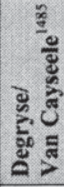 & 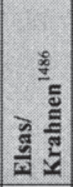 & 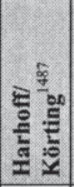 & 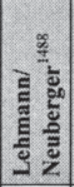 & 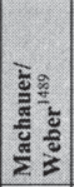 & 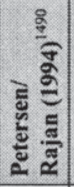 & 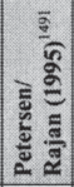 & 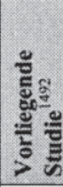 \\
\hline \multirow{6}{*}{$\begin{array}{l}\text { Bezie- } \\
\text { hungs- } \\
\text { bezogen }\end{array}$} & Dauer der GB & $\mathrm{x}$ & $\mathrm{x}$ & $\mathrm{x}$ & $\mathrm{x}$ & $\mathrm{x}$ & $\mathrm{x}$ & $\mathrm{x}$ & $\mathrm{x}$ & $\mathrm{x}$ & & \\
\hline & $\begin{array}{l}\begin{array}{l}\text { Zusătzliche } \\
\text { Dienstleistun- } \\
\text { gen }\end{array} \\
\end{array}$ & & & $\mathrm{x}$ & $\mathrm{x}$ & & $\mathrm{x}$ & & & $\mathrm{x}$ & & \\
\hline & $\begin{array}{l}\text { Sicherhei- } \\
\text { tenstellung }\end{array}$ & & $\mathrm{x}$ & & & $\mathrm{x}$ & $\mathrm{x}$ & $\mathrm{x}$ & $\mathrm{x}$ & & & \\
\hline & $\begin{array}{l}\text { Kreditvolu- } \\
\text { men }\end{array}$ & & & & & & & & $\mathrm{x}$ & & & \\
\hline & Mitgliedschaft & $x$ & & & & & & & & & & $\mathrm{x}$ \\
\hline & $\begin{array}{l}\text { Distanz zu } \\
\text { Bank }\end{array}$ & & & $\mathrm{x}$ & & & & & & & & \\
\hline $\begin{array}{l}\text { Markt- } \\
\text { bezogen }\end{array}$ & $\begin{array}{l}\text { Marktkonzen- } \\
\text { tration }\end{array}$ & $\mathrm{x}$ & & $\mathrm{x}$ & & $\mathrm{x}$ & & & & $\mathrm{x}$ & $\mathrm{x}$ & \\
\hline \multirow{2}{*}{$\begin{array}{l}\text { Verhal- } \\
\text { tens- } \\
\text { wiss. }\end{array}$} & Vertrauen & & & & & & $x$ & $\mathrm{x}$ & & & & $x$ \\
\hline & Commitment & & & & & & & & & & & $\mathrm{x}$ \\
\hline \multicolumn{2}{|c|}{ Korrigiertes $\mathrm{R}^{2}$} & 0,17 & 0,17 & 0,22 & 0,22 & 0,32 & 0,28 & 0,26 & 0,59 & 0,16 & 0,16 & 0,28 \\
\hline
\end{tabular}

Tab. B-90: Vergleich des Erklärungsgehalts in Bezug auf den Zinssatz mit anderen Studien

\section{5 Überprüfung der Hypothesen zur Sicherheitenstellung}

\subsubsection{Operationalisierung der Sicherheitenstellung}

Mit den Sicherheiten wird im Folgenden ein weiterer Kreditvertragsbestandteil untersucht. In Kapitel A.4.3.2.3 wurden bereits Ergebnisse bestehender Studien vorgestellt. In den Studien werden allerdings zum Teil unterschiedliche Operationalisierungsansätze verfolgt. BERGer/Udell, DEgRYSE/VAN CAYSEELE und HARHOFF/KöRTING unterscheiden bei ihren Untersuchungen nicht hinsichtlich der Höhe der Sicherheitenstellung, sondern untersuchen ausschließlich, ob Sicherheiten gestellt werden. Es wird nicht differenziert, ob die Besicherung $1 \%$ oder $100 \%$ beträgt. ${ }^{143}$ MACHAUER/WEBER hingegen untersuchen den Blankoanteil der Kreditlinie. ${ }^{1444}$

Darüber hinaus ist zu hinterfragen, ob der korrekte Bezugspunkt der Kunde oder ein einzelner Kredit ist. Zwar ist es auch denkbar, die Besicherung eines einzelnen Darlehens, sei es in Form einer binärcodierten Betrachtung oder in Form des Blankoanteils, zu analysieren. ${ }^{1995}$ Dieses Vorgehen haben DegrYSE/VAN CAYSEELE und BER-

\footnotetext{
1493 Einen Überblick über die Berücksichtigung von Sicherheiten in den verschiedenen Studien gibt Tab. B-29.

1494 Vgl. Machauer/Weber (1998), S. $1368 \mathrm{f}$.

1495 Vgl. Degryse/Van Cayseele (1998), S. 22.
} 
GER/UDELL gewählt. ${ }^{1496}$ Vor dem Hintergrund, dass der Einfluss von unternehmensund beziehungsbezogenen Parametern auf die Sicherheitenstellung analysiert werden soll, erscheint dieser Ansatz aber wenig zielführend, da die Sicherheitenquote für einen einzelnen Kredit gering sein bzw. Null betragen kann, während selbige für einen anderen Kredit des gleichen Kunden hoch sein kann. Ferner wird bei Sicherungsverträgen zwischen einem engen und einem weiten Sicherungszweck unterschieden. Während bei dem engen Sicherungszweck die Sicherheit nur zur Besicherung einer einzelnen Forderung, die auch Anlass der Sicherheitenbestellung gewesen ist, dient, wird bei einem weiten Sicherungszweck selbiger auch auf andere, nicht anlassbezogene Verbindlichkeiten ausgedehnt. In diesem Fall besteht keine exakte Zuordnung einer Sicherheit zu einer Verbindlichkeit. Da bei einer Sicherheitenstellung durch den Kreditnehmer selbst ein weiter Sicherungszweck üblich ist, wird folgerichtig in den weiteren Untersuchungen der Kunde und nicht der einzelne Kredit als Bezugspunkt gewählt. Wie bei ELSAS wird die Besicherung im Folgenden durch zwei Größen bzw. Variablen gemessen: ${ }^{1497}$

- EXIST_SICH: Es handelt sich hierbei um eine binäre Variable, die den Wert eins annimmt, wenn ein Engagement besichert ist, und im anderen Fall null beträgt.

- SICH_Q: Hierbei wird der Wert der insgesamt gestellten Sicherheiten ins Verhältnis zum gesamten Kreditvolumen des Kunden gestellt, ausgedrückt in \%. Die Kennzahl drückt den Grad der Besicherung eines Engagements bzw., wenn man diesen von eins subtrahiert, den unbesicherten Anteil aus. Der so ermittelte Blankoanteil kann auch als Maß für das Exposure einer Bank interpretiert werden.

In Abhängigkeit von der gewählten Variablen sind auch die statistischen Verfahren zu wählen. Aus diesem Grund werden die Variablen nacheinander analysiert, zunächst wird der Einfluss auf die binäre Variable EXIST_SICH und anschließend auf die Variable SICH_Q untersucht. Auf die Darstellung der Korrelationen der unabhängigen Variablen untereinander wird an dieser Stelle verzichtet. Zwar weicht die für die Untersuchung der Sicherheiten verwendete Datenbasis geringfügig von der Datenbasis ab, die als Grundlage der Korrelationsanalysen des Zinssatzes herangezogen wurde. Die Ergebnisse unterscheiden sich aber nicht wesentlich. ${ }^{1498}$ Das weitere Vorgehen ähnelt selbigem bei der Analyse des Einflusses auf den Zinssatz. Auch bei der Sicherheitenstellung wird erwartet, dass sich drei wesentliche Einflussbereiche unterscheiden lassen: Finanzkennzahlen, beziehungsbezogene und verhaltenswissenschaftliche Variablen. Ferner spielen möglicherweise auch weitere unternehmens- und bankbezogene Variablen eine Rolle, so dass der Einfluss derselbigen auf die Sicherheitenstellung ebenfalls untersucht wird.

\footnotetext{
1496 Vgl. Degryse/Van Cayseele (1998), S. 22, Berger/Udell (1995), S. 372 f.

1497 Vgl. Elsas (2001), S. 201.

1498 Vgl. auf die Darstellung der Korrelationsanalysen für die modifizierten wird aus dem Grund verzichtet, dass die Korrelationskoeffizienten sich lediglich an der 4 Nachkommastelle unterscheiden und keine Unterschiede bei den Signifikanzen vorliegen. 


\subsubsection{Sicherheiten - Binärcodierung}

\subsubsection{Durchführung der Korrelationsanalyse}

In einem ersten Schritt wurde eine Korrelationsanalyse zwischen der Sicherheitenstellung, gemessen als binäre Variable, sowie den Finanzkennzahlen durchgeführt. In vielen Relationship Banking-Studien, die sich mit der Sicherheitenstellung beschäftigen, wird der Zusammenhang zwischen der Sicherheitenstellung und der Bonität hergestellt. Sofern dieser Zusammenhang besteht, sollten sich hier bereits erste Hinweise ergeben. Da es sich bei der Variablen EXIST_SICH um eine dichotome Variable und bei den anderen Variablen um metrische Variablen handelt, wird die punktbiseriale Korrelation ermittelt. In den folgenden Tabellen werden nur die auf dem $1 \%$ - und 5\%Niveau signifikanten Korrelationen dargestellt.

In Tab. B-91 werden zunächst die Korrelationen der Finanzkennzahlen mit der Variablen EXIST_SICH abgebildet. Der Anteil an Verbindlichkeiten gegenüber Kreditinstituten, insbesondere an langfristigen Verbindlichkeiten, weist signifikante Korrelationen mit der Sicherheitenstellung auf. Das Vorzeichen entspricht insofern den Erwartungen, als dass ein höherer Anteil an langfristigen Verbindlichkeiten mit einer wahrscheinlicheren Sicherheitenstellung einhergeht. In einem nächsten Schritt wurde diese Variable als Kontrollvariable in den weiteren Auswertungen berücksichtigt, da selbige signifikante Korrelationen zu den diversen anderen hier verwendeten unabhängigen Variablen aufweist. ${ }^{1499}$ Nach Bereinigung um diesen Effekt weisen nur noch die Variablen ZINSDECK, KREDZIEL und VERB_KI_LANG_R_LN eine signifikante Korrelation auf. Die Zinsdeckung ist definiert als das Verhältnis von Betriebsergebnis vor Steuern zu Zinsaufwand. Auch hier erscheint es plausibel, dass Unternehmen mit einer geringeren Zinsdeckung mehr Sicherheiten stellen müssen. Hingegen kann keine direkte Erklärung für die negative Korrelation des Kreditorenziels mit der Sicherheitenstellung gefunden werden. Lange Zahlungsziele können einerseits auf Liquiditätsschwierigkeiten hindeuten, andererseits aber auch ein Indikator für die Branchenzugehörigkeit sein, denn die Mittelwerte des Kreditorenziels in den einzelnen Branchen schwanken zwischen 31,5 Tagen bei Handelsunternehmen, 68,43 Tagen bei Produktionsunternehmen, 131,36 Tagen bei Bauunternehmen und 222,28 Tagen bei Dienstleistungsunternehmen. ${ }^{1500}$ Die Variable VERB_KI_LANG_R_LN als Logarithmus der VERB_KI_LANG_R weist trotz Integration der Letzteren als Kontrollvariable eine signifikante positive Korrelation auf, was derart interpretiert werden kann, dass der nicht-lineare Effekt zusätzlich von Relevanz ist.

\footnotetext{
1499 Vgl. Anhang 4, Tab. AN 4-1.

1500 Vgl. Kapitel B.1.2.1.
} 


\begin{tabular}{|l|r|r|}
\hline Kontrollvariable & - & \multicolumn{1}{|c|}{$\begin{array}{l}\text { VERB_KI_ } \\
\text { LANG_R }\end{array}$} \\
\hline VERB_KI_LANG_R & $0,2259^{* * *}$ & \\
\hline VERB_KI_R & $0,2117^{* * *}$ & 0,0588 \\
\hline KASSE_R & $-0,1493^{* *}$ & $-0,1333$ \\
\hline ZINSDECK & $-0,1876^{* * *}$ & $-0,1692^{* *}$ \\
\hline KREDZIEL & $-0,2579^{* * *}$ & $-0,2434^{* * *}$ \\
\hline UMVORR & $-0,1419^{* *}$ & $-0,1631$ \\
\hline VERB_KI_LANG_R_LN & $0,1925^{* *}$ & $0,2178^{* *}$ \\
\hline VERB_KI_R_LN & $0,2444^{* * *}$ & 0,0314 \\
\hline KASSE_R_LN & $-0,1575^{* *}$ & 0,0214 \\
\hline VERB_KI_A_LN & $0,1472^{* *}$ & $-0,0718$ \\
\hline KASSE_A_LN & $-0,1584^{* *}$ & $-0,0463$ \\
\hline TSC_JA_AGG & $-0,1718^{* *}$ & $-0,1530$ \\
\hline
\end{tabular}

Tab. B-91: Bivariate und partielle Korrelationen der Finanzkennzahlen mit der Sicherheitenstellung

Die unternehmensbezogenen Variablen, d.h. Branche, Rechtsform und Alter, hingegen weisen keinerlei signifikante Korrelationen mit der Variablen EXIST_SICH auf. Im nächsten Schritt erfolgt eine Korrelationsanalyse der beziehungsbezogenen Variablen mit der Sicherheitenstellung. Auch hier ist in Tab. B-92 wiederum deutlich zu erkennen, dass bei den Variablen, die die Finanzierungsstruktur beschreiben, starke Korrelationen mit der Sicherheitenstellung bestehen. Ein großer Anteil der jeweiligen Bank an der gesamten Finanzierung (ANT_BANK_IN) geht einher mit einer hohen Wahrscheinlichkeit der Sicherheitenstellung. Dies spiegelt sich auch in den weiteren Variablen wider, die Ausdruck für den Finanzierungsanteil der Bank sind (VERB_EIG_LANG_R, VERB_EIG_KURZ_R, VERB_EIG_R, VERB_EIG_LANG_A, VERB_EIG_A). Die Variable AÑZ_BER_J weist zwar einen signifikanten positiven Zusammenhang mit der Sicherheitenstellung auf, allerdings lässt sich dies vermutlich auf Korrelationen mit der Finanzierungsstruktur zurückführen, denn die partielle Korrelation nach Einführung der Kontrollvariable ANT_BANK_IN ist nicht mehr signifikant. Ein hoher Finanzierungsanteil der Bank erfordert zahlreiche Beratungsgespräche. Die Ursache der Korrelation zur Sicherheitenstellung liegt somit weniger in den Beratungsgesprächen als im Finanzierungsanteil. Nach Bereinigung um diesen Effekt aus dem Anteil der Bankfinanzierung weisen die Variablen HAUSBANK_K, ANT_ZV, DARL, VERM_ANL, VERSICH, PRIVATKONT, DAU_BEZ_ERR und ANZÄHL_PRODUKT weiterhin positive signifikante Korrelationen und die Variablen DIST_UNT und ZINS_VERFÜG negative signifikante Korrelationen auf. Der positive Zusammenhang zwischen dem Hausbankstatus und der genutzten Produkte auf der einen Seite und der Sicherheitenstellung auf der anderen Seite ergibt sich möglicherweise daher, dass daraus eine bessere Kenntnis der Bank bzgl. der Möglichkeiten der Sicherheitenstellung resultiert und somit mehr Sicherheiten gefordert werden. ${ }^{1501}$

1501 Vgl. Degryse/Van Cayseele (2000), S. 106. 


\begin{tabular}{|c|c|c|}
\hline Kontrollvariable & - & ANT_BANK_IN \\
\hline VERB_EIG_LANG_R & $0,2081^{* * *}$ & 0,1113 \\
\hline VERB_EIG_KURZ_R & $0,1349 * *$ & 0,0807 \\
\hline VERB EIG $\mathrm{R}$ & $0,2156^{* * *}$ & 0,1265 \\
\hline VERB_EIG_LANG_A & $0,1491^{* *}$ & 0,0185 \\
\hline VERB_EIG_A & $0,1649 * *$ & 0,0422 \\
\hline HAUSBANK_K & $0,2276^{* * *}$ & $0,1965^{* *}$ \\
\hline ANZ_BER_J & $0,2268^{* * *}$ & 0,0768 \\
\hline GK SALD & $-0,1583 * *$ & $-0,1389$ \\
\hline GES_KREDIT & $0,1379 * *$ & 0,1219 \\
\hline ANT_ZV & $0,2492 * * *$ & $0,2470^{* * *}$ \\
\hline ANT_BANK_IN & $0,2708^{* * *}$ & \\
\hline ANT_BANK_HB_MOD & $0,2068^{* * *}$ & $-0,1198$ \\
\hline DIST_UNT & $-0,1871^{* * *}$ & $-0,2527 * * *$ \\
\hline DARL & $0,4928 * * *$ & $0,4106^{* * *}$ \\
\hline VERM_ANL & $0,2413^{* * *}$ & $0,2459 * * *$ \\
\hline VERSICH & $0,2262 * * *$ & $0,2435^{* * *}$ \\
\hline PRIVATKONT & $0,1726^{* *}$ & $0,2473^{* * *}$ \\
\hline ZINS_VERFÜG & $-0,2154 * * *$ & $-0,2396 * * *$ \\
\hline DAU BEZ ERR & $0,1455^{* *}$ & $0,1931^{* *}$ \\
\hline ANT_VERB_EIG_KURZ & $0,2556^{* * *}$ & 0,1628 \\
\hline ANT_VERB_EIG_GES & $0,2245^{* * *}$ & 0,1111 \\
\hline ANZAHL_PRODUKT & $0,4120^{* * *}$ & $0,4355^{* * *}$ \\
\hline DAU_PERS_ERR_LN & $0,1581^{* *}$ & 0,1582 \\
\hline
\end{tabular}

Tab. B-92: Bivariate und partielle Korrelationen der beziehungsbezogenen Variablen mit der Sicherheitenstellung

Abschließend erfolgt eine Korrelationsanalyse der verhaltenswissenschaftlichen Parameter mit der Sicherheitenstellung. Wie in Tab. B-93 dargestellt, steht die organisationale Glaubwürdigkeit als einziger Parameter in keinem statistisch signifikanten $\mathrm{Zu}$ sammenhang zur Sicherheitenstellung, während bei allen anderen Parametern ein negativer signifikanter Zusammenhang ermittelt wurde. Je größer das organisationale Wohlwollen, d.h. je niedriger der Punktwert auf der Ratingskala, desto eher werden Sicherheiten gestellt. Gleiches gilt für die anderen Parameter: je größer die personale Glaubwürdigkeit, das personale Wohlwollen, die organisationale Gebundenheit, die organisationale Verbundenheit oder die personale Verbundenheit, desto eher werden Sicherheiten gestellt. Eine Erklärung für die wahrscheinlichere Sicherheitenstellung bei größerem Wohlwollen und größerer Verbundenheit besteht darin, dass die Bereitschaft steigt, der Bank im Falle der Insolvenz einen bevorrechtigten Zugriff auf das Vermögen einzuräumen. In Kapitel B.2.3 wurde ein signifikanter Zusammenhang für die Glaubwürdigkeit und die Verbundenheit - jeweils auf organisationaler und personaler Ebene - vermutet. Es wurden ausschließlich sicherheitenreduzierende Effekte postuliert. 


\begin{tabular}{|l|r|}
\hline & Korrelation \\
\hline ORG_GLAUB & 0,1057 \\
\hline ORG_WOHL & $-0,1563^{*}$ \\
\hline PERS_GLAUB & $-0,1413^{*}$ \\
\hline PERS_WOHL & $-0,2545^{* *}$ \\
\hline ORG_GEB & $-0,2674 * *$ \\
\hline ORG_VER & $-0,1899^{* *}$ \\
\hline PERS_VER & $-0,2344 * *$ \\
\hline PERS_WOHL_VERB & $-0,2059^{* *}$ \\
\hline
\end{tabular}

Tab. B-93: Bivariate Korrelationen der verhaltenswissenschaftlichen Variablen mit der Sicherheitenstellung

Abschließend wurde eine Korrelationsanalyse der bankbezogenen Parameter mit der Sicherheitenstellung durchgeführt (vgl. Tab. B-94). So steht ein hoher Marktanteil der Bank in einem statistisch signifikanten positiven Zusammenhang mit der Sicherheitenstellung. Ursächlich hierfür könnte die resultierende Marktmacht der Bank sein. Denn je größer die Macht der Bank ist, desto mehr Sicherheiten kann sie für sich einfordern bzw. fordert sie für sich ein.

\begin{tabular}{|l|r|}
\hline & Korrelation \\
\hline MARKTAN_GES & $0,1451^{*}$ \\
\hline UMFELD_LÄND & $0,1631^{*}$ \\
\hline
\end{tabular}

Tab. B-94: Bivariate Korrelationen der bankbezogenen Variablen mit der Sicherheitenstellung

Nach der univariaten Analyse des Zusammenhangs zwischen der Sicherheitenstellung einerseits und den Finanzkennzahlen, den beziehungsbezogenen, den verhaltenswissenschaftlichen und den bankbezogenen Variablen andererseits folgt die Analyse des Zusammenhangs im multivariaten Kontext.

\subsubsection{Beschreibung der logistischen Regression}

Da aufgrund der Binärcodierung wesentliche Anwendungsvoraussetzungen nicht gegeben sind, können die Einflüsse auf die Sicherheitenstellung nicht mit dem Verfahren der linearen Regression untersucht werden. Ebenso wie bei DEGRYSE/VAN CAYSEELE und BERGER/UDELL wird die binäre logistische Regression verwendet, um den $\mathrm{Zu}$ sammenhang zwischen den unabhängigen Variablen sowie der abhängigen Variablen EXIST_SICH zu untersuchen. ${ }^{1502}$ Das logistische Regressionsmodell lautet:

$$
P\left(Y_{i}=\left\{X_{i}=x_{i}\right)=\frac{\exp \left(\beta_{0}+\beta_{1} X_{1}+\ldots+\beta_{n} X_{n}\right)}{1+\exp \left(\beta_{0}+\beta_{1} X_{1}+\ldots+\beta_{n} X_{n}\right)}\right.
$$

Das Wahrscheinlichkeitsverhältnis oder das Chancenverhältnis, d.h. das Verhältnis von $P\left(Y_{i}=1\right)$ zur Gegenwahrscheinlichkeit 1-P(Y $\left.Y_{i}=1\right)$ bzw. $P\left(Y_{i}=0\right)$ bei der Codie- 
rung der Alternativkategorie mit 0 , sind die Odds. ${ }^{1503}$ Die Odds können Werte im Bereich von Null bis plus unendlich annehmen, der Wertebereich nach unten nähert sich asymptotisch Null an.

(F.2) Odds $\left(Y_{100}\right)=\frac{P\left(Y_{i}=1\right)}{1-P\left(Y_{i}=1\right)}=\frac{P\left(Y_{i}=1\right)}{P\left(Y_{i}=0\right)}$

Ein unbeschränkter Wertebereich wird durch die Transformation der Odds in die sog. Logits erreicht, so dass Werte zwischen minus und plus unendlich erzielt werden können.

(F.3) $\operatorname{Logit}\left(Y_{10}\right)=\ln \left(\operatorname{Odds}\left(Y_{10}\right)\right)=\ln \frac{P\left(Y_{i}=1\right)}{1-P\left(Y_{i}=1\right)}$

Im Rahmen der logistischen Regression wird dann die Regressionsgleichung

(F.4) Logit $\left(Y_{10} \mid X_{i}=x_{i}\right)=\beta_{0}+\beta_{1} X_{1}+\ldots+\beta_{n} X_{n}$

geschätzt. Dadurch werden Regressionsgewichte bestimmt, nach denen die geschätzten Logits für eine gegebene Matrix der unabhängigen Variablen $\mathrm{X}$ berechnet werden können. Der Logitkoeffizient gibt die durchschnittliche lineare Veränderung des Logits an, wenn die unabhängige Variable um eine Einheit zunimmt. Aufgrund der schwierigen Interpretierbarkeit der so ermittelten Logitkoeffizienten werden durch die Bildung des Antilogarithmus häufig sog. Effektkoeffizienten $\exp \left(\beta_{n}\right)$ ermittelt. In Konsequenz bezieht sich die Regressionsgleichung auf die Odds:

(F.5) Odds $\left(Y_{10} \mid X_{i}=X_{i}\right)=\exp \left(\beta_{0}+\beta_{1} X_{1}+\ldots+\beta_{n} X_{n}\right)$

Das Logit ist hierbei nun die abhängige, transformierte Variable, die wieder linear von der unabhängigen Variablen $X$ abhängt. ${ }^{1504}$ Die Effektkoeffizienten $\exp \left(\beta_{n}\right)$ geben den Faktor für die Vervielfachung des Wahrscheinlichkeitsverhältnisses, d.h. des Odds, an, wenn c.p. die zugehörige exogene Variable um eine Einheit erhöht wird. Koeffizienten kleiner eins haben einen negativen Einfluss auf die Odds, Koeffizienten größer eins einen positiven Einfluss (vgl. Tab. B-95). Mittels einer weiteren Transformation lassen sich die Einflüsse der logistischen Regression auch als Einflüsse auf die Wahrscheinlichkeiten $P=\left(Y_{i}=1\right)$ ausdrücken:

$$
P\left(Y_{i}=1 X_{i}=x_{i}\right)=\frac{\exp \left(\beta_{0}+\beta_{1} X_{1}+\ldots+\beta_{n} X_{n}\right)}{1+\exp \left(\beta_{0}+\beta_{1} X_{1}+\ldots+\beta_{n} X_{n}\right)}
$$

Die Auswirkungen der Veränderung der unabhängigen Variablen um eine Einheit in Bezug auf die Logits, die Odds und die Wahrscheinlichkeit werden in Tab. B-95 dargestellt.

is03 Vgl. Diaz-Bone (2006), S. 234.

I504 Vgl. Diaz-Bone (2006), S. 234. 


\begin{tabular}{|c|c|c|c|c|}
\hline $\begin{array}{c}\text { Logit- } \\
\text { koeffizient }\end{array}$ & $\begin{array}{c}\text { Effekt- } \\
\text { koeffizient }\end{array}$ & Logit & Odds $=\frac{\mathbf{P}\left(\mathbf{Y}_{\mathrm{i}}=1\right)}{\mathbf{P}\left(\mathbf{Y}_{\mathbf{i}}=\mathbf{0}\right)}$ & $\mathbf{P}\left(\mathbf{Y}_{\mathrm{i}}=\mathbf{1}\right)$ \\
\hline$\beta_{\mathrm{i}}<0$ & $0<\exp \left(\beta_{\mathrm{i}}\right)<1$ & $\begin{array}{c}\text { nimmt um } \\
\beta_{\mathrm{i}} \mathrm{ab}\end{array}$ & $\begin{array}{c}\text { nehmen um den } \\
\text { Faktor exp }\left(\beta_{\mathrm{i}}\right) \mathrm{ab}\end{array}$ & nimmt ab \\
\hline$\beta_{\mathrm{i}}=0$ & $\exp \left(\beta_{\mathrm{i}}\right)=1$ & unverändert & unverändert & unverändert \\
\hline$\beta_{\mathrm{i}}>0$ & $\exp \left(\beta_{\mathrm{i}}\right)>1$ & $\begin{array}{c}\text { nimmt um } \beta_{\mathrm{i}} \\
\text { zu }\end{array}$ & $\begin{array}{c}\text { nehmen um den } \\
\text { Faktor exp }\left(\beta_{\mathrm{i}}\right) \mathrm{zu}\end{array}$ & nimmt zu \\
\hline
\end{tabular}

Tab. B-95: Auswirkungen der Veränderung der unabhängigen Variablen ${ }^{150}$

Inferenzstatistische Verfahren stehen sowohl für die einzelnen Regressionskoeffizienten als auch für das Gesamtmodell zur Verfügung. Mittels des Likelihood-QuotientenTests wird die Anpassungsverbesserung des endgültigen Modells im Vergleich zum Nullmodell auf Signifikanz geprüft. ${ }^{1506}$ Im Nullmodell werden die Regressionskoeffizienten der unabhängigen Variablen auf Null gesetzt. ${ }^{1507}$ In den Tabellen zur logistischen Regression wird die ermittelte Differenz der sog. Devianzwerte als LikelihoodQuotienten-Test sowie dessen Signifikanz ausgewiesen.

$\mathrm{Da}$ im logistischen Regressionsmodell eine Varianzzerlegung, mit deren Hilfe im linearen Regressionsmodell ein Determinationskoeffizient konstruiert wird, nicht möglich ist, kann zur Beurteilung der Erklärungsleistung eines logistischen Regressionsmodells nicht auf den Determinationskoeffizienten $\mathrm{R}^{2}$ aus der linearen Regression zurückgegriffen werden. ${ }^{1508}$ Aus diesem Grund wird häufig McFaddens-Pseudo- ${ }^{2}$ verwendet, welches angibt, in welchem Grad die unabhängigen Variablen zur Anpassungsverbesserung des logistischen Regressionsmodells beitragen. ${ }^{1509}$ Dazu wird das Modell, in dem die unabhängige Variable nicht berücksichtigt wird, mit einem Modell verglichen, in dem selbige berücksichtigt wird. ${ }^{1510}$ Das Pseudo- $\mathrm{R}^{2}-\mathrm{Ma} \beta$ erfasst die relative Anpassungsverbesserung des vollständigen Modells im Vergleich zum Ausgangsmodell. Während Pseudo- $R^{2}$-Werte unter 0,05 einen nur schwachen Zusammenhang aufweisen, deuten Werte von über 0,2 auf einen starken Zusammenhang hin. Werte über 0,4 treten nur selten auf. ${ }^{1511}$ Häufig verwendet werden ferner das Pseudo- ${ }^{2}$ nach Cox und Snell sowie das Pseudo- ${ }^{2}$ nach Nagelkerke. ${ }^{1512}$ Während bei Ersterem das mögliche Maximum des Pseudo- $\mathrm{R}^{2}$ kleiner 1 ist, wird das Pseudo- $\mathrm{R}^{2}$ von Nagelkerke hinzugezogen, da dieses bei perfektem Modell-Fit einen Wert von genau 1 erreicht. Pseudo- $\mathrm{R}^{2}$-Werte liegen in der Regel unter dem $\mathrm{R}^{2}$ der linearen Regression und sollten deshalb nicht unterschätzt werden. ${ }^{1513}$ Werte größer als 0,5 können als gut ange-

\footnotetext{
1505 Vgl. Backhaus et al. (2007), S. 445.

1506 Vgl. Diaz-Bone (2006), S. 249.

1507 Vgl. Backhaus et al. (2007), S. 447.

${ }_{1508}$ Vgl. Diaz-Bone (2006), S. 244.

1509 Vgl. Diaz-Bone (2006), S. 244.

1510 Vgl. Diaz-Bone (2006), S. 244.

I5ı Vgl. Andress et al. (1997), S. 288.

1512 Vgl. Backhaus et al. (2007), S. $448 \mathrm{ff}$.

1513 Vgl. Diaz-Bone (2006), S. 244.
} 
sehen werden. ${ }^{1514}$ Zudem erfolgt ein Ausweis der korrekt klassifizierten Werte. Es wird aufgezeigt, wie viel Prozent der Nein- bzw. Null-Ausprägung, der Ja- bzw. EinsAusprägung der abhängigen Variablen sowie wie viel Prozent insgesamt durch das logistische Regressionsmodell korrekt vorhergesagt wurden.

Vergleichbar mit dem T-Test für die einzelnen Regressionskoeffizienten bei der linearen Regression können auch hier die einzelnen Variablen $X_{i}$ unter der Hypothese getestet werden, dass sie in der Grundgesamtheit keinen Einfluss auf die abhängige Variable ausüben und dass die Ausprägung des Effektkoeffizienten in der Stichprobe nur zufällig von eins abweicht und somit, wie in Tab. B-95 dargestellt, nur zufällig einen Einfluss auf die Wahrscheinlichkeit hat. Eine mögliche Teststatistik bietet der in dieser Studie verwendete Likelihood-Quotienten-Test. ${ }^{\text {Isis }}$

Im Vergleich zur linearen multiplen Regression hat die logistische Regressionsanalyse weniger Anwendungsvoraussetzungen. ${ }^{1510}$ Ähnlich wie bei anderen Verfahren der Regression kann eine Multikollinearität zwischen den Einflussgrößen zu verzerrten Schätzungen und erhöhten Standardfehlern führen. ${ }^{1517}$ Ferner sollten die beiden Kategorien an unabhängigen Variablen nicht extrem ungleich belegt sein. Des Weiteren müssen die unabhängigen Variablen ein metrisches Skalenniveau aufweisen oder binärcodiert sein. Die Schätzungen für die Logit-Analyse verlangen eine Stichprobengröße von größer als 100.

Zur Vermeidung der Multikollinearität wird auf Basis der Erkenntnisse der Korrelationsanalyse bei zwei hoch korrelierenden Variablen stets nur eine der beiden Variablen verwendet. Die weiteren Voraussetzungen können als erfüllt betrachtet werden.

\subsubsection{Durchführung der logistischen Regression}

Vergleichbar mit dem Vorgehen bei der Analyse des Einflusses auf den Zinssatz erfolgt hier ebenfalls eine blockweise Betrachtung, d.h. zunächst werden die Finanzkennzahlen, anschließend die beziehungsbezogenen und danach die verhaltenswissenschaftlichen Variablen isoliert untersucht. Die Bereiche werden jeweils in eine gemeinsame Regression integriert.

In einem ersten Schritt werden nur die Finanzkennzahlen betrachtet. Die verschiedenen theoretischen Modelle in Kapitel A.4.3.1.3 haben gezeigt, dass in Fällen der adversen Selektion eher die guten Kreditnehmer Sicherheiten stellen, im Falle des Moral Hazard hingegen eher die schlechten Kreditnehmer. ${ }^{1518}$ Aus diesem Grund soll zunächst analysiert werden, inwiefern die Bonität des Unternehmens, losgelöst von sonstigen Parametern, die Existenz von Sicherheiten erklären kann. In Regression 1 in Tab. B-96 wurde ausschließlich die Ausfallwahrscheinlichkeit als die zentrale Größe zur Bonitätsbeurteilung betrachtet, in Regression 2 wurden ferner die Finanzkennzahlen

\footnotetext{
Isi4 Vgl. Backhaus et al. (2007), S. 448.

1515 Vgl. Diaz-Bone (2006), S. 250.

1516 Vgl. Diaz-Bone (2006), S. 232.

1517 Vgl. Diaz-Bone (2006), S. 232.

1518 Vgl. Hartmann-Wendels/Pfingsten/Weber (2007), S. 146. 
mit signifikanten partiellen Korrelationen ${ }^{1519}$ zur Sicherheitenstellung bei Integration der Kontrollvariablen VERB_KI_LANG_R herangezogen. Aufgrund der zentralen Bedeutung der Teilscores aus dem Rating bei der Beurteilung der Bonität wurden trotz der fehlenden signifikanten Korrelation des Teilscores für die qualitativen Daten beide Teilscores berücksichtigt.

Während bei alleiniger Betrachtung der Ausfallwahrscheinlichkeit in $74,65 \%$ der Fälle die Sicherheitenstellung korrekt vorhergesagt wird, kann dieser Anteil durch die Integration der Finanzkennzahlen und der Teilscores auf $80,00 \%$ signifikant gesteigert werden. Allerdings wird die Nicht-Existenz von Sicherheiten bei ausschließlicher Verwendung der Ausfallwahrscheinlichkeit in $0,00 \%$ der Fälle und bei Integration der weiteren Finanzkennzahlen lediglich in $29,27 \%$ der Fälle korrekt vorhergesagt. Der positive Logitkoeffizient der Ausfallwahrscheinlichkeit in allen drei Regressionen zeigt jedoch, dass ein Anstieg der Ausfallwahrscheinlichkeit des Unternehmens die Wahrscheinlichkeit der Sicherheitenstellung erhöht. Wie es sich bereits bei den Korrelationsanalysen im Kapitel B.3.5.2.1 angedeutet hat, führt ferner die Erhöhung der langfristigen Verbindlichkeitenquote gegenüber Kreditinstituten sowie die Verschlechterung der Zinsdeckung zu einer höheren Wahrscheinlichkeit der Sicherheitenstellung. Vergleicht man die Ergebnisse mit vorherigen Studien, so stimmen diese mit den Ergebnissen von BERGER/UDELL überein, die ebenfalls den Zusammenhang zwischen Kreditnehmerrisiko und Sicherheitenstellung untersucht haben. Ein höherer Leverage Ratio, d.h. eine höhere Relation von Fremd- zu Eigenkapital, und somit ein höheres Kreditnehmerrisiko führt in ihrer Studie zu einer höheren Wahrscheinlichkeit der Sicherheitenstellung. ${ }^{1520}$ Vergleichbare Ergebnisse finden sich in den Untersuchungen von HESTER und in einer älteren Studie von BERGER/UDELL: sie bestätigen jeweils das "Sorting-by-observed-risk"-Paradigma, bei dem Kunden mit schlechter Bonität mehr Sicherheiten stellen. ${ }^{1521}$ Untersuchungen von LEHMANN/NEUBERGER hingegen zeigen, dass Kreditnehmer mit einer schlechten Ratingbeurteilung weniger Sicherheiten stellen als gute Kreditnehmer. ${ }^{1522}$ Deren Ergebnis entspricht somit dem „Sorting-by-privateinformation"-Paradigma gemäß BESANKO/THAKOR. Bei MACHAUER/WEBER konnte kein eindeutiges Ergebnis erzielt werden. ${ }^{1523}$ Ursache für die divergierenden Ergebnisse könnte sein, dass Sicherheiten mal als Anreiz- und mal als Signalling-Instrument verwendet werden, wobei allerdings offen ist, welche Parameter die Verwendung bestimmen.

Ferner wurde in Regression 3 als unternehmensbezogene Variable auch die Rechtsform integriert, da hier basierend auf den existierenden empirischen Studien ${ }^{1524}$ vermutet wurde, dass die Rechtsform aufgrund der persönlichen Haftung der Gesellschafter bei Personengesellschaften einen Einfluss haben könnte. Da bei Personengesellschaften die Gesellschafter mit ihrem privaten Vermögen unbeschränkt haften, ist die Si-

\footnotetext{
1519 Vgl. Tab. B-102.

1520 Vgl. Berger/Udell (1995), S. 377.

1521 Vgl. Hester (1979), S. 349 ff., Berger/Udell (1990), S. 21 ff. und Berger/Udell (1995), S. 377.

1522 Vgl. Lehmann/Neuberger (2001), S. 23.

1523 Vgl. Machauer/Weber (1998), S. $1368 \mathrm{f}$.

1524 Vgl. Kapitel A.4.3.2.3.
} 
cherheitenstellung hier weniger bedeutsam als bei Kapitalgesellschaften. ${ }^{1525}$ Regression 3 kann diesen Zusammenhang nicht bestätigen. Kapitalgesellschaften inklusive $\mathrm{GmbH}$ \& Co. KG stellen weniger Sicherheiten, der Koeffizient ist allerdings nicht signifikant und die Güte des Gesamtmodells bleibt nahezu unverändert. Bei dieser Betrachtung wurden die Kapitalgesellschaften um $\mathrm{GmbH} \& \mathrm{Co}$. KG erweitert, da der unbeschränkt haftende Gesellschafter eine $\mathrm{GmbH}$ ist und das genannte Argument der unbeschränkten Haftung mit dem Privatvermögen hier nicht zutrifft. Die Ergebnisse stimmen überein mit LEHMANN/NEUBERGER. Selbige zeigen, dass Kapitalgesellschaften weniger Sicherheiten stellen. ${ }^{1526}$ LEHMANN/NEUBERGER argumentieren, dass die Rechtsform als Proxy für das Ausfallrisiko herangezogen wird, Kapitalgesellschaften seltener ausfallen und somit das „Sorting-by-observed-risk“-Paradigma bestätigt wird. ${ }^{1527}$ Auch die deskriptive Auswertung in Kapitel B.1.2.1 hat gezeigt, dass die Ausfallwahrscheinlichkeit bei Kapitalgesellschaften mit 1,67\% unter der Ausfallwahrscheinlichkeit von Nicht-Kapitalgesellschaften von 2,45\% liegt. Bei Betrachtung von Kapitalgesellschaften inkl. GmbH \& Co. KG hingegen liegt die Ausfallwahrscheinlichkeit mit 2,12\% über der Ausfallwahrscheinlichkeit von $1,23 \%$ bei Nicht-Kapitalgesellschaften exkl. GmbH \& Co. KG. Für den belgischen Markt zeigen DEGRYSE/VAN CAYSEELE, dass Kapitalgesellschaften im Vergleich zu Einzelunternehmen häufiger besichert sind. ${ }^{1528}$

\begin{tabular}{|c|c|c|c|c|c|c|}
\hline \multirow{2}{*}{ Einflussgröße } & \multicolumn{2}{|c|}{ Regression 1} & \multicolumn{2}{|c|}{ Regression 2} & \multicolumn{2}{|c|}{ Regression 3} \\
\hline & B & $\operatorname{Exp}(B)$ & B & $\operatorname{Exp}(\mathbf{B})$ & B & $\operatorname{Exp}(B)$ \\
\hline Konstante & 0,9045 & 2,4708 & $-0,5882$ & 0,5554 & $-0,5341$ & 0,5862 \\
\hline AUSFALLW B & $0,1677^{*}$ & 1,1826 & 0,2130 & 1,2373 & 0,2139 & 1,2385 \\
\hline ZINSDECK & & & $-0,0001^{* * *}$ & 0,9999 & $-0,0001^{* * *}$ & 0,9999 \\
\hline KREDZIEL & & & $-0,0032 * * *$ & 0,9968 & $-0,0032 * * *$ & 0,9968 \\
\hline VERB_KI_LANG_R & & & $0,0374 * * *$ & 1,0381 & $0,0371^{* * *}$ & 1,0378 \\
\hline TSC JA AGG & & & 0,0058 & 1,0058 & 0,0060 & 1,0060 \\
\hline TSC_QA_AGG & & & 0,0157 & 1,0158 & 0,0156 & 1,0157 \\
\hline KAP GMBHCOKG & & & & & $-0,0635$ & 0,9385 \\
\hline Likelihood-Quotienten-Test & & 3,0650 & & 35,7829 & & 35,7932 \\
\hline Signifikanz & & 0,0800 & & 0,0000 & & 0,0000 \\
\hline Cox und Snell & & 0,0140 & & 0,1950 & & 0,1950 \\
\hline Nagelkerke & & 0,0207 & & 0,2892 & & 0,2893 \\
\hline McFadden & & 0,0125 & & 0,1934 & & 0,1935 \\
\hline Korrekt: Nein (\%) & & 0,0000 & & 29,2683 & & 29,2683 \\
\hline Korrekt: Ja (\%) & & 100,0000 & & 96,7742 & & 96,7742 \\
\hline Korrekt: Gesamt (\%) & & 74,6500 & & 80,0000 & & 80,0000 \\
\hline $\mathbf{N}$ & & 217 & & 201 & & 201 \\
\hline
\end{tabular}

Tab. B-96: Logistische Regression der Finanzkennzahlen

\footnotetext{
is2s Vgl. hierzu auch Kapitel B.1.2.2.

$1526 \mathrm{Vgl}$. Lehmann/Neuberger (2001), S. 23.

1527 Vgl. Lehmann/Neuberger (2001), S. 23.

1528 Vgl. Degryse/Van Cayseele (2000), S. 106.
} 
In einem nächsten Schritt wird geprüft, inwiefern die beziehungsbezogenen Parameter die Existenz von Sicherheiten erklären können. Es werden wiederum die Variablen verwendet, die im Rahmen der partiellen Korrelationsanalyse, d.h. bei Bereinigung des Einflusses des Finanzierungsanteils durch das jeweilige Institut, signifikante Korrelationen mit der Variablen EXIST_SICH aufgewiesen haben. Der Anteil an korrekt klassifizierten Fällen steigt von vorher $74,65 \%$ bzw. 80,00\% auf nunmehr $84,19 \%$ (vgl. Tab. B-97, Regression 1). Einen signifikanten Einfluss haben lediglich die Variablen ANT_ZV, DIST_UNT und DARL. Der positive Zusammenhang zwischen der Wahrscheinlichkeit der Sicherheitenstellung und der Existenz von Darlehen ist evident. Eine höhere Distanz des Unternehmens zur Bank führt zu signifikant weniger Sicherheiten. Die Ursache könnte darin liegen, dass der Kunde aus dem Geschäftsgebiet einer anderen Bank kommt und ihm aus diesem Grund ein Zugeständnis in Form niedrigerer Sicherheiten gemacht wird. Allerdings liegt der Effektkoeffizient nahe bei eins, so dass die Auswirkungen auf die Odds, d.h. die Wahrscheinlichkeitsverhältnisse, relativ gering sind.

Gleiches lässt sich in Bezug auf den Anteil des Zahlungsverkehrs bei dem jeweiligen Institut feststellen. Ein Anstieg des Zahlungsverkehrs führt zu einer geringfügig kleineren Wahrscheinlichkeit der Sicherheitenstellung. Ursächlich hierfür könnten die besseren Informationen der Bank und somit eine bessere Bonitätsbeurteilung durch den Firmenkundenbetreuer sein. Regression 2 in Tab. B-97 zeigt, dass die gemeinsame Betrachtung der Finanzkennzahlen und der beziehungsbezogenen Parameter nur unter Verwendung der signifikanten Parameter zu einer leichten Verbesserung des Erklärungsgehalts führt, eine Regression ausschließlich mit den signifikanten Variablen bestätigt die Ergebnisse (vgl. Tab. B-97, Regression 3). 


\begin{tabular}{|c|c|c|c|c|c|c|}
\hline \multirow{2}{*}{ Einflussgröße } & \multicolumn{2}{|c|}{ Regression 1} & \multicolumn{2}{|c|}{ Regression 2} & \multicolumn{2}{|c|}{ Regression 3} \\
\hline & B & $\operatorname{Exp}(B)$ & B & $\operatorname{Exp}(B)$ & B & $\operatorname{Exp}(B)$ \\
\hline Konstante & $-0,5315$ & 0,5877 & $-1,4426$ & 0,2363 & $-0,1707$ & 0,8431 \\
\hline VERB KI LANG R & & & $0,0303^{*}$ & 1,0308 & $0,0244^{*}$ & 1,0247 \\
\hline ZINSDECK & & & $-0,0002 * *$ & 0,9998 & $-0,0001^{* *}$ & 0,9999 \\
\hline KREDZIEL & & 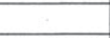 & $-0,0023^{* * * *}$ & 0,9977 & $-0,0024^{*}$ & 0,9976 \\
\hline HAUSBANK K & 0,1307 & 1,1396 & $-0,7818$ & 0,4576 & & \\
\hline ANT ZV & $-0,0008^{* *}$ & 0,9992 & 0,0205 & 1,0207 & & \\
\hline DIST UNT & $-0,0241^{* *}$ & 0,9762 & $-0,0221^{* * *}$ & 0,9781 & $-0,0299^{*}$ & 0,9705 \\
\hline DARL & $2,3721^{*}$ & 10,7203 & $1,7955^{* *}$ & 6,0226 & $2,1644^{*}$ & 8,7096 \\
\hline VERM ANL & 1,0498 & 2,8570 & $1,5485^{*}$ & 4,7045 & $1,4628^{*}$ & 4,3182 \\
\hline VERSICH & 0,6230 & 1,8645 & $-0,3624$ & 0,6960 & & \\
\hline PRIVATKONT & 0,2209 & 1,2472 & $-0,0028$ & 0,9972 & & \\
\hline ZINS VERFÜG & $-1,1473$ & 0,3175 & $-0,9088$ & 0,4030 & & \\
\hline DAU_BEZ ERR & 0,0278 & 1,0282 & 0,0221 & 1,0224 & & \\
\hline ANZAHL PRODUKT & $-0,2295$ & 0,7949 & 0,0110 & 1,0111 & & \\
\hline ANT_BANK_IN & 0,0118 & 1,0118 & 0,0156 & 1,0158 & & \\
\hline Likelihood-Quotienten-Test & & 69,4212 & & 82,2037 & & 81,6815 \\
\hline Signifikanz & & 0,0000 & & 0,0000 & & 0,0000 \\
\hline Cox und Snell & & 0,2983 & & 0,3634 & & 0,3422 \\
\hline Nagelkerke & & 0,4494 & & 0,5669 & & 0,5181 \\
\hline McFadden & & 0,3250 & & 0,4408 & & 0,3877 \\
\hline Korrekt: Nein (\%) & & 52,1739 & & 65,7895 & & 57,7778 \\
\hline Korrekt: Ja (\%) & & 94,0000 & & 93,7500 & & 94,0000 \\
\hline Korrekt: Gesamt (\%) & & 84,1837 & & 87,9121 & & 85,6410 \\
\hline $\mathbf{N}$ & & 216 & & 182 & & 195 \\
\hline
\end{tabular}

Tab. B-97: Logistische Regression der beziehungsbezogenen Variablen und der Finanzkennzahlen

Im nächsten Schritt werden die verhaltenswissenschaftlichen Parameter untersucht. In Regression 1 in Tab. B-98 werden ausschließlich die Original-Faktoren verwendet, in Regression 2 wird der modifizierte Faktor PERS_WOHL_VERB integriert. Nur unter Berücksichtigung der verhaltenswissenschaftlichen Parameter werden $\mathbf{7 9 , 9 0 \%}$ der Variablen (vgl. Tab. B-98) richtig klassifiziert, was ungefähr den Werten der Finanzkennzahlen entspricht.

Bei Betrachtung der organisationalen Ebene lassen sich folgende Zusammenhänge hinsichtlich der Vertrauensdimensionen beobachten. Ein niedrigerer Faktorwert der organisationalen Glaubwürdigkeit, d.h. eine Verbesserung derselben, reduziert die Wahrscheinlichkeit der Sicherheitenstellung. Eine hohe organisationale Glaubwürdigkeit und damit einhergehend ein Vertrauen in die Unternehmensentscheidungen im Allgemeinen und das Vertrauen in sinnvolle Investitionsentscheidungen im Speziellen führt somit zu niedrigeren Sicherheitenforderungen. Bei gegebener Glaubwürdigkeit wird die Notwendigkeit zu extrinsischen Anreizen reduziert, d.h. die Wahrnehmung des Kunden als kompetent und eine resultierende Vermutung des Firmenkundenbetreuers, dass der Kunde sich ohnehin, d.h. auch ohne zusätzliche Sicherheitenstellung, anstrengen wird, führt zu niedrigeren Sicherheitenforderungen. Die Hypothese H5 kann somit bestätigt werden. Gleichermaßen, wenn auch nicht signifikant, führt ein niedrigerer Faktorwert des organisationalen Wohlwollens, d.h. eine Verbesserung 
desselben, zu einer Reduktion der Wahrscheinlichkeit der Sicherheitenstellung. Hier wurde ex ante angenommen, dass ein erhöhtes Wohlwollen die Gefahr des Moral Hazard reduziert und somit weniger Sicherheiten von der Bank gefordert werden.

H5: Je größer die organisationale Glaubwürdigkeit des Unternehmens, desto weniger Sicherheiten werden gestellt. (Best. - 5\%-Niveau)

H6: Je größer das organisationale Wohlwollen des Unternehmens, desto weniger Sicherheiten werden gestellt. (Best. - keine Signifikanz)

Auf personaler Ebene führen niedrigere Faktorwerte, d.h. eine Verbesserung der Ausprägung, sowohl der Glaubwürdigkeit als auch des Wohlwollens zu einer höheren Wahrscheinlichkeit der Sicherheitenstellung. Beide Effekte sind signifikant. Hinsichtlich der personalen Glaubwürdigkeit wurde der gleiche Zusammenhang wie bei der organisationalen Glaubwürdigkeit vermutet. Es wurde ferner angenommen, dass die personale Glaubwürdigkeit eher einen verstärkenden Effekt auf die organisationale Glaubwürdigkeit ausübt und das Letztere in gewisser Weise eine Voraussetzung für das Wirken der personalen Glaubwürdigkeit ist. Warum sich gegenläufige Effekte ergeben, kann nicht erklärt werden. Hypothese $\mathrm{H} 7$ kann nicht bestätigt werden. Hinsichtlich des interpersonalen Wohlwollens wurde angenommen, dass selbiges - ebenso wie das organisationale Wohlwollen - die Gefahr des Moral Hazard reduziert und somit weniger Sicherheiten von der Bank gefordert werden. Die Untersuchung zeigt aber, dass eine Verbesserung des Wohlwollens zu einer größeren Wahrscheinlichkeit der Sicherheitenstellung führt. Möglicherweise ist der Ansprechpartner des Unternehmens bei einem höheren Wohlwollen eher zu (nicht-monetären) Zugeständnissen in Form zusätzlicher Sicherheiten bereit. Hypothese H8 kann somit nicht bestätigt werden.

H7: Je größer die interpersonale Glaubwürdigkeit des Ansprechpartners im Unternehmen, desto weniger Sicherheiten werden gestellt. (Abl. - 10\%-Niveau)

H8: Je größer das interpersonale Wohlwollen des Ansprechpartners im Unternehmen, desto weniger Sicherheiten werden gestellt. (Abl. - 10\%-Niveau)

Bei Betrachtung der Commitment-Dimension lässt sich lediglich für die organisationale Gebundenheit ein auf dem 5\%-Niveau signifikanter Effekt feststellen. Niedrige Faktorwerte, d.h. eine hohe Gebundenheit, führen zu einer hohen Wahrscheinlichkeit der Sicherheitenstellung. Eine mögliche Erklärung besteht darin, dass aus der Gebundenheit eine Machtstellung der Bank resultiert, welche diese durch Forderung höherer Sicherheiten ausnutzt. Ferner kann die hohe Gebundenheit auch Konsequenz einer geringen Bonität sein, so dass die eigentliche Ursache die schlechte Bonität des Unternehmens ist. Die Hypothese H9 kann somit signifikant bestätigt werden.

Bei der Verbundenheit führen auf organisationaler Ebene höhere Faktorwerte, d.h. eine Verschlechterung, und auf personaler Ebene niedrigere Faktorwerte, d.h. eine Verbesserung, zu einer größeren Wahrscheinlichkeit der Sicherheitenstellung. Sowohl für die organisationale als auch für die personale Verbundenheit wurde vermutet, dass selbige - vergleichbar mit den Effekten aus dem Wohlwollen - zu einer erhöhten Motivation des Unternehmens führt, so dass die Anreizfunktion der Sicherheiten nicht 
mehr notwendig ist. Infolgedessen sollte die Wahrscheinlichkeit der Sicherheitenstellung sinken. Die personale Verbundenheit wird nur dann einen reduzierenden Effekt auf die Sicherheitenstellung ausüben, wenn der Einfluss des Ansprechpartners im Unternehmen hinreichend groß ist, so dass seine Entscheidungen für den unternehmerischen Erfolg bedeutsam sind. Die mangelnde Signifikanz der personalen Verbundenheit könnte auf einen geringen Einfluss des Ansprechpartners im Unternehmen hindeuten. Die Wirkungsrichtung bei der organisationalen Verbundenheit bestätigt, wenngleich auch nicht signifikant, die Hypothese H10. Die Hypothese H11 zur personalen Verbundenheit hingegen kann auch nicht von der Wirkungsrichtung bestätigt werden.

H 9: Je größer die organisationale Gebundenheit des Unternehmens, desto mehr Sicherheiten werden gestellt. (Best. - 5\%-Niveau)

H 10: Je größer die organisationale Verbundenheit des Unternehmens, desto weniger Sicherheiten werden gestellt. (Best. - keine Signifikanz)

H 11: Je größer die personale Verbundenheit des Ansprechpartners im Unternehmen, desto weniger Sicherheiten werden gestellt. (Abl. - keine Signifikanz)

\begin{tabular}{|c|c|c|c|c|}
\hline \multirow{2}{*}{ Einflussgröße } & \multicolumn{2}{|c|}{ Regression 1} & \multicolumn{2}{|c|}{ Regression 2} \\
\hline & B & $\operatorname{Exp}(B)$ & B & $\operatorname{Exp}(B)$ \\
\hline Konstante & $1,3912^{* * *}$ & 4,0196 & $1,2552^{* * *}$ & 3,5084 \\
\hline ORG_GLAUB & $0,7878 * *$ & 2,1986 & $0,7557^{* *}$ & 2,1291 \\
\hline ORG WOHL & 0,0389 & 1,0396 & $-0,2146$ & 0,8068 \\
\hline PERS_GLAUB & $-0,5371^{*}$ & 0,5844 & $-0,6010^{*}$ & \\
\hline PERS WOHL & $-0,5863^{*}$ & 0,5564 & & \\
\hline ORG_GEB & $-0,5101^{* *}$ & 0,6005 & $-0,4344^{*}$ & 0,6476 \\
\hline ORG VER & 0,0004 & 1,0004 & 0,0371 & 1,0378 \\
\hline PERS VER & $-0,2017$ & 0,8174 & & 0,5483 \\
\hline PERS WOHL_VERB & & & $-0,3358$ & 1,3990 \\
\hline Likelihood-Quotienten-Test & & 30,1012 & & 23,7846 \\
\hline Signifikanz & & 0,0001 & & 0,0006 \\
\hline Cox und Snell & & 0,1437 & & 0,1127 \\
\hline Nagelkerke & & 0,2173 & & 0,1675 \\
\hline McFadden & & 0,1432 & & 0,1071 \\
\hline Korrekt: Nein (\%) & & 24,4444 & & 20,4082 \\
\hline Korrekt: Ja (\%) & & 96,6443 & & 96,6667 \\
\hline Korrekt: Gesamt (\%) & & 79,8969 & & 77,8894 \\
\hline $\mathbf{N}$ & & 192 & & 197 \\
\hline
\end{tabular}

Tab. B-98: Logistische Regression der verhaltenswissenschaftlichen Variablen

In einem letzten Schritt (vgl. Tab. B-99) werden alle verhaltenswissenschaftlichen Variablen zuzüglich der signifikanten Variablen der vorherigen Regressionen berücksichtigt. Die gemeinsame Integration aller Variablen erscheint nicht zielführend, da in diesem Fall die Variablenzahl zu groß wäre. Es wird erneut sowohl eine Regression mit den Originalfaktoren (vgl. Tab. B-99, Regression 1) als auch eine Regression mit dem modifizierten Faktor (vgl. Tab. B-99, Regression 2) durchgeführt. Die verhaltenswissenschaftlichen Faktoren sind bei der kombinierten Betrachtung nicht signifikant. Der Vergleich mit der Regression ohne Berücksichtigung der verhaltenswissen- 
schaftlichen Parameter in Tab. B-97 zeigt aber, dass die Integration derselbigen zu einer besseren Klassifizierung führt. So steigt der Anteil der richtig klassifizierten Werte von $85,64 \%$ auf $88,50 \%$. Auch die Pseudo- $\mathbf{R}^{2}$-Werte liegen über den entsprechenden Werten der Regression ohne die verhaltenswissenschaftlichen Parameter (Cox und Snell: 0,3712 vs. 0,3422 , Nagelkerke: 0,5807 vs. 0,5181 und McFadden 0,4550

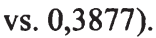

\begin{tabular}{|c|c|c|c|c|}
\hline \multirow{2}{*}{ Einflussgröße } & \multicolumn{2}{|c|}{ Regression 1} & \multicolumn{2}{|c|}{ Regression 2} \\
\hline & B & $\operatorname{Exp}(B)$ & B & $\operatorname{Exp}(B)$ \\
\hline Konstante & 0,0902 & 1,0944 & $-0,0455$ & 0,9555 \\
\hline VERB KI LANG R & 0,0091 & 1,0091 & 0,0220 & 1,0222 \\
\hline ZINSDECK & $-0,0002 * *$ & 0,9998 & $-0,0001^{* *}$ & 0,9999 \\
\hline KREDZIEL & $-0,0025^{* * *}$ & 0,9975 & $-0,0028^{* * *}$ & 0,9972 \\
\hline DIST UNT & $-0,0165^{* *}$ & 0,9836 & $-0,0176^{* * *}$ & 0,9826 \\
\hline DARL & $2,3325 * * *$ & 10,3036 & $2,0385^{* * *}$ & 7,6789 \\
\hline VERM ANL & $1,5306^{* *}$ & 4,6208 & $1,6501^{* *}$ & 5,2073 \\
\hline ORG_GLAUB & 0,7280 & 2,0709 & 0,5185 & 1,6794 \\
\hline ORG_WOHL & $-0,0498$ & 0,9514 & $-0,1962$ & 0,8218 \\
\hline PERS GLAUB & $-0,5537$ & 0,5748 & $-0,4936$ & 0,6104 \\
\hline PERS WOHL & $-0,2404$ & 0,7863 & & \\
\hline ORG GEB & $-0,3613$ & 0,6968 & $-0,2258$ & 0,7979 \\
\hline ORG VER & 0,1921 & 1,2117 & 0,0863 & 1,0902 \\
\hline PERS VER & $-0,2325$ & 0,7926 & & \\
\hline PERS WOHL VERB & & & 0,0212 & 1,0215 \\
\hline Likelihood-Quotienten-Test & & 80,7252 & & 81,7041 \\
\hline Signifikanz & & 0,0000 & & 0,0000 \\
\hline Cox und Snell & & 0,3712 & & 0,3697 \\
\hline Nagelkerke & & 0,5807 & & 0,5673 \\
\hline MeFadden & & 0,4550 & & 0,4377 \\
\hline Korrekt: Nein $(\%)$ & & 61,1111 & & 64,1026 \\
\hline Korrekt: Ja (\%) & & 95,6522 & & 94,9275 \\
\hline Korrekt: Gesamt (\%) & & 88,5057 & & 88,1356 \\
\hline $\mathbf{N}$ & & 174 & & 177 \\
\hline
\end{tabular}

Tab. B-99: Logistische Regression der Finanzkennzahlen, der beziehungsbezogenen und der verhaltenswissenschaftlichen Variablen

Die Ergebnisse werden in Tab. B-100 zusammengefasst. Auffälig ist, dass sich die Wirkungsrichtung des organisationalen Wohlwollens bei der kombinierten Betrachtung im Vergleich zur isolierten Betrachtung umkehrt. Während bei isolierter Betrachtung das organisationale Wohlwollen zu einer Sicherheitenreduktion führt, bewirkt es bei der kombinierten Betrachtung einen Anstieg. Es kann resümiert werden, dass die verhaltenswissenschaftlichen Variablen zwar signifikante Effekte auf die Sicherheitenstellung ausüben, aber die Wirkungsrichtung der Effekte nicht immer der angenommenen Richtung entspricht. 


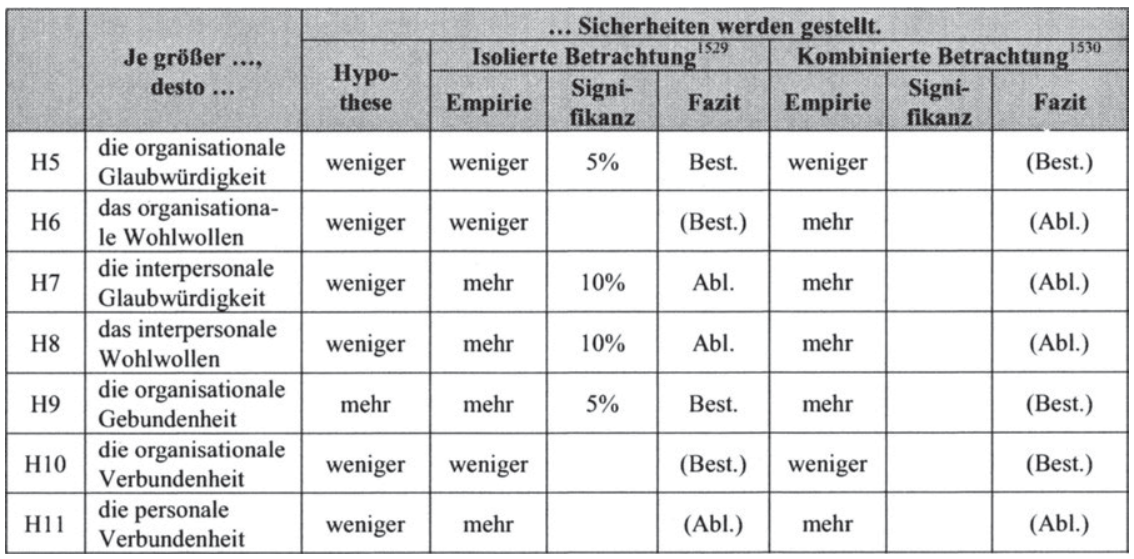

Tab. B-100: Zusammenfassung der Ergebnisse zur Sicherheitenstellung

Wie bereits bei dem Zinssatz soll im Folgenden ein Vergleich der durchgeführten Regressionen zur Sicherheitenstellung mit bereits bestehenden Studien erfolgen. In diesem Kapitel erfolgt ausschließlich ein Vergleich mit Studien, die die Sicherheitenstellung ebenfalls als binär codierte Variable berücksichtigt haben. Allerdings ist die Vergleichbarkeit der Gütemaße eingeschränkt, da einige Autoren die logistische Regression und einige Autoren die Probit-Analyse verwendet haben. ${ }^{1531}$ Ferner werden bei der logistischen Regression nicht die gleichen Gütemaße angegeben. BERGER/ UDELL weisen zwar aus, dass das Modell insgesamt signifikant ist, eine Aussage zum Erklärungsgehalt oder zum Anteil der richtig klassifizierten Variablen machen sie nicht. ${ }^{1532}$ Gleiches gilt für Degreyse/VAN CAYSEELE. ${ }^{1533}$ Auch bei mangelnder Vergleichbarkeit kann der Wert für das $\mathbf{R}^{2}$ von 0,58 sowie der Anteil der richtig klassifizierten Variablen von $88,51 \%$ als hoch eingestuft werden.

\section{Vgl. Tab. B-98, Regression 1.}

1530 Vgl. Tab. B-99, Regression 1.

1531 Harhoff/Körting und Elsas haben eine Probit-Regression verwendet. Vgl. Harhoff/Körting (1998a), S. 30 f., Elsas (1999), S. 213. Berger/Udell, Degreyse/Van Cayseele und Scott/Dunkelberg verwenden eine logistische Regression. Vgl. Berger/Udell (1995), S. 374, Degreyse/Van Cayseele (1998), S. 33 f., Scott/Dunkelberg (2003), S. 1010 f.

1532 Vgl. Berger/Udell (1995), S. 374. Berger/Udell unterscheiden bei ihrer Regression unterschiedliche Größenklassen: Unternehmen mit einer Bilanzsumme kleiner 500.000 USD, Unternehmen mit einer Bilanzsumme größer 500.000 USD sowie alle Unternehmen. Alle Regressionen sind signifikant.

1533 Vgl. Degreyse/Van Cayseele (1998), S. 33 f., Degreyse/Van Cayseele (2000), S. 105. 


\begin{tabular}{|c|c|c|c|c|c|c|c|c|}
\hline & & 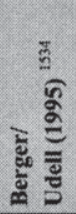 & $\frac{\hbar}{\tilde{\infty}}$ & 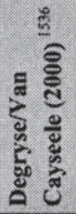 & $\frac{\text { है }}{\text { 쏘 }}$ & 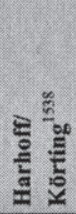 & 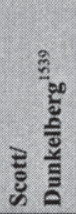 & 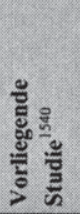 \\
\hline \multirow{6}{*}{$\begin{array}{l}\text { Unter- } \\
\text { neh- } \\
\text { mensbe- } \\
\text { zogen }\end{array}$} & Rechtsform & $\mathrm{X}$ & $\mathrm{X}$ & $\mathrm{X}$ & & $\mathrm{X}$ & $\mathrm{X}$ & \\
\hline & Branche & & & & $\mathrm{x}$ & $\mathrm{X}$ & $\mathrm{X}$ & \\
\hline & $\begin{array}{l}\text { Kreditnehmer- } \\
\text { qualität }\end{array}$ & $\mathrm{x}$ & & & $\mathrm{x}$ & (X) & $\mathrm{x}$ & $\mathrm{x}$ \\
\hline & Größe & $\mathrm{X}$ & $\mathrm{X}$ & $\mathrm{x}$ & $\mathrm{x}$ & $\mathrm{X}$ & $\mathrm{X}$ & \\
\hline & Alter & $\mathrm{X}$ & (X) & (X) & & $\mathrm{X}$ & $\mathrm{X}$ & \\
\hline & $\begin{array}{l}\text { Anzahl der } \\
\text { Bankverbindun- } \\
\text { gen }\end{array}$ & & & & & $\mathrm{x}$ & $\mathrm{x}$ & \\
\hline \multirow{4}{*}{$\begin{array}{l}\text { Bezie- } \\
\text { hungs- } \\
\text { bezogen }\end{array}$} & Dauer der GB & $\mathrm{X}$ & $\mathrm{X}$ & $\mathrm{x}$ & & $\mathrm{x}$ & $\mathrm{x}$ & \\
\hline & $\begin{array}{l}\text { Zusätzliche } \\
\text { Dienstleistungen }\end{array}$ & & $\mathrm{X}$ & $\mathrm{x}$ & & & & $\mathrm{x}$ \\
\hline & Kreditvolumen & & $\mathrm{x}$ & $\mathrm{x}$ & $\mathrm{x}$ & $\mathrm{x}$ & $\mathrm{X}$ & \\
\hline & Distanz zur Bank & & & & & & & $\mathrm{x}$ \\
\hline \multirow{5}{*}{$\begin{array}{l}\text { Verhal- } \\
\text { tenswiss. }\end{array}$} & Vertrauen & & & & & $\mathrm{x}$ & & $\mathrm{x}$ \\
\hline & Commitment & & & & & & & $\mathrm{x}$ \\
\hline & $\mathrm{N}$ & 437 & 17.776 & 17.429 & 472 & 465 & & 174 \\
\hline & Pseudo- $\mathrm{R}^{2}$ & - & - & - & 0,56 & 0,1294 & - & $0,58^{1541}$ \\
\hline & $\begin{array}{l}\text { Richtig } \\
\text { klassifiziert }\end{array}$ & - & - & - & - & - & - & $88,51 \%$ \\
\hline
\end{tabular}

Tab. B-101: Vergleich des Erklärungsgehalts in Bezug auf die Sicherheitenstellung mit anderen Studien

\subsubsection{Besicherungsquote}

\subsubsection{Durchführung der Korrelationsanalyse}

Nachdem bisher ausschließlich die Existenz von Sicherheiten bzw. die Wahrscheinlichkeit der Sicherheitenstellung untersucht wurde, folgt nun eine Analyse der Besicherungsquote. Der Regressionsanalyse wird erneut eine Korrelationsanalyse vorgelagert, um die relevanten Parameter zu identifizieren. Bei Verwendung des Korrelationskoeffizienten nach Pearson müssen beide Variablen normalverteilt sein. Bei zu starken Abweichungen von der Normalverteilung muss stattdessen auf Rangkorrela-

\footnotetext{
1534 Vgl. Berger/Udell (1995), S. 374.

1535 Vgl. Degreyse/Van Cayseele (1998), S. 33 f.

1536 Vgl. Degreyse/Van Cayseele (2000), S. 105.

1537 Vgl. Elsas (1999), S. 213.

1538 Vgl. Harhoff/Körting (1998a), S. $30 \mathrm{f}$.

1539 Vgl. Scott/Dunkelberg (2003), S. $1010 \mathrm{f}$.

1540 Vgl. Tab. B-99, Regression 1.
}

1541 Bei dem Pseudo- $R^{2}$ der vorliegenden Studie wird das $\mathbf{R}^{2}$ nach Nagelkerke ausgewiesen. 
tionen zurückgegriffen werden. Da die Voraussetzung der Normalverteilung bei der Sicherheitenquote nicht vollständig eingehalten wird, ${ }^{1542}$ erfolgt neben der Berechnung des Korrelationskoeffizienten nach Pearson ferner auch die Ermittlung von Spearmans Rangkorrelationskoeffizienten. ${ }^{1543}$

Im Rahmen der Korrelationsanalyse werden - wie auch zuvor in Kapitel B.3.4.2.1 und B.3.5.2.1 - nur die auf dem 1\%- und 5\%-Niveau signifikanten Korrelationen dargestellt. Lediglich bei den verhaltenswissenschaftlichen Parametern werden aufgrund der zentralen Bedeutung für diese Studie alle Korrelationen ausgewiesen. Die Korrelationen der Finanzkennzahlen mit der Besicherungsquote zeigen (vgl. Tab. B-102), dass ein höherer Anteil an Verbindlichkeiten gegenüber Kreditinstituten - dies betrifft sowohl die kurz- als auch die langfristigen Verbindlichkeiten - mit einer höheren Besicherungsquote einhergeht. In Verbindung mit dem negativen Zusammenhang der Eigenkapitalquote, der Zinsdeckung und des quantitativen Teilscores sowie dem positiven Zusammenhang der Ausfallwahrscheinlichkeit, bestätigt sich wie auch in Kapitel B.3.5.2.3 die These - allerdings zunächst nur im univariaten Kontext -, dass Kreditnehmer mit schlechten Bonitäten mehr Sicherheiten stellen. Ferner stellen Unternehmen, die ein größeres langfristiges Vermögen (VERM_LA_R) in ihrer Bilanz ausweisen, mehr Sicherheiten. Dies lässt sich dadurch erklären, dass selbige mehr Möglichkeiten zur Sicherheitenstellung haben. Da Bürgschaften häufig nicht bewertet und bei der Ermittlung der Besicherungsquote somit nicht berücksichtigt werden, ${ }^{154}$ kann eine geringe Sicherheitenstellung in Ermangelung von bilanzierten Sicherungsgütern durch diese Form der Besicherung nicht kompensiert werden. Auch nach Auspartialisierung mit der Variablen VERB_KI_LANG_R bestehen noch signifikante Korrelationen der Variablen KASSE_R, EKQ und TSC_JA_AGG mit der Besicherungsquote. Die Bonität gemessen an denVariablen EKQ und TSC_JA_AGG steht offensichtlich in einem unmittelbaren Zusammenhang zur Sicherheitenstellung.

\footnotetext{
1542 Vgl. hierzu auch die deskriptive Auswertung der Sicherheitenquote in Kapitel B.1.2.2.

1543 Vgl. hierzu aus Kapitel B.3.4.2.1.

1544 Vgl. hierzu auch ausführlich Kapitel B.1.2.2.
} 


\begin{tabular}{|c|c|c|c|}
\hline \multirow[b]{2}{*}{ Kontrollvariable } & \multicolumn{2}{|c|}{ Pearson } & \multirow{2}{*}{$\frac{\text { Spearman }}{-}$} \\
\hline & - & $\begin{array}{l}\text { VERB_KI } \\
\text { LANG_R }\end{array}$ & \\
\hline VERB_KI_LANG_R & $0,3058^{* * *}$ & & $0,3374 * * *$ \\
\hline VERB_KI_KURZ_R & 0,1130 & 0,1377 & $0,1453^{* *}$ \\
\hline VERB_KI_R & $0,2881^{* * *}$ & 0,1377 & $0,3264^{* * *}$ \\
\hline VERM_LA_R & $0,1683^{* *}$ & 0,1272 & $0,1656^{* * *}$ \\
\hline KASSE_R & $-0,1402^{* *}$ & $-0,1377^{* *}$ & $-0,1069$ \\
\hline VERB_KI_LANG_A & 0,1051 & $-0,0492$ & $0,2444^{* * *}$ \\
\hline VERB_KI_A & 0,1064 & 0,0171 & $0,1722^{* *}$ \\
\hline KASSE A & $-0,0515$ & $-0,2091$ & $-0,1553^{* *}$ \\
\hline UMSATZ & $-0,0361$ & 0,0444 & $-0,1568^{* *}$ \\
\hline DEBZIEL & $-0,1668^{* *}$ & $-0,1030$ & $-0,1796^{* * *}$ \\
\hline EKQ & $-0,1900^{* * *}$ & $-0,2028^{* *}$ & $-0,2460^{* * *}$ \\
\hline ZINSDECK & $-0,1546^{* *}$ & $-0,1463$ & $-0,1456^{* *}$ \\
\hline KREDZIEL & $-0,1979 * * *$ & $-0,1451$ & $-0,1545^{* *}$ \\
\hline UMSATZW & 0,0409 & $-0,1344$ & $-0,1554^{* *}$ \\
\hline ANZ_ÜB_GES & 0,1048 & 0,1104 & $0,1824 * * *$ \\
\hline VERB_KI_LANG_R_LN & $0,2450^{* * *}$ & 0,1599 & $0,1899^{* *}$ \\
\hline VERB_KI_R_LN & $0,3045^{* * *}$ & 0,1155 & $0,2744^{* * *}$ \\
\hline KASSE_A_LN & $-0,1734^{* *}$ & $-0,0629$ & $-0,1939^{* * *}$ \\
\hline UMSATZ_LN & $-0,0901$ & $-0,0342$ & $-0,1568^{* *}$ \\
\hline AUSFALLW_B & 0,1076 & 0,1357 & $0,2294^{* * *}$ \\
\hline TSC_JA_AGG & $-0,2959 * * *$ & $-0,2895^{* *}$ & $-0,2820^{* * *}$ \\
\hline
\end{tabular}

Tab. B-102: Bivariate und partielle Korrelation der Finanzkennzahlen mit der Besicherungsquote

In Bezug auf die unternehmensbezogenen Parameter weist lediglich die Variable KAP_GMBHCOKG signifikante Korrelationen (Pearson: $-0,1555^{* *}$, Spearman: $\left.-0,16 \mathbf{6}^{* *}\right)$ mit der Besicherungsquote auf. Gemäß der vorliegenden Studie weisen Kapitalgesellschaften inkl. GmbH \& Co. KG niedrigere Besicherungsquoten auf als Personengesellschaften exkl. GmbH \& Co. KG. Dieser Zusammenhang ist - wie auch zuvor bei der Analyse der Sicherheitenstellung als Binärvariable erläutert - unerwartet.

Bei den beziehungsbezogenen Variablen wird deutlich, dass der Finanzierungsanteil des jeweiligen Instituts die Sicherheitenquote stark beeinflusst. Wie aus Tab. B-103 ersichtlich, weisen alle Parameter, die den Finanzierungsanteil des jeweiligen Instituts beschreiben, signifikante Korrelationen auf. Ferner ist die Dauer der Kundenbeziehung sowie die Dauer der Beziehung mit dem betreuenden Firmenkundenbetreuer signifikant positiv korreliert mit der Sicherheitenquote, d.h. Unternehmen die eine lange Beziehung aufweisen, stellen mehr Sicherheiten. Die positive Korrelation der Anzahl der jährlichen Beratungsgespräche bleibt auch nach Integration der Kontrollvariablen VERB_EIG_LANG_R weiterhin signifikant. Möglicherweise erlangt die Bank durch die umfangreichen Beratungsgespräche einen Informationsvorsprung hinsichtlich der Sicherheitenstellung. Denkbar wäre es aber auch, dass die Anzahl der Beratungsgespräche eine Korrelation mit einer Finanzkennzahl aufweist, z.B. dem TSC_JA_AGG, und diese die eigentliche Ursache für den Zusammenhang ist. An dieser Stelle wird 
allerdings für eine weitere Analyse der Zusammenhänge auf die multivariate Analyse in Kapitel B.3.5.3.2 verwiesen.

\begin{tabular}{|c|c|c|c|}
\hline \multirow[b]{2}{*}{ Kontrollvariablen } & \multicolumn{2}{|c|}{ Pearson } & \multirow{2}{*}{$\begin{array}{c}\text { Spearman } \\
-\end{array}$} \\
\hline & - & $\begin{array}{l}\text { VERB_EIG_- } \\
\text { LANG_R }\end{array}$ & \\
\hline VERB_EIG_LANG_R & $0,3457 * * *$ & & $0,4828^{* * *}$ \\
\hline VERB_EIG_KURZ_R & $0,1839^{* * *}$ & 0,1375 & $0,2370 * * *$ \\
\hline VERB_EIG_R & $0,3405^{* * *}$ & 0,1375 & $0,4659^{* * *}$ \\
\hline VERB_EIG_LANG_A & $0,2528 * * *$ & 0,0434 & $0,4471^{* * *}$ \\
\hline VERB_EIG_KURZ_A & 0,0577 & 0,0530 & $0,2041^{* * *}$ \\
\hline VERB_EIG_A & $0,2329 * * *$ & 0,0548 & $0,4099 * * *$ \\
\hline HAUSBANK_K & $0,2525 * * *$ & $0,2634^{* * *}$ & $0,2596^{* * *}$ \\
\hline ANZ_BER_J & $0,1466^{* *}$ & $0,1602^{* *}$ & 0,1272 \\
\hline GK_SALD & $-0,2072 * * *$ & $-0,2224 * * *$ & $-0,2287^{* * *}$ \\
\hline GES_KREDIT & 0,0445 & 0,0364 & $0,2389^{* * *}$ \\
\hline ANT_ZV & $0,2959 * * *$ & $0,3103^{* * *}$ & $0,2822 * * *$ \\
\hline ANT_BANK_IN & $0,3192 * * *$ & $0,3187 * * *$ & $0,2943 * * *$ \\
\hline ANT_BANK_HB_MOD & $0,2538^{* * *}$ & $0,2365^{* * *}$ & $0,2374 * * *$ \\
\hline ANZ_B_AGG & $-0,1210$ & $-0,0761$ & $-0,1744 * *$ \\
\hline DIST_UNT & $-0,1350 * *$ & $-0,0867$ & $-0,1693^{* *}$ \\
\hline DARL & $0,4841^{* * *}$ & $0,4144 * * *$ & $0,4537 * * *$ \\
\hline VERM_ANL & $0,2969^{* * *}$ & $0,2940^{* * *}$ & $0,2933^{* * *}$ \\
\hline VERSICH & $0,1520^{* *}$ & 0,0347 & 0,1226 \\
\hline ZINS_VERFÜG & $-0,1820 * * *$ & $-0,1399$ & $-0,1501^{* *}$ \\
\hline ZINSSENS & $0,1525^{* *}$ & 0,1493 & $0,1698^{* *}$ \\
\hline DAU_BEZ_ERR & $0,1514^{* *}$ & 0,1358 & $0,1944 * * *$ \\
\hline DAU_PERS_ERR & $0,1513 * *$ & $0,2180^{* * *}$ & $0,1665^{* *}$ \\
\hline ANZ_B_AGG & $-0,1220$ & $-0,0761$ & $-0,1737 * *$ \\
\hline ANZ_B_AGG_PL & $-0,1310$ & $-0,0885$ & $-0,1898^{* * *}$ \\
\hline VERB_EIG_LANG_R_LN & $0,2900^{* * *}$ & 0,2205 & $0,3048^{* * *}$ \\
\hline VERB_EIG_R_LN & $0,4456^{* * *}$ & 0,1226 & $0,4105^{* * *}$ \\
\hline VERB_EIG_A_LN & $0,3454 * * *$ & $-0,1257$ & $0,2663 * * *$ \\
\hline ANT_VERB_EIG_LANG & $0,3020^{* * *}$ & 0,0858 & $0,4143^{* * *}$ \\
\hline ANT_VERB_EIG_KURZ & $0,3291^{* * *}$ & 0,1758 & $0,3265^{* * *}$ \\
\hline ANT_VERB_EIG_GES & $0,3461^{* * *}$ & 0,0944 & $0,4174 * * *$ \\
\hline ANZAHL_PRODUKT & $0,3906^{* * *}$ & $0,0494^{* *}$ & $0,3786^{* * *}$ \\
\hline DAU_BEZ_ERR_LN & 0,1340 & $0,0465^{* *}$ & $0,1944 * *$ \\
\hline DAU_PERS_ERR_LN & $0,1581^{* *}$ & 0,2736 & $0,1665^{* *}$ \\
\hline
\end{tabular}

Tab. B-103: Bivariate Korrelation der beziehungsbezogenen Variablen mit der Besicherungsquote

Die Analyse der Korrelation der verhaltenswissenschaftlichen Parameter (vgl. Tab. B104) zeigt, dass ein hoher Faktorwert der organisationalen Glaubwürdigkeit, d.h. eine geringe Glaubwürdigkeit, mit einer hohen Sicherheitenquote einhergeht. Auch hier wird wiederum bestätigt, dass Unternehmen mit einer geringen Bonität tendenziell mehr Sicherheiten stellen. Die weiteren Faktoren sind negativ korreliert. Eine geringe organisationale Gebundenheit, eine geringe organisationale Verbundenheit, ein niedri- 
ges personales Wohlwollen sowie eine geringe personale Verbundenheit stehen mit niedrigen Sicherheitenquoten im Zusammenhang.

\begin{tabular}{|l|r|r|}
\hline & \multicolumn{1}{|c|}{ Pearson } & \multicolumn{1}{|c|}{ Spearman } \\
\hline ORG_GLAUB & $0,1727^{* *}$ & $0,1677^{* *}$ \\
\hline ORG_WOHL & $-0,0760$ & $-0,0399$ \\
\hline PERS_GLAU & $-0,0163$ & 0,0172 \\
\hline PERS_WOHL & $-0,1670^{* *}$ & $-0,0875$ \\
\hline ORG_GEB & $-0,2705^{* * *}$ & $-0,2340^{* * *}$ \\
\hline ORG_VER & $-0,1529^{* *}$ & $-0,1444^{* *}$ \\
\hline PERS_VER & $-0,1889^{* * *}$ & $-0,1373^{* *}$ \\
\hline PERS_WOHL_VERB & $-0,1636^{* *}$ & $-0,0880$ \\
\hline
\end{tabular}

Tab. B-104: Bivariate Korrelation der verhaltenswissenschaftlichen Variablen mit der Besicherungsquote

Ferner zeigt die Analyse, dass bei Banken bzw. bei Firmenkundenbetreuern, die eine risikoorientierte Bepreisung praktizieren, die Sicherheitenquoten niedriger sind als bei solchen, die selbige nicht praktizieren (Pearson: $-0,1801^{* * *}$, Spearman: $-0,1666^{* *}$ ). Die Interpretation erscheint aber nur in Verbindung mit dem Zinssatz sinnvoll. Da bei der risikoorientierten Bepreisung der erwartete Verlust im Zinssatz eingepreist ist, bedeutet dies, dass bei gleichem Zins und bei gleicher Ausfallwahrscheinlichkeit eines Kunden die höhere Sicherheitenquote einen niedrigeren erwarteten Verlust ergibt und somit eine höhere Marge für die Bank bedeutet.

\subsubsection{Durchführung der Regressionsanalyse}

Das Vorgehen bei der Regressionsanalyse zur Überprüfung der Hypothesen zur Sicherheitenquote ähnelt dem Vorgehen zur Überprüfung der Hypothesen zum Zinssatz, d.h. die Variablen der verschiedenen Bereiche werden blockweise und kombiniert geprüft. Zunächst erfolgt eine ausführliche Prüfung des Einflusses der Finanzkennzahlen, da in zahlreichen Studien die Bonität als wesentliche Einflussgröße herausgestellt wurde. Unter der Prämisse, dass die Bonität ein wesentlicher Erklärungsfaktor ist, sollte die Ausfallwahrscheinlichkeit die Sicherheitenquote zu großen Teilen erklären können. Regression 1 in Tab. B-105 zeigt, dass nur 0,69\% der Varianz der Sicherheitenquote durch die Ausfallwahrscheinlichkeit erklärt werden können. In Regression 2 wurden ausschließlich die originären Finanzkennzahlen herangezogen, die hohe bivariate Korrelationen mit der Sicherheitenquote aufweisen. Bei hohen Korrelationen der unabhängigen Variablen untereinander wurde jeweils die Variable mit der höheren bivariaten Korrelation zur Sicherheitenquote verwendet. Deshalb wurde bspw. die Eigenkapitalquote aufgrund des Zusammenhangs zur Verbindlichkeitenquote nicht berücksichtigt, obwohl selbige auch nach Korrektur des Einflusses der Verbindlichkeiten noch eine signifikante Korrelation aufweist. Es erfolgte eine Regression unter Verwendung der Einschlussmethode mit listenweisem Fallausschluss. Diese Regressi- 
on erklärt immerhin $11,56 \%$ der Varianz. Bei Durchführung einer schrittweisen Regression sinkt das korrigierte $\mathrm{R}^{2}$ auf $11,00 \%$. Die Quote der langfristigen Verbindlichkeiten gegenüber Kreditinstituten ist hier von wesentlicher statistischer und ökonomischer Bedeutung. Ein Anstieg derselbigen um einen Prozentpunkt führt zu einem Anstieg der Besicherungsquote um einen halben Prozentpunkt. Im Vergleich zur Ausfallwahrscheinlichkeit erklären die Finanzkennzahlen die Höhe der Sicherheitenquote somit deutlich besser.

\begin{tabular}{|c|c|c|c|c|c|c|}
\hline \multirow[b]{2}{*}{ Einflussgröße } & \multicolumn{2}{|c|}{ Regression 1} & \multicolumn{2}{|c|}{ Regression 2} & \multicolumn{2}{|c|}{ Regression 3} \\
\hline & Beta & $\begin{array}{l}\text { Beta } \\
\text { stand. }\end{array}$ & Beta & $\begin{array}{l}\text { Beta } \\
\text { stand. }\end{array}$ & Beta & $\begin{array}{l}\text { Beta } \\
\text { stand. }\end{array}$ \\
\hline Konstante & 55,0438 & & 54,6514 & & 49,5997 & \\
\hline AUSFALLW B & 0,4314 & 0,1076 & & & & \\
\hline VERB KI LANG $R$ & & & $0,3508^{* * *}$ & 0,2308 & $0,4498(1)$ & $0,2960^{* * *}$ \\
\hline VERM LA R & & & 0,0614 & 0,0385 & & \\
\hline KASSE $R$ & & & $-0,0823$ & $-0,0284$ & & \\
\hline DEBZIEL & & & $-0,0981$ & $-0,0711$ & & \\
\hline ZINSDECK & & & $-0,0005^{*}$ & $-0,1206$ & & \\
\hline KREDZIEL & & & $-0,0232^{* *}$ & $-0,1695$ & $-0,0229(2)$ & $-0,1670^{* *}$ \\
\hline $\mathbf{R}$ & & 0,1076 & & 0,3777 & & 0,3451 \\
\hline R-Quadrat & & 0,0116 & & 0,1427 & & 0,1191 \\
\hline Korrigiertes $\mathbf{R}^{2}$ & & 0,0069 & & 0,1156 & & 0,1100 \\
\hline Signifikanz F-Test & & 0,1173 & & 0,0000 & & 0,0000 \\
\hline Durbin-Watson & & 0,6877 & & 1,0256 & & 0,9180 \\
\hline $\mathbf{N}$ & & 213 & & 197 & & 203 \\
\hline
\end{tabular}

Tab. B-105: Regression der Finanzkennzahlen (1)

Im nächsten Schritt wird geprüft, inwiefern die gemeinsame Betrachtung von Ratingund Finanzkennzahlen die Sicherheitenquote besser erklären kann. Es erfolgt zunächst eine Regression der Variablen mit hohen signifikanten Korrelationen zur Sicherheitenquote im Einschlussverfahren und anschließend per schrittweiser Regression (vgl. Tab. B-106, Regression 1 und Regression 2). Das korrigierte $\mathrm{R}^{2}$ steigt auf $16,50 \%$ bzw. 16,76\%. Im Vergleich zur Regression mit den Finanzkennzahlen kann durch die Ratingkennzahlen somit eine Verbesserung um ca. 5 Prozentpunkte erzielt werden. Die Ergebnisse stimmen somit überein mit den Erkenntnissen aus der Analyse der Sicherheiten als binärcodierte Variable. ${ }^{1545}$ 


\begin{tabular}{|c|c|c|c|c|}
\hline \multirow[b]{2}{*}{ Einflussgröße } & \multicolumn{2}{|c|}{ Regression 1} & \multicolumn{2}{|c|}{ Regression 2} \\
\hline & Beta & $\begin{array}{l}\text { Beta } \\
\text { stand. }\end{array}$ & Beta & $\begin{array}{c}\text { Beta } \\
\text { stand. }\end{array}$ \\
\hline Konstante & 76,1394 & & 81,5624 & \\
\hline VERB KI LANG $R$ & 0,2037 & 0,1340 & $0,2886(1)$ & $0,1898 * *$ \\
\hline VERM LA R & 0,1434 & 0,0885 & & \\
\hline KASSE R & $-0,0961$ & $-0,0300$ & & \\
\hline DEBZIEL & $-0,1960$ & $-0,1276^{*}$ & $-0,2361(4)$ & $-0,1536 * *$ \\
\hline ZINSDECK & $-0,0003$ & $-0,0858$ & & \\
\hline KREDZIEL & $-0,0245$ & $-0,1858^{* *}$ & $-0,0233(3)$ & $-0,1766^{* *}$ \\
\hline AUSFALLW B & 0,1981 & 0,0551 & & \\
\hline TSC JA AGG & $-0,3313$ & $-0,1763^{* *}$ & $-0,3678(2)$ & $-0,1958^{* *}$ \\
\hline $\mathbf{R}$ & & 0,4525 & & 0,4329 \\
\hline R-Quadrat & & 0,2048 & & 0,1874 \\
\hline Korrigiertes $\mathbf{R}^{2}$ & & 0,1650 & & 0,1676 \\
\hline Signifikanz F-Test & & 0,0000 & & 0,0000 \\
\hline Durbin-Watson & & 1,0086 & & 0,9043 \\
\hline $\mathrm{N}$ & & 169 & & 174 \\
\hline
\end{tabular}

Tab. B-106: Regression der Finanzkennzahlen (2)

In einem nächsten Schritt werden die Variablen mit signifikanten Koeffizienten aus Tab. B-106 um unternehmensbezogene Daten erweitert. In Tab. B-107 wird eine Regression unter Anwendung des Einschlussverfahrens sowie eine schrittweise Regression dargestellt. Während die Rechtsform bzw. die Dummyvariable KAP_GMBHCOKG im univariaten Kontext noch signifikante Korrelationen aufweist, trägt selbige im multivariaten Kontext nicht zu einer Steigerung der Varianzerklärung bei. Wenngleich auch der Koeffizient nicht signifikant ist, stellen Kapitalgesellschaften inkl. GmbH \& Co. KG tendenziell weniger Sicherheiten als Personengesellschaften exkl. GmbH \& Co. KG. Das Ergebnis stimmt überein mit dem der logistischen Regression. ${ }^{1546}$

Im nächsten Schritt (vgl. Tab. B-108) erfolgt eine Regressionsanalyse ausschließlich der beziehungsbezogenen Variablen. Es werden wiederum nur die Variablen mit signifikanten Korrelationen zur Sicherheitenquote berücksichtigt. In Regression 1 erfolgt eine Regression unter Verwendung des Einschlussverfahrens und in Regression 2 eine schrittweise Regression. Aufgrund der geringen Datenbasis wird anschließend eine Validierung der Erkenntnisse aus Regression 2 mittels des Einschlussverfahrens in Regression 3 vorgenommen. Die beziehungsbezogenen Variablen können in Regression $318,31 \%$ der Varianz erklären und somit liegt der Erklärungsanteil über dem maximalen Erklärungsanteil der Finanzkennzahlen in Höhe von 16,76\% (vgl. Tab. B-106, Regression 2). Der Anteil der Verbindlichkeiten bei dem jeweiligen Institut in Relation zur Bilanzsumme hat den höchsten standardisierten Beta-Koeffizienten. Ein Anstieg des Finanzierungsanteils um einen Prozentpunkt führt zu einer Erhöhung der Sicherheitenquote um ca. einen halben Prozentpunkt. Ein höherer Anteil des Zahlungsverkehrs bei dem jeweiligen Institut führt ebenso wie eine längere Beziehungsdauer zum 
Firmenkundenbetreuer zu einer höheren Sicherheitenquote. Eine Erklärung könnte darin liegen, dass mehr Informationen über die Möglichkeiten der Besicherung preisgegeben werden und somit die Bank einfacher die Sicherheiten einfordern kann. Eine weitere Erklärung ist, dass der Bank negative Informationen über das Unternehmen zukommen, die zu einer höheren Sicherheitenforderung führen. Anders als bei DEGRYSE/VAN CAYSEELE kann kein signifikanter Zusammenhang zur Produktnutzung im Allgemeinen hergestellt werden. DEGRYSE/VAN CAYSEELE stellen fest, dass für einen Kunden mit einer umfangreichen Produktnutzung bei einer Bank die Wahrscheinlichkeit der Sicherheitenstellung steigt. ${ }^{1547}$

\begin{tabular}{|c|c|c|c|c|}
\hline \multirow[b]{2}{*}{ Einflussgröße } & \multicolumn{2}{|c|}{ Regression 1} & \multicolumn{2}{|c|}{ Regression 2} \\
\hline & Beta & $\begin{array}{l}\text { Beta } \\
\text { stand. }\end{array}$ & Beta & $\begin{array}{l}\text { Beta } \\
\text { stand. }\end{array}$ \\
\hline Konstante & 79,4242 & & 67,7368 & \\
\hline DEBZIEL & $-0,0812$ & $-0,0471$ & & \\
\hline KREDZIEL & $-0,0298$ & $-0,1831^{* *}$ & $-0,0306$ & $-0,1881^{* *}$ \\
\hline TSC_JA_AGG & $-0,4070$ & $-0,2302 * * *$ & $-0,4336$ & $-0,2453^{* * *}$ \\
\hline VERB_KI_LANG_R & 6,2707 & $0,1762^{*}$ & 7,3136 & $0,2056^{* *}$ \\
\hline KAP_GMBHCOKG & $-9,4783$ & $-0,1000$ & & \\
\hline $\mathbf{R}$ & & 0,4321 & & 0,4178 \\
\hline R-Quadrat & & 0,1867 & & 0,1745 \\
\hline Korrigiertes $\mathbf{R}^{2}$ & & 0,1531 & & 0,1544 \\
\hline Signifikanz F-Test & & 0,0001 & & 0,0000 \\
\hline Durbin-Watson & & 1,1550 & & 1,1480 \\
\hline $\mathbf{N}$ & & 167 & & 167 \\
\hline
\end{tabular}

Tab. B-107: Regression der Finanzkennzahlen und der unternehmensbezogenen Variablen

In der vorliegenden Studie führt die zunehmende Dauer der persönlichen Beziehung zwischen dem Firmenkundenbetreuer und dem Kunden zu einer erhöhten Sicherheitenquote. Die Dauer der Bankbeziehung hat keinen signifikanten Effekt. Auch DEGRYSE/VAN CAYSEELE können weder in der Untersuchung von 1998 noch in der Untersuchung von 2000 einen Zusammenhang zwischen der Dauer der Bankbeziehung und der Wahrscheinlichkeit der Sicherheitenstellung feststellen. ${ }^{1548}$ BERGER/UDELL ${ }^{1549}$ und HARHOFF/KÖRTING ${ }^{1550}$ hingegen finden heraus, dass mit steigender Dauer der Bankbeziehung die Wahrscheinlichkeit der Sicherheitenstellung sinkt. Der von ihnen nachgewiesene Zusammenhang bestätigt das Modell von BOOT/THAKOR, welches zeigt, dass Kreditnehmer mit längeren Bankbeziehungen weniger oft Sicherheiten stellen. ${ }^{15 s 1}$

1547 Vgl. Degryse/Van Cayseele (2000), S. 92. Zu möglichen Ursachen vgl. Degryse/Van Cayseele (2000), S. 106 und Kapitel B.3.5.2.3.

1548 Vgl. Ongena/Smith (2000a), S. 239. Während bei den anderen Studien stets mehrere Banken untersucht wurden, haben Degryse/Van Cayseele genau eine Bank untersucht. Vgl. Degryse/ Van Cayseele (2000), S. 106.

1549 Vgl. Berger/Udell (1995), S. 373.

1550 Vgl. Harhoff/Körting (1998a), S. 14.

1551 Vgl. Boot/Thakor (1994), S. 903. 
Während bei der Betrachtung der Variablen EXIST_SICH die Variablen DIST_UNT, DARL und VERM_ANL einen signifikanten Einfluss auf die Wahrscheinlichkeit der Sicherheitenstellung ausüben, beeinflussen selbige nicht die Höhe der Sicherheitenquote. Die Variable ANT_ZV beeinflusst sowohl die Wahrscheinlichkeit der Sicherheitenstellung als auch die Höhe der Besicherungsquote.

\begin{tabular}{|c|c|c|c|c|c|c|}
\hline \multirow[b]{2}{*}{ Einflussgröße } & \multicolumn{2}{|c|}{ Regression 1} & \multicolumn{2}{|c|}{ Regression 2} & \multicolumn{2}{|c|}{ Regression 3} \\
\hline & Beta & $\begin{array}{l}\text { Beta } \\
\text { stand. }\end{array}$ & Beta & $\begin{array}{l}\text { Beta } \\
\text { stand. }\end{array}$ & Beta & $\begin{array}{c}\text { Beta } \\
\text { stand. }\end{array}$ \\
\hline Konstante & 14,1474 & & 24,8993 & & 22,0222 & \\
\hline VERB EIG LANG R & 0,2452 & $0,1886^{*}$ & 0,3803 & $0,2924 * * *$ & 0,4950 & $0,2979^{* * *}$ \\
\hline HAUSBANK K & 3,1620 & 0,0403 & & & & \\
\hline ANZ_BER_J & $-2,6114$ & $-0,1133$ & & & & \\
\hline GK SALD & 0,0000 & $-0,1585^{*}$ & & & & \\
\hline ANT ZV & 0,2545 & $0,2411^{*}$ & 0,3861 & $0,3658^{* * *}$ & 0,2854 & $0,2304 * * *$ \\
\hline DIST_UNT & $-0,6668$ & $-0,1749^{* *}$ & & & & \\
\hline VERM ANL & 7,8518 & 0,1150 & & & & \\
\hline ZINSSENS & 8,0009 & 0,1329 & & & & \\
\hline DAU_BEZ_ERR & 0,1398 & 0,0483 & & & & \\
\hline DAU_PERS ERR & 0,9861 & $0,1756^{*}$ & 0,9426 & $0,1679^{* *}$ & 1,0740 & $0,1661^{* * *}$ \\
\hline ANT_VERB_EIG_LANG & 0,0273 & 0,0703 & & & & \\
\hline ANT_VERB_EIG_KURZ & 0,0740 & 0,0925 & & & & \\
\hline ANT_VERB EIG_GES & 0,0093 & 0,0186 & & & & \\
\hline ANZAHL_PRODUKT & 0,4188 & 0,0174 & & & & \\
\hline $\mathbf{R}$ & & 0,6469 & & 0,5636 & & 0,4415 \\
\hline R-Quadrat & & 0,4185 & & 0,3176 & & 0,1949 \\
\hline Korrigiertes $\mathbf{R}^{2}$ & & 0,3300 & & 0,2977 & & 0,1831 \\
\hline Signifikanz F-Test & & 0,0000 & & 0,0000 & & 0,0000 \\
\hline Durbin-Watson & & 1,4722 & & 0,8851 & & 0,9092 \\
\hline $\mathbf{N}$ & & 107 & & 106 & & 209 \\
\hline
\end{tabular}

Tab. B-108: Regression der beziehungsbezogenen Variablen

Es resultiert die Frage, inwiefern die Finanzkennzahlen zusätzlich zu den beziehungsbezogenen Variablen eine Erklärung liefern und inwiefern selbige möglicherweise bei gemeinsamer Betrachtung irrelevant werden, so dass die Variablen mit signifikanten Koeffizienten aus den beiden Bereichen kombiniert werden (vgl. Tab. B-109). Es wird wiederum eine Regression nach dem Einschlussverfahren (Regression 1) und eine schrittweise Regression (Regression 2) durchgeführt. Bei gemeinsamer Betrachtung der Variablen steigt der Erklärungsanteil auf ca. 25\%, d.h. der Erklärungsanteil steigt im Vergleich zur Regression nur mit beziehungsbezogenen Variablen um ca. 7\% (vgl. Tab. B-108, Regression 3). Es fällt insbesondere auf, dass die langfristige Verbindlichkeitenquote gegenüber Kreditinstituten im Allgemeinen bei gleichzeitiger Berücksichtigung der langfristigen Verbindlichkeitenquote des jeweiligen Instituts keinen signifikanten Effekt ausübt. Die beziehungsbezogenen Variablen bleiben weiterhin signifikant. 


\begin{tabular}{|c|c|c|c|c|}
\hline \multirow[b]{2}{*}{ Einflussgröße } & \multicolumn{2}{|c|}{ Regression 1} & \multicolumn{2}{|c|}{ Regression 2} \\
\hline & Beta & $\begin{array}{l}\text { Beta } \\
\text { stand. }\end{array}$ & Beta & $\begin{array}{l}\text { Beta } \\
\text { stand. }\end{array}$ \\
\hline Konstante & 48,2462 & & 47,9148 & \\
\hline VERB EIG LANG R & 0,1643 & $0,0977^{* *}$ & 0,2996 & $0,1781^{* *}$ \\
\hline ANT $Z V$ & 0,3369 & $0,2698^{* * *}$ & 0,3291 & $0,2636^{* * *}$ \\
\hline DAU_PERS_ERR & 1,2270 & $0,1935^{* * *}$ & 1,2046 & $0,1899^{* * *}$ \\
\hline VERB KI LANG R & 0,1280 & 0,0859 & & \\
\hline DEBZIEL & $-0,0969$ & $-0,0673$ & & \\
\hline KREDZIEL & $-0,0218$ & $-0,1943^{* * *}$ & $-0,0225$ & $-0,2004^{* * *}$ \\
\hline TSC_JA_AGG & $-0,4115$ & $-0,2307 * * *$ & $-0,4316$ & $-0,2420 * * *$ \\
\hline $\mathbf{R}$ & & 0,5358 & & 0,5287 \\
\hline R-Quadrat & & 0,2871 & & 0,2795 \\
\hline Korrigiertes $\mathbf{R}^{2}$ & & 0,2576 & & 0,2585 \\
\hline Signifikanz F-Test & & 0,0000 & & 0,0000 \\
\hline Durbin-Watson & & 0,9875 & & 0,9864 \\
\hline $\mathbf{N}$ & & 173 & & 176 \\
\hline
\end{tabular}

Tab. B-109: Regression der beziehungsbezogenen Variablen und der Finanzkennzahlen

Im Anschluss daran erfolgt eine Analyse ausschließlich der verhaltenswissenschaftlichen Parameter. Selbige können bei Verwendung des Einschlussverfahrens 10\% (vgl. Tab. B-110, Regression 1) und bei der schrittweisen Regression immerhin 6,85\% (vgl. Tab. B-110, Regression 2) der Streuung erklären. Die gemeinsame Betrachtung der verhaltenswissenschaftlichen Variablen mit den beziehungsbezogenen Variablen und den Finanzkennzahlen führt nicht zu einer Verbesserung des Erklärungsgehalts. Das korrigierte $\mathrm{R}^{2}$ beträgt bei Berücksichtigung der verhaltenswissenschaftlichen Variablen $24,97 \%$ (vgl. Tab. B-111, Regression 1) im Vergleich zu 25,85\% ohne Berücksichtigung der verhaltenswissenschaftlichen Parameter (vgl. Tab. B-109, Regression 2). Die Integration des modifizierten Faktors - dargestellt in Tab. B-110 und Tab. B-111 jeweils als Regression 3 und 4 - liefert keinen Erkenntnisgewinn. Auf eine ausführliche Diskussion der Hypothesen wird an dieser Stelle verzichtet, stattdessen wird auf die Analyse der binärcodierten Sicherheitenvariable EXIST_SICH in Kapitel B.3.5.2.3 verwiesen. 


\begin{tabular}{|c|c|c|c|c|c|c|c|c|}
\hline \multirow[b]{2}{*}{ Einflussgröße } & \multicolumn{2}{|c|}{ Regression 1} & \multicolumn{2}{|c|}{ Regression 2} & \multicolumn{2}{|c|}{ Regression 3} & \multicolumn{2}{|c|}{ Regression 4} \\
\hline & Beta & $\begin{array}{c}\text { Beta } \\
\text { stand. }\end{array}$ & Beta & $\begin{array}{r}\text { Beta } \\
\text { stand. }\end{array}$ & Beta & $\begin{array}{c}\text { Beta } \\
\text { stand. }\end{array}$ & Beta & $\begin{array}{r}\text { Beta } \\
\text { stand. }\end{array}$ \\
\hline Konstante & 55,9342 & & 55,9033 & & 55,7965 & & 55,9038 & \\
\hline ORG GLAUB & 11,2007 & $0,2622 * *$ & & & 10,7033 & $0,2398^{* * *}$ & & \\
\hline ORG WOHL & $-0,6542$ & $-0,0139$ & & & $-2,6076$ & $-0,0548$ & & \\
\hline PERS_GLAUB & $-2,4436$ & $-0,0542$ & & & \begin{tabular}{|l|}
$-2,8195$ \\
\end{tabular} & $-0,0633$ & & \\
\hline PERS WOHL & $-4,3345$ & $-0,0941$ & & & & & & \\
\hline ORG_GEB & $-5,9300$ & $-0,1349^{*}$ & $-11,8946$ & $-0,2705^{* * *}$ & $-6,6339$ & $-0,1513^{*}$ & $-11,0088$ & $-0,2511^{* * * *}$ \\
\hline ORG_VER & $-1,0699$ & $-0,0248$ & & & 0,0682 & 0,0016 & & \\
\hline PERS VER & $-6,1733$ & $-0,1410$ & & & & & & \\
\hline PERS WOHL_VERB & & & & & $-6,8369$ & $-0,1579$ & & \\
\hline $\mathbf{R}$ & & 0,3603 & & 0,2705 & & 0,3226 & & 0,2511 \\
\hline R-Quadrat & & 0,1298 & & 0,0732 & & 0,1041 & & 0,0630 \\
\hline Korrigiertes $\mathbf{R}^{2}$ & & 0,0978 & & 0,0685 & & 0,0756 & & 0,0582 \\
\hline Signifikanz F-Test & & 0,0004 & & 0,0001 & & 0,0018 & & 0,0004 \\
\hline Durbin-Watson & & 1,0435 & & 0,8692 & & 0,9516 & & 0,8503 \\
\hline $\mathbf{N}$ & & 191 & & 197 & & 196 & & 213 \\
\hline
\end{tabular}

Tab. B-1 10: Regression der verhaltenswissenschaftlichen Variablen

\begin{tabular}{|c|c|c|c|c|c|c|c|c|}
\hline \multirow[b]{2}{*}{ Einflussgröße } & \multicolumn{2}{|c|}{ Regression 1} & \multicolumn{2}{|c|}{ Regression 2} & \multicolumn{2}{|c|}{ Regression 3} & \multicolumn{2}{|c|}{ Regression 4} \\
\hline & Beta & $\begin{array}{r}\text { Beta } \\
\text { stand. }\end{array}$ & Beta & $\begin{array}{c}\text { Beta } \\
\text { stand. }\end{array}$ & Beta & $\begin{array}{c}\text { Beta } \\
\text { stand. }\end{array}$ & Beta & $\begin{array}{l}\text { Beta } \\
\text { stand. }\end{array}$ \\
\hline Konstante & 40,2305 & & 54,3992 & & 36,9985 & & 53,4983 & \\
\hline KREDZIEL & $-0,0188$ & $-0,1674^{* *}$ & $-0,0222$ & $-0,1975^{* * *}$ & $-0,0213$ & $-0,1698^{* *}$ & $-0,0259$ & $-0,2064^{* * *}$ \\
\hline TSC JA AGG & $-0,2713$ & $-0,1521^{*}$ & $-0,3895$ & $-0,2184^{* * *}$ & $-0,2490$ & $-0,1292$ & $-0,3356$ & $-0,1741^{* *}$ \\
\hline VERB EIG LANG R & 0,3184 & $0,1893 * *$ & 0,3064 & $0,1822 * *$ & 0,4565 & $0,2637 * * *$ & 0,4459 & $0,2576 * * *$ \\
\hline ANT ZV & 0,3234 & $0,2590^{* * * *}$ & 0,3262 & $0,2613^{* * *}$ & 0,2826 & $0,2192^{* * *}$ & 0,2625 & $0,2036^{* * *}$ \\
\hline DAU_BEZ_ERR & 0,3629 & $0,1167^{*}$ & & & 0,4927 & $0,1444^{* *}$ & & \\
\hline ORG GLAUB & 9,8355 & $0,2302 * *$ & & & 0,4927 & $0,1444^{* *}$ & & \\
\hline ORG WOHL & 3,7958 & 0,0809 & & & 8,2847 & $0,1781^{*}$ & & \\
\hline PERS GLAUB & $-6,0601$ & $-0,1344$ & & & 3,8898 & 0,0886 & & \\
\hline PERS_WOHL & $-3,5647$ & $-0,0774$ & & & & & & \\
\hline ORG GEB & $-0,1235$ & $-0,0028$ & & & 0,5074 & 0,0107 & & \\
\hline ORG VER & 3,1318 & 0,0725 & & & $-0,7095$ & $-0,0161$ & & \\
\hline PERS VER & $-5,8967$ & $-0,1347$ & & & & & & \\
\hline PERS_WOHL_VERB & & & & & $-2,8287$ & $-0,0639$ & & \\
\hline $\mathbf{R}$ & & 0,5493 & & 0,4939 & & 0,5431 & & 0,5071 \\
\hline R-Quadrat & & 0,3017 & & 0,2440 & & 0,2950 & & 0,2571 \\
\hline Korrigiertes $\mathbf{R}^{2}$ & & 0,2497 & & 0,2261 & & 0,2415 & & 0,2376 \\
\hline Signifikanz F-Test & & 0,0000 & & 0,0000 & & 0,0000 & & 0,0000 \\
\hline Durbin-Watson & & 1,1459 & & 0,9529 & & 1,1499 & & 0,9726 \\
\hline $\mathbf{N}$ & & 155 & & 173 & & 157 & & 171 \\
\hline
\end{tabular}

Tab. B-111: Regression der Finanzkennzahlen, der beziehungsbezogenen und der verhaltenswissenschaftlichen Variablen

In Tab. B-112 werden die Ergebnisse der Hypothesenprüfung in Bezug auf die Sicherheitenstellung bei Operationalisierung über die Sicherheitenquote dargestellt. Zusammenfassend lässt sich feststellen, dass die Wirkungsrichtung nicht immer mit der ver- 
muteten Wirkungsrichtung übereinstimmt. Hinsichtlich der organisationalen Glaubwürdigkeit kann aber eindeutig aufgezeigt werden, dass selbige zu einer Reduktion der Sicherheiten führt. Bei den anderen Vertrauens- und Commitment-Dimensionen sind die Ergebnisse nicht immer eindeutig und signifikant.

\begin{tabular}{|c|c|c|c|c|c|c|c|c|}
\hline & \multirow{3}{*}{$\begin{array}{c}\text { Je größer .... } \\
\text { desto ... }\end{array}$} & \multicolumn{7}{|c|}{... Sicherheiten werden gestellt. } \\
\hline & & \multirow[b]{2}{*}{ Hypothese } & \multicolumn{3}{|c|}{ Isolierte Betrachtung ${ }^{1552}$} & \multicolumn{3}{|c|}{ Kombinierte Betrachtung ${ }^{1533}$} \\
\hline & & & Empirie & $\begin{array}{l}\text { Signi- } \\
\text { fikanz }\end{array}$ & Fazit & Empirie & $\begin{array}{l}\text { Signi- } \\
\text { fikanz }\end{array}$ & Fazit \\
\hline H5 & $\begin{array}{l}\text { die organisationale } \\
\text { Glaubwürdigkeit }\end{array}$ & weniger & weniger & $5 \%$ & Best. & weniger & $5 \%$ & Best. \\
\hline H6 & $\begin{array}{l}\text { das organisationale } \\
\text { Wohlwollen }\end{array}$ & weniger & mehr & & (Abl.) & weniger & & (Best.) \\
\hline $\mathrm{H} 7$ & $\begin{array}{l}\text { die interpersonale } \\
\text { Glaubwürdigkeit }\end{array}$ & weniger & mehr & & (Abl.) & mehr & & (Abl.) \\
\hline $\mathrm{H} 8$ & $\begin{array}{l}\text { das interpersonale } \\
\text { Wohlwollen }\end{array}$ & weniger & mehr & & (Abl.) & mehr & & (Abl.) \\
\hline H9 & $\begin{array}{l}\text { die organisationale } \\
\text { Gebundenheit }\end{array}$ & mehr & mehr & $10 \%$ & Best. & mehr & & (Best.) \\
\hline $\mathrm{H} 10$ & $\begin{array}{l}\text { die organisationale } \\
\text { Verbundenheit }\end{array}$ & weniger & mehr & & (Abl.) & weniger & & (Best.) \\
\hline $\mathrm{H} 11$ & $\begin{array}{l}\text { die personale } \\
\text { Verbundenheit }\end{array}$ & weniger & mehr & & (Abl.) & mehr & & (Abl.) \\
\hline
\end{tabular}

Tab. B-1 12: Zusammenfassung der Ergebnisse zur Sicherheitenstellung

Wie bereits auch bei Betrachtung der Sicherheitenstellung als binärcodierte Variable erfolgt ein Vergleich des Erklärungsgehalts mit verschiedenen bestehenden Studien (vgl. Tab. B-113). Die Werte für das korrigierte $\mathrm{R}^{2}$ schwanken in den verschiedenen Studien zwischen 0,204 und 0,337. Der Erklärungsgehalt in dieser Studie liegt mit einem korrigierten $\mathrm{R}^{2}$ von 0,2497 im mittleren Bereich. Die zitierten Studien wurden jeweils in Deutschland durchgeführt, so dass die Unterschiede nicht aus Unterschieden in den Finanzsystemen resultieren können. Datenbasis der Studie von MACHAUER/WEBER und ELSAS sind die Geschäftsbeziehungen von Kunden der ehemaligen Bayerischen Hypo- und Vereinsbank ${ }^{1554}$, der Deutschen Bank, der ehemaligen DG Bank ${ }^{155}$, der Dresdner Bank und der WestLB. ${ }^{1556}$ Die Datenbasis der Studie von LEHMANN/NEUBERGER umfasst im Wesentlichen die gleichen Banken. Grundlage bei LEHMANN/NEUBERGER sind die Geschäftsbeziehungen von Kunden der ehemaligen Bayerischen Hypo- und Vereinsbank, der Deutschen Bank, der Dresdner Bank, der

1552 Grundlage für die Beurteilung der isolierten Betrachtung sind die Ergebnisse der Regression 1 aus Tab. B-110.

1553 Grundlage für die Beurteilung der isolierten Betrachtung sind die Ergebnisse der Regression 1 aus Tab. B-111.

1554 Die Bayrische Vereinsbank ist mittlerweile in der HypoVereinsbank aufgegangen und gehört somit zur UniCredit Group. Vgl. HypoVereinsbank (2008). 
Commerzbank, der Sparkassen und der Genossenschaftsbanken. ${ }^{1557}$ Bei der vorliegenden Studie wurden ausschließlich Daten des Genossenschaftssektors herangezogen.

\begin{tabular}{|c|c|c|c|c|c|}
\hline & & $\begin{array}{l}\text { Lehmann/ } \\
\text { Neuberger }\end{array}$ & $\begin{array}{l}\text { Machauer/ } \\
\text { Weber }\end{array}$ & Elsas & $\begin{array}{c}\text { Vorliegende } \\
\text { Studie }\end{array}$ \\
\hline \multirow{5}{*}{$\begin{array}{l}\text { Unterneh- } \\
\text { mensbezogen }\end{array}$} & Rechtsform & $\mathrm{x}$ & $\mathrm{x}$ & & \\
\hline & Branche & $\mathrm{X}$ & & $\mathrm{x}$ & \\
\hline & Kreditnehmerqualität & $\mathrm{x}$ & $\mathrm{X}$ & $\mathrm{x}$ & \\
\hline & Größe & $\mathrm{x}$ & & $\mathrm{X}$ & \\
\hline & $\begin{array}{l}\text { Anzahl der Bankver- } \\
\text { bindungen }\end{array}$ & & $\mathrm{x}$ & & \\
\hline \multirow{3}{*}{$\begin{array}{l}\text { Beziehungs- } \\
\text { bezogen }\end{array}$} & Dauer der GB & $\mathrm{X}$ & $\mathrm{x}$ & $\mathrm{X}$ & $\mathrm{x}$ \\
\hline & $\begin{array}{l}\text { Zusätzliche Dienstleis- } \\
\text { tungen }\end{array}$ & & $x^{1558}$ & $\mathrm{X}^{1559}$ & $\mathrm{x}$ \\
\hline & Kreditvolumen & & $\mathrm{x}$ & & \\
\hline \multirow{2}{*}{$\begin{array}{l}\text { Verhaltens- } \\
\text { wissenschaft- } \\
\text { lich }\end{array}$} & Vertrauen & $(\mathrm{X})$ & & & $\mathrm{X}$ \\
\hline & Commitment & & . & & $\mathrm{X}$ \\
\hline & Korrigiertes $\mathrm{R}^{2}$ & $0,337^{1560}$ & 0,204 & 0,29 & $0,2497^{1561}$ \\
\hline & $\mathrm{N}$ & 329 & $\begin{array}{c}125 \text { (Kundenbezie- } \\
\text { hungen) }\end{array}$ & 472 & 155 \\
\hline
\end{tabular}

Tab. B-1 13: Vergleich des Erklärungsgehalts in Bezug auf Sicherheiten mit anderen Studien

\section{6 Überprüfung der Hypothesen zur Kreditverfügbarkeit}

\subsubsection{Operationalisierung der Kreditverfügbarkeit}

Eine Schwierigkeit bei der Analyse der relevanten Bestimmungsgrößen für die Kreditverfügbarkeit besteht in der geeigneten Operationalisierung der Letzteren. So kann die Kreditverfügbarkeit nur sehr schwer direkt gemessen werden. Beispielsweise würde bei Betrachtung der Fremdkapitalquote die Kreditverfügbarkeit unterschätzt, da Firmen eine niedrige Fremdkapitalquote haben können, entweder weil das Unternehmen keine Fremdmittel mehr zur Verfügung gestellt bekommt (Angebotsrestriktion) oder

1557 Vgl. Lehmann/Neuberger (2001), S. 14.

1558 Machauer/Weber verwenden hier die Variable Hausbankstatus. Vgl. Machauer/Weber (1998), S. $1370 \mathrm{ff}$.

1559 Elsas verwendet hier die Variable Hausbankstatus. Vgl. Elsas (1999), S. 213.

1560 Vgl. Lehmann/Neuberger (2001), S. 31. Grundlage ist eine Tobit-Regression. Das korrigierte $\mathrm{R}^{2}$ beträgt bei der Regression ohne die Variable Vertrauen 0,294. Die Datenbasis ist in diesem Fall mit $\mathbf{N}=\mathbf{3 3 9}$ geringfügig größer.

1561 Grundlage für die Daten der vorliegenden Studie ist die Regression 1 in Tab. B-111.

1562 Gemäß Machauer/Weber sind im Datensatz 125 Kunde-Bank-Beziehungen enthalten. Für diese Beziehungen wurden im Zeitraum 1992-1996 Daten erhoben. Es geht aus der Veröffentlichung nicht hervor, wie viele Datensätze für diese Regression verwendet wurden. 
weil es keine zusätzliche Mittel mehr benötigt (Nachfragerestriktion). ${ }^{1563}$ Ferner wird die Fremdkapitalquote auch von dem Kreditangebot der Banken bestimmt. ${ }^{1564} \mathrm{Gemäß}$ ANGELINI/DI SALVO/FERRI wird von einem ökonomischen Agenten gesagt, dass er unter Liquiditätsbeschränkungen leidet, wenn er zu einem Zinssatz, der seiner Risikoklasse entspricht, ein größeres Kreditvolumen nachfragt als er im Markt erlangen kann. ${ }^{1565}$ In der Realität können direkte Messgrößen für diese Liquiditätsrestriktionen allerdings nicht beobachtet werden, so dass in der empirischen Literatur eine Vielzahl von Proxys verwendet werden. ${ }^{1566}$ Eine ausführliche Darstellung derselbigen wurde in Kapitel A.4.3.2.4 vorgenommen. Um eine direkte Messung der Liquiditätsrestriktionen der Unternehmen zu erlangen, haben ANGELINI/DI SALVO/FERRI die Unternehmen befragt, inwiefern ein Kreditbedarf besteht und inwiefern ihre Bank bereit ist, selbigen zu befriedigen. ${ }^{1567}$ Zwei der angebotenen Antwortmöglichkeiten für das Unternehmen lauteten „Die Bank wurde noch nicht angesprochen.“ und „Das Unternehmen dachte, die Bank würde den Kredit ablehnen.“. ${ }^{1568}$ Die Einschätzung der Kreditverfügbarkeit basiert somit auf der subjektiven Wahmehmung des Unternehmens. Der Aspekt, dass ein expliziter Kreditbedarf seitens des Unternehmers bestehen muss, wird zwar sinnvoller Weise berücksichtigt. Die für den Kreditentscheid notwendige Bereitschaft der Bank zu einer zusätzlichen Kreditvergabe wird aber nur unzureichend abgebildet.

Bezüglich der Kreditvergabe sind verschiedene Fälle in Betracht zu ziehen. Die Kreditverfügbarkeit kann sich sowohl in einer kompletten Kreditablehnung oder -annahme als auch in einer nur teilweisen Kreditbewilligung widerspiegeln. So ist es denkbar, dass dem Unternehmer keine Ausweitung der aktuellen Kreditlinie im gewünschten Umfang, sondern nur in Teilen genehmigt wird. Diese Aspekte werden in der vorliegenden Studie berücksichtigt, indem die tatsächlich erfolgten Kreditablehnungen oder -quotierungen innerhalb der letzten fünf Jahre erfragt wurden (ABL_PAR_KRED_FRÜ). Ferner erfolgt die Abfrage, inwiefern der Kunde heute eine Ausweitung der Kreditlinie erhalten würde (AUS_KRED_HEU_EUN). Hierbei handelt es sich um eine rein hypothetische Antwort. Inwiefern ein Kreditwunsch beim Unternehmer besteht, kann nicht abgebildet werden. $10,23 \%$ der Kunden haben in den letzten fünf Jahren eine vollständige Kreditablehnung, 7,94\% eine teilweise Kreditablehnung erhalten und $12,81 \%$ der Kunden würden heute keine Kreditausweitung bekommen. Des Weiteren wäre es auch denkbar, dass sich die Kreditverfügbarkeit dahingehend differenziert, wie schnell ein Kreditantrag im Vergleich zur bankweiten durchschnittlichen Bearbeitungszeit bewilligt wird. ${ }^{1569}$ Eine objektive Messung stellte sich aber im Rahmen einer Voruntersuchung bei Banken aufgrund der nicht zur Verfügung stehenden bzw. nicht erhebbaren Daten als nicht realisierbar heraus. So lässt sich weder eine bankweite durchschnittliche Bearbeitungszeit noch die tatsächliche Bearbeitungszeit eines Kre-

\footnotetext{
1563 Vgl. Petersen/Rajan (1994), S. 18.

1564 Vgl. Petersen/Rajan (1994), S. 18.

is65 Vgl. Angelini/Di Salvo/Ferri (1998), S. 930.

1566 Vgl. Angelini/Di Salvo/Ferri (1998), S. 930.

1567 Vgl. Angelini/Di Salvo/Ferri (1998), S. 931 f. und Kapitel A.4.3.2.4.

$1568 \mathrm{Vgl}$. Angelini/Di Salvo/Ferri (1998), S. $931 \mathrm{f}$.

1569 Zur Dauer der Kreditbewilligung vgl. Berens et al. (2005), S. 784.
} 
dits geeignet ermitteln. Aus diesem Grund wurde die subjektive Einschätzung des Firmenkundenbetreuers bzgl. der Dauer der Kreditbewilligung des letzten Kredits des Kunden im Vergleich zum bankweiten Durchschnitt auf einer 5-Punkt-Ordinalskala erfragt (DAU_KRED_BEW). Eine Eins bedeutet, dass die Kreditbewilligung sehr viel schneller im Vergleich zum bankweiten Durchschnitt erfolgt ist, und eine Fünf, dass die Kreditbewilligung sehr viel langsamer im Vergleich zum bankweiten Durchschnitt verlief. Aus Sicht des Unternehmens kann insbesondere in einer liquiditätsmäßig angespannten Situation eine schnelle Kreditentscheidung und -bereitstellung sehr bedeutsam sein.

Zur Analyse der Einflussgrößen der verschiedenen Variablen zur Kreditverfügbarkeit wird wiederum zunächst eine Korrelationsanalyse der Einflussgrößen mit den ökonomischen Parametern und anschließend eine Regressionsanalyse durchgeführt. Um mögliche unterschiedliche Effekte auf die jeweiligen Parameter, insbesondere hinsichtlich der Kreditverfügbarkeit einerseits und der Schnelligkeit der Kreditbewilligung andererseits, bereits in einem ersten Schritt identifizieren zu können, wird die Korrelationsanalyse für die drei verwendeten Operationalisierungen der Kreditverfügbarkeit vergangene Kreditablehnungen, potenzielle Kreditausweitungen und Dauer der Kreditbewilligung - gemeinsam durchgeführt.

\subsubsection{Korrelationsanalyse zur Kreditverfügbarkeit}

Wie in Abb. B-26 dargestellt, wird die Korrelationsanalyse - wie in den vorherigen Kapiteln B.3.4.2.1, B.3.5.2.1 und B.3.5.3.1 - zunächst für die verschiedenen Bereiche wie Finanzkennzahlen, beziehungsbezogene Variablen, verhaltenswissenschaftliche Variablen und bankbezogene Variablen durchgeführt. Die Korrelationen werden zunächst für die drei verschiedenen Operationalisierungen der Kreditverfügbarkeit gemeinsam ermittelt und dargestellt. Die Ergebnisse der Korrelationsanalyse werden jeweils bei der Analyse der Auswirkungen auf die verschiedenen Operationalisierungen der Kreditverfügbarkeit herangezogen. 


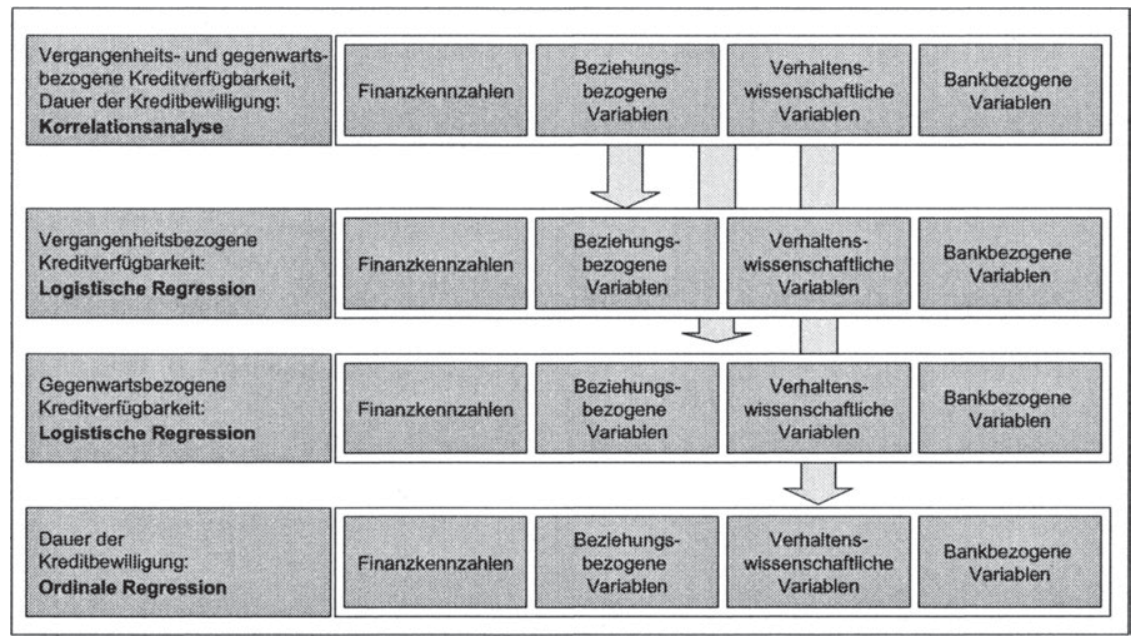

Abb. B-26: Vorgehen zur Analyse der Kreditverfügbarkeit

Für die dichotomen Variablen ABL_PAR_KRE_FRÜ und AUS_KRED_HEU_EUN werden punktbiseriale Korrelationen und für die Variable DAU_KRED_BEW Spearman's Rangkorrelationskoeffizient sowie Kendall's Tau ermittelt. ${ }^{1570}$ Während die Variable AUS_KRED_HEU_EUN die gegenwärtige Bereitschaft zur Kreditausweitung misst, ${ }^{1571}$ erfasst die Variable ABL_PAR_KRE_FRÜ vergangene Kreditablehnungen.

In Übereinstimmung mit dieser konträren Definition - gegenwärtige Bereitschaft zur Ausweitung vs. vergangene Kreditablehnungen - verweisen alle aufgeführten Korrelationen der Finanzkennzahlen mit diesen beiden Parametern (vgl. Tab. B-114) jeweils unterschiedliche Vorzeichen auf. Außer bei der Variablen KASSE_R bewegt sich die Stärke des Zusammenhangs auf dem gleichen Niveau, die Koeffizienten weichen maximal um 0,05 ab. Ferner sind auch die Vorzeichen der Korrelationskoeffizienten für die vergangenen Kreditablehnungen (ABL_PAR_KRE_FRÜ) identisch mit den Vorzeichen für die Dauer der Kreditbewilligung. Eine höhere Ausprägung bei der Dauer der Kreditbewilligung bedeutet eine langsamere Bewilligung. Insbesondere die Variablen, die Ausdruck der Bonität des Unternehmens sind, weisen eine starke Korrelation auf: EKQ, ANZ_ÜB_GES, AUSFALLW_B, TSC_JA_AGG und TSC_QA_AGG. Eine gute Bonität des Unternehmens steht jeweils im positiven Zusammenhang mit einer hohen, vergangenheits- und gegenwartsbezogenen Kreditverfügbarkeit und einer schnellen Kreditbewilligung.

$1570 \quad$ Vgl. zu den Korrelationsmaßen Kapitel B.3.4.2.1.

1571 Bei der Variablen AUS_KRED_HEU_EUN wurden die Antworten „Unbekannt“ nicht berücksichtigt. 


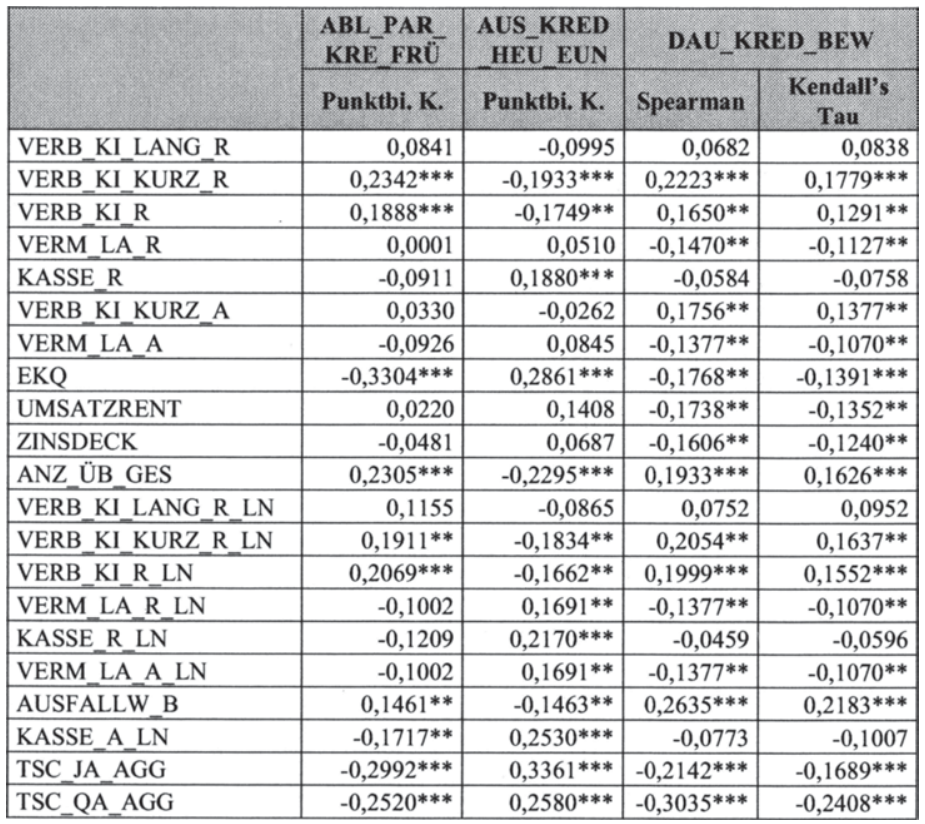

Tab. B-114: Bivariate Korrelationen der Finanzkennzahlen mit der Kreditverfügbarkeit

Hinsichtlich der beziehungsbezogenen Variablen (vgl. Tab. B-115) weist der Hausbankstatus signifikante negative Korrelationen mit der Variablen ABL_PAR_KRE_FRÜ auf, d.h. im Rahmen einer Hausbankbeziehung gibt es weniger Kreditablehnungen. Wie auch bei den deskriptiven Auswertungen in Kapitel B.1.2.4 wird hier die von ELSAS häufig angeführte Liquiditätsversicherungsfunktion der Hausbank bestätigt. $^{1572}$ Der positive Zusammenhang zwischen einer aktuellen oder vergangenen Intensivbetreuung und einer Kreditablehnung ergibt sich aus der Funktion der Intensivbetreuung, da ausfallgefährdete Bestandskunden dieser Sonderbehandlung unterliegen und selbigen aufgrund der Ausfallgefährdung gegenwärtig keine Kredite mehr gegeben werden. Ferner weist die Variable GK_ZINS mit den Variablen ABL_PAR_KRE_FRÜ und AUS_KRED_HEU_EUN signifikante Korrelationen derart auf, dass hohe Zinsen mit vergangenen oder gegenwärtigen, potenziellen Kreditablehnungen sowie einer längeren Dauer der Kreditbewilligung einhergehen. Dies könnte daher resultieren, dass der Kreditzins selbst durch die Bonität des Unternehmens bestimmt wird. In Kapitel B.3.4.2.3 wurde gezeigt, dass die Eigenkapitalquote einen signifikanten Einfluss auf den Kreditzins hat. So beträgt die partielle Korrelation des Zinssatzes

1572 Vgl. Elsas (2001), S. 23 ff. Diesen Zusammenhang haben auch Lehmann/Neuberger bestätigt.

Vgl. Lehmann/Neuberger (2001), S. 25. 
mit der Variablen ABL_PAR_KRE_FRÜ und AUS_KRED_HEU_EUN bei Berücksichtigung der Effekte des quantitativen Teilscores statt 0,2490 (Signifikanzniveau: $1 \%$ ) nur noch 0,1336 (Signifikanzniveau: 10\%) bzw. statt -0,1932 (Signifikanzniveau: $1 \%$ ) nur noch $-0,1120$ (Signifikanzniveau: keine Signifikanz). Bei Berücksichtigung der Effekte der Eigenkapitalquote beträgt die partielle Korrelation mit der Variablen ABL_PAR_KRE_FRÜ und AUS_KRED_HEU_EUN statt 0,2490 (Signifikanzniveau: 1\%) nur noch 0,1170 (Signifikanzniveau: $10 \%$ ) bzw. statt $-0,1932$ (Signifikanzniveau: 1\%) nur noch -0,0940 (Signifikanzniveau: keine Signifikanz). Ferner besteht ein positiver Zusammenhang zwischen der Mitgliedschaft und der Bereitschaft, dem Kunden heute eine Kreditausweitung zu bewilligen, sowie ein negativer Zusammenhang zwischen der Mitgliedschaft und der Dauer der Bewilligung, so dass aus der Mitgliedschaft in beiderlei Hinsicht positive Effekte resultieren. ${ }^{1573}$ Ferner lässt sich eine positive Korrelation zwischen der Anzahl der Produkte und der Bereitschaft zu zusätzlichen Krediten beobachten, d.h. ein Kunde, der viele Produkte der Bank nutzt, bekommt eher zusätzliche Kredite. Der Anteil des Zahlungsverkehrs und der Finanzierung des jeweiligen Instituts ist signifikant negativ mit vergangenen Kreditablehnungen korreliert. Sowohl die Korrelation mit der Anzahl der Produkte als auch die Korrelation mit den Zahlungsverkehrs- und Finanzierungsanteilen lässt sich möglicherweise auf die erhöhten Informationen und somit die Möglichkeit zur besseren Risikoeinschätzung zurückführen. Dieser Zusammenhang findet sich auch bei COLE; COLE kommt zu der Erkenntnis, dass die Wahrscheinlichkeit für eine Kreditverlängerung oder Neuvergabe steigt, wenn der potenzielle Kreditgeber bereits Produktlieferant für Spar- oder Anlagekonten und Financial Management-Dienstleistungen war. ${ }^{1574}$ Wenn bei den Kreditgesprächen weitere Produkte angesprochen worden sind und es mittlerweile zu Produktabschlüssen (CROSS_SELL) gekommen ist, dann ist die Kreditvergabe schneller abgewickelt worden. Gleiches gilt für den Fall, dass der Unternehmer auch seine Privatkonten bei der Bank unterhält. Ein signifikanter Zusammenhang zur Sicherheitenquote konnte nicht festgestellt werden, so dass im univariaten Kontext die Modelle von BESTER sowie von BESANKO/THAKOR nicht bestätigt werden können..$^{1575}$ In diesen Modellen wurden Kreditsicherheiten als Selektionskriterium oder Sorting-Device eingefügt, um die Kreditnehmerqualität zu identifizieren. ${ }^{1576}$

1573 Einen positiven Zusammenhang zwischen der Mitgliedschaft und der Kreditverfügbarkeit konnten auch Angelini/Di Salvo/Ferri aufzeigen. Vgl. Angelini/Di Salvo/Ferri (1998), S. 948.

1574 Vgl. Cole (1998), S. 962.

is7s Vgl. Bester (1985), S. 854 und Besanko/Thakor (1987a), S. 67I ff. Vgl. zu den Modellen auch Kapitel A.4.3.1.4.1.

1576 Vgl. Bester (1985), S. 854 und Besanko/Thakor (1987a), S. 671 ff. Eine Modellinterpretation findet sich bei Machauer/Weber (1998), S. 1360. 


\begin{tabular}{|c|c|c|c|c|}
\hline & \multirow{2}{*}{$\begin{array}{l}\text { ABL_PAR } \\
\text { KRE_FRŌ }\end{array}$} & \multirow{2}{*}{$\begin{array}{c}\begin{array}{c}\text { AUS_KRED } \\
\text { HEU_EUN }\end{array} \\
\text { Punktbi. K. }\end{array}$} & \multicolumn{2}{|c|}{ DAU_KRED_BEW } \\
\hline & & & Spearman & $\begin{array}{c}\text { Kendall's } \\
\text { Tau }\end{array}$ \\
\hline VERB_EIG_LANG_R & 0,0266 & $-0,1383^{* *}$ & 0,0185 & 0,0210 \\
\hline VERB_EIG_KURZ_R & 0,1176 & $-0,1115$ & $0,2224 * * *$ & $0,1864 * * *$ \\
\hline VERB_EIG_R & 0,0713 & $-0,1517 * *$ & 0,0575 & 0,0707 \\
\hline VERB_EIG_KURZ_A & 0,0028 & $-0,0283$ & $0,2303 * * *$ & $0,1921^{* * *}$ \\
\hline HAUSBANK_K & $-0,1421 * *$ & $0,1693 * *$ & $-0,1255$ & $-0,1332$ \\
\hline INT_BET & $0,3547 * * *$ & $-0,1614^{* *}$ & 0,0765 & 0,0808 \\
\hline GK_SALD & $-0,0523$ & 0,0801 & $-0,1338^{* * *}$ & $-0,1064^{* *}$ \\
\hline GK_ZINS & $0,2490 * * *$ & $-0,1932^{* * *}$ & $0,2435^{* * *}$ & $0,1919^{* * *}$ \\
\hline SÜ & 0,0986 & 0,0262 & 0,0149 & 0,0157 \\
\hline FORD AB & 0,1171 & $-0,1689 * *$ & 0,1066 & 0,1126 \\
\hline VERPFÄ & $0,1562^{* *}$ & $-0,0349$ & $-0,0191$ & $-0,0202$ \\
\hline CROSS_SELL & $-0,0119$ & $-0,0220$ & $-0,2417 * * *$ & $-0,2277^{* *}$ \\
\hline ANT_ZV & $-0,1436 * *$ & 0,0875 & $-0,0988$ & $-0,1239$ \\
\hline ANT_BANK_IN & $-0,1462 * *$ & 0,0944 & $-0,0667$ & $-0,0815$ \\
\hline MITGLIED & $-0,0814$ & $0,2536^{* * *}$ & $-0,2590 * * *$ & $-0,2446^{* * *}$ \\
\hline PRIVATKONT & 0,0402 & 0,0339 & $-0,1592^{* *}$ & $-0,1503 * *$ \\
\hline ZINS_VERFÜG & $-0,1772 * * *$ & $0,2922 * * *$ & $-0,1121$ & $-0,1188$ \\
\hline ZINSSENS & $0,2890 * * *$ & $-0,1669 * *$ & $0,1862 * * *$ & $0,1728 * * *$ \\
\hline ANZAHL_PRODUKT & $-0,0353$ & $0,1628 * *$ & $-0,1613^{* *}$ & $-0,1364 * *$ \\
\hline
\end{tabular}

Tab. B-115: Bivariate Korrelationen der beziehungsbezogenen Variablen mit der Kreditverfügbarkeit

Hinsichtlich der verhaltenswissenschaftlichen Parameter zeigt Tab. B-116, dass mit Ausnahme des Parameters ORG_GEB alle Parameter eine signifikante, positive Korrelation mit der Dauer der Kreditbewilligung aufweisen. Eine hohe Glaubwürdigkeit, ein hohes Wohlwollen sowie eine hohe Verbundenheit führen zu einer schnellen Kreditbewilligung. Bei der Gebundenheit ist der Zusammenhang negativ, so dass eine niedrige Gebundenheit zu einer schnellen Kreditbewilligung führt. Die Erklärung liegt vermutlich darin, dass der Kunde aufgrund der niedrigen Gebundenheit den Kredit in der Zwischenzeit bei einer anderen Bank beantragen könnte. Auch hinsichtlich der vergangenheits- und gegenwartsbezogenen Kreditverfügbarkeit bewirken eine hohe organisationale und personale Glaubwürdigkeit, ein hohes organisationales Wohlwollen sowie eine niedrige Gebundenheit weniger Kreditablehnungen. Im univariaten Kontext wird für alle verhaltenswissenschaftlichen Parameter mit Ausnahme der organisationalen Gebundenheit der vermutete Zusammenhang zur Kreditverfügbarkeit bestätigt. Eine mögliche Erklärung für den Zusammenhang zur Gebundenheit besteht darin, dass bei einer hohen Gebundenheit der Kunde keinen Kredit bei einer anderen Bank bekommen würde und der Druck für die bestehende Bank, einen gegebenenfalls risikoreichen Kredit zu vergeben, somit sehr niedrig ist. 


\begin{tabular}{|c|c|c|c|c|}
\hline & \multirow{2}{*}{$\begin{array}{l}\text { ABL_PAR } \\
\text { KRE_FRŪ } \\
\text { Punktbi. K. }\end{array}$} & \multirow{2}{*}{$\begin{array}{c}\text { AUS_KRED } \\
\text { HEU_EUN } \\
\text { Punktbi. K. }\end{array}$} & \multicolumn{2}{|c|}{ DAU_KRED_BEW } \\
\hline & & & Spearman & $\begin{array}{c}\text { Kendall's } \\
\text { Tau }\end{array}$ \\
\hline ORG_GLAUB & $0,3271^{* * *}$ & $-0,3711^{* * *}$ & $0,3488^{* * *}$ & $0,2778^{* * *}$ \\
\hline ORG_WOHL & $0,2435^{* * *}$ & $-0,2527 * * *$ & $0,2175^{* * *}$ & $0,1671^{* * *}$ \\
\hline PERS_GLAUB & $0,2512^{* * *}$ & $-0,2107^{* * *}$ & $0,2768^{* * *}$ & $0,2195^{* * *}$ \\
\hline PERS_WOHL & 0,1125 & $-0,1313$ & $0,1847 * * *$ & $0,1426 * * *$ \\
\hline ORG_GEB & $-0,1772^{* * *}$ & $0,2722 * * *$ & $-0,1805^{* * *}$ & $-0,1416^{* * *}$ \\
\hline ORG_VER & 0,0666 & $-0,0312$ & $0,2335^{* * *}$ & $0,1858 * * *$ \\
\hline PERS_VER & 0,1271 & $-0,1018$ & $0,2087^{* * *}$ & $0,1627 * * *$ \\
\hline PERS WOHL VER & 0,1218 & $-0,1357$ & 0,1628 & 0,2093 \\
\hline
\end{tabular}

Tab. B-116: Bivariate Korrelationen der verhaltenswissenschaftlichen Variablen mit der Kreditverfügbarkeit

Bei den bankbezogenen Parametern (vgl. Tab. B-117) besteht ein positiver Zusammenhang zwischen einem jungen Firmenkundenbetreuer sowie einem hohen Ausbildungsstand, z.B. abgeschlossenes (berufsbegleitendes) Studium, und einer wertorientierten Vergütung in Abhängigkeit von dem Ergebnis des Firmenkundenbetreuers auf der einen Seite und einer schnellen Kreditbewilligung auf der anderen Seite. Möglicherweise möchte sich der junge Firmenkundenbetreuer durch eine schnelle Kreditbearbeitung profilieren. Der Zusammenhang zwischen dem Ausbildungsstand und der Dauer der Kreditbearbeitung könnte daher resultieren, dass Firmenkundenbetreuer mit einem hohen Ausbildungsstand zielstrebiger sind. Die Interdependenz zur wertorientierten Vergütung könnte durch motivationale Einflüsse bedingt sein. Da zwischen dem Ausbildungsstand und dem Alter sowie dem Alter und dem Vergütungssystem ein Zusammenhang besteht, kann nicht abgeleitet werden, welche Variablen ursächlich für die schnellere Bearbeitung sind.

\begin{tabular}{|l|r|r|r|r|}
\hline & $\begin{array}{r}\text { ABL_PAR } \\
\text { KRE_FRŪ }\end{array}$ & $\begin{array}{r}\text { AUS_KRED } \\
\text { HEU EUN }\end{array}$ & \multicolumn{2}{|c|}{ DAU_KRED_BEW } \\
\cline { 2 - 5 } & Punktbi. K. & Punktbi. K. & Spearman & $\begin{array}{c}\text { Kendall's } \\
\text { Tau }\end{array}$ \\
\hline FKB_JÜ30 & $-0,1008$ & 0,0961 & $-0,1496^{* *}$ & $-0,1415^{* *}$ \\
\hline FKB_BERUF_ST & 0,0824 & $-0,0262$ & $-0,1503^{* *}$ & $-0,1420^{* *}$ \\
\hline FKB_STUD & $-0,0821$ & 0,0183 & $-0,2193^{* * *}$ & $-0,2072^{* * *}$ \\
\hline LEI_WERT_FKB & $-0,0229$ & 0,0430 & $-0,1412^{* *}$ & $-0,1334$ \\
\hline
\end{tabular}

Tab. B-117: Bivariate Korrelation der bankbezogenen Variablen mit der Kreditverfügbarkeit 


\subsubsection{Kreditverfügbarkeit - Binärcodierung}

\subsubsection{Logistische Regression der vergangenheitsbezogenen Kreditverfügbar- keit}

Wie bei den Regressionsanalysen zum Zinssatz und den Sicherheiten wird die Analyse der Einflussgrößen bei der logistischen Regression der vergangenheitsbezogenen Kreditverfügbarkeit zunächst getrennt nach Bereichen durchgeführt. Die Analyse der Finanzkennzahlen mit der Kreditverfügbarkeit in Tab. B-118 zeigt, dass die Ausfallwahrscheinlichkeit als zentrale Größe zur Messung der Bonität Kreditablehnungen nicht erklären kann. Sowohl die verschiedenen Pseudo- $\mathbf{R}^{2}$ mit einem Erklärungsanteil jeweils unter 2,5\% als auch der Anteil der korrekt klassifizierten Fälle, bei denen es zu Kreditablehnungen kommt, mit einem Wert von 3,23\% sind bei der Regression $1 \mathrm{sehr}$ niedrig. Zumindest führt ein Anstieg der Ausfallwahrscheinlichkeit bei isolierter Betrachtung (vgl. Tab. B-118, Regression 1) zu einem Anstieg der Wahrscheinlichkeit einer vollständigen oder partiellen Kreditablehnung. Der Zusammenhang ist auf dem 5\%-Niveau signifikant. Bei Untersuchung nur der originären Finanzkennzahlen mit hohen, signifikanten Korrelationen (vgl. Tab. B-118, Regression 2) sowie bei Ergänzung derselbigen um die Ausfallwahrscheinlichkeit und um die Teilscores aus dem Rating (vgl. Tab. B-118, Regression 3) kann zwar eine Verbesserung, allerdings noch kein zufriedenstellendes Ergebnis erzielt werden. Nur 16\% der Kreditablehnungen können bei der Regression 3 korrekt vorhergesagt werden. Während die Ausfallwahrscheinlichkeit bei kombinierter Betrachtung gar das Vorzeichen ändert und somit eine Erhöhung derselben zu einer Reduktion der Wahrscheinlichkeit der Kreditablehnung führt, bewirkt ein Anstieg der Eigenkapitalquote eine Reduktion der Wahrscheinlichkeit der Kreditablehnung. Die Kennzahl ANZ_ÜB_GES übt keinen signifikanten Effekt aus, was überraschend ist, da diese Kennzahl als deutliches Warnsignal betrachtet werden kann.

Auch bei anderen Studien, z.B. LEHMANN/NEUBERGER, reduziert eine schlechte Kreditnehmerqualität, gemessen an der Ratingklasse, die Wahrscheinlichkeit der Kreditzusage. ${ }^{1577}$ Ebenso zeigt COLE, dass ein Zusammenhang zwischen der Kreditnehmerqualität und der Kreditverfügbarkeit besteht. ${ }^{1578}$ Anders als in der vorliegenden Studie haben bei COLE Zahlungsprobleme in der Vergangenheit, gemessen in der Zahl der Überziehungen, einen negativen Effekt auf die Kreditverfügbarkeit. Bei PETERSEN/RAJAN zahlen profitablere Firmen zwar die Lieferantenverbindlichkeiten seltener zu spät als weniger profitable Firmen, was als Indiz für eine hohe Kreditverfügbarkeit betrachtet wird, allerdings ist dieser Effekt nicht signifikant. ${ }^{1579}$ Bei ANGELINI/DI SALVO/FERRI hat die Performance des Unternehmens keinen Einfluss auf die Kreditverfügbarkeit. ${ }^{1580}$

\footnotetext{
1577 Vgl. Lehmann/Neuberger (2001), S. 24.

1578 Vgl. Cole (1998), S. 975.

1579 Vgl. Petersen/Rajan (1994), S. 26.

1580 Vgl. Angelini/Di Salvo/Ferri (1998), S. 934.
} 


\begin{tabular}{|c|c|c|c|c|c|c|}
\hline \multirow[b]{2}{*}{ Einflussgröße } & \multicolumn{2}{|c|}{ Regression 1} & \multicolumn{2}{|c|}{ Regression 2} & \multicolumn{2}{|c|}{ Regression 3} \\
\hline & B & $\operatorname{Exp}(B)$ & B & $\operatorname{Exp}(\mathbf{B})$ & B & $\operatorname{Exp}(\mathbf{B})$ \\
\hline Konstante & $-1,8439$ & 0,1581 & $-1,8060$ & 0,1643 & 0,7330 & 2,0814 \\
\hline AUSFALLW B & $0,0257^{* *}$ & 1,0259 & & & $-0,0003$ & 0,9997 \\
\hline TSC_JA_AGG & & & & & $-0,0139$ & 0,9862 \\
\hline TSC QA AGG & & & & & $-0,0240$ & 0,9763 \\
\hline VERB KI_KURZ_R $\mathbf{R}^{1581}$ & & & $-0,0036$ & 0,9964 & $-0,0187$ & 0,9815 \\
\hline EKQ & & & $-0,0158^{* * *}$ & 0,9844 & $-0,0156^{* *}$ & 0,9845 \\
\hline ANZ_ÜB_GES & & & 0,0039 & 1,0040 & 0,0016 & 1,0016 \\
\hline Likelihood-Quotienten-Test & & 2,9576 & & 19,7423 & & 22,4268 \\
\hline Signifikanz & & 0,0855 & & 0,0002 & & 0,0010 \\
\hline Cox und Snell & & 0,0137 & & 0,0881 & & 0,1196 \\
\hline Nagelkerke & & 0,0244 & & 0,1566 & & 0,2143 \\
\hline McFadden & & 0,0167 & & 0,1115 & & 0,1559 \\
\hline Korrekt: Nein (\%) & & 99,4536 & & 98,9071 & & 97,3510 \\
\hline Korrekt: Ja (\%) & & 3,2258 & & 9,6774 & & 16,0000 \\
\hline Korrekt: Gesamt (\%) & & 85,5140 & & 85,9813 & & 85,7955 \\
\hline $\mathbf{N}$ & & 214 & & 214 & & 176 \\
\hline
\end{tabular}

Tab. B-118: Regression der Finanzkennzahlen

Im nächsten Schritt erfolgt die Analyse der beziehungsbezogenen Parameter. Die Variablen INT_BET, GK_ZINS, ZINS_VERFÜG und ZINSSENS wurden trotz der signifikanten Korrelationen nicht berücksichtigt, da diese Variablen nach Meinung des Verfassers aufgrund vermuteter Zirkelschlüsse nicht als Erklärung für die Kreditverfügbarkeit geeignet sind. ${ }^{1582}$ Die Vorzeichen der logistischen Regression entsprechen den Erwartungen (vgl. Tab. B-119, Regression 1). Der Hausbankstatus, ein hoher Anteil der Zahlungsverkehrsabwicklung sowie ein hoher Anteil an Bankverbindlichkeiten bei dem jeweiligen Institut reduziert die Wahrscheinlichkeit der Kreditablehnung. Die Wirkung des Hausbankstatus resultiert unter anderem aus der besonderen Verantwortung der Hausbank. Zwar hängen die beiden weiteren Variablen eng mit dem Hausbankstatus zusammen, sie haben aber auch eine eigene, direkte Wirkung, so dass hier nur partielle Mediatoreffekte vorliegen. Der hohe Anteil des Zahlungsverkehrs ermöglicht eine umfangreiche Informationsproduktion durch die Bank, so dass die Qualität des Unternehmens präziser beurteilt werden kann und die Bank eher bereit ist Kredite zu vergeben. Hinsichtlich des Anteils an Bankverbindlichkeiten lässt sich

1581 Die kurzfristige Verbindlichkeitenquote sowie die Eigenkapitalquote werden gemeinsam betrachtet, da hier nicht von einer Multikollinearität ausgegangen wird.

1582 Die Variable INT_BET hat eine positive Korrelation mit der vergangenheitsbezogenen Kreditverfügbarkeit. Dies resultiert u.a. daher, dass Problemkunden und somit auch Kunden deren Kredite nicht bewilligt worden sind, der Intensivbetreuung zugewiesen werden. Die Intensivbetreuung beschreibt somit einen ähnlichen Sachverhalt wie eine tatsächlich erfolgte, vergangene Kreditablehnung. Die Präferenz des Kunden für eine höhere Kreditverfügbarkeit resultiert vermutlich im Wesentlichen aus einem Mangel derselbigen, so dass die Variable ZINS_VERFÜG die Konsequenz einer mangelnden Verfügbarkeit beschreibt. Auch der Zinssatz dient nicht als Erklärung, sondern beschreibt vermutlich vielmehr eine alternative Auswirkung einer schlechten Bonität oder einer schlechten Beziehungsqualität. Vgl. hierzu auch Kapitel B.3.4.2. und B.3.6.2. 
der Zusammenhang derart interpretieren, dass der Wert der Informationen über die Firmenspezifika bei der Bank größer ist, wenn das Unternehmen nur bei einer oder wenigen Banken Kredite aufnimmt. ${ }^{1583}$ Dies stimmt überein mit den Ergebnissen von ONGENA/SMITH, welche zeigen, dass Unternehmen mit wenigen Bankbeziehungen selbige nicht so schnell beenden wie Unternehmen mit vielen Bankbeziehungen. ${ }^{1584}$ Deshalb vermuten sie, dass eine bestehende Bankbeziehung für Unternehmen mit wenigen Verbindungen einen größeren Wert stiftet. Der Anteil der erklärten Streuung sowie die Anteile der korrekt klassifizierten Werte sind in der vorliegenden Untersuchung allerdings sehr niedrig. Der Anteil der korrekt klassifizierten Kreditablehnungen beträgt gar $0,00 \%$. Dementsprechend liefert die gemeinsame Regression von Finanzkennzahlen und beziehungsbezogenen Variablen keinen Erkenntnisgewinn (vgl. Tab. B-119, Regression 2). Der Erklärungsgehalt entspricht dem der Finanzkennzahlen (vgl. Tab. B-118, Regression 3).

\begin{tabular}{|c|c|c|c|c|}
\hline \multirow{2}{*}{ Einflussgröße } & \multicolumn{2}{|c|}{ Regression 1} & \multicolumn{2}{|c|}{ Regression 2} \\
\hline & B & $\operatorname{Exp}(\mathbf{B})$ & B & $\operatorname{Exp}(B)$ \\
\hline Konstante & $-0,7394$ & 0,4774 & $-1,4091$ & 4,0924 \\
\hline VERB KI KURZ R & & & 0,0200 & 0,9802 \\
\hline EKQ & & & $0,0165^{* *}$ & 0,9836 \\
\hline ANZ_ÜB_GES & & & 0,0021 & 1,0021 \\
\hline AUSFALLW B & & & $-0,0036$ & 0,9964 \\
\hline TSC_JA_AGG & & & $-0,0133$ & 0,9868 \\
\hline TSC_QA_AGG & & & $-0,0219$ & 0,9783 \\
\hline HAUSBANK_K & $-0,4454$ & 0,6405 & $-0,0383$ & 0,9624 \\
\hline ANT ZV & $-0,0057$ & 0,9943 & $-0,0108$ & 0,9893 \\
\hline ANT BANK IN & $-0,0043$ & 0,9957 & $-0,0003$ & 0,9997 \\
\hline Likelihood-Quotienten-Test & & 6,0532 & & 23,1474 \\
\hline Signifikanz & & 0,1090 & & 0,0059 \\
\hline Cox und Snell & & 0,0292 & & 0,1302 \\
\hline Nagelkerke & & 0,0510 & & 0,2277 \\
\hline McFadden & & 0,0348 & & 0,1645 \\
\hline Korrekt: Nein (\%) & & 100,00 & & 98,5816 \\
\hline Korrekt: Ja (\%) & & 0,00 & & 16,0000 \\
\hline Korrekt: Gesamt (\%) & & 84,80 & & 86,1446 \\
\hline $\mathbf{N}$ & & 204 & & 166 \\
\hline
\end{tabular}

Tab. B-119: Regression der beziehungsbezogenen Variablen und der Finanzkennzahlen

Im nächsten Schritt erfolgt die Analyse der verhaltenswissenschaftlichen Variablen (vgl. Tab. B-120) hinsichtlich deren Einfluss auf die Kreditverfügbarkeit. Während in Regression 1 die Originalfaktoren verwendet werden, wird in Regression 2 der modifizierte Faktor verwendet. Auf organisationaler Ebene wurde vermutet, dass insbesondere die organisationale Glaubwürdigkeit die Unsicherheit der Bank bzw. des Firmenkundenbetreuers hinsichtlich der Auswahl eines investitionsrechnerisch guten Projek- 
tes und die Verhaltensunsicherheit hinsichtlich einer möglichen Asset Substitution reduziert. Die gesunkene Unsicherheit führt zu einem Anstieg der Kreditverfügbarkeit. Dieser Zusammenhang wird durch die vorliegende Untersuchung bestätigt, wenngleich auch nicht signifikant. Ferner führt das Wohlwollen des Unternehmens, welches sich ggf. durch Vermittlung von Neukunden ausgedrückt hat, zu einer erhöhten Kreditverfügbarkeit. Hier könnte die Reziprozität des Wohlwollens ursächlich sein. Während die Hypothese $\mathrm{H} 12$ nicht signifikant bestätigt werden kann, wird die Hypothese H13 auf dem 5\%-Niveau unterstützt.

H12: Je größer die organisationale Glaubwürdigkeit des Unternehmens, desto größer ist die Kreditverfügbarkeit bzw. desto geringer ist die Wahrscheinlichkeit der Kreditablehnung. (Best. - keine Signifikanz)

H13: Je größer das organisationale Wohlwollen des Unternehmens, desto größer ist die Kreditverfügbarkeit bzw. desto geringer ist die Wahrscheinlichkeit der Kreditablehnung. (Best. - 5\%-Niveau)

Hinsichtlich der Effekte auf interpersonaler Ebene wurde vermutet, dass diese lediglich aufgrund von personellen Verflechtungen und somit einer fehlenden Trennung zwischen organisationaler und personaler Ebene wirken. Diese fehlende Trennung resultiert u.a. aus der Einheit von Eigentum und Leitung des Unternehmers, die in der Wahrnehmung des Firmenkundenbetreuers zu einer Gleichsetzung von Organisation und Person führen kann. ${ }^{1585}$ Die Hypothese hinsichtlich der interpersonalen Glaubwürdigkeit (H14) wird bestätigt, allerdings nicht signifikant. Eine erhöhte Glaubwürdigkeit bewirkt eine geringere Wahrscheinlichkeit der Kreditablehnung. Ein hohes interpersonales Wohlwollen hingegen führt zu einer höheren Wahrscheinlichkeit der Kreditablehnung. Dies widerspricht dem in $\mathrm{H} 15$ vermuteten Zusammenhang, allerdings sind die Ergebnisse nicht signifikant. Bezüglich des personalen Wohlwollens ist es denkbar, dass selbiges nur zinsreduzierend wirkt. Dieser Zusammenhang zum Zinssatz konnte auf dem 1\%-Niveau bestätigt werden (vgl. Tab. B-89). Der Firmenkundenbetreuer ist bei einer guten Beziehung zum Ansprechpartner des Unternehmens eher bereit, Zugeständnisse bei den Zinsen zu machen als einen gegebenenfalls sehr risikobehafteten Kredit zu vergeben.

H14: Je größer die interpersonale Glaubwürdigkeit des Ansprechpartners im Unternehmen, desto größer ist die Kreditverfügbarkeit bzw. desto geringer ist die Wahrscheinlichkeit der Kreditablehnung. (Best. - keine Signifikanz)

H15: Je größer das interpersonale Wohlwollen des Ansprechpartners im Unternehmen, desto größer ist die Kreditverfügbarkei bzw. desto geringer ist die Wahrscheinlichkeit der Kreditablehnung. (Abl. - keine Signifikanz)

Die organisationale Gebundenheit wurde als Voraussetzung für die intertemporale Konditionengestaltung betrachtet, so dass das Vorliegen von Gebundenheit die Kreditverfügbarkeit erhöht und die Wahrscheinlichkeit der Kreditablehnung reduziert. Ein 
ähnlicher Effekt hinsichtlich der intertemporalen Konditionengestaltung wurde in Bezug auf die Verbundenheit vermutet. Bezüglich der Verbundenheit auf organisationaler und personaler Ebene wurde ferner angenommen, dass die Bank eine höhere Verpflichtung zur Unterstützung des Kunden empfindet und somit die Kreditverfügbarkeit im Sinne einer größeren Wahrscheinlichkeit der Kreditbereitstellung steigt. Während die personale Verbundenheit zu einer erhöhten Kreditverfügbarkeit führt und somit die Hypothese H18 - wenngleich auch nicht signifikant - bestätigt wird, kann der Zusammenhang hinsichtlich der organisationalen Gebundenheit (H16) und Verbundenheit (H17) nicht bestätigt werden.

H16: Je größer die organisationale Gebundenheit, desto größer ist die Kreditverfügbarkeit bzw. desto geringer ist die Wahrscheinlichkeit der Kreditablehnung. (Abl. - keine Signifikanz)

H17: Je größer die organisationale Verbundenheit, desto größer ist die Kreditverfügbarkeit bzw. desto geringer ist die Wahrscheinlichkeit der Kreditablehnung. (Abl. - keine Signifikanz)

H18: Je größer die personale Verbundenheit, desto größer ist die Kreditverfügbarkeit bzw. desto geringer ist die Wahrscheinlichkeit der Kreditablehnung. (Best. keine Signifikanz) 


\begin{tabular}{|c|c|c|c|c|}
\hline \multirow{2}{*}{ Einflussgröße } & \multicolumn{2}{|c|}{ Regression 1} & \multicolumn{2}{|c|}{ Regression 2} \\
\hline & B & $\operatorname{Exp}(B)$ & B & $\operatorname{Exp}(B)$ \\
\hline Konstante & $-2,1138$ & 0,1208 & $-2,1265$ & 0,1192 \\
\hline ORG GLAUB & 0,3871 & 1,4728 & 0,3686 & 1,4457 \\
\hline ORG WOHL & $0,8568^{* *}$ & 2,3556 & $0,7838^{* *}$ & 2,1897 \\
\hline PERS GLAUB & 0,2807 & 1,3240 & 0,2358 & 1,2659 \\
\hline PERS WOHL & $-0,3562$ & 0,7003 & & \\
\hline ORG_GEB & $-0,4338$ & 0,6481 & $-0,5165$ & 0,5966 \\
\hline ORG_VER & $-0,1241$ & 0,8833 & $-0,0652$ & 0,9369 \\
\hline PERS VER & 0,0692 & 1,0717 & & \\
\hline PERS VER WOHL & & & $-0,2048$ & 0,8148 \\
\hline Likelihood-Quotienten-Test & & 26,1890 & & 22,2976 \\
\hline Signifikanz & & 0,0005 & & 0,0011 \\
\hline Cox und Snell & & 0,1281 & & 0,1075 \\
\hline Nagelkerke & & 0,2266 & & 0,1921 \\
\hline McFadden & & 0,1645 & & 0,1387 \\
\hline Korrekt: Nein (\%) & & 98,1595 & & 98,2143 \\
\hline Korrekt: Ja (\%) & & 14,2857 & & 3,5714 \\
\hline Korrekt: Gesamt (\%) & & 85,8639 & & 84,6939 \\
\hline $\mathbf{N}$ & & 191 & & 196 \\
\hline
\end{tabular}

Tab. B-120: Regression der verhaltenswissenschaftlichen Variablen

Im Folgenden werden die Finanzkennzahlen, die beziehungsbezogenen und die verhaltenswissenschaftlichen Variablen gemeinsam betrachtet (vgl. Tab. B-121, Regression 1). Der Anteil der durch das Modell korrekt klassifizierten Kreditablehnungen steigt auf 36,36\%. Ferner steigt auch der Erklärungsgehalt bei Ergänzung der Finanzkennzahlen und der beziehungsbezogenen Variablen um verhaltenswissenschaftliche Variablen erheblich an. Nagelkerkes Pseudo- $R^{2}$ steigt von 22,77\% (vgl. Tab. B-119, Regression 2) auf 39,39\% (vgl. Tab. B-121, Regression 1). Bei gemeinsamer Betrachtung der Variablen kann erneut die Hypothese H13 in Bezug auf das organisationale Wohlwollen bestätigt werden. Die weiteren Faktoren üben in diesem Modell keinen signifikanten Einfluss mehr aus.

Der Vergleich mit den vorherigen Regressionen zeigt (vgl. Tab. B-122), dass die verhaltenswissenschaftlichen Variablen alleine die Kreditablehnungen nahezu genauso gut erklären wie die Finanzkennzahlen und wie die Finanzkennzahlen zuzüglich der beziehungsbezogenen Variablen. Die gemeinsame Betrachtung aller drei Variablengruppen führt zu einem erheblichen Anstieg der Güte des Gesamtmodells.

Aufgrund der fehlenden Zusammenhänge der bankbezogenen Variablen zur vergangenheitsbezogenen Kreditverfügbarkeit werden selbige im Rahmen der Regressionsanalyse nicht weiter betrachtet. Die Ergebnisse hinsichtlich der Kreditverfügbarkeit, an dieser Stelle untersucht als Inverse, d.h. der Wahrscheinlichkeit der Kreditablehnung, werden in Tab. B-123 zusammengefasst. 


\begin{tabular}{|c|c|c|c|c|}
\hline \multirow{2}{*}{ Einflussgröße } & \multicolumn{2}{|c|}{ Regression 1} & \multicolumn{2}{|c|}{ Regression 2} \\
\hline & B & Exp(B) & B & $\operatorname{Exp}(B)$ \\
\hline Konstante & $-1,3631$ & 0,2559 & $-0,8685$ & 0,4196 \\
\hline VERB KI KURZ R & $-0,0199$ & 0,9803 & $-0,0272$ & 0,9731 \\
\hline EKQ & $-0,0175^{* *}$ & 0,9826 & $-0,0168^{* *}$ & 0,9834 \\
\hline AUSFALLW_B & $-0,0113$ & 0,9888 & 0,0043 & 1,0043 \\
\hline TSC JA AGG & 0,0046 & 1,0046 & 0,0119 & 1,0120 \\
\hline $\mathrm{TSC} \mathrm{QA}_{\mathrm{AGG}}$ & $-0,0109$ & 0,9891 & $-0,0190$ & 0,9812 \\
\hline HAUSBANK K & 1,0671 & 2,9069 & 0,7013 & 2,0163 \\
\hline ANT_ZV & $-0,0157$ & 0,9844 & $-0,0162$ & 0,9839 \\
\hline ANT BANK IN & $-0,0024$ & 0,9976 & $-0,0009$ & 0,9991 \\
\hline ANZ ÜB GES & 0,0051 & 1,0051 & 0,0042 & 1,0042 \\
\hline ORG_GLAUB & 0,0925 & 1,0970 & 0,1530 & 1,1653 \\
\hline ORG WOHL & $1,0341^{* *}$ & 2,8125 & $0,8778^{*}$ & 2,4056 \\
\hline PERS GLAUB & 0,4851 & 1,6244 & 0,4681 & 1,5970 \\
\hline PERS WOHL & $-0,8871^{*}$ & 0,4119 & & \\
\hline ORG_GEB & $-0,5967$ & 0,5506 & $-0,7656^{*}$ & 0,4651 \\
\hline ORG VER & $-0,7341$ & 0,4800 & $-0,4903$ & 0,6125 \\
\hline PERS VER & 0,5066 & 1,6597 & & \\
\hline PERS VER WOHL & & & $-0,8685$ & 0,7479 \\
\hline Likelihood-Quotienten-Test & & 38,2716 & & 32,3059 \\
\hline Signifikanz & & 0,0014 & & 0,0058 \\
\hline Cox und Snell & & 0,2239 & & 0,1903 \\
\hline Nagelkerke & & 0,3969 & & 0,3392 \\
\hline McFadden & & 0,3052 & & 0,2564 \\
\hline Korrekt: Nein (\%) & & 96,1240 & & 96,1832 \\
\hline Korrekt: Ja (\%) & & 36,3636 & & 27,2727 \\
\hline Korrekt: Gesamt (\%) & & 87,4172 & & 86,2745 \\
\hline $\mathrm{N}$ & & 151 & & 153 \\
\hline
\end{tabular}

Tab. B-121: Regression der Finanzkennzahlen, der beziehungsbezogenen und der verhaltenswissenschaftlichen Variablen

\begin{tabular}{|c|c|c|c|c|}
\hline & $\begin{array}{c}\text { Finanz- } \\
\text { kennzahlen }^{1586}\end{array}$ & $\begin{array}{c}\text { Finanzkennzahlen } \\
\text { und beziehungsbe- } \\
\text { zogene Variablen }^{1587}\end{array}$ & $\begin{array}{l}\text { Verhaltenswis- } \\
\text { senschaftliche } \\
\text { Variablen } \\
\text { 1588 }\end{array}$ & $\begin{array}{c}\text { Alle drei Variab- } \\
\text { lengruppen } \\
\text { gemeinsam }^{1589}\end{array}$ \\
\hline Cox und Snell & 0,1196 & 0,1302 & 0,1281 & 0,2239 \\
\hline Nagelkerke & 0,2143 & 0,2277 & 0,2266 & 0,3969 \\
\hline McFadden & 0,1559 & 0,1645 & 0,1645 & 0,3052 \\
\hline Korrekt: Nein (\%) & 97,3510 & 98,5816 & 98,1595 & 96,1240 \\
\hline Korrekt: Ja (\%) & 16,0000 & 16,0000 & 14,2857 & 36,3636 \\
\hline Korrekt: Gesamt (\%) & 85,7955 & 86,1446 & 85,8639 & 87,4172 \\
\hline
\end{tabular}

Tab. B-122: Vergleich der Güte der verschiedenen Modelle zur Kreditverfügbarkeit

$\begin{array}{ll}1586 & \text { Vgl. Tab. B-118, Regression } 3 . \\ 1587 & \text { Vgl. Tab. B-119, Regression 2. } \\ 1588 & \text { Vgl. Tab. B-120, Regression 1. } \\ 1589 & \text { Vgl. Tab. B-121, Regression 1. }\end{array}$ 


\begin{tabular}{|c|c|c|c|c|c|c|c|c|}
\hline & \multirow{3}{*}{$\begin{array}{c}\text { Je größer...., } \\
\text { desto ... }\end{array}$} & \multicolumn{7}{|c|}{... ist die Wahrscheinlichkeit von Kreditablehnungen. } \\
\hline & & \multirow[b]{2}{*}{ Hypothese } & \multicolumn{3}{|c|}{ Isolierte Betrachtung } & \multicolumn{3}{|c|}{ Kombinierte Betrachtung ${ }^{1591}$} \\
\hline & & & Empirie & $\begin{array}{l}\text { Signi- } \\
\text { fikanz }\end{array}$ & Fazit & Empirie & $\begin{array}{l}\text { Signi- } \\
\text { fikanz }\end{array}$ & Fazit \\
\hline $\mathrm{H} 12$ & $\begin{array}{l}\text { die organisationale } \\
\text { Glaubwürdigkeit }\end{array}$ & kleiner & kleiner & & (Best.) & kleiner & & (Best.) \\
\hline $\mathrm{H} 13$ & $\begin{array}{l}\text { das organisationale } \\
\text { Wohlwollen }\end{array}$ & kleiner & kleiner & $5 \%$ & Best. & kleiner & $5 \%$ & Best. \\
\hline $\mathrm{H} 14$ & $\begin{array}{l}\text { die interpersonale } \\
\text { Glaubwürdigkeit }\end{array}$ & kleiner & kleiner & & (Best.) & kleiner & & (Best.) \\
\hline $\mathrm{H} 15$ & $\begin{array}{l}\text { das interpersonale } \\
\text { Wohlwollen }\end{array}$ & kleiner & größer & & (Abl.) & größer & & (Abl.) \\
\hline $\mathrm{H} 16$ & $\begin{array}{l}\text { die organisationale } \\
\text { Gebundenheit }\end{array}$ & kleiner & größer & & (Abl.) & größer & & (Abl.) \\
\hline $\mathrm{H} 17$ & $\begin{array}{l}\text { die organisationale } \\
\text { Verbundenheit }\end{array}$ & kleiner & größer & & (Abl.) & größer & $10 \%$ & Abl. \\
\hline $\mathrm{H} 18$ & $\begin{array}{l}\text { die personale } \\
\text { Verbundenheit }\end{array}$ & kleiner & kleiner & & (Best.) & kleiner & & (Best.) \\
\hline
\end{tabular}

Tab. B-123: Zusammenfassung der Ergebnisse zur Kreditverfügbarkeit

Zusammenfassend lässt sich feststellen, dass die verhaltenswissenschaftlichen Variablen den Erklärungsgehalt der erfolgten und der nicht-erfolgten Kreditablehnungen erheblich steigern können. Die Wahrscheinlichkeit der Kreditablehnung wurde auf Basis von tatsächlich erfolgten vollständigen oder partiellen Kreditablehnungen der Vergangenheit ermittelt. Nachteilig an der vorgenommenen Untersuchung ist das Timelag. Während sich die Kreditablehnungen auf die vergangenen fünf Jahre bezogen haben, entstammen die verwendeten unabhängigen Variablen der unmittelbaren Gegenwart bzw. die Finanzkennzahlen dem letzten vorliegenden Geschäftsjahr. So könnten sich die Finanzkennzahlen und die sonstigen Daten im Vergleich zum Zeitpunkt der Kreditablehnung mittlerweile verbessert haben. Aus diesem Grund wird im nächsten Schritt eine Analyse der gegenwartsbezogenen Kreditverfügbarkeit vorgenommen. Bei dieser Vorgehensweise basiert die Einschätzung auf dem aktuellen Informationsstand des Firmenkundenbetreuers. Die Variable spiegelt die subjektive Einschätzung des Firmenkundenbetreuers wider.

\subsubsection{Logistische Regression der gegenwartsbezogenen Kreditverfügbarkeit}

Das Vorgehen bei der Analyse der gegenwartsbezogenen Kreditverfügbarkeit entspricht selbigem der vorherigen Analysen. Tab. B-124 zeigt zunächst den Zusammenhang zu den Finanzkennzahlen. Bei gemeinsamer Betrachtung von Finanz- und Ratingkennzahlen werden in Regression 3 lediglich 10,53\% der vermutlich nicht gewährten Kreditausweitungen korrekt geschätzt. Der TSC_JA_AGG hat einen positiven signifikanten Effekt auf die Kreditausweitungen, gleiches gilt für die Kassenposition

\footnotetext{
1590 Grundlage für die Beurteilung der isolierten Betrachtung sind die Ergebnisse der Regression 1 aus Tab. B-120.

1591 Grundlage für die Beurteilung der kombinierten Betrachtung sind die Ergebnisse der Regression 1 aus Tab. B-121.
} 
KASSE_A_LN. Ein bei absoluter Betrachtung hoher Kassenbestand erhöht somit die Wahrscheinlichkeit der Kreditausweitung, wobei der Effekt abnimmt, d.h. eine Ausweitung von 500 Tsd. EUR auf 1 Mio. EUR wirkt stärker als eine Ausweitung von 2,5 Mio. EUR auf 3 Mio. EUR. Da es sich hierbei um eine rein hypothetische Bereitschaft einer zusätzliche Kreditausweitung handelt, d.h. ohne dass der Firmenkunde eine Anfrage gestellt und der Firmenkundenbetreuer sich aus diesem Anlass mit den Unternehmenskennzahlen beschäftigt hat, basiert die Einschätzung des Firmenkundenbetreuers nicht auf einer Analyse der Finanzkennzahlen. Der Zusammenhang resultiert ausschließlich aus dem Wissen des Firmenkundenbetreuers hinsichtlich der Kennzahlenausprägungen. Aus diesem Grund fällt der Zusammenhang zu einzelnen Kennzahlen möglicherweise schwächer aus, als dies nach einer fundierten Bilanzanalyse der Fall wäre. Wie auch bereits bei den tatsächlich erfolgten Kreditablehnungen in Kapitel B.3.6.3.1 aufgezeigt, führt eine bessere Kreditnehmerqualität zu einer höheren Verfügbarkeit.

\begin{tabular}{|c|c|c|c|c|c|c|}
\hline \multirow{2}{*}{ Einflussgröße } & \multicolumn{2}{|c|}{ Regression 1} & \multicolumn{2}{|c|}{ Regression 2} & \multicolumn{2}{|c|}{ Regression 3} \\
\hline & B & $\operatorname{Exp}(B)$ & B & Exp(B) & B & Exp(B) \\
\hline Konstanter Term & $1,9878^{* * *}$ & 7,2997 & $-1,2822$ & 0,2774 & $-3,8846$ & 0,0206 \\
\hline AUSFALLW B & $-0,0247$ & 0,9756 & & & $-0,0058$ & 0,9942 \\
\hline TSC_JA_AGG & & & & & $0,0432 * *$ & 1,0441 \\
\hline TSC_QA_AGG & & & & & 0,0200 & 1,0202 \\
\hline VERB_KI KURZ R & & & 0,0161 & 1,0162 & 0,0258 & 1,0262 \\
\hline EKQ & & & $0,0117^{*}$ & 1,0118 & 0,0042 & 1,0042 \\
\hline VERM LA R LN & & & 0,0503 & 1,0516 & $-0,0274$ & 0,9730 \\
\hline KASSE A LN & & & $0,3355^{* *}$ & 1,3986 & $0,2802^{*}$ & 1,3234 \\
\hline ANZ_ÜB_GES & & & $-0,0037$ & 0,9963 & 0,0031 & 1,0031 \\
\hline Likelihood-Quotienten-Test & & 2,6978 & & 17,6028 & & 22,6364 \\
\hline Signifikanz & & 0,1005 & & 0,0034 & & 0,0038 \\
\hline Cox und Snell & & 0,0132 & & 0,0889 & & 0,1343 \\
\hline Nagelkerke & & 0,0247 & & 0,1734 & & 0,2573 \\
\hline McFadden & & 0,0174 & & 0,1295 & & 0,1954 \\
\hline Korrekt: Nein (\%) & & 3,8462 & & 4,5455 & & 10,5263 \\
\hline Korrekt: Ja (\%) & & 99,4350 & & 99,4012 & & 98,5507 \\
\hline Korrekt: Gesamt (\%) & & 87,1921 & & 88,3598 & & 87,8981 \\
\hline $\mathbf{N}$ & & 203 & & 189 & & 157 \\
\hline
\end{tabular}

Tab. B-124: Regression der Finanzkennzahlen

Im nächsten Schritt erfolgt die Analyse des Einflusses der beziehungsbezogenen Variablen (vgl. Tab. B-125, Regression 1). Neben den Variablen mit hohen Korrelationen wurde ferner die Besicherungsquote bei der Regression berücksichtigt. In dem Fragebogen wurde nach dem Grund einer Kreditablehnung gefragt. Da die fehlenden Besicherungsmöglichkeiten der einzige mehrfach erwähnte Grund für potenzielle Kreditablehnungen war, besteht auch hier die Möglichkeit eines Zusammenhangs. Die beziehungsbezogenen Variablen können nur 8,70\% der Kreditablehnungen korrekt klassifizieren. Auch liegen die Pseudo- $\mathrm{R}^{2}$ mit Werten zwischen 0,12 und 0,23 unter den Wer-

ten der Regression 3 für die Finanzkennzahlen. Der Hausbankstatus sowie die Mitgliedschaft erhöhen die Wahrscheinlichkeit einer Kreditausweitung. Dies bestätigt die 
Ergebnisse von ANGELINI/Di SALVO/FERRI. Sie zeigen, dass Mitglieder von Genossenschaftsbanken einfacher Kredite erhalten als Nicht-Mitglieder. ${ }^{1592}$ Wenngleich nicht signifikant, führt eine größere Anzahl an genutzten Produkten zu einer größeren Wahrscheinlichkeit der Kreditausweitung. Wie bereits im Kontext der vergangenheitsbezogenen Kreditverfügbarkeit angesprochen, zeigt auch COLE, dass die Wahrscheinlichkeit für eine Kreditverlängerung oder Neuvergabe steigt, wenn der potenzielle Kreditgeber bereits Produktlieferant für Spar- oder Anlagekonten und Financial Management-Dienstleistungen war. ${ }^{1593}$ Der negative signifikante Zusammenhang zur Verbindlichkeitenquote des jeweiligen Kreditinstituts lässt sich derart erklären, dass die Bank den Anteil der Gesamtfinanzierung des Unternehmens und somit ihr Risiko nicht ausweiten möchte.

\begin{tabular}{|c|c|c|c|c|}
\hline \multirow{2}{*}{ Einflussgröße } & \multicolumn{2}{|c|}{ Regression 1} & \multicolumn{2}{|c|}{ Regression 2} \\
\hline & B & $\operatorname{Exp}(B)$ & B & $\operatorname{Exp}(B)$ \\
\hline Konstanter Term & 0,5761 & 1,7791 & $-8,4345^{* *}$ & 0,0002 \\
\hline VERB EIG $R$ & $-0,0192^{* *}$ & 0,9810 & 0,0126 & 1,0127 \\
\hline HAUSBANK K & $1,6604^{* * *}$ & 5,2614 & 1,6197 & 5,0516 \\
\hline MITGLIED & $1,3349^{* *}$ & 3,7996 & $2,0489 * * *$ & 7,7590 \\
\hline ANZAHL PRODUKT & 0,0990 & 1,1040 & 0,0143 & 1,0144 \\
\hline SICH_Q & $-0,0082$ & 0,9918 & $-0,0121$ & 0,9880 \\
\hline VERB KI KURZ R & & & $-0,0007$ & 0,9993 \\
\hline AUSFALLW_B & & & 0,0193 & 1,0195 \\
\hline TSC_JA_AGG & & & $0,0644^{*}$ & 1,0666 \\
\hline TSC_QA_AGG & & & $-0,0111$ & 0,9889 \\
\hline EKQ & & & 0,0008 & 1,0008 \\
\hline VERM LA R LN & & & 0,2962 & 1,3447 \\
\hline KASSE_A_LN & & & $0,4036^{*}$ & 1,4972 \\
\hline ANZ_ÖB_GES & & & 0,0022 & 1,0022 \\
\hline Likelihood-Quotienten-Test & & 24,0825 & & 39,8195 \\
\hline Signifikanz & & 0,0002 & & 0,0001 \\
\hline Cox und Snell & & 0,1185 & & 0,2359 \\
\hline Nagelkerke & & 0,2275 & & 0,4756 \\
\hline McFadden & & 0,1714 & & 0,3927 \\
\hline Korrekt: Nein (\%) & & 8,6957 & & 31,2500 \\
\hline Korrekt: Ja (\%) & & 98,2143 & & 96,9697 \\
\hline Korrekt: Gesamt (\%) & & 87,4346 & & 89,8649 \\
\hline $\mathbf{N}$ & & 191 & & 148 \\
\hline
\end{tabular}

Tab. B-125: Regression der Finanzkennzahlen und der beziehungsbezogenen Variablen

Bei gemeinsamer Betrachtung der Finanzkennzahlen und der beziehungsbezogenen Variablen steigt der Anteil der korrekt klassifizierten potenziellen Kreditausweitungen auf $31,25 \%$. Ferner steigen auch die Werte für die drei Pseudo- $\mathrm{R}^{2}$ erheblich an (vgl. Tab. B-125, Regression 2). Bei dieser Betrachtung sind ausschließlich die Mitgliedschaft, der Kassenbestand sowie der Teilscore für die Jahresabschlussdaten relevant.

\footnotetext{
1592 Vgl. Angelini/Di Salvo/Ferri (1998), S. 948.

1593 Vgl. Cole (1998), S. 962.
} 
Die Besicherungsquote übt weder bei der isolierten Betrachtung der beziehungsbezogenen Variablen noch bei der gemeinsamen Betrachtung derselben mit den Finanzkennzahlen einen signifikanten Einfluss aus; jedoch führt eine höhere Besicherungsquote zu einer größeren Wahrscheinlichkeit der Kreditausweitung.

In Tab. B-126 erfolgt die Analyse der verhaltenswissenschaftlichen Parameter mit der Kreditausweitung. Regression 1 stellt die Auswertung unter Verwendung der Originalfaktoren, Regression 2 die Auswertung unter Verwendung des modifizierten Faktors dar. Hinsichtlich der organisationalen Glaubwürdigkeit wurde vermutet, dass eine Verbesserung derselben zu einer Reduktion der Unsicherheit der Bank führt und somit die Kreditverfügbarkeit steigt. Die Hypothese $\mathrm{H} 12$ kann in der vorliegenden Untersuchung bestätigt werden. Gleichermaßen wird auch für die Hypothese H13 in Bezug auf das organisationale Wohlwollen eine Bestätigung erzielt. Obwohl vermutet wurde, dass das Wohlwollen im Vergleich zur Glaubwürdigkeit eher von nachgelagerter Bedeutung ist, bewirken die Veränderungen auf der Ratingskala um eine Einheit jeweils ca. eine Veränderung des Odds um den Faktor 0,5, so dass hier keine großen Unterschiede sichtbar sind.

H12: Je größer die organisationale Glaubwürdigkeit des Unternehmens, desto größer ist die Kreditverfügbarkeit und desto weniger Kreditablehnungen gibt es. (Best. - 10\%-Niveau)

H13: Je größer das organisationale Wohlwollen des Unternehmens, desto größer ist die Kreditverfügbarkeit und desto weniger Kreditablehnungen gibt es. (Best. $10 \%$-Niveau)

Auf personaler Ebene ist die Wirkungsrichtung nicht einheitlich. Während ein Anstieg des personalen Wohlwollens - wie in Hypothese H15 vermutet - die Wahrscheinlichkeit der Kreditausweitung und somit auch die Kreditverfügbarkeit erhöht, führt ein Anstieg der personalen Glaubwürdigkeit zur Reduktion derselbigen. Hypothese H14 muss somit verworfen werden. Während die Hypothesen auf organisationaler Ebene auf dem 10\%-Niveau signifikant bestätigt werden können, sind die Werte auf personaler Ebene nicht signifikant. In Kapitel B.3.6.3.1 wurde im Kontext der vergangenheitsbezogenen Kreditverfügbarkeit ein ähnlicher Zusammenhang festgestellt. Möglicherweise sind für die Kreditvergabe ausschließlich organisationale Aspekte entscheidend. Die personale Ebene hingegen beeinflusst die Zinshöhe.

H14: Je größer die interpersonale Glaubwürdigkeit des Ansprechpartners im Unternehmen, desto größer ist die Kreditverfügbarkeit und desto weniger Kreditablehnungen gibt es. (Abl. - keine Signifikanz)

H15: Je größer das interpersonale Wohlwollen des Ansprechpartners im Unternehmen, desto größer ist die Kreditverfügbarkeit und desto weniger Kreditablehnungen gibt es. (Best. - keine Signifikanz)

Ferner wurde vermutet, dass die organisationale Gebundenheit und Verbundenheit erst eine intertemporale Konditionengestaltung ermöglichen und somit die Kreditverfügbarkeit erhöhen. Dieser Zusammenhang, dargestellt in den Hypothesen H16 und H17, kann nicht bestätigt werden. Eine mögliche Erklärung für den umgekehrten Zusam- 
menhang bei der Gebundenheit besteht darin, dass die Ursache der Gebundenheit in der Bonität des Kunden liegt. Der Kunde bekommt somit aufgrund der schlechten Bonität keine zusätzlichen Kredite.

H16: Je größer die organisationale Gebundenheit, desto größer ist die Kreditverfügbarkeit und desto weniger Kreditablehnungen gibt es. (Abl. - 5\%-Niveau)

H17: Je größer die organisationale Verbundenheit, desto größer ist die Kreditverfügbarkeit und desto weniger Kreditablehnungen gibt es. (Abl. - keine Signifikanz)

Dahingegen führt ein Anstieg der personalen Verbundenheit, wie in H18 postuliert, zu einem Anstieg der Kreditverfügbarkeit. Der Zusammenhang ist jedoch nicht signifikant.

H18: Je größer die personale Verbundenheit, desto größer ist die Kreditverfügbarkeit und desto weniger Kreditablehnungen gibt es. (Best. - keine Signifikanz)

\begin{tabular}{|c|c|c|c|c|}
\hline \multirow{2}{*}{ Einflussgröße } & \multicolumn{2}{|c|}{ Regression 1} & \multicolumn{2}{|c|}{ Regression 2} \\
\hline & B & $\operatorname{Exp}(B)$ & B & $\operatorname{Exp}(B)$ \\
\hline Konstanter Term & 2,5036 & 12,2260 & $2,5321^{* * *}$ & 12,5802 \\
\hline ORG GLAUB & $-0,7297^{*}$ & 0,4820 & $-0,6086$ & 0,5441 \\
\hline ORG WOHL & $-0,6922^{*}$ & 0,5005 & $-0,6155$ & 0,5404 \\
\hline PERS GLAUB & 0,1223 & 1,1301 & 0,1182 & 1,1255 \\
\hline PERS_WOHL & $-0,0605$ & 0,9413 & & \\
\hline ORG_GEB & $0,8969^{* *}$ & 2,4520 & $1,0086^{* * *}$ & 2,7419 \\
\hline ORG VER & 0,2544 & 1,2896 & 0,3538 & 1,4244 \\
\hline PERS VER & $-0,0554$ & 0,9461 & & \\
\hline PERS VER WOHL & & & $-0,3491$ & 0,7053 \\
\hline Likelihood-Quotienten-Test & & 105,3504 & & 109,0640 \\
\hline Signifikanz & & 0,0001 & & 0,0006 \\
\hline Cox und Snell & & 0,1639 & & 0,1490 \\
\hline Nagelkerke & & 0,3067 & & 0,2822 \\
\hline McFadden & & 0,2342 & & 0,2149 \\
\hline Korrekt: Nein (\%) & & 17,3913 & & 13,0435 \\
\hline Korrekt: Ja (\%) & & 98,0892 & & 96,9136 \\
\hline Korrekt: Gesamt (\%) & & 87,7778 & & 86,4865 \\
\hline $\mathbf{N}$ & & 180 & & 185 \\
\hline
\end{tabular}

Tab. B-126: Regression der verhaltenswissenschaftlichen Variablen

Bei gemeinsamer Betrachtung der verhaltenswissenschaftlichen Variablen mit den Finanzkennzahlen und den beziehungsbezogenen Variablen ergibt sich, dass sich der Einfluss des organisationalen und des interpersonalen Wohlwollens umkehrt, d.h. eine Verbesserung derselben führt gar zu einer Reduktion der Kreditverfügbarkeit (vgl. Tab. B-127, Regression 1). 


\begin{tabular}{|c|c|c|c|c|}
\hline \multirow{2}{*}{ Einflussgröße } & \multicolumn{2}{|c|}{ Regression 1} & \multicolumn{2}{|c|}{ Regression 2} \\
\hline & B & $\operatorname{Exp}(B)$ & B & $\operatorname{Exp}(B)$ \\
\hline Konstante & $-8,5755^{*}$ & 0,0002 & $-13,9766 * * *$ & 0,0000 \\
\hline VERB EIG $R$ & 0,0165 & 1,0167 & 0,0282 & 1,0286 \\
\hline HAUSBANK K & 1,5729 & 4,8206 & 2,4266 & 11,3205 \\
\hline MITGLIED & 1,4997 & 4,4803 & $2,2708^{*}$ & 9,6874 \\
\hline ANZAHL PRODUKT & $-0,0045$ & 0,9955 & 0,0781 & 1,0812 \\
\hline ANZ UB GES & $-0,0021$ & 0,9979 & 0,0053 & 1,0053 \\
\hline SICH_Q & 0,0071 & 1,0071 & 0,0062 & 1,0062 \\
\hline VERB KI KURZ R & 0,0039 & 1,0039 & $-0,0521$ & 0,9493 \\
\hline EKQ & $-0,0073$ & 0,9927 & 0,0139 & 1,0140 \\
\hline VERM LA R LN & 0,2343 & 1,2640 & 0,3037 & 1,3549 \\
\hline KASSE_A_LN & $0,5041^{*}$ & 1,6554 & 0,0893 & 1,0934 \\
\hline AUSFALLW B & 0,0246 & 1,0249 & $1,4339 * *$ & 4,1949 \\
\hline TSC JA_AGG & $0,1110^{* * *}$ & 1,1173 & $0,1537 * * *$ & 1,1662 \\
\hline TSC QA AGG & $-0,0456$ & 0,9555 & 0,0044 & 1,0045 \\
\hline ORG_GLAUB & $-0,8014$ & 0,4487 & $-0,9764$ & 0,3767 \\
\hline ORG WOHL & 0,3963 & 1,4863 & 0,5137 & 1,6714 \\
\hline PERS GLAUB & 0,5852 & 1,7954 & 0,1118 & 1,1183 \\
\hline PERS WOHL & 0,6185 & 1,8561 & & \\
\hline ORG GEB & 0,9180 & 2,5042 & 1,4146 & 4,1149 \\
\hline ORG VER & 0,4691 & 1,5986 & $1,7498^{*}$ & 5,7535 \\
\hline PERS VER & $-1,2598$ & 0,2837 & & \\
\hline PERS VER WOHL & & & $-1,4351$ & 0,2381 \\
\hline Likelihood-Quotienten-Test & & 44,8675 & & 48,4314 \\
\hline Signifikanz & & 0,0012 & & 0,0002 \\
\hline Cox und Snell & & 0,2900 & & 0,3033 \\
\hline Nagelkerke & & 0,5879 & & 0,6214 \\
\hline McFadden & & 0,5038 & & 0,5397 \\
\hline Korrekt: Nein $(\%)$ & & 50,0000 & & 71,4286 \\
\hline Korrekt: Ja (\%) & & 98,2906 & & 99,1667 \\
\hline Korrekt: Gesamt (\%) & & 93,1298 & & 96,2687 \\
\hline 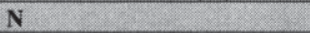 & & 131 & & 134 \\
\hline
\end{tabular}

Tab. B-127: Regression der Finanzkennzahlen, der beziehungsbezogenen und der verhaltenswissenschaftlichen Variablen

Der Vergleich der Güte der verschiedenen Messmodelle (vgl. Tab. B-128) ergibt, dass die verhaltenswissenschaftlichen Variablen die Kreditverfügbarkeit besser erklären können als die Finanzkennzahlen. Die Berücksichtigung der verhaltenswissenschaftlichen Variablen zusätzlich zu den Finanzkennzahlen und den beziehungsbezogenen Variablen führt zu einem erheblichen Anstieg der Modellgüte.

Da auch bei den potenziellen Kreditausweitungen kein Zusammenhang zu bankbezogenen Variablen hergestellt werden konnte, wird auf eine Erweiterung der Regression um bankbezogene Einflüsse verzichtet. Die Ergebnisse hinsichtlich des Einflusses der verhaltenswissenschaftlichen Parameter werden in Tab. B-129 zusammengefasst. Die Hypothesen zur organisationalen Glaubwürdigkeit sowie zur personalen Verbundenheit hingegen können in allen Fällen von der Richtung her bestätigt werden, allerdings nicht immer signifikant. 


\begin{tabular}{|c|c|c|c|c|}
\hline & $\begin{array}{c}\text { Finanz- } \\
\text { kennzahlen }^{1594}\end{array}$ & $\begin{array}{c}\text { Finanzkennzahlen } \\
\text { und beziehungsbe- } \\
\text { zogene Variablen }^{1595}\end{array}$ & $\begin{array}{l}\text { Verhaltenswissen- } \\
\text { schaftliche Variab- } \\
\text { len }{ }^{1596}\end{array}$ & $\begin{array}{l}\text { Alle drei Variab- } \\
\text { lengruppen ge- } \\
\text { meinsam }^{1597}\end{array}$ \\
\hline Cox und Snell & 0,1343 & 0,2359 & 0,1639 & 0,2900 \\
\hline Nagelkerke & 0,2573 & 0,4756 & 0,3067 & 0,5879 \\
\hline McFadden & 0,1954 & 0,3927 & 0,2342 & 0,5038 \\
\hline Korrekt: Nein (\%) & 10,5263 & 31,2500 & 17,3913 & 50,0000 \\
\hline Korrekt: Ja (\%) & 98,5507 & 96,9697 & 98,0892 & 98,2906 \\
\hline Korrekt: Gesamt (\%) & 87,8981 & 89,8649 & 87,7778 & 93,1298 \\
\hline
\end{tabular}

Tab. B-128: Vergleich der Güte der verschiedenen Modelle zur Kreditverfügbarkeit

\begin{tabular}{|c|c|c|c|c|c|c|c|c|}
\hline & \multirow{3}{*}{$\begin{array}{c}\text { Je größer.... } \\
\text { desto ... }\end{array}$} & \multicolumn{7}{|c|}{... ist die Wahrscheinlichkeit von Kreditausweitungen. } \\
\hline & & \multirow[b]{2}{*}{ Hypothese } & \multicolumn{3}{|c|}{ Isolierte Betrachtung ${ }^{1598}$} & \multicolumn{3}{|c|}{ Kombinierte Betrachtung ${ }^{1599}$} \\
\hline & & & Empirie & $\begin{array}{l}\text { Signi- } \\
\text { fikanz }\end{array}$ & Fazit & Empirie & $\begin{array}{l}\text { Signi- } \\
\text { fikanz }\end{array}$ & Fazit \\
\hline $\mathrm{H} 12$ & $\begin{array}{l}\text { die organisationale } \\
\text { Glaubwürdigkeit }\end{array}$ & größer & größer & $10 \%$ & Best. & größer & & (Best.) \\
\hline $\mathrm{H} 13$ & $\begin{array}{l}\text { das organisationale } \\
\text { Wohlwollen }\end{array}$ & größer & größer & $10 \%$ & Best. & kleiner & & (Abl.) \\
\hline $\mathrm{H} 14$ & $\begin{array}{l}\text { die interpersonale } \\
\text { Glaubwürdigkeit }\end{array}$ & größer & kleiner & & (Abl.) & kleiner & & (Abl.) \\
\hline $\mathrm{H} 15$ & $\begin{array}{l}\text { das interpersonale } \\
\text { Wohlwollen }\end{array}$ & größer & größer & & (Best.) & kleiner & & (Abl.) \\
\hline H16 & $\begin{array}{l}\text { die organisationale } \\
\text { Gebundenheit }\end{array}$ & größer & kleiner & $5 \%$ & Abl. & kleiner & & (Abl.) \\
\hline H17 & $\begin{array}{l}\text { die organisationale } \\
\text { Verbundenheit }\end{array}$ & größer & kleiner & & (Abl.) & kleiner & & (Abl.) \\
\hline H18 & $\begin{array}{l}\text { die personale } \\
\text { Verbundenheit }\end{array}$ & größer & größer & & (Best.) & größer & & (Best.) \\
\hline
\end{tabular}

Tab. B-129: Zusammenfassung der Ergebnisse zur Kreditverfügbarkeit

Verglichen mit der Analyse der vergangenheitsbezogenen Kreditverfügbarkeit ergibt sich eine Übereinstimmung hinsichtlich der Hypothesen H12, H16, H17 und H18 und weitestgehend auch bei H13. Eine erhöhte organisationale Glaubwürdigkeit und eine erhöhte personale Verbundenheit führt in allen Auswertungen zu einer besseren Kreditverfügbarkeit. Auch ein hohes personales Wohlwollen bewirkt in nahezu allen Auswertungen eine bessere Kreditverfügbarkeit. Hingegen führt eine hohe organisationale Ge- und Verbundenheit zu einer schlechteren Kreditverfügbarkeit. Auffallend ist, dass bei der Kreditverfügbarkeit - aber auch in etwas weniger deutlichem Umfang

\footnotetext{
1594 Vgl. Tab. B-118, Regression 3.

1595 Vgl. Tab. B-125, Regression 2.

1596 Vgl. Tab. B-126, Regression 1.

1597 Vgl. Tab. B-127, Regression 1.
}

1598 Grundlage für die Beurteilung der isolierten Betrachtung sind die Ergebnisse der Regression 1 aus Tab. B-126.

1599 Grundlage für die Beurteilung der kombinierten Betrachtung sind die Ergebnisse der Regression 1 aus Tab. B-127. 
bei dem Zinssatz und der Sicherheitenstellung - der Erklärungsgehalt der Modelle durch die Integration der verhaltenswissenschaftlichen Variablen erheblich gesteigert werden kann. Die Hypothesen in Bezug auf die verschiedenen Dimensionen hingegen werden vielfach nicht signifikant bestätigt. Eine mögliche Erklärung besteht darin, dass die einzelnen Dimensionen noch nicht hinreichend trennscharf operationalisiert wurden.

\begin{tabular}{|l|l|c|c|c|c|}
\hline \multirow{2}{*}{ Dimension } & \multicolumn{2}{|c|}{ Isolierte Betrachtung } & \multicolumn{2}{c|}{ Kombinierte Betrachtung } \\
\cline { 3 - 6 } & Vergang. & Gegenw. & Vergang. & Gegenw. \\
\hline H12 & $\begin{array}{l}\text { organisationale } \\
\text { Glaubwürdigkeit }\end{array}$ & (Best.) & Best. & (Best.) & (Best.) \\
\hline H13 & $\begin{array}{l}\text { organisationales } \\
\text { Wohlwollen }\end{array}$ & Best. & Best. & Best. & (Abl.) \\
\hline H14 & $\begin{array}{l}\text { interpersonale } \\
\text { Glaubwürdigkeit }\end{array}$ & (Best.) & (Abl.) & (Best.) & (Abl.) \\
\hline H15 & $\begin{array}{l}\text { interpersonale } \\
\text { Wohlwollen }\end{array}$ & (Abl.) & (Best.) & (Abl.) & (Abl.) \\
\hline H16 & $\begin{array}{l}\text { organisationale } \\
\text { Gebundenheit }\end{array}$ & (Abl.) & Abl. & (Abl.) & (Abl.) \\
\hline H17 & $\begin{array}{l}\text { organisationale } \\
\text { Verbundenheit }\end{array}$ & (Abl.) & (Abl.) & Abl. & (Abl.) \\
\hline H18 & $\begin{array}{l}\text { personale Verbun- } \\
\text { denheit }\end{array}$ & (Best.) & (Best.) & (Best.) & (Best.) \\
\hline
\end{tabular}

Tab. B-130: Vergleich der Ergebnisse der beiden Operationalisierungen der Kreditverfügbarkeit

Der Vergleich mit bereits bestehenden Studien verdeutlicht (vgl. Tab. B-131), dass der Erklärungsgehalt der vorliegenden Studie deutlich über den Werten der bisherigen Studien liegt. Die Vergleichbarkeit der Studien ist allerdings aus zweierlei Gründen nur eingeschränkt gegeben. Zum einen wird die Kreditverfügbarkeit unterschiedlich operationalisiert. Bei PETERSEN/RAJAN und HARHOFF/KöRTING wird die Kreditverfügbarkeit anhand der verspäteten Zahlung bzw. dem Anteil der Skontoziehungen gemessen. ${ }^{1600}$ Es erfolgt somit eine indirekte Messung. ANGELINI/DI SALVO/FERRI berücksichtigen den tatsächlichen Kreditwunsch des Kunden. ${ }^{1601}$ COLE misst die Kreditverfügbarkeit anhand tatsächlich erfolgter Kreditablehnungen. ${ }^{1602}$ Diese Operationalisierung ist vergleichbar mit der vergangenheitsbezogenen Kreditverfügbarkeit in der vorliegenden Studie. Hier liegt das $\mathrm{R}^{2}$ mit 0,3969 deutlich über dem $\mathrm{R}^{2}$ von COLE in Höhe von 0,224.

Zum anderen wird die Vergleichbarkeit der Studien durch die unterschiedlichen angewendeten Verfahren eingeschränkt. So kommen logistische Regressionen, Tobit- und Probit-Analysen zur Anwendung. Da COLE ebenfalls eine logistische Regression durchgeführt hat, ist die Vergleichbarkeit mit dieser Studie gegeben.

\footnotetext{
1600 Vgl. Petersen/Rajan (1994), S. 27, Harhoff/Körting (1998b), S. 1346 f.

1601 Vgl. Angelini/Di Salvo/Ferri (1998), S. 944.

1602 Vgl. Cole (1998), S. 974 f.
} 


\begin{tabular}{|c|c|c|c|c|c|c|c|c|c|c|}
\hline & & 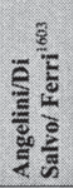 & $\frac{5}{8}$ & 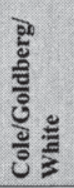 & 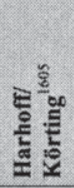 & 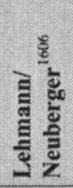 & 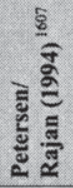 & 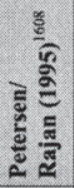 & 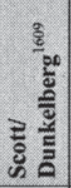 & 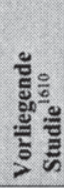 \\
\hline \multirow{6}{*}{$\begin{array}{l}\text { Unterneh- } \\
\text { mens- } \\
\text { bezogen }\end{array}$} & Rechtsform & & & & $\mathrm{x}$ & & $\mathrm{x}$ & $\mathrm{x}$ & $\mathrm{x}$ & \\
\hline & Branche & & & & $\mathrm{x}$ & & & & $\mathrm{x}$ & \\
\hline & $\begin{array}{l}\text { Kreditneh- } \\
\text { merqualităt }\end{array}$ & $\mathrm{x}$ & $\mathrm{x}$ & & (X) & $\mathrm{x}$ & $\mathrm{x}$ & $\mathrm{x}$ & $\mathrm{x}$ & $\mathrm{x}$ \\
\hline & Größe & $\mathrm{x}$ & $\mathrm{x}$ & & $\mathrm{x}$ & & $\mathrm{x}$ & $\mathrm{x}$ & $\mathrm{x}$ & \\
\hline & Alter & (X) & $\mathrm{x}$ & & $\mathrm{x}$ & & $\mathrm{x}$ & $\mathrm{x}$ & $\mathrm{x}$ & \\
\hline & $\begin{array}{l}\text { Anzahl der } \\
\text { Bank- } \\
\text { verbindungen }\end{array}$ & $\mathrm{x}$ & $\mathrm{x}$ & & $\mathrm{x}$ & & $\mathrm{x}$ & $\mathrm{x}$ & $\mathrm{x}$ & \\
\hline \multirow{6}{*}{$\begin{array}{l}\text { Beziehungs- } \\
\text { bezogen }\end{array}$} & $\begin{array}{l}\text { Dauer der } \\
\text { GB }\end{array}$ & $\mathrm{x}$ & $\mathrm{x}$ & & $\mathrm{x}$ & (X) & $\mathrm{x}$ & $\mathrm{x}$ & $\mathrm{x}$ & \\
\hline & $\begin{array}{l}\text { Zusätzliche } \\
\text { Dienstleis- } \\
\text { tungen }\end{array}$ & & $\mathrm{x}$ & & & & $\mathrm{x}$ & & & $\mathrm{x}$ \\
\hline & $\begin{array}{l}\text { Sicherheiten- } \\
\text { stellung }\end{array}$ & & & & & (X) & & & & \\
\hline & \begin{tabular}{|l|} 
Art der \\
Sicherheit
\end{tabular} & & & & & & & & & \\
\hline & $\begin{array}{l}\text { Kredit- } \\
\text { wunsch }\end{array}$ & & & & $\mathrm{x}$ & & & & & \\
\hline & $\begin{array}{l}\text { Kreditvolu- } \\
\text { men }\end{array}$ & & & & & & & & & \\
\hline
\end{tabular}

1603 Angelini/Di Salvo/Ferri führen eine Probit-Analyse durch. Das $\mathrm{R}^{2}$ beträgt mit und ohne Berücksichtigung der Variablen Alter 0,09. Die Kreditverfügbarkeit wird hier durch einen beim Kunden bestehenden Kreditwunsch operationalisert. Vgl. Angelini/Di Salvo/Ferri (1998), S. 944. Cole führt eine logistische Regression durch. Die Kreditverfügbarkeit wird operationalisiert durch erfolgte Kreditablehnungen der Vergangenheit.Wenn in der Datenbasis nur solche Unternehmen berücksichtigt werden, die einen einen Kreditwunsch zur Finanzierung von Working Capital haben, beträgt das $\mathrm{R}^{2} 0,29$. Vgl. Cole (1998), S. $974 \mathrm{f}$.

Harhoff/Körting führen eine Tobit-Regression durch. Als abhängige Variable verwenden sie den Anteil der Skontoziehungen. Vgl. Harhoff/Körting (1998b), S. 1346 f.

Lehmann/Neuberger führen eine Probit-Analyse durch. Als abhängige Variable verwenden sie die Kreditbewilligungen. Wenn in der Regression die Vertrauensvariablen nicht berücksichtigt werden, beträgt das $\mathbf{R}^{2}$ 0,371. Vgl. Lehmann/Neuberger (2001), S. 32.

Bei Petersen/Rajan wird die Kreditverfügbarkeit gemessen am Anteil der verspäteten Zahlungen. Sie führen eine Tobit-Analyse durch. Vgl. Petersen/Rajan (1994), S. 27.

Bei Petersen/Rajan wird die Kreditverfügbarkeit gemessen am Anteil der Inanspruch genommenen Skonto. Sie führen eine Tobit-Analyse durch. Vgl. Petersen/Rajan (1995), S. 428. Scott/Dunkelberg führen eine logistische Regression durch. Als abhängige Variable verwenden sie die Kreditbewilligungen. Vgl. Scott/Dunkelberg (2003), S. 1010 f.

Bei dem ausgewiesenen $R^{2}$ wurde die gegenwartsbezogene Kreditverfügbarkeit und in Klammern die vergangenheitsbezogene Kreditverfügbarkeit dargestellt. Vgl. hierzu Regression 1 in Tab. B-127 bzw. Regression 1 in Tab. B-121. Es erfolgt hier ein Ausweis des R $^{2}$ gemäß Nagelkerke. 


\begin{tabular}{|c|c|c|c|c|c|c|c|c|c|c|}
\hline & & 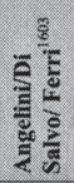 & $\frac{0}{8}$ & 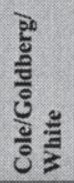 & 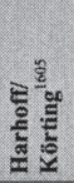 & 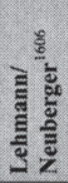 & 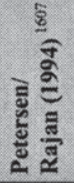 & 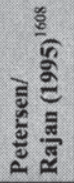 & 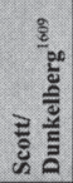 & 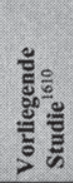 \\
\hline & $\begin{array}{l}\text { Mitglied- } \\
\text { schaft }\end{array}$ & $\mathrm{x}$ & & & & & & & & \\
\hline & $\begin{array}{l}\text { Distanz zu } \\
\text { Bank }\end{array}$ & & & & & & & & & \\
\hline $\begin{array}{l}\text { Markt- } \\
\text { bezogen }\end{array}$ & $\begin{array}{l}\text { Markt- } \\
\text { konzentration }\end{array}$ & $\mathrm{x}$ & & & $x$ & & $\mathrm{x}$ & $\mathrm{x}$ & $\mathrm{x}$ & $\mathrm{x}$ \\
\hline \multirow{4}{*}{$\begin{array}{l}\text { Verhaltens- } \\
\text { wissenschft. }\end{array}$} & Vertrauen & & & & (X) & (X) & & & & $\mathrm{x}$ \\
\hline & Commitment & & & & & & & & & $\mathrm{x}$ \\
\hline & Pseudo- $\mathrm{R}^{2}$ & 0,09 & 0,224 & & 0,018 & 0,429 & - & - & - & $\begin{array}{c}0,5879 \\
(0,3969)\end{array}$ \\
\hline & $\mathrm{N}$ & 1.824 & 2.007 & & 881 & 389 & 1.119 & & 1.474 & 151 \\
\hline
\end{tabular}

Tab. B-131: Vergleich des Erklärungsgehalts in Bezug auf die Kreditverfügbarkeit mit anderen Studien

\subsubsection{Kreditverfügbarkeit - Dauer der Kreditbewilligung}

\subsubsection{Beschreibung der ordinalen Regression}

Für die multivariate Analyse der Einflussfaktoren auf die Dauer der Kreditbewilligung wird die ordinale Regression herangezogen. Wie auch bei der linearen und der logistischen Regression wird analysiert, inwiefern die Einflussfaktoren gemeinsam in der Lage sind, die Schwankungsbreite der Dauer der Kreditbewilligung zu erklären. Aufgrund der nicht gegebenen Intervallskalierung kann die „normale“ multiple Regression nicht angewendet werden. Da die multinomiale logistische Regression die Rangfolge der Werte nicht berücksichtigen kann, wird an dieser Stelle auf die ordinale Regression zurückgegriffen. ${ }^{161}$ Das Logit-Modell als die populärste Modellvariante weist eine hohe Nähe zur binären logistischen Regression auf. Bei der logistischen Regression stellen die Odds das Verhältnis von $P\left(Y_{i}=1\right)$ zur Gegenwahrscheinlichkeit 1-P( $\left.Y_{i}=1\right)$ bzw. $P\left(Y_{i}=0\right)$ dar. ${ }^{1612}$ Bei der ordinalen Regression hingegen werden nicht die Wahrscheinlichkeiten zweier Alternativen, sondern die kumulierten Wahrscheinlichkeiten in Relation gesetzt.

(F.7) Odds $(Y)=\frac{P(Y \leq j)}{1-P(Y \leq j)}$

1611 Vgl. hierzu und im Folgenden Bühl/Zöfel (2005), S. 370-378, Gerpott/Mahmudova (2006), S. $495 \mathrm{ff}$., McCullagh (1980), S. $109 \mathrm{ff}$. Zum verwandten Verfahren der logistischen Regression Vgl. Backhaus et al. (2006), S. 417-477. Die ordinale Regression gehört zu den so genannten „ordered logit“ Verfahren. Vgl. zu Letzteren ausführlich Borooah (2002), S. $1 \mathrm{ff}$. 
Wie auch bei der normalen Regression werden für die unabhängigen Variablen Regressionskoeffizienten, die so genannten Lageschätzer, ermittelt, anhand derer Aussagen über die Stärke und Signifikanz des Einflusses möglich sind. Die Beurteilung der Signifikanz erfolgt anhand des Wald-Tests. Es werden ferner wie bei der logistischen Regression Pseudo- $\mathrm{R}^{2}$ angegeben. Selbige stellen eine Maßgröße für den durch die unabhängigen Variablen erklärten Anteil der Schwankung der abhängigen Variablen dar. Dazu werden auch hier die Pseudo- $\mathrm{R}^{2}$ Cox und Snell, Nagelkerke und McFadden ermittelt. Ferner wird wie bei der logistischen Regression die Verbesserung der Devianz des endgültigen Modells im Vergleich zum Nullmodell sowie die entsprechende Signifikanz ausgewiesen. Zudem wird der Anteil der insgesamt korrekt vorhergesagten Werte aufgeführt.

\subsubsection{Durchführung der ordinalen Regression}

Die Durchführung der ordinalen Regression entspricht dem Vorgehen bei den vorherigen Regressionen. Zunächst werden blockweise die einzelnen Variablenbereiche untersucht, wobei jeweils die Variablen mit signifikanten Korrelationen betrachtet werden. Anschließend werden die Bereiche gemeinsam analysiert. In einem ersten Schritt erfolgt die Betrachtung der Finanzkennzahlen. In Regression 1 in Tab. B-132 wird zunächst der Einfluss der Ausfallwahrscheinlichkeit betrachtet. Eine höhere Ausfallwahrscheinlichkeit führt zwar zu einer längeren Dauer der Kreditbewilligung, allerdings ist dieser Effekt nicht signifikant.

\begin{tabular}{|c|c|c|c|c|c|c|}
\hline \multirow[b]{2}{*}{ Einflussgröße } & \multicolumn{2}{|c|}{ Regression 1} & \multicolumn{2}{|c|}{ Regression 2} & \multicolumn{2}{|c|}{ Regression 3} \\
\hline & Schätzer & $\begin{array}{l}\text { Signi- } \\
\text { fikanz }\end{array}$ & Schätzer & $\begin{array}{l}\text { Signi- } \\
\text { fikanz }\end{array}$ & Schătzer & $\begin{array}{l}\text { Signi- } \\
\text { fikanz }\end{array}$ \\
\hline AUSFALLW B & 0,0062 & 0,6541 & & & 0,0001 & 0,1121 \\
\hline VERB KI_KURZ R & & & 0,0110 & 0,2758 & $-0,0054^{*}$ & 0,0940 \\
\hline VERM LA R & & & $-0,0106$ & 0,0732 & $-0,0056$ & 0,4065 \\
\hline EKQ & & & $-0,0048$ & 0,2660 & $-0,0185$ & 0,3120 \\
\hline UMSATZRENT & & & $-0,0320^{*}$ & 0,0698 & 0,0000 & 0,4793 \\
\hline ZINSDECK & & & 0,0000 & 0,4528 & $-0,0003$ & 0,5665 \\
\hline ANZ ÜB GES & & & 0,0030 & 0,2421 & $-0,0257$ & 0,9288 \\
\hline TSC JA AGG & & & & & $-0,0255$ & 0,9916 \\
\hline TSC_QA_AGG & & & & & $0,0196 * *$ & 0,0364 \\
\hline Likelihood-Quotienten-Test & & 0,2266 & & 24,5206 & & 29,2304 \\
\hline Signifikanz & & 0,6340 & & 0,0004 & & 0,0006 \\
\hline Cox und Snell & & 0,0011 & & 0,1117 & & 0,1580 \\
\hline Nagelkerke & & 0,0012 & & 0,1238 & & 0,1753 \\
\hline McFadden & & 0,0005 & & 0,0509 & & 0,0743 \\
\hline Korrekte Vorhersage (\%) & & 48,3412 & & 52,6570 & & 52,1765 \\
\hline $\mathbf{N}$ & & 211 & & 207 & & 170 \\
\hline
\end{tabular}

Tab. B-132: Ordinale Regression der Finanzkennzahlen

Regression 2 zeigt, dass ein höherer Anteil des langfristigen Vermögens, eine größere Eigenkapitalquote und eine höhere Umsatzrentabilität zu einer schnelleren Kreditbewilligung führt, wobei die Koeffizienten nicht signifikant sind. Bei gemeinsamer Be- 
trachtung der Finanzkennzahlen und der Ratingkennzahlen steigen die Werte für die Pseudo- $\mathrm{R}^{2}$, wobei selbige deutlich unter $20 \%$ liegen und somit nicht zufriedenstellend sind.

Die Analyse der beziehungsbezogenen Variablen (vgl. Tab. B-133, Regression 1) zeigt, dass die Mitgliedschaft nicht nur, wie in Kapitel B.3.6.3.2 erläutert, einen positiven Effekt auf die Wahrscheinlichkeit der Kreditausweitung, sondern auch auf die Schnelligkeit der Kreditbewilligung hat. Je größer der Anteil der kurzfristigen Verbindlichkeiten des Kreditinstituts an der gesamten Finanzierung ist, desto länger dauert die Kreditbewilligung (vgl. Tab. B-133, Regression 1). Dieser bei isolierter Betrachtung der beziehungsbezogenen Variablen auf dem 1\%-Niveau signifikante Effekt wird allerdings bei Integration der Finanzkennzahlen ins Gegenteil umgedreht. Bei der kombinierten Betrachtung übt stattdessen die Variable VERB_KI_KURZ_R einen signifikanten Effekt aus. Je größer die kurzfristige Verbindlichkeitenquote ist, desto länger dauert die Kreditbewilligung (vgl. Tab. B-133, Regression 2). Ferner führt der Abschluss von zusätzlichen Produkten im Rahmen der Kreditbeantragung zur schnelleren Bewilligung. Die Variable CROSS_SELL_EUN, welche misst, inwiefern bei dem letzten Kreditgespräch zusätzliche Produkte angesprochen worden sind und es bei selbigen bereits zum Abschluss gekommen ist, ist in beiden Regressionen signifikant. Die Bank ist bei gleichzeitigem Abschluss angehalten, sich hinsichtlich der Kreditentscheidung zu beeilen, denn ansonsten läuft sie Gefahr, dass der Kunde den möglicherweise noch nicht unterschriebenen Vertrag bzgl. der weiteren Produkte nicht bei der Bank einreicht. 


\begin{tabular}{|c|c|c|c|c|}
\hline \multirow[b]{2}{*}{ Einflussgröße } & \multicolumn{2}{|c|}{ Regression 1} & \multicolumn{2}{|c|}{ Regression 2} \\
\hline & Schätzer & $\begin{array}{c}\text { Signifi- } \\
\text { kanz }\end{array}$ & Schätzer & $\begin{array}{l}\text { Signifi- } \\
\text { kanz }\end{array}$ \\
\hline VERB EIG KURZ R & $0,0376 * * *$ & 0,0022 & $-0,0031$ & 0,8734 \\
\hline GK SALD & 0,0000 & 0,6600 & 0,0000 & 0,5319 \\
\hline CROSS_SELL_EUN & $-0,9810^{* * *}$ & 0,0026 & $-0,8822^{* *}$ & 0,0260 \\
\hline MITGLIED & $-1,4720^{* * *}$ & 0,0031 & $-1,1921^{* * *}$ & 0,0099 \\
\hline VERM ANL & $-0,2603$ & 0,5929 & $-1,0640$ & 0,0856 \\
\hline VERSICH & 0,1140 & 0,8115 & $-0,4348$ & 0,4564 \\
\hline PRIVATKONT & $-0,8669$ & 0,1021 & $-0,4275$ & 0,4230 \\
\hline ANZAHL_PRODUKT & 0,2283 & 0,4999 & 0,1216 & 0,5333 \\
\hline AUSFALLW B & & & $-0,0305^{*}$ & 0,0870 \\
\hline VERB_KI_KURZ_R & & & $0,0282^{*}$ & 0,0670 \\
\hline VERM LA R & & & $-0,0075$ & 0,3172 \\
\hline EKQ & & & $-0,0065$ & 0,3262 \\
\hline UMSATZRENT & & & 0,0013 & 0,9632 \\
\hline ZINSDECK & & & 0,0000 & 0,5887 \\
\hline ANZ_OB_GES & & & 0,0007 & 0,8392 \\
\hline TSC_JA_AGG & & & $-0,0033$ & 0,7881 \\
\hline TSC_QA_AGG & & & $-0,0206$ & 0,1253 \\
\hline Likelihood-Quotienten-Test & & 39,4668 & & 49,9714 \\
\hline Signifikanz & & 0,0000 & & 0,0000 \\
\hline Cox und Snell & & 0,1940 & & 0,3030 \\
\hline Nagelkerke & & 0,2141 & & 0,3330 \\
\hline McFadden & & 0,0912 & & 0,1501 \\
\hline Korrekte Vorhersage (\%) & & 54,0984 & & 55,1020 \\
\hline $\mathbf{N}$ & & 183 & & 147 \\
\hline
\end{tabular}

Tab. B-133: Ordinale Regression der Finanzkennzahlen und der beziehungsbezogenen Variablen

Die Analyse der verhaltenswissenschaftlichen Parameter in Tab. B-134 weist nach, dass selbige auch einen Einfluss auf die Schnelligkeit der Kreditbewilligung ausüben. Es wurde bei allen Parametern ein Zusammenhang derart angenommen, dass eine Verbesserung derselben zu einer schnelleren Kreditbewilligung führt. Dieser Zusammenhang wird bestätigt für die organisationale und personale Glaubwürdigkeit $(\mathrm{H} 12$ und H14). Für das organisationale Wohlwollen und interpersonale Wohlwollen kann der Zusammenhang hingegen nicht bestätigt werden (H13 und H15). Die Glaubwürdigkeit drückt aus, inwiefern das Unternehmen bzw. der Ansprechpartner als kompetent angesehen wird und inwiefern darauf vertraut wird, dass geplante Investitionen vorteilhaft sind. Somit steht hier die fachliche Zuverlässigkeit im Vordergrund, die nun in geringerem Umfang erforderlichen Kontroll- und Prüf- sowie Informationssammlungsaktivitäten ermöglichen einen schnelleren Kreditentscheid. Das Wohlwollen wird eher als emotionale Komponente betrachtet und bewirkt, dass der Kunde der Bank keinen Schaden zufügen möchte und sich besonders anstrengt. Der Firmenkundenbetreuer möchte möglicherweise das Wohlwollen des Kunden zurückgeben. In der vorliegenden Studie fördert selbiges keine schnellere Kreditentscheidung. 
H12: Je größer die organisationale Glaubwürdigkeit des Unternehmens, desto größer ist die Kreditverfügbarkeit und desto weniger Kreditablehnungen gibt es. (Best. - keine Signifikanz)

H13: Je größer das organisationale Wohlwollen des Unternehmens, desto größer ist die Kreditverfügbarkeit und desto weniger Kreditablehnungen gibt es. (Abl. keine Signifikanz)

H14: Je größer die interpersonale Glaubwürdigkeit des Ansprechpartners im Unternehmen, desto größer ist die Kreditverfügbarkeit und desto weniger Kreditablehnungen gibt es. (Best. - keine Signifikanz)

H15: Je größer das interpersonale Wohlwollen des Ansprechpartners im Unternehmen, desto größer ist die Kreditverfügbarkeit und desto weniger Kreditablehnungen gibt es. (Abl. - keine Signifikanz)

Auf Ebene des Commitments wird der vermutete positive Zusammenhang für die organisationale und personale Verbundenheit ( $\mathrm{H} 17$ und $\mathrm{H} 18)$ bestätigt, hingegen nicht für die Gebundenheit (H16). Eine höhere organisationale Gebundenheit führt gemäß der vorliegenden Studie dazu, dass die Kreditentscheidung länger dauert. Aufgrund der Gebundenheit bestehen zwar Möglichkeiten zur intertemporalen Konditionengestaltung, so dass die Entscheidung über den Kredit eher positiv ausfallen wird, aber der Druck der Bank für einen schnellen Kreditentscheid ist gering. Eine hohe Gebundenheit kann dazu führen, dass die Bank die Machtposition ausnutzt und die Entscheidung länger dauert. Ferner kann die Gebundenheit aus einer schlechten Bonität des Kunden resultieren, so dass die Prüfung der Unterlagen eine längere Zeit in Anspruch nimmt. Hinsichtlich der Verbundenheit des Unternehmens ist dagegen die Gefahr groß, dass selbige durch ein unvorteilhaftes Verhalten der Bank schnell verloren geht, bspw. durch eine überdurchschnittlich langsame Kreditvergabe. Es wird davon ausgegangen, dass ein geringeres Risiko der Bank in Bezug auf einen Vertragsabschluss die Entscheidung beschleunigt. Folgerichtig kann die Bank bei einer großen Verbundenheit des Kunden die Kreditentscheidung deswegen schneller treffen, weil sie weiß, dass der Kunde bei der Bank bleibt und mögliche Verluste durch Anschlussgeschäfte kompensiert werden können. Die Bank kann die Prüf- und Kontrollaktivitäten sowie die Informationssammlung schlanker gestalten.

H16: Je größer die organisationale Gebundenheit, desto größer ist die Kreditverfügbarkeit und desto weniger Kreditablehnungen gibt es. (Abl. - 5\%-Niveau)

H17: Je größer die organisationale Verbundenheit, desto größer ist die Kreditverfügbarkeit und desto weniger Kreditablehnungen gibt es. (Best. - 1\%-Niveau)

H18: Je größer die personale Verbundenheit, desto größer ist die Kreditverfügbarkeit und desto weniger Kreditablehnungen gibt es. (Best. - keine Signifikanz) 


\begin{tabular}{|c|c|c|c|c|}
\hline \multirow[b]{2}{*}{ Einflussgröße } & \multicolumn{2}{|c|}{ Regression 1} & \multicolumn{2}{|c|}{ Regression 2} \\
\hline & Schätzer & $\begin{array}{l}\text { Signi- } \\
\text { fikanz }\end{array}$ & Schätzer & $\begin{array}{l}\text { Signi- } \\
\text { fikanz }\end{array}$ \\
\hline ORG GLAUB & 0,2909 & 0,2245 & 0,2864 & 0,2349 \\
\hline ORG WOHL & $-0,0906$ & 0,7186 & 0,1115 & 0,6514 \\
\hline PERS_GLAUB & 0,2626 & 0,3191 & 0,3255 & 0,2062 \\
\hline PERS WOHL & $-0,0712$ & 0,7750 & & \\
\hline ORG GEB & $-0,4421^{* *}$ & 0,0195 & $-0,4662$ & 0,0135 \\
\hline ORG_VER & $0,5494^{* * *}$ & 0,0098 & 0,6127 & 0,0039 \\
\hline PERS VER & 0,0766 & 0,7666 & & \\
\hline PERS_VER_WOHL & & & $-0,2270$ & 0,3637 \\
\hline Likelihood-Quotienten-Test & & 29,3880 & & 32,2926 \\
\hline Signifikanz & & 0,0001 & & 0,0000 \\
\hline Cox und Snell & & 0,1440 & & 0,1533 \\
\hline Nagelkerke & & 0,1592 & & 0,1696 \\
\hline McFadden & & 0,0662 & & 0,0709 \\
\hline Korrekte Vorhersage $(\%)$ & & 51,3227 & & 51,0309 \\
\hline $\mathbf{N}$ & & 189 & & 194 \\
\hline
\end{tabular}

Tab. B-134: Ordinale Regression der verhaltenswissenschaftlichen Variablen

Die gemeinsame Betrachtung der verhaltenswissenschaftlichen Variablen mit den Finanzkennzahlen und den beziehungsbezogenen Variablen ergibt, dass die Variablen zum Abschluss von zusätzlichen Produkten sowie zur Mitgliedschaft weiterhin signifikant sind (vgl. in Tab. B-135, Regression 1 und Regression 2). Kunden bekommen dann schneller einen Kredit, wenn Cross-Selling-Aspekte im Rahmen der Kreditgespräche angesprochen worden sind, wenn sie Mitglieder der Genossenschaftsbank sind, wenn sie Privatkonten bei der Bank unterhalten, wenn die Anzahl der genutzten Produkte bei der Bank gering ist, wenn die Ausfallwahrscheinlichkeit hoch ist und wenn der Anteil der kurzfristigen Verbindlichkeiten gegenüber Kreditinstituten gering ist. Die Vorzeichen bei der Anzahl der Produkte und der Ausfallwahrscheinlichkeit erscheinen zunächst unplausibel. Allerdings beinhaltet die Anzahl der Produkte auch die Produkte Darlehen und Zahlungsverkehrskonten. Eine große Anzahl von Produkten impliziert zwangsläufig, dass der Kunden Darlehen und Zahlungsverkehrskonten bei der Bank unterhält, so dass hier möglicherweise das höhere Risiko der Bank zu einer langsameren Kreditbewilligung führt. Der Effekt, dass eine höhere Ausfallwahrscheinlichkeit zu einer schnelleren Kreditbewilligung führt, lässt sich derart erklären, dass der Kunde eventuell einen Liquiditätsengpass hat und somit eine beschleunigte Kreditbewilligung erlangt, um ihn vor einer Krise zu bewahren. Bei der kombinierten Betrachtung weist keine der verhaltenswissenschaftlichen Variablen signifikante Koeffizienten auf. Die Integration der bankbezogenen bzw. der betreuerspezifischen Variablen liefert folgende Erkenntnisse (vgl. in Tab. B-135, Regression 3). Ein Firmenkundenbetreuer mit einem berufsbegleitenden Studium oder einem Vollzeitstudium bewilligt die Kredite schneller als ein Firmenkundenbetreuer, der ausschließlich eine Bankausbildung absolviert hat. 


\begin{tabular}{|c|c|c|c|c|c|c|}
\hline \multirow[b]{2}{*}{ Einflussgröße } & \multicolumn{2}{|c|}{ Regression 1} & \multicolumn{2}{|c|}{ Regression 2} & \multicolumn{2}{|c|}{ Regression 3} \\
\hline & Schătzer & $\begin{array}{l}\text { Signi- } \\
\text { fikanz }\end{array}$ & Schätzer & $\begin{array}{l}\text { Signi- } \\
\text { fikanz }\end{array}$ & Schätzer & $\begin{array}{l}\text { Signifi- } \\
\text { kanz }\end{array}$ \\
\hline VERB EIG KURZ R & 0,0064 & 0,7595 & 0,0045 & 0,8338 & $-0,0072$ & 0,7600 \\
\hline GK SALD & 0,0000 & 0,7107 & 0,0000 & 0,7815 & 0,0000 & 0,9411 \\
\hline CROSS_SELL EUN & $-0,9969 * *$ & 0,0313 & $-0,9964 * *$ & 0,0327 & $-1,1574 * *$ & 0,0156 \\
\hline MITGLIED & $-2,0541^{* * *}$ & 0,0038 & $-2,2438^{* * *}$ & 0,0019 & $-2,1355^{* * *}$ & 0,0054 \\
\hline VERM ANL & $-0,9317$ & 0,1953 & $-1,2018^{*}$ & 0,0917 & $-1,0248$ & 0,1914 \\
\hline VERSICH & $-0,6337$ & 0,3280 & $-0,8008$ & 0,2085 & $-0,7211$ & 0,3033 \\
\hline PRIVATKONT & $-1,1144$ & 0,1410 & $-1,2312$ & 0,1061 & $-1,6706^{* *}$ & 0,0443 \\
\hline ANZAHL PRODUKT & $0,8360^{*}$ & 0,0919 & 0,9796 & 0,0486 & $1,1184^{* *}$ & 0,0414 \\
\hline AUSFALLW B & $-0,0280$ & 0,1377 & 0,0540 & 0,8224 & $-0,0410^{* *}$ & 0,0422 \\
\hline VERB KI KURZ R & 0,0266 & 0,1123 & 0,0213 & 0,2216 & $0,0499 * * *$ & 0,0147 \\
\hline VERM LA R & $-0,0101$ & 0,2532 & $-0,0121$ & 0,1572 & $-0,0118$ & 0,2154 \\
\hline EKQ & 0,0004 & 0,9564 & $-0,0009$ & 0,9075 & 0,0041 & 0,6099 \\
\hline UMSATZRENT & 0,0014 & 0,9683 & $-0,0123$ & 0,7130 & 0,0123 & 0,7345 \\
\hline ZINSDECK & 0,0000 & 0,3704 & 0,0000 & 0,3658 & 0,0000 & 0,1767 \\
\hline ANZ_UB GES & 0,0010 & 0,8069 & 0,0007 & 0,8727 & $-0,0004$ & 0,9185 \\
\hline TSC_JA_AGG & 0,0001 & 0,9953 & 0,0077 & 0,6078 & $-0,0036$ & 0,8162 \\
\hline TSC QA AGG & $-0,0157$ & 0,2856 & $-0,0182$ & 0,2222 & $-0,0157$ & 0,3214 \\
\hline ORG_GLAUB & $-0,0561$ & 0,8645 & $-0,0530$ & 0,8737 & $-0,1757$ & 0,6228 \\
\hline ORG_WOHL & 0,3434 & 0,3343 & 0,4672 & 0,1909 & 0,0652 & 0,8666 \\
\hline PERS_GLAUB & 0,3864 & 0,3178 & 0,4917 & 0,2020 & $-0,2806$ & 0,3162 \\
\hline PERS WOHL & $-0,3719$ & 0,2492 & & & 0,3964 & 0,1906 \\
\hline ORG GEB & $-0,2395$ & 0,3639 & $-0,2806$ & 0,2856 & 0,3853 & 0,3427 \\
\hline ORG VER & 0,3884 & 0,1638 & 0,5176 & 0,0663 & $-0,2288$ & 0,5145 \\
\hline PERS_VER & $-0,0328$ & 0,9240 & & & 0,3169 & 0,3875 \\
\hline PERS VER WOHL & & & $-0,6931$ & 0,0444 & & \\
\hline FKB JÜ 30 & & & & & $-0,2104$ & 0,6140 \\
\hline FKB BERUF ST & & & & & $-1,8903^{* * *}$ & 0,0001 \\
\hline FKB STUD & & & & & $-0,0275^{*}$ & 0,0602 \\
\hline $\begin{array}{l}\text { Likelihood-Quotienten- } \\
\text { Test }\end{array}$ & & 54,8617 & & 59,2080 & & 71,1336 \\
\hline Signifikanz & & 0,0003 & & 0,0000 & & 0,0000 \\
\hline Cox und Snell & & 0,3380 & & 0,3572 & & 0,4190 \\
\hline Nagelkerke & & 0,3713 & & 0,3914 & & 0,4601 \\
\hline McFadden & & 0,1711 & & 0,1813 & & 0,2249 \\
\hline $\begin{array}{l}\text { Korrekte Vorhersage } \\
(\%)\end{array}$ & & 54,8871 & & 54,4776 & & 60,3053 \\
\hline $\mathbf{N}$ & & 133 & & 134 & & 131 \\
\hline
\end{tabular}

Tab. B-135: Ordinale Regression der Finanzkennzahlen, der beziehungsbezogenen, der verhaltenswissenschaftlichen und der bankbezogenen Variablen

Der Vergleich der verschiedenen durchgeführten Regressionen in Tab. B-136 zeigt, dass der Erklärungsgehalt der verhaltenswissenschaftlichen Variablen ähnlich hoch wie der Erklärungsgehalt der Finanzkennzahlen ist. Die gemeinsame Betrachtung aller drei Variablengruppen gemeinsam führt zu einem erheblichen Anstieg der korrekten Vorhersage sowie der Pseudo- $\mathrm{R}^{2}$. 


\begin{tabular}{|c|c|c|c|c|}
\hline & $\begin{array}{c}\text { Finanz- } \\
\text { kennzahlen }^{1613}\end{array}$ & $\begin{array}{c}\text { Finanzkennzahlen } \\
\text { und beziehungsbe- } \\
\text { zogene Variablen }^{1614}\end{array}$ & $\begin{array}{l}\text { Verhaltenswis- } \\
\text { senschaftliche } \\
\text { Variablen }^{1615}\end{array}$ & $\begin{array}{l}\text { Alle drei Variab- } \\
\text { lengruppen } \\
\text { gemeinsam }^{1616}\end{array}$ \\
\hline Cox und Snell & 0,1580 & 0,3030 & 0,1440 & 0,4190 \\
\hline Nagelkerke & 0,1753 & 0,3330 & 0,1592 & 0,4601 \\
\hline McFadden & 0,0743 & 0,1501 & 0,0662 & 0,2249 \\
\hline $\begin{array}{l}\text { Korrekte } \\
\text { Vorhersage (\%) }\end{array}$ & 52,1765 & 55,1020 & 51,3227 & 60,3053 \\
\hline $\mathbf{N}$ & 170 & 147 & 189 & 131 \\
\hline
\end{tabular}

Tab. B-136: Vergleich der Güte der verschiedenen Modelle zur Kreditverfügbarkeit

Abschließend lässt sich zusammenfassen, dass sowohl bei isolierter als auch bei kombinierter Betrachtung die Hypothese bestätigt wird, dass bei größerer organisationaler Verbundenheit Kredite schneller bewilligt werden. Diese Erkenntnis stimmt überein mit dem Einfluss der Mitgliedschaft, da die Mitgliedschaft als ein Indiz der organisationalen Verbundenheit gewertet werden kann und selbige - wie in Tab. B-135, Regression 1 dargestellt - dazu führt, dass die Kredite schneller vergeben werden. Ein Überblick über die Bestätigungen und Ablehnungen der Hypothesen kann Tab. B-137 entnommen werden.

\begin{tabular}{|c|c|c|c|c|c|c|c|c|}
\hline & \multirow{3}{*}{$\begin{array}{c}\text { Je größer .... } \\
\text { desto ... }\end{array}$} & \multicolumn{7}{|c|}{... werden Kredite bewilligt. } \\
\hline & & \multirow[b]{2}{*}{$\begin{array}{l}\text { Hypothe- } \\
\text { se }\end{array}$} & \multicolumn{3}{|c|}{ Isolierte Betrachtung $^{1617}$} & \multicolumn{3}{|c|}{ Kombinierte Betrachtung ${ }^{1618}$} \\
\hline & & & Empirie & $\begin{array}{l}\text { Signi- } \\
\text { fikanz }\end{array}$ & Fazit & Empirie & $\begin{array}{l}\text { Signi- } \\
\text { fikanz }\end{array}$ & Fazit \\
\hline $\mathrm{H} 12$ & $\begin{array}{l}\text { die organisationale } \\
\text { Glaubwürdigkeit }\end{array}$ & schneller & schneller & & (Best.) & langsamer & & (Abl.) \\
\hline $\mathrm{H} 13$ & $\begin{array}{l}\text { das organisationale } \\
\text { Wohlwollen }\end{array}$ & schneller & langsamer & & (Abl.) & schneller & & (Best.) \\
\hline $\mathrm{H} 14$ & $\begin{array}{l}\text { die interpersonale } \\
\text { Glaubwürdigkeit }\end{array}$ & schneller & schneller & & (Best.) & schneller & & (Best.) \\
\hline $\mathrm{H} 15$ & $\begin{array}{l}\text { das interpersonale } \\
\text { Wohlwollen }\end{array}$ & schneller & langsamer & & (Abl.) & langsamer & & (Abl.) \\
\hline $\mathrm{H} 16$ & $\begin{array}{l}\text { die organisationale } \\
\text { Gebundenheit }\end{array}$ & schneller & langsamer & $5 \%$ & Abl. & langsamer & & (Abl.) \\
\hline $\mathrm{H} 17$ & $\begin{array}{l}\text { die organisationale } \\
\text { Verbundenheit }\end{array}$ & schneller & schneller & $1 \%$ & Best. & schneller & & (Best.) \\
\hline $\mathrm{H} 18$ & $\begin{array}{l}\text { die personale } \\
\text { Verbundenheit }\end{array}$ & schneller & schneller & & (Best.) & langsamer & & (Abl.) \\
\hline
\end{tabular}

Tab. B-137: Zusammenfassung der Ergebnisse zur Dauer der Kreditbewilligung

1613 Vgl. Tab. B-132, Regression 3.

1614 Vgl. Tab. B-133, Regression 2.

1615 Vgl. Tab. B-134, Regression 1.

1616 Vgl. Tab. B-135, Regression 1.

1617 Grundlage für die Beurteilung der isolierten Betrachtung sind die Ergebnisse der Regression 1 aus Tab. B-134.

1618 Grundlage für die Beurteilung der isolierten Betrachtung sind die Ergebnisse der Regression 1 aus Tab. B-135. 


\section{Abschließende Betrachtung}

\section{$1 \quad$ Limitationen der Untersuchung}

Die vorgestellten Ergebnisse der Studie lassen Schiussfolgerungen hinsichtlich der Ausgestaltung der Kunde-Bank-Beziehung und der Auswirkungen der verhaltenswissenschaftlichen Variablen auf die ökonomischen Parameter Kreditzins, Sicherheitenstellung und Kreditverfügbarkeit zu. Die Art der durchgeführten Untersuchung beinhaltet jedoch z.T. Limitationen, so dass die Aussagekraft und die Möglichkeit der Verallgemeinerung teilweise eingeschränkt wird. Diese Limitationen werden im Folgenden erläutert.

\section{Behandlung von fehlenden Werten und Bereinigung von Dateninkonsistenzen}

Wie in Kapitel B.1.1.3 dargestellt, waren nicht alle Fragebögen und Datenerhebungsbögen vollständig ausgefüllt. Damit die verwendeten multivariaten Analyseverfahren uneingeschränkt durchgeführt werden konnten, wurde eine Imputation der fehlenden Werte vorgenommen. Im Rahmen dieser Imputation wurden fehlende Werte durch Imputationswerte ersetzt. ${ }^{1619}$ Ein derartiger Eingriff führt zu einer gewissen Manipulation des Datensatzes und in Konsequenz möglicherweise zu einer Verfälschung der Analyseergebnisse. Insgesamt wurden allerdings nur bei drei Variablen fehlende Werte ergänzt.

Ähnliche Kritikpunkte sind aufgrund der durchgeführten Bereinigung von Dateninkonsistenzen vorzubringen. Hier wurden ausschließlich die minimal erforderlichen Bereinigungen vorgenommen: Nur für den Fall, dass offensichtliche, gravierende Inkonsistenzen vorlagen, sind selbige durch den Auswertenden beseitigt worden. Sofern bspw. die Dauer der Kundenbeziehung zur Bank größer war als das Alter des Unternehmens, wurde eine Korrektur durchgeführt. Es gab genau zwei Variablengruppen mit jeweils drei Variablen, innerhalb derer Widersprüche beseitigt wurden. Da der Umfang der vorgenommenen Datensatzbereinigung sowohl aufgrund fehlender Werte als auch aufgrund von Dateninkonsistenzen nur sehr gering ausgefallen ist, müssen nur sehr unwesentliche Abstriche in Bezug auf die Aussagekraft der Ergebnisse gemacht werden. ${ }^{1620}$

\section{Antwortverhalten der Studienteilnehmer}

Die Aussagekraft der Ergebnisse von statistischen Analysen basierend auf einer Umfrage muss grundsätzlich in Frage gestellt werden. ${ }^{1621}$ Es besteht das (allgemeingültige) Problem, dass die Studienteilnehmer möglicherweise Antworten geben, die nicht der Wahrheit entsprechen. ${ }^{1622}$ In Kapitel B.1.1.2. wurde darlegt, dass zahlreiche Maßnahmen zur Vermeidung einer derartigen Verzerrung getroffen wurden. Beispielsweise wurde das Forschungsvorhaben nicht im Detail erläutert, so dass der Befragte nicht

\footnotetext{
1619 Vgl. hierzu Abb. B-4, S. 168.

1620 Vgl. auch hierzu Kapitel B.1.1.3.

1621 Vgl. Flacke (2007), S. 272.

1622 Vgl. hierzu auch ausführlich Kapitel B.1.1.2.
} 
das Ziel verfolgen konnte, dem Befragungsdurchführenden zu gefallen. Ferner wurde der Fragebogen vollständig anonymisiert. Der Firmenkundenbetreuer musste nicht befürchten, dass sein Fragebogen zurückverfolgt werden kann, wenn er Antworten gibt, die von Bankvorgaben abweichen. Dennoch kann nicht ausgeschlossen werden, dass durch bewusstes oder unbewusstes Verhalten der Befragten die Antworten von der Wahrheit abweichen.

\section{Operationalisierung der Konstrukte Vertrauen und Commitment}

Bisher existierten für den Dienstleistungssektor im Allgemeinen sowie den Bankensektor im Speziellen noch keine Skalen zur Messung von Vertrauen und Commitment bzw. zur Messung der verschiedenen jeweiligen Dimensionen. ${ }^{1623}$ Eine weitere Novität besteht nach Kenntnis des Autors in der Erhebung von Vertrauen und Commitment im Rahmen einer Studie bei gleichzeitiger Abbildung der verschiedenen Dimensionen. ${ }^{1624}$ Aus diesem Grund wurde für die vorliegende Untersuchung ein neues Messmodell entwickelt. Hier bedarf es weiterer Studien, um die Konzeptualisierung und Operationalisierung möglicherweise noch zu verbessern.

Hinsichtlich des Vertrauens wurde an diversen Stellen auf die Reziprozität desselbigen hingewiesen. Es wurde angenommen, dass ein durch den Kunden wahrgenommenes größeres Wohlwollen des Firmenkundenbetreuers zu einem erhöhten Informationsfluss des Kunden in Richtung Bank führt. Da in der vorliegenden Studie das wahrgenommene Wohlwollen des Firmenkundenbetreuers nicht erhoben wurde, wurde unterstellt, dass das Wohlwollen reziprok ist und ein wahrgenommenes Wohlwollen des Kunden mit einem wahrgenommenen Wohlwollen des Firmenkundenbetreuers einhergeht. Es wäre ferner interessant, auch bei den Kunden eine Befragung zur Messung des Vertrauens durchzuführen, um daraus zusätzliche Erkenntnisse für die Zusammenhänge in der Geschäftsbeziehung zu erlangen. Für die Analyse der ökonomischen Auswirkungen resultieren nur geringfügige oder keine Einschränkungen, denn hier ist der tatsächliche Informationsfluss zum Firmenkundenbetreuer relevant. Die Auswirkungen sind unabhängig davon, ob ein erhöhter Informationsfluss die Konsequenz eines gestiegenen Vertrauens seitens des Kunden ist.

Schließlich wurde bei der Operationalisierung von Vertrauen und Commitment bankseitig nur der Firmenkundenbetreuer berücksichtigt. Bei der Konditionengestaltung hat der Marktfolgemitarbeiter aufgrund der in den MaRisk vorgeschriebenen Funktionstrennung zwischen Markt und Marktfolge ebenfalls ein Recht bzw. die Pflicht, sich am Entscheidungsprozess zu beteiligen. Dieser mögliche Einfluss wurde in der vorliegenden Untersuchung nicht betrachtet. Da der Marktfolgemitarbeiter aber im Allgemeinen nicht im unmittelbaren Kontakt zum Kunden steht und somit nur wenige Interaktionen stattfinden, ist der Einfluss der verhaltenswissenschaftlicher Parameter des Marktfolgemitarbeiters nur sehr gering.

\footnotetext{
1623 Vgl. Seppänen/Blomqvist/Sundqvist (2007), S. 251 und Kapitel A.5.2.3.1.2.

1624 Bspw. haben auch Morgan/Hunt Vertrauen und Commitment innerhalb einer Studie erhoben, allerdings haben sie nicht zwischen den verschiedenen Dimensionen der Konstrukte unterschieden. Vgl. Morgan/Hunt (1994), S. 35.
} 
Operationalisierung der ökonomischen Parameter Sicherheitenstellung und Kreditverfügbarkeit

Hinsichtlich der Operationalisierung der ökonomischen Parameter Sicherheitenstellung und Kreditverfügbarkeit bestehen aufgrund nachstehender Kritikpunkte Einschränkungen. Die undifferenzierte Verwendung der Besicherungsquote ist insofern nicht optimal, da gestellte Bürgschaften nicht immer in die Berechnung der Besicherungsquote durch die Bank einfließen. Um Bürgschaften berücksichtigen zu können, wäre es erforderlich, die Vermögensverhältnisse des Bürgen ausführlich zu untersuchen. Darauf wird in der Praxis in aller Regel verzichtet, so dass selbige mit einem Sicherheitenwert von Null angesetzt werden und die Besicherungsquote tendenziell unterschätzt wird. Eine geeignete Möglichkeit zur Korrektur konnte nicht gefunden werden.

Bei der Operationalisierung der Kreditverfügbarkeit wäre eine Kombination von Kunden- und Bankensicht wünschenswert. Die isolierte Einschätzung des Kunden, inwiefern selbiger glaubt, einen Kredit von seiner Bank zu erhalten, ist nicht zielführend. Gerade verhaltenswissenschaftliche Aspekte, wie das Wohlwollen und die Glaubwürdigkeit, oder die Perspektive rentabler Anschlussgeschäfte für die Bank kann bei einer Beurteilung durch den Kunden nicht berücksichtigt werden. Die in dieser Studie zugrunde gelegte isolierte Einschätzung der Bank bzw. des Firmenkundenbetreuers, inwiefern der Kunde heute einen Kredit bekommen würde, vernachlässigt allerdings den tatsächlichen Bedarf des Kunden. Bei dieser bankseitigen Betrachtung werden auch solche Kunden inkludiert, die keinen Kreditwunsch haben. Idealerweise müsste die bank- und die kundenseitige Betrachtung, bspw. durch eine dyadische Befragung, zusammengeführt werden. Mit einer derartigen Befragung könnte ermittelt werden, inwiefern für die Kunden, die einen aktuellen Kreditwunsch haben, ein Kredit durch die Bank genehmigt werden würde. Hierbei handelt es sich allerdings - wie auch bei der gegenwartsbezogenen Kreditverfügbarkeit in der vorliegenden Studie - um ein hypothetisches Konstrukt. Das tatsächliche Verhalten der Bank bzw. des Firmenkundenbetreuers hängt auch vom konkreten Kreditwunsch ab, da bspw. die Beurteilung des zu finanzierenden Investitionsobjektes entscheidungsrelevant ist. Bei Beantragung der Ausweitung einer Kreditlinie ist es bspw. von Bedeutung, ob selbige aufgrund eines Umsatzwachstums des Unternehmens oder aufgrund der schlechten Zahlungsmoral der Abnehmer gewünscht wird.

In Bezug auf die Operationalisierung der Kreditverfügbarkeit als Dauer der Kreditbewilligung wurde in dieser Studie in Ermangelung eines objektiven Kriteriums auf die subjektive Einschätzung des Firmenkundenbetreuers zurückgegriffen. Die Firmenkundenbetreuer haben im Fragebogen die Dauer der letzten Kreditbewilligung im Vergleich zum bankweiten Durchschnitt angegeben. Idealerweise müssten jedoch die tatsächlichen Prozesszeiten erhoben werden, um sowohl die antragsbezogene als auch die bankweite durchschnittliche Bearbeitungsdauer der Kreditbewilligung zu ermitteln.

Da diese Daten nach Kenntnis des Autors in keiner Bankensoftware im genossenschaftlichen Sektor erfasst werden, konnte zum Zeitpunkt der Datenerhebung auf diese Informationen nicht zurückgegriffen werden. 


\section{Repräsentativität der Erhebung}

Die Repräsentativität der Ergebnisse wird durch folgende Aspekte eingeschränkt. Die Erhebung wurde nur bei Genossenschaftsbanken durchgeführt. Eine Übertragbarkeit auf die anderen in Deutschland existierenden Bankengruppen ist nicht uneingeschränkt gegeben. Gerade bei Großbanken wirken vermutlich noch andere Einflussfaktoren bzw. bestimmte, im Rahmen dieser Studie identifizierte Einflussfaktoren haben bei diesen Banken keinen Effekt. Beispielsweise ist bei selbigen das Regionalprinzip nicht gegeben. Aufgrund der auch im Sparkassensektor vorliegenden Mittelstandsfokussierung lassen sich die Ergebnisse möglicherweise auch in dieser Bankengruppe anwenden. Für die Variable „Mitgliedschaft“ konnten in diversen Auswertungen der vorliegenden Arbeit signifikante Effekte nachgewiesen werden. Diese Einflüsse lassen sich selbstverständlich nicht auf den Sparkassensektor übertragen, da es sich hierbei um ein genossenschaftliches Differenzierungsmerkmal handelt. ${ }^{1625}$

Bei der Auswahl der Banken war es Voraussetzung, dass selbige die Software MinD.banker® einsetzen. Da die Software MinD.banker® von den Banken ein Umdenken bei der Beratung im Firmenkundengeschäft erfordert, ${ }^{1626}$ sind in der Stichprobe eher innovative und aufgeschlossene Genossenschaftsbanken enthalten. Die Übertragbarkeit auf den gesamten Genossenschaftssektor ist zu hinterfragen.

Die Repräsentativität muss auch hinsichtlich der untersuchten Unternehmen geprüft werden. Unter der Annahme, dass alle deutschen Unternehmen die Grundgesamtheit darstellen, zeigt der Vergleich der Branchen-, Größen- und Rechtsformverteilungen der Stichprobe und der Erhebungsgesamtheit teilweise Abweichungen auf. ${ }^{1627}$ Gegenstand der vorliegenden Arbeit sind allerdings nur die mittelständischen Unternehmen, so dass bei dem Vergleich der Branchen-, Größen- und Rechtsformverteilungen die in dieser Untersuchung verwendete Mittelstandsdefinition berücksichtigt werden müsste. Eine Beurteilung hinsichtlich der Repräsentativität der ausgewählten Unternehmen für den deutschen Mittelstand ist infolgedessen nur schwer bzw. gar nicht möglich.

Da die Übertragbarkeit der Ergebnisse auf andere Bankgruppen eventuell nicht gegeben ist, sollte geprüft werden, inwiefern die ausgewählten Unternehmen als repräsentativ für die Genossenschaftsbanken oder ggf. für die Genossenschaftsbanken und die Sparkassen erachtet werden können. Für diese Einschätzung wäre es erforderlich, die Stichprobe mit dem Firmenkundenportfolio dieser Bankengruppen zu vergleichen. Hierzu liegen allerdings keine hinreichenden Informationen vor. Aufgrund der zufälligen Kundenauswahl kann die Repräsentativität der Datenbasis zumindest für die Genossenschaftsbanken ohne Einschränkung angenommen werden.

\footnotetext{
1625 Vgl. Kapitel A.2.2.2.

1626 Vgl. mind (2008).

1627 Vgl. hierzu auch ausführlich Kapitel B.1.1.1.
} 


\section{Erhebungszeitraum}

Die Datenerhebung wurde in einem relativ kurzen Zeitraum - primärer Erhebungszeitraum war Dezember 2007 bis Januar 2008 - durchgefuihrt. Der Vorteil einer derartigen Vorgehensweise ist, dass bspw. Veränderungen der wirtschaftlichen Rahmenbedingungen oder der Risikostrategie der Banken vernachlässigt werden können, da selbige in einem derart kurzen Zeitraum nicht gravierend sein werden bzw. die Auswirkungen häufig noch nicht messbar sind. Der Nachteil besteht darin, dass jedes Unternehmen mit genau einer Zeitpunktbetrachtung in die Datenbasis eingeflossen ist. Bei dem theoretischen Modell von FORD ${ }^{1628}$ wurde gezeigt, dass eine Geschäftsbeziehung mehrere Phasen durchläuft. Es wäre aufschlussreich, die Entwicklung der Kunde-BankBeziehung über einen mehrjährigen Zeitraum zu analysieren. ${ }^{1629}$ Möglicherweise verändert sich die Ausprägung der verhaltenswissenschaftlichen Faktoren im Zeitablauf sowie die Wirkung derselben in Bezug auf die ökonomischen Parameter. Diese zeitliche Entwicklung wurde in der vorliegenden Arbeit nicht abgebildet.

Abschließend lässt sich feststellen, dass die aufgezeigten Limitationen als gering erachtet werden können. Die vorliegende Untersuchung trägt somit dazu bei, Erkenntnisse zur Ausgestaltung von Kunde-Bank-Beziehungen, insb. im Genossenschaftssektor, zu gewinnen. Eine Zusammenfassung der zentralen Ergebnisse wird im folgenden Kapitel C.2 gegeben.

\footnotetext{
1628 Vgl. hierzu auch ausführlich Kapitel A.5.2.2.2.
}

1629 Ein derartiges Vorgehen haben bspw. Machauer/Weber und Elsas gewählt. Vgl. Machauer/Weber (1998), S. 1361, Elsas (1999), S. $79 \mathrm{ff}$. 


\section{Zusammenfassung}

Die Bankfinanzierung stellt für viele mittelständische Unternehmen die wichtigste Finanzierungsquelle dar. Aufgrund der daraus resultierenden Abhängigkeit der Unternehmen von den Banken ist es insbesondere aus Unternehmersicht von Interesse, welche ökonomischen Auswirkungen sich durch die Ausgestaltung der Kunde-BankBeziehung ergeben. Die ökonomischen Auswirkungen sind für den Unternehmer vor allem in den zentralen, kreditrelevanten Parametern - Kreditzins, Sicherheitenstellung und Kreditverfügbarkeit - sichtbar.

Ausgangspunkt der Arbeit ist der aktuelle Stand der Relationship Banking-Forschung. Sowohl in den Modellen als auch in den klassischen empirischen Studien wird die Konditionengestaltung im Wesentlichen durch die Informationsasymmetrien zwischen den Geschäftspartnern erklärt. In der konzeptionellen Arbeit von SEGBERS wurde dargelegt, dass auch verhaltenswissenschaftliche Aspekte einen Einfluss auf die Konditionen haben. ${ }^{1630}$ Darauf aufbauend bestand das Ziel der vorliegenden Arbeit in der Untersuchung, ob sich dieser Einfluss empirisch nachweisen lässt. Ein besonderes Augenmerk bei der Analyse der verhaltenswissenschaftlichen Auswirkungen liegt auf der Interaktion der beteiligten Personen, d.h. des Firmenkundenbetreuers und des Ansprechpartners des Unternehmens. Bei dieser Interaktion spielen die Konstrukte Vertrauen und Commitment eine zentrale Rolle.

Vor Durchführung der Analyse werden die beiden involvierten Parteien, d.h. mittelständische Unternehmen und Banken, betrachtet. Es erfolgt zunächst eine Abgrenzung der relevanten Unternehmen. Für die vorliegende Studie erscheint es sinnvoll, eine Fokussierung auf mittelständische Unternehmen vorzunehmen. Die Fokussierung wird zum einen damit begründet, dass die Geschäftsbeziehungen zwischen Kunde und Bank zu heterogen sind, als dass alle Beziehungen gleichermaßen erklärt werden können. So unterscheidet sich die Geschäftsbeziehung eines Einmannbetriebs wesentlich von der Geschäftsbeziehung eines global agierenden Konzerns. Die Abgrenzung ist somit notwendig, um im Rahmen einer empirischen Analyse aussagekräftige Ergebnisse ermitteln zu können. Zum anderen bilden in der herkömmlichen Relationship Banking-Theorie die bestehenden Informationsasymmetrien zwischen den Geschäftspartnern den zentralen Erklärungsansatz für die Ausgestaltung der ökonomischen Parameter. Der Grad der Informationsasymmetrie scheint bei der Kunde-Bank-Beziehung von mittelständischen Unternehmen besonders hoch zu sein. Mittelständische Unternehmen unterliegen weniger bzw. vereinfachten Veröffentlichungsvorschriften als große Unternehmen. Zudem stellt die Bankfinanzierung bei mittelständischen Unternehmen einen besonders hohen Anteil an der gesamten Unternehmensfinanzierung dar. Aus diesem Grund ist diese Unternehmensgruppe umso stärker prädestiniert für diese Untersuchung. Als untersuchungsrelevant werden solche Unternehmen definiert, deren Umsatz kleiner als 50 Mio. EUR und der Mitarbeiterzahl kleiner als 500 ist. Ferner sollen sich weniger als $25 \%$ des Kapitals in der Hand eines anderen Unternehmens befinden. Letzteres Kriterium stellt sicher, dass nicht aufgrund der Verflechtung mit 
einem Großunternehmen für den Mittelstand atypische Strukturen vorliegen und die Untersuchungsergebnisse dadurch verfälscht werden.

Es folgt eine Betrachtung der Bankseite. Während bspw. in den USA ein Trennbankensystem existiert, herrscht in Deutschland das Universalbanksystem vor. Die beiden Systeme grenzen sich dadurch ab, dass beim Universalbanksystem alle banknahen Geschäfte von einer Bank angeboten werden dürfen. Im Trennbankensystem hingegen darf eine Bank nur eine Teilmenge aller Leistungen anbieten. Die Unterscheidung ist insofern relevant, als dass daraus Implikationen für die Vergleichbarkeit der amerikanischen mit den deutschen Relationship Banking-Studien resultieren. Bankseitig erfolgt eine Fokussierung auf den Genossenschaftssektor. Aufgrund des Regionalprinzips und der Mittelstandsorientierung der Genossenschaftsbanken sind selbige besonders geeignet für die Analyse des Einflusses verhaltenswissenschaftlicher Faktoren auf die ökonomischen Parameter. Der hohe Anteil des Firmenkundengeschäfts und hier insbesondere des Kreditgeschäfts am Gesamtertrag der Bank führt dazu, dass die Analyse der Kunde-Bank-Beziehung auch aus Bankensicht von Relevanz ist.

Für die Analyse der ökonomischen Parameter der Kreditbeziehung stellen die rechtlichen Rahmenbedingungen, die Relationship Banking-Forschung und die verhaltenswissenschaftlichen Ansätze die zentralen Einflussbereiche dar. Bei der nachstehenden Zusammenfassung werden kurz die theoretische bzw. rechtliche Grundlage dieser drei Bereiche sowie die Implikationen für die Konditionengestaltung dargelegt, um diese im Anschluss jeweils mit den empirischen Resultaten der vorliegenden Studie zu vergleichen. Durch diese Gegenüberstellung wird unmittelbar aufgezeigt, in welchem Grad die Theorie durch die Empirie bestätigt wird.

Der Finanzsektor ist durch diverse rechtliche Vorschriften reglementiert. In Bezug auf die ökonomischen Parameter der Geschäftsbeziehung zwischen mittelständischen Kunden und ihren Banken sind zum einen die Vorschriften hinsichtlich der Eigenkapitalausstattung, die verkürzt nur Basel II genannt werden, und zum anderen die Mindestanforderungen an das Risikomanagement (MaRisk) als relevant zu erachten. Basel II tätigt Vorgaben hinsichtlich der Höhe der Eigenkapitalausstattung der Kreditinstitute, hinsichtlich des Überprüfungsprozesses der spezifischen Risikosituation des Instituts sowie hinsichtlich der Offenlegung. Für die vorliegende Untersuchung sind primär die Vorgaben in Bezug auf die Eigenkapitalausstattung bedeutsam. In Abhängigkeit vom Risiko der einzelnen Kreditnehmer wird die Höhe des vorzuhaltenden Eigenkapitals bestimmt. Das vorzuhaltende Eigenkapital stellt eine Kostenkomponente des Kreditzinses für das Unternehmen dar. Da durch die Stellung von Sicherheiten durch das Unternehmen die Höhe des potenziellen Forderungsausfalls reduziert werden kann, führt eine höhere Sicherheitenstellung zu niedrigeren Eigenkapitalkosten. Basel II enthält keine expliziten Vorgaben hinsichtlich der Kreditkonditionen. Bei einer kostenorientierten Konditionenfestlegung führt eine erhöhtes Ausfallrisiko des Unternehmens allerdings aufgrund der durch Basel II geforderten höheren Eigenkapitalhinterlegung zu höheren Zinsen.

Die MaRisk stellen die Umsetzung des bankaufsichtlichen Überprüfungsprozesses im Allgemeinen und des Prozesses zur Bestimmung des Eigenkapitalbedarfs im Speziel- 
len dar. In Form einer Sollte-Bestimmung fordern die MaRisk einen Zusammenhang zwischen der Bonität des Unternehmens und den Konditionen des Kunden. In welcher Form dies konkret umzusetzen ist, wird in den MaRisk nicht präzisiert. Diese Forderung bewirkt, dass eine Veränderung der Eigenkapitalkosten aufgrund eines veränderten Risikos des Unternehmens oder aufgrund einer veränderten Sicherheitenstellung nicht nur bei betriebswirtschaftlicher Betrachtung, sondern auch bedingt durch rechtliche Vorgaben die Zinshöhe beeinflusst. Die Sicherheiten betreffend schreiben die MaRisk vor, dass selbige durch die Marktfolge zu bewerten sind. Es können keinerlei Vorschriften identifiziert werden, die eine Auswirkung auf die Höhe der Sicherheitenstellung haben oder die einen Zusammenhang zwischen der Bonität und der Höhe der Sicherheitenstellung herstellen. Auswirkungen aus den MaRisk auf die Kreditverfügbarkeit resultieren im Wesentlichen daher, dass selbige die Formulierung einer Kreditrisikostrategie vorschreiben. Die Kreditrisikostrategie beinhaltet u.a. die Festlegung, an welche Schuldner, z.B. welche Branchen, Unternehmensgrößen oder Risikoklassen, die Bank Kredite vergeben möchte. Ferner fordern die MaRisk eine Funktionstrennung zwischen Markt und Marktfolge. Für die vorliegende Studie ist dies insofern bedeutsam, als dass nicht allein die Einschätzung des Marktes, sondern auch die Einschätzung der Marktfolge Auswirkungen auf die Konditionengestaltung haben kann. Für die empirische Untersuchung wurden allerdings nur die Einschätzungen der Marktmitarbeiter erhoben.

Die empirischen Auswertungen in dieser Arbeit zeigen, dass weder die Bonität noch der erwartete Verlust die ökonomischen Parameter Zinssatz, Sicherheitenstellung und Kreditverfügbarkeit erklären können. Die Variablen Sicherheitenquote und Ausfallwahrscheinlichkeit können lediglich 7,61\% und der erwartete Verlust nur 1,89\% der Varianz des Zinssatzes des Kontokorrentkontos erklären. Da die Bonität nicht zwangsläufig durch die Ausfallwahrscheinlichkeit gemessen werden muss, wurden weitere Finanzkennzahlen hinzugezogen. Je nach Auswahl der zusätzlichen Kennzahlen können zwischen 13,08\% und 17,69\% der Varianz erklärt werden. ${ }^{1631}$ Die Ergebnisse zeigen, dass neben der Ausfallwahrscheinlichkeit auch zusätzliche Finanzkennzahlen bei der Zinsfestlegung berücksichtigt werden. Bei der Ausfallwahrscheinlichkeit und der Sicherheitenstellung kann über den erwarteten Verlust ein mathematischer Zusammenhang zum Zinssatz derart hergestellt werden kann, dass ein erwarteter Verlust in Höhe von $1 \%$ zu einer Zinserhöhung von $1 \%$ führen sollte. Ein vergleichbarer $\mathrm{Zu}$ sammenhang bspw. zwischen der Eigenkapitalquote und dem Zinssatz kann nicht hergestellt werden. Die Berücksichtigung dieser zusätzlichen Finanzkennzahlen bei der Zinsfestlegung kann nur über die Erfahrung des Firmenkundenbetreuers erfolgen. Bei nahezu allen Regressionen zum Zinssatz konnte herausgearbeitet werden, dass die Unternehmensgröße einen signifikanten zinsreduzierenden Effekt hat. Inwiefern die Unternehmensgröße als Indikator für die Bonität des Unternehmens betrachtet wird oder vielmehr Ausdruck der Verhandlungsmacht ist, kann nicht geklärt werden.

Auch wenn sich eine Beeinflussung der Sicherheitenstellung durch die Finanzkennzahlen nicht unmittelbar aus den rechtlichen Vorgaben ergibt, werden die Ergebnisse 
an dieser Stelle dargestellt. Die Sicherheitenstellung wurde zum einen als binärcodierte Variable und zum anderen als Besicherungsquote operationalisiert. Die Auswertungsergebnisse sind ähnlich. Die Ratingklasse hat bei beiden Formen der Operationalisierung nur einen geringen Erklärungsgehalt. Zentrale Größen für die Beeinflussung der Sicherheitenstellung sind vor allem die Zinsdeckungsquote und die Quote der langfristigen Verbindlichkeiten gegenüber Kreditinstituten. Während die Zinsdeckungsquote Ausdruck für die Kapitaldienstfähigkeit des Unternehmens ist, drückt die Verbindlichkeitenquote die Abhängigkeit von der Bankfinanzierung aus. Bei der logistischen Regression mit den Finanzkennzahlen beträgt das Pseudo- $\mathrm{R}^{2}$ immerhin 28,92\%. Die Möglichkeit, dass das Unternehmen keine Sicherheiten stellt, wird in diesem Regressionsmodell allerdings nur in ca. 29\% der Fälle korrekt vorhergesagt. Bei der linearen Regression mit der Besicherungsquote als Regressand kann in Abhängigkeit von den zugrunde gelegten Finanzkennzahlen lediglich 11,56\% der Varianz der Besicherungsquote erklärt werden.

Die Kreditverfügbarkeit wird in der vorliegenden Untersuchung in drei Varianten operationalisiert: die tatsächlich erfolgten Kreditablehnungen als vergangenheitsbezogene Kreditverfügbarkeit, die durch den Firmenkundenbetreuer geschätzte Möglichkeit der aktuellen Kreditausweitung als gegenwartsbezogene Kreditverfügbarkeit und die Dauer der Kreditbewilligung. Auch bei der Kreditverfügbarkeit hätte erwartet werden können, dass ein Zusammenhang zur Ausfallwahrscheinlichkeit besteht. Beispielsweise ist gemäß den MaRisk durch jede Bank eine Kreditrisikostrategie zu formulieren. Es wird jedoch gezeigt, dass die Ausfallwahrscheinlichkeit alleine - als ein Indikator für die Bonität des Unternehmens - nicht in hohem Umfang zur Erklärung beiträgt. Der Erklärungsgehalt für erfolgte oder potenzielle, zukünftige Kreditablehnungen ist gering. Möglicherweise ist die Ausfallwahrscheinlichkeit nicht expliziter Bestandteil dieser Kreditrisikostrategie. Bei Berücksichtigung zusätzlicher Finanzkennzahlen kann bei der vergangenheitsbezogenen Kreditverfügbarkeit ein Pseudo- $\mathrm{R}^{2}$ von $21 \%$ und bei der gegenwartsbezogenen Kreditverfügbarkeit ein Pseudo- $\mathrm{R}^{2}$ von $26 \%$ ermittelt werden. Die Auswertungen zeigen, dass die Eigenkapitalquote für die Kreditentscheidung herangezogen wird; selbige weist bei allen Regressionen der Finanzkennzahlen einen statistisch signifikanten Einfluss auf. Banken sind somit nur so lange bereit Kredite zu vergeben, bis eine bestimmte Relation von Eigen- und Fremdkapital nicht unterschritten wird.

Als erstes Zwischenresümee kann festgehalten werden, dass die rechtlichen Rahmenbedingungen nicht dazu führen, dass die Ausfallwahrscheinlichkeit und die Finanzkennzahlen die ökonomischen Parameter in einem erheblichen Umfang erklären können. Darüber hinaus kann auch eine eher betriebswirtschaftlich motivierte, risikoorientierte Konditionenfestlegung nicht beobachtet werden. Die objektive Bonität des Unternehmens kann somit die Konditionen nicht vollständig erklären.

Einen weiteren Erklärungsansatz liefert die klassische Relationship BankingForschung. In der Relationship Banking-Forschung wird davon ausgegangen, dass die Konditionen auch durch beziehungsbezogene Größen beeinflusst und erklärt werden. Den theoretischen Bezugsrahmen für die Relationship Banking-Forschung bildet die Neue Institutionenökonomie und hier insbesondere der Prinzipal-Agenten-Ansatz. Die 
Informationsasymmetrien zwischen dem Kunden und der Inside-Bank sowie die Informationsasymmetrien zwischen der Inside-Bank und den Outside-Banks stellen die wesentlichen Einflussgrößen bei der Konditionensetzung dar.

In der Relationship Banking-Forschung wurden mehrere Modelle zur Erklärung des Kreditzinses, der Sicherheitenstellung und der Kreditverfügbarkeit entwickelt. Die Modelle in Bezug auf den Kreditzins kommen allerdings zu unterschiedlichen Ergebnissen; so gibt es sowohl Modelle, die von steigenden Zinsen als auch Modelle, die von sinkenden Zinsen im Zeitablauf ausgehen. ${ }^{1632}$ Bei den Modellen wird davon ausgegangen, dass die Informationsasymmetrien zwischen Kunde und Inside-Bank im Laufe der Beziehung sinken und gleichzeitig die Informationsasymmetrien zwischen InsideBank und Outside-Bank steigen. Die im Zeitablauf generierten Informationen führen zu einer präziseren Risikoeinschätzung und einer Reduktion der Unsicherheit bezüglich des Verhaltens und der Fähigkeiten des Kreditnehmers. In Konsequenz sinken der zu fordernde Risikoaufschlag sowie die Monitoring-Kosten. Die Modelle unterscheiden sich dahingehend, inwiefern diese Kosteneinsparungen an den Kunden weitergegeben werden. Die Weitergabe der Kosteneinsparung führt zu sinkenden Zinsen im Zeitablauf der Beziehung. Die Informationsgenerierung innerhalb der Beziehung bewirkt einen Informationsvorsprung gegenüber den Outside-Banken, so dass die Bank eine Machtstellung einnimmt. Der Kunde kann die Bank nicht so leicht wechseln. Dies kann die Inside-Bank ausnutzen und im Zeitablauf höhere Zinsen fordern und ihre Gewinne erhöhen. Der Zinssatz muss allerdings unter dem Zinssatz der OutsideBanken liegen.

Darüber hinaus wird die Machtstellung auch durch den Markt selbst, z.B. der Anzahl der für den Kunden verfügbaren Alternativen, sowie der Ausgestaltung der Finanzierungsstruktur des Kunden, z.B. die Anzahl der Bankbeziehung des Kunden, bestimmt. Eine geringe Marktmacht der Bank führt dazu, dass selbige eher dazu gezwungen wird, die Kosteneinsparungen in Form von niedrigen Zinsen an den Kunden weiterzugeben. Bei einer hohen Marktmacht kann sie durch die Kosteneinsparungen ihre Gewinnmarge erhöhen.

Diese verschiedenen möglichen Auswirkungen auf den Zinssatz spiegeln sich auch in den uneinheitlichen Ergebnissen der empirischen Relationship Banking-Forschung wider. Bei den Studien werden vor allem Variablen verwendet, die die Möglichkeit der Informationsproduktion durch die Inside-Bank (z.B. Dauer der Bankbeziehung, Produktnutzung), den relativen Informationsvorsprung gegenüber den Outside-Banken (z.B. Anteil der Bankfinanzierung, Anzahl der Bankverbindungen) oder den Umfang der im Markt verfügbaren Informationen (z.B. Alter des Unternehmens) abbilden. Die Variablen zum Informationsvorsprung gegenüber der Outside-Bank sind gleichzeitig Ausdruck der Macht der Bank. Zudem wird die Macht der Bank häufig durch Variablen, welche die Marktkonzentration messen, berücksichtigt. In den bestehenden Studien weisen die verschiedenen verwendeten Variablen keine einheitlichen Vorzeichen hinsichtlich des Einflusses auf den Zinssatz aus. 
In der vorliegenden Studie konnten keine signifikanten Effekte der Variablen identifiziert werden, die als Operationalisierung des Grades der Informationsasymmetrie und der Marktmacht der Bank verstanden werden können. Einen zinsreduzierenden Effekt hat jedoch der Besitz von Genossenschaftsanteilen bei dem jeweiligen Institut. Ferner bewirkt ein hohes externes Limit auf dem jeweiligen Konto eine Zinsreduktion. Hier zeigt sich, dass die Macht des Kunden einen Einfluss auf den Zinssatz hat. Denn je größer das Limit, desto größer ist der Ertrag der Bank und desto größer fällt der Verlust bei einem Bankwechsel auf. Die Bank ist hier eher zu Eingeständnissen bereit. Zudem zahlen Kunden, die sich in der Intensivbetreuung befinden, höhere Zinsen. Diese beziehungsbezogenen Variablen können - je nach gewählter Regressionsmethode $-22 \%$ oder $23 \%$ der Varianz des Zinssatzes und somit einen größeren Anteil der Varianz als die Finanzkennzahlen erklären. Die gemeinsame Betrachtung der Finanzkennzahlen und der beziehungsbezogenen Kennzahlen steigert den Erklärungsanteil auf insgesamt ca. $27 \%$, wobei die Koeffizienten weiterhin signifikant bleiben. Offensichtlich messen die beziehungsbezogenen Variablen somit etwas anderes als die Finanzkennzahlen. Obwohl ein enger inhaltlicher Zusammenhang zwischen der Intensivbetreuung und der Ausfallwahrscheinlichkeit besteht, bleibt auch der Regressionskoeffizient der Variablen Intensivbetreuung bei gemeinsamer Betrachtung mit den Finanzkennzahlen signifikant. Die beziehungsbezogenen Variablen erklären zwar in Ansätzen die Zinsfestsetzung; der Grad der Informationsasymmetrie hat in der vorliegenden Studie allerdings nur einen geringen Einfluss.

Den Sicherheiten als einen weiteren zentralen ökonomischen Parameter werden in der Relationship Banking-Forschung zwei zentrale Funktionen zugeschrieben. ${ }^{1633}$ Sicherheiten dienen zum einen als Signalling-Instrument und zum anderen als Anreizinstrument. Zur Erfüllung der Signalling-Funktion stellt die Bank dem Firmenkunden verschiedene Zins-Sicherheiten-Kombinationen zur Auswahl. Da ein bonitätsmäßig einwandfreier Kunde nicht von einem Projektausfall ausgeht und somit nicht befürchten muss, seine Sicherheiten zu verlieren, ist er bereit umfangreiche Sicherheiten zu stellen. Der Kunde signalisiert durch eine hohe Sicherheitenstellung, dass er ein guter Kreditnehmer ist. Dafür bekommt er im Gegenzug die niedrigeren Zinsen.

Sicherheiten können aber auch als Anreizinstrument fungieren. Durch eine hohe Sicherheitenstellung soll der Firmenkunde den Anreiz haben, sich nicht gläubigerschädigend zu verhalten und seine Anstrengungen zu erhöhen. In diesem Fall fordern die Banken von bonitätsmäßig schlechten Kunden mehr Sicherheiten. In der theoretischen Relationship Banking-Forschung werden beide Funktionen und somit beide Zusammenhänge modelliert. Es bleibt offen, unter welchen Bedingungen welche Sicherheitenfunktion zur Anwendung kommt. Dementsprechend uneinheitlich sind auch die Ergebnisse der bestehenden empirischen Studien. Wie im Kontext mit den gesetzlichen Rahmenbedingungen erläutert, können in der vorliegenden Arbeit weder die Ausfallwahrscheinlichkeit noch die sonstigen Finanzkennzahlen die Sicherheitenstellung, d.h. weder die Wahrscheinlichkeit der Sicherheitenstellung noch die Besicherungsquote, erklären. 
Die bestehenden empirischen Relationship Banking-Studien berücksichtigen neben der Kreditnehmerqualität auch Aspekte wie den Informationsstand und die Macht der Bank. Ein hoher Informationsstand kann unter Umständen dazu führen, dass die Bank die beim Unternehmen zur Verfügung stehen Vermögensgegenstände besser kennt und somit eher in der Lage ist, geeignete Sicherungsgegenstände zu fordern. Die Macht der Bank drückt aus, inwiefern die Bank in der Lage ist, ihre Forderungen durchzusetzen.

In der vorliegenden Studie brachte die Analyse der beziehungsbezogenen Variablen folgende Erkenntnisse. Bei isolierter Betrachtung der beziehungsbezogenen Variablen können selbige mit einem Pseudo- $\mathrm{R}^{2}$ von $45 \%$ in der logistischen Regression deutlich besser die Wahrscheinlichkeit der Sicherheitenstellung erklären als die Finanzkennzahlen alleine. Bei gemeinsamer Betrachtung der beziehungsbezogenen Variablen und der Finanzkennzahlen liegt das Pseudo- $\mathrm{R}^{2}$ deutlich über $50 \%$. Die geographische Distanz des Unternehmens zur Bank, die Existenz von Darlehenskonten bei der Bank sowie der Abschluss von Produkten aus dem Bereich der Vermögensanlage haben einen signifikanten Einfluss auf die Sicherheitenstellung. Insbesondere der Einfluss der beiden letztgenannten Variablen ist ökonomisch signifikant. Der Zusammenhang zwischen den Darlehenskonten und der Wahrscheinlichkeit der Sicherheitenstellung resultiert daher, dass Darlehen nur in den seltensten Fällen unbesichert vergeben werden. Der Umstand, dass der Abschluss von Produkten aus dem Bereich der Vermögensanlage die Wahrscheinlichkeit der Sicherheitenstellung erhöht, kann derart erklärt werden, dass die Bank ihr Wissen um die Existenz von Vermögen zum Einfordern desselbigen als Sicherheiten nutzt.

Bei der Besicherungsquote - als eine zweite Form der Operationalisierung - steigt der Anteil der Varianzerklärung von ca. $16 \%$ bei ausschließlicher Verwendung der Finanzkennzahlen deutlich auf ca. $26 \%$ bei zusätzlicher Berücksichtigung der beziehungsbezogenen Variablen. Die Besicherungsquote wird signifikant beeinflusst von dem Anteil der langfristigen Verbindlichkeiten gegenüber dem jeweiligen Institut in Relation zur Bilanzsumme. Ebenso führt ein höherer Anteil des Zahlungsverkehrs bei dem Institut zu einer höheren Besicherungsquote. Analog zur Argumentation bei der Vermögensanlage lässt sich Letzteres dadurch erklären, dass die Bank Zugang zu mehr Informationen über das Unternehmen hat und somit mehr Sicherheiten einfordert. Ferner bewirkt eine längere Dauer der persönlichen Beziehung zum Kundenbetreuer eine höhere Besicherungsquote. Auch dieser Zusammenhang stützt die Vermutung, dass die Bank die besseren Informationen über den Kunden dazu nutzt, mehr Sicherheiten zu fordern. Offensichtlich wird die Besicherungsquote somit durch den Umfang

der zur Verfügung stehenden Informationen beeinflusst. Eine Auswirkung der Macht der Bank, z.B. gemessen am Anteil der Bank an der gesamten Bankfinanzierung des Unternehmens, konnte nicht nachgewiesen werden.

Als weiterer wichtiger Parameter der Kunde-Bank-Beziehung wird die Kreditverfügbarkeit untersucht. Die theoretischen Modelle zum Zinssatz können in der Regel auch als Modelle zur Kreditverfügbarkeit interpretiert werden. ${ }^{164}$ Zentraler Ansatzpunkt bei 
dieser Argumentation ist die Festlegung des Zinssatzes. Wenn die Bank den Kreditzins als Durchschnittspreis über alle Kreditnehmer für die gesamte Laufzeit festlegt, liegt der Zinssatz für die bonitätsmäßig guten Kreditnehmer über dem für das Risiko des Kunden angemessenen Preis. Dabei berücksichtigt die Bank, dass die schlechten Kreditnehmer die Zinsen und Tilgung nicht leisten können. Aufgrund der Durchschnittsbetrachtung wird es zu adverser Selektion kommen, denn die guten Kreditnehmer sind nicht bereit diesen Preis zu zahlen und verlassen den Markt. Es kommt gegebenenfalls zu einem Marktzusammenbruch.

Die Bank kann stattdessen aber auch in der ersten Periode Verluste in Kauf nehmen und einen Zinssatz unterhalb des Durchschnittspreises anbieten. In der zweiten Periode haben die schlechten Kreditnehmer den Markt verlassen bzw. sie bekommen keine Kredite mehr. Die Bank wird dann den Zinssatz derart setzen, dass sie die Verluste der ersten Periode ausgleichen kann. Sie fordert von den bonitätsmäßig guten Kreditnehmern einen Zinssatz, der oberhalb des risikoadäquaten Zinssatzes, aber unterhalb des Preises der ersten Periode liegt. Durch diese Möglichkeit der intertemporalen Konditionengestaltung kann die Kreditverfügbarkeit beeinflusst bzw. sichergestellt werden. Damit die Bank in der zweiten Periode einen Zinssatz, der oberhalb des risikoadäquaten Zinssatzes liegt, fordern und dadurch die Verluste aus der ersten Periode ausgleichen kann, ist es erforderlich, dass sie eine entsprechende Monopolstellung innehat. Nur wenn die Bank bei der Konditionenfestlegung sicher sein kann, dass das Unternehmen in der nächsten Periode weiterhin Kunde bei der Bank ist, kann sie eine derartige intertemporale Konditionengestaltung vornehmen. Die in diesen Modellen zugrunde gelegte Monopolstellung kann aus den Marktstrukturen und aus dem Informationsvorsprung resultieren. Im Umkehrschluss lässt sich daraus ableiten, dass erst eine Monopolstellung der Bank intertemporale Konditionengestaltung ermöglicht und somit die Kreditverfügbarkeit erhöht. Es gibt ferner eine zweite Modellgruppe. Bei diesen Modellen wird der Zusammenhang zwischen der Sicherheitenstellung und der Kreditverfügbarkeit modelliert. Eine höhere Sicherheitenstellung führt zu einer höheren Kreditverfügbarkeit. Anders als bei den Modellen zum Zinssatz ist die Wirkungsrichtung bezüglich der Kreditverfügbarkeit innerhalb der beiden Modellgruppen jeweils identisch: eine größere Monopolmacht und eine höhere Sicherheitenstellung bewirkt in allen Modellen eine größere Verfügbarkeit.

In der vorliegenden Untersuchung können bei der Kreditverfügbarkeit folgende $\mathrm{Zu}$ sammenhänge identifiziert werden. Hinsichtlich der vergangenheitsbezogenen Kreditverfügbarkeit kann beobachtet werden, dass die einzelnen beziehungsbezogenen Variablen keinen signifikanten Einfluss ausüben. Es kann auch keine erhebliche Verbesserung des Erklärungsgehalts festgestellt werden. Während das Pseudo- $\mathrm{R}^{2}$ bei ausschließlicher Berücksichtigung der Finanzkennzahlen $21,43 \%$ beträgt, führt die zusätzliche Integration der beziehungsbezogenen Kennzahlen nur zu einem geringfügigen Anstieg auf 22,77\%. Ein Einfluss der Monopolstellung, so wie selbige in den theoretischen Modellen postuliert wurde, kann nicht beobachtet werden.

Bei der gegenwartsbezogenen Kreditverfügbarkeit hingegen können signifikante Einflüsse der beziehungsbezogenen Variablen festgestellt werden. Bei alleiniger Betrachtung der beziehungsbezogenen Variablen kann immerhin ein Pseudo- $\mathrm{R}^{2}$ von 47,56\% 
ermittelt werden im Vergleich zu einem Pseudo- $\mathrm{R}^{2}$ von $25,73 \%$ bei ausschließlicher Betrachtung der Finanzkennzahlen. Einen auf dem 1\%-Niveau signifikanten Einfluss übt hierbei die Mitgliedschaft aus. Der Besitz von Genossenschaftsanteilen führt zu einer besseren Kreditverfügbarkeit. Weitere beziehungsbezogene Variablen sind bei der kombinierten Regression nicht signifikant. Der Einfluss der Sicherheitenquote, welche in den theoretischen Modellen als eine zentrale Größe genannt wurde, ist nicht signifikant.

Gleichermaßen interessante Erkenntnisse weist die ordinale Regression hinsichtlich der Dauer der Kreditbewilligung auf. Während das Pseudo- $\mathrm{R}^{2}$ der Regression mit den Finanzkennzahlen $17,53 \%$ beträgt, wird bei ausschließlicher Berücksichtigung der beziehungsbezogenen Variablen ein Pseudo- $\mathrm{R}^{2}$ von $21,41 \%$ ermittelt. Die Dauer der Kreditbewilligung wird somit stärker durch beziehungsbezogene Aspekte als durch die Bonität bestimmt. Erneut übt die Mitgliedschaft einen signifikanten Einfluss aus; Unternehmen, die Genossenschaftsanteile halten, bekommen schneller einen Kredit als Unternehmen, die keine Anteile haben. Ferner fältt der Prozess der Kreditbewilligung kürzer aus, wenn bei der Kreditbeantragung gleichzeitig weitere Bankprodukte angesprochen und bei selbigen mittlerweile ein Vertrag abgeschlossen wurde.

Als Zwischenfazit in Bezug auf die klassische Relationship Banking-Forschung kann Folgendes festgehalten werden. Durch die Integration der beziehungsbezogenen Variablen kann die Konditionenfestlegung sowohl für den Kreditzins, für die Sicherheitenstellung als auch für die Kreditverfügbarkeit besser erklärt werden als bei ausschließlicher Berücksichtigung der Finanzkennzahlen. Ein Fazit derart, dass die Informationsasymmetrien und eine Machtstellung der Bank in erheblichem Umfang die Konditionengestaltung beeinflussen, kann nicht getroffen werden. Lediglich bei der Sicherheitenstellung spielt die Information der Bank eine Rolle. Es resultiert die Frage, inwiefern der bisher nicht erklärte Anteil der Varianz der Konditionen durch bisher nicht berücksichtigte Einflussfaktoren bestimmt wird.

Sowohl die Modelle der Relationship Banking-Forschung als auch die empirischen Studien weisen eine wesentliche Forschungslücke auf. Es wird in der Regel davon abstrahiert, dass bei der Interaktion zwischen der Bank und dem Unternehmen einzelne Personen beteiligt sind. Dieser Aspekt wird jedoch insbesondere bei der Analyse von Geschäftsbeziehungen im Investitionsgütermarketing hervorgehoben. Bei dieser

Analyse nehmen verhaltenswissenschaftliche Elemente eine zentrale Stellung ein. Um diese Lücke bei der Relationship Banking-Forschung - zumindest teilweise - schließen zu können, werden aus bestehenden Interaktionsmodellen die für die Analyse der Kunde-Bank-Beziehung zusätzlich relevanten Aspekte herausgearbeitet. Das statische Modell der IMP-Group betont, dass im Rahmen einer Geschäftsbeziehung die Atmosphäre derselbigen sowie der soziale Austausch zwischen den Interaktionspartnern elementar ist ${ }^{1635}$. In dem dynamischen Modell von FORD wird die Geschäftsbeziehung in den verschiedenen Entwicklungsstadien betrachtet. ${ }^{1636}$ So nehmen die Erfahrung und

\footnotetext{
1635 Vgl. hierzu ausführlich Kapitel A.5.2.2.1.

1636 Vgl. hierzu ausführlich Kapitel A.5.2.2.2.
} 
das Commitment im Zeitablauf der Beziehung zu, Unsicherheit und Distanz zwischen den Geschäftspartnern sinkt. Während sich diese Modelle mit Geschäftsbeziehungen im Allgemeinen auseinandersetzen, hat SEGBERS ein Modell zur Deskription und Analyse der Kunde-Bank-Beziehung entwickelt. ${ }^{1637}$ In diesem Modell hat er u.a. die Wirkung von Vertrauen, Verbundenheit und Gebundenheit untersucht. In allen zuvor genannten Modellen nehmen die Konstrukte Vertrauen und Commitment bzw. Verbundenheit und Gebundenheit als zwei Dimensionen von Commitment eine zentrale Stellung ein. So erscheint es offensichtlich, dass der Umfang der durch die Bank generierten Informationen nicht nur von beziehungsbezogenen Parametern wie der Dauer der Beziehung, sondern bspw. auch durch die Ausgestaltung der Beziehung oder die Atmosphäre zwischen dem Ansprechpartner des Unternehmens oder dem Firmenkundenbetreuer beeinflusst wird.

Da eine Auswirkung der Konstrukte Vertrauen und Commitment auf die ökonomischen Parameter angenommen wird, ist es zunächst erforderlich, die Konstrukte jeweils zu definieren bzw. die Dimensionen festzulegen. Letzteres ist deswegen wichtig, da es sich bei Vertrauen und Commitment nicht um homogene Phänomene handelt. Insbesondere die Unterscheidung zwischen der personalen und der organisationalen Ebene ist bedeutsam. So kann der Firmenkundenbetreuer bspw. dem Ansprechpartner des Unternehmens ein hohes $\mathrm{Ma} \beta$ an Kompetenz und Sachverstand zuschreiben, gleichzeitig aber Zweifel an der Sinnhaftigkeit bestimmter unternehmensweiter (Investitions-)Entscheidungen haben. Allein die Unterscheidung nach Bezugsobjekten erscheint noch nicht ausreichend, sondern es muss ferner nach inhaltlichen Dimensionen differenziert werden. Basierend auf dem aktuellen Stand der Forschung kann abgeleitet werden, dass Vertrauen durch die folgenden vier Dimensionen gemessen werden kann:

- Organisationale Glaubwürdigkeit

- Organisationales Wohlwollen

- Personale Glaubwürdigkeit

- Personales Wohlwollen

Gleichermaßen können bei dem Commitment die nachstehenden Dimensionen unterschieden werden:

- Organisationale Gebundenheit

- Organisationale Verbundenheit

- Personale Verbundenheit

Aus diesen verschiedenen Dimensionen lassen sich unterschiedliche Auswirkungen auf die ökonomischen Parameter Kreditzins, Sicherheitenstellung und Kreditverfügbarkeit erwarten. Hinsichtlich der Auswirkungen auf den Kreditzins wurde angenommen, dass alle vier Vertrauensdimensionen einen zinsreduzierenden Effekt haben. Ein Einfluss der Commitment-Dimensionen wurde nicht angenommen. Eine erhöhte Glaubwürdigkeit - insbesondere auf organisationaler Ebene - führt zu einer geringeren Unsicherheit der Bank. Bei einer Weitergabe des niedrigeren Risikoaufschlags auf den

1637 Vgl. hierzu ausführlich Kapitel A.5.2.2.3. 
Zinssatz an den Kunden, sollte der Zinssatz sinken. Ein erhöhtes Wohlwollen - insbesondere auf personaler Ebene - fördert den Informationsfluss und somit die Präzision der Risikoeinschätzung. Ferner wird der Firmenkundenbetreuer aufgrund der Reziprozität von Vertrauen das ihm entgegengebrachte Wohlwollen auch erwidern. Beide Wirkungen sollten eine Zinsreduktion hervorrufen. Die empirischen Auswertungen zeigen, dass ein Anstieg der organisationalen Glaubwürdigkeit und des personalen Wohlwollens zu niedrigeren Zinsen führt. Beide Effekte sind signifikant; die anderen Einflüsse hingegen weisen keine Signifikanzen auf. Insgesamt kann gezeigt werden, dass die verhaltenswissenschaftlichen Variablen bei isolierter Betrachtung immerhin $11 \%$ der Varianz des Zinssatzes erklären. Die Integration dieser Variablen in die Regression mit den Finanzkennzahlen und den beziehungsbezogenen Variablen führt zu einem leichten Anstieg des Erklärungsgehalts von $27 \%$ auf $29 \%$.

Bei der Sicherheitenstellung wurde angenommen, dass sich sowohl die Vertrauensdimensionen als auch die Verbundenheit reduzierend auf die Sicherheitenstellung auswirken. Eine organisationale Gebundenheit hingegen sollte zu einer höheren Sicherheitenstellung führen. Bei gegebener Glaubwürdigkeit wird die Gefahr des Scheiterns als gering erachtet, so dass die Bank weniger Sicherheiten fordern wird. Sicherheiten sollen aber auch die Gefahr des Moral Hazard reduzieren. Ein wohlwollendes Unternehmen wird nicht versuchen, der Bank zu schaden, so dass bei Wohlwollen weniger Sicherheiten gefordert werden. Ein ähnlicher Effekt wird bei der Verbundenheit des Unternehmens erwartet. Die Notwendigkeit für die Bank, Anreize zu schaffen und Sicherheiten zu fordern, sinkt. Die organisationale Gebundenheit führt zu einer erhöhten Wahrscheinlichkeit der Sicherheitenstellung, denn in dieser Situation wird die Bank die Machtstellung ausnutzen und möglichst viele Sicherheiten fordern.

Zunächst sollen die Erkenntnisse hinsichtlich der binärcodierte Variable Sicherheitenstellung aufgezeigt werden. Die organisationale Glaubwürdigkeit führt - wie erwartet zu einer signifikanten Reduktion der Sicherheitenstellung. Somit findet nicht die im Zusammenhang mit der Relationship Banking-Theorie beschriebene SignallingFunktion, sondern die Anreizfunktion Anwendung. Die Wirkungsrichtung kann wenngleich nicht signifikant - auch für die organisationale Verbundenheit in allen

Fällen beobachtet werden. Des Weiteren kann in allen Regressionen signifikant bestätigt werden, dass eine höhere organisationale Gebundenheit mit einer höheren Wahrscheinlichkeit der Sicherheitenstellung einhergeht. Die Bank nutzt somit ihre Machtstellung aus. Die Ergebnisse für die anderen verhaltenswissenschaftlichen Faktoren sind nicht immer eindeutig, allerdings steigt der Erklärungsgehalt der Regression mit Finanzkennzahlen und beziehungsbezogenen Variablen von $51,81 \%$ bei zusätzlicher Berücksichtigung der verhaltenswissenschaftlichen Variablen auf $58,07 \%$.

Die Auswirkungen der verhaltenswissenschaftlichen Variablen auf die Sicherheitenquote sind vergleichbar. Auch hier zeigt sich, dass die organisationale Glaubwürdigkeit in allen Regressionen zu einer statistisch signifikanten Reduktion der Sicherheitenquote führt. Dahingegen bewirkt ein Anstieg der organisationalen Gebundenheit in allen Fällen eine statistisch signifikante Erhöhung der Sicherheitenquote. Die Einflüsse der anderen Dimensionen sind nicht signifikant. Eine Verbesserung des Erklärungsge- 
halts durch die Integration der verhaltenswissenschaftlichen Variablen kann nicht erreicht werden.

In einem letzten Auswertungsblock wurde die Kreditverfügbarkeit untersucht. Es wurde angenommen, dass sowohl die Vertrauensdimensionen als auch die Commitment-Dimensionen die Kreditverfügbarkeit erhöhen. Ein Anstieg der Glaubwürdigkeit des Unternehmens führt dazu, dass die Wahrscheinlichkeit des Scheiterns sinkt und die Bank eher bereit ist, Kredite zu vergeben. Das Wohlwollen wirkt derart, dass der Firmenkundenbetreuer sich bei dem Unternehmen für vergangene Handlungen durch ein wohlwollendes Verhalten seinerseits revanchieren möchte. Die Gebundenheit und die Verbundenheit eröffnen die Möglichkeit zur intertemporalen Konditionengestaltung und erhöhen dadurch die Kreditverfügbarkeit.

Die Analyse der vergangenheitsbezogenen Kreditverfügbarkeit zeigt, dass die organisationale Glaubwürdigkeit, das organisationale Wohlwollen, die interpersonale Glaubwürdigkeit und die personale Verbundenheit die Kreditverfügbarkeit in allen Regressionen, d.h. bei isolierter Betrachtung der verhaltenswissenschaftlichen Variablen und bei gemeinsamer Betrachtung mit Finanzkennzahlen und beziehungsbezogenen Variablen, erhöhen. Signifikant ist der Effekt allerdings nur bei dem organisationalen Wohlwollen. Bei der Gebundenheit ist der Einfluss in allen Regressionen derart, dass eine höhere Gebundenheit zu einer geringeren Kreditverfügbarkeit führt. Eine denkbare Erklärung besteht darin, dass die höhere Gebundenheit aus der schlechten Bonität resultiert und der Kunde auch bei keiner anderen Bank einen Kredit bekommen würde. Der Einfluss der anderen verhaltenswissenschaftlichen Variablen ist nicht in allen Regressionen eindeutig. Allerdings bleibt festzuhalten, dass die Integration dieser Variablen zu einem erheblichen Anstieg der Werte für das Pseudo- $\mathrm{R}^{2}$ führt. Bei alleiniger Betrachtung von Finanzkennzahlen und beziehungsbezogenen Kennzahlen beträgt selbiges $22,77 \%$, nach Integration der verhaltenswissenschaftlichen Variablen $39,69 \%$. Auch der Vergleich mit bestehenden Studien zeigt, dass die Werte sehr aussagekräftig sind. In der Studie von COLE, bei der angesichts der gewählten Operationalisierung und statistischen Methodik die beste Vergleichbarkeit gegeben ist, wurde ein Pseudo- $\mathrm{R}^{2}$ von $22,4 \%$ ermittelt. Eine zusätzliche interessante Information zur Modell-

güte liefert der Anteil der durch das Regressionsmodell richtig klassifizierten Fälle. Die verschiedenen Modelle der vorliegenden Arbeit können jeweils ca. zwischen $95 \%$ und $99 \%$ der Fälle, bei denen es nicht zu einer Kreditablehnung gekommen ist, korrekt vorhersagen. Es ist aber hervorzuheben, dass vor der Integration der verhaltenswissenschaftlichen Variablen nur 16,00\% und nach Integration derselben immerhin 36,36\% der tatsächlich erfolgen Kreditablehnungen durch das Regressionsmodell korrekt vorhergesagt werden.

Bei der gegenwartsbezogenen Kreditverfügbarkeit sind die Ergebnisse ähnlich. Auch hier führt eine höhere organisationale Glaubwürdigkeit und eine höhere personale Verbundenheit zu einer größeren Wahrscheinlichkeit der Kreditausweitung. Die organisationale Ge- und Verbundenheit führt in allen Fällen wiederum zu einer geringeren Wahrscheinlichkeit der Kreditausweitung. Durch die Integration der verhaltenswissenschaftlichen Variablen steigt der Erklärungsgehalt erheblich von zuvor - bei aus- 
schließlicher Betrachtung der Finanzkennzahlen und der beziehungsbezogenen Variablen $-47,56 \%$ auf $58,79 \%$. Ferner können statt $31,25 \%$ nunmehr $50,00 \%$ der potenziell nicht gewährten Kreditausweitungen durch das Regressionsmodell korrekt vorhergesagt werden.

Hinsichtlich der Dauer der Kreditbewilligung ist insbesondere hervorzuheben, dass die organisationale Verbundenheit zu einer - allerdings nicht signifikanten - schnelleren Kreditbewilligung führt. Auch hier zeigt sich wiederum, dass die Integration der verhaltenswissenschaftlichen Variablen zu einem Anstieg des Erklärungsgehalts von $33,30 \%$ auf $46,01 \%$ führt. Ferner fällt auf, dass die verhaltenswissenschaftlichen Variablen bei isolierter Betrachtung ein Pseudo- $\mathrm{R}^{2}$ von 15,92\% aufweisen und somit nur einen minimal geringeren Erklärungsgehalt als die Finanzkennzahlen mit Pseudo- $\mathrm{R}^{2}$ von $17,53 \%$ haben.

Resümierend lässt sich feststellen, dass die verhaltenswissenschaftlichen Variablen insgesamt einen erheblichen Erklärungsbeitrag für die Sicherheitenstellung und die Kreditverfügbarkeit leisten können. Der Einfluss auf den Zinssatz scheint eher von nachrangiger Bedeutung. Die zentralen Erkenntnisse der vorliegenden Arbeit können wie folgt zusammengefasst werden: Durch die Integation der verhaltenswissenschaftlichen Variablen steigt der Erklärungsgehalt der logistischen Regression für die Sicherheitenstellung von $52 \%$ auf $58 \%$. Eine hohe organisationale Gebundenheit führt in allen Regressionen zu einer höheren Wahrscheinlichkeit der Sicherheitenstellung und zu einer höheren Sicherheitenquote. Eine hohe organisationale Glaubwürdigkeit reduziert in allen Regressionen die Wahrscheinlichkeit der Sicherheitenstellung und die Höhe der Sicherheitenquote. In beiden Fällen sind die Ergebnisse jedoch nicht immer signifikant.

Die verhaltenswissenschaftlichen Variablen bewirken bei der Regression für die vergangenheitsbezogene Kreditverfügbarkeit einen Anstieg des Erklärungsgehalt auf $40 \%$ im Vergleich zu $23 \%$ bei ausschließlicher Betrachtung der Finanzkennzahlen und der beziehungsbezogenen Variablen. Gleichermaßen lässt sich bei der gegenwartsbezogenen Kreditverfügbarkeit durch die Integration der verhaltenswissenschaftlichen Varia-

blen eine Verbesserung des Pseudo- $\mathrm{R}^{2}$ von $47 \%$ auf $58 \%$ erzielen. Eine hohe organisationale Glaubwürdigkeit und eine hohe personale Verbundenheit führt in allen Regressionen - sowohl bei der vergangenheits- als auch bei der gegenwartsbezogenen Operationalisierung - zu einer höheren Kreditverfügbarkeit. Im Gegensatz dazu bewirkt eine hohe organisationale Gebundenheit in allen Regressionen eine niedrigere Kreditverfügbarkeit. 


\section{Anhang}

Anhang 1: Anschreiben und Fragebogen der Datenerhebung Anhang 2: Vollständige Tabellen der desriptiven Auswertung Anhang 3: Prüfung der Voraussetzungen der Faktorenanalyse Anhang 4: Vollständige Korrelationsanalyse für die Datenbasis „Zinssatz“ Anhang 5: Ergänzende Regressionsanalysen für den Zinssatz 


\section{Anhang 1: Fragebogen und Begleitschreiben}

Düsseldorf, den 12. November 2007

\section{Analyse der Geschäftsbeziehung zwischen Kundenbetreuer und Firmenkunden}

\section{Sehr geehrter Herr $X X X$}

ich bin Mitarbeiterin bei der BMS Consulting $\mathrm{GmbH}$ und promoviere gegenwärtig am Lehrstuhl fü Controlling der Westfälischen Wilhelms-Universität Münster. Im Rahmen meines Promotionsvorhabens untersuche ich die Geschäftsbeziehung zwischen den Kundenbetreuern von genossenschaftlichen Banken und ihren Firmenkunden. Ziel der Untersuchung ist u.a. die Überprüfung folgender Fragestellungen:

- Hat eine gute Kundenbeziehung einen Einfluss auf die Kreditvertugbarkeit und den Umfang der Geschäftsbeziehung mit dem Kunden?

- Wirkt sich eine Hausbankbeziehung auf den Umfang der zur Verfügung gestellten Sicherheiten aus?

- Zahien Kunden, die eine gute Beziehung zum Kundenbetreuer haben, hohere Zinssătze?

Diese Untersuchung soll u.a. dazu dienen, Ansatzpunkte für eine bessere und erfolgreichere Betreuung von Firmenkunden in Genossenschaftsbanken identifizieren zu kơnnen. Zu diesem Zweck würde ich gerne bei lhrer Bank einige Daten erheben. Die Firmenkundenbetreuer werden gebeten, in Schrifttorm einige Fragen zu ihren Kunden zu beantworten. Der Zeitaufwand je Kundenbetreuer belauft sich auf ca. $15 \mathrm{~min}$.

Weitere notwendige Informationen wie bspw. die Ratingnote oder der Bankenspiegel können von mir unmiltelbar aus der Anwendung MinD.banker extrahiert werden. Hierzu benótige ich lediglich einen Zugang zu einem Rechner mit MinD.banker, für Sie entstehen an dieser Stelle keine weiteren Arbeiten. Die Datenauswertung erfotgt anschließend anonym bei der Westfalischen Wilhelms-Universităt Münster. Selbstverständlich werden die Daten streng vertraulich behandelt.

Abb. AN 1-1: Anschreiben 
Die Untersuchungsergebnisse werden in aggregierter Form im Rahmen meiner Dissertation veroffentlicht. Im Idealfall können die Ergebnisse Ihrer Bank wertvolle Hinweise für die Gestaltung der Kundenbeziehung liefern. Bei Interesse stelle ich Ihnen die Ergebnisse der Studie gerne zur Verfugung. Da ich die Datenerhebung bei Ihnen vor Ort durchfúhren müsste, kann ich Ihnen des Weiteren anbieten, in diesem Rahmen bspw. eine ca, $90 \mathrm{~min}$. Schulung der Firmenkundenbetreuer hinsichtlich der neuen Funktionen aus MinD.banker kostenlos durchzufuhren.

Ich werde Sie innerhalb der nalchsten Tage einfach noch mal telefonisch kontaktie ren. Bei Ruckfragen stehe ich Ihnen selbstverständlich jederzeit gerne zur Verfugung (Mail: Tel.

Ich wurde mich freuen, wenn Sie an der Untersuchung teilnehmen würden.

Mit freundlichen Grußen

Tina Püthe

(Comarthani) 


\section{Hilfe zum Vervoliständigen des Fragenbogens}

\section{$1 \quad$ Hintergrund der empirischen Erhebung}

Ich bin Mitarbeiterin bei der Bits Consulting GmbH und promoviere gegenwartig am Lehrstuhi für Controlling der Westfalischen Wilhelms-Universität Münster. Im Rahmen meines Promotionsvorhabens untersuche ich dle Geschäftsbeziehung zwischen den Kundenbetreuern von gerossenschaftichen Banken und ithren Firmenkunden. Damit Ihr Antwortverhalten nicht beeinflusst wird, möchte ich Ihnen im Vorfeld keine genauen Details angeben, ich stehe Ihnen aber gerne für Fragen zur Verfugung. Um eine für den gesamten Kundenbestand repräsentative Datenbasis zu erhalten wurde eine zufällige Kundenauswahl durchgeführt. Zur Durchführung der Untersuchung bin ich auf Ihre Unterstützung angewlesen. Ich danke Ihnen schon mal im Voraus für Ihre Mitarbeit.

\section{Deckblatt}

Da im Fragenbogen selbst weder Kundenname noch Kundennummer auftauchen, dient das Deckblatt lediglich für Sie zur Identifikation des Kunden. Bitte entfernen Sie das Deckblatt nach Vervollständigen des Datenerhebungsbogens, so dass keine Möglichkeiten eines Rückschlusses auf konkrete Kunden möglich sind.

\section{$3 \quad$ Allgemein}

Bitte ergänzen Sle die Daten nach Ihrem besten Wissensstand (Schätzungen sind besser als keine Antworten). Bei einigen fragen geht es um thre subjektive Elnschätzung über das Unternelinien, somit versuchen Sie bitte bei diesen Fragen Ihren subjektiven Elndruck im Fragenbogen arizugeben.

\section{Vorausgefüllte Fragen}

Einen Teil der Fragen konnte durch die in Minv. banker hinterlegten Daten automatisiert ausgefüllt werden. Sofern die Daten nicht stimmen oder unvollständig sind, können bzw. soliten Sie die Daten korrigieren.

\section{Rückgabe der Fragebögen}

Die Fragebögen soliten bitte bis zum 11. Januar zur BMS Consulting zurückgeschickt werden.

\section{Herzlichen Dank für Ihre Unterstützungl}

Bei Fragen: Tina Püthe

Abb. AN 1-2: Begleitschreiben 
Datenerhebungsbogen für die Analyse der Geschäftsbeziehung im Firmenkundensektor der genossenschaftlichen Banken (Automatisch)

Kunden-Nr::
Zugrunde liegendes Geschaftsjahr:
Institut:
1. Unternehmensdaten

Branchennummer

Branchenbezeichnung

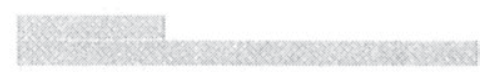

Rechtsform des Kunden

Postleitzahl des Hauptsitzes des

Kunden

Grüdungsjahr des Unternehmens

\section{Jahresabschluss- und Ratingdaten}

2.1 Jahresabschlussdaten - Datenherkunft: GENO-FBS

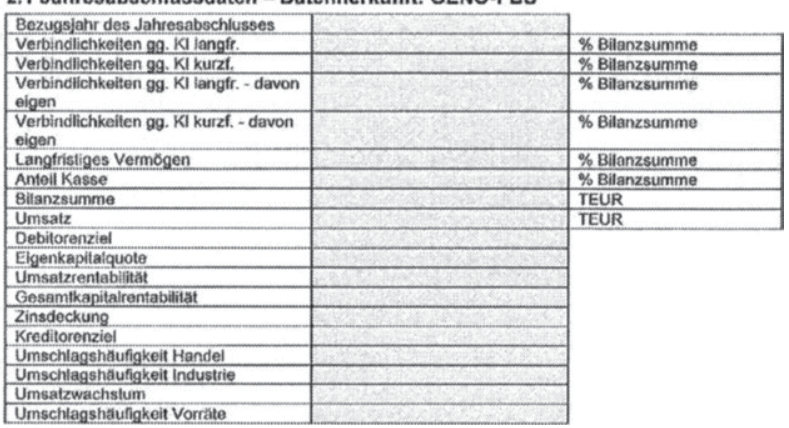

Abb. AN 1-3: Datenerhebungsbogen 


\subsection{Ratingdaten - BVR-11-Ratingmodul}

\begin{tabular}{|l|l|}
\hline Annderungsdaturn & \\
\hline $\begin{array}{l}\text { Ratingnote nach BVR-II-Rating } \\
2005\end{array}$ & \\
\hline 2004 & \\
\hline 2003 & \\
\hline 2002 & \\
\hline 2001 & \\
\hline Teilscore JA MS & \\
\hline Teilscore qual. Daten MS & \\
\hline Teilscore JA OMS & \\
\hline Teilscore qual. Daten OMS & \\
\hline Anzahl Bankverbindungen & \\
\hline Oberziehungen 30: & \\
\hline Oberziehungen B0: & \\
\hline Oberziehungen 90: & \\
\hline Oberziehungen Gesamt: & \\
\hline Kundenbeziehung seit: & \\
\hline $\begin{array}{l}\text { Geschaltsfahrer arbeitet in Bran- } \\
\text { che seit: }\end{array}$ & \\
\hline $\begin{array}{l}\text { Geschaftsfuhrer arbeitet in Unter- } \\
\text { nehmen seit: }\end{array}$ & \\
\hline
\end{tabular}

Gibt es in der Geschäftsleitung eine Person mit betriebswirtschaftlicher Ausbildung?

\section{$\square$ Ja $\square$ Nein}

Sind Absprachen bezïglich der Einhaltung des Termins der Elnreichung JA, Aus. gleich der Oberziehung, Verwendung von Krediten, Ausweltung Obligos bel anderon Banken, Tilgungsvereinbarungen, Boibringung zugesagter Unterlagen, Sicherheiten, extermer Berater, leitender Angestoliter etc. getroffen worden und wurden dilese eingehalten?

Es wurden keine Absprachen getroffen

Alle getroffenen Absprachen wurden eingehaiten.

$\square$ Mindestens eine Absprache wurde nichl eingehalten.

Fortsetzung Abb. AN 1-3: Datenerhebungsbogen 
Fürt der Kunde bzw. sein WP/Steuerberater regelmäßig Planungsrechnungen durch? Wenn ja, welche (Mehrfachnennungen möglich)?

Ja Nein

Wenn ja, welche?

Ergebnisplanung

Finanz-/ Liquiditatsplanung

Solilist-Vergleich for Ergebnisplanung

Solilist-Vergleich for Finanz \& Liquiditatsplanung

Ja Nein

$\square \square$

$\square \quad \square$

$\square \quad \square$

$\square \square$

Wurden Alternativen/Szenarien in der Planung berilcksichtigt?

D Ja

$\square$ Nein

$\square$ Unbekannt

Sind die beantragten Kreditmittel und Investitionen in der Planung berucksichtigt?

$\square$ Ja $\square$ Nein

Existiert ein Controlling oder interne Revision?

$\square$ da $\square$ Nein

Seite 3 von 4

Fortsetzung Abb. AN 1-3: Datenerhebungsbogen 
Wie wurden der Bank bisher wichtige Unternehmensentscheidungen erlăutert?

Konzept von Unternehmensleitung mit Planungsrechnung vorgestellt und ausreichend eriatulert

Konzept von Unternehmensleitung ohne Planungsrechnung vorgestellt und ausreichend erlautert

$\square$ Nicht ausreichend erlautert

Welchen Einblick hat die Bank in die wesentlichen Entwicklungen im Unternehmen (Entlassungen oder Ernennungen von Geschaftsfuhrernfleitenden Angesteliten, sonstige Elnschnitte im Personalberalch, Verănderung der Gesellschaftsstruktur, etc.)?

$\square$ Wir setzen die Bank zumeist selbststandig und zeitnah in Kenntnis.

Bei uns haben sich keine derartigen Entwicklungen gegeben. Es bestehen keine Anhallspunkte zur Beantwortung dieser Frage.

Die Bank wird nur dann informiert, wenn ein entsprechender Bedarf an finanziellen Mitteln bei uns entstanden ist. Ansonsten werden soiche Unternehmensinterna nicht kommuniziert.

Ist Ihre Unternohmensleitung in der Lage, die wirtschaftliche Entwicklung auch unterJahrig zutreffond darzustellen?

[ Ja, mit Planungsdaten, BWAs/unterjahrigen Zwischenzahlen und Soll//st-Vergleich

$\square$ Ja, mit aktuellen und aussagekraftigen BWAs/unterjährigen Zwischenzahlen

$\square$ Ja, mit BWAs/unterjahrigen Zwischenzahlen und ergänzenden Erlăuterungen

$\square$ Eingeschränkt, mit nicht ausreichend qualifizierten BWAs oder Einzeldarstellung

$\square$ Nein

Seile 4 von 4

Fortsetzung Abb. AN 1-3: Datenerhebungsbogen 
Volksbank

Datenerhebungsbogen für die Analyse der Geschàftsbeziehung im Firmonkundensektor der genossenschaftlichen Banken (Manuell)

Kunden-Nr:
Zugrunde liegendes Geschaftsjahr:
Institut:
1. Unternehmensdaten

1.) Jahr der Anlage des Firmenkun$\rightarrow$ Alternativ: denikundenbeziehung seit geschătzte

Dauer der Jahre Bankbeziehung

2.) Ist thre Bank die Hausbank des O Ja ONein OUnbekannt Unternehmens?

3.) Hat thre Bank einen Sitz in einem Aufsichtsgremium (z.B. Bei- O Ja O Nein O Unbekannt rat des Unternehmens)?

4.) Seit wann wird das Unternahmen von Ihnen persönlich betreut?

$\rightarrow$ Alternativ: geschatzle Dauer der Be ziehung

5.) Wie viele Mitarbeiler hat das Unternehmen?

Personen

6.) Bitte geben Sie die Anzahl der Gesellschafter an:

Personen

7.) Befinden sich mehr als $90 \%$ des

Kapitals in der Hand der Ge- O Ja schaftsfohrung?

O Nein

O Unbekannt

8.) Sind mehr ats $25 \%$ des Kapitals im Besitz eines anderen Unternehmens? flrrelevant wonn Fra-

O Ja

O Nein

O Unbekannt ge $7 \mathrm{mit}$ ja beantwortet wurde)

9.) War der Kunde schon mal in der Intensivbetreuung oder wurde das Engagement als Problemkredit eingestuft?

10.) Bitte geben Sie die Anzahl der mit diesem Unternehmen gefahrten Beratungsgesprache je Jahr an (Durchschnitt der letzlen bejden Jahre):

Abb. AN 1-4: Manueller Fragebogen 
11.) Bitte geben Sie die Anzahl der sonstigen Kontakte mit diesem Unternehmen (z.B. Telefonate, Mail, .Kurzbesuche") je Jahr an Stuck pro (Durchschnitt der letzten beiden Jahr Jahre):

12.) Welcher Organisationsebene ist thr (Haupt-)Ansprechpartner im Unternehmen zuzuordnen?

\author{
O Der Geschäftsfuhrung \\ O Außerhalb der Geschaftsfuhrung
}

Im Folgenden werden Ihnen eine Reihe von Aussagen in Bezug auf das Unternehmen vorgelegt. Bitte entscheiden Sio, inwiefern die Aussagen Ihrer Ansicht nach zutreffen oder nicht (je Aussage bitte nur ein Kreuz). Eine . $1^{*}$ bedeutet, dass die Aussage ,voll zu trift" und eine $6^{\circ}$, dass die Aussage uberhaupt nicht zutrift:

$\begin{aligned} & \text { 13.) Wir konnen uns auch dann auf die Informatio- } \\ & \text { nen verlassen, wenn uns das Unternehmen zu } \\ & \text { außergewohnlichen Sachverhalten (z.B. auffal- } \\ & \text { lige Kennzahlenentwicklung, starke Verănde- } \\ & \text { rung der Lieferantenstruktur) auf den ersten } \\ & \text { Blick eher unwahrscheinliche Erklärungen lie- } \\ & \text { fert. }\end{aligned}$
$\begin{aligned} & \text { 14.) Das Unternehmen hat die Absprachen ein, die } \\ & \text { es uns mit uns getroffen hat (z.B. schnellere } \\ & \text { Einreichung des Jahresabschlusses im Folge- } \\ & \text { jahi). }\end{aligned}$

Fortsetzung Abb. AN 1-4: Manueller Fragebogen 


\begin{tabular}{|l|l|}
\hline $\begin{array}{l}\text { 18.) Wenn wir dem Unternehmen von aufgetrete- } \\
\text { nen Problemen berichten (z.B. Bearbeitungs- } \\
\text { fehler, Falschbuchungen, Verzögerungen im } \\
\text { Zahlungsverkehr), konnen wir kain Verstand- } \\
\text { nis von diesem Unternehmen erwarten. }\end{array}$ \\
$\begin{array}{l}\text { 19.) Wir können uns darauf verlassen, dass das } \\
\text { Unternehmen uns bei einschneidenden Ent- } \\
\text { scheidungen, die die betriabswirtschaftiche } \\
\text { Entwicklung des Unternehmens maßgeblich } \\
\text { betreffen, rechtzeitig und umfassen informiert } \\
\text { (z.B. Standortschließung, personelle Verande- } \\
\text { rungen in der Geschaftsleilung, Umsatzein- } \\
\text { bruch). }\end{array}$ \\
\hline $\begin{array}{l}\text { 20.) Das Unternehmen hat uns schon mal einen } \\
\text { Kunden vermittelt bzw, wöde uns bei Gele- } \\
\text { genheit Kunden vermitteln. }\end{array}$
\end{tabular}

\section{Daten zum Kreditvertrag}

Bankenspiegel

\begin{tabular}{|c|c|c|c|c|c|c|}
\hline \multicolumn{5}{|l|}{ Elgenobligo } & \multicolumn{2}{|c|}{ Silend 16.11 .2000} \\
\hline $\begin{array}{l}\text { Kontonumene } \\
\text { Kneftar }\end{array}$ & $\begin{array}{c}\text { Vespe.0at } \\
\text { saldo }\end{array}$ & tonterness Lind & wat & Debsote & Zivutinduse & Mivilds: \\
\hline 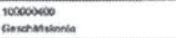 & nax & 25000 & EUR & $12,75 \mathrm{~s}$ & $\ldots$ & - \\
\hline $\begin{array}{l}100000030 \\
\text { Amalatendalativen }\end{array}$ & $\begin{array}{l}\text { secen } \\
\text { seorz }\end{array}$ & 25000 & Euk & ras * & - & - \\
\hline 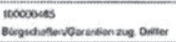 & .20 .100 & 20.100 & EUR & $200 \%$ & - & - \\
\hline 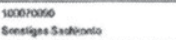 & $\begin{array}{r}-0 \\
-11 \operatorname{sen}\end{array}$ & $\sin n$ & EUR & $0,00 \mathrm{~s}$ & -- & - \\
\hline
\end{tabular}

Fortsetzung Abb. AN 1-4: Manueller Fragebogen 


\section{Konditionen und Besicherung}

24.) Bitte geben Sie die Besicherungsquote for den Kunden an:

$\% \rightarrow$ Alternativ: Blankoanteil

25.) Welche Sicherheiten haben derzeit den großsten Anteil bei der Engagementsicherstellung? Bitte geben Sie die drei wichtigsten Sicherheiten an:

O Grundschulu/hypothek

O BurgschafvGarantie

O Sicherungsebereignung

o Forderungsabtretung/zession

O Verpfandungen

O Sonstige

26.) Wurde innerhalb der letzten 3 Jahre ein Kre-

O Ja O Nein O Unbekannt ditwunsch durch diesen Kunden an Sie herangetragen und abgelehnt?

Aus welchem Grund?

27.) Ist in den letzien 3 Jahren ein Kredit nur teilweise bewilligt worden, d.h. es wurde nur ein geringeres als das gewonschte Volumen genehmigt?

28.) Wurden Sie diesem Kunden heute eine Ausweitung der Kreditlinie ermoglichen oder zusătzliche Kredite gewahren?

O Ja ONein OUnbekannt

29.) Wie schnell (im Vergleich zum bankweiten Durchschnitt for diese Kreditart) konnte der letzle Kredit dieses Kunden bewilligt werden? Bitte geben Sie thre subjektive Einschaltzung gemessen an der Durchlaufzeit an:

O Langsamer

O Deutlich langsamer

30.)Wurden bei der letzten Kreditvergabe weitere Produkte oder Dienstleistungen angesprochen, bei denen es mittlerweile zum Abschluss gekommen ist?

Fortsetzung Abb. AN 1-4: Manueller Fragebogen 
31.) Welche Aussage trift Ihrer Meinung nach am besten zu:

- Bonilatsmaßig gute Kunden slellen tendenziell mohr Sicherheilton.

(Donn er vorsucht dhach die Si-

cherhetten seine Quabitít zu slgna. lisieran.)

- Ein bonitêtsmaßBig schlechler Kun. de stellt tendenziel mehr Sicherheiten. (Dem die Bank fordent mohr Sichorhoilton)

- Es gibt keinen Zusammenhang zwischen der Qualitat des Kredit. nehmers und der Besicherung.

\section{Daten zur Produktnutzung des Kunden}

Bitte geben Sie folgende Informationen zur Produktnutzung an:

32.) Wie viel Prozent des Zahlungsverkehrs (volumenbezogen) wickelt das Unterneh men ober Ihr Institut ab?

33.)Wie hoch ist der Antell Ihrer Bank an den gesamten Bankverbindlichkeiten des Unternehmens?

34.)Wie hoch ist der Anteil der wichtigsten Bank an den gesamten Bankverbindlichkeiten des Untemehmens? (sofern nicht Ihr Institut dessen Hauptbank ist)?

35.) Bitte schatzen Sie die Entfernung zwischen dem Sitz des Unternehmens (Sitz Ihres Ansprechpartners, sofern das Unternehmen mehrere Niederlassungen hat) und der Filiale/Bankstelle, in der Sie tatig sind?

36.) Ist das Unternehmen Mitglied Ihrer Bank? O Ja O Nein O Unbekannt 
Produktnutzung des Kunden bef fhrer Bank

\begin{tabular}{|l|}
\hline Produktbozeichnung \\
\hline Investition und Finanzierung \\
\hline Wechsel \\
\hline Borgschaften/Garantien \\
\hline Verbund-Hypothek \\
\hline Vermogensaniage \\
\hline Spar \\
\hline Termingeid \\
\hline PVS \\
\hline Llquiditlit und Zahlungsverkehr \\
\hline Kontokorrent \\
\hline Kartensysteme \\
\hline Risiko und Absicherung \\
\hline R+VHaftpflichtversicherung \\
\hline R+V Tierversicherung \\
\hline R+V Transportversicherung \\
\hline
\end{tabular}

Sofern in obiger Tabelle nicht alle Produkte aufgefistet sind, die der Kunde bel fhrer Bank nutzt, vervollständigen Sie bitto nachstehende Tabelle: Welche der folgenden Produkte nutzt der Kunde bel Threr Bank?

\begin{tabular}{l|c|c|c|} 
& \multicolumn{3}{|c|}{ Nutzung } \\
& Ja & Noin & Unbekannt \\
\hline Darlehen & 0 & 0 & 0 \\
\hline Zahlungsverkehrs-Kontokorrentkonten & 0 & 0 & 0 \\
\hline Vermögens-1Geldanlage & 0 & 0 & 0 \\
\hline Versicherungon & 0 & 0 & 0 \\
\hline Privatkonten (Kredit-, Anlagokonten etc.) & 0 & 0 & 0 \\
\hline
\end{tabular}

37.)Bitte beurteilen Sie, was aus threr Sicht for das Unternehmen von großerer Bedeutung ist. ein niedriger Zins far die KK-Linie oder eine größere Kreditverfugbarkeit im Sinne einer großeren KKLinie?

38.) Haben Sie diesem Unternehmen schon mal geschaftiche Kontakte oder Auftrage vermittelt?

O Nein, noch nie

39.)Bitte beurteilen Sie die Zinssensibilitat O Hoch O Mittel O Gering des Unternehmens?

Fortsetzung Abb. AN 1-4: Manueller Fragebogen 
40.) Bitte geben Sie an, wie hoch thr Vertrau- O Hoch O Mittel o Gering en zum Unternehmen ist:

\section{Geschäisboziehung}

Im Folgenden werden Ithen eine Reihe von Aussagen in Bezug auf Ihren (Haupt-) Ansprechpartner des Unternehmens vorgelegt. Bitte entscheiden Sie, inwiefern die Aussagen ihrer Ansicht nach zutreften oder nicht (je Aussage bitte nur ein Kreuz). Eine .1" bedeutet, dass die Aussage ,voll zu trifft und eine, $6^{*}$, dass die Aussage oberhaupt nicht zutriff:

\begin{tabular}{|c|c|}
\hline & $=0$ m \\
\hline \multicolumn{2}{|l|}{$\begin{array}{l}\text { 41.) Mein Ansprechpartner hat mir die Gründe } \\
\text { fur Zahlungsschwierigkeiten oder Proble- } \\
\text { me bei der rechtzeitigen Bereitstellung von } \\
\text { Informationen/Daten (z.B. Bilanzen, Plan- } \\
\text { daten, BWA, Projektentwicklung) stets of- } \\
\text { fen und zeitnah erlautert. }\end{array}$} \\
\hline \multicolumn{2}{|l|}{$\begin{array}{l}\text { 42.) Mein Ansprechpartner ist stets auf dem } \\
\text { aktuellsten Stand was branchenspezifische } \\
\text { Themen angeht (z.B. Konkurrenzsituation, } \\
\text { Produktneuheiten, Branchenwachstum). }\end{array}$} \\
\hline \multicolumn{2}{|l|}{$\begin{array}{l}\text { 43.) Mein Ansprechpartner hat nur geringe } \\
\text { Kenntnisse im betriebswirtschaftlichen Be- } \\
\text { reich (z.B. Interpretation von Bilanzkenn- } \\
\text { zahlen, Erstellung von Pianen, Interpretati- } \\
\text { on der Controllingdaten). }\end{array}$} \\
\hline \multicolumn{2}{|l|}{$\begin{array}{l}\text { 44.)Mein Ansprechpartner stellit keine unan- } \\
\text { gemessenen Forderungen. So wörde er } \\
\text { mir bezaglich seiner Konditionen (Zinsen } \\
\text { und Besicherung) bei anderen Banken in } \\
\text { Verhandlungen nicht antogen, um dadurch } \\
\text { bessere zu Konditionen bei uns zu erzie- } \\
\text { len. }\end{array}$} \\
\hline & $=0$ \\
\hline \multicolumn{2}{|l|}{$\begin{array}{l}\text { 45.) Mein Ansprechpartner nimmt die aus sei- } \\
\text { ner Sicht eher formalen Tatigkeiten, wie } \\
\text { 2.B. Aufstellung Warenlager, Erstellung } \\
\text { Zessionslisten, nur widerwilig in Kauf, er } \\
\text { kann die Notwendigkeit for uns nicht nach- } \\
\text { vollziehen. }\end{array}$} \\
\hline $\begin{array}{l}\text { 46.) Mein Ansprechpartner warde bei Unzufrie- } \\
\text { denheit mit unserer Bank oder unseren } \\
\text { Konditionen unmittelbar den personlichen } \\
\text { Kontakt zu mir suchen. }\end{array}$ & \\
\hline
\end{tabular}

Fortsetzung Abb. AN 1-4: Manueller Fragebogen 


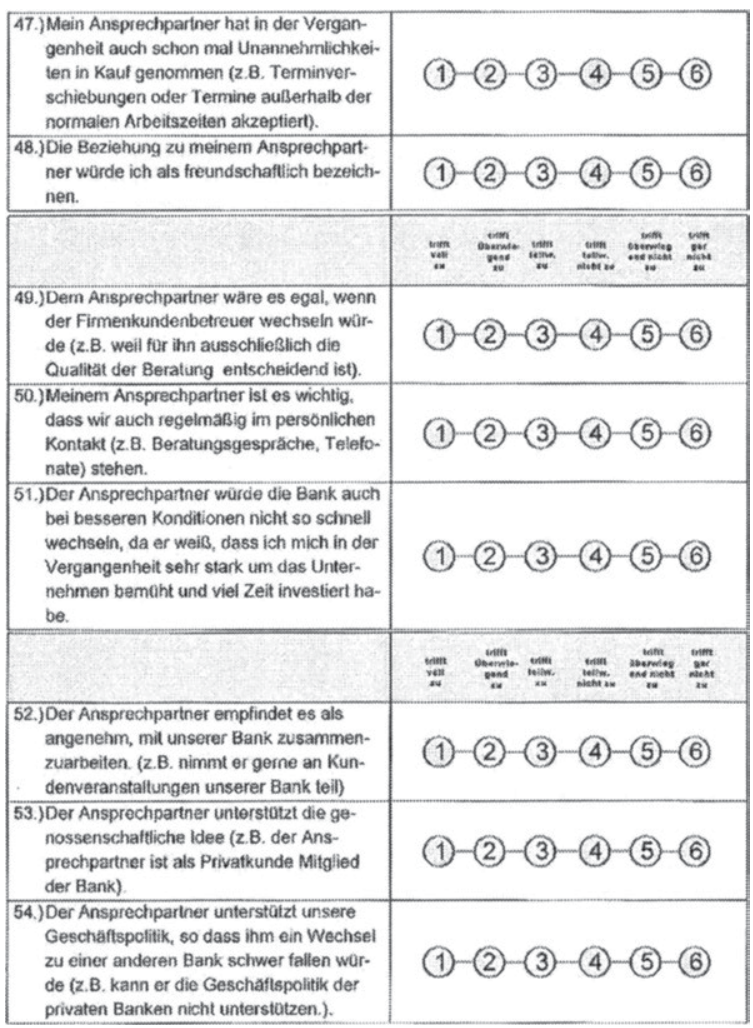

Fortsetzung Abb. AN 1-4: Manueller Fragebogen 


\section{Daten zur Bank}

55.) Bitte geben Sie den Marktanteil Ihrer Bank in Ihrer StadURegion an

\begin{tabular}{|c|c|c|c|}
\hline \multicolumn{2}{|l|}{ a. bezogen auf den gesamten Markt: } & \multicolumn{2}{|l|}{$\%$} \\
\hline bezogen auf das Firmenkundengeschaft: & & $\%$ & \\
\hline 56.)Bitte beurteilen Sie das Mariktumfeld Ihrer Bank? & $\begin{array}{l}\text { O Eher } \\
\text { ländlich }\end{array}$ & $\begin{array}{l}\text { O Sowohl als } \\
\text { auch }\end{array}$ & $\begin{array}{l}\text { O Eher } \\
\text { stadtisch }\end{array}$ \\
\hline \multicolumn{4}{|l|}{$\begin{array}{l}\text { 57.) Erhalten Firmenkundenbetreuor eine leistungs- } \\
\text { orientierte Vergotung? Wenn ja, welche? (Sio kon- } \\
\text { nen auch mehrere Antworten ankreuzen) }\end{array}$} \\
\hline & \multirow{2}{*}{\multicolumn{3}{|c|}{$\begin{array}{l}\text { O Wertorientiert (Zins. } \\
\text { Provisionsergobnis/DB des FKB) } \\
\text { O. Wertorientiert (Zins. } \\
\text { /Provisionsergebris/DB des Teams, } \\
\text { der Bank) } \\
\text { O Volumenorientiert } \\
\text { O Aktivitatenorientiert }\end{array}$}} \\
\hline & & & \\
\hline & \multicolumn{3}{|c|}{$\begin{array}{l}\text { O Nein, keino leistungsorientierte Ver } \\
\text { gutung }\end{array}$} \\
\hline $\begin{array}{l}\text { 58.) Existiert in Ihrer Bank eine risikoorientierte Beprei- } \\
\text { sung? }\end{array}$ & O Ja & $\mathrm{ON}$ & \\
\hline
\end{tabular}

Vielen Dank fär Ihre Teilnahmo!

Fortsetzung Abb. AN 1-4: Manueller Fragebogen 


\begin{tabular}{|c|c|c|}
\hline $\begin{array}{l}\text { Variablen- } \\
\text { bezeichnung }\end{array}$ & $\begin{array}{l}\text { Kennzahlen- } \\
\text { bezeichnung }\end{array}$ & Kennzahlendefinition \\
\hline EKQ & $\begin{array}{l}\text { Eigenkapital- } \\
\text { quote }\end{array}$ & $\frac{\text { Bilanzielles Eigenkapital }}{\text { Bereinigte Bilanzsumme }}$ \\
\hline DEBZIEL & Debitorenziel & $\frac{\text { Forderungen aus Lieferung \& Leistung }}{\text { Umsatz }} \times 360$ \\
\hline $\begin{array}{l}\text { UMSATZ- } \\
\text { RENT }\end{array}$ & $\begin{array}{l}\text { Umsatzren- } \\
\text { tabilität }\end{array}$ & $\frac{\text { Betriebsergebnis vor Steuern vom Einkommen \& Ertrag }}{\text { Gesamtleistung }}$ \\
\hline $\begin{array}{l}\text { GESAMT- } \\
\text { RENT }\end{array}$ & $\begin{array}{l}\text { Gesamtren- } \\
\text { tabilität }\end{array}$ & $\frac{\text { (Betriebsergebnis vor Steuern vom Einkommen \& Ertrag + Zinsaufwand) }}{\text { Bereinigte Bilanzsumme }}$ \\
\hline ZINSDECK & Zinsdeckung & $\frac{\text { Betriebsergebnis vor Steuern vom Einkommen \& Ertrag }}{\text { Zinsaufwand }}$ \\
\hline KREDZIEL & Kreditorenziel & $\frac{\text { (Verbindlichkeiten aus Lieferung \& Leistung }+ \text { Wechsel) }}{\text { Materialaufwand }} \times 360$ \\
\hline UMHANDEL & $\begin{array}{l}\text { Umschlagshäu- } \\
\text { figkeit Handel }\end{array}$ & $\frac{\text { Materialaufwand }}{\text { Fertigerzeugnisse \& Waren }}$ \\
\hline UMIND & $\begin{array}{l}\text { Umschlagshäu- } \\
\text { figkeit Industrie }\end{array}$ & $\frac{\text { Materialaufwand }}{\text { Fertigerzeugnisse \& Waren }}$ \\
\hline UMSATZW & $\begin{array}{l}\text { Umsatzwachs- } \\
\text { tum }\end{array}$ & $\frac{\text { Umsatz aktuelles Jahr }}{\text { Umsatz Vorjahr }}-1$ \\
\hline UMVORR & $\begin{array}{l}\text { Umschlagshäu- } \\
\text { figkeit Vorräte }\end{array}$ & $\frac{\text { Umsatz }}{\text { Vorräte }}$ \\
\hline
\end{tabular}

Tab. AN 1-1: Kennzahlendefinitionen 


\section{Anhang 2: Deskriptive Auswertungen}

\begin{tabular}{|c|c|c|c|c|c|c|}
\hline & \multicolumn{2}{|c|}{ Kapitalgesellschaften } & \multicolumn{2}{|c|}{$\begin{array}{c}\text { Nicht- } \\
\text { Kapitalgesellschaften }\end{array}$} & \multicolumn{2}{|c|}{ Signifikanz } \\
\hline & Mittelwert & Median & Mittelwert & Median & T-Test & $\begin{array}{c}\text { Kolmogorov- } \\
\text { Smirnov }\end{array}$ \\
\hline VERB_KI_LANG_R & 16,21 & 9,50 & 30,29 & 23,30 & 0,0001 & 0,0006 \\
\hline VERB KI KURZ R & 10,61 & 5,30 & 15,24 & 5,70 & 0,0782 & 0,0841 \\
\hline VERB_KI_R & 26,82 & 19,60 & 45,52 & 39,05 & 0,0001 & 0,0011 \\
\hline VERM_LA_R & 29,44 & 25,20 & 42,51 & 39,45 & 0,0001 & 0,0003 \\
\hline KASSE_R & 10,80 & 3,80 & 6,38 & 2,55 & 0,0119 & 0,0109 \\
\hline VERB_KI_LANG_A & 639,33 & 67,68 & 471,08 & 175,30 & 0,6036 & 0,0489 \\
\hline VERB_KI_KURZ_A & 283,73 & 42,85 & 262,02 & 53,00 & 0,8529 & 0,1630 \\
\hline VERB_KI_A & 923,07 & 188,14 & 733,09 & 259,60 & 0,6209 & 0,1837 \\
\hline VERM LA A & 831,20 & 291,45 & 1032,88 & 382,99 & 0,3916 & 0,2103 \\
\hline KASSE_A & 224,28 & 51,95 & 188,17 & 24,93 & 0,7104 & 0,0860 \\
\hline BILANZS & $2.544,00$ & $1.289,00$ & $2.379,32$ & $1.277,80$ & 0,7673 & 0,4522 \\
\hline UMSATZ & $5.441,17$ & $2.890,10$ & $4.851,26$ & $2.013,50$ & 0,5424 & 0,0220 \\
\hline DEBZIEL & 36,30 & 29,73 & 30,42 & 27,16 & 0,1177 & 0,1027 \\
\hline EKQ & 20,39 & 19,08 & 3,41 & 12,25 & 0,0036 & 0,0023 \\
\hline UMSATZRENT & 3,15 & 2,15 & 7,07 & 4,89 & 0,0011 & 0,0014 \\
\hline GESAMTRENT & 9,36 & 7,93 & 2098,52 & 16,37 & 0,2069 & 0,0001 \\
\hline ZINSDECK & $2.121,24$ & 277,11 & $1.098,47$ & 265,22 & 0,4447 & 0,9001 \\
\hline KREDZIEL & 106,93 & 38,90 & 115,68 & 46,77 & 0,8607 & 0,5425 \\
\hline UMHANDEL & 51,08 & 10,12 & 24,03 & 9,35 & 0,1178 & 0,5436 \\
\hline UMIND & 442,17 & 29,10 & 237,46 & 15,61 & 0,3431 & 0,1325 \\
\hline UMSATZW & 222,67 & 10,65 & 14,71 & 2,03 & 0,4137 & 0,0171 \\
\hline UMVORR & 74,26 & 12,93 & 65,63 & 12,42 & 0,7764 & 0,5679 \\
\hline ANZ_ÜB_30 & 0,14 & 0,00 & 0,21 & 0,00 & 0,2915 & 0,7821 \\
\hline ANZ_ÜB_60 & 0,04 & 0,00 & 0,11 & 0,00 & 0,1273 & 1,0000 \\
\hline ANZ_ÜB_90 & 0,04 & 0,00 & 0,11 & 0,00 & 0,1273 & 1,0000 \\
\hline ANZ_ÜB_GES & 25,65 & 1,00 & 42,01 & 0,50 & 0,0674 & 0,0177 \\
\hline AUSFALLW_B & 1,67 & 0,50 & 2,45 & 0,50 & 0,5596 & 0,2819 \\
\hline TSC_JA_AGG & 61,56 & 64,50 & 53,72 & 56,50 & 0,0156 & 0,0565 \\
\hline TSC_QA_AGG & 70,48 & 71,00 & 66,38 & 67,00 & 0,0951 & 0,3286 \\
\hline $\mathrm{N}$ & & 133 & & 84 & & \\
\hline
\end{tabular}

Tab. AN 2-1: Finanzierungsstrukturen differenziert nach Kapitalgesellschaft vs. Nicht-Kapitalgesellschaft 


\begin{tabular}{|c|c|c|c|c|c|c|}
\hline & \multicolumn{2}{|c|}{$\begin{array}{l}\text { Umsatz kleiner } \\
\text { 2,5 Mio. EUR }\end{array}$} & \multicolumn{2}{|c|}{$\begin{array}{l}\text { Umsatz größer } \\
\text { 2,5 Mio. EUR }\end{array}$} & \multicolumn{2}{|c|}{ Signifikanz } \\
\hline & Mittelwert & Median & Mittelwert & Median & T-Test & $\begin{array}{l}\text { Kolmogorov- } \\
\text { Smirnov }\end{array}$ \\
\hline VERB_KI_LANG_R & 26,83 & 15,00 & 16,43 & 10,70 & 0,0031 & 0,1047 \\
\hline VERB KI KURZ R & 14,42 & 6,50 & 10,37 & 3,80 & 0,1139 & 0,0809 \\
\hline VERB_KI_R & 41,25 & 28,10 & 26,80 & 20,85 & 0,0021 & 0,0799 \\
\hline VERM_LA_R & 37,38 & 34,90 & 31,60 & 29,10 & 0,0774 & 0,3458 \\
\hline KASSE_R & 10,39 & 4,60 & 7,77 & 2,70 & 0,1278 & 0,2852 \\
\hline BILANZS & $1.219,75$ & 517,90 & $3.752,43$ & $2.606,00$ & 0,0000 & 0,0000 \\
\hline UMSATZ & $1.287,45$ & $1.163,00$ & $9.174,53$ & $5.894,35$ & 0,0000 & 0,0000 \\
\hline DEBZIEL & 34,55 & 29,23 & 33,49 & 28,86 & 0,7725 & 0,1063 \\
\hline EKQ & 3,23 & 13,37 & 24,50 & 21,51 & 0,0002 & 0,0172 \\
\hline UMSATZRENT & 5,41 & 3,27 & 3,92 & 2,76 & 0,2066 & 0,1053 \\
\hline GESAMTRENT & $1.616,94$ & 9,75 & 11,80 & 8,57 & 0,3199 & 0,1066 \\
\hline ZINSDECK & 751,98 & 218,72 & $2.683,11$ & 304,70 & 0,1375 & 0,2093 \\
\hline KREDZIEL & 164,30 & 42,17 & 60,58 & 41,03 & 0,0305 & 0,1677 \\
\hline UMHANDEL & 41,00 & 12,71 & 40,04 & 9,11 & 0,9551 & 0,1703 \\
\hline UMIND & 126,77 & 23,67 & 512,78 & 22,39 & 0,0720 & 0,8669 \\
\hline UMSATZW & 14,49 & 3,57 & 269,11 & 8,44 & 0,3044 & 0,0337 \\
\hline UMVORR & 114,28 & 18,46 & 31,31 & 10,35 & 0,0047 & 0,0032 \\
\hline ANZ_ÜB_30 & 0,27 & 0,00 & 0,06 & 0,00 & 0,0054 & 0,3363 \\
\hline ANZ_ÜB_60 & 0,10 & 0,00 & 0,03 & 0,00 & 0,0996 & 1,0000 \\
\hline ANZ_ÜB_90 & 0,10 & 0,00 & 0,03 & 0,00 & 0,0996 & 1,0000 \\
\hline ANZ_ÜB_GES & 46,28 & 4,00 & 17,56 & 0,00 & 0,0009 & 0,0249 \\
\hline AUSFALLW_B & 3,15 & 0,75 & 0,79 & 0,35 & 0,0700 & 0,0018 \\
\hline TSC_JA_AGG & 52,35 & 53,00 & 64,80 & 68,00 & 0,0001 & 0,0000 \\
\hline TSC_QA_AGG & 66,19 & 66,00 & 71,76 & 73,25 & 0,0208 & 0,0079 \\
\hline $\mathrm{N}$ & & 109 & & 108 & & \\
\hline
\end{tabular}

Tab. AN 2-2: Finanzierungsstrukturen differenziert nach Unternehmensgröße

\begin{tabular}{|l|r|}
\hline & SICH_Q \\
\hline N & 213 \\
\hline Mittelwert & 55,9033 \\
\hline Standardfehler des Mittelwertes & 2,6577 \\
\hline Median & 61 \\
\hline Standardabweichung & 38,7877 \\
\hline Varianz & $1.504,4818$ \\
\hline Schiefe & $-0,3475$ \\
\hline Standardfehler der Schiefe & 0,1667 \\
\hline Kurtosis & $-1,4168$ \\
\hline Standardfehler der Kurtosis & 0,3318 \\
\hline Spannweite & 100 \\
\hline Minimum & 0 \\
\hline Maximum & 100 \\
\hline
\end{tabular}

Tab. AN 2-3: Schiefe und Kurtosis bei der Sicherheitenquote 


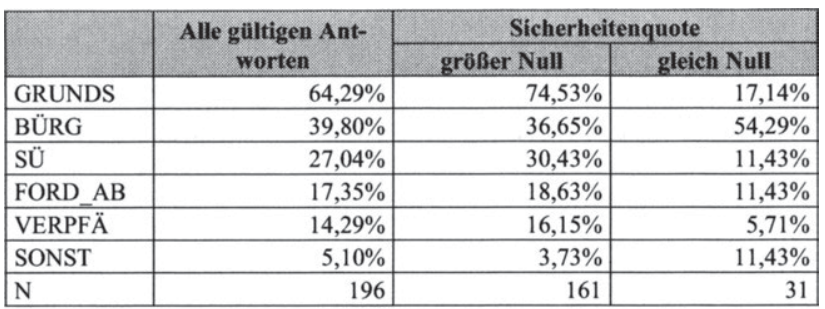

Tab. AN 2-4: Nutzung der verschiedenen Sicherheiten

\begin{tabular}{|l|r|r|r|}
\hline & $\begin{array}{c}\text { Nicht- } \\
\text { Kapitalgesellschaft }\end{array}$ & Kapitalgesellschaft & $\begin{array}{c}\text { Kolmogorov- } \\
\text { Smirnov }\end{array}$ \\
\hline GRUNDS & $72,73 \%$ & $58,82 \%$ & 0,3267 \\
\hline BÜRG & $32,47 \%$ & $44,54 \%$ & 0,5036 \\
\hline SÜ & $33,77 \%$ & $22,69 \%$ & 0,6147 \\
\hline FORD_AB & $14,29 \%$ & $19,33 \%$ & 0,9998 \\
\hline VERPFÄ & $19,48 \%$ & $10,92 \%$ & 0,8835 \\
\hline SONST & $3,90 \%$ & $5,88 \%$ & 1,0000 \\
\hline N & 77 & 119 & \\
\hline
\end{tabular}

Tab. AN 2-5: Sicherheitenart differenziert nach Rechtsform 


\begin{tabular}{|l|r|r|r|r|r|r|r|r|}
\hline & \multicolumn{3}{|c|}{$\begin{array}{c}\text { Nicht- } \\
\text { Hausbankbeziehung }\end{array}$} & \multicolumn{2}{|c|}{ Hausbankbeziehung } & T-Test & $\begin{array}{c}\text { Kolmo- } \\
\text { gorov- } \\
\text { Smirnov }\end{array}$ \\
\cline { 2 - 6 } & N & $\begin{array}{c}\text { Mittel- } \\
\text { wert }\end{array}$ & Median & N & $\begin{array}{c}\text { Mittel- } \\
\text { wert }\end{array}$ & Median & & \\
\hline VERB_KI_LANG_R & 48 & 18,69 & 14,4 & 168 & 22,63 & 12,5 & 0,2854 & 0,6959 \\
\hline VERB_KI_KURZ_R & 48 & 14,75 & 7,9 & 168 & 11,81 & 3,8 & 0,3594 & 0,1706 \\
\hline VERB_KI_R & 48 & 33,44 & 23,8 & 168 & 34,44 & 22,1 & 0,8357 & 0,1573 \\
\hline VERM_LA_R & 48 & 32,86 & 25,0 & 168 & 35,14 & 33,4 & 0,5701 & 0,3801 \\
\hline KASSE_R & 48 & 4,87 & 1,2 & 168 & 10,13 & 4,1 & 0,0101 & 0,0045 \\
\hline VERB_KI_LANG_A & 48 & $1.096,71$ & 118,4 & 168 & 428,33 & 103,0 & 0,0787 & 0,4582 \\
\hline VERB_KI_KURZ_A & 48 & 308,13 & 105,7 & 168 & 267,59 & 36,4 & 0,7276 & 0,0589 \\
\hline VERB_KI_A & 48 & $1.404,84$ & 284,2 & 168 & 695,93 & 211,5 & 0,1159 & 0,3329 \\
\hline VERM_LA_A & 48 & $1.062,56$ & 371,6 & 168 & 870,66 & 311,6 & 0,5567 & 0,9948 \\
\hline KASSE_A & 48 & 182,80 & 16,5 & 168 & 218,06 & 44,0 & 0,6726 & 0,0439 \\
\hline BILANZS & 48 & $3.473,44$ & $1.474,8$ & 168 & $2.207,50$ & $1.235,5$ & 0,1816 & 0,3560 \\
\hline UMSATZ & 48 & $5.327,52$ & $2.966,8$ & 168 & $5.200,24$ & $2.428,5$ & 0,9039 & 0,9694 \\
\hline DEBZIEL & 48 & 41,00 & 34,0 & 168 & 31,83 & 27,3 & 0,0404 & 0,0858 \\
\hline EKQ & 48 & 12,93 & 17,6 & 168 & 13,75 & 17,4 & 0,9080 & 0,9694 \\
\hline UMSATZRENT & 48 & 3,69 & 3,0 & 168 & 4,96 & 2,9 & 0,2480 & 0,7558 \\
\hline GESAMTRENT & 48 & $3.649,78$ & 8,0 & 168 & 13,82 & 9,3 & 0,0615 & 0,8392 \\
\hline ZINSDECK & 48 & 820,47 & 246,1 & 161 & $1.999,96$ & 277,1 & 0,1829 & 0,8510 \\
\hline KREDZIEL & 45 & 128,03 & 62,4 & 161 & 105,84 & 38,3 & 0,7094 & 0,0149 \\
\hline UMHANDEL & 29 & 18,24 & 9,3 & 113 & 41,74 & 9,8 & 0,0262 & 0,6188 \\
\hline UMIND & 23 & 316,22 & 9,0 & 72 & 377,20 & 26,2 & 0,8017 & 0,0478 \\
\hline UMSATZW & 47 & 14,72 & 9,7 & 168 & 177,92 & 6,7 & 0,3064 & 0,9656 \\
\hline UMVORR & 44 & 56,56 & 9,9 & 154 & 69,57 & 13,7 & 0,6249 & 0,3518 \\
\hline AUSFALLW_B & 48 & 3,21 & 0,5 & 168 & 1,63 & 0,5 & 0,4685 & 0,6346 \\
\hline TSC_JA_AGG & 43 & 56,78 & 60,0 & 142 & 58,76 & 62,00 & 0,6014 & 0,8878 \\
\hline TSC_QA_AGG & 42 & 66,19 & 63,0 & 136 & 69,55 & 70,00 & 0,2403 & 0,1256 \\
\hline
\end{tabular}

Tab. AN 2-6: Hausbankbeziehung - Finanzkennzahlen 


\begin{tabular}{|c|c|c|c|c|c|c|c|c|}
\hline & \multicolumn{3}{|c|}{$\begin{array}{c}\text { Nicht- } \\
\text { Hausbankbeziehung }\end{array}$} & \multicolumn{3}{|c|}{ Hausbankbeziehung } & \multirow{2}{*}{ T-Test } & \multirow{2}{*}{$\begin{array}{l}\text { Kolmo- } \\
\text { gorov- } \\
\text { Smirnov }\end{array}$} \\
\hline & N & Mittelwert & Median & N & Mittelwert & Median & & \\
\hline VERB_EIG_LANG_R & 48 & 3,53 & 0,0 & 168 & 15,76 & 4,8 & 0,0011 & 0,0001 \\
\hline VERB_EIG_KURZ_R & 48 & 4,39 & 1,0 & 168 & 7,26 & 0,0 & 0,1933 & 0,1223 \\
\hline VERB_EIG_R & 48 & 7,93 & 3,9 & 168 & 23,02 & 9,1 & 0,0025 & 0,0003 \\
\hline ANT_VERB_EIG_LANG & 35 & 18,06 & 0,0 & 125 & 67,66 & 79,9 & 0,0000 & 0,0000 \\
\hline ANT_VERB_EIG_KURZ & 37 & 35,34 & 28,6 & 112 & 58,18 & 84,9 & 0,0052 & 0,0012 \\
\hline ANT_VERB_EIG_GES & 43 & 24,67 & 13,8 & 145 & 62,20 & 69,3 & 0,0002 & 0,0000 \\
\hline VERB_EIG_LANG_A & 48 & 64,12 & 0,0 & 168 & 212,44 & 43,2 & 0,0225 & 0,0010 \\
\hline VERB_EIG_KURZ_A & 48 & 46,95 & 12,3 & 168 & 72,62 & 0,0 & 0,2121 & 0,4861 \\
\hline VERB_EIG_A & 48 & 111,07 & 27,6 & 168 & 285,05 & 97,3 & 0,0252 & 0,0106 \\
\hline INT_BET & 48 & 0,15 & 0,0 & 168 & 0,11 & 0,0 & 0,5517 & 1,0000 \\
\hline ANZ_BER_J & 48 & 1,90 & 2,0 & 168 & 3,05 & 3,0 & 0,0000 & 0,0001 \\
\hline ANZ_KONT_J & 48 & 5,79 & 5,0 & 168 & 12,89 & 10,0 & 0,0086 & 0,0002 \\
\hline GK_SALD & 46 & $-27.127,43$ & $-12.613,0$ & 167 & $-25.699,44$ & $-15.047,0$ & 0,9638 & 0,1152 \\
\hline GK_LIM_EX & 46 & $122.220,35$ & $90.531,0$ & 166 & $181.860,53$ & $100.564,5$ & 0,0502 & 0,1598 \\
\hline GK_ZINS & 46 & 10,51 & 10,5 & 167 & 10,36 & 10,3 & 0,5915 & 0,8312 \\
\hline GES_KREDIT & 47 & $268.932,30$ & $102.258,0$ & 168 & $556.251,99$ & $249.972,0$ & 0,0108 & 0,0064 \\
\hline SICH_Q & 47 & 36,00 & 40,0 & 165 & 61,91 & 73,0 & 0,0001 & 0,0001 \\
\hline ABL_KRED_VER & 48 & 0,23 & 0,0 & 168 & 0,09 & 0,0 & 0,0234 & 0,6041 \\
\hline PAR_KRED_VER & 48 & 0,17 & 0,0 & 168 & 0,09 & 0,0 & 0,8464 & 1,0000 \\
\hline AUS_KRED_HEU & 48 & 0,92 & 1,0 & 166 & 0,94 & 1,0 & 0,0173 & 0,7392 \\
\hline KRED_VERF_HEU_FRÜ & 47 & 0,32 & 0,0 & 167 & 0,19 & 0,0 & 0,0493 & 0,5302 \\
\hline ANT ZV & 48 & 24,91 & 20,0 & 166 & 82,63 & 90,0 & 0,0000 & 0,0000 \\
\hline ANT_BANK_IN & 42 & 22,75 & 20,0 & 166 & 77,73 & 90,0 & 0,0000 & 0,0000 \\
\hline DIST_UNT & 48 & 13,68 & 10,0 & 168 & 10,63 & 6,0 & 0,3355 & 0,1223 \\
\hline MITGLIED & 48 & 0,58 & 1,0 & 166 & 0,73 & 1,0 & 0,0436 & 0,3590 \\
\hline DARL & 48 & 0,48 & 0,0 & 167 & 0,78 & 1,0 & 0,0000 & 0,0019 \\
\hline ZV_KK & 48 & 0,98 & 1,0 & 168 & 1,00 & 1,0 & 0,0612 & 1,0000 \\
\hline VERM_ANL & 48 & 0,17 & 0,0 & 161 & 0,61 & 1,0 & 0,0000 & 0,0000 \\
\hline VERSICH & 48 & 0,29 & 0,0 & 165 & 0,50 & 0,0 & 0,0152 & 0,0214 \\
\hline PRIVATKONT & 48 & 0,50 & 0,5 & 166 & 0,80 & 1,0 & 0,0000 & 0,0030 \\
\hline DAU_BEZ_ERR & 48 & 17,35 & 16,5 & 168 & 19,87 & 20,0 & 0,1813 & 0,6653 \\
\hline DAU_PERS_ERR & 48 & 10,58 & 5,0 & 167 & 7,43 & 6,0 & 0,5990 & 0,5309 \\
\hline ANZ_B_AGG & 46 & 2,72 & 2,5 & 148 & 2,07 & 2,0 & 0,0001 & 0,0040 \\
\hline ANZ_B_AGG_PL & 46 & 2,72 & 2,5 & 148 & 2,11 & 2,0 & 0,0002 & 0,0153 \\
\hline
\end{tabular}

Tab. AN 2-7: Hausbankbeziehung - Beziehungsbezogene Variablen

\begin{tabular}{|l|r|r|r|r|}
\hline & \multicolumn{2}{|c|}{$\begin{array}{c}\text { Nicht-Hausbank- } \\
\text { beziehung }\end{array}$} & \multicolumn{2}{|c|}{$\begin{array}{c}\text { Hausbank- } \\
\text { beziehung }\end{array}$} \\
\cline { 2 - 5 } & N & Prozent & N & Prozent \\
\cline { 2 - 5 } & 47 & $19,15 \%$ & 167 & $7,78 \%$ \\
\hline ABL_KRED_VER_EUN & 46 & $8,70 \%$ & 167 & $7,78 \%$ \\
\hline PAR_KRED_VER_EUN & 42 & $76,19 \%$ & 160 & $90,00 \%$ \\
\hline AUS_KRED_HEU_EUN & 47 & $31,91 \%$ & 167 & $18,56 \%$ \\
\hline KRED_VERF_HEU_FRÜ & & &
\end{tabular}

Tab. AN 2-8: Kreditverfügbarkeit differenziert nach Nicht-Haus- vs. Hausbankbeziehungen 


\section{Anhang 3: Prüfung der Voraussetzungen der Faktorenanalyse}

\begin{tabular}{|l|r|r|r|r|r|r|r|r|}
\hline & $\begin{array}{c}\text { ORG } \\
\text { GLAUB }\end{array}$ & $\begin{array}{r}\text { ORG }_{-} \\
\text {WOHL }\end{array}$ & $\begin{array}{c}\text { PERS } \\
\text { GLAUB }\end{array}$ & $\begin{array}{c}\text { PERS } \\
\text { WOHL }\end{array}$ & $\begin{array}{c}\text { ORG_- } \\
\text { GEB }\end{array}$ & $\begin{array}{c}\text { ORG_- } \\
\text { VER }\end{array}$ & $\begin{array}{c}\text { PERS_- } \\
\text { VER }\end{array}$ & $\begin{array}{c}\text { PERS- } \\
\text { VER- } \\
\text { WOHL }\end{array}$ \\
\hline KMO & 0,7770 & 0,6672 & 0,6986 & 0,6484 & 0,6565 & 0,6794 & 0,6730 & 0,7801 \\
\hline Bartlett-Signifikanz & 0,0000 & 0,0000 & 0,0000 & 0,0000 & 0,0000 & 0,0000 & 0,0000 & 0,0000 \\
\hline MSA 1 & 0,7934 & 0,6613 & 0,6780 & 0,6314 & 0,7544 & 0,7492 & 0,7325 & 0,8219 \\
\hline MSA 2 & 0,8162 & 0,7591 & 0,7058 & 0,6531 & 0,6818 & 0,6735 & 0,6705 & 0,7576 \\
\hline MSA 3 & 0,7601 & 0,6272 & 0,7150 & 0,6837 & 0,6681 & $-0,2828$ & 0,6366 & 0,7665 \\
\hline MSA 4 & 0,7515 & 0,7051 & & 0,6446 & 0,6236 & & & 0,7903 \\
\hline
\end{tabular}

Tab. AN 3-1: Prüfung der Voraussetzungen der Faktorenanalyse - BARTLETT-Test und MSA

\begin{tabular}{|l|c|c|c|c|c|c|c|c|}
\hline & $\begin{array}{c}\text { ORG } \\
\text { GLAUB }\end{array}$ & $\begin{array}{c}\text { ORG } \\
\text { WOHL }\end{array}$ & $\begin{array}{c}\text { PERS } \\
\text { GLAUB }\end{array}$ & $\begin{array}{l}\text { PERS } \\
\text { WOHL }\end{array}$ & $\begin{array}{c}\text { ORG_- } \\
\text { GEB }\end{array}$ & $\begin{array}{c}\text { ORG_- } \\
\text { VER }\end{array}$ & $\begin{array}{c}\text { PERS_- } \\
\text { VER }\end{array}$ & $\begin{array}{c}\text { PERS_ } \\
\text { VER } \\
\text { WOHL }\end{array}$ \\
\hline \multirow{4}{*}{$\begin{array}{l}\text { Nicht-Diagonal- } \\
\text { Variablen }\end{array}$} & $-0,2065$ & $-0,1001$ & $-0,2394$ & $-0,2652$ & $-0,0699$ & $-0,1275$ & $-0,1351$ & $-0,0896$ \\
\cline { 2 - 9 } & $-0,1227$ & $-0,2679$ & $-0,2291$ & $-0,1020$ & $-0,0007$ & $-0,2162$ & $-0,2246$ & $-0,1917$ \\
\cline { 2 - 9 } & $-0,1379$ & $-0,0958$ & $-0,1841$ & $-0,2474$ & $-0,0538$ & 0,6402 & $-0,2843$ & $-0,0845$ \\
\cline { 2 - 9 } & $-0,0685$ & $-0,1250$ & & $-0,2122$ & $-0,1304$ & & & $-0,1909$ \\
\cline { 2 - 9 } & $-0,1023$ & $-0,0409$ & & $-0,0564$ & $-0,2477$ & & & $-0,2133$ \\
\cline { 2 - 9 } & $-0,2458$ & $-0,2123$ & & 0,0639 & $-0,2635$ & & & $-0,1286$ \\
\hline $\begin{array}{l}\text { Anteil Nicht- } \\
\text { Diagonal-Werte } \\
\text { ungleich Null } \\
(>0,09)\end{array}$ & $83,33 \%$ & $33,33 \%$ & $0,00 \%$ & $33,33 \%$ & $50,00 \%$ & $0,00 \%$ & $0,00 \%$ & $33,33 \%$ \\
\hline
\end{tabular}

Tab. AN 3-2: Prüfung der Voraussetzungen der Faktorenanalyse - DzIUBAN/SHIRKEY 


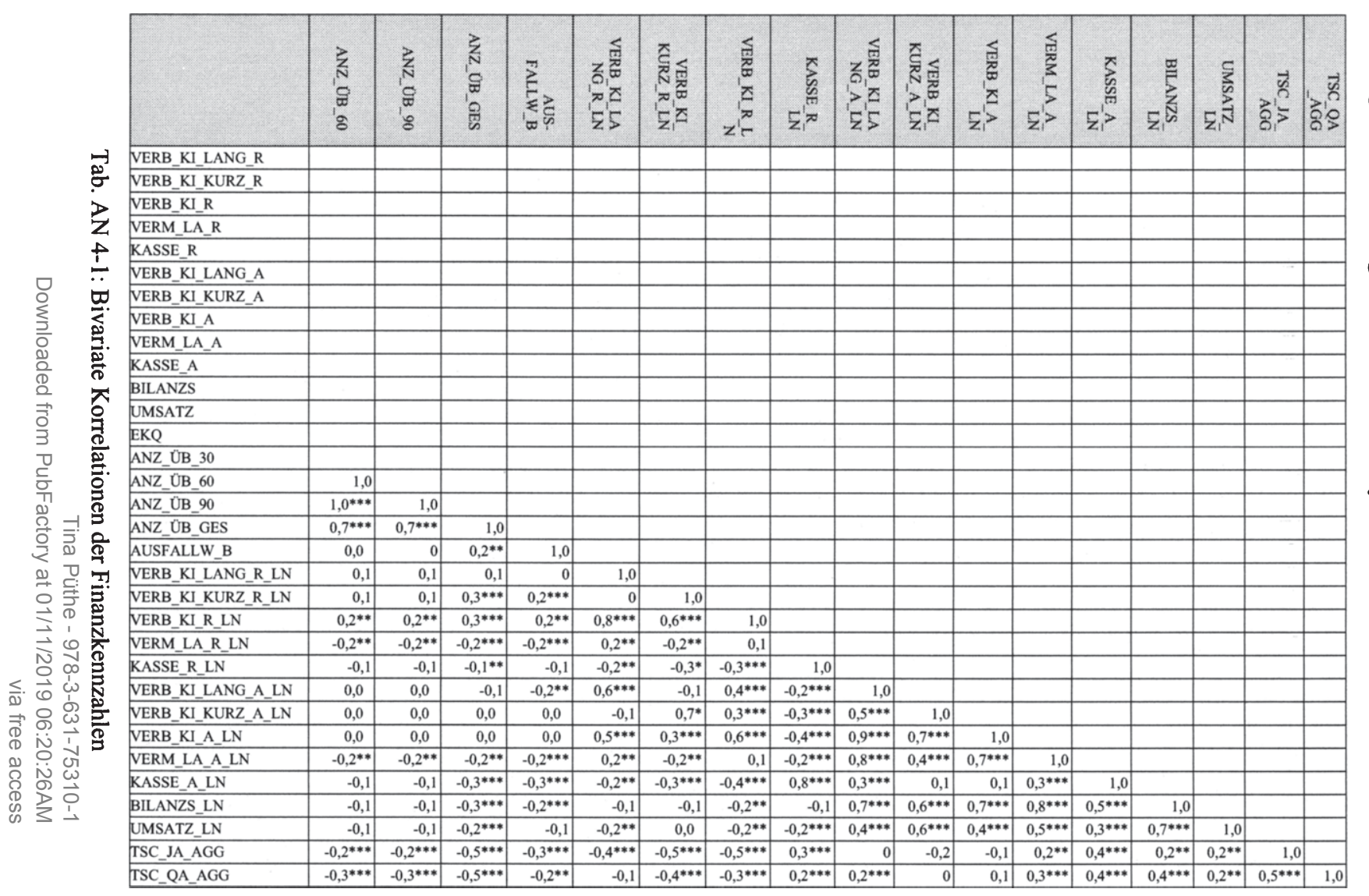




\begin{tabular}{|c|c|c|c|c|c|c|c|c|c|c|c|c|c|c|}
\hline & 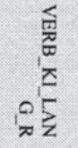 & 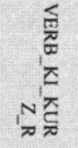 & $\begin{array}{l}\text { 멈 } \\
\text { 苋 } \\
\text { 짐 }\end{array}$ & $\begin{array}{l}\frac{\mathbf{d}}{\pi} \\
\frac{5}{5} \\
\frac{5}{\pi}\end{array}$ & $\begin{array}{l}\sum_{0}^{\pi} \\
\text { 㤩 } \\
\pi\end{array}$ & 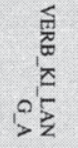 & 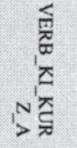 & 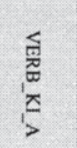 & $\begin{array}{l}\frac{5}{\pi} \\
\frac{1}{3} \\
5 \\
5\end{array}$ & 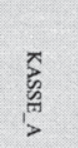 & 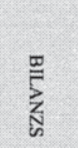 & $\frac{5}{\frac{5}{5}}$ & 囬 & $\begin{array}{l}Z_{\mathrm{N}} \\
\mathrm{C} \\
\mathrm{W} \\
\mathrm{w}\end{array}$ \\
\hline VERB_KI_LANG_R & 1,0 & & & & & & & & & & & & & \\
\hline VERB_KI_KURZ_R & $0,2^{* * *}$ & 1,0 & & & & & & & & & & & & \\
\hline VERB_KI_R & $0,8^{* * *}$ & $0,7^{* * *}$ & 1,0 & & & & & & & & & & & \\
\hline VERM_LA_R & $0,5 * * *$ & $-0,1$ & $0,3^{* * *}$ & 1,0 & & & & & & & & & & \\
\hline KASSE_R & $-0,3 * * *$ & $-0,3^{* * * *}$ & $-0,4^{* * *}$ & $-0,3^{* * * *}$ & 1,0 & & & & & & & & & \\
\hline VERB_KI_LANG_A & $0,3 * * *$ & 0,0 & $0,2^{* * *}$ & 0,1 & $-0,1^{*}$ & 1,0 & & & & & & & & \\
\hline VERB_KI_KURZ_A & 0,1 & $0,4^{* * * *}$ & $0,2^{* * * *}$ & 0,0 & $-0,1^{* *}$ & $0,4^{* * * *}$ & 1,0 & & & & & & & \\
\hline VERB_KI_A & $0,3 * * *$ & 0,1 & $0,3^{* * * *}$ & 0,1 & $-0,1$ & $1,0^{* * *}$ & $0,6^{* * *}$ & 1,0 & & & & & & \\
\hline VERM_LA_A & 0,1 & 0 & 0,1 & $0,4^{* * * *}$ & $-0,1$ & $0,4^{* * * *}$ & $0,5^{* * *}$ & $0,5^{* * *}$ & 1,0 & & & & & \\
\hline KASSE_A & $-0,1^{* *}$ & $-0,1$ & $-0,2^{* *}$ & $-0,1$ & $0,5 * * *$ & 0,1 & 0,1 & 0,1 & $0,2^{* * *}$ & 1,0 & & & & \\
\hline BILANZS & 0,0 & 0,0 & 0,0 & 0,1 & 0,0 & $0,7^{* * * *}$ & $0,5^{* * *}$ & $0,8^{* * *}$ & $0,8^{* * *}$ & $0,4^{* * *}$ & 1,0 & & & \\
\hline UMSATZ & $-0,1$ & 0,1 & $-0,1$ & 0,0 & $-0,1^{* *}$ & $0,2^{* *}$ & $0,6^{* * *}$ & $0,3^{* * *}$ & $0,6^{* * *}$ & 0,1 & $0,6^{* * *}$ & 1,0 & & \\
\hline EKQ & $-0,5 * * *$ & $-0,7 * * *$ & $-0,7 * * *$ & 0,0 & $0,2^{* * * *}$ & 0,0 & 0,0 & 0,0 & $0,1^{* *}$ & $0,2^{* * *}$ & $0,2^{* *}$ & $0,1^{* *}$ & 1,0 & \\
\hline ANZ_OOB_30 & 0,1 & $0,3^{* * *}$ & $0,2^{* * * *}$ & 0,0 & $-0,1$ & 0,0 & 0,1 & 0,0 & $-0,1$ & 0 & $-0,1$ & $-0,1$ & $-0,2^{* * *}$ & 1,0 \\
\hline ANZ_ÜB_60 & 0,0 & $0,2^{* * *}$ & 0,1 & 0,0 & $-0,1$ & 0,0 & 0,1 & 0,0 & $-0,1$ & $-0,1$ & $-0,1$ & $-0,1$ & $-0,2^{* *}$ & $0,8^{* * *}$ \\
\hline ANZ_OB_90 & 0,0 & $0,2^{* * *}$ & 0,1 & 0,0 & $-0,1$ & 0,0 & 0,1 & 0,0 & $-0,1$ & $-0,1$ & $-0,1$ & $-0,1$ & $-0,2^{* *}$ & $0,8^{* * *}$ \\
\hline ANZ_OB_GES & $0,1^{* *}$ & $0,5^{* * *}$ & $0,4^{* * * *}$ & 0,0 & $-0,1^{* *}$ & $-0,1$ & 0,0 & 0,0 & $-0,1^{* *}$ & $-0,1$ & $-0,2^{* *}$ & $-0,1$ & $-0,4 * * *$ & $0,8^{* * *}$ \\
\hline AUSFALLW_B & 0 & $0,4^{* * *}$ & $0,2^{* * *}$ & 0,0 & $-0,1$ & 0,0 & 0,0 & 0,0 & $-0,1$ & 0,0 & $-0,1$ & $-0,1$ & $-0,4^{* * * *}$ & 0,1 \\
\hline VERB_KI_LANG_R_LN & $0,8^{* * * *}$ & 0,1 & $0,7^{* * *}$ & $0,5^{* * *}$ & $-0,3^{* * * *}$ & $0,2^{* * * *}$ & 0,1 & $0,2^{* * * *}$ & 0,1 & $-0,2^{* * *}$ & 0,1 & $-0,1$ & $-0,4 * * *$ & 0,1 \\
\hline VERB_KI_KURZ_R_LN & 0,1 & $0,8^{* * *}$ & $0,5^{* * *}$ & $-0,1$ & $-0,3^{* * *}$ & 0,0 & $0,3^{* * *}$ & 0,1 & 0,0 & $-0,1$ & 0,0 & 0,0 & $-0,4 * * *$ & $0,2^{* * *}$ \\
\hline VERB_KI_R_LN & $0,7^{* * * *}$ & $0,5^{* * *}$ & $0,8^{* * *}$ & $0,3^{* * * *}$ & $-0,4 * * *$ & $0,2^{* *}$ & $0,2^{* * *}$ & $0,2^{* * *}$ & 0,0 & $-0,2^{* * *}$ & 0,0 & $-0,1$ & $-0,5 * * *$ & $0,2^{* * *}$ \\
\hline VERM_LA_R_LN & $0,2^{* * * *}$ & $-0,2^{* *}$ & 0,1 & $0,6^{* * *}$ & $-0,2^{* * * *}$ & $0,3^{* * *}$ & $0,3^{* * *}$ & $0,4^{* * *}$ & $0,7 * * *$ & $0,2^{* * *}$ & $0,6^{* * * *}$ & $0,5^{* * *}$ & $0,2^{* * * *}$ & $-0,2^{* * *}$ \\
\hline KASSE_R_LN & $-0,2^{* * * *}$ & $-0,3^{* * * *}$ & $-0,3^{* * *}$ & $-0,2^{* * * *}$ & $0,8^{* * * *}$ & $-0,1$ & $-0,2^{* * *}$ & $-0,1^{* *}$ & $-0,1$ & $0,3^{* * *}$ & $-0,1$ & $-0,2^{* * *}$ & $0,2^{* * * *}$ & $-0,1$ \\
\hline VERB_KI_LANG_A_LN & $0,4^{* * * *}$ & $-0,1$ & $0,3^{* * * *}$ & $0,4^{* * * *}$ & $-0,3 * * *$ & $0,5 * * *$ & $0,4^{* * * *}$ & $0,5^{* * *}$ & $0,6 * * *$ & $0,2^{* * *}$ & $0,6^{* * * *}$ & $0,4^{* * *}$ & 0,1 & $-0,1$ \\
\hline VERB_KI_KURZ_A_LN & $-0,1$ & $0,4^{* * *}$ & $0,2^{* *}$ & $-0,1$ & $-0,3^{* * * *}$ & $0,3^{* * * *}$ & $0,6^{* * * *}$ & $0,4^{* * * *}$ & $0,4^{* * * *}$ & $0,2^{* *}$ & $0,5^{* * *}$ & $0,5^{* * *}$ & 0,0 & 0,0 \\
\hline VERB_KI_A_LN & $0,4^{* * * *}$ & $0,2^{* * *}$ & $0,4^{* * * *}$ & $0,3^{* * * *}$ & $-0,4^{* * * *}$ & $0,4^{* * * *}$ & $0,5^{* * * *}$ & $0,5^{* * *}$ & $0,6^{* * * *}$ & 0,1 & $0,5^{* * *}$ & $0,4^{* * * *}$ & 0,0 & 0,0 \\
\hline VERM_LA_A_LN & $0,2^{* * *}$ & $-0,2^{* *}$ & 0,1 & $0,6^{* * * *}$ & $-0,2^{* * *}$ & $0,3^{* * *}$ & $0,3^{* * *}$ & $0,4^{* * *}$ & $0,7^{* * *}$ & $0,2^{* * *}$ & $0,6^{* * * *}$ & $0,5^{* * *}$ & $0,2^{* *}$ & $-0,2^{* * * *}$ \\
\hline KASSE_A_LN & $-0,3 * * *$ & $-0,4^{* * *}$ & $-0,4^{* * *}$ & $-0,1$ & $0,6^{* * *}$ & $0,1^{* *}$ & 0 & $0,1^{* *}$ & $0,3^{* * * *}$ & $0,5^{* * *}$ & $0,4^{* * *}$ & $0,3^{* * *}$ & $0,4^{* * * *}$ & $-0,2^{* * *}$ \\
\hline BILANZS_LN & $-0,1$ & $-0,2^{* * * *}$ & $-0,2^{* *}$ & 0 & 0 & $0,3^{* * * *}$ & $0,4^{* * *}$ & $0,4^{* * *}$ & $0,6^{* * * *}$ & $0,3^{* * * *}$ & $0,7^{* * * *}$ & $0,6^{* * * *}$ & $0,3 * * *$ & $-0,2^{* *}$ \\
\hline UMSATZ_LN & $-0,2^{* * * *}$ & 0,0 & $-0,2^{* *}$ & $-0,2^{* *}$ & $-0,1$ & 0,1 & $0,4^{* * * *}$ & $0,2^{* * *}$ & $0,3^{* * * *}$ & 0,1 & $0,4^{* * * *}$ & $0,8^{* * *}$ & $0,2^{* * * *}$ & $-0,2^{* * *}$ \\
\hline TSC_JA_AGG & $-0,4^{* * * *}$ & $-0,5^{* * *}$ & $-0,6^{* * *}$ & 0 & $0,3^{* * *}$ & $-0,1$ & $-0,1$ & $-0,1$ & 0,1 & $0,2^{* * *}$ & 0,1 & $0,2^{* *}$ & $0,7 * * *$ & $-0,3^{* * *}$ \\
\hline TSC_QA_AGG & $-0,1$ & $-0,5 * * *$ & $-0,3 * * *$ & 0,1 & $0,2^{* * * *}$ & 0,0 & 0,0 & 0,0 & $0,2^{* * *}$ & $0,2^{* * *}$ & $0,2^{* *}$ & $0,2 * * *$ & $0,4 * * *$ & $-0,4^{* * * *}$ \\
\hline
\end{tabular}




\begin{tabular}{|c|c|c|c|c|c|c|c|}
\hline Korrelationen & PROD & HAND & DIENST & BAU & $\begin{array}{c}\text { KAP- } \\
\text { GESELL }\end{array}$ & ALTER & $\begin{array}{c}\text { ALTER } \\
\text { LN }\end{array}$ \\
\hline PROD & 1,0000 & $-0,3564$ & $-0,2585$ & $-0,3227$ & 0,0051 & $-0,1244^{*}$ & $-0,1530^{* *}$ \\
\hline HAND & $-0,3564$ & 1,0000 & $-0,2680$ & $-0,3346$ & 0,0084 & $0,1915^{* * *}$ & $0,1903^{* * *}$ \\
\hline DIENST & $-0,2585$ & $-0,2680$ & 1,0000 & $-0,2427$ & $-0,0903$ & $-0,1292 * *$ & $-0,1354^{* *}$ \\
\hline BAU & $-0,3227$ & $-0,3346$ & $-0,2427$ & 1,0000 & 0,0521 & $-0,0044$ & 0,0299 \\
\hline KAPGESELL & 0,0051 & 0,0084 & $-0,0903$ & 0,0521 & 1,0000 & $-0,2044 * *$ & $-0,1487^{* *}$ \\
\hline ALTER & $-0,1244^{*}$ & 0,1915 & $-0,1292$ & $-0,0044$ & $-0,2044^{* * *}$ & 1,0000 & \\
\hline VERB_KI_LANG_R & 0,0011 & 0,0876 & $0,1366^{* *}$ & $-0,2288^{* * *}$ & $-0,2639 * * *$ & 0,0981 & $0,0365^{* *}$ \\
\hline VERB_KI_KURZ_R & $-0,0461$ & $0,2009^{* * *}$ & 0,0173 & $-0,1013$ & $-0,1198^{*}$ & 0,0087 & 0,0590 \\
\hline VERB_KI_R & $-0,0240$ & $0,1737^{* *}$ & 0,1111 & $-0,2252^{* * *}$ & $-0,2614^{* * *}$ & $0,0778^{* *}$ & 0,0579 \\
\hline VERM_LA_R & 0,0545 & $-0,0954$ & $0,1379^{* *}$ & $-0,1924^{* * *}$ & $-0,2647^{* * *}$ & 0,2215 & $0,1833^{* * *}$ \\
\hline KASSE_R & $-0,0742$ & $-0,1404^{* *}$ & $0,1597^{* *}$ & 0,0026 & $0,1705^{* *}$ & $-0,1769^{*}$ & $-0,1473^{* *}$ \\
\hline VERB_KI_LANG_A & $-0,0358$ & 0,0190 & $0,1306^{*}$ & $-0,0971$ & 0,0354 & $0,0687^{*}$ & 0,0958 \\
\hline VERB_KI_KURZ_A & $-0,0551$ & $0,2863^{* * *}$ & $-0,0778$ & $-0,1382^{* *}$ & 0,0127 & 0,0469 & 0,0996 \\
\hline VERB_KI_A & $-0,0470$ & 0,1033 & 0,0865 & $-0,1241$ & 0,0338 & 0,0722 & 0,1112 \\
\hline VERM_LA_A & 0,0965 & 0,0371 & $-0,0024$ & $-0,1793^{* * *}$ & $-0,0584$ & 0,1655 & $0,2062^{* * *}$ \\
\hline KASSE_A & 0,0348 & $-0,0759$ & $-0,0048$ & $-0,0729$ & 0,0253 & $-0,0131$ & 0,0148 \\
\hline BILANZS & 0,0540 & 0,0802 & $-0,0038$ & $-0,1562 * *$ & 0,0202 & 0,1323 & $0,1918^{* * *}$ \\
\hline UMSATZ & 0,0203 & $0,3032^{* * *}$ & $-0,1842^{* * *}$ & $-0,1672 * *$ & 0,0416 & 0,1292 & $0,1922^{* * *}$ \\
\hline EKQ & 0,0476 & $-0,0363$ & $-0,1445^{* *}$ & 0,0743 & $0,1969^{* * *}$ & 0,0189 & 0,0276 \\
\hline ANZ_ÜB_30 & $-0,0677$ & 0,0074 & 0,0983 & 0,0349 & $-0,0719$ & $-0,0909$ & $-0,0757$ \\
\hline ANZ_ÜB_60 & $-0,0859$ & 0,0082 & 0,0669 & 0,0595 & $-0,1038$ & $-0,0702$ & $-0,0808$ \\
\hline ANZ_ÜB_90 & $-0,0859$ & 0,0082 & 0,0669 & 0,0595 & $-0,1038$ & $-0,0702 * * *$ & $-0,0808$ \\
\hline ANZ_ÜB_GES & $-0,0903$ & 0,0585 & 0,0928 & $-0,0250$ & $-0,1244^{*}$ & $-0,0744 * *$ & $-0,0713$ \\
\hline VERB_KI_LANG_R_LN & 0,0780 & $-0,0815$ & 0,0798 & $-0,1361^{*}$ & $-0,3395^{* * *}$ & 0,0478 & $-0,0068$ \\
\hline VERB_KI_KURZ_R_LN & $-0,0754$ & $0,1761^{* *}$ & $-0,0879$ & $-0,0542$ & 0,0034 & $-0,0517 * *$ & $-0,0160$ \\
\hline VERB_KI_R_LN & $-0,0375$ & 0,1387 & 0,0343 & $-0,1660^{* *}$ & $-0,2194^{* * *}$ & $0,0549^{* * *}$ & 0,0335 \\
\hline VERM_LA_R_LN & $0,1156^{*}$ & $0,1337^{* *}$ & $-0,1060$ & $-0,2724^{* * *}$ & $-0,0698$ & 0,2479 & $0,2753^{* * *}$ \\
\hline KASSE_R_LN & $-0,0960$ & $-0,1416^{* *}$ & $0,1449 * *$ & 0,0580 & 0,0683 & $-0,1703^{* *}$ & $-0,1165$ \\
\hline VERB_KI_LANG_A_LN & 0,0625 & 0,0801 & $-0,0114$ & $-0,2530^{* * *}$ & $-0,1510$ & $0,1181 * *$ & 0,1201 \\
\hline VERB_KI_KURZ_A_LN & 0,0260 & $0,2711 * * *$ & $-0,1634^{* *}$ & $-0,2344^{* * *}$ & 0,0757 & 0,0459 & $0,1387^{*}$ \\
\hline VERB_KI_A_LN & 0,0541 & $0,2309^{* * *}$ & $-0,0477$ & $-0,3336 * * *$ & $-0,0926$ & 0,1597 & $0,1896^{* *}$ \\
\hline VERM_LA_A_LN & 0,1156 & $0,1337^{* *}$ & $-0,1060$ & $-0,2724^{* * *}$ & $-0,0698$ & $0,2479 * * *$ & $0,2753^{* *}$ \\
\hline KASSE_A_LN & $-0,0230$ & $-0,0353$ & 0,0552 & $-0,0780$ & 0,0624 & $-0,0441$ & 0,0353 \\
\hline BILANZS_LN & 0,1121 & $0,1561^{* *}$ & $-0,1659^{* *}$ & $-0,2045^{* * *}$ & 0,0910 & $0,1667^{* *}$ & $0,2346^{* * *}$ \\
\hline UMSATZ_LN & 0,0704 & $0,2817^{* * *}$ & $-0,2733^{* * *}$ & $-0,1680^{* *}$ & $0,1246^{*}$ & $0,1418^{* *}$ & $0,1939 * *$ \\
\hline AUSFALLW_B & $0,1436^{* *}$ & $-0,0441$ & $-0,0270$ & $-0,0619$ & $-0,0398$ & $-0,0371$ & $-0,0399$ \\
\hline TSC_JA_AGG & 0,1110 & $-0,1391$ & $-0,0158$ & 0,0147 & $0,1770^{* *}$ & $-0,0087$ & 0,0396 \\
\hline TSC_QA_AGG & 0,1052 & $-0,0258$ & $-0,0380$ & $-0,0802$ & $0,1251^{*}$ & 0,0296 & 0,1073 \\
\hline
\end{tabular}

Tab. AN 4-2: Bivariate Korrelationen der Finanzkennzahlen mit den unternehmensbezogenen Variablen 


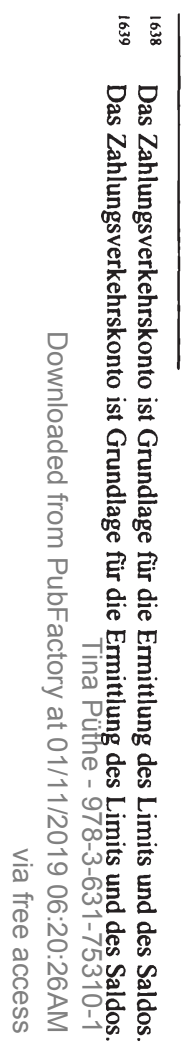

\begin{tabular}{|c|c|c|c|c|c|c|c|c|c|c|}
\hline & 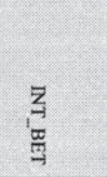 & 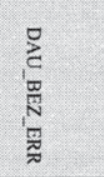 & 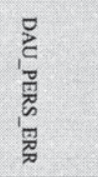 & 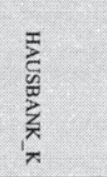 & $\begin{array}{l}0 \\
\frac{0}{\pi} \\
0 \\
0\end{array}$ & $\begin{array}{l}\frac{0}{x} \\
\frac{5}{3} \\
\bar{x}\end{array}$ & 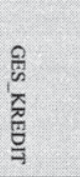 & $\begin{array}{l}\sum_{-1} \\
\sum^{\prime} \\
\sum_{\pi} \\
\bar{z} \\
\bar{z}\end{array}$ & 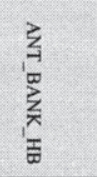 & 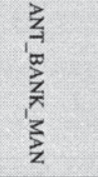 \\
\hline INT_BET & 1,0000 & & & & & & & & & \\
\hline DAU_BEZ_ERR & 0,0247 & 1,0000 & & & & & & & & \\
\hline DAU_PERS_ERR & $-0,01$ & $0,3114^{* * *}$ & 1,0000 & & & & & & & \\
\hline HAUSBANK_K & $-0,0353$ & 0,0657 & $-0,0329$ & 1,0000 & & & & & & \\
\hline GK_SALD & $-0,1265$ & 0,0429 & $-0,0197$ & 0,0196 & 1,0000 & & & & & \\
\hline GK_LIM_EX & $-0,018$ & 0,0886 & 0,0192 & 0,0968 & $-0,1585^{* *}$ & 1,0000 & & & & \\
\hline GES_KREDIT & 0,0143 & 0,1068 & 0,0171 & 0,1038 & $0,1433^{* *}$ & 0,5332 & 1,0000 & & & \\
\hline ANT_BANK_IN & $-0,0546$ & 0,0232 & $-0,0474$ & $0,6309 * * *$ & 0,0961 & 0,0323 & 0,0360 & 1,0000 & & \\
\hline ANT_BANK_HB & $0,2866^{* * *}$ & 0,0090 & $-0,2354^{* *}$ & $-0,2473^{* *}$ & 0,1757 & $-0,1229$ & 0,0893 & $-0,3905^{* * *}$ & 1,0000 & \\
\hline ZINS_VERFÜG & $-0,2639 * * *$ & 0,1238 & $-0,0196$ & 0,0437 & 0,1339 & $-0,073$ & $-0,015$ & $-0,0080$ & $-0,0440$ & 0,0851 \\
\hline SICH_Q & $-0,0008$ & $0,1553^{* *}$ & $0,1494^{* *}$ & $0,2643^{* * *}$ & $-0,2077 * * *$ & 0,0483 & 0,0483 & $0,3242 * * *$ & $-0,1601$ & $-0,1195$ \\
\hline ANT_ZV & $-0,0108$ & 0,0723 & $-0,0046$ & $0,7740^{* * *}$ & 0,0232 & 0,082 & 0,0392 & $0,6561^{* * *}$ & $-0,2614^{* *}$ & $0,3985^{* * *}$ \\
\hline MITGLIED & 0,0607 & $0,3154^{* * *}$ & $0,1355^{* *}$ & 0,1197 & 0,0027 & 0,0299 & 0,0690 & 0,0775 & $-0,0252$ & $-0,0397$ \\
\hline DARL & $-0,0136$ & $0,1494^{* *}$ & $-0,0316$ & $0,2916^{* * *}$ & $-0,1090$ & $-0,1386$ & $-0,0608$ & $0,2650^{* * *}$ & 0,0218 & $0,2017 * * *$ \\
\hline ZV_KK & 0,0216 & 0,1002 & 0,0711 & 0,1275 & ${ }_{-}^{1639}$ & 1638 & 0 & 0,1229 & 0,0244 & $-0,1835^{* *}$ \\
\hline VERM_ANL & $-0,0494$ & 0,1093 & 0,1070 & $0,3482^{* * *}$ & 0,0149 & 0,0608 & 0,0860 & $0,2812^{* * *}$ & $-0,1714$ & $-0,1674^{* *}$ \\
\hline VERSICH & 0,0157 & $-0,0182$ & 0,0638 & $0,1473^{* *}$ & $-0,0738$ & 0,0028 & $-0,0560$ & $0,1816^{* * *}$ & $-0,1988$ & $0,2103^{* * *}$ \\
\hline PRIVATKONT & $-0,0285$ & $0,1675^{* *}$ & $0,1436 * *$ & $0,2546^{* * *}$ & $-0,0169$ & 0,0505 & 0,0132 & 0,1356 & $-0,0744$ & $-0,1700^{* *}$ \\
\hline EL & $0,3938^{* * *}$ & $-0,1129$ & $-0,0773$ & $-0,2091 * * *$ & $-0,0362$ & $-0,0570$ & $-0,0506$ & $-0,2364 * * *$ & $0,3100^{* * *}$ & $-0,0109$ \\
\hline
\end{tabular}




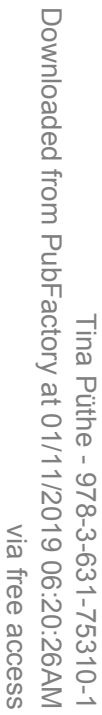




\begin{tabular}{|c|c|c|c|c|c|c|c|c|}
\hline & $\begin{array}{c}\text { ORG_- } \\
\text { GLAUB }\end{array}$ & $\begin{array}{l}\text { ORG_- } \\
\text { WOHL }\end{array}$ & $\begin{array}{c}\text { ORG } \\
\text { GEB }\end{array}$ & $\begin{array}{c}\text { ORG } \\
\text { VER }\end{array}$ & $\begin{array}{l}\text { PERS_- } \\
\text { GLAUB }\end{array}$ & $\begin{array}{l}\text { PERS_- } \\
\text { WOHL }\end{array}$ & $\begin{array}{c}\text { PERS } \\
\text { VER }\end{array}$ & $\begin{array}{l}\text { PERS_- } \\
\text { VER_- } \\
\text { WOHL }\end{array}$ \\
\hline VERB_KI_LANG_R & $0,2200 * * *$ & 0,0384 & $-0,2372 * * *$ & $-0,0520$ & 0,1109 & $-0,0174$ & $-0,0400$ & $-0,0234$ \\
\hline VERB_KI_KURZ_R & $0,3353 * * *$ & 0,0265 & $-0,2401 * * *$ & $-0,0046$ & $0,2357 * * *$ & 0,0128 & 0,0156 & 0,0240 \\
\hline VERB_KI_R & $0,3387^{* * *}$ & 0,0427 & $-0,3026 * * *$ & $-0,0416$ & $0,2047^{* * *}$ & $-0,0069$ & $-0,0222$ & $-0,0052$ \\
\hline VERM_LA_R & 0,0281 & $-0,0106$ & $-0,0270$ & $-0,0671$ & 0,0732 & 0,0078 & $-0,0774$ & $-0,0484$ \\
\hline KASSE_R & $-0,2055^{* * *}$ & $-0,0788$ & $0,1953 * * *$ & 0,0042 & 0,0311 & $-0,0138$ & 0,0319 & 0,0241 \\
\hline VERB_KI_LANG_A & $-0,0340$ & $-0,0795$ & 0,0320 & 0,0659 & $-0,1084$ & $-0,0396$ & $-0,0453$ & $-0,0477$ \\
\hline VERB_KI_KURZ_A & $-0,0200$ & $-0,0630$ & $-0,0588$ & $-0,0077$ & $-0,1045$ & $-0,0506$ & $-0,0603$ & $-0,0353$ \\
\hline VERB_KI_A & $-0,0348$ & $-0,0863$ & 0,0091 & 0,0532 & $-0,1232$ & $-0,0488$ & $-0,0566$ & $-0,0510$ \\
\hline VERM_LA_A & $-0,1688^{* *}$ & $-0,1043$ & $0,1889^{* * *}$ & 0,0460 & $-0,1356$ & $-0,1042$ & $-0,0829$ & $-0,0927$ \\
\hline KASSE_A & $-0,1001$ & $-0,0982$ & $0,2120 * * *$ & 0,0814 & $-0,0622$ & $-0,0632$ & $-0,0233$ & $-0,0500$ \\
\hline EKQ & $-0,3646$ & $-0,0790$ & $0,3227^{* * *}$ & $-0,0047$ & $-0,2674$ & $-0,0538$ & $-0,0554$ & $-0,0602$ \\
\hline BILANZS & $-0,1624^{* *}$ & $-0,1050$ & $0,2054 * \cdots$ & 0,1119 & $-0,1925^{* * *}$ & $-0,0906$ & $-0,0301$ & $-0,0610$ \\
\hline UMSATZ & $-0,1814^{* * *}$ & $-0,1469 * *$ & 0,0627 & $-0,0513$ & $-0,2409 * * *$ & $-0,1254$ & $-0,0635$ & $-0,0945$ \\
\hline ANZ_OB_30 & $0,2190^{* * *}$ & $-0,0309$ & $-0,0807$ & $-0,0119$ & $0,1931^{* * *}$ & 0,1174 & 0,0528 & 0,1048 \\
\hline ANZ_UB_60 & $0,1747^{* *}$ & $-0,0248$ & $-0,0739$ & 0,0226 & $0,2069 * * *$ & 0,0976 & 0,0576 & 0,0848 \\
\hline ANZ_OB_90 & $0,1747^{* *}$ & $-0,0248$ & $-0,0739$ & 0,0226 & $0,2069 * * *$ & 0,0976 & 0,0576 & 0,0848 \\
\hline ANZ_OB_GES & $0,3592 * * *$ & 0,0115 & $-0,1938 * * *$ & 0,0342 & $0,3301 * * *$ & 0,1203 & 0,0557 & 0,1125 \\
\hline AUSFALLW_B & $0,4128 * * *$ & 0,0808 & $-0,2985^{* * *}$ & 0,0775 & $0,3020 * * *$ & 0,0668 & 0,0367 & 0,0549 \\
\hline VERB_KI_LANG_R_LN & $0,1818^{* *}$ & $-0,0100$ & $-0,1085$ & 0,0067 & 0,1189 & $-0,0224$ & $-0,1014$ & $-0,0587$ \\
\hline VERB_KI_KURZ_R_LN & $0,3605 * * *$ & 0,1095 & $-0,1597$ & $-0,0060$ & $0,2302 * * *$ & 0,0290 & 0,0486 & 0,0213 \\
\hline VERB_KI_R_LN & $0,2873 * * *$ & 0,0366 & $-0,2188 * * *$ & $-0,0577$ & 0,1338 & $-0,0529$ & $-0,0833$ & $-0,0710$ \\
\hline VERM_LA_R_LN & $-0,1521 * *$ & $-0,0888$ & $0,1406 * *$ & $-0,0254$ & $-0,1810^{* * *}$ & $-0,1395 * *$ & $-0,1539 * *$ & $-0,1723 * *$ \\
\hline KASSE_R_LN & $-0,1957^{* * *}$ & $-0,0835$ & $0,2215^{* * *}$ & 0,0715 & 0,0814 & $-0,0244$ & 0,0523 & 0,0357 \\
\hline VERB_KI_LANG_A_LN & $-0,0501$ & $-0,1227$ & 0,1180 & 0,0655 & $-0,1681^{* *}$ & $-0,1023$ & $-0,1957^{* *}$ & $-0,1776 * *$ \\
\hline VERB_KI_KURZ_ $\Lambda \_L N$ & 0,0718 & $-0,0322$ & 0,0512 & $-0,0172$ & $-0,0952$ & $-0,0770$ & $-0,0636$ & $-0,0975$ \\
\hline VERB_KI_A_LN & $-0,0104$ & $-0,0823$ & 0,0608 & $-0,0215$ & $-0,1603 * *$ & $-0,1395$ & $-0,1644^{* *}$ & $-0,1754^{* *}$ \\
\hline VERM_LA_A_LN & $-0,1521^{* *}$ & $-0,0888$ & $0,1406 * *$ & $-0,0254$ & $-0,1810^{* * *}$ & $-0,1395 * *$ & $-0,1539 * *$ & $-0,1723^{* *}$ \\
\hline KASSE_A_LN & $-0,3081^{* * *}$ & $-0,1669 * *$ & $0,3404 * * *$ & 0,1144 & $-0,1199$ & $-0,0930$ & $-0,0266$ & $-0,0655$ \\
\hline BILANZS_LN & $-0,1961^{* * *}$ & $-0,1487^{* *}$ & $0,2200 * * *$ & 0,0275 & $-0,2606 * * *$ & $-0,1636 * *$ & $-0,1585 * *$ & $-0,1979 * * *$ \\
\hline UMSATZ_LN & $-0,1765^{* *}$ & $-0,1636^{* *}$ & 0,0948 & $-0,0575$ & $-0,3356 * * *$ & $-0,1773^{* *}$ & $-0,0685$ & $-0,1284$ \\
\hline TSC_JA_AGG & $-0,4471 * * *$ & $-0,0633$ & $0,4166 * * *$ & $-0,0049$ & $-0,2724^{* * *}$ & $-0,0790$ & 0,0022 & $-0,0270$ \\
\hline TSC_QA_AGG & $-0,3881^{* * *}$ & $-0,1236$ & $0,3611 * * *$ & $-0,0621$ & $-0,2706^{* * *}$ & $-0,0747$ & $-0,1354$ & $-0,1200$ \\
\hline
\end{tabular}

Tab. AN 4-4: Bivariate Korrelationen der verhaltenswissenschaftlichen Variablen mit den Finanzkennzahlen 


\begin{tabular}{|l|c|c|c|c|c|c|c|c|}
\hline & $\begin{array}{c}\text { ORG_- } \\
\text { GLAUB }\end{array}$ & $\begin{array}{c}\text { ORG_ } \\
\text { WOHL }\end{array}$ & $\begin{array}{c}\text { ORG_ } \\
\text { GEB }\end{array}$ & $\begin{array}{c}\text { ORG_- } \\
\text { VER }\end{array}$ & $\begin{array}{c}\text { PER__ } \\
\text { GL_AUB }\end{array}$ & $\begin{array}{c}\text { PERS_ } \\
\text { WOHL_ }\end{array}$ & $\begin{array}{c}\text { PERS_ } \\
\text { VER }\end{array}$ & $\begin{array}{c}\text { PER_VER } \\
\text { WOHL }\end{array}$ \\
\hline PROD & $-0,0809$ & $-0,1464^{* *}$ & $-0,0149$ & 0,0389 & $-0,1172^{*}$ & $-0,1078$ & $-0,1288^{*}$ & $-0,1215^{*}$ \\
\hline HAND & 0,0605 & 0,0362 & $-0,1267^{*}$ & $-0,1138^{*}$ & $-0,0449$ & $-0,0889$ & 0,0273 & $-0,0386$ \\
\hline DIENST & 0,0356 & 0,0930 & 0,0480 & 0,0298 & $0,1365^{*}$ & $0,1443^{* *}$ & 0,0333 & 0,0866 \\
\hline BAU & 0,0439 & 0,0845 & 0,0381 & 0,0958 & 0,0882 & 0,0617 & 0,0694 & 0,0666 \\
\hline KAPGESELL & $-0,1110$ & 0,0335 & $0,2432^{* * *}$ & 0,0789 & $-0,0618$ & $0,1614^{* *}$ & 0,0541 & 0,0725 \\
\hline ALTER & $-0,1301^{*}$ & $-0,0571$ & 0,0711 & $-0,1331^{*}$ & $-0,1060$ & $-0,1502^{* *}$ & $-0,0713$ & $-0,1245^{*}$ \\
\hline ALTER_LN & $-0,1279^{*}$ & $-0,0652$ & $0,1542^{* *}$ & $-0,1577^{* *}$ & $-0,0948$ & $-0,1603^{* *}$ & $-0,0892$ & $-0,1371^{* *}$ \\
\hline
\end{tabular}

Tab. AN 4-5: Korrelationsanalyse der verhaltenswissenschaftlichen Variablen mit den unternehmensbezogenen Variablen 


\begin{tabular}{|c|c|c|c|c|c|c|c|c|}
\hline 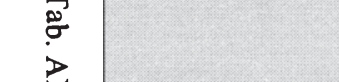 & $\begin{array}{l}\text { ORG_ } \\
\text { GLAUB }\end{array}$ & $\begin{array}{l}\text { ORG_ } \\
\text { WOHL }\end{array}$ & $\begin{array}{l}\text { ORG_- } \\
\text { GEB }\end{array}$ & $\begin{array}{l}\text { ORG_ } \\
\text { VER }\end{array}$ & $\begin{array}{l}\text { PERS_ } \\
\text { GLAUB }\end{array}$ & $\begin{array}{l}\text { PERS_- } \\
\text { WOHL }\end{array}$ & $\begin{array}{l}\text { PERS } \\
\text { VER }\end{array}$ & $\begin{array}{l}\text { PERS_ } \\
\text { VER_WOHL }\end{array}$ \\
\hline INT_BET & $0,2874^{* * *}$ & 0,0521 & $-0,1988^{* * *}$ & $-0,0041$ & $0,1447 * *$ & 0,0831 & 0,0691 & 0,0906 \\
\hline DAU_BEZ_ERR & $-0,0971$ & $-0,0846$ & $0,1265^{*}$ & $-0,2089 * * *$ & $-0,0668$ & $-0,1662^{* *}$ & $-0,1031$ & $-0,1548^{* *}$ \\
\hline DAU_PERS_ERR & $-0,0863$ & $-0,1429 * *$ & 0,0934 & $-0,1057$ & $-0,1516^{* *}$ & $-0,2343 * * *$ & $-0,2369 * * *$ & $-0,2574^{* * *}$ \\
\hline DAU_BEZ_ERR_LN & $-0,0865$ & $-0,0932$ & $0,1356^{* *}$ & $-0,2245^{* * *}$ & $-0,0307$ & $-0,1464 * *$ & $-0,1062$ & $-0,1384$ \\
\hline DAU_PERS_ERR_LN & $-0,1182$ & $-0,1487^{* *}$ & 0,0574 & $-0,1181$ & $-0,1494^{* *}$ & $-0,2713^{* * *}$ & $-0,2535^{* * *}$ & $-0,272$ \\
\hline HAUSBANK_K & $-0,1011$ & $-0,2930^{* * *}$ & $-0,2047^{* * *}$ & $-0,3446^{* * *}$ & $-0,1278$ & $-0,1485^{* *}$ & $-0,2513^{* * *}$ & $-0,2023^{* * *}$ \\
\hline GK_SALD & $-0,1668^{* *}$ & $-0,0425$ & $0,3003^{* * *}$ & 0,0417 & $-0,0594$ & $-0,0194$ & 0,105 & 0,0445 \\
\hline GK_LIM_EX & $-0,1819^{* * *}$ & $-0,1695^{* *}$ & $-0,0154$ & $-0,0607$ & $-0,1699^{* *}$ & $-0,1315$ & $-0,1349^{*}$ & $-0,1413^{* *}$ \\
\hline GES_KREDIT & $-0,1376^{* *}$ & $-0,1773^{* * *}$ & $-0,0033$ & $-0,0433$ & $-0,1854^{* * *}$ & $-0,1885^{* * *}$ & $-0,1375^{* *}$ & $-0,1839^{* * *}$ \\
\hline ANT_BANK_IN & 0,0231 & $-0,3155^{* * *}$ & $-0,2245^{* * *}$ & $-0,3106^{* * *}$ & $-0,062$ & $-0,1850^{* * *}$ & $-0,2481^{* * *}$ & $-0,2175 * * *$ \\
\hline ANT_BANK_HB & $0,2073^{*}$ & $0,2121^{*}$ & $-0,0564$ & $0,2134^{*}$ & $0,2640^{* *}$ & $0,2120^{*}$ & $0,2961^{* * *}$ & $0,2382^{* *}$ \\
\hline ANZ_B_AGG & $-0,1334^{*}$ & 0,0577 & $0,1805^{* *}$ & 0,0281 & $-0,0896$ & 0,0058 & 0,0656 & 0,0262 \\
\hline ZINS_VERFÜG & $-0,1802^{* * *}$ & 0,0594 & $0,3468^{* * *}$ & $0,1439 * *$ & 0,0036 & 0,0741 & $0,2278^{* * *}$ & $0,1673^{* *}$ \\
\hline SICH_Q & $0,1596^{* *}$ & $-0,0951$ & $-0,2656^{* * *}$ & $-0,1586^{* *}$ & $-0,0294$ & $-0,1788^{* *}$ & $-0,2041^{* * *}$ & $-0,1636^{* *}$ \\
\hline ANT_ZV & $-0,0765$ & $-0,3075^{* * *}$ & $-0,2994^{* * *}$ & $-0,3585^{* * *}$ & $-0,1074$ & $-0,1563^{* *}$ & $-0,2569 * * *$ & $-0,2320^{* * *}$ \\
\hline 总 & 0,1093 & $-0,0877$ & $-0,2311^{* * *}$ & $-0,1620^{* *}$ & $-0,0947$ & $-0,1585^{* *}$ & $-0,1183$ & $-0,0874$ \\
\hline ZV_KK & 0,0191 & 0,0438 & $-0,0438$ & $-0,0862$ & 0,0715 & $-0,0001$ & $-0,0104$ & 0,0022 \\
\hline VERM_ANL & $-0,1062$ & $-0,2099 * * *$ & $-0,0348$ & $-0,2832^{* * *}$ & $-0,0259$ & $-0,2146^{* * *}$ & $-0,3346^{* * *}$ & $-0,2896^{* * *}$ \\
\hline VERSICH & 0,0495 & $-0,1268^{*}$ & $-0,2353^{* * *}$ & $-0,2090^{* * *}$ & $-0,043$ & $-0,0956$ & $-0,2039 * * *$ & $-0,1362^{* *}$ \\
\hline PRIVATKONT & $-0,0886$ & $-0,1146^{*}$ & 0,0407 & $-0,1537^{* *}$ & $-0,0179$ & $-0,1251^{*}$ & $-0,2220^{* * *}$ & $-0,1770^{* *}$ \\
\hline 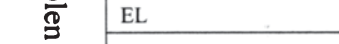 & $0,2421^{* * *}$ & $0,1306^{*}$ & $-0,0424$ & $0,1439^{* *}$ & $0,2197^{* * *}$ & $0,1702^{* *}$ & $0,1553^{* *}$ & $0,1608^{* *}$ \\
\hline DIST_UNT & 0,0896 & 0,0159 & $-0,0072$ & 0,0399 & 0,0572 & $-0,0607$ & 0,0274 & 0,0383 \\
\hline ANZ_BER_J & $-0,0031$ & $-0,2931^{* * *}$ & $-0,2734 * * *$ & $-0,1914^{* * *}$ & $-0,1645^{* *}$ & $-0,2792^{* * *}$ & $-0,3007 * * *$ & $-0,2932^{* * *}$ \\
\hline ANZ_KONT_J & 0,0012 & $-0,1396^{* *}$ & $-0,1477^{* *}$ & $-0,1213$ & $-0,0439$ & $-0,1271$ & $-0,2023^{* * *}$ & $-0,1845^{* * *}$ \\
\hline
\end{tabular}




\begin{tabular}{|c|c|c|c|c|c|c|c|c|c|}
\hline & $\stackrel{m}{\frac{m}{2}}$ & $\begin{array}{l}\mathscr{n}_{1} \\
\text { के }^{\prime} \\
\frac{\infty}{1}\end{array}$ & $\begin{array}{l}\frac{6}{5} \\
\frac{0}{4} \\
\frac{1}{4}\end{array}$ & $\frac{c}{\frac{c}{2}}$ & $\frac{6}{\infty}$ & $\frac{9}{\infty}$ & $\begin{array}{l}\frac{5}{3} \\
\frac{6}{2} \\
\frac{2}{2} \\
\frac{1}{2}\end{array}$ & $\frac{1}{2} \frac{1}{2}$ & $\frac{0}{3}$ \\
\hline FKB_J030 & 1,0000 & & & & & & & & \\
\hline FKB_30_50 & $-0,3988 * * *$ & 1,0000 & & & & & & & \\
\hline FKB_ÖB50 & $-0,1371 * *$ & $-0,8537 * * *$ & 1,0000 & & & & & & \\
\hline FBK_BANK & 0,0551 & $-0,1230$ & 0,1016 & 1,0000 & & & & & \\
\hline FKB_BERUF_ST & $-0,0776$ & 0,1026 & $-0,0668$ & $-0,3449 * * *$ & 1,0000 & & & & \\
\hline FKB_STUD & $0,2057^{* * *}$ & 0,0231 & $-0,1418^{* *}$ & 0,0466 & $-0,0553$ & 1,0000 & & & \\
\hline MARKTAN_GES & $0,3674^{* * * *}$ & $-0,1094$ & $-0,0905$ & $0,2027 * * *$ & 0,0330 & $-0,0048$ & 1,0000 & & \\
\hline MARKTAN_FK & $0,3987 * * *$ & $-0,1330$ & $-0,0828$ & $0,1723 * *$ & $-0,0011$ & 0,0583 & $0,8792 * * *$ & 1,000 & \\
\hline UMFELD_LÄND & $0,1514^{* *}$ & $-0,0289$ & $-0,0547$ & $0,1848^{* * * *}$ & $-0,0561$ & 0,0017 & $0,4025^{* * * *}$ & $0,241 * * *$ & 1,000 \\
\hline UMFELD_LÄSTÄ & $-0,1247^{* *}$ & 0,0321 & 0,0362 & $-0,1272$ & $0,1462 * *$ & $-0,0129$ & $-0,0815$ & $-0,036$ & $-0,676^{* * * *}$ \\
\hline UMFELD_STÄ & $-0,0232$ & $-0,0060$ & 0,0197 & $-0,0599$ & $-0,1191$ & 0,0145 & $-0,3802 * * *$ & $-0,254^{* * * *}$ & $-0,340^{* * * *}$ \\
\hline LEI_WERT_FKB & 0,0550 & 0,1177 & $-0,1582 * *$ & 0,0910 & 0,0865 & 0,1332 & $0,3032 * * *$ & $0,384 * * *$ & 0,084 \\
\hline LEI_WERT_BA & $-0,0812$ & $-0,2215^{* * *}$ & $0,2851^{* * *}$ & 0,0607 & $-0,0842$ & $-0,0554$ & 0,0321 & 0,108 & $-0,070$ \\
\hline LEI_VOL & $-0,1052$ & $0,1468^{* * *}$ & $-0,0998$ & 0,1099 & 0,0149 & $-0,1000$ & $0,2124 * * *$ & $0,255^{* * * *}$ & $-0,095$ \\
\hline LEI_AKT & $-0,1236$ & 0,1254 & $-0,0663$ & 0,0558 & 0,0606 & $-0,0936$ & $0,2883^{* * *}$ & $0,296 * * *$ & $-0,120$ \\
\hline LEI_KEIN & 0,0062 & 0,0022 & $-0,0059$ & $-0,1175$ & $-0,0912$ & $-0,1060$ & $-0,3517^{* * * *}$ & $-0,401 * * *$ & 0,002 \\
\hline RISIKO_BEPREIS & 0,0763 & $0,1419^{* * *}$ & $-0,1967^{* * * *}$ & 0,0010 & $-0,0360$ & $0,1538^{* * *}$ & $-0,0209$ & 0,0594 & $-0,178^{* * *}$ \\
\hline BIL_BA & $-0,0624$ & $-0,1408^{* *}$ & $0,1876^{* * * *}$ & $-0,4497^{* * *}$ & 0,0177 & 0,0271 & $-0,2210^{* * *}$ & $-0,1024$ & $-0,223^{* * *}$ \\
\hline
\end{tabular}

Tab. AN 4-7: Bivariate Korrelationen der bankbezogenen Variablen 


\begin{tabular}{|c|c|c|c|c|c|c|c|c|c|}
\hline & $\frac{\sqrt[5]{5}}{\sqrt[5]{3}}$ & $\begin{array}{l}\frac{1}{6} \\
\frac{6}{2} \\
\frac{52}{2}\end{array}$ & 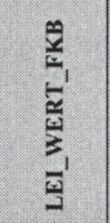 & $\frac{5}{1}$ & $\begin{array}{l}0 \\
\frac{1}{3} \\
\overline{5}\end{array}$ & $\begin{array}{l}\frac{5}{2} \\
\frac{1}{2} \\
\frac{5}{2}\end{array}$ & $\frac{z}{\frac{3}{2}}$ & $\frac{\frac{2}{3}}{\frac{2}{2}}$ & $\frac{\pi}{\infty}$ \\
\hline UMFELD_LÄSTÄ & 1,0000 & & & & & & & & \\
\hline UMFELD_STÄ & $-0,4630^{* * * *}$ & 1,0000 & & & & & & & \\
\hline LEI_WERT_FKB & $-0,0358$ & $-0,0563$ & 1,0000 & & & & & & \\
\hline LEI_WERT_BA & $-0,0648$ & $0,1692^{* *}$ & $-0,0183$ & 1,0000 & & & & & \\
\hline LEI_VOL & 0,1211 & $-0,0406$ & $0,4002 * * *$ & $0,2429 * * *$ & 1,0000 & & & & \\
\hline LEI_AKT & $0,1376^{* *}$ & $-0,0317$ & $0,2839 * * *$ & $0,2203^{* * *}$ & $0,6958^{* * *}$ & $1,0000^{* * *}$ & & & \\
\hline LEI_KEIN & 0,0200 & $-0,0283$ & $-0,7473^{* * *}$ & $-0,3475^{* * *}$ & $-0,4222 * * *$ & $-0,4915^{* * *}$ & 1,0000 & & \\
\hline RISIKO_BEPREIS & 0,0544 & $0,1452^{* *}$ & $0,2048^{* *}$ & 0,1005 & 0,1324 & 0,1550 & $-0,2649 * * *$ & 1,0000 & \\
\hline BIL_BA & 0,0896 & $0,1537^{* *}$ & $-0,0433$ & $-0,0740$ & $-0,0169$ & $-0,1052$ & 0,0896 & 0,1077 & 1,0000 \\
\hline
\end{tabular}

Fortsetzung Tab. AN 4-7: Bivariate Korrelationen der bankbezogenen Variablen 


\section{Anhang 5: Ergänzende Auswertungen für den Zinssatz}

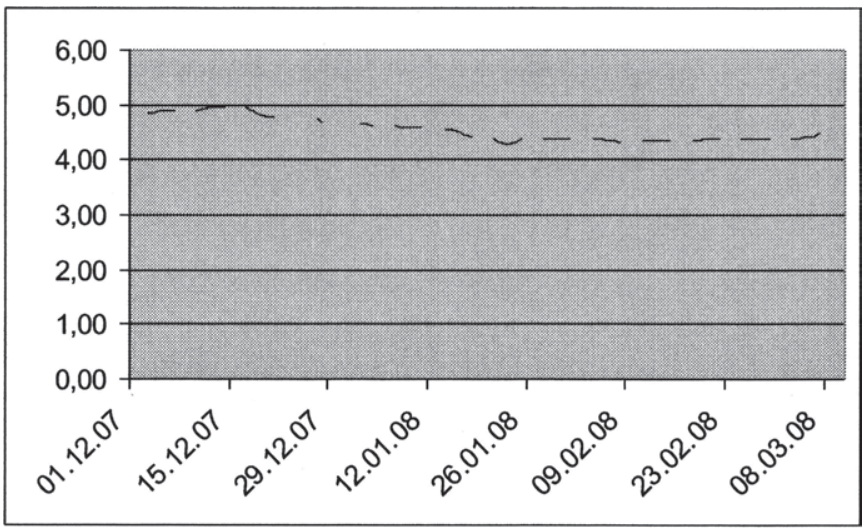

Abb. AN 5-1: Entwicklung des Euribor im Zeitablauf ${ }^{1640}$

\begin{tabular}{|l|r|r|r|}
\hline Kontrollvariablen & - & UMSATZ & \multicolumn{1}{c|}{$\begin{array}{c}\text { TSC_QA } \\
\text { AGG }\end{array}$} \\
\hline ORG_GLAUB & $0,2760^{* * *}$ & $0,2206^{* * *}$ & $0,2148^{* * *}$ \\
\hline ORG_WOHL & 0,0669 & 0,0323 & 0,0446 \\
\hline PERS_GLAUB & $0,1906^{* * *}$ & 0,1120 & 0,1052 \\
\hline PERS_WOHL & $0,1859^{* * *}$ & $0,1647^{* *}$ & $0,1687 * *$ \\
\hline ORG_GEB & $-0,2319^{* * *}$ & $-0,2061^{* * *}$ & $-0,2160^{* * *}$ \\
\hline ORG_VER & 0,0796 & 0,0370 & $-0,0006$ \\
\hline PERS_VER & 0,0763 & 0,0699 & 0,0470 \\
\hline PERS_VER_WOHL & 0,1189 & 0,1123 & 0,1066 \\
\hline
\end{tabular}

Tab. AN 5-1: Bivariate und partielle Korrelationen der verhaltenswissenschaftlichen Variablen mit dem Zinssatz

1640 Eigene Darstellung. Datenbasis Bundesbank (2007) und Bundesbank (2008c). 


\begin{tabular}{|c|c|c|c|c|c|c|}
\hline \multirow[b]{2}{*}{ Einflussgröße } & \multicolumn{2}{|c|}{ Regression 1} & \multicolumn{2}{|c|}{ Regression 2} & \multicolumn{2}{|c|}{ Regression 3} \\
\hline & Beta & $\begin{array}{c}\text { Beta } \\
\text { stand. }\end{array}$ & Beta & $\begin{array}{c}\text { Beta } \\
\text { stand. }\end{array}$ & Beta & $\begin{array}{c}\text { Beta } \\
\text { stand. }\end{array}$ \\
\hline Konstante & 9,8584 & & 10,7215 & & 10,5225 & \\
\hline GK LIM EX & 0,0000 & $-0,4688^{* * *}$ & 0,0000 & $-0,3783 * *$ & 0,0000 & $-0,3369$ \\
\hline INT BET & 1,3009 & $0,2744^{* * * *}$ & 1,1320 & $0,2272 * * *$ & 1,1206 & $0,2342 * * *$ \\
\hline ANT BANK HB & 0,0142 & $0,2222 * *$ & & & & \\
\hline HAUSBANK $K$ & & & 0,0207 & 0,0051 & & \\
\hline ANT BANK IN & & & & & 0,0030 & $0,0642 * * *$ \\
\hline $\mathbf{R}$ & & 0,6618 & & 0,4443 & & 0,4132 \\
\hline R-Quadrat & & 0,4380 & & 0,1974 & & 0,1708 \\
\hline Korrigiertes $\mathbf{R}^{2}$ & & 0,4166 & & 0,1857 & & 0,1582 \\
\hline Signifikanz F-Test & & 0,0000 & & 0,0000 & & 0,0000 \\
\hline Durbin-Watson & & 1,8447 & & 1,8725 & & 1,8594 \\
\hline $\mathbf{N}$ & & 203 & & 203 & & 201 \\
\hline
\end{tabular}

Tab. AN 5-2: Regression der beziehungsbezogenen Variablen (1)

\begin{tabular}{|l|r|r|}
\hline Einflussgröße & \multicolumn{1}{|c|}{ Beta } & \multicolumn{1}{|c|}{$\begin{array}{c}\text { Beta } \\
\text { stand. }\end{array}$} \\
\hline Konstante & 11,4883 & 19,7260 \\
\hline INT BET & 0,9591 & $2,7277^{* * *}$ \\
\hline DAU BEZ ERR & $-0,0046$ & $-0,4244$ \\
\hline GK_LIM EX & 0,0000 & $-4,0361^{* * *}$ \\
\hline GES KREDIT & 0,0000 & 0,6806 \\
\hline MITGLIED & $-0,5538$ & $-2,0022^{* *}$ \\
\hline ZINS VERFÜG & $-0,4250$ & $-1,6151$ \\
\hline SICH_Q & 0,0054 & 1,3426 \\
\hline ANZ B AGG & $-0,1547$ & $-1,2078$ \\
\hline DARL & $-0,0118$ & $-0,0368$ \\
\hline VERM ANL & $-0,2346$ & $-0,7998$ \\
\hline VERSICH & $-0,0434$ & $-0,1604$ \\
\hline PRIVATKONT & $-0,1788$ & $-0,5485$ \\
\hline ANT ZV & 0,0062 & 0,8986 \\
\hline ANT BANK IN & $-0,0017$ & $-0,3432$ \\
\hline HAUSBANK K & $-0,1129$ & $-0,2209$ \\
\hline R & & 0,4995 \\
\hline R-Quadrat & & 0,2495 \\
\hline Korrigiertes R & & 0,1754 \\
\hline Signifikanz F-Test & & 1,5535 \\
\hline Durbin-Watson & & 0,0001 \\
\hline N & & 167 \\
\hline D & & \\
\hline
\end{tabular}

Tab. AN 5-3: Regression der beziehungsbezogenen Variablen (2) 


\begin{tabular}{|c|c|c|c|c|}
\hline \multirow[b]{2}{*}{ Einflussgröße } & \multicolumn{2}{|c|}{ Regression 1} & \multicolumn{2}{|c|}{ Regression 2} \\
\hline & Beta & $\begin{array}{c}\text { Beta } \\
\text { stand. }\end{array}$ & Beta & $\begin{array}{l}\text { Beta } \\
\text { stand. }\end{array}$ \\
\hline Konstante & 10,3959 & 0,1810 & 10,3996 & \\
\hline ORG_GLAUB & 0,3575 & $-0,1096^{*}$ & $0,4510(1)$ & $0,2283^{* * *}$ \\
\hline ORG WOHL & $-0,2299$ & $-0,1880$ & & \\
\hline PERS GLAUB & 0,0833 & 0,1155 & & \\
\hline ORG GEB & $-0,3644$ & $0,0406^{* *}$ & $-0,2951(2)$ & $-0,1523^{* * *}$ \\
\hline ORG_VER & 0,0780 & 0,0420 & & \\
\hline PERS WOHL VERB & 0,2218 & 0,1810 & & \\
\hline $\mathbf{R}$ & & 0,3291 & & 0,3090 \\
\hline R-Quadrat & & 0,1083 & & 0,0955 \\
\hline Korrigiertes $\mathbf{R}^{\mathbf{2}}$ & & 0,0800 & & 0,0861 \\
\hline Signifikanz F-Test & & 0,0013 & & 1,6430 \\
\hline Durbin-Watson & & 2,0541 & & 1,9296 \\
\hline $\mathbf{N}$ & & 195 & & 195 \\
\hline
\end{tabular}

Tab. AN 5-4: Regression der verhaltenswissenschaftlichen Variablen

\begin{tabular}{|c|c|c|c|c|}
\hline \multirow[b]{2}{*}{ EinflussgröBe } & \multicolumn{2}{|c|}{ Regression 1} & \multicolumn{2}{|c|}{ Regression 2} \\
\hline & Beta & $\begin{array}{c}\text { Beta } \\
\text { stand. }\end{array}$ & Beta & $\begin{array}{r}\text { Beta } \\
\text { stand. }\end{array}$ \\
\hline Konstante & 12,1542 & & 12,3202 & \\
\hline BILANZS LN & $-0,1411$ & $-0,1100$ & $-0,1954(5)$ & $-0,1523^{* * * *}$ \\
\hline AUSFALLW B & 0,1320 & 0,1177 & $0,1974(2)$ & $0,1761^{* *}$ \\
\hline GK LIM EX & 0,0000 & $-0,3315^{* * *}$ & $0,0000(1)$ & $-0,3063^{* * *}$ \\
\hline INT BET & 0,6294 & $0,1279^{*}$ & $0,8383(4)$ & $0,1703 * *$ \\
\hline MITGLIED & $-0,5021$ & $-0,1352 * *$ & $-0,6328(3)$ & $-0,1704^{* *}$ \\
\hline ZINS VERFÜG & $-0,3503$ & $-0,1016$ & & \\
\hline ORG_GLAUB & 0,1118 & 0,0560 & & \\
\hline ORG WOHL & $-0,2435$ & $-0,1155$ & & \\
\hline PERS_GLAUB & 0,0037 & 0,0018 & & \\
\hline ORG GEB & $-0,1971$ & $-0,1013$ & & \\
\hline ORG VER & 0,1260 & 0,0651 & & \\
\hline PERS WOHL VERB & 0,1369 & 0,0705 & & \\
\hline $\mathbf{R}$ & & 0,5632 & & 0,5389 \\
\hline R-Quadrat & & 0,3172 & & 0,2904 \\
\hline Korrigiertes $\mathbf{R}^{2}$ & & 0,2714 & & 0,2713 \\
\hline Signifikanz F-Test & & 0,0000 & & 1,4733 \\
\hline Durbin-Watson & & 2,0964 & & 1,9819 \\
\hline $\mathbf{N}$ & & 191 & & 191 \\
\hline
\end{tabular}

Tab. AN 5-5: Regression der Finanzkennzahlen, der beziehungsbezogenen und der verhaltenswissenschaftlichen Variablen 


\section{Literaturverzeichnis}

Akerlof, G.A. (1970):

Markets for Lemons: Quality Uncertainty and the Markets Mechanism, in: Quarterly Journal of Economics, Vol. 84 (1970), No. 3, S. 488-500.

Allen, F. (1990):

The Market for Information and the Origin of Financial Intermediation, in: Journal of Financial Intermediation, Vol. 1 (1990), No. 1, S. 3-30.

Allen, L.; Saunders, A.;Udell, G.F. (1991):

The Pricing of Retail Deposits: Concentration and Information, in: Journal of Financial Intermediation, Vol. 1 (1991), No. 4, S. 335-361.

Allianz (2008):

Allianz verkauft Dresdner Bank an Commerzbank, URL: http://www.allianz deutschland.de/presse/news/news_2008-08-31.htm, abgerufen am 27.09.2008.

Amtsblatt EU (2003):

Amtsblatt der Europäischen Union (2003/361/EG).

Andaleeb, S.S. (1992):

The Trust Concept: Research Issues for Channels of Distribution, in: Research in Marketing, Vol. 11 (1992), S. 1-34.

Andaleeb, S. S. (1995):

Dependence relations and the moderating role of trust: implications for behavioral intentions in marketing channels, in: International Journal of Research in Marketing, Vol. 12 (1995), No. 2, S. 157-172.

Andaleeb, S.S. (1996):

An Experimental Investigation of Satisfaction and Commitment in Marketing Channels: The Role of Trust and Dependence, in: Journal of Retailing, Vol. 72, No. 1, S. 77-93.

Anderson, J.C.; Gerbing, D.W. (1988):

Structural Equation Modeling in Practise: A Review and Recommended Two-Step Approach, in: Psychological Bulletin, Vol. 103 (1988), No. 3, S. 411-423.

Anderson, J.C.; Gerbing, D.W. (1991):

Predicting the Performance of Measures in a Confirmatory Factor Analysis With a Pretest Assessment of Their Substantive Validities, in: Journal of Applied Psychology, Vol. 76 (1991), S. 732-740.

Anderson, J. C.; Narus, J. A. (1990):

A model of distributor firm and manufacturer firm working partnerships, in: Journal of Marketing, Vol. 54 (1990), No. 1, S. 42-58.

Anderson, J.C.; Weitz, B. (1989):

Determinant of Continuity in Conventional Industrial Channel Dyads, in: Marketing Science, Vol. 8 (1989), No. 4, S. 310-323. 
Anderson, E.; Weitz, B. (1992):

The Use of Pledges to Build and Sustain Commitment in Distribution Channels, in: Journal of Marketing Research, Vol. 29 (1992), No. 1, S. 18-34.

Andrae, K.A. (1962):

Der industrielle Mittelstand in der Wettbewerbsordnung, Köln 1962.

Andress, H. J.; Jacques, A. H.; Kühnel, S. (1997):

Analyse von Tabellen und kategorialen Daten, Berlin u.a. 1997.

Angele, J. (2007):

Insolvenzen 2006 - Statistisches Bundesamt - Wirtschaft und Statistik 4/2007, S. 352-361.

Angelini, P.; Di Salvo, R.; Ferri, G. (1998):

Availability and cost of credit for small businnesses: Customer relationships and credit cooperatives, in: Journal of Banking and Finance, Vol. 22 (1998), S. 925-954.

Aoki, M; Dinc, S. (1997):

Relational Financing as an Institution and its Viability under Competition, Working Paper No. 97011, Stanford University, Department of Economics 1997.

Arabsheibani, G.; De Meza, D.; Maloney, J.; Pearson, B. (2000):

And a vision appeared unto them of a great profit: evidence of self-deception among the self-employed, in: Economic Letters, Vol. 67 (2000), No. 1, S. 35-41.

Arbeitskreis 'Finanzierung' der Schmalenbach-Gesellschaft (1988):

Ansätze zur Gestaltung des Netzes von Bankverbindungen durch eine Unternehmung, in: Zeitschrift für betriebswirtschaftliche Forschung, 40. Jg. (1988), Heft 4, S. 739-766.

\section{Arrow, K.J. (1985):}

The Economics of Agency, in: Principals and Agents: The Structure of Business, Hrsg.: Pratt, J.W., Zeckhauser, R.J., Boston 1985, S. 37-51.

Axelssohn, B.; G. Easton (1992):

Industrial Networks - A New View of Reality, London 1992.

Backhaus, K.; Voeth, M. (2007):

Industriegütermarketing, München 2007.

Backhaus, K.; Erichson, B.; Plinke, W.; Weiber, R. (2006):

Multivariate Analysemethoden, Berlin/Heidelberg/New York 2006.

BaFin (2005):

Mindestanforderungen an das Kreditgeschäft - Rundschreiben 18/2005.

\section{BaFin (2008):}

http://www.bafin.de/cln_116/nn_722882/DE/BaFin/Internationales/InternationaleZ usammenarbeit/BaselerAusschuss/baselerausschuss_node.html? _nnn=true, abgerufen am 28.08.2008. 
Bagozzi, R.P. (1982):

A Field Investigation of Causal Relations Among Cognitions, Affect, Intentions and Behavior, in: Journal of Marketing Research, Vol. 19 (1982), S. 562-584.

Bagozzi, R.; Phillips, L. (1982):

Representing and Testing Organizational Theories: A Holistic Construal, in: Administrative Science Quarterly, Vol. 27 (1982), S. 459-489.

Bailom, F.; Hinterhuber, H.H.; Matzler, K.; Sauerwein, E. (1996):

Das Kano-Modell der Kundenzufriedenheit, in: Marketing ZFP, 18. Jg. (1996), Heft 2, S. 117-126.

Bankhofer, U. (1995):

Unvollständige Daten- und Distanzmatrizen in der Multivariaten Datenanalyse, Bergisch Gladbach/Köln 1995.

Bankhofer, U.; Praxmarer, S. (1998):

Zur Behandlung fehlender Daten in der Marktforschungspraxis, in: Marketing ZFP, 20. Jg. (1998), Heft 2, S. 109-118.

Barro, R.J. (1976):

Rational Expectations and the Role of Monetary Policy, in: Monetary Economy, Vol 2 (1976), No. 1, S. 1-32.

Baseler Ausschuss für Bankenaufsicht (2004):

Internationale Konvergenz der Kapitalmessung und Eigenkapitalanforderungen. Überarbeitete Rahmenvereinbarung, Basel 2004.

Baseler Ausschuss für Bankenaufsicht (2006):

Basel Committee on Banking Supervision Results of the fifth quantitative impact study (QIS 5), Basel 2006.

Bejou, D. (1997):

Relationship marketing: Evolution, present state, and future, in: Psychology and Marketing, Vol. 14 (1997), No. 8, S. 727-735.

Berekhoven, L.; Eckert, W.; Ellenrieder, P. (2001):

Marktforschung - Methodische Grundlagen und praktische Anwendung, Wiesbaden 2001.

Berens, W.; Knappkötter, R.; Segbers, K.; Siemes, A.; Ulirich, T. (2005):

Der Firmenkundenkredit - Kreditprozess, Informationsbeschaffung und Kundenorientierung, in: Zeitschrift für das gesamte Kreditwesen, 58. Jg. (2005), Heft 15, S. 784-789.

Berens, W.; Högemann, B.; Segbers, K. (2005):

Das mittelständische Unternehmen - Status Quo und Perspektiven der Finanzierung, in: Unternehmensentwicklung mit Finanzinvestoren - Eigenkapitalstärkung, Wertsteigerung, Unternehmensverkauf, Hrsg.: Berens, W., Brauner, H.U., Frodermann, J., Stuttgart 2005, S. 7-30. 
Berger, A.N.; Kashyap, A.K.; Scalise, J.M. (1995):

The transformation of the U.S. banking industry: What a long, strange trip it's been, in: Brookings Papers on Economic Activity, 1995, S. 55-218.

Berger, A.N.; Udell, G.F. (1990):

Collateral, loan quality, and bank risk, in: Journal of Monetary Economics, Vol. 25 (1990), S. 21-42.

Berger, A.N.; Udell, G.F. (1992):

Some evidence on the empirical significance of credit rationing, in: Journal of Political Economy, Vol. 100 (1992), No. 5, S. 1047-1077.

Berger, A.N.; Udell, G.F. (1995):

Relationship lending and lines of credit in small firm finance, in: Journal of Business, Vol. 68 (1995), No. 3, S. 351-382.

Berger, A.N.; Udell, G.F. (1996):

Universal banking and the future of small business lending, in: Financial System Design: The Case for Universal Banking, Hrsg.: Saunders, A.; Walter, I., Burr Ridge 1996, S. 559-627.

Berlin, M. (1996):

For Better and For Worse: Three Lending Relationships, Business Review, Federal Reserve Bank of Philadelphia, December 1996, S. 3-12.

Berlin, M., Mester, L.J. (1998):

On the profitability and cost of relationship lending, in: Journal of Banking and Finance, Vol. 22 (1998), S. 873-897.

Berry, L.L.; Parasuraman, A. (1991):

Marketing Services: Competing Through Quality, New York 1991.

Besanko, D.; Thakor, A. (1987a):

Collateral and Rationing: Sorting Equilibria in Monopolistic and Competitive Credit Markets, in: International Economic Review, Vol. 28 (1987), S. 671-698.

Besanko, D.; Thakor, A. (1987b):

Competitive equilibrium in the credit market under asymmetric information, in: Journal of Economic Theory, Vol. 42 (1987), S. 167-182.

Bester, H. (1985):

Screening vs. Rationing in Credit Markets with Imperfect Information, in: American Economic Review, Vol. 75 (1985), S. 850-855.

Bester, H. (1987):

The role of collateral in credit markets with imperfect information, in: European Economic Review, Vol. 31 (1987), No. 4, S. 887-899.

Bester, H. (1994):

The Role of Collateral in a Model of Debt Renegotiation, in: Journal of Money, Credit and Banking, Vol. 26 (1994), No. 1, S. 72-86. 
Bester, H.; Hellwig, M. (1989):

Moral Hazard and Equilibrium Credit Rationing: An Overview of the Issues, in: Agency Theory, Information, and Incentives, Hrsg.: Bamberg, G., Spremann, K., Berlin u.a. 1989, S. 135-166.

\section{BGH (1998):}

BGH NJW (1998) 2047.

Bhattacharya, S.; Chiesa, G. (1995):

Propietary information, financial intermediation and research incentives, in: Journal of Financial Intermediation, Vol. 4 (1995), No. 4, S. 328-357.

Bhattacharya, S.; Thakor, A. (1993):

Contemporary banking theory, in: Journal of Financial Intermediation, Vol. 3 (1993), No. 1, S. 2-50.

Bickel, W. (1962):

Das unbestrittene Feld kleiner und mittlerer Wirtschaftseinheiten in der gewerblichen Wirtschaft der Bundesrepublik Deutschland, Diss. Universität Mannheim, Mannheim 1962.

Bigley, Gegory A.; Pearce, J. L. (1998):

Straining for shared meaning in organization science: problems of trust and distrust, in: Academy of Management Review, Vol. 23 (1998), No. 3, S. 405-421.

Bigus, J.; Langer, T.; Schiereck, D. (2005):

Warum gibt es Kreditsicherheiten?, in: Kredit und Kapital, 38. Jg. (2005), Heft 4, S. 573-618.

Billet, M.T.; Flannery, M.J.; Garfinkel, J.A. (1995):

The Effeckt of Lender Identity on a Borrowing Firm's Equity Return, in: Journal of Finance, Vol. 50 (1995), No. 2, S. 699-718.

Black, F. (1975):

Bank funds management in an efficient market, in: Journal of Financial Economics, Vol. 2 (1975), No. 4, S. 323-339.

Blackwell, N.R.; Santomero, A.M. (1982):

Bank credit rationing and the customer relation, in: Journal of Monetary Economics, Vol. 9 (1982), No. 1, S. 121-129.

Blackwell, D.W.; Winters, D.B. (1997):

Banking relationships and the effect of monitoring in loan pricing, in: Journal of Financial Research, Vol. 20 (1997), S. 275-289.

Bleymüller, J.; Gehlert, G.; Gülicher, H. (2008):

Statistik für Wirtschaftswissenschaftler - WiSt-Studienkurs, München 2008.

Bliemel, F.W.; Eggert, A. (1997):

Relationship Marketing under Fire, Kaiserslautener Schriftenreihe Marketing, Nr. 4/97, Lehrstuhl für Marketing der Universität Kaiserslautern, Kaiserslautern 1997. 
Blois, Keith J. (1999):

Trust in Business Relationships: an evaluation of its status, in: Journal of Management Studies, Vol. 36 (1999), No. 2, S. 197-215.

\section{BMWI (2004):}

Der Mittelstand in der Bundesrepublik Deutschland: Eine volkswirtschaftliche Bestandsaufnahme, BMWI Dok. 561, URL: http://ifm-bonn.org/assets/documents/BMWI-Dokumentation-561.pdf, abgerufen am 08.08.2008.

Boehm-Bezing, C.L. (2002):

Zukunftsstrategien im mittelständischen europäischen Firmenkundengeschäft, in: Handbuch Firmenkundengeschäft, Hrsg.: Juncker, K.; Priewasser, E., Frankfurt 2002, S. 81-90.

\section{Bongartz, U. (2001):}

Investment-Banking: Die Internet-Herausforderung, in: Die Bank, Jg. 2001, Heft 1, S. 16-20.

Borooah, V.K. (2002):

Logit and Probit: Ordered and Multinomial Models, Thousand Oaks 2002.

Boot, A.W.A. (2000):

Relationship banking: What do we know?, in: Journal of Financial Intermediation, Vol. 9 (2000), No. 1, S. 7-25.

Boot, A.W.A.; Thakor, A.V. (1994):

Moral hazard and secured lending in an indefinitely repeated credit market game, in: International Economic Review, Vol. 35 (1994), No. 4, S. 899-920.

Boot, A.W.A.; Thakor, A.V. (2000):

Can relationship banking survive competition?, in: Journal of Finance, Vol. 55. (2000), No. 2, S. 679-713.

Boot, A.W.A.; Thakor, A.V; Udell, G.F. (1991):

Credible commitments, contract enforcement problems and banks: Intermediation as credibility assurance, in: Journal of Banking and Finance, Vol. 15 (1991), No. 3, S. 605-632.

\section{Börner, C. J. (2005):}

Konzeptioneller Rahmen: Strategisches Managment und Strategieparameter, in: Bankstrategien im Firmenkundengeschäft Konzeption - Management Dimensionen, Hrsg.: Börner, C. J.; Maser, H.; Schulz, T.C., Wiesbaden 2005, S. 3163.

Börner, C.J.; Maser, H.; Schulz, T.C. (2005):

Kreditgeschäft am Scheideweg? Thesen, PRobleme und Lösungsansätze für das Firmenkundengeschäft der Banken in: Bankstrategien im Firmenkundengeschäft Konzeption - Management - Dimensionen, Hrsg.: Börner, C. J.; Maser, H.; Schulz, T.C., Wiesbaden 2005, S. 11-30.

Bortz, J. (2005):

Statistik für Human- und Sozialwissenschaftler, Berlin et al. 2005. 
Bortz, J.; Döring, N. (2006):

Forschungsmethoden und Evaluation für Human- und Sozialwissenschaften, Heidelberg 2006.

Boyd, J.H.; Prescott, E.C. (1986):

Financial intermediary-coalitions, in: Journal of Economic Theory, Vol. 38 (1986), No. 2, S. 211-232.

Breuer, W. (1995):

Finanzintermediation und Reputationseffekte, in: Kredit und Kapital, 28 Jg. (1995), S. 516-533.

Brezski, E. (2006):

Mezzanine - Eine moderne Finanzierungsform für den Mittelstand, in: foerderland Wissen für Gründer, URL: http://www.foerderland.de/fachbeitraege/beitrag/Mezzanine-Eine-moderne-Finanzierungsform-fuer-den-Mittelstand/f2c569f1a8/, abgerufen am: 08.08.2008.

Broecker, T. (1990):

Creditworthiness Tests and Interbank Competition, in: Econometrica, Vol. 58 (1990), No. 2, S. 429-452.

Brosius, F. (2002):

SPSS 11, Bonn 2002.

Buchanan, B. (1974):

Building Organizational Commitment: The Socialization of Managers in Work Organizations, in: Administrative Science Quarterly, Vol. 19 (1974), No. 4, S. 533546.

Büchs, M.J. (1991):

Zwischen Markt und Hierarchie - Kooperation als alternative Kooperationsform, in: Zeitschrift für Betriebswirtschaft, Ergänzungsheft 1, 1991, S. 1-37.

Bühl, A.; Zöfel, P. (2005):

SPSS 12, München 2005.

Bühner, M. (2004) :

Einführung in die Test- und Fragebogenkonstruktion, München u.a. 2004.

Bundesbank (2003):

Monatsbericht Dezember 2003, Frankfurt 2003.

Bundesbank (2005):

Ergebnisse der vierten Auswirkungsstudie zu Basel II, Frankfurt 2005.

Bundesbank (2006a):

Monatsbericht Dezember 2006, Frankfurt 2006.

Bundesbank (2006b):

Bundesbank: Entwicklung des Bankstellennetzes im Jahr 2005, URL: www.bundesbank.de/download/bankenaufsicht/pdf/bankstellenbericht06.pdf, abgerufen am 08.08.2008. 


\section{Bundesbank (2007):}

Zeitreihe ST0316: Geldmarktsätze/EURIBOR- Dreimonatsgeld/Tagessatz, URL: http://www.bundesbank.de/statistik/statistik_zeitreihen.php?open=\&func=row\&tr= ST0316\&year $=2007$, abgerufen am 08.08.2008.

\section{Bundesbank (2007b):}

Bankenstatistik Juli 2007 -Statistisches Beiheft 1 zum Monatsbericht Juli 2007, Frankfurt 2007.

\section{Bundesbank (2008a):}

Hochgerechnete Angaben aus Jahresabschlüssen deutscher Unternehmen, URL: http://www.bundesbank.de/download/statistik/stat_sonder/statso5_1994_2006.xls, abgerufen am 08.08.2008.

\section{Bundesbank (2008b):}

Verhältniszahlen aus Jahresabschlüssen deutscher Unternehmen von 2005 bis 2006 http://www.bundesbank.de/download/statistik/stat_sonder/statso6_2005_2006_vorl aeufig.xls, abgerufen am 08.08.2008.

\section{Bundesbank (2008c):}

Zeitreihe ST0316: Geldmarktsätze / EURIBOR Dreimonatsgeld / Tagessatz, URL: http://www.bundesbank.de/statistik/statistik_zeitreihen.php?open=\&func=row\&tr= ST0316\&year $=2008$, abgerufen am 08.08.2008.

\section{Bundesbank (2008d):}

Monatsbericht Juni 2008, URL: http://www.bundesbank.de/download/volkswirtschaft/monatsberichte/2008/200806mb_bbk_la.pdf, abgerufen am 08.08.2008.

\section{Burghof, H.P. (2000):}

Credit and information in universal banking, in: Schmalenbach Business Review, Vol. 52 (2000), No. 3, S. 282-309.

Büschgen, H. E. (1998):

Bankbetriebslehre, Wiesbaden 1998.

Busse von Colbe, W.; Hammann, P.; Laßmann, G. (1992):

Betriebswirtschaftstheorie Band 2, Absatztheorie, Berlin et al. 1992.

Busse von Colbe, W. (1964):

Die Planung der Betriebsgröße, Wiesbaden 1964.

Bussiek, J. (1994):

Anwendungsorientierte Betriebswirtschaftslehre für Klein- und Mittelunternehmen, München/Wien 1994.

Butler, J. K. (1991):

Toward understanding and measuring conditions of trust: Evolution of a conditions of trust Inventory, in: Journal of Management, Vol. 17 (1991), No. 3, S. 643-663. 


\section{BVR (2005):}

Ergebnisse der vierten quantitativen Auswirkungsstudie zu den neuen Eigenkapitalreglungen (QIS 4) für die Kreditgenossenschaften Az.: BIZ-QIS, Vermerk, Berlin 2005.

\section{BVR (2007a):}

Konsolidierter Jahresabschluss des genossenschaftlichen FinanzVerbundes 2006, Berlin 2007.

\section{BVR (2007b):}

Zinsanpassungsklausel 2001, Einführung der Zinsänderungsklausel 2007, Vermerk 2. Juli 2007, 2007.

\section{BVR (2007c):}

Entwicklung der Volks- und Raiffeisenbanken ab 1970, URL: http://www.bvr.de/ public.nsf/199E06BCBAE5F69FC1257134003D2A8F/\$FILE/070305\%20wk\%20zahlen-ab1970.pdf, abgerufen am 04.08.2008.

\section{BVR (2008a):}

Alle Volks- und Raiffeisenbanken per Ende 2007, URL: http://www.bvr.de/ public.nsf/EED3EEC9F7C7273AC1256F87003532A6/\$FILE/alle_banken_2007.pdf, abgerufen am 04.08.2008.

\section{BVR (2008b):}

Alle Volks- und Raiffeisenbanken per Ende 2007, URL: http://www.bvr.de/public.nsf/42EC3DEBD4CF856FC1257134003C1BAB/\$FILE/ entwick12007.pdf, abgerufen am 04.08.2008.

\section{BVR (2008c):}

URL: http://www.bvr.de/public.nsf/index.html!ReadForm\&main=3\&sub=20, abgerufen am 04.08.2008.

\section{Cassier, S. C. (1976):}

Mittelständische Unternehmen und Finanzierung, in: Handwörterbuch der Finanzwirtschaft, Bd. 2, Hrsg.: Büschgen, H.E. u.a., Stuttgart 1976.

\section{Chan, Y.S.; Kanatas, G. (1985):}

Asymmetric Valuations and the Role of Collateral in Loan Agreements, in: Journal of Money, Credit, and Banking, Vol. 17 (1985), No. 1, S. 84-95.

Chan, Y.S.; Thakor A.V. (1987):

Collateral and Competitive Equilibria with Moral Hazard and Private Information, in: Journal of Finance, Vol. 42 (1987), No. 2, S. 345-363.

Churchill, G.A. (1979):

A Paradigm for Developing Better Measures of Marketing Constructs, in: Journal of Marketing Research, Vol. 19 (1979), No. 1, S. 491-504.

\section{Coase, R.H. (1963):}

The Nature of the Firm, in: Readings in Price Theory, Hrsg.: Stigler, G.J., Boulding, K.E., London 1963, S. 331-351, Wiederabdruck des Artikels aus: Economica, Vol. 4 (1937), S. 386-405. 


\section{Cole, R. A. (1998):}

The importance of relationship to the availability of credit, in: Journal of Banking and finance, Vol. 22 (1998), No. 6-8, S. 959-977.

Cole, R.A.; Goldberg, L.G.; White, L.J. (2001):

Cookie-Cutter versus Character: The Micro-Structure of Small Business Lending by Large and Small Banks, EFA 2002 Berlin Meetings Discussion Paper, gehalten am 14. Februar 2002.

Cole, Rebel A.; Wolken, John D. (1995):

Financial services used by small businesses: Evidence from the 1993 national survey of small business finances, in: Federal Reserve Bulletin, Vol. 81 (1995), S. 629639.

\section{Coleman, J. S. (1982a):}

Systems of trust: A rough theoretical framework, in: Angewandte Sozialforschung, 10. Jg. (1982), Heft 3, S. 277-299.

Coleman, J. S. (1982b):

Vertrauen als Eigenschaft von Interaktionssystemen Entwurf eines theoretischen Bezugsrahmens, in: Angewandte Sozialforschung, 10. Jg. (1982), Heft 3, S. 301 307.

\section{Comdirect (2008):}

URL:

http://isht.comdirect.de/html/detail/main.html?sTab=overview\&sCat=CUR\&sSym= DUSDEUR.TGT, abgerufen am 07.07.2008.

Cortina, J.M. (1993):

What Is Coefficient Alpha? An Examination of Theory an Applications, in: Journal of Applied Psychology, Vol. 78 (1993), No. 1, S. 98-104.

Cromme, G. (2008):

Gute Corporate Governance als Bindeglied zwischen Banken und Unternehmen, in: Zeitschrift für das gesamte Kreditwesen, 61. Jg. (2008), Heft 10, S. 431-433.

Crosby, L.A.; Evans, K.R.; Cowles, D. (1990):

Relationship Quality in Services Selling - An Interpersonal Influence Perspective, in: Journal of Marketing, Vol. 54 (1990), No. 3, S. 68-81.

Curral, S. C.; Judge, T. A. (1995):

Measuring Trust between Organizational Boundary Role Persons, in: Organizational Behavior and Human Decision Process, Vol. 64 (1995), No. 2, S. 151-170.

\section{D'Auria, C.; Foglia, A.; Reedtz, P. M. (1999):}

Bank interest rates and credit relationships in Italy, in: Journal of Banking and Finance, Vol. 23 (1999), No. 7, S. 1067-1093.

Dahmen, A.; Jacobi, P. (1997):

Firmenkundengeschäft der Kreditinstitute, Frankfurt 1997. 
De Meza, D. (2002):

Overlending?, in: Economic Journal, Vol. 112 (2002), February, S. F17-F31.

De Meza, D.; Southey, C. (1996):

The Borrower's Curse: Optimism, Finance and Entrepreneurship, in: Economic Journal, Vol. 106 (1996), S. 375-386.

Degryse, H.; Ongena, S. (2005):

Distance, Lending Relationships, and Competition, in: Journal of Finance, Vol. 60 (2005), No. 1, S. 231-266.

Degryse, H.; Van Cayseele, P. (1998):

Relationship Lending within Bank-Based System, Discussion Paper, Center for Economic Studie, Leuven 1998.

Degryse, H.; Van Cayseele, P. (2000):

Relationship Lending within Bank-Based System: Evidence from European Small Business Date, in: Journal of Financial Intermediation, Vol. 9 (2000), No. 1, S. 90 109.

Dell'Ariccia, G.; Marquez, R. (2004):

Information and bank credit allocation, in: Journal of Finanical Economics, Vol. 72 (2004), No. 1, S. 185-214.

Detragiache, E.; Garella, P.; Guiso, L. (2000):

Multiple versus single banking relationship, in: Journal of Finance, Vol. 55 (2000), No. 3, S. 1133-1161.

Deutsch, M. (1962):

Cooperation and Trust: Some Theoretical Notes, in: Nebraska Symposium on Motivation, Hrsg.: Jones, M.R., Lincoln 1962, S. 275-319.

Diamond, D.W. (1984):

Financial Intermediation and Delegated Monitoring, in: Review of Economic Studies, Vol. 51 (1984), No. 3, S. 393-414.

Diamond, D.W. (1989):

Reputation acquisition in debt markets, in: Journal of Political Economy, Vol. 97 (1989), No. 4, S. 828-862.

Diamond, D.W. (1991):

Monitoring and reputation: The choice between bank loans and directly placed debt, in: Journal of Political Economy, Vol. 99 (1991), No. 4, S. 689-721.

Diaz-Bone, R. (2006):

Statistik für Soziologen, Konstanz 2006.

Diller, H. (1994):

Bestandsaufnahme und Entwicklungsperspektiven des Beziehungsmanagement, in: Beziehungsmarketing - neue Wege zur Kundenbindung, Dokumentation des Workshops vom 24. Juni 1994, Hrsg.: Meffert, H.; Wagner, H.; Backhaus, K., Münster 1994, S. 6-30. 
Diller, H.; Kusterer, M. (1988):

Beziehungsmanagement, in: Marketing ZFP, 10. Jg (1988), Heft 3, S. 211-220.

Doberanzke, V. (1993):

Exklusive Finanzierung mittelständischer Unternehmen, Schriftenreihe für Kreditwirtschaft und Finanzierung, Bd. 16, zugl. Frankfurt (Main), Univ., Diss, 1992 Wiesbaden 1993.

Doney, P.; Cannon, J. (1997):

An Examination of the Nature of Trust in Buyer-Seller-Relationships, in: Journal of Marketing, Vol. 61 (1997), No. 2, S. 35-51.

\section{DSGV (2006a):}

Märkte 2006, Berlin 2006.

DSGV (2006b):

Mindestanforderungen an das Risikomanagement - Interpretationsleitfaden, Version $1.0,2006$.

\section{Duca, J.V. (1998):}

Comment on Cole, in: Journal of Banking and finance, Vol. 22 (1998), No. 6-8, S. 978-981.

\section{Duca, J.V.; Rosenthal, S.S. (1993):}

Borrowing constraints, household debt, and racial discrimination in loan markets, in: Journal of Financial Intermediation, Vol. 3 (1993), No. 1, S. 77-103.

Dufey, G.; U. Hommel (1999):

Financing the German Mittelstand, in: Structure and Dynamics of the German Mittelstand , WHU Koblenz - Otto Beisheim Graduate School of Management (Hrgs.), Heidelberg 1999, S. 183-228.

\section{Dwyer, F.R.; R.R. Lagace (1987):}

On the nature and role of buyer-seller trust, in: Journal of Marketing, Vol. 51 (1987), No. 2, S. 11-27

Dwyer, F.R.; Schurr, P.H.; Oh, S. (1987):

Developing buyer-seller relationships, in: Journal of Marketing, Vol. 51 (1987), No. 2, S. 11-27.

Dwyer, F.R.; Oh, S. (1987):

Output Sector Munificence Effects on the Internal Political Economy of Marketing Channels, in: Journal of Marketing Research, Vol. 24, S. 347-358.

DZ Bank (2008a):

DZ Bank Geschäftsbericht 2007, Frankfurt 2008.

\section{DZ Bank (2008b):}

URL: http://www.dzbank.de/unternehmen/index.jsp;jsessionid=0000cjYBny-hjwRQ-9TYuiviNtN:10mv51hct?path=/dz_profil_dzbank_portrait.html, abgerufen am 12.08.2008. 


\section{DZ Equity Partner (2008):}

URL:http://www.dzbank.de/internet_gr/index.jsp;jsessionid=0000BPVrHL8hEX OG49sfsMTnlkh:10f7pcc35?_DARGS=/internet_gr/navigation/nav_main_level3.js p_A\&_DAV $=$ Wir_ber_uns\&mDE $=$ Wir_ber_uns\&mZE $=d z \_$equity_partner\&mame=internet_gr_konzerntoechter\&mEE=konzerntoechter\&path=/konzerntoechter/dz_equity_partner/Wir__ber_uns\&flagNav=true\&fname=index.html, abgerufen am 12.08.2008.

\section{Ebers, M.; Gotsch, W. (2006):}

Institutionenökonomische Theorien der Organisation, in: Organisationstheorien, Hrsg.: Kieser, A. u.a., Stuttgart, 2006, S.199-251.

Eggert, A. (1999):

Kundenbindung aus Kundensicht, Wiesbaden 1999.

Eggert, A. (2000):

Konzeptualisierung und Operationalisierung der Kundenbindung aus Kundensicht, in: Marketing ZFP, 22. Jg. (2000), Heft 2, S. 119-130.

Eggert, A. (2002):

Der Einfluss elektronischer Medien auf Geschäftsbeziehungen Eine empirische Studie am Beispiel des Electronic Banking, in: Marketing ZFP, 24. Jg. (2002), Heft 3, S. 195-205.

Eller, R.; Gruber, W.; Reif, M. (Hrsg.) (2003):

Handbuch MaK: Organisation - Risikoklassifizierung - Kreditbepreisung, Stuttgart 2003.

Elsas, R. (2001):

Die Bedeutung der Hausbank, Wiesbaden 2001.

Elsas, R. (2005):

Empirical Determinants of Relationship Lending, in: Journal of Financial Intermediation, Vol. 14 (2005), No. 1, S. 32-57.

Elsas, R.; Krahnen, J.P. (1998):

Is relationship lending special? Evidence from credit-file data in Germany, in: Journal of Banking and Finance, Vol. 22. (1998), No. 10-11, S. 1283-1316.

Elsas, R.; Krahnen, J.P. (2002):

Collateral, Default Risk, and Relationship Lending: An Empirical Study on Financial Contracting, Center for Financial Studies, Working Paper, Frankfurt am Main, Version vom 23. Dezember 2002.

Ennew, C. T.; Binks, M. (1995):

The Provision of Finance to Small Businesses: Does the Banking Relationship Constrain Performance, in: Journal of Small Business Finance, Vol. 4 (1995), No. 1, S. $57-73$. 


\section{EU Kommission (2001):}

Verständigung über Anstaltslast und Gewährträgerhaftung, URL: http://www.lbbw.de/imperia/md/content/lbbwde/investorrelations/de/verstaendigung_eu.pdf, abgerufen am 08.08.2008.

\section{EU Kommission (2003a):}

KMU-Definition, URL: http://ec.europa.eu/enterprise/enterprise_policy/sme_definition/index_de.htm, abgerufen am 04.08.2008.

EU Kommission (2003b):

Empfehlung der EU-Kommission - betreffend die Definition der Kleinstunternehmen sowie der kleinen und mittleren Unternehmen - vom 6. Mai 2003 (2003/361/ EG).

\section{Euler Hermes Kreditversicherung (2005):}

FiKomM - FinanzKommunikation im Mittelstand, Hamburg 2005.

\section{EZB (1998):}

Amtsblatt der Europäischen Gemeinschaften (98/C 412/01).

Fama, E.F. (1980):

Banking in the theory of finance, in: Journal of Monetary Economics, Vol. 6 (1980), No. 1, S. 39-57.

Fama, E.F. (1985):

What's different about banks?, in: Journal of Monetary Economics, Vol. 15 (1985), No. 1, S. 29-39.

Farinha, L.A.; Santos, J.A.C. (2002):

Switching from Single to Multiple Bank Lending Relationships: Determinants and Implications, in: Journal of Financial Intermediation, Vol. 11 (2002), No. 2, S. 124151.

FAZ (2005):

http://www.faz.net/s/RubC9401175958F4DE28E143E68888825F6/Doc E852C400 81CD94F51A18860208FB40DFA ATpl Ecommon Scontent.html, abgerufen am 12.08.2008.

Fazzari, S.M.; Hubbard, R.G.; Petersen, B.C. (1988):

Financing constraints and corporate investment, in: Brookings Papers on Economic Activity, Vol. 1988, No. 1, S. 141-206.

Finanzierungs-Report (2004):

Finanzienungs-Report, in: Finanz Betrieb, 4. Jg. (2004), Heft 4, S. 269-270.

Fischer, K. (1990):

Hausbankbeziehungen als Instrument der Bindung zwischen Banken und Unternehmen, Bonn 1990. 
Fisman, R.; Khanna, T. (1999):

Is trust a historical residue? Information flows and trust levels, in: Journal of Economic Behaviour and Organization, Vol. 38 (1999), No. 1, S. 79-92.

Flacke, K. (2007):

Controlling in mittelständischen Unternehmen - Ausgestaltung, Einflussfaktoren der Instrumentennutzung und Einfluss auf die Bankkommunikation, Westfälische Wilhelmsuniversität Münster, Münster 2007.

Flacke, K.; Siemes, A. (2005):

Veränderte Finanzierungsrahmenbedingungen für den Mittelstand und dessen Unternehmenscontrolling; in: Controlling, Heft 4-5/2005, S. 251-260.

Ford, D. (1978):

Stability Factors in industrial marketing channels, in: Industrial Marketing Management, Vol. 7 (1978), No. 6, S. 410-422.

Ford, D. (1990):

The Development of Buyer-Seller Relationships in Industrial Markets in: Understanding Business Markets: Interaction, Relationships and Networks, Hrsg.: Ford, D., London u.a. 1990, S. 42-57, Wiederabdruck des Artikels aus: European Journal of Marketing, Vol. 14 (1980), No.5/6, S. 339-354.

Ford, D.; Håkansson; H. Johanson, J. (1986):

How do companies interact? in: Industrial Marketing and Purchasing, Vol. 1 (1986), No. 1 (1986), S. 25-41.

Fornell, C.; Larcker, D.F. (1981):

Evaluating Structural Equation Models with Unobservable Variables and Measurement Error, in: Journal of Marketing Research, Vol. 18 (1981), No. 1, S. 39-50.

Freixas, X.; Rochet, J.C. (1997):

Microeconomics of Banking, Cambridge u.a. 1997.

Ganesan, S. (1994):

Determinants of Long-Term Orientation in Buyer-Seller Relationships, in: Journal of Marketing, Vol. 58 (1994), No. 2, S. 1-19.

Ganesan, S.; Hess, R. (1997):

Dimensions and levels of trust: Implications for commitment to a relationship, in: Marketing Letters, Vol. 8 (1997), No. 4, S. 439-448.

Gantzel, K. J. (1962):

Wesen und Begriff der mittelständischen Unternehmung, Köln/Opladen 1962.

Garczorz, I.; Jochims, M. (2004):

Ganzheitliche Optimierung der Kreditbearbeitung und MaK, in: Zeitschrift für das gesamte Kreditwesen, 57. Jg. (2004), Heft 13, S. 31-36.

Gaydoul, P. (1980):

Controlling in der deutschen Unternehmenspraxis, Darmstadt 1980. 
Geiseler, C. (1999):

Das Finanzierungsverhalten kleiner und mittlerer Unternehmen, Wiesbaden 1999.

Gemünden, H.G. (1990):

Innovationen in Geschäftsbeziehungen und Netzwerken, Karlsruhe 1990.

Genossenschaftsgesetz (2007):

Genossenschaftsgesetz in der Fassung der Bekanntmachung vom 16. Oktober 2006 (BGBl. I S. 2230), zuletzt geändert durch Artikel 2 des Gesetzes vom 3. September 2007 (BGBl. I S. 2178).

Gerpott, T.J.; Mahmudova, I. (2006):

Ordinale Regression - Eine anwendungsorientierte Einführung, in: WiSt - Wirtschaftswissenschaftliches Studium, 35. Jg. (2006), Heft 9, S. 495-498.

Gertler, M.; Gilchrist, S.G. (1994):

Monetary policy, business cycles and the behaviour of small manufacturing firms, in: Quarterly Journal of Economics, Vol. 109 (1994), No. 2, S. 309-340.

Göbel, E. (2002):

Neue Institutionenpolitik. Konzeption und betriebswirtschaftliche Anwendungen, Stuttgart 2002.

Goldberg, V.P. (1976):

Regulation and Administered Contracts, in: Bell Journal of Economics and Management Science, Vol. 7 (1976), No. 2, S. 426-448.

Greenbaum, S.I.; Kanatas, G.; Venezia, I. (1989):

Equilibrium loan pricing under the bank-client relationship, in: Journal of Banking and Finance, Vol. 13 (1989), No. 2, S. 221-235.

Greenbaum, S.I.; Thakor, A.V. (1995):

Contemporary Financial Intermediation, Dryden u.a. 1995.

Groß, Th.; Michaelis, H. (2002):

Wertschöpfungskettenmanagement im Firmenkundengeschäft einer Bank, in: Handbuch Firmenkundengeschäft, Hrsg.: Juncker, K.; Priewasser, E., Frankfurt 2002, S. 163-176.

Grosskopf, W. (1989):

Strukturfragen der deutschen Genossenschaften - Der Förderungsauftrag moderner Genossenschaftsbanken und seine Umsetzung in die Praxis, Frankfurt 1989.

Grüger, W. (1991):

Strategische Maßnahmen zur Förderung des Image einer Bankengruppe am Beispiel der Kreditgenossenschaften, in: Handbuch des Bankmarketing, Süchting, J.; van Hooven, E.(Hrsg.):, Wiesbaden 1991, S. 367-375.

Grünberg, E. (1932):

Der Mittelstand in der kapitalistischen Gesellschaft. Eine ökonomische und soziologische Untersuchung, Leipzig/Hirschfeld 1932. 
Grüntker, H.; Kühn, S. (2007):

Basel II: Pilotprojekt zur aufsichtsrechtlichen Abnahme der internen Ratingsysteme, in: Zeitschrift für das gesamte Kreditwesen, 60. Jg. (2007), Heft 14, S. 716-717.

Günterberg, B.; Wolter, H.J. (2002):

Mittelstand in der Gesamtwirtschaft - Anstelle einer Definition-, in: Unternehmensgrößenstatistik 2001/2002, Hrsg.: Institut für Mittelstandsforschung Bonn, Bonn 2002, S. 1-22.

Günterberg, B.; Kayser, G. (2004):

SMES in Germany, Facts and Figures 2004, Bonn 2004.

Günzel, D. (1975):

Das betriebswirtschaftliche Größenproblem kleiner und mittlerer industrieller Unternehmen, Göttingen 1975.

Hadwich, K. (2003):

Die Rolle der Beziehungsqualität im Relationship Marketing, Wiesbaden 2003.

Hahn, H.; Meyer, H. (2003):

Rechnungswesen für Büroberufe, Troisdorf 2003.

Håkansson, H. (Hrsg.) (1982):

International Marketing and Purchasing of Industrial Goods: An Introduction Approach, Chichester u.a. 1982.

Hallén, L.; Johanson, J.; Seyed-Mohamed, N. (1991):

Interfirm adaption business relationships, in: Journal of Marketing, Vol. 55 (1991), No. 2, S. 29-37.

Hamer, E. (1987):

Das mittelständische Unternehmen. Eigenarten, Bedeutung, Chancen und Risiken, Stuttgart 1987.

Hannemann, R.; Schneider, A.; Hanenberg, L. (2003):

Mindestanforderungen an das Kreditgeschäft (MaK) - Eine einführende Kommentierung, Stuttgart 2003.

Harhoff, D.; Körting, T. (1998a):

Lending relationships in Germany - Empirical evidence from survey data, Working Paper.

Harhoff, D.; Körting, T. (1998b):

Lending relationships in Germany - Empirical evidence from survey data, in: Journal of Banking and Finance, 22. Jg. (1998), No. 10, S. 1317-1353.

Hartmann-Wendels, T.; Pfingsten, A.; Weber, M. (2007):

Bankbetriebslehre, Berlin u.a. 2007.

Hauswald, R.; Marquez, R. (2002):

Competition and strategic information acquisition in credit markets, Working Paper, Social Science Research Network, 2002. 
Hellwig, M. (1991):

Banking, Financial Intermediation, and Corporate Finance, in: European Financial Integration, Giovanni, A., Mayer, C. (Hrsg.), Cambridge University Press, Cambridge 1991, S. 35-63.

Hellwig, M. (1997):

Unternehmensfinanzierung, Unternehmenskontrolle und Ressourcenallokation: Was leistet das Finanzsystem?, in: Finanzmärkte, Hrsg.: Gahlen, B., Hesse, H., Ramser, H.J.,Tübingen 1997, S. 211-243.

Hempelmann, B.; Lürwer, M. (2003):

Der Customer Lifetime Value - Ansatz zur Bestimmung des Kundenwertes, in: WiSu, Das Wirtschaftsstudium, 32. Jahrgang 2003, Heft 3, S. 336-341.

Hester, D. (1979):

Customer relationships and terms of loans: Evicende from a pilot survey. in: Journal of Money, Credit and Banking, Vol. 11 (1979), No. 3, S. 349-357.

Heydebreck, P. (1995):

Technologische Verflechtung: ein Instrument zum Erreichen von Produkt- und Prozeßinnovationserfolg, Frankfurt 1995.

Hinderer, M. (1984):

Die mittelständische Unternehmung: Selbstverständnis in der Marktwirtschaft Analyse und Strategie, München 1984.

Hirschmann, E.C.; Holbrook, M.B. (1982):

Hedonic Consumption: Emerging Concepts, Methods and Propositions, in: Journal of Marketing, Vol. 46 (1982), No. 3, S. 92-101.

Hodgman, D.R. (1963) :

Commercial Bank Loan and Investment Policy, Bureau Economics and Business Research, University of Illinois, Champaign, 1963.

Homans, G.C. (1950):

The Human Group, New York 1950.

Homburg, C. (2000):

Kundennähe von Industriegüterunternehmen: Konzeption - Erfolgsauswirkungen Determinanten, Wiesbaden 2000.

Homburg, C.; Giering, A. (1996):

Konzeptualisierung und Operationalisierung komplexer Konstrukte - Ein Leitfaden für die Marketingforschung, in: Marketing ZFP, 18. Jg (1996), Heft 1, S. 5-24.

Homburg, C.; Schäfer, H. (2002):

Die Erschließung von Kundenpotenzialen durch Cross-Selling: Konzeptionelle Grundlagen und empirische Ergebnisse, Marketing - Zeitschrift für Forschung und Praxis, Vol. 24 (2002), Heft 1, S. 7-26. 


\section{Hommel, U.; Schneider, H. (2004):}

Die Bedeutung der Hausbankbeziehung für die Finanzierung des Mittelstands Empirische Ergebnisse und Implikationen, in: Finanzbetrieb, 2004, Heft 9, S. $577-$ 584.

\section{Hornung, K. (2002):}

Anforderungen eines Konzerns an das Firmenkundengeschäft einer Bank, in: Handbuch Firmenkundengeschäft - Technologie, Rating und Risikosteuerung als Kernkompetenz einer Bank, Hrsg.: Juncker, K.; Priewasser, E., Frankfurt 2002, S. 65-69.

\section{Horiuchi, T. (1994):}

The Effect of Firm Status on Banking Relationships and Loan Syndication, in: The Japanese Main Bank System, Hrsg.: Aoki, M., Patrick, H., Oxford 1994, Oxford University Press, S. 258-294.

Hoshi, T.; Kashyap, A.; Scharfstein, D.S. (1990):

The role of banks in reducing the cost of financial distress in Japan, in: Journal of Financial Economics, Vol. 27 (1990), No. 1, S. 67-88.

Houston, J.; James, C. (1996):

Bank information monopolies and the mix of public and private debt claims, in: Journal of Finance, Vol. 51 (1996), No. 5, S. 1863-1889.

\section{Hromadka, J.; Döhring, J. (2007):}

Entwicklung und Einsatz interner Ratingverfahren in einer genossenschaftlichen Zentralbank, in: Handbuch Rating, Hrsg.: Büschgen, H.E, München 2007, S.S. $247-$ 272.

\section{Hunt, S. D. (1990):}

Truth in Marketing Theory and Research, in: Journal of Marketing, Vol. 54 (1990), No. 3, S. 1-15.

\section{Hunt, S.D. (1991):}

Modern Marketing Theory: Critical Issues in the Philosophy of Marketing Science, in: Journal of the Academy of Marketing Science, Vol. 20 (1992), No. 4, S. 301311.

\section{HypoVereinsbank (2008):}

URL: http://geschichte.hypovereinsbank.de/gesc_veba_1869.php, abgerufen am 08.08.2008.

Iacobucci, D.; Ostrom, A. (1996):

Commercial and Interpersonal Relationships: Using the Structure of Interpersonal Relationships to Understand Individual-to-Individual, Individual-to-Firm, and Firmto-Firm Relationships in Commerce, in: International Journal of Research in Marketing, Vol. 13 (1996), No. 1, S. 53-72.

\section{IFM (2005):}

Arbeitsbericht 2005, Bonn, 2005. 


\section{IMP Group (1982):}

An interaction Approach, in: Understanding Business Markets: Interaction, Relationships and Networks, London u.a., Hrsg.: Ford, D., London u.a, 1990, S. 10-27.

Jaffee, D.M.; Russell, T. (1976):

Imperfect information, uncertainty, and credit rationing, in: Quarterly Journal of Economics, Vol. 90 (1976), No. 4, S. 651-666.

Jaffee, D.M.; Stiglitz, J.E. (1990):

Credit rationing, in: Handbook of Monetary Economics, 2. Band, Hrsg.: Friedman, B.M.und Hahn, F.H., S. 837-888.

James, C. (1987):

Some Evidence on the Uniqueness of Bank Loans, in: Journal of Financial Economics, Vol. 19 (1987), No. 2, S. 217-235.

James, C.; Wier, P. (1990):

Borrowing relationships, intermediation, and the cost of issuing public securities, in: Journal of Financial Economics, Vol. 28 (1990), No. 1-2, S. 149-171.

\section{Jensen, M.C.; Meckling, W.H. (1976):}

Theory of the firm: Managerial Behavior, agency costs and ownership structure, in: Journal of Financial Economics, Vol. 3 (1976), No. 4, S. 305-360.

Johnson-George, C.; Swap, W.C. (1982):

Measurement of specific interpersonal trust: construction and validation of a scale to assess trust in a specific other, in: Journal of Personality and Social Psychology, Vol. 43 (1982), No. 6, S. 1306-1317.

Juncker, K.; Priewasser, E. (2002):

Handbuch Firmenkundengeschäft - Technologie, Rating und Risikosteuerung als Kernkompetenz einer Bank, Frankfurt 2002.

Jung, S. (1999):

Das Management von Geschäftsbeziehungen: ein Ansatz auf transaktionskostentheoretischer, sozialpsychologischer und spieltheoretischer Basis, Wiesbaden 1999.

Kahneman, D.; Tversky, A. (1979):

Prospect theory: an analysis of decision under risk, in: Econometrica, Vol. 47 (1979), No. 2, S. 263-291.

Kane, E. J.; Malkiel, B.G. (1965):

Bank Portfolio Allocation, Deposit Variability, and the Availability Doctrine, in: Quarterly Journal of Economics, Vol. 79 (1965), No. 1, S. 113-134.

Kern, E. (1990):

Der Interaktionsansatz im Investitionsgütermarketing, Berlin 1990. 
Kessler, K.U.; Marquardt, S. (2005):

Strategien europäischer Banken im Firmenkundengeschäft. Strategieimplementierung im Firmenkundengeschäft, in: Bankstrategien im Firmenkundengeschäft, Hrsg.: Börner, C.J.; Maser, H.; Schulz, T.C., Wiesbaden 2005, S.167-201.

Kim, K.; Frazier, G.L. (1997):

On distributor commitment in industrial channels for distribution: a multicomponent approach, in: Psychology and Marketing, Vol. 14 (1997), No.8, S. 847-877.

Kirsch, W.; Kutschker, M. (1978):

Das Marketing von Investitionsgütern. Theoretische und empirische Perspektiven eine Interaktionsansatzes, Wiesbaden 1978.

Klaus, E. (2002):

Vertrauen in Unternehmensnetzwerken - Eine interdisziplinäre Analyse, zugelassene Dissertation, Universität Hohenheim, Wiesbaden, 2002.

Klenke, T.; Pfetsch, S.; Baetge, K. (2007):

Der kurze Weg zum Kredit - Automatisierung im Firmenkundengeschäft, in: Die Bank, Jg. 2007, Heft 6, S. 34-41.

Koch, F.-K. (1987):

Verhandlungen bei der Vermarktung von Investitionsgütern. Eine Plausibilitätsund Explorationsanalyse, zugelassene Dissertation, Mainz 1987.

Koch, G. (1959):

Betriebsgröße, in: Handwörterbuch der Sozialwissenschaften, 2. Band, Hrsg.: Beckerath, E.v. u.a., Stuttgart u.a 1959, Sp. 82-92.

Koller, M. (1997):

Psychologie interpersonalen Vertrauens - Eine Einführung in theoretische Ansätze, in: Interpersonales Vertrauen: Theorien und empirische Befunde, Hrsg.: Schweer, M., Opladen 1997, S. 13-26.

Koop, M. J.; Maurer, K. (2006):

Mittelstandsfinanzierung in Deutschland - Finanzierungskonzepte im Zeitalter von Basel II, Saarbrücken 2006.

Kosmider, A. (1994):

Controlling im Mittelstand, Stuttgart 1994.

Kumar, N.; Scheer, L.K.; Steenkamp, J.B. (1995):

The Effects of Perceived Interdependence on Dealer Attitudes, in: Journal of Marketing Research, Vol. 32 (1995), August, S. 348-356.

Kwan, S.H. (1994):

The certification value of bank loans, Working Paper, Tuscon University of Arizona, 1994. 


\section{Landesdatenbank NRW (2007):}

Umsatzsteuerpflichtige, Steuerbarer Umsatz und Umsatzsteuervorauszahlung nach Wirtschaftsabteilungen (75) der WZ 2003 - Land - Jahr (ab 2002) URL: https:// www.landesdatenbank.nrw.de/dbnrw/online/dWerteabruf_Page;jsessionid=FA6A44 756652CEAFF2B1E04FC9E3DBC2.worker3, abgerufen am 04.08.2008.

\section{Langer, T.; Waller, P. (2003):}

Loss Aversion in a Model of Loan Collateralization, zur Veröffentlichung, SFB504 Discussion Paper 98-33, Mannheim 2003.

\section{Larzeler, R.; Huston, T. (1980):}

The dyadic trust scale toward understanding interpersonal trust in close relationships, Journal Marriage and the Family, Vol. 1980, August, S. 595-604.

\section{Lehmann, E.; Neuberger, D. (2000):}

Do Lending Relationships Matter? Evidence from Bank Survey Data in Germany; Working Paper 2000.

\section{Lehmann, E.; Neuberger D. (2001):}

Do lending relationships matter? Evidence form bank survey data in Germany, in: Journal of Economic Behavior and Organization, Vol. 45 (2001), No. 4, S. 339-359.

Leland, H.E.; Pyle D.H. (1977):

Informational asymmetries, financial structure, and financial intermediation, in: Journal of Finance, Vol. 32 (1977), No. 2, S. 371-387.

\section{Lewicki, R.J.; Tomlinson, E.C.; Gillespie, N. (2006):}

Models of Interpersonal Trust Development: Theoretical Approaches, Empirical Evidence, and Future Directions, in: Journal of Management, Vol. 32 (2006), No. 6, S. 991-1022.

\section{Liberti, J.M. (2005):}

How does Organizational Form Matter? Distance, Communication and Soft Information, Working Paper, London Business School, 2005.

\section{Lindner-Lehmann, M. (2001):}

Regulierung und Kontrolle von Banken, Wiesbaden 2001.

\section{Little, R.J.A.; Schenker, N. (1995):}

Missing Data, in: Handbook of Statistical Modeling for the Social and Behavioral Sciences, Hrsg.: Arminger, G.; Clogg, C.C.; Sobel, M.E., New York 1995, S. 39-75.

Longhofer, S.D.; Santos, J.A. (2000):

The importance of bank seniority for relationship lending, in: Journal of Financial Intermediation, Vol. 9 (2000), No. 1, S. 57-89.

Lücke, W. (1967):

Betriebs- und Unternehmensgröße, Stuttgart 1967.

Luhmann, N. (2000):

Vertrauen, 4. Aufl., Stuttgart 2000. 


\section{Lummer, S.; McConnell, J. J. (1989):}

Further evidence on the bank lending process and capital market response to bank loan agreements, in: Journal of Financial Economics, Vol. 25 (1989), No. 1, S. 99122.

Main, J. (1982):

How bank lure the rich, Fortune, 1982 November, S. 64-66.

Macharzina, K. (1999):

Unternehmensführung: Das internationale Managementwissen, Konzepte - Methoden - Praxis, Wiesbaden 1999.

Machauer, A. (1999):

Bankverhalten in Kreditbeziehungen, Wiesbaden 1999.

Machauer, A.; Weber, M. (1998):

Bank behavior based on internal credit ratings of borrowers, in: Journal of Banking and Finance, Vol. 22 (1998), No. 10, S. 1355-1383.

Mantzel, D.; Ramke, T.; Schöning, S. (2007):

MaRisk: Handlungsbedarf für Kreditinstitute im Bereich der operationellen Risiken, in: Zeitschrift für das gesamte Kreditwesen, Jg. 60 (2007), Heft 2, S. 88-92.

MaRisk (2007):

Rundschreiben 5/2007 (BA) - Mindestanforderungen an das Risikomanagement MaRisk, URL:http://www.bafin.de/cln_109/nn_724304/SharedDocs/Veroeffentlichungen/DE/Service/Rundschreiben/2007/rs_0705_ba.html, abgerufen am 04.08.2008.

Marwede, E. (1983):

Die Abgrenzungsproblematik mittelständischer Unternehmen - Eine Literaturanalyse, Institut für Volkswirtschaftslehre der Universität Augsburg, Augsburg 1983.

Mattern, F.; Orlopp, B. (2002):

Wettbewerbstrends im europäischen Firmenkundengeschäft der Banken, in: Handbuch Firmenkundengeschäft - Technologie, Rating und Risikosteuerung als Kernkompetenz einer Bank, Hrsg.: Juncker, K.; Priewasser, E., Frankfurt 2002, S. 51-64.

Mayer, C. (1988):

New Issues in Corporate Finance, in: European Economic Review, Vol. 32 (1988), No. 5, S. 1167-1189.

McCullagh, P. (1980):

Regresssion Models for Ordinal Date, in Journal of the Royal Statistical Society, Series B, Vol. 42 (1980), No. 2, S. 109-142.

McEvily, B.; Tortoriello, M. (2007):

Measuring Trust in Organizational Research: Review and Recommendations, Unpublishe Working Paper, 2007. 
McKullin, E. (1984):

A Case for Scientific Realism, in: Scientific Realism, Hrsg.: Leplin, J., Berkeley 1984 , S. $8-40$.

Meffert, H. (2000):

Marketing - Grundlagen marktorientierter Unternehmensführung, Wiesbaden 2000.

Meyer, J.P.; Allen, N.J. (1984):

Testing the 'Side-Bet Theory' of Organzizational Commitment: Some Methodological Considerations, in: Journal of Applied Psychology, Vol. 69 (1984), No.3, S. 372-378.

Metcalf, L.E.; Frear, C. R.; Krishnan, R. (1992):

Buyer-Seller Relationships: An Application of the IMP Interaction Model, in: European Journal of Marketing, Vol. 26 (1992), No. 2, S. 27-46.

MIND (2006):

Mittelstand in Deutschland - Aufschwung aus eigener Kraft, Hrsg.: Gruner \& Jahr AG \& Co. KG, Köln 2006.

mind (2008):

URL: http://http://www.min-d.de/index.php?cid=216, abgerufen am 08.08.2008.

Mohr, J.; Nevin, J.R. (1990):

Communication Strategies in Marketing Channels: A Theorecitcal Perspective, in: Journal of Marketing, Vol. 54 (1990), No. 4, S. 36-51.

Mohr, J. J.; Spekman, R. (1994):

Characteristics of partnership success: Partnership attributes, communication behavior, and conflict resolution techniques, in: Strategic Management Journal, Vol. 15 (1994), No. 2, S. 135-152.

Molitor, B. (1980):

Mittelstand in unserer Zeit, in: Wirtschaftspolitische Chronik, 29. Jg. (1980), Heft 1, S. 57-65.

Moorman, C.; Deshpandé, R.; Zaltman, G. (1992):

Factors Affecting Trust in Market Research Relationships, in: Journal of Marketing Research, Vol. 29 (1992), No. 3, S. 314-28.

Moorman, C.; Deshpandé, R.; Zaltman, G. (1993):

Factors affecting trust in market research relationships, in: Journal of Marketing, Vol. 57 (1993), No. 1, S. 81-101.

Morgan, R.M.; Hunt, S.D. (1994):

The Commitment-Trust Theory of Relationship Marketing, in: Journal of Marketing, Vol. 58 (1994), July, S. 20-38.

\section{Moriarty, R.T; Kimball, R.C; Gay, J.H (1983):}

The management of corporate banking relationships, in: Sloan Management $\mathrm{Re}-$ view, Vol. 24 (1983), No. 3, S. 3-15. 
Moser, K. (1996):

Commitment in Organisationen, Bern 1996.

Moulin L.; Aerts, L. (1954):

Les Classes Moyennes, Essai de bibliographic critique d'une definition, in: Revue d'Histoiré Economique et Sociale, 1954.

Mowday, R.; Steers, R.M.; Porter, L.W. (1979):

The Measurement of Organizational Commitment, in: Journal of Vocational Behavior, Vol. 14 (1979), No. 2, S. 224-247.

\section{Mugler, J. (1998):}

Betriebswirtschaftslehre der Klein- und Mittelbetriebe - Band 1, 3. Aufl., Wien/ New York 1998.

Müller, S.; Brackschulze, K.; Mayer-Friedrich, M.D.; Ordemann, T. (2006):

Finanzierung mittelständischer Unternehmen: Selbstrating, Risikocontrolling, Finanzierungsalternativen, München 2006.

\section{Müller, S.; KPMG (2004):}

Finanzierung mittelständischer Unternehmen aus Sicht von Kreditinstituten und Unternehmen, Bremen 2005.

\section{Nakamura, L.I. (1994):}

Small borrowers and the survival of the small bank: Is mouse bank mighty or Mickey?, in: Federal Reserve Bank of Philadelphia Business Review, November/December (1994), S. 3-15.

Noordewier, T.G.; John; G.; Nevin, J.R. (1990):

Performance Outcomes of Purchasing Arrangements in Industrial Buyer-Vendor Relationships, in: Journal of Marketing, Vol. 54 (1990), No. 4, S. 80-93.

Nunnally, J. (1978):

Psychometric Theory, New York (1978).

N-TV (2008):

URL: http://www.n-tv.de/909848.html, abgerufen am: 28.06.2008.

Ongena, S.; Smith, D.C. (2000a):

Bank relationships: A review, in: Performance of financial institutions, Hrsg.: Harker, P.T., Zenios, S.A., Cambridge 2000, S. 221-258.

Ongena, S.; Smith, D.C. (2000b):

What Determines the Number of Bank Relationships? Cross-Country Evidence, in: Journal of Financial Intermediation, Vol. 9, 26-56.

Ongena, S.; Smith, D.C. (2001):

The duration of bank relationships, in: Journal of Financial Economics, Vol. 61 (2001), No. 3, S. 449-475. 
Orgler, Y. (1970):

A credit scoring model for commercial loans, in: Journal of Money, Credit and Banking, Vol. 2 (1970), No. 4, S. 435-445.

Paul, S.; Stein S. (2003):

Auf der Bremsspur: Für den Mittelstand und seine Banken zeigt die Qualitätsampel gelb-rot, in: Finanzbetrieb, 2003, Heft 7/8, S. 417-512.

Peek, J.; Rosengren, E.S. (1996):

Small business credit availability: How important is size of lender?, in: Financial System Design: The Case for Universal Banking, Hrsg.: Saunders, A., Walter, I., Burr Ridge 1996, S. 628-655.

Pepels, W. (1995):

Käuferverhalten und Marktforschung: eine praxisorientierte Einführung, Stuttgart 1995.

Pepels, W. (2004):

Marketing: Lehr- und Handbuch, 2004

Perrien, J.; Richard, L. (1995):

The Meaning of a Marketing Relationship, in: Industrial Marketing Management, Vol. 24 (1995), No. 1, S. 37-43.

Peter, P.J. (1979):

Reliability: A Review of Psychometric Basics and Recent Marketing Practices, in: Journal of Marketing Research, Vol. 16 (1979), No. 1, S. 6-17.

Petersen, M.A.; Rajan, R.G. (1994):

The benefits of lending relationships: Evidence from small business data, in: Journal of Finance, Vol. 49 (1994), No. 1, S. 3-37.

Petersen, M.A.; Rajan, R.G. (1995):

The effect of credit market competition on lending relationships, in: Quarterly Journal of Economics, Vol. 110 (1995), No. 2, S. 407-443.

Petersen, M.A.; Rajan, R.G. (2002):

Does distance still matter? The information revolution in small business lending, in: Journal of Finance, Vol. 57 (2002), No. 6, S. 2533-2570.

Pfohl, H.C. (1997):

Betriebswirtschaftslehre der Mittel- und Kleinbetriebe, Berlin 1997.

Picot, A.; Dietl, H.; Frank, E. (2005):

Organisation, 4. Aufl., Stuttgart: Schäffer-Poeschel, 2005.

Plinke, W. (1989):

Die Geschäftsbeziehung als Investition. in: Marketing-Schnittstellen: Herausforderungen für das Management, Hrsg.: Specht, G., Engelhardt, W.H., Stuttgart (1989), S. 305-326. 
Pointl, H. (2003):

Ratingkriterien bei Kreditinstituten: "Fast alles wichtig", in: Unternehmermagazin, 51. Jg. (2003), Heft 10, S. 38-39.

Popper, K.R. (1963):

Conjectures and Refutations: The Growth of Scientific Knowledge, New York 1963.

Priewasser, E.; Lippmann, I. (2000):

Die Priewasser-Prognose zum Firmenkundengeschäft. Ergebnisse der Expertenbefragung 2000 zur Zukunft des Firmenkundengeschäfts, Frankfurt 2000.

Priewasser, E. (2002):

Aus dem Blickwinkel der Zukunftsforschung: Umweltbedingungen und Funktionen des Firmenkundengeschäfts, in: Handbuch Firmenkundengeschäft - Technologie, Rating und Risikosteuerung als Kernkompetenz einer Bank, Hrsg.: Juncker, K., Priewasser, E. (Hrsg.), Frankfurt 2002, S. 23-38.

Quitzau, H. (2007):

Workout-Management im Wandel, in: Zeitschrift für das gesamte Kreditwesen, 60. Jg., Heft 13 (2007), S. 15-18.

Rajan, R.G. (1992):

Insiders and Outsiders: The Choice between Informed and Arm's-Length Debt, in: Journal of finance, Vol. 47 (1992), No. 4, S. 1367-400.

Rajan, R.G. (1996):

Is There a Future in Banking? Towards a New Theory of the Commercial Bank, in: Journal of Applied Corporate Finance, Vol. 1996, No. 2, S. 112-132.

Ramakrishnan, R.T.; Thakor A.V. (1984):

Information reliability and a theory of financial intermediation, in: Review of Economic Studies, Vol. 51 (1984), No. 3, S. 415-432.

Reinemann, H. (1999):

Was ist Mittelstand?, in: Wirtschaftswissenschaftliches Studium, 28. Jg. (1999), Heft 12, S. 661-662.

Rempel, J.K.; Holmes, J.G.; Zanna, M.P. (1985):

Trust in close relationships, in: Journal of Personality \& Social Psychology, Vol. 49 (1985), No. 1, S. 95-112.

Richter, R.; Furubotn, E. (1999):

Neue Institutionenökonomik, Tübingen 1999.

Rickes, R. (2006):

Leistungsfähigkeit des deutschen Bankenmarktes durch plurale Bankenstruktren sichern, in: Vierteljahreshefte zur Wirtschaftsforschung, Vol. 75 (2006), No. 4, S. 151-166. 


\section{Riemer, K. (2005):}

Sozialkapital und Kooperation - Zur Rolle von Sozialkapital im Management zwischenbetrieblicher Kooperation, Tübingen 2005.

Rinker, A.; Putzer, A.; Käser, B. (2004): zeb/-Firmenkundenstudie 2004, Münster 2004.

Rössl, D. (1994):

Gestaltung komplexer Austauschbeziehungen - Analyse zwischenbetrieblicher Kooperation; in: Schriftenreihe „neue betriebswirtschaftliche Forschung“, Band 128, Wiesbaden 1994.

Rotering, J. (1993):

Zwischenbetriebliche Kooperation als alternative Organisationsform - Ein transaktionstheoretischer Erklärungsansatz, Stuttgart 1993.

Rotter, J.B. (1967):

A New Scale for the Measurement of Interpersonal Trust, in: Journal of Personality, Vol. 35 (1967), No. 4, S. 651-665.

Rousseau, D.M.; Sitkin, S.B.; Burt, R.S.; Camerer, C. (1998):

Not so different at all: A cross-discipline view of trust, in: Academy of Management Review, Vol. 23 (1998), No. 3, S. 393-404.

Rusbult, C.E. (1983):

A Longitudal Test of the Investment Model: The Development (and Deterioration) of Satisfaction and Commitment in Heterosecual Involvements, in: Journal of Personality and Social Psychology, Vol. 45 (1983), No. 1, S. 101-117.

Schade, C.; Schott, E. (1993):

Instrumente des Kontraktgütermarketing, in: Die Betriebswirtschaft, Jg. 53 (1993), S. 491-511.

Schiereck, D. (2005):

Guarantees, Borrower Quality, and Relationship Lending: a Note on the German Mittelstand, Working Paper, European Business School Oestrich-Winkel 2005.

Schmidt, R. H. (1992):

Transaktionskostenorientierte Organisationstheorie, in: Handwörterbuch der Organisation, Hrsg.: Frese, E., Stuttgart 1992, Sp. 1854-1865.

Schmidt-Mohr, U. (1997):

Rationing versus Collateralization in Competitive and Monopolistic Credit Markets with Asymmetric Information, in: European Economic Review, Vol. 41 (1997), No. 7, S. 1321-1342.

Schmitz, G. (1997):

Marketing für professionelle Dienstleistungen, Wiesbaden 1997.

Schoch, R. (1969):

Der Verkaufsvorgang als sozialer Interaktionsprozess, Winterthur 1969. 
Schrader, S. (1993):

Kooperation, in: Ergebnisse empirischer betriebswirtschaftlicher Forschung - Zu einer Realtheorie der Unternehmung, Hausschild, J., Grün, O. (Hrsg.), Stuttgart 1993, S. 223-254.

Schramm, B. (1982):

Die Volksbanken und Raiffeisenbanken, Frankfurt 1982.

Schulte-Mattler, H.; Manns, T. (2004):

Basel II: Falscher Alarm für die Kreditkosten des Mittelstandes, in: Die Bank, 104. Jg. (2004), Heft 6-7, S. 376-380.

Schulte-Mattler, H.; von Kenne, U. (2004):

Basel II Framework - Meilenstein der Bankenaufsicht, in: Die Bank, 104. Jg. (2004), Heft 9, S. 37-40.

Schurr, P. H.; Ozanne, J. L (1985):

Influences on Exchange Processes: Buyers' Preconceptions of a Seller's Trustworthiness and Bargaining Toughness, in: Journal of Consumer Research, Vol. 11 (1985), No. 4, S. 939-953.

Schuster, P. (1991):

Erfolgsorientierte Steuerung kleiner und mittlerer Unternehmen - Funktionale, instrumentale und organisatorische Aspekte eines größengerechten Controlling-Systems, Berlin u.a. 1991.

Scott, J.A.; Smith, T.C. (1986):

The effect of the Bankruptcy Reform Act of 1978 on small business loan pricing, in: Journal of Financial Economic, Vol. 16 (1986), No. 1, S. 119-140.

Scott, J.A.; Dunkelberg, W.C. (2003):

Bank mergers and small firm financing, in: Journal of Money, Credit, and Banking, Vol. 35 (2003), No. 6, S. 999-1018.

Sharpe, S.A. (1990):

Asymmetric information, bank lending, and implicit contracts: A stylized model of customer relationships, in: Journal of Finance, Vol. 45 (1990), No. 4, S. 1069-1087.

Segbers, K. (2005):

Die Auswirkungen von Basel II auf Kreditkonditionen und Kreditverfügbarkeit für mittelständische Unternehmen - Eine Analyse eines Musterkreditportfolios, Arbeitspapier Nr. 9-1 des Lehrstuhls für Betriebswirtschaftslehre, insb. Controlling an der Wirtschaftswissenschaftlichen Fakultät der Westfälischen Wilhelms-Universität Münster 2005.

Segbers, K. (2007):

Die Geschäftsbeziehung zwischen mittelständischen Unternehmen und ihrer Hausbank - Eine ökonomische und verhaltenswissenschaftliche Analyse, zugelassene Dissertation, Münster, 2006, Frankfurt, 2007. 
Segbers, K.; Siemes, A. (2005a):

Der Dialog zwischen Firmenkunde und Bank kann durch Softwareunterstützung deutlich verbessert werden; in: Kredit \& Rating Praxis; o. Jg. (2005), Heft 2; S. 20 22.

\section{Segbers, K.; Siemes, A. (2005b):}

Mittelständische Unternehmen und ihr Kommunikationsverhalten gegenüber der Bank - Ergebnisse einer empirischen Studie (II), in: Finanzbetrieb, 2005, Heft 5, S. 311-320.

Seppänen, R.; Blomqvist, K.; Sundqvist, S. (2007):

Measuring inter-organizational trust-a critical review of the empirical research in 1990-2003, in: Industrial Marketing Management, Vol. 36 (2007), No. 2, S. 249265.

Shockley, R.L.; Thakor, A.V (1997):

Bank Loan Commitment Contracts: Data, Theory, and Tests, in: Journal of Money, Credit and Banking, Vol. 29 (1997), No. 4, S. 517-534.

Sjögren, H. (1994):

Long-Term Financial Contracts in the Bank-Oriented Financial System, in: Scandinavian Journal of Management, Vol. 10 (1994), No. 3, S. 315-330.

Smith, A. M. (1989):

Service Quality: Relationships Between Banks and their Small Business Clients, in: International Journal of Bank Marketing, Vol. 7 (1989), No. 5, S. 28-35.

Söhlke, T. (2002):

Regulatorische Erfassung des Kreditrisikos. Eine theoretische und empirische Analyse der Auswirkungen von Basel II auf Basis des zweiten Konsultationspapiers, Wiesbaden 2002.

Söllner, A. (1993):

Commitment in Geschäftsbeziehungen, Wiesbaden 1993.

\section{SolvV (2006):}

Verordnung über die angemessene Eigenmittelausstattung von Instituten, Institutsgruppen und Finanzholding-Gruppen (Solvabilitätsverordnung - SolvV), 14. Dezember $2006 \mathrm{http}: / /$ www.bundesbank.de/download/bankenaufsicht/pdf/solvv_070119.pdf, abgerufen am 04.08.2008.

\section{Sparkasse (2004):}

URL:https://sicherheit.sparkasse-leipzig.de/module/static/agb/agb.pdf? IFLBSERVERID=IF@@@...\&PHPSESSID=d73ee472959ea0dc23e844aabd9ef5aa, abgerufen am 04.08.2008.

\section{Sparkassen-Finanzgruppe (2008):}

http://www.sparkassen-finanzgruppe.de, abgerufen am 04.08.2008.

Spence, M. A. (1973):

Job Market Signaling, in: Quarterly Journal of Economics, Vol. 87 (1973), No. 3, S. 355-374. 
Spence, M. A. (1974):

Market Signalling: Informational Transfer in Hiring an Related Screening Processes, Cambridge u.a. 1974.

Spence, M. A. (1976):

Informational Aspects of Market Structure: An Introduction, in: Quarterly Journal of Economics, Vol. 90 (1976), No. 4, S. 591-597.

Speyer, B. (2002):

Verstärkte Kapitalmarktfinanzierung statt klassischem Bankkredit; in: Handbuch Firmenkundengeschäft - Technologie, Rating und Risikosteuerung als Kernkompetenz einer Bank, Hrsg.: Juncker, K.; Priewasser, E., Frankfurt 2002, S. 197-210.

Spremann, K. (1990):

Asymmetrische Information, in: Zeitschrift für Betriebswirtschaft, 60. Jg. (1990), S. 561-586.

Staehle, W.H (1999):

Management: Eine verhaltenswissenschaftliche Perspektive, München 1999.

Statistisches Bundesamt (2007a):

Steuerpflichtige Unternehmen - Umsatzsteuerstatistik 2006: Steuerpflichtige Unternehmen und deren Lieferungen und Leistungen nach wirtschaftlicher Gliederung (Tabelle 2.3 der Jahrespublikation, Fachserie 14 Reihe 8), URL: https:// www-ec.destatis.de/csp/shop/sfg/bpm.html.cms.cBroker.cls?cmspath=struktur, vollanzeige.csp\&ID=1021641, abgerufen am 04.08.2008.

Statistisches Bundesamt (2007b):

Steuerpflichtige Unternehmen - Umsatzsteuerstatistik 2006Eckdaten der jährlichen Umsatzsteuerstatistik. Zeitreihenergebnisse zu steuerlichen Merkmalen und Strukturdaten zu den Steuerpflichtigen und deren Lieferungen und Leistungen nach Wirtschaftsabschnitten, Größenklassen, Rechtsform und Bundesländern, URL: https://www-ec.destatis.de/csp/shop/sfg/bpm.html.cms.cBroker.cls? cmspath= struktur, vollanzeige.csp\&ID=1021643, abgerufen am 04.08.2008.

Statistisches Bundesamt (2007c):

Klassifikation der Wirtschaftszweige, Ausgabe 2003 (WZ 2003), URL: http:// www.destatis.de/jetspeed/portal/cms/Sites/destatis/Internet/DE/Content/Klassifikati onen/GueterWirtschaftklassifikationen/KlassifikationenWZ2003_xls, property=file .xls, abgerufen am 04.08.2008.

Stauss, B. (1999):

Kundenzufriedenheit, in: Marketing - Zeitschrift für Forschung und Praxis, 21. Jg. (1999), S. 5-24.

Stiglitz, J.; Weiss, A. (1981):

Credit rationing in markets with imperfect information, in: American Economic Review, Vol. 71 (1981), No. 3, S. 393-410. 
Strahan, P.E.; Weston, J.P. (1998):

Small business lending and the changing structure of the banking industry, in: Journal of Banking and Finance, Vol. 22 (1998), No. 6, S. 821-845.

Stützle, W. (2006):

Prozess der Weiterentwicklung der Mindestanforderungen (MaH, MaIR, MaK) zu den Mindestanforderungen an das Risikomanagement (MaRisk), in: Handbuch MaRisk, Hrsg.: Becker, A.; Gruber, W.; Wohlert, D., Frankfurt a. M. 2006, S. 9-28.

Süchting (1978):

Zuwachsraten im verteilten Markt, in: Perspektiven, Schriftenreihe der WGZ, II76/78.

Süchting, J.; Paul, S. (1998):

Bankmanagement, Stuttgart 1998.

Suyter, A. (2006):

Basel II: Internationales Level Playing Field in der Institutsaufsicht? in: Zeitschrift für das gesamte Kreditwesen, Jg. 59 (2006), Heft 24, S. 1328-1330.

Sydow, J. (1995):

Konstitutionsbedingungen von Vertrauen in Unternehmensnetzwerken - Theoretische und empirische Einsichten, in: Die Dimensionierung des Unternehmens, Bühner, R., Haase, K.D., Wilhelm, J. (Hrsg.), Stuttgart 1995.

Swary, I.; Udell, G. F. (1988):

Information Production and the Secured Line of Credit, New York University working paper (March), New York University, New York 1988.

Taylor, M.P. (1987):

The Simple Analytics of Implicit Labour Contracts; in: Surveys in the Economics of Uncertainty, Hrsg.: Hey, J.D., Lambert, P.J., Oxford und New York, 1987, S. 124-150.

Theileis, U.;Althoff, F.; Hörlin, S. (2006):

MaRisk - Ein Vergleich mit den MaK, MaH und MaIR, Deloitte \& Touche GmbH Wirtschaftsprüfungsgesellschaft, München 2006.

Theurl, T. (2005):

Kooperative Governancestrukturen, Arbeitspapiere des Instituts für Genossenschaftswesen der Westfälischen Wilhelms-Universität Münster, Nr. 48, Juni 2005.

tns infratest (2008):

Firmen FMDS 2007

Tröndle, D. (1987):

Kooperationsmanagement: Steuerung interaktioneller Prozesse bei Unternehmenskooperationen, Bergisch Gladbach 1987.

Turnbull, P.W.; Valla, J.P. (1986):

Strategies for international industrial marketing, London 1986. 
Turnbull, P.; Gibbs, M. (1990):

Marketing bank services to corporate customers: the importance of relationships, in: Understanding Business Markets: Interaction, Relationships and Networks, Hrsg.: Ford, D., London u.a. 1990, S. 359-364.Wiederabdruck des Artikels aus: International Journal of Bank Marketing, Vol. 5 (1987), No.1, S. 19-26.

Unterreitmeier, A. (2004):

Unternehmenskultur bei Mergersc \& Acquisitions - Ansätze zur Konzeptionalisierung und Operationalisierung, Deutscher Universitätsverlag Wiesbaden, zugelassene Dissertation München (2004).

Urban, D.; Mayerl, J. (2006):

Regressionsanalyse:Theorie, Technik und Anwendung, Wiesbaden 2006.

Urban, D.; Mayerl, J. (2007):

Mediator-Effekte in der Regressionsanalyse (direkt, indirekte und totale Effekte), Working Paper, Version 1.3; Januar 2007.

\section{Uzzi, B. (1999):}

Social relations and networks in the making of financial capital, in: American Sociological Review, Vol. 64 (1999), No. 4, S. 481-505.

Uzzi, B.; Gillespie, J.J. (2002):

Knowledge spillover in corporate financing networks: Embeddedness and the firm's debt performance, in: Strategic Management Journal, Vol. 23 (2002), No. 7, S. 595618.

\section{Uzzi, B.; Lancaster, R. (2003):}

Relational Embeddedness and Learning: The Case of Bank Loan Managers and Their Clients, in: Management Science, Vol. 49 (2003), No. 4, S. 383-399.

\section{Vogt, J. (1997):}

Vertrauen und Kontrolle in Transaktionen: Eine institutionenökonomische Analyse, Wiesbaden 1997.

\section{von Thadden, E.L. (1995):}

Long-Term Contracts, Short-Term Investment and Monitoring, in: Review of Economic Studies, Vol. 62 (1995), No. 4, S. 557-575.

von Thadden, E.L. (2001):

Asymmetric Information, Bank Lending and Implicit Contracts: The Winner's Curse, Université de Lausanne Discussion Paper 9808, 2001.

\section{VR Finanzplan Mittelstand (2006):}

VR Finanzplan Mittelstand - Projekthandbuch, Wiesbaden 2006.

\section{VR Mittelstandskapital (2008):}

http://www.vr-mittelstandskapital.de/de/vr-mittelstandskapital/start/wir-ueber-uns/ index.html, abgerufen am 04.08.2008. 
Wagner, R.; Themme, T.; Decker, R. (1998):

Die Behandlung fehlender Wert in der angewandten Marktforschung, in: Jahrbuch der Absatz- und Verbrauchsforschung, 44. Jg. (1998), Heft 4, S. 395-417.

Wansley, J.W.; Elayan, F.A.; Collins, M.C. (1992):

Investment opportunities and firm quality - An empirical investigation of the information in bank lines of credit, Working Paper, University of Tennessee, Tennessee 1992.

Welter (2003):

Strategie, KMU und Umfeld - Handlungsmuster udn Strategiegenese in kleinen und mittleren Unternehmen, Berlin 2003.

Werp, R. (1998):

Aufbau von Geschäftsbeziehungen, zugelassene Dissertation Oldenburg 1997, Wiesbaden, 1998.

WGZ (2008):

Geschäftsbericht 2007, Düsseldorf 2008.

WGZ Corporate Finance (2008):

WGZ Corporate Finance Beratung GmbH, http://www.wgz-cfb.de/de/wgzcorporate-finance-beratung/unternehmen/ueber-uns/index.html, abgerufen am 04.08.2008.

WGZ Initiativkapital (2008):

http://www.wgz-initiativkapital.de/de/wgz-initiativkapital/mezzanine-finanzierungen/leistungsangebot/index.html, abgerufen am 04.08.2008.

Williamson, O.E. (1990):

Die ökonomischen Institutionen des Kapitalismus, Tübingen 1990.

Wilson, D.T. (1995):

An Integrated Model of Buyer-Seller Relationships, in: Journal of the Academic of Marketing Science, Vol. 23 (1995), No. 4, S. 335-345.

Wirtschaftswoche (2008):

URL: http://www.wiwo.de/handelsblatt/die-eigenkapitalquote-steigt-299181/, abgerufen am 09.08.2008.

Zeitel, G. (1979):

Mittelstand und Mittelstandspolitik, Sonderdruck aus Handwörterbuch des Genossenschaftswesens, Wiesbaden 1979. 


\title{
Beiträge zum Controlling
}

\author{
Herausgegeben von Wolfgang Berens
}

Band 1 Wolfgang Berens / Joachim Strauch: Due Diligence bei Unternehmensakquisitionen - eine empirische Untersuchung. Unter Mitarbeit von Thorsten Behrens und Julia Lescher. 2002.

Band 2 Andreas Siemes: Marktorientierte Kreditrisikobewertung. Eine empirische Untersuchung mittels Künstlicher Neuronaler Netze. 2002.

Band 3 Karl Christoph Heinen: Die Berücksichtigung von Kosten in der Konkurrenzanalyse. 2002.

Band 4 Thomas Mosiek: Inteme Kundenorientierung des Controlling. 2002.

Band 5 Vera Sũdmeyer: Wettbewerbsvorteile durch strategisches Betriebsformenmanagement. Ein dynamischer Bezugsrahmen für Einzelhandelsunternehmen. 2003.

Band 6 Wolfgang Berens / Walter Schmitting (Hrsg.): Controlling im E-Business. Rückkehr zur Rationalităt. 2004.

Band 7 René Bertelsmann: Entwicklung einer Controlling-Konzeption im verallgemeinerten Neuen Steuerungsmodell für Trăgerorganisationen der gesetzlichen Unfallversicherung. 2005.

Band 8 Mirko Tillmann: Risikokapitalbasierte Steuerung in der Schaden- und Unfallversicherung. Konzeption einer modellgestützten Risikoanalyse. 2005.

Band 9 Andreas Hoffjan: Risikorechnung bei industrieller Auftragsfertigung. Theoretische Konzeption und Anwendung für die Bauwirtschaft. 2006.

Band 10 Pascal Nevries: Die Marketingwirkungen von Börsengängen. Eine konzeptionelle Analyse. 2006.

Band 11 Klaus Segbers: Die Geschäftsbeziehung zwischen mittelständischen Unternehmen und ihrer Hausbank. Eine ökonomische und verhaltenswissenschaftliche Analyse. 2007.

Band 12 Andreas Rőhrig: Wirkungsorientiertes Controlling im politisch-administrativen System. Unter besonderer Berücksichtigung der Gestaltungsmöglichkeiten von offentlichen Verwaltungen. 2008.

Band 13 Nino Raddao: Potenzialorientierte Kundensegmentierung zur Optimierung des Leistungsportfolios in der Firmenkundenbank. Konzeption und Implementierung einer efficient customization am Beispiel von Genossenschaftsbanken. 2009.

Band 14 Thorsten Pieper: Wirkungsorientiertes Controlling staatlichen Handelns. Systematische Identifikation und Bewertung der gesamtgesellschaftlichen Wirkungen staatlichen Handelns. 2009.

Band 15 Tina Püthe: Mittelstăndische Unternehmen und Genossenschaftsbanken. Eine empirische Analyse der Wirkung oknonomischer und verhaltenswissenschaftlicher Faktoren. 2009.

www.peterlang.de 


\section{Potenzialorientierte}

\section{Kundensegmentierung}

zur Optimierung des

\section{Leistungsportfolios in der Firmenkundenbank}

\section{Konzeption und Implementierung einer efficient customization am Beispiel von Genossenschaftsbanken}

Frankfurt am Main, Berlin, Bern, Bruxelles, New York, Oxford, Wien, 2009. XVIII, 123 S., zahlr. Abb. und Tab.

Beiträge zum Controlling. Herausgegeben von Wolfgang Berens. Bd. 13 ISBN 978-3-631-58354-8 · br. $€ 27.50$ *

Aufgrund der hohen Substituierbarkeit klassischer Bankprodukte kommt dem Management der Kundenbeziehung als Differenzierungsstrategie im Firmenkundengeschäft eine entscheidende Bedeutung zu. Eine wesentliche Herausforderung stellt dabei die Ausgestaltung des Leistungsangebotes der Bank dar. Einerseits ist die Kunde-Bank-Beziehung so zu gestalten, dass ein erlebbarer Mehrwert für den Firmenkunden entsteht. Andererseits muss dabei bankseitig auch eine angemessene Rentabilität der Geschäftsbeziehung und ein effizienter Einsatz der Betreuungsressourcen gewährleistet werden. Dieser Beitrag - der auf der mit dem DZ BANK Karriere-Preis ausgezeichneten Diplomarbeit des Autors basiert - wird ein multidimensionales Segmentierungsmodell entwickelt, das als Ausgangspunkt eines ganzheitlichen Vertriebsmanagements verstanden werden kann. Der Autor verknüpft den entwickelten Ansatz mit einer empirischen Analyse zur Anforderungsstruktur von Firmenkunden und leitet daraus Implikationen zur segmentspezifischen Optimierung des Leistungsportfolios von Banken ab.

Frankfurt am Main - Berlin - Bern - Bruxelles - New York · Oxford · Wien

Auslieferung: Verlag Peter Lang AG

Moosstr. 1, $\mathrm{CH}-2542$ Pieterlen

Telefax $0041(0) 32 / 3761727$

*inklusive der in Deutschland gültigen Mehrwertsteuer

Preisänderungen vorbehalten

Homepage http://www.peterlang.de 
Tina Püthe - 978-3-631-75310-1

Downloaded from PubFactory at 01/11/2019 06:20:26AM

via free access 
Tina Püthe - 978-3-631-75310-1

Downloaded from PubFactory at 01/11/2019 06:20:26AM

via free access 